\title{
Hanford Waste Vitrification Plant Full-Scale Feed Preparation Testing with Water and Process Simulant Slurries
}
J.R. Gaskill
D.E. Larson
S.D. Halstead
M.H. Langowski
L.K. Jagofa ECEIVED
G.P. Abrigo
R.L. Myers
J.T. Daume
M.R. Beckette
R.E. Graves
C.J. Freeman
R.L. McKay AUG O 51997
OSTI

March 1996

Prepared for the U.S. Department of Energy under Contract DE-AC06-76RLO 1830

Pacific Northwest National Laboratory Operated for the U.S. Department of Energy by Battelle Memorial Institute 


\section{DISCLAMIER}

Portions of this docament moy be illegible in electronic image products. Images are produced from the best available original document 
PNNL-11011

UC-810

Project Technical Information

\section{Hanford Waste Vitrification Plant Full-Scale Feed Preparation Testing with Water and Process Simulant Slurries}

\author{
J. R. Gaskill \\ D. E. Larson \\ G. P. Abrigo \\ J. T. Daume \\ R. E. Graves \\ S. D. Halstead \\ M. H. Langowski
}

March 1996

Prepared for

the U.S. Department of Energy

under Contract DE-AC06-76RLO 1830

\author{
R. L. Myers \\ M. R. Beckette \\ C. J. Freeman \\ L. K. Jagoda \\ B. K. Hatchell \\ R. L. McKay
}

Pacific Northwest National Laboratory

Richland, Washington 99352 


\title{
DISCLAIMER
}

This report was prepared as an account of work sponsored by an agency of the United States Government. Neither the United States Government nor any agency thereof, nor Battelle Memorial Institute, nor any of their employees, makes any warranty, express or implied, or assumes any legal liability or responsibility for the accuracy, completeness, or.usefulness of any information, apparafus, product, or process disclosed, or represents that its use would not infringe privately owned rights. Reference herein to any specific commercial product, process, or service by trade name, trademark, manufacturer, or otherwise does not necessarily constitute or imply its endorsement, recommendation, or favoring by the United States Government or any agency thereof, or Battelle Memorial Institute. The views and opinions of authors expressed herein do not necessarily state or reflect those of the United States Government or any agency thereof.

\section{PACIFIC NORTHWEST NATIONAL LABORATORY operated by \\ BATTELLE \\ for the \\ UNITED STATES DEPARTMENT OF ENERGY \\ under Contract DE-AC06-76RLO 1830}

\author{
Printed in the United States of America \\ Available to DOE and DOE contractors from the \\ Ofifice of Scientific and Technical Information, P.O. Box 62, Oak Ridge, TN 37831; \\ prices, available from (615) 576-8401.
}

Available to the public from the National Technical Information Service,

U.S. Department of Commerce, 5285 Port Royal Rd., Springfield, VA 22161 


\begin{abstract}
The Hanford Waste Vitrification Plant was intended to convert selected, pretreated defense highlevel waste and transuranic waste from the Hanford Site into a borosilicate glass. A full-scale testing program was conducted with nonradioactive waste simulants to develop information for process and equipment design of the feed-preparation system. The equipment systems tested included the Slurry Receipt and Adjustment Tank, Slurry Mix Evaporator, and Melter-Feed Tank. The areas of data generation included heat transfer (boiling, heating, and cooling), slurry mixing, slurry pumping and transport, slurry sampling, and process chemistry.
\end{abstract}


.

. 


\section{Summary}

The Hanford Waste Vitrification Plant (HWVP) was intended to convert selected, pretreated defense high-level waste (HLW) and transuranic (TRU) waste at the Hanford Site into a borosilicate glass. The glass would be cast into stainless steel canisters suitable for disposal. The filled canisters would be stored on site until they could be shipped to a federal repository for disposal. Vitrification technology is being similarly implemented at the Defense Waste Processing Facility (DWPF) at the Savannah River Site (SRS) in Aiken, South Carolina, and the West Valley Demonstration Project (WVDP) in West Valley (WV), New York. Existing vitrification technology was adapted for use in the HWVP. The full-scale feed-preparation testing program was developed to verify the adaptability of the DWPF feed-preparation technology for processing Hanford feeds. The results were needed for the HWVP design in addition to being used for HWVP permitting, feed processability studies, operations, and safety assessments.

The program for the full-scale feed-preparation systems characterized process performance and evaluated equipment performance. The process evaluation included determination of foaming tendency during boiling and formating; off-gas generation rate, composition, and decontamination factors (DFs) during boiling and formating; condensate composition; tendency of slurry solids to cake on equipment; redox adjustment by formic acid addition; and chemical additions. Equipment was evaluated for its capability to obtain and maintain a homogenous slurry, concentrate (heat, boil, and cool) the slurry, take representative samples, transfer slurry, accurately sense slurry processing parameters (level, temperature, density), feed the melter, operate safely, and produce a consistent product.

The HWVP design and process were evaluated with test equipment which is as close to plant design as practical. The test approach was to establish baseline equipment performance with water. Then, each unit operation of the feed-preparation process for the Slurry Receipt and Adjustment Tank (SRAT), Slurry Mix Evaporator (SME), and Melter-Feed Tank (MFT) was completed in the test tank with nonradioactive HWVP feed simulant. For each process step, equipment was observed and data taken to characterize the process and evaluate equipment performance.

The parameters varied included the slurry type, liquid level, and agitation speed. The two liquid levels primarily used in the test tank were a nominal high level (approximately $7800 \mathrm{gal}$ ) and an intermediate level 6 in. above the tank heating/cooling coils (approximately $5700 \mathrm{gal}$ ). The agitator was characterized at various speeds $(45,85$, and $130 \mathrm{rpm})$ with water, during the equipment performance testing, and with the HWVP feed slurry simulant. The test media included HWVP simulated dilute feed (approximately $31 \mathrm{~g}$ waste oxide/L melter feed), concentrated HWVP feed (approximately $140 \mathrm{~g}$ waste oxide/L meiter feed), formated slurry (approximately $150 \mathrm{~g}$ waste oxide/L melter feed), and melter feed (approximately $500 \mathrm{~g}$ total oxide $/ \mathrm{L}$ melter feed). 
The following conclusions and observations resulted from the testing program:

- The slurries tested had the following rheological characteristics:

- Dilute Neutralized Current Acid Waste (NCAW): Newtonian fluid.

- Concentrated NCAW: Bingham plastic which changed to Newtonian fluid at higher shear rates.

- Formated NCAW: Bingham plastic which changed to Newtonian fluid at higher shear rates.

- Melter Feed: Bingham plastic.

- The yield stress of the melter feed at a concentration of $500 \mathrm{~g}$ waste oxide/L increased with time after makeup.

- The yield stress and apparent viscosity of the melter feed could be easily reduced by adding small amounts of dilution water.

- The yield stress of the melter feed increased with concentration.

- The melter feed formed a gel-like material (Bingham plastic) when no shear was applied.

- The tank-coil heat-transfer coefficients were comparable to or somewhat higher than those determined for similar equipment and processes at TNX [Training and Experimental (SRI. Area)] at SRS for DWPF. The higher values were attributed to new equipment, testing conditions, and equations.

- For very viscous materials such as the melter feed, the boiling, heating, and cooling heattransfer coefficients are significantly lower (by a factor of 2 to 3 ) compared to other materials tested.

- There was no evidence of vapor binding during tank-coil heat-transfer tests.

- Heat loss from the tank was higher than predicted by the HWVP architect-engineer due to differences in testing conditions and lack of insulation on the test tank bottom.

- Slurries tested could be kept homogeneous under all conditions tested, which included agitator speeds $\geq 45 \mathrm{rpm}$ and volumes of 5700 to 7800 gal. For melter feed, the agitator speed was maintained at $130 \mathrm{rpm}$ to inhibit "gelling." 
- The process samples were determined to be representative of all slurries in the tank. The analytical standard deviations for wt $\%$ solids were $1 \%$ to $3 \%$. The sample values accurately represented what was calculated to be in the tank based on the slurry makeup procedure.

- The only solid to significantly accumulate in or coat the tank was the melter feed, because of its Bingham-plastic properties. The melter-feed buildup was enriched with solids. The melter feed tended to accumulate on hot surfaces and not on cooler surfaces. The buildup could be easily removed by. washing with water or applying a shear stress.

- The Bingham-plastic melter feed inhibited flow between the heat-transfer coils.

- When the slurry level drops below the coil top, the slurry may become nonhomogeneous due to poor mixing.

- The Holledge level detection system was damaged during testing by water turbulence "sloshing" during agitation at low. water level.

- The presence of non-condensable gas in the condenser process vapor reduced the condensate flow rate, increased liquid entrainment in the condenser off-gas, and reduced the condenser heat-transfer coefficient. The detrimental effects of non-condensable gas were more pronounced at higher evaporation rates and higher non-condensible gas flow rates.

- The measured pressure.drop in the condenser was close to that calculated for cooling-water flow.

- For the boiling conditions tested, the DFs between the tank contents and condensate were $10^{3}$ and $10^{6}$, depending on the element analyzed for and the testing conditions.

- Observation of the condenser heat-transfer coefficient revealed no apparent condenser surface "fouling" or vapor binding.

- No lumps built up in the melter feed during melter feeding.

- Measured pressure drops for $1 / 2-, 1$, and 2 -in. pipes and a portion of the melter-feed system are consistently about one-half the values calculated over the flow range tested from 3 to $10^{\circ} \mathrm{ft} / \mathrm{s}$.

- Twenty seconds of prime-water flow was required to prime the transfer and sample pumps.

- The outlet valve on the transfer pump had to be partially closed to provide sufficient back pressure to prime the pump. 
- Slurry level in tank has the greatest effects on the head and capacity characteristics of the transfer pump.

- Temperature and agitation had no apparent significant effect on pump performance.

- Acceptable measurements of pressure drops in the long radius elbows could not be made because the test instrumentation and the testing arrangement were insufficiently sensitive.

- Foaming did occur, but not to the extent that concentration, formating, and digestion operations were hampered. Foaming was encountered only at higher heating rates and could be controlled by either lowering the heating rate or adding Dow Corning 544 Antifoam $^{\otimes}$.

- The magnirude of the tank pressure fluctuations increased with increasing heating-coil flow rate. The tank pressure fluctuations could be controlled by lowering the steam flow in the heating coils.

- Solids concentrations were so low in the condensate line that intermittent line-sampling methods were inadequate for determining the composition of solids in the condensate line. If these smaller concentrations of solids are still a concern, the condensate line could be sampled with an in-line filter so that solids can be accumulated over longer periods of time.

- Surges in offgas generation during formating caused pressure spikes and consequent tripping of the automatic safety interlocks. It may be necessary to increase the tank vacuum or to add $\mathrm{HCOOH}$ at a lower rate.

- Of the initial nitrogen present in the slurry, $92 \%$ was accounted for in the mass balance calculation. Uncertainty in the analytical measurements, offgas measurements, and offgas system condensate calculations contributed to the error in the mass balance.

- A negligible amount of $\mathrm{NH}_{3}$ and $\mathrm{H}_{2}(\approx 11$ moles) were. produced during formating testing. The amounts of $\mathrm{NH}_{3}$ and $\mathrm{H}_{2}$ were expected to be low because the NCAW simulant did not contain noble metals.

- While 7400 gal of NCAW simulant without noble metals were formated and digested, 5228 moles of $\mathrm{NO}_{x}$ were generated at a maximum rate of 37 moles $/ \mathrm{min}$. These numbers are expected to be $10 \%$ to $15 \%$ low due to the effect of $\mathrm{NO}_{2}$ stripped by the offgas system condensate. Discontinuous $\mathrm{HCOOH}$ addition may affect the reported maximum and minimum offgas generation rate for a $1.2 \mathrm{gpm} \mathrm{HCOOH}$ addition rate. 
- Two reactions are predicted to produce NOx in the SRAT:

$$
\begin{gathered}
2 \mathrm{NaNO}_{2}+3 \mathrm{HCOOH} \rightarrow \begin{array}{c}
2 \mathrm{NO}+\mathrm{CO}_{2}+2 \mathrm{NaCOOH}+2 \mathrm{H}_{2} \\
\text { (nitrite reduction by } \mathrm{HCOOH} \text { ) }
\end{array} \\
3 \mathrm{HNO}_{2} \rightarrow 2 \mathrm{NO}+\mathrm{NO}_{3}^{-}+\mathrm{H}^{+}+\mathrm{H}_{2} \mathrm{O} \text { (disproportionation of nitrous acid) }
\end{gathered}
$$

- Calculation by the $\mathrm{CO}_{2}$ balance method showed that $\approx 22 \%$ of the NOx was from disproportionation of nitrous acid. The formate balance method showed $\approx 42 \%$ of the NOx from disproportionation. The calculations assumed all of the carbonate was destroyed and that none of the $\mathrm{MnO}_{2}$ was reduced to $\mathrm{Mn}^{+2}$. If $80 \%$ of the $\mathrm{MnO}_{2}$ were assumed to be reduced to $\mathrm{Mn}^{+2}$, the results would be $37 \%$ and $58 \%$, respectively, from the carbon dioxide and formate balance methods. Uncertainty in analytical measurements as well as incomplete knowledge of the siurry chemistry accounts for the discrepancy.

- The $\mathrm{NO} \rightarrow \mathrm{NO}_{2}$ conversion was estimated to be $45 \%$ to $94 \%$ complete when the offgas was measured. Offgas measurements should be representative of the reactions occurring in the tank vapor space and condenser. The range encompasses the uncertainty in the NOx generation values, the assumption that condensate nitrate and nitrite result from the reaction of $\mathrm{NO}_{2}$ with the condensate, the assumption that the increase slurry nitrate is (or is not) the result of $\mathrm{NO} \rightarrow \mathrm{NO}_{2} \rightarrow \mathrm{NO}_{3}{ }^{-}$, and the uncertainty in $\mathrm{N}_{2}$ and $\mathrm{O}_{2}$ inleakage.

- Condenser operation cooled the condensate to $50^{\circ} \mathrm{C}$ and below during periods of high NOx generation.

- The condensate collection system design affected the condensate temperature. At low condensate generation rates $(<2 \mathrm{gpm})$, the condensate temperature increased about $50^{\circ} \mathrm{C}$. The increase in temperature was probably caused by heat transfer through the condenser separator unit, which had process vapor (steam) on one side and condensate on the other side. External heating of the condensate exit pipe by the radiant heat from the SRAT might also have occurred.

- Approximately $27 \%$ of the nitrogen generated as NOx was present in the condensate as nitrate or nitrite. This assumes that $\mathrm{NO} \rightarrow \mathrm{NO}_{2} \rightarrow \mathrm{NO}_{2}^{-}$and $\mathrm{NO}_{3}{ }^{-}$in the condensate.

- Silver buildups were observed on tank components after testing was completed. Analyses showed between $20 \%$ and $25 \%$ of the silver in the waste simulant was reduced during feed preparation. 


\section{Recommendations}

The following recommendations were developed from the testing program and experience:

- Additional testing is needed to determine the decrease in heat-transfer coefficient with operating time, or selection of a conservative heat-transfer coefficient should be based on testing to date and the potential for fouling.

- The condenser design may require modification to inhibit entrainment and condensate buildup, depending on which operating conditions are selected for use.

- The slurry process characteristics need to be controlled to be within the operating parameters of the equipment.

- A full-scale formating test needs to be performed with continuous formic acid addition to determine offgas-generation characteristics. 


\section{Acronyms}

$\begin{array}{ll}\text { AA } & \text { atomic absorption } \\ \text { ACFM } & \text { actual cubic feet per minute } \\ \text { ADC } & \text { analog-digital converters } \\ \text { BWG } & \text { Birmingham Wire Gage } \\ \text { CDF } & \text { condensate decontamination factor } \\ \text { cfS } & \text { cubic feet per second } \\ \text { CG\&A } & \text { calibration, grooming, and alignment } \\ \text { CNCAW } & \text { concentrated neutralized current acid waste } \\ \text { CPU } & \text { Central Processing Unit } \\ \text { CRT } & \text { cathode-ray tube } \\ \text { DCS } & \text { Digital Control System } \\ \text { DAS } & \text { data acquisition system } \\ \text { DF } & \text { decontamination factor } \\ \text { DSC } & \text { differential scanning calorimetry } \\ \text { DOE } & \text { U.S. Department of Energy } \\ \text { DTA } & \text { differential thermal analysis } \\ \text { DWPF } & \text { Defense Waste Processing Facility } \\ \text { DNCAW } & \text { diluted neutralized current acid waste } \\ \text { EP } & \text { equipment performance } \\ \text { FPSMT } & \text { Feed Preparation System Materials Testing } \\ \text { FPTS } & \text { Feed Preparation Test System } \\ \text { FNCAW } & \text { formated neutralized current acid waste } \\ \text { gpm } & \text { gallons per minute } \\ \text { HEPA } & \text { high-efficiency particulate air (filter) } \\ \text { HFDAS } & \text { high-frequency data acquisition system } \\ \text { HLW } & \text { high-level waste } \\ \text { HWVP } & \text { Hanford Waste Vitrification Plant } \\ \text { IC } & \text { lon Chromatography } \\ \text { ICP } & \text { inductively coupled plasma } \\ \text { ICP-MS } & \text { lon Coupled Plasma Mass Spectroscopy } \\ \text { IEEE } & \text { Institute of Electrical and Electronics Engineers } \\ \text { ISA } & \text { industry standard architecture } \\ \text { LFCM } & \text { liquid fed ceramic melter } \\ \text { LEL } & \text { lower explosive limit } \\ \text { LL } & \text { liquid level } \\ \text { LRB } & \text { Laboratory Record Book } \\ \text { M\&TE } & \text { measuring and test equipment } \\ \text { MF } & \text { melter feed } \\ \text { MFT } & \text { melter-feed tank } \\ \text { NCAW } & \text { neutralized current acid waste } \\ & \end{array}$




\begin{tabular}{|c|c|}
\hline NPSHA & net positive suction head available \\
\hline P\&ID & piping and instrumentation diagram \\
\hline $\mathrm{PC}$ & process characterization \\
\hline PHA & Precipitate Hydrolysis Aqueous \\
\hline PHTD & PNL HWVP Technology Development \\
\hline PI & process instruction \\
\hline PNL & Pacific Northwest Laboratory \\
\hline POG & process off gas \\
\hline PSCM & pilot-scale ceramic melter \\
\hline psi & per square inch \\
\hline PVV & process vessel ventilation \\
\hline QC & quality control \\
\hline RP/PLT & Radioactive Process/Product Laboratory Testing \\
\hline rpm & revolutions per minute \\
\hline $\mathrm{R} / \mathrm{RCE}$ & Redox/Rheology Control Evaluation \\
\hline RWCT & recycle waste collection tank \\
\hline SBS & submerged bed scrubber \\
\hline scfh & standard cubic feet per hour \\
\hline scfm & standard cubic feet per minute \\
\hline SEM & scanning electron microscope \\
\hline SIE & specific ion electrode \\
\hline SIPT & slurry-integrated performance testing \\
\hline SME & Slurry Mix Evaporator \\
\hline SMECT & Slurry Mix Evaporator Condensate Tank \\
\hline SpG & specific gravity \\
\hline SRAT & slurry receipt and adjustment tank \\
\hline SRL & Savannah River Laboratory \\
\hline SRP & Savannah River Plant \\
\hline SRS & Savannah River Site \\
\hline STL & slurry testing loop \\
\hline TBD & to be determined \\
\hline TEFC & totally enclosed fan cooled \\
\hline TIC & total inorganic carbon \\
\hline TNX & Training and Experimental (SRL Area) \\
\hline TOC & total organic carbon \\
\hline TRU & transuranic \\
\hline UEL & upper explosive limit \\
\hline WC & water column \\
\hline WFQ & Waste Form Qualification \\
\hline WHC & Westinghouse Hanford Company \\
\hline WM\&EC & Waste Management and Environmental Compliance \\
\hline WSRC & Westinghouse Savannah River Company \\
\hline WV & West Valley \\
\hline
\end{tabular}


WVDP

West Valley Demonstration Project

XRD

$\mathrm{X}$-ray diffraction

xiii 


\section{Acknowledgments}

The authors acknowledge the following Pacific Northwest Laboratory staff who made the technical effort and document possible:

R. E. Thornhill supervised design, procurement, installation, and startup of most of the equipment.

G. A. Jensen provided general testing guidance and document review as Task Manager.

D. L. Widrig and F. Hara provided analytical support.

A. H. Ignatov and S. K. Loverne edited the document.

H. C. Morgan and A. A. Taylor supervised document typing and assembly. 


\section{Contents}

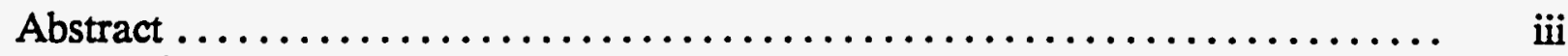

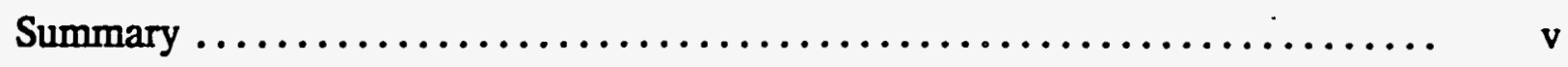

Acronyms $\ldots \ldots \ldots \ldots \ldots \ldots \ldots \ldots \ldots \ldots \ldots \ldots \ldots \ldots \ldots \ldots \ldots \ldots \ldots \ldots \ldots$

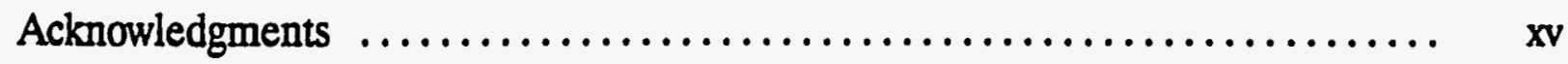

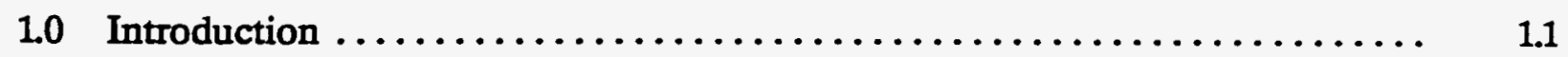

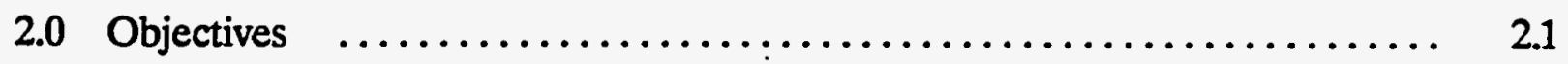

2.1 Process Characterization $\ldots \ldots \ldots \ldots \ldots \ldots \ldots \ldots \ldots \ldots \ldots . . .1$

2.2 Equipment Performance $\ldots \ldots \ldots \ldots \ldots \ldots \ldots \ldots \ldots \ldots \ldots . . .1$

2.3 Fluor-Daniel Technology Data Needs $\ldots \ldots \ldots \ldots \ldots \ldots \ldots \ldots .2 .3$

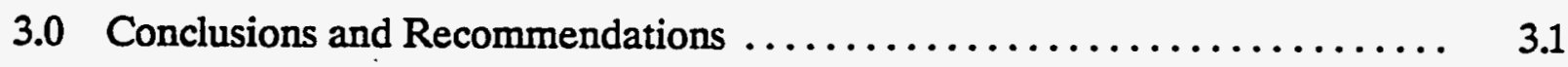

3.1 Conclusions $\ldots \ldots \ldots \ldots \ldots \ldots \ldots \ldots \ldots \ldots \ldots \ldots \ldots \ldots \ldots, 3.1$

3.2 Recommendations $\ldots \ldots \ldots \ldots \ldots \ldots \ldots \ldots \ldots \ldots \ldots \ldots \ldots \ldots \ldots . \ldots \ldots \ldots$

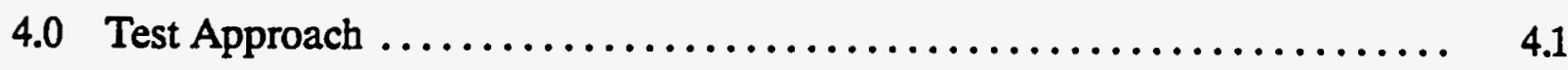

4.1 HWVP Process Description ........................ 4.1

4.2 Test Methodology $\ldots \ldots \ldots \ldots \ldots \ldots \ldots \ldots \ldots \ldots \ldots \ldots \ldots \ldots, 4.1$

5.0 Process Test Equipment $\ldots \ldots \ldots \ldots \ldots \ldots \ldots \ldots \ldots \ldots \ldots \ldots \ldots . \ldots . \ldots \ldots$

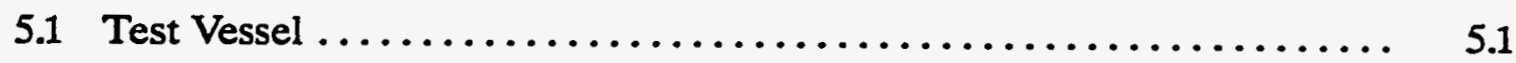

5.2 Heat-Transfer Coils $. \ldots \ldots \ldots \ldots \ldots \ldots \ldots \ldots \ldots \ldots \ldots \ldots . . \ldots . . \ldots \ldots$

5.3 Condenser $\ldots \ldots \ldots \ldots \ldots \ldots \ldots \ldots \ldots \ldots \ldots \ldots \ldots \ldots \ldots \ldots . .6 .3$

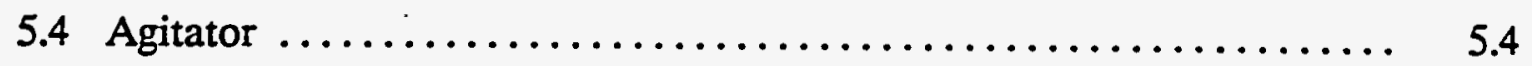

5.5 Slurry Transfer Pump $\ldots \ldots \ldots \ldots \ldots \ldots \ldots \ldots \ldots \ldots \ldots \ldots \ldots .5 .5$ 
5.6 Feed Delivery Systems $\ldots \ldots \ldots \ldots \ldots \ldots \ldots \ldots \ldots \ldots \ldots \ldots \ldots . .5$

5.7 Sample System $\ldots \ldots \ldots \ldots \ldots \ldots \ldots \ldots \ldots \ldots \ldots \ldots \ldots \ldots \ldots \ldots$

5.8 Thermowell $\ldots \ldots \ldots \ldots \ldots \ldots \ldots \ldots \ldots \ldots \ldots \ldots \ldots \ldots \ldots \ldots .6 .7$

5.9 Slurry Transfer Test Loop $\ldots \ldots \ldots \ldots \ldots \ldots \ldots \ldots \ldots \ldots \ldots \ldots . \quad 5.7$

5.10 Holledge Level Detection System $\ldots \ldots \ldots \ldots \ldots \ldots \ldots \ldots \ldots \ldots, \quad 5.8$

5.11 Holledge Calibration Tank $\ldots \ldots \ldots \ldots \ldots \ldots \ldots \ldots \ldots \ldots \ldots . \quad 5.8$

5.12 Support Equipment $\ldots \ldots \ldots \ldots \ldots \ldots \ldots \ldots \ldots \ldots \ldots \ldots \ldots \ldots \ldots . .6$

5.13 Measuring and Test Equipment $\ldots \ldots \ldots \ldots \ldots \ldots \ldots \ldots \ldots \ldots \ldots \ldots \ldots \ldots \ldots$

6.0 Process Slurries Makeup and Characterization $\ldots \ldots \ldots \ldots \ldots \ldots \ldots .6 .1$

6.1 General Remarks $\ldots \ldots \ldots \ldots \ldots \ldots \ldots \ldots \ldots \ldots \ldots \ldots \ldots \ldots .6 .1$

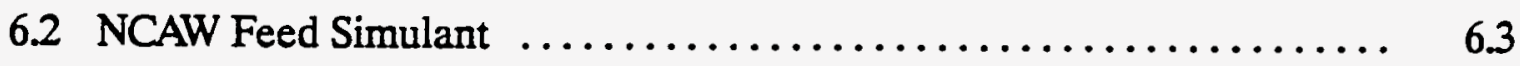

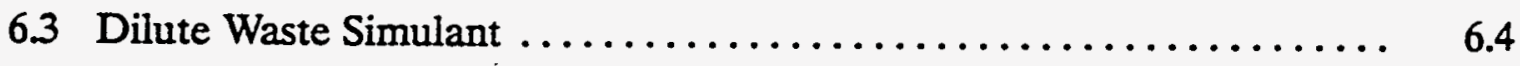

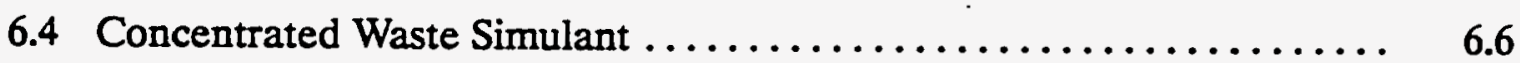

6.5 Formated Waste Simulant $\ldots \ldots \ldots \ldots \ldots \ldots \ldots \ldots \ldots \ldots \ldots .6 .7$

6.6 Recycle Waste Simulant $\ldots \ldots \ldots \ldots \ldots \ldots \ldots \ldots \ldots \ldots \ldots \ldots . \ldots . . \ldots$

6.7 Formated Waste Simulant with Recycle $\ldots \ldots \ldots \ldots \ldots \ldots \ldots \ldots .6 .12$

6.8 Dry Process Frit Properties $\ldots \ldots \ldots \ldots \ldots \ldots \ldots \ldots \ldots \ldots \ldots \ldots .6 . \ldots \ldots$

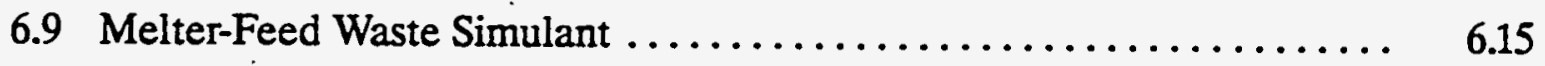

6.10 Rheological Discussion $\ldots \ldots \ldots \ldots \ldots \ldots \ldots \ldots \ldots \ldots \ldots \ldots \ldots .6 .16$

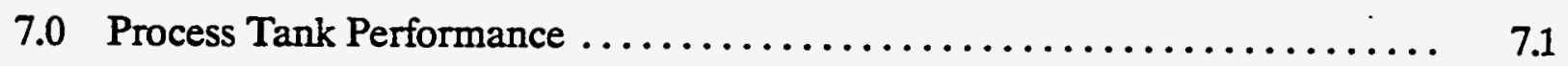

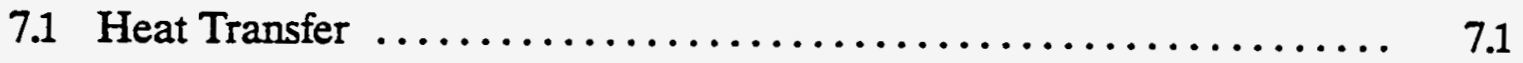

7.2 Mixing and Sampling Performance $\ldots \ldots \ldots \ldots \ldots \ldots \ldots \ldots \ldots \ldots . . .24$ 


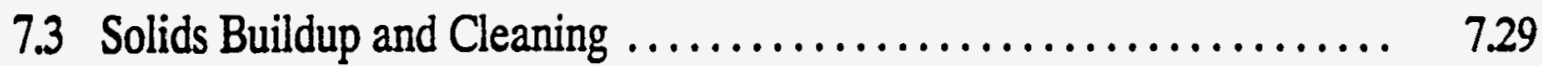

7.4 Instrumentation $\ldots \ldots \ldots \ldots \ldots \ldots \ldots \ldots \ldots \ldots \ldots \ldots \ldots \ldots \ldots \ldots \ldots \ldots \ldots \ldots, \quad 7.31$

8.0 Condensers Performance . ................................ 8.1

8.1 Effect of Non-Condensable Gas on Heat Transfer ............. 8.1

8.2 Condenser Shell-Side Pressure Drop $\ldots \ldots \ldots \ldots \ldots \ldots \ldots \ldots \ldots \ldots . \quad 8.17$

8.3 Slurry Carryover During Boiling ........................... 8.18

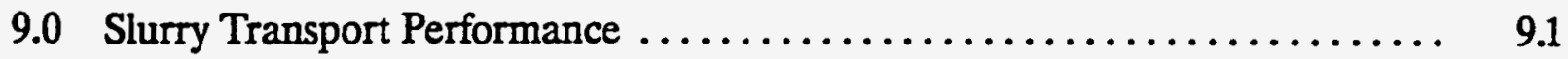

9.1 Process Slurry Flow in Pipes and Fittings $\ldots \ldots \ldots \ldots \ldots \ldots \ldots \ldots \ldots . \quad 9.1$

9.2 Melter Feeding $\ldots \ldots \ldots \ldots \ldots \ldots \ldots \ldots \ldots \ldots \ldots \ldots \ldots \ldots \ldots \ldots \ldots \ldots \ldots, \quad 9.30$

9.3 Melter Feed/Transfer and Sample Pump Performance ............ 9.44

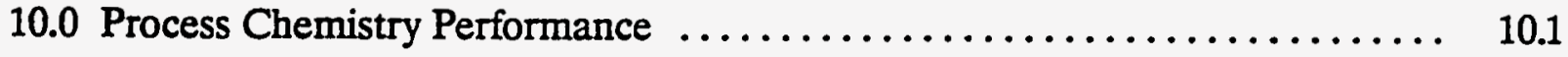

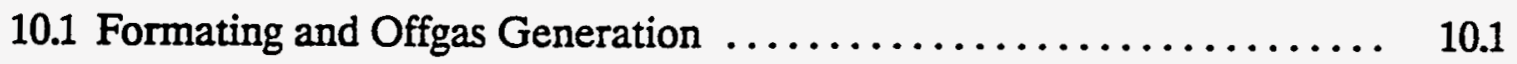

10.2 Foaming Suppression $\ldots \ldots \ldots \ldots \ldots \ldots \ldots \ldots \ldots \ldots \ldots \ldots \ldots \ldots \ldots \ldots \ldots \ldots, 10.30$

10.3 Silver Coating of Feed-Preparation System Components During Testing 10.44

10.4 Comparison of Bench-Scale and Full-Scale Formating and Digestion Process Behavior ........................... 10.48

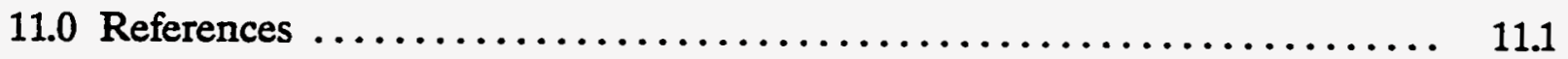

Appendix A - Equipment Description Figures $\ldots \ldots \ldots \ldots \ldots \ldots \ldots \ldots \ldots \ldots \ldots \ldots \ldots \ldots$ A.1

Appendix B - Chemical Compositions-Calculated Target Compositions for Each Simulant $\ldots \ldots \ldots \ldots \ldots \ldots \ldots \ldots \ldots \ldots \ldots \ldots \ldots \ldots, \quad$ B.1

Appendix C - Chemical Compositions - Comparison of Target Compositions to Measured Compositions for Each Simulant $\ldots \ldots \ldots \ldots \ldots \ldots \ldots \ldots$ C.1

Appendix D - Rheological Properties-Settling Rates and Rheograms ......... D.1

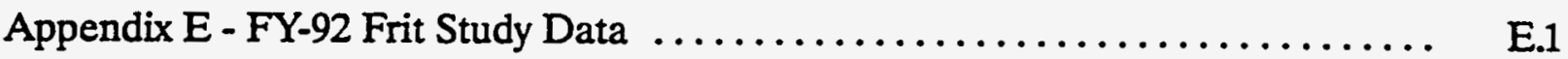


Appendix F - Rheogram Overlays and Summary Data $\ldots \ldots \ldots \ldots \ldots \ldots \ldots$ F.1

Appendix G - Tank Design Calculations . .................... G.1

Appendix H - Evaporator Performance Graphs $\ldots \ldots \ldots \ldots \ldots \ldots \ldots \ldots \ldots \ldots$ H.1

Appendix I - Tank Heat Transfer Test Summary Tables ............... I.1

Appendix J - Homogeneity/Sampling Data Tables $\ldots \ldots \ldots \ldots \ldots \ldots \ldots \ldots$ J.1

Appendix K - Solids Buildup Pictures $\ldots \ldots \ldots \ldots \ldots \ldots \ldots \ldots \ldots \ldots \ldots \ldots \ldots \ldots \ldots \ldots \ldots \ldots$

Appendix L - Condenser Design Calculations $\ldots \ldots \ldots \ldots \ldots \ldots \ldots \ldots \ldots$ L.1

Appendix M - Condenser Heat Transfer Process Data Tables ............ M.1

Appendix N - Interpolated Data at Standard Conditions - Summary Tables ..... N.1

Appendix O - Condenser Performance Graphs $\ldots \ldots \ldots \ldots \ldots \ldots \ldots \ldots \ldots . . .1$

Appendix P - Condenser Shell-Side Pressure Drop Calculation ............ P.1

Appendix Q - Calculation of Line Loss for Condenser Shell-Side Pressure Drop ... Q.1

Appendix R - Condensate Analyses $\ldots \ldots \ldots \ldots \ldots \ldots \ldots \ldots \ldots \ldots \ldots \ldots . \quad$ R.1

Appendix S - Additional Condenser Performance Tables ................ S.1

Appendix T - Slurry Flow Pressure Drop Data and Calculations $\ldots \ldots \ldots \ldots \ldots$ T.1

Appendix U - Slurry Flow Engineering Analyses $\ldots \ldots \ldots \ldots \ldots \ldots \ldots \ldots \ldots$ U.1

Appendix V - Pressure And Flow Run Data Plots On Melter Feed Line ....... V.

Appendix W - Pressure And Flow Run Data Plots On Melter Feed Recycle Loop W.1

Appendix X - Summary Of Log Book And Laboratory Record Book Entries .... X.1

Appendix Y - Reynold's Number Calculation For Melter Feed Line And Recycle Loop Y.1

Appendix Z - Pumping Sample Calculations $\ldots \ldots \ldots \ldots \ldots \ldots \ldots \ldots \ldots \ldots \ldots \ldots \ldots \ldots \ldots$

Appendix AA - Key Formating Test Events $\ldots \ldots \ldots \ldots \ldots \ldots \ldots \ldots \ldots \ldots$ AA.1 
Appendix AB - Formating Nitrogen Mass Balance Calculations $\ldots \ldots \ldots \ldots \ldots$ AB.1 Appendix AC - Condensate Analyses $\ldots \ldots \ldots \ldots \ldots \ldots \ldots \ldots \ldots \ldots \ldots \ldots$ AC.1 Appendix AD - Fluid Transport Information $\ldots \ldots \ldots \ldots \ldots \ldots \ldots \ldots \ldots \ldots$ AD. 1 


\section{Figures}

$5.1 \quad$ Feed Preparation System $\ldots \ldots \ldots \ldots \ldots \ldots \ldots \ldots \ldots \ldots \ldots \ldots \ldots \ldots . \ldots \ldots \ldots$

6.1 Simulant Flowsheet for Slurry-Integrated Performance Testing ........ 6.2

6.2 Daily Yield Stress Data for Melter Feed $\ldots \ldots \ldots \ldots \ldots \ldots \ldots \ldots \ldots \ldots, 6.21$

6.3 Yield Stress and Oxide Loading Data for Melter Feed from Selected Samples ......................................... $\quad 6.23$

6.4 Yield Stress of Melter Feed as a Function of Oxide Loading $\ldots \ldots \ldots \ldots .6 .24$

6.5 Yield Stress and $\mathrm{pH}$ Data for Melter Feed from Selected Samples ...... 6.25

7.1 Set-Up for Holledge Sensor Calibration with Holledge Sensor Calibrator .. 7.34

7.2 Actual Level Versus Holledge Level for Sensor $1005 \ldots \ldots \ldots \ldots \ldots \ldots .7 .35$

7.3 Holledge Sensor Error Versus Actual Level for Sensor 1005 ......... 7.36

7.4 Actual Level Versus Holledge Level for Sensor $1002 \ldots \ldots \ldots \ldots \ldots \ldots . . \ldots .37$

7.5 Holledge Sensor Error Versus Actual Level for Sensor 1002 ......... 7.38

7.6 Actual Level Versus Holledge Level for Sensor 1003 ............... 7.39

7.7 Holledge Sensor Error Versus Actual Level for Sensor 1003 .......... 7.40

8.1 Condenser Heat Transfer Coefficient Versus Process Evaporation Rate ... 8.10

8.2 Condenșer Heat Transfer Coefficient Versus Off-Gas Flow ........... 8.11

8.3 Decrease in Condenser Heat Transfer Coefficient Versus Off-Gas Flow ... 8.12

8.4 Shell-Side Pressure Drop Versus Flow Rate for SIPT Condenser ....... 8.20

8.5 Shell-Side Pressure Drop Versus Flow Rate for SIPT Condenser ....... 8.22

8.6 Condenser Heat Transfer Coefficient Versus Steam Flow for NCAW-1

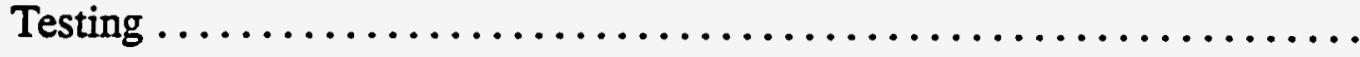

8.7 Condenser Overhead Flowrate Versus Steam Flow for NCAW-1 Testing $\ldots \quad 8.26$ xxii 
9.1 Flow Curves for Various Types of Time-Independent Fluids $\ldots \ldots \ldots \ldots .9 .2$

9.2 HWVP Process Slurry Fluid Behavior $\ldots \ldots \ldots \ldots \ldots \ldots \ldots \ldots \ldots .9 .4$

9.3 Water-Flow Pressure Drop in 1/2-in. Schedule 40 Stainless Steel Pipe

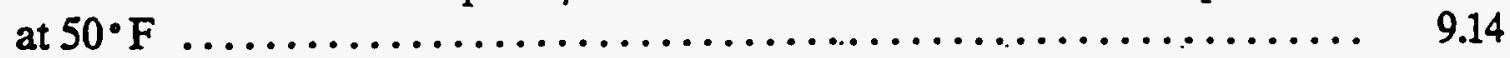

9.4 Water-Flow Pressure Drop in 1-in. Schedule 40 Stainless Steel Pipe

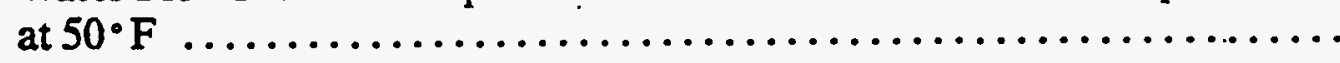

9.5 Water-Flow Pressure Drop in 2-in. Schedule 40 Stainless Steel Pipe

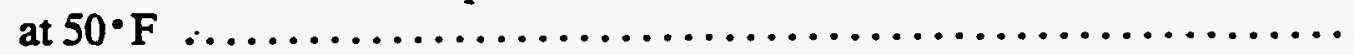

9.6 DNCAW Pressure Drop in 1/2-in. Schedule 40 Stainless Steel Pipe

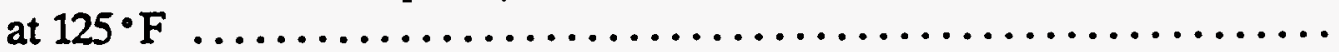

9.7 DNCAW Pressure Drop in 1-in. Schedule 40 Stainless Steel Pipe at $125^{\circ} \mathrm{F}$. $\quad 9.18$

9.8 DNCAW Pressure Drop in 2-in. Schedule 40 Stainless Steel Pipe at $125 \cdot \mathrm{F}$. 9.19

9.9 CNCAW Pressure Drop in 1/2-in. Schedule 40 Stainless Steel Pipe at $125 \cdot \mathrm{F}$

9.10 CNCAW Pressure Drop in 1-in. Schedule 40 Stainless Steel Pipe at $125^{\circ} \mathrm{F}$. .

9.11 CNCAW Pressure Drop in 2-in. Schedule 40 Stainless Steel Pipe at $125^{\circ} \mathrm{F}$..

9.12 FNCAW Pressure Drop in 1/2-in. Schedule 40 Stainless Steel Pipe at $125^{\circ} \mathrm{F}$

9.13 FNCAW Pressure Drop in 1-in. Schedule 40 Stainless Steel Pipe at $125^{\circ} \mathrm{F}$..

9.14 FNCAW Pressure Drop in 2-in. Schedule 40 Stainless Steel Pipe at 125 F .. 9.25

9.15 MF Pressure Drop in 1/2-in. Schedule 40 Stainless Steel Pipe at $125^{\circ} \mathrm{F} \ldots$. .

9.16 MF Pressure Drop in 1-in. Schedule 40 Stainless Steel Pipe at $125^{\circ} \mathrm{F} . \ldots$.

9.17 MF Pressure Drop in 2-in. Schedule 40 Stainless Steel Pipe at $125^{\circ} \mathrm{F} \ldots \ldots$.

9.18 Pressure Drop (PI-1020 - PI-1034) versus Flow (FI-1023) for First Two Parts of the-Melter Feed-Line Section 
9.19 Pressure Drop (PI-1034 - 1 atm) versus Flow (FI-1023) for Last Part of the Melter Feed-Line Section $(8-\mathrm{ft}$ coil) $\ldots \ldots \ldots \ldots \ldots \ldots \ldots \ldots \ldots . \quad 9.33$

9.20 Melter Feed-Line Pressure Drop (PI-1020 - PI-1034) Divided by Flow (FI-1023) versus Run Time (from 4/17/93 12:00 a.m.), [0.20 to $0.35 \mathrm{gpm}] \ldots \ldots \ldots .6 .35$

9.21 Melter Feed-Line Pressure Drop (PI-1034 - 1 atm) Divided by Flow (FI-1023) versus Run Time (from 4/17/93 12:00 a.m.), [0.20 to $0.35 \mathrm{gpm}$ ] ......... 9.36

9.22 Recycle-Loop Pressure Drop (PI-1031 - PI-1020) Divided by Flow (FI-1024) Squared versus Run Time (from 4/17/93 12:00 a.m.), [77 to $90 \mathrm{gpm}$ ] ..... 9.37

9.23 Viscosity Comparison with Oxide Concentration, $\mathrm{pH}$, and Temperature of Simulated Melter Feed versus Run Time $\ldots \ldots \ldots \ldots \ldots \ldots \ldots \ldots . .9 .38$

9.24 Cross-Flow Strainer Effects on Frit and Waste Ratio ................ 9.43

9.25 Total Head versus Capacity (Water) Transfer Pump Manufacturer's Curve and Experimental Curve ................................. 9.46

9.26 Total Head versus Capacity (Water) Sample Pump Manufacturer's Curve .. $\quad 9.47$

9.27 Total Head versus Capacity (Water) Transfer-Pump Speed Variation ...... 9.48

9.28 Total Head versus Capacity (Water) Transfer-Pump Speed Variation ..... 9.49

9.29 Total Head versus Capacity (Water) Transfer-Pump Temperature Variation .......................................... 9.50

9.30 Total Head versus Capacity (Water) Transfer-Pump Agitation Variation ... 9.51

9.31 Total Head versus Capacity (Water) Transfer-Pump Speed Variation ..... 9.52

9.32 Total Head versus Capacity (Water) Transfer-Pump Speed Variation ..... 9.53

9.33 Total Head versus Capacity (Water) Transfer-Pump Speed Variation ...... 9.54

9.34 Total Head versus Capacity (Water) Transfer-Pump Tank-Level Variation .. 9.55

9.35 Total Head versus Capacity (Water) Sample-Pump Speed Variation $\ldots . . .9 .56$

9.36 Total Head versus Capacity (Water) Sample-Pump Speed Variation $\ldots . . .9 .57$

9.37 Total Head versus Capacity (Water) Sample-Pump Speed Variation $\ldots . . .9 .58$ 
9.38 Total Head versus Capacity (Water) Sample-Pump Tank-Level Variation .. 9.59

9.39 Total Head versus Capacity (Dilute Feed) Transfer-Pump Speed Variation . $\quad 9.60$

9.40 Total Head versus Capacity (Dilute Feed) Transfer-Pump Speed Variation . $\quad 9.61$

9.41 Total Head versus Capacity (Dilute Feed) Transfer-Pump Tank-Level

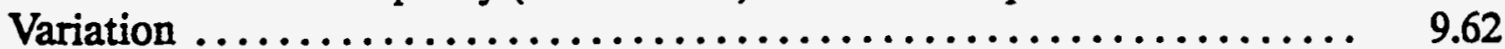

9.42 Total Head versus Capacity (Dilute Feed) Transfer-Pump Temperature Variation $. . . \ldots \ldots \ldots \ldots \ldots \ldots \ldots \ldots \ldots \ldots \ldots \ldots \ldots \ldots \ldots, \quad 9.63$

9.43 Total Head versus Capacity (Dilute Feed) Transfer-Pump Agitation Variation ........................................... 9.64

9.44 Total Head versus Capacity (Concentrated Feed) Transfer-Pump Speed

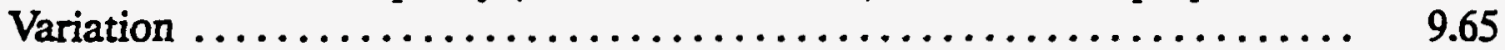

9.45 Total Head versus Capacity (Concentrated Feed) Transfer-Pump Speed

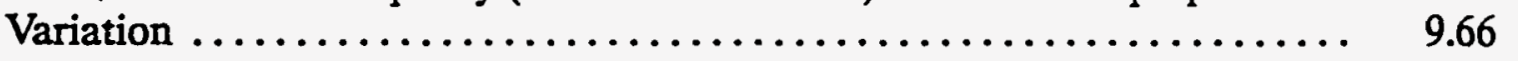

9.46 Total Head versus Capacity (Concentrated Feed) Transfer-Pump

Tank-Level Variation ................................ 9.67

9.47 Total Head versus Capacity (Concentrated Feed) Transfer-Pump

Temperature Variation $\ldots . \ldots \ldots \ldots \ldots \ldots \ldots \ldots \ldots \ldots \ldots . ., 9.68$

9.48 Total Head versus Capacity (Concentrated Feed) Transfer-Pump Agitation

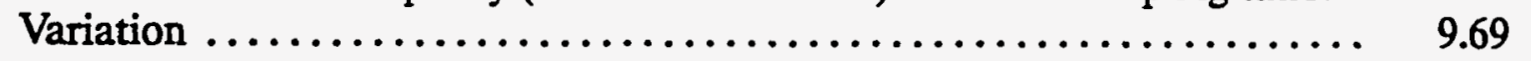

9.49 Total Head versus Capacity (Formatted Feed) Transfer-Pump Speed Variation $\ldots \ldots \ldots \ldots \ldots \ldots \ldots \ldots \ldots \ldots \ldots \ldots \ldots \ldots \ldots, \quad 9.70$

9.50 Total Head versus Capacity (Melter Feed) Transfer-Pump Speed Variation 9.71

9.51 Total Head versus Capacity Transfer-Pump Fluid Variation ........... 9.72

9.52 Total Head versus Capacity (Dilute Feed) Sample-Pump Speed Variation 9.73

9.53 Total Head versus Capacity (Dilute Feed) Sample-Pump Speed Variation . 9.74

9.54 Total Head versus Capacity (Dilute Feed) Sample-Pump Tank-Level Variation 
9.55 Total Head versus Capacity (Dilute Feed) Sample-Pump Temperature Variation

9.56 Total Head versus Capacity (Dilute Feed) Sample-Pump Agitation Variation

9.57 Total Head versus Capacity (Concentrated Feed) Sample-Pump Speed Variation

9.58 Total Head versus Capacity (Concentrated Feed) Sample-Pump Speed Variation

9.59 Total Head versus Capacity (Concentrated Feed) Sample-Pump Tank-Level Variation

9.60 Total Head versus Capacity (Concentrated Feed) Sample-Pump

Temperature Variation

9.61 Total Head versus Capacity (Concentrated Feed) Sample-Pump Agitation

Variation

9.62 Total Head versus Capacity (Formatted Feed) Sample-Pump Speed

Variation

9.63 Total Head versus Capacity $\ldots \ldots \ldots \ldots \ldots \ldots \ldots \ldots \ldots \ldots . \ldots . \ldots . . \ldots 4$

9.64 Total Head versus Capacity Sample-Pump Fluid Variation $\ldots . \ldots \ldots . .9 .85$

10.1 Formic Acid Addition Rate and Amount as a Function of Process Time .. 10.3

10.2 Slurry Temperature and $\mathrm{pH}$ Process Profiles for the Formating and Digestion Phases

10.3 Cumulative Gallons of Condensate Produced During Formating and Digestion

10.4 Offgas Flow Rate as a Function of Time

10.5 Slurry $\mathrm{pH}, \mathrm{CO}_{2}, \mathrm{NO}_{x}$ and $\mathrm{N}_{2} \mathrm{O}$ Process Profiles During Formating and

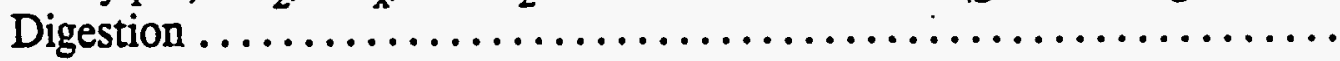

10.6 $\mathrm{H}_{2}$ Offgas Generation During Formating and Digestion

10.7 Cumulative Moles of $\mathrm{H}_{2}$ Generated During Formating and Digestion .... 10.11 
$10.8 \mathrm{CO}_{2}$ Offgas Generation During Formating and Digestion $\ldots \ldots \ldots \ldots \ldots .10 .12$

10.9 Cumulative Moles of $\mathrm{CO}_{2}$ Generated During Formating and Digestion ... 10.12

$10.10 \mathrm{NO}_{\mathrm{x}}$ Offgas Generation During Formating and Digestion $\ldots \ldots \ldots \ldots \ldots .10 .13$

10.11 Cumulative Moles of $\mathrm{NO}_{\mathrm{x}}$ Generated During Formating and Digestion .... 10.13

$10.12 \mathrm{~N}_{2} \mathrm{O}$ Offgas Generation During Formating and Digestion $\ldots \ldots \ldots \ldots \ldots \quad 10.14$

10.13 Cumulative Moles of $\mathrm{N}_{2} \mathrm{O}$ Generated During Formating and Digestion .... 10.14

10.14 CO Offgas Generation During Formating and Digestion $\ldots \ldots \ldots \ldots \ldots .10 .15$

$10.15 \mathrm{~N}_{2}$ and $\mathrm{O}_{2}$ In-Leakage (moles/min) During Formating and Digestion $\ldots \ldots \quad 10.21$

10.16 Cumulative Moles of Nitrogen and Oxygen In-Leakage During Formating and Digestion $\ldots \ldots \ldots \ldots \ldots \ldots \ldots \ldots \ldots \ldots \ldots \ldots \ldots \ldots \ldots \ldots \ldots \ldots, 10.22$

10.17 Cumulative Moles of $\mathrm{NO}, \mathrm{NO}_{x}$ and $\mathrm{NO}_{2}$ Generated During Formating

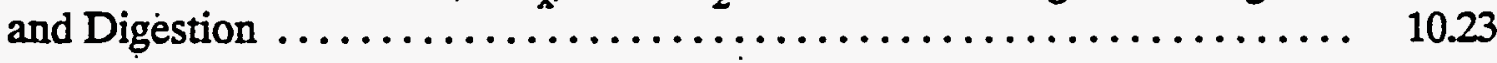

$10.18 \mathrm{NO}_{x}$ NO Offgas Generation During Formating and Digestion $\ldots \ldots \ldots, 10.23$

$10.19 \mathrm{NO} / \mathrm{NO}_{x}$ Ratio Process Profile During Formating and Digestion ....... 10.24

10.20 Condenser, Offgas, and Condensate Temperatures and $\mathrm{NO}_{\mathrm{x}}$ Generation Rate Process Profiles During Formating and Digestion $\ldots \ldots \ldots \ldots \ldots \ldots . \quad 10.25$

10.21 Condensate, Temperature and Condensate Flow Rate Process Profiles During Formating and Digestion $\ldots \ldots \ldots \ldots \ldots \ldots \ldots \ldots \ldots, 10.27$

10.22 Cumulative Moles of Nitrite and Nitrate in the Cumulative Gallons of Condensate Produced During Formating and Digestion ........... 10.28

10.23 High-Tank-Level (7800 gal) Dilute Waste Simulant Evaporator and Condenser Testing $\ldots \ldots \ldots \ldots \ldots \ldots \ldots \ldots \ldots \ldots \ldots, 10.33$

10.24 High-Tank-Level (7800 gal) Dilute Waste Simulant Feed Concentration, January 13,1993 .......................................... 10.35

10.25 High-Tank-Level (7800 gal) Dilute Waste Simulant Feed Concentration,

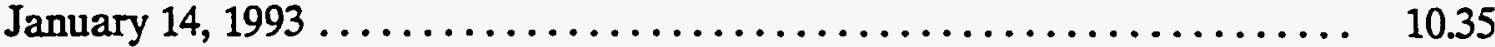


10.26 High-Tank-Level (7800 gal) Dilute Waste Simulant Feed Concentration,

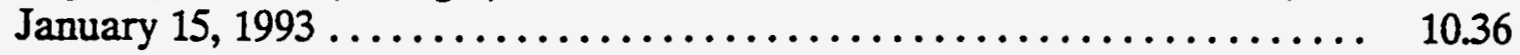

10.27 High-Tank-Level (7800 gal) Dilute Waste Simulant Feed Concentration

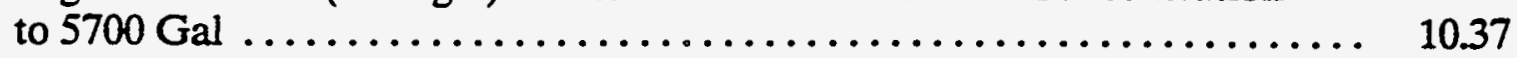

10.28 Low-Tank-Level (5700 gal) Concentrated Waste Simulant Evaporator and Condenser Testing $\ldots \ldots \ldots \ldots \ldots \ldots \ldots \ldots \ldots \ldots . . \ldots \ldots .38$

10.29 High-Tank-Level (7800 gal) Concentrated Waste Simulant Feed Concentration $\ldots \ldots \ldots \ldots \ldots \ldots \ldots \ldots \ldots \ldots \ldots \ldots \ldots, 10.38$

10.30 Formated Waste Simulant ( $7400 \mathrm{gal})$ Formic Acid Addition $\ldots \ldots \ldots \ldots . . \ldots .39$

10.31 Formated Waste Simulant ( $7400 \mathrm{gal}$ ) Feed Concentration Before to Recycle Addition Formated Waste Concentration Before Recycle Addition ....... 10.40

10.32 Melter-Feed Waste and Recycle Simulant (6200 gal) Concentration Prior .. 10.41

10.33 Melter-Feed Waste and Recycle Simulant (6200 gal) Frit Addition . . . . . 10.42

10.34 Observed Silver Buildup on the Flat-Bladed Impeller .............. 10.44

10.35 Observed Silver Buildup on the Transfer-Pump Intake Section $\ldots \ldots \ldots . \quad 10.45$

10.36 Schematic of Specified Regions of Observed Silver Buildup ........... 10.46

10.37 SIPT Formic Acid Addition Rate and Amount as a Function of Process Time

10.38 Bench-Scale: Formic Acid Addition Rate and Amount as a Function of Process Time

10.39 Cumulative $90 \mathrm{wt} \%$ Formic Acid Added for L NCAW Simulant ......... 10.54

10.40 Time Versus Temperature (during formating and digestion) $\ldots \ldots \ldots \ldots 10.55$

10.41 Time Versus $\mathrm{pH}$ (during formating and digestion) $\ldots \ldots \ldots \ldots \ldots \ldots \ldots . .56$

$10.42 \mathrm{NO}_{\mathrm{x}}$ and $\mathrm{N}_{2} \mathrm{O}$ Generation Versus Time $\ldots \ldots \ldots \ldots \ldots \ldots \ldots \ldots \ldots . \ldots \ldots . . . \ldots \ldots$

10.43 Graph of Measured Offgases Produced $\ldots \ldots \ldots \ldots \ldots \ldots \ldots \ldots \ldots . \ldots \ldots$

10.44 Shear Stress Versus Shear Rate for Bench-Scale at Various Times ...... 10.62 
10.45 Shear Stress Versus Shear Rate for Pilot Scale (Tank) and Bench-Scale (Lab) at 24 hours and 4 weeks 


\section{Tables}

5.1 Surface Area Differences Between HWVP and FPTS Heating/Cooling Coils 5.3

$5.2 \quad$ SIPT Control Loops $\ldots \ldots \ldots \ldots \ldots \ldots \ldots \ldots \ldots \ldots \ldots \ldots \ldots \ldots \ldots \ldots$

6.1 General Properties for Feed Simulant - Batch $1 \ldots \ldots \ldots \ldots \ldots \ldots . \ldots$

6.2 General Properties of Feed Simulant - Batch $2 \ldots \ldots \ldots \ldots \ldots \ldots$

6.3 General Properties of Low-Level Dilute Waste Simulant . . . . . . . . . 6.5

6.4 General Properties of High-Level Dilute Waste Simulant $\ldots \ldots \ldots \ldots$

6.5 General Properties of Low-Level Concentrated Waste Simulant . . . . . . 6.8

6.6 General Properties of High-Level Concentrated Waste Simulant ...... 6.9

6.7 General Properties of High-Level Concentrated Waste Simulant ...... 6.10

6.8 General Properties of Formated Waste Simulant ............... 6.11

6.9 General Properties of Recycle Waste Simulant $\ldots \ldots \ldots \ldots \ldots \ldots \ldots . \ldots \ldots$

6.10 General Properties of Formated Waste Simulant with Recycle ....... 6.13

6.11 General Properties of Formated Waste Simulant with Recycle . . . . . . . 6.14

6.12 Dry Process Frit Composition $\ldots \ldots \ldots \ldots \ldots \ldots \ldots \ldots \ldots \ldots \ldots \ldots \ldots$

6.13a General Properties for Melter-Feed Waste Simulant . . . . . . . . . . 6.16

$6.13 \mathrm{~b}$ General Properties for Melter-Feed Waste Simulant . . . . . . . . . . . 6.17

6.14 General Properties of Melter-Feed Waste Simulant $\ldots \ldots \ldots \ldots \ldots \ldots . \ldots$

6.15 Days of Samples and Sample Numbers from Hydragard Overflow . . . . . . 6.22

7.1 Summary of Evaporator Performance Tests $\ldots \ldots \ldots \ldots \ldots \ldots \ldots \ldots \ldots$

7.2 Heat-Transfer Coefficient During Heating for Water and NCAW Simulant . 7.13

7.3 Comparison of Overall Heating Heat-Transfer Coefficients . . . . . . . . 7.14 
7.4 Comparison of Boiling Heat-Transfer Coefficients at Maximum

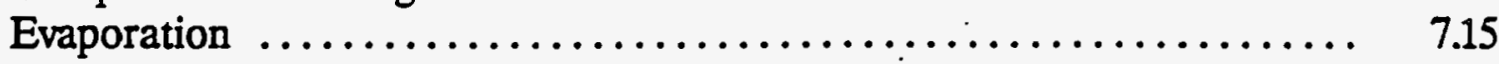

7.5 Heat-Transfer Coefficient During Cooling for Water and NCAW Simulant . 7.18

7.6 Comparison of Overall Cooling Heat-Transfer Coefficients . .......... 7.19

7.7 Heating Heat-Transfer Coefficient for Water $\ldots \ldots \ldots \ldots \ldots \ldots \ldots \ldots .7 .20$

7.8 Test Conditions used to Predict Boiling Heat Transfer $\ldots \ldots \ldots \ldots \ldots \ldots .7 .20$

7.9 Comparison of Predicted and Actual Boiling Heat-Transfer Coefficient at $10 \mathrm{gpm}$ Evaporation ................................ 7.21

7.10 Cooling Heat-Transfer Coefficient for Water $\ldots \ldots \ldots \ldots \ldots \ldots \ldots \ldots .7 .21$

7.11 Agitator Heating Test Results with Water $\ldots \ldots \ldots \ldots \ldots \ldots \ldots \ldots \ldots .7 .22$

7.12 Evaporator Tank Experimental Heat Loss, in Btu $/ \mathrm{h} \ldots \ldots \ldots \ldots \ldots \ldots .7 .23$

7.13 Summary of Homogeneity Tests $\ldots \ldots \ldots \ldots \ldots \ldots \ldots \ldots \ldots \ldots \ldots, 7.25$

7.14 Sampling Locations Used at Each Volume $\ldots \ldots \ldots \ldots \ldots \ldots \ldots \ldots . . \ldots .27$

7.15 Comparison of Calculated to Measured Slurry Properties ............ 7.27

8.1 Hanford Waste Vitrification Plant Condenser Process Design Conditions .. $\quad 8.1$

8.2 Hanford Waste Vitrification Plant Condenser Process Design Conditions .. $\quad 8.2$

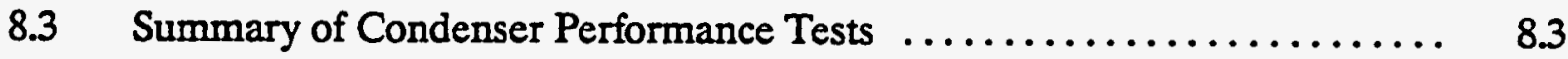

8.4 Condenser Energy Balance Summary at High Air Flows $\ldots \ldots \ldots \ldots \ldots . . .15$

8.5 Predicted Condenser Performance During Case 2 and Case 4 Hydrogen Mitigation Conditions ................................. 8.16

8.6 Predicted Process Water Lost During Case 2 and Case 4 Hydrogen Mitigation Conditions ................................. 8.16

8.7 Shell-Side Pressure Drop Information for SIPT Condenser $\ldots \ldots \ldots \ldots \ldots . \quad 8.19$ 
8.8 Shell-Side Pressure Drop Information for SIPT Condenser $\ldots \ldots \ldots \ldots \ldots . \quad 8.21$

8.9 Heat-Transfer and Condensate Flow Rates as a Function of Steam Flow ... 8.24

8.10 Concentrations of Ions in Tank and Condensate $\ldots \ldots \ldots \ldots \ldots \ldots \ldots . \quad 8.27$

8.11 Condensate Decontamination Factors $\ldots \ldots \ldots \ldots \ldots \ldots \ldots \ldots \ldots, \quad 8.27$

9.1 Testing Matrix for Slurry Test Loop Testing $\ldots \ldots \ldots \ldots \ldots \ldots \ldots \ldots .9 .12$

9.2 Velocity and Reynolds Number for Water at Test Flow Rates ......... 9.34

9.3 Velocity and Reynolds Number for Simulated Melter Feed ........... 9.34

$9.4 \quad$ Laser Analysis Results $\ldots \ldots \ldots \ldots \ldots \ldots \ldots \ldots \ldots \ldots \ldots \ldots \ldots \ldots . . \ldots \ldots \ldots$

9.5 Wt\% Frit Measured in Melter Feed Slurry of Daily Samples .......... 9.42

9.6 Wt\% Frit Measured in Melter Feed Slurry Samples From Various Locations Within the Tank ....................................... 9.44

9.7 Matrix of Tests Performed $\ldots \ldots \ldots \ldots \ldots \ldots \ldots \ldots \ldots \ldots \ldots \ldots, \quad 9.45$

9.8 Sample/Transfer Pump Prime-Water Requirement - Process Fluid: Water . $\quad 9.87$

9.9 Sample/Transfer Pump Prime-Water Requirement - Process Fluid: Dilute

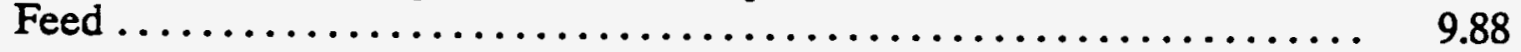

9.10 Sample/Transfer Pump Prime-Water Requirement - Process Fluid:

Concentrated Feed.

9.11 Sample/Transfer Pump Prime-Water Requirement - Process Fluid:

Formatted Feed $\ldots \ldots \ldots \ldots \ldots \ldots \ldots \ldots \ldots \ldots \ldots \ldots \ldots \ldots \ldots$

9.12 Sample/Transfer Pump Prime-Water Requirement - Process Fluid:

Melter Feed

9.13 Matrix of Test Conditions $\ldots \ldots \ldots \ldots \ldots \ldots \ldots \ldots \ldots \ldots \ldots . . . \ldots . . . \ldots 2$

10.1 Summary of Test Information $\ldots \ldots \ldots \ldots \ldots \ldots \ldots \ldots \ldots \ldots \ldots, 10.2$

10.2 Total Offgas Produced and Peak Gas Generation Rates During Formating and Digestion of NCAW Simulant Without Noble Metals ............ 10.9 
10.3 Mass Balance for Nitrogen: Formating and Digestion $\ldots \ldots \ldots \ldots \ldots, 10.16$

10.4 Estimated Percent of NO from the Disproportionation of Nitrous Acid ... 10.18

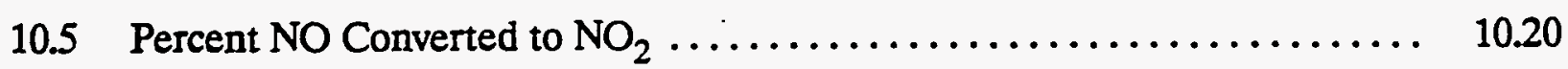

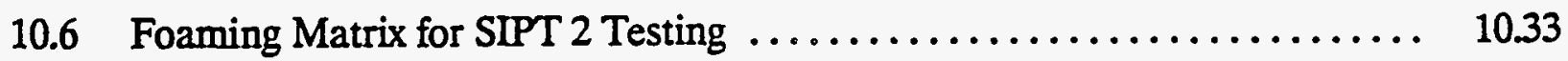

10.7 Calculated Decrease in Silver from the Waste Simulant During Feed

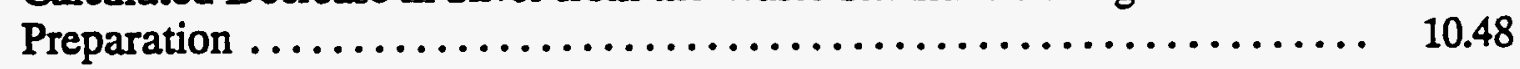

10.8 Summary of Test Variables $\ldots \ldots \ldots \ldots \ldots \ldots \ldots \ldots \ldots \ldots \ldots \ldots \ldots . \ldots \ldots .49$

10.9 Formating Equipment/Test Condition Differences Between

Full-Scale and Bench-Scale Tests . . . . . . . . . . . . . . . . . 10.50

10.10 Nitrogen Mass Balance $\ldots \ldots \ldots \ldots \ldots \ldots \ldots \ldots \ldots \ldots \ldots . \ldots \ldots . \ldots \ldots$

10.11 Peak Generation Rates and Total Offgas $\ldots \ldots \ldots \ldots \ldots \ldots \ldots \ldots \ldots .61$

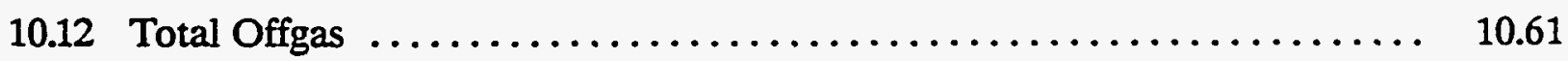




\subsection{Introduction}

The Hanford Waste Vitrification Plant (HWVP) was intended to convert selected, pretreated defense high-level waste (HLW) and transuranic (TRU) waste at the Hanford Site into a borosilicate glass. The glass would be cast into stainless steel canisters suitable for disposal. The filled canisters would be stored on site until they could be shipped to a federal repository for disposal. Vitrification technology is being similarly implemented at the Defense Waste Processing Facility (DWPF) at the Savannah River Site (SRS) in Aiken, South Carolina, and the West Valley Demonstration Project (WVDP) in West Valley (WV), New York. Existing vitrification technology was adapted for use in the HWVP. The full-scale feed preparation testing program was developed by $\mathrm{PNL}^{(\mathrm{a})}$ to verify the adaptability of the DWPF feed-preparation technology for processing Hanford feeds. The results were needed for the HWVP design in addition to being used for the HWVP permitting; feed processability studies, operations, and safety assessments.

The test program for the full-scale feed-preparation systems evaluated process equipment performance and characterized feed-preparation process performance. The process evaluation included determination of foaming tendency during boiling and formating; off-gas generation rate, composition, and decontamination factors (DFs) during boiling and formating; condensate composition, tendency of slurry solids to cake on equipment; redox adjustment by formic acid addition; and chemical additions. Equipment was evaluated for its capability to obtain and maintain a homogenous slurry, concentrate (heat, boil, and cool) the slurry, take representative samples, transfer slurry, accurately sense slurryprocessing parameters (level, temperature, density), feed the melter, operate safely, and produce a consistent product.

The results of the process and equipment testing are reported in this document. The introduction and objectives provide a context for the testing program and are followed by the testing conclusions and recommendations in Section 3. Further context and bases for the program are provided in the testing approach and equipment description in Sections 4 and 5, respectively. The methods to make up the process slurries for testing are described together with their properties in Process Slurries Makeup and Characterization, Section 6. Program results and analyses are provided in Section 7 and include process and equipment by each technical area of interest. The References are provided in Section 11. The Appendices provide additional detailed description, data, and calculations that provide the bases for the results and analyses.

(a) Pacific Northwest Laboratory is operated by Battelle Memorial Institute for the U.S. Department of Energy. 


\subsection{Objectives}

There are two categories of objectives in the HWVP full-scale feed-preparation testing program: process characterization and equipment performance. Specific test objectives were compiled from the HWVP Applied Technology Plans: WHC-EP-0350 and -0224 (Kruger 1990 and 1989), the Fiscal Year 1991 Statment of Work (Kruger 1991), and Fluor Daniel HWVP Design Technology Concerns and Data Requirements. ${ }^{(a)}$ Westinghouse Hanford Company (WHC) and Fluor Daniel test objectives are described in the following sections.

\subsection{Process Characterization}

The process characterization objectives are described below:

1. Characterize the off-gas composition $\left(\mathrm{CO}, \mathrm{CO}_{2}, \mathrm{NH} 3, \mathrm{NOx}, \mathrm{H}_{2}\right.$, etc.), generation rate, and foaming during formic acid addition and during digestion. Compare test results with predicted results from laboratory testing.

2. Observe and document the conditions that lead to condenser component fouling, so that they can be avoided in equipment operation. Recommend a method for detecting condenser fouling and demonstrate cleaning if necessary during testing.

3. Observe and document the processing parameters that promote tank component fouling as of solids agglomerate into lumps and cake on the coils. Recommend tank-scale cleaning and lump destruction procedures as appropriate during testing.

4. Determine carryover during evaporation at selected slurry heights during concentration of HWVP dilute feed, formated feed, and melter feed and during formic acid addition and digestion. Evaluate the effect of boiling rate on carryover during concentration of dilute feed and during Slurry Mix Evaporator (SME) concentration cycle.

5. Evaluate use of antifoaming agent to control foaming should foaming become rate or DF limiting during concentration or formating.

\subsection{Equipment Performance}

The equipment performance objectives are described below:

(a) Letter No. 9150147: R. A. Smith to J. M. Creer, January 28, 1991, "Fluor Daniel, Inc. Technology Needs Data Sheet Update." 
1. Test and calibrate the process liquid level and density sensor in the four test slurries at several liquid levels, temperatures, and agitator speeds. Develop a correlation for each process condition that compares the readings taken in agitated slurries to the stagnant calibrated readings and laboratory measured densities.

2. Determine the capability of the equipment to produce a homogeneous slurry. Evaluate several agitator speeds and liquid levels for producing acceptable homogeneity in the four test slurries. Determine agitator power required to agitate tank contents at each test condition.

3. Evaluate the capability of the sampling system to collect a representative sample of the tank contents.

4. Determine heating, boiling, and cooling capacities (heat-transfer coefficients) of the tank coils for each test slurry as a function of agitator speed and liquid level. Note impacts of component fouling. Determine heat loss through the test-vessel insulation.

5. Determine the condensing capacity (heat-transfer coefficient) of the condenser tubes as a function of condensible to noncondensible flow ratio. Determine tube-side and shell-side pressure drops. Note impacts of component fouling.

6. Determine minimum attainable tank heels resulting from slurry transfer from the tank at selected agitator speeds in water.

7. Determine the supply pressure, flow rate, and elapsed time required for priming the transfer/ melter-feed pump and the sampling pump for each slurry type in terms of minimizing the amount of priming water required. Note the resulting slurry dilution. (Only melter feed will be tested in the melter-feed pump configuration.)

8. Determine the supply pressure, flow rate, and volume (amount of water used) required for flushing each test slurry from the transfer/melter pump, the melter-feed piping, the transfer piping, and the sampler piping. (Only melter feed will be tested in the meiter-feed pump configuration.)

9. Evaluate the adequacy of the restricting orifice and the pump speed for controlling flow rate of the melter-feed pump and sampling pump for each test slurry. Evaluate the design of the pump and piping in terms of tendency toward plugging (solids buildup).

10. Determine transfer/melter-feed pump and sampling pump operating performance curves for each test slurry.

11. Determine the pressure drop in piping for the transfer of each test slurry and water with the transfer/melter-feed pump for appropriate pipe sizes/configuration and flow rates.

12. Evaluate melter-feed system before and during the Liquid Fed Ceramic Melter (LFCM) run to evaluate melter-feed rate control, plugging frequency with associated required flushing frequency (including cross-flow strainer), and feed-system flushing techniques. Determine pressure in melter-feed line. 


\subsection{Fluor-Daniel Technology Data Needs}

The Fluor-Daniel technology data needs are described below:

1. Determine the degree of settling or solids accumulation at the tank periphery. (Fluor-Daniel Need Item 1.1a)

a. Slurry concentration (by wt\% total solids) will be determined in the full-scale test vessel for dilute, concentrated, formated, and melter-feed simulants as a function of

- agitator speed $(45,85,130 \mathrm{rpm})$

- sample location (top, middle, and bottom)

- slurry height ( 2 dilute, 2 concentrated, 1 formated, and 2 melter-feed simulants).

b. Pictures will be taken of the empty tank after completion of slurry testing.

2. Determine the effect of varying process parameters on the evaporation rate. (Fluor-Daniel Need Item 1.1b)

a. Water Testing - Heat-transfer rates and condensate flow rates will be examined as a function of steam flow rate, air inleakage flow rate (100 to $500 \mathrm{scfm})$, liquid volume (8000 and $5500 \mathrm{gal})$, and condenser cooling water flow rate $(350,275$, and $200 \mathrm{gpm})$ at a constant agitation rate $(85 \mathrm{rpm})$.

b. Slurry Testing - Heat-transfer rates and condensate flow rates will be examined as a function of liquid volume (8000 and $5500 \mathrm{gal}$ ) and test vessel contents (dilute, concentrated, formated, and meiter-feed simulant) at the maximum steam flow rate, agitation rate $(85 \mathrm{rpm})$, and nominal off-gas flow rate. The condenser cooling water flow rate will be adjusted to obtain $125^{\circ} \mathrm{F}$ condensate.

c. Vapor binding, to the extent that it occurs, will be documented in cases 2.a and 2.b.

3. Determine the liquid carryover during condenser operation. (Fluor-Daniel Need Item 1.2a)

a. Heat-transfer rates and condensate flow rates will be examined as a function of liquid volume (approximately 8000 and $5500 \mathrm{gal}$ ) and test vessel contents (dilute, concentrated, formated, and melter-feed simulant) at maximum steam flow rate, agitation rate ( $85 \mathrm{rpm})$, and nominal off-gas flow rate with slurry as the test medium. The condenser cooling water flow rate will be adjusted to obtain $125^{\circ} \mathrm{F}$ condensate.

b. Aerosol samples from the off-gas line and condensate samples from the condensate line will be taken during concentration of the dilute-feed simulant, formating, digestion, and during concentration before addition of frit. The sample will be analyzed to determine decontamination factors and liquid carryover. 
4. Determine the condenser shell-side pressure drop. (Fluor-Daniel Need Item 1.2b)

a. The condenser shell-side pressure drop versus cooling-water flow rate under boiling and non-boiling conditions will be determined.

b. A shell-side pressure drop calculation will be performed for the slurry-integrated performance testing (SIPT) condenser.

5. Determine the effect of non-condensibles on condenser performance. (Fluor-Daniel Need Item 1.2c)

a. Condensate temperature and flow rate and condenser exit air temperature, pressure, and flow rate will be determined as a function of off-gas flow rate $(100$ to $500 \mathrm{scfm})$ and steam flow rate (minimum, medium, maximum) with water as a test medium. The condenser cooling-water flow rate will be adjusted to obtain condensate at $125^{\circ} \mathrm{F}$. The test will be conducted at nominal agitation rate $(85 \mathrm{rpm})$.

6. Determine the heating and cooling coil-heat-transfer coefficients. (Fluor-Daniel Need Item 1.3a)

a. Heat-transfer coefficients during boiling will be determined as a function of liquid level $(8000$ and $5500 \mathrm{gal})$ and steam flow rate (minimum, medium, maximum) at nominal agitation rate $(85 \mathrm{rpm})$, and air inleakage or off-gas flow rate. The condenser cooling-water flow rate will be varied to obtain $125^{\circ} \mathrm{F}$ condensate.

b. The energy input from the agitator will be measured as a function of liquid volume ( 8000 and 5500 gal) and agitation rate $(40,85$, and $130 \mathrm{rpm})$.

c. Heat transfer rates during heating will be determined as a function of slurry temperature $\left(50^{\circ} \mathrm{C}\right.$ to $\left.100^{\circ} \mathrm{C}\right)$ at the nominal agitation rate $(85 \mathrm{rpm})$ and air inleakage or off-gas flow rate. The condenser cooling-water flow rate will be varied to obtain $125^{\circ} \mathrm{F}$ condensate.

d. Cooling coefficients during cooling at a constant fluid temperature of $125^{\circ} \mathrm{F}$ will be measured for a cooling-coil flow rate of $120 \mathrm{gpm}$.

e. External heat losses during heating and boiling will be examined.

f. Test parameter data (temperatures, flow, and pressures) of steam, condensates, and gases will be recorded.

g. The above information will be determined with water and dilute, concentrated, formated, and melter-feed simulants as test media. 
7. Determine the use of water for coil cleaning. (Fluor-Daniel Need Item 1.3b)

a. Heat-transfer coefficients during boiling will be determined as a function of liquid level (8000 and $5500 \mathrm{gal}$ ) at the maximum steam flow rate and at the nominal agitation rate $(85 \mathrm{rpm})$ and air inleakage or off-gas flow rate. The condenser cooling-water flow rate will be varied to obtain $125^{\circ} \mathrm{F}$ condensate.

b. Heat-transfer rates during heating will be determined as a function of slurry temperature $\left(50^{\circ} \mathrm{C}\right.$ to $\left.100^{\circ} \mathrm{C}\right)$ at the nominal agitation rate $(85 \mathrm{rpm})$ and air inleakage or off-gas flow rate. The condenser cooling water flow rate will be varied to obtain $125^{\circ} \mathrm{F}$ condensate.

c. Cooling coefficients during cooling at a constant fluid temperature of $125^{\circ} \mathrm{F}$ will be examined at a cooling-coil flow rate of $120 \mathrm{gpm}$.

d. Visual observations (pictures) will be made of the tank during cleaning and of the coils and tank peripheries before and after cleaning.

8. Determine the performance of the melter-feed loop and the cross-flow strainer. (Fluor-Daniel Need Item 1.4a)

a. Particle size distribution tests will be performed on the test vessel's contents during melter feeding to determine whether coarse particles accumalte in the melter-feed tank (MFT). Samples will be taken at the start and completion of melter feeding and at 1000-gal intervals during meiter feeding.

9. Determine the pressure drop across the melter-feed loop. (Fluor-Daniel Need Item 1.4b)

a. The pressure drop in the melter-feed tube over the designed flow rate range $(0.1$ to $0.75 \mathrm{gpm}$ ) will be determined.

b. The frequency at which plugging occurs will be noted.

c. Feed-system operating conditions (e.g., pressures, pump speed) needed to obtain flows and unplugging method will be recorded.

10. Determine the effectiveness of antifoaming agents. (Fluor-Daniel Need Item 1.5b)

a. DOW Corning 544 Antifoam $^{\oplus}$ agent will be added to the full-scale test vessel in concentrations of $100 \mathrm{ppm}$ after every 12 hours of boiling during the formic acid addition and digestion processes. The anti-foam agent can prevent foaming, and carryover of solids will be examined.

b. Condensate DFs and foam level during formating and digestion will be determined. 
11. Determine the hydraulic properties of slurries. (Fluor-Daniel Need Item 1.8b)

a. Pressure-drop measurements as a function of flow rate in 2-, 1-, and 1/2-in. stainless steel schedule- 40 pipes and long-radius elbows for water and dilute, concentrated, formated, and melter-feed simulants over a flow range of 3 to $10 \mathrm{ft} / \mathrm{sec}$ will be performed at approximately $50^{\circ} \mathrm{C}$.

b. The viscosity and density of each of the simulants at $50^{\circ} \mathrm{C}$ will be determined.

12. Determine homogeneity of the feed simulant at different concentrations. (Fluor-Daniel Need Item 1.12a)

a. Determine slurry concentration (by wt\% total solids) in the full-scale test vessel for dilute, concentrated, formated, and melter-feed simulants as a function of

- agitator speed $(40,85$, and $130 \mathrm{rpm})$

- sample location (top, middle, and bottom)

- slurry height.

b. Slurry temperature will be measured at different depths.

13. Determine NOx generation in the slurry receipt and adjustment tank (SRAT) during formating. (Fluor-Daniel Need Item 3.4a)

a. Process assumptions about formic-acid consumption and off-gas generation must be tested to ensure that the formic acid addition time does not impact the HWVP time-motion study. The concentration of NOx and the total vent-gas flow rate should be measured to determine the maximum NOx release during formic acid addition.

b. Bench scale testing should evaluate the effect of the formic acid addition rate on the NOx generation rate. The formic acid addition rate should be varied.

c. The NOx removal rate in the process vessel ventilation (PVV) submerged bed scrubber (SBS) should also be determined. The total gas flow rate and the inlet and outlet concentrations of the NOx should be measured to determine the removal of NOx in the SBS. 


\subsection{Conclusions and Recommendations}

This section lists conclusions and recommendations that resulted from the HWVP Full-Scale Feed Preparation Systems Testing.

\subsection{Conclusions}

The following conclusions resulted from the testing program:

- The slurries that were tested possessed the following rheological characteristics:

- Dilute Neutralized Current Acid Waste (NCAW): Newtonian fluid.

- Concentrated NCAW: Bingham plastic, which changed to Newtonian fluid at higher shear rates.

- Formated NCAW: Bingham plastic, which changed to Newtonian fluid at higher shear rates.

- Melter Feed: Bingham plastic.

- The yield stress of the melter feed at 500 gwo/L increased with time after make up.

- The yield stress and apparent viscosity of the melter feed could be easily decreased by dilution with small amounts of water.

- The yield stress of the melter feed increased with concentration.

- The melter feed formed a gel-like material when no shear was applied (Bingham plastic).

- The tank coil-heat-transfer coefficients were comparable to or somewhat higher than those determined for similar equipment and processes at TNX [Training and Experimental (SRL Area)] at SRS for DWPF. The higher values were attributed to new equipment, testing conditions, and equations used to determine values.

- For viscous materials, such as the melter feed, the boiling, heating, and cooling heat-transfer coefficients are significantly reduced by a factor of 2 to 3 compared to other materials tested.

- There was no evidence of yapor binding during tank coil-heat transfer tests.

- Heat loss from the tank was higher than predicted by the HWVP architect-engineer because testing conditions were different and no insulation was present on the bottom of the test tank. 
- Slurries tested could be maintained, homogeneous under all conditions tested, which included agitator speeds $45 \mathrm{rpm}$ and volumes from 5700 to $7800 \mathrm{gal}$. For melter feed the agitator speed was maintained at $130 \mathrm{rpm}$ to inhibit gelling.

- The process samples were determined to be representative of all siurries in the tank. The analytical standard deviations for wt $\%$ solids were $1 \%$ to $3 \%$. The sample values accurately represented what was calculated from the slurry makeup procedure.

- Solids did not significantly accumulate in or coat the tank except for Bingham-plastic melter feed. The melter feed tended to accumulate more on hot surfaces and not on cooler surfaces. The melter feed could be easily removed by washing with water or applying a shear stress. The melter feed buildup was enriched with solids.

- The Bingham-plastic melter feed inhibited flow between the heat transfer coils.

- When the slurry level drops below the coil top, the slurry may become heterogeneous due to poor mixing.

- The Holledge level detection system was damaged during testing by water turbulence (sloshing) during agitation at low water level.

- The presence of non-condensable gas in the condenser process vapor reduced the condensate flow rate, increased liquid entrainment in the condenser off-gas, and reduced the condenser heat-transfer coefficient. The detrimental effects of non-condensable gas were more pronounced at higher evaporation rates and non-condensable gas flow rates.

- The measured pressure drop in the condenser was close to that calculated for cooling water flow.

- For the boiling conditions tested, the DFs between the tank contents and condensate were between $10^{3}$ and $10^{6}$, depending on the element analyzed for and the testing conditions.

- Observation of the condenser heat-transfer coefficient revealed no apparent condenser-surface fouling nor vapor binding.

- No lumps appeared in the meiter feed during melter feeding.

- Measured pressure drops for 1/2-, 1-, and 2-in. pipes and a portion of the melter feed system are consistently about one-half to the values calculated over the flow range tested from 3 to $10 \mathrm{ft} / \mathrm{s}$.

- Twenty seconds of water flow was required to prime the transfer and sample pumps.

- The outlet valve on the transfer pump had to be partially closed to provide sufficient back pressure to prime the pump.

- Slurry level in the tank has the greatest effect on the head and capacity characteristics of the transfer pump. 
- Temperature and agitation did not seem to have a significant effect on pump performance.

- Insufficient sensitivity in the test instrumentation and the testing arrangement precluded acceptable measurement of pressure drops in the long-radius elbows.

- Foaming did occur but not so much as to hamper concentration, formating, and digestion operations. Foaming was encountered only at higher heating rates and could be controlled by either lowering the heating rate or adding Dow Corning 544 Antifoam. ${ }^{\otimes}$

- The magnitude of the tank pressure fluctuations increased with increasing heating-coil flow rate. The pressure fluctuations could be controlled by slowing the stream flow in the heating coils.

- Solids concentrations in the condensate line were so low that intermittent line sampling methods were inadequate. If these smaller concentrations of solids remain a concern, the condensate line could be sampled with an in-line filter, so that solids could accumulate.

- Surges in offgas generation caused pressure spikes that tripped the automatic safety interlocks. It may be necessary to increase the tank vacuum or to add $\mathrm{HCOOH}$ at a lower rate to prevent safety interlock activation.

- Of the initial nitrogen present in the slurry, $92 \%$ was accounted for in the mass balance calculation. Uncertainty in the analytical measurements, offgas measurements, and offgas system condensate calculations contributed to the error.

- A negligible amount of $\mathrm{NH}_{3}$ and $\mathrm{H}_{2}(\approx 11$ moles) were produced during formate. The amounts of $\mathrm{NH}_{3}$ and $\mathrm{H}_{2}$ were expected to be low because the NCAW simulant did not contain noble metals.

- While 7400 gal of NCAW simulant without noble metals were formated and digested, 5228 moles of NOx were produced at a maximum generation rate of $37 \mathrm{moles} / \mathrm{min}$. These numbers are expected to be $10 \%$ to $15 \%$ low due to the effect of $\mathrm{NO}_{2}$ stripped by the offgas system condensate. Discontinuous $\mathrm{HCOOH}$ addition rate may affect the reported maximum and minimum offgas generation rate at a $1.2 \mathrm{gpm} \mathrm{HCOOH}$ addition rate.

- Two reactions are predicted to produce NOx in the SRAT:

$$
\begin{array}{r}
2 \mathrm{NaNO}_{2}+3 \mathrm{HCOOH} \rightarrow \underset{\text { (nitrite reduction by } \mathrm{HCOOH} \text { ) }}{2 \mathrm{NO}}+\mathrm{CO}_{2}+2 \mathrm{NaCOOH}+2 \mathrm{H}_{2} \\
\text { (n) }
\end{array}
$$

$$
3 \mathrm{HNO}_{2} \rightarrow 2 \mathrm{NO}+\mathrm{NO}_{3}^{-}+\mathrm{H}^{+}+\mathrm{H}_{2} \mathrm{O} \text { (disproportionation of nitrous acid) }
$$

- Calculation by the carbon dioxide and formate balance methods showed that $\approx 22 \%$ and $\approx 42 \%$, respectively, of the NOx was from disproportionation of nitrous acid. The calculations assumed all of the carbonate was destroyed and that none of the $\mathrm{MnO}_{2}$ was reduced to 
$\mathrm{Mn}^{+2}$. If $80 \%$ of the $\mathrm{MnO}_{2}$ were assumed to be reduced to $\mathrm{Mn}^{+2}$, the resuits were $37 \%$ and $58 \%$, respectively. Uncertainty in analytical measurements, as well as incomplete knowledge about the slurry chemistry, accounts for the range of numbers by different methods.

- The $\mathrm{NO} \rightarrow \mathrm{NO}_{2}$ conversion was estimated to be $45 \%$ to $94 \%$ complete when the offgas was measured. Calculations of offgas residence time should yield offgas measurements that are representative of the reactions occurring in the tank vapor space and condenser. The range encompasses uncertainty in NOx generation, the assumption that condensate nitrate and nitrite result from the reaction of $\mathrm{NO}_{2}$ with the condensate, the assumption that the increase slurry nitrate is (or is not) the result of $\mathrm{NO} \rightarrow \mathrm{NO}_{2} \rightarrow \mathrm{NO}_{3}^{-}$, and uncertainty in $\mathrm{N}_{2}$ and $\mathrm{O}_{2}$ inleakage.

- Condenser operation cooled the condensate to $50^{\circ} \mathrm{C}$ and below during periods of high NOx generation.

- The condensate collection-system design affected the condensate temperature. At low condensate generation rates $(<2 \mathrm{gpm})$, the condensate temperature increased about $50^{\circ} \mathrm{C}$. The increase in condensate temperature was probably caused by heat transfer through the condenser separator unit, which had process vapor (steam) on one side and condensate on the other. External heating of the condensate exit pipe by radiant heat from the SRAT also may have occurred.

- Approximately $27 \%$ of the nitrogen generated as NOx was present in the condensate as nitrate or nitrite. This assumes that $\mathrm{NO} \rightarrow \mathrm{NO}_{2} \rightarrow \mathrm{NO}_{2}^{-}$and $\mathrm{NO}_{3}^{-}$in the condensate.

- Silver buildups were observed on tank components after testing was completed. Analyses showed between $20 \%$ and $25 \%$ of the silver in the waste simulant was reduced during feed preparation.

\subsection{Recommendations}

The following recommendations were developed from the testing program:

- Additional testing is needed to determine the decrease in heat-transfer coefficient with operating time, or choice of a conservative heat-transfer coefficient can be based on testing to date and the potential for fouling.

- The condenser design may require modification to inhibit entrainment and accumulation of condensate, depending on operating conditions.

- The slurry process characteristics should be controlled within the operating parameters of the equipment.

- A full-scale formating test should be performed with continuous formic acid addition to determine offgas generation characteristics. 


\subsection{Test Approach}

The testing approach and its bases are described in the subsequent sections.

\subsection{HWVP Process Description}

The following paragraphs briefly describe the HWVP feed preparation process in the envisioned plant. The feed preparation process provides the model for testing.

The HWVP would have received pretreated waste slurry (HWVP feed) in the slurry receipt and adjustment tank (SRAT). The tank would have been batch filled to its operating capacity and the slurry heated to boiling. The HWVP feed would have been continuously added to the SRAT as the slurry was concentrated from 31 to $140 \mathrm{gwo} / \mathrm{L}$ melter feed. The tank contents would have been cooled to $203^{\circ} \mathrm{F}$ $\left(95^{\circ} \mathrm{C}\right)$. Then, based on the analyses of the HWVP feed in the SRAT, $90 \mathrm{wt} \%$ formic acid would have been added to control glass redox in the melter and to reduce the apparent viscosity and yield stress of the melter feed. The slurry would have been digested for about 4 hours with full condensate boil-off to complete the chemical reactions and produce a formated HWVP feed. The tank contents would have been cooled and then sampled. Based on the chemical analyses, any required chemical adjustments would have been made. The tank contents would then have been transferred to the Slurry Mix Evaporator (SME).

In the SME, the concentrated feed would have been heated and available inventory of spent frit and process waste recycle added and concentrated as necessary. This step could require two cycles of concentration and slurry addition. The SME contents would have been cooled and a sample taken. The SME contents would again be heated and concentrated and the process frit (glass formers) slurry added. Additional formic acid or sugar would be added, if necessary, and the slurry digested for 2 hours if additional reductant were added. Then, the slurry would have been cooled to $122^{\circ} \mathrm{F}\left(50^{\circ} \mathrm{C}\right)$ and a sample taken. Based on the results of a chemical analysis, any final chemical adjustments would have been made to form the melter feed. The nominal concentration of the melter feed was $42 \mathrm{wt} \%$ solids or $500 \mathrm{~g} / \mathrm{L}$ of total oxides. The melter feed would have been transferred to the melter feed tank (MFT).

In the MFT, the melter feed would be continuously agitated and fed to the melter.

\subsection{Test Methodology}

The HWVP process equipment design and process performance were determined with test equipment that was as close to plant design as practical. The test approach was to establish baseline equipment performance with water (Equipment Acceptance Testing). Then, each unit of the feed preparation process for the SRAT, SME, and MFT was completed in the test tank with the simulated HWVP feed. For each process step, equipment performance was observed and data were taken to . characterize the process and evaluate equipment performance. 
Equipment was tested with water followed by simulated nonradioactive HWVP process slurries. Initial equipment performance was determined with a nonhazardous fluid (water) to verify the acceptability and operability of the test equipment and systems, to allow operators to develop familiarity with the equipment and test procedures, and to determine baseline equipment performance. Simulated process slurries are classified as hazardous chemicals, and slurry disposal would be more involved and expensive than water. If problems, water can be routed to the process sewer and the equipment easily cleaned.

Use of water as the initial test medium allowed determination of baseline equipment performance for comparison with literature. Testing included tank calibration; tank heating, boiling, and cooling; pumping; and attainable tank-heel evaluations. Tank calibration determined water volume in the tank with the Holledge liquid level detector and a totalizing flowmeter. Heating, boiling, and cooling testing evaluated the efficiency of the tank heating/cooling coils and condenser as a function of steam flow, agitation, liquid level, and air flow rate. Pump testing evaluated the sample/transfer pump performance, pipe pressure losses, and the Hydragard ${ }^{\Phi}$ sampling system. Tank heel testing evaluated the tank heel level as a function of agitator speed.

When testing with water was complete, operations with simulated HWVP process slurry began. The reference NCAW feed simulant was tested with process operations planned for HWVP. Heating, boiling, and cooling heat-transfer coefficients were determined throughout the concentration process. Parametric testing included testing of agitation rates, pumping rates, and heel levels.

The varied parameters (independent variables) included the process slurry type, liquid level, and agitator speed. The liquid levels primarily considered were a nominal high level (approximately $7800 \mathrm{gal}$ ) and an intermediate level $6 \mathrm{in}$. above the tank heating/cooling coils (approximately $5700 \mathrm{gal}$ ). The agitator operation was characterized at 45,85 , and $130 \mathrm{rpm}$ with water during the equipment performance testing and with the HWVP simulant feed slurry. The test media included HWVP simulated dilute feed (approximately $31 \mathrm{gwo} / \mathrm{L}$ ), concentrated HWVP feed (approximately $140 \mathrm{gwo} / \mathrm{L}$ ), formated slurry (approximately $150 \mathrm{gwo} / \mathrm{L}$ ), and melter feed (approximately $500 \mathrm{~g}$ to/L).

The parameters measured included both the varied parameters (independent variables) and those they affected (dependent variables). 


\subsection{Process Test Equipment}

The feed preparation test system (FPTS) is an adaptation of the DWPF feed preparation system. The FPTS represents the proposed HWVP feed preparation system that was being designed by HWVP architect-engineer (Fluor-Daniel, Inc.). The equipment was used to test the application of the DWPF design to Hanford Site waste feed. The FPTS consists of a vessel (evaporator), heat transfer coils, condenser, slurry transfer pump, slurry transfer test loop, sample pump, sample system, agitator, Holledge Level Detection/Density Measurement System, and supporting process monitoring and control equipment as described below. A schematic diagram of the test system is provided in Figure 5.1.

\subsection{Test Vessel}

The purpose of the test vessel is to receive, hold, and process the simulated slurries. The test vessel is a full-scale representation of the DWPF SRAT/SME/MFT with the exception of remote features, and the MFT only has cooling coils. Vessel fabrication details are given in Richmond Machine and Fabricating drawings D-10183-1 through D-10183-3 in Appendix A.

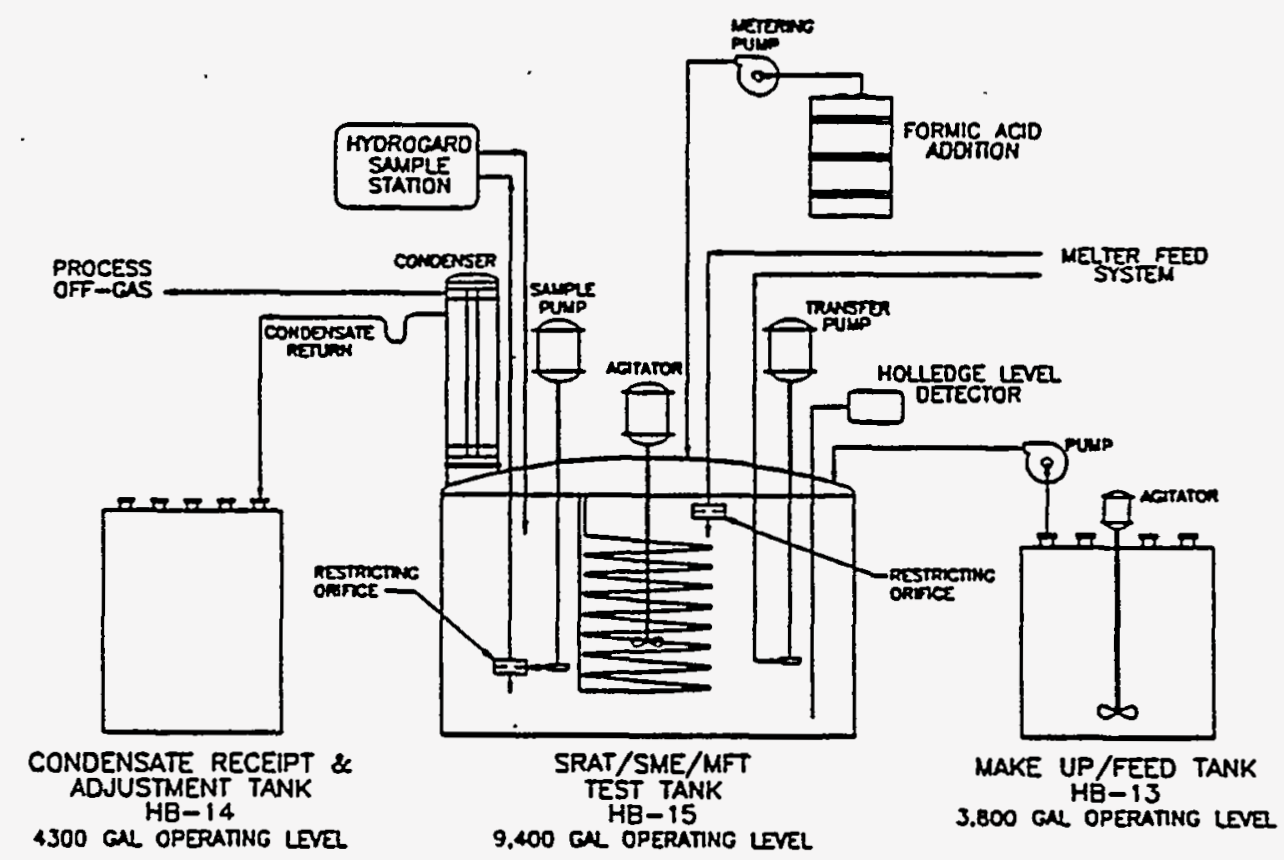

Figure 5.1. Feed Preparation System 
The vessel has a $12-\mathrm{ft}$ inside diameter, is $161 / 2 \mathrm{ft}$ tall, and has a maximum capacity of $10,200 \mathrm{gal}$. The totally enclosed vessel is constructed from Carpenter $20 \mathrm{Cb}-3$ steel; the support structure is fabricated from carbon steel. The overall vessel height, including the support structure, is $18 \mathrm{ft}$. The vessel has a 2:1 elliptical head equipped with 25 .standard pipe flange nozzles ranging in size from 3 to 72 in. These flanged penetrations are used to support the condenser, transfer and sample pumps, center coils, agitator, data acquisition/control instrumentation, and chemical addition, water, condensate reflux, and vent lines. Although not prototypic to the DWPF design, the vessel can be equipped with four removable $3 / 8$-in. by 12 -in. by 150 -in. baffies. Six guides attached to the shell near the bottom of the vessel are centered on the nozzles designated for the Holledge level detector, the thermowell, the sample and transfer pumps, the auxiliary level detector, and the auxiliary sample system. The guides support those components against radial defiection from slurry impingement. The vessel bottom head is flat with a $23 / 8$-in.-inside knuckle radius transition to the straight flange. The floor slopes $1 / 4$ in. per foot toward a sump near the vessel wall. An agitator shaft guide, welded at the center of the bottom head, protects the coil assembly against unstable shaft deflection and is designed so as not to contact the shaft during normal operation. The vessel is supported by eight wide-flange I-beams under the bottom head. The I-beams are attached to a 3/4-in.-thick skirt that is formed around the lower quadrant of the vessel exterior. Three wide-flanged I-beams, which serve as the vessel support legs, are attached to the skirt on $120^{\circ}$ radial centerlines. Through the support legs, the vessel is mounted to three load (strain gauge) cells to allow weighing of contents.

The vessel can be completely drained with a 2-in. line that is connected to the sump. The drain line is routed to an air-operated double-diaphragm pump, which can discharge the tank contents to the process sewer or to Tank HB-13. Additionally, the pump can be used to transfer solution through the Hydragard ${ }^{\otimes}$ sample station through the sample cooler. The vessel is vented through the condenser to the facility Process Off-Gas (POG) system. A regulating valve is installed in the off-gas line to control vessel pressure at -5 in. $\mathrm{H}_{2} \mathrm{O}$. Air flow is a function of processing (i.e., boil down and off-gas flow) as well as air in-leakage through pump and agitator shaft seals. Air in-leakage into the vessel can be increased by using an air line routed to a tank nozzle. This line is equipped with a flow control valve interlocked to an explosive gas monitor.

If an unacceptable level of $\mathrm{H}_{2}$ is generated the system will automatically dilute and maintain $\mathrm{H}_{2}$ concentrations below explosive limits. If $>0.5 \mathrm{vol} \%$ of explosive gas is detected, the off-gas control valve opens to increase system flow capacity. If $>1$ vol\% [or $25 \%$ of lower explosive limit (LEL)] is detected, the process is immediately shut down. Air flow into the vessel was also increased through the air inlet-line flow-control valve.

The test vessel is covered by approximately $1500 \mathrm{sq}$ ft of 6 -mm-thick MICROTHERM ${ }^{\oplus}$ insulation on its vertical surfaces. The insulation is covered with a stainless steel sheeting to maintain an $R$ value of 1.51. The design is similar to the HWVP design basis, which is two layers of MICROTHERM ( $3 \mathrm{~mm}$ each) covered with stainless steel $(R$ value $=1.51$ ).

\subsection{Heat-Transfer Coils}

The heat-transfer coils heat, cool, and boil the simulated slurrys. The heat-transfer or center-coil assembly is shown on Richmond Machine and Fabrication construction drawing D-10183-4 in Appendix A. The assembly consists of three sets of coils suspended from an $861 / 2$-in.-diameter by 
2 1/4-in.-thick Carpenter $20 \mathrm{Cb}-3$ flange. This flange is mounted to the head. The coils are constructed from 2-in. schedule 40 Hastelloy Alloy C-276 pipe. Each set of coils consists of 19 rows on a 3.5-in. pitch. The inner water-cooling coils have a centerline diameter of 46.5 in. The middle and outer sets are steam coils and have centerline diameters of 52.5 and $58.5 \mathrm{in}$., respectively. The heattransfer area of the cooling coil is $143.9 \mathrm{ft}^{2}$. The combined heat-transfer area of the two steam coils is $343.5 \mathrm{ft}^{2}$. Air lines attached to the steam and water supply inlets allow residual condensate or water to be discharged before assembly removal for inspection.

The heating/cooling coil arrangement for the FPTS is similar to that of the HWVP except in the case of the MFT. In the HWVP, the MFT is cooled by a pair of cooling coils. In the FPTS, the test vessel, which represents the SRAT, SME, and MFT, contains only one cooling coil. Table 5.1 summarizes the HWVP and FPTS heating/cooling coil heat-transfer surface area.

Discussions with WHC, Westinghouse Savannah River Company (WSRC), and DOE Richland Operations Office, led to modifications to stabilize the coils which were subject to defiection by fluid currents generated by the agitator. These modifications were performed in accordance with those at DWPF. They required that the structural supports of the heat-transfer coil be stiffened by the addition of reinforcing plate, chanrel, and formed-angle cross bracing.

\subsection{Condenser}

The condenser is a full-scale representative prototype of the SRAT/SME condenser (excluding remote features) and is shown on sheets 1 and 2 of Alaskan Copper Works fabrication drawing M-4636 in Appendix A. It has an overall height of $14 \mathrm{ft}$ and is constructed from stainless steel. The shell, which is $24 \mathrm{in}$. in diameter, encloses 314 ss vertical 0.75 -in.-diameter by $14-B W G$ by 88 -in.-long tubes. The tubes, which have an inside heat transfer area of $373.8 \mathrm{ft}^{2}$ (outside heat-transfer area of $450.6 \mathrm{ft}^{2}$ ), surround a 6-in. central riser that is insulated from the shell-side cooling water by an 8-in. pipe. Vapors from the SRAT/SME are drawn up the riser and then down through the tube bundle. A flow meter mounted in a trap in the condensate exit line is used to measure the rate and amount of condensate. Analytical samples are removed through a sample port in the trap. The condensate normally drains to Tank HB-14 for collection. The non-condensables are sampled through a port in the off-gas line before being exhausted to the facility POG system. Cooling-water flow as well as inlet and outlet pressure and temperatures are monitored to determine heat-transfer coefficients and pressure drop.

Table 5.1. Surface Area Differences Between HWVP and FPTS Heating/Cooling Coils

\begin{tabular}{lccc} 
& HWVP, $\left(\mathrm{ft}^{2}\right)$ & & FPTS, $\left(\mathrm{ft}^{2}\right)$ \\
\cline { 2 - 2 } SRAT/SME Heating & 340 & 343 \\
SRAT/SME Cooling & 140 & \\
MFT Heating & N/A & 344 \\
MFT Cooling & 300 & 144
\end{tabular}


A chevron-type mist eliminator and a condenser baffle were installed in the condenser to minimize noncondensables carryover. Both can be removed should test results warrant. Important design parameters include the following:

- Shell-side baffle spacing

- Inlet baffie spacing

- Tube pitch and configuration

- Tube configuration

- Baffle \% cut

- Number of baffles
$727 / 32$ in.

$89 / 16$ in.

$15 / 16$ in.

Triangular

$20 \%$

10.

Cooling water is supplied to the condenser through a 4-in. line. The supply line makes a $45^{\circ}$ angle approximately 6 in. upstream of the condenser inlet flange and reduces to a 3 -in. line at the flange. Similarly, a 3-in. to 4-in. diameter expansion connects the outlet flange to a 4-in. discharge line, which . makes a $45^{\circ}$ angle 6 in. downstream of the flange. An Endress and Hauser FTI 1943 VARIOMAX Magnetic Flowmete ${ }^{\infty}$ in the supply line measures cooling-water flow rate. Inlet and outlet pressures are monitored by Rosemount Model 3051 C Coplanar Smart Pressure Transmitters. ${ }^{\circ}$ The pressure transmitter in the supply line is located approximately $6 \mathrm{ft}$ upstream of the inlet flange. The transmitter in the discharge line is approximately $1 \mathrm{ft}$ downstream of the outlet flange.

\subsection{Agitator}

The agitator is designed to mix and suspend solids in the simulated slurry. The agitator assembly, shown in the Philadelphia Mixer outline dimension drawing 90EUZ0631-1 in Appendix A, comprises a drive motor, gear box, and agitator shaft with impellers. The overall assembly length is approximately $23 \mathrm{ft}$. A 100-hp, totally enclosed, fan-cooled (TEFC) high-efficiency motor drives the agitator. The high-efficiency motor allows shaft speed to vary from 14 to $140 \mathrm{rpm}$. The controller is equipped with a process-control interface, so that the agitator can be operated from the MICON control system. The controller is also equipped with voltage, amperage, and frequency indicators. The motor start/operating frequency of 6 to $60 \mathrm{~Hz}$ directly corresponds to the agitator shaft speed of 14 to $140 \mathrm{rpm}$. The gear box is equipped with an auxiliary oil pump to provide adequate gear lubrication during operation at lower speeds. The agitator shaft, which is approximately $18 \mathrm{ft}$ long, is attached to the gear box output shaft with a hydraulic coupling developed by E. I. Dupont and is constructed from Nitronic-60. The agitator shaft is constructed from Hastelloy Alloy C-276 and is equipped with two 36-in.-diameter impellers. The bottom impeller is a four-blade vertically flat (radial) type located approximately 7 in. above the vessel floor. Two radial impeller blades are constructed of Hastelloy Alloy C-276, and two 
from Hastelloy Alloy C-22. The second impeller, located 60 in. above the radial impeller, is a threebladed hydrofoil, or turbine-type, impeller constructed of Hastelloy Alloy C-276.

\subsection{Slurry Transfer Pump}

The slurry transfer pump, shown in Lawrence Pump fabrication drawing M46313 in Appendix A, is a vertical, cantilevered, centrifugal-type variable-speed pump used to transfer feed out of the vessel. The transfer pump is also used as the melter-feed pump because the DWPF design specifications for both pumps are identical. The pump is driven by a 20-hp TEFC electric motor, which can be controlled from the MICON control station or manually operated with a rheostat mounted at the controller. The pump has a 100 -gpm design transfer capacity with a 2 -in. discharge. The intake is equipped with a 2-in. water priming system. The impeller and casing are constructed from stellite; the remainder of the pump is fabricated from stainless steel.

Fluid currents created by agitator operation necessitated modifications for stabilizing the sample and transfer pumps. These modifications were performed in accordance with those at DWPF. The modifications require that 1 ) the sample and transfer pumps be modified by the addition of a plate and guide pin welded to the suction and water prime lines (tailpipes) and 2) two pump support rings be added inside the test vessel. As each pump was lowered into the test vessel, the tail pipe guide pin (which faced downward) engaged the support ring attached to the vessel wall, effectively bracing the tailpipes.

\subsection{Feed Delivery Systems}

The feed delivery system is designed to transfer feed to the melter. Schematics of the feed delivery/transfer system are shown on the process and instrument diagrams (sheets 1 through 4 of drawing SK-3-27797) in Appendix A. With the transfer pump, feed can be transferred to the feed make-up tank, the slurry test loop, Tank HB-13, or the LFCM. The destination for the transfer is determined by the configuration (open or closed) of two isolation valves in the pump discharge piping.

Transfers to HB-13 are accomplished with a 2-in. stainless steel line that is routed to the top of the tank. An in-line flow meter is used to monitor the transfer.

The LFCM-feed system was constructed, based on design input from Fluor Daniel, to be prototypic of the HWVP melter-feed system. The feed system consists of five components. The first component is a recirculation loop, approximately $300 \mathrm{ft}$ long, constructed from 2 -in. schedule 40 stainless steel pipe. This loop extends from the pump outlet to a point near the LFCM and back to the vessel. The loop is equipped with in-line pressure, temperature, and flow sensing elements. The second component of the system is the cross-flow strainer, which is shown in drawing SK-3-27814 in Appendix A. The strainer, installed approximately in the middle of the recirculation loop (the portion of the loop nearest the meiter), diverts slurry flow from the 2-in. line to a $3 / 8$-in. line that feeds the melter, 
FPTS-9103 in Appendix A. The strainer helps protect the 3/8-in. line against plugging by filtering or straining out any particles greater than $0.05 \mathrm{in}$. in size. The third portion of the system is the $3 / 8$-in. schedule 80 stainless steel melter-feed line, which is equipped with pressure-sensing and flow-sensing elements as well as a 3-way Everlasting valve. If feed-flow drops below predetermined rates, as might be experienced if the feed nozzle plugged, the valve will automatically divert flush water through the line. Specific testing was performed to assess the adequacy of DWPF-recommended methods to prevent clogging of the melter-feed line and nozzle. The fourth component is the restriction orifice (drawing SK-3-27815 in Appendix A) installed in the recirculation loop where it re-enters the vessel. The function of the restriction orifice is to maintain back pressure on the recirculation loop so that feed is forced through the cross-flow strainer, the feed line, and ultimately into the melter. The final system component is the melter feed line nozzle, which is a portion of the LFCM test system. The melter feed line and modifications necessary for SIPT 2 testing are shown in Figures FPTS-9103 and FPTS-9103A in Appendix A.

Flow tests conducted before the LFCM-8 melter-feed run indicated that the flow in the melter feed line was significantly greater than the maximum LFCM processing level, even with the restriction orifice removed. To decrease the flow to the melter, part of the melter feed line was replaced with a smaller diameter and a longer tube (FPTS-9103A, Appendix A). The line between the Everlasting ${ }^{\circ}$ valve and the nozzle was replaced with $17 \mathrm{ft}$ of 3/8-in.-diameter, 0.065 -in. wall thickness $(0.245$-in. internal diameter), stainless steel tubing. The final $8 \mathrm{ft}$ of line (total length) was coiled into a 6-in.diameter helix because of space constraints. During the LFCM-8 run the feed-loop pressure dropped as the level in Tank HB-15 dropped causing a corresponding drop in flow rate. To compensate, the 8-ft coiled helix was replaced by a 6-ft (total length) coiled helix.

\subsection{Sample System}

The sample system was designed to transfer simulated slurry from the tank to the Hydragard Sampler. The sample pump, shown on Lawrence Pump fabrication drawing M46315 in Appendix A, is used to recirculate slurry through the sample system at a rate of 5 to $10 \mathrm{gpm}$ and is similar in construction to the transfer pump. The pump is driven by a 15-hp TEFC electric motor and has a maximum capacity of $58 \mathrm{gpm}$. The motor-controller operating features and physical location are the same as those described for the transfer pump. Most of the slurry is discharged directly back into the vessel through a ceramic restriction orifice installed into the outlet line. Therefore, during maximum operating speed it is expected that approximately $48 \mathrm{gpm}$ of slurry will be discharged back into the vessel and approximately $10 \mathrm{gpm}$ circulated through the sample station. A portion of the process stream is diverted from the recycle loop through a $15-\mathrm{mL}$ sample bottle when the sampler is activated. This sample is removed for analyses after the sampler is closed.

The sample station, shown on drawing SK-3-28257 in Appendix A, consists of one 2-way and one 3-way Fujikin ${ }^{\star}$ valve, one standard ball valve, a Hydragard ${ }^{\oplus}$ in-line sampler, a flow meter, and a pressure gauge. Slurry is transferred to the station through a 1/2-in. schedule 40 stainless steel line through the sample pump. This line is connected to the 3-way Fujikin ${ }^{\otimes}$ valve. From the valve the slurry is 
routed to the Hydragard sampler. Between the valve and the sampler are the pressure gauge and the flow element. The 1/2-in. schedule 40 return line leaves the station through the 2-way Fujikin ${ }^{\star}$ valve and is routed back to the vessel through a connection on the sample-pump flange. When the sampler is engaged, the slurry flows through the sampler to a separate line that is teed into the return line. The 3-way Fujikin and standard ball valves are operated as required either to obtain a sample or to backflush the lines with water.

An auxiliary sample system was used to obtain additional testing data. The system was designed to transfer simulated slurry from one of seven sampling lines located at different heights in the tank. A Warren Rupp 1-in. diaphragm pump is used to recirculate the slurry through the sampling system. The auxiliary sampling station (see Figure B-4 in Appendix A) was designed to sample simulated feed slurry from seven elevations within the tank. Seven $1 / 2$-in. schedule 40 stainless steel pipe legs extend from the top of the tank to the 0.5-, 2-, 4-, 6.5-, 7-, 8.5-, and 9.25-ft. levels above the bottom. These lines are connected by 3/4-in. stainless steel tubing to separate ball valves through a common header to the diaphragm pump. The valves allow the operator to sample from one of the seven locations while the slurry constantly recirculates through the diaphragm pump and discharges back into the tank. A 1/4-in. valve on the diaphragm pump discharge is used to collect the sample while the slurry is recirculating. A water supply line is connected to the header system for flushing after operations are complete.

\subsection{Thermowell}

The FPTS stainless steel thermowell design uses six replaceable thermocouples to provide temperature-profile data on vessel contents. The guard pipe and thermowell tube support and attachment details mimic the designs developed for the DWPF thermowell assembly. The FPTS thermowell is shown on drawing SK-3-28256 in Appendix A.

\subsection{Slurry Transfer Test Loop}

The slurry transfer test loop is designed to measure the pressure drop that occurs in various sizes of pipes and elbows. An isometric drawing of the slurry transfer test loop is shown on worksheet no. FPTS 91-06 Rev 0 in Appendix A. The test loop is constructed of 1/2-in., 1-in., and 2-in. schedule 40 type 304 stainless steel pipe. Ball valves are used to direct the flow in the loop. The test loop is composed of three sections of straight pipe and three sections of standard long radius $90^{\circ}$ elbows of different diameter. A Rosemount model 3051 differential pressure transmitter is installed on the upstream and downstream ends of each test section.

The slurry test loop is tied into the melter-feed-transfer loop and will be disconnected during melter feed runs. The flow through the test loop is controlled by transfer pump speed and is measured by the flow elements in the feed-transfer header and in the slurry test loop. 


\subsection{Holledge Level Detection System}

The Holledge level-detection system (Figure 1 in Appendix A) is designed to monitor the level of the tank contents and density of the simulated slurry. The detector, which is shown on Bechtel drawing W752204 in Appendix A, works on a principle similar to a dip-tube bubbler. Dip-tube bubblers bleed a small flow of air from a set of tubes into the fluid. Because the tubes are set at different known heights in the fluid, pressure on the air flowing into each tube is different. The differences in pressures are translated into a level measurement. In the Holledge level detector, the dip tubes are sealed by a Holledge PB-30 diaphragm sensor constructed from Hastelloy C-276. A thin Hastelloy diaphragm $(\sim 0.003$-in.) seals the sensor from the slurry. Inside the diaphragm, a needle valve is positioned above a valve seat, which is attached to the metal diaphragm (Figure 2 in Appendix A). Purge air, at a flow rate of $1.5 \mathrm{SCFH}$, is fed to the needle valve by a constant differential purge meter. The needle valve restricts the purge-air flow and increases the purge-air pressure proportionately to the diaphragm deflection. A differential pressure transmitter can then measure the required purge-air pressure and transmit the pressure signal to the data acquisition system (DAS). The needle valve is factory set so that the purge-air pressure is as close as possible to the process-fiuid pressure defiecting the diaphragm. As the diaphragm flexes from liquid pressure the space between the venturi face and the diaphragm decreases and back pressure increases correspondingly. Air leaving the venturis faces of the PB-30 sensors exhausts into the head space of the vessel.

The Holledge level detector for the HWVP FPTS was fabricated in accordance with construction details developed for the DWPF feed-preparation vessels. However, the HWVP design will not use a bottom sensor for the detection of mercury. Instead, the FPTS detector will be fabricated with the capability to measure slurry densities with 30 -in. reference-tube spacing, as in the case of the DWPF MFT system, or 50-in. reference spacing, as in the case of the DWPF SRAT and SME detectors. Sketch no. FPTS-91-01, in Appendix A, shows the arrangement for the FPTS.

\subsection{Holledge Calibration Tank}

An early problem encountered by DWPF with the Holledge level system was the calibration of its instruments. The pressure response of Holledge sensors varies directly with temperature. If the liquid level is held constant and the temperature is increased the instrument will indicate an increase in the liquid level.

To account for the temperature effect on level detection, it was necessary to build a calibration facility that could closely control the temperature and the liquid level: The calibration stand is a 6-in. pipe oriented vertically to house the Holledge Level System. The purpose of the calibration stand is to generate curves that characterize the response of the Holledge sensors. To accomplish this, a Rosemount Model 3051C differential pressure transmitter was used to measure the actual hydrostatic pressure of the water just above the calibration vessel drain. The level and temperature in the tank was controlled with two 2.5 -amp Micropumps ${ }^{\oplus}$ that continuously mixed the tank to achieve temperature equilibrium. The mixing action was slow enough to be considered static and had negligible effect 
on the data produced by the Holledge sensors. One pump filled the tank at about $50 \mathrm{in}$, and the other emptied the tank from near the bottom. By regulating the flow rates of each pump, the level in the tank can be accurately controlled. The tank was initially full and then emptied in increments so as to characterize the Holledge sensor's behavior. This test is performed at five different temperatures between $20^{\circ} \mathrm{C}$ and $100^{\circ} \mathrm{C}$. The test was then reversed (i.e., initially empty and filled incrementally) to test for hysteresis effects. The temperature of the liquid inside the stand was controlled with a small exterior tank (attached to both pumps) that is equipped with a Watlow ${ }^{\otimes} 240 \mathrm{~V}$ heating coil and temperature monitoring equipment.

\subsection{Support Equipment}

Miscellaneous support equipment is required to test the FPTS. The following describes each component or system and its function.

\subsubsection{High Bay Cranie}

The 324 Building High Bay is equipped with a 5-ton capacity crane for use in handling major equipment components (e.g., sample and transfer pumps, agitator, coil assembly) for maintenance or inspection purposes. The crane has a 48-ft lifting clearance and will also be used to handle bulk chemicals during slurry preparation.

\subsubsection{Steam Supply and Condensate Return}

The steam coil assembly is supplied by a 6-in. header located in the northwest corner of the facility. The steam source is the 300 Area power plant. Pressure at the header is approximately 90 psig at $318^{\circ} \mathrm{F}$; the HWVP plant design steam pressure is 150 psig. Tests at Savannah River Laboratory (SRL) indicate that the design boil-up rate of $10 \mathrm{gpm}$ can be readied. Low steam pressure is not expected to impact the quality or extent of tests. Steam condensate is returned to the powerhouse by a 4-in. condensate header located in the northwest corner of the facility.

\subsubsection{Air and Water Services}

Air and water services are supplied from the 300 Area power house. All water service to the FPTS (coiling coils, condenser, flush water, etc.) is supplied by two 2 -in. water lines that are routed on the first and second floors along the east and west walls of the High Bay 324. Water pressure at the 6-in. building header is $60 \mathrm{psig}$.

The instrument air source is a 1 -in. line routed along the east wall on the second floor. It terminates at an air dryer above a fume hood installed specifically to support FPTS operations. At the dryer, the 60-psig air pressure is reduced to 15 psig before distribution to the differential-pressure transmitters and converters that constitute a portion of the FP.TS monitoring and control systems. 


\subsubsection{Process Off-Gas System}

The source of the High Bay Process Off-Gas system is a blower in the 324 Building tank pit. The blower has an 800-scfm capacity at -140 in. $\mathrm{H}_{2} \mathrm{O}$. The blower exhausts to the Zone 2 tunnel, and off gas exits the facility stack after passing through two sets of high-efficiency particulate air (HEPA) filters. Tanks HB-14 and HB-15 are tied into the POG blower by a 6-in. header that runs along the east wall on the first floor of High Bay. Should off-gas conditions warrant, the existing pilot-scale ceramic melter submerged-bed scrubber and high-efficiency mist eliminator can be valved into the system.

\subsubsection{Tank HB-14}

A stainless steel tank approximately 9-ft dia by 9-ft high was installed for use as the Slurry Mix Evaporator Condensate Tank (SMECT). The tank, designated HB-14, has a 3800-gal operating volume and is the primary receiver for condensate generated from SRAT/SME condenser operations. Tank instrumentation includes a capacitance probe for real-time level measurement and a pH probe for on-line condensate $\mathrm{pH}$ measurement. The tank is located in the northeast corner of the High Bay first floor and is equipped with an air sparge system. The sparge system will be used to obtain representative $\mathrm{pH}$ measurements and may be used in the event that chemical additions are required to neutralize the condensate. It may also be used to re-suspend any particulates carried over from the condensing process. The vessel does not have an agitator because clearance above the tank is limited. Tank HB-14 also serves as an emergency overflow containment vessel for HB-15. The Tank HB-14 bottom side drain is attached to a double-diaphragm air-operated pump P-1400. The pump outlet is routed to a header that allows solution to be transferred to the process sewer, HB-13, HB-15, or weigh-tank 900 in the second-floor fume hood.

\subsubsection{Tank HB-13}

Tank HB-13 was used to make up initial concentrations of simulated feed, recycle, and frit slurries for transfer to the test vessel. This stainless steel tank is equipped with a 7.5-hp agitator and has an operating volume of $4300 \mathrm{gal}$. Its primary function is slurry makeup for transfer to Tank HB-15. Tank HB-13 is located on the first floor in the southwest comer of High Bay. The tank is mounted on load cells to weigh the contents. The tank has access for adding bulk chemicals. Solutions can be transferred to HB-13 from Tanks 311 and 315 in the chemical makeup room or from Tank 900 in the High Bay fume hood. A bottom side drain is routed to a double-diaphragm air-driven pump for transfer of contents to HB-15. The transfer line is equipped with a flow element for determination of transfer rate, a sample port for solution grab samples, and a control valve that can be opened or closed from the Micon control station.

\subsubsection{Fume Hood}

The fume hood removes offgas generated during formic addition to the test vessel. An approximately 6 - $\mathrm{ft}$ by 10 -ft walk-in fume hood serves as a chemical makeup area for the FPTS. Operator(s) 
will be inside the hood during chemical makeup and formic acid handling. The hood, which has a stainless-steel floor and a full face guillotine-type door, is located in the northwest corner of the High Bay second floor. Air from High Bay is drawn through the hood at a rate of approximately $300 \mathrm{scfm}$ and exhausted directly to the building exterior.

\subsubsection{Tank 900}

Tank 900 was used to weigh condensate from the test-vessel condenser. It is a 150-gal capacity stainless steel tank located in the High Bay fume hood. The tank can be used as a chemical addition tank or can be used to verify the flow rate of any process stream associated with the FPTS operations because it is mounted on load cells. The top of the tank is flanged so that it may be fully enclosed if required. A mixer can be installed in the tank. The tank inlet header is configured such that lines for process water, chemicais from Tanks 311 and 315, steam-coils condensate, or condenser-process condensate can be valved for flow into the tank. The tank outlet is connected to an air-operated doublediaphragm pump, which discharges to a header that can be valved to the process sewer, Tank HB-11, Tank HB-13, Tank HB-14, or Tank HB-15.

\subsection{Measuring and Test Equipment}

Measuring and test equipment includes the process control system, data acquisition system, and offgas sampling system. The piping and instrumentation diagrams (P\&IDs) in Appendix A for details controlled and measured signals. Process control, data acquisition, off-gas sampling equipment, and test instrumentation are described in the following sections.

\subsubsection{Process Control System}

The control system monitors process variables, controls the action of certain equipment, and automatically initiates sequences of actions according to specified interlocks. It feeds the sensor signals to the DAS.

The primary components of the control system are 5 Micon MR-240 controllers and 2 operator consoles. Each Micon controller provides 15 analog inputs, 8 analog outputs, 8 discrete (on/off) outputs, and 16 discrete inputs. It provides 8 control loops, each of which controls one of the analog outputs.

Each operator console provides a cathode-ray tube (CRT) display and a dedicated keyboard. The CRTs can display either text-based or graphical images. Text displays are specified as part of the configuration process. Graphical displays are designed separately from supplied graphical building blocks. During operation the operator can select from among the previously defined displays. The special process-control keyboards are designed for easy access to control functions. Touch-sensitive membrane switches ensure reliable operation in dirty environments. 
The system controls the behavior of process components according to specified set points and realtime process data and initiates sequences of steps based on defined process interlocks. The process monitors approximately 70 process variables, mostly temperatures, pressures, and flow rates. Some of these data are used for process control, others are stored in the DAS.

Process control functions are performed by several (mostly) independent control loops, as shown in Table 5.2.

Interlocks initiate specified actions or sequences of actions when a specified condition occurs. For the feed preparation system, the following interlocks were provided:

1. On high pressure in HB-15

a. Shut off steam to heating coils

b. Shut off formic acid feed pump

2. On high liquid level in $\mathrm{HB}-15$

a. Shut off feed from TK-900

b. Shut off feed/water from HB-13

3. On low liquid level in HB-15

a. Shut off steam supply

Table 5.2. SIPT Control Loops

Controlled Variable

flow into HB-15 from TK-900

flow into HB-15 from HB-13

flow of steam into the heating coils of HB-15

off-gas vacuum pressure

flow from HB-15 to meiter

flow in sample loop

plant air flow into HB-15

temperature of slurry from $\mathrm{HB}-13$
Controlled Device

control valve

control valve

control valve

control valve

variable speed pump

variable speed pump

control value

heater 
4. On high hydrogen concentration in HB-15
a. Purge tank head space with air
b. Shut off steam to heating coils
c. Open off-gas system control valve $100 \%$

5. On feed recycle loop line failure

a. Shut down transfer/feed pump

6. On low flow in melter feed line

a. Flush feed line with water

Tank HB-15 temperature was manually controlled by the heating and cooling coils.

\subsubsection{Data Acquisition System}

\section{Hardware}

The high-frequency data acquisition system (HFDAS) comprises three physical parts:

1. Acquisition unit - Hewlett Packard HP-3852 scanning voltmeter.

2. Processing unit - INTEL 80386-based AT-architecture computer.

3. IEEE-488 communications interface with remote extenders.

The HP-3852 interfaces directly to the Micon controllers and performs all engineering unit conversions on the data acquired from its internal analog-digital converters (ADC). It contains internal memory to allow initial buffering of the converted data, before transmission to the host processing unit.

Communication between the HP-3852 and the processing unit computer is accomplished by an IEEE-488 parallel instrumentation bus. Since the HP-3852 and the computer are physically separated by a significant distance, remote extenders are used to extend the range of the IEEE-488 bus.

The processing unit is an INTEL 80386 central processing unit (CPU) operating on an industry standard architecture (ISA) bus. This is the original IBM PC-AT bus. The CPU contains a minimum of one fixed disk of $\geq 100$ Mbytes formatted capacity and a streaming-tape-cartridge unit for data archiving. The display provides 640 pixels by 480 pixels resolution with 16 colors. 
The processing unit, which had network capability, accepts the converted data from the acquisition unit, performs alarm range checking, displays user-selected data values in both textual and graphical forms, and provides data archiving facilities.

\section{Software}

The HFDAS software is designed, developed, and validated. User interface functions are password protected to prevent unauthorized or inadvertent disruption of the application.

Transfer of acquired data from the HP-3852 can be temporarily suspended during data archiving operations without disturbing data acquisition. After an operator has initiated the data archiving, the computer application transfers the data files. At the end of the archiving process, the user is prompted to remove the archive tape cartridge and place it in long-term storage.

Through the network connection, users at remote locations can copy files from the Processing Unit, so that data analysis can be performed on the remote computers. This process is password protected, and allows reading from, but not writing to, the processing unit disk drive.

\subsubsection{Off-Gas Sampling System}

To establish the process vessel vent source term as a function of feed preparation activities, an offgas sampling network characterizes the nature and magnitude of process effluent losses (see Figures $4.2 \mathrm{a}$ and $4.2 \mathrm{~b}$ in Appendix A). Since feed-preparation activities are expected to produce dynamic off-gas conditions, real time or quasi-continuous measurements of noncondensable gas-emission rates were made for all major gases generated by feed-processing steps. Gas concentrations continuously tracked during these studies include $\mathrm{H}_{2}, \mathrm{CO}, \mathrm{CO}_{2}, \mathrm{NO}, \mathrm{NO}_{2}, \mathrm{~N}_{2} \mathrm{O}, \mathrm{NH}_{3}$, and $\mathrm{HCOOH}$. Off-gas concentrations of $\mathrm{CO}, \mathrm{CO}_{2}, \mathrm{HCOOH}$, and $\mathrm{N}_{2} \mathrm{O}$ are monitored by nondispersive infrared absorption techniques. A chemi-luminescent $\mathrm{NOx}$ analyzer is used to measure $\mathrm{NO}$ and $\mathrm{NO}_{2}$, and an electrochemical sensor is used to detect gas-phase concentrations of $\mathrm{NH}_{3}$. Hydrogen concentrations are measured using gas chromatography, the most cost-effective analytical alternative that provides chemical specificity. To verify on-line instrumental measurements, an off-line mass spectrometer periodically analyzes process off-gas grab samples.

The concentration, size, and average composition of process-generated aerosols were characterized through all phases of feed-preparation testing. To obtain this information, off-gas aerosols were collected by conventional filtration techniques and analyzed by appropriate off-line methods. Only average composition of condensed phase effluent was measured.

\subsubsection{Test Instrumentation}

Measuring and test equipment includes sensors for pressure, flow, temperature, etc. Refer to the P\&IDs in Appendix A for more detail. 


\subsection{Process Slurries Makeup and Characterization}

Non-radioactive feed preparation simulants were prepared to meet the HWVP reference feed nominal compositions. The melter-feed simulant in the full-scale test vessel (based on 500 gto/L melter feed) was composed of $68.66 \mathrm{wt} \%$ frit oxides, $28 \mathrm{wt} \%$ waste oxides, and $3.33 \mathrm{wt} \%$ recycle oxides. The melter feed is the sum of multiple phases of process operations: NCAW feed simulant (two batches), dilute waste simulant, concentrated waste simulant, formated waste simulant, recycle waste simulant, formated waste simulant with recycle, dry process frit, and melter feed waste simulant. Each simulant had to be prepared at the correct composition to yield 7800 gal of melter-feed waste simulant with 500 gto/L feed. All feed preparation was performed in Tank HB-13. (Formic acid and dry process frit were added directly to the process test vessel, $\mathrm{HB}-15$.)

The following sections describe preparation of the HWVP NCAW simulant. The simulants were prepared and tested in Tank HB-15 and represented the expected waste streams of the SRAT, SME, and MFT. Figure 6.1 shows general order of the simulant preparation, including some general information on the slurry-integrated performance testing (SIPT) process simulants. Information pertaining to simulant makeup and properties is provided in the following sections.

\subsection{General Remarks}

General remarks on slurry compositions and rheology provide context for the rest of Section 6.

\subsubsection{Physical Properties}

All samples for analysis were taken from the bottom sampling port of Tank HB-15. Appendix B gives the calculated target slurry compositions, and Appendix $C$ shows a comparison of target compositions to measured compositions for each simulant.

The target values for each simulant were based on the known amounts of chemicals (by mass) added to the feed make-up tank. The measured masses were converted to wt $\%$ solids for each compound and $w t \%$ oxides for its corresponding complementary oxide. Agreement between these target values and average measured values from samples was generally good. The reference feed specification requires that deviations from the nominal feed composition be less than $+1-5 \mathrm{wt} \%$ for the major components and $+/-10 \mathrm{wt} \%$ for the minor components. Although some of the elemental (oxide) comparisons in Appendix C show poor agreement (particularly for $\mathrm{Ag}, \mathrm{B}, \mathrm{Sr}, \mathrm{P}, \mathrm{S}$, and sometimes $\mathrm{Zn}$ ), the comparisons were usually within 10 to $15 \%$. The reasons for the poor agreement are unknown (the concentration was close to the detection limit, perhaps), but the results are consistent. The elemental target concentration is often less than $1 \mathrm{wt} \%$, which can be difficult to measure accurately from a sample. The elemental concentrations recorded in Appendix $\mathrm{C}$ are within the detection limits of the testing equipment. 


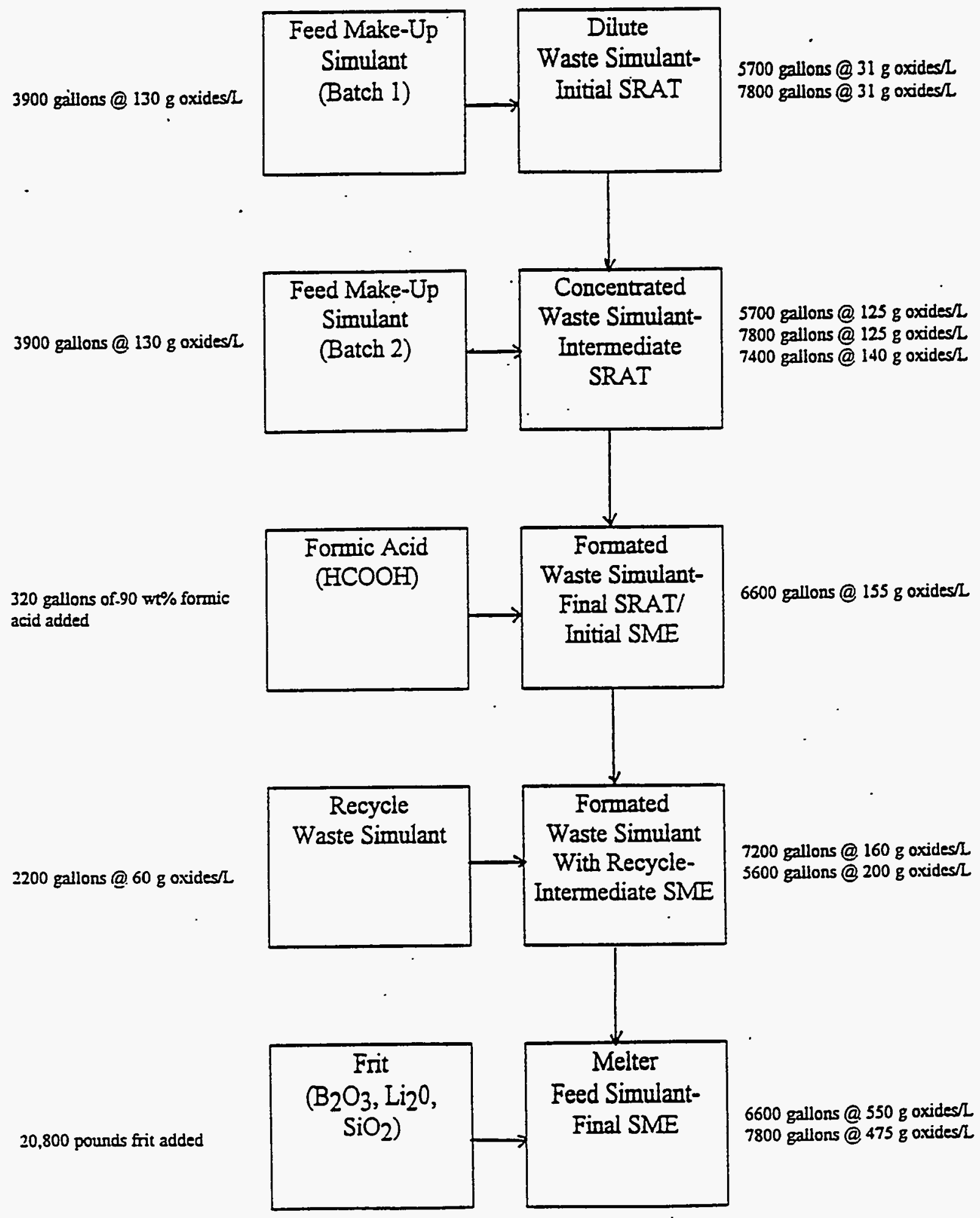

Figure 6.1. Simulant Flowsheet for Slurry-Integrated Performance Testing 


\subsubsection{Rheological Properties}

The simulant rheograms and settling rate plots are provided in Appendix D. The rheograms were generated by increasing the shear rate from 0 to $441 \mathrm{~s}^{-1}$ in two minutes and then decreasing the shear rate to 0 in two minutes. All data reported in the general slurry property tables are from the increasing shear rate portion or up curve. A difference between the up and down curve is called hysteresis. Thixotropy describes a rheological phenomenon that is caused by the breakdown of complex chemical, molecular, or particle interactions. A thixotropic fluid exhibits a decreasing shear stress over time when shear rate and temperature are constant. The up rheogram is a measure of the material as it is sheared. The down rheogram is measuring material that has been affected by shear forces. Almost all of the melter feed rheograms show a thixotropic hysteresis, as shown in Figure D14 (Appendix D).

Testing was done to determine if aging of the samples (after removal from the tank) affected the rheograms. Throughout the course of melter feeding, the rheologies of the melter-feed samples were time dependent (i.e., each sample's rheology changed over time) although the samples before frit addition were not. Therefore, all melter feed samples were run within a few hours of sample collection. Unless stated otherwise, all samples were taken at $50^{\circ} \mathrm{C}$.

The dilute and recycle waste simulants are essentially Newtonian fluids, that is, little or no yield stress is apparent before the plot becomes linear. The other waste simulants without frit, particularly the concentrated and formated waste simulants, exhibit a yield pseudoplastic behavior. These simulants then behave as a Newtonian fluid after subjected to a certain shear rate. This phenomenon has been associated with many other heavily concentrated suspensions but is not fully understood. The rheogram shows two distinct curves with the intersection marked by a "break point." The first half of the curve behaves like a yield pseudoplastic; a yield point is followed by a plastic viscosity curve until the break point occurs, usually somewhere around 150 to $225 \mathrm{~s}^{-1}$. From that shear rate onward, the fluid acts as a Newtonian fluid. The melter feed (containing frit) waste simulant is much more influenced by molecular interaction and retains a thixotropic, yield pseudoplastic behavior throughout the tested regime; it is visually similar to chocolate pudding.

\subsection{NCAW Feed Simulant (Batch 1 and Batch 2)}

The HWVP NCAW simulant was prepared in two equal batches in Tank HB-13. A 7.5-hp agitator was used to mix the slurry before addition to the feed-preparation test vessel Tank HB-15. The first batch was used to prepare the dilute waste simulant (low level and high level), while the second batch was used to prepare the concentrated waste simulant (low level and high level). Each batch was approximately $3900 \mathrm{gal}$ at $130 \mathrm{gwo} / \mathrm{L}$.

The chemicals used to prepare the dilute waste simulant were arranged into six separate material groups that were based on similar chemical properties and compatibility. All of the chemicals, with the following exceptions, were added directly as dry compounds. The exceptions were $\mathrm{Mg}\left(\mathrm{NO}_{3}\right)_{2}+$ $6 \mathrm{H}_{2} \mathrm{O}$ (delivered by the manufacturer in solution); $\mathrm{AgNO}_{3}, \mathrm{~Pb}\left(\mathrm{NO}_{3}\right)_{2}, \mathrm{KOH}$, and $\mathrm{SeO}_{2}$ (possible hazards when added dry); $\mathrm{Nd}(\mathrm{OH})_{3}, \mathrm{La}(\mathrm{OH})_{3}$, and $\mathrm{Ca}(\mathrm{OH})_{2}$ (highly insoluble; would settle to the bottom of the tank); and $\mathrm{NaI}$ and $\mathrm{SnSO}_{4}$ (small quantities; easier to disperse in solution). 
Also added to each batch of feed was approximately 51 (55-gal) drums of mixed-hydroxide slurry containing aluminum, ferric, manganese, nickel, and zirconium oxides as well as small amounts of $\mathrm{H}_{3} \mathrm{BO}_{3}, \mathrm{Ca}(\mathrm{OH})_{2}, \mathrm{NaOH}, \mathrm{SiO}_{2}$, and $\mathrm{TiO}_{2}$. Solids comprised approximately $15 \mathrm{wt} \%$ of the slurry. Adding these chemicals in a hydroxide mixture made the simulant more representative of the actual waste. Three samples of the hydroxide slurry established that the concentrations of $\mathrm{Al}, \mathrm{Fe}, \mathrm{Mn}$, and $\mathrm{Ni}$ would be less than $5 \mathrm{wt} \%$ different from the overall specified HWVP nominal feed composition. On the other hand, $\mathrm{Zr}$ was more than $12 \mathrm{wt} \%$ deficient in the overall feed composition and therefore had to be shimmed in the form of $\mathrm{Zr}(\mathrm{OH})_{4}$.

Tables 6.1 and 6.2 show the general properties of each batch of the feed make-up simulant. The measured values approach the target property values reported in Tables B1 and B2 in Appendix B. The measured properties are a little higher because the samples were taken before the water was added to adjust the feed for the second batch. Therefore, in that batch the measured values and the elemental compositions (Tables $\mathrm{C} 1$ and $\mathrm{C} 2$ in Appendix C) were slightly higher. No rheological properties were measured in these preparation batches.

\subsection{Dilute Waste Simulant (Initial SRAT)}

A portion (1363 gal) of the first NCAW feed simulant batch was transferred from Tank HB-13 to the clean full-scale test vessel. This batch was diluted with water to $31 \mathrm{gwo} / \mathrm{L}$ feed in $5700 \mathrm{gal}$. Homogeneity, pumping, slurry transfer, and evaporator/condenser testing were then performed on the low-level dilute waste simulant.

Table 6.1. General Properties for Feed Simulant - Batch 1 (after dilution)

\begin{tabular}{lr}
\multicolumn{2}{c}{ Physical Properties - Slurry } \\
\hline & \\
total solids (wt \%) & 16.34 \\
total oxides (wt\%) & 12.04 \\
total oxides $(\mathrm{g} / \mathrm{L})$ & 132.48 \\
density $(\mathrm{g} / \mathrm{mL})$ & 1.10 \\
pH & 11.50
\end{tabular}

Table 6.2. General Properties for Feed Simulant - Batch 2 (before dilution)

\begin{tabular}{lc}
\multicolumn{2}{c}{ Physical Properties - Slurry } \\
\hline total solids (wt\%) & 18.82 \\
total oxides (wt\%) & 13.88 \\
total oxides (g/L) & 151.98 \\
density $(\mathrm{g} / \mathrm{mL})$ & 1.095 \\
$\mathrm{pH}$ & 11.60
\end{tabular}


For the high-level dilute waste simulant, 499 gal from Tank HB-13 was added to the low-level dilute waste simulant in the full-scale test vessel. Water was added to dilute the simulant to $31 \mathrm{gwo} / \mathrm{L}$ feed at $7800 \mathrm{gal}$. Homogeneity, pumping, slurry transfer, and evaporator/condenser testing were then performed on the high-level dilute waste simulant.

Tables 6.3 and 6.4 show the general properties of the low-level and high-level dilute waste simulants. These values agreed with the target properties reported in Tables B3 and B4 in Appendix B. The elemental oxide comparisons in Tables $\mathrm{C} 3$ and $\mathrm{C4}$ (Appendix C) generally had good agreement, with the exception of $\mathrm{Ag}, \mathrm{B}, \mathrm{P}, \mathrm{S}$, and $\mathrm{Zn}$ (also $\mathrm{Cr}, \mathrm{Mg}, \mathrm{Te}$ in the high level).

Table 6.3. General Properties of Low-Level Dilute Waste Simulant (5700 gal)

Physical Properties - Slurry

\begin{tabular}{|c|c|}
\hline $\begin{array}{l}\text { total solids (wt\%) } \\
\text { total oxides ( } w t \%) \\
\text { total oxides }(g / \mathrm{L}) \\
\text { density }(\mathrm{g} / \mathrm{mL}) \\
\text { settled solids (vol\%) } \\
\text { settled solids (wt\%) } \\
\text { heat capacity }\left(\mathrm{J} / \mathrm{g} /{ }^{\circ} \mathrm{C}\right) \\
\text { boiling point }\left({ }^{\circ} \mathrm{C}\right) \\
\text { pH }\end{array}$ & $\begin{array}{c}4.25 \\
3.08 \\
32.03 \\
1.04 \\
13.70 \\
13.60 \\
\text { not available } \\
100 \\
11.20\end{array}$ \\
\hline \multicolumn{2}{|c|}{ Physical Properties - Supernate } \\
\hline $\begin{array}{l}\text { total solids (wt\%) } \\
\text { density }(\mathrm{g} / \mathrm{mL})\end{array}$ & $\begin{array}{l}1.53 \\
1.02\end{array}$ \\
\hline \multicolumn{2}{|c|}{ Rheological Properties (see Figure D3) } \\
\hline $\begin{array}{l}\text { apparent viscosity at } 101 / \mathrm{s}(\mathrm{cP}) \\
\text { apparent viscosity at } 251 / \mathrm{s}(\mathrm{cP}) \\
\text { apparent viscosity at } 1831 / \mathrm{s}(\mathrm{cP}) \\
\text { curve fit viscosity - Newtonian fit }(\mathrm{cP})^{(\mathrm{a})} \\
\text { curve fit viscosity - Bingham plastic fit }(\mathrm{cP})^{(\mathrm{a})} \\
\text { yield stress - Bingham plastic fit }(\mathrm{Pa})^{(\mathrm{a})} \\
\text { settling rate }\end{array}$ & $\begin{array}{c}27.21 \\
13.17 \\
5.45 \\
5.96 \\
5.73 \\
0.05 \\
\text { See Figure D1 }\end{array}$ \\
\hline
\end{tabular}

Note: Bingham plastic fit: 0 to $451 \mathrm{~s}^{-1}$ shear rate

Newtonian fit: 0 to $451 \mathrm{~s}^{-1}$ shear rate

(a) Recommend that the Newtonian fit be used since it is more representative. 
Table 6.4. General Properties of High-Level Dilute Waste Simulant (7800 gal)

Physical Properties - Slurry

\begin{tabular}{|c|c|}
\hline $\begin{array}{l}\text { total solids (wt\%) } \\
\text { total oxides (wt\%) } \\
\text { total oxides }(\mathrm{g} / \mathrm{L}) \\
\text { density }(\mathrm{g} / \mathrm{mL}) \\
\text { settled solids (vol\%) } \\
\text { settled solids }(\mathrm{wt} \%) \\
\text { heat capacity }\left(\mathrm{J} / \mathrm{g} /{ }^{\circ} \mathrm{C}\right) \\
\text { boiling point }\left({ }^{\circ} \mathrm{C}\right) \\
\mathrm{pH}\end{array}$ & $\begin{array}{c}4.33 \\
3.19 \\
33.18 \\
1.04 \\
13.40 \\
13.60 \\
\text { not available } \\
100 \\
11.40\end{array}$ \\
\hline \multicolumn{2}{|c|}{ Physical Properties - Supernate } \\
\hline $\begin{array}{l}\text { total solids (wt } \%) \\
\text { density }(\mathrm{g} / \mathrm{mL})\end{array}$ & $\begin{array}{l}1.60 \\
1.03\end{array}$ \\
\hline \multicolumn{2}{|c|}{ Rheological Properties (see Figure D4) } \\
\hline $\begin{array}{l}\text { apparent viscosity at } 10 \mathrm{l} / \mathrm{s}(\mathrm{cP}) \\
\text { apparent viscosity at } 251 / \mathrm{s}(\mathrm{cP}) \\
\text { apparent viscosity at } 183 \mathrm{l} / \mathrm{s}(\mathrm{cP}) \\
\text { curve fit viscosity - Newtonian fit }(\mathrm{cP})^{(\mathrm{a})} \\
\text { curve fit viscosity - Bingham plastic fit(cP) } \\
\text { yield stress - Bingham plastic fit }(\mathrm{Pa})^{(\mathrm{a})} \\
\text { settling rate }\end{array}$ & $\begin{array}{c}27.89 \\
12.51 \\
5.51 \\
5.84 \\
5.47 \\
0.06 \\
\text { See Figure D1 }\end{array}$ \\
\hline
\end{tabular}

Note: Bingham plastic fit: 0 to $451 \mathrm{~s}^{-1}$ shear rate Newtonian fit: 0 to $451 \mathrm{~s}^{-1}$ shear rate

(a) Recommend that the Newtonian fit be used since it is more representative.

The dilute waste simulants can be regarded as Newtonian fluids as indicated in Figures D3 and D4 in Appendix D. A curve-fit for a Bingham plastic was plotted through the data and yielded a low (almost zero) yield stress. The values reported were averages of two samples taken for each simulant. The range of low shear stresses reported is not in the optimum range for the Haake viscometer, and the readings contained much "noise."

\subsection{Concentrated Waste Simulant (Intermediate SRAT)}

The low-level concentrated waste simulant was prepared by adding the remaining 2038 gal of the first batch from Tank HB-13 to the high-level dilute waste simulant and concentrating the overall 
volume ( $\sim 9800 \mathrm{gal}$ ) down to $5700 \mathrm{gal}$. To maintain a constant volume, $1441 \mathrm{gal}$ of the second batch (diluted to approximately 4 to $5 \mathrm{wt} \%$ solids) from Tank HB-13 was transferred to the full-scale test vessel during boiling. The evaporation rate while boiling varied between 7 and 12 gal per minute. The resulting low-level concentrated waste simulant was approximately $125 \mathrm{gwo} / \mathrm{L}$. After concentration, homogeneity, pumping, slurry transfer, and evaporator/condenser testing were performed.

To create the high-level concentrated waste simulant, the rest of the second batch ( $2459 \mathrm{gal}$ ) was added to the low-level concentrated waste simulant in the full-scale test vessel. Additional water was removed to concentrate the simulant to $125 \mathrm{gwo} / \mathrm{L}$ feed at $7800 \mathrm{gal}$. Homogeneity, pumping, slurry transfer, and evaporator/condenser testing were then performed.

The contents of the test vessel were concentrated from $125 \mathrm{gwo} / \mathrm{L}$ at $7800 \mathrm{gal}$ to $140 \mathrm{gwo} / \mathrm{L}$ at $7400 \mathrm{gal}$ before addition of formic acid.

Tables 6.5, 6.6, and 6.7 show the general simulant properties, respectively, for the low-level and high-level concentrated waste simulants and concentrated waste simulant before formic acid addition. These values agreed well with the target values reported in Tables B5 and B6 (Appendix B). The elemental oxide comparisons given in Tables $\mathrm{C} 5$ and $\mathrm{C} 6$ in Appendix $\mathrm{C}$ generally showed good agreement, with the exception of $\mathrm{Ag}, \mathrm{B}, \mathrm{Ce}, \mathrm{P}, \mathrm{S}, \mathrm{Si}, \mathrm{Sr}, \mathrm{Te}$ (also Al, Fe, Mg, Mo, and $\mathrm{Ti}$ in high level). The high-level concentrated waste simulant seemed to be on the low side of the target compositions.

The rheograms are shown as Figures D5 and D6 in Appendix D. Although not shown in the plots (only data pertaining to the up curve are shown), the presence of a slight hysteresis implies thixotropic behavior. The break point occurred at about $190 \mathrm{~s}^{-1}$ for the low-level and high-level concentrated (before formic acid addition) waste simulants. A curve-fit for a Bingham plastic was plotted through the first part of the data and yielded yield stresses significantly higher than the dilute waste simulants. A curve-fit for a Newtonian fluid was plotted through the second half of the data. The values reported were averages of two samples taken for each simulant.

\subsection{Formated Waste Simulant (Final SRAT)}

HWVP formated waste simulant was prepared by adding $90 \mathrm{wt} \%$ formic acid to the high-level concentrated waste simulant in the full-scale test vessel. First, the contents of the test vessel were concentrated from $125 \mathrm{gwo} / \mathrm{L}$ at $7800 \mathrm{gal}$ to $140 \mathrm{gwo} / \mathrm{L}$ at $7400 \mathrm{gal}$ as described in Section 6.4.

Approximately $320 \mathrm{gal}$ of the $90 \mathrm{wt} \%$ formic acid were added to the vessel in semi-continuous fashion at -1 gal per minute. During the addition, the tank temperature was kept constant at $95^{\circ} \mathrm{C}$ $\left( \pm 2^{\circ} \mathrm{C}\right)$. The condensate was recycled to the test vessel to maintain a constant volume.

After formic acid addition, the slurry was heated to boiling (evaporation rate -4 gal per minute) and digested for 4 hours. The condensate was collected in the condensate-receipt Tank HB-14. The final concentration in Tank HB-15 was approximately $153 \mathrm{gwo} / \mathrm{L}$, and the final volume was about 6600 gal. Homogeneity, pumping, slurry transfer, and evaporator/condenser testing were performed with the formated waste simulant. 
Table 6.5. General Properties of Low-Level Concentrated Waste Simulant (5700 gal)

Physical Properties - Slurry

\begin{tabular}{|c|c|}
\hline \multicolumn{2}{|c|}{ Physical Properties - Slurry } \\
\hline $\begin{array}{l}\text { total solids (wt \%) } \\
\text { total oxides (wt\%) } \\
\text { total oxides }(\mathrm{g} / \mathrm{L}) \\
\text { density }(\mathrm{g} / \mathrm{mL}) \\
\text { settled solids (vol \%) } \\
\text { settled solids }(\mathrm{wt} \%) \\
\text { heat capacity }\left(\mathrm{J} / \mathrm{g} /{ }^{\circ} \mathrm{C} \text { ) }\right. \\
\text { boiling point }\left({ }^{\circ} \mathrm{C}\right) \\
\text { pH }\end{array}$ & $\begin{array}{c}15.55 \\
11.47 \\
126.17 \\
1.10 \\
42.3 \\
45.1 \\
\text { not available } \\
101 \\
11.60\end{array}$ \\
\hline \multicolumn{2}{|c|}{ Physical Properties - Supernate } \\
\hline $\begin{array}{l}\text { total solids (wt\%) } \\
\text { density }(\mathrm{g} / \mathrm{mL})\end{array}$ & $\begin{array}{r}6.12 \\
-1.05\end{array}$ \\
\hline \multicolumn{2}{|c|}{ Rheological Properties (see Figure D5) } \\
\hline $\begin{array}{l}\text { apparent viscosity at } 101 / \mathrm{s}(\mathrm{cP}) \\
\text { apparent viscosity at } 251 / \mathrm{s}(\mathrm{cP}) \\
\text { apparent viscosity at } 1831 / \mathrm{s}(\mathrm{cP}) \\
\text { curve fit viscosity - Newtonian fit (cP) } \\
\text { curve fit viscosity - Bingham plastic fit (cP) } \\
\text { yield stress - Bingham plastic fit (Pa) } \\
\text { settling rate }\end{array}$ & $\begin{array}{r}140.45 \\
62.56 \\
12.70 \\
12.59 \\
6.00 \\
1.34 \\
\text { See Figure D1 }\end{array}$ \\
\hline
\end{tabular}

Note: Bingham plastic fit: 0 to $190 \mathrm{~s}^{-1}$ shear rate Newtonian fit: 190 to $451 \mathrm{~s}^{-1}$ shear rate

Table 6.8 shows the general simulant properties of the formated waste simulant. The values in this table were numerically close to the target values reported in Table B7 in Appendix B. The elemental oxide comparisons given in Table C7 in Appendix C generally had good agreement, with the exception of $\mathrm{Ag}, \mathrm{B}, \mathrm{La}, \mathrm{Na}, \mathrm{P}, \mathrm{S}$, and $\mathrm{Te}$.

The rheogram is shown as Figure D7 in Appendix D. Although not shown in the plot (only data pertaining to the up curve are shown), a slight hysteresis implies thixotropic behavior. The break point of the formated waste simulant occurred at about $160 \mathrm{~s}^{-1}$. A curve-fit for a Bingham plastic plotted through the first part of the data $\left(0\right.$ to $\left.160 \mathrm{~s}^{-1}\right)$ revealed yield stresses slightly lower than those of the concentrated waste simulants. That was unexpected because the solids concentration was slightly 
Table 6.6. General Properties of High-Level Concentrated Waste Simulant $(7800 \mathrm{gal})$

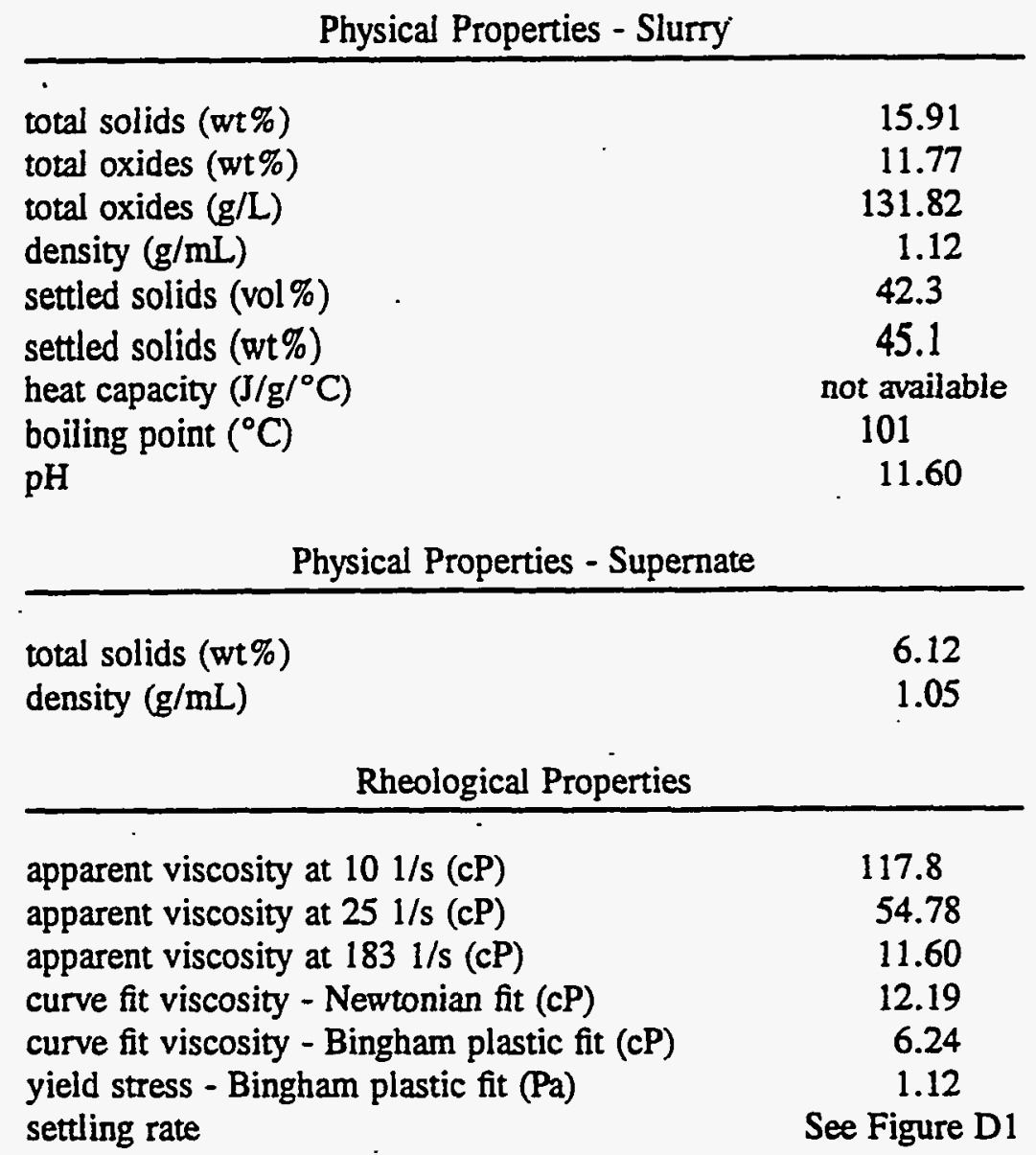

Note: Bingham plastic fit: 0 to $190 \mathrm{~s}^{-1}$ shear rate Newtonian fit: 190 to $451 \mathrm{~s}^{-1}$ shear rate

higher in the formated waste simulant. The lower $\mathrm{pH}$ of the formated waste simulant $(5.95$ for formated and 11.6 for concentrated waste simulants) may have caused chemical changes that affected the rheological properties. A curve-fit for a Newtonian fluid was plotted through the second half of the data (160 to $451 \mathrm{~s}^{-1}$ ). The values reported were averages of two samples taken for each simulant.

\subsection{Recycle Waste Simulant (Initial SME)}

The HWVP recycle waste simulant was prepared in one batch in Tank HB-13 and then transferred to Tank HB-15. The batch size was approximately $2200 \mathrm{gal}$ at $60 \mathrm{~g}$ recycle oxides $/ \mathrm{L}$ feed. 
Table 6.7. General Properties of High-Level Concentrated Waste Simulant (before formic acid addition - $7400 \mathrm{gal}$ )

Physical Properties - Slurry

\begin{tabular}{|c|c|}
\hline $\begin{array}{l}\text { total solids (wt \%) } \\
\text { total oxides (wt \%) } \\
\text { total oxides (g/L) } \\
\text { density (g/mL) } \\
\text { settled solids (vol \%) } \\
\text { settled solids (wt\%) } \\
\text { heat capacity }\left(\mathrm{J} / \mathrm{g} /{ }^{\circ} \mathrm{C}\right) \\
\text { boiling point }\left({ }^{\circ} \mathrm{C}\right) \\
\text { pH }\end{array}$ & $\begin{array}{c}16.75 \\
12.40 \\
138.88 \\
1.12 \\
42.9 \\
46.0 \\
\text { not available } \\
101 \\
11.60\end{array}$ \\
\hline \multicolumn{2}{|c|}{ Physical Properties - Supernate } \\
\hline $\begin{array}{l}\text { total solids (wt\%) } \\
\text { density }(\mathrm{g} / \mathrm{mL})\end{array}$ & $\begin{array}{l}6.53 \\
1.05\end{array}$ \\
\hline \multicolumn{2}{|c|}{ Rheological Properties (See Figure D6) } \\
\hline $\begin{array}{l}\text { apparent viscosity at } 101 / \mathrm{s}(\mathrm{cP}) \\
\text { apparent viscosity at } 251 / \mathrm{s}(\mathrm{cP}) \\
\text { apparent viscosity at } 1831 / \mathrm{s}(\mathrm{cP}) \\
\text { curve fit viscosity - Newtonian fit (cP) } \\
\text { curve fit viscosity - Bingham plastic fit (cP) } \\
\text { yield stress - Bingham plastic fit (Pa) } \\
\text { settling rate }\end{array}$ & $\begin{array}{c}151.1 \\
68.5 \\
14.39 \\
13.92 \\
6.92 \\
1.47 \\
\text { See Figure D1 }\end{array}$ \\
\hline $\begin{array}{l}\text { Note: Bingham plastic fit: } 0 \text { to } 195 \mathrm{~s}^{-1} \text { she } \\
\text { Newtonian fit: } 195 \text { to } 451 \mathrm{~s}^{-1} \text { shear }\end{array}$ & \\
\hline
\end{tabular}

The chemicals, with the following exceptions, were added to Tank HB-13 directly as dry compounds. The exceptions were $\mathrm{KMnO}_{4}$ (highly reactive in dry form) and $90 \mathrm{wt} \% \mathrm{HCOOH}$ (a liquid at room temperature).

About 1900 gal of condensate from Tank HB-14 was added to the batch feed to minimize hazardous waste disposal costs. Two $100-\mathrm{mL}$ samples were taken from the condensate tank before feed. makeup to determine the concentrations of cations and anions in solution by ICP and IC, respectively. It was concluded that the $70 \mathrm{wt} \% \mathrm{HNO}_{3}$ was not needed in the recycle feed because the concentration of $\mathrm{NO}_{3}^{+}$in the condensate was high enough. The presence of sodium in the condensate also reduced the amount of $\mathrm{NaNO}_{3}$ that was needed. 
Table 6.8. General Properties of Formated Waste Simulant (6600 gal)

Physical Properties - Slurry

\begin{tabular}{|c|c|}
\hline $\begin{array}{l}\text { total solids (wt\%) } \\
\text { total oxides (wt\%) } \\
\text { total oxides }(\mathrm{g} / \mathrm{L}) \\
\text { density }(\mathrm{g} / \mathrm{mL}) \\
\text { settled solids }(\mathrm{vol} \%) \\
\text { settled solids (wt\%) } \\
\text { heat capacity }\left(\mathrm{J} / \mathrm{g} /{ }^{\circ} \mathrm{C}\right) \\
\text { boiling point }\left({ }^{\circ} \mathrm{C}\right) \\
\text { pH }\end{array}$ & $\begin{array}{r}19.60 \\
13.50 \\
153.90 \\
1.14 \\
43.20 \\
46.70 \\
3.58 \\
101 \\
5.95\end{array}$ \\
\hline \multicolumn{2}{|c|}{ Physical Properties - Supernate } \\
\hline $\begin{array}{l}\text { total solids (wt\%) } \\
\text { density }(g / m L)\end{array}$ & $\begin{array}{l}10.39 \\
1.065\end{array}$ \\
\hline \multicolumn{2}{|c|}{ Rheological Properties (see Figure D7) } \\
\hline $\begin{array}{l}\text { apparent viscosity at } 101 / \mathrm{s}(\mathrm{cP}) \\
\text { apparent viscosity at } 251 / \mathrm{s}(\mathrm{cP}) \\
\text { apparent viscosity at } 183 \mathrm{l} / \mathrm{s}(\mathrm{cP}) \\
\text { curve fit viscosity - Newtonian fit (cP) } \\
\text { curve fit viscosity - Bingham plastic fit (cP) } \\
\text { yield stress - Bingham plastic fit (Pa) } \\
\text { settling rate }\end{array}$ & $\begin{array}{c}123.25 \\
56.50 \\
13.46 \\
13.04 \\
6.73 \\
1.19 \\
\text { See Figure D1 }\end{array}$ \\
\hline
\end{tabular}

Note: Bingham plastic fit: 0 to $160 \mathrm{~s}^{-1}$ shear rate Newtonian fit: 160 to $451 \mathrm{~s}^{-1}$ shear rate

Table 6.9 shows the general properties of the recycle waste simulant in Tank HB-13. Agreement was good between these values and the target values reported in Table B8 in Appendix B. To calculate the target elemental compositions shown in Table C8 in Appendix C, the compositions of diatomaceous earth and zeolite (IE-96) had to be estimated. The elemental comparisons generally agreed well with the exception of $\mathrm{Ca}, \mathrm{Fe}, \mathrm{Mg}$, and $\mathrm{Mn}$. Since these elements are primarily found in diatomaceous earth and zeolite, it is possible that the errors resulted from poor estimation.

The recycle waste simulant was Newtonian in nature. As seen in Figure D8 in Appendix D, a curve-fit for a Bingham plastic plotted through the data revealed a low (almost zero) yield stress. The values reported were averages of two samples taken for each simulant. Low shear stresses reported are not in the optimum range for the Haake viscometer, so that the readings were "noisy." 
Table 6.9. General Properties of Recycle Waste Simulant (2200 gal)

Physical Properties - Slurry

\begin{tabular}{|c|c|}
\hline $\begin{array}{l}\text { total solids (wt\%) } \\
\text { total oxides (wt\%) } \\
\text { total oxides (g/L) } \\
\text { density }(\mathrm{g} / \mathrm{mL}) \\
\text { settled solids (vol\%) } \\
\text { settled solids }(\mathrm{wt} \%) \\
\text { heat capacity }\left(\mathrm{J} / \mathrm{g} /{ }^{\circ} \mathrm{C}\right) \\
\text { boiling point }\left({ }^{\circ} \mathrm{C}\right) \\
\text { pH }\end{array}$ & $\begin{array}{c}10.06 \\
5.75 \\
60.38 \\
1.05 \\
11.30 \\
11.60 \\
3.80 \\
100 \\
4.40\end{array}$ \\
\hline \multicolumn{2}{|c|}{ Physical Properties - Supernate } \\
\hline $\begin{array}{l}\text { total solids ( } w t \%) \\
\text { density }(g / m L)\end{array}$ & $\begin{array}{l}7.08 \\
1.056\end{array}$ \\
\hline \multicolumn{2}{|c|}{ Rheological Properties (see Figure D8) } \\
\hline $\begin{array}{l}\text { apparent viscosity at } 101 / \mathrm{s}(\mathrm{cP}) \\
\text { apparent viscosity at } 251 / \mathrm{s}(\mathrm{cP}) \\
\text { apparent viscosity at } 1831 / \mathrm{s}(\mathrm{cP}) \\
\text { curve fit viscosity - Newtonian fit }(\mathrm{cP})^{(\mathrm{a})} \\
\text { curve fit viscosity - Bingham plastic fit(cP) } \\
\text { yield stress - Bingham plastic fit }(\mathrm{Pa})^{(\mathrm{a})} \\
\text { settling rate }\end{array}$ & $\begin{array}{c}22.88 \\
11.79 \\
5.33 \\
5.77 \\
5.64 \\
0.10 \\
\text { See Figure D1 }\end{array}$ \\
\hline $\begin{array}{l}\text { Note: Bingham plastic fit: } 0 \text { to } 451 \mathrm{~s}^{-1} \text { shea } \\
\text { Newtonian fit: } 0 \text { to } 451 \mathrm{~s}^{-1} \text { shear rate } \\
\text { (a) Recommend that the Newtonian fit be use } \\
\text { representative. }\end{array}$ & it is more \\
\hline
\end{tabular}

\subsection{Formated Waste Simulant with Recycle (Intermediate SME)}

The HWVP formated waste simulant with recycle was the result of adding recycle waste simulant to formated waste simulant that had been concentrated to 5700 gal.

The recycle was added to the tank at approximately $40 \mathrm{gal}$ per minute. About 3 gal per minute of water evaporated during the process. The final concentration in the tank was approximately $160 \mathrm{~g}$ oxides $/ \mathrm{L}$, and the final volume was about $7200 \mathrm{gal}$.

Before frit addition, this simulant was concentrated from $160 \mathrm{~g}$ oxides $/ \mathrm{L}$ to $200 \mathrm{~g}$ oxides $/ \mathrm{L}$. 
Tables 6.10 and 6.11 show the general properties of the formated waste simulant with recycle (160 $\mathrm{g}$ oxides $/ \mathrm{L})$ and formated waste simulant with recycle before frit addition $(200 \mathrm{~g}$ oxides $/ \mathrm{L})$, respectively. Table 6.10 agreed well with the target properties reported in Table B9 in Appendix B. The elemental oxide comparisons shown in Table $C 9$ in Appendix $C$ generally had good agreement with the exception of $\mathrm{Ag}, \mathrm{B}, \mathrm{Ba}, \mathrm{Na}, \mathrm{P}$, and $\mathrm{Sr}$.

Table 6.10. General Properties of Formated Waste Simulant with Recycle $(7200 \mathrm{gal})$

Physical Properties - Slurry

\begin{tabular}{|c|c|}
\hline $\begin{array}{l}\text { total solids (wt\%) } \\
\text { total oxides (wt\%) } \\
\text { total oxides }(\mathrm{g} / \mathrm{L}) \\
\text { density }(\mathrm{g} / \mathrm{mL}) \\
\text { settled solids (vol.\%) } \\
\text { settled solids }(\mathrm{wt} \%) \\
\text { heat capacity }\left(\mathrm{J} / \mathrm{g} /{ }^{\circ} \mathrm{C}\right) \\
\text { boiling point }\left({ }^{\circ} \mathrm{C}\right) \\
\mathrm{pH}\end{array}$ & $\begin{array}{r}20.46 \\
13.90 \\
158.46 \\
1.14 \\
42.65 \\
46.15 \\
3.38 \\
101 \\
6.09\end{array}$ \\
\hline \multicolumn{2}{|c|}{ Physical Properties - Supernate } \\
\hline $\begin{array}{l}\text { total solids (wt\%) } \\
\text { density (g/mL) }\end{array}$ & $\begin{array}{r}11.85 \\
1.08\end{array}$ \\
\hline \multicolumn{2}{|c|}{ Rheological Properties (see Figure D9) } \\
\hline $\begin{array}{l}\text { apparent viscosity at } 101 / \mathrm{s}(\mathrm{cP}) \\
\text { apparent viscosity at } 251 / \mathrm{s}(\mathrm{cP}) \\
\text { apparent viscosity at } 1831 / \mathrm{s}(\mathrm{cP}) \\
\text { curve fit viscosity - Newtonian fit (cP) } \\
\text { curve fit viscosity - Bingham plastic fit (cP) } \\
\text { yield stress - Bingham plastic fit (Pa) } \\
\text { settling rate }\end{array}$ & $\begin{array}{c}109.48 \\
49.78 \\
12.28 \\
12.00 \\
6.02 \\
1.05 \\
\text { See Figure D1 }\end{array}$ \\
\hline $\begin{array}{l}\text { Note: Bingham plastic fit: } 0 \text { to } 160 \mathrm{~s}^{-1} \text { she } \\
\text { Newtonian fit: } 160 \text { to } 451 \mathrm{~s}^{-1} \text { shear }\end{array}$ & \\
\hline
\end{tabular}


Table 6.11. General Properties of Formated Waste Simulant with Recycle (before frit addition - $5600 \mathrm{gal}$ )

Physical Properties - Slurry.

\begin{tabular}{|c|c|}
\hline $\begin{array}{l}\text { total solids (wt\%) } \\
\text { total oxides (wt\%) } \\
\text { total oxides (g/L) } \\
\text { density (g/mL) } \\
\text { settled solids (vol\%) } \\
\text { settled solids (wt\%) } \\
\text { heat capacity }\left(\mathrm{J} / \mathrm{g} /{ }^{\circ} \mathrm{C}\right) \\
\text { boiling point }\left({ }^{\circ} \mathrm{C}\right) \\
\text { pH }\end{array}$ & $\begin{array}{c}25.01 \\
16.91 \\
200.38 \\
1.185 \\
52.0 \\
55.3 \\
3.25 \\
101 \\
6.30\end{array}$ \\
\hline \multicolumn{2}{|c|}{ Physical Properties - Supernate } \\
\hline $\begin{array}{l}\text { total solids (wt\%) } \\
\text { density }(\mathrm{g} / \mathrm{mL})\end{array}$ & $\begin{array}{r}14.73 \\
1.09\end{array}$ \\
\hline \multicolumn{2}{|c|}{ Rheological Properties (see Figure D10) } \\
\hline $\begin{array}{l}\text { apparent viscosity at } 101 / \mathrm{s}(\mathrm{cP}) \\
\text { apparent viscosity at } 251 / \mathrm{s}(\mathrm{cP}) \\
\text { apparent viscosity at } 1831 / \mathrm{s}(\mathrm{cP}) \\
\text { curve fit viscosity - Newtonian fit (cP) } \\
\text { curve fit viscosity - Bingham plastic fit (cP) } \\
\text { yield stress - Bingham plastic fit (Pa) } \\
\text { settling rate }\end{array}$ & $\begin{array}{c}248.8 \\
110.4 \\
21.62 \\
17.72 \\
8.14 \\
2.49 \\
\text { See Figure D1 }\end{array}$ \\
\hline
\end{tabular}

Note: Bingham plastic fit: 0 to $240 \mathrm{~s}^{-1}$ shear rate Newtonian fit: 240 to $451 \mathrm{~s}^{-1}$ shear rate

Although not shown in Figures D9 and D10 in Appendix D (only data pertaining to the up curve are shown), the presence of a slight hysteresis implies thixotropic behavior. The break point occurred at about $160 \mathrm{~s}^{-1}$ and $240 \mathrm{~s}^{-1}$ for the formated waste simulant with recycle and formated waste simulant with recycle before frit addition, respectively. A curve-fit for a Bingham plastic was plotted through the first part of the data for both simulants. The addition of the recycle waste simulant had little or no effect on the rheology of the formated waste simulant. However, the formated waste simulant with recycle before frit addition ( $200 \mathrm{~g}$ oxides $/ \mathrm{L}$ ) had significantly higher yield stress than did the concentrated waste simulants. A curve-fit for a Newtonian fluid was plotted through the second half of the data for both simulants. The values reported were averages of two samples of each simulant. 


\subsection{Dry Process Frit Properties (Final SME)}

The process frit was added directly to HB- 15 as a dry solid that contained approximately 73 wt\% $\mathrm{SiO}_{2}, 20 \mathrm{wt} \% \mathrm{~B}_{2} \mathrm{O}_{3}$, and $7 \mathrm{wt} \% \mathrm{LiO}_{2}$. The frit was formed by melting the compounds together to make glass and broken into -80 to 200 -mesh particles. The frit was delivered in $50 \mathrm{lb}$ bags that were added through the in-tank camera viewing port on the top of the tank. The amount of frit to be added was calculated to be $20,800 \mathrm{lb} ; 416(50 \mathrm{lb})$ bags were added to the tank to meet this requirement. Table 6.12 shows the process frit composition. Also added to the tank were approximately 23 gal of $90 \mathrm{wt} \%$ formic acid. Table B10 in Appendix B presents the bulk and particle density information.

\subsection{Melter-Feed Waste Simulant (SME/MFT)}

The HWVP melter-feed simulant was made by adding dry process frit and $90 \mathrm{wt} \%$ formic acid to the formated waste simulant with recycle. This simulant was concentrated from $160 \mathrm{~g}$ oxides $/ \mathrm{L}$ to $200 \mathrm{~g}$ oxides/L before frit addition.

Over 4 to 5 hours, approximately $20,800 \mathrm{lb}$ of the dry process frit was added to the test vessel at $50^{\circ} \mathrm{C}$. The contents of the vessel were then heated to $90^{\circ} \mathrm{C}$, and $23 \mathrm{gal}$ of $90 \mathrm{wt} \%$ formic acid was added at 1 gal per minute. The resulting melter feed simulant was brought to boiling, digested for 2 hours, and cooled to $50^{\circ} \mathrm{C}$. Immediately after digestion, the melter-feed simulant was about $550 \mathrm{gto} / \mathrm{L}$ at $6600 \mathrm{gal}$ but was later diluted to $7200 \mathrm{gal}$ to approximate the HWVP target of $500 \mathrm{gto} / \mathrm{L}$.

Homogeneity, pumping, slurry transfer, and evaporator/condenser testing were performed on the melter-feed simulant. At the conclusion of testing, the melter-feed simulant was fed to the LFCM melter for the LFCM-8 test.

Tables $6.13 \mathrm{a}$ and $6.13 \mathrm{~b}$ show the general properties of the melter-feed waste simulant on different days. Table 6.14 lists the properties of simulant accumulated on the coils. These tables agreed well with the table of compositional targets reported as Table B11 in Appendix B. The elemental oxide comparisons shown as Table C10 in Appendix C generally had good agreement, with the exception of $\mathrm{Ce}, \mathrm{Cr}, \mathrm{La}, \mathrm{Mg}, \mathrm{P}, \mathrm{Pb}, \mathrm{S}, \mathrm{Te}$, and $\mathrm{Zn}$.

Table 6.12. Dry Process Frit Composition

\begin{tabular}{lrrr}
\multicolumn{1}{c}{ Compounds } & & Wt\% & Approximate Amount (lb) \\
$\mathrm{SiO}_{2}$ & 73 & 15,184 \\
$\mathrm{~B}_{2} \mathrm{O}_{3}$ & 20 & 4,160 \\
$\mathrm{LiO}_{2}$ & 7 & 1,456 \\
Totals & 100 & 20,800
\end{tabular}


Table 6.13a. General Properties for Melter-Feed Waste Simulant (6600 to $7800 \mathrm{gal}$ )

\begin{tabular}{|c|c|c|c|c|c|c|}
\hline Physical Properties - Slurry & Day $1^{(z)}$ & Day 1 & Day $2^{(b)}$ & Day $2^{(c)}$ & Day $3^{(b)}$ & Day $3^{(c)}$ \\
\hline total solids (wt\%) & 45.77 & 43.45 & 46.11 & 43.71 & 42.94 & 42.34 \\
\hline total oxides (wt $\%$ ) & 39.22 & 37.31 & 39.29 & 37.11 & 36.36 & 35.97 \\
\hline total oxides $(g / L)$ & 541.24 & 507.42 & 534.34 & 504.70 & 490.86 & 489.19 \\
\hline density (g/mL) & 1.38 & 1.36 & 1.36 & 1.36 & 1.35 & 1.36 \\
\hline settled solids (vol\%) & 77.9 & 74 & 82 & 77.7 & 77.1 & 73.8 \\
\hline settled solids (wt\%) & 82.1 & 78.7 & 84.7 & 81.3 & 80.8 & 78.4 \\
\hline heat capacity $\left(\mathrm{J} / \mathrm{g} /{ }^{\circ} \mathrm{C}\right)$ & NA & NA & 2.70 & NA & NA & NA \\
\hline $\mathrm{pH}$ & 9.02 & 9.09 & 9.2 & 9.2 & 9.2 & 9.15 \\
\hline \multicolumn{7}{|l|}{ Physical Properties - Supernate } \\
\hline total solids (wr\%) & 20.21 & 19.15 & NA & NA & 19.73 & 20.17 \\
\hline density (g/mL) & NA & NA & & NA & NA & NA \\
\hline \multicolumn{7}{|l|}{ Rheological Properties } \\
\hline apparent viscosity at $101 / \mathrm{s}(\mathrm{cP})$ & 1982 & 1621 & 3768 & 2702 & 3400 & 2651 \\
\hline apparent viscosity at $251 / \mathrm{s}(\mathrm{cP})$ & 869 & 692 & 1720 & 1148 & 1500 & 1089 \\
\hline apparent viscosity at $183 \mathrm{l} / \mathrm{s}$ (cP) & 128 & 102 & 243 & 169 & 208 & 167 \\
\hline curve fit viscosity - Bingham (cP) & 11 & 8.6 & 12.4 & 10.1 & 2.8 & 11 \\
\hline yield stress - Bingham Plastic $\left(\mathrm{Pa}_{2}\right)$ & 21 & 17 & 43 & 28 & 37 & 28 \\
\hline
\end{tabular}

$\mathrm{NA}=$ Not Available

(a) Taken at $100 \mathrm{rpm}$ agitator speed

(b) Taken before dilution

(c) Taken after dilution

The rheograms of the melter feed waste simulant are shown as Figures D11, D12, and D13 in Appendix D. Although not shown in the plots (only data pertaining to the up curve are shown), a hysteresis indicates thixotropic behavior. The yield point occurs between 0 and $15 \mathrm{~s}^{-1}$. A curve-fit for a Bingham plastic plotted through the data showed significantly higher yield stresses than those of the formated waste simulant with recycle simulants. The apparent viscosities were very high, especially for the samples obtained from the coils. The rheological properties of the melter feed waste simulant vary significantly over time.

\subsection{Rheological Discussion}

Laboratory testing and comparison with the large-scale behavior of melter feed theological properties are discussed below. 
Table 6.13b. General Properties for Meiter-Feed Waste Simulant (6600 to $7800 \mathrm{gal}$ )

\begin{tabular}{|c|c|c|c|c|c|c|}
\hline Physical Properties - Slurry & Day 4 & Day 5 & Day 10 & Day 11 & Day 20 & Day 24 \\
\hline total solids (wt\%) & 42.08 & 42.26 & 40.8 & 42.39 & NA & 47.71 \\
\hline total oxides (wt\%) & 35.81 & 36.04 & 35.28 & 35.95 & 35.43 & 36.07 \\
\hline total oxides $(g / L)$ & 479.85 & 486.54 & 469.22 & 481.73 & 471.22 & 486.95 \\
\hline density $(g / m L)$ & 1.34 & 1.35 & $\cdot 1.33$ & 1.34 & 1.33 & 1.35 \\
\hline settled solids (vol\%) & 75.9 & 75.2 & 74.2 & 79.6 & NA & 74.8 \\
\hline settled solids (wt\%) & 80 & 80.1 & 78.5 & 83.4 & NA & 78.8 \\
\hline heat capacity $\left(\mathrm{J} / \mathrm{g} /{ }^{\circ} \mathrm{C}\right)$ & NA & 2.83 & 2.67 & NA & 2.83 & NA \\
\hline $\mathrm{pH}$ & 9.27 & 9.28 & NA & 9.25 & 9.22 & NA \\
\hline \multicolumn{7}{|l|}{ Physical Properties - Supernate } \\
\hline total solids (wt\%) & 19.09 & 20.45 & 19.18 & 20.75 & NA & 22.66 \\
\hline density $(\mathrm{g} / \mathrm{mL})$ & NA & $\mathrm{NA}$ & 1.08 & 1.08 & NA & 1.10 \\
\hline \multicolumn{7}{|l|}{ Rheological Properties } \\
\hline apparent viscosity at $101 / \mathrm{s}(\mathrm{cP})$ & 2548 & 2690 & 1833 & 3206 & 3324 & NA \\
\hline apparent viscosity at $251 / \mathrm{s}$ (cP) & 1184 & 1106 & 798 & 1289 & 1390 & NA \\
\hline apparent viscosity at $183 \mathrm{1} / \mathrm{s}$ (cP) & 172 & 169 & 117 & 192 & 181 & NA \\
\hline curve fit viscosity - Bingham (cP) & 14.3 & 17.9 & 10.6 & 15.2 & NA & NA \\
\hline Yield Stress - Bingham Plastic (Pa) & 29 & 27 & 20 & 33 & 32 & NA \\
\hline \multicolumn{7}{|l|}{ NA $=$ Not Available } \\
\hline $\begin{array}{l}\text { (a) Taken at } 100 \mathrm{mpm} \text { agitator speed } \\
\text { (b) Taken before dilution } \\
\text { (c) Taken after dilution }\end{array}$ & & & & & & \\
\hline
\end{tabular}

\subsubsection{Background}

The concentrated NCAW waste simulant used in this test, as well as the corresponding melter feed, was complex non-Newtonian liquid. It flowed similarly to a yield pseudoplastic. Very dilute NCAW waste simulant and recycle waste simulant were Newtonian. The simulant containing frit (melter feed waste simulant) was thixotropic.

Fluid properties of simulated waste slurries at SRS and WVDP generated concerns about the impact of rheological factors on the ability to mix and transport Hanford NCAW melter feed waste simulant in full-scale testing and melter feeding. Laboratory-scale tests were undertaken at PNL to evaluate the rheology of NCAW slurries and address the potential for high apparent viscosities and yield stresses to interfere with the melter-feeding processes. Melter-feed waste simulant, aged at $50^{\circ} \mathrm{C}$ in 500-mL reaction vessels, often acquired the consistency of "pudding" and attained yield stress values 
Table 6.14. General Properties of Melter-Feed Waste Simulant (material on coils -6600 to $7800 \mathrm{gal}$ )

\begin{tabular}{|c|c|c|c|}
\hline \multicolumn{4}{|c|}{ Physical Properties - Slurry } \\
\hline total solids (wt $\%$ ) & 39.01 & 45.17 & 48.6 \\
\hline total oxides (wt\%) & 32.3 & 38.53 & 42.33 \\
\hline total oxides $(\mathrm{g} / \mathrm{L})$ & 429.59 & 539.42 & 601.10 \\
\hline density $(\mathrm{g} / \mathrm{mL})$ & 1.33 & 1.40 & 1.42 \\
\hline settled solids (vol\%) & NA & 91.5 & 92.5 \\
\hline settled solids (wt\%) & NA & 91.4 & 93.8 \\
\hline pH & NA & NA & NA \\
\hline \multicolumn{4}{|c|}{ Physical Properties - Supernate } \\
\hline total solids (wt $\dot{\phi}$ ) & 20.86 & 21.21 & 22.29 \\
\hline density (g/mL) & 1.06 & 1.09 & 1.26 \\
\hline \multicolumn{4}{|c|}{ Rheological Properties } \\
\hline apparent viscosity at $10 \mathrm{l} / \mathrm{s}(\mathrm{cP})$ & 487.6 & 932.3 & 1961.0 \\
\hline apparent viscosity at $251 / \mathrm{s}$ (cP) & 250.0 & 531.2 & 1006.0 \\
\hline apparent viscosity at $1831 / \mathrm{s}(\mathrm{cP})$ & 37.8 & 81.8 & 142.2 \\
\hline yield stress - Bingham Plastic $(\mathrm{Pa})$ & 60 & 135 & 245 \\
\hline
\end{tabular}

of $\geq 30 \mathrm{~Pa}$. The HWVP design limit for yield stress is $26 \mathrm{~Pa}$; the nominal is $10 \mathrm{~Pa}$. ${ }^{\mathrm{a}}$ ) Since the laboratory-scale data exceeded this limit, further tests were conducted to determine the cause(s) of the elevated apparent viscosities and yield stresses and the potential mitigation techniques.

A single cause of the high yield stresses and corresponding apparent viscosities was not isolated, but several factors exacerbated the problem. In addition, use of HWVP FY 1992 high lithia frit resulted in faster and more intense changes in the rheological properties of melter feed waste simulant than frit formulations previously used with NCAW waste simulant. As a result, a frit study was performed to determine whether the problem was inherent with the use of frit or if the frit was a small component of the overall problem. This study was performed by placing the frit in simple supernates of deionized water and weak acid solutions to determine whether significant leaching was occurring. Indeed, the FY 1992 frit leached rapidly.

The HWVP FY 1992 frit is a three-component frit. It is composed of silica, lithia, and boria. This combination makes a durable waste form when mixed with the waste components, but the frit itself has little leach resistance. In a supernate of deionized water, needle-like crystals are visible in less than one week. An X-ray diffraction (XRD) analysis identified the crystals as lithium borate hydrate. Ion chromatography and inductively coupled plasma (IC and ICP) analyses of the supernate showed significant leaching of all three components after 24 hours. When the frit was placed in a solution of $0.6 \mathrm{wt} \%$ formic acid, the supernate formed a strong gel (believed to be a silica gel) in less than

(a) Kalia, J. 1994. Rev. 6-5. Hanford Waste Vitrification Plant Project Technical Data Package. Westinghouse Hanford Co., Richland, Washington. 
24 hours. Scanning electron microscope (SEM) pictures of the frit while still partially wet, in addition to a dry state, showed extreme structural changes that helped explain the severity of the problem.

These data are included in Appendix E.

The rheological changes that cause high apparent viscosities and yield stresses were also encountered with NCAW meiter feed waste simulant containing other frit formulations. The laboratory-scale tests conducted by PNL evaluated Savannah River 202 and HWVP 39-4. The use of HWVP FY 1992 frit exacerbated the problem. It cannot be concluded at this time whether the problem is inherent with the use of frit.

Laboratory-scale testing revealed four critical parameters that either intensified or accelerated the rheological changes. The first, which has already been addressed, is the use of HWVP FY 1992 frit. Another critical parameter is boiling. Boiling accelerated the rheological changes in all of the frit types tested. Boiled simulants quickly exhibit higher yield stresses and apparent viscosities, reaching a relative maximum within a few days. Simulants aged at $50^{\circ} \mathrm{C}$ can take 3 days to 4 weeks to reach the same range of yield stresses and viscosities as a simulant that is boiled. Simulants aged at room temperature $\left(25^{\circ} \mathrm{C}\right)$ exhibit the same properties but only after 1 to 4 months. Another critical parameter is drying; dried samples that are rehydrated exhibit the highest yield stresses. Even partial dehydration can affect the rheology. It was proposed that dehydration was the primary cause of the problem in bench-scale testing. Although that theory has merit, rheology changes occurred in the full-scale test, where drying was minimal. Therefore, drying is not likely the only factor. The final factor shown to influence the slurry rheology is $\mathrm{pH}$. This parameter has a interdependent relationship with the rheological properties, but it is not possible to state with assurance which is the cause and which is the effect. The $\mathrm{pH}$ and the yield stress increase with time. Boiling accelerates both effects. It is possible that leaching drives the $\mathrm{pH}$ up which, in turn, accelerates the leaching. What can be stated is that an adjustment of the $\mathrm{pH}$ can temporarily affect the yield stress and viscosity. This solution was one of the more successful mitigation techniques.

\subsubsection{NCAW-1 Testing}

The NCAW-1 melter-feed waste simulant was subject to three of the four parameters that cause significant rheological changes in simulant-containing frit: a highly leachable frit, extensive periods of boiling, and little or no $\mathrm{pH}$ adjustment to counter the expected rise to $\geq 9$ after boiling. As a result, it was expected that the rheological changes, which had the potential to cause mixing and transport problems, would develop in NCAW-1 full-scale testing.

Frit was added to the formated waste simulant on the afternoon of April 6, 1993. The tank was brought to a boil that evening and was boiled for 2 hours. The yield stress of the feed in the tank exceeded $20 \mathrm{~Pa}$ by 2:00 p.m. the following afternoon. On the morning of April 9, the second day after frit addition, the yield stress of the melter feed was $>40 \mathrm{~Pa}$. To reduce the yield stress, 250 gal of water were added to the tank. This brought the yield stress down to just under $30 \mathrm{~Pa}$. However, the next morning, it was back up to approximately $38 \mathrm{~Pa}$. Slurry test loop testing and pump priming added an additional 50 to $100 \mathrm{gal}$ by the end of the third day after frit addition. By the fourth day, the yield stress was just under $30 \mathrm{~Pa}$. Since the agitator was still mixing the slurry adequately, no measures were to be taken to drop the yield stress further unless a mixing or transport problem developed. To monitor the situation, rheology measurements were taken every day. Overlays of selected rheograms 
can be found in Appendix F. The yield stresses from these measurements (shown in Figure 6.2) remained between $20 \mathrm{~Pa}$ and $30 \mathrm{~Pa}$. Table 6.15 shows how the days and sample numbers relate.

A laboratory-scale verification test was run in October 1993 to determine if laboratory-scale data was a good indicator of full-scale performance in several areas. The rheology data from this test were representative. A strong correlation is shown in the overlay of the full-scale and laboratory-scale data (Appendix F). In addition, laboratory-scale work performed before the pilot-scale run had predicted the rheology complications. Therefore, laboratory studies can be used to further study this problem with some degree of assurance.

\subsubsection{Analysis}

The concentrated NCAW waste simulant (without frit) behaved as a pseudoplastic until it reached a critical shear rate and then like a Newtonian fluid. This flow curve has been seen in other research on solid suspension slurries. Details of the rheological properties exhibited by the various simulants (which do not contain frit) were reported in Section 6.0. Melter feed that contains frit flows as a yield pseudoplastic over all shear rates. The large hysteresis in the rheograms suggests thixotropy (see Figure D14 in Appendix D). The up curve has a strong yield point followed by a line with a shallow slope. A hyperbolic or logarithmic curve is usually the best mathematical fit for this type of behavior. A Bingham plastic model is used to extract the yield point and viscosity data because it is the most representative of the flow models. It does not have the best mathematical fit because the yield measured is both stress- and rate-dependent and, therefore, is not a true yield point. The down curve consistently fits with the Casson flow model, which is used most often in the chocolate industry. The up curve is representative of the fluid mobilization profile; the down curve provides information on the behavior of the sheared fluid.

The yield stress of meiter-feed waste simulant was affected by temperature. The yield was consistently lower at $25^{\circ} \mathrm{C}$ than at $50^{\circ} \mathrm{C}$, often by as much as $25 \%$. Selected theogram overlays that illustrate the temperature and shear effects are included in Appendix F.

Correlations with other data suggest a strong relationship between the total-solids loading and the yield point in melter feed waste simulant, as illustrated in Figures 6.3 and 6.4. Figure 6.4 has a linear regression that shows the correlation over that range. The outlying points, labeled pre-dilution, are data from the first day after frit addition when leaching of the frit, and the resulting rise in yield stress had not been completely achieved. The strong correlation noted is not unusual; in suspensions with a high solids loading, the yield can have an exponential relationship with the solids concentration, even if chemical bonding is not occurring. That is undoubtedly why dilution was a successful mitigation technique. The data also suggests a correlation between yield point and $\mathrm{pH}$, but not as dramatic as the solids-loading dependency (see Figure 6.5). Thus, the yield stress is affected by the $\mathrm{pH}$ and solids concentration. 


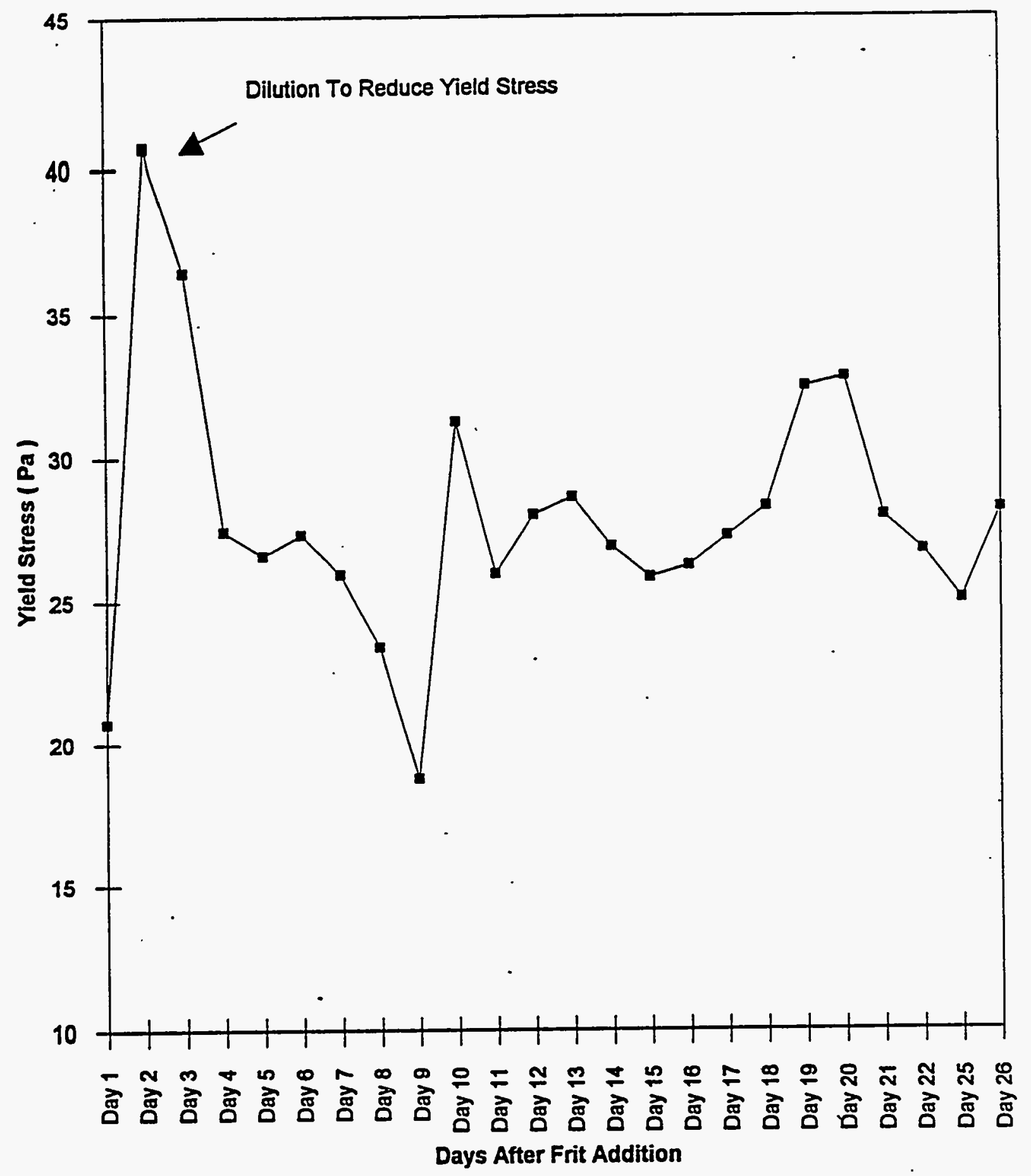

Figure 6.2. Daily Yield Stress Data for Meiter Feed 
Table 6.15. Days of Samples and Sample Numbers from Hydragard Overfiow

\begin{tabular}{|c|c|c|c|}
\hline Day & Date & Time & Sample Number \\
\hline 1 & $4 / 07 / 93$ & $9: 25$ & SIPT 2-27.0.2 \\
\hline 1 & $4 / 07 / 93$ & $9: 25$ & SIPT 2-27.0.3 \\
\hline 1 & $4 / 07 / 93$ & $11: 38$ & SIPT 2-27.0.4 \\
\hline 2 & $4 / 08 / 93$ & $9: 30$ & SIPT 2-27.0.5 \\
\hline 2 & $4 / 08 / 93$ & $9: 30$ & SIPT 2-27.0.6 \\
\hline 2 & $4 / 08 / 93$ & $10: 51$ & SIPT 2-27.0.7 \\
\hline 3 & $4 / 09 / 93$ & $10: 17$ & SIPT 2-27.0.9 \\
\hline 4 & $4 / 10 / 93$ & $14: 24$ & SIPT 2-27.0.15 \\
\hline 5 & $4 / 11 / 93$ & $16: 44$ & SIPT 2-27.0.17 \\
\hline 6 & $4 / 12 / 93$ & $15: 38$ & SIPT $2-27.0 .20$ \\
\hline 7 & $4 / 13 / 93$ & $15: 24$ & SIPT 2-27.0.21 \\
\hline 9 & $4 / 15 / 93$ & $15: 15$ & SIPT 2-27.0.23 \\
\hline 10 & $4 / 16 / 93$ & $16: 00$ & SIPT 2-27.0.24 \\
\hline 11 & $4 / 17 / 93$ & $9: 14$ & SIPT 2-27.0.26 \\
\hline 12 & $4 / 18 / 93$ & $21: 28$ & SIPT 2-27.0.28 \\
\hline 13 & $4 / 19 / 93$ & $15: 58$ & SIPT. 2-27.0.30 \\
\hline 14 & $4 / 20 / 93$ & $15: 35$ & SIPT 2-27.0.32 \\
\hline 15 & $4 / 21 / 93$ & $15: 54$ & SIPT 2-27.0.34 \\
\hline 16 & $4 / 22 / 93$ & $17: 25$ & SIPT 2-27.0.35 \\
\hline 17 & $4 / 23 / 93$ & $16: 03$ & SIPT 2-27.0.37 \\
\hline 18 & $4 / 24 / 93$ & $4: 18$ & SIPT 2-27.0.39 \\
\hline 19 & $4 / 25 / 93$ & $1: 50$ & SIPT $2-27.0 .42$ \\
\hline 20 & $4 / 26 / 93$ & $8: 11$ & SIPT 2-27.0.43 \\
\hline 20 & $4 / 26 / 93$ & $21: 45$ & SIPT $2-27.0 .55$ \\
\hline 21 & $4 / 27 / 93$ & $15: 05$ & SIPT 2-27.0.56 \\
\hline 22 & $4 / 28 / 93$ & $15: 58$ & SIPT 2-27.0.71 \\
\hline 24 & $4 / 30 / 93$ & $16: 00$ & SIPT 2-27.0.75 \\
\hline 27 & $5 / 03 / 93$ & $14: 15$ & SIPT 2-27.0.77 \\
\hline
\end{tabular}




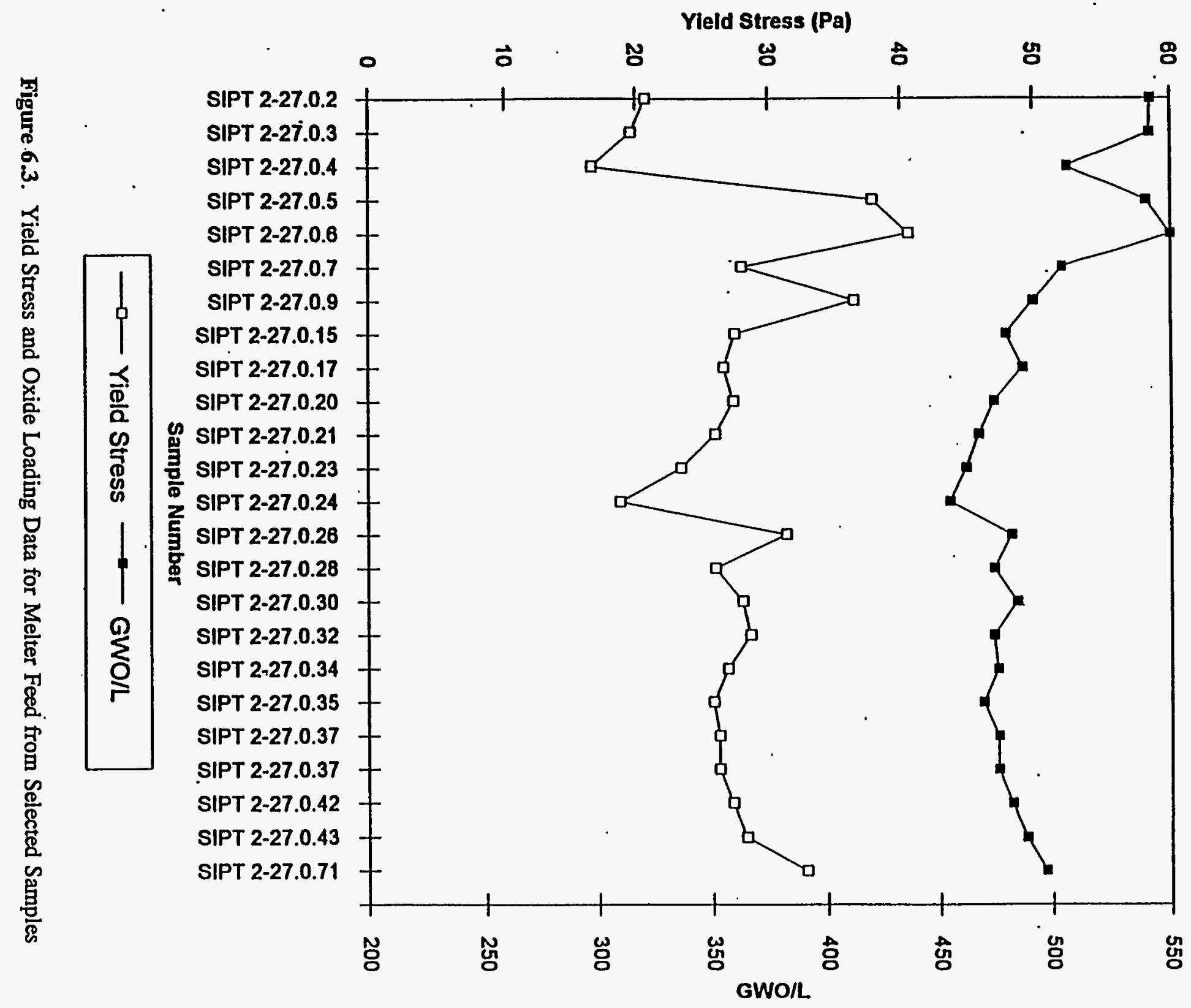




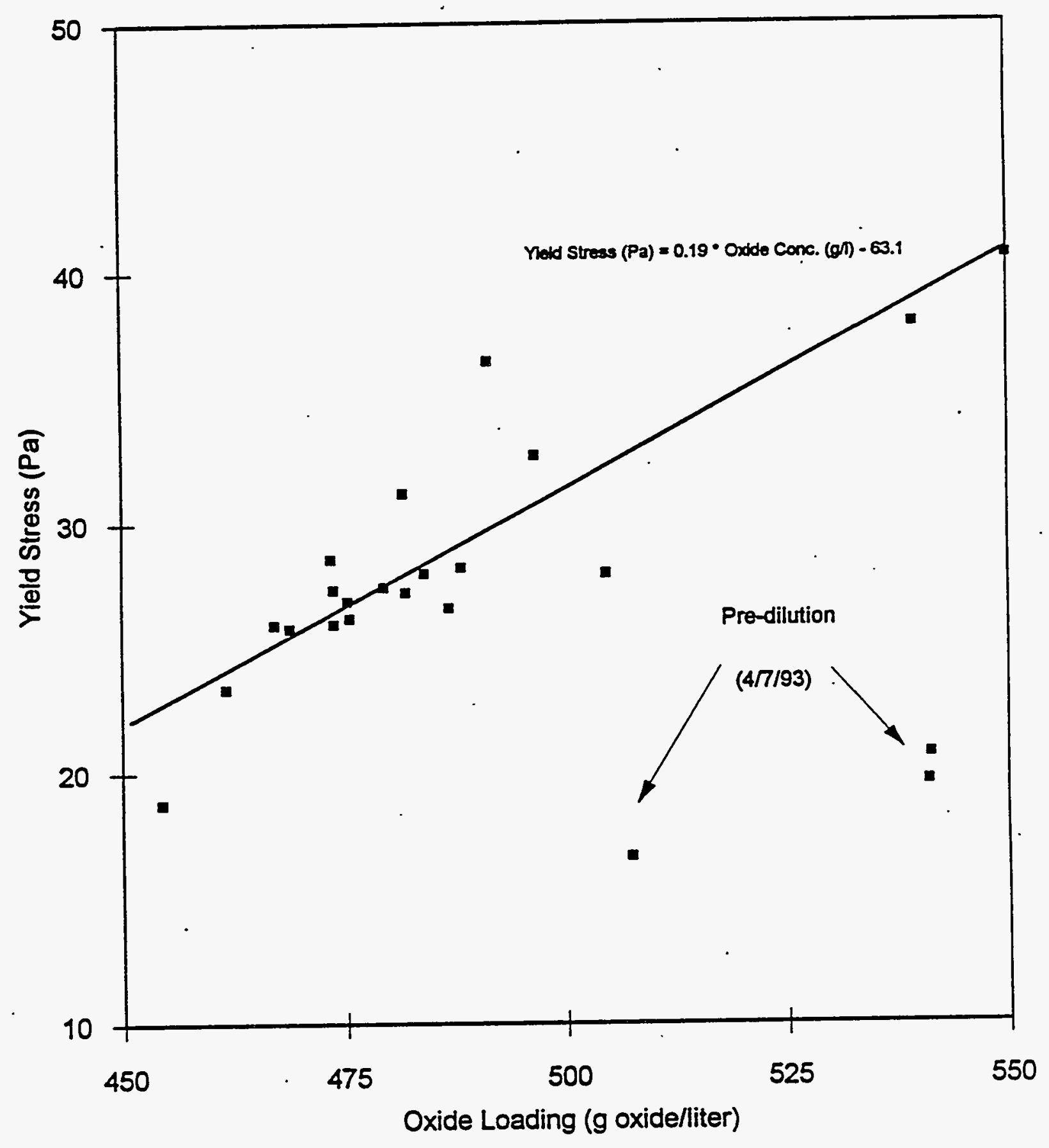

Figure 6.4. Yield Stress of Melter Feed as a Function of Oxide Loading 


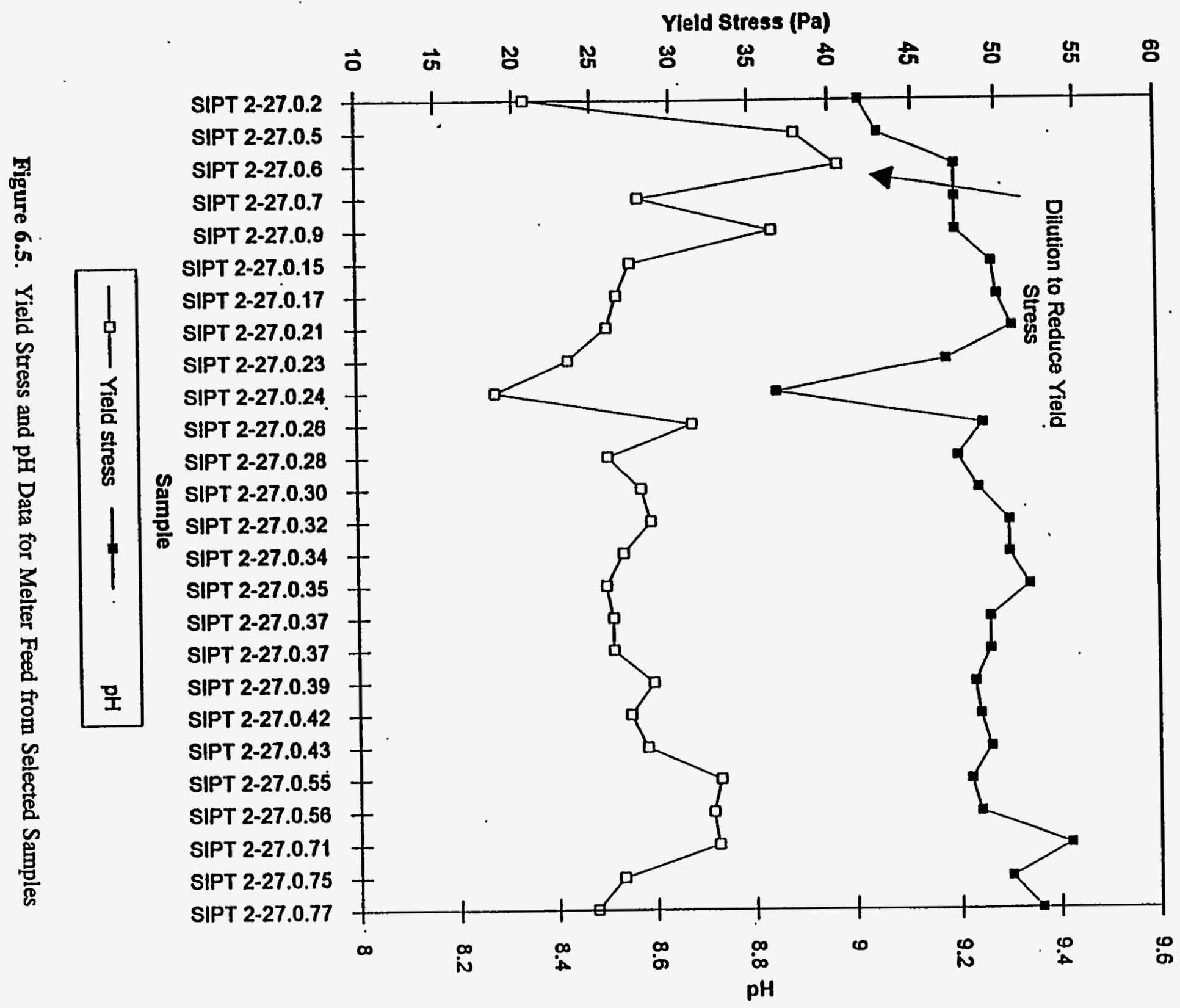




\subsubsection{Melter-Feed Rheology Profile}

The NCAW-1 melter-feed waste simulant was a complex non-Newtonian liquid. It exhibited a thixotropic, yield pseudoplastic behavior. The thixotropic nature of the feed endows it with a pseudo yield point and makes it sensitive to shear. The significant hysteresis, shown in the rheograms of melter feed, reflects the thixotropy.

Pseudoplastic liquids show a drastic apparent viscosity decrease as the shear rate is increased. Such shear thinning is a common behavior of emulsions, suspensions, and dispersions. Under shear conditions, particles/molecules acquire an orientation more conducive to flow, which lowers the viscosity. For a classic pseudoplastic liquid, shear thinning is reversible. As the shear rate drops, the apparent viscosity climbs with little or no lag time since the causative orientation of particles and molecules will be lost. Thixotropy is more complex because it usually involves bonds that form a threedimensional network. This structure is easily broken down under the influence of shear but will begin rebuilding as soon as the shear is removed. If a thixotropic liquid is measured at a constant shear rate, the apparent viscosity will drop asymptotically with time to the lowest viscosity achievable at that shear rate, called the sol-state. The time to rebuild is variable depending on the material. In practical terms, it takes less energy to maintain a flow than the energy it took to achieve it.

NCAW-1 melter-feed waste simulant containing HWVP FY 1992 frit is highly thixotropic. As the frit dissolves, a gel-like structure forms agglomerates that attract each other and trap liquid in the voids. The slurry becomes the consistency of pre-set pudding while in constant motion. If allowed to set, it becomes solid enough that a sample can be tipped over without spilling. In small reaction vessels these agglomerates may build up on the walls to such an extent that only a column the diameter of the propeller blades remains in a fluid state. In the full-scale tank, several inches of material accumulated on the coils and other surfaces.

The agglomerated gel-like structure imparted a pseudo yield point to the fluid. Theoretically, the yield stress is the minimum amount of stress required to overcome the structural network of a plastic fluid and begin flow. In the rheograms from NCAW-1 melter feed waste simulant, the yield point is defined as the point on the graph where the slope changes from vertical to horizontal. This is not a true yield point because it is both rate and stress dependent. It is, however, a valid representation of the stress that would be required to restart flow in a tank or pipes if this material were allowed to set for a length of time.

\subsubsection{Conclusions and Recommendations}

The rheology in the feed preparation system during NCAW-1 testing was higher than planned for yield stress and apparent viscosity. The equipment was capable of handling the higher yield-stress material. However, the melter feed was diluted to facilitate mixing and pumping. 


\subsection{Process Tank (SRAT/SME/MFT) Performance}

\subsection{Heat Transfer (Boiling, Heating, Cooling)}

Heating, boiling, and cooling heat transfer testing of process slurries in the test tank are discussed in this section.

\subsubsection{Heating, Boiling, and Cooling Tests}

Table 7.1 summarizes the water and NCAW-testing campaign as related to evaporator heat transfer performance. The following general procedure was used for water testing (TST019 and TST052):

1. Process water in the test vessel was heated to boiling at the maximum steam flow rate while maintaining an agitator speed of $85 \mathrm{rpm}$.

2. The process water was boiled at several steam flow rates, ranging from 1500 to $6000 \mathrm{lb} / \mathrm{h}$. During TST019, condensate generated during boiling was sent to the condensate receipt tank; during TST052, the process level in the tank was held constant by recycling condensate to the tank. A constant agitation speed of $85 \mathrm{rpm}$ was maintained during boiling.

3. At each steam flow rate, the process was allowed to stabilize for about 30 minutes before continuing to the next set point.

Table 7.1. Summary of Evaporator Performance Tests

\begin{tabular}{|c|c|c|c|c|}
\hline $\begin{array}{c}\text { Test } \\
\text { Number }\end{array}$ & Date & Concentration & Level, gal & Remarks \\
\hline TST019 & $5 / 7 / 92$ & water & $8300-5400$ & high to low level \\
\hline TST052 & $12 / 22 / 92$ & water & 8200 & high level \\
\hline BKH001 & $12 / 30 / 92$ & dilute & 5900 & low level \\
\hline BKH0O2 & $1 / 6 / 93$ & dilute & 7600 & high level \\
\hline BKH0O3 & $1 / 28 / 93$ & concentrate & 5700 & low level \\
\hline BKH0O4 & $2 / 4 / 93$ & concentrate & 8000 & high level \\
\hline RYC001 & $3 / 23 / 93$ & formated & $7100-6500$ & during recycle addition \\
\hline FRT002 & $4 / 6 / 93$ & melter feed & 6600 & $\begin{array}{l}\text { steam traps limited steam } \\
\text { flow to } 2500 \mathrm{lb} / \mathrm{h}\end{array}$ \\
\hline
\end{tabular}


The following general procedure was used for dilute and concentrate testing (BKH001 through BKH004). During these tests, condensate generated during boiling was recycled to the evaporator.

1. The process liquid in the evaporator tank was heated from below $52^{\circ} \mathrm{C}\left(125^{\circ} \mathrm{F}\right)$ to boiling at the maximum steam flow rate while maintaining the agitator speed at $85 \mathrm{rpm}$. Initially, the steam flow was increased slowly to limit thermal transients.

2. The process liquid in the evaporator tank was at a constant agitator speed of $85 \mathrm{rpm}$ and steam flow rates of 6000,5200 , and $4200 \mathrm{lb} / \mathrm{h}$.

3. The process liquid in the evaporator tank was then boiled at agitator speeds of 45 and $130 \mathrm{rpm}$ and a constant steam flow rate of $5200 \mathrm{lb} / \mathrm{h}$.

4. The process liquid in the evaporator tank was then cooled from boiling to $52^{\circ} \mathrm{C}\left(125^{\circ} \mathrm{F}\right)$ at a cooling water flow rate of $120 \mathrm{gpm}$ and an agitator speed of $85 \mathrm{rpm}$.

Heat transfer performance was also evaluated after formic acid addition (RYC001) and after frit addition (FRT002). During these tests, the process liquid was heated and cooled by the method described above. During the boiling segments of RYCO01, the steam flow was from 4000 to $4800 \mathrm{lb} / \mathrm{h}$, and the condensate generated was sent to the condensate receipt tank. Foam generation during boiling kept steam flows between 4000 and $4800 \mathrm{lb} / \mathrm{h}$. During FRT002, the high yield stress and viscosity of the slurry caused sludge impaction (caking) around the steam coils, which resulted in poor heat transfer. With limited heat transfer, the in-line steam traps restricted the steam flow to approximately $2500 \mathrm{lb} / \mathrm{h}$, the most rapid flow that could be fully condensed.

\subsubsection{Agitator Heating Tests}

In addition to mixing the contents of the evaporator, the agitator also transmits frictional heating to the process liquid. The purpose of this test was to correlate the shaft-output power with the latent heat increase of the process liquid. Three different agitator speeds $(45,85$, and $130 \mathrm{mpm})$ were investigated. The agitator heating tests were conducted on 2 days: April 8, 1992 (45 and $85 \mathrm{rpm}$ ), and April 9, $1992(130 \mathrm{rpm})$. The tank was filled with approximately $45,000 \mathrm{lb}(5400 \mathrm{gal})$ of water. After the temperature in the tank reached steady state, the agitator was turned on and operated at a constant speed for several hours. The temperature rise of the process water was then used to determine agitator heat input.

\subsubsection{Tank Heat-Loss Tests}

Tank heat loss is important for two reasons: 1) tank heat loss increases the amount of plant steam required to heat and concentrate the process slurries, and 2) tank heat loss must be removed by the plant HVAC to maintain plant temperature. The temperature distribution at the top of the tank head and on the surface of the insulation on the skirt of the tank was measured directly. Tank heat loss was determined experimentally by allowing the evaporator tank to cool. At the conclusion of a boiling test 
with process water, the agitator and steam flow were turned off as quickly as safety procedures would allow. The blower maintained a minimum vacuum in the tank (-2 in.-wc). The tank was allowed to cool for an extended period of time to permit measurement of heat loss from the tank to the environment. The temperature of the process and temperature of the High-Bay ambient were measured and recorded every 5 minutes.

\subsubsection{Calculations}

This section summarizes the calculations used to predict evaporator heat transfer for water processing and to extract heat-transfer coefficients from test data. Also included are the calculations used to estimate the agitator process heating. Detailed calculations are provided in Appendix G.

\subsubsection{Predicted Heat-Transfer Coefficients}

Standard correlations were used to predict the heat-transfer coefficients during heating, boiling, and cooling of process water. Since water is a well-defined Newtonian fluid, correlations were readily available. Process data (temperatures, pressures, flow rates) were used to evaluate properties and to determine flow speed. The predicted heat-transfer coefficients for water were used to validate the experimental heat-transfer coefficients.

Resistances to Heat Transfer. During heating, boiling, and cooling, the following resistances to heat transfer between the tube-side fluid and the process fluid must be evaluated to determine the overall heat-transfer coefficient, $U$.

Tube-side heat-transfer coefficient $h_{\text {io }}$, based on outside tube area $\left(B t u / h-\mathrm{ft}^{2}{ }^{\circ} \mathrm{F}\right)$

Tube-side fouling factor $f_{i}$

Resistance through the tube wall $R\left(h-\mathrm{ft}^{2}{ }^{\circ} \mathrm{F} / \mathrm{Btu}\right)$

Process-side fouling factor $\mathrm{f}_{0}$

Process-side heat-transfer coefficient $h_{o}\left(B t u / h-\mathrm{ft}^{2} \mathrm{~F}\right)$

For each process operation, each resistance was evaluated by standard correlations at actual process conditions.

Tube-Side Heat-Transfer Coefficient. Two methods were used to determine the tube side heattransfer coefficient, depending on whether the heat-transfer fluid was cooling water or steam. For cooling water, the Nusselt number $(\mathrm{Nu})$ was evaluated with the following correlation for turbulent flow inside a pipe:

$$
\mathrm{Nu}=\frac{\mathrm{h}_{\mathrm{i}} \mathrm{D}_{\mathrm{i}}}{\mathrm{k}}=0.027 \operatorname{Re} 0.8_{\mathrm{d}} \operatorname{Pr}^{1 / 3}\left(\frac{\mu}{\mu_{\mathrm{w}}}\right)^{0.14} \quad \text { (Holman 1972, p. 178) }
$$


where $\mathrm{Nu}=$ Nusselt number

$$
\begin{aligned}
\operatorname{Re}_{\mathrm{d}} & =\text { Reynolds number } \\
\operatorname{Pr} & =\text { Prandit number } \\
\mu & =\text { fluid viscosity at bulk temperature, } \mathrm{lb} / \mathrm{ft}-\mathrm{h} \\
\mu_{\mathrm{w}} & =\text { fluid viscosity at pipe wall temperature, } \mathrm{lb} / \mathrm{ft}-\mathrm{h} .
\end{aligned}
$$

The tube-side heat-transfer coefficient, $h_{i}$, is based on the inside heat-transfer area. The tube-side heattransfer coefficient based on outside area, $h_{i o}$, is found according to

$$
h_{i o}=h_{i} \frac{D_{i}}{D_{0}} \quad(\operatorname{Kern} 1950, \text { p. 86) }
$$

where $\mathrm{D}_{\mathrm{i}}=$ pipe inside diameter, $\mathrm{ft}$

$$
\begin{aligned}
& D_{0}=\text { pipe outside diameter, } \mathrm{ft} \\
& \mathrm{h}_{\mathrm{i}}=\text { tube-side heat-transfer coefficient based on inside area, } B t u / h-\mathrm{ft}^{2 \circ} \mathrm{F} .
\end{aligned}
$$

For steam condensing on the inside of a pipe, it is customary to adopt a conservative value for the film coefficient, since it is never controlling, rather than obtain one by calculation. For air-free steam, a value of $1500 \mathrm{Btu} / \mathrm{h}-\mathrm{ft}^{2}{ }^{\circ} \mathrm{F}$ was used (see Kern 1950, p. 164).

Process-Side Heat-Transfer Coefficient. For a submerged tube coil subjected to mechanical agitation, Kern (1950, p. 722) offers the following correlation for the process-side heat-transfer coefficient.

$$
\frac{h_{o} D_{j}}{k}=0.87\left(\frac{L^{2} N \rho}{\mu}\right]^{2 / 3}\left[\frac{c \mu}{k}\right)^{1 / 3}\left[\frac{\mu}{\mu_{w}}\right]^{0.14} \quad \text { (Kern 1950, p. 722) }
$$

where $h_{0}=$ process-side heat-transfer coefficient, $B t u / h-\mathrm{ft}^{2}{ }^{\circ} \mathrm{F}$

$$
\begin{aligned}
D_{j} & =\text { vessel diameter, } \mathrm{ft} \\
\mathrm{k} & =\text { process conductivity at bulk temperature, Btu/h-ft }{ }^{\circ} \mathrm{F} \\
\mathrm{L} & =\text { blade diameter, } \mathrm{ft}
\end{aligned}
$$




$$
\begin{aligned}
N & =\text { agitator speed, revolutions } / \mathrm{h} \\
\rho & =\text { process density at bulk temperature, } \mathrm{lb} / \mathrm{ft}^{3} \\
\mathrm{c} & =\text { process-specific heat at bulk temperature, } \mathrm{Btu} / \mathrm{lb}-{ }^{\circ} \mathrm{F} \\
\mu & =\text { process viscosity at bulk temperature, } \mathrm{lb} / \mathrm{ft}-\mathrm{h} \\
\mu_{\mathrm{w}} & =\text { process viscosity at wall temperature, } \mathrm{lb} / \mathrm{ft}-\mathrm{h} .
\end{aligned}
$$

This equation accounts for the increase in convective heat transfer created by the agitator but neglects any additional boiling effects. It is therefore applicable during process heating and cooling; it was also used during process boiling.

Boiling heat transfer can be divided into different regions of behavior: natural convection, nucleate boiling, transitional boiling, and film boiling (Lienhard 1981, p. 391), depending on the amount of heat flux between the liquid and the heat-transfer surface. Boiling in the evaporator will occur during nucleate, transitional, or film boiling. In general, boiling during nucleate or film boiling increases the heat transfer of a process. During transitional boiling, however, the heat-transfer surface is engulfed in a layer of vapor, which acts as insulation. Because of the complexities involved in calculating a boiling heat-transfer coefficient, the effect of boiling was ignored, and a coefficient based only on forced convection was calculated. The results were compared to actual test data to validate this simplification.

Resistance Through the Tube Wall. The resistance, $R$, through the pipe wall depends only on the conductivity of the pipe, $K_{\text {tube }}$, and the inside and outside diameters of the pipe, $D_{i}$ and $D_{0}$ :

$$
R=\frac{2.3 D_{0}}{2 K_{\text {tube }}} \log \left(\frac{D_{0}}{D_{i}}\right) \quad(\operatorname{Kern} 1950, \text { p. 86) }
$$

Fouling Factors. After the heat-transfer coils have been in service for some time, their performance may decrease as scale builds up on the inside and outside of the coils. This process is known as fouling. Fouling resistance increases thermal resistance. Fouling resistances compiled by the Tubular Exchanger Manufacturers Association (1952) for heat exchangers using steam and water were used in the calculations to account for approximately one year of service.

Overall Heat-Transfer Coefficient. After all the individual resistances to heat transfer were calculated, the overall heat-transfer coefficients, including the effects of fouling, were determined according to

$$
\frac{1}{U_{D}}=\frac{1}{h_{i o}}+\frac{1}{h_{o}}+R+f_{i}+f_{o} \quad(\operatorname{Kern} 1950, \text { p. 86) }
$$


where $\quad \mathrm{U}_{\mathrm{D}}=$ overall heat-transfer coefficient (dirty), Btu/h- $\mathrm{ft}^{2 \circ} \mathrm{F}$.

$\mathrm{f}_{\mathrm{i}}=$ fouling factor inside of tube

$f_{0}=$ fouling factor outside of tube

This equation should provide the heat-transfer coefficient after one year of service, and therefore provide a minimum value. During the initial operation of the evaporator, fouling should be negligible. The following equation calculates a "clean" heat-transfer coefficient.

$$
\frac{1}{\mathrm{U}_{\mathrm{C}}}=\frac{1}{\mathrm{~h}_{\mathrm{io}}}+\frac{1}{\mathrm{~h}_{\mathrm{o}}}+\mathrm{R}
$$

where $\mathrm{U}_{\mathrm{C}}=$ overall heat-transfer coefficient (clean), Btu/h- $\mathrm{ft}^{2}{ }^{\circ} \mathrm{F}$.

\subsubsection{Experimental Heat-Transfer Coefficients}

This section provides the calculations that were used to extract the heating, boiling, and cooling heat-transfer coefficients from the test data.

Transient-Batch Heating Heat-Transfer Coefficient. The overall heat-transfer coefficient, $U_{0}$, during heating was calculated with a correlation for transient heating in a coil-in-tank vessel and an isothermal heating medium:

$$
\ln \left[\frac{T_{1}-t_{1}}{T_{1}-t_{2}}\right)=\frac{U_{0} A \theta}{M c} \quad(\operatorname{Kern} 1950, p \cdot 627)
$$

where $T_{1}=$ isothermal medium temperature, ${ }^{\circ} \mathrm{F}$

$$
\begin{aligned}
& t_{1}=\text { initial process temperature, }{ }^{\circ} \mathrm{F} \\
& t_{2}=\text { final process temperature, }{ }^{\circ} \mathrm{F} \\
& \theta=\text { heating time, } \mathrm{h} \\
& \mathrm{c}=\text { specific heat of process, } \mathrm{Btu} / \mathrm{lb} \mathrm{o}^{\circ} \mathrm{F} \\
& \mathrm{M}=\text { mass of process liquid, } \mathrm{lb} \\
& \mathrm{A}=\text { heat-transfer area, } \mathrm{ft}^{2} \\
& \mathrm{U}_{0}=\text { overall heating heat-transfer coefficient, Btu/h- } \mathrm{ft}^{2 \circ} \mathrm{F} .
\end{aligned}
$$


The following assumptions are inherent in this equation:

The heat-transfer coefficient is constant throughout the heating process.

Steam flow is constant.

Specific heat of the process is constant.

Heating medium has a constant inlet temperature.

Agitation produces a uniform-batch fluid temperature.

The heating medium is isothermal.

No partial phase changes occur.

Heat loss from the tank is negligible.

Heating due to sub-cooling the steam condensate is neglected.

To determine how $\mathrm{U}$ varies with process temperature, an instantaneous heat-transfer coefficient, $\mathrm{U}_{\mathrm{i}}$, was determined at each time increment during the heating process. The $\mathrm{U}_{\mathrm{i}}$ calculated here is based on the actual heat transferred through the coils and thus neglects the heat input by the agitator, tank heat losses, and other minor variables. A small time increment was used (15 seconds), so that the temperature of the steam condensate and the process temperature were essentially constant. The total heat transferred from the steam to the process was determined from:

$$
Q=q(\text { desuperheat })+q(\text { condense })+q(\text { subcool })
$$

where $\quad Q=$ total heat transferred, Btu/h

$q($ desuperheat $)=$ heat transferred to desuperheat the steam from incoming temperature to saruration temperature (this value is small, unless the steam valve is partially closed), Btu/h

$q($ condense $)=$ heat transferred to condense steam, Btu/h

$q($ subcool $)=$ heat transferred to subcool steam to outlet temperature, Btu/h

Once $Q$ was determined, the instantaneous heating heat transfer was determined using Fourier's Law:

$$
Q=U_{i} A \Delta T
$$

where $\mathrm{U}_{\mathrm{i}}=$ instantaneous heat-transfer coefficient, $\mathrm{Btu} / \mathrm{h}-\mathrm{ft}^{2} \mathrm{~F}$

$$
A=\text { heat-transfer area }=144 \mathrm{ft}^{2}
$$

$\Delta \mathrm{T}=$ temperature difference between steam and process, ${ }^{\circ} \mathrm{F}$. 
The temperature difference between steam and process $(\Delta T)$ was determined as follows. A separate temperature difference between the process and the steam was calculated for each phase (desuperheating, condensing, and subcooling). The overall $\Delta \mathrm{T}$ was calculated by weighting the individual temperature differences by the amount of heat transferred in each phase (see Kern 1950, p. 291).

In Section 7.1.5.1, an average instantaneous heat-transfer coefficient over the entire heating period, from $125^{\circ} \mathrm{F}$ to boiling, is also calculated for comparison with the overall heat-transfer coefficient, $U_{0}$.

Boiling Heat-Transfer Coefficient. Fourier's Law was used in conjunction with test data to determine the overall heat-transfer coefficient between the coil side and the vessel side.

$$
Q=U A \Delta T
$$

where $U=$ boiling heat-transfer coefficient, $B t u / h-\mathrm{ft}^{2}{ }^{\circ} \mathrm{F}$

$$
A=\text { outside heat-transfer area of the coils }=343 \mathrm{ft}^{2}
$$

$\Delta \mathrm{T}=$ temperature difference between the coil side fluid and the process, ${ }^{\circ} \mathrm{F}$.

Two techniques were used to evaluate $Q$, depending on the steam flow rate. At maximum steam flow, the steam enters the heating coils in a saturated condition, condenses, and is subcooled below the saturation temperature. Therefore, during maximum steam flow conditions,

$$
Q=q_{c}+q_{s}
$$

where $Q=$ total coil-heat-transfer, Btu/h

$\mathrm{q}_{\mathrm{c}}=$ heat transferred to condense steam, Btu/h

$q_{s}=$ heat transferred to cool steam condensate from the saturation temperature to the coil outlet temperature, Btu/h.

At lower steam-flow rates, a valve was used to reduce the pressure and flow of the incoming steam. The consequent reduced saturation temperature of the steam results in superheated steam at the coil inlet. During lower steam flow rates,

$$
Q=q_{d}+q_{c}+q_{s}
$$


where $q_{d}=$ heat transferred to cool steam from a superheated temperature to the saturation temperature, Btu/h.

The overall temperature difference between the coil-side steam and the process liquid was calculated as follows. First, a separate temperature difference was calculated for each heat transfer phase (desuperheating, condensing, and subcooling). Each temperature difference is weighted by the amount of heat transferred during each phase according to the following equation (see Kern 1950, p. 291):

$$
\Delta T=\frac{Q}{\frac{q_{d}}{\Delta t_{d}}+\frac{q_{c}}{\Delta t_{c}}+\frac{q_{s}}{\Delta t_{s}}}
$$

Transient Batch-Cooling Heat-Transfer Coefficient. Calculation of the overall heat-transfer coefficient, $\mathrm{U}_{\mathrm{o}}$, during cooling used a correlation for transient cooling in a coil-in-tank vessel with a nonisothermal cooling medium:

$$
\ln \left[\frac{T_{1}-t_{1}}{T_{2}-t_{1}}\right]=\frac{w c}{M C}\left[\frac{e^{U_{0} A / w c}-1}{e^{U_{0} A / w c}}\right] \theta \quad \text { (Kern 1950, p. 628) }
$$

where $\quad t_{1}=$ inlet water temperature, ${ }^{\circ} \mathrm{F}$

$\mathrm{T}_{1}=$ initial process temperature, ${ }^{\circ} \mathrm{F}$

$\mathrm{T}_{2}=$ final process temperature, ${ }^{\circ} \mathrm{F}$

$\theta=$ cooling time, $h$

$w=$ water flow, $\mathrm{lb} / \mathrm{h}$

$c=$ specific heat of cooling water, $B \mathrm{Btu} / \mathrm{lb}{ }^{\circ} \mathrm{F}$

$\mathrm{M}=$ mass of process liquid, $\mathrm{lb}$

$\mathrm{C}=$ specific heat of process, $\mathrm{Btu} / \mathrm{lb}^{\circ} \mathrm{F}$

$\mathrm{U}_{\mathrm{o}}=$ overall heating heat-transfer coefficient, $\mathrm{Btu} / \mathrm{h}-\mathrm{ft}^{2}{ }^{\circ} \mathrm{F}$.

$A=$ cooling coil outside area, $\mathrm{ft}^{2}$ 
The following assumptions are inherent in this equation.

- The heat-transfer coefficient is constant throughout the cooling process.

- Cooling-water flow is constant.

- Specific heats are constant.

- Cooling medium has a constant iniet temperature.

- Agitation maintains a uniform batch fluid temperature.

- No partial phase changes occur.

- Heat loss from the tank is negligible.

The instantaneous transient cooling heat-transfer coefficient was also evaluated to determine how the coefficient varies with process temperature. A small time segment (15 seconds) was used between data points so that the temperature at the cooling-water inlet and exit and the vessel process temperature were essentially constant over the time increment. Fourier's law was used to determine the overall heat-transfer coefficient as follows:

$$
\begin{gathered}
\mathrm{Q}=\mathrm{U}_{\mathrm{i}} \mathrm{A} \Delta \mathrm{T} \quad(\operatorname{Kern} 1950, \text { p. 86) } \\
\Delta \mathrm{T}=\frac{\Delta \mathrm{t}_{2}-\Delta \mathrm{t}_{1}}{\ln \left(\Delta \mathrm{t}_{2} / \Delta \mathrm{t}_{1}\right)} \quad(\operatorname{Kern} 1950, \text { p. 42) }
\end{gathered}
$$

where $Q=$ heat transferred through coils, Btu/h

$\mathrm{U}_{\mathrm{i}}=$ instantaneous heat-transfer coefficient, $\mathrm{Btu} / \mathrm{h}-\mathrm{ft}^{2 \circ} \mathrm{F}$

$A=$ cooling coil outside area, $\mathrm{ft}^{2}$.

$\Delta \mathrm{T}=\log$ Mean Temperature Difference between Cooling water and process, ${ }^{\circ} \mathrm{F}$

$\Delta t_{1}=$ the higher temperature of the hot fluid $(-)$ the higher temperature of the cold liquid, ${ }^{\circ} \mathrm{F}$

$\Delta t_{2}=$ the lower temperature of the hot fluid $(-)$ the lower temperature of the cold liquid, ${ }^{\circ} \mathrm{F}$.

The heat transferred through the coils was determined from the temperature increase in the cooling water, i.e.: 


$$
\mathrm{Q}=\dot{\mathrm{m}} \mathrm{c}_{\mathrm{p}} \Delta \mathrm{T}
$$

where $Q=$ heat transferred through coils, Btu/h

$$
\begin{aligned}
\dot{m} & =\text { mass flow of cooling water, } \mathrm{lb} / \mathrm{h} \\
c_{\mathrm{p}} & =\text { specific heat of cooling water, } \mathrm{Btu} / \mathrm{lb}{ }^{\circ} \mathrm{F} \\
\Delta \mathrm{T} & =\text { temperature increase of cooling water, }{ }^{\circ} \mathrm{F} .
\end{aligned}
$$

In Section 7.1.5.3, an average instantaneous heat-transfer coefficient over the entire cooling period, from boiling to $125^{\circ} \mathrm{F}$, was also calculated for comparison with the overall cooling heat-transfer coefficient, $\mathrm{U}_{\mathbf{0}}$.

\subsubsection{Agitator Heat Input}

The temperature rise of the process water was used to experimentally determine agitator heat input. If heat loss from the tank is neglected (likely, because the temperature difference between the tank and ambient is small), the heat input to the process by the agitator can be found by:

$$
\mathrm{Q}=\frac{\mathrm{m} \mathrm{C}_{\mathrm{p}} \Delta \mathrm{T}}{\Delta \mathrm{t}}
$$

where $\mathrm{m}=$ mass of water

$$
\begin{aligned}
& C_{p}=\text { specific heat of water } \\
& \Delta T=\text { temperature rise of water } \\
& \Delta t=\text { time interval. }
\end{aligned}
$$

The agitator is driven by a 100-horsepower, 3-phase motor. The motor start/operating frequency of 6 to 60 hertz corresponds to a motor shaft speed of 178.5 to $1785 \mathrm{rpm}$ and an agitator shaft speed of 14 to $140 \mathrm{rpm}$. Performance data were used to relate the measured current to the horsepower. A polynomial curve was fit through the current versus horsepower points to create an equation that related horsepower as a function of current. Motor performance data are available only at $1785 \mathrm{rpm}$; at lower speeds, the frictional losses will be less and the calculated power output will be underestimated. This method is therefore accurate only at higher speeds, but since the power draw at low speeds is small, this is acceptable from an energy balance standpoint. Power out is equated to power into the process liquid. 


\subsubsection{Test Results}

This section summarizes the heat transfer performance on the evaporator using water and various process simulants during heating, boiling, and cooling. The results include a comparison of predicted and actual heat-transfer coefficients, agitator heat input, and evaporator tank heat loss. Graphs of various quantities are provided in Appendix $\mathrm{H}$.

\subsubsection{Batch Heating}

During testing, heating of process liquid was initiated at low steam flow (to avoid thermal shock) and increased slowly to a maximum steam flow, of 5200 to $7500 \mathrm{lb} / \mathrm{h}$. The agitator speed was held constant at $85 \mathrm{rpm}$, except during melter-feed processing, when it was increased to $130 \mathrm{rpm}$ in an attempt to avoid caking around the coils. The history of the coil-heat-transfer coefficients during heating periods at maximum steam flow for initial water runs and NCAW dilute, concentrate, formate, and melter feed is provided in Figure H-1. Data at both high and low levels are provided for dilute and concentrate NCAW simulant.

In general, the heat-transfer coefficient decreased with increasing concentration, except during water testing, when plant steam was limited to $5200 \mathrm{lb} / \mathrm{h}$, and after formating, which reduces the viscosity of the simulant. Caking during melter-feed processing resulted in an extremely low heat-transfer coefficient (approximately $50 \mathrm{Btu} / \mathrm{h}-\mathrm{ft}^{2}{ }^{\circ} \mathrm{F}$ ).

The heat-transfer coefficient increased with process temperature for water, dilute feed, concentrated feed, and formated feed, but decreased with process temperature for melter feed. Also, the heattransfer coefficient (as any concentration) did not increase significantly as the process approached boiling; therefore, process boiling does not increase the effective heat-transfer rate.

Table 7.2 provides heat-up times, process volume, and heat-transfer coefficients for the heating periods of the NCAW campaign. The average instantaneous heat-transfer coefficient, $U_{i}$, was averaged over the entire heating process. The overall heat-transfer coefficient, $U_{0}$, was calculated with the overall transient heating equation provided in Section 7.1.4.2. Since the specific heat of the simulant at each concentration was unavailable for NCAW simulant when this report was written, it was necessary to rely on SRL experience with a simulant of similar concentration. ${ }^{(a)}$

The overall heat-transfer coefficients $\left(U_{0}\right)$ are much lower than the instantaneous values $\left(U_{i}\right)$, apparently because the equation used to determine $U_{0}$ is inadequate for this situation. The equation assumes an isothermal heating medium and neglects cooling of the steam condensate. Subcooling the steam condensate transfers much heat over a small temperature difference between the process and coilside. It is believed that $U_{i}$ gives a better indication of heat transfer performance, but $U_{0}$ may be more useful in conservatively predicting heating times. Also, since SRL publishes only the overall heattransfer coefficient, it is necessary to calculate $U_{0}$ to compare to historical data.

(a) Baron, M. R. 1987. "Summary of Fabrication, Start-up, and Runs \#1 and \#2 of the DWPF Full Scale SRAT/SME," Memorandum DPST-87-794 of the Savannah River Laboratory. 
Table 7.2. Heat-Transfer Coefficient During Heating for Water and NCAW Simulant

\begin{tabular}{|c|c|c|c|c|c|c|c|}
\hline Description & $\begin{array}{l}\text { TST019 } \\
\text { Water } \\
\text { High } \\
\text { Level }\end{array}$ & 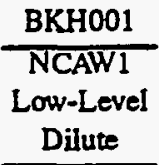 & $\begin{array}{c}\text { BKH002 } \\
\text { NCAW1 } \\
\text { High-Level } \\
\text { Dilute }\end{array}$ & $\begin{array}{c}\text { BKH003 } \\
\text { NCAW1 } \\
\text { Low-Level } \\
\text { Concentrate }\end{array}$ & $\begin{array}{c}\text { BKH0O4 } \\
\text { NCAW1 } \\
\text { High-Level } \\
\text { Concentrate }\end{array}$ & $\begin{array}{l}\text { RYCOO1 } \\
\text { NCAW1 } \\
\text { Formated } \\
\text { Feed }\end{array}$ & $\begin{array}{c}\text { FRT002. } \\
\text { NCAWI } \\
\text { Melter } \\
\text { Feed }\end{array}$ \\
\hline Weight \% Solids & $0.0 \%$ & $4.2 \%$ & $4.4 \%$ & $15.5 \%$ & $15.5 \%$ & $19.0 \%$ & $41.0 \%$ \\
\hline Specific Gravity & 1 & 1.03 & 1.03 & 1.11 & 1.11 & 1.13 & 1.4 \\
\hline $\begin{array}{l}\text { Specific Heat, } \\
\text { But } / \mathrm{l} \mathrm{b}^{\circ} \mathrm{F}\end{array}$ & 1.00 & 1.00 & 1.00 & 0.90 & 0.90 & 0.90 & 0.79 \\
\hline Elapsed Time, h & 1.20 & 0.58 & 0.78 & 0.48 & 0.93 & 0.97 & 2.25 \\
\hline Volume, gai & 8272 & 5887 & 7627 & 5656 & 8035 & 7069 & 6562 \\
\hline $\begin{array}{l}\text { Average Steam Flow, } \\
\mathrm{lb} / \mathrm{h}\end{array}$ & 5190 & 7084 & 6934 & 6602 & 5985 & 5324 & 2652 \\
\hline Start Temp, ${ }^{\circ} \mathrm{F}$ & 126 & 129 & 127 & 146 & 127 & 125 & 128 \\
\hline End Temp, ${ }^{\circ} \mathrm{F}$ & 210 & 209 & 210 & 210 & 210 & 210 & 212 \\
\hline $\begin{array}{l}\text { Average Instantaneous } \\
\mathrm{U}_{\mathrm{i}}, \mathrm{Btu} / \mathrm{h}-\mathrm{ft}^{2}{ }^{\circ} \mathrm{F}\end{array}$ & 161 & 189 & 196 & 181 & 159 & 154 & 53 \\
\hline Over all $U_{0}, B u t / h-\mathrm{ft}^{2 \circ} \mathrm{F}$ & 78 & 122 & 125 & 123 & 117 & 110 & 43 \\
\hline
\end{tabular}

(a) Savannah River Laboratory data.

Table 7.3 provides a comparison of the SIPT Feed Prep Test System heating heat-transfer coefficients with processing data from the Savannah River TNX facility. (a) Since both plants use essentially the same evaporator design, it was expected that the heat-transfer coefficients would be similar. In both sets of data, the heat-transfer coefficients decreased with slurry concentration. The heat-transfer coefficients were, in general, higher for SIPT than the TNX facility, because SIPT NCAW data was at a higher steam flow $(6000-7000 \mathrm{lb} / \mathrm{h}$ for SIPT versus $5000 \mathrm{lb} / \mathrm{h}$ for TNX).

\subsubsection{Boiling}

This section summarizes the results of testing conducted to determine the performance of the evaporator during process boiling. The boil-up rate and the heat-transfer coefficient were determined as a function of steam flow and agitation speed. An energy balance was also performed on the evaporator to verify the accuracy of the instrumentation and the calculations. In addition, the presence and extent of vapor binding were evaluated. Evaporator performance spreadsheets (see Appendix I)

(a) Baron, M. R. 1987. "Summary of Fabrication, Start-up, and Runs \#1 and \#2 of the DWPF Full Scale SRAT/SME," Memorandum DPST-87-794 of the Savannah River Laboratory. 
Table 7.3. Comparison of Overall Heating Heat-Transfer Coefficients

\begin{tabular}{|c|c|c|}
\hline Plant & Processing Cycle & $\mathrm{U}, \mathrm{Btu} / \mathrm{h}-\mathrm{ft}^{2{ }^{2} \mathrm{~F}}$ \\
\hline Savannah River & Unformated Sludge, SRAT\#2 & 100 \\
\hline TNX & Frit Slurry, SME $\# 2$ & 90 \\
\hline HWVP & Design & 120 \\
\hline SIPT Feed Prep Test System & $\begin{array}{l}\text { Water, High Level } \\
\text { Dilute, Low Level } \\
\text { Dilute, High Level } \\
\text { Concentrate, Low Level } \\
\text { Concentrate, High Level } \\
\text { Formate Recycle } \\
\text { Melter Feed }\end{array}$ & $\begin{array}{r}78 \\
122 \\
125 \\
123 \\
117 \\
110 \\
43\end{array}$ \\
\hline
\end{tabular}

provide heat-transfer coefficients, pressure drop across steam coils, evaporation rate, and energy balance results during boiling. Each spreadsheet is divided into segments of constant evaporation rate, where process variables were essentially constant.

Heat-Transfer Performance. The effects of steam flow on the evaporation rate and heat-transfer coefficient are shown in Figures H-2 and H-3, respectively, for the NCAW simulant campaign. Data are provided for water (high level), dilute feed (low and high level), concentrated feed (low and high level), formated feed (one level), and melter feed (one level).

The relationship between steam flow and process evaporation is highly linear (see Figure H-2), regardless of concentration and level. During all boiling phases except boiling of formated feed, process condensate from the outlet of the condenser was refluxed into the evaporator. During boiling segments in which the condensate is refluxed, part of the heat supplied by the steam coils was used to reheat the condensate to boiling. For this reason, the evaporation rate was slightly higher during boiling of formated feed, when the condensate was not refluxed. Refluxing should have no effect on the evaporator-coil-heat-transfer coefficient, however. The in-line steam traps restricted the total steam flow to $2500 \mathrm{lb} / \mathrm{h}$ during boiling of meiter feed, as caking around the steam coils significantly reduced the heat-transfer rate.

The boiling heat-transfer coefficients increased with steam flow (see Figure H-3). Heat-transfer coefficient during boiling of dilute, concentrated, and formated feed were nearly the same as for water. Coil caking caused a low heat-transfer coefficient (approximately $50 \mathrm{Btu} / \mathrm{h}-\mathrm{ft}^{2}{ }^{\circ} \mathrm{F}$ ) during boiling of melter feed. 
The effect of agitator speed on the heat-transfer coefficient is shown in Figure $\mathrm{H}-4$ for dilute and concentrated feed at $5200 \mathrm{lb} / \mathrm{h}$ steam flow and 130 psia steam-header pressure. Increasing the agitator speed provided a modest increase in the heat-transfer coefficient.

Table 7.4 provides a comparison of the SIPT Feed Prep Test System boiling heat-transfer coefficients with processing data at the Savannah River TNX facility. (a) Since both facilities use essentially the same evaporator design, it was expected that the heat-transfer coefficients would be similar. In both sets of data, the heat-transfer coefficients decreased with slurry concentration. The heattransfer coefficients were, in general, higher for SIPT than the TNX plant, because SIPT NCAW data was at a higher steam flow (6000 to $7000 \mathrm{lb} / \mathrm{h}$ for SIPT versus $5000 \mathrm{lb} / \mathrm{h}$ for TNX).

Energy Balance Results. This section provides a basis for the energy balance calculations that were used. When the evaporator tank is used as a control volume, it may transfer heat into the tank.

Table 7.4. Comparison of Boiling Heat-Transfer Coefficients at Maximum Evaporation

\begin{tabular}{|c|c|c|}
\hline Plant & Processing Cycle & $\mathrm{U}, \mathrm{Btu} / \mathrm{h}-\mathrm{ft}^{2}{ }^{\circ} \mathrm{F}$ \\
\hline \multirow{5}{*}{$\begin{array}{l}\text { Savannah River } \\
\operatorname{TNX}^{(a)}\end{array}$} & Water & 180 \\
\hline & Unformated Sludge, SRAT\#1 & 160 \\
\hline & Frit Slurry, SME\#1 & 140 \\
\hline & Unformated Sludge, SRAT\#2 & 135 \\
\hline & Frit Slurry, SME\#2 & 115 \\
\hline HWVP & Design & 120 \\
\hline \multirow[t]{7}{*}{ SIPT Feed Prep Test System ${ }^{(b)}$} & Water, High Level & 200 \\
\hline & Dilute, Low Level & 203 \\
\hline & Dilute, High Level & 202 \\
\hline & Concentrate, Low Level & 191 \\
\hline & Concentrate, High Level & 190 \\
\hline & Formate Recycle & 194 \\
\hline & Meiter Feed & 65 \\
\hline
\end{tabular}

(a) 90 psig steam.

(b) 110 psig steam.

(a) Baron, M. R. 1987. "Summary of Fabrication, Start-up, and Runs \#1 and \#2 of the DWPF Full Scale SRAT/SME," Memorandum DPST-87-794 of the Savannah River Laboratory. 
Heat is transferred out by losses to ambient, by reheating of the refiux condensate from the condenser outlet temperature to boiling (if the condensate is refluxed), and by evaporation of the process steam. Equating heat in to heat out:

$$
q_{\text {steam }}+q_{\text {agitator }}=q_{\text {loss }}+q_{\text {evap }}+q_{\text {reheat }}
$$

where $\mathrm{q}_{\text {steam }}=$ heat input by steam

$$
\begin{gathered}
q_{\text {agitator }}=\text { heat input by agitator } \\
q_{\text {loss }}=\text { heat losses to ambient } \\
q_{\text {reheat }}=\text { heat required to reheat condensate } \\
q_{\text {evap }}=\text { heat of process evaporation. }
\end{gathered}
$$

Heat is input by the steam during desuperheating, condensing, and subcooling. At known temperature, pressure, and flow rate of the steam, these quantities were determined by use of latent heat (i.e., $c_{p} \Delta T$ ) calculations and steam tables. For simplicity, agitator heat input was found by the actual agitator motor power draw (see Section 7.1.2). Figure H-5 provides the agitator motor output versus agitator speed for water (high level), dilute feed (high and low level), concentrate feed (high and low level), formated feed (one level), and melter feed (one level). As shown, the agitator motor output increases with speed, concentration, and level.

The heat lost from the tank to ambient as a function of process temperature is discussed in Section 7.1.4.3. During boil-up, the tank losses were $207,000 \mathrm{Btu} / \mathrm{h}$ for a process-liquid level of $7550 \mathrm{gal}$.

If the condensate is reflux from the outlet of the condenser to the evaporator, the condensate must be reheated from condenser-outlet temperature to boiling. The heat required to reheat the condensate is determined from the condensate flow rate and the required temperature rise. The heat of process evaporation was determined by measuring the evaporation rate of overhead vapors from the tank.

Energy balance calculations are provided in the evaporator performance summary spreadsheets (see Appendix 1). At maximum steam flow $(6000 \mathrm{lb} / \mathrm{h})$, the balance closed within $3 \%$, which helps to confirm the accuracy of the instrumentation. In general, at lower steam flows, the energy balance did not close quite as well, but the total heat transferred was lower, which resulted in a higher percentage error.

Vapor Binding. Vapor binding around heating coils during boiling is caused by a combination of high viscosity and high wall-temperatures, which can result in the formation of a blanket of water vapor around a heat-transfer surface. Test results were used to calculate the evaporator heat-transfer coefficient and evaporation rate at several steam flows. An increase in heating coil steam flow and a 
consequent decrease in the evaporator heat-transfer coefficient and evaporation rate would have been an indication of vapor binding. During testing with water and NCAW simulant, no evidence of vaporbinding during boiling segments was apparent. Increasing the steam flow, which will increase the coilwall temperature, increased the heat-transfer coefficient and the evaporation rate at all steam flows up to $6000 \mathrm{lb} / \mathrm{h}$.

\subsubsection{Batch Cooling}

Batches of process liquid were cooled from boiling to $125^{\circ} \mathrm{F}$ at a cooling-water flow of $120 \mathrm{gpm}$. During cooling, the agitator speed was held constant at $85 \mathrm{rpm}$, except during melter feed processing, when the agitator speed was increased to $130 \mathrm{rpm}$ in an attempt to avoid caking around the coils. The history of the coil-heat-transfer coefficients during cooling periods for initial water runs and NCAW dilute, concentrate, formated, and melter feed is provided in Figure H-6. Data at both high and low levels in the tank are provided for dilute and concentrate NCAW simulant.

The heat-transfer coefficient decreased with increasing concentration, except after formating, which reduces the viscosity of the simulant and helps recover the loss in heat transfer. The heat-transfer coefficient increased with process temperature for water, dilute feed, concentrated feed, and formated feed, but decreased with process temperature for melter feed. The cooling heat-transfer coefficient reached a minimum of approximately $120 \mathrm{Btu} / \mathrm{h}-\mathrm{ft}^{2}{ }^{\circ} \mathrm{F}$ during melter-feed processing. Cooling coils remained relatively clean throughout the NCAW campaign, but considerable amount of caking occurred on the steam coils. The low transient cooling heat-transfer coefficient is a result of two factors: 1) the buildup on the steam coils prevented the melter feed from flowing through the coils, and 2) the high viscosity and yield stress of the melter feed make it a relatively poor heat-transfer medium.

Table 7.5 provides cool-down times, process volume, and heat-transfer coefficients for cooling periods of the NCAW campaign. The average instantaneous heat-transfer coefficient, $U_{i}$, is averaged over the entire heating process. The overall heat-transfer coefficient, $\mathrm{U}_{0}$, was calculated from the overall transient heating equation provided in Section 7.1.4.2. Since the specific heat of NCAW simulant at each concentration was unavailable when this report was written, it was necessary to rely on SRL experience with a simulant of similar concentration. (a) The excellent agreement of the average instantaneous and overall heat-transfer coefficients suggests that the assumptions used to establish the overall heat-transfer equation were reasonable.

Table 7.6 provides a comparison of the SIPT Feed Prep Test System evaporator-cooling heat-transfer coefficients with processing data at the Savannah River TNX facility. ${ }^{\text {(a) }}$ Since both facilities use essentially the same evaporator design, the heat-transfer coefficients were expected to be similar. In both sets of data, the heat-transfer coefficients decreased with slurry concentration. The cooling heattransfer coefficients were significantly higher for SIPT; use of a different equation to calculate the TNX data may have caused the discrepancy:

(a) Baron, M. R. 1987. "Summary of Fabrication, Start-up, and Runs \#1 and \#2 of the DWPF Full Scale SRAT/SME," Memorandum DPST-87-794 of the Savannah River Laboratory. 
Table 7.5. Heat-Transfer Coefficient During Cooling for Water and NCAW Simulant

\begin{tabular}{|c|c|c|c|c|c|c|c|}
\hline Test & TST019 & BKH001 & BKH0O2 & BKH003 & BKH004 & RYCOO1 & FRT002 \\
\hline Description & $\begin{array}{l}\text { Water } \\
\text { High } \\
\text { Level }\end{array}$ & $\begin{array}{c}\text { NCAW1 } \\
\text { Low-Level } \\
\text { Dilute }\end{array}$ & $\begin{array}{c}\text { NCAW1 } \\
\text { High-Level } \\
\text { Dilute }\end{array}$ & $\begin{array}{c}\text { NCAW I } \\
\text { Low-Level } \\
\text { Concentrate }\end{array}$ & $\begin{array}{c}\text { NCAW1 } \\
\text { High-Level } \\
\text { Concentrate }\end{array}$ & $\begin{array}{l}\text { NCAWI } \\
\text { Formated } \\
\text { Feed }\end{array}$ & $\begin{array}{l}\text { NCAW1 } \\
\text { Melter } \\
\text { Feed }\end{array}$ \\
\hline Weight $\%$ Solids & $0.0 \%$ & $4.2 \%$ & $4.4 \%$ & $15.5 \%$ & $15.5 \%$ & $19.0 \%$ & $41.0 \%$ \\
\hline Specific Gravity & 1 & 1.03 & 1.03 & 1.11 & 1.11 & 1.13 & 1.4 \\
\hline $\begin{array}{l}\text { Specific Heat, } \\
\text { Btu/ } / b^{\circ} \mathrm{F}\end{array}$ & 1.00 & 1.00 & 1.00 & 0.90 & 0.90 & 0.90 & 0.79 \\
\hline Elapsed Time, h & 1.62 & 1.92 & 2.60 & 2.17 & 3.28 & 2.47 & 4.58 \\
\hline Volume, gal & 5405 & 5751 & 7425 & 5488 & 7870 & 6548 & 6463 \\
\hline $\begin{array}{l}\text { Average Cooling } \\
\text { Water Flow, gpm }\end{array}$ & 122 & 118 & 116 & 119 & 120 & 115 & 115 \\
\hline Start Temp, ${ }^{\circ} \mathrm{F}$ & 205 & 204 & 207 & 207 & 208 & 207 & 212 \\
\hline End Temp, ${ }^{\circ} \mathrm{F}$ & 125 & 125 & 125 & 125 & 125 & 125 & 125 \\
\hline $\begin{array}{l}\text { Average } \\
\text { Instantaneous } \mathrm{U}_{\mathrm{i}} \text {, } \\
\text { Btu/h-}-\mathrm{ft}^{2}{ }^{\circ} \mathrm{F}\end{array}$ & 271 & 267 & 265 & 218 & 207 & 219 & 105 \\
\hline 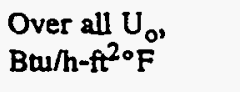 & 241 & 260 & 260 & 200 & 192 & 215 & 114 \\
\hline
\end{tabular}

(a) Savannah River data.

\subsubsection{Water Testing-Actual Versus Predicted Results}

As described in Section 7.1.4, calculations were performed to predict the heating, boiling, and cooling heat-transfer coefficients for water. Since water is a well defined, Newtonian fluid, standard correlations were readily available. In this section, these predicted heat-transfer coefficients are compared to results of actual tests with water as the process medium. For comparison, both clean $\left(U_{c}\right)$ and dirty $\left(\mathrm{U}_{\mathrm{D}}\right)$ heat-transfer coefficients were calculated, to account the presence or absence of coil fouling. The calculation of $U_{D}$ includes fouling to account for one year of processing with water and does not account or fouling from slurry processing. During water testing, the steam and cooling coils were new 
Table 7.6. Comparison of Overall Cooling Heat-Transfer Coefficients

\begin{tabular}{|c|c|c|}
\hline Plant & Processing Cycle & $\mathrm{U}, \mathrm{Btu} / \mathrm{h}-\mathrm{ft}^{2 \circ} \mathrm{F}$ \\
\hline \multirow[t]{3}{*}{ Savannah River - TNX } & Formate Reflux \#3 & 140 \\
\hline & Unformated Sludge, SRAT\#3 & 67 \\
\hline & Frit Slurry, SME\#3 & 54 \\
\hline HWVP & Design & 70 \\
\hline \multirow[t]{7}{*}{ SIPT } & Water, Low Level & 241 \\
\hline & Dilute, Low Level & 260 \\
\hline & Dilute, High Level & 260 \\
\hline & Concentrate, Low Level & 200 \\
\hline & Concentrate, High Level & 192 \\
\hline & Formate Recycle & 215 \\
\hline & Melter Feed & 114 \\
\hline
\end{tabular}

and initially clean. It is expected that with use, fouling will cause the heat-transfer coefficients to decrease as occurred at the Savannah River TNX facility during the first three runs of the DWPF SRAT/SME. (a)

To determine the effect of process temperature on the heat-transfer coefficients, transient heating and cooling heat-transfer coefficient were evaluated at process temperatures of $125^{\circ} \mathrm{F}, 168^{\circ} \mathrm{F}$, and $212^{\circ} \mathrm{F}$ (boiling).

Heating Heat-Transfer Coefficients. Figure $\mathrm{H}-7$ provides a plot of the actual and predicted heating heat-transfer coefficients versus temperature of process water. Table 7.7 summarizes the predicted and actual heat-transfer coefficients for transient heating. A straight line was fitted through the actual heat-transfer coefficient curve. It was expected that the actual heat-transfer coefficient would be nearly equal to $U_{C}$, since the coils were essentially new when testing occurred, and the coils had been exposed only to water. However, the actual heat-transfer coefficient is only slightly above the line of predicted $U_{D}$, which would suggest that significant fouling had occurred. During water processing, the coils may be oversurfaced for the application. The finding that the steam condensate temperature (exit) is only slightly higher than the process temperature during heat-up suggests that nearly all the heat is being extracted from the steam.

(a) Baron, M. R. 1987. "Summary of Fabrication, Start-up, and Runs \#1 and \#2 of the DWPF Full Scale SRAT/SME," Memorandum DPST-87-794 of the Savannah River Laboratory. 
Table 7.7. Heating Heat-Transfer Coefficient for Water

\begin{tabular}{|c|c|c|c|}
\hline Process Temperature, ${ }^{\circ} \mathrm{F}$ & 212 & 168 & 125 \\
\hline $\mathrm{U}_{\mathrm{C}}$, Predicted, Btu $/ \mathrm{h}-\mathrm{ft}^{2 \circ} \mathrm{F}$ & 252 & 241 & 227 \\
\hline $\mathrm{U}_{\mathrm{D}}$, Predicted, Btu/h- $\mathrm{ft}^{2 \circ} \mathrm{F}$ & 155 & 150 & 145 \\
\hline $\mathrm{U}_{\mathrm{o}}$, actual, Btu/h- $\mathrm{ft}^{2}{ }^{\circ} \mathrm{F}$ & 79 & 79 & 79 \\
\hline $\mathrm{U}_{\mathrm{i}}$, actual, Btu/h- $\mathrm{ft}^{2 \circ} \mathrm{F}$ & 186 & 160 & 133 \\
\hline
\end{tabular}

The actual overall heat-transfer coefficients $\left(U_{0}\right)$ are much lower than the predicted heat-transfer coefficients $\left(U_{C}\right.$ and $\left.U_{D}\right)$ and the instantaneous values $\left(U_{i}\right)$, apparently because the equation used to determine the overall heating heat-transfer coefficient is inadequate for the situation (see Section 7.1.4.2). That equation assumes an isothermal heating medium and neglects cooling of the steam condensate; subcooling the steam condensate transfers a large amount of heat.

Boiling Heat-Transfer Coefficients. Heat transfer in the tank will be a combination of forced convection by agitation and boiling heat transfer. Due to the complexities involved in calculating a boiling heat-transfer coefficient, the effect of boiling was neglected, and the calculated heat-transfer coefficient was based only on forced convection. This heat-transfer coefficient was compared to actual test data to validate this simplification. Actual test data were used for property evaluation, flow rates, etc. A predicted heat-transfer coefficient was calculated for the actual test conditions provided in Table 7.8.

Since the effects of boiling are neglected, the situation becomes identical to transient heating. Thus, the equations and fouling factors used to predict the transient heating heat-transfer coefficient were used to compute boiling. A comparison of the predicted and actual boiling heat-transfer. coefficients is provided in Table 7.9.

No boiling effects were considered in deriving the predicted heat-transfer coefficient, and yet the actual coefficient is bracketed by the predicted clean and dirty coefficients. Therefore, boiling in the test vessel does not increase the heat-transfer rate above that due to forced convection.

Table 7.8. Test Conditions used to Predict Boiling Heat Transfer

Steam Iniet Pressure

Steam Flow

Steam Inlet Temperature

Condensate Outlet Temperature

Boil-up Rate
126 psia

$5760 \mathrm{lb} / \mathrm{h}$

$345^{\circ} \mathrm{F}$

$213^{\circ} \mathrm{F}$

$10.2 \mathrm{gpm}$ 
Table 7.9. Comparison of Predicted and Actual Boiling Heat-Transfer Coefficient at $10 \mathrm{gpm}$ Evaporation

$$
\begin{aligned}
& \mathrm{U}_{\mathrm{C}}, \text { predicted } \\
& \mathrm{U}_{\mathrm{D}} \text {, predicted } \\
& \mathrm{U} \text {, actual }
\end{aligned}
$$

\author{
$253 \mathrm{Btu} / \mathrm{h}-\mathrm{ft}^{2 \circ \mathrm{F}}$ \\ $155 \mathrm{Btu} / \mathrm{h}-\mathrm{ft}^{2}{ }^{\circ} \mathrm{F}$ \\ $177 \mathrm{Btu} / \mathrm{h}-\mathrm{ft}^{2 \circ} \mathrm{F}$
}

Cooling Heat-Transfer Coefficients. Figure H-8 provides a plot of the actual and predicted cooling heat-transfer coefficients for process water. These transient coefficients are summarized in Table 7.10. A straight line was fitted through the actual heat curve. It was expected that the actual coefficient would be nearly equal to $U_{C}$, since the coils were essentially new when testing occurred, and the coils had been exposed only to water. In fact, the instantaneous coefficient $\left(U_{i}\right)$ was slightly higher than the predicted clean coefficient Uc, which is somewhat surprising but not alarming, considering the accuracy of the correlations. The coils are relatively new and it is expected that the cooling heat-transfer coefficient will decrease with time to the dirty value, Ud. The actual coefficient increased slightly with process temperature, as predicted. Since the overall coefficient is affected by tank heat loss, it is somewhat lower than the instantaneous coefficient.

Agitator Heating-Water Testing. Testing with process water was used to correlate the power output of the agitator motor with latent heat input. Table 7.11 summarizes the test results at 45,85 , and $130 \mathrm{rpm}$.

The horsepower for the $45 \mathrm{rpm}$ run was set to zero, since the calculated horsepower was negative. This reflects the fact that the motor shaft speed is much less than $1785 \mathrm{rpm}$ (the motor speed used to establish the performance curves). Because frictional losses are lower at $45 \mathrm{rpm}$, shaft output would be higher, and the method is therefore not accurate at $45 \mathrm{rpm}$. At $85 \mathrm{rpm}$, the horsepower/current equation underpredicts the motor power from the agitator, since the motor speed is again less than $1785 \mathrm{rpm}$. This may explain the fact that the power from the agitator motor is somewhat lower than the power into the process water, which was calculated from the temperature rise. For the $130 \mathrm{rpm}$ case, the power out of the motor is somewhat greater than the power into the process, which is probably due to other energy losses.

For.energy balance calculations, the power out is equated to power transferred into the process liquid. This method is only accurate at higher speeds, but since the power draw at low speeds is small, from an energy balance standpoint, this is acceptable. This neglects frictional losses from the agitator

\begin{tabular}{|c|c|c|}
\hline Process Temperature, ${ }^{\circ} \mathrm{F}$ & 212 & 168 \\
\hline $\mathrm{U}_{\mathrm{C}}$, Predicted, Btu $/ \mathrm{h}-\mathrm{ft}^{2}{ }^{\circ} \mathrm{F}$ & 262 & 247 \\
\hline $\mathrm{U}_{\mathrm{D}}$, Predicted, Btu/h- $\mathrm{ft}^{2 \circ} \mathrm{F}$ & 147 & 142 \\
\hline $\mathrm{U}_{\mathrm{o}}$, actual, Btu $/ \mathrm{h}-\mathrm{ft}^{2 \circ} \mathrm{F}$ & 241 & 241 \\
\hline $\mathrm{U}_{\mathrm{i}}$, actual, $\mathrm{Btu} / \mathrm{h}-\mathrm{ft}^{2 \circ} \mathrm{F}$ & 281 & 273 \\
\hline
\end{tabular}
gears, bearings, etc.

Table 7.10. Cooling Heat-Transfer Coefficient for Water 
Table 7.11. Agitator Heating Test Results with Water

\begin{tabular}{|c|c|c|c|}
\hline Speed, rpm & 45 & 85 & 130 \\
\hline Motor Shaft Speed, rpm & 570 & 1,080 & 1,660 \\
\hline Temperature Rise, ${ }^{\circ} \mathrm{F} / \mathrm{h}$ & 0.018 & 0.513 & 1.666 \\
\hline Current, amps & 24.50 & 33.79 & 55.80 \\
\hline Voltage, volts & 460 & 460 & 460 \\
\hline Horsepower & 0.00 & 6.95 & 43.57 \\
\hline Shaft Power Out, Btu/h & 0 & 17,700 & 110,900 \\
\hline $\begin{array}{l}\text { Calculated Heat Input by agitator } \\
\text { due to temperature rise, Btu/h }\end{array}$ & 800 & 23,100 & 75,000 \\
\hline
\end{tabular}

Tank Heat Loss. As described in Section 7.1.3, the heat lost from the evaporator to the environment was calculated by measuring the temperature drop of process water versus time from boiling to $125^{\circ} \mathrm{F}$. Detailed test results are available in CALC-SIPT-0O3 in Appendix G. To validate these experimental heat-loss results, a computational thermal analysis was conducted to analytically determine both the heat loss from the evaporator tank and the temperature distribution on the outside of the tank (see CALC-SIPT-011 in Appendix G). The model considered conduction through the evaporator wall and heat loss due to radiation and convection.

Two types of convective heat-transfer coefficients were separately applied to the outside of the tank: natural and forced. The natural convection coefficient, $h_{\mathrm{b}}$, was calculated with standard correlations for the cooling of bodies in still air. Fluor Daniel ${ }^{(a)}$ used natural convection correlations to estimate the tank heat loss. Since the air was forced around the outside of the tank by the ventilation system, it was felt that natural convection could not account for the heat loss. The forced convection coefficient, $h_{f}$, was based on trial and error. Attempts were made at matching both the recorded temperature distribution and the measured heat loss. While either one of the two items was easily matched, it was not possible to match both items exactly.

The results of the computer model are compared to calculations performed by Fluor Daniel(a) and to experimental heat loss results in Table 7.12. Several conclusions have been drawn from this table:

1. The Fluor Daniel calculations ${ }^{(a)}$ for heat loss was low in comparison to the analytical natural convection model for two reasons:

(a) Fluor Daniel Calculations, pp 10.27, Heat Gain to HVAC, Contract No. 845724, CWBS 3212 and 3214, MF-0029, October 23, 1989. 
Table 7.12. Evaporator Tank Experimental Heat Loss, in Btu/h

\begin{tabular}{|c|c|c|c|c|}
\hline Water Temp, ${ }^{\circ} \mathrm{F}$ & $\begin{array}{c}\text { Fluor Daniel } \\
\text { Calculation }\end{array}$ & Experimental & $\begin{array}{l}\text { Analytical } \\
\text { Natural } \\
\text { Convection }\end{array}$ & $\begin{array}{l}\text { Analytical } \\
\text { Forced } \\
\text { Convection }\end{array}$ \\
\hline 125 & NA & 32,000 & 25,000 & 35,000 \\
\hline 168 & NA & 82,000 & 58,000 & 82,000 \\
\hline 212 & 54,000 & 207,000 & 88,000 & 126,000 \\
\hline
\end{tabular}

(a)

a. Fluor Daniel assumed that the tank bottom was insulated, while the bottom of the test vessel is not insulated.

b. Fluor Daniel assumed that the ambient temperature was $104^{\circ} \mathrm{F}$, which represents plant conditions, while the analytical model assumed an ambient temperature of $62^{\circ} \mathrm{F}$, which was the high bay temperature during the experimental heat loss test.

2. Since the experimental heat loss is much greater than the heat loss assuming natural convection, results indicate that the outside heat-transfer coefficient is higher than can be calculated through the use of natural convection correlations.

3. For the lower tank temperatures of $50^{\circ} \mathrm{C}$ and $75^{\circ} \mathrm{C}$, the forced convection analytical model was able to reasonably predict the tank heat loss and temperature distribution.

4. At higher temperatures, the forced convection analytical model was not able to accurately predict tank heat loss, but the temperature prediction was reasonable. There are other mechanisms of heat loss in the tank that have not been accounted for in the model.

5. Heat loss due to the loss of process evaporation was at high temperatures, and the experimental heat loss at high temperatures had to be corrected by subtracting the heat of vaporization attributed to the measured condensate flow from the condenser. Since condensate flow measurement was somewhat erratic at low flow rates, the calculated heat loss as $212^{\circ} \mathrm{F}$ may not be exact.

6. There was a comparison made between the $h_{h}$ for the natural convection and the forced convection. The model results indicated that for the boiling water case, $h_{f}$ for the natural convection varied from $0.37 \mathrm{Btu} / \mathrm{h}-\mathrm{ft}^{2 \circ} \mathrm{F}$ to $1.08 \mathrm{Btu} / \mathrm{h}-\mathrm{ft}^{2 \circ} \mathrm{F}$. The forced convection term used for the case of boiling water was $1.44 \mathrm{Btu} / \mathrm{h}-\mathrm{ft}^{2 \circ} \mathrm{F}$. It was expected that the forced convection terms would be somewhat higher than the natural convection terms. 


\subsubsection{Conclusions}

The heat-transfer performance of the SIPT Feed Prep Test System evaporator was affected by the coil steam flow, slurry concentration, agitator speed, and, to a lesser extent, the process level in the tank. The following summarizes the trends regarding NCAW processing:

- Heat-transfer coefficients for dilute, concentrated, and formate recycle were nearly as high as for water. After frit addition, extended processing and lithium and boron leaching increased the viscosity and yield stress of the melter feed, which resulted in significant caking around the steam coils and poor heat transfer. The in-line steam traps restricted the total steam flow to $2500 \mathrm{lb} / \mathrm{h}$ (the maximum steam fiow that could be completely condensed) during heating of melter feed. The design heat-transfer coefficient may be too high for melter feed processing during heating and boiling.

- In most cases, increasing the process level reduced the heat-transfer coefficients, although the effect was not significant.

- Increasing the agitator speed provided a modest increase in the boiling heat-transfer coefficient.

- Vapor binding was not evident at any concentration.

- Calculated clean and dirty (fouled) heat-transfer coefficients for water processing bounded and helped confirm the experimental results.

\subsection{Mixing (agitation) and Sampling Performance}

Slurry mixing tests to determine slurry homogeneity and slurry sampling tests to determine sampling accuracy are discussed below.

\subsubsection{Test Approach}

A series of six tests were performed to determine the level of homogeneity and solids accumulation at the tank periphery under a variety of process conditions. Tests were conducted to measure the specific gravity and weight percent oxides as a function of agitator speed, sampling height, and slurry type/concentration. Table 7.13 summarizes the testing parameters.

The following approach was used for homogeneity testing.

1. The tank temperature was adjusted to the test temperature $\left(52^{\circ} \mathrm{C}, 125^{\circ} \mathrm{F}\right)$, and the tank pressure was adjusted to -5 in. of water. 
Table 7.13. Summary of Homogeneity Tests

\begin{tabular}{|c|c|c|c|c|c|c|}
\hline Test No. & Simulant & Description & $\begin{array}{c}\text { Tank } \\
\text { Volume } \\
\text { (gal) }\end{array}$ & $\begin{array}{c}\text { Tank Level } \\
\text { (in.) }{ }^{(a)} \\
\end{array}$ & $\begin{array}{l}\text { Agitator } \\
\text { Speeds } \\
\text { (rpm) }\end{array}$ & $\begin{array}{c}\text { Sample } \\
\text { Heights } \\
\text { (in.) }\end{array}$ \\
\hline 1 & Dilute Waste & SRAT, initial & 5700 & 82 & $45,85,130$ & $6,24,48$ \\
\hline 2 & Dilute Waste & SRAT, Initial & 7800 . & 113 & $45,85,130$ & $6,84,102$ \\
\hline 3 & Concentrated Waste & SRAT, prior to $\mathrm{HCOOH}$ & 5700 & 82 & $45,85,130$ & $6,24,48$ \\
\hline 4 & Concentrated Waste & SRAT, prior to HCOOH & 7800 & 113 & $45,85,130$ & $6,84,102$ \\
\hline 5 & Formated Waste & SRAT, final & 6500 & 94 & $45,85,130$ & $6,78,84$ \\
\hline 6 & Melter Feed & SME \& MFT & 7100 & 103 & 130 & $6,78,84$ \\
\hline
\end{tabular}

(a) Height in inches from the tank bottom.

2. The agitator speed was adjusted to $45 \mathrm{rpm}$ and maintained for at least 30 minutes $^{(\mathrm{a})}$ before initiating sampling activities.

3. The auxiliary and Hydragard sampling systems were started. The contents of the tank were allowed to circulate through the sampling systems for at least 5 minutes.

4. The first 28 samples were normally taken (seven sets of four samples) in a random order. A recirculation time of one minute was allowed between samples.

5. The agitator speed was adjusted to $85 \mathrm{rpm}$ and maintained for at least 30 minutes before initiating sampling activities.

6. The second 28 samples were normally taken (seven sets of four samples) in a random order. A recirculation time of one minute was allowed between samples.

7. The agitator speed was adjusted to $130 \mathrm{rpm}$ and maintained for at least 30 minutes before initiating sampling activities. ${ }^{(a)}$

8. The last 28 samples were normally taken (seven sets of four samples) in a random order. A recirculation time of one minute was allowed between samples.

9. The sampling systems were flushed, the sampling pumps were shut off, and the agitator speed was set at $85 \mathrm{rpm}$ (nominal process conditions).

Test \#6 was performed at $130 \mathrm{rpm}$ only, because lowering the agitator speed would cause the melter feed simulant, a highly viscous thixotropic slurry, to become rigid. Consequently, steps two through six were not performed with meiter feed simulant; the agitator speed was set at $130 \mathrm{rpm}$ for step nine. In all cases, the agitator operated at the test speed for a minimum of 30 minutes before taking samples.

(a) An assumption was made that 30 minutes was enough time for steady-state (i.e., homogeneous) conditions to develop. 


\subsubsection{Sampling}

For the purposes of these tests, a minimum number of samples had to be established to satisfy a criterion for statistical analysis. The required (minimum) number of samples at each process condition depends on many factors, some of which can be directly controlled based on the experimental objectives. These factors include the size of the standard deviation of replicate samples and analyses, the probability of making erroneous conclusions from statistically designed tests concerning the homogeneity of the slurries, and the desired detectable differences between the average weight percent oxides $^{(\mathrm{a})}$ and densities at different locations.

Seven samples at each of the four locations for each process condition results in at least a $95 \%$ probability of detecting a true difference of at least 2 total weight percent between any two of the sample concentration means. This determination assumes that there is a $5 \%$ probability of concluding either that the mix is not homogeneous when in fact it is homogeneous or that the slurry is homogeneous when it is not.

For each homogeneity test, seven sets of four samples were taken in random order for each agitator speed.(Total: 28 samples for each agitator speed and 84 samples for each test). Three of the samples were taken at different tank levels using the auxiliary sampler. In general, the three auxiliary locations were designated as 1) one sample immediately below the slurry surface, 2) one sample at about 1 to $2 \mathrm{ft}$ below the slurry surface, and 3 ) one sample at approximately the same depth as the prototypic sample pump intake.

The fourth sample was taken using the prototypic Hydragard Sampler. This was labeled as $(\mathrm{H})$-approximately 6 in. from the bottom of the tank. Table 7.14 shows each of the four sampling locations as a function of process tank volume. The relative locations of (1) and (2) of the auxiliary sampling system change with the process tank volume.

\subsubsection{Test Results: Homogeneity Testing}

In a homogeneous tank, the solids distribution and elemental chemical composition are required to be uniform (the tank contents temperature would also tend to be uniform). Two factors must be considered when considering homogeneity: 1) The sample or measuring point must represent the vessel contents, and 2) the sampling and analytical system must obtain accurate and reproducible results. Samples were taken of each slurry type under various testing conditions at different tank heights. A comparison was made between the calculated oxides (based on chemical addition) and the average oxides (based on sampling) during homogeneity testing. Within analytical accuracy, it was determined that the concentrations could be regarded as the same and thus represent the vessel contents. The results of this comparison are given in Table 7.15.

Comparisons of sample analyses were also made as a function of tank height for the different slurry types, slurry heights, and agitator speeds as shown in Appendix J. No difference in concentration from

(a) Three analytical methods were considered for measurement of the total solids content. These methods included 1) Weight Percent Centrifuged Solids, 2) Weight Percent Total Solids, and 3) Weight Percent Total Oxides. Comparison of these analytical methods demonstrated that, of the three, measurements of weight percent total oxides were the most precise. 
Table 7.14. Sampling Locations Used at Each Volume

\begin{tabular}{|c|c|c|c|c|c|c|}
\hline $\begin{array}{c}\text { Sampling } \\
\text { Location } \\
\text { (instrument) }\end{array}$ & $\begin{array}{l}\text { Sampling } \\
\text { System }\end{array}$ & $\begin{array}{c}\text { Sample } \\
\text { Height }^{(2)} \text {, (ft) }\end{array}$ & $\begin{array}{l}\text { Sample Label, } \\
(5700 \mathrm{gal})\end{array}$ & $\begin{array}{c}\text { Sample Label, } \\
\text { (6500 gal) }\end{array}$ & $\begin{array}{c}\text { Sample Label, } \\
(7100 \text { gal) }\end{array}$ & $\begin{array}{c}\text { Sample Label, } \\
(7800 \mathrm{gal})\end{array}$ \\
\hline Hydragand & Hydragard & 0.5 & (H) & (H) & (H) & (H) \\
\hline SPL 3/4-V01 & Auxiliary & 0.5 & (3) & (3) & (3) & (3) \\
\hline SPL 3/4-V02 & Auxiliary & 2.0 & (2) & & & \\
\hline SPL 3/4-V03 & Auxiliary & 4.0 & (1) & & & \\
\hline SPL 3/4-V04 & Auxiliary & 6.5 & & (2) & (2) & \\
\hline SPL 3/4-V05 & Auxiliary & 7.0 & & (1) & (1) & (2) \\
\hline SPL 3/4-V06 & Auxiliary & 8.5 & & & & (1) \\
\hline
\end{tabular}

(a) From the tank bottom.

Table 7.15. Comparison of Calculated to Measured Slurry Properties

\begin{tabular}{|c|c|c|c|c|c|}
\hline $\begin{array}{c}\text { Simulant } \\
\text { Name } \\
\text { (concentration) }\end{array}$ & HWVP Tank & $\begin{array}{l}\text { Process } \\
\text { Volume, } \\
\text { - gal }\end{array}$ & $\begin{array}{c}\text { Calculated } \\
\text { Oxides (brget), } \\
\text { wt } \%\end{array}$ & $\begin{array}{l}\text { Average Oxides } \\
\text { (measured), } \\
\text { wt\% }\end{array}$ & $\begin{array}{c}\text { Percent } \\
\text { Difference, } \\
w t \%\end{array}$ \\
\hline Dilute & Initial SRAT & 5700 & 3.039 & 3.041 & 0.07 \\
\hline Dilute & Initial SRAT & 7800 & 3.051 & 3.172 & 3.97 \\
\hline Concentrated & Intermediate SRAT & 5700 & 11.030 & 11.364 & 3.03 \\
\hline Concentrated & Intermediate SRAT & 7800 & 11.789 & 11.307 & 4.09 \\
\hline Formated & Final SRAT/Initial SME & 6500 & 13.563 & 13.476 & 0.64 \\
\hline Melter Feed & Final SME/MFT & 7100 & 39.639 & 39.213 & 1.07 \\
\hline
\end{tabular}

the bottom to the top of the tank implies homogeneity. For the purposes of this study, a zero concentration gradient is defined to be less than a 5\% difference between the average concentrations taken from any two heights. Scatter in the data points, average values, and range of values were considered when comparing sets of concentrations.

The best analytical tool for evaluating data scatter is the standard deviation. The tables in Appendix J show the number of samples, the sample range, the sample average, the range of error, the average error, the sample standard deviation, the normalized standard deviation, and the confidence level. All standard deviations were normalized to the average sample values for each simulant so that individual values could be compared. Confidence levels were calculated to measure how precise the data is. The confidence level (expressed as a percent) was determined from a calculated interval based on the average error and standard deviation.

Analytical results were entered manually into a Microsoft Excel database for display and manipulation on a personal computer. Other data (including tank temperature) were converted from the instrumentation system data format to Microsoft Excel format. The data were then summarized and used to perform calculations for evaluating homogeneity. The resulting tables are shown in Appendix J. 
Test Results and Analysis. It was determined that the values of specific gravity and percent oxides were uniform with agitator speed, sampling location, and slurry type/concentration over the range tested. These results are discussed in the following sections.

Agitator Speed. Based on results of the samples taken, homogeneity was achieved at all agitator speeds tested. Sample concentrations for all heights sampled were uniform (see Appendix J) at all agitator speeds tested. All samples analyzed for specific gravity generally differed by $5 \%$ or less from the average sample value. Samples analyzed for weight percent oxides were less than $4 \%$ from the sample average value. The minimum agitator speed required to produce homogeneity (at testing conditions) is believed to be below $45 \mathrm{rpm}$. The minimum agitator speed required to produce homogeneity for melter feed simulant, which contained frit, is below $130 \mathrm{rpm}$.

Slurry Height. Homogeneity was also achieved in the test vessel as a function of slurry height. There also appeared to be no change in the ability to homogenize the tank contents when the slurry volume was changed from 5700 gal to 7800 gal for the dilute and concentrated feed. Sample concentrations for all heights sampled were uniform (see Appendix J) at all agitator speeds tested. For all samples analyzed for specific gravity, the range in the data points varied $5 \%$ or less from the average sample value and the normalized standard deviations were generally under $2 \%$. Conversely, for all samples analyzed for weight percent oxides, the range in the data points varied $4 \%$ or less from the average sample value, and all normalized standard deviations were less than $1 \%$.

Slurry Type. Homogeneity was also achieved as a function of slurry type (concentration). The sample concentration did not change as a function of sampling height (see Appendix J). For samples analyzed for specific gravity, the average error (or percent difference) for each simulant was under $1 \%$, and the average normalized standard deviation was under $3 \%$ overall. For samples analyzed for weight percent oxides, the average error for each simulant was under $1 \%$ for all data points, and the average normalized standard deviation was under $1 \%$ overall.

Out of the 448 samples that were taken during testing, the results from three fell outside the ranges discussed. The reason for the outlying data is currently unknown but is believed to be analytical error. There were also no significant differences noted from samples taken from the hydargard sampler and the auxiliary sampler.

Temperature Gradients. The degree of homogeneity in the process test vessel was also evaluated by examining the temperature at different levels. If the temperatures were the same throughout the test vessel, then general homogeneity may be inferred. Three to four thermowell sensors, Tl-1046 (26 in.), Tl-1045 (54 in.), Tl-1044 (80 in.), and Tl-1043 (106 in.), were used to determine temperature, which depended on how high the liquid level was. The temperatures during testing, as given by the thermowell sensors, differed by no more than $0.5^{\circ} \mathrm{C}$. However, the calibration of the sensors was accurate only to $2.2^{\circ} \mathrm{C}$. From the results, it may be inferred that the vessel appeared homogeneous at all process conditions within the accuracy of the instrumentation.

\subsubsection{Conclusions and Recommendations}

Based on the test results and observations, the following conclusions and recommendations are made: 
- Homogeneity was achieved at all test conditions tested as a function of agitator speed, sample height, and slurry type/concentration.

- The minimum agitator speed required to produce homogeneity for each type of simulant is presently unknown (<45 rpm for the non-fritted simulants and $<130 \mathrm{rpm}$ for melter feed simulant). Homogeneity testing at lower agitation speeds is recommended to obtain these parameters and will be implemented in funure NCAW testing. Resuspension of solids (after a prescribed amount of settling time) should also be performed.

- Tests with melter feed simulant indicate that when the slurry level drops below the coil top that the slurry may become non-homogeneous, but further testing is needed to confirm this.

\subsection{Solids Buildup and Cleaning}

The tank solids buildup results are reported in the subsequent sections.

\subsubsection{SRAT/Initial SME_Pre Melter Feed}

There were no solids accumulations along the tank wall or internals with the dilute, concentrated, and formated waste simulants. This general conclusion is supported by the concentration of waste oxides from samples taken throughout the tank agreeing with the calculated oxide concentrations from chemical addition.

\subsubsection{Final SME/MFT-Melter Feed}

After the frit was added to the tank to form (melter feed simulant), accumulations of melter feed solids were observed on the heating coils, internal support structures, and test vessel walls. Photographs taken during these activities are included in Appendix K. The cause of the solids buildup was its non-Newtonian fluid properties (Bingham plastic).

\subsubsection{Melter-Feed Mixing and Flow Patterns}

With the addition of dry frit into the test vessel, the resulting melter feed simulant was observed to behave as a "Bingham plastic" or "thick pudding." The "thickness" or apparent viscosity of the simulant depended on the mixing in the test vessel. If the agitator speed was reduced, the slurry appeared to "set up" or become more "gel-like." To promote thorough mixing during test activities with the melter feed simulant, the agitator was maintained at a constant speed of $130 \mathrm{rpm}$.

Despite operating the agitator at a maximum speed, stagnant areas or areas of poor mixing were observed in several locations within the test vessel. From the large flange on the south side of the vessel (in-tank viewing system flange), areas of stagnation were observed near the tank walls and near the sample pump intake and the thermowell to the right. Occasional "burps" of slurry burst through the surface (directly below the south flange). In general, there was very little surface motion: slurry movement was slow, beginning at the outside of the vessel and moving in a clock-wise direction toward 
the center of the vessel. A very minimal drawdown at the agitator was observed. The mixing in the tank, as indicated by surface motion, improved as the slurry was diluted by flush water and prime water from pump operation.

When the level in the vessel decreased to the top of the coils during melter feeding, the slurry was observed to flow over the two outer steam coils and through the inner cooling coil. As the level in the tank continued to drop, there was little or no slurry surrounding the cooling coil or between the cooling coil and the inner steam coil. It also became apparent that there was a considerable difference in slurry level from the outside of the coils to the inside of the coils (about 6 to $12 \mathrm{in.).} \mathrm{To} \mathrm{reduce} \mathrm{the} \mathrm{rocking}$ back and forth of the coils and coil support structure, it was necessary to reduce the agitator speed from $130 \mathrm{rpm}$ to $105 \mathrm{rpm}$. As would be expected, decreasing the agitator speed reduced the level of apparent mixing.

Once the slurry level dropped below the top of the coils, slurry build-up on and around the coils prevented the melter feed simulant from flowing through the coils. Rather, the slurry movement was toward the coils from the tank wall and from the slurry surface to some point below the slurry surface (i.e., slurry was drawn down at the interface between the slurry and the coil build-up). While probing the bottom of the tank with a stainless steel pole, a surprisingly strong current was at the bottom of the tank. The current was not strong enough to pull the tube from one's hands, but did cause an obvious deflection of the tube.

As the slurry level continued to drop, material that had built up along the outside of the coils began sluffing off from the coils. Occasionally, slurry was able to flow through the coils to the agitator in the center of the coils. Eventually, the flow would dwindle until there was no movement through the coils.

With the tank volume below the top of the coils, samples were taken at different locations in the tank using the Hydragard sampler and a "tree" sampler. (The "tree" sampler, which consisted of a long pole with one or more sample bottles attached to the end of the pole, was used to collect samples just below the slurry surface). Samples were analyzed to determine weight percent oxides. A comparison of the weight percent oxides indicated that variations in the slurry concentration (i.e., concentration gradients) existed in the melter-feed simulant once the slurry level dropped below the top of the coils.

\subsubsection{Melter-Feed Solids Accumulation}

Heat-Transfer Coils. During meiter feeding it became apparent that there was 4 to 6 in. of material that had built up along the outside of the coils. While probing the tank with a long pole, it became apparent that the thickness of the material increased with tank depth. As the slurry level dropped, the material on the outside of the coils fell away into the slurry. The material between the coils, however, generally remained intact. Material on the top two steam coils and on the steam supply line to the coils dried over time. The sample pump discharge caused a build-up of material approximately 6 to 8 in. deep on top of the coils immediately below the discharge. The inside of the coils appeared to be fairly clean with little coating, lumps, and agglomerations. There appeared to be little, if any, material between the cooling coil and inner steam coil.

Analytical results of samples collected from the heat transfer coils indicated a much higher solids and oxide loading. The weight and volume percent centrifuged solids of the coil samples was generally 10 to $15 \%$ higher than that of the bulk slurry. Elemental analysis by ICP revealed the waste oxide 
loading of the material on the coils to be much higher than that of the bulk slurry. It was also noted that the boron and sodium concentrations were significantly lower in the coil buildup material.

Agitator. The agitator blades seemed to be fairly clean with a small amount of slurry coating and agglomerations. In general, the shaft was coated with a thin uniform build-up. The material appeared to be thickest where the shaft would have been exposed during boiling.

Piping and Internal Support Structures. Before boiling the melter feed simulant, a thin coating was observed on the tank walls and internal support structures above the slurry surface. Small clumps and agglomerations were visible immediately above the slurry surface. The tank walls and support structures near the sample pump were coated with slurry from the sample pump operation. After boiling, clumps and agglomerations approximately 1 in. thick were on the coil support structures just above the slurry surface. As the level in the tank was reduced during melter feeding, the build-up on the support structure was much less. The cooling water supply line, located between the steam supply line and steam condensate lines, appeared to be virnually void of material build-up (i.e, there were no lumps or agglomerations and only a slight coating of material). On the other hand, the steam supply line and steam condensate and cooling water return lines were caked with material.

Tank Bottom. Toward the end of melter feeding, the melter feed heel in the test vessel was pumped from the tank via a diaphragm pump from the tank sump. Two to $3 \mathrm{in}$. of material was on the bottom of the tank. This was believed to be material that would not flow to the sump during removal of the melter feed heel and not solids that had settled on the bottom of the vessel. It was aiso noted that areas of thicker material existed on the bottom of the tank. This material was always located beneath a support structure on the outside of the vessel and was thought to have dropped to the tank bottom with the slurry as the melter feed heel was pumped from the vessel.

\subsubsection{Conclusions and Recommendations}

The following conclusions and recommendations resulted from the test results and observations:

- Solids (slurry) buildup was noted only when testing with the melter simulant. The most substantial (thickest) buildup occurred between and outside the heating coils. Other modest buildup areas included the agitator shaft, the internal support structures, the steam supply lines, the sides of the tank (including the tank bottom), and the piping. The buildup seemed to be the greatest in the areas above the working slurry surface on the steam coils. The only area where minimal or no solids accumulation occurred was the cooling water supply line and cooling coils. This buildup of melter feed simulant appears to be due to the intrinsic properties of a Bingham plastic.

- There appeared to be no significant settled solids buildup on the tank bottom of the simulants tested.

\subsection{Instrumentation}

Level detection instrumentation experience is discussed below. 


\subsubsection{Holledge Level Detection System Failure}

On March 25, 1992, during baseline testing of the feed preparation test tank with water, the Holledge Level Detection System failed while evaluating the effects of agitation on Holledge Level Detection System performance. The test required that the vessel be filled with approximately $1000 \mathrm{gal}$ (about 15 to 16 in.) of water. The agitator was then started and set sequentially at $45 \mathrm{rpm}, 85 \mathrm{rpm}$, and finally $130 \mathrm{rpm}$. After approximately one minute at $130 \mathrm{rpm}$, excessive vibrations developed in the test tank system and an emergency shut down of the agitator was initiated. Immediately before it was shut down, the agitator moved from side to side with an increasing amplitude. Also, a highpitched sound, apparently emanating from the gear box, was heard.

\subsubsection{Initial Investigation}

The agitator and other in-tank equipment, other than the Holledge system, were not damaged.

On the DAS, there was a difference between the Holledge readings before agitation began and after agitation was terminated. These readings differed by as much as 4 in. for the bottom sensor (i.e., 14.0 in. before, 9.80 in. after).

\subsubsection{Damage Assessment}

On March 30, 1992, the DAS reading for the bottom Holledge sensor had decreased from 9.80-in. to 7.99-in. The Holledge Level Detection System was removed from the tank and a visible inspection of the sensors was performed. No visible damage was detected on any of the three sensors.

The Holledge Level Detection System was moved to the calibration tank and an incremental fill test was performed to determine the extent of the damage. Data from this test were compared to data from pre-failure calibration tests. For the bottom sensor, the post-failure pressure readings differed from pre-failure readings by as much as 35 in. (25\%). Similarly, the top sensor differed by up to 5 in. (6\%). A second calibration test was conducted 2 days later. Data obtained from the second test duplicated data from the first test, except that the discrepancy in the bottom sensor grew by 3 or 4 in.

At this point, it was clear that the Holledge Level Detection System was not functioning properly. However, identifying a specific problem with the Holledge Level Detection System was not possible because the sensors and tubing are contained within the Holledge shell. Therefore, it is nearly impossible to isolate the sensors from the tubing.

\subsubsection{Additional System Testing/Repair}

The entire unit was shipped to SRL for further testing and repair.

A leak test was performed .with the sensors still attached to the system to determine if the supply or exhaust tubing had sustained any damage. This indicated that no leaks or cracks were present in the system. 
The second leak test required that the sensors be removed from the Holledge unit. Each sensor was then tested separately with a Holledge Gauge Calibrator (see Figure 7.1), which was developed at SRL. Each separate sensor was tested to 140-in.

The test results for five different tests were compared to ascertain the extent of the damage to the Holledge Level Detection System. These tests were as follows:

- a pre-failure calibration test performed with the calibration stand

- two post-failure calibration tests performed with the calibration stand

- two post-failure pressure tests performed with Holledge Gauge Calibration system

The following sections include an evaluation of the test results for each individual Holledge sensor. Two types of plots are included for each sensor. Figures 7.2, 7.4, and 7.6 show the actual level versus the Holledge level, and Figures 7.3, 7.5, and 7.7 show the error (actual level minus Holledge level) versus Holledge level.

Sensor 1005 (Bottom Sensor). Figures 7.2 and 7.3 contain data related to sensor 1005

The pre-failure run shows a primarily linear response with minimal error between the actual level and the Holledge level. The two post-failure calibration runs and the Druck pressure runs indicate the following results:

Calibration run 1 - maximum error approximately 35 in. $(\approx 25 \%)$

Calibration run $2-$ maximum error approximately 40 in. $(\approx 29 \%)$

Druck pressure runs $1 \& 2$ - consistent error of approximately 10 in.

The error for the calibration tests increased with level, while the data for the Druck pressure tests indicated a consistent offset from the actual level. In addition to the error that is evident, there was a change in reading for the two calibration runs, and another change from the calibrations runs to the Druck pressure runs. This is not a normal scenario. In general, the pressure readings for all calibration runs and the Druck pressure runs should be consistent.

Sensor 1002 (Middle Sensor). Figures 7.4 and 7.5 contain data related to sensor 1002

The pre-failure run shows a primarily linear response with minimal error between the actual level and the Holledge level. The two post-failure calibration runs and the Druck pressure runs indicate the following results.

Calibration runs $1 \& 2-$ both runs match well with pre-failure data

Druck pressure 1 - maximum error approximately 50 in. $(\approx 40 \%)$

Druck pressure 2 - maximum error approximately 70 in. $(\approx 60 \%)$

It is unusual for the Druck pressure data to differ from the calibration runs. In addition, the two Druck pressure runs show inconsistent results.

Sensor 1003 (Top Sensor). Figures 7.6 and 7.7 contain data related to sensor 1003. 


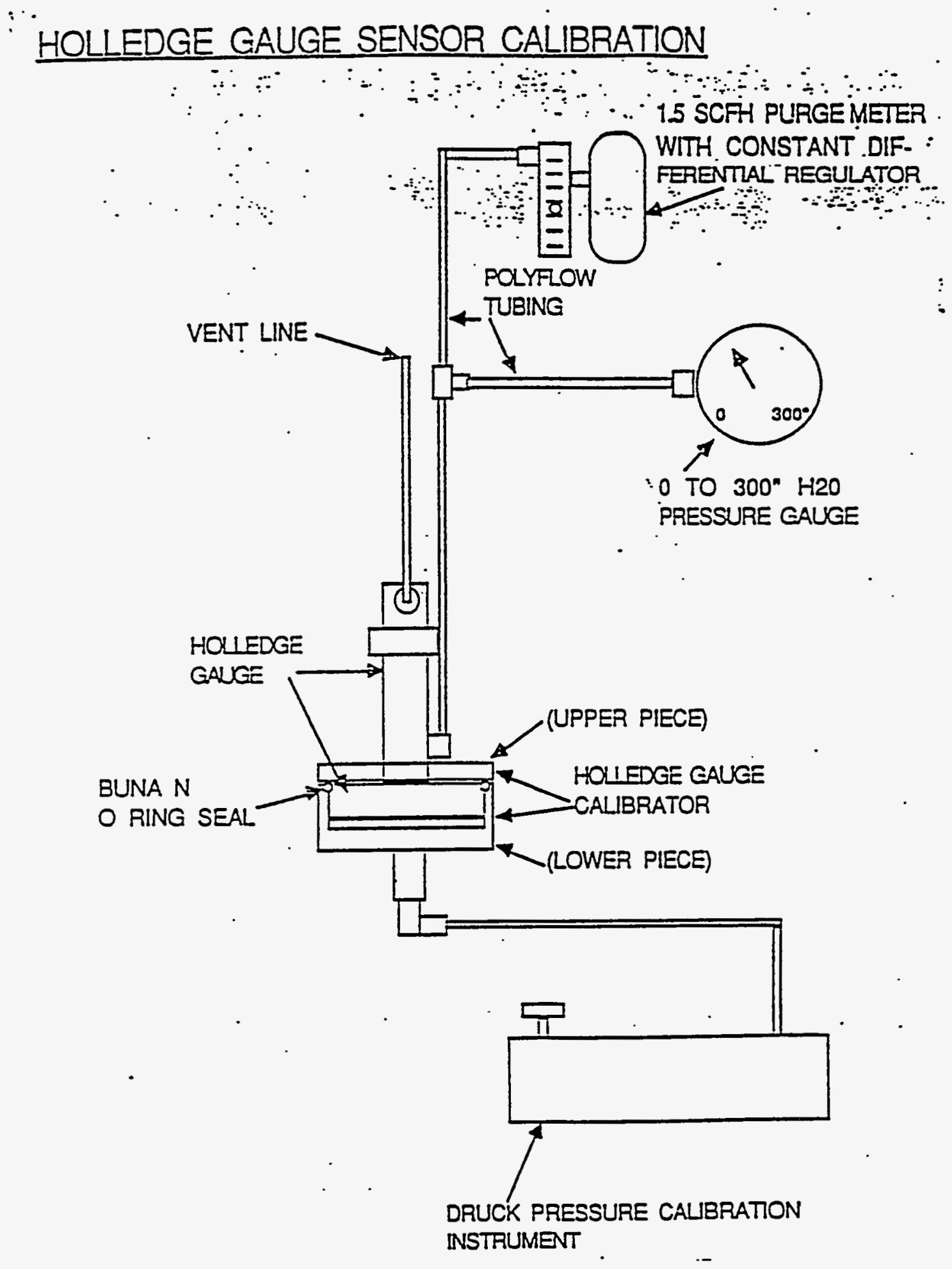

Figure 7.1. Set-Up for Holledge Sensor Calibration with Holledge Sensor Calibrator 


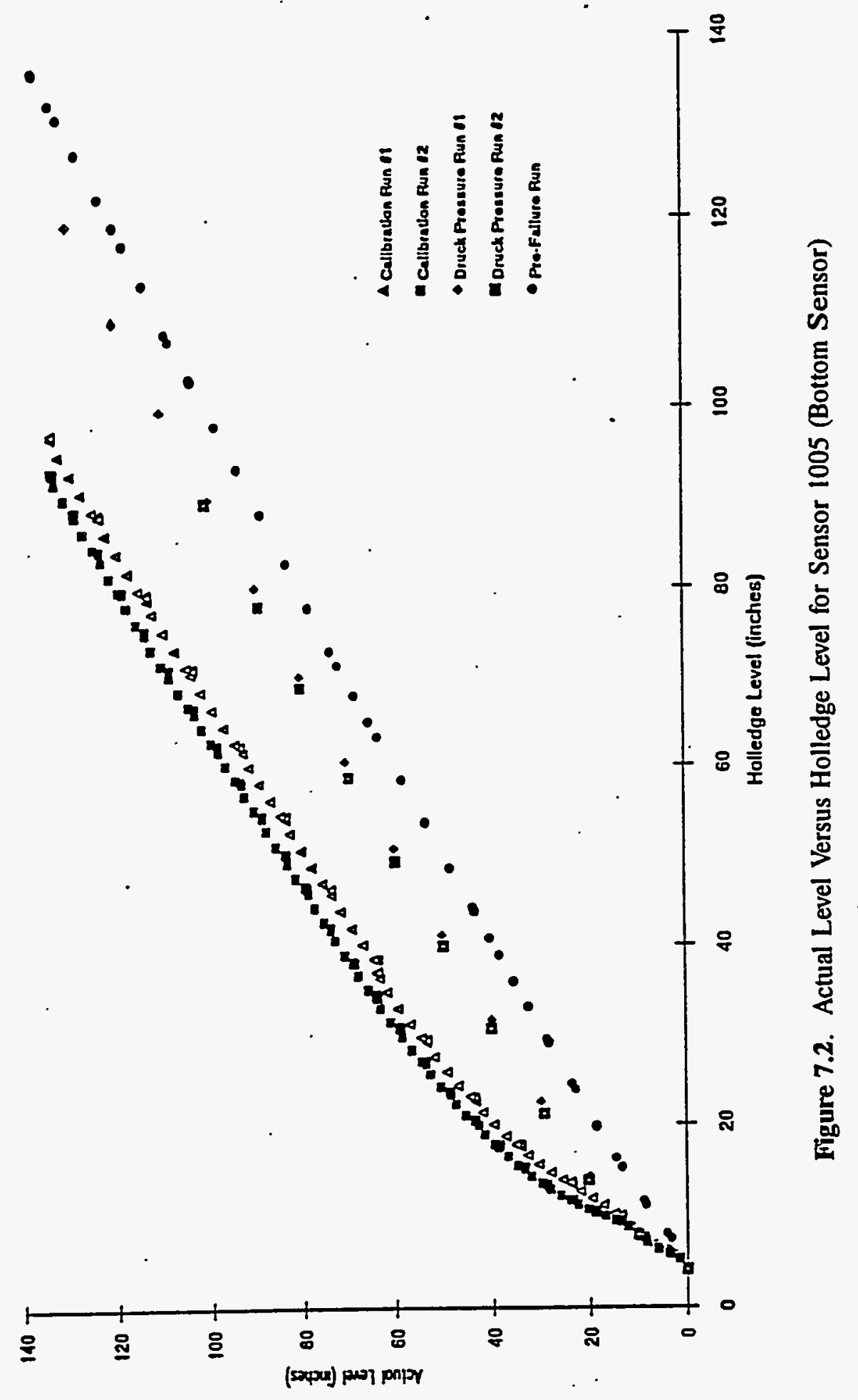




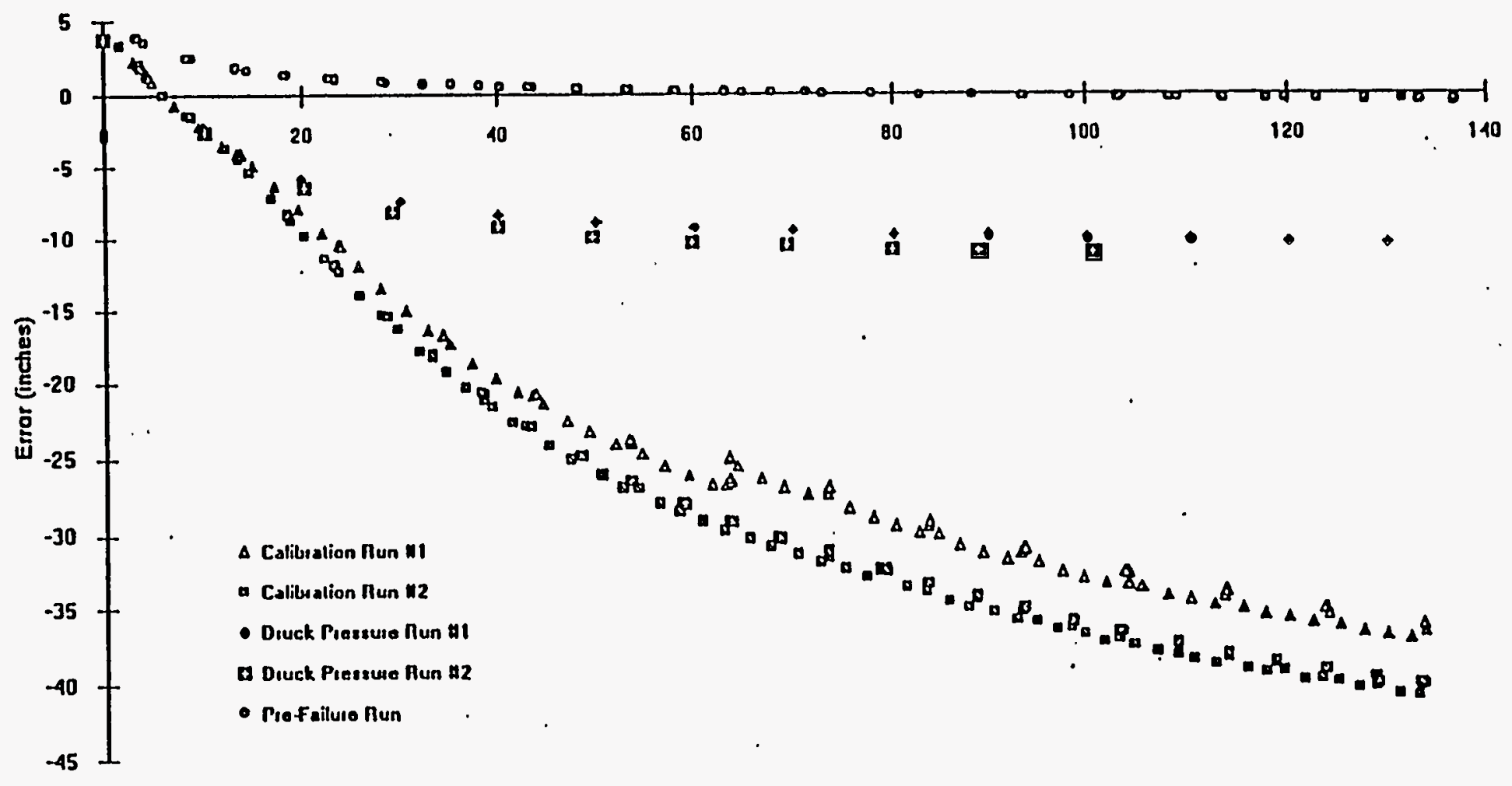

Actual Laval (inches)

Figure 7.3. Holledge Sensor Error Versus Actual Level for Sensor 1005 


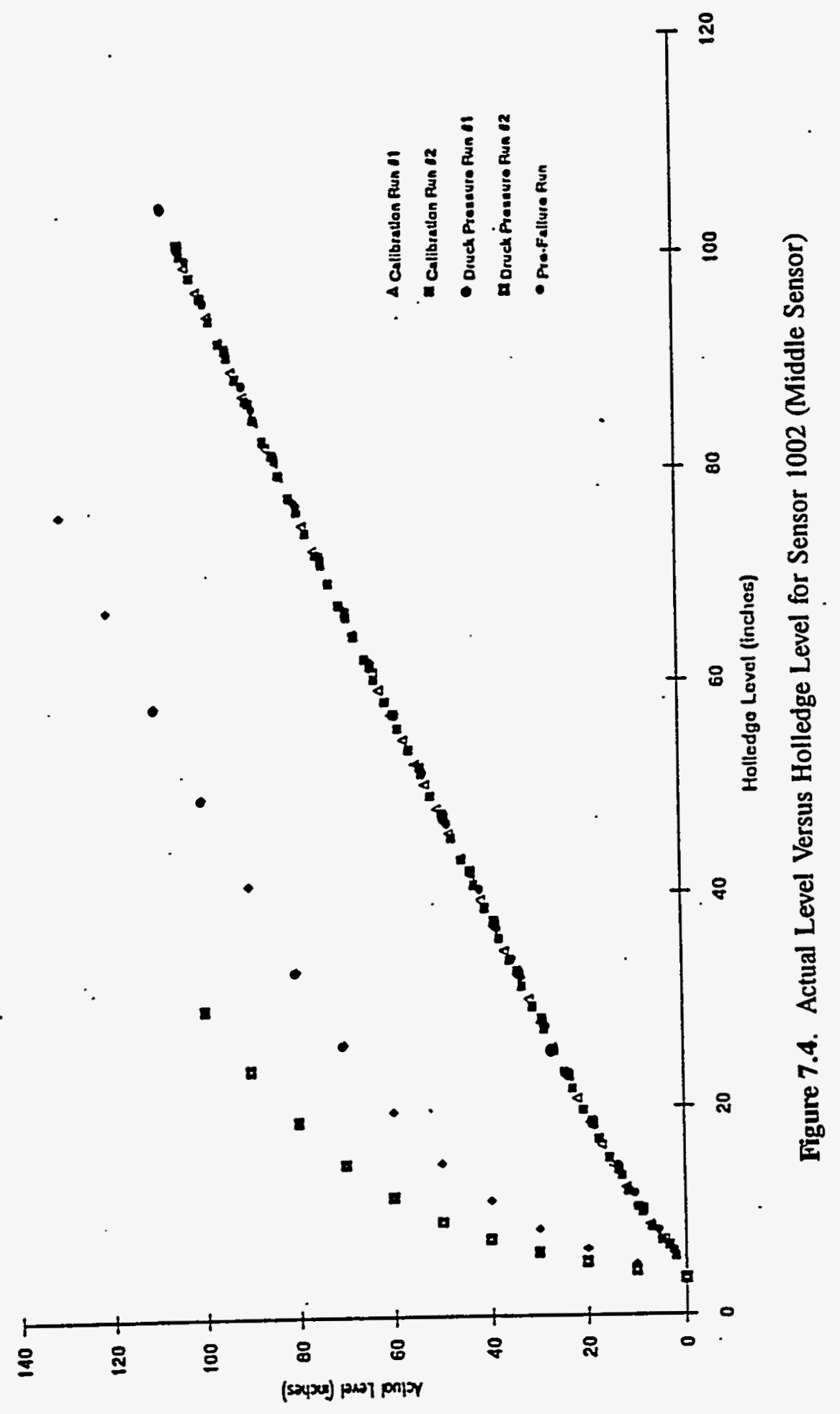




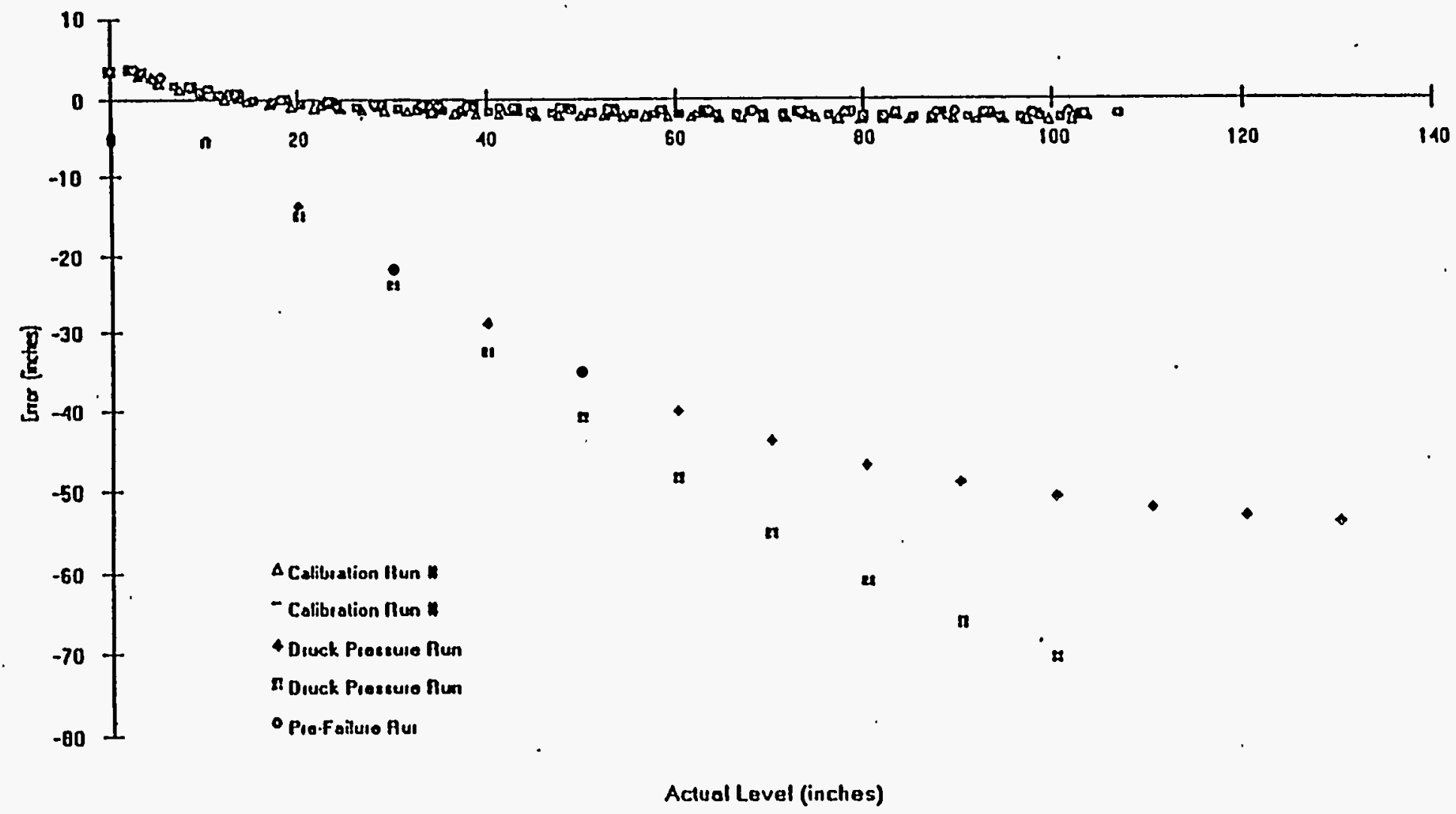

Figure 7.5. Holledge Sensor Error Versus Actual Level for Sensor 1002 


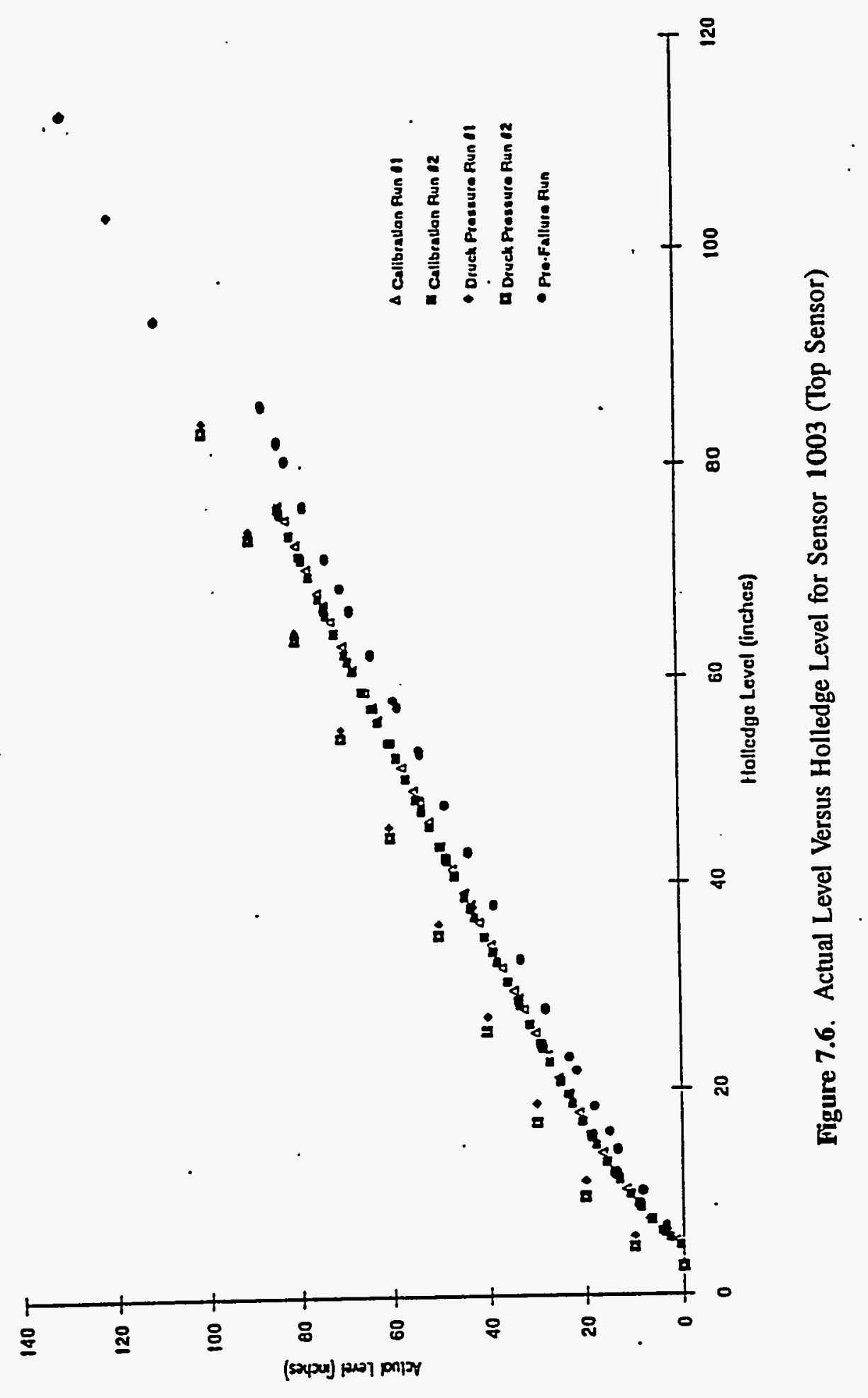




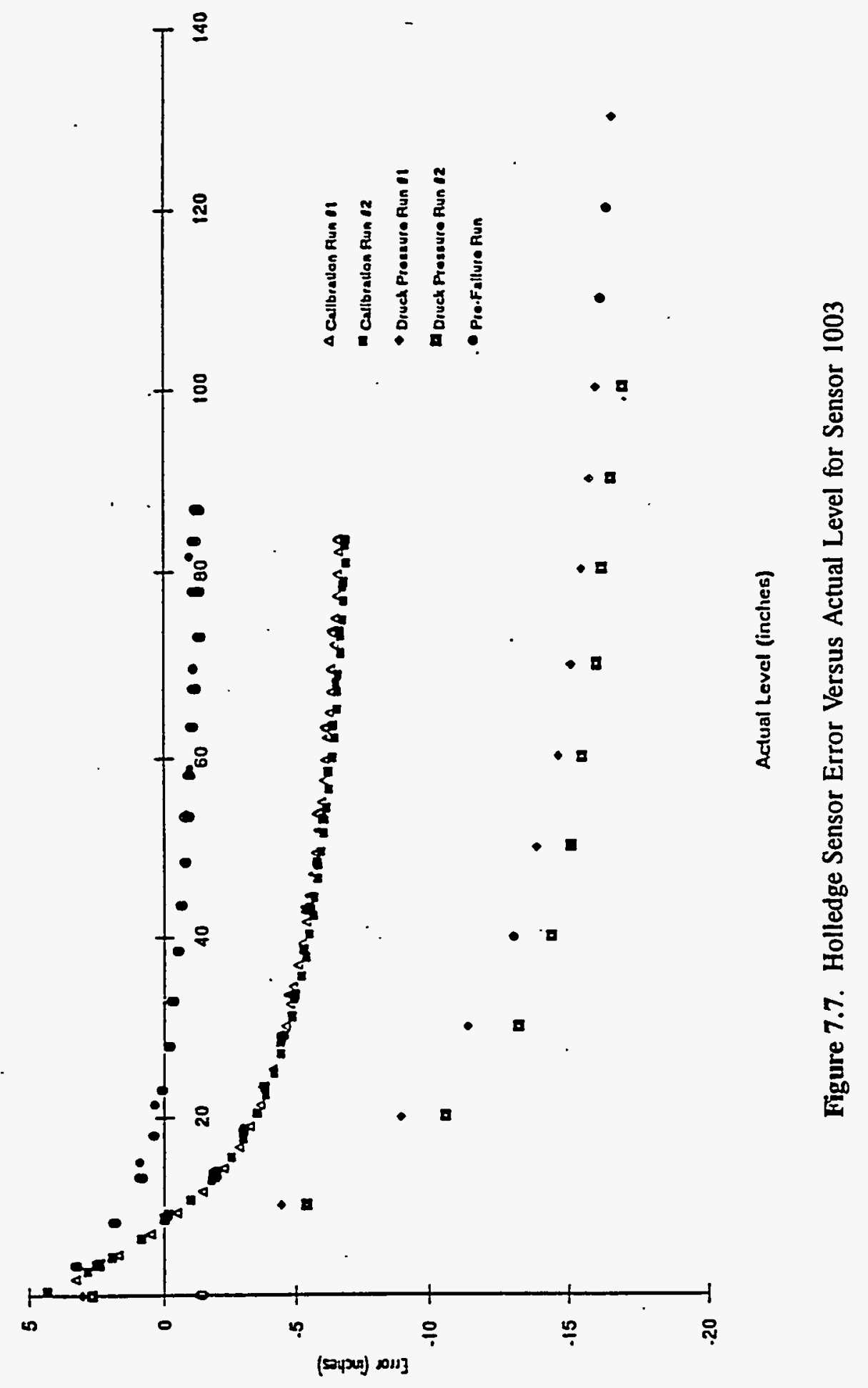


The pre-failure run shows a primarily linear response with minimal error between the actual level and the Holledge level. The two post-failure calibration runs and the Druck pressure runs indicate the following results.

Calibration runs $1 \& 2-$ consistent error approximately 7 in.

Druck pressure runs $1 \& 2-$ consistent error of approximately 15 in.

Both the calibration runs and the Druck pressure runs for this sensor indicated a consistent offset from the pre-failure calibration runs. Of the three sensors, sensor 1003 indicated the most consistent results.

\subsubsection{Conclusions and Recommendations}

Conclusions. The results for the post-failure calibration tests for each sensor indicated irreparable damage, although no physical damage to the system was observed. Sensors 1005 and 1003 showed significant error immediately following the failure. Results for sensors 1005 and 1003 indicate a disruption inside the sensor due to the agitator-induced vibration.

Sensor 1002 was not affected by the agitator-induced vibration but showed significant error upon testing after removal from the system. The Holledge sensors are sensitive, and the calibration can be affected by excessive heat (during welding), vent line plugging during air purge, excessive vacuum on the diaphragm, wear on the diaphragm face, or strain on the housing. In addition, the 0.003 -in. metal diaphragm can be punctured by a blow from another object, when the air purge supply pressure exceeds 15 psig while the exhaust line is plugged or whenever the air supply exceeds 150 psig. Additionally, during removal of the sensors from the unit, if any small particles get into the sensor assembly, the sensor will most likely be ruined. Sensor 1002 was probably damaged during removal from the Holledge Level Detection System by either overpressurization or by foreign material disrupting the internal components.

Additional conclusions based on the events that occurred and the testing that was done are as follows:

- The Holledge Level Detection System sustained damage as a result of vibrations induced by agitation during baseline testing of the Feed Preparation Test System.

- The excessive vibrations experienced during baseline testing of the agitation system coincided with low fluid level in tank HB-15 ( $<6$ in. covering bottom impeller) in conjunction with high agitator rpm. This type of vibration has not occurred under any other conditions.

- The three Holledge sensors sustained irreparable damage. Non-destructive testing indicated that the damage was most likely inside the sensors rather than associated with the outer diaphragm.

- As a result of the damage to the Holledge sensors, new sensors must be installed. No decrease in system reliability is expected.

- Because of changes in operational parameters regarding agitation at low tank levels, no future vibrational problems involving Tank HB-15 internal components were experienced. 
- No additional design changes are required. The currently installed in-tank supports are sufficient for stabilization of the Holledge Level Detection System.

Recommendations. If future agitation tests at low fluid level combined with high agitator rpm are discontinued, the current in-tank constraints being used for the Holledge Level Detection System are likely adequate. Careful monitoring and calibration procedures for the system should be adhered to in order to avoid future problems. Because of the amount of time involved in transporting the Holledge Level Detection System offsite for repair, a formal training session on test/repair procedures should be coordinated between PNL and SRL personnel so that future testing/repairs can be performed onsite.

- Do not operate the agitator at a speed greater than $85 \mathrm{rpm}$ with less than 12 in. of water covering the bottom impeller. All related test plans, test procedures, run plans, etc., should be modified to reflect this change.

- Obtain and install new sensors. Because of the lead time involved in obtaining sensors, order backup sensors for future use.

- Continue to calibrate the Holledge Level Detection System regularly. At a minimum, calibration should be performed following any significant testing activity.

\subsubsection{Operating Experience with the Diptube Level Detection Bubblers}

After failure of the Holledge Level Detection System, a diptube set was designed and installed into Tank HB-15 on July 31, 1992, to provide level and pressure readings for the tank. The diptube system was used for all slurry testing performed with the SIPT system. The diptube system is described in Section 5.0 and Appendix A.

\subsubsection{Operations}

Slurry was first introduced into Tank HB-15 on December 28, 1992, with concentration tests being conducted through January 1993. The diptube appeared to partially plug on January 28, 1993, but no corrective action was required because the tubes cleared themselves. There were no further problems with the diptubes until after adding frit to the slurry to form melter feed. The longest tube plugged on April 22, 1993. Several attempts at air blowing the diptube failed. It was cleared with a steel cable rammed through the tube. Then, on May 5, 1993, all the tubes in the slurry plugged and had to be filled with water to soak for several hours before they could be cleared with the cable.

Tank HB-15 was drained on August 18, 1993, in preparation for the removal of the agitator and coils for installation of the tank baffles. This left the diptubes hanging in air until January 10, 1994, when water was added to the tank for recycle waste collection tank (RWCT) testing. The diptubes again plugged on February 22, 1994, possibly facilitated by residue left inside of them during the baffle installation being softened by RWCT simulant. The diptubes were found plugged on May 31, 1994, and all attempts to clear them have been unsuccessful. 


\subsubsection{Conclusion}

The diptubes performed well for level measurement in applications where the liquids do not have a high solids content. The simulant slurries that were tested in the SIPT system, however, ranged up to $45 \mathrm{wt} \%$ total solids (melter feed). Although the diptubes did not require constant attention with melter feed, the tubes plugged at regular intervals with solids material and required some type of cleaning action. 


\subsection{Condenser (SRAT/SME) Performance}

\subsection{Effect of Non-Condensable Gas on Heat Transfer}

Condenser heat-transfer performance, including the effects of non-condensable gases is discussed below.

\subsubsection{Approach}

Non-condensable gas will be present in the process vapor of the HWVP Feed Preparation System. Air can leak into the process tank through seals and gaskets or be deliberately added to the system via the air sweep for hydrogen concentration control. Other non-condensable gases will be generated from formic acid reactions and from radiolysis of water. Table 8.1 summarizes the limiting operating cases for non-condensable flow during hydrogen mitigation. ${ }^{(a)}$

There is a concern that non-condensable gas may accumulate in the top portion of the condenser and reduce the effective heat-transfer area, or that the outlet separator section of the condenser is too small to disengage the condensate from the non-condensable gases. ${ }^{\text {(b) }}$ The result could be significant overhead condensate entrainment in condenser off-gas.

Table 8.1. Hanford Waste Vitrification Plant Condenser Process Design Conditions

\begin{tabular}{|c|c|c|}
\hline & $\begin{array}{c}\text { SRAT Boiling, } \\
\text { Case } 2\end{array}$ & $\begin{array}{c}\text { SRAT Refluxing, } \\
\text { Case } 4\end{array}$ \\
\hline Inlet Temperature, ${ }^{\circ} \mathrm{F}$ & 214 & 214 \\
\hline Outlet Temperature, ${ }^{\circ} \mathrm{F}$ & 125 & 125 \\
\hline Inlet Pressure, psia & 14.08 & 14.08 \\
\hline Outlet Pressure, psia & 13.54 & 13.54 \\
\hline Cooling Duty, $10^{6} \mathrm{Btu} / \mathrm{h}$ & 5.1264 & 0.9016 \\
\hline Inlet Density, $\mathrm{lb} / \mathrm{ft}^{3}$ & 0.0404 & 0.0516 \\
\hline $\mathrm{H}_{2}, \mathrm{lb} / \mathrm{h}$ & 1.8 & 6.0 \\
\hline$N_{2}, \mathrm{lb} / \mathrm{h}$ & 2010 & 6024.8 \\
\hline $\mathrm{O}_{2}, \mathrm{lb} / \mathrm{h}$ & 606.2 & 1816.9 \\
\hline $\mathrm{H}_{2} \mathrm{O}, \mathrm{lb} / \mathrm{h}$ & 5000 & 1500 \\
\hline $\mathrm{CO}_{2}, \mathrm{Ib} / \mathrm{h}$ & 0 & 313.6 \\
\hline $\mathrm{NO}, \mathrm{lb} / \mathrm{h}$ & 0 & 49.7 \\
\hline Total Mass, lb/h & 7618 & 9711 \\
\hline
\end{tabular}

(a) Sharp, S. D. September 11, 1992. "Overhead Entrainment.from Boiling Tank Condensers." Interoffice Correspondence from Fluor Daniel to B. G. Johnson.

(b) Sharp, S. D. December 4, 1992. "Proposed Re-design of Boiling Tank Condensers." Interoffice Correspondence from Fluor Daniel to B. G. Johnson. 
The DWPF condenser, which provided the baseline design for the HWVP condenser, was designed to operate with only minimal amounts of air and other non-condensables in the inlet steam. To perform adequately during hydrogen mitigation, another condenser design was being evaluated. The major improvements to the design will include additional heat transfer area and possibly a longer separator section and demister. ${ }^{(a)}$ Testing of the HWVP SIPT condenser at the same tube inlet velocities as the proposed new condenser design dictated lower condenser feed rates, as shown in Table 8.2.

To determine the effect of non-condensable gas on condenser performance, PNL completed a series of condenser tests with variable amounts of water vapor and air flow rates ranging from normal inleakage to approximately 500 SCFM. Condenser cooling-water flow, pressure, and temperature; condensate flow and temperature; off-gas flow and temperature; condenser pressure and temperature; and process evaporation rate were measured at each off-gas flow to quantify condenser performance. Tests have been conducted at conditions simulating Case 2, but current system capacity restricts air flow to less than 500 SCFM. Data at Case 4 conditions could only be obtained by extrapolating data from lower air flow rates.

The condenser heat-transfer tests were performed with a new condenser that had not been exposed to vapors from boiling slurries. It is expected that boiling with slurries will increase the degree of condenser fouling and decrease the heat-transfer coefficient to some lower value.

A series of five tests with water were conducted to characterize condenser performance under a variety of process conditions. Tests were conducted to determine the condensate flow rate and condenser heat-transfer coefficients as a function of off-gas flow rate and process evaporation rate.

Table 8.3 summarizes the testing.

Table 8.2. Hanford Waste Vitrification Plant Condenser Process Design Conditions

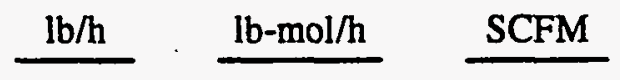

Case 2:

$\begin{array}{lrcr}\mathrm{H}_{2} \mathrm{O} & 4353.5 & 241.64 & 1528.4 \\ \text { Air } & 2279.5 & 79.76 & 504.5 \\ \text { Total } & 6632.9 & 321.4 & 2031.9\end{array}$

Case 4:

$\begin{array}{lllr}\mathrm{H}_{2} \mathrm{O} & 1306 & 72.49 & 458.5 \\ \text { Air } & 7149.2 & 246.9 & 1561.9 \\ \text { Total } & 8455 & 319.44 & 2020.4\end{array}$

(a) Sharp, S. D. December 4, 1992. "Proposed Re-design of Boiling Tank Condensers." Interoffice Correspondence from Fluor Daniel to B. G. Johnson. 
Table 8.3. Summary of Condenser Performance Tests

\begin{tabular}{|c|c|c|c|c|}
\hline Test & Date & $\begin{array}{c}\text { Off-Gas } \\
\text { Flow, SCFM }\end{array}$ & $\begin{array}{l}\text { Level, } \\
\text { Gallons }\end{array}$ & $\begin{array}{c}\text { Evaporation } \\
\text { Rate, gpm }\end{array}$ \\
\hline TST053 & $11 / 19 / 92$ & Nominal & 8100 & $2.6-13.4$ \\
\hline TST038 & $11 / 19 / 92$ & 110 & 7800 & $2.6-13.6$ \\
\hline TST052 & $12 / 22 / 92$ & $190-250$ & 8300 & $2.7-11.0$ \\
\hline TST051 & $12 / 21 / 92$ & $280-350$ & 8200 & $2.8-10.9$ \\
\hline TST050 & $12 / 18 / 92$ & $330-480$ & 8500 & $3.0-10.8$ \\
\hline
\end{tabular}

During all tests, the condensate generated during boiling was recycled from the condenser back into the evaporation vessel, and the condenser cooling-water flow was held constant at $350 \mathrm{gpm}$. The off-gas flow was held constant, to the extent possible, throughout each test; however, the capacity of the blower limited the off-gas flows at higher air flow/evaporation rate combinations. The test vessel configuration required to achieve the indicated air flows is provided below.

- Nominal: Since Tank HB-15 operates at a vacuum, a certain amount of air leaks into the tank through seals, gaskets, etc. The nominal configuration allowed 30 to 65 SCFM of air into the tank.

- 110 to 350 SCFM: Air was metered into the test vessel through an air line at the top of the test vessel. A valve in this line was controlled to achieve approximately the required off-gas flow.

- Flows greater than 350 SCFM: To achieve high air flows, the valve used to control the air flow through the test vessel air line was opened fully. It was also necessary to partially open a flange on top of the tank and to operate the tank at a lower vacuum pressure $(<2$ in. of water vacuum versus 5 in. used in normal operation).

Modifications to the steam system that supplies steam to the evaporator coils allowed much higher steam flows and a higher evaporation rate ( $>13 \mathrm{gpm}$ ) than was previously possible. To determine the effect of air flow at high evaporation rates, it was desirable to conduct the testing at the maximum evaporation rate possible. The following procedure was used for these tests:

1. Process water in the test vessel was heated to boiling at the maximum steam flow rate while maintaining an agitator speed of $85 \mathrm{rpm}$.

2. The process water was boiled at several steam flow rates, ranging from $7150 \mathrm{lb} / \mathrm{h}$ to $1500 \mathrm{lb} / \mathrm{h}$, while maintaining a constant volume of water in the test vessel by recycling condensate back into the tank. A constant agitator speed of 85 rpm was maintained during boiling.

3. At each steam fiow rate, the process was allowed to stabilize for about $30 \mathrm{~min}$ before continuing to the next set point.

4. The condenser cooling-water flow rate was kept constant at $350 \mathrm{gpm}$. 
Problems occurred during the maximum evaporation segment of Tests TST053 and TST038. The high evaporation rate ( $>13 \mathrm{gpm}$ ) caused an increase in the liquid level in the condenser, due to the increase in condenser tube-side pressure drop with overhead steam flow. Normally, the condensate generated in the condenser must overcome this pressure drop to be recycled back into the evaporator. During these tests, however, the pressure drop was too high to permit adequate reflux flow, and the condensate overflowed into the off-gas line.

To prevent condensate from overflowing to the off-gas line, tests were conducted to determine the effect of air flow on condenser performance at a lower maximum evaporation rate (approximately $11 \mathrm{gpm}$ ) and to determine the evaporation rate that will cause incipient condenser overflow. The actual procedure used for air-flow testing was identical to the procedure described above, except that the maximum steam flow was limited to $6000 \mathrm{lb} / \mathrm{h}$. Tests TST050, TST051, and TST052 were conducted with this procedure. After the completion of the air-flow tests, the evaporation rate to cause incipient condenser overflow, because of high pressure drop, was determined.

\subsubsection{Calculations}

This section summarizes the calculations used to determine the condenser heat-transfer coefficient, the evaporation rate of process vapor into the condenser, the amount of liquid and water vapor entrainment in the condenser off-gas, and the condenser energy balance. Sample calculations are provided in Appendix L.

\subsubsection{Predicted Heat-Transfer Coefficient}

The following resistances to heat transfer between the tube side process and the shell side cooling water must be evaluated to determine the condenser overall heat-transfer coefficient $U$ :

Tube side heat-transfer coefficient $h_{o i}$, based on outside tube area

Tube side fouling factor $f_{i}$

Resistance through the tube wall $\mathbf{R}$

Shell side fouling factor $f_{0}$

Shell side heat-transfer coefficient $h_{0}$

The tube side heat-transfer coefficient was calculated with a semi-empirical condensate curve for the condensation of a vapor inside a vertical tube. This calculation neglects the effect of noncondensables in the process vapor. A significant decrease in the condensation heat-transfer coefficient can result from the presence of non-condensables (Rohsenow 1973) because the condensing vapor must now diffuse through a layer of non-condensable gas to get to the cold tube wall. Offsetting this effect is the increase in overall flow rate (and Reynold's number) that results from the increase in noncondensable gas flow. In general, however, the presence of non-condensable gas will tend to reduce $\mathrm{h}_{\mathrm{oi}}$, as shown by the testing results.

The fouling factors $f_{i}$ and $f_{o}$ account for the inevitable deposition of dirt and scale on the inside and outside of the tube wall. In general, fouling factors depend on the nature of the liquid medium and the length of time the tubes have been in service. The liquid medium in this case was process drinking water, and the test condenser has been in service for only a short time. However, even for this relatively favorable situation (when compared to processing slurry), the fouling factors suggested 
by current references are quite significant. The determination of fouling factors increases the uncertainty in calculating the overall heat-transfer coefficient.

The resistance, $R$, through the pipe wall depends only on the conductivity of the pipe, $K_{\text {tube }}$, and the inside and outside diameter of the pipe, $D_{i}$ and $D_{0}$ (see Kern 1950, p. 86):

$$
R \quad \frac{2.3 \mathrm{D}_{\mathrm{o}}}{2 \mathrm{~K}_{\text {tube }}} \log \left(\frac{\mathrm{D}_{\mathrm{o}}}{\mathrm{D}_{\mathrm{i}}}\right)
$$

The shell side heat-transfer coefficient was found with a shell-side heat transfer curve for fluid flowing through the shell-side of a condenser with $25 \%$ cut segmental baffles (see Kern 1950, p. 838). The shell-side heat-transfer coefficient depends on the cross flow area inside the condenser. The standard equation for calculating the cross flow area does not include the effect of the riser and assumes a maximum number of tubes for the specified shell diameter. The cross flow area equation was modified to account for the center riser and the free space outside the tube bundle (see Appendix L).

Once these quantities were calculated, $U$ was determined according to the following equation (see Kern 1950, p. 86):

$$
\frac{1}{U} \quad \frac{1}{h_{i o}} \quad \frac{1}{h_{0}} \quad \frac{2.3 D_{0}}{2 K_{\text {tube }}} \log \left(\frac{D_{0}}{D_{i}}\right) \quad f_{i} \quad f_{0}
$$

All of these quantities are based on the outside surface area of the condenser tubes.

\subsubsection{Data Treatment}

Test data was first converted from the instrumentation data format into a Microsoft Excel spreadsheet for display and manipulation on a personal computer. Separate evaporator and condenser performance spreadsheets (see Appendix M) were used to extract average process information from the raw data spreadsheets and perform heat transfer, pressure drop, and energy balance calculations. Each spreadsheet was divided into segments of constant evaporation rate, where process variables were essentially constant. Conversions and formulas used to prepare summary process spreadsheets and spreadsheet verification calculations are presented in Appendix L.

Since the condenser cooling-water flow was held constant during the tests, condenser process variables were dependant only on the evaporation rate and the air flow rate through the condenser. To maximize the use of the data, it was desirable to plot process variables with lines of constant air flow or constant evaporation rate. However, small variations between the target air flow rates and the actual flow rates prevented the presentation of the raw data in terms of curves of constant evaporation rate and air flow. To convert the data to a consistent set of conditions, the following data reduction method was used: 
First, a set of constant air flows $(50,100,200,300,400$, and 500 SCFM) and evaporation rates $(2.5,5.5,8$, and $10 \mathrm{gpm})$ was chosen. To calculate process variables at these standard conditions, the method of least squares was used to determine a plane that best fit the data in the vicinity of the desired air flow/evaporation rate combination. The relationship between evaporation rate or air flow and the process variables was usually non-linear, so the use of all the data as a basis of interpolation was not indicated. Rather, four data points surrounding the desired data point (in the case of interpolation). or closest to the desired data point (in the case of extrapolation) were used as input to the least squares method. Calculation CALC-SIPT-010 is provided in Appendix $L$ to document the raw data points that were used as a basis for interpolation and extrapolation and the resulting data at the desired set of standard conditions.

\subsubsection{Experimental Heat-Transfer Coefficient}

The experimental condenser heat-transfer coefficient was determined from Fourier's Law (see Kern 1950, p. 86):

$$
\text { Q U A } \Delta \mathrm{T}_{\mathbf{W}}
$$

where $Q^{\circ}=$ Total heat transferred

$\mathrm{U}=$ Overall condenser heat-transfer coefficient

$A=$ Tube outside heat transfer area

$\Delta \mathrm{T}_{\mathrm{w}}=$ Weighted temperature difference between cooling water and the process

The total heat transferred, $Q$, is the sum of the energy required to condense the process vapor plus the energy required to subcool the condensate. The tube outside the surface area was $450.6 \mathrm{ft}^{2}$. To calculate the weighted temperature difference, $\Delta T_{w}$, it was first necessary to calculate separately the log mean temperature difference between the cooling water and the process for both the condensing phase and the subcooling phase. These temperature differences were then weighted by the amount of energy transferred in each phase to determine the overall, weighted temperature difference. Because the condenser is a one-pass tube and shell (1-1) counter flow heat exchanger, no further correction factor is needed. This method is illustrated in the calculations in Appendix L (see also Kern 1950, p. 291).

\subsubsection{Determining the Evaporation Rate and Water Entrainment in Condenser Off-gas}

During all tests, the condensate generated during boiling was recycled from the condenser back into the evaporation vessel. Therefore, in the absence of entrainment of process liquid and vapor in condenser off-gas, the level of process liquid in the evaporator vessel decreases slowly due to water loss as air humidity. If process liquid or vapor is entrained in off-gas, the level of liquid in the tank gradually decreases in a linear fashion at an increased rate. Two bubbler gauges were used to measure the liquid level inside the evaporator vessel to determine the evaporation rate and the water content in condenser off-gas. 
To determine the average amount of entrainment over a particular boiling segment, the slopes of the bubbler gauge plots were determined with linear regression. The reported level change in the tank was determined by averaging the slope of the two bubbler lines and converting this to an equivalent volume change. If the calculated volume change was slightly negative (which indicates an increase in process liquid), the measurement was attributed to instrument fluctuations and discarded.

The evaporation rate of process vapors entering the condenser was found by adding the condensate flow rate to the volume change of process liquid in the tank. Conversely, the amount of water entrained in the condenser off-gas was equal to the volume change of process liquid in the evaporator tank.

Water will always be present in the off-gas of the condenser in the form of water vapor (humidity). The mass ratio of process water vapor in the condenser off-gas was determined with a psychometric chart for an air/water vapor mixture. It was assumed that the water vapor was in a saturated state (100\% humidity) at the measured off-gas temperature. Knowing the total off-gas flow, the flow of process water vapor in the off-gas could be calculated. The amount of entrapped liquid droplets was assumed to be the total process volume in the off-gas minus the amount of water vapor predicted with the psychometric chart.

\subsubsection{Condenser Energy Balance}

With the condenser as a control volume, an energy balance was conducted during each boiling segment. For this condenser energy balance, the energy required to condense and subcool the condensate was equated to the latent energy increase of the condenser cooling water. The energy balance was used to verify the accuracy of instrumentation for tests at low air flows and no liquid entrainment. During tests when significant amounts of process liquid was lost in the condenser off-gas, the condenser energy balance was used to establish if the process vapor passed through the condenser without condensing, or if the process vapor was condensed, and whether entrainment occurred in the condenser separator section. In the case of liquid entrainment, the condenser energy balance will not close, since the condensate flow rate was used as a basis for the calculation.

\subsubsection{Test Results}

Condenser heat transfer testing results are provided below.

\subsubsection{Process Variables, Graphs, and Calculated Data}

Evaporator and condenser performance spreadsheets (see Appendix $M$ ) provide heat transfer, pressure drop, and energy balance results based on actual test conditions. Each spreadsheet is divided into segments of constant evaporation rate, when process variables were essentially constant. Important variables (water content of off-gas, condensate flow, condenser heat-transfer coefficient, condensate temperature, and off-gas temperature) from these process data tables have been condensed into data analyses summary tables, which are available in Appendix $N$. Each variable is provided versus evaporation rate (at a constant off-gas flow) and versus off-gas flow (at a constant evaporation rate). Standard air flows (50, 100, 200, 300, 400, and 500 SCFM) and standard evaporation rates $(2.5,5.5,8$, and $10 \mathrm{gpm}$ ) were utilized to provide maximum use of the data. The method used to perform this interpolation of test conditions to a standard set of conditions is described in Section 8.1.2.2 of this 
document and also CALC-SIPT-010 (provided in Appendix L). The segments of Tests TST053 and TST038 at maximum boil-up were not included in the interpolation scheme, since the entrainment that occurred during these tests was due to the high boil-up rate, not air flow. Extrapolation was required to obtain estimates of process variables at an air flow of 500 SCFM (higher than the maximum air flow used in testing).

Graphs of condenser process variables versus evaporation rate and off-gas flow are available in Appendix 0.

\subsubsection{Process Condensate Flow}

Graphs of condensate flow versus evaporation rate and off-gas flow are available in Figures $\mathrm{O}-1$ and $0-6$, respectively. Increasing the air flow from nominal to 500 SCFM reduces the condensate flow rate. This was more apparent at higher evaporation rates ( $>5 \mathrm{gpm})$.

\subsubsection{Condensate and Off-gas Temperature}

Graphs of condensate temperature versus evaporation rate and off-gas flow are available in Figures $0-2$ and $0-7$, respectively. The condenser was able to subcool the condensate below $125^{\circ} \mathrm{F}$ (the target value) for all evaporation and off-gas flows rates. No effort was made to control the condensate temperature; rather, a constant $350 \mathrm{gpm}$ cooling-water flow rate was used, which provided more than adequate cooling. The graphs indicate that subcooling the condensate was never a significant challenge for the condenser and that there is no consistent relationship between condensate temperature and offgas flow for every evaporation rate. At the $2.5 \mathrm{gpm}$ evaporation rate, the condensate temperature decreased with off-gas flow, while at higher evaporation rates, the condensate temperature was not consistently affected by air flow. However, since testing occurred over several weeks, changing ambient conditions may be responsible for part of the data scatter. These trends may change if the non-condensable gas is hot, as would be the case with reaction gases created during formatting.

At 50, 100; and 200 SCFM off-gas fiow rates, the condensate temperature was higher at $2.5 \mathrm{gpm}$ boil-up than at $5.5 \mathrm{gpm}$ (see Figure 0-2). One possible explanation for this is that at lower evaporation rates, only a small amount of condensate is present in the condenser separator section. Due to the proximity of the condenser to the evaporator, the condensate may be heated as it passes through the separator section.

Graphs of off-gas temperature versus evaporation rate and off-gas flow are available in Figures O-3 and $0-8$, respectively. Increasing the evaporation rate (at a constant off-gas flow) increased the off-gas temperature, while increasing the off-gas fiow (at a constant evaporation rate) decreased the off-gas temperature.

It is often assumed that the off-gas and condensate temperature exit a condenser at the same temperature. Test results indicate this can be an invalid assumption, depending on operating conditions (off-gas flow, cooling-water flow, evaporation rate, etc.). Figure 0-11 provides a plot of the off-gas temperature minus the condensate temperature versus off-gas flow. At a $2.5 \mathrm{gpm}$ evaporation rate, the off-gas temperature is approximately $5^{\circ} \mathrm{F}$ cooler than the condensate temperature. At higher evaporation rates, the off-gas temperature was significantly hotter than the condensate temperature. 
For example, at $10 \mathrm{gpm}$ evaporations rate, the off-gas temperature was $35^{\circ} \mathrm{F}$ hotter than the condensate temperature. In summary, the plot indicates two trends: 1) Increasing the evaporation rate increases the $\Delta T$ between the off-gas and the condensate, and 2) increasing the off-gas flow decreases the $\Delta T$.

The explanation for this phenomenon is as follows. In the headspace of the test vessel, the air is mixed with process steam. This will no doubt increase the temperature of the air from ambient to some higher temperature. The air/steam mixture enters the condenser where the steam is condensed and subcooled. The layer of condensate on the tube wall provides an insulating layer between the cool tube wall and the air. Therefore, the off-gas should be hotter than the condensate, and it generally is. It is also possible that the air flows through the condenser at a faster rate than the condensate, which would allow less time for cooling the air. Only at $2.5 \mathrm{gpm}$ is the off-gas temperature lower than the condensate temperature. Here, it is believed that so much air is entering the test vessel (when compared to $2.5 \mathrm{gpm}$ ) that the temperature of the air is not greatly affected. At the extreme, if an infinite amount of air entered the test vessel, the off-gas would exit the condenser at ambient temperature.

\subsubsection{Condenser Heat-Transfer Coefficient}

Graphs of condenser heat-transfer coefficient versus evaporation rate and off-gas flow are available in Figures 8.1 and 8.2, respectively. The condenser heat-transfer coefficient decreased significantly with increasing off-gas flow. This decrease in condenser heat-transfer coefficient $(\Delta U)$, from the baseline values established at nominal off-gas flow, is provided in Figure 8.3. In general, $\Delta U$, due to the presence of air, increases (in absolute value) with air flow.

With actual test data, heat-transfer coefficients were calculated by applying the method described in Section 8.1.2. The calculations were performed at two evaporation rate/condenser cooling-water flow combinations: medium evaporation rate $(5.9 \mathrm{gpm})$ and condenser cooling-water flow (150 gpm), and high evaporation rate $(10.2 \mathrm{gpm})$ and condenser cooling water flow $(200 \mathrm{gpm})$. The calculated heattransfer coefficients were $132 \mathrm{Btu} / \mathrm{h} \mathrm{ft}{ }^{\circ} \mathrm{F}$ at $10.2 \mathrm{gpm}$ and $129 \mathrm{Btu} / \mathrm{h} \mathrm{ft}{ }^{\circ} \mathrm{F}$ at $5.9 \mathrm{gpm}$, which are essentially the same. This is because that reducing the evaporation rate in the laminar region will increase the tube-side heat-transfer coefficient (see Kern 1950, p. 270, Figure 12.12), but reducing the condenser cooling water flow will reduce the shell-side coefficient (see Kern 1950, p. 838, Figure 28). These values neglect the presence of non-condensable air. The tests described herein used a higher condenser cooling-water flow (350 gpm). It has been determined experimentally that the condenser cooling-water flow has little effect on the condenser heat-transfer coefficient at these cooling-water flow rates. ${ }^{(a)}$

Fluor Daniel calculated $170 \mathrm{Btu} / \mathrm{h} \mathrm{ft}{ }^{2}{ }^{\circ} \mathrm{F}$ for the overall condenser heat-transfer coefficient at $10 \mathrm{gpm}$ evaporation rate. ${ }^{\text {(b) }}$ However, for design purposes, Fluor Daniel used a lower value of $127 \mathrm{Btu} / \mathrm{h} \mathrm{ft}{ }^{\circ} \mathrm{F}$ to account for the expected decrease in heat-transfer coefficient with time, due to fouling.

(a) Hatchell, B. K., and J. R. Gaskill. 1992. "Detailed Design Data Package Item 1.2c." PHTD-91-03.03C-K900 (1.2c), Rev. 0, Effect of Non-Condensables on Condenser Performance.

(b) Fluor Daniel Preliminary Calculations for Hanford Waste Vitrification Plant, Calculation 3210MF-0013, page 58. 


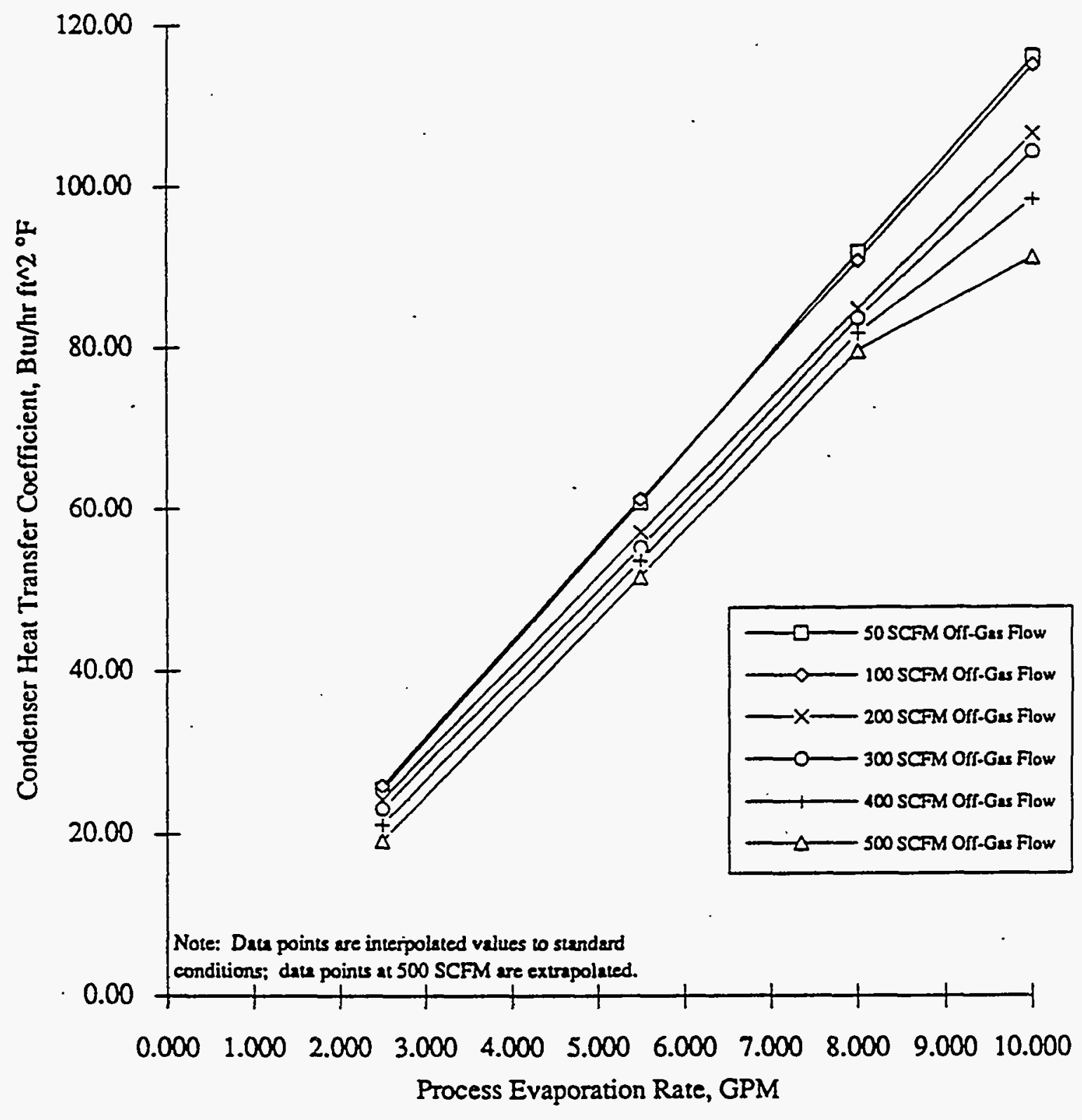

Figure 8.1. Condenser Heat-Transfer Coefficient Versus Process Evaporation Rate 


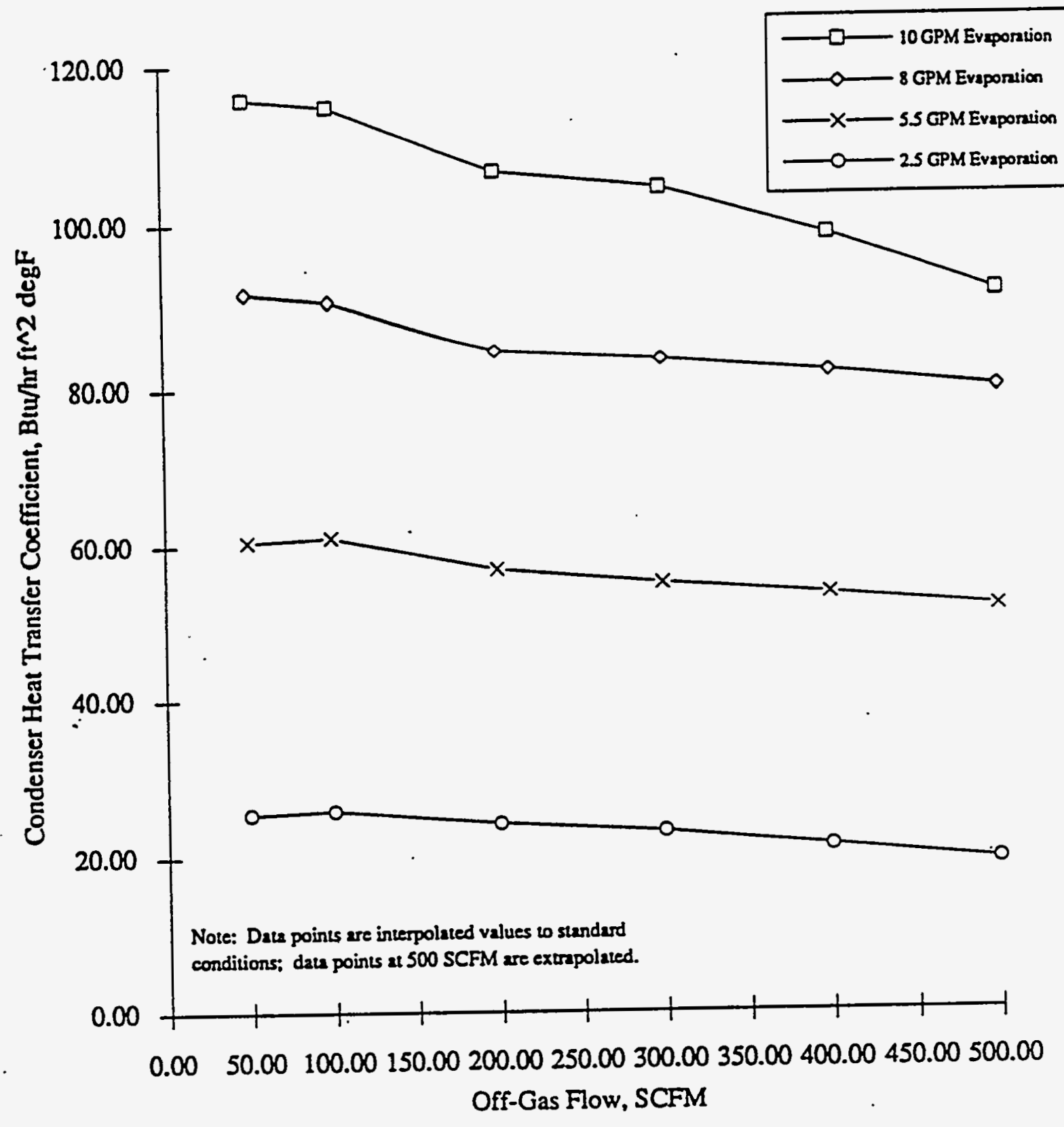

Figure 8.2. Condenser Heat-Transfer Coefficient Versus Off-Gas Flow 


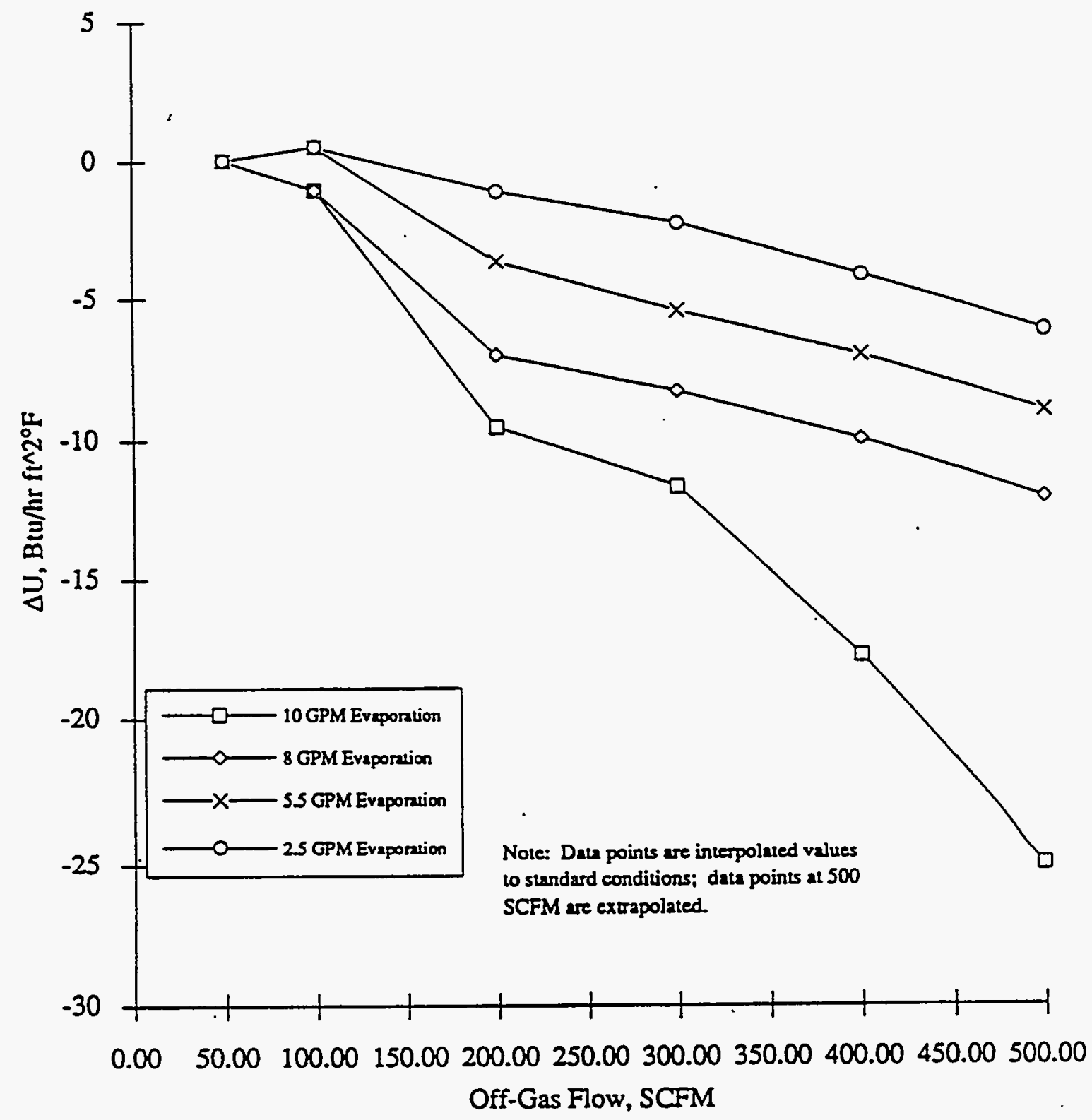

Figure 8.3. Decrease in Condenser Heat-Transfer Coefficient Versus Off-Gas Flow 
Fluor Daniel's calculation differed from the calculation used here primarily in the determination of fouling factors and the tube-side heat-transfer coefficient. The Fluor Daniel calculation used 0.001 for both tube-side and shell-side fouling factors $\left(f_{i}\right.$ and $f_{0}$ ), while a fouling factor of 0.002 was used for both sides in the present calculations. A fouling factor of 0.002 is typical for city water at temperatures greater than $125^{\circ} \mathrm{F}$ (Welty et al. 1976), which is applicable for the tube-side condensing process vapor. The condenser shell-side cooling water enters at approximately $85^{\circ} \mathrm{F}$, but leaves at a temperature slightly higher than $125^{\circ} \mathrm{F}$ at higher evaporation rates. It was feit that the use of the higher fouling factor $(0.002)$ for the shell-side was prudent, even though it is only applicable for a portion of the condenser. For the tube-side heat-transfer coefficient $\left(\mathrm{h}_{\mathrm{oj}}\right)$, Fluor Daniel used a correlation for condensation on the outside of the tube, while the present calculation used a correlation for condensation inside the tube. However, the method used to determine $h_{0 i}$ had little impact on the overall condenser heattransfer coefficient.

The calculated value of $132 \mathrm{Btu} / \mathrm{h} \mathrm{ft}^{2}{ }^{\circ} \mathrm{F}$ (which neglected the effect of air) at $10.2 \mathrm{gpm}$ evaporation rate is in reasonable agreement with the value of $116 \mathrm{Btu} / \mathrm{h} \mathrm{ft}{ }^{2}{ }^{\circ} \mathrm{F}$ determined at $10 \mathrm{gpm}$ evaporation rate and nominal off-gas flow (see Table $N-1$ of Appendix $N$ ). These values are somewhat higher than the value of $91 \mathrm{Btu} / \mathrm{h} \mathrm{ft}^{2}{ }^{\circ} \mathrm{F}$ predicted at 500 SCFM off-gas flow (see Table N-6 of Appendix N). The presence of air in the process vapor therefore decreases the condenser heat-transfer coefficient. These heat-transfer coefficients are expected to decrease in the HWVP due to fouling with slurry solids.

Also, the measured heat-transfer coefficient dropped rapidly with evaporation rate, while the correlations predicted a fairly constant heat-transfer coefficient. This is probably an artifact of the calculation. The condenser was designed to condense $10 \mathrm{gpm}$, so at lower evaporation rates, the condenser has excess surface area. The experimental condenser heat-transfer coefficient was determined from Fourier's Law $\left[\mathrm{U}=\mathrm{Q} /\left(\mathrm{A} \Delta \mathrm{T}_{\mathrm{w}}\right)\right.$ ]. At lower evaporation rates, the total heat transferred to the cooling water, $Q$, is lower, while the heat transfer area remains constant. In addition, the weighted temperature difference between the cooling water and the process $\left(\Delta T_{w}\right)$ is fairly constant, since the temperature of the incoming condenser cooling water is held nearly constant by the cooling tower. This situation results in a lower effective heat-transfer coefficient at lower evaporation rates.

\subsubsection{Process Water Lost in the Condenser Off-Gas}

The total mass of process water (vapor and entrapped water droplets) in the off-gas was determined experimentally by subtracting the condensate flow from the evaporation rate. This measured process water in the off-gas, expressed in terms of equivalent condensed liquid, is plotted versus evaporation rate and off-gas flow in Figures $0-4$ and $0-9$, respectively. Clearly, the amount of entrapped liquid in the off-gas increases with off-gas flow. The 50 and 100 SCFM water-loss curves cross at about 6 gpm boil-up rate (see Figure $0-4$ ). This is apparently due to experimental error at these low entrainment levels $(<0.1 \mathrm{gpm})$.

\subsubsection{Condenser Tube-Side Pressure Drop}

Graphs of condenser tube-side pressure drop versus evaporation rate and off-gas flow are available in Figures 0-5 and 0-10, respectively. The tube-side pressure drop increases with process vapor flow rate and off-gas flow rate, as expected. At $10 \mathrm{gpm}$ and 500 SCFM, the tube-side pressure drop was 0.365 psi (10.1 in. WC). 
Segments of Tests TST053 and TST038 were conducted at very high steam flow rates, which resulted in evaporation rates greater than $13 \mathrm{gpm}$. The high evaporation rate caused an increase in the liquid level in the condenser, due to the increase in condenser tube-side pressure drop with process vapor flow. Normally, the condensate generated in the condenser must overcome this pressure drop to be recycled back into the evaporator. During these tests, however, the pressure drop was too high to permit adequate reflux flow, and the condensate overflowed into the off-gas line. The maximum evaporation rate during Test TST053 was $13.4 \mathrm{gpm}$ at nominal off-gas flow, which resulted in a condenser tube-side pressure drop of $0.305 \mathrm{psi}$ (8.4-in. WC) and $4.2 \mathrm{gpm}$ of condensate water flow into condenser off-gas. The maximum evaporation rate during Test TST038 was $13.6 \mathrm{gpm}$ at 60 SCFM off-gas flow, which resulted in a condenser tube-side pressure drop of $0.381 \mathrm{psi}(10.6 \mathrm{in}$. WC) and $7.1 \mathrm{gpm}$ of condensate water flow into condenser off-gas.

The instrument used to measure condenser pressure was submerged during these overflow conditions, so the actual tube-side pressure drop was greater than the measured values. Examination of the condensate reflux line (see Figure A-1 in Appendix A) reveals that a pressure drop of at least 16 in. WC is required to raise the level of the condensate (in the separator section) above the off-gas line. The pressure drop during the high boil-up segments was therefore greater than 16 in. WC. The maximum allowable process side pressure drop for the HWVP condenser is 15 in.

At the conciusion of the testing described herein, a sight glass was installed on the outside of the condenser to monitor the level of condensate inside the condenser separator section. It was found that during subsequent slurry testing, the liquid level increased dramatically with boil-up rate; at $6000 \mathrm{lb} / \mathrm{h}$ coil steam flow, the condensate level in the condenser separator section was approximately 6.5 in., while at $5300 \mathrm{lb} / \mathrm{h}$, the condensate level was approximately $4 \mathrm{in}$. The column of water above condensate reflux seal is 7.5 in. greater than the condensate level in the separator section. Because the pressure drop in the condensate reflux line should be negligible, the condensate level inside the condenser (plus 7.5 in.) should be comparable to the measured condenser tube-side pressure drop. The tube-side pressure drop was $7.5 \mathrm{in}$. WC at $6000 \mathrm{lb} / \mathrm{h}$ steam flow and $5.5 \mathrm{in}$. of water at $5300 \mathrm{lb} / \mathrm{h}$. These results indicate that the measured tube-side pressure drop was at least 6 -in. WC less than the tube-side pressure drop determined by the condenser sight glass.

\subsubsection{Condenser Energy Balance Considerations}

Condenser energy balance calculations are provided in Appendix $M$ during all boiling phases. The condenser energy balance was closed to within $3 \%$ of the total heat transferred during the tests at nominal air in-leakage (TST053) and 100 SCFM (TST038), except during periods of maximum evaporation, where the condensate overfilled the condenser separator section (see Section 8.1.3.6). This supports the accuracy of instrumentation used to measure the condenser cooling water and the process water vapor. At higher air flows, the condenser energy balance did not close, and the percent difference between heat in (based on temperature rise of the condenser cooling water) and heat out (based on the condensate flow rate and temperature) increased with air flow. Table 8.4 summarizes condenser energy balance closure at low and high evaporation rates and high air flows, plus the percent difference between the condensate and evaporation flow rate. 
Table 8.4. Condenser Energy Balance Summary at High Air Flows

\begin{tabular}{ccccc}
$\begin{array}{c}\text { Evaporation } \\
\text { Rate, gpm }\end{array}$ & $\begin{array}{c}\text { Air Flow, } \\
\text { SCFM }\end{array}$ & & $\begin{array}{c}\text { \% Difference } \\
\text { Heat-in versus } \\
\text { Heat-out }\end{array}$ & $\begin{array}{c}\text { \% Difference } \\
\text { Condensate Flow } \\
\text { versus } \\
\text { Evaporation Rate }\end{array}$ \\
\cline { 5 - 5 } 2.7 & 250 & & 5 & 6 \\
11.0 & 220 & & 7 & 10 \\
2.8 & 330 & & 13 & 18 \\
10.8 & 280 & 14 & 16 \\
3.0 & 480 & 16 & 29 \\
10.8 & 330 & 27 & 27
\end{tabular}

Table 8.4 indicates that if the evaporation rate was used as a basis instead of the condensate flow rate, the energy balance would close much more closely. The condenser energy balance therefore provides evidence that nearly. all the process water vapor entering the condenser is condensed, regardless of air-flow, and that liquid entrainment in the condenser-separator section is the cause of the majority of the process water lost in the condenser off-gas.

\subsubsection{Condenser Performance During Case 2 and Case 4 Conditions}

Test conditions were extrapolated to predict the performance of the condenser during anticipated hydrogen mitigation operating conditions. Table 8.5 summarizes predicted condenser performance during SRAT boiling (Case 2) and SRAT refluxing (Case 4). The method used to extrapolate test data for these conditions is documented in Appendix L. Briefly, four actual data points closest to Cases 2 and 4 data points were used as a basis for extrapolation.

Condenser performance was determined experimentally for process water vapor flow of approximately $9.5 \mathrm{gpm}$ and variable air flows, ranging from 30 to 423 SCFM air, so only minor extrapolation was.necessary to predict Case 2 condenser performance. However, since the maximum air flow achieved in testing was 481 SCFM during test TST050 at a $3.0 \mathrm{gpm}$ boil-up rate, significant errors may occur in extrapolating to Case 4 conditions, where the air flow rate will be 1500 SCFM.

If the current condenser operated under Case 2 conditions, testing to date would indicate that $1.1 \mathrm{gpm}$ of water would be entrained, and the condenser heat-transfer coefficient would be reduced to $88 \mathrm{Btu} / \mathrm{h} \mathrm{ft}{ }^{2} \mathrm{~F}$; under Case 4 conditions, nearly all process water would be lost in condenser off-gas, and the condenser heat-transfer coefficient would be essentially zero. Also, the tube-side pressure drop for Cases 2 and 4 was also determined by extrapolation to be 0.296 psia $(8.2$ in. WC) and 0.222 psi (6.2 in. WC), respectively. Because of the non-linear dependance of pressure drop on flow rate, the pressure drop predicted for Case 4 is probably nonconservative. 
Table 8.5. Predicted Condenser Performance During Case 2 and Case 4 Hydrogen Mitigation Conditions

\begin{tabular}{|c|c|c|c|c|c|}
\hline Case & $\begin{array}{l}\text { Process Water } \\
\text { Vapor Flow, gpm }\end{array}$ & $\begin{array}{c}\text { Air Flow } \\
\text { Rate, SCFM }\end{array}$ & $\begin{array}{l}\text { Total Water } \\
\text { Lost in Off- } \\
\text { Gas, gpm }\end{array}$ & $\begin{array}{l}\text { Condensate } \\
\text { Flow, gpm }\end{array}$ & $\begin{array}{l}\text { Condenser U, } \\
\mathrm{Btu} / \mathrm{h} \mathrm{ft}{ }^{2}{ }^{\circ} \mathrm{F}\end{array}$ \\
\hline $\begin{array}{l}2 \\
4\end{array}$ & $\begin{array}{l}8.79 \\
2.64\end{array}$ & $\begin{array}{r}504 \\
1560\end{array}$ & $\begin{array}{l}1.05 \\
2.51\end{array}$ & $\begin{array}{l}7.74 \\
0.13\end{array}$ & $\begin{array}{r}88 \\
0\end{array}$ \\
\hline
\end{tabular}

The off-gas temperature test data was extrapolated to estimate the off-gas temperature during Cases 2 and 4 operating conditions to determine the water content in the off-gas that could be attributed to humidity. Table 8.6 provides the predicted off-gas temperature, water losses attributed to vapor saturation, water loss due to liquid entrainment, and total water loss.

The off-gas temperature predicted for Case 4 is essentially ambient for the tests. Of course, the actual ambient temperature inside the plant will be higher (above $100^{\circ} \mathrm{F}$ ). If the off-gas temperature for Case 4 was the same as Case 2, the process vapor saturation loss would be $1.15 \mathrm{gpm}$.

\subsubsection{Summary}

Condenser performance was determined as a function of evaporation rate, from approximately 2.5 to $13.5 \mathrm{gpm}$, and air flow rate, from nominal air in-leakage (approximately 30 SCFM) to 480 SCFM. The presence of non-condensable gas in the process vapor reduced the condensate flow rate, increased the liquid entrainment in condenser off-gas, and reduce the condenser heat-transfer coefficient. The detrimental effect of non-condensable gas was more pronounced at higher evaporation rates. Test conditions close to Case 2 condenser hydrogen mitigation conditions were achieved, and condenser performance was predicted with minor extrapolation. During Case 2, the estimated total condensate loss was $1.05 \mathrm{gpm}$. Predicting Case 4 performance required significant extrapolation of test data, but the results indicate that $2.51 \mathrm{gpm}$, or $95 \%$, of the condensate will be lost in the off-gas.

Table 8.6. Predicted Process Water Lost During Case 2 and Case 4 Hydrogen Mitigation Conditions

\begin{tabular}{|c|c|c|c|c|}
\hline Case & $\begin{array}{c}\text { Off-Gas } \\
\text { Temperature, } \\
{ }^{\circ} \mathrm{F}\end{array}$ & $\begin{array}{c}\text { Process Vapor } \\
\text { Saturation Loss, } \\
\text { gpm } \\
\end{array}$ & $\begin{array}{l}\text { Process Liquid } \\
\text { Entrainment, } \\
\text { gpm }\end{array}$ & $\begin{array}{l}\text { Total Water Lost } \\
\text { in Off-Gas, gpm }\end{array}$ \\
\hline 2 & 122 & 0.37 & 0.68 & 1.05 \\
\hline 4 & 73 & 0.26 & 2.25 & 2.51 \\
\hline
\end{tabular}


The condenser energy balance provides evidence that nearly all the process water vapor entering the condenser is condensed, regardless of air flow, and that liquid entrainment in the condenser separator section is the cause of the majority of the process water lost in the condenser off-gas. Condenser tube-side pressure drop versus evaporation rate and air flow provided in this document must be considered in the condenser design, since any condenser modification must be achieved without increasing the tube-side pressure drop beyond acceptable limits.

\subsection{Condenser Shell-Side Pressure Drop}

Condenser shell-side pressure drop testing is discussed below.

\subsubsection{Test Strategy}

The strategy for the test is discussed in the Slurry-Integrated Performance Testing FY 1991 Test Plan. (a) During the initial test, water was supplied to the condenser through the 4-in. supply line at a flow rate of $350 \mathrm{gpm}$. The upstream transmitter measured a pressure of approximately $7 \mathrm{psi}$, while the downstream instrument measured no pressure. To enable pressure measurements to be made more accurately, a back pressure was created in the discharge line by installing a special fiange with a 2-in.diameter hole approximately $20 \mathrm{ft}$ downstream of the condenser.

\subsubsection{Calculated Pressure Drop}

A Preliminary shell-side pressure drop calculation performed by Fluor ${ }^{(b)}$ demonstrated a pressure drop of approximately 40 psi for a condenser cooling water flow rate of $350 \mathrm{gpm}$. Examination of the Fluor calculation revealed that several of the design parameters used in the Fluor calculation were different than those of the SIPT condenser. With the SIPT condenser design parameters and by modifying the cross flow area term used in the calculation to more accurately refiect the SIPT condenser configuration, a pressure drop of approximately 4 psi was calculated for a condenser cooling-water flow rate of $350 \mathrm{gpm}$ (see Appendix P).

\subsubsection{Test Results}

Table 8.7 lists the measured pressure drop through the SIPT condenser as a function of flow rate. Line losses were calculated (see Appendix Q) and subtracted from the measured pressure drops to obtain the flange-to-fiange pressure drops. It is important to note that the flow meter used in the

(a) Ketner, G. L. October 1991. Test Plan for Slurry-Integrated Performance Testing and Feed Preparation System Materials Testing. HWVP-91-1.2.2.03.03B, PNL HWVP Technology Development Program, Richland, Washington.

(b) Feldon, M. July 1990. Equipment Sizing Calculations for the Hanford Waste Vitrification Plant, Feed Prep Systems 12, 20, 22. Calculation No. 3210-MF-0022. Prepared for the U.S. Department of Energy Office by Fluor Daniel, Inc., Irvine, California. 
shell-side pressure drop test is calibrated only to $400 \mathrm{gpm}$ and, therefore, measurements provided for rates above $400 \mathrm{gpm}$ are reported here for informational purposes only. Figure 8.4 graphs the shellside pressure drop versus flow rate for the SIPT condenser.

Table 8.8 lists condenser shell-side pressure drop measurements observed during heating, boiling, and cooling testing. Figure 8.5 plots these measurements with those taken during the condenser shellside pressure drop testing. Calculated values determined with the method identified in Appendix $\mathrm{P}$ are also plotted in Figure 8.5.

\subsection{Slurry Carryover During Boiling}

Slurry carryover during boiling is discussed below.

\subsubsection{Testing Approach}

Evaporator and Condenser testing was performed for five HWVP feed preparation slurries (dilute waste, concentrated waste, formate waste, formate waste with recycle, and melter feed) in addition to water. For each composition, tests were performed at two different levels in Feed Preparation Test System (FPTS) Tank HB-15: the nominal operating volume (7800 gal) and 9 in. from the top of the heating coils ( $5700 \mathrm{gal})$. Heat transfer rates and condensate flow rates were also examined as a function of nominal steam flow rate $(6000,5200,4200 \mathrm{lb} / \mathrm{h})$, agitation rate $(45,85,130 \mathrm{rpm})$, and nominal off-gas flow rate (30-80 SCFM). Pressure drop through the tube-side of the condenser, condensate flow rate and temperature, and condenser exit temperature and flow rate were measured as a function of the boiling rate at the nominal air inleakage/off-gas rate. The condenser cooling-water flow was held constant at $350 \mathrm{gpm}$ for all of these segments.

The following tank conditions were recorded: the HB-15 condenser vacuum, HB-15 temperature, heating-coil steam flow rate, HB-15 agitator speed, and HB-15 tank weight. The vacuum in HB-15 was usually set between 5 and 15 in. of water throughout testing.

To calculate decontamination factors, compositions for both the tank contents and condensate were measured. In addition, samples from the condensate line were taken intermittently during testing to monitor solids carryover. Condensate line samples were analyzed for wt\% solids by drying the samples at $105^{\circ} \mathrm{C}$. The off-gas from the HB-15 condenser was isokinetically sampled and any aerosols were collected on a filter for analysis. 
Table 8.7. Shell-Side Pressure Drop Information for SIPT Condenser

\begin{tabular}{|c|c|c|c|c|c|c|c|c|}
\hline & $\begin{array}{c}\text { Flow Rate } \\
\text { (gpm) } \\
\text { Fl-1102 }\end{array}$ & $\begin{array}{c}\text { Supply } \\
\text { Pressure } \\
\text { (psi) } \\
\text { PI-1101 }\end{array}$ & $\begin{array}{c}\text { Discharge } \\
\text { Pressure } \\
\text { (psi) } \\
\text { PI-1102 }\end{array}$ & $\begin{array}{c}\text { Measured } \\
\text { Pressure } \\
\text { Drop } \\
\text { (psi) }\end{array}$ & $\begin{array}{c}\text { Line Loss } \\
\text { (psi) }\end{array}$ & $\begin{array}{c}\text { Flange-to-Flange } \\
\text { Pressure Drop } \\
\text { (psi) } \\
\end{array}$ & $\begin{array}{c}\text { Supply } \\
\text { Temperature } \\
\left({ }^{\circ} \mathrm{C}\right) \\
\text { TI-1104 } \\
\end{array}$ & $\begin{array}{c}\text { Discharge } \\
\text { Temperature } \\
\left({ }^{\circ} \mathrm{C}\right) \\
\text { TI-1102 } \\
\end{array}$ \\
\hline$\infty$ & 245.43 & 2.7 & 0.39 & 2.31 & 0.36 & 1.95 & 10.09 & 10.16 \\
\hline 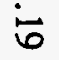 & 263.01 & 4.76 & 2.05 & 2.71 & 0.41 & 2.30 & 10.05 & 10.16 \\
\hline & 295.04 & 8.32 & 4.98 & 3.34 & 0.51 & 2.83 & 10.05 & 10.16 \\
\hline & 322.71 & 12.11 & 8.09 & 4.02 & 0.61 & 3.41 & 10.07 & 10.16 \\
\hline & 347.17 & 15.59 & 11.02 & 4.57 & 0.71 & 3.86 & 10.07 & 10.18 \\
\hline & 373.36 & 19.86 & 14.52 & 5.34 & 0.82 & 4.52 & 10.14 & 10.23 \\
\hline & 396.17 & 23.57 & 17.54 & 6.03 & 0.92 & 5.11 & 10.15 & 10.24 \\
\hline & 427.49 & 29.73 & 22.71 & 7.02 & 1.07 & 5.95 & 10.14 & 10.25 \\
\hline & 449.77 & 34.12 & 26.3 & 7.82 & $1.18^{\circ}$ & 6.64 & 10.14 & 10.23 \\
\hline & 465.65 & 37.62 & 29.29 & 8.33 & 1.27 & 7.06 & 10.15 & 10.28 \\
\hline
\end{tabular}




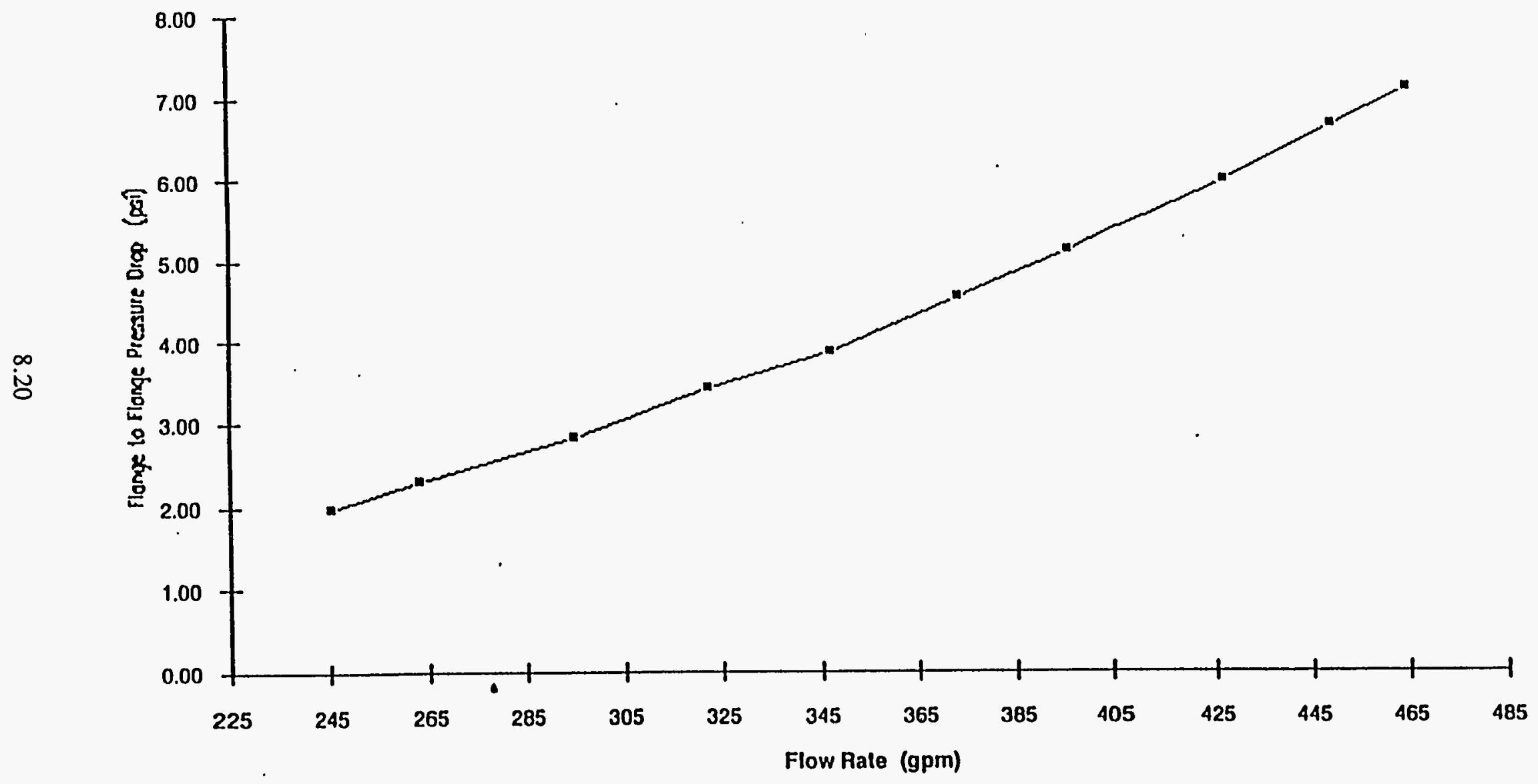

Figure 8.4. Shell-Side Pressure Drop Versus Flow Rate for SIPT Condenser (Flange-to-Flange Pressure Drop) 
Table 8.8. Shell-Side Pressure Drop Information for SIPT Condenser (Heating, Boiling, and Cooling Tests)

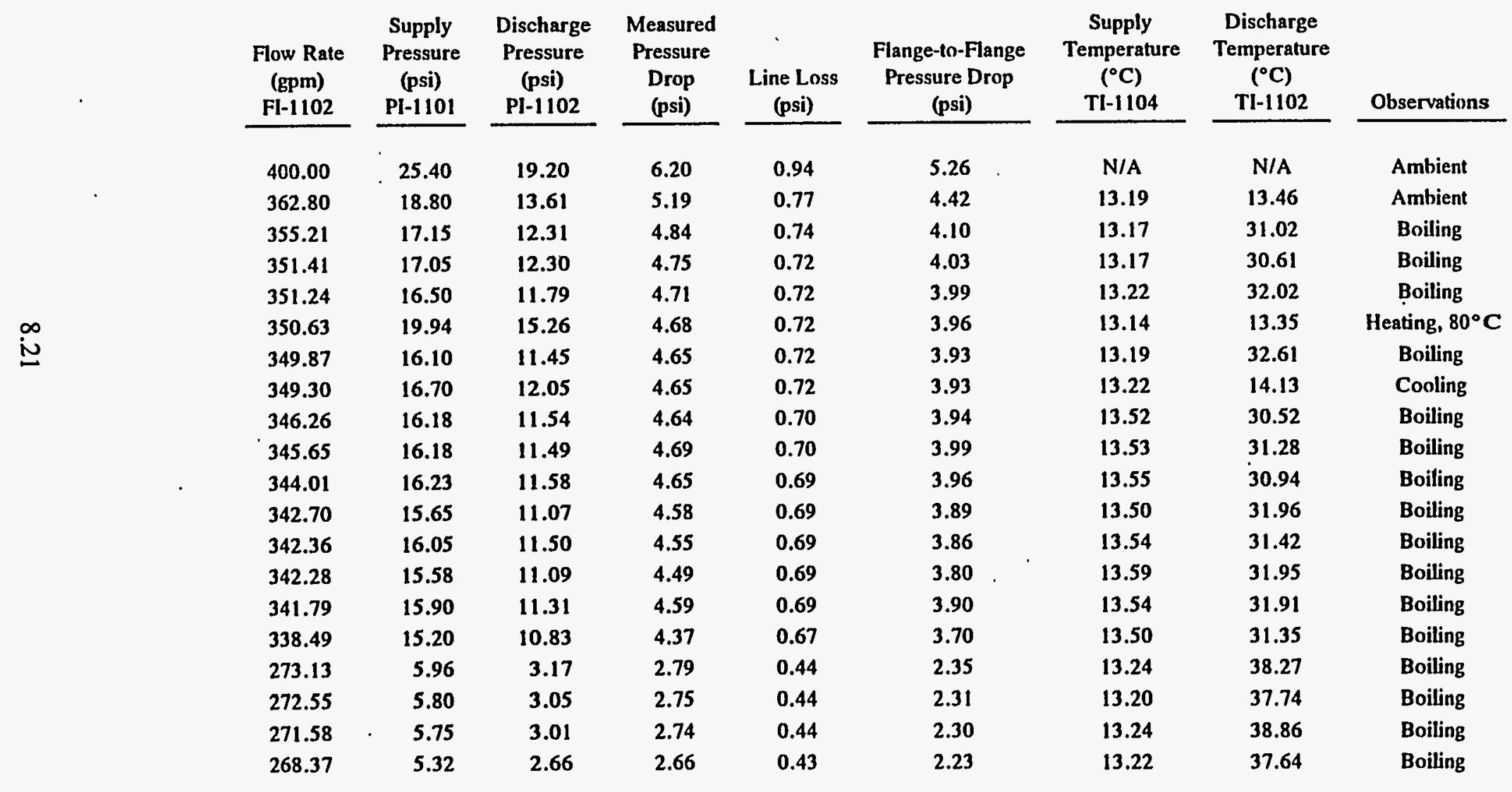




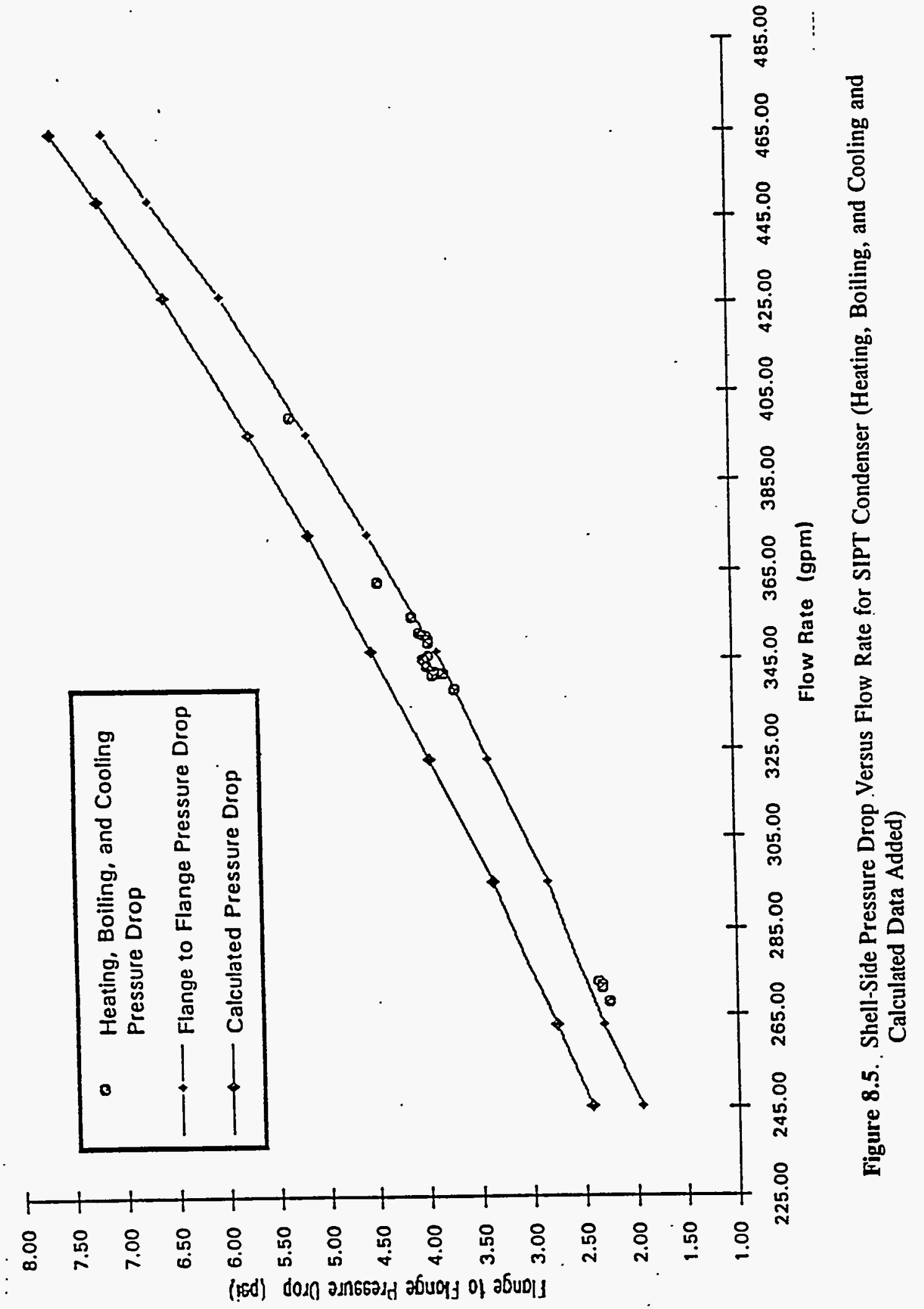




\subsubsection{Test Results}

Slurry carryover testing results are provided below.

\subsubsection{NCAW-1 Condenser Testing}

Various condenser tests were performed during each of the NCAW-1 feed preparation segments. These condenser tests invoived analyzing the heat-transfer coefficients, condensate flow rates, and condensate compositions for the condenser. The heat transfer analyses that occurred for each of these test segments was presented in Section 8.1. The gas samples taken from the condenser outlet were not examined. Thus, the gas outlet solids loadings are not reported. The feed preparation segments that involved evaporator/condenser testing included the following:

1. Dilute waste simulant (high and low tank levels)

2. Concentrated waste simulant (high and low tank levels)

3. Formate waste simulant (formatting and digestion)

4. Formate waste simulant with recycie (before to frit addition)

\section{Melter feed}

To determine whether fouling and/or vapor binding occurred in the condenser, two plots of the condenser heat-transfer coefficient and overhead condensate flow rate, respectively, were plotted as a function of steam flow. The average values of heat-transfer coefficients and condensate flow rates as a function of steam flow are included in Table 8.9 for water and each simulant.

The heat-transfer coefficient data given in Figure 8.6 shows that little change in the heat-transfer coefficient versus steam data occurred with each test segment. The initial water testing data for the feed preparation system is also shown in Figure 8.6. This water testing data is representative of the condenser performance with a clean off-gas stream and clean heat transfer surfaces. Each of the other heat-transfer coefficients show good comparisons with those for water testing except the formate waste simulant with recycle, which is slightly off-set from the heat-transfer coefficient versus steam flow rate curve. The off-set is mostly due to the way the condenser was operated during this test segment. This segment was the only one for which the condensate liquid was refluxed back into the feed preparation tank. As a result, all of the data in Figure 8.6 (except the formate feed with recycle data) was fitted with a linear regression to quantify the heat-transfer coefficient as a function of steam flow rate for no condenser refluxing. A comparison similar to the one above was performed by plotting the condensate flow rate versus steam flow rate for each of the NCAW-1 test segments in Figure 8.7.

Figure 8.7 shows a linear dependency similar to that in Figure 8.6. The formate waste simulant with recycle again showed slightly off-set data from the other test data. A linear regression of all test data (except the formate waste simulant with recycle data) was performed to quantify condenser operation. 
Table 8.9. Heat-Transfer and Condensate Flow Rates as a Function of Steam Flow

\begin{tabular}{|c|c|c|c|c|}
\hline Simulant $^{(a)}$ & $\begin{array}{c}\text { Stream Flow } \\
(\mathrm{lb} / \mathrm{h})\end{array}$ & $\begin{array}{c}\text { Heat-Transfer } \\
\text { Coefficient } \\
\left(\mathrm{Btu} / \mathrm{h} \mathrm{ft}^{2 \circ \mathrm{F})}\right.\end{array}$ & $\begin{array}{c}\text { Condensate Flow } \\
\text { (gpm) }\end{array}$ & $\begin{array}{l}\text { Offgas Flow } \\
\text { (SCFM) }\end{array}$ \\
\hline Water & 3331.49 & 66.51 & 5.96 & 37.65 \\
\hline Water & 3353.61 & 66 & 5.91 & 107.92 \\
\hline Water & 5301.01 & 110.8 & 9.44 & 27.36 \\
\hline Water & 5510.84 & 114.43 & 9.68 & 104.66 \\
\hline Low-Level Dilute & 4152.35 & 84.91 & 7.41 & 46.73 \\
\hline Low-Level Dilute & 5272.36 & 112.65 & 9.56 & 50.85 \\
\hline Low-Level Dilute & 5998.13 & 129.54 & 10.89 & 56.59 \\
\hline High-Level Dilute & 4170.47 & $86.03^{\circ}$ & 7.47 & 46.13 \\
\hline High-Level Dilute & 5184.85 & 109.28 & 9.34 & 49.63 \\
\hline High-Level Dilute & 6048.51 & 129.76 & 10.98 & 56.36 \\
\hline Low-Level Concentrated & 4140.09 & 83.36 & 7.4 & 33.66 \\
\hline Low-Level Concentrated & 5244.77 & 109.8 & 9.47 & 36.7 \\
\hline Low-Level Concentrated & 5946.43 & 124.11 & 10.71 & 40.27 \\
\hline High-Level Concentrated & 4199.61 & 83.06 & 7.4 & 32.55 \\
\hline High-Level Concentrated & 5222.61 & 108.5 & 9.36 & 35.42 \\
\hline High-Level Concentrated & 6011.31 & 126.96 & 10.77 & 39.79 \\
\hline Fomated Feed plus Recycle & 4096.88 & 90.1 & 8 & 66.97 \\
\hline Fomated Feed plus Recycle & 4518.95 & 102.72 & 9.03 & 75.72 \\
\hline Fomated Feed plus Recycle & 4612.11 & 103.57 & 9.13 & 78.9 \\
\hline Fomated Feed plus Recycle & 4794.60 & 108.36 & 9.54 & 76.6 \\
\hline Melter Feed & 2482.07 & 44.01 & 4.2 & 37.86 \\
\hline Melter Feed & 2719.69 & 48.25 & 4.58 & 38.44 \\
\hline
\end{tabular}

(a) Level refers to slurry level in tank.

\subsubsection{Condensate Contaminant Effects On Condenser Performance}

The condenser performance plots in Figures 8.6 and 8.7 show little to no change in condenser heattransfer coefficients and flow rates for equivalent operating conditions with each test segment. Therefore, it appears that no measurable condenser fouling was observed. Condensate samples were taken during evaporator/condenser testing and during concentration, formatting, and digestion steps from the condensate stream to determine whether any solids were being carried over, which could foul the condenser and affect its heat transfer. Samples were analyzed for wt\% solids, cesium [by atomic adsorption (AA)], cation concentration [by inductively coupled plasma (ICP)], and anion concentration [by ion chromatography (IC)]. Nearly all of the condensate samples taken during the NCAW-1 test segments had no visible solids in them; analysis for wt\% solids measured below detection limits. The results of these analyses are included in Appendix $R$. 


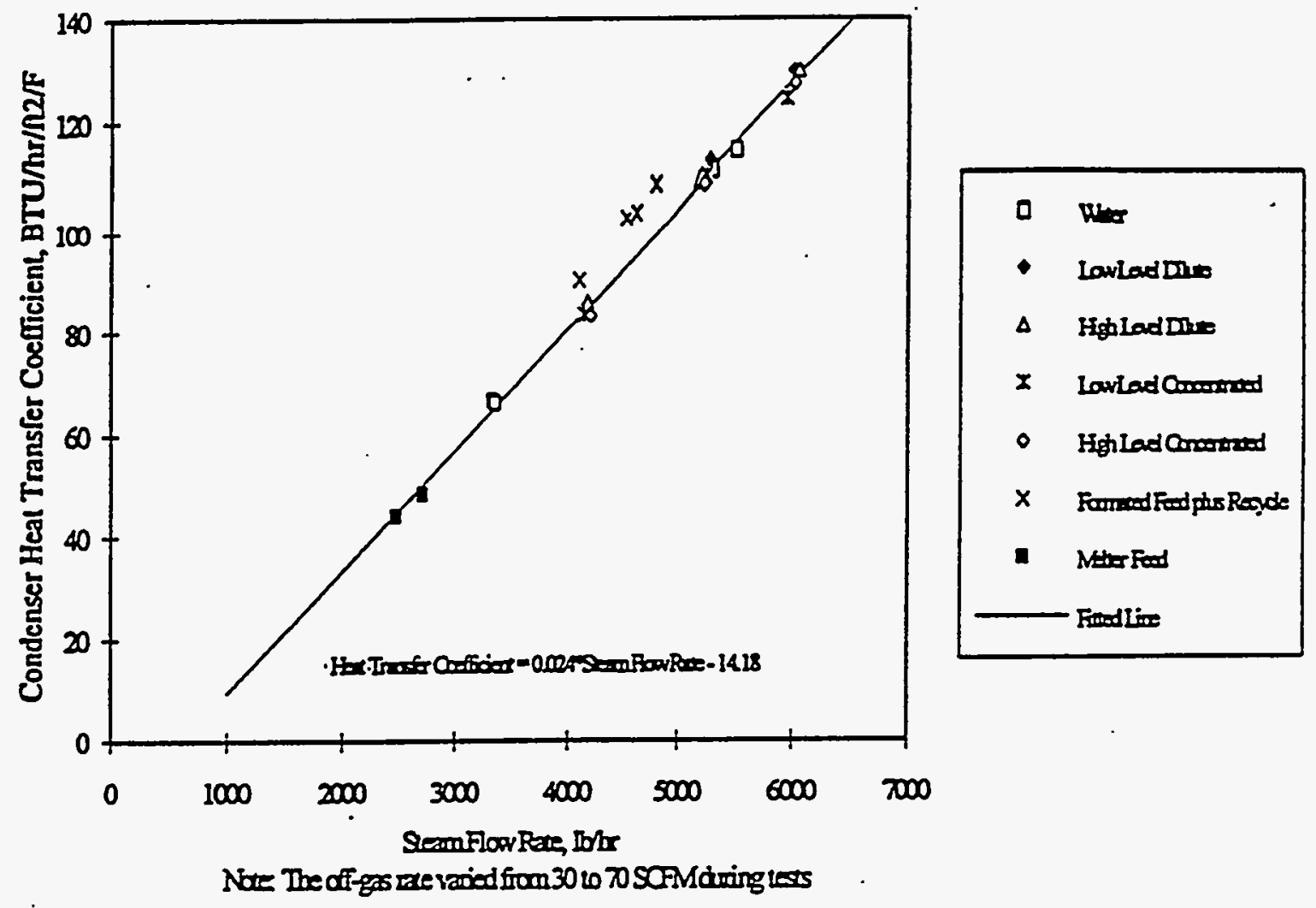

Figure 8.6. Condenser Heat-Transfer Coefficient Versus Steam Flow for NCAW-1 Testing

Based on condensate and tank composition analyses, Condensate Decontamination Factors (CDFs) are defined in this report as

$\mathrm{CDF}=$ Component Concentration in tank/Component Concentration in condensate

The concentrations of the component ions (in the tank and condensate) are provided in Table 8.10. The calculated condensate decontamination factors are presented in Table 8.11. For the most part, the condensate decontamination factors are on the order of $10^{3}$ to $10^{6}$, which would suggest negligible entrainment of solids in the condensate. In other words, the CDF data indicate that the tank contents liquid carryover is minor.

Throughout all the different stages of the simulant testing in HB-1.5, the condensate samples were analyzed for wt\% solids. Throughout all the tests the wt\% solids in the condensate samples were near detection limits of the instrument. The concentration of cesium in condensate was also analyzed throughout testing. The level of cesium in the condensate samples was always near or below the detection limits of AA analysis $(<0.2 \mathrm{ppm}$ ). Cesium concentrations in samples were very similar for both the dilute and concentrated waste simulants. 


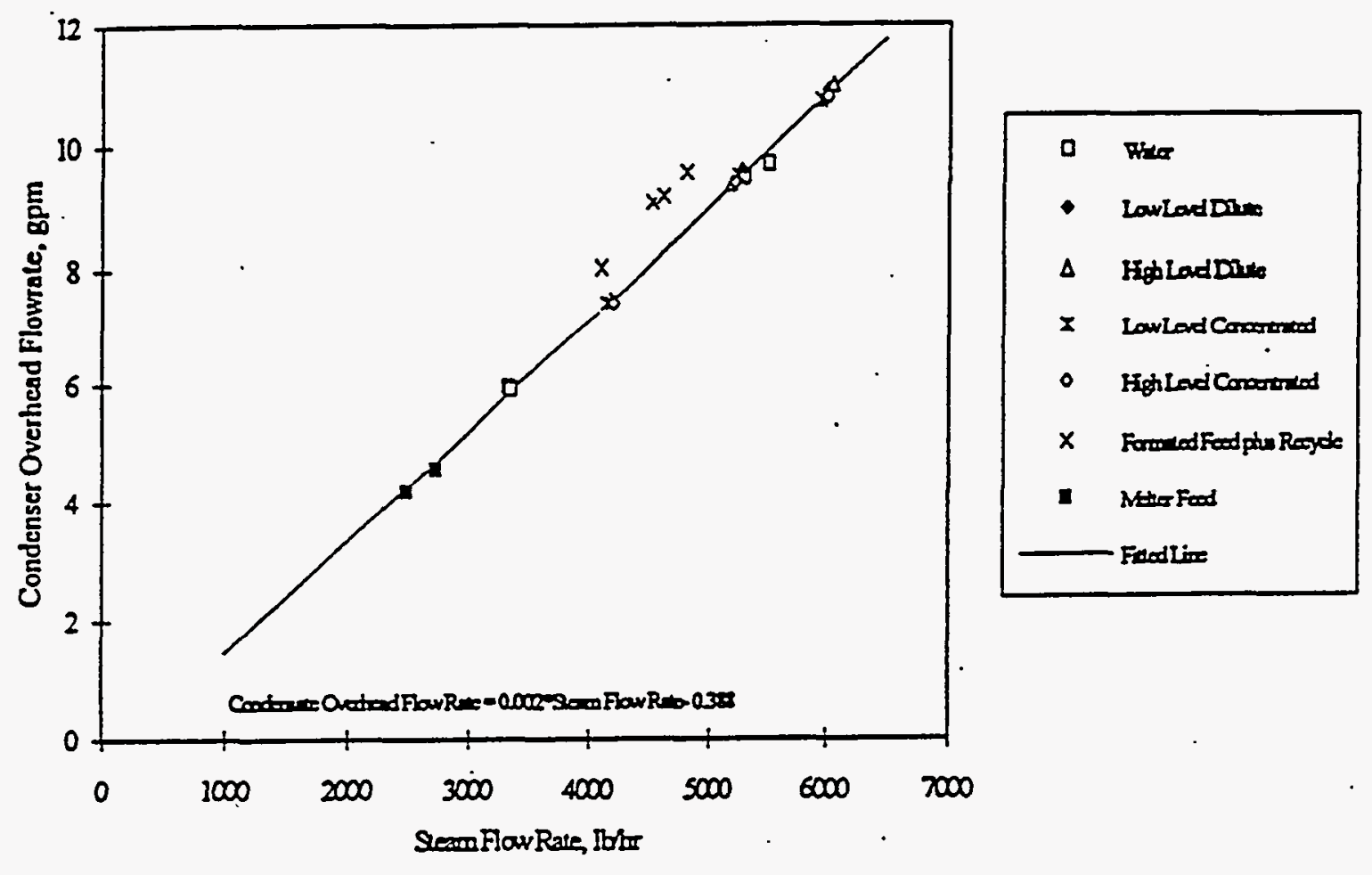

Figure 8.7. Condenser Overhead Flow Rate Versus Steam Flow for NCAW-1 Testing

During condenser testing of dilute and concentrated waste simulant (first four columns in Table 8.10) the only measurable cations in the condensate were $\mathrm{Ca}$ and $\mathrm{Na}$. Si was not detected in the dilute waste simulant condensate samples but was detected in the concentrated waste simulant condensate samples in concentrations higher than $\mathrm{Ca}$ and $\mathrm{Na}$.

During formic acid addition and digestion, $\mathrm{Al}, \mathrm{Fe}$, and $\mathrm{Ni}$ concentrations in the condensate samples increased beyond ICP detection limit. $\mathrm{Na}$ and $\mathrm{Ca}$ concentrations essentially remained the same. $\mathrm{NO}_{3}$ and $\mathrm{NO}_{2}$ concentrations increased from below detection limits to over 35,000 and $2,000 \mathrm{ppm}$, respectively.

During feed concentration of the formate waste simulant before recycle addition, the major cation constituents in the condensate samples were $\mathrm{Al}, \mathrm{Fe}, \mathrm{Na}, \mathrm{Ni}$, and $\mathrm{Si}$. The major anions present were $\mathrm{HCOO}, \mathrm{NO}_{2}$, and $\mathrm{NO}_{3}$. Concentrations of $\mathrm{NO}_{2}$ and $\mathrm{NO}_{3}$ had decreased greatly from condensate samples taken from formic acid addition and digestion concentrations. During feed concentration of the formate waste simulant with recycle in preparation of adding frit, condensate samples were also taken. The major cations present were still $\mathrm{Al}, \mathrm{Fe}, \mathrm{Na}, \mathrm{Ni}$, and $\mathrm{Si}$. The major anions present were $\mathrm{HCOO}, \mathrm{NO}_{2}$, and $\mathrm{NO}_{3}$. 
Table 8.10. Concentrations of Ions in Tank and Condensate

\begin{tabular}{|c|c|c|c|c|c|c|c|}
\hline Date & $\begin{array}{l}\text { Dilute } \\
\text { Waste } \\
1 / 6 / 93\end{array}$ & $\begin{array}{c}\begin{array}{c}\text { Dilute } \\
\text { Waste }\end{array} \\
12 / 30 / 93\end{array}$ & $\begin{array}{c}\begin{array}{c}\text { Concentrated } \\
\text { Waste }\end{array} \\
2 / 2 / 93\end{array}$ & $\begin{array}{c}\begin{array}{c}\text { Concentrated } \\
\text { Waste }\end{array} \\
1 / 28 / 93\end{array}$ & $\begin{array}{c}\begin{array}{c}\text { Formic } \\
\text { Addition }\end{array} \\
3 / 10 / 93\end{array}$ & $\begin{array}{c}\text { Formate } \\
\text { Waste }\end{array}$ & $\begin{array}{c}\text { Formate \& } \\
\text { Recycle }\end{array}$ \\
\hline Tank Level (gal) & 5700 & 7800 & 5700 & 7800 & 7900 & 6600 & 7200 \\
\hline Oxide Loading (g/L) & 32 & 33 & 126 & 132 & 139 & 154 & 200 \\
\hline Tank (wt\% solids) & 4.25 & 4.33 & 15.55 & 15.91 & 16.75 & 19.6 & 25.01 \\
\hline$A \mathrm{~g}(g / L)$ & 1.56 & 1.57 & 6.08 & 6.53 & 6.45 & 7.72 & 7.08 \\
\hline$C a(g / L)$ & 0.19 & 0.19 & 0.75 & 0.8 & 0.8 & 0.96 & 0.88 \\
\hline $\mathrm{Fe}(\mathrm{g} / \mathrm{L})$ & 6.64 & 6.66 & 25.85 & 27.77 & 27.42 & 32.82 & 30.08 \\
\hline$N a(g / L)$ & 4.93 & 4.95 & 19.27 & 20.78 & 20.52 & 24.56 & 28.03 \\
\hline $\mathrm{Ni}(g / L)$ & 0.59 & 0.59 & 2.3 & 2.48 & 2.45 & 2.93 & 2.68 \\
\hline Si $(g / L)$ & 0.65 & 0.65 & 2.52 & 2.71 & 2.67 & 3.2 & 2.94 \\
\hline HCOO (ppm) & - & - & - & - & $3.51 E+04$ & $3.64 E+04$ & $5.39 E+04$ \\
\hline NO3 (ppm) & $1.84 E+03$ & $1.60 E+03$ & $6.10 E+03$ & $5.88 E+03$ & $2.41 E+04$ & $2.40 E+04$ & $4.08 E+0.4$ \\
\hline NO2 (ppm) & $5.75 E+03$ & $5.13 E+03$ & $1.94 \mathrm{E}+04$ & $1.95 E+04$ & $1.66 E+03$ & $1.64 E+03$ & $2.06 E+03$ \\
\hline Condenate (wr\% solids) & $>0.01$ & $>0.01$ & $>0.03$ & $>0.03$ & $>0.01$ & $>0.01$ & $>0.15$ \\
\hline $\mathrm{Al}$ (ppm) & $>0.03$ & $>0.03$ & $>0.03$ & $>0.03$ & 0.14 & 0.31 & 0.14 \\
\hline C. (ppm) & 0.23 & 0.24 & 0.28 & 0.21 & 0.26 & $>0.01$ & $>0.01$ \\
\hline Fe (ppm) & $>0.005$ & $>0.005$ & $>0.005$ & $>0.005$ & 10.9 & 1.37 & 0.14 \\
\hline$N a$ (ppm) & $>0.05$ & 0.45 & 0.25 & 0.21 & $>0.05$ & 0.2 & 0.94 \\
\hline $\mathrm{Ni}$ (ppm) & $>0.02$ & $>0.02$ & $>0.02$ & $>0.02$ & 2.26 & 0.27 & 0.33 \\
\hline Si (ppm) & $>0.01$ & $>0.01$ & 10.3 & 6.34 & 1.13 & 4.75 & 8.43 \\
\hline HCOO (ppm) & $>2$ & $>2$ & $>2$ & $>2$ & $>2$ & 276 & 88.4 \\
\hline NO3 (ppm) & $>2$ & $>2$ & $>2$ & $>2$ & 37800 & 738 & 215 \\
\hline NO2 (ppm) & $>1$ & $>1$ & $>1$ & $>1$ & 2060 & 3.5 & 1.2 \\
\hline
\end{tabular}

Table 8.11. Condensate Decontamination Factors (CDFs for NCAW-1 Testing)

\begin{tabular}{|c|c|c|c|c|c|c|c|}
\hline & Dilute Warte & Dilute Waste & $\begin{array}{l}\text { Concentrated } \\
\text { Whaste }\end{array}$ & $\begin{array}{l}\text { Concentrated } \\
\text { Waste }\end{array}$ & $\begin{array}{l}\text { Formic } \\
\text { Addition }\end{array}$ & $\begin{array}{l}\text { Formate } \\
\text { Warte }\end{array}$ & $\begin{array}{l}\text { Formite \& } \\
\text { Recycle }\end{array}$ \\
\hline Date & $1 / 6 / 93$ & $12 / 30 / 93$ & $2 / 2 / 93$ & $1 / 28 / 93$ & $3 / 10 / 93$ & $3 / 23 / 93$ & $4 / 2 / 93$ \\
\hline Tunk Level (gal) & 5700 & 7800 & 5700 & 7800 & 7900 & 6600 & 7200 \\
\hline Oxide Londing $(\mathrm{g} / \mathrm{L})$ & 32 & 33 & 126 & 132 & 139 & 154 & 200 \\
\hline Al & $>5.20 \mathrm{E}+04$ & $>5.23 E+04$ & $>2.03 E+05$ & $>2.18 E+05$ & $4.61 E+04$ & $2.49 \mathrm{E}+04$ & $5.06 \mathrm{E}+04$ \\
\hline Ca & $8.26 \mathrm{E}+02$ & $7.92 E+02$ & $2.68 E+03$ & $3.81 E+03$ & $3.08 E+03$ & $>9.60 \mathrm{E}+04$ & $>8.80 \mathrm{E}+04$ \\
\hline Fo & $>1.33 E+06$ & $>1: 33 E+06$ & $>5.17 \mathrm{E}+06$ & $>5.55 \mathrm{E}+06$ & $2.52 E+03$ & $2.40 E+04$ & $2.15 E+05$ \\
\hline $\mathrm{Na}$ & $>9.86 \mathrm{E}+04$ & $1.10 E+04$ & $7.71 E+04$ & $9.90 \mathrm{E}+04$ & $>4.1 E+05$ & $1.23 E+05$ & $2.98 E+04$ \\
\hline $\mathrm{Ni}$ & $>2.95 \mathrm{E}+04$ & $>2.95 E+04$ & $>1.15 E+05$ & $>1.24 E+05$ & $1.08 E+03$ & $1.09 E+04$ & $8.12 E+03$ \\
\hline Si & $>6.50 E+04$ & $>6.50 E+04$ & $2.45 E+02$ & $4.27 E+02$ & $2.36 E+03$ & $6.74 \mathrm{E}+02$ & $3.49 \mathrm{E}+02$ \\
\hline HCOO & - & - & - & - & $>1.76 E+04$ & $1.32 E+02$ & $6.10 E+02$ \\
\hline NO3 & $>9.20 \mathrm{E}+02$ & $>8.00 E+02$ & $>3.05 \mathrm{E}+03$ & $>2.94 E+03$ & $6.38 \mathrm{E}-01$ & $3.25 E+01$ & $1.90 \mathrm{E}+02$ \\
\hline $\mathrm{NO} 2$ & $>5.75 E+03$ & $>5.13 E+03$ & $>1.94 E+04$ & $>1.95 E+04$ & 8.06E-01 & $4.69 E+02$ & $1.72 E+03$ \\
\hline
\end{tabular}

$>$ numbers indicate that samples were below the detection limit 


\subsubsection{Discussion}

Additional tables for the condenser performance are shown in Appendix $T$. These tables summarize all the major parameters measured during each evaporator/condenser test as well as an overall energy balance. Vapor binding and fouling were not observed during the evaluation of condenser performance. ${ }^{(a)}$ A decrease in both the heat transfer rate and the overhead condensate flow as a function of steam flow was not observed from test to test.

Condensate from the condenser flowed through a line and accumulated in a collection Tank (HB-14). Grab samples from the condensate line were taken periodically during testing. These grab samples were tested for wt\% solids by drying the samples at $105^{\circ} \mathrm{C}$. The tests indicated that their solids composition was lower than detection limits in most cases and had negligible solids content. Even though these condensate solids were less than the detection limit, it is believed that problematic levels of condensate solids would have been measured with this sampling system. However, a better method of sampling the condensate line would have been to install a filter in the line that would accumulate the solids over time for each test.

\subsubsection{Conclusions and Recommendations}

The following conclusions and recommendations resulted from the test results and observations:

- The condenser heat-transfer coefficient and overhead condensate flow varied linearly as a function of steam flow. No vapor binding was noted.

- Because the heat-transfer coefficient versus steam flow rate plot did not change during testing, there did not appear to be any fouling of the heat transfer surfaces in the condenser.

- Solids concentrations were so low in the condensate line samples that there were essentially no solids carried over into the condenser. (The entrainment of solids and liquids noted in the condensate line can be considered negligible.) CDFs mostly ranged from $10^{3}$ to $10^{6}$.

- If a more quantifiable solids sample is desired, a filter should be installed into the condensate line to accumulate solids over the period of the test.

(a) Hatchell, B. K. 1993. Detailed Design Data Package: 1.1b - Boiling rates, 1.3a - Coil Heat Transfer Coefficients (Testing with Water and NCAW Simulant). PHTD-K1017, Rev. 0., Pacific Northwest Laboratory, Richland Washington. 


\subsection{Slurry Transport Performance}

HWVP slurry transport testing through piping systems and pumps are treated in this chapter.

\subsection{Process Slurry Flow in Pipes and Fittings}

Slurry transport testing through pipes and fittings are discussed below.

\subsubsection{Approach}

The tests were conducted to collect pressure-drop data for HWVP slurry simulants in $1 / 2-, 1-$, and 2-in.-diameter Schedule 40 stainless steel horizontal straight piping over a range of flow rates. The slurry compositions, concentrations, and temperatures were nominal HWVP design conditions (Chapter 6.0). The slurries tested were simulants of the HWVP feed preparation flowsheet slurries: Neutralized Current Acid Waste (NCAW) (dilute and concentrated), Formatted Neutralized Current Acid Waste (FNCAW), and Melter Feed (MF). The testing piping system and related instrumentation are described in the equipment description section (Chapter 5.0). The slurry properties measured are included in Chapter 6.0. Laboratory measurements included flow curves with a Haake Viscometer and density.

The transport testing results are presented in Section 9.1.4 as pressure drop as a function of flow rate for different diameter piping for nominal HWVP process conditions. In this form the data can be used directly for design for the testing conditions considered. Also, some limited interpolation of the data can be performed. The results of comparable pressure drop calculations based on correlations and laboratory data are also provided for comparison.

The laboratory data can be used in conjunction with literature correlations to estimate flow and pressure drop conditions to perform piping system design. This approach is presented here to enable piping system design with the use of inexpensively obtained laboratory data.

\subsubsection{Calculations Description}

Calculation approaches are provided to enable the use of laboratory data to determine the effects of HWVP process slurry characteristics on slurry flow pressure drop in piping systems.

Slurry rheology behavior determines the equations to be used to calculate the flow component of pressure drop in pipes. The slurry data needed as input to the equations for computation are provided according to process slurry type in Chapter 6.0. The correlations for specific types of slurry behavior in laminar and turbulent flow regimes are provided. Because many of the correlations have been developed for smooth straight pipes (tubing), some discussion is provided on the effects of fittings, roughness, and entrance/exit. 


\subsubsection{HWVP Slurry Property Characteristics}

Slurry and process characteristics that affect transport include slurry composition, solids concentration, temperature, and process history. These characteristics determine more specific slurry properties including rheology and density that affect flow characteristics. For piping system design, the rheological properties determine what equations will be used and the data needed to make pressure drop calculations for fluid flow in piping systems. The subsequent discissions are in the context of HWVP process slurries.

\subsubsection{Fluid Behavior Classification}

Fluid flow behavior may be classified Newtonian or non-Newtonian. For Newtonian fluids the shear stress is proportional to the shear rate as indicated in Figure 9.1. For non-Newtonian, a variety of shear stress and shear rate relationships can exist as indicated in Figure 9.1. The HWVP process slurries tested have been classified as either Newtonian or Bingham fluids. The actual slurry properties may not precisely replicate the definition of these fluids, but the behavior is close enough as to enable the use of appropriate correlations. A description and correlation for Pseudoplastic (power law) fluids are also included, because it is likely that these types of fluids will also be encountered in HWVP.

The quantitative relationships between shear stress and shear rates for various types of fluids are as follows: (Always check units in equations used for consistency. Unit conversion such as using $g_{c}$ is common.)

$$
\text { Newtonian: } \tau_{\mathrm{yx}}=\frac{\mu}{\mathrm{g}_{\mathrm{c}}} \frac{\mathrm{du}}{\mathrm{dy}} \quad \text { (Skelland 1967, p.3) }
$$

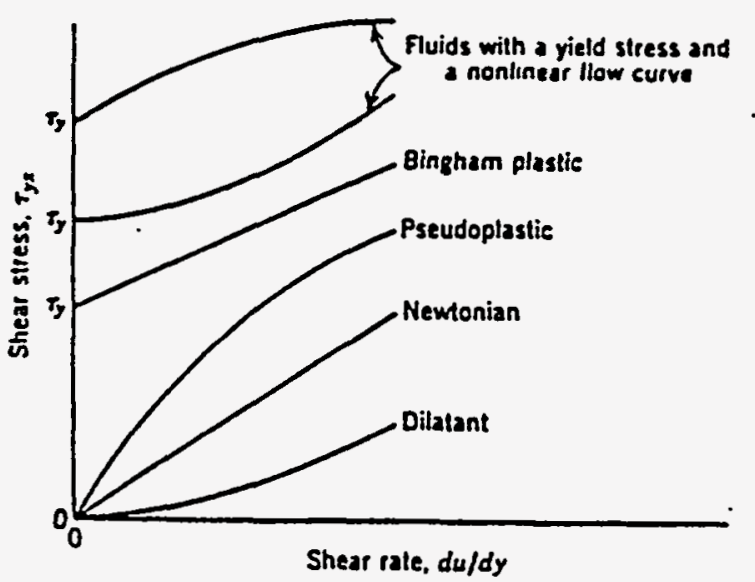

Figure 9.1. Flow Curves for Various Types of Time-Independent Fluids 
where $\tau_{\mathrm{yx}}=$ shear stress in $\mathrm{x}$-direction on surfaces normal to $\mathrm{y}, \mathrm{lb}$ force/ $/ \mathrm{ft}^{2}$

$\mu=$ viscosity (Newtonian fluid), lb mass/ft sec or lb mass/ft h ( $\mu$ can have a variety of units check for unit consistency and conversion.)

$\mathrm{u}=$ local value of linear velocity in the $\mathrm{x}$-direction, $\mathrm{ft} / \mathrm{sec}$ or $\mathrm{ft} / \mathrm{h}$

$g_{c}=$ conversion factor, $32.174 \mathrm{lb}$ mass $\mathrm{ft} / \mathrm{lb}$ force $\sec ^{2}$ or $4.17 \times 10^{8} \mathrm{lb}$ mass $\mathrm{ft} / \mathrm{lb}$ force $\mathrm{h}^{2}$

$y=$ coordinate direction

Bingham plastic: $\tau_{\mathrm{yx}} \cdot \tau_{\mathrm{y}}=\frac{\eta}{\mathrm{g}_{\mathrm{c}}}\left[\frac{\mathrm{du}}{\mathrm{dy}}\right] \quad$ (Skelland 1967, p. 6)

where $\quad \tau_{\mathrm{y}}=$ yield shear stress, $\mathrm{lb}$ force $/ \mathrm{ft}^{2}$

$\eta=$ coefficient of rigidity or plastic viscosity, $\mathrm{lb}$ mass/ft $\mathrm{sec}$

Pseudoplastic (PowerLaw): $\tau_{\mathrm{yx}}=\frac{\mathrm{K}}{\mathrm{g}_{\mathrm{c}}}\left[\frac{\mathrm{du}}{\mathrm{dy}}\right]^{\mathrm{n}} \cdot \quad$ (Skelland 1967, p. 8)

where $\mathrm{K}=$ fluid consistency index in the power law, $\mathrm{lb}$ mass $\sec ^{\mathrm{n}-2} \mathrm{ft}^{-1}$

$\mathrm{n}=$ flow behavior index in the power law, dimensionless.

The nature of the slurry rheology behavior can change with process conditions. For example, it is common that a slurry will have Newtonian flow properties when dilute, but as the slurry is concentrated the behavior becomes more non-Newtonian, as shown in Figure 9.2. Also, as the filuid temperature changes, the fluid rheology characteristics may change. Many fluids become less viscous with temperature, and the rheology behavior may change.

\subsubsection{Flow Correlations for Pressure Drop}

The flow correlations for pressure drop are subsequently presented. The correlations are determined by the fluid rheology characteristics and also the fluid flow regime, laminar or turbulent. For transition flow it is assumed the flow is turbulent if no other applicable information exists. To determine the fluid flow regime, the Reynolds Number needs to be calculated; then the flow correlation can be selected. 


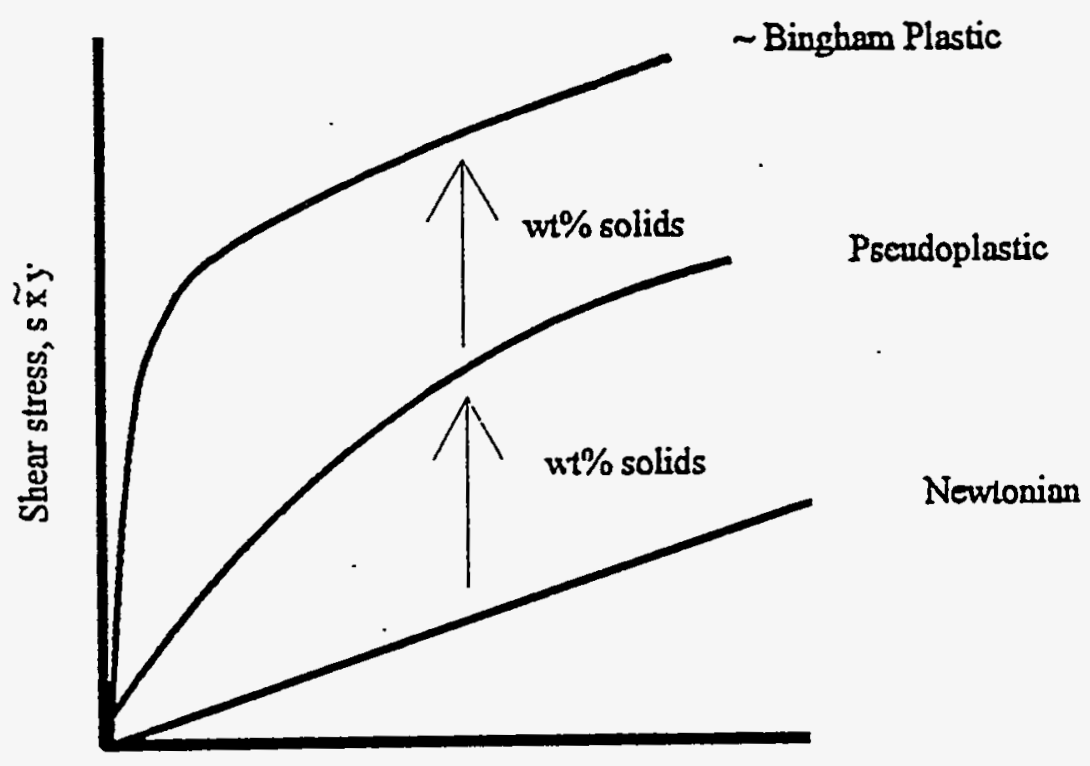

Shcar rate, dw/dy

Figure 9.2. HWVP Process Slurry Fluid Behavior

Reynolds Number. The Reynoids Number is calculated as follows to determine the fluid flow regime: (The viscosity, $\mu$, must have consistent units to make $\mathrm{N}_{\mathrm{Re}}$ dimensionless.)

$$
\text { Newtonian: } \mathrm{N}_{\mathrm{Re}}=\frac{\mathrm{DV} \rho}{\mu}
$$

where $\mathrm{N}_{\mathrm{Re}}=$ Reynolds Number for use with Newtonian fluids, dimensionless

$\mathrm{D}=$ tube diameter, $\mathrm{ft}$

$\mathrm{V}=$ average linear flow velocity in the $\mathrm{x}$-direction, $\mathrm{ft} / \mathrm{sec}$

$\rho=$ density, $\mathrm{lb}$ mass $/ \mathrm{ft}^{2}$

$$
\text { Bingham plastic: } \mathrm{N}_{\mathrm{Re}}=\frac{\mathrm{DV} \rho}{\mu_{e}} \quad \text { (Skelland 1967, p. 74) }
$$


where $\quad \mu_{\mathrm{e}}=\frac{\tau_{\mathrm{y}} \mathrm{g}_{\mathrm{c}} \mathrm{D}}{6 \mathrm{~V}}+\eta \quad$ (Skelland 1967, p.72)

The effective viscosity $\left(\mu_{e}\right)$ is defined as the viscosity that makes Poiseuille's equation (Skelland 1967, p. 72) fit any set of laminar flow conditions for time independent fluids.

Pseudoplastic (Power Law): $\quad N_{R e, B}=\frac{D^{n} V^{2-n} \rho 8}{K}\left[\frac{n}{6 n+2}\right]^{n}$ (Skelland 1967, p. 110)

where $N_{R e, B}=$ Reynolds Number for power law fluids in laminar flow-through tubes, - dimensionless

The following criteria is used to establish the flow regime:

Laminar: $\mathrm{N}_{\mathrm{Re}}<2100$

Turbulent: $\mathrm{N}_{\mathrm{Re}}>2100$ (assume transition fiow is turbulent)

Pressure Drop for Newtonian Fluid in Laminar Flow. The pressure drop of a Newtonian fluid in laminar flow in a straight and horizontal pipe is as follows: Poiseuille equation

$$
\Delta \mathrm{P}=\frac{32 \mu \mathrm{LV}}{\mathrm{g}_{\mathrm{c}} \mathrm{D}^{2}} \quad(\text { Skelland 1967, p. 72) }
$$

where $\Delta \mathrm{P}=$ pressure drop due to friction, upstream minus downstream conditions, $\mathrm{lb}$ force/ $\mathrm{ft}^{2}$

$L=$ length in direction of flow, $\mathrm{ft}$

Pressure Drop for Bingham Plastic in Laminar Flow. The pressure drop of a Bingham plastic fluid in laminar flow in a straight and horizontal pipe is as follows: Buckingham's Equation

$$
\Delta P=\frac{32 \mu_{e} L V}{g_{c} D^{2}} \quad(\text { Skelland } 1967 \text { p. 74) }
$$


Equation 9.6 is an approximate solution to Buckingham's equation, and the error in using it is generally minor (Skelland 1967, p. 73).

Pressure Drop for Pseudoplastic (Power Law) in Laminar Flow. The pressure drop of a Pseudoplastic fluid in a straight and horizontal pipe is as follows:

$$
\Delta P=2 K\left[\frac{3 n+1}{n}\right]^{n} \frac{V^{2} L}{g_{c} R^{n+1}} \quad \text { (Skelland 1967, p. 110) }
$$

where $\quad R=$ tube radius, $\mathrm{ft}$

Pressure Drop for Newtonian Fluid in Turbulent Flow. The pressure drop of a Newtonian fluid in a straight horizontal pipe is as follows: Fanning or Darcy Equation

$$
\Delta P=\frac{2 f \rho L V^{2}}{g_{c} D} \quad \text { (Skelland 1967, p. 164) }
$$

where $f=$ Fanning friction factor, defined by Equation 9.11, dimensionless [Care must be exercised when using $f$ values taken from literature. They may differ by a factor depending on how the author defined the friction factor. For example, the Fanning friction factor in Skelland (1967) is a factor of 4 lower than Crane (1965).]

Crane (1965) provides the approach commonly used to determine pressure drop for Newtonian fluid flow in piping systems. Figures AD-1 and AD-2 in Appendix AD (Crane 1965, p. A-24 and A-25) present the correlation of pressure drop in horizontal and straight pipe as a function of Reynolds Number. With Figures $A D-1$ and $A D-2$ the friction factor is a factor of 4 higher than defined in Equation 9.11. Also, the following should be defined:

$$
\begin{aligned}
\mathrm{R}_{e} & =N_{\mathrm{Re}} \\
\mathrm{v} & =\mathrm{V} \\
\mu_{\mathrm{e}} & =\mu \text { (Note } \mu_{\mathrm{e}} \text { in Figures } \mathrm{AD}-1 \text { and } \mathrm{AD}-2 \text { is not the same } \mu_{\mathrm{e}} \text { as in Equation 9.6) } \\
\mathrm{h}_{\mathrm{L}} & =\text { head loss, } \mathrm{ft} \text { of fiuid }=\Delta \mathrm{P} / \rho \\
\mathrm{g} & =\mathrm{g}_{\mathrm{c}}
\end{aligned}
$$

The Reynolds Number as defined in Equation 9.4 is employed to use the correlations in Figures $\mathrm{AD}-1$ and $\mathrm{AD}-2$. 
Pressure Drop for Bingham Plastic Fluid in Turbulent Flow. The pressure drop of a Bingham plastic fluid in a straight and horizontal pipe is as follows:

$$
\Delta P=\frac{2 f_{B} \rho L V^{2}(1-c)}{g_{c} D} \quad \text { (Skelland 1967, p. 76) }
$$

where $f_{B}=$ friction factor defined by Equation 9.12 for use with Figure AD-3 in Appendix AD, (Skelland 1967, p. 198) for Bingham Plastic fluids, dimensioniess

$$
c=\text { defined by the following equation }
$$

$$
V=\frac{\operatorname{Rg}_{c} \tau_{y}}{\eta}\left[\frac{c^{4}-4 c+3}{12 c}\right] \quad \text { (Skelland 1967, p. 75) }
$$

The friction factor, $f_{B}$, for use with this correlation is taken from Figure $A D-3$ in Appendix $A D$, which requires the use of a Reynolds Number defined as follows:

$$
\mathrm{N}_{\mathrm{Re}, \mathrm{B}}^{\prime}=\frac{\mathrm{DV} \rho}{\eta} \phi_{c^{\prime}}=\frac{\mathrm{DV} \rho}{\eta} \frac{(1-\mathrm{c})\left(\mathrm{c}^{4}-4 \mathrm{c}+3\right)}{3} \quad \text { (Skelland 1967, p. 76) }
$$

Use of this correlation requires the solution of Equation 9.13 for $c$ with other known parameters for use in Equations 9.12 and 9.14 and Figure AD-3 in Appendix AD.

Pressure Drop for Pseudoplastic (Power Law) Fluid in Turbulent Flow. The pressure drop of a Power Law fluid in a straight and horizontal pipe is as follows:

$$
\Delta \dot{P}=\frac{3 f_{p} L \rho V^{2}(3 n+1)}{2 D g_{c}(2 n+1)} \quad \text { (Skelland 1967, p. 198) }
$$

where $f_{P}=$ friction factor defined by Equation 9.15 for use with Figure AD-4 in Appendix AD (Skelland 1967, p. 199) which requires the use of a Reynolds Number defined as follows: 


$$
N_{\text {Re,p }}=\frac{6[(3 n+1) / n]^{1-n}}{2^{n}[(2 n+1) / n]} \frac{D^{n} V^{2-n} \rho}{K} \quad \text { (Skelland 1967, p. 198) }
$$

Use of the correlation in Equation 9.15 for pressure drop requires Figure $A D-4$ in Appendix $A D$ in conjunction with the Reynolds Number defined in Equation 9.16.

Discussion of Pipe Fittings, Roughness, and Entrance/Exit Losses. The effects on flow pressure drop of Newtonian fluid flow through rough pipe, fittings, and entrances/exits have been well developed and effectively treated elsewhere (Crane 1965) and will not be repeated here. The effects of pipe roughness, fittings, and entrance/exit losses on pressure drop for flow of Bingham plastic and Pseudoplastic (Power Law) fluids in pipes have not been studied extensively. There has been some study on entrance effects of Pseudoplastic (power law) fluids into pipes (Grovier and Aziz 1987). In general, literature sources recommend the use of the same approaches as used for Newtonian fluids such as equivalent length $(\mathrm{Le}=\mathrm{L} / \mathrm{D})$, resistance coefficients $(\mathrm{K})$, and effects on friction factors (f) where applicable data and correlations are not available. Literature sources also caution that use of this approach may lead to significant errors, depending on the flow properties of the fluid. If experimental data is available, it is prudent to check the calculation approach.

Fittings. There is limited literature on the effects of fittings on non-Newtonian fiuid flow and related pressure drop. Literature sources recommend the use of correlations developed for Newtonian fluids to determine the effects of fittings such as equivalent pipe lengths provided in Table AD-1 in Appendix AD (Crane 1965, p. A-30) and resistance coefficients provided in Figure AD-5 in Appendix $A D$ (Crane 1965, p. A-26). The resistance coefficient or velocity head loss (K) is defined by the formula below.

$$
\Delta \mathrm{P}=\frac{\mathrm{K} \rho \mathrm{V}^{2}}{2 \mathrm{~g}_{\mathrm{c}}} \quad(\text { Crane } 1965)
$$

where $\mathrm{K}=\mathrm{fl} / \mathrm{D}$

The equivalent pipe length (Le) is the equivalent length of pipe it would require to exhibit the same effect as expressed in the following equation:

$$
\mathrm{Le}=\frac{\mathrm{L}}{\mathrm{D}} \quad(\text { Crane 1965) }
$$


These factors are applied to the Fanning equation (Equation 9.11), the same as for Newtonian fluids.

Roughness. There is limited literature on the effects of pipe roughness on non-Newtonian turbulent fluid flow and related pressure drop. Literature sources recommend the use of correlations developed for Newtonian fluids.

In laminar flow, literature does not indicate that there are any effects of pipe wall roughness on fluid flow or the related pressure drop. Thus, no corrections are required for Newtonian fluids, Bingham plastic fluids, and Pseudoplastic (Power Law ) fluids.

For transition flow, it is assumed that approaches applied for use with turbulent flow will be adequate where not explicitly discussed here.

For Newtonian fluids for which the Reynolds Number can be calculated $\left(\mathrm{N}_{\mathrm{Re}}=\rho \mathrm{VD} / \mu\right)$ directly, Figures $A D-1$ and $A D-2$ in Appendix $A D$ can be used to determine the effects of pipe roughness on the Fanning friction factor ( $f$ ). From these figures the Fanning friction factor can be taken for insertion into the Fanning equation (Equation 9.11) to calculate the associated pressure drop.

For viscous non-Newtonian fiuids, reasonably smooth pipe such as stainless steel and pipe sizes used in plants, pipe roughness can be neglected as a first approximation within the accuracy of the ability to calculate pressure drop (see Section 9.1.4, results discussion).

To estimate the effect of piping roughness, the following approach may be considered for Bingham plastic fluids. The Fanning friction factor is calculated with Tomita's modified friction factor. For Bingham plastic fluids, Tomita's modified friction factor and the Fanning friction factor are related as follows:

$$
\mathrm{f}=(1-\mathrm{x}) \mathrm{f}_{\mathrm{BT}} \quad \text { (Grovier and Aziz 1987, p. 229) }
$$

where $f=$ Fanning friction factor

$$
\mathrm{x}=\tau_{\mathrm{y}} / \tau_{\mathrm{x}} \text { (see Grovier and Aziz 1987, p. 229) }
$$

$f_{B T}=$ Tomita's modified friction factor (see Grovier and Aziz 1987, p. 229)

Then with Figure AD-1 in Appendix AD, for the calculated Fanning friction factor (correct for constant if necessary), move to the right horizontally on the graph until the curve is intersected for smooth pipe. Then, move vertically on the graph until the curve is intersected for the correct pipe roughness. Next, move horizontally left to read the related Fanning friction factor (correct for constant if necessary). Then convert the Fanning friction factor to Tomita's modified friction factor by using Equation 9.19. Finally, the pressure drop in the rough pipe can be calculated by inserting Tomita's modified friction factor into the appropriate pressure drop equation, Equation 9.12. 
The effect of pipe roughness on Pseudoplastic (power law) fluids is projected in the same manner as for Bingham fluids with Tomita's friction factor, which is related to the Fanning friction factor as follows:

$$
f=\frac{1+3 n}{1+2 n}\left[\frac{3}{4}\right] f_{\text {PTL }} \quad \text { (Grovier and Aziz 1987, p. 220) }
$$

From the calculated $f_{\mathrm{PTL}}$, the fanning friction factor is calculated from Equation 9.20. Then with Figure $\mathrm{AD}-1$ in Appendix $\mathrm{AD}$ (correct for the constant if necessary), for the calculated Fanning friction factor, move right horizontally on the graph until the curve is intersected for smooth pipe. Then, move vertically on the graph until the curve is intersected for the correct pipe roughness. Next, move horizontally left to read the related Fanning friction factor (correct for the constant if necessary). Now; convert the Fanning friction factor to Tomita's friction factor with Equation 9.20. Finally, the pressure drop in the rough pipe can be calculated by inserting Tomita's modified friction factor into the appropriate Equation 9.15.

Entrance/Exit. Entrance effects on Newtonian fluid flow and the related pressure drop have been studied to a significant extent, and the effects correlated in terms of resistance coefficients $(\mathrm{K})$ are presented in Figure AD-5 in Appendix AD. The related effects on pressure drop are determined in the same manner as fittings, described above.

No work was found on entrance/exit effects for Bingham plastic fluids, exit effects on Pseudoplastic (power law) fluids, and entrance effects for Pseudoplastic (power law) fluids in turbulent flow. For these fluids, literature suggests the same approach be used as for Newtonian fluids (with the resistance coefficients in Figure AD-5 in Appendix AD).

For power law fluids in laminar flow, the pressure drop may be calculated with the following equation:

$$
\frac{2 \Delta \mathrm{Pg}_{\mathrm{c}}}{\rho \mathrm{V}^{2}}=\frac{2^{\mathrm{n}+2}\left[\frac{1+3 \mathrm{n}}{\mathrm{n}}\right]^{2}}{\mathrm{Re}_{\mathrm{PL} 1}}\left[\frac{2 \mathrm{X}_{\mathrm{D}}}{\mathrm{D}}\right]+\mathrm{C} \quad \text { (Grovier and Aziz 1987, p.207) }
$$

\footnotetext{
where $\frac{2 X_{D}}{D_{R e} e_{P 1}}$ comes from Figure $A D-6$ in Appendix $A D$ (Grovier and Aziz 1987, p. 207)

$\mathrm{n}=$ Power law exponent
} 
$\mathrm{C}=$ Excess dimensionless pressure drop from Figure $\mathrm{AD}-7$ in Appendix $\mathrm{AD}$ (Grovier and Aziz 1987, p. 207).

Minimum and Standard Velocities for Settling Slurries. Experimental studies (Holland and Chapman 1966) have been performed and the data correlated to determine the minimum velocity (velocity at which some solids settle) and standard velocity (velocity at which solids in pipe have homogeneous concentration, fully mixed) of solids slurries. The equations for minimal and standard velocities are as follows:

Minimum Velocity

$$
u_{1}=\left[0.0251 \operatorname{gd}_{s}\left(\frac{\rho_{\mathrm{m}} \mathrm{d}_{\mathrm{i}}}{\mu}\right)^{0.775}\left[\frac{\rho_{\mathrm{s}}-\rho}{\rho}\right)\right]^{1 / 1.225}
$$

(Holland and Chapman 1966, p.296)

Standard Velocity

$$
\mathrm{u}_{2}=\left[0.0741 \operatorname{gd}_{\mathrm{s}}\left[\frac{\rho_{\mathrm{m}} \mathrm{d}_{\mathrm{i}}}{\mu}\right]^{0.775}\left[\frac{\rho_{\mathrm{s}}-\rho}{\rho}\right]\right]^{1 / 1.225} \quad \text { (Holland and Chapman 1966, p.296) }
$$

where $u_{1}=$ mean minimum linear slurry velocity in horizontal pipe

$u_{2}=$ mean standard linear slurry velocity in horizontal pipe

$\mathrm{g}=$ gravitational acceleration

$\mathrm{d}_{\mathrm{s}}=$ nominal particle diameter

$\rho_{\mathrm{m}}=$ slurry mixture density

$\mathrm{d}_{\mathrm{i}}=$ inside pipe diameter

$\mu=$ slurry viscosity

$\rho_{\mathrm{s}}=$ solid particle density

$\rho=$ liquid density 
Equations 9.22 and 9.23 are based on experimental data for solid particle diameters in the range of 0.06 to $0.6 \mathrm{~mm}$ and pipe diameters of 1 to $12 \mathrm{in}$. The equations appear to be for Newtonian fluids. To use these equations for non-Newtonian fluids, it is presumed that apparent viscosity or an appropriate equivalent should be used. Because the slurry likely contains a variety of solids, the calculations should be based on the solid particles that have the greatest settling velocity. For non-Newtonian fluids, the solution would be trial and error since the apparent viscosity is velocity-dependent. The correlation development infers that the flow conditions are turbulent, but this is not stated. It is not certain how valid these correlations are for HWVP slurries.

\subsubsection{Test Approach}

The test matrix for slurry pumping tests is provided in Table 9.1. Once flow was initiated in a particular test section, flow was maintained in the line until all sections had been tested. This was achieved by starting the procedure by testing the 2 -in. line over the flow rate specified. When the entire range of velocities ( 3 to $10 \mathrm{ft} / \mathrm{sec}$ ) had been tested in the 2-in. line, the flow was reduced as far as possible while still maintaining turbulent flow. The 1-in. line was then opened, and testing was performed. Similarly testing was performed with the $1 / 2$-in. line. As soon as the tests were complete, all process lines were completely flushed with water.

For the 2-in.-line test, the flow rate was controlled by reducing the pump speed. Flow was initiated and the pump speed increased to obtain the upper flow rate specification (Table 9.1). After a sufficient waiting period (usually about 1 to 2 minutes) to ensure steady-state conditions, the pump speed was reduced enough to reduce the fiow rate by approximately $10 \mathrm{gpm}$. This process was repeated until the lowest specified flow rate was obtained. During these tests, data were being recorded by the data acquisition system (DAS) every 15 seconds.

The 1-in. line was then opened $100 \%$. Since minimum flow was being maintained in the 2-in. line, the flow rate in the 1-in. line was reduced by throttling a downstream valve. A downstream valve was used to ensure a full pipe during the tests. The flow rate was reduced incrementally ( $\approx 5 \mathrm{gpm})$ as in the 2 in.-test.

Table 9.1. Testing Matrix for Slurry Test Loop Testing

\begin{tabular}{lccccccc}
$\begin{array}{l}\text { Fluid to be } \\
\text { Analyzed }\end{array}$ & $\begin{array}{c}\text { Nominal Pipe } \\
\text { Size (in.) }\end{array}$ & $\begin{array}{c}\text { Pipe } \\
\text { Schedule }\end{array}$ & $\begin{array}{c}\text { Velocity } \\
\text { (ft/sec) }\end{array}$ & Fittings & \multicolumn{1}{c}{$\begin{array}{c}\text { Temp. } \\
\left({ }^{\circ} \mathrm{F}\right)\end{array}$} \\
$\begin{array}{l}\text { Waste Oxide/Frit } \\
\text { Mixture }\end{array}$ & $1 / 2$ & & 40 & 3 to 10 & Straight Pipen & 125 \\
$\begin{array}{l}\text { Waste Oxide/Frit } \\
\text { Mixture }\end{array}$ & 1 & 40 & 3 to 10 & Straight Pipe & 125 \\
$\begin{array}{l}\text { Waste Oxide/Frit } \\
\text { Mixture }\end{array}$ & 2 & 40 & 3 to 10 & Straight Pipe & 125
\end{tabular}


Similarly, the 1/2-in. line was tested with flow maintained in both 1-in. and 2-in. lines. The system was then fiushed clean with water.

\subsubsection{Test Results}

Differential pressure measurements were made across straight sections of pipe over a predetermined range of flow rates. Tests were performed with water, dilute feed, concentrated feed, formatted feed, and melter feed. Test data is contained in Figures T-1 through T-15 of Appendix T. Figures 9.3 through 9.17 provide curve-fit plots of the data and calculated pressure drops with laboratory rheology and density data used with the methodology described in Section 9.1.2. The data from pressure drop tests were obtained with the slurry test loop (STL).

Preliminary results from testing with water as the test medium revealed a difference between the experimental pressure-drop values and calculated pressure-drop values. In all cases, the experimental values were less than the calculated values when used with a typical commercial steel pipe roughness $(e=0.00015)$. This difference between the calculated values (with $e=0.00015)$ and the experimental values for water testing is shown in Figures 9.3, 9.4, and 9.5 for 1/2-, 1-, and 2-in. straight pipes, respectively, with a water temperature of $50^{\circ} \mathrm{F}$. The figures indicate that the measured pressure drop was between that calculated for commercial pipe $(e=0.00015)$ and smooth pipe $(e=0)$ for the 2-in. and 1-in. pipe within measurement accuracy. The measured pressure drop in the $1 / 2$-in. pipe was slightly less than for smooth pipe. This $1 / 2$-in. pipe result was attributed to system measurement accuracy as substantiated by studies ${ }^{(a)}$ which indicated the pressure drop to be the same as for smooth pipes. An engineering assessment was performed to evaluate data accuracy (included as Appendix U). The conclusion was that the calculated values were derived with a roughness value higher than what actually exists in the STL system and that the experimental pressure-drop results given are, in fact, valid. It was concluded that the pipe used in the STL system has a roughness value between zero (perfectly smooth) and commercial steel $(e=0.00015)$. Consultation with several steel manufacturers confirmed that this is well within reason.

The experimental straight pipe test results were curve fitted with a polynomial equation, usually second-order. A second-order polynomial fit works well for turbulent flow, since pressure drop is usually a function of flow velocity squared. A linear plot is more suited to laminar flow, although a second order fit can work. For complex flow such as observed with melter feed in a 2-in. pipe, higher order polynomials are needed to reflect transition of laminar to turbulent flow. The data-fit equations may be used to predict pressure drop for any flow rate of any specific fluid included for the pipe diameter, pipe roughness, and fluid properties tested. Extrapolation and interpolation may be.performed for pipe sizes not included in this study. Calculation approaches to assess pipe flow pressure drop were evaluated to provide a methodology to determine pressure drop inexpensively from fluid laboratory properties data. This avoids large-scale and expensive testing with flow loops and slurry simulants.

Because of the large differences in pressure drops over the flow rate range for the different size pipes, the pressure drop versus flow rate for all three pipe sizes are shown separately for "readability."

(a) G. Abrigo, June 1994. Hydraulic Properties of Hanford Waste Vitrification Project $39-4$ Frit Slurries, PHTD-K1018, Pacific Northwest Laboratory, Richland WA. 


\section{WATER PRESSURE DROP AT 5OF 0.5 in. Dia. Sch. 40 Pipe $+e=0 \quad \Delta \quad e=.000150$ DATA}

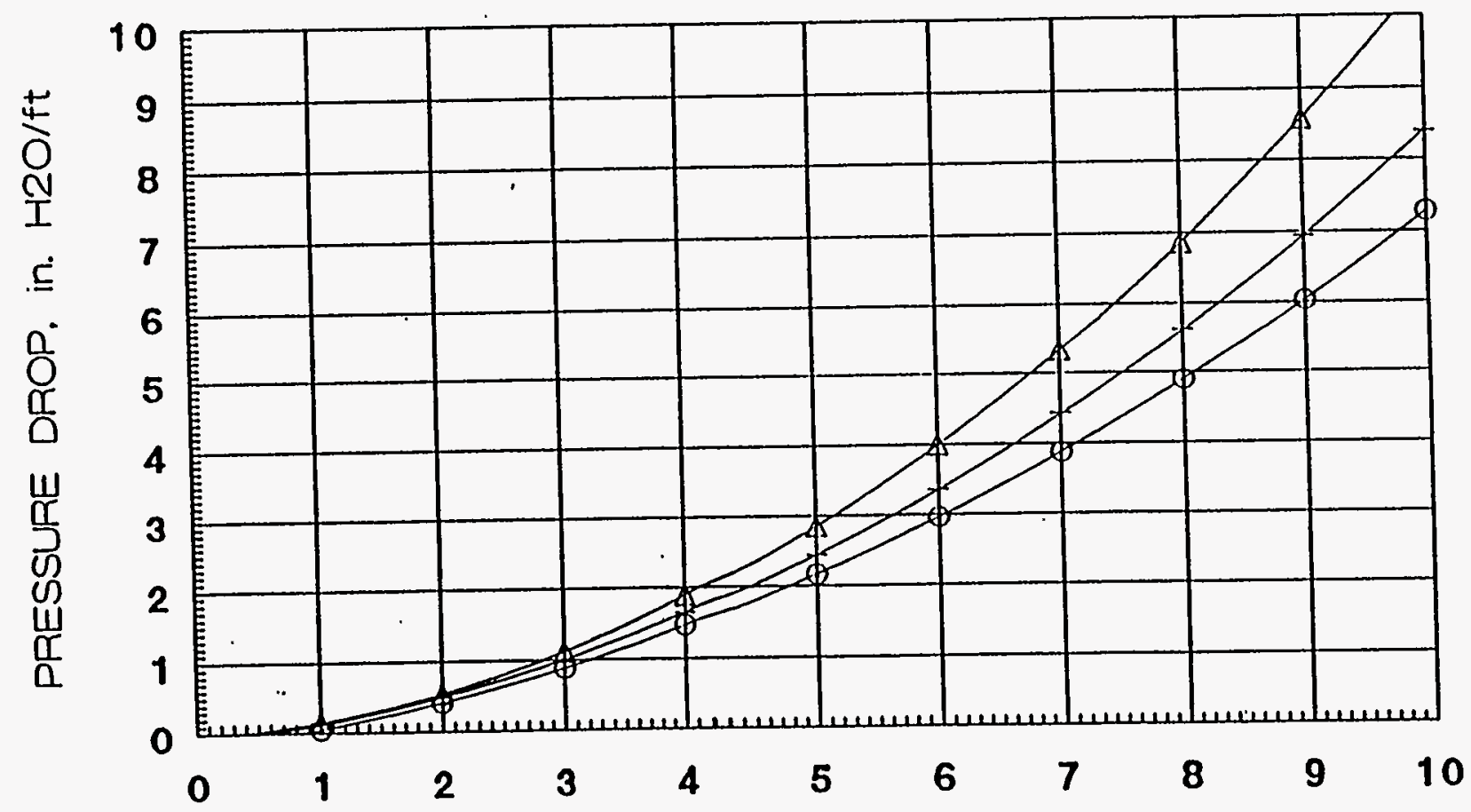

FLOW RATE, ft/s

Figure 9.3. Water-Flow Pressure Drop in $1 / 2$-in. Schedule 40 Stainless Steel Pipe at $50^{\circ} \mathrm{F}(\mathrm{e}=$ pipe roughness) 


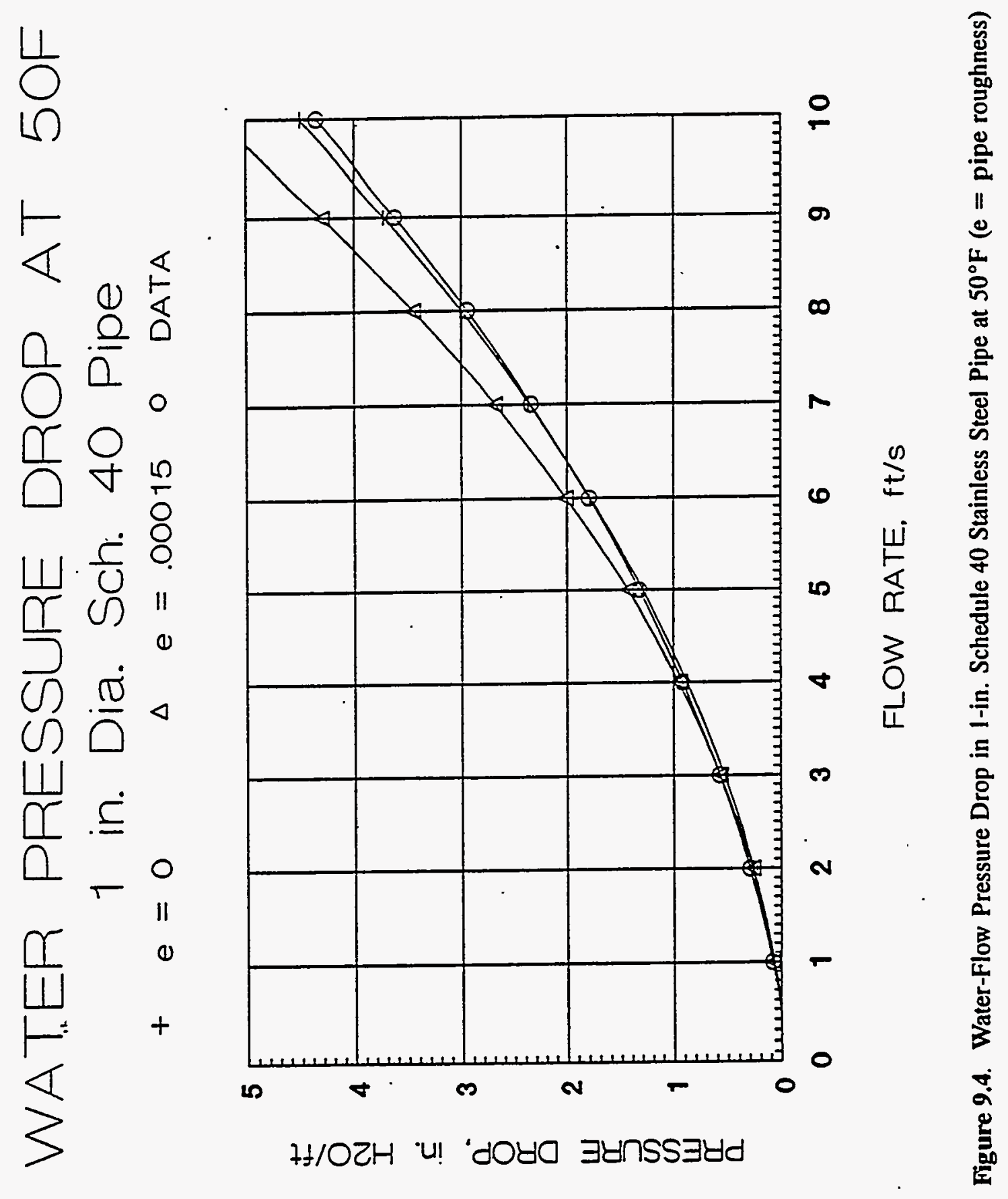




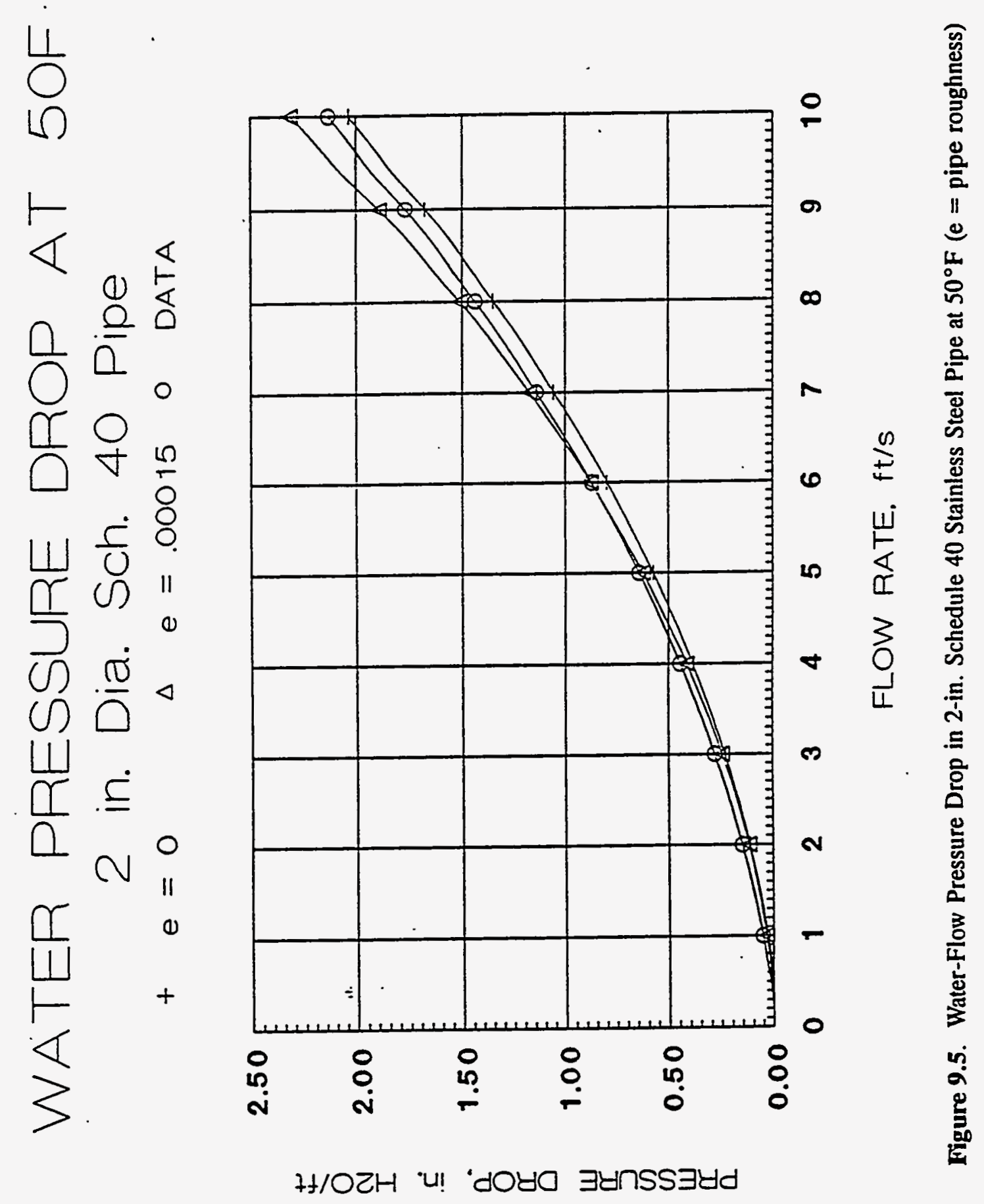




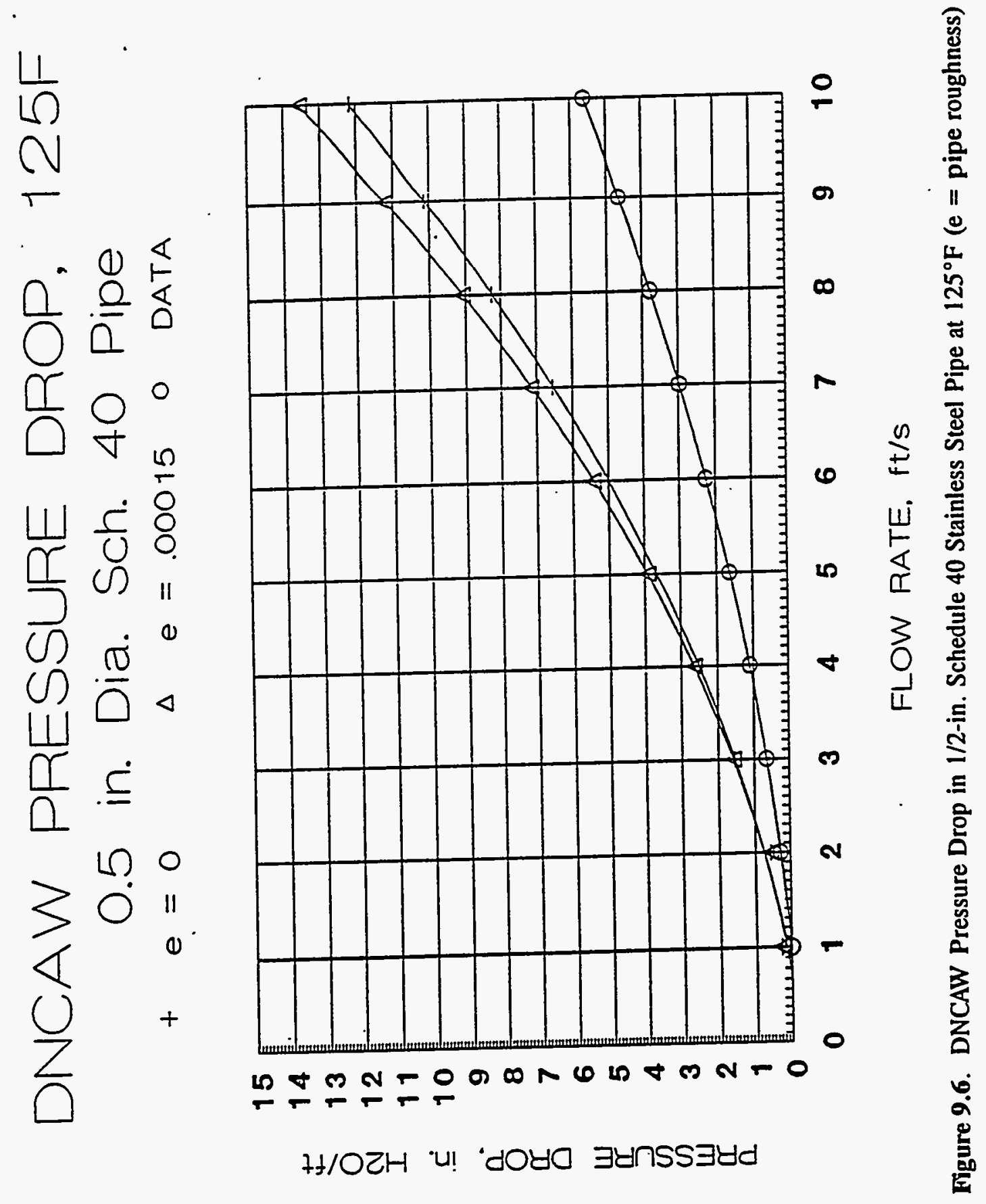



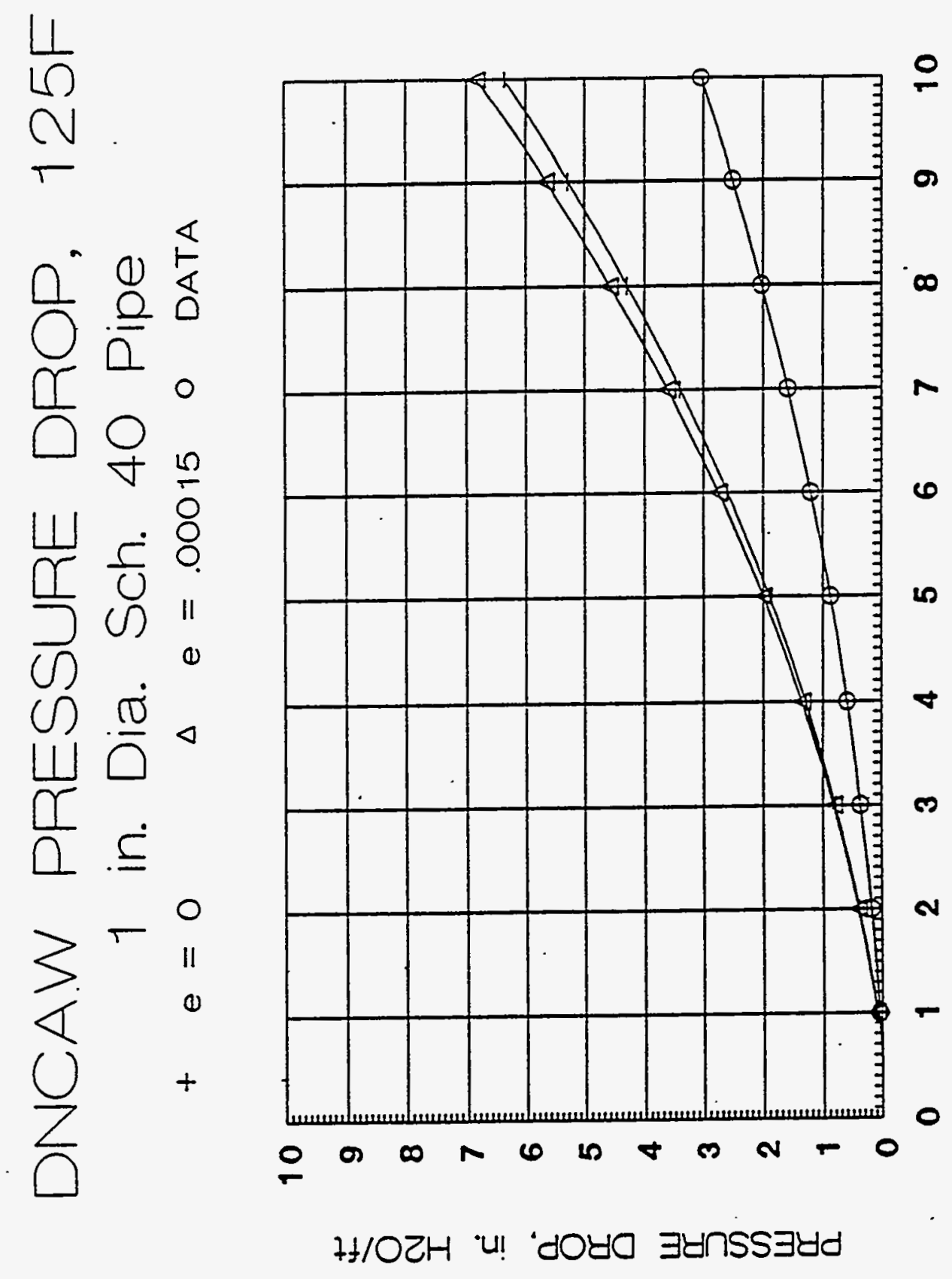

氛 


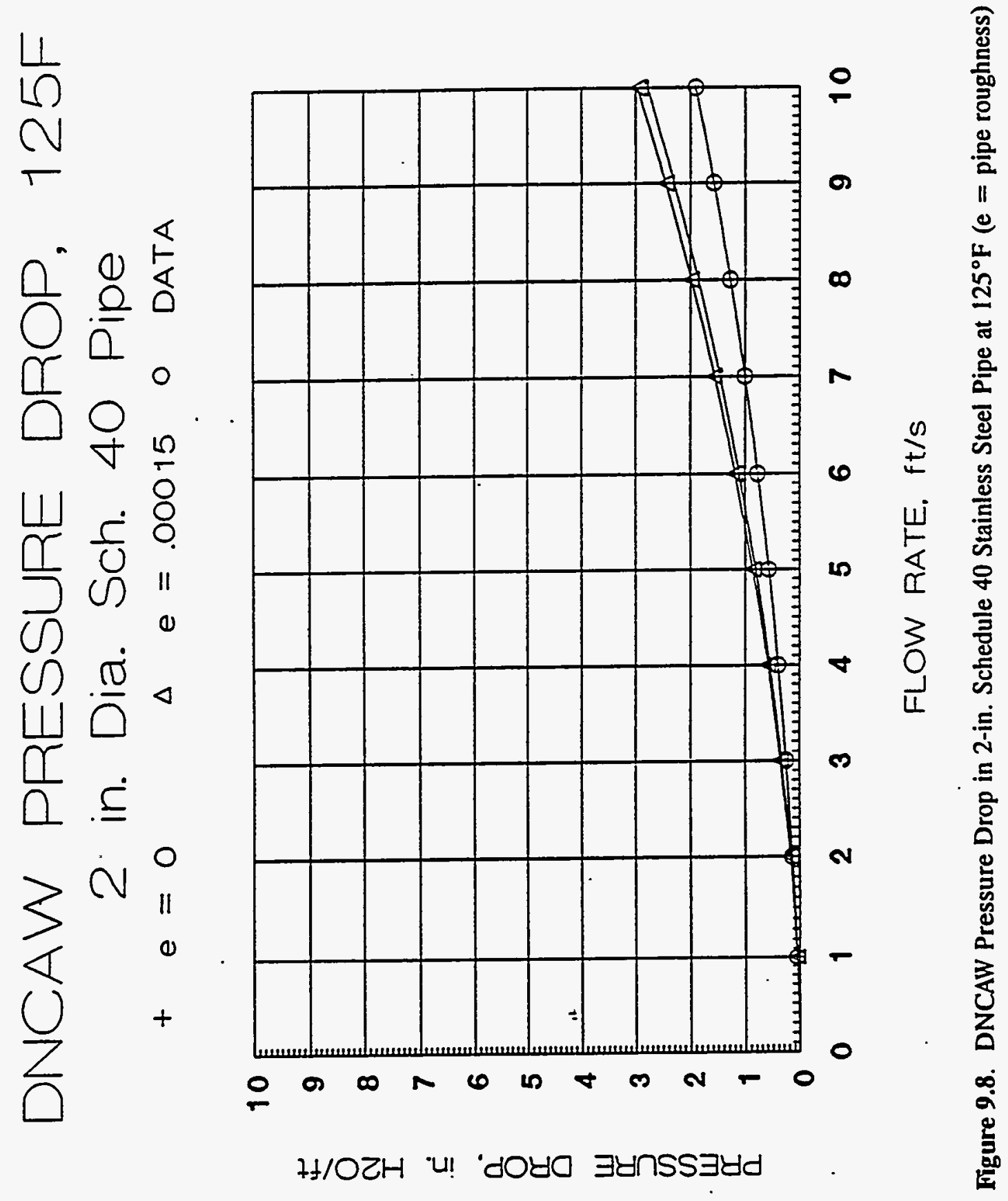




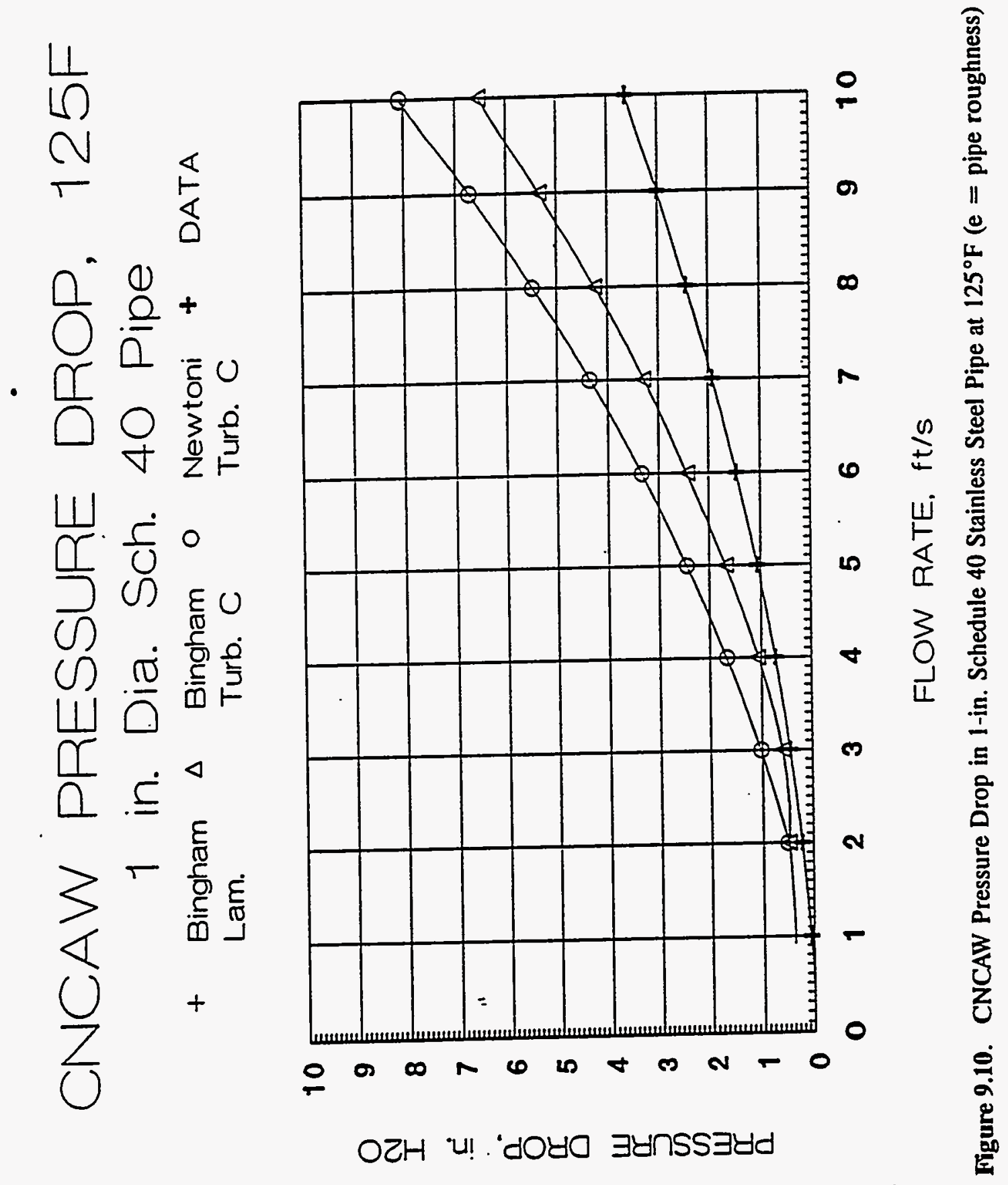




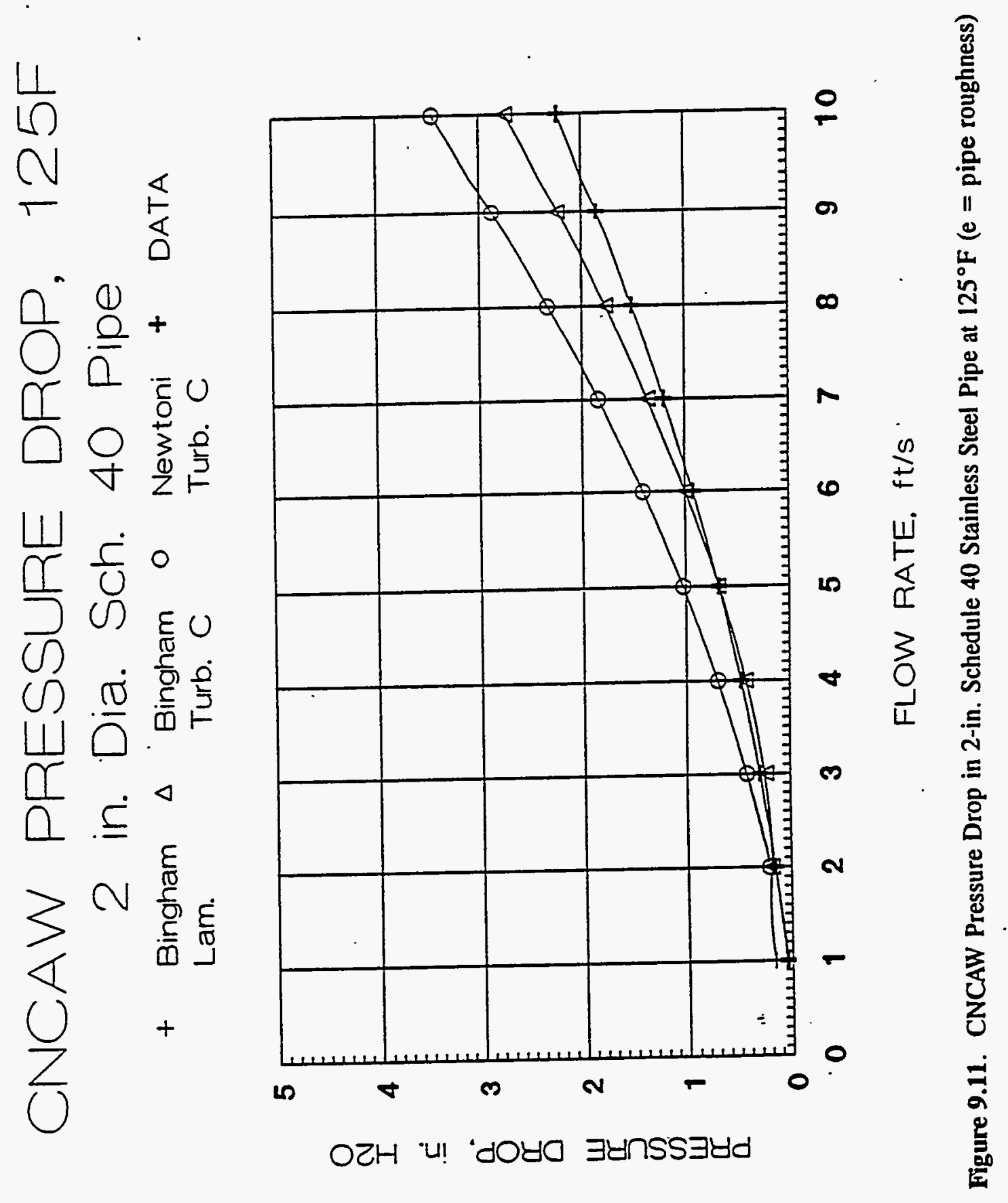




\section{FNCAW PRESSURE DROP, 125F \\ 0.5 in. Dia. Sch. 40 Pipe}

$\begin{array}{ll}\text { Bingham } \Delta \quad \begin{array}{l}\text { Bingham } \\ \text { Lam. }\end{array} & \begin{array}{l}\text { Newton } \\ \text { Turb. } C\end{array}\end{array}+$ DATA

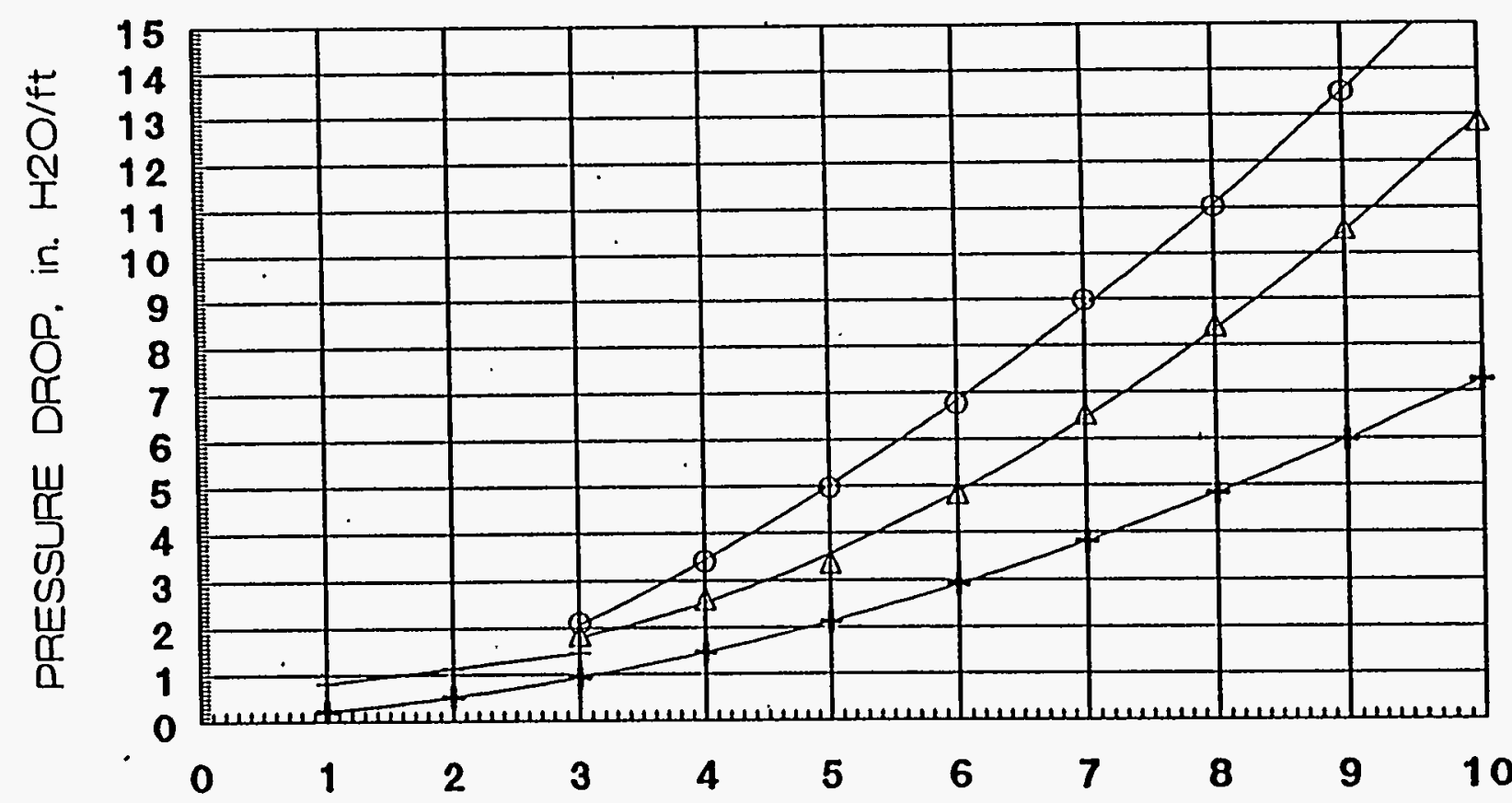

FLOW RATE, ft/s

Figure 9.12. FNCAW Pressure Drop in $1 / 2$-in. Schedule 40 Stainless Steel Pipe at $125^{\circ} \mathrm{F}(\mathrm{e}=$ pipe roughness) 


\section{FNCAW PRESSURE DROP, $125 \mathrm{~F}$ \\ 1 in. Dia. Sch. 40 Pipe}

+ Bingham $\Delta$ Bingham $\circ$ Newtoni + DATA Lam.

Turb. C Turb. C

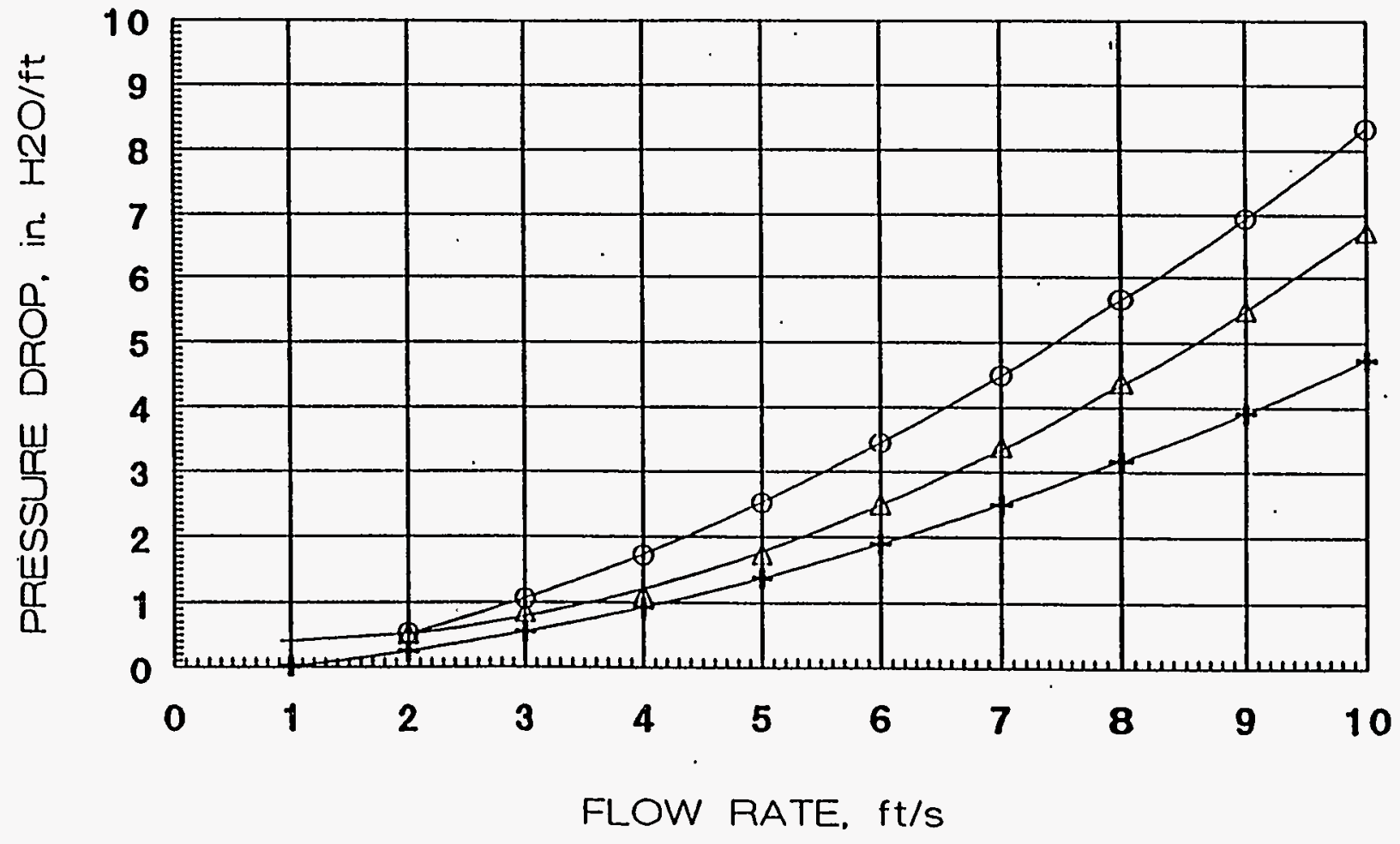

Figure 9.13. FNCAW Pressure Drop in 1-in. Schedule 40 Stainless Steel Pipe at $125^{\circ} \mathrm{F}(\mathrm{e}=$ pipe roughness) 
$\stackrel{4}{2}$

$\frac{8}{5}$

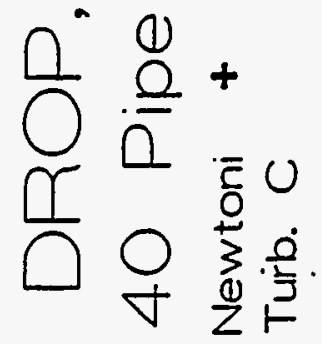

Ш

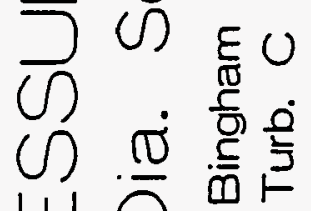

Ш

$\frac{\Upsilon}{\square} \subseteq \triangleleft$

$\sum_{\longleftarrow}{ }^{N}+$

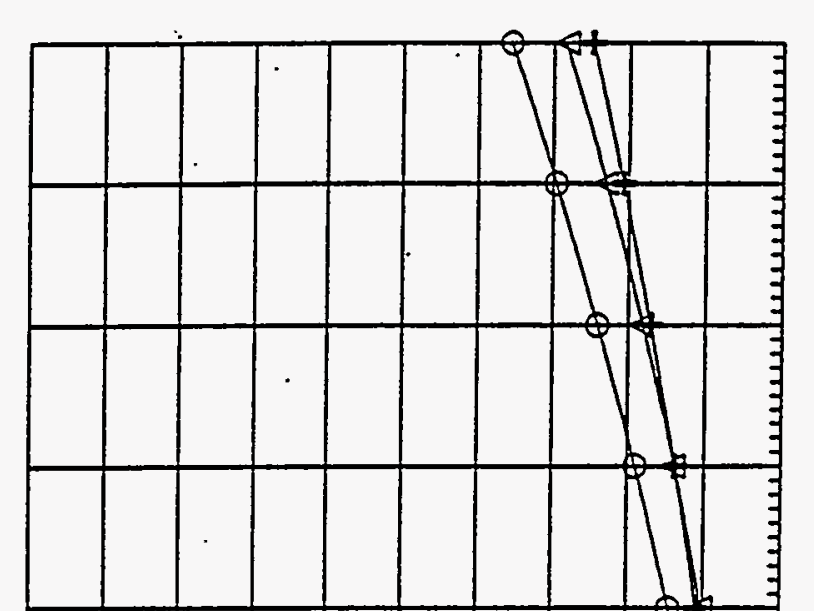

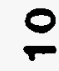

氙

0

$\infty$

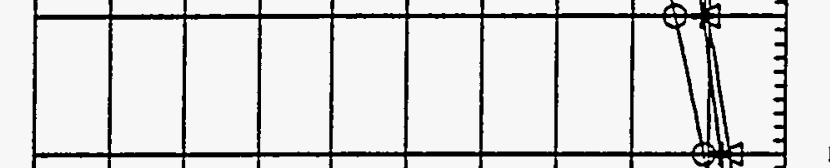

$\sim \stackrel{\infty}{ \pm}$

$0 \stackrel{4}{\infty}$

山 莺

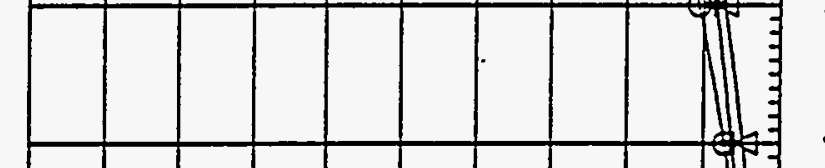

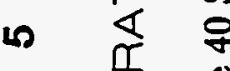

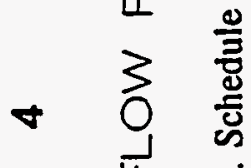

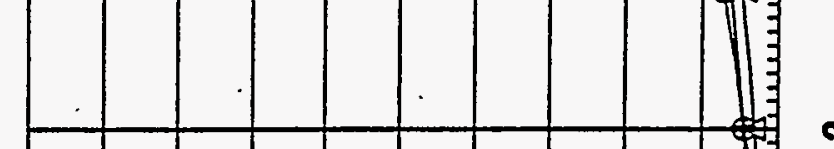

U

$\boldsymbol{\infty}$

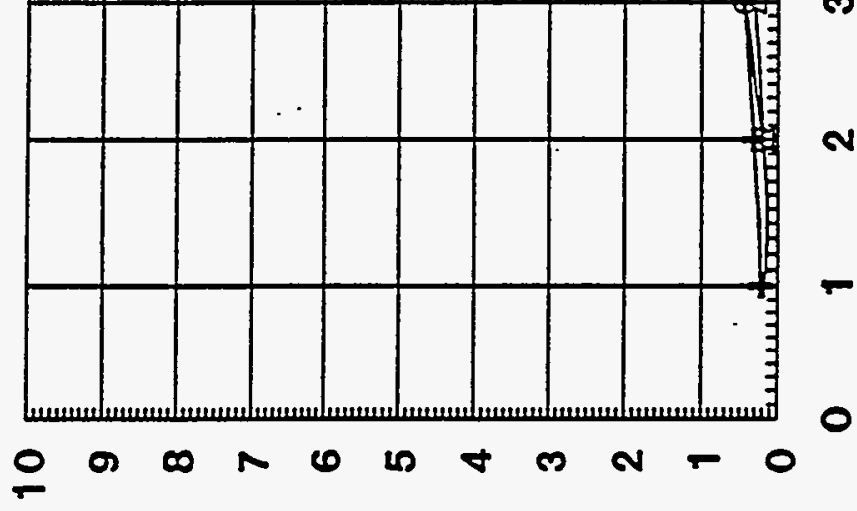

H/OZH U! 'dOHO $\exists U I S S \exists H d$ 


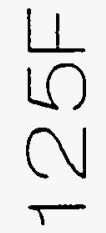

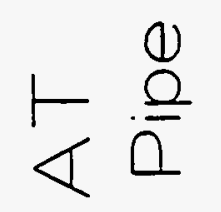

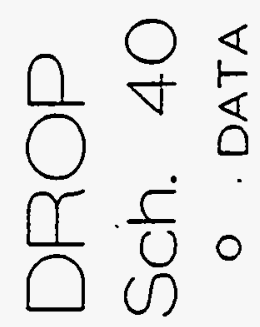

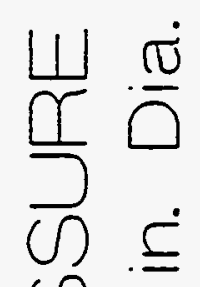

$(\Omega$

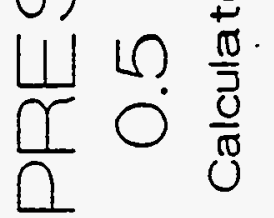

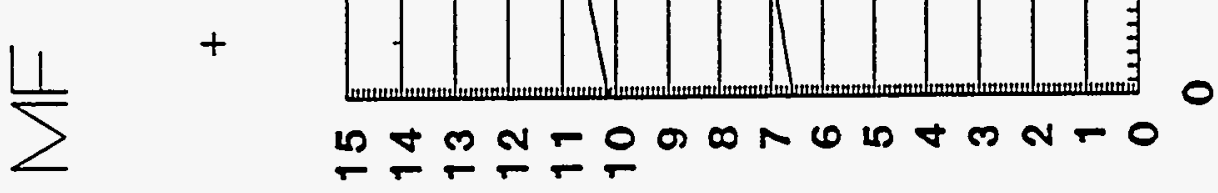

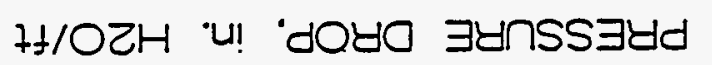




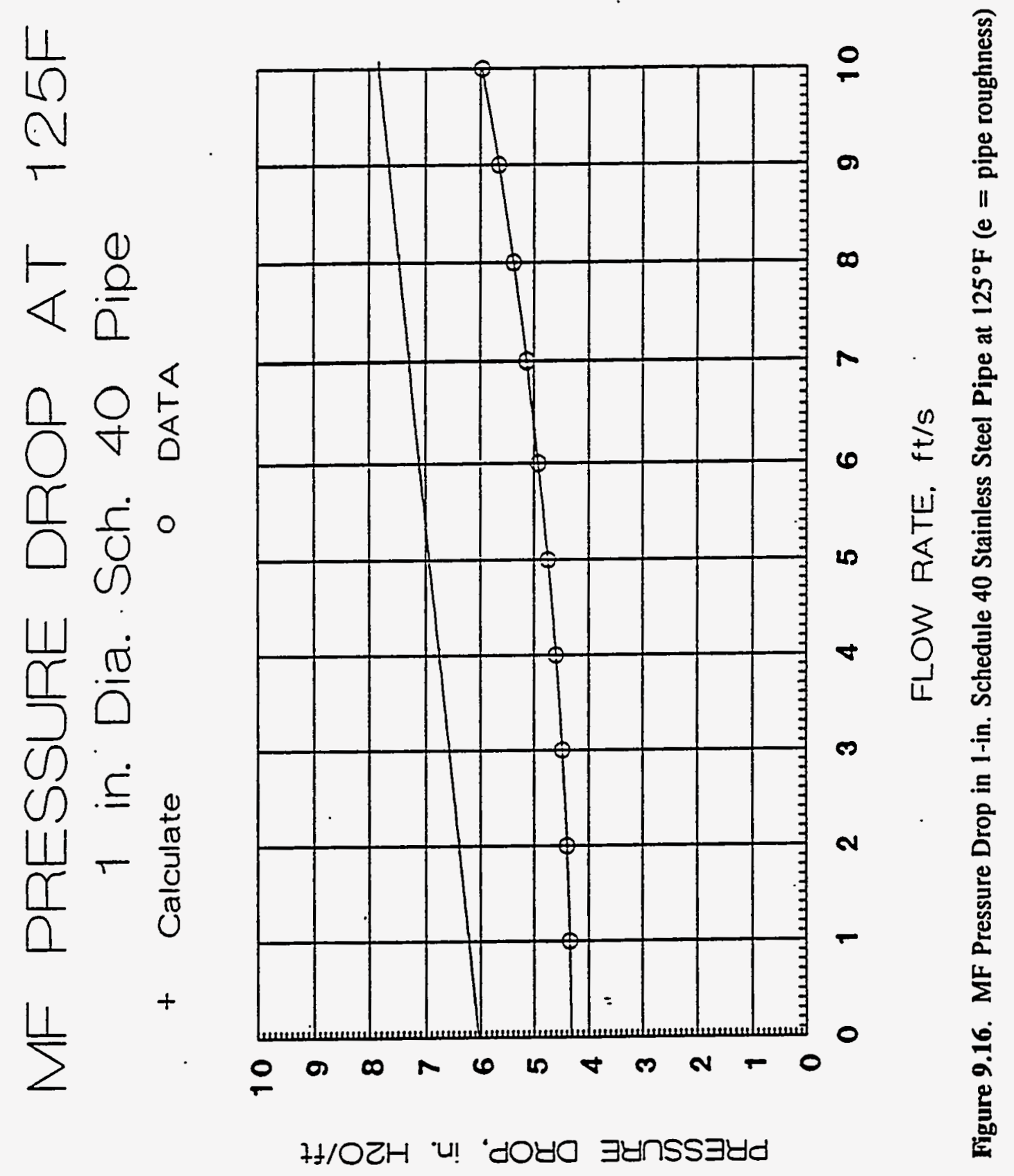




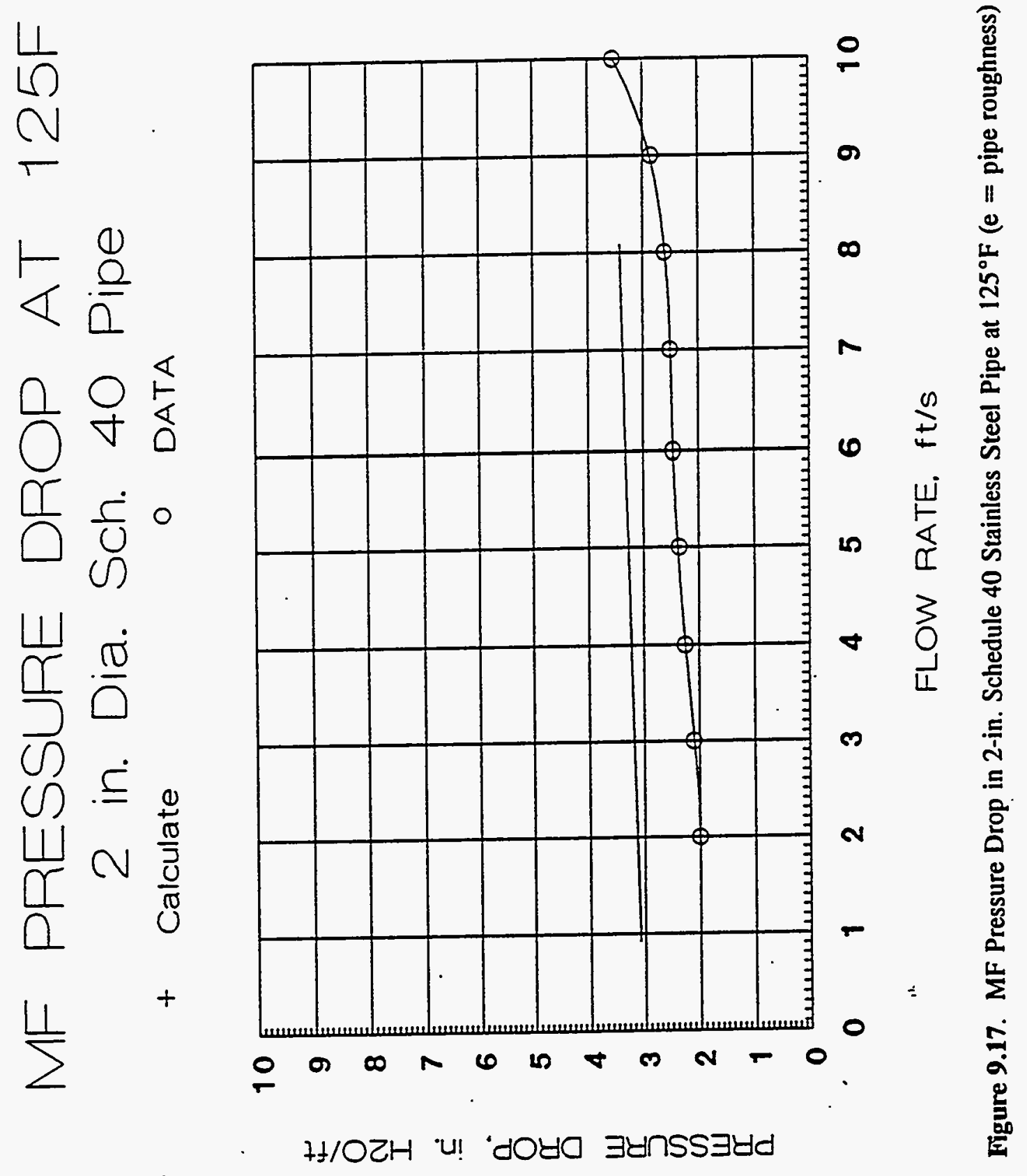


Figures 9.3 to 9.5 show results from water testing at approximately $50^{\circ} \mathrm{F}$. All other tests were performed at $125^{\circ} \mathrm{F}$. At $50^{\circ} \mathrm{C}$, water is a Newtonian fluid with a viscosity of $1.308 \mathrm{cP}$ and a density of $0.9997 \mathrm{~g} / \mathrm{ml}$. The water-flow tests were included for system verification and are discussed above in this section and in Appendix $U$. There does appear to be a trend that as the pipe diameter decreased the negative relative deviation between the calculated and measured pressure drop appears to increase. No explanation is offered for this behavior.

For the DNCAW, the type of flow was Newtonian (see Table 6.4). For the testing conditions, the viscosity of the DNCAW was $5.84 \mathrm{cP}\left(122^{\circ} \mathrm{F}\right)$ as compared to $1.3 \mathrm{cP}\left(50^{\circ} \mathrm{F}\right)$ for water, and the specific gravity of DNCAW was 1.03 (room temperature) as compared to 1.00 (room temperature) for water. As expected, the calculated pressure drop increased with flow rate for a given pipe diameter. Unexpectantly, the measured pressure drop decreased as compared to water for equivalent flow rate and pipe diameter. Also, the deviation between the calculated and measured pressure drop for equivalent conditions is significant. For the 0.5 -in. pipe, the measured pressure drop is roughly $46 \%$ of that calculated. As the pipe diameters increase the ratio of measured to calculated pressure drop increases to $46 \%$ and $62 \%$ for 1 -in.- and 2 -in.-diameter pipe, respectively. The reason for this behavior was not identified. As seen in subsequent analyses this behavior is characteristic. However, as the material becomes more viscous the agreement between calculated and measured values improves.

The CNCAW and FNCAW have interesting flow properties in that the rheogram flow properties are initially those of a Bingham plastic fluid between shear rates of 0 to $190 \mathrm{~s}^{-1}$ for CNCAW and 0 to $160 \mathrm{~s}^{-1}$ for FNCAW. Then the flow characteristics change to those of a Newtonian fluid. The measured flow properties and densities of the two fluids are similar (CNCAW: yield stress $=1.12 \mathrm{~Pa}$, plastic viscosity $=6.24 \mathrm{cP}$, Newtonian viscosity $=12.17 \mathrm{cP}$, specific gravity $=1.12 ;$ FNCAW: yield stress $=1.19 \mathrm{~Pa}$, plastic viscosity $=6.73 \mathrm{cP}$, and Newtonian viscosity $=13.04 \mathrm{cP}$, specific gravity =1.14). As would be expected the calculated and measured pressure drops are similar for equivalent test conditions, which also indicates reproducability of test and calculation results. Again, as the pipe diameter increases, the agreement between calculated and measured results improve from measured to calculated pressure-drop ratio of about $46 \%$ for 0.5 -in. diameter pipe to $80 \%$ in the 2 -in. pipe. At low flow rates in the 2-in. pipe there is agreement between calculated and measured values. The pressure drops of the slurries are about the same as the $50^{\circ} \mathrm{F}$ water and greater than that of DNCAW, as expected.

For the melter feed the type of flow was Bingham plastic (see Tables 6.13a and 6.13b). For testing conditions the yield stress $=24.5 \mathrm{~Pa}$, plastic viscosity $=10.6 \mathrm{cP}$, and specific gravity $=1.34$. The ratio of measured to calculated pressure drop remained roughly constant at about 0.7 for all conditions tested. In the 2-in. pipe at flows above $8 \mathrm{gpm}$ the flow became turbulent, which accounts for the nonlinearity indicated. The fluid flow was laminar for other conditions tested.

\subsubsection{Conclusions and Recommendations}

The following conclusions and recommendations resulted from the test:

- The baseline experimental pressure drop data with water as the test medium does not closely match pressure-drop calculations used with water and commercial pipe properties. Possibilities for this discrepancy have been analyzed, and the results indicate that the experimental data is valid within system measurement accuracy. Test results show that the tests are repeatable and show appropriate 
trends. The difference between experimental data and calculated pressure drop largely appears to be due to a difference in pipe roughness values used in the calculation and the actual roughness of the STL piping system.

- For the slurries tested, the calculated pressure drop is consistently greater than the measured pressure drop. This difference generally decreases as the pipe diameter increases and the slurry becomes more viscous. The reasons for this behavior have not been determined.

- The use of appropriate pressure-drop calculations based on commercial piping properties and slurry rheological and physical properties will provide conservative pipe system designs to achieve appropriate flow rates.

- Additional rheological studies are needed to ensure accurate and reproducible measurements for use in calculations.

- Additional STL studies are needed to ensure accurate measurements.

- Studies indicate that for the commercial stainless steel pipe tested, it is appropriate to use smooth pipe $(e=0)$ for calculations. This simplification greatly assists the ease for calculating pressure drops for non-Newtonian fluids.

- The STL testing procedures should be modified; including re-zeroing the instrumentation before a test whenever non-zero values are displayed.

- Results from slurry tests with melter feed have indicated that initial estimates for the calibration range of pressure instrumentation are overly conservative. The pressure transmitters should be recalibrated with the following ranges:

2 in. straight: 0 to 150 in. $\mathrm{H}_{2} \mathrm{O}$

1 in. straight: 0 to 250 in. $\mathrm{H}_{2} \mathrm{O}$

$1 / 2$ in. straight: 0 to 350 in. $\mathrm{H}_{2} \mathrm{O}$

\subsection{Melter Feeding}

The performance of the meiter-feed system is discussed in this section.

\subsubsection{Test Approach}

Data collection of the pressure drop and flow measurement of melter feed in the melter feed line was conducted during the liquid-fed ceramic meiter run (LFCM)-8. The SIPT equipment operation consisted of operating the transfer and feed pump, sample pump, and recording data on the DAS.

\subsubsection{Test Results}

The melter feeding testing results are subsequently discussed. 


\subsubsection{Melter Feed Tube Pressure Drop Versus Flow Rate}

Data Description. The required flow in the melter feed line was set by adjusting the speed of the transfer/feed pump. Because the melter feed-line pressure-drop and flow data was obtained during an actual melter run, it represents actual operating conditions and does not fully characterize the pressure drop of the melter feed line across the design flow range. Also, because of the changes made in the melter feed line (see Chapter 5.0) to achieve the required flow rates, the melter feed line was not prototypic of the HWVP design. The data applies to the configuration described in Chapter 5.0 and not necessarily the prototypic HWVP design.

The data from the LFCM-8 run was recorded by the DAS every 15 seconds, resulting in a large amount of data. The number of data points was reduced by averaging every four data points, giving the equivalent of one data point every minute. The data that is used in generating the plots included in Appendices $\mathrm{V}$ and $\mathrm{W}$ are the average data points per minute.

The flow rate in the melter feed line, FI-1023; the pressure in the recycle loop, PI-1020; and the two pressures in the melter feed line, PI-1033 and PI-1034, are plotted together as a function of time for the duration of the LFCM-8 run. These plots are shown in Appendix V. The flow rate plot is shown in bold on the plots. An examination of this data reveals time of obvious perturbations to the flow. By reviewing the LFCM log book and the SIPT Laboratory Record Book (LRB), most but not quite all, of the perturbations can be explained by events recorded in one of these records. An extraction of the recorded events that impact the flow is shown in Appendix X.

Pumping of feed to the melter started at 1:50 p.m. on April 17, 1993, and some adjustments were made to obtain the desired flow rate. Data recording started at 4:00 p.m. and continued for 12 days until 6:00 p.m. on April 29, 1993 (290 h). The major perturbations shown on the plots in Appendix V are attributable to shutting the feed off, flushing water from the 3-way valve forward through the feed nozzle and backward through the cross flow strainer, and changes in the transfer/feed pump speed to increase or decrease the flow rate. Some changes in flow rate were observed when the sample pump was started to take samples of feed from HB-15. A few changes or perturbations to the flow rate are noted in the LRB or log book without any apparent cause. Most, if not all, of these unexplained fluctuations in flow rate were caused by plugging or build-up of material in the feed line or the sudden release of built-up material. Indeed, just such an event was observed several times during the course of the LFCM-8 run on the tip of the nozzle.

Pressure Drop and Flow Analysis Across Melter Feed Line. To examine the changes in the melter feed line pressure drop versus flow, the run data was analyzed for periods when the least amount of melter feed line build-up was expected to have occurred. It was determined that these periods occurred after each melter feed line flushing event. Feed line flushing occurred periodically during melter feeding and was performed more frequently toward the end of the melter test. The frequency of flushing is discussed in Section 9.2.2.2.

The pressure in the melter feed line was measured with pressure transmitters: PI-1020, PI-1033, and PI-1034 (See Appendix A). PI-1020 is located on the 2-in. return line, several feet after the crossfiow strainer. Part of the simulated melter feed is diverted through a cross flow strainer to the melter feed loop, which includes a pressure instrument (PI-1033), 3/8-in. pipe (0.423 in. ID), a 3-way melter feed slurry valve, a flow meter (FI-1023), several elbows, a pressure instrument (PI-1034), 3/8-in. tubing (0.245-in. ID), and the melter feed nozzle. Part of the 3/8-in. tubing was coiled into a 
helix to provide enough flow restriction in the line to control the flow of the melter feed. Between $4 / 17 / 93$ (14:45) and 4/29/93 (1:26) an 8-ft coiled jumper (3/8-in. tubing) was used as the melter feed line restriction.

The feed line flushes that occurred during this time were identified and 5-min of process data was averaged after each flush occurrence. This average was calculated after a 5-min delay from flushing to provide time for the fiush water to be completely purged from the system. The data averages consisted of not only the melter feed-line pressures and flows but also the pressure and fiow data from the recycle loop. The recycle loop data was used to compare and support any rheological changes in the feed material.

The pressure-drop data from the melter feed through the melter feed line was expected to maintain either laminar or turbulent flow, depending on flow rate. The melter feed-line pressure drop and flow data were plotted against one another to verify this relationship. As previously described, the 5-min averaged post-fiush data was used to plot this information for different sections of the melter feed line. The first section was from the recycle loop downstream of the cross flow strainer (PI-1020) to the downstream side of the 3-way water flush valve (PI-1034). (See Appendix A for the layout.) The plot of this pressure drop data versus melter feed-line flow rate is shown in Figure 9.18.

As seen by the pressure drop versus fiow data in Figure 9.18, there is substantial scatter in the data. The pressure drop data at $0.24 \mathrm{gpm}$ ranges from approximately 6.0 to $6.7 \mathrm{psi}$. When the impacts of the error bars are included in the analysis no apparent trend in the data is obvious.

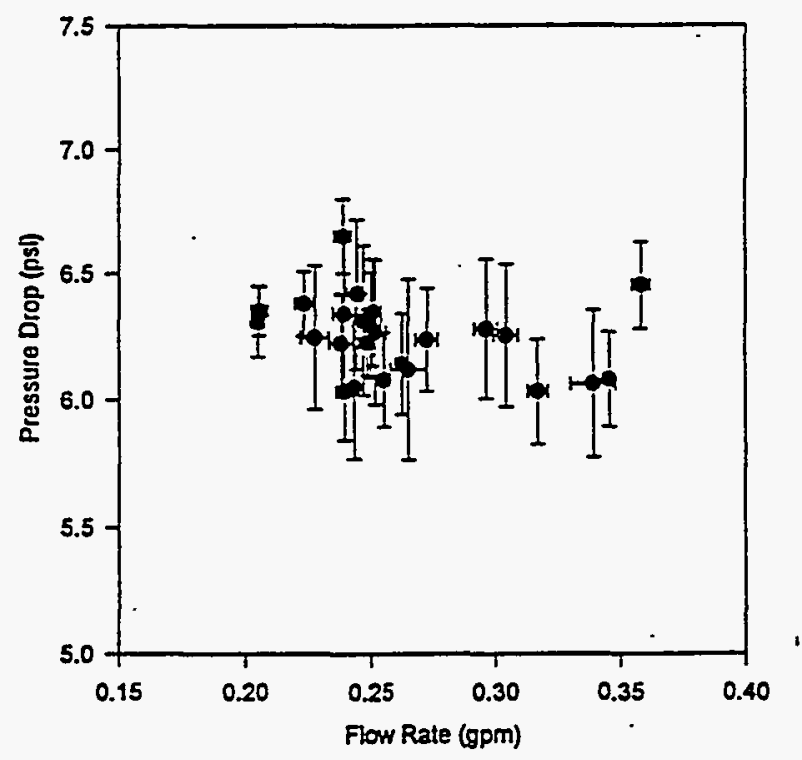

Figure 9.18. Pressure Drop (PI-1020 - PI-1034) Versus Flow (FI-1023) for First Two Parts of the Melter Feed-Line Section 
A second section within the meiter feed line was also analyzed for post-flush performance. This section extended from downstream of the 3-way water flush valve (PI-1034) to the outlet of the melter feed nozzle. The melter feed nozzle outlet extends into the melter plenum, which is kept under a slight vacuum. This vacuum, however, is only a few inches of water, which makes the feed nozzle outlet pressure effectively atmospheric. Figure 9.19 shows the post-flushing pressure drop versus flow performance across this final section of the melter feed line.

As mentioned previously, the time period for which the post-flushing data was collected corresponded to the time that an 8-ft restrictive coil was installed between the 3-way fush valve and the melter feed nozzle. Therefore, the pressure drop versus flow data in Figure 9.19 is for that 8 -ft section. Once again, as in Figure 9.18, the data scatter in Figure 9.19 shows a lack of pressure drop dependency on flow rate.

The effect of time on the data was examined to see if any rheological or system changes could have occurred over the course of testing. The use of the high lithia HWVP 6/34 frit for the test posed some initial theology concerns, which made potential long-term effects suspect.

The first step in this examination was to predict whether laminar or turbulent flow was occurring in the melter feed line over the flow ranges tested. These flows varied from approximately $0.20 \mathrm{gpm}$ to $0.35 \mathrm{gpm}$. For this flow range, Reynold Numbers were first calculated with the rheological properties for water. These Reynold Numbers and the velocity through the melter feed line are shown in Table 9.2.

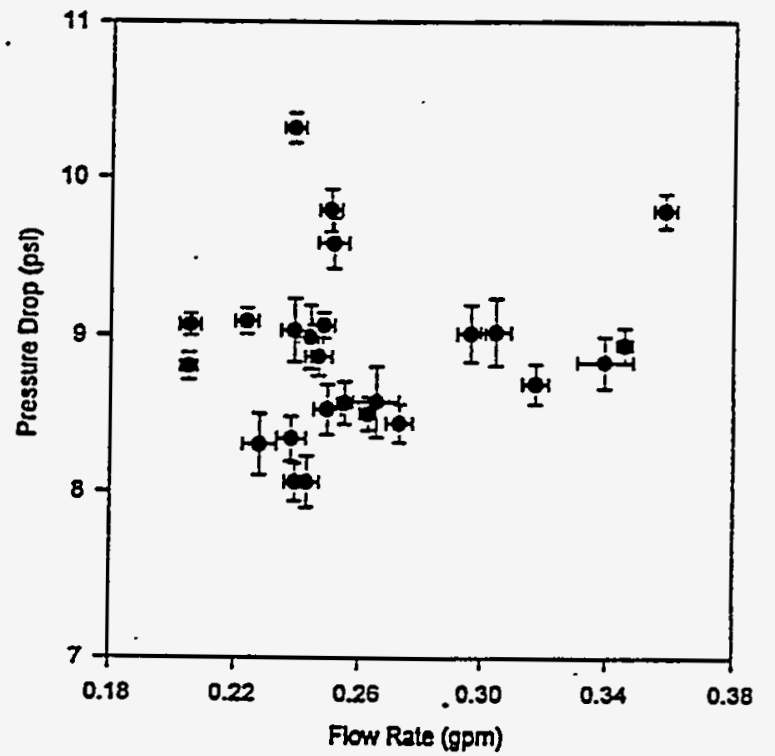

Figure 9.19. Pressure Drop (PI-1034 - $1 \mathrm{~atm}$ ) Versus Flow (FI-1023) for Last Part of the Melter Feed-Line Section (8-ft coil) 
Table 9.2. Velocity and Reynolds Number for Water at Test Flow Rates

$\begin{array}{ccc}\text { Line Size } & \begin{array}{c}\text { Velocity (ft/s) } \\ {[0.20 \mathrm{gpm} \text { to } 0.35 \mathrm{gpm}]}\end{array} & \begin{array}{c}\text { Reynolds Number } \\ \text { for Water }\end{array} \\ \text { 3/8 in.-tube (0.245 in. ID) } & 1.361 & 2550.8 \\ & 2.382 & 4463.9 \\ \text { 3/8 in.-pipe (0.423 in. ID) } & 0.457 & 1477.4 \\ & 0.799 & 2585.5\end{array}$

The Reynolds Number was calculated (Appendix $Y$ ) with the use of water properties with a density of approximately $1 \mathrm{~g} / \mathrm{mL}$ and a viscosity of $1 \mathrm{cP}$. According to Crane, flow is not turbulent until $\operatorname{Re}>4000$ (greater than transition flow). Water flowing through most of melter feed test lines, moving at the same flow rate as the simulated melter feed, is not turbulent (except for the 3/8-in. tubing at $0.35 \mathrm{gpm})$. Because the viscosity of melter feed is much higher than water, it is reasonable to conclude that flow of the waste simulant into the melter was laminar.

The Bingham/Reynolds Number for the waste simulant in the meiter feed test line was also calculated with experimental values for density and effective viscosity (Appendix $Y$ ). The results of these calculations are shown in Table 9.3. The simulated melter feed density was approximately $1.3 \mathrm{~g} / \mathrm{mL}$, and the calculated effective viscosity ranged from $46 \mathrm{cP}$ to $360 \mathrm{cP}$ depending on the fluid velocity and pipe diameter. The maximum viscosity required for the flow to be turbulent was approximately $1 \mathrm{cP}$ (the viscosity of water). Since the Re were all substantially less than 4000 and the viscosity of the melter feed is substantially higher than water, the flow in the melter feed line (3/8-in. pipe and 3/8-in. tubing) between PI-1033 and PI-1034 is again concluded to be laminar.

Table 9.3. Velocity and Reynolds Number for Simulated Melter Feed

\begin{tabular}{|c|c|c|}
\hline Line Size & $\begin{array}{c}\text { Velocity }(\mathrm{ft} / \mathrm{s}) \\
0.20 \mathrm{gpm} \text { to } 0.35 \mathrm{gpm}\end{array}$ & $\begin{array}{l}\text { Reynolds Number for } \\
\text { Waste Simulant }\end{array}$ \\
\hline $3 / 8$ in.-tube (0.245 in. ID) & $\begin{array}{l}1.36 \\
2.38\end{array}$ & $\begin{array}{r}44 \\
130\end{array}$ \\
\hline $3 / 8$ in.-pipe (0.423 in. ID) & $\begin{array}{l}0.46 \\
0.80\end{array}$ & $\begin{array}{r}5 \\
16\end{array}$ \\
\hline
\end{tabular}


Since a laminar flow regime was expected in the melter feed line, the approximate Buckinham's equation suggests that the pressure drop divided by the flow rate should remain constant over time if the physical properties of a fluid and the system piping are unchanged. Therefore, a plot of pressure drop divided by the flow rate versus time should yield a straight (constant) line. To check this prediction, plots were generated for the melter feed line section between PI-1020 and PI-1034, as well as for the section between PI-1034 and the melter plenum. These plots are shown in Figures 9.20 and 9.21 , below.

Figures 9.20 and 9.21 show that the pressure drop over flow-rate parameter for each melter feedline section changes considerably with time. Buckingham's equations suggests that this change could be due to changes in the effective viscosity $\left(\mu_{e}\right)$ of the material or the diameter of the piping in the system. The pipe diameter was not expected to have changed during the test, therefore, rheological dependencies were examined. The daily apparent viscosity analyses performed during meiter feeding. were analyzed for changes with time. Since Bingham plastic behavior was observed during these analyses, the apparent viscosity at only one viscometer shear rate $\left[100 \mathrm{~s}^{-1}\right]$ was accumulated from each analysis (see Section 6.0). This dato was obtained for identifying rheological trends and not for quantitative evaluations; however, it should correspond to the apparent viscosity. Figures 9.20 and 9.21 show this viscosity information superimposed on the melter feed line information. Indeed, the general trends in melter feed-line pressure drop over flow rate versus time appear to follow those in the viscosity data, as suggested by Buckingham's equation.

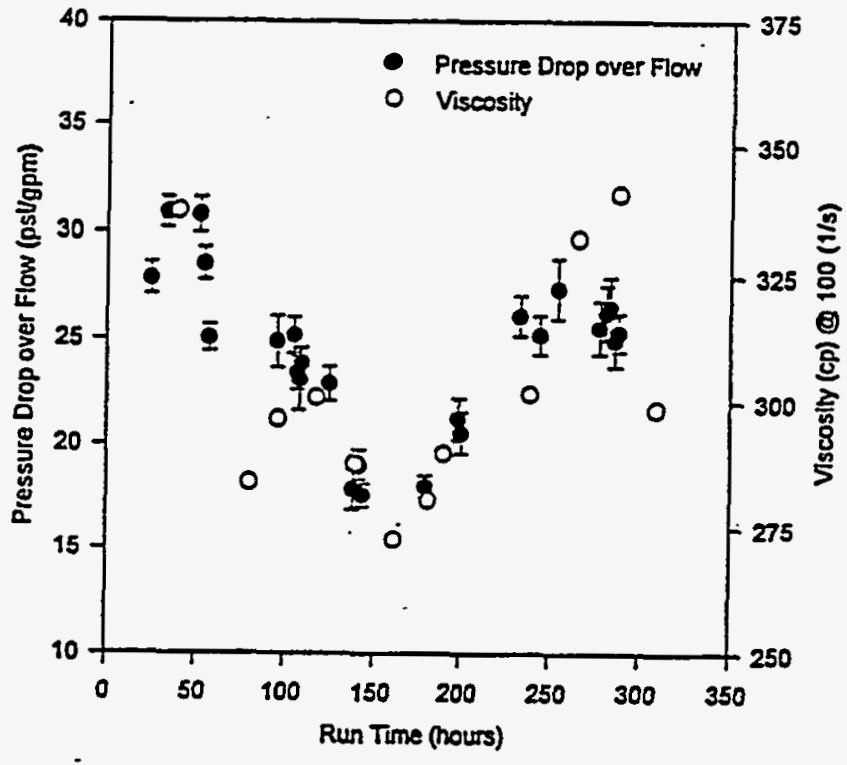

Figure 9.20. Melter Feed-Line Pressure Drop (PI-1020 - PI-1034) Divided by Flow (FI-1023) Versus Run Time (from 4/17/93 12:00 a.m.), [0.20 to $0.35 \mathrm{gpm}]$ 


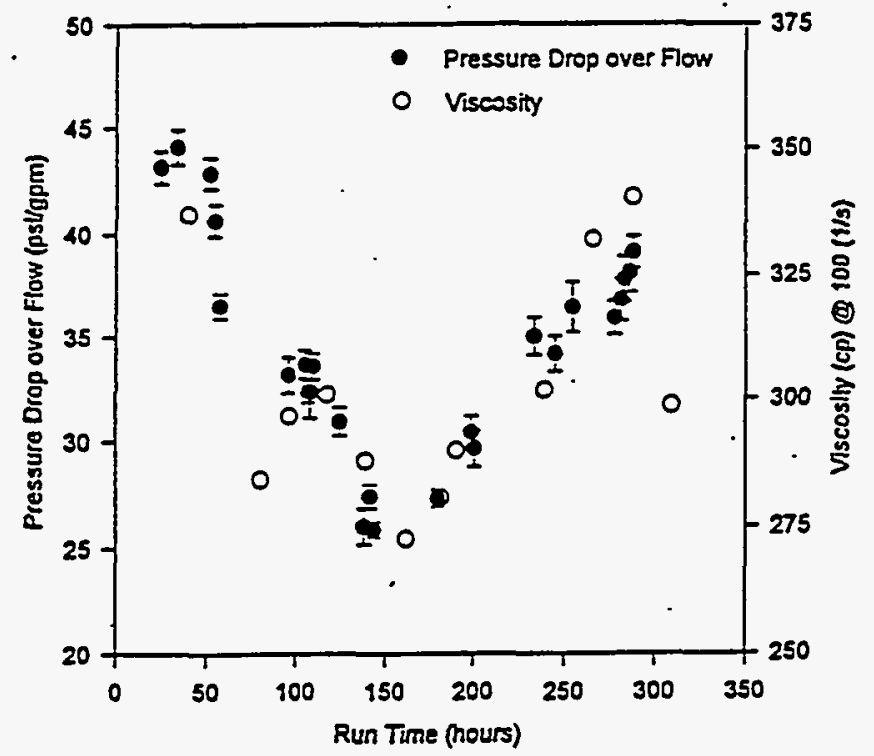

Figure 9.21. Melter Feed-Line Pressure Drop (PI-1034 - $1 \mathrm{~atm}$ ) Divided by Flow (FI-1023) Versus Run Time (from 4/17/93 12:00 a.m.), [0.20 to $0.35 \mathrm{gpm}$ ]

The viscometry information, shown in Section 6.0, shows large swings in yield stress over time. These swings visually support the rheology changes being described. Some slight deviations between the apparent viscosity and melter feed-line trends could be due to delays in the viscosity analyses from the time of sampling. Most samples were analyzed within $3 \mathrm{~h}$ of sampling and were kept at $50^{\circ} \mathrm{C}$ up until analysis; however, the temperature alone may not have fully simulated tank conditions. Hence, the apparent viscosity data in Figures 9.20 and 9.21 was plotted against sampling time, not analysis time.

The melter feed-line data was taken from segments following line flushing so that pipe build-up could be kept at a minimum. Because of the scatter observed in the pressure-drop versus flow data for the melter feed line; a backup analysis of an independent part of the feed system was performed to substantiate that the rheological changes were the primary influences in the scatter. The data analyzed to support this theory was obtained from the 2-in. recycle loop of the melter-feed system.

To plot this information correctly, calculations showing laminar or turbulent behavior in this piping section were done, similar to those for the melter feed line. The same melter feed flowed through this line but at higher velocities ( $77 \mathrm{gpm}$ to $90 \mathrm{gpm}$, FI-1020). With the same values (as for the melter feed-line calculations) for waste simulant properties, the resulting Reynold Number ranged from 1350 to 1800 . The calculated effective viscosity ranged from 98 to $110 \mathrm{cP}$. However, even though this suggests that the recycle loop flow was in the laminar region, it was decided to plot the pressure drop over 


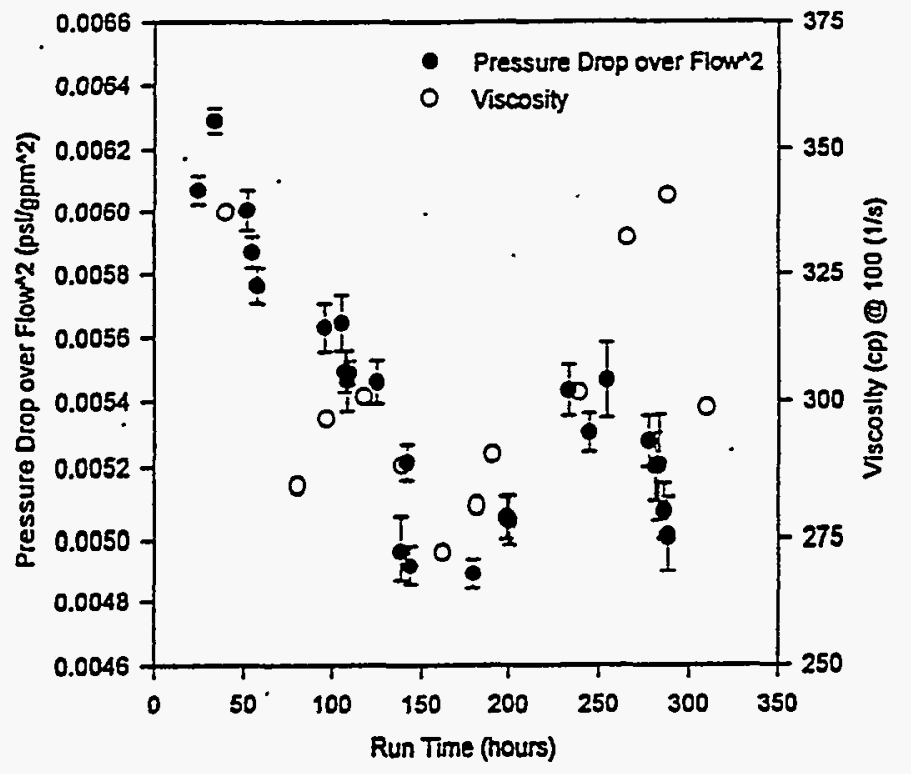

Figure 9.22. Recycle-Loop Pressure Drop (PI-1031 - PI-1020) Divided by Flow (FI-1024) Squared Versus Run Time (from 4/17/93 12:00 a.m.), [77 to 90 gpm]

the square of the flow rate versus time due to the closeness to the transition range. This approximate square dependency of pressure drop on flow rate was discussed previously in Section 9.1.2.3. This recycle loop plot is shown in Figure 9.22. Even if a non-squared normalization were chosen the comparison would not be drastically different because an apparent dependence on rheology, even in the larger pipe size, would still remain.

Indeed, the results of the recycle pressure drop over flow rate squared versus time plot show the same sorts of trends with apparent viscosity as did the melter feed-line data. Because the recycle loop was a 2-in. line and the melter feed line was a 3/8-in. line, size effect on the data appears to be minimal. Feed rheology appears to be the dominating factor in melter feed-line pressure drop versus flow dependencies rather than material build-up in the melter feed loop during the post-fiush time periods examined.

Since the relationship between pressure drop and flow appears to depend on rheology of the slurry, the viscosity data from samples of the simulated melter feed were compared with other properties of the simuiant to determine any other condition that affects viscosity and, therefore, the pressure drop versus flow characteristics. Specifically, three things were examined: oxide concentration of the simulated melter feed, $\mathrm{pH}$, and temperature. These three characteristics are plotted with the viscosity in Figure 9.23. 


\begin{tabular}{|c|c|c|c|}
\hline$\times$ OXIDE $(g /)$ & $\begin{array}{l}\text { D VISCOSITY @ } \\
100(1 / s)\end{array}$ & $\begin{array}{l}\triangle 10 X \\
\text { TEMPERATURE }\end{array}$ & - PH FROM METER \\
\hline
\end{tabular}

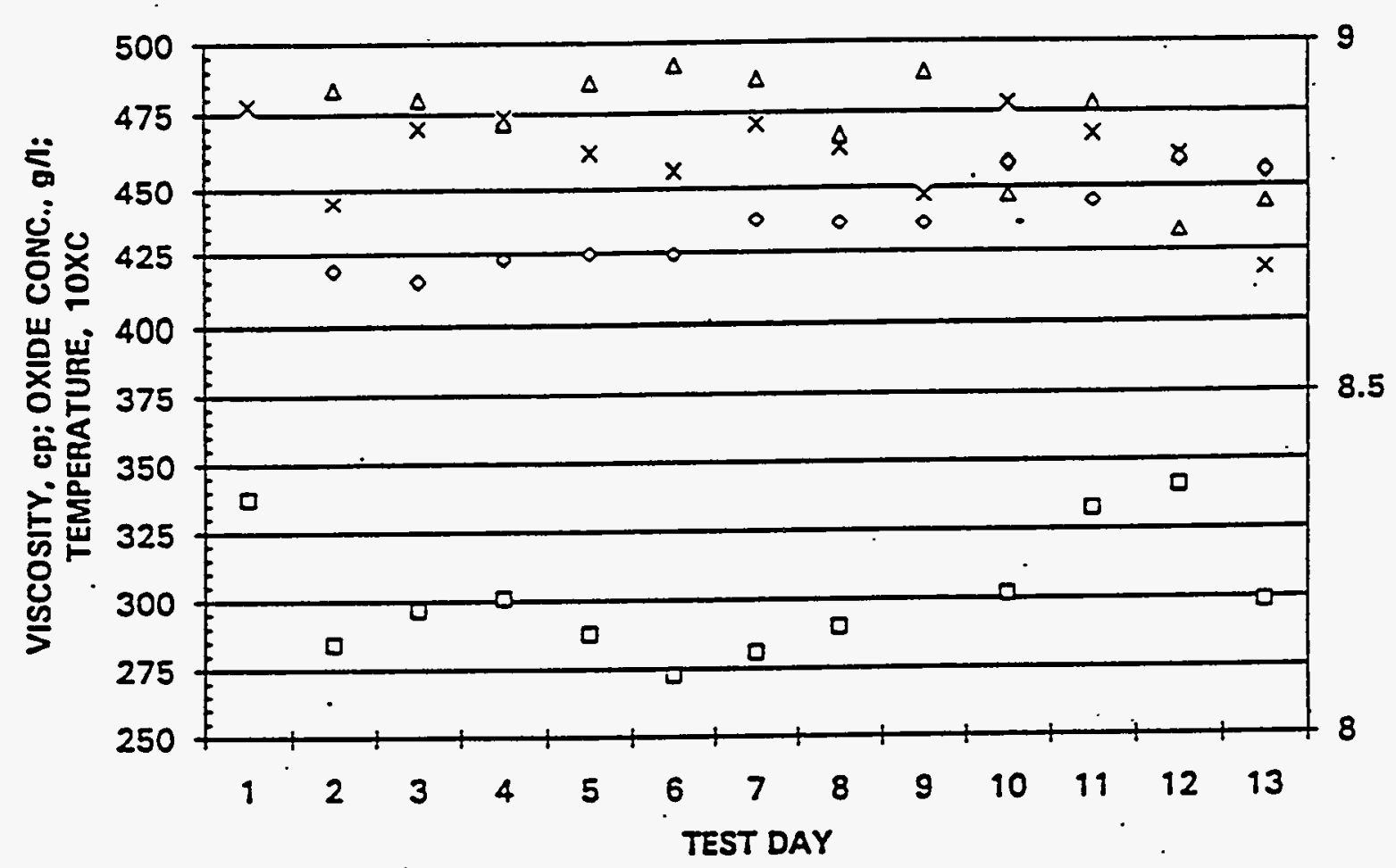

Figure 9.23. Viscosity Comparison with Oxide Concentration, pH, and Temperature of Simulated Melter Feed Versus Run Time

Oxide composition was determined from chemical analysis of samples taken from Tank HB-15 during the melter feed run and varied from $418 \mathrm{~g} / \mathrm{L}$ on the 13 th test day to $478 \mathrm{~g} / \mathrm{L}$ on the first test day. The variation in oxide concentration follows the variations in apparent viscosity during the first 7 days, or roughly half of the test run. During the second half of the test run the apparent correlation between oxide concentration and apparent viscosity is less distinctive.

Visual observations made inside Tank HB-15 during the LFCM-8 melter feed test run and recorded in the LRB indicate a significant material build-up on the internal tank components, particularly the heating and cooling coils. During the latter part of the run when the level of simulated melter feed went below the coils, the build-up was especially noticeable. Occasionally, large chunks of the buildup material fell off into the simulated melter feed. These occurrences may account for some of the variation in oxide concentration, i.e., increased oxide concentration occurring right after a large piece of material fell off the coils into the tank. The first notation about material build-up falling from the coils into the feed was made on April 25, 1993, on day 9 of the test run. . Several additional notations were made on that day and 2 days later. 
The $\mathrm{pH}$ of the melter feed was measured two ways: 1) with a $\mathrm{pH}$ probe directly in Tank HB-15 and 2) from chemical analyses of samples taken from Tank HB-15 during the test run. These measurements were made and entered once per day during the LFCM-8 melter feed test run. The pH from the sample analysis is slightly higher (approximately 0.6) than measured in the tank, but both curves are flat with a maximum variation of 0.2 during the 14-day test. The temperature varies somewhat but is still reasonably constant, staying within a $6^{\circ} \mathrm{C}$ range during the test. The conclusion drawn from these data is that there was little apparent chemical reaction that affected apparent viscosity taking place in the simulated melter feed during the course of the test.

Careful observation of the viscosity-temperature data in Figure 9.23 shows an inverse correlation during the first 8 days of the test run, but the correlation doesn't hold during the final days of the test run. Although this is an interesting observation, the magnitude of the temperature variation $\left(2{ }^{\circ} \mathrm{C}\right.$ during the first 8 days) is not great enough to significantly affect the apparent viscosity.

\subsubsection{Plugging Frequency and Methods Used to Clear Plugging}

The flow of melter feed to the LFCM was established by setting the valves in the melter feed recycle loop to allow flow through the loop and back to HB-15. The transfer/feed pump was started and set to the desired speed. The 3-way valve in the melter feed line was set to allow melter feed to flow from the recycle loop to the melter. Once flow was established, the magnitude of the flow was controlled by adjusting the speed of the pump. The flow rate was set to satisfy the operating requirements of the melter. Under ideal conditions, the flow rate would be set to satisfy the operating requirements of the melter and remain set at that point for the duration of the melter run.

As time progressed during the melter feed run, the flow rate would gradually decrease. There are two reasons for this decrease in flow rate. As the melter feed is transferred to the melter, the level in the test vessel, HB-15, decreases. With the decreasing level in HB-15, more of the pressure drop across the pump is used to lift the melter feed out of the tank and, therefore, the pump discharge pressure decreases. The flow in the melter feed line decreases as a result of the decrease in pressure in the recycle loop. The second reason for decreasing flow rate in the melter feed line is the build-up of material in the melter feed line, thus effectively reducing the flow area and flow rate. Visual evidence of this phenomenon was observed at the end of the nozzle where material was building up and would occasionally fall off or be knocked off. Build-up of solids was also observed in the 3-way valve during a visual inspection after the run when the valve was disassembled. It is a safe assumption that build-up occurred at other parts of the system, particularly where there is a changing cross-section, as in the 3-way valve or cross-flow strainer.

To compensate for the decreasing flow rate, the pump speed was periodically increased. Also, the 3-way valve was used to fiush the meiter feed line from the valve forward to the nozzle and again from the valve backwards to the cross flow strainer. Normally, this operation resulted in a definite increase in pump speed. The entries in the log book and, sometimes, the LBB regarding flushing times and feed on-off times are summarized in Appendix X. 


\subsubsection{Conclusions}

The pressure-drop dependency in the simulated melter feed line during melter feeding was highly dependent on slurry rheology for the LFCM-8 melter feed test. However, assuming Bingham plastic behavior, the pressure-drop data was normalized with flow rate (based on laminar or turbulence) and plotted against time. Therefore, this information can be used to determine the observed pressure drops for a given flow rate and any time during melter feeding. Additionally, the changes in fluid rheology appear to be the result of changes in oxide concentration within the slurry. Therefore, this information can be used to predict similar potential changes for other melter feeding systems. Line plugging and flushing frequency were reported and showed that a higher flushing frequency was required toward the end of the test.

\subsubsection{Solid Lump Build-Up in Melter-Feed System}

The discussion of melter feed lump growth and accumulation during the melter run is included in this section.

\subsubsection{Approach}

Methodology and analytical methods are discussed below.

Particle Size Analysis. To determine if a build-up of large particles was occurring during the melter feeding, daily samples from the melter run feed were analyzed with a Brinkman laser particlesize counter, Model 2010. Because of the inconclusiveness of this method, sieve analyses technique was also used. Based on the wt\% frit recovered from the samples, the sieve analyses method was a direct measure of frit to waste ratio. Some determinations were possible by comparing the results from both methods of analysis.

Sampling Procedure and Handling. Melter feed samples for rheology were acquired daily from the Hydragard sampling system and were assumed to be representative of the overall tank makeup. After the daily rheology measurements were made, the samples were stored at room temperature until further analysis was required. Toward the end of the melter run, these samples were heated and maintained at $50^{\circ} \mathrm{C}$ overnight. After being shaken thoroughly, a small sample was removed from each of the bottles and sent to be measured for its particle-size distribution. The sample numbers corresponded directly to the day of melter feeding (e.g., PS-5 was the fifth day of melter feeding, PS-7 was the seventh, etc.). PS-1 was taken a few hours before actual feeding began and is the baseline particie-size distribution.

The samples were maintained in a drying oven or a water bath at $50^{\circ} \mathrm{C}$ for a minimum of $2 \mathrm{~h}$ before analyzing. Each sample was vigorously shaken before analysis.

\subsubsection{Particle Size Analysis Results from Laser Particle-Size Counter}

While a slight trend toward an increasing mean particle size is observed during the first half of the test, later days are lower again (see Table 9.4). Even within that trend there are some low numbers that would give rise to doubts of the validity of this trend. The data obtained with the particle-size analyzer would indicate that there is not a selectivity problem with the cross-fiow strainer, but it is inconclusive. 
Table 9.4. Laser Analysis Results

\begin{tabular}{|c|c|c|c|}
\hline Sample Name & $\begin{array}{l}\text { Mean Size, } \mu \mathrm{m} \\
\quad \text { (volume) }\end{array}$ & $\begin{array}{l}\text { Standard } \\
\text { Deviation } \\
\text { (volume) }\end{array}$ & $\begin{array}{c}\text { Confidence \% } \\
\text { (volume) }\end{array}$ \\
\hline PS-1 & 30.49 & 24.97 & 99.18 \\
\hline PS-1 R & 40.8 & 26.43 & 99.92 \\
\hline PS-2 & 34.09 & 34.45 & 96.78 \\
\hline PS-3 & 43.62 & 33.1 & 99.57 \\
\hline PS-4 & 57.81 & 33.5 & 99.98 \\
\hline PS-5 & 18.98 & 19.57 & 96.43 \\
\hline PS-6 & 54.77 & 26.1 & 100 \\
\hline PS-6 R & 53.43 & 26.57 & 100 \\
\hline PS-7 & 14.39 & 12.98 & 98.36 \\
\hline PS-8 & 75.97 & 36.99 & 100 \\
\hline PS-9 & 78.27 & 39.75 & 100 \\
\hline PS-10 & 39.82 & 28.03 & 99.79 \\
\hline PS-11 & 20.44 & 16.86 & 99.13 \\
\hline PS-12 & 56.78 & 27.67 & 100 \\
\hline PS-13 & 64.13 & 28.85 & 100 \\
\hline PS-14 & 33.57 & 23.76 & 99.78 \\
\hline PS-15 & 43.57 & 29.39 & 99.86 \\
\hline PS-15 R & 48.85 & 26.04 & 100 \\
\hline
\end{tabular}


The confidence rating is high for the values given in the table, but it is important to note that this is the machine's own rating of its performance. Because of the severe dilution of the samples before loading into the machine, it is possible to obtain a great deal of scatter when measuring concentrated siurries with this method. The data obtained is a testament to this potential problem. Of the three samples that were duplicated to verify accuracy, one showed a significant change. If an appreciable trend is present in these samples, it is lost within the scatter.

The data obtained from Brinkman was inconclusive. While it indicated that no appreciable shift in the frit and waste ratio occurred, the data scatter was substantial. To obtain conclusive data, not only for this test but for future meiter feed runs as well, it would be necessary to find or develop a different method to detect a shift in this ratio.

\subsubsection{Particle Analyses Results from Sieve Analysis}

The data obtained from Brinkman was inconclusive because of instrument-specific errors. Therefore, a different method to detect a shift in the frit and waste ratio was proposed and developed.

The calculated target-feed composition was a slurry that contained approximately $28 \%$ frit by weight. The frit concentration of the measured samples ranged from $17 \mathrm{wt} \%$ to $23 \mathrm{wt} \%$ with an average of $20 \mathrm{wt} \%$. No trends are evident when the $3 \%$ margin for error (inherent within the analytical technique) is considered (see Table 9.5 and Figure 9.24). The reason for the difference between target and frit concentration measurement are not apparent at this time.

Several other archived samples were run from different spots in the tank, including the coils and the bottom (see Table 9.6). They show some of the concentration variations within the tank at any given time. Also, a separate hydragard sample, which corresponds directly to PS-12, was run yielding a $3 \%$ difference between the two samples. This further confirms the range of error inherent in the method.

Table 9.5. Wt\% Frit Measured in Melter Feed Slurry of Daily Samples

\begin{tabular}{|c|c|c|c|}
\hline Sample & wt\% Frit & Sample & wt\% Frit \\
\hline PS-1 & 23 & PS-9 & 17 \\
\hline PS-2 & N/A & PS-10 & N/A \\
\hline PS-3 & 22 & PS-11 & 21 \\
\hline PS-4 & 21 & PS-12 & 18 \\
\hline PS-5 & $\mathrm{N} / \mathrm{A}$ & PS-13 & 21 \\
\hline PS- 6 & 23 & PS-14 & 20 \\
\hline PS-7 & 19 & PS-15 & $N / A$ \\
\hline PS-8 & 18 & Average & 20 \\
\hline
\end{tabular}




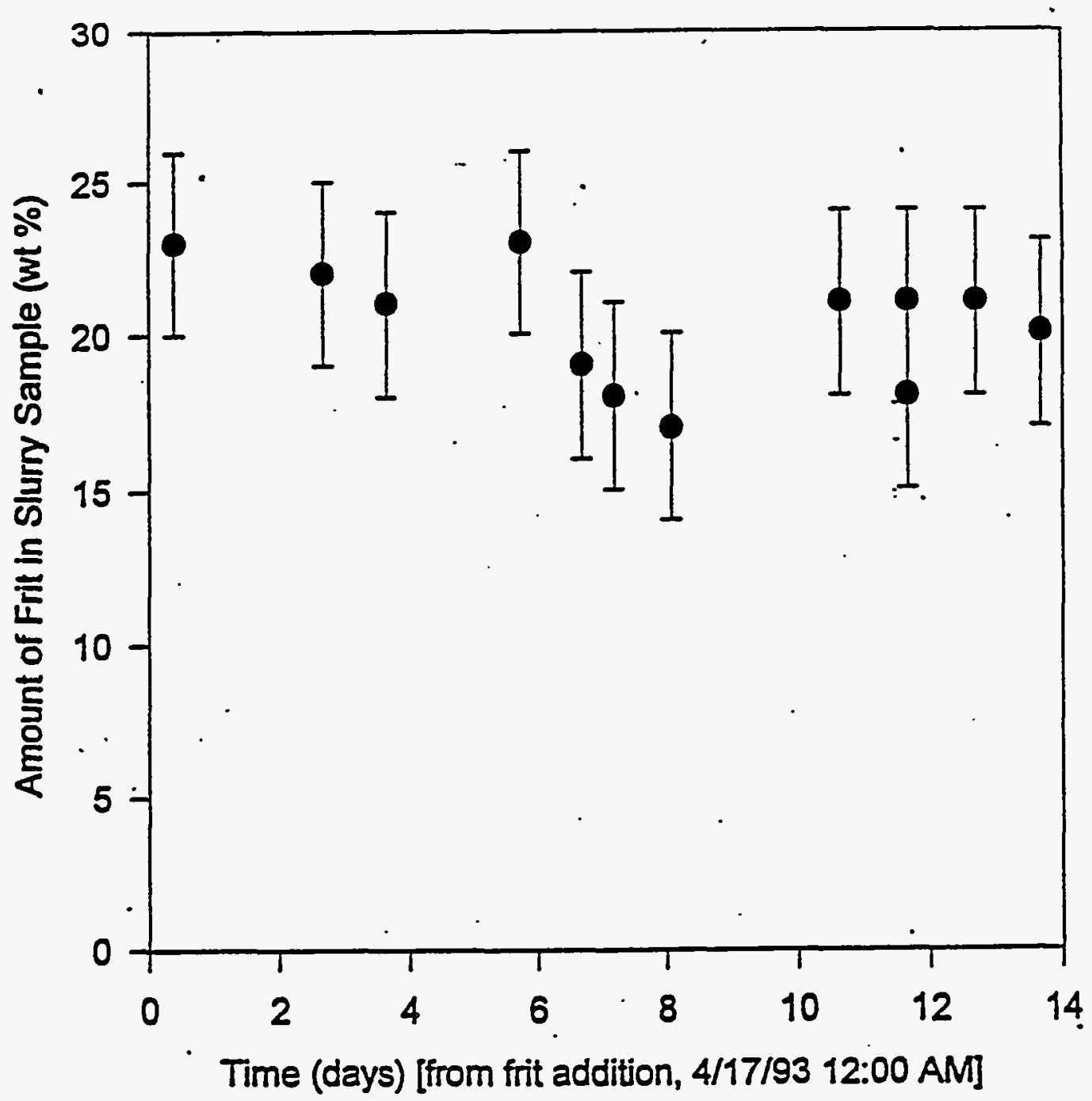

Figure 9.24. Cross-Flow Strainer Effects on Frit and Waste Ratio

\subsubsection{Conclusions and Recommendations}

Conclusions. Because of the high capacity for error inherent in the laser analysis and the newness of the sieve procedure, neither method taken alone would be conclusive. However, neither method indicated that a build-up of larger frit particles in the feed preparation tank occurred. Therefore, the data does not conclude that the cross-flow strainer was particle-size selective during melter feeding.

Crystals were observed in the samples after several days at room temperature. While these sampies were heated and maintained at $50^{\circ} \mathrm{C}$ for several hours before analysis, it is unknown what effect, if any, these crystals may have had on the measurements. 
Table 9.6. Wt\% Frit Measured in Melter Feed Slurry Samples From Various Locations Within the Tank HB-15

\begin{tabular}{|c|c|c|}
\hline Date & Description & wt\% Frit \\
\hline $4 / 29 / 93$ & coils/inner (next to coils) & 20 \\
\hline $4 / 29 / 93$ & coils/surface (actual coil material) & 33 \\
\hline $4 / 29 / 93$ & slurry surface (northwest side) & 25 \\
\hline $4 / 29 / 93$ & slurry surface (west side) & 21 \\
\hline $4 / 29 / 93$ & hydragard sampler (normal sample) & 21 \\
\hline $5 / 4 / 93$ & bottom (northeast side) & 22 \\
\hline $5 / 4 / 93$ & hydragard sampler (normal sample) & 19 \\
\hline
\end{tabular}

The sieve analysis of the samples occurred 6 months after the laser-light analysis. Varying degrees of drying may have occurred in the samples even though they were stored in Nalgene bottles with fitted lids.

Because of several sources of error and the unusual nature of this particular feed, it is not possible to conclude that the cross-flow strainer will have no effect on any melter feed runs. It can be stated, however, that it had no appreciable effect on the particle-size distribution of this meiter run.

\subsection{Melter Feed/Transfer and Sample Pump Performance}

Melter feed/transfer and sample pump performance testing are discussed in this section.

\subsubsection{Pumping Test Approach}

Two types of tests were performed: 1) pump priming requirement and 2) head-capacity characterization. These tests were performed with water, dilute feed, concentrated feed, formatted feed, and melter feed. The graphical results for the head-capacity characterization tests for both pumps are listed according to figure number. The testing matrix is shown in Table 9.7.

A comparison of the manufacturer's Head-Capacity curve with water and the Transfer pump's experimental curve with water is shown in Figure 9.25. The manufacturer's Head-Capacity curve with water for the Sample pump is shown in Figure 9.26. It was not possible to compare the manufacturer's Head-Capacity curve with the experimental Head-Capacity curve with water for the Sample pump because the manufacturer characterized this pump with a 2-in. outlet, and the experimental system is equipped with a $1 / 2$-in. outlet. Therefore, the experimental range of flow rates for the two systems did not coincide.

The variability in Head versus Capacity for the different fluid or slurry types for the Transfer and Sample pumps is shown in Figures 9.27 and 9.64, respectively. 
Table 9.7. Matrix of Tests Performed

\begin{tabular}{|c|c|c|c|c|c|}
\hline Test Type & Water & Dilute Feed & $\begin{array}{l}\text { Concentrated } \\
\text { Feed }\end{array}$ & $\begin{array}{l}\text { Formatted } \\
\text { Feed }\end{array}$ & Melter Feed \\
\hline $\begin{array}{l}\text { Pump Speed Variation } \\
\text { (Ambient Temp.) }\end{array}$ & TP-Figure 9.27 & & & & \\
\hline $\begin{array}{l}\text { Pump Speed Variation } \\
\text { (Temp }=52^{\circ} \mathrm{C} \text { ) }\end{array}$ & TP-Figure 9.28 & & & & \\
\hline $\begin{array}{l}\text { Pump Speed Variation } \\
(8000 \text { gal })\end{array}$ & $\begin{array}{l}\text { TP-Figure } 9.31 \\
\text { SP-Figure } 9.35\end{array}$ & $\begin{array}{l}\text { TP-Figure } 9.40 \\
\text { SP-Figure } 9.53\end{array}$ & $\begin{array}{l}\text { TP-Figure } 9.45 \\
\text { SP-Figure } 9.58\end{array}$ & $\begin{array}{l}\text { TP-Figure } 9.49 \\
\text { (6800 gal) } \\
\text { SP-Figure } 9.62 \\
(7500 \text { gal) }\end{array}$ & $\begin{array}{l}\text { TP-Figure } 9.50 \\
\text { (7500 gal) } \\
\text { SP-Figure } 9.63 \\
(7000 \mathrm{gal})\end{array}$ \\
\hline $\begin{array}{l}\text { Pump Speed Variation } \\
(-5600 \mathrm{gal})\end{array}$ & $\begin{array}{l}\text { TP-Figure } 9.32 \\
\text { SP-Figure } 9.36\end{array}$ & $\begin{array}{l}\text { TP-Figure } 9.39 \\
\text { SP-Figure } 9.52\end{array}$ & $\begin{array}{l}\text { TP-Figure } 9.44 \\
\text { SP-Figure } 9.57\end{array}$ & & \\
\hline $\begin{array}{l}\text { Pump Speed Variation } \\
(3200 \mathrm{gal})\end{array}$ & $\begin{array}{l}\text { TP-Figure } 9.33 \\
\text { SP-Figure } 9.37\end{array}$ & & & & \\
\hline Temperature Variation & TP-Figure 9.29 & $\begin{array}{l}\text { TP-Figure } 9.42 \\
\text { SP-Figure } 9.55\end{array}$ & $\begin{array}{l}\text { TP-Figure } 9.47 \\
\text { SP-Figure } 9.60\end{array}$ & & \\
\hline Tank-Level Variation & $\begin{array}{l}\text { TP-Figure } 9.34 \\
\text { SP-Figure } 9.38\end{array}$ & $\begin{array}{l}\text { TP-Figure } 9.41 \\
\text { SP-Figure } 9.54\end{array}$ & $\begin{array}{l}\text { TP-Figure } 9.46 \\
\text { SP-Figure } 9.59\end{array}$ & & \\
\hline Agitation Variation & TP-Figure 9.30 & $\begin{array}{l}\text { TP-Figure } 9.43 \\
\text { SP-Figure } 9.56\end{array}$ & $\begin{array}{l}\text { TP-Figure } 9.48 \\
\text { SP-Figure } 9.61\end{array}$ & & \\
\hline
\end{tabular}

\subsubsection{Pump Priming}

Pump priming is required on centrifugal pumps when the NPSHA (net positive suction head available) is less than atmospheric pressure. Priming is performed by injecting water directly into the suction side of the rotating impeller until the pump produces a significant increase in outlet pressure. Test results include priming times as a function of agitator speed, liquid level, and how much water was required to successfully prime each pump. It is important to minimize the amount of prime water required because additional water in the system during actual operation is undesirable and could affect the overall material balance. 


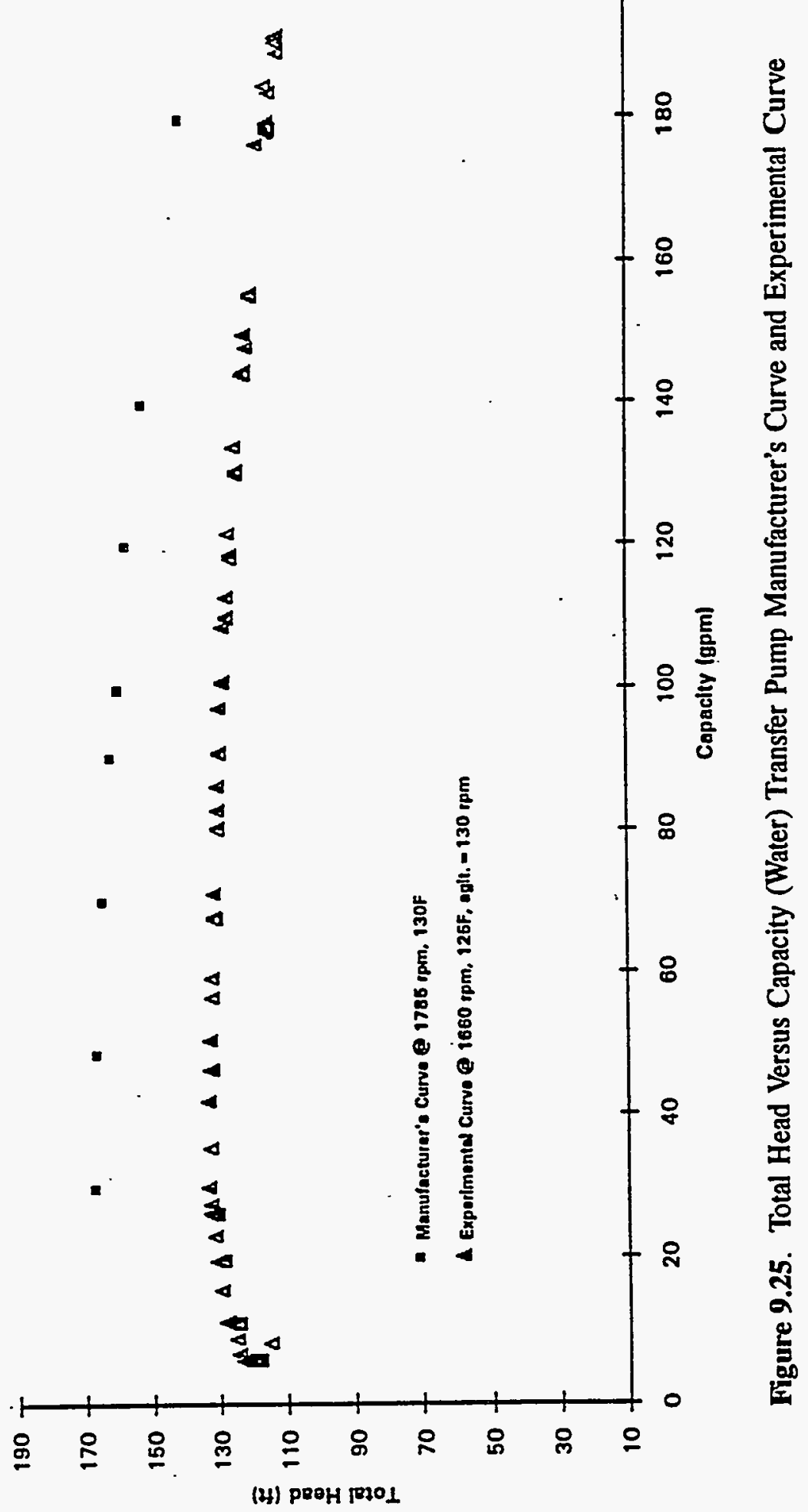




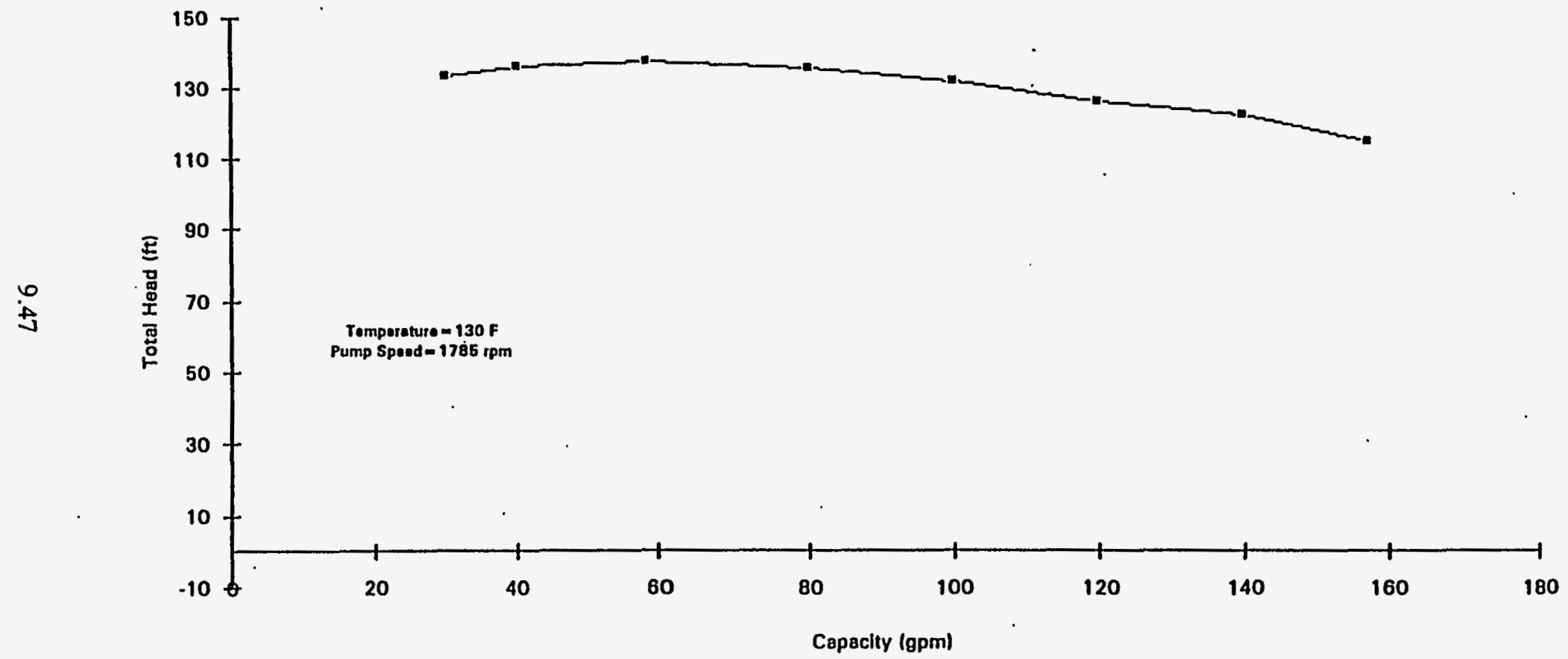

Figure 9.26. Total Head Versus Capacity (Water) Sample Pump Manufacturer's Curve 


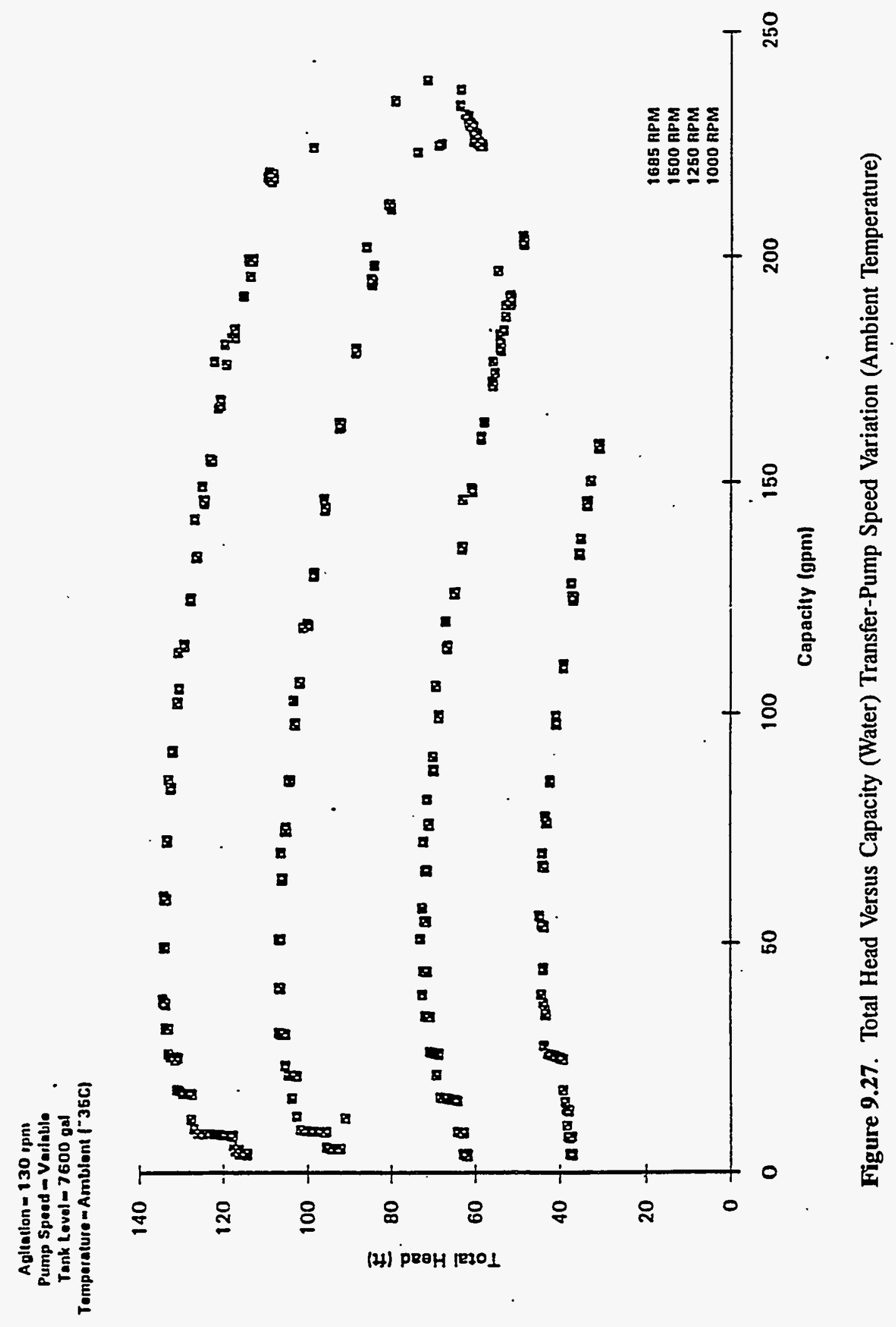




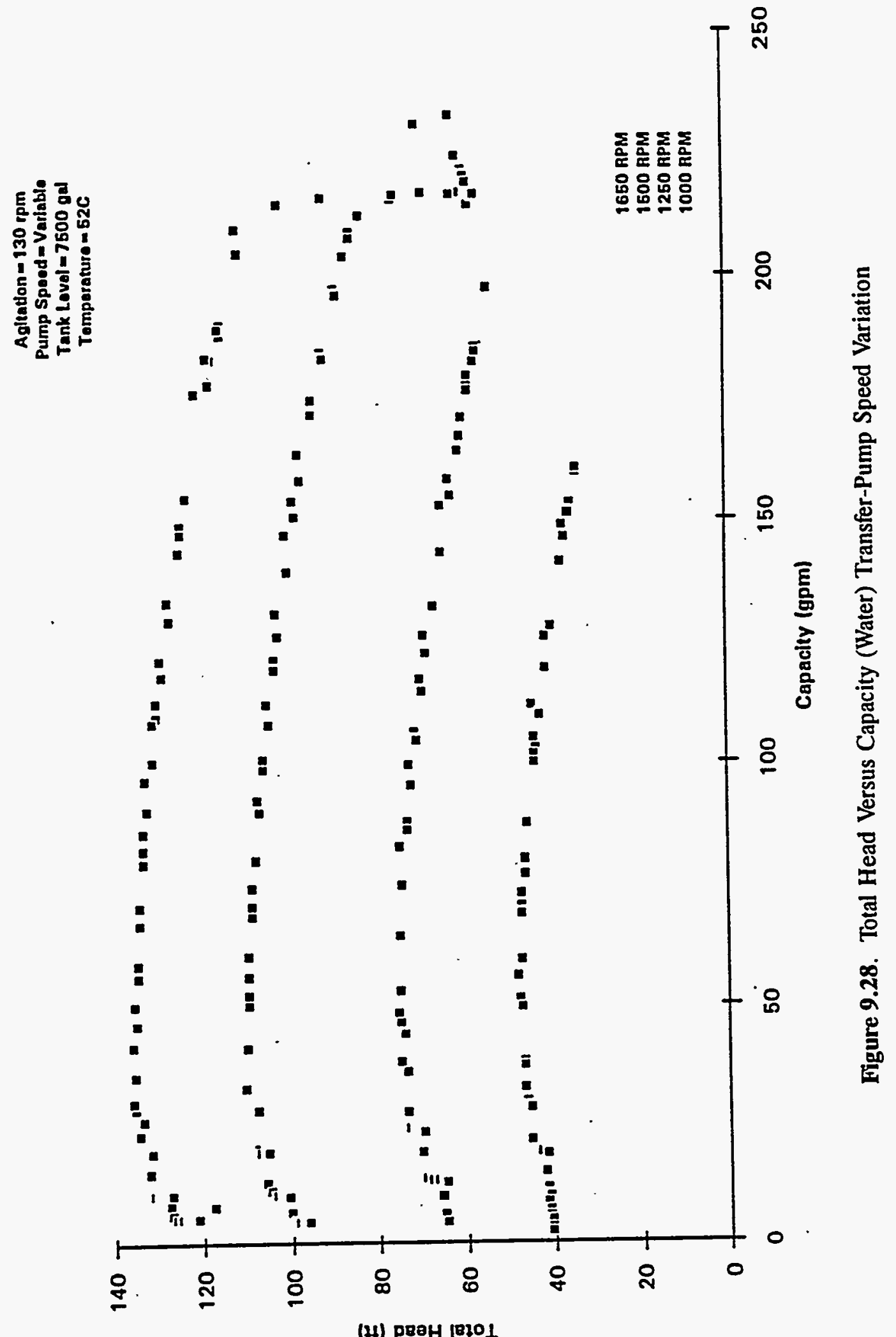

(H) P8OH j8101 


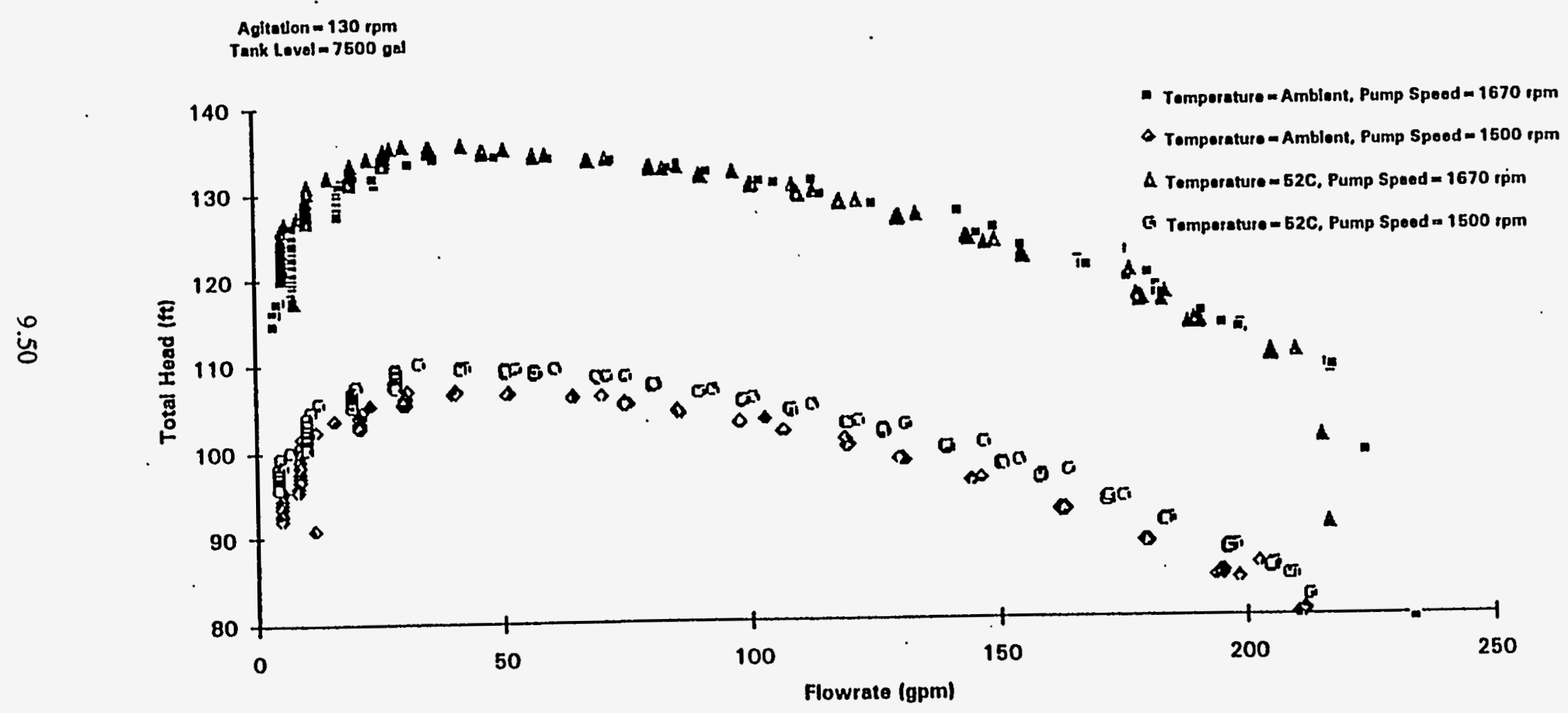

Figure 9.29. Total Head Versus Capacity (Water) Transfer-Pump Temperature Variation 


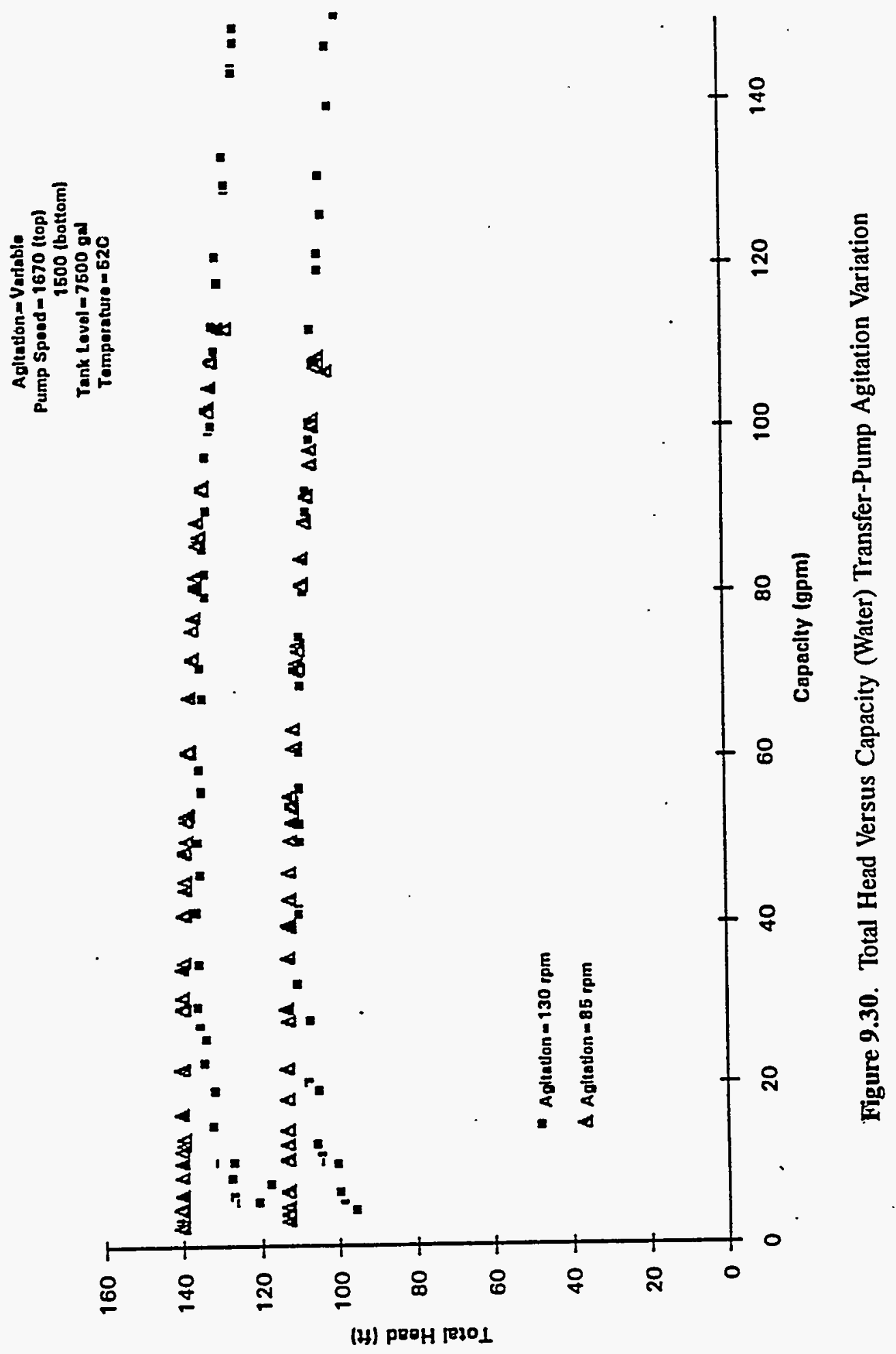




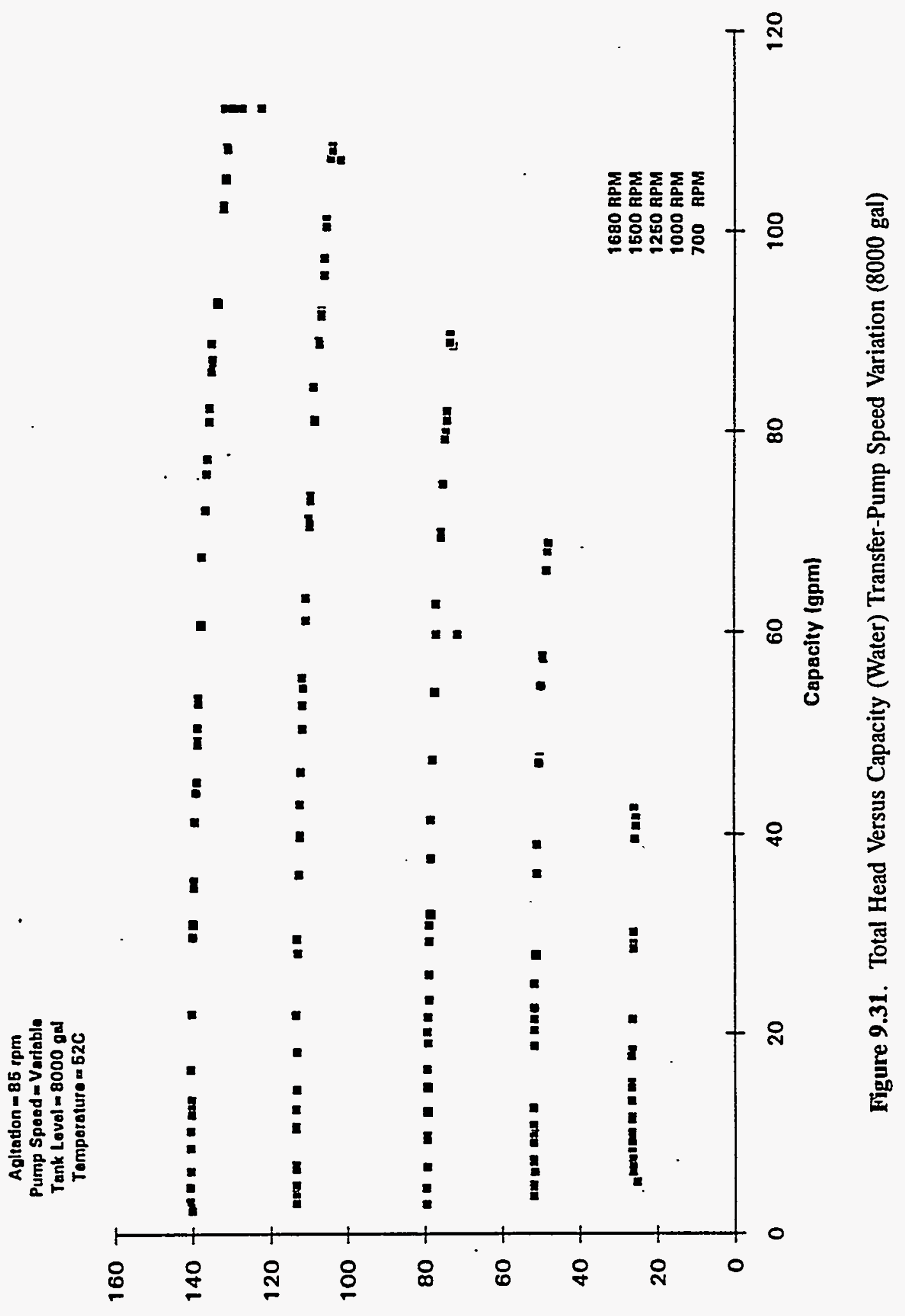

(4) PaOH [B3OL 


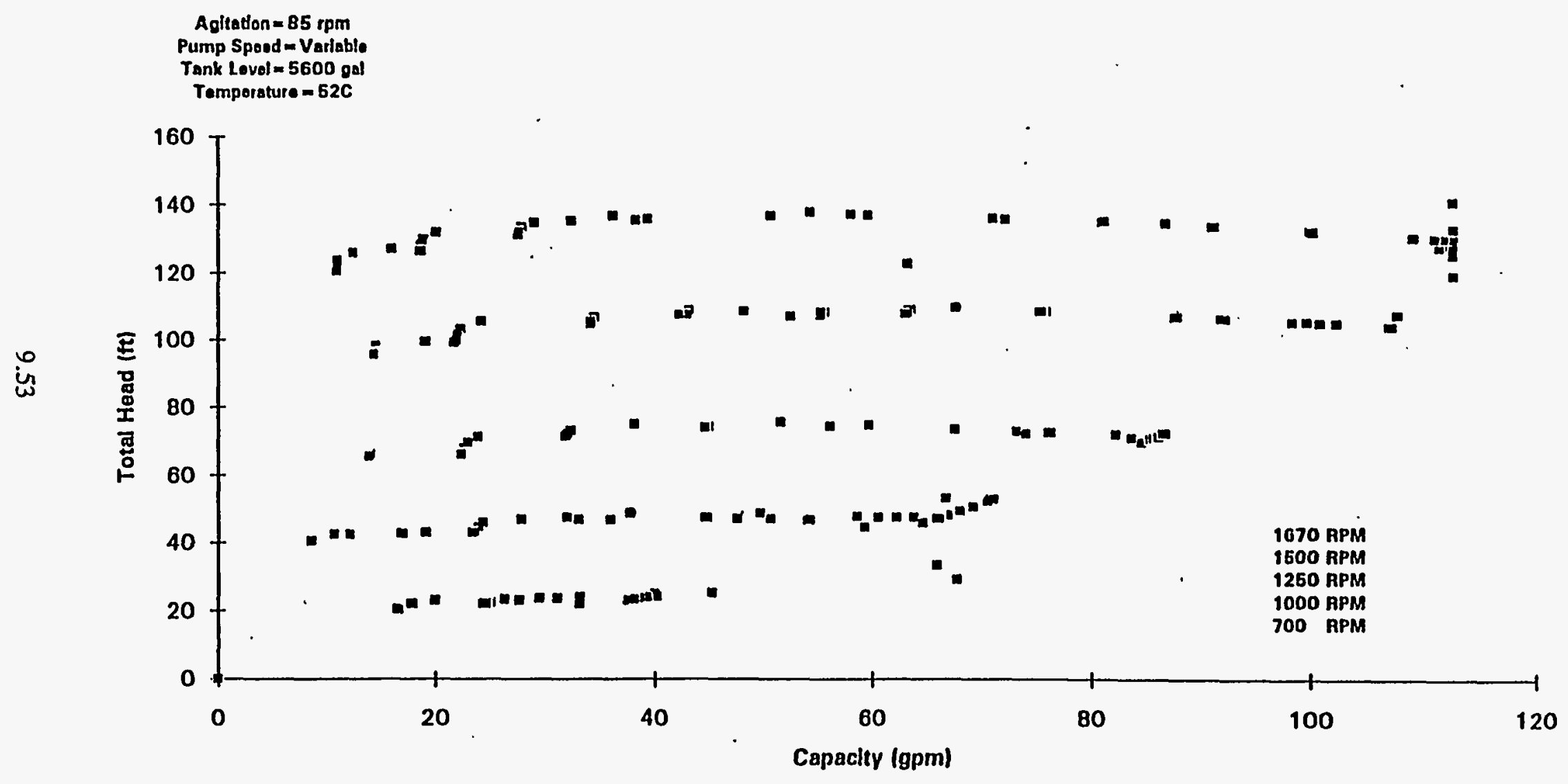

Figure 9.32. Total Head Versus Capacity (Water) Transfer-Pump Speed Variation (5600 gal) 


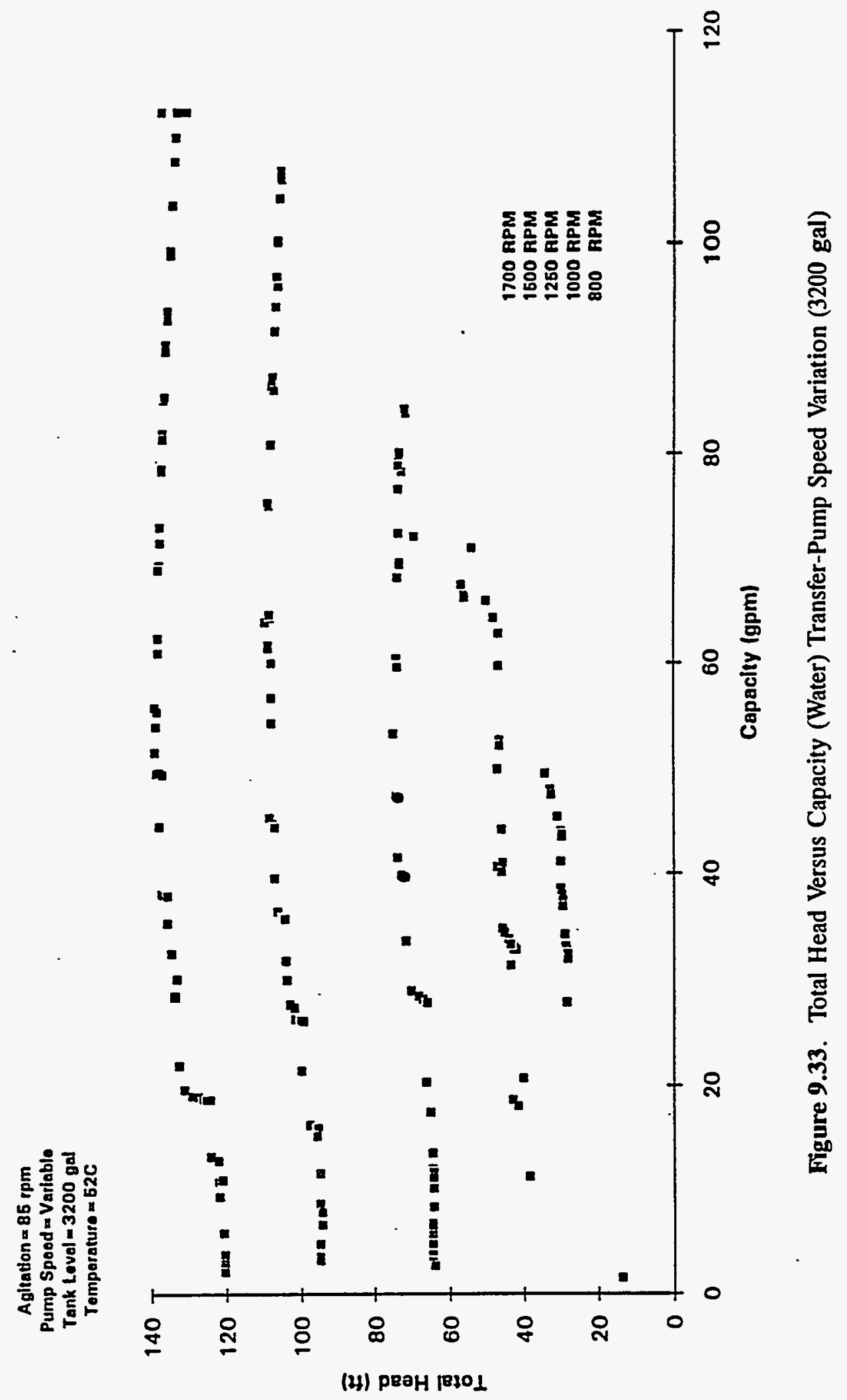




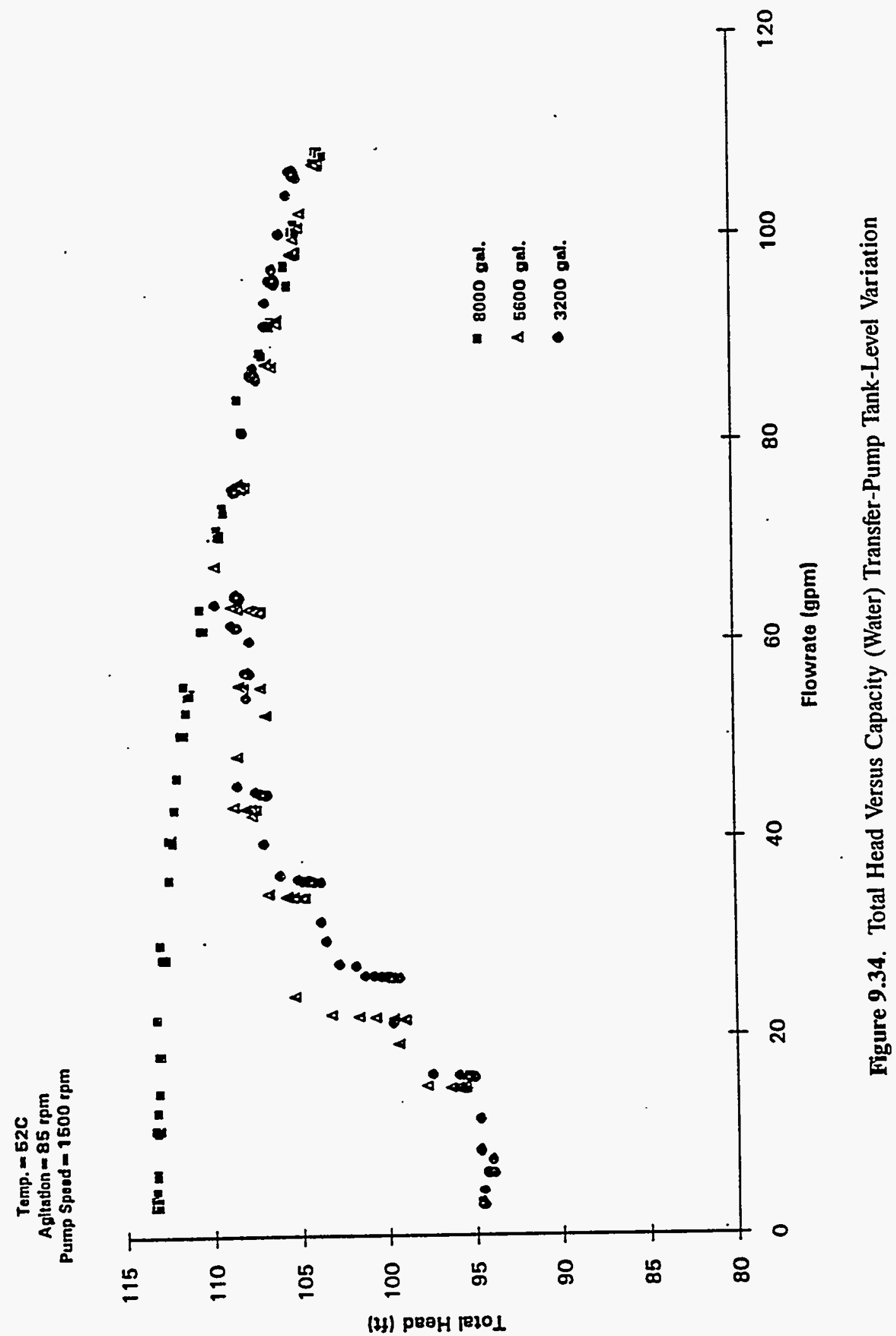




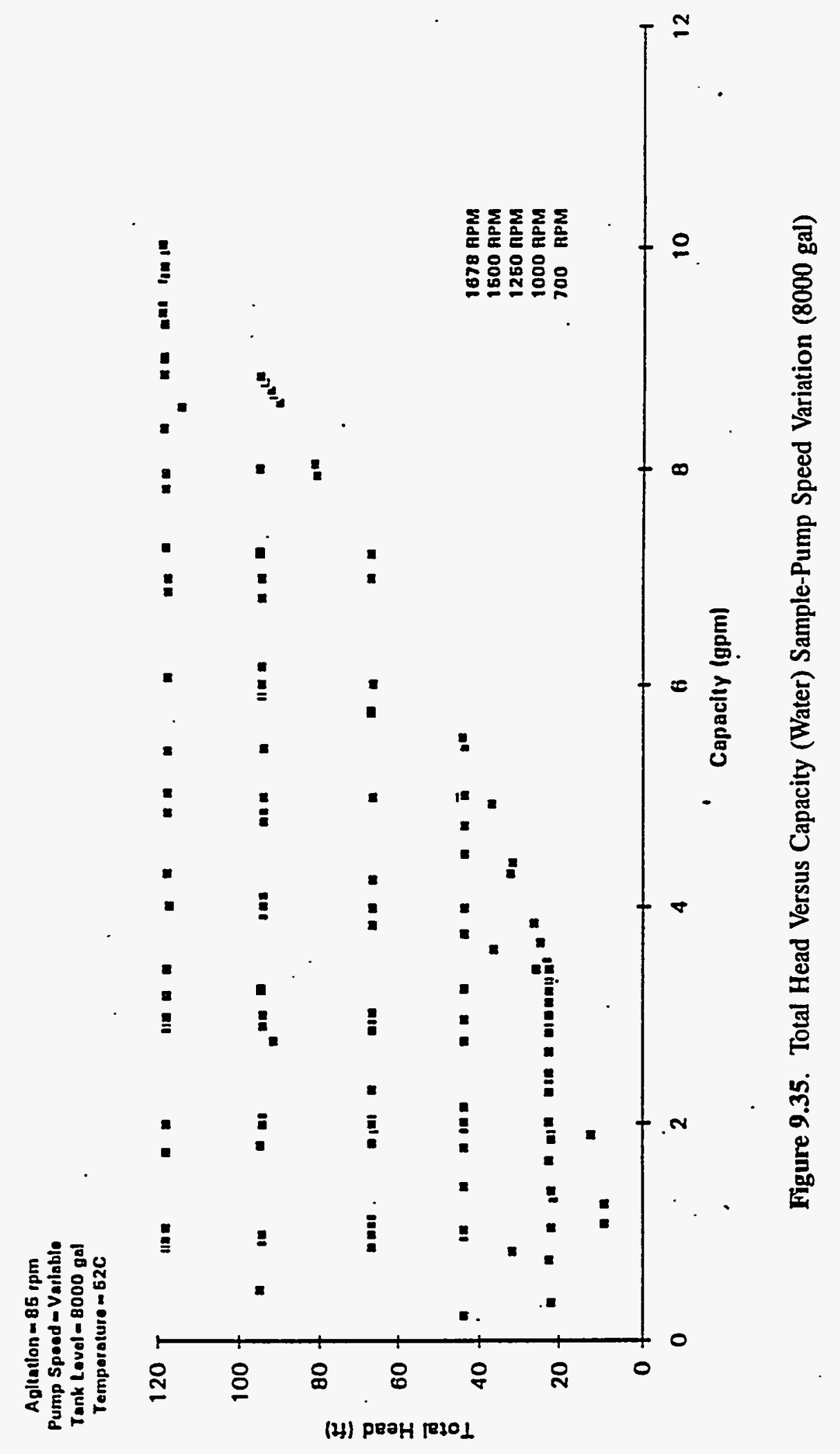




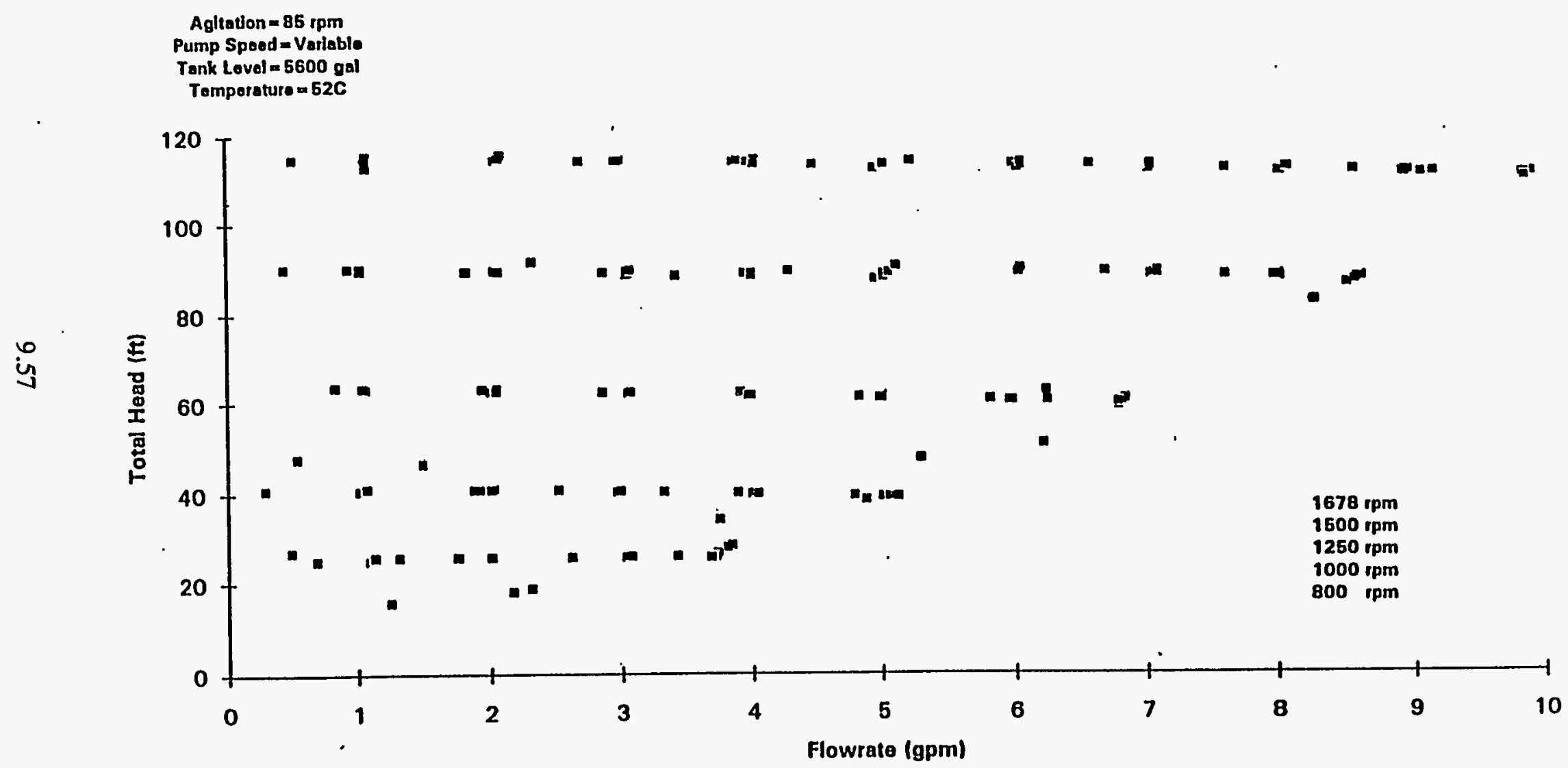

Figure 9.36. Total Head Versus Capacity (Water) Sample-Pump Speed Variation (5600 gal) 


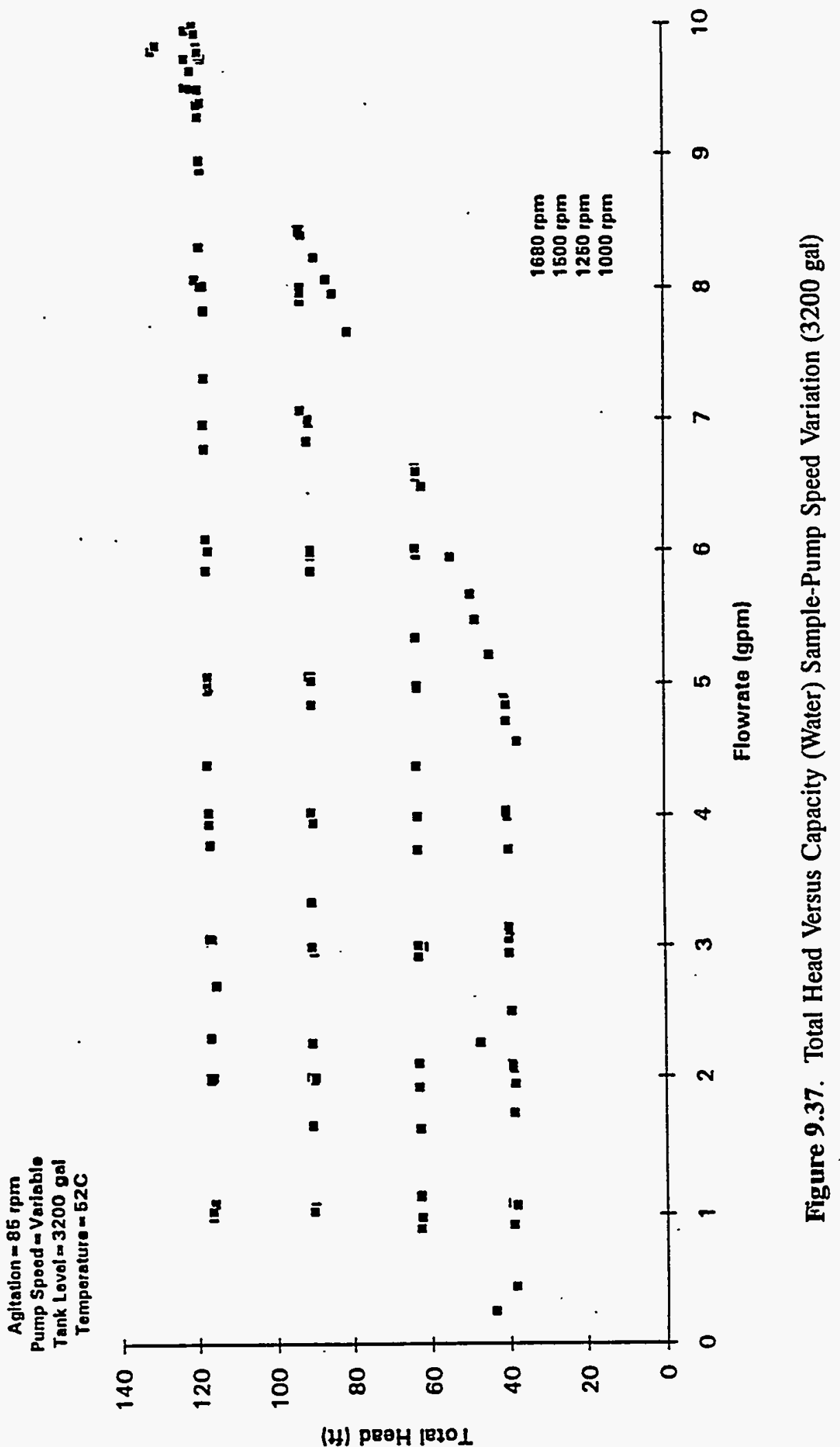




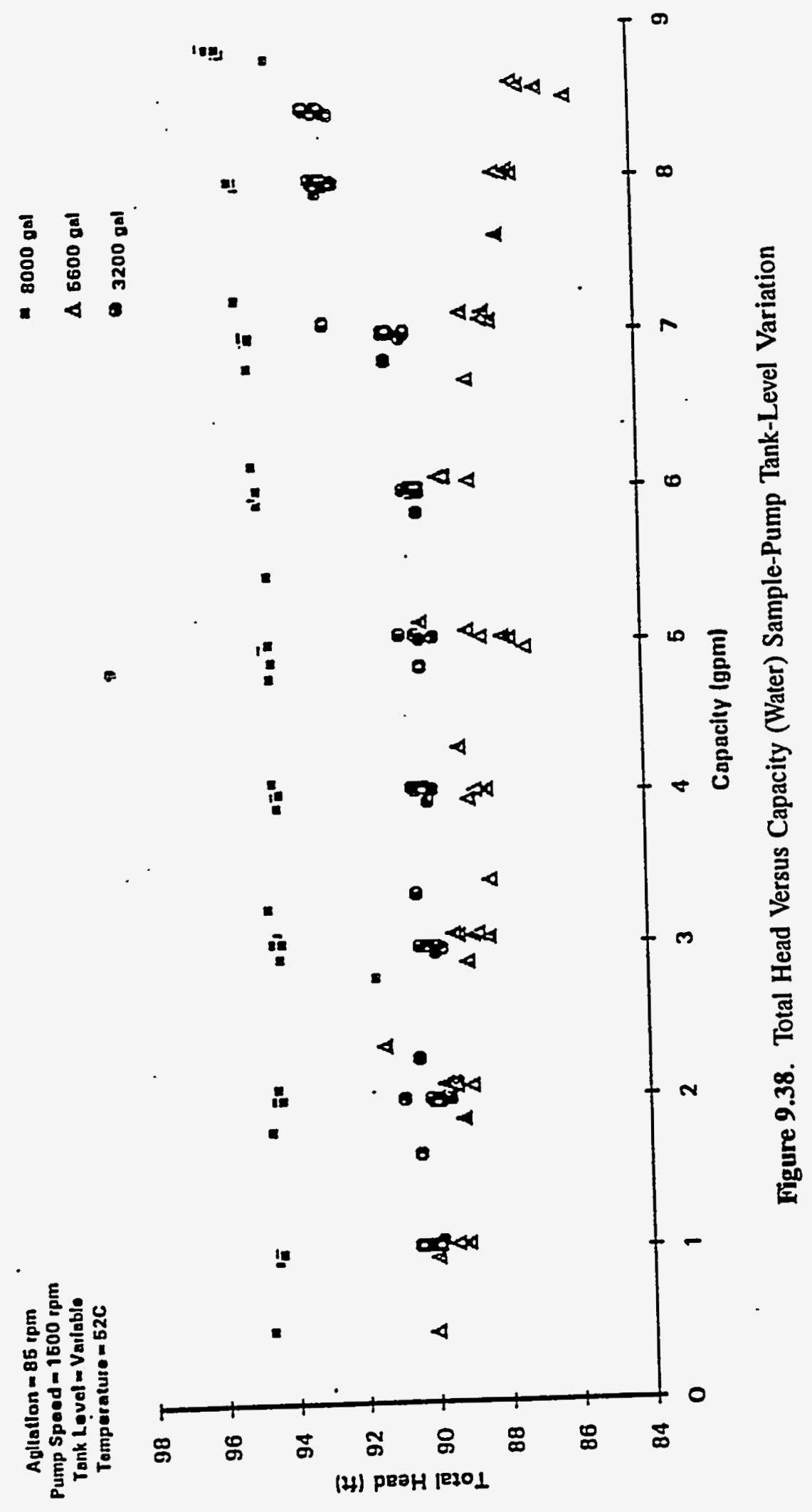




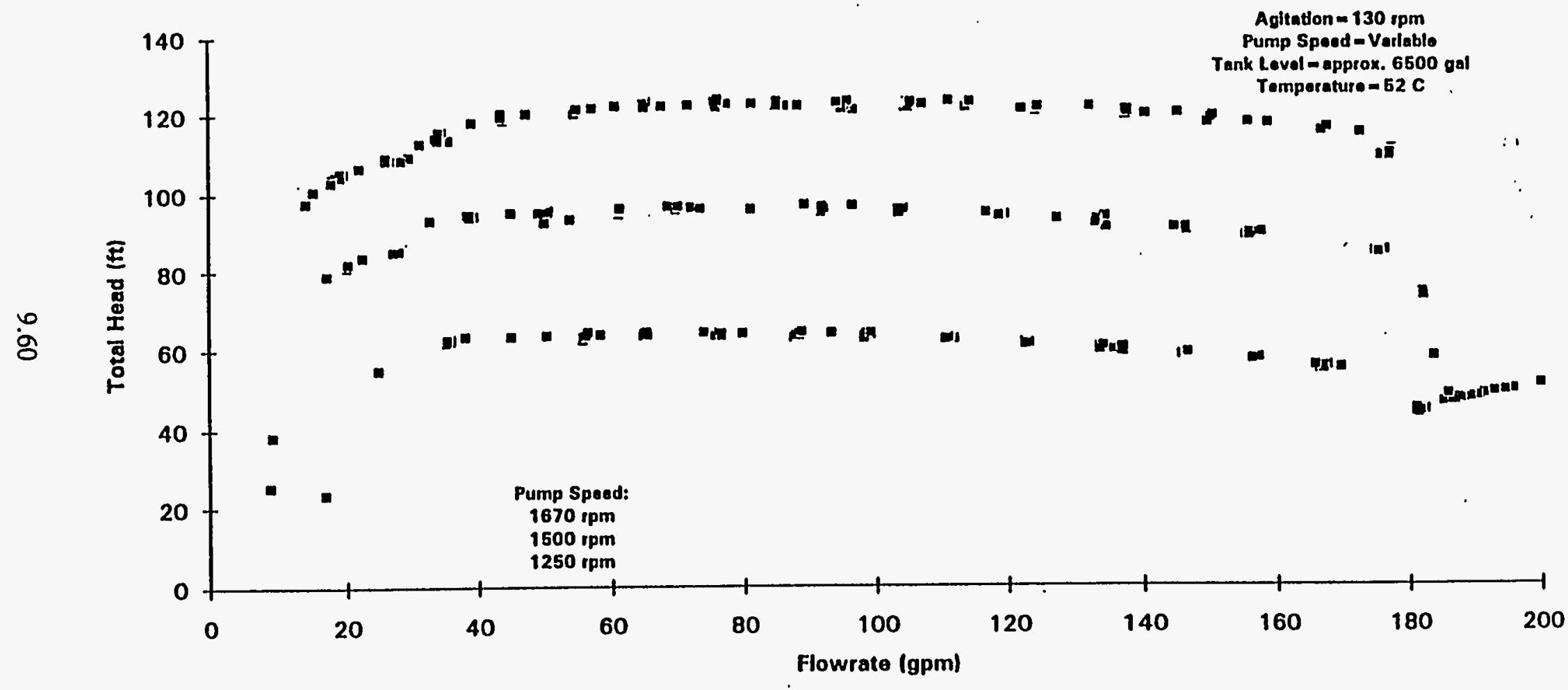

Figure 9.39. Total Head Versus Capacity (Dilute Feed) Transfer-Pump Speed Variation (Low Level) 


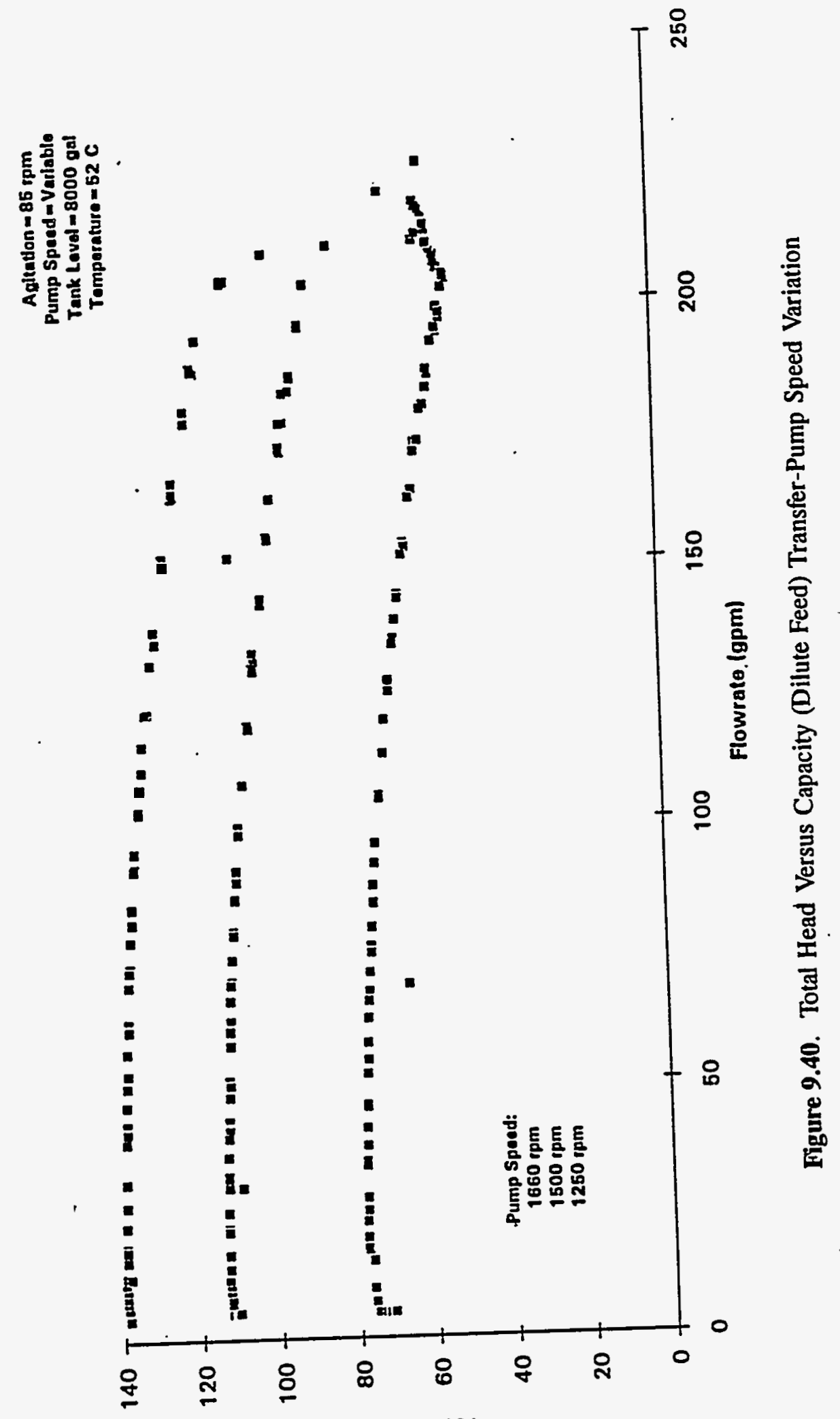

(H) PBOH 12201 


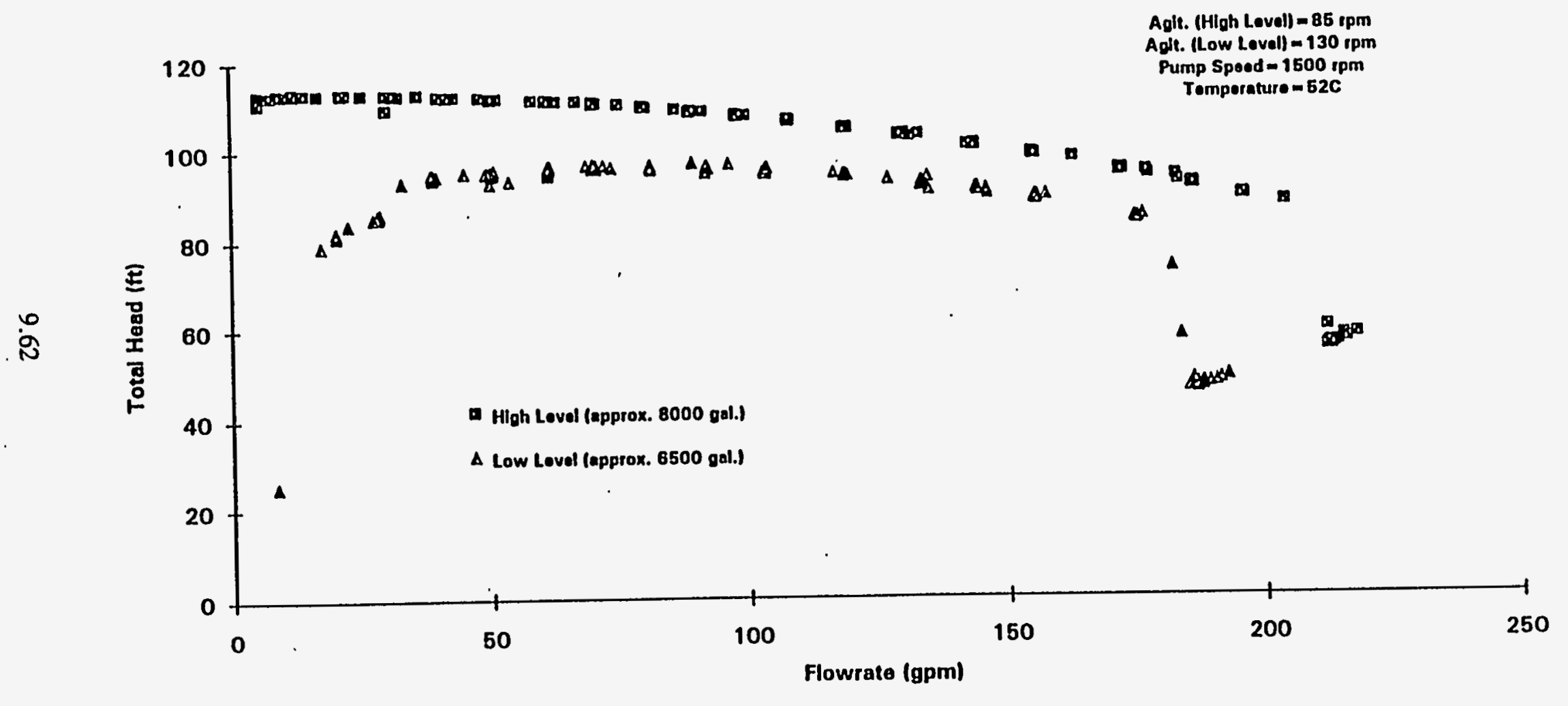

Figure 9.41. Total Head Versus Capacity (Dilute Feed) Transfer-Pump Tank-Level Variation 


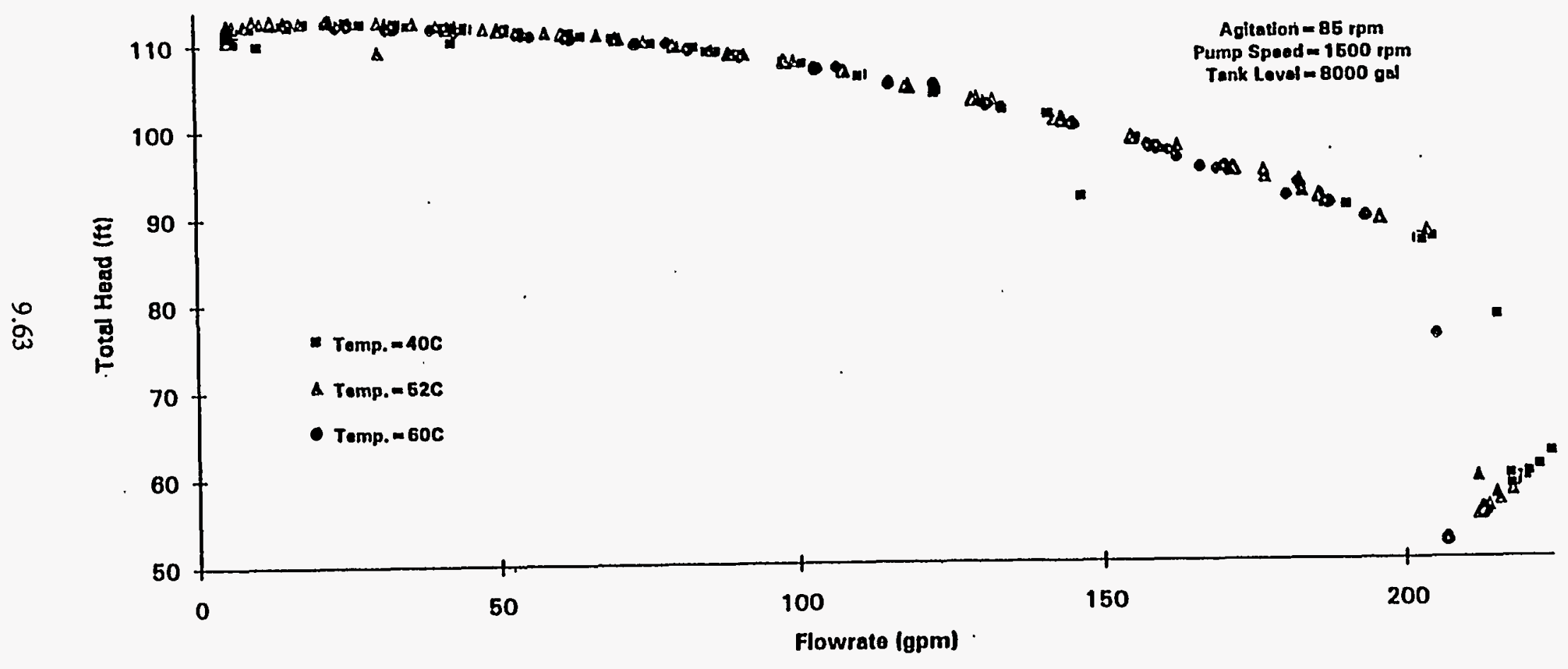

Figure 9.42. Total Head Versus Capacity (Dilute Feed) Transfer-Pump Temperature Variation 


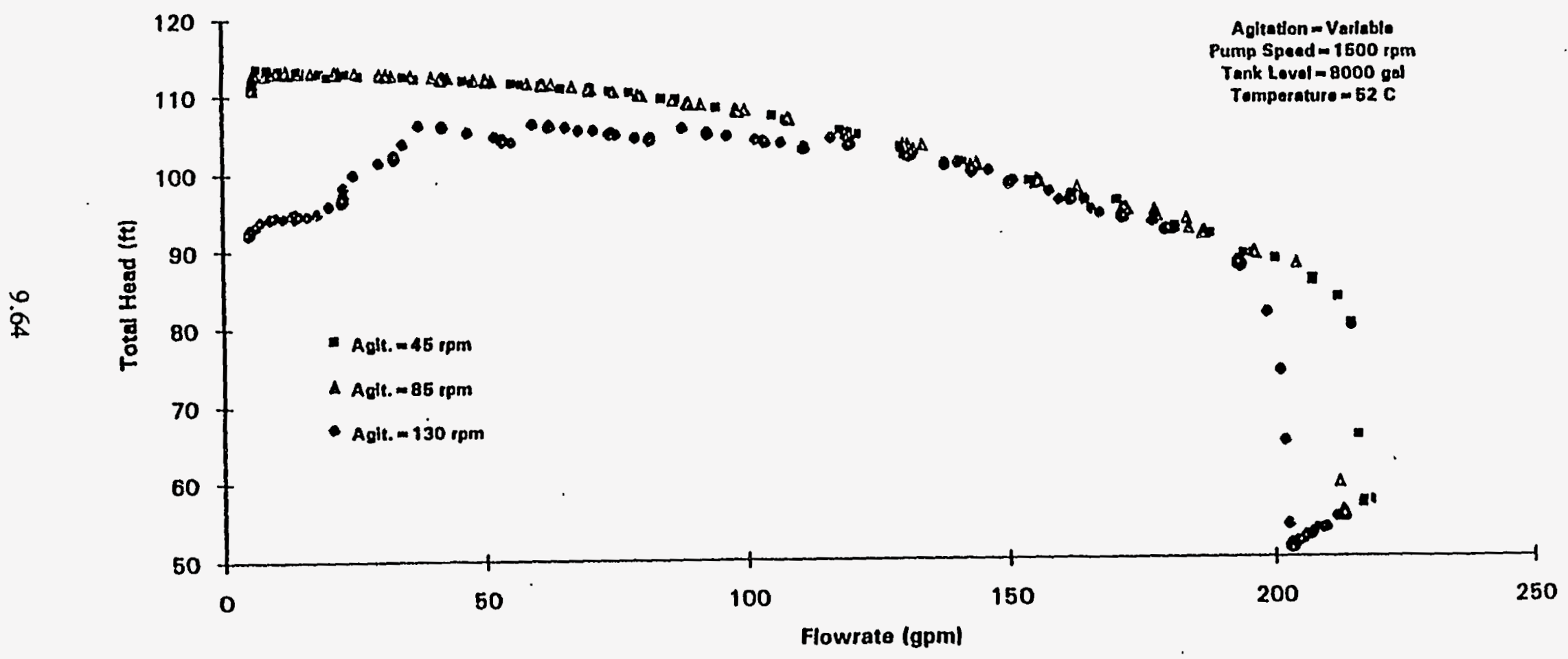

Figure 9.43. Total Head Versus Capacity (Dilute Feed) Transfer-Pump Agitation Variation 


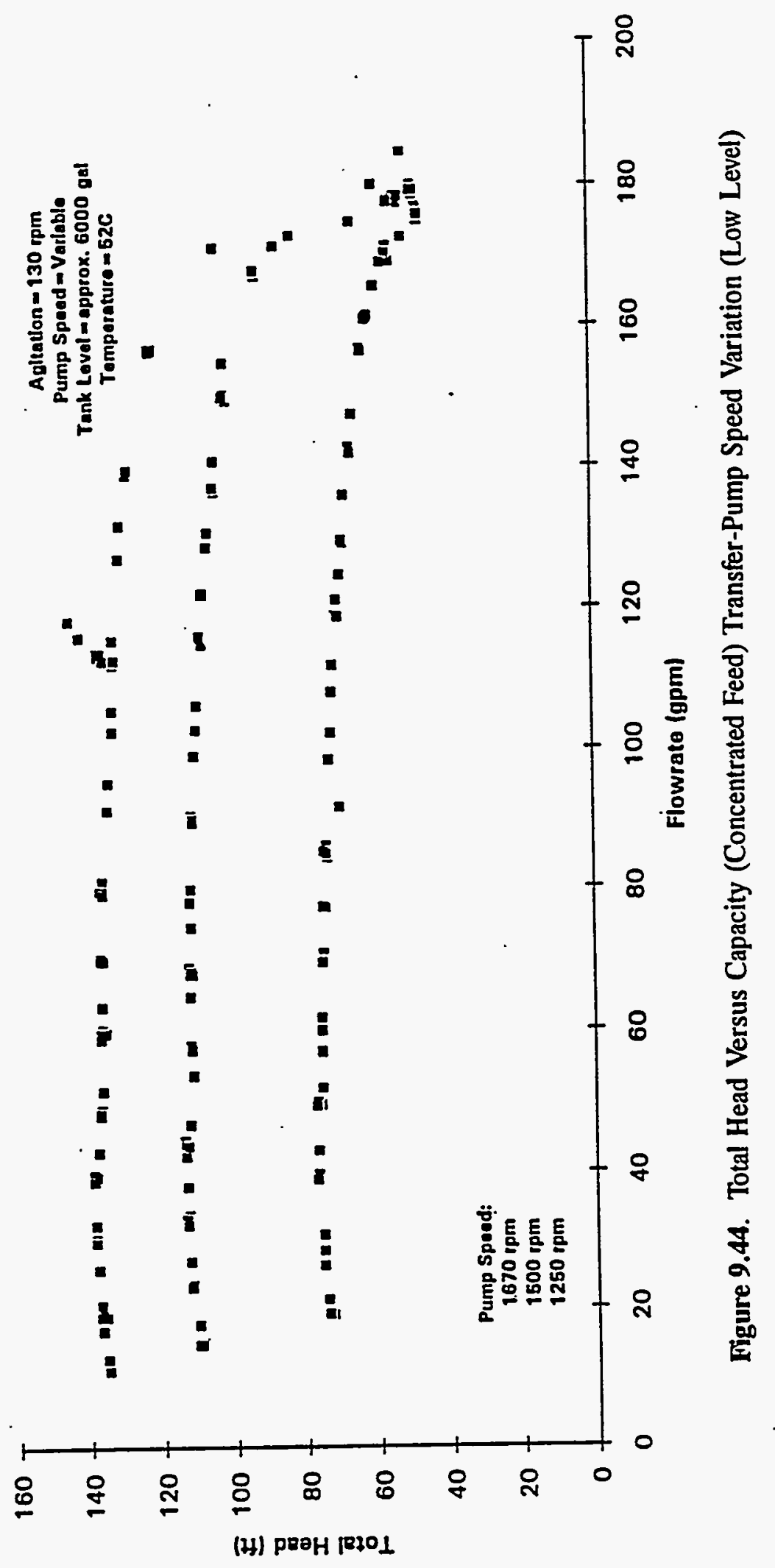

9.65 


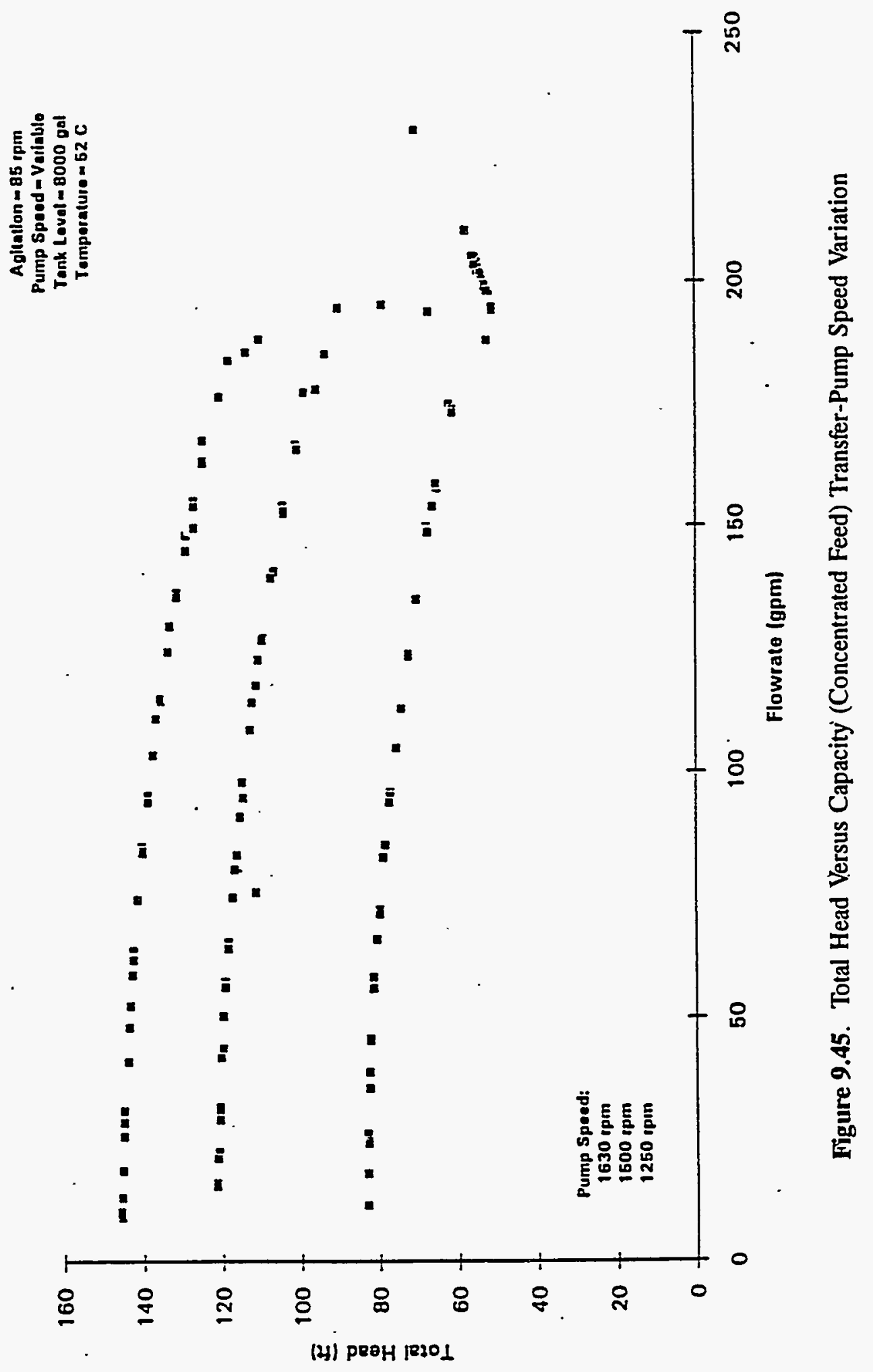




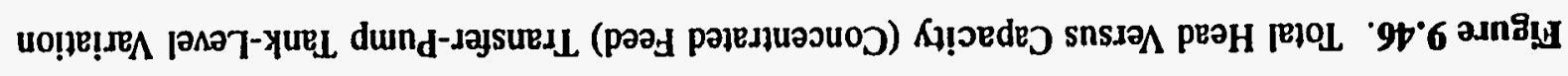

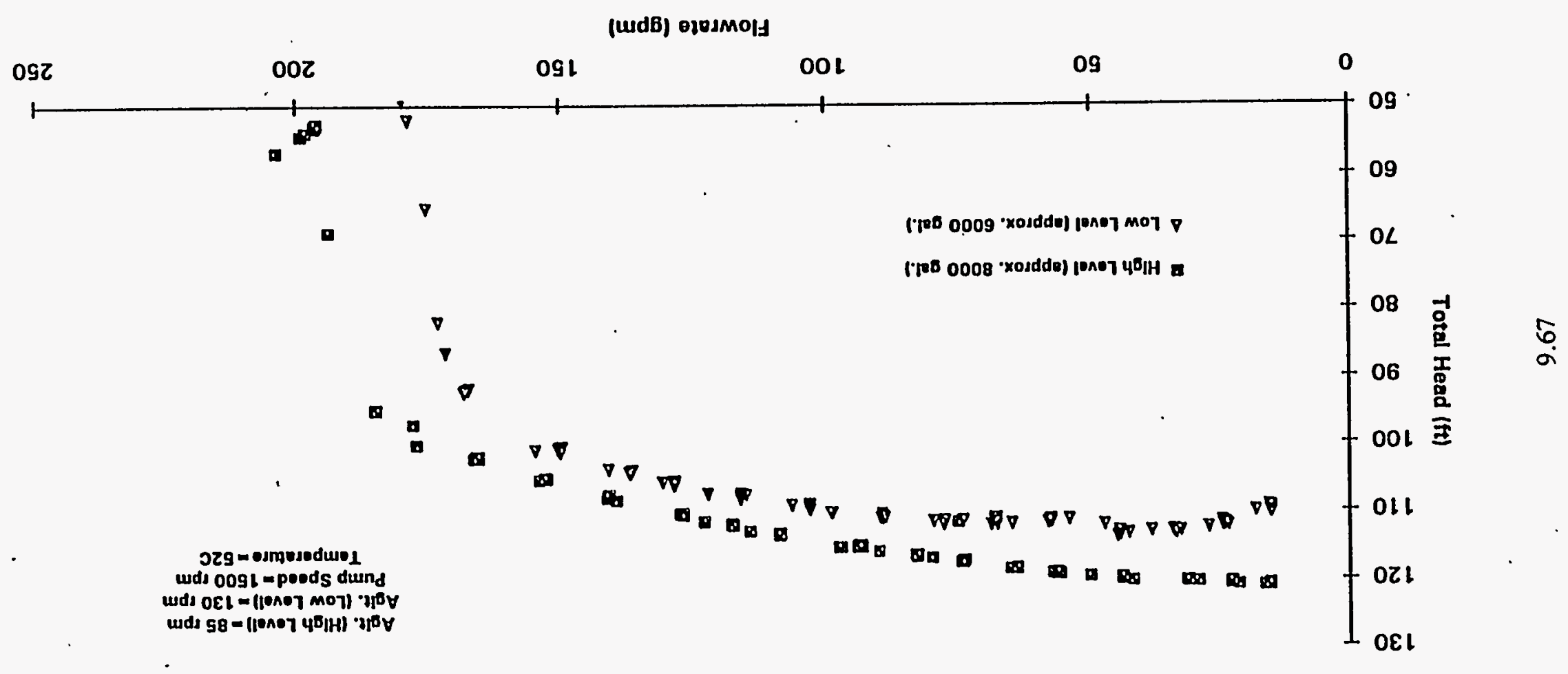




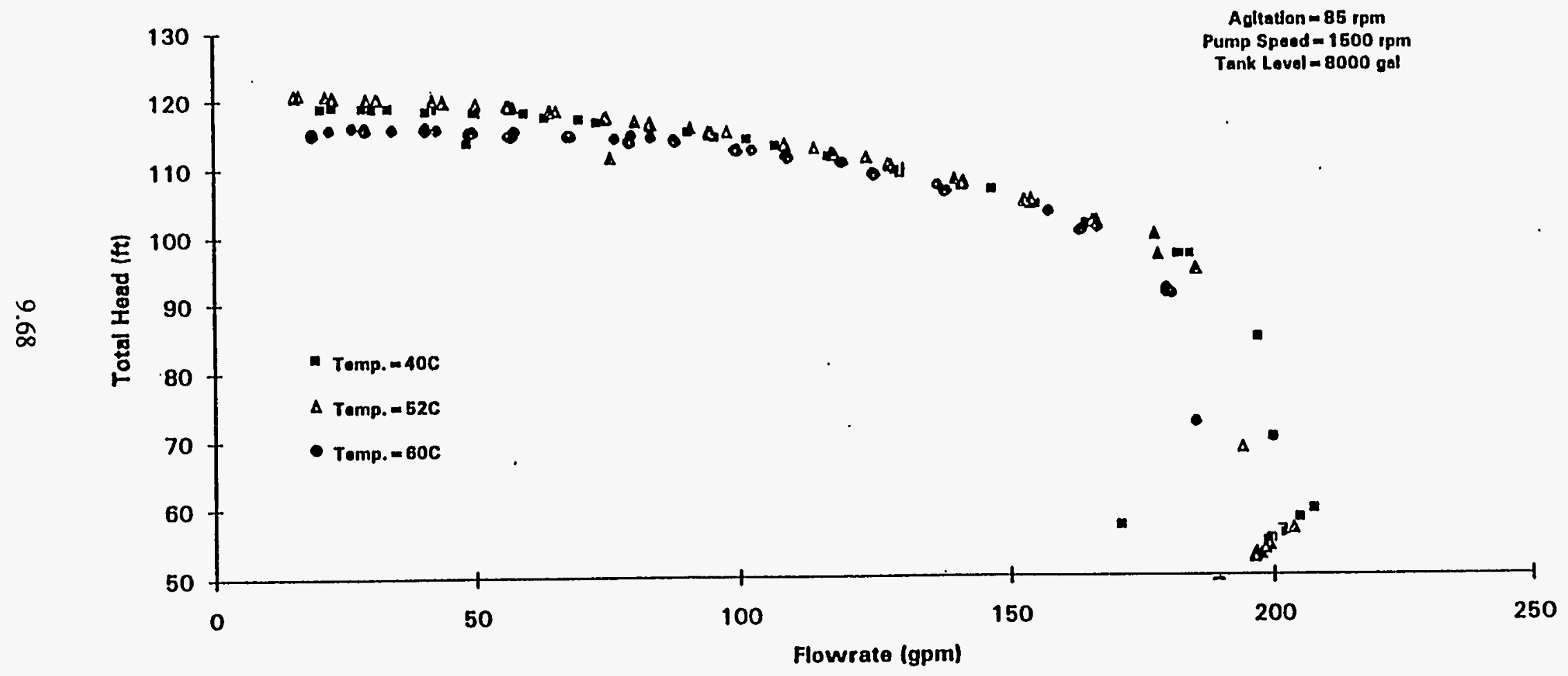

Figure 9.47. Total Head Versus Capacity (Concentrated Feed) Transfer-Pump Temperature Variation 


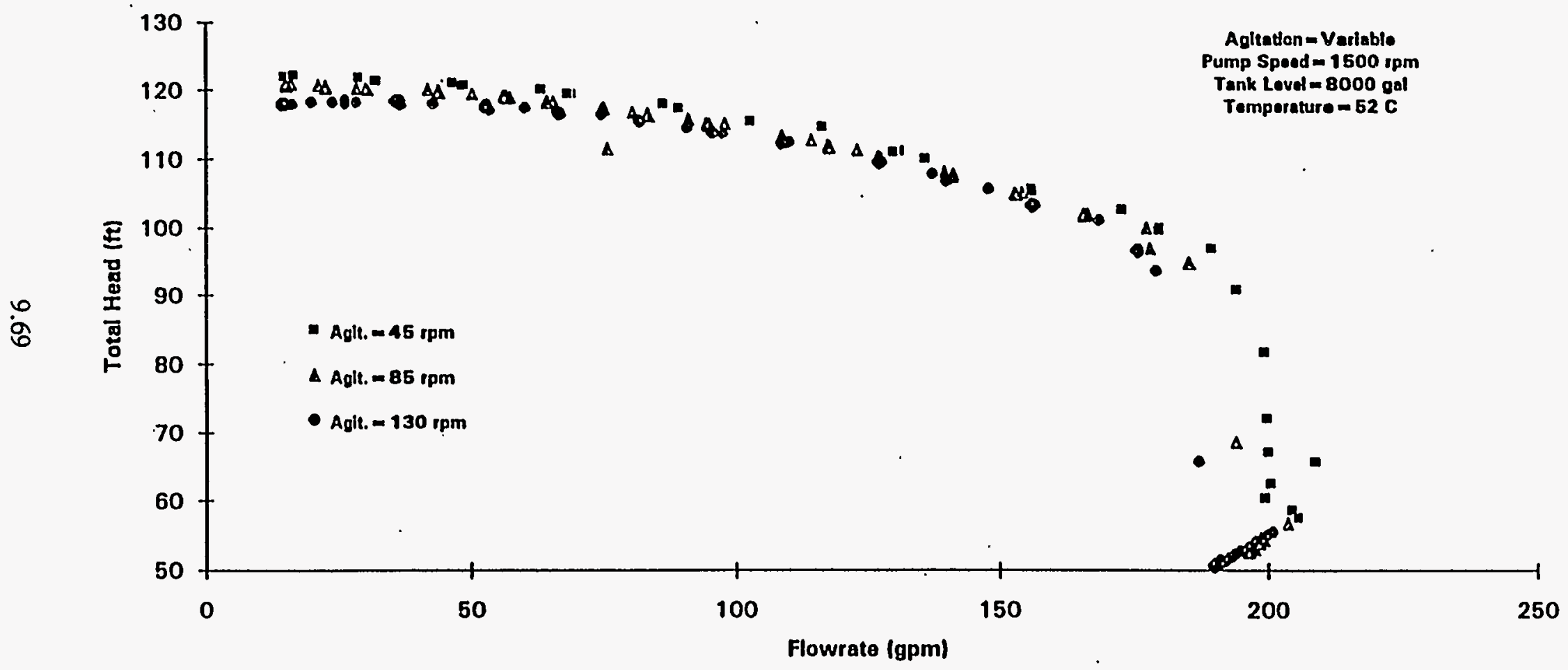

Figure 9.48. Total Head Versus Capacity (Concentrated Feed) Transfer-Pump Agitation Variation 


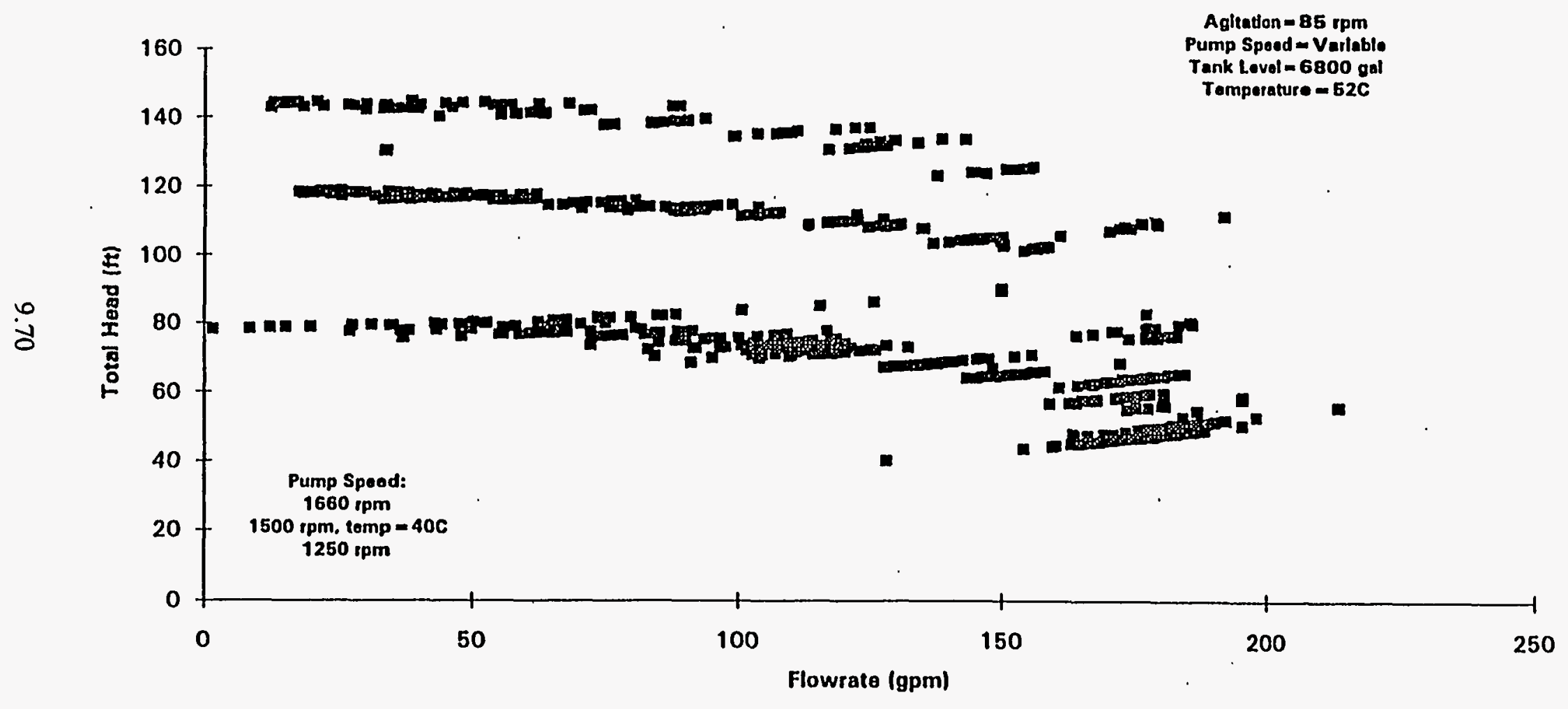

Figure 9.49. Total Head Versus Capacity (Formatted Feed) Transfer-Pump Speed Variation 


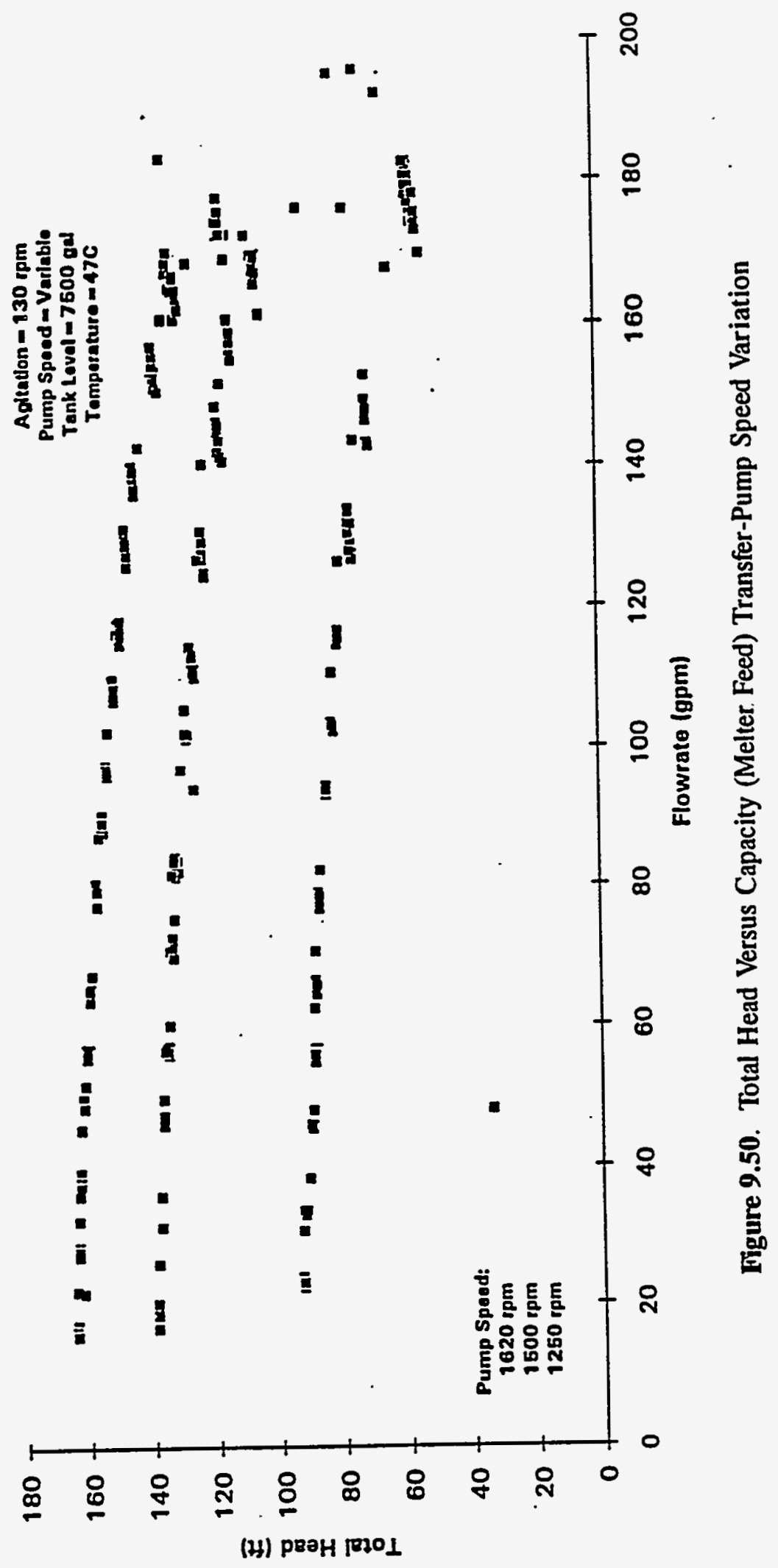

9.71 

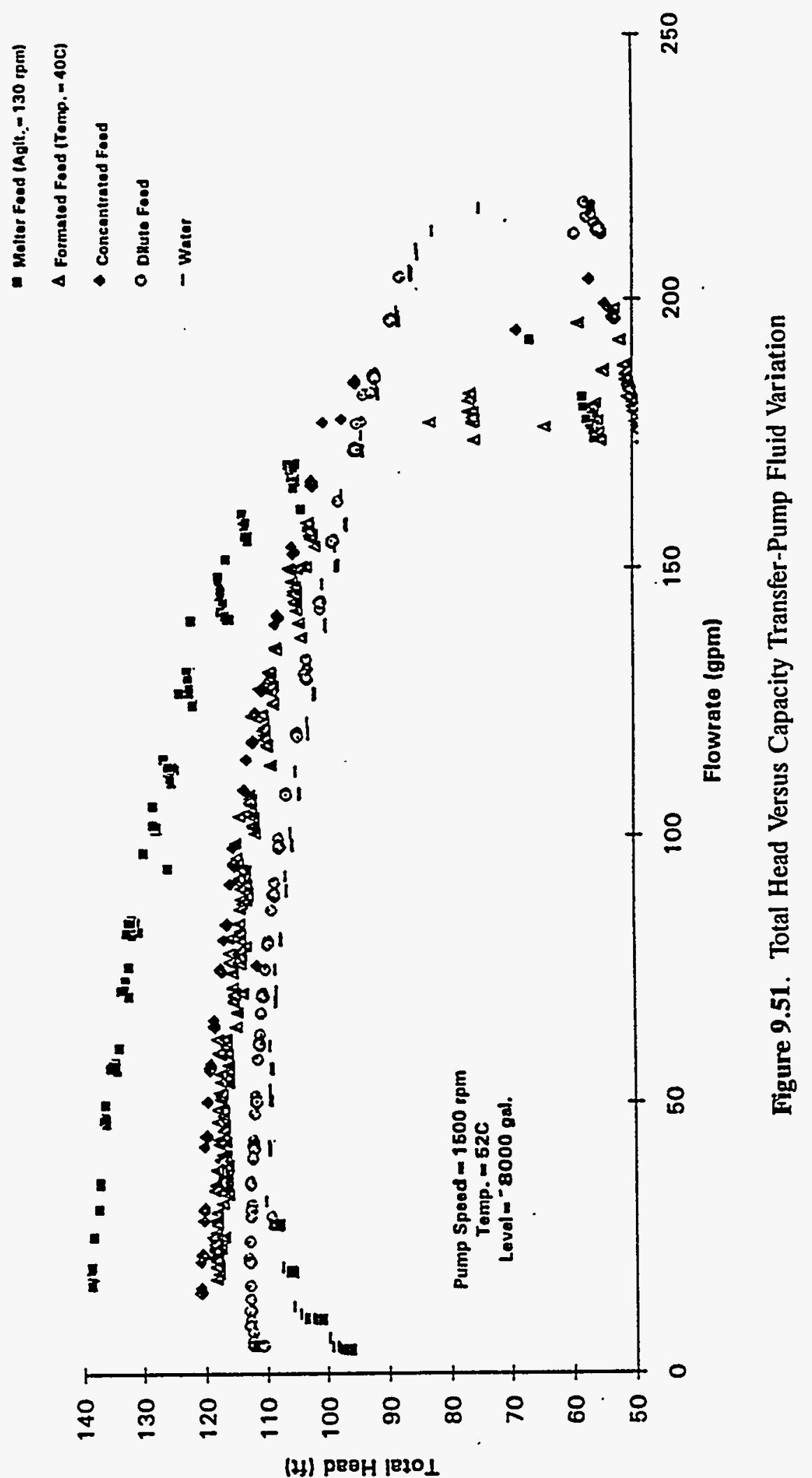


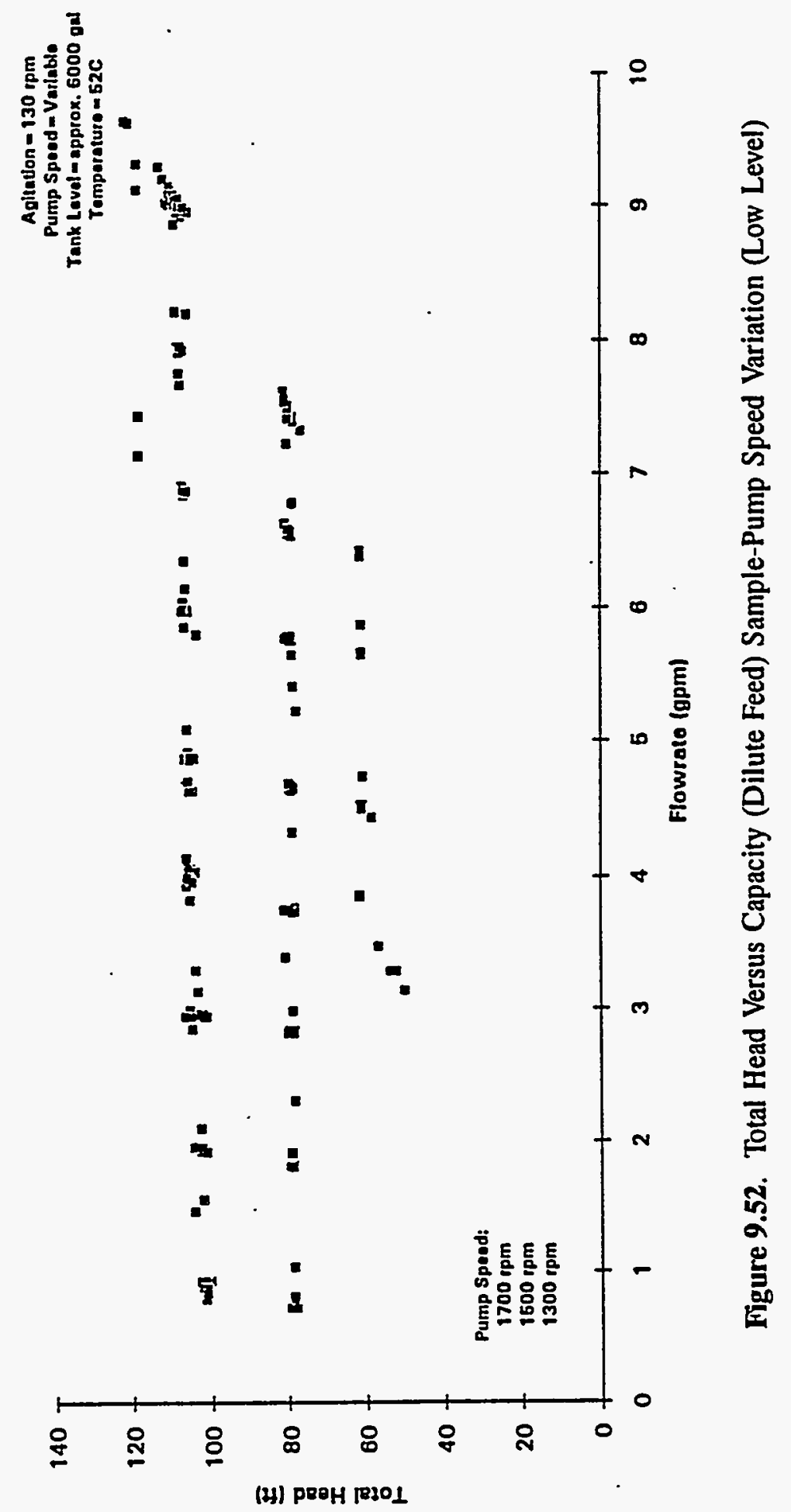




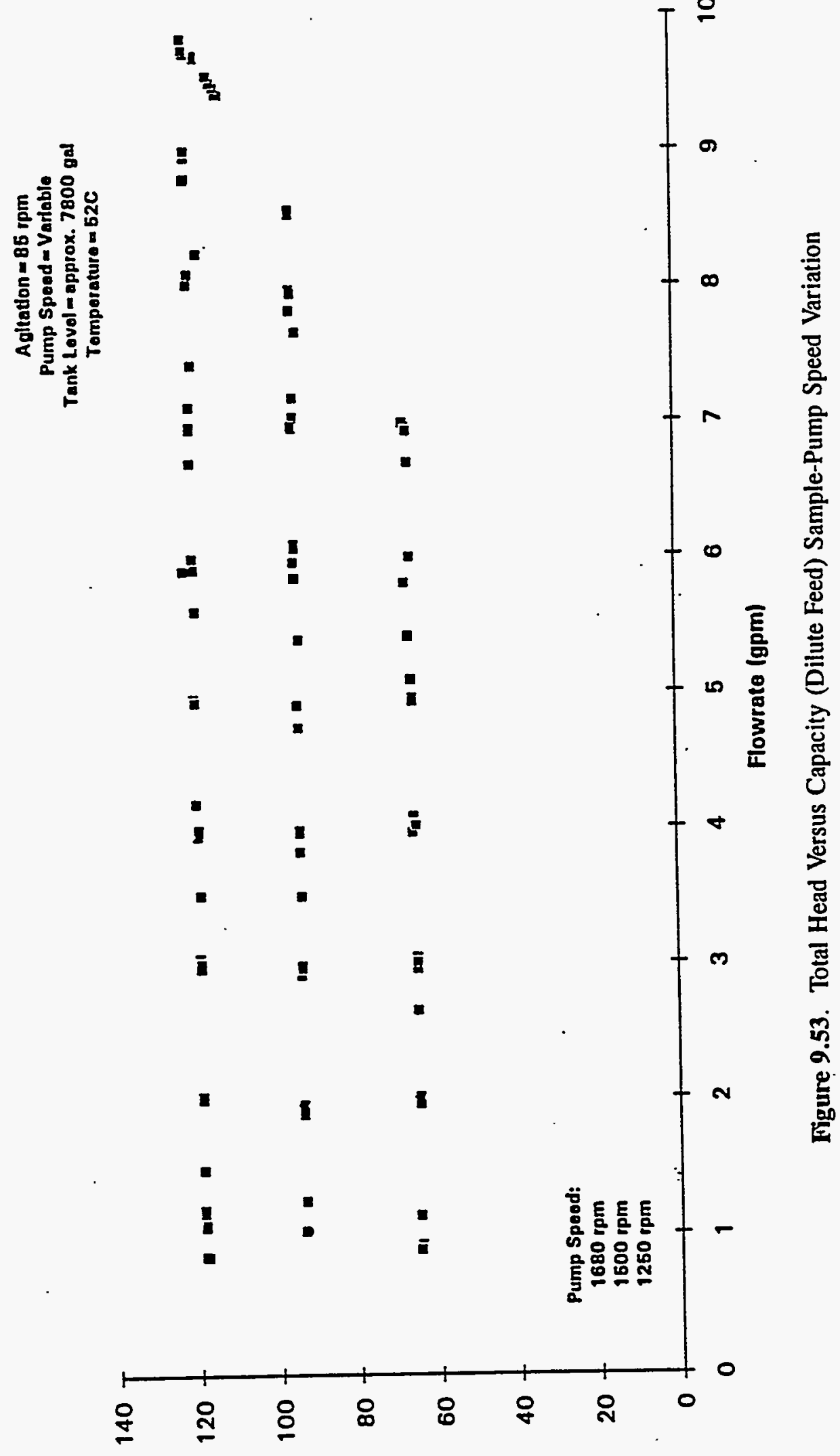

(4) PEOH [RIOL

9.74 


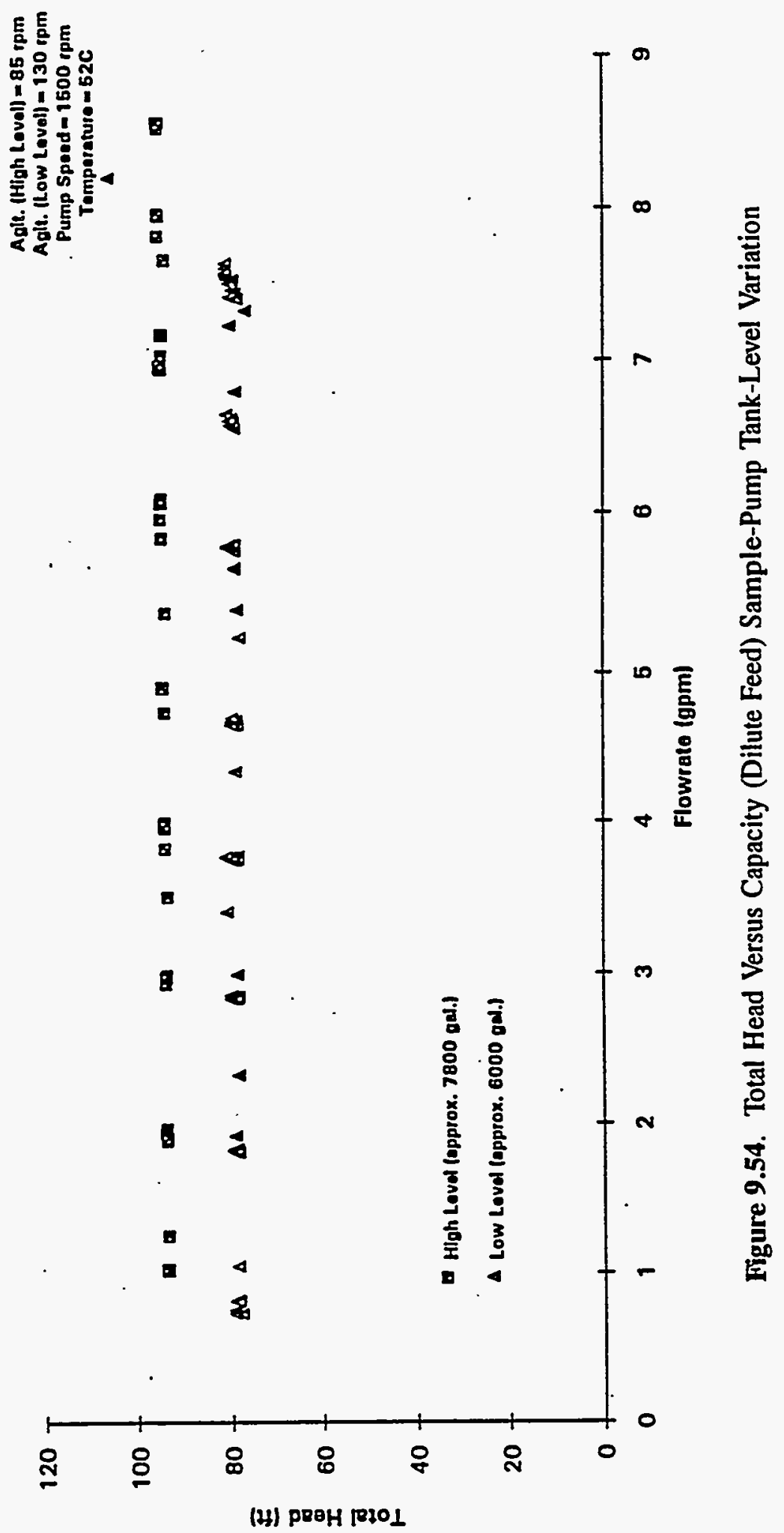

9.75 


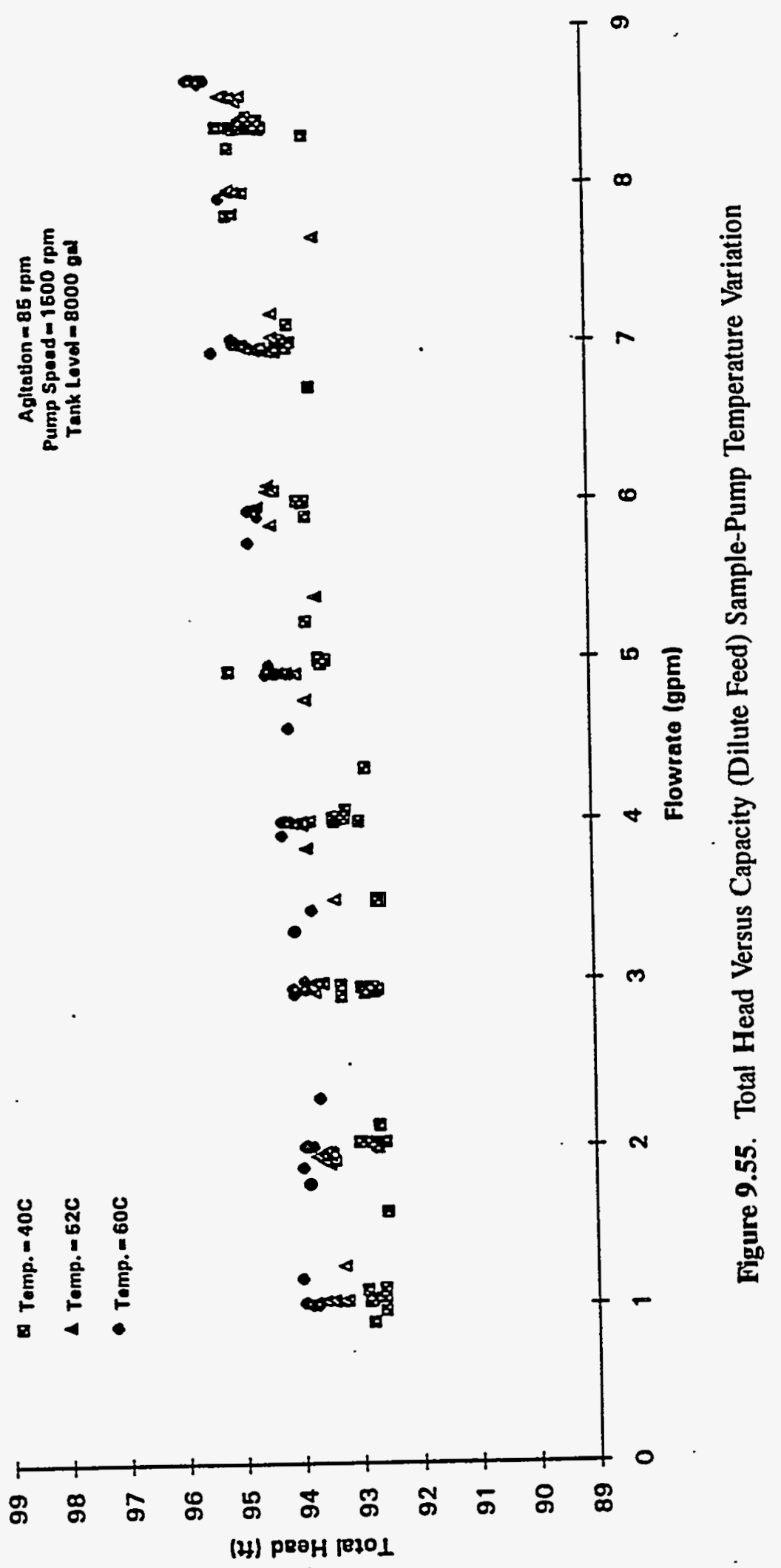




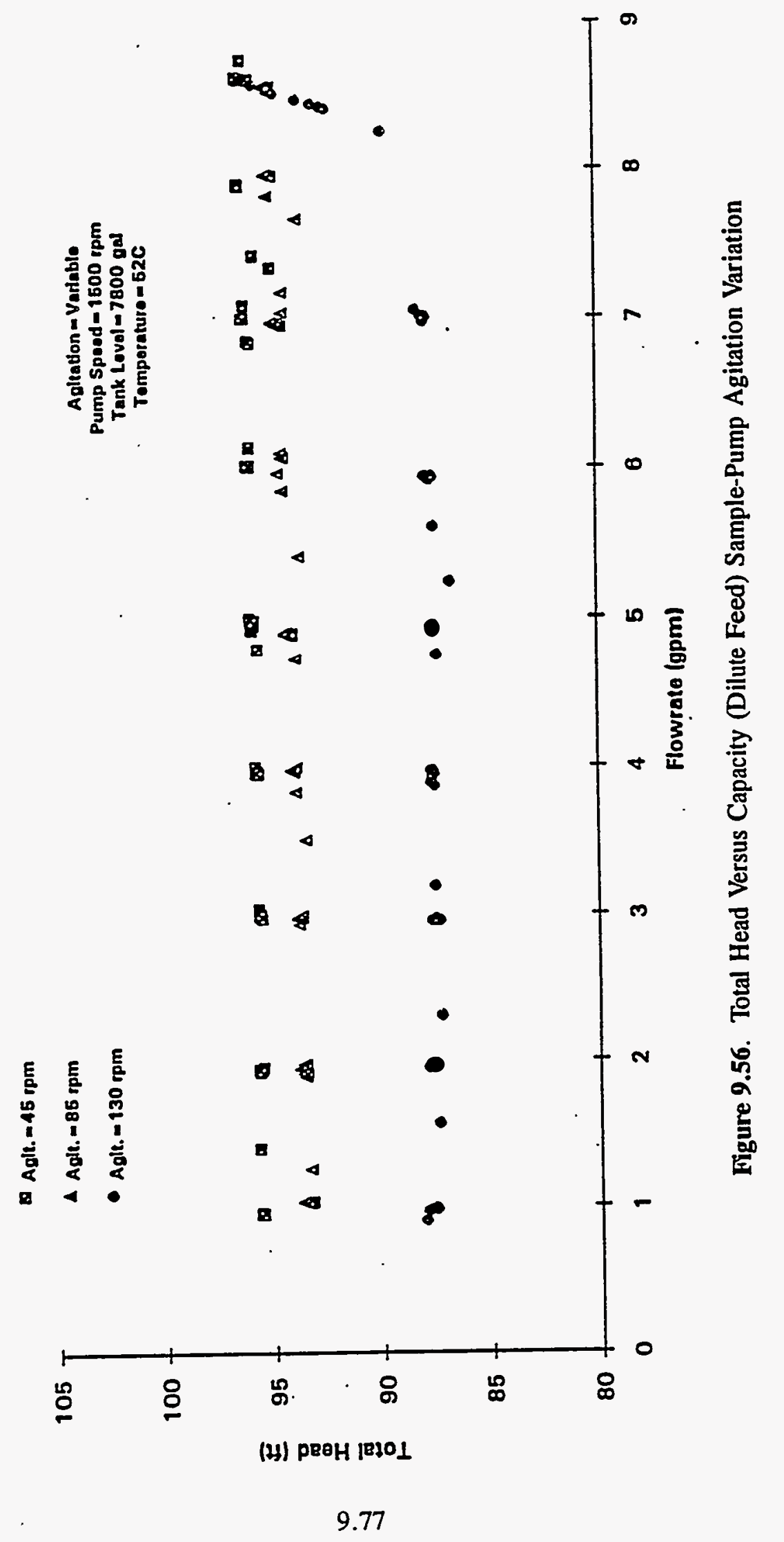




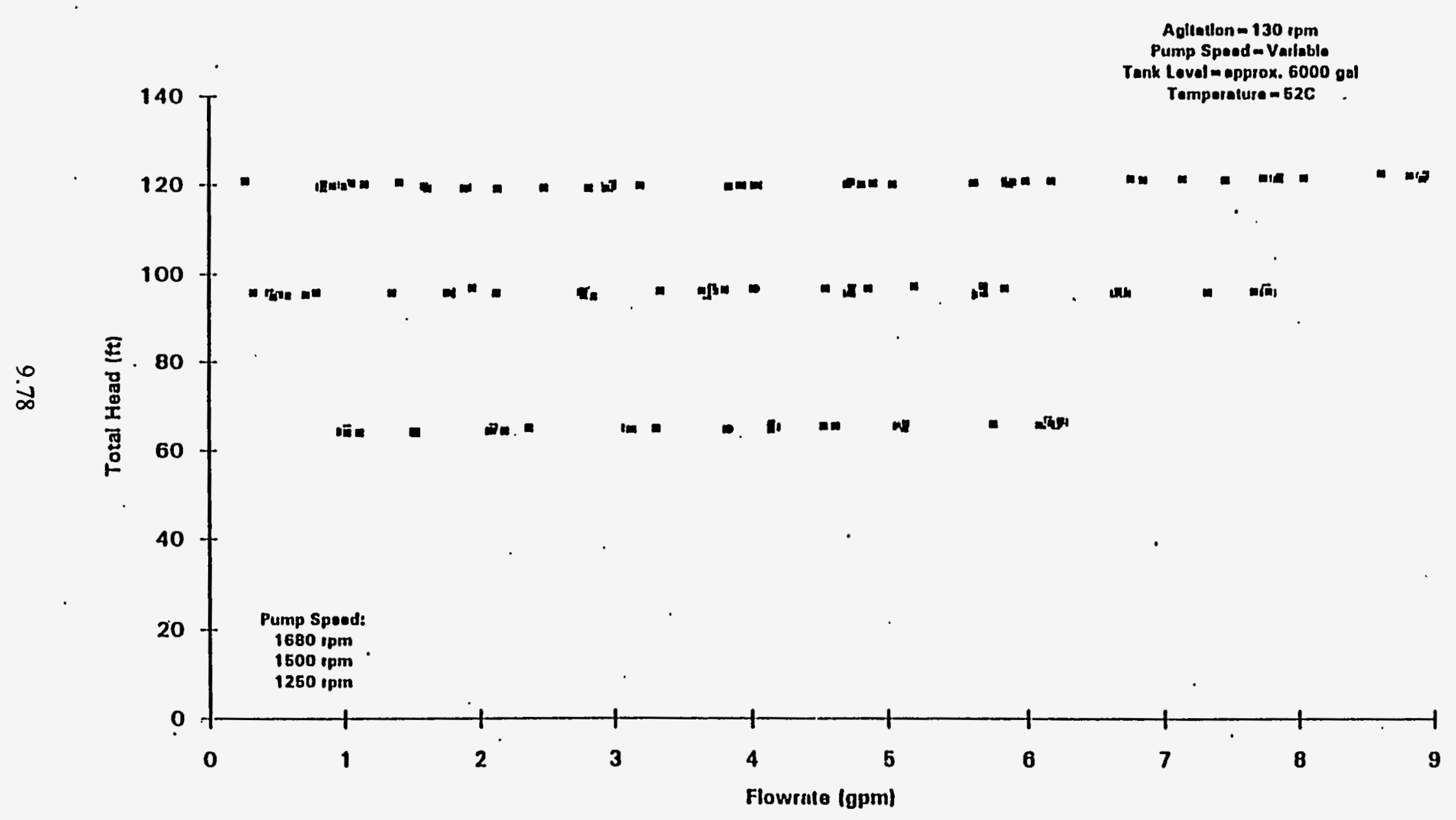

Figure 9.57. Total Head Versus Capacity (Concentrated Feed) Sample-Pump Speed Variation (Low Level) 

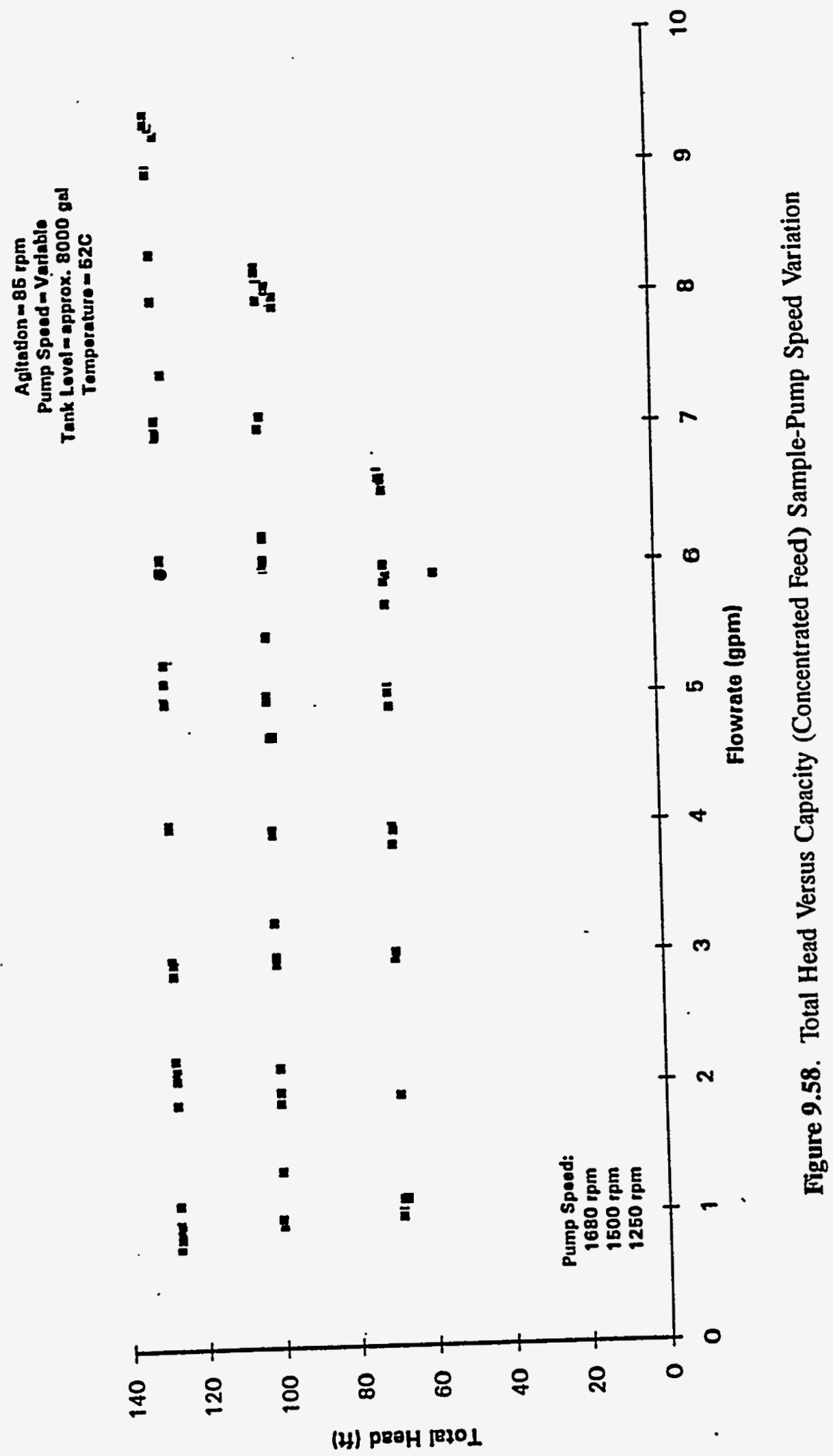


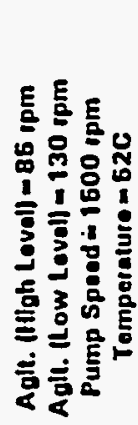

$\infty$

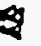
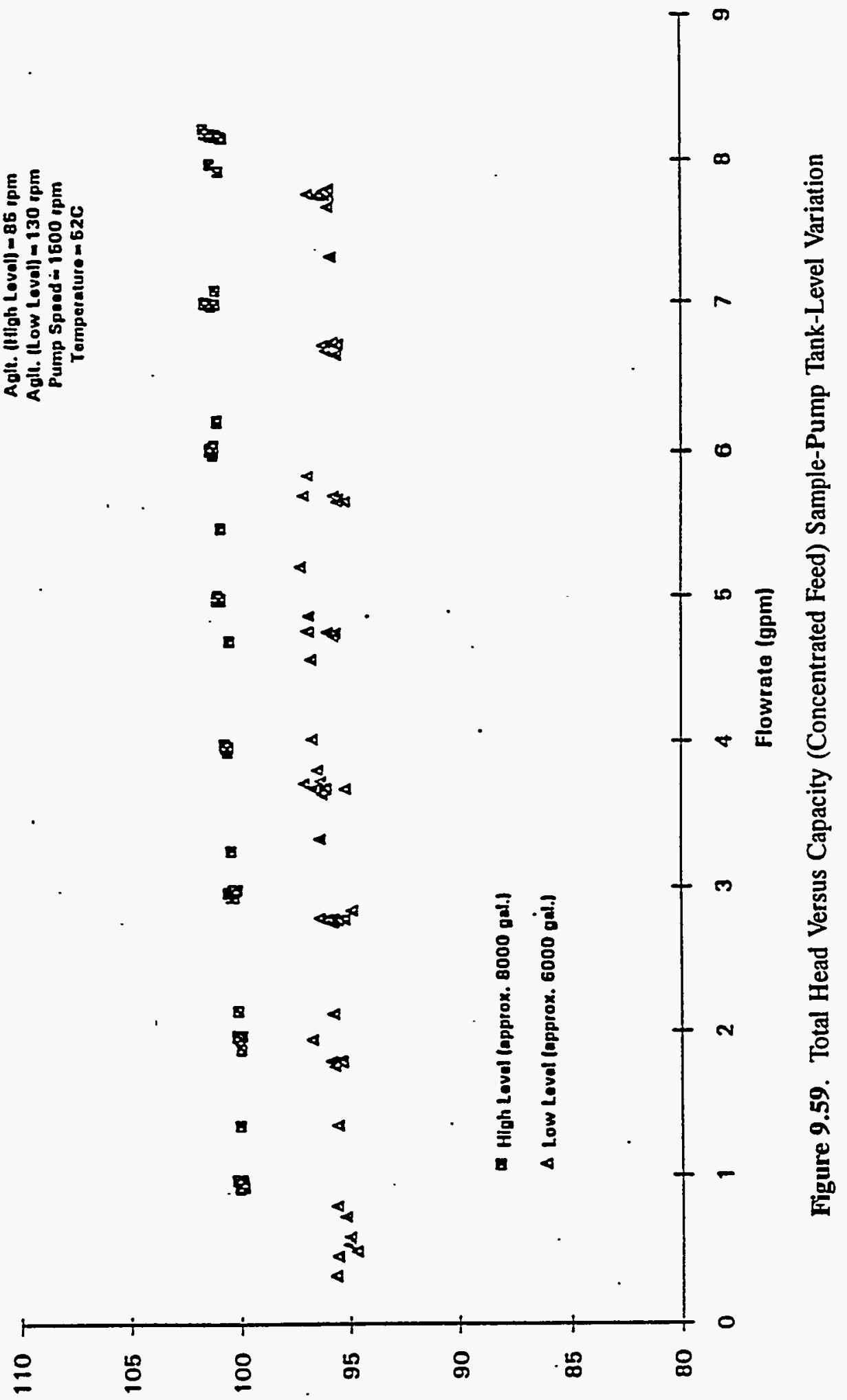

(4) рвән Fедо 


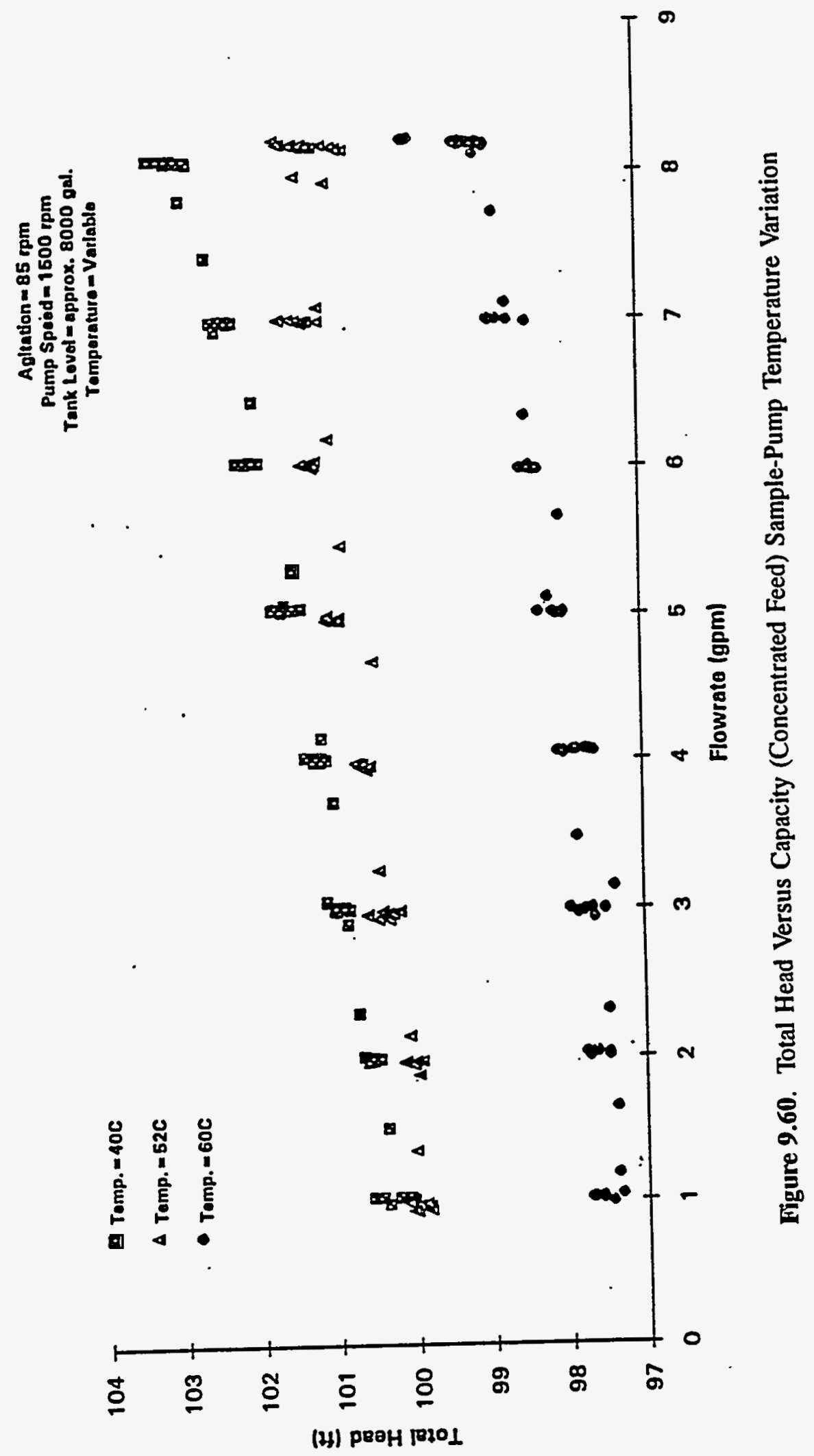




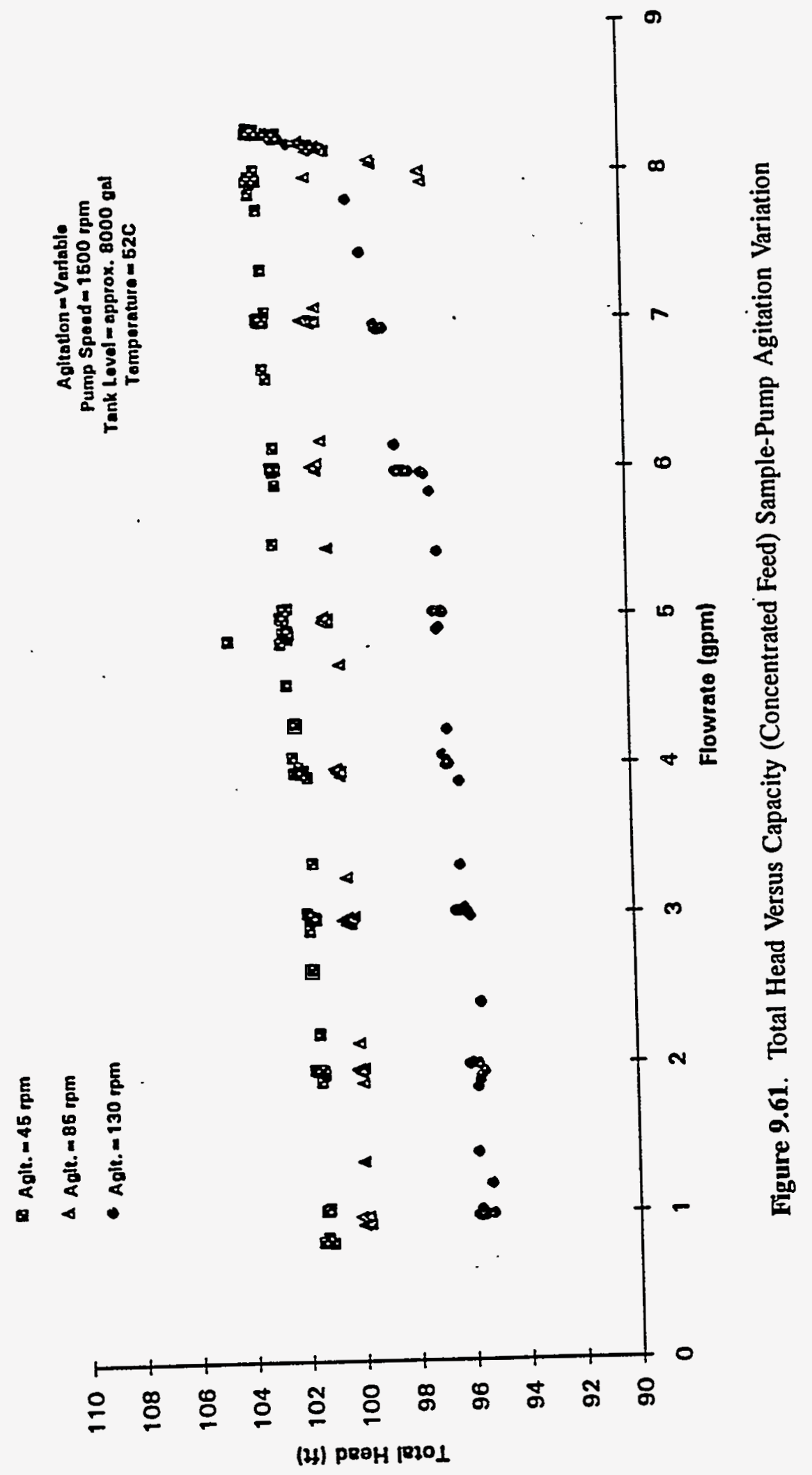




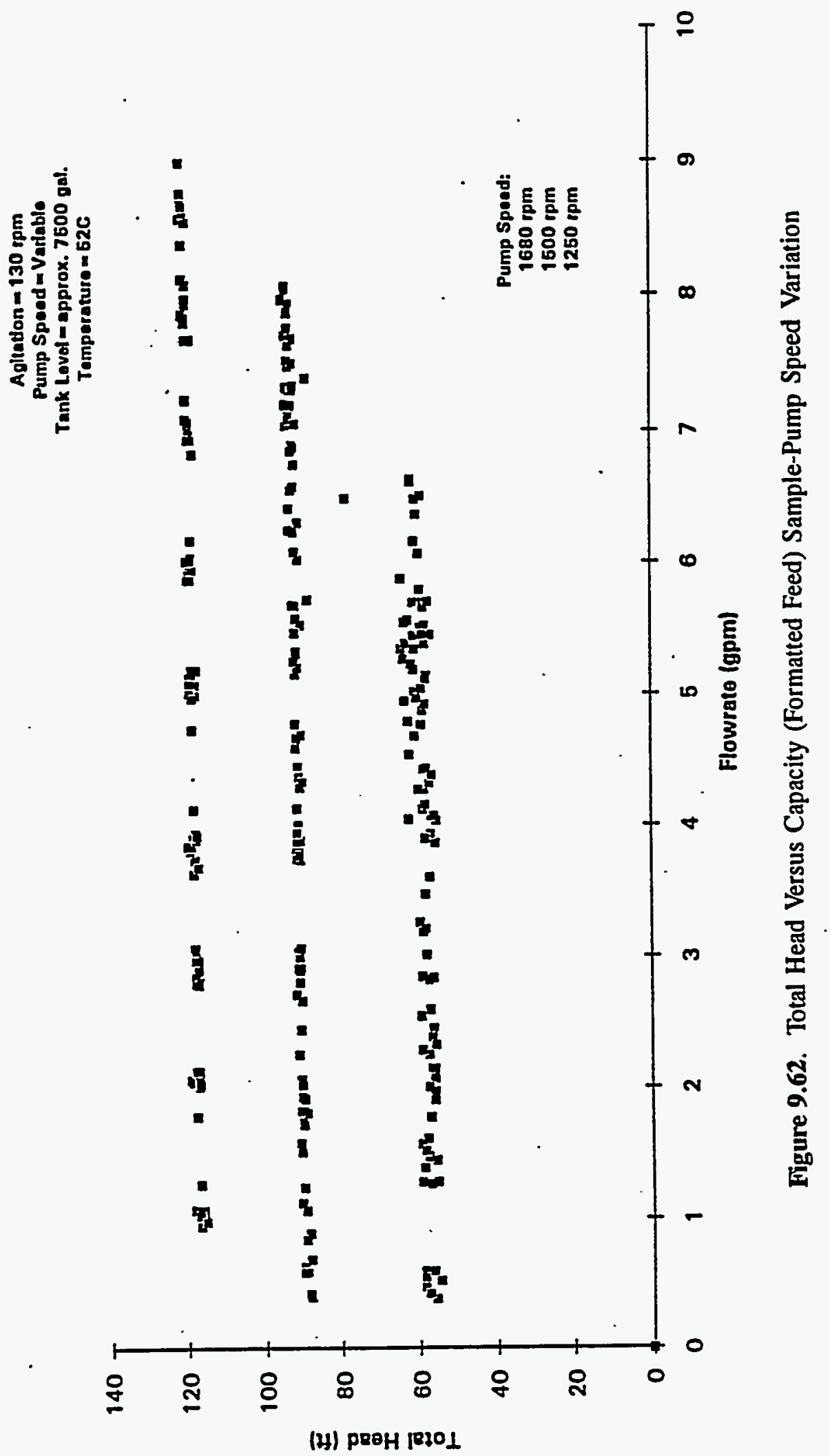




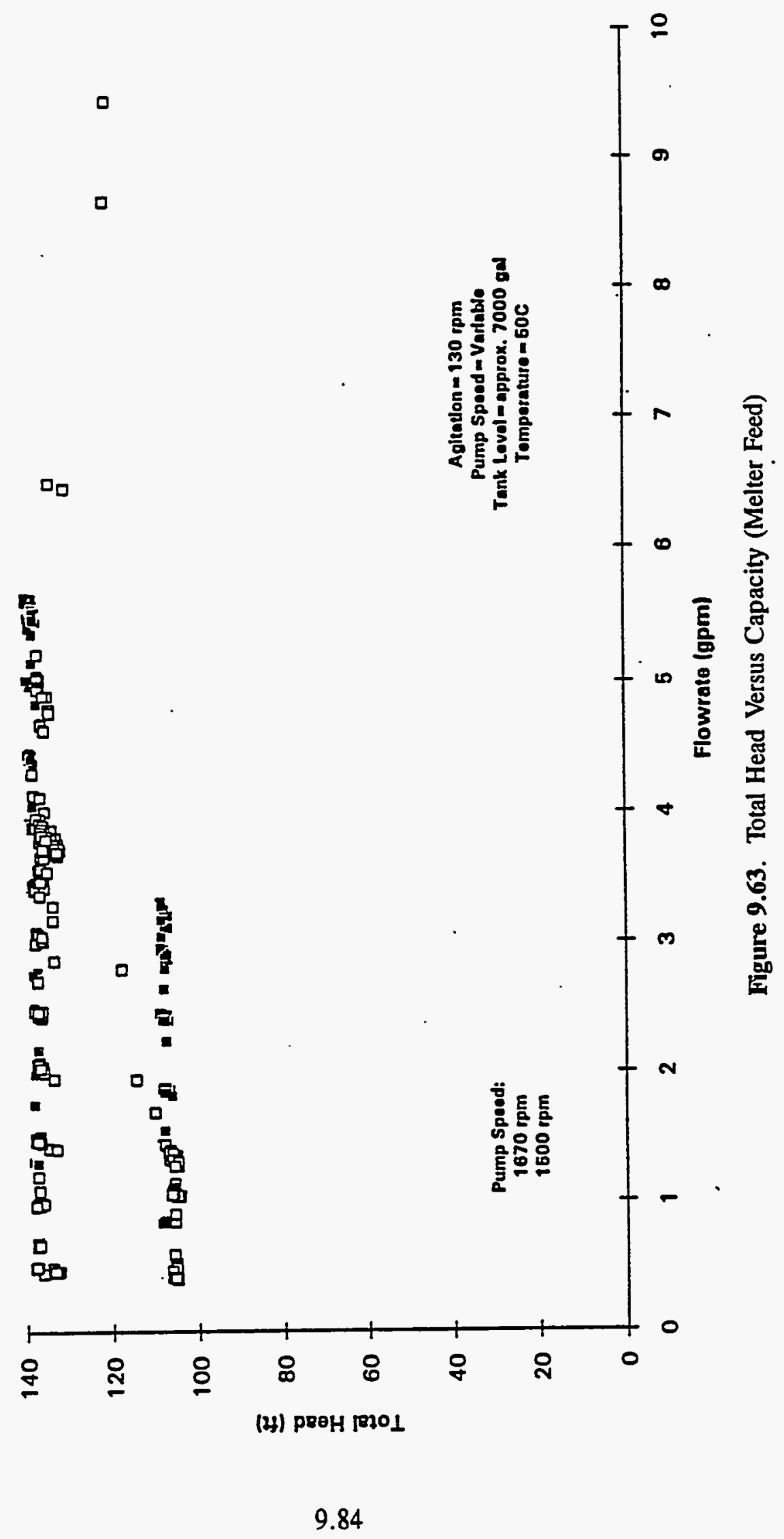




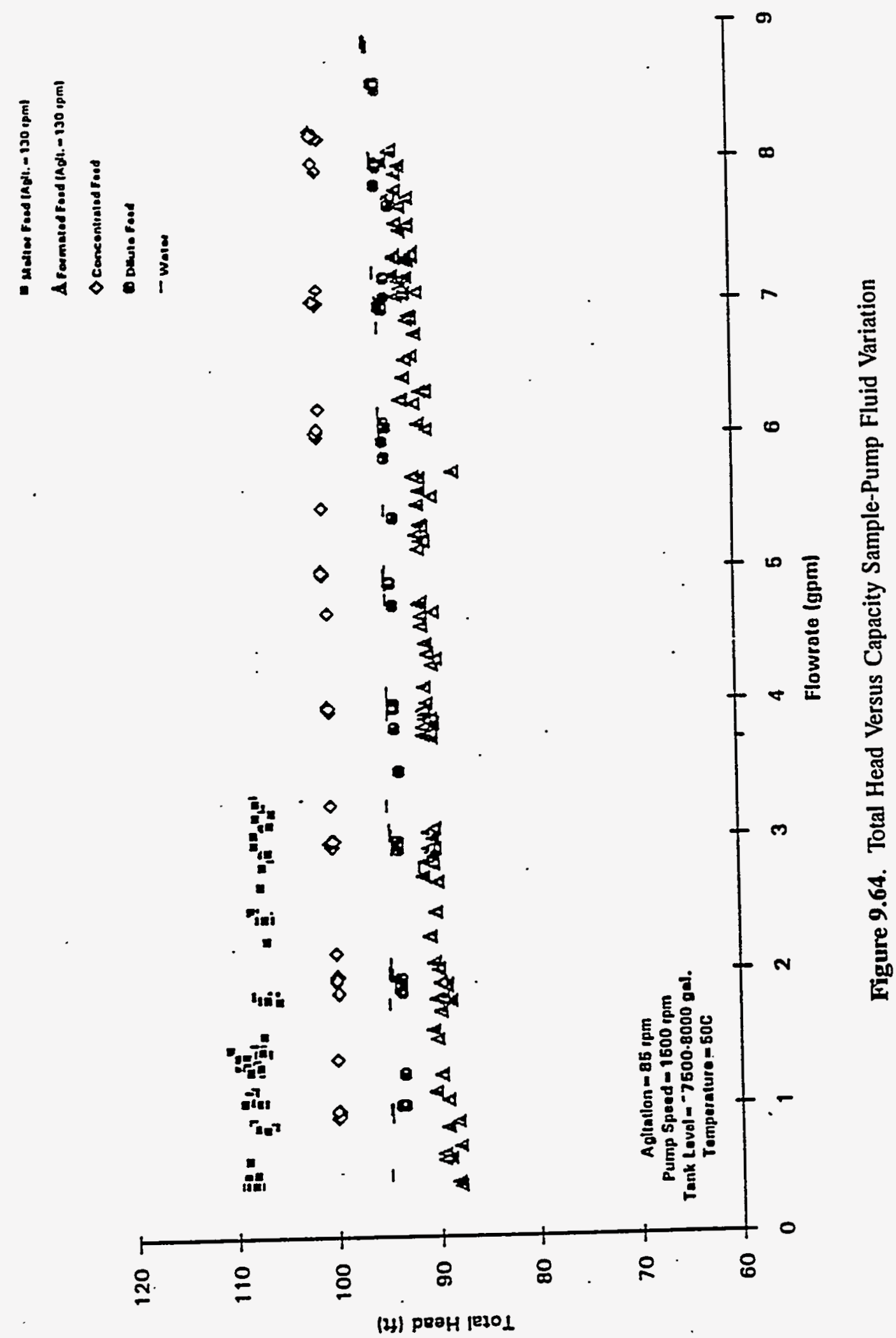

9.85 
During the priming operation it is often difficult to determine when the pump is sufficiently primed. As long as the pump is cavitating, the differential pressure will be small, but as soon as the pump begins to develop a significant differential pressure, it is assumed to have been primed.

Results from the prime-water requirement tests for water, dilute feed, concentrated feed, formatted feed, and melter feed are shown in Tables 9.8, 9.9, 9.10, 9.11, and 9.12, respectively. It is difficult to accurately determine the amount of time required to prime the pump since it is not always apparent exactly when sufficient priming has been achieved. Also, it is not possible for the test operator to be absolutely consistent (to the second) in writing down.exact times. In order to be consistent, the test procedure specifies that the total prime time is the amount of time between starting the pump (this action automatically opens the prime water solenoid valve) and the time at which the flow in the sample loop reaches steady state or the discharge pressure reaches a specific level (SIPT 1 and NCAW $1-30$ psi). The operator is able to track the flow rate (or pressure) as it ramps up following start-up of the pump. In some cases (in Tables 9.8 through 9.12), the "prime time" was not given, rather, steadystate values for flow and pressure were recorded.

One of the most important factors in determining the minimum prime water requirement is the back pressure (discharge pressure) required for successful prime of the Transfer pump under varying conditions. Specific tests to determine these values were not performed during SIPT 1 and NCAW 1. Because of the geometry of the Sample pump, e.g., internal restriction orifice, 1/2-in. discharge line, priming of this pump was not a problem. The prime water requirement information contained in this report is limited to the amount of water necessary to successfully prime each pump. There is limited information on exact times when the discharge pressure reached a specific level ( $30 \mathrm{psi})$. The value of 30 psi during these initial test runs was set arbitrarily as a baseline pressure.

After the prime water is shut off (automatically by solenoid valve), if the flow rate does not increase or decrease and the discharge pressure remains high, the pump has been successfully primed.

\subsubsection{Pump Characterization}

Pump characterization, i.e., determination of the Head-Capacity curve (herein referred to as the $\mathrm{H}-\mathrm{C}$ curve), was performed by holding the pump at various speeds and adjusting the flow rate (with the discharge valve) while measuring the outlet pressure of the pump. Pump characterization curves were produced for three pump speeds, three agitator speeds, and three different temperatures. A curve of total head in feet of water versus flow capacity in gallons per minute was produced for each condition listed in Table 9.13 for each pump. Various combinations of these tests were generated, as listed in Table 9.7. These curves can be used to determine the operating envelope for each pump under specific process conditions.

\subsubsection{Test Results}

\subsubsection{Calculation Method}

The following method was used to calculate the total pump head available as a function of flow rate (H-C curve). A sample calculation for the Transfer Pump is included in Appendix Z. Also, a sample spreadsheet for each pump is included which shows all pump parameters and their relative effect(s). The geometrical' dimensions described below are shown schematically in Figure Z.1. 
Table 9.8. Sample/Transfer Pump Prime-Water Requirement - Process Fluid: Water

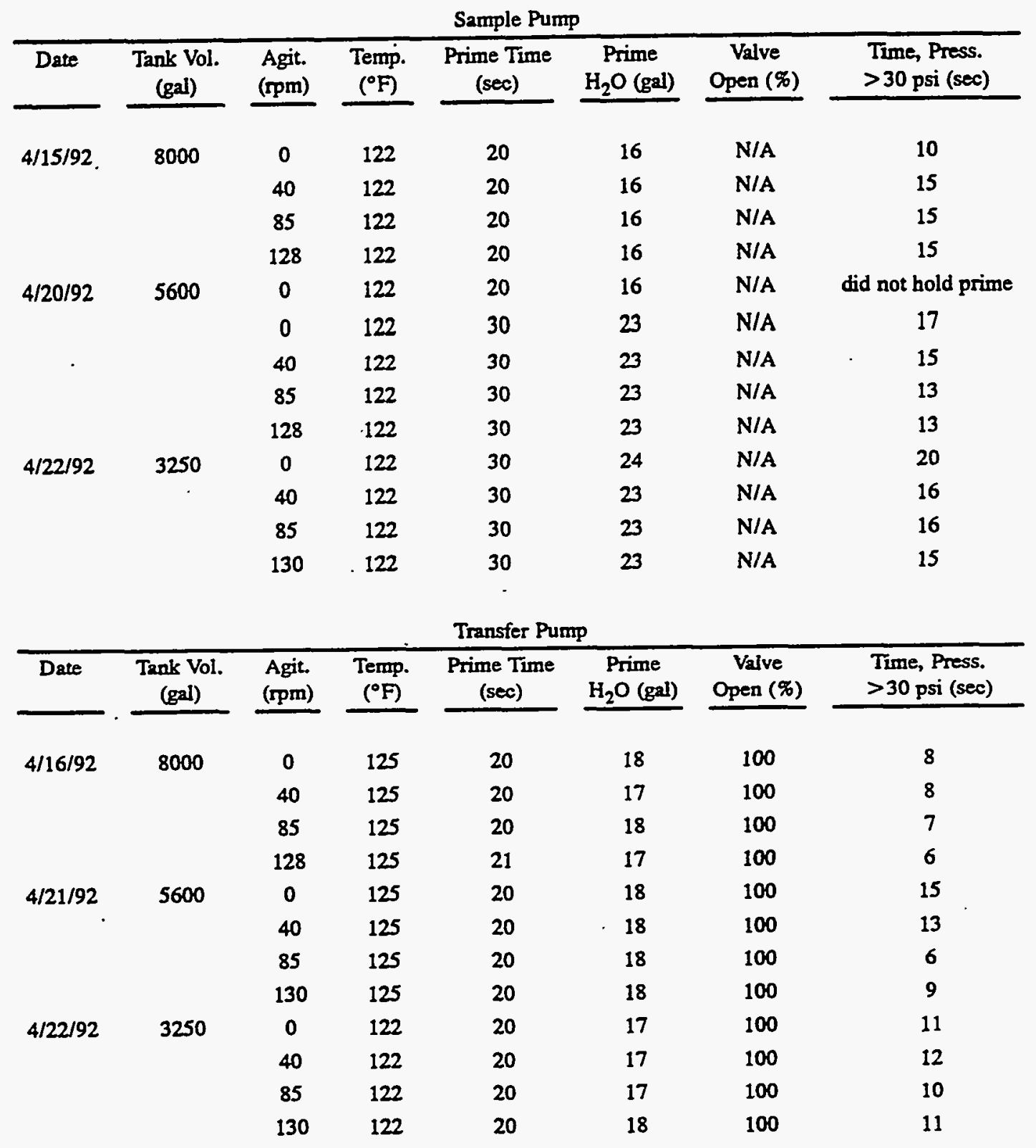


Table 9.9. Sample/Transfer Pump Prime-Water Requirement - Process Fluid: Dilute Feed

Sample Pump

\begin{tabular}{|c|c|c|c|c|c|c|c|c|}
\hline \multicolumn{2}{|c|}{ Date/Time } & \multirow{2}{*}{$\begin{array}{c}\begin{array}{c}\text { Tank Vol. } \\
(\mathrm{gal})\end{array} \\
5700\end{array}$} & \multirow{2}{*}{$\begin{array}{l}\begin{array}{c}\text { Agit. } \\
\text { (rpm) }\end{array} \\
\end{array}$} & \multirow{2}{*}{$\begin{array}{c}\text { Temp. } \\
\left({ }^{\circ} \mathrm{F}\right)\end{array}$} & \multirow{2}{*}{$\begin{array}{c}\begin{array}{c}\text { Prime } \\
\text { Time }(\mathrm{sec})\end{array} \\
30\end{array}$} & \multirow{2}{*}{$\begin{array}{c}\begin{array}{c}\text { Prime } \\
\mathrm{H}_{2} \mathrm{O} \text { (gal) }\end{array} \\
24\end{array}$} & \multirow{2}{*}{$\begin{array}{c}\text { Time, Press. } \\
>30 \text { psi }(\mathrm{sec}) \\
14.5\end{array}$} & \multirow{2}{*}{$\begin{array}{c}\text { Steady-State Pressure/Flow } \\
9 \mathrm{gpm}\end{array}$} \\
\hline $12 / 31 / 92$ & $09: 48$ & & & & & & & \\
\hline $12 / 31 / 92$ & 10:01 & 5700 & 85 & 54 & 30 & 24 & 14 & $9.5 \mathrm{gpm}$ \\
\hline $12 / 31 / 92$ & $10: 08$ & 5700 & 130 & 54 & 30 & 24 & 16 & 9 gpm \\
\hline 1/7/92 & $13: 44$ & 7800 & 45 & 53 & 20 & 16 & 10 & $9 \mathrm{gpm}$ \\
\hline $1 / 7 / 92$ & $13: 54$ & 7800 & 85 & 53 & 20 & 17 & 14 & $9 \mathrm{gpm}$ \\
\hline $1 / 7 / 92$ & $14: 00$ & 7800 & 130 & 53 & 20 & 17 & 11 & $9 \mathrm{gpm}$ \\
\hline
\end{tabular}

Transfer Pump

\begin{tabular}{|c|c|c|c|c|c|c|c|c|}
\hline \multicolumn{9}{|c|}{ Transfer Pump } \\
\hline \multicolumn{2}{|c|}{ Date/Time } & $\begin{array}{c}\text { Tank Vol. } \\
\text { (gal) }\end{array}$ & $\begin{array}{l}\text { Agit. } \\
\text { (rpm) }\end{array}$ & $\begin{array}{l}\text { Temp. } \\
\left({ }^{\circ} \mathrm{F}\right)\end{array}$ & $\begin{array}{l}\text { PrimeTime } \\
(\mathrm{sec})\end{array}$ & $\begin{array}{c}\text { Prime } \\
\mathrm{H}_{2} \mathrm{O} \text { (gal) }\end{array}$ & $\begin{array}{l}\text { Time, Press. } \\
>30 \text { psi (sec) }\end{array}$ & Steady-State Pressure/Flow \\
\hline $1 / 4 / 93$ & $10: 59$ & 5700 & 45 & 53 & 20 & 19 & 20 & \\
\hline $1 / 4 / 93$ & 11:09 & 5700 & 85 & 53 & 20 & 16 & no prime & \\
\hline $1 / 4 / 93$ & $11: 16$ & 5700 & 85 & 53 & 25 & 19 & no prime & \\
\hline $1 / 4 / 93$ & $11: 21$ & 5700 & 85 & 53 & 30 & 22 & no prime & \\
\hline $1 / 4 / 93$ & $11: 31$ & 5700 & 85 & 53 & 35 & 25 & no prime & \\
\hline $1 / 4 / 93$ & $11: 37$ & 5700 & 85 & 53 & 40 & 28 & no prime & \\
\hline $1 / 4 / 93$ & $11: 59$ & 5700 & 130 & 53 & 60 & 41 & no prime & \\
\hline 1/9/93 & 09:55 & 7800 & 45 & 53 & 20 & 17 & & $12 \mathrm{psi} / 220 \mathrm{gpm}$ \\
\hline $1 / 9 / 93$ & $10: 21$ & 7800 & 45 & 53 & 20 & 16 & & $15.8 \mathrm{psi} / 220 \mathrm{pm}$ \\
\hline $1 / 9 / 93$ & $10: 29$ & 7800 & 85 & 53 & 20 & 16 & 11 & $15.6 \mathrm{psi} / 236 \mathrm{gpm}$ \\
\hline $1 / 9 / 93$ & $10: 37$ & 7800 & 128.5 & 53 & 20 & 16 & 11 & $14.7 \mathrm{psi} / 237 \mathrm{gpm}$ \\
\hline
\end{tabular}


Table 9.10. Sample/Transfer Pump Prime-Water Requirement - Process Fluid: Concentrated Feed

\begin{tabular}{|c|c|c|c|c|c|c|c|c|}
\hline \multicolumn{9}{|c|}{ Sample Pump } \\
\hline Date/Time & $\begin{array}{c}\text { Tank Vol. } \\
\text { (gal) }\end{array}$ & $\begin{array}{l}\text { Agit. } \\
\text { (rpm) }\end{array}$ & $\begin{array}{l}\text { Temp. } \\
\left({ }^{\circ} \mathrm{F}\right)\end{array}$ & $\begin{array}{c}\text { Prime } \\
\text { Time (sec) }\end{array}$ & $\begin{array}{l}\text { Prime } \mathrm{H}_{2} \mathrm{O} \\
\quad \text { (gal) }\end{array}$ & $\begin{array}{c}\text { Valve } \\
\text { Open (\%) }\end{array}$ & $\begin{array}{l}\text { Time, Press. } \\
>30 \text { psi (sec) }\end{array}$ & $\begin{array}{c}\text { Steady-State } \\
\text { Pressure/Flow }\end{array}$ \\
\hline 1/29/93 9:40 & 6000 & 45 & 52 & 20 & 16 & $N / A$ & 12 & \\
\hline 1/29/93 9:59 & 6000 & 85 & 52 & 20 & 17 & $\mathrm{~N} / \mathrm{A}$ & 13 & $45 \mathrm{psi} / 9 \mathrm{gpm}$ \\
\hline 1/29/93 10:13 & 6000 & 130 & 52 & 20 & 16 & $\mathrm{~N} / \mathrm{A}$ & 14 & \\
\hline $2 / 8 / 9310: 04$ & 8000 & 45 & 52 & 20 & 17 & $\mathrm{~N} / \mathrm{A}$ & 13 & $48 \mathrm{psi} / 9.5 \mathrm{gpm}$ \\
\hline $2 / 8 / 9310: 18$ & 8000 & .85 & 52 & 20 & 16 & N/A & 15 & $9.5 \mathrm{gpm}$ \\
\hline $2 / 8 / 9310: 23$ & 8000 & 129 & 52 & 20 & 16 & N/A & 10 & $9.5 \mathrm{gpm}$ \\
\hline \multicolumn{4}{|c|}{$\cdot$} & \multicolumn{2}{|c|}{ Transfer Pump } & & & \\
\hline Date/Time & $\begin{array}{c}\text { Tank Vol. } \\
\text { (gal) }\end{array}$ & $\begin{array}{l}\text { Agit. } \\
\text { (rpm) }\end{array}$ & $\begin{array}{c}\text { Temp. } \\
\left({ }^{\circ} \mathrm{F}\right) \\
\end{array}$ & $\begin{array}{c}\text { Prime } \\
\text { Time (sec) } \\
\end{array}$ & $\begin{array}{l}\text { Prime } \mathrm{H}_{2} \mathrm{O} \\
\text { (gal) } \\
\end{array}$ & $\begin{array}{c}\text { Valve } \\
\text { Open (\%) } \\
\end{array}$ & $\begin{array}{l}\text { Time, Press. } \\
>30 \text { psi (sec) } \\
\end{array}$ & $\begin{array}{c}\text { Steady-State } \\
\text { Pressure/Flow }\end{array}$ \\
\hline $1 / 29 / 938: 50$ & 6000 & 45 & 52 & 45 & 34 & 100 & no prime & \\
\hline 1/29/93 9:20 & 6000 & 45 & 52 & 45 & 34 & 50 & 12 & $51.7 \mathrm{psi} / 114.5 \mathrm{gpm}$ \\
\hline 1/29/93 9:27 & 6000 & 45 & 52 & 20 & 16 & 50 & 10 & $51 \mathrm{psi} / 114 \mathrm{gpm}$ \\
\hline I/29/93 9:58 & 6000 & 85 & 52 & 20 & 15 & 50 & 11 & $49 \mathrm{psi} / 113 \mathrm{gpm}$ \\
\hline 1/29/93 10:07 & 6000 & 130 & 52 & 20 & 17 & 50 & 9 & \\
\hline $2 / 9 / 9310: 28$ & 8000 & 85 & 52 & 20 & 19 & 50 & 14 & \\
\hline $2 / 9 / 93 \quad 10: 33$ & 8000 & 85 & 52 & 20. & 16 & 75 & & \\
\hline $2 / 9 / 93 \quad 10: 39$ & 8000 & 85 & 52 & 20 & 16 & 75 & & \\
\hline $2 / 9 / 9310: 41$ & 8000 & 85 & 52 & 20 & 16 & 100 & & \\
\hline $2 / 9 / 9310: 44$ & 8000 & 45 & 52 & 20 & 15 & 100 & & \\
\hline $2 / 9 / 93 \quad 10: 47$ & 8000 & 128 & 52 & 20 & 16 & 100 & & \\
\hline
\end{tabular}


Table 9.11. Sample/Transfer Pump Prime-Water Requirement - Process Fluid: Formatted Feed

\begin{tabular}{|c|c|c|c|c|c|c|c|c|c|}
\hline \multicolumn{10}{|c|}{ Sample Pump } \\
\hline \multicolumn{2}{|c|}{ Date/Time } & $\begin{array}{c}\text { Tank Vol. } \\
\text { (gal) }\end{array}$ & $\begin{array}{l}\text { Agit. } \\
\text { (rpm) }\end{array}$ & $\begin{array}{l}\text { Temp. } \\
\left({ }^{\circ} \mathrm{F}\right)\end{array}$ & $\begin{array}{c}\text { Prime } \\
\text { Time (sec) }\end{array}$ & $\begin{array}{c}\text { Prime } \\
\mathrm{H}_{2} \mathrm{O} \text { (gal) }\end{array}$ & $\begin{array}{c}\text { Valve } \\
\text { Open (\%) }\end{array}$ & $\begin{array}{l}\text { Time, Press. } \\
>30 \text { psi (sec) }\end{array}$ & $\begin{array}{l}\text { Steady-State } \\
\text { Pressure/Flow }\end{array}$ \\
\hline $3 / 16 / 93$ & $11: 40$ & 7000 & 45 & 52 & 20 & 16 & N/A & 15 & \\
\hline $3 / 16 / 93$ & $11: 46$ & 7000 & 85 & 52 & 20 & 16 & N/A & 14 & \\
\hline $3 / 16 / 93$ & $11: 51$ & 7000 & 129 & 52 & 20 & 16 & N/A & 12 & \\
\hline \multicolumn{10}{|c|}{ Transfer Pump } \\
\hline \multicolumn{2}{|c|}{ Date/Time } & $\begin{array}{c}\text { Tank Vol. } \\
\text { (gal) }\end{array}$ & $\begin{array}{l}\text { Agit. } \\
\text { (rpm) }\end{array}$ & $\begin{array}{c}\text { Temp. } \\
\left({ }^{\circ} \mathrm{F}\right) \\
\end{array}$ & $\begin{array}{c}\text { Prime } \\
\text { Time }(\mathrm{sec}) \\
\end{array}$ & $\begin{array}{c}\text { Prime } \\
\mathrm{H}_{2} \mathrm{O} \text { (gal) } \\
\end{array}$ & $\begin{array}{c}\text { Valve } \\
\text { Open (\%) }\end{array}$ & $\begin{array}{l}\text { Time, Press. } \\
>30 \mathrm{psi}(\mathrm{sec}) \\
\end{array}$ & $\begin{array}{c}\text { Steady-State } \\
\text { Pressure/Flow }\end{array}$ \\
\hline $3 / 17 / 93$ & $09: 48$ & 7500 & 45 & 52 & 20 & 20 & 50 & & $31 \mathrm{psi} / 185 \mathrm{gpm}$ \\
\hline $3 / 17 / 93$ & $10: 11$ & 7500 & 45 & 52 & 20 & 17 & 60 & & $\begin{array}{c}24.4 \mathrm{psi} / 191 \\
\mathrm{gpm}\end{array}$ \\
\hline $3 / 17 / 93$ & $10: 16$ & 7500 & 45 & 52 & 20 & 17 & 70 & & 19 psi/184 gpm \\
\hline $3 / 17 / 93$ & $10: 21$ & 7500 & 45 & 52 & 20 & 17 & 85 & & $13 \mathrm{psi} / 185 \mathrm{gpm}$ \\
\hline $3 / 17 / 93$ & $10: 26$ & 7500 & 45 & 52 & 20 & 17 & 100 & & $\begin{array}{l}10.8 \mathrm{psi} / 195 \\
\mathrm{gpm}\end{array}$ \\
\hline $3 / 17 / 93$ & $12: 59$ & 7500 & 85 & 52 & 20 & 17 & 100 & & $\begin{array}{l}9.5 \mathrm{psi} / 181 \\
\mathrm{gpm}\end{array}$ \\
\hline $3 / 17 / 93$ & $13: 12$ & 7500 & 128 & 52 & 20 & 17 & 100 & no prime & \\
\hline $3 / 17 / 93$ & $13: 23$ & 7500 & 128 & 52 & 20 & 17 & 75 & & $\begin{array}{l}13.84 \mathrm{psi} / 167 \\
\mathrm{gpm}\end{array}$ \\
\hline
\end{tabular}


Table 9.12. Sample/Transfer Pump Prime-Water Requirement - Process Fluid: Melter Feed

Sample Pump

\begin{tabular}{|c|c|c|c|c|c|c|c|c|c|}
\hline \multicolumn{2}{|c|}{ Date/Time } & $\begin{array}{c}\text { Tank Volume } \\
\text { (gal) }\end{array}$ & \multirow{2}{*}{$\begin{array}{l}\begin{array}{l}\text { Agit. } \\
\text { (rpm) }\end{array} \\
\frac{127}{}\end{array}$} & \multirow{2}{*}{$\begin{array}{c}\begin{array}{c}\text { Temp. } \\
\left({ }^{\circ} \mathrm{F}\right)\end{array} \\
48\end{array}$} & \multirow{2}{*}{$\begin{array}{c}\begin{array}{c}\text { Prime Time } \\
(\mathrm{sec})\end{array} \\
20\end{array}$} & \multirow{2}{*}{$\begin{array}{c}\begin{array}{c}\text { Prime } \\
\mathrm{H}_{2} \mathrm{O}(\mathrm{gal})\end{array} \\
16\end{array}$} & \multirow{2}{*}{$\begin{array}{c}\begin{array}{c}\text { Valve } \\
\text { Open (\%) }\end{array} \\
\text { N/A }\end{array}$} & \multirow{2}{*}{$\begin{array}{c}\begin{array}{c}\text { Time, Press. } \\
>30 \text { psi (sec) }\end{array} \\
15\end{array}$} & \multirow[t]{2}{*}{$\begin{array}{l}\text { Steady-State } \\
\text { Pressure/Flow }\end{array}$} \\
\hline 4/9/93 & 09:04 & & & & & & & & \\
\hline $4 / 10 / 93$ & $14: 15$ & 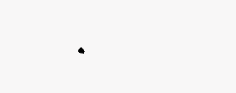 & 127 & 47 & 20 & 16 & N/A & & $\begin{array}{c}54.1 \mathrm{psi} / 4.75 \\
\mathrm{gpm}\end{array}$ \\
\hline
\end{tabular}

Transfer Pump

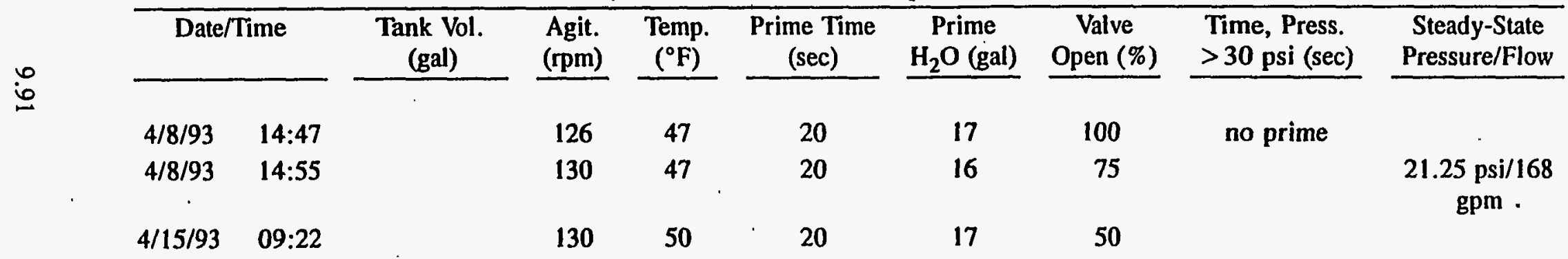


Table 9.13. Matrix of Test Conditions

$\begin{array}{cccc}\begin{array}{c}\text { Temperature } \\ \left({ }^{\circ} \mathrm{C}\right)\end{array} & \begin{array}{c}\text { Agitation Speed } \\ (\mathrm{rpm})\end{array} & \text { Pump Speed (rpm) } \\ 40 & 85 & & 1500 \\ 52 & 85 & & 1250,1500,1785(\mathrm{max}) \\ 52 & 130 & & 1500 \\ 52 & 45 & 1500 \\ 60 & 85 & 1500\end{array}$

Pump "Head" is a quantity used to express a form (or combination of forms) of the energy content of the liquid per unit weight of the liquid referred to any arbitrary datum. In terms of foot-pounds of energy per pound of liquid, all head quantities have the dimensions of feet of liquid.

The unit for measuring head is the foot. The relation between a pressure expressed in pounds per square inch (psi) and that expressed in feet of head is

$$
\operatorname{Head}(\text { feet })=p s i * \frac{2.31 * 62.3}{w}=p s i * \frac{2.31}{\mathrm{~s}}
$$

where $w=$ specific weight in pounds per cubic foot

$$
s=\text { specific gravity of the liquid. }
$$

All pressure readings are converted into feet of the liquid being pumped. The datum elevation is defined as the centerline of the impeller for each pump.

The velocity head $\left(h_{v}\right)$ is the kinetic energy per unit weight of the liquid at a given section. Velocity head is specifically defined by the expression:

$$
h_{v}=\frac{v^{2}}{2 g}
$$

where $\mathrm{g}=$ Acceleration due to gravity and will be defined as $32.2 \mathrm{ft}$ per second per second

$\mathrm{V}=$ Velocity in the pipe in feet per second. 
$\mathrm{V}$ is obtained by dividing the discharge (cubic feet per second, cfs) by the actual area of the pipe crosssection in square feet.

The total suction head is defined by the following:

$$
\mathrm{H}_{\mathrm{s}}=\mathrm{Z}_{\mathrm{w}}+\mathrm{h}_{\mathrm{fs}}
$$

where $\mathrm{h}_{\mathrm{fs}}=$ pipe friction loss in the suction piping in feet of liquid

$Z_{w}=$ distance between the datum and the water level through which the water must be "lifted."

Since a suction lift exists, the total suction head shall be negative.

In our case, the total discharge head is defined by the following:

$$
H_{d}=h_{g}+h_{v}+Z_{d}+h_{f d}
$$

where $h_{g}=$ discharge pressure gage reading (feet of liquid)

$Z_{d}=$ vertical distance between datum and location of discharge pressure gage, $f t$

$h_{\mathrm{fd}}=$ pipe friction loss in discharge piping (including fittings), before the pressure gage, $\mathrm{ft}$.

The total head or total dynamic head $\left(\mathrm{H}_{\mathrm{T}}\right)$ is the measure of the energy increase per pound of the liquid imparted to the liquid by the pump and is, therefore, defined by the following:

$$
\mathrm{H}_{\mathrm{T}}=\mathrm{H}_{\mathrm{d}}-\mathrm{H}_{\mathbf{s}}
$$

As shown in Figure 9.25 (Manufacturer's curve), the total head should decrease as the flow rate (capacity) increases. This holds true for the Transfer pump. However, as explained below, the H-C curve for the Sample pump behaves differently.

\subsubsection{Sample Pump}

Sample Pump Prime-Water Requirement. Tables 9.8 through 9.12 list the prime water required to successfully prime the Sample pump during various stages of SIPT 1 and NCAW 1. The prime time was originally set at 20 seconds. During initial water testing, a prime attempt was unsuccessful at $5600 \mathrm{gal}$ and, therefore, the time was increased by 10 seconds to 30 seconds. It was not readily apparent what caused the pump to lose its prime. A prime time of 30 seconds was used until halfway 
through the dilute feed testing, when it was again reset to 20 seconds. No further problems were observed. As mentioned above, the operator did not always record the exact time at which the discharge pressure reached $30 \mathrm{psi}$, but rather recorded the steady-state flow or pressure following closure of the prime water solenoid valve. For the Sample pump, either quantity is useful in that it shows the amount of water used was sufficient. The discharge pressure on the Sample pump was sufficient under all conditions. There are two reasons for this: 1) The internal restriction orifice creates a significant back pressure, which prevents the pump from cavitating and losing prime, and 2) the discharge piping (1/2 in.) also creates a significant back pressure, which has an additional effect. A small increase can be seen in the time required for the discharge pressure to reach $30 \mathrm{psi}$ as the agitation increases. As would be expected, the tank level has a slightly larger effect. However, these effects are not significant. For these reasons, it is apparent that 20 seconds is sufficient for priming the Sample pump.

Sample Pump Head-Capacity Characterization. The main objective of the pump tests performed during SIPT 1 and NCAW 1 was to gain insight into the operating characteristics of centrifugal pumps under a variety of test conditions. In order for these tests to provide meaningful data, the pump must be able to be isolated from the rest of the system. The Transfer pump system was designed in such. a way. However, the Sample pump system was not. The main purpose for the Sample pump was to provide a continuous feed to the Hydragard Sampler in order to obtain samples during various stages of feed preparation testing to determine the level of homogeneity in the tank. Currently, it is not possible to isolate the Sample pump from the rest of the system. The reason is that the Sample pump has an internal recirculating system that is not bypassable. Rather than discharging to a 2-in. pipe, as with the transfer pump, the flow is divided between the 1/2-in. discharge line and the internal restriction before the discharge pressure is measured. Rather than modify the system to enable this measurement, it was decided to leave the system "as is" so that it remains "prototypic" of the HWVP system. This means that the data obtained during characterization testing does not represent the operating characteristics of the Sample pump but the operating characteristics of a large part of the Sample system. Therefore, the $\mathrm{H}-\mathrm{C}$ curves obtained are not "pump curves," but rather "system curves." The information provided is useful only for a system that "sees" identical back pressures as those tested. This fact is evident in the $\mathrm{H}-\mathrm{C}$ curves for the Sample pump. As mentioned earlier, the total Head should decrease with increasing flow rate. While this is true for the Transfer pump, it is not the case for the Sample pump. In fact, in most cases, the Total Head actually increases with increasing flow rate. This is because as the flow rate increases, an unknown, or at least difficult to accurately estimate, amount of fluid is diverted through the restriction orifice. This amount varies with flow rate, thereby changing the pressure that the discharge pressure transmitter "sees."

For the above reasons, it is stressed that the pump (or system) curves shown for the Sample pump are not representative of any standard 15-hp cantilever centrifugal pump which may be used. This information is useful only for a "system" that is identical to the sample pump system tested. It is not possible to obtain specific pump operating characteristics from these curves. The retrieval of such specific information should be restricted to the results from the Transfer pump tests.

\subsubsection{Transfer Pump}

Transfer Pump Prime-Water Requirement. As with the Sample pump prime tests, it was determined that 20 seconds was sufficient for priming of the Transfer pump. However, a significant difference exists. It was determined (about halfway through dilute feed testing) that the back pressure created by the discharge piping was not sufficient enough for the priming to be successful. During dilute feed testing at the low level, it was not possible to prime the pump (See Table 9.9). The prime 
time was increased to as high as 60 seconds without positive results. Therefore, the prime tests at the low level were abandoned. The pump could not "lift" the fluid high enough and maintain prime. The prime tests at the high level were successful with a prime time of 20 seconds.

After similar results were observed during low-level concentrated feed testing (Table 9.10), it was decided that the back pressure was not high enough. It was then decided that the discharge valve would be "throttled" in order to increase the back pressure. This action was successful and resulted in enabling the prime time to be reduced back to 20 seconds. The rest of the tests were carried out with the valve being opened or closed a variable amount. A limited amount of information was obtained.

Transfer Pump Head-Capacity Characterization. The results of the Transfer pump characterization tests are shown graphically in Figures $9.25,9.27$ to 9.34 , and 9.39 to 9.51. As shown in Table 9.7, these graphs depict the Head-Capacity relationship under a variety of conditions. The H-C curves define the limitations of the pump at the specific pump speed, agitation level, temperature, and liquid (tank) level specified on the chart(s). Figure 9.25 shows a comparison between the manufacturer's curve and the experimental curve under similar conditions. Theoretically, these curves should be identical. However, some variation should be expected since the manufacturer's curve is obtained under "ideal" conditions. The experimental curve, which is compared to the manufacturer's curve, was constructed at maximum tank level and similar temperature $\left(\approx 130^{\circ} \mathrm{F}\right)$. As can be seen in Figure 9.25, there is a significant separation between the manufacturer's curve and the experimental curve. After installation into the full-scale testing system, the maximum attainable pump speed $(\approx 1650-1700 \mathrm{rpm})$ was less than that used for construction of the manufacturer's curve (1785 rpm). The reason for the lower maximum speed is the type of speed controller used. Most of the difference seen in Figure 9.25 can be attributed to this difference in pump speed. As can be seen on the other plots, total head diminishes rapidly as pump speed decreases. As an example, a reduction in pump speed of $150 \mathrm{rpm}$ from 1650 to $1500 \mathrm{rpm}$ caused a decrease in total head of just under $25 \%$ (Figure 9.28). The difference between the manufacturer's curve and the experimental curve is just above $25 \%$. Therefore, this difference is reasonable.

As can be seen in Figures 9.34, 9.38, 9.41, and 9.46, the level of fluid/slurry in the tank has the greatest effect on the $\mathrm{H}-\mathrm{C}$ characteristic of the Transfer pump. For example, Figure 9.41 shows a significant difference in Total Head between $6500 \mathrm{gal}$ and $8000 \mathrm{gal}$. Similar differences can be seen on the other Tank Level Variation plots.

Temperature and agitation did not seem to have a significant effect on the overall performance of the pump. Figure 9.43 (Agitation Variation - Dilute Feed) does show a large decrease in Total Head for Agitation = $130 \mathrm{mpm}$ at the low flow rates. A similar, though smaller, effect can be seen in Figure 9.30 (Agitation Variation - Water). However, this type of behavior is not evident in Figure 9.48 (Agitation Variation - Concentrated Feed). A possible explanation may be that as the flow rate decreases, the vortices that are created by the agitation inside the tank have a greater effect on the performance of the pump. As the fluid gets "heavier" (more concentrated), these effects are not as apparent.

Figure 9.51 shows the effect of fluid/slurry type on the total head of the transfer pump. As expected, the overall $\mathrm{H}-\mathrm{C}$ curve increases with increasing concentration. There is a maximum difference of approximately $30 \mathrm{ft}$ of Total Head between water and melter feed. 


\subsubsection{Summary of Results}

The Sample pump system is designed in such a way that the results presented here depict the operating characteristics of the Sample "system" and not the Sample pump. Data that is to be used in the design and specification of centrifugal pumps should be associated with the Transfer pump.

It was determined during NCAW 1 that back pressure is the most significant variable in determining minimum conditions for successfully priming the Transfer pump. The data obtained during the tests described above do not adequately evaluate this parameter. However, a 30 psi back pressure appeared to satisfactorily prime and operate the transfer pump. 


\subsection{Process Chemistry Performance}

\subsection{Formating and Off-Gas Generation}

The feed-preparation chemistry is discussed in this section. More specifically, the feed-formating chemistry and related off-gas generation are treated.

\subsubsection{Test Approach}

The test strategy was to add formic acid at a rate of $2 \mathrm{gpm}$ to $7400 \mathrm{gal}$ of NCAW simulant without noble metals at $95^{\circ} \mathrm{C}$. The target formic acid addition rate was subsequently reduced to $1 \mathrm{gpm}$. This was done to reduce onsite and offsite $\mathrm{NO}_{\mathrm{x}}$ exposure levels to safe limits. The NCAW simulant was prepared without noble metals because of the prohibitive cost of the noble metals (especially $\mathrm{Rh}$ ). Also, bench-scale tests ${ }^{(a)}$ showed that $\mathrm{NO}_{\mathrm{X}}$ generation rates and amounts were greatest for feeds that did not contain noble metals. Thus, in order to obtain data for the upper limit of $\mathrm{NO}_{x}$ generation a feed without noble metals was desirable. Offgas measurements were made during formic acid addition and digestion. The offgases monitored were $\mathrm{N}_{2} \mathrm{O}, \mathrm{CO}, \mathrm{CO}_{2}, \mathrm{NO}, \mathrm{NO}_{\mathrm{X}}, \mathrm{H}_{2}, \mathrm{O}_{2}$, and $\mathrm{N}_{2}$. The condensate and slurry were sampled and $\mathrm{NH}_{3}$, nitrate and nitrite analyses performed. A summary of test variables and test information to which the data apply are listed in Table 10.1. Key test events are summarized in Table AA. 1 in Appendix AA.

The data generated by this test may not be representative of HWVP operations since noble metals are contained in the feed which may affect the $\mathrm{N}_{2} \mathrm{O} / \mathrm{NO}_{x}$ generation rate/amount (which alternately affects the $\mathrm{NO} \rightarrow \mathrm{NO}_{2}$ conversion and $\mathrm{NO}_{2}$ rate/amount). As stated previously, the maximum limiting case for $\mathrm{NO}_{\mathrm{x}}$ generation occurs when the slurry does not have noble metals. Therefore, the data presented represents the upper limit for a discontinuous $\mathrm{HCOOH}$ addition rate of $1.2 \mathrm{gpm}$ (actual addition rate). Although some of the data provided may not be representative of HWVP operations, it will be used to determine the validity of scale-up (i.e., full-scale data will be compared to laboratory and pilot-scale data) for use in HWVP design.

Seventy-four-hundred gal of NCAW concentrated waste simulant (without noble metals) @ $140 \mathrm{~g}$ waste oxide per liter (WO/L) were heated to $95 \pm 2.6^{\circ} \mathrm{C}$ in the test vessel. Ninety wt\% formic acid was added to the tank from 55-gal drums at an average rate of $1.2 \mathrm{gpm}$ (instantaneous rate). The $\mathrm{HCOOH}$ addition was not continuous. Eight to thirty min. lapsed between the addition of each drum. The time lag was due to the time required to flush the formic acid addition line with the rinse water from the empty $\mathrm{HCOOH}$ drum containers and the time required for drum hookup/disassembly. The $\mathrm{HCOOH}$ addition rate and cumulative $\mathrm{HCOOH}$ added are shown in Figure 10.1. The total $90 \mathrm{wt} \%$ $\mathrm{HCOOH}$ added was $320.5 \mathrm{gal}$ and was determined from the weight measurement of the drums.

Figure 10.1 also includes the 10 to $20 \mathrm{gal}$ of flush water that were added to the test vessel (Note: The

(a) Wiemers, K. D., M. H. Langowski, M. R. Powell, and D. E. Larson. 1993. Evaluation of. HWVP Feed Preparation Chemistry for an NCAW Simulant-Fiscal 1991: Evaluation of Offgas Generation, Reductant Requirements and Thermal Stability. PHTD-C93-03.02A K899, Pacific Northwest Laboratory, Richland, Washington. 
Table 10.1. Summary of Test Information

\begin{tabular}{|c|c|}
\hline Initial slurry volume & $7400 \mathrm{gal}$ \\
\hline Initial pH (at $\left.95^{\circ} \mathrm{C}\right)$ & 9 \\
\hline Final pH & 5.5 \\
\hline Test $\mathrm{pH}$ range & 4.5 to 9 \\
\hline Amount of formic acid & $320.5 \mathrm{gal}$ of $90 \mathrm{wt} \% \mathrm{HCOOH}$ \\
\hline Formic acid addition rate & Discontinuous (acid added in 7 batches) \\
\hline Average per drum & $1.2 \mathrm{gpm}$ \\
\hline Average over test & $0.8 \mathrm{gpm}$ \\
\hline Lag time between batch additions & 8 to $30 \mathrm{~min}$ \\
\hline $\mathrm{HCOOH}$ addition line flush water & 10 to $20 \mathrm{gal}$ \\
\hline Formating temperature & $95^{\circ} \mathrm{C} \pm 2.6^{\circ} \mathrm{C}$ \\
\hline Digestion temperature & $100^{\circ} \mathrm{C} \pm 1.3^{\circ} \mathrm{C}$ \\
\hline Offgas flow rate during testing & 50 to $158 \mathrm{ACFM}$ \\
\hline In-leakage at start of formating (air) & 50 ACFM \\
\hline Amount of condensate(total) & $1344 \mathrm{gal}$ \\
\hline During formating & $457 \mathrm{gal}$ (refluxed to SRAT, HB-15) \\
\hline During digestion & 874 gal (collected in HB-13) \\
\hline During cool-down & 12 gal (collected in HB-13) \\
\hline \multicolumn{2}{|l|}{$\begin{array}{l}\text { Test times (correlation to offgas } \\
\text { figures and key test events table) }\end{array}$} \\
\hline $\mathrm{HCOOH}$ addition & 0 to $394 \mathrm{~min}$ \\
\hline Heat up to $100^{\circ} \mathrm{C}$ & 405 to $435 \mathrm{~min}$ \\
\hline Digestion & 430 to $672 \mathrm{~min}$ \\
\hline Cool down & 672 to $828 \mathrm{~min}$ \\
\hline Total & 0 to $828 \mathrm{~min}$ \\
\hline
\end{tabular}

flow meter was not reset for the flush water addition, so it was not possible to graph just the HCOOH addition). The temperature and $\mathrm{pH}$ process profiles are shown in Figure 10.2. The slurry was formatted under reflux conditions (i.e., $458 \mathrm{gal}$ of condensate were added back to the tank). The cumulative gal of condensate as a function of time are shown in Figure 10.3. The offgas flow rate as a function of time is shown in Figure 10.4. 


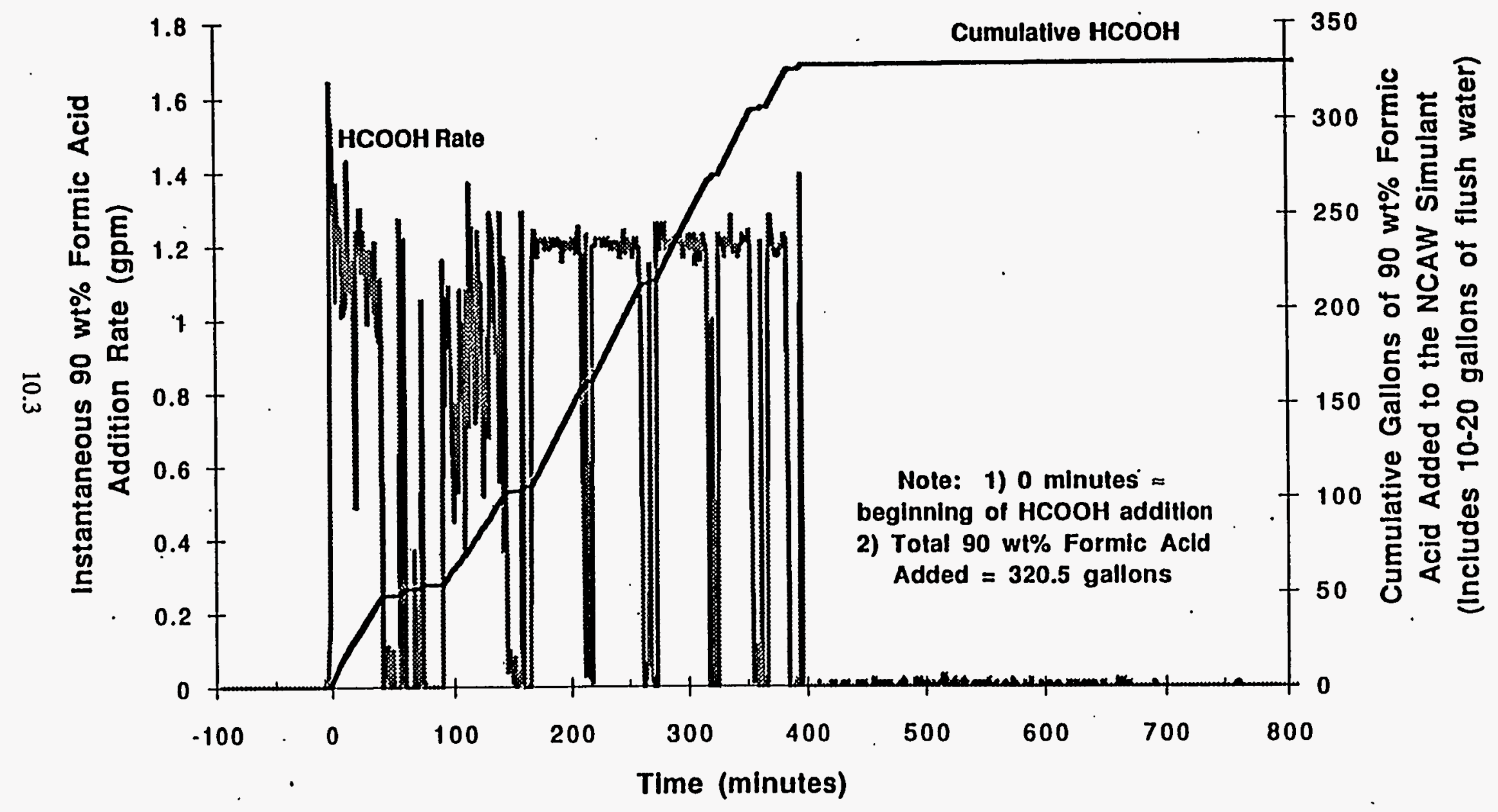

Figure 10.1. Formic Acid Addition Rate and Amount as a Function of Process Time 


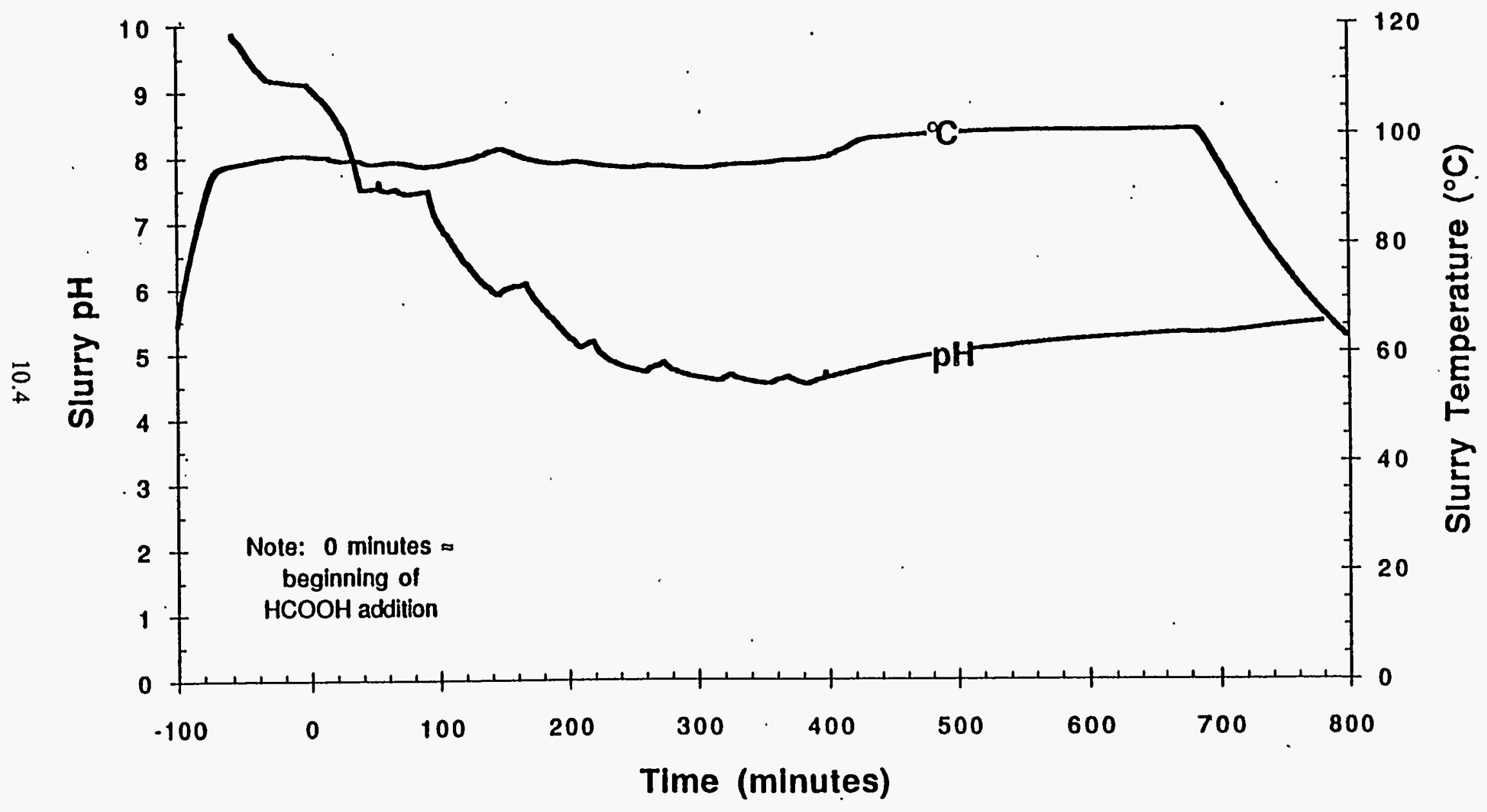

Figure 10.2. Slurry Temperature and $\mathrm{pH}$ Process Profiles for the Formating and Digestion Phases 


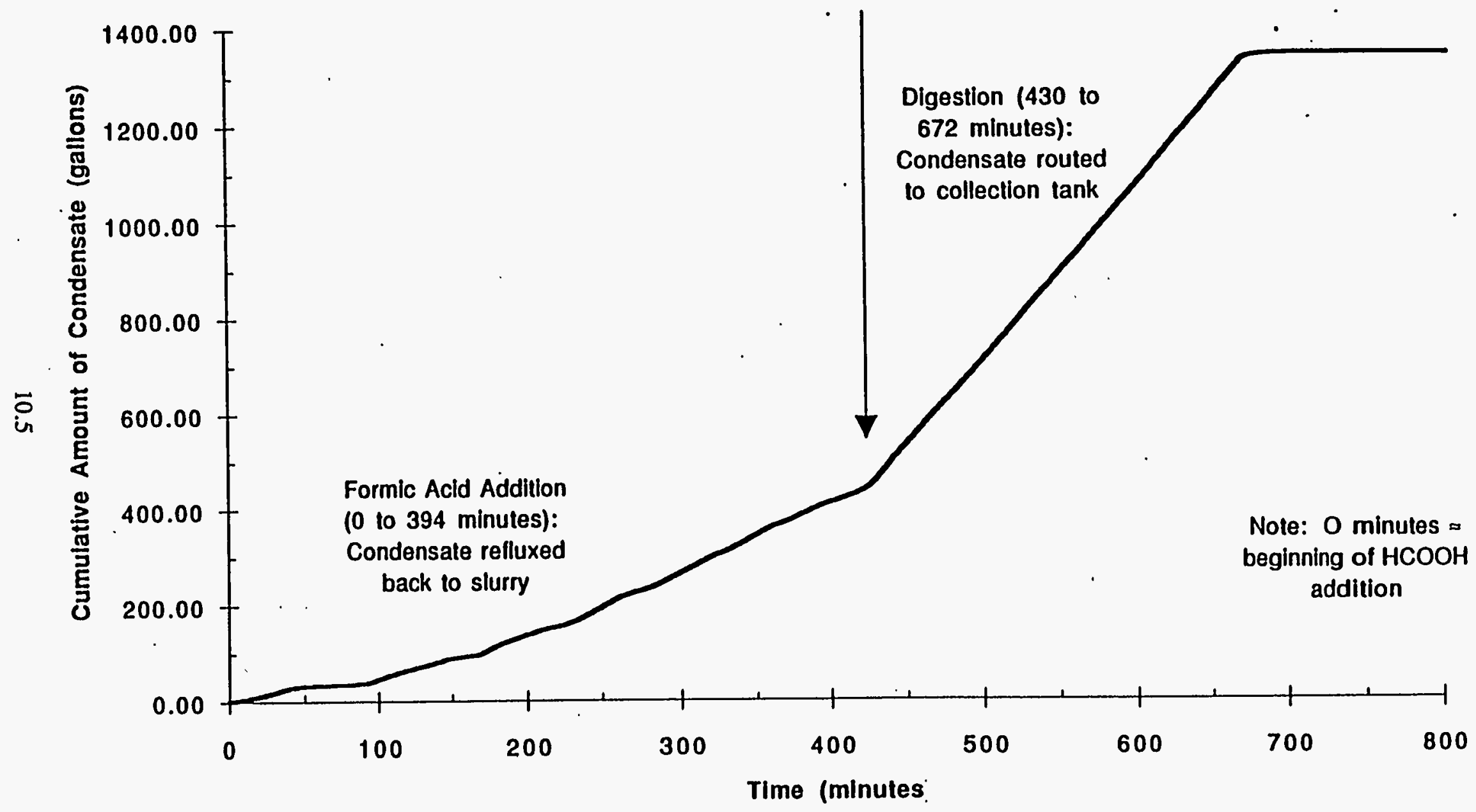

Figure 10.3. Cumulative Gallons of Condensate Produced During Formating and Digestion 


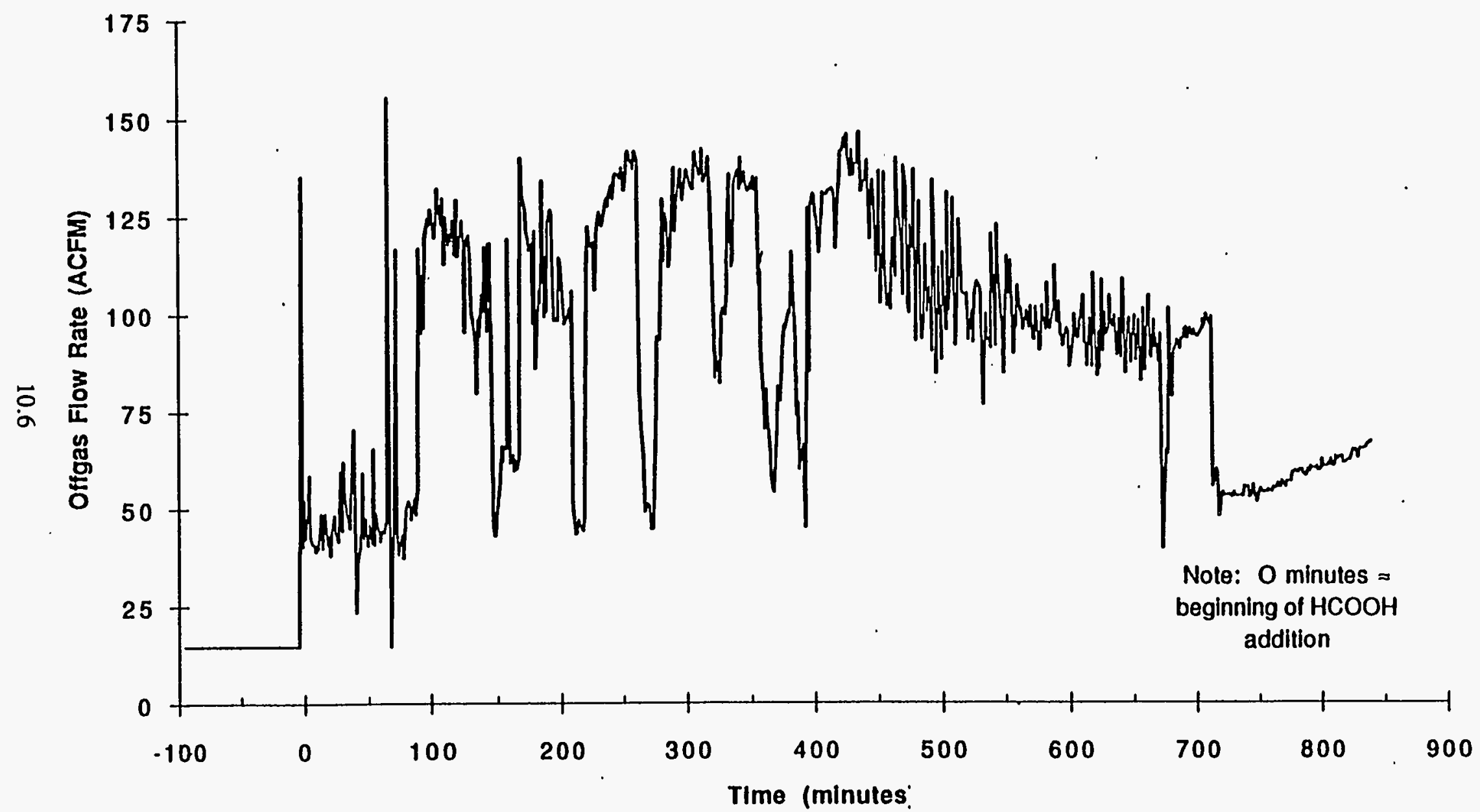

Figure 10.4. Offgas Flow Rate as a Function of Time 
The slurry was heated to $100^{\circ} \mathrm{C}$ and digested for $4 \mathrm{~h}$ at a slight boiling rate. Condensate was collected during the digestion period and routed to a separate collection tank. Approximately $874 \mathrm{gal}$ of condensate were collected during digestion.

The slurry was cooled to $50^{\circ} \mathrm{C}$ over a 2-h period. Twelve gal of condensate were collected during the cool-down period. The total process condensate generated during the test was therefore $1344 \mathrm{gal}$.

Slurry samples were removed before adding formic acid and 4 days after the end of digestion. It was necessary, for safety reasons, to wait 4 days before sampling the slurry because $\mathrm{NO}_{\mathrm{X}}$ was still being generated. Condensate samples were taken during formating and digestion.

Initially, the tank vacuum was set at -5.0 in. $\mathrm{H}_{2} \mathrm{O}$. The safety interlocks were designed to automatically trip if the pressure exceeded -1.0 in. of $\mathrm{H}_{2} \mathrm{O}$. Large changes in the offgas flow rate (50 ACFM to 158 ACFM) produced pressure spikes, causing the safety interlocks to trip four times while $\mathrm{HCOOH}$ was added. The safety interlocks appeared to be unable to handle the rate of the offgas generation. It was necessary to lower the tank vacuum to -10 in. of $\mathrm{H}_{2} \mathrm{O}$ to compensate for the pressure spikes. By lowering the tank vacuum, it was possible to add $\mathrm{HCOOH}$ to the system continually without tripping the safety interlocks.

\subsubsection{Results}

Calculations for the nitrogen mass balance and the estimated percentages of NO from the disproportionation of nitrous acid are provided in Appendix AB. Moles of offgas produced, $\mathrm{HCOOH}$ amounts, and chemical compounds in this report are reported in g-moles, not lb-moles.

\subsubsection{Offgas Production}

As stated previously, the NCAW simulant used in full-scale testing did not contain noble metals. Laboratory-scale (1.5-L batch size) tests ${ }^{(a)}$ performed with NCAW simulant with noble metals have seen considerably more $\mathrm{N}_{2} \mathrm{O}$ generated $\left(\mathrm{N}_{2} \mathrm{O} / \mathrm{NO}_{x} \approx 7\right.$ ) than laboratory-scale tests performed with NCAW simulant without noble metals $\left(\mathrm{N}_{2} \mathrm{O} / \mathrm{NO}_{x}<1\right)$. However, even when noble metals were present in the simulant (laboratory-scale tests batch sizes $\leq 1.5 \mathrm{~L}$ ) the $\mathrm{N}_{2} \mathrm{O} / \mathrm{NO}_{\mathrm{x}}$ ratio can be less than 1. (b)(c) The presence of noble metals, therefore, may impact the $\mathrm{N}_{2} \mathrm{O} / \mathrm{NO}_{x}$ ratio by increasing the amount of $\mathrm{N}_{2} \mathrm{O}$ generation relative to $\mathrm{NO}_{x}$ generation.

(a) Wiemers, K. D., M. H. Langowski, M. R. Powell, and D. E. Larson. 1993. Evaluation of HWVP Feed Preparation Chemistry for an NCAW Simulant-Fiscal 1991: Evaluation of Offgas Generation, Reductant Requirements and Thermal Stability, PHTD-C93-03.02A K899. Prepared by the Pacific Northwest Laboratory, Richland, Washington.

(b) Langowski, M. H., E. V. Morrey, M. R. Beckette, J. M. Tingey. 1993. Offgas Characterization from the Radioactive NCAW Core Sample (102-AZ-CI) and Simulant During HWVP Feed Preparation Testing, PHTD-C93-05.05B. Prepared by the Pacific Northwest Laboratory, Richland, Washington.

(c) Smith, H. D., K. D. Wiemers, M. H. Langowski, M. R. Powell, and D. E. Larson, 1993. Evaluation of HWVP Feed Preparation Chemistry for an NCAW Simulant-Fiscal Year 1992: Evaluation of Offgas Generation and Ammonia Formation, PHTD-C93-03.02B. Prepared by the Pacific Northwest Laboratory, Richland, Washington. 
Since nitrite is the primary reactant for both $\mathrm{N}_{2} \mathrm{O}$ and $\mathrm{NO}_{\mathrm{X}}$ generation, less $\mathrm{NO}_{\mathrm{x}}$ is generated when $\mathrm{N}_{2} \mathrm{O}$ is generated in significant amounts. This could impact the $\mathrm{NO} \rightarrow \mathrm{NO}_{2}$ conversion by reducing the amount of $\mathrm{NO}$ available for reaction with $\mathrm{O}_{2}$. Temperatures in the SRAT and vessel vent system are increased by the exothermic reaction $2 \mathrm{NO}+\mathrm{O}_{2} \rightarrow 2 \mathrm{NO}_{2}$. If $\mathrm{N}_{2} \mathrm{O}$ were the primary product from the reactant nitrite, it is expected that the temperature increases would be less. Large increases of $\mathrm{N}_{2} \mathrm{O}$, however, may not be desirable because $\mathrm{N}_{2} \mathrm{O}$ is an oxidant, which may impact the lower flammability limit (LFL) of $\mathrm{H}_{2}$ and some organics.

The conditions under which $\mathrm{N}_{2} \mathrm{O}$ and $\mathrm{NO}_{x}$ are generated are not yet completely understood. Recent work by Langowski et al. ${ }^{(a)}$ and Smith et al. ${ }^{(b)}$ have shown that the acid/base neutralization capacity of the slurry affects the $\mathrm{N}_{2} \mathrm{O} / \mathrm{NO}$ ratio. Simulants that were intentionally spiked with hydroxide or carbonate showed increased production of $\mathrm{N}_{2} \mathrm{O}$. Ratios of $\mathrm{N}_{2} \mathrm{O} / \mathrm{NO}_{\mathrm{x}}$ were shown to vary from $<1$ to 18.5. Testing by Smith et al. ${ }^{(b)}$ indicated that $\mathrm{N}_{2} \mathrm{O}$ production appeared to be favored over $\mathrm{NO}_{x}$ generation at $\mathrm{pH}$ 's greater than $\approx 6.3$. Thus, the $\mathrm{pH}$ may be the critical factor rather than the acid/ base neutralization capacity.

The total moles of gas and the peak gas generation rates observed during the formating and digestion of full-scale testing are shown in Table 10.2. Figure 10.5 shows the process profile for siurry $\mathrm{pH}$ and the generation of $\mathrm{CO}_{2}, \mathrm{NO}_{x}$, and $\mathrm{N}_{2} \mathrm{O}$. Hydrogen generation which had a peak generation rate of $0.036 \mathrm{~mole} / \mathrm{min}$ is shown in Figure 10.6. Ammonia and $\mathrm{CO}$ generation were below detection limits. Figures 10.6 through 10.13 show individual offgas profiles for $\mathrm{H}_{2}, \mathrm{CO}_{2}, \mathrm{NO}_{\mathrm{x}}$, and $\mathrm{N}_{2} \mathrm{O}$. Two plots are shown for each gas. The first plot shows the offgas generation rate as a function of time. The second plot shows cumulative moles of gas as a function of time. Figure 10.14 shows the $\mathrm{CO}$ generation rate as a function of time. The generation of $\mathrm{CO}$ was below detection limits, as seen in the figure, after the interference from $\mathrm{N}_{2} \mathrm{O}$ is subtracted out.

Two quantities of offgas sampler condensate were removed during testing. The cumulative amount of condensate was collected at the end of formating (i.e., offgas condensate generated during formating) and at the end of digestion (i.e., offgas condensate generated during digestion). The offgas condensate was analyzed for $\mathrm{NO}_{3}{ }^{-}$and $\mathrm{NO}_{2}^{-}$. These concentrations and the average generation rate of $\mathrm{NO}_{\mathrm{x}}$ over the formating and digestion periods, respectively, were used to calculate the moles of $\mathrm{NO}_{\mathrm{x}}$. An estimated 520 moles of $\mathrm{NO}_{\mathrm{x}}$ were not measured by the offgas $\mathrm{NO} / \mathrm{NO}_{\mathrm{x}}$ analyzer due to the offgas condensate stripping of $\mathrm{NO}_{2}$ (i.e., $\mathrm{H}_{2} \mathrm{O}$ and $\mathrm{NO}_{2}$ react to produce $\mathrm{NO}_{3}^{-}$and $\mathrm{NO}_{2}^{-}$which are trapped by the $\mathrm{H}_{2} \mathrm{O} /$ condensate). Of the 520 moles, 256 were calculated to have been produced during formic acid addition and 264 were calculated to have been generated during digestion. The calculations are shown in Appendix AB. The peak generation rate, total moles, and offgas process profiles for $\mathrm{NO}_{\mathrm{x}}$ are estimated to have a 10 to $15 \%$ error (i.e., to be low) due to the offgas condensate collection of $\mathrm{NO}_{2}$.

(a) Langowski, M. H., E. V. Morrey, M. R. Beckette, J. M. Tingey. 1993. Offgas Characterization from the Radioactive NCAW Core Sample (102-AZ-C1) and Simulant During HWVP Feed Preparation Testing, PHTD-C93-05.05B. Prepared by the Pacific Northwest Laboratory, Richland, Washington.

(b) Smith, H. D., K. D. Wiemers, M. H. Langowski, M. R. Powell, and D. E. Larson. 1993. Evaluation of HWVP Feed Preparation Chemistry for an NCAW Simulant-Fiscal Year 1992: Evaluation of Offgas Generation and Ammonia Formation, PHTD-C93-03.02B. Prepared by the Pacific Northwest Laboratory, Richland, Washington. 
Table 10.2. Total Offgas (Moles) Produced and Peak Gas Generation Rates (moles/min) During Formating and Digestion of NCAW Simulant Without Noble Metals

\begin{tabular}{|c|c|c|c|c|}
\hline Gas & $\begin{array}{l}\text { Formating } \\
\text { (moles) }\end{array}$ & $\begin{array}{l}\text { Digestion } \\
\text { (moles) }\end{array}$ & $\begin{array}{l}\text { Total Moles of Offgas } \\
\text { (formating plus digestion) }\end{array}$ & $\begin{array}{l}\text { Peak Generation Rate } \\
\text { (moles/min) }\end{array}$ \\
\hline $\mathrm{CO}_{2}$ & 7800 & 1200 & 9000 & 47 \\
\hline $\mathrm{H}_{2}$ & 2 & 9 & 11 & 0.036 \\
\hline $\mathrm{N}_{2} \mathrm{O}$ & 375 & 85 & 460 & 2.7 \\
\hline $\mathrm{NO}_{\mathrm{x}}^{(\mathrm{a})}$ & 4150 & 1078 & $5228^{(a)}$ & 37 \\
\hline $\mathrm{CO}$ & $b d l^{(b)}$ & $\mathrm{bdl}^{(\mathrm{b})}$ & $b_{d l}{ }^{(b)}$ & $\mathrm{bdl}^{(\mathrm{b})}$ \\
\hline $\mathrm{NH}_{3}$ & $\mathrm{bdl}^{(b)}$ & $\mathrm{bdl}^{(\mathrm{b})}$ & bdl ${ }^{(b)}$ & $\mathrm{bdl}^{(\mathrm{b})}$ \\
\hline Total & 12327 & 2372 & 14699 & NA \\
\hline
\end{tabular}

(a) Analysis of the offgas system condensate indicated that $\approx 520$ moles of $\mathrm{NO}_{2}$ were not detected by the NO/NOx analyzer. Total NOx $\approx 520+5228 \rightarrow 5748$ moles.

(b) bdl = below detection limit $\mathrm{dl} \rightarrow \mathrm{CO} \approx 0.03 \%, \mathrm{NH}_{3} \approx 1 \%$ (molar percent at the analyzer).

The addition of formic acid was not continuous but consisted of seven additions.

The effect on offgas generation is clearly seen in offgas generation process profiles. For example in Figure 10.5, seven distinct peaks are seen for $\mathrm{CO}_{2}$ generation. The seven peaks correspond to the seven separate additions of formic acid. In addition, the $\mathrm{pH}$ is seen to drop in a step-wise fashion corresponding to the addition of $\mathrm{HCOOH}$. Figure 10.1 shows the discontinuous addition in cumulative gal and gpm.

The effect of a discontinuous rate would be strongest on reactions that are $\mathrm{pH}$ dependent. The relative total amounts of $\mathrm{N}_{2} \mathrm{O}$ and $\mathrm{NO}_{\mathrm{x}}$ may change if $\mathrm{HCOOH}$ is added continuously. The disproportionation reaction for the production of NO is favored under acid conditions because nitrite forms nitrous acid.

The simulant shows a buffering phenomena when titrated with acid. This can be seen in Figure 10.2 as the $\mathrm{pH}$ rises slightly between the addition of each drum after the slurry reaches a $\mathrm{pH}=5.75$. The lowest $\mathrm{pH}$ would not be expected to occur during a discontinuous addition of formic acid because the slurry is constantly buffering. The longer the additions between the drums the more. time available for the $\mathrm{pH}$ to rise. The lower the $\mathrm{pH}$, the more $\mathrm{NO}_{2}^{-} \rightarrow \mathrm{HNO}_{2}(\mathrm{pKa}=3.35)$. Thus, more NO might be produced for a given amount of acid based on $\mathrm{pH}$ behavior. The $\mathrm{HCOOH}$ addition rate and continuous/discontinuous addition rate are two factors that affect $\mathrm{pH}$ behavior and thus potentially affect the generation of NO. 


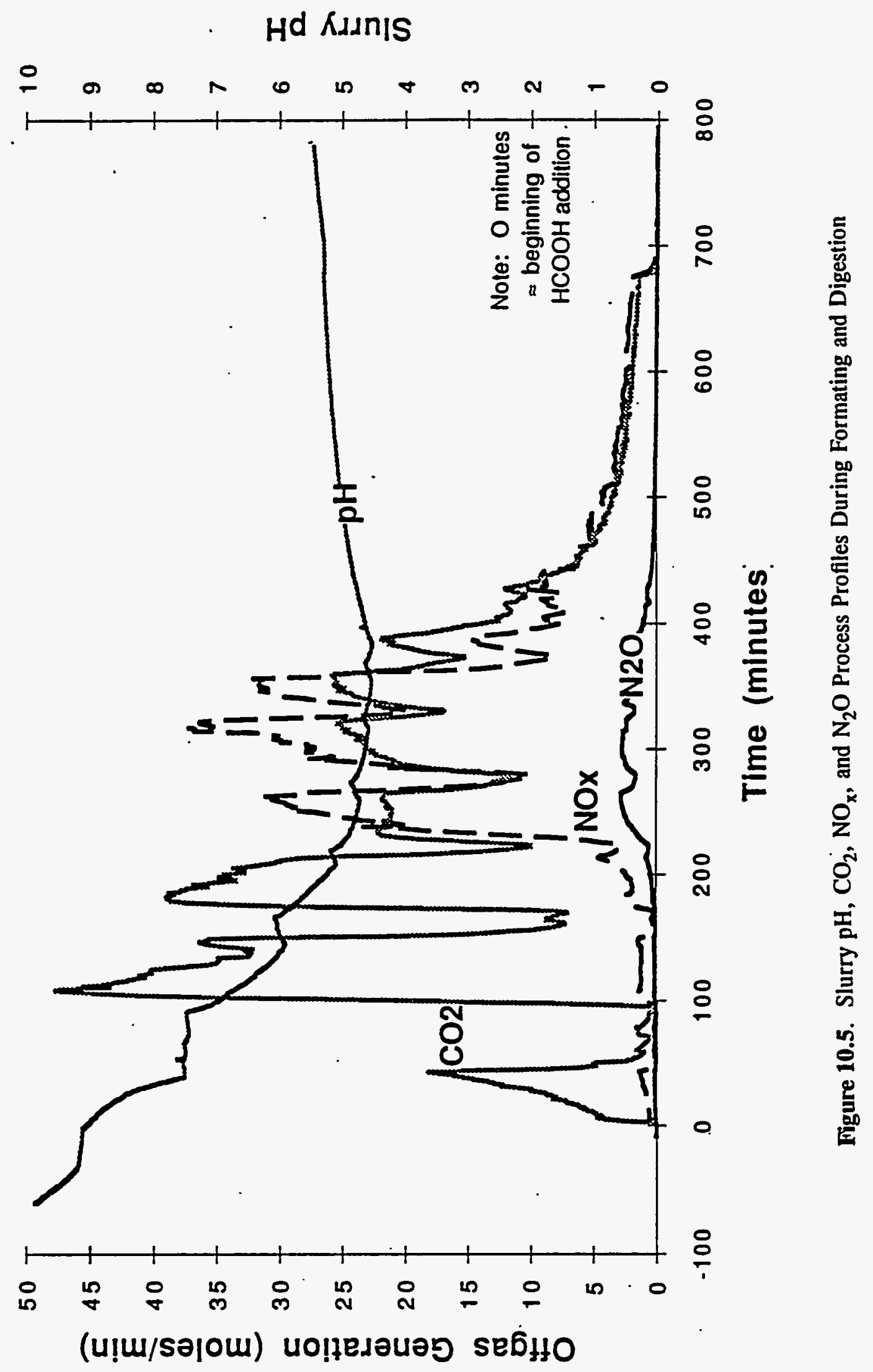

10.10 


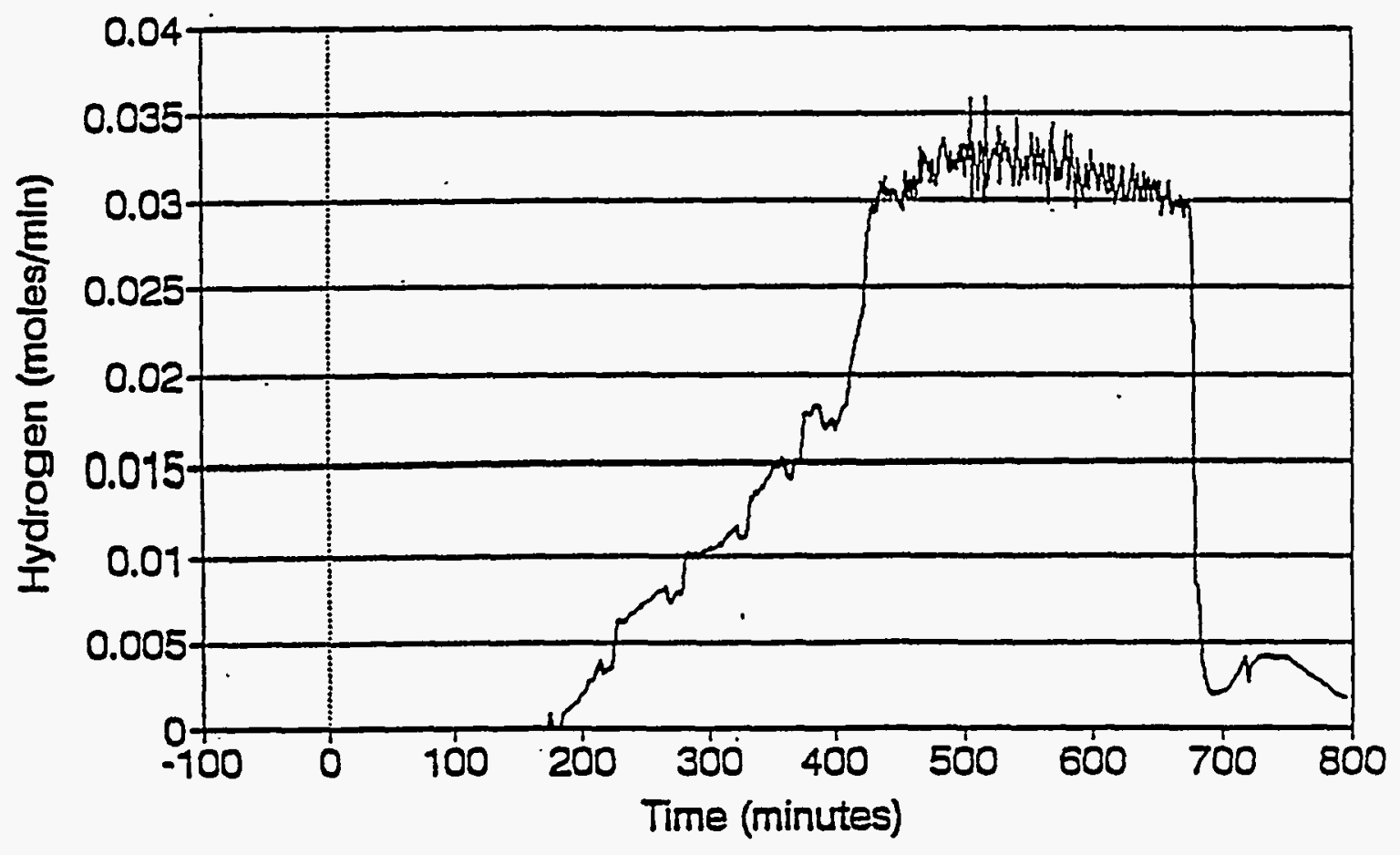

Figure 10.6. $\mathrm{H}_{2}$ Offgas Generation During Formating and Digestion

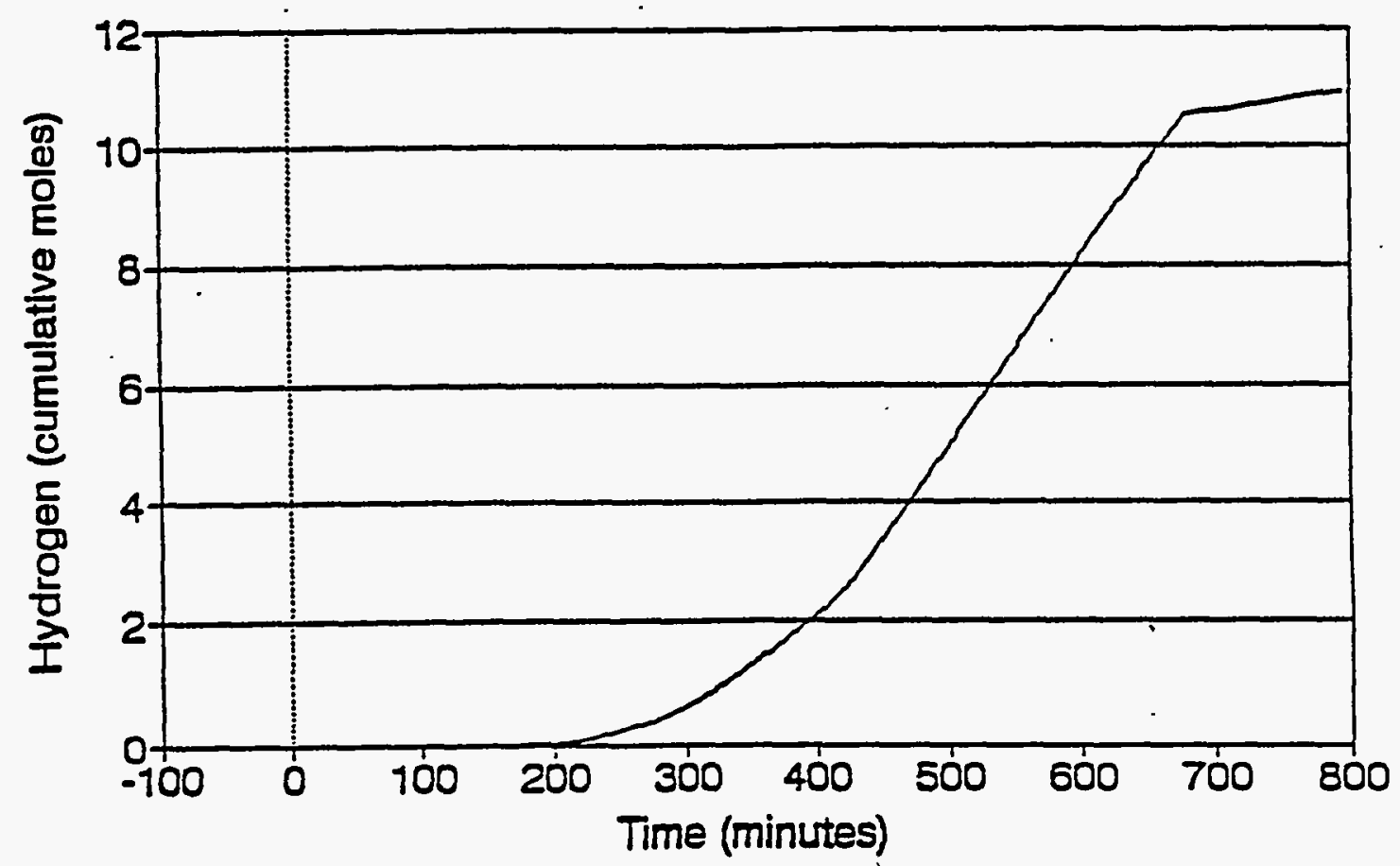

Figure 10.7. Cumulative Moles of $\mathrm{H}_{2}$ Generated During Formating and Digestion 


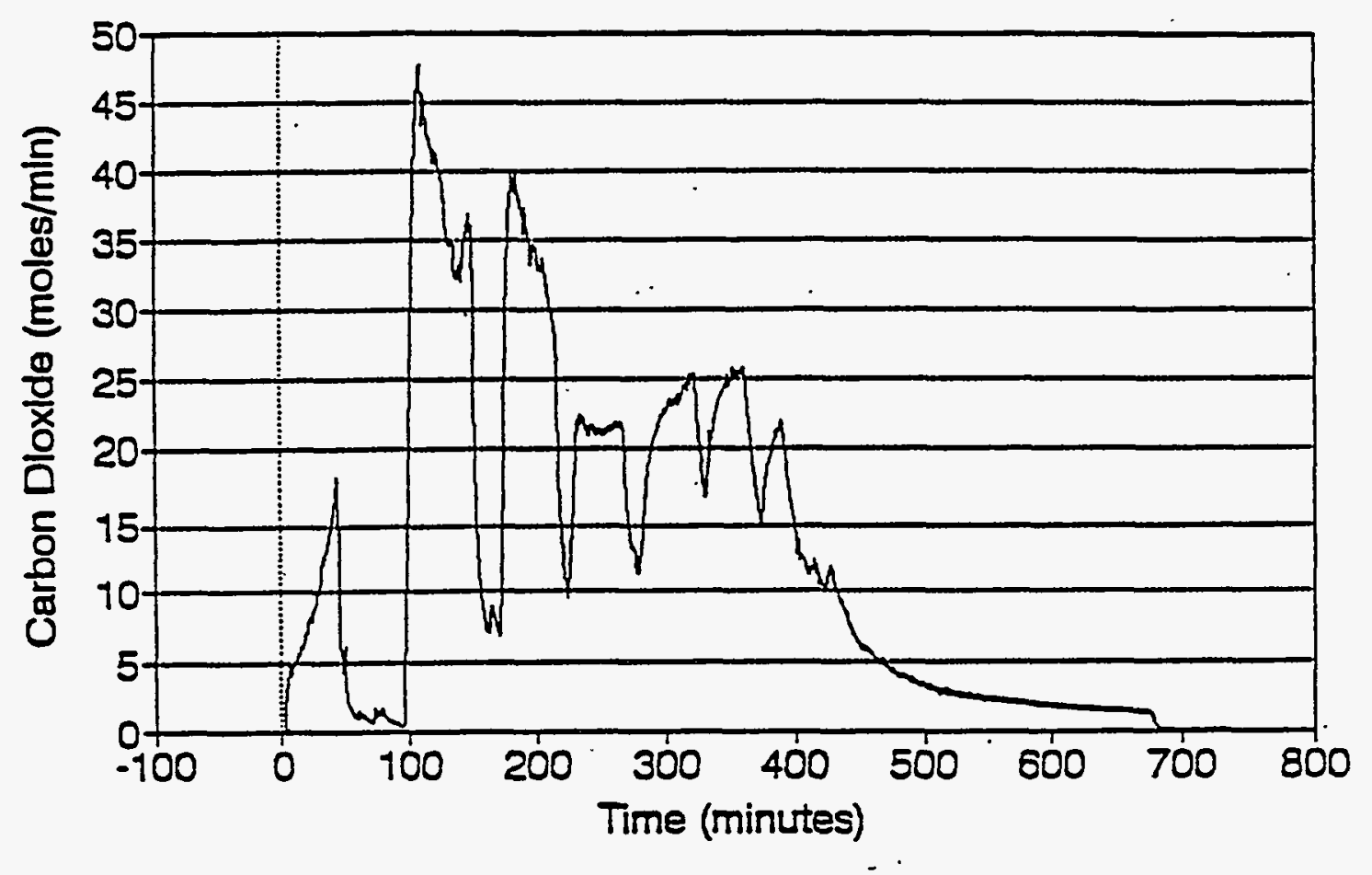

Figure 10.8. $\mathrm{CO}_{2}$ Offgas Generation During Formating and Digestion

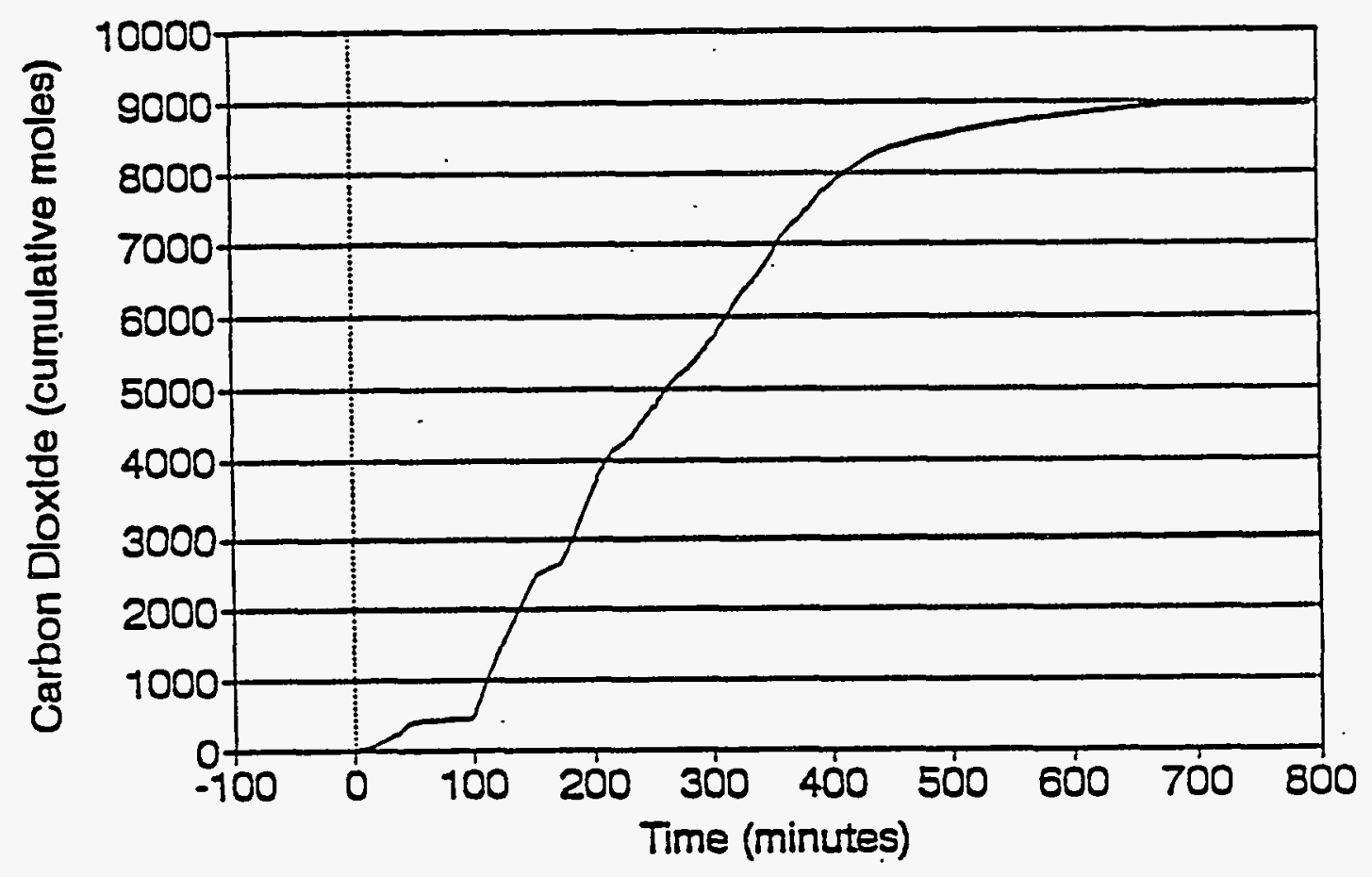

Figure 10.9. Cumulative Moles of $\mathrm{CO}_{2}$ Generated During Formating and Digestion 


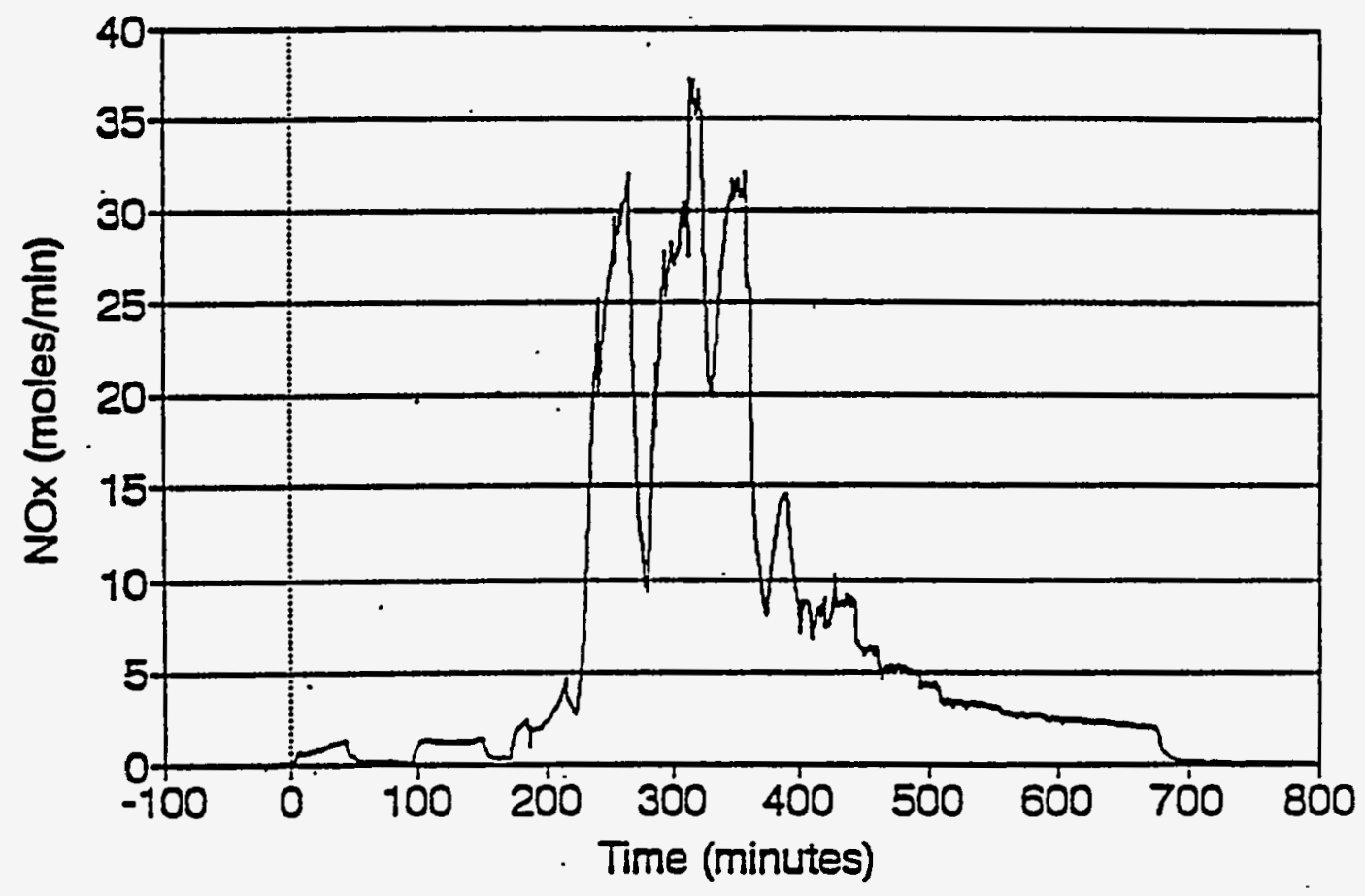

Figure 10.10. $\mathrm{NO}_{\mathrm{x}}$ Offgas Generation During. Formating and Digestion

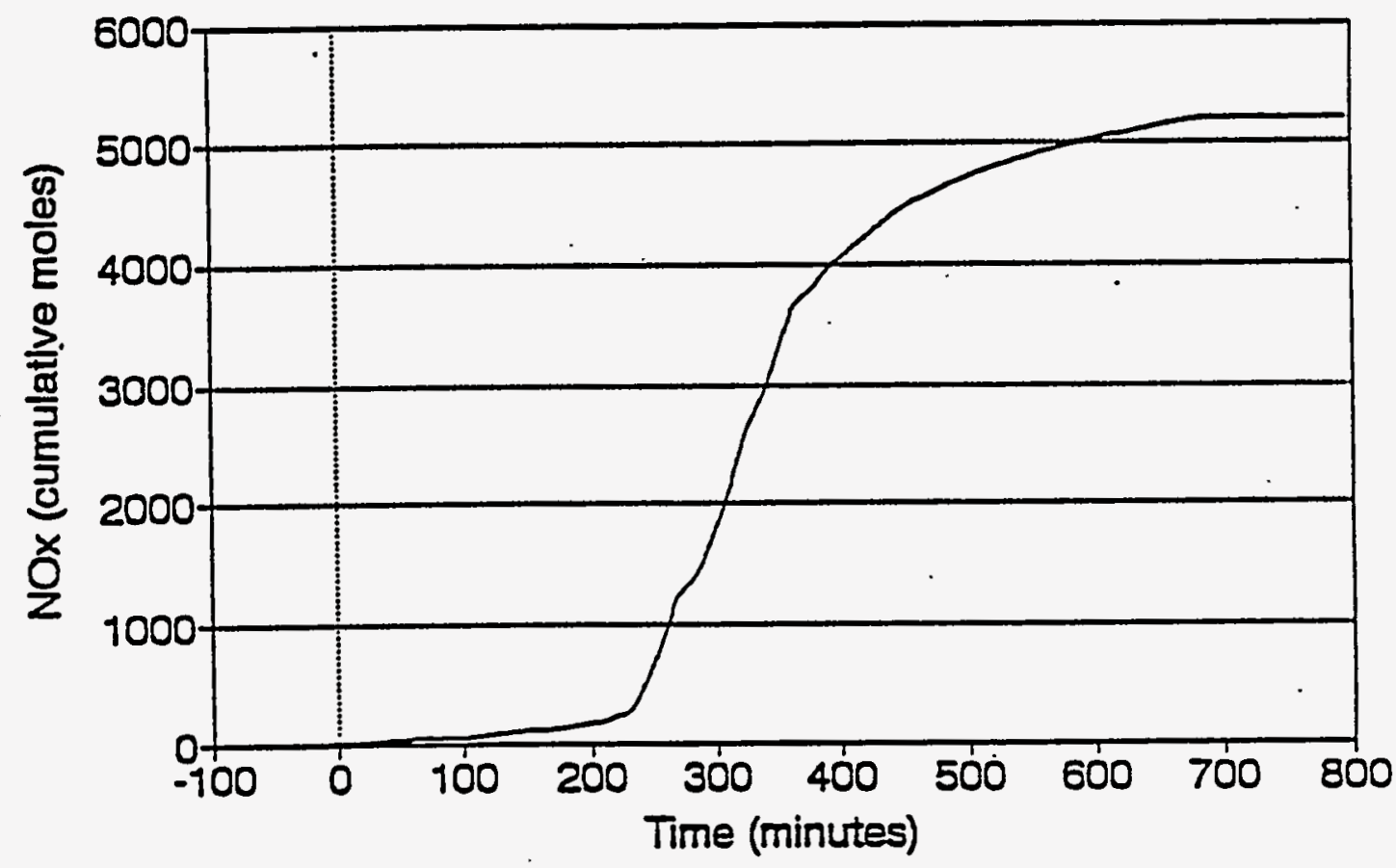

Figure 10.11. Cumulative Moles of $\mathrm{NO}_{\overline{\mathrm{x}}}$ Generated During Formating and Digestion 


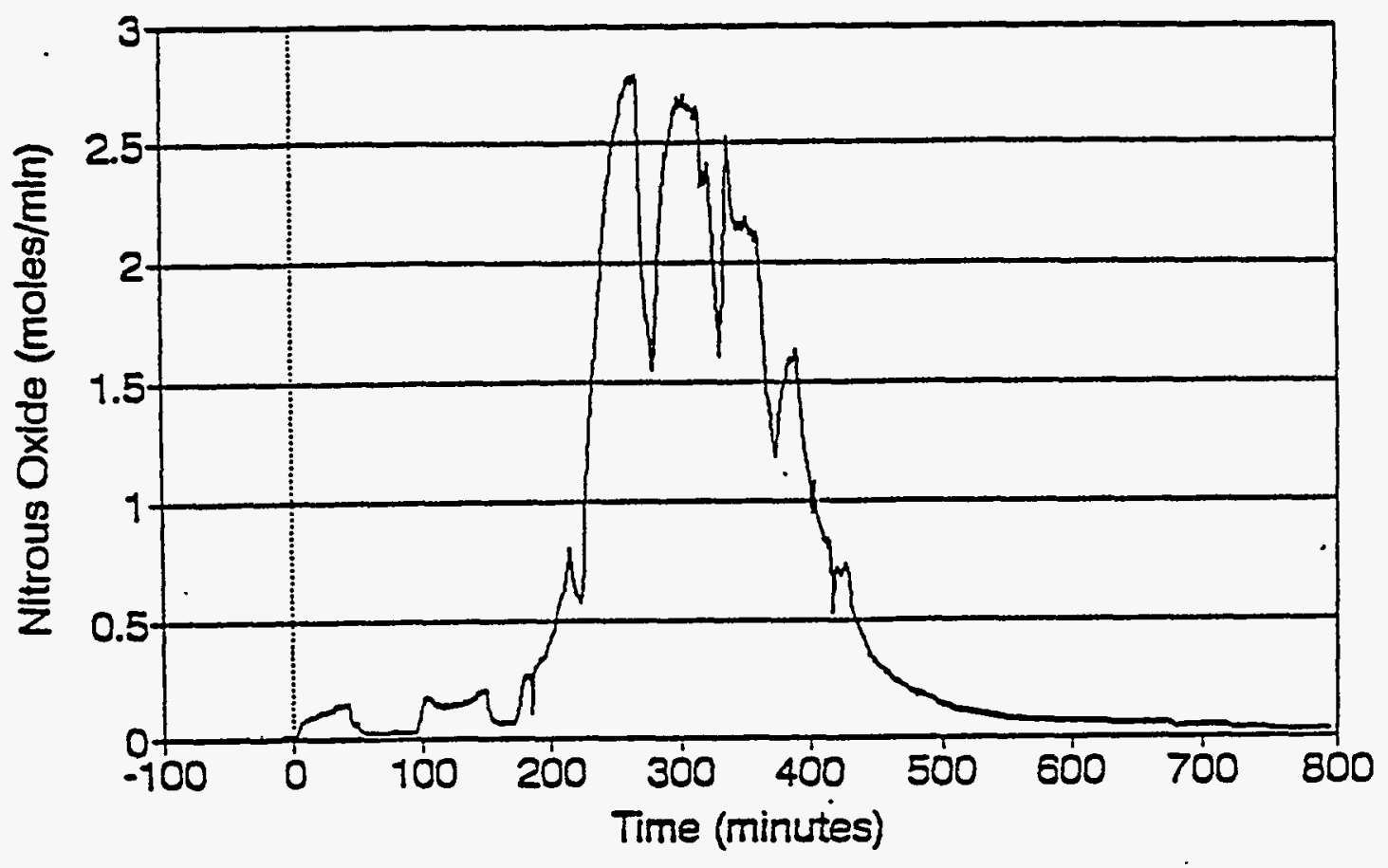

Figure 10.12. $\mathrm{N}_{2} \mathrm{O}$ Offgas Generation During Formating and Digestion

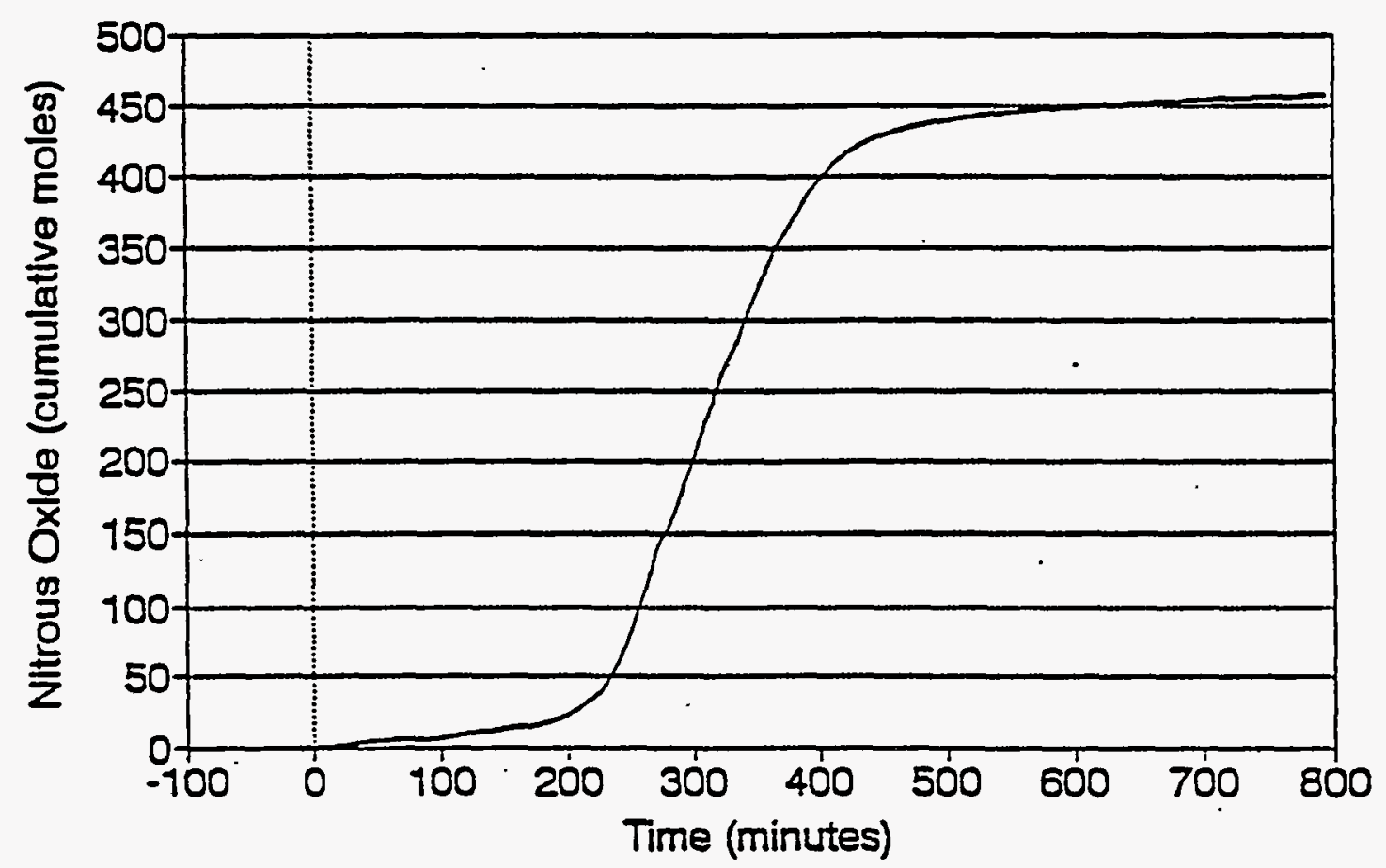

Figure 10.13. Cumulative Moles of $\mathrm{N}_{2} \mathrm{O}$ Generated During Formating and Digestion 


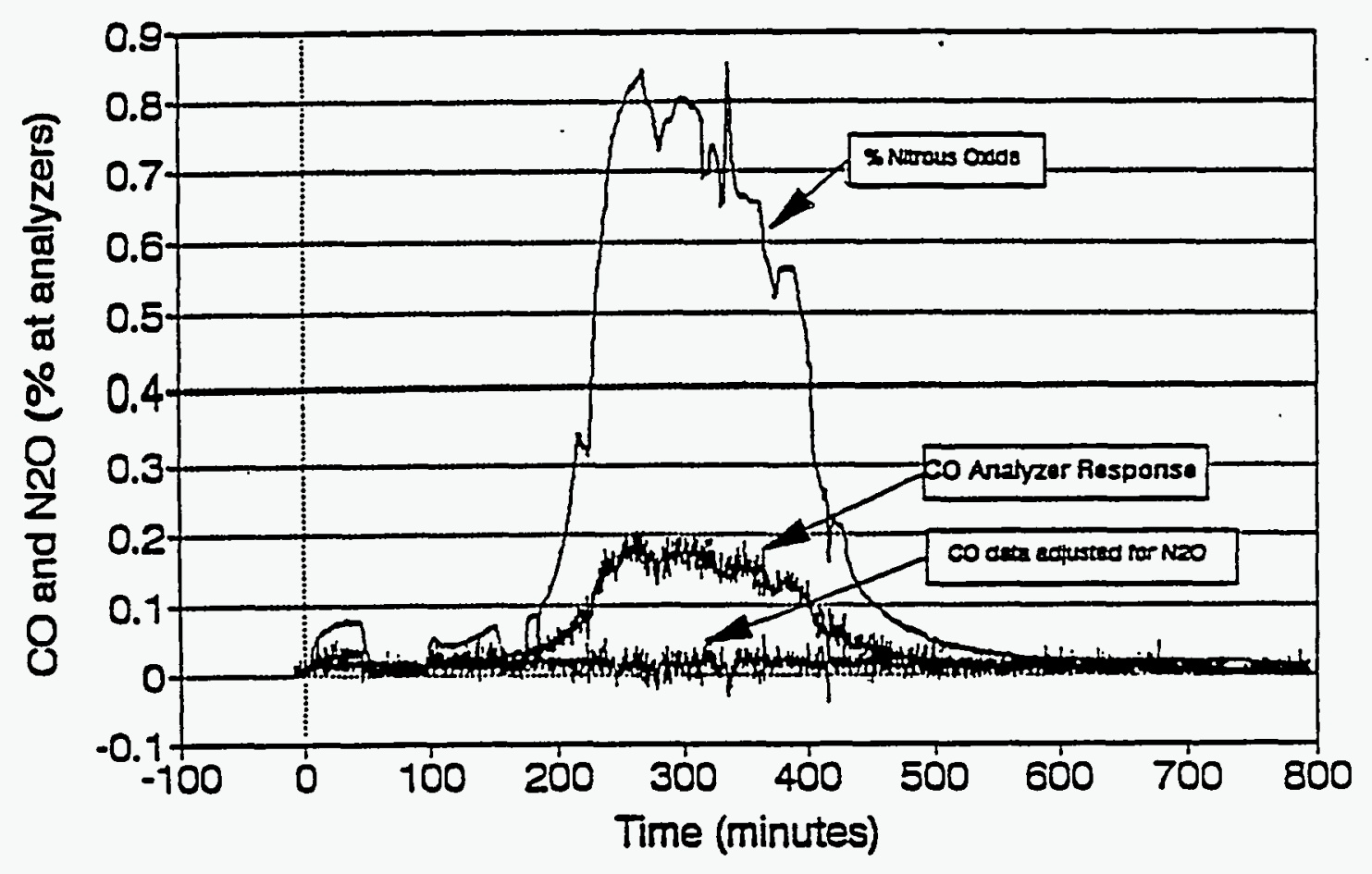

Figure 10.14. CO Offgas Generation During Formating and Digestion

\subsubsection{Nitrogen Mass Balance}

A nitrogen mass balance was performed over the formating and digestion periods. The mass balance is shown in Table 10.3. Because of continued production of $\mathrm{NO}_{\mathrm{x}}$, the slurry was sampled 4 days after the digestion phase was completed and when slurry offgassing had ceased. Amounts of $\mathrm{N}_{2} \mathrm{O}$ and $\mathrm{NO}_{x}$ were estimated for the 4-day period before slurry sampling occurred to account for any $\mathrm{N}_{2} \mathrm{O}$ and $\mathrm{NO}_{x}$ amounts that would not be measured by the offgas analyzers. The estimation was made by taking the last known rates for $\mathrm{N}_{2} \mathrm{O}$ and $\mathrm{NO}_{x}$ and assuming that at the end of 4 days the rates had linearly decreased to zero.

The initial nitrogen value of 17,744 moles was determined from the results of the nitrite and nitrate analysis of the NCAW simulant, originally in the tank (i.e., before formic acid addition). The final nitrogen value was determined by the addition of nitrate and nitrite in the slurry, nitrate and nitrite in the condensate, $\mathrm{N}_{2} \mathrm{O}$ and $\mathrm{NO}_{\mathrm{X}}$ in the offgas, estimated $\mathrm{N}_{2} \mathrm{O}$ and $\mathrm{NO}_{x}$ produced after digestion, and scale-up of nitrate from the offgas condensate. Ninety-two percent of the nitrogen was accounted for in the mass balance. This result is consistent with results from mass balances from Redox/Rheology Control Evaluation (R/RCE) ${ }^{(a)}$ and Radioactive Process/Product

(a) Smith, H. D., K. D. Wiemers, M. H. Langowski, M. R. Powell, and D. E. Larson. 1993. Evaluation of HWVP Feed Preparation Chemistry for an NCAW Simulant-Fiscal Year 1992: Evaluation of Offgas Generation and Ammonia Formation, PHTD-C93-03.02B. Prepared by the Pacific Northwest Laboratory, Richland, Washington. 
Table 10.3. Mass Balance for Nitrogen: Formating and Digestion

Initial nitrogen in slurry (moles)

Final nitrogen in slurry (moles) ${ }^{(a)}$

17,744

$\mathrm{N}_{2} \mathrm{O}$ and $\mathrm{NO}_{\mathrm{X}}$ offgas nitrogen (moles)

8,895

Nitrogen in condensate (moles) ${ }^{(a)}$

6,148

345

Estimated $\mathrm{NO}_{\mathrm{X}}$ produced after digestion ${ }^{(\mathrm{b})}$

Estimated $\mathrm{N}_{2} \mathrm{O}$ produced after digestion ${ }^{(b)}$

Scale-up from offgas system condensate ${ }^{(\mathrm{C})}$

520

$\mathrm{NH}_{3}$ in slurry

\% nitrogen accounted for by mass balance

$92 \%$

(a) The slurry nitrate increased by $\approx 2,167$ moles not including the nitrate from the condensate. The total final nitrogen in the slurry includes 1,708 moles of nitrate and 81.5 moles of nitrite added back to the slurry from the condensate generated during formic acid addition. The 345 moles of nitrogen in the condensate is from the digestion condensate which was not refiuxed back to the slurry. Condensate samples were removed at various times over formic acid addition and digestion periods. The amount of condensate generated during a specific time period was multiplied by the average concentration of nitrate and nitrite determined from the samples removed before at the end of each time period. The assumption made was that the amount of nitrate and nitrite in the condensate was constant over the time period and that the sample was representative of the time period. Results were summed to determine the total amount of $\mathrm{N}$ in the condensate from formic acid addition and digestion. Approximately 35 condensate samples were removed during formating and digestion.

(b) The slurry was still producing small amounts of $\mathrm{NO}_{x}$ and $\mathrm{N}_{2} \mathrm{O}$ at the end of digestion. The $\mathrm{N}_{2} \mathrm{O}$ and $\mathrm{NO}_{x}$ amounts are based on the last recorded generation rate linearly decaying to zero over a 4-day period. The analysis of final slurry nitrogen in the mass balance does not include these amounts because samples were removed 4 days after digestion.

(c) See previous section for explanation of 520 moles of offgas system condensate. 
Laboratory Testing (RP/PLT). (a) Possible sources of uncertainty include $5 \%$ uncertainty in the analytical measurements, $5 \%$ in the offgas measurements, and 5 to $10 \%$ in offgas system condensate scaleup/offgas produced after digestion values. Negligible amounts of $\mathrm{NH}_{3}\left(<1.42 \times 10^{-3} \mathrm{~g} \mathrm{NH}_{3} / \mathrm{L}\right.$ of simulant) were observed during SIPT2 formating and digestion (conservative detection limit $\approx 0.5 \mathrm{ppm} \mathrm{NH} 3$.

\subsubsection{Percent NO from Disproportionation}

An attempt was made to estimate the \% NO produced from disproportionation. Results are summarized in Table 10.4. Calculations are shown in Appendix AB.

The following proposed slurry chemistry reactions ${ }^{(b)}$ were used to estimate the amount of NO from disproportionation:

$$
\begin{gathered}
\mathrm{H}_{2} \mathrm{CO}_{3} \rightarrow \mathrm{CO}_{2}+\mathrm{H}_{2} \mathrm{O} \\
2 \mathrm{NaNO}_{2}+4 \mathrm{HCOOH} \rightarrow \mathrm{N}_{2} \mathrm{O}+2 \mathrm{CO}_{2}+2 \mathrm{NaCOOH}+3 \mathrm{H}_{2} \mathrm{O} \\
\mathrm{HCOOH} \rightarrow \mathrm{H}_{2}+\mathrm{CO}_{2} \text { (catalyzed by noble metals) } \\
\mathrm{MnO}_{2}+3 \mathrm{HCOOH} \rightarrow \mathrm{Mn}^{2+}+2 \mathrm{HCOO}^{-}+2 \mathrm{H}_{2} \mathrm{O}+\mathrm{CO}_{2} \\
2 \mathrm{NaNO}_{2}+3 \mathrm{HCOOH} \rightarrow 2 \mathrm{NO}+\mathrm{CO}_{2}+2 \mathrm{NaCOOH}+2 \mathrm{H}_{2} \mathrm{O} \\
3 \mathrm{HNO}_{2} \rightarrow \mathrm{H}^{+}+\mathrm{NO}_{3}^{-}+2 \mathrm{NO}+\mathrm{H}_{2} \mathrm{O}
\end{gathered}
$$

Percent NO from Disproportionation by Carbon Dioxide Balance. A number of different ways can be used to estimate \% NO from reaction (10.6). Based on the measured total moles of $\mathrm{N}_{2} \mathrm{O}$ and $\mathrm{H}_{2}$, the target simulant carbonate concentration, and the target simulant manganese concentration, $\mathrm{CO}_{2}$ production can be predicted from the above reactions. The predicted amount of $\mathrm{CO}_{2}$ (determined from the initial target carbonate in the slurry) can be subtracted from the measured $\mathrm{CO}_{2}$ to determine the amount of $\mathrm{CO}_{2}$ produced from reaction (10.5).

The amount of NO due to reaction (10.5) can then be calculated. The remaining NO is predicted to be from reaction $(10.6)$.

(a) Langowski, M. H., E. V. Morrey, M. R. Beckette, J. M. Tingey. 1993. Offgas Characterization from the Radioactive NCAW Core Sample (102-AZ-C1) and Simulant During HWVP Feed Preparation Testing, PHTD-C93-05.05B. Prepared by the Pacific Northwest Laboratory, Richland, Washington.

(b) Wiemers, K. D., M. H. Langowski, M. R. Powell, and D. E. Larson. 1993. Evaluation of HWVP Feed Preparation Chemistry for an NCAW Simulant-Fiscal 1991: Evaluation of Offgas Generation, Reductant Requirements and Thermal Stability, PHTD-C93-03.02A K899. Prepared by the Pacific Northwest Laboratory, Richland, Washington. 
Table 10.4. Estimated Percent of NO from the Disproportionation of Nitrous Acid

\begin{tabular}{|c|c|c|c|}
\hline Method & Assumptions & $\begin{array}{l}\text { Estimated \% NO } \\
\text { Produced by } \\
\text { Disproportionation of } \\
\text { Nitrous Acid, (\%) }\end{array}$ & $\begin{array}{l}\text { Estimate } \% \text { NO from } \\
\text { the Reduction of Nitrite } \\
\text { by Formate, }(\%)\end{array}$ \\
\hline Carbon Dioxide Balance & $\begin{array}{l}100 \% \text { Carbonate Destruction and } 0 \% \mathrm{MnO}_{2} \\
\text { reduction to } \mathrm{Mn}^{2+}\end{array}$ & 22 & 78 \\
\hline Carbon Dioxide Balance & $\begin{array}{l}100 \% \text { Carbonate Destruction and } 80 \% \mathrm{MnO}_{2} \\
\text { reduction to } \mathrm{Mn}^{2+}\end{array}$ & 37 & 63 \\
\hline Formate Balance & $\begin{array}{l}100 \% \text { Carbonate Destruction and } 0 \% \mathrm{MnO}_{2} \\
\text { reduction to } \mathrm{Mn}^{2+}\end{array}$ & 42 & 58 \\
\hline Formate Balance & $\begin{array}{l}100 \% \text { Carborate Destruction and } 80 \% \mathrm{MnO}_{2} \\
\text { reduction to } \mathrm{Mn}^{2+}\end{array}$ & 57 & 43 \\
\hline
\end{tabular}

Assuming all the carbonate is converted to $\mathrm{CO}_{2}$, and no $\mathrm{MnO}_{2}$ is reduced through reaction (10.4), $22 \%$ of the NO was calculated to be from reaction (10.6). The remaining $78 \%$ of NO was predicted to be from reaction (10.5).

Assuming all the carbonate is converted to $\mathrm{CO}_{2}$ and $80 \%{ }^{(\mathrm{a})}$ of $\mathrm{MnO}_{2}$ is reduced via reaction (10.4), 37\% of the NO was calculated to be from reaction (10.6). The remaining $63 \%$ of NO was predicted to be from reaction (10.5).

Percent NO from Disproportionation by Formate Balance. The \% NO from reaction (10.6) can also be estimated by examining the \% $\mathrm{HCOOH}$ consumed. By subtracting the amount of HCOOremaining in the slurry (determined by ion chromatography from the amount of $\mathrm{HCOOH}$ added, the percent of $\mathrm{HCOOH}$ consumed can be calculated. With equations (10.2) to (10.4), formic acid consumption from $\mathrm{MnO}_{2}$ reduction and $\mathrm{N}_{2} \mathrm{O}$ and $\mathrm{H}_{2}$ production can be predicted. Subtracting the predicted amounts of $\mathrm{HCOOH}$ consumed by reactions (10.2) to (10.4) from the actual HCOOH consumed gives the amount of $\mathrm{HCOOH}$ consumed by reaction (10.5). The amount of NO due to reaction (10.5) and subsequently reaction (10.6) can then be calculated.

Assuming all the carbonate is converted to $\mathrm{CO}_{2}$, and no $\mathrm{MnO}_{2}$ is reduced through reaction (10.4), $42 \%$ of the NO was calculated to be from reaction (10.6). The remaining $58 \%$ of NO was predicted to be from reaction (10.5).

Assuming all the carbonate is converted to $\mathrm{CO}_{2}$, and $80 \%$ of $\mathrm{MnO}_{2}$ is reduced through reaction (10.4), $58 \%$ of the NO was calculated to be from reaction (10.6). The remaining $42 \%$ of NO was predicted to be from reaction (10.5).

(a) Unpublished work by Langowski and Wiemers showed that $80 \%$ of the Mn was detected as soluble $\mathrm{Mn}^{2+}$ in the supernate of a non-noble metal NCAW simulant at a $\mathrm{pH} \approx 4$. 
The discrepancy between the $\mathrm{CO}_{2}$ balance and the formate balance methods for determining \% NO from disproportionation can be accounted for by the $8 \%$ error in closing the nitrogen mass balance, by the uncertainty in analytical and offgas measurements, and by the fact that the slurry chemistry is still not completely understood.

\subsubsection{NO $\rightarrow$ Nitrogen Dioxide Conversion}

It is predicted that $\mathrm{NO}$ will react with $\mathrm{O}_{2}$ to produce $\mathrm{NO}_{2}$ by the reaction below:

$$
2 \mathrm{NO}+\mathrm{O}_{2} \rightarrow 2 \mathrm{NO}_{2}
$$

It is possible to calculate the $\mathrm{NO} \rightarrow \mathrm{NO}_{2}$ conversion percentage in a number of ways. The different methods and results are summarized in Table 10.5 and are explained in the following sections.

The equations used to calculate the $\mathrm{NO} \rightarrow \mathrm{NO}_{2}$ conversion are also shown in Table 10.5. The calculated percent conversion of $\mathrm{NO} \rightarrow \mathrm{NO}_{2}$ varied from $45 \%$ to $94 \%$. The variability in the percentages is a result of the mass balance for nitrogen showing $92 \%$ closure, error in offgas and analytical measurements, and assumptions made for offgas system condensate scale-up. Slurry chemistry is also not completely understood with regards to proportion of reactions that produce NO and $\mathrm{NO}_{3}^{-}$(i.e., the.percentage of $\mathrm{NO}_{2}^{-} \rightarrow \mathrm{HNO}_{2} \rightarrow \mathrm{NO}_{3}{ }^{-}$and $\mathrm{NO}$ vs. the percentage of $\mathrm{NO} \rightarrow \mathrm{NO}_{2} \rightarrow$ $\mathrm{NO}_{3}^{-}$).

Rough calculations showed that residence time of the offgas at 100 ACFM in the tank vapor space is $\approx 5.5 \mathrm{~min}$. (a) This is long compared to the $\approx 1 \mathrm{sec}$ it takes for.the offgas to reach the sampling point and the $\approx 30 \mathrm{sec}$ it takes for the offgas to travel from the sampling point to the point at which the offgas stream is measured. It is reasonable to assume that most of the $\mathrm{NO} \rightarrow \mathrm{NO}_{2}$ conversion occurred in the tank vapor space and condenser not between the condenser and measuring point because the offgas spent the majority of its time in the tank vapor space and condenser. Therefore, the offgas measurements should be representative of the reactions occurring in the tank vapor space and condenser.

Percent $\mathrm{NO} \rightarrow \mathrm{NO}_{2}$ Conversion Calculated by $\mathrm{O}_{2}$ and $\mathrm{N}_{2}$ In-Leakage. Figure 10.15 shows inleakage for $\mathrm{N}_{2}$ and $\mathrm{O}_{2}$. During periods of $\mathrm{NO}_{x}$ generation, $\mathrm{O}_{2}$ was consumed by the $\mathrm{NO} \rightarrow \mathrm{NO}_{2}$ conversion. The consumption of $\mathrm{O}_{2}$ is shown in Figure 10.15 by the measurement of $\mathrm{O}_{2}$ in-leakage effectively being reduced to zero. Figure 10.16 shows the cumulative moles of $\mathrm{N}_{2}$ and $\mathrm{O}_{2}$ in-leakage as function of time. The $\mathrm{O}_{2}$ and $\mathrm{N}_{2}$ curves would be parallel if $\mathrm{O}_{2}$ were not participating in reaction with NO. Based on 49,549 moles of $\mathrm{N}_{2}$ in-leakage, 13171 moles of $\mathrm{O}_{2}$ should have been measured if $\mathrm{O}_{2}$ in-leakage were not consumed in any reaction (Note: Air is $\approx 79 \% \mathrm{~N}_{2}$ and $21 \% \mathrm{O}_{2}$ ). The actual measured $\mathrm{O}_{2}$ in-leakage was 9486 moles. Therefore, 3685 moles of $\mathrm{O}_{2}$ were consumed. Based on this amount, $\approx 94 \%$ of $\mathrm{NO}$ was converted to $\mathrm{NO}_{2}$ via $2 \mathrm{NO}+\mathrm{O}_{2} \rightarrow 2 \mathrm{NO}_{2}$. This $.94 \%$ quantity assumes that the increase in slurry nitrate did not involve the consumption of $\mathrm{O}_{2}$. In other words, the increase in slurry nitrate is riot due to $\mathrm{NO} \rightarrow \mathrm{NO}_{2} \rightarrow \mathrm{NO}_{3}^{-}$but to $\mathrm{NO}_{2}^{-} \rightarrow \mathrm{HNO}_{2} \rightarrow \mathrm{NO}_{3}^{-}$. It is not

(a) Personnel communication with M: R. Powell. 
Table 10.5. Percent NO Converted to $\mathrm{NO}_{2}$

Estimated Percentage of NO

Converted to $\mathrm{NO}_{2}$ by the

Method

Reaction $2 \mathrm{NO}+\mathrm{O}_{2} \rightarrow 2 \mathrm{NO}_{2}$,

Determined from offgas measurements $\left(\mathrm{NO}_{\mathrm{X}}-\mathrm{NO}\right) /\left(\mathrm{NO}_{\mathrm{x}}\right)$

Determined from offgas measurements includes the offgas

system condensate

$\left[\left(\mathrm{NO}_{\mathrm{X}}-\mathrm{NO}\right)+\mathrm{OSC}\right] /\left(\mathrm{NO}_{\mathrm{x}}+\mathrm{OSC}\right)$

Determined from offgas measurements includes the offgas

63

system condensate and the process condensate

$[(\mathrm{NOx}-\mathrm{NO})+\mathrm{OSC}+\mathrm{PC}] /\left(\mathrm{NO}_{\mathrm{X}}+\mathrm{OSC}+\mathrm{PC}\right)$

Determined from the $\mathrm{N}_{2}$ and $\mathrm{O}_{2}$ in-leakage

$\mathrm{N}_{2}$ in-leakage $\rightarrow 49,549$ moles

$\mathrm{O}_{2}$ in-leakage $\rightarrow 9486$ moles

$\{[(49549 / 0.79)-49,549]-9486\} * 2 /(\mathrm{NOx}+\mathrm{OSC}+\mathrm{PC})$

Determined from the $\mathrm{N}_{2}$ and $\mathrm{O}_{2}$ in-leakage

$\mathrm{N}_{2}$ in-leakage $\rightarrow 49,549$ moles

$\mathrm{O}_{2}$ in-leakage $\rightarrow 9486$ moles

$\{[(49549 / 0.79)-49,549]-9486\} * 2 /(\mathrm{NOx}+\mathrm{OSC}+\mathrm{PC}+$

.ISN)

Assume ISN is due to $\mathrm{NO} \rightarrow \mathrm{NO} 2 \rightarrow \mathrm{NO}_{3}^{-}$

Where: $\mathrm{NO}_{\mathrm{x}} \quad=5228$ moles measured from the offgas stream

$\left(\mathrm{NO}_{\mathrm{X}}-\mathrm{NO}\right)=2333$ moles of $\mathrm{NO}_{2}$

OSC $=520$ moles of $\mathrm{NO}_{2}$ scaled up from the nitrate.concentration in the offgas system condensate

PC $=2135$ moles of $\mathrm{NO}_{2}$ calculated from the moles of nitrite and nitrate in 1344 gal of process condensate

ISN = The slurry nitrate increased by 2167 moles (increase not due to condensate addition during formating). Some of the nitrate is from the disproportionation of $3 \mathrm{HNO}_{2} \rightarrow 2 \mathrm{NO}+\mathrm{NO}_{3}^{-}+\mathrm{H}_{2} \mathrm{O}+\mathrm{H}^{+}$. Some of the nitrate is due to $2 \mathrm{NO}+\mathrm{O}_{2} \rightarrow 2 \mathrm{NO}_{2}, 3 \mathrm{NO}_{2}+\mathrm{H}_{2} \mathrm{O} \rightarrow 2 \mathrm{NO}_{3}^{-}+2 \mathrm{H}^{+}+\mathrm{NO}$. The proportion of each reaction is unknown.

known at this time what percentages of slurry nitrate are due to a particular slurry chemistry reaction. The increase in slurry nitrate was not included in calculation for the $94 \% \mathrm{NO} \rightarrow \mathrm{NO}_{2}$ conversion number (see Table 10.5). 


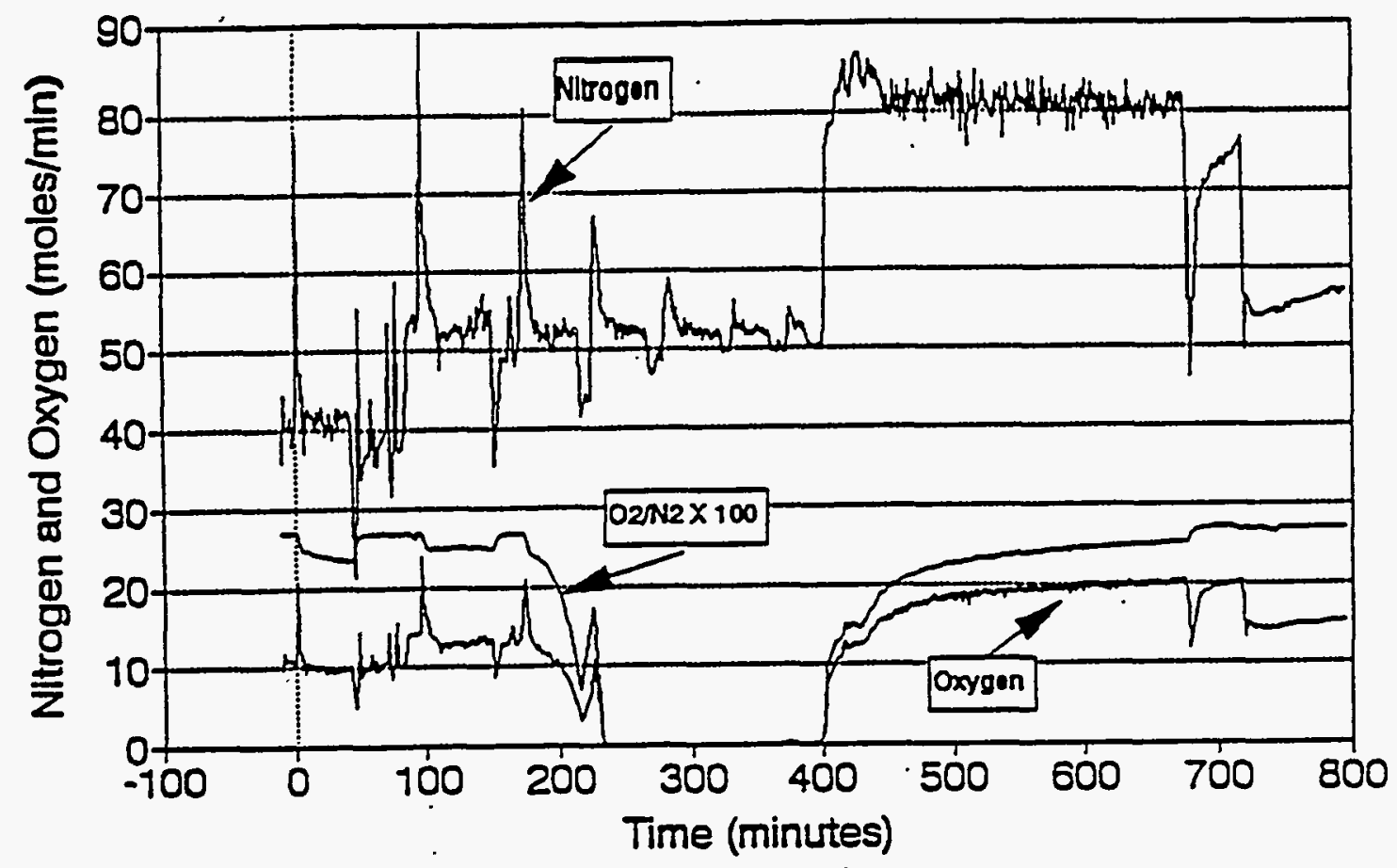

Figure 10.15. $\mathrm{N}_{2}$ and $\mathrm{O}_{2}$ In-Leakage (moles/min) During Formating and Digestion

The nitrate in the slurry was increased by approximately 2167 moles. If the $\mathrm{NO} \rightarrow \mathrm{NO}_{2}$ conversion is recalculated to inciude the increase in slurry nitrate, then the percentage decreases to $73 \% \mathrm{NO} \rightarrow \mathrm{NO}_{2}$ (see Table 10.5).

The $\mathrm{NO} / \mathrm{NO}_{\mathrm{x}}$ ratio is not always an accurate indicator of the extent of $\mathrm{NO} \rightarrow \mathrm{NO}_{2}$ conversion, especially if a large quantity of the $\mathrm{NO}_{2}$ is stripped out in the condensate. For example, the $\mathrm{NO} / \mathrm{NO}_{\mathrm{x}}$ was $\approx 0.8$ at 300 min when zero $\mathrm{O}_{2}$ in-leakage was being measured. The $\mathrm{O}_{2}$ in-leakage indicated that a significant portion of the $\mathrm{NO}$ was being consumed to form $\mathrm{NO}_{2}$. However, because most of the $\mathrm{NO}_{2}$ is being stripped by the condensate in the condensers (before offgas measurements), the $\mathrm{NO} / \mathrm{NO}_{\mathrm{x}}$ ratio indicated that the offgas was mostly NO (which it was at the point it was measured).

The $\mathrm{NO} \rightarrow \mathrm{NO}_{2}$ conversion was limited by the amount of $\mathrm{O}_{2}$ available for reaction. Had more air been present (as would be expected at in-leakages > 50 ACFM @ -5 in. $\mathrm{H}_{2} \mathrm{O}, 65 \mathrm{ACFM} @-10$ in. $\mathrm{H}_{2} \mathrm{O}$ ) then the percent conversion could have been higher. However, at very high dilutions of $\mathrm{NO}_{x}$ by air, the $\mathrm{NO} \rightarrow \mathrm{NO}_{2}$ conversion is slower because $\mathrm{NO}$ must find an $\mathrm{O}_{2}$ in a large volume.

Percent $\mathrm{NO} \rightarrow \mathrm{NO}_{2}$ Conversion Calculated Measured NO/NO Ratio. Figure 10.17 shows NO, $\mathrm{NO}_{2}$, and $\mathrm{NO}_{\mathrm{x}}$ generation (in cumulative moles) as a function of process time. Figure 10.18 shows the offgas generation rate for $\mathrm{NO}_{\mathrm{x}}$ and NO. Figure 10.19 shows the $\mathrm{NO} / \mathrm{NO}_{\mathrm{x}}$ ratio as a function of time. Figures 10.17 to 10.19 do not take into account the offgas system condensate scale-up of $\approx 520$ additional moles of $\mathrm{NO}_{2}$ or the amount of $\mathrm{NO}_{2}$ that was stripped into the 1344 gal of condensate collected in the condensate receipt tank or refiuxed back to the test vessel. 


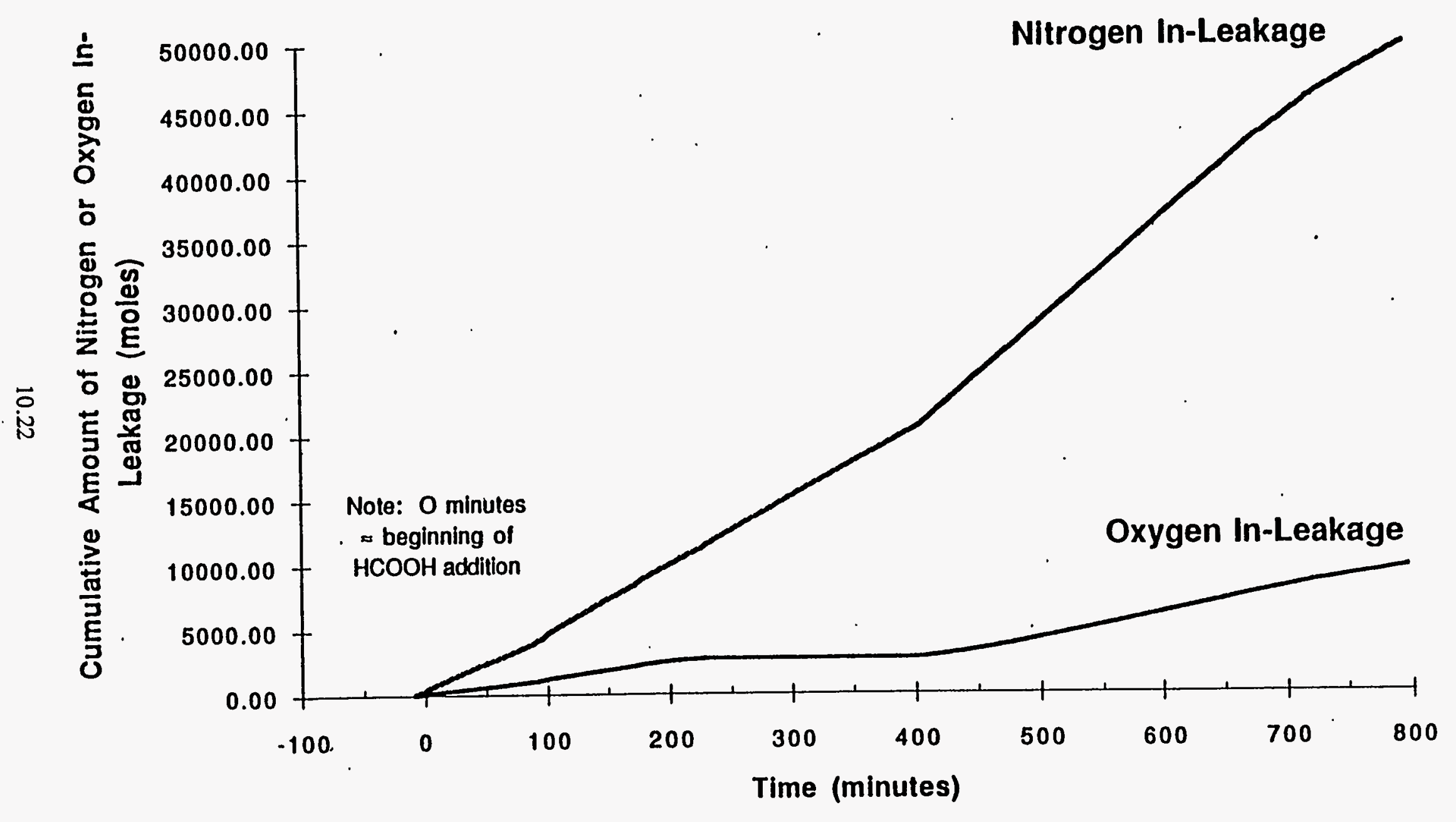

Figure 10.16. Cumulative Moles of Nitrogen and Oxygen In-Leakage During Formating and Digestion 


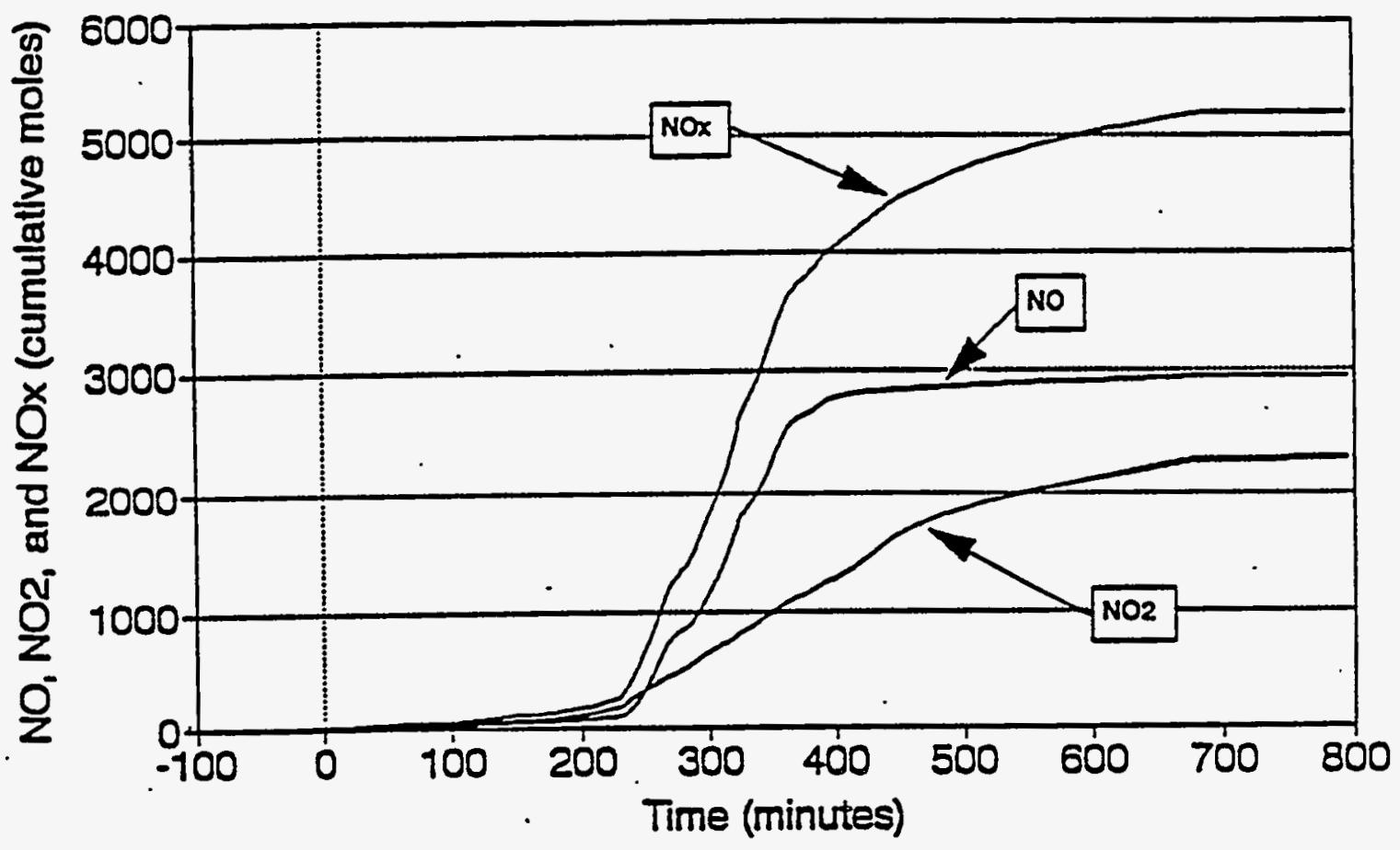

Figure 10.17. Cumulative Moles of $\mathrm{NO}, \mathrm{NOx}$, and $\mathrm{NO}_{2}$ Generated During Formating and Digestion

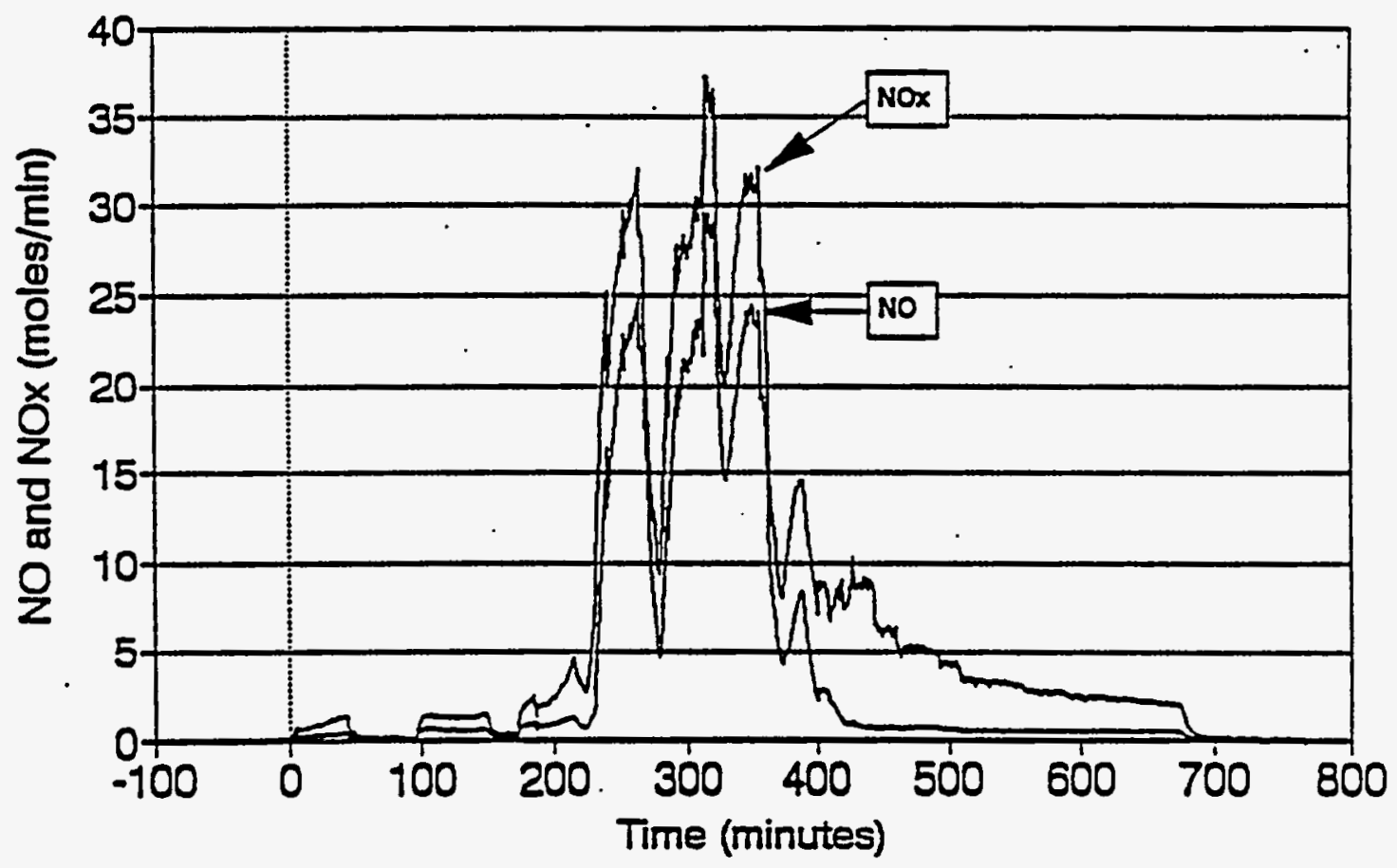

Figure 10.18. NOx, NO Offgas Generation During Formating and Digestion 


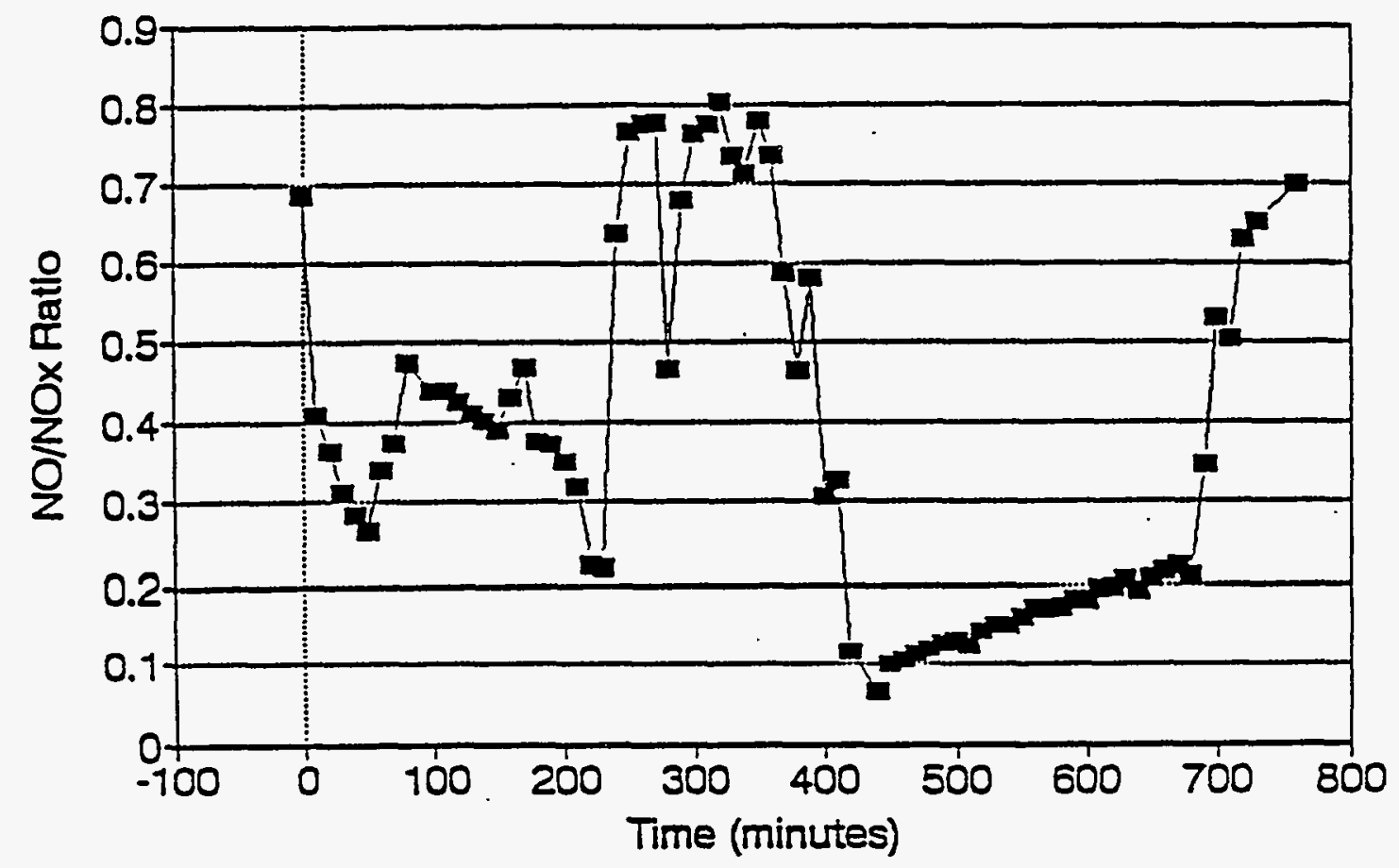

Figure 10.19. $\mathrm{NO}_{\mathrm{NO}}$, Ratio Process Profile During Formating and Digestion

In Figure $10.17,45 \%$ of the measured $\mathrm{NO}_{\mathrm{x}}$ is shown to consist of $\mathrm{NO}_{2}$ at the point at which the offgas stream was measured. If the offgas system condensate is accounted for in the calculation, $50 \%$ of the $\mathrm{NO}_{x}$ consisted of $\mathrm{NO}_{2}$. If both the offgas system condensate and $1344 \mathrm{gal}$ of process condensate (see Table 10.5) are taken into account, $63 \%$ of the $\mathrm{NO}_{\mathrm{x}}$ consists of $\mathrm{NO}_{2}$ at the point at which the offgas stream was measured. The results of $\% \mathrm{NO} \rightarrow \mathrm{NO}_{2}$ conversion are summarized in Table 10.5.

Process Temperatures of the Condenser, Offgas, and Condensate. The condenser temperature (inlet steam temperature), offgas temperature (exit temperature of offgas from condenser), condensate temperature (exit temperature of condensate from condenser), and $\mathrm{NO}_{\mathrm{x}}$ generation rate are plotted as a function of process time in Figure 10.20.

Figure 10.3 shows the cumulative gal of condensate generated during formic acid addition and digestion. During the first $100 \mathrm{~min}$ little condensate is generated. Consequently, in Figure 10.20 , the condensate temperature is about $57^{\circ} \mathrm{C}$. Between $100 \mathrm{~min}$ and $440 \mathrm{~min}$, more condensate is generated, and the condensate temperature drops to 45 to $50^{\circ} \mathrm{C}$. The temperature remains fairly constant, even during the peak generation rate of $\mathrm{NO}_{\mathrm{x}}$ and peak condenser temperatures. When digestion begins, the generation rate of condensate significantly increases. The temperature of the condensate decreases to $\approx 42^{\circ} \mathrm{C}$. After digestion ( $\approx 675 \mathrm{~min}$ ), when the tank is being cooled the condensate temperature is observed to rapidly rise to $60^{\circ} \mathrm{C}$ as the condensate flow rate abruptly decreases to near zero. In Figure 10.20 , it is also observed that the offgas temperature stayed below $45^{\circ} \mathrm{C}$. The maximum offgas temperature was observed during periods of peak $\mathrm{NO}_{\mathrm{x}}$ generation. 


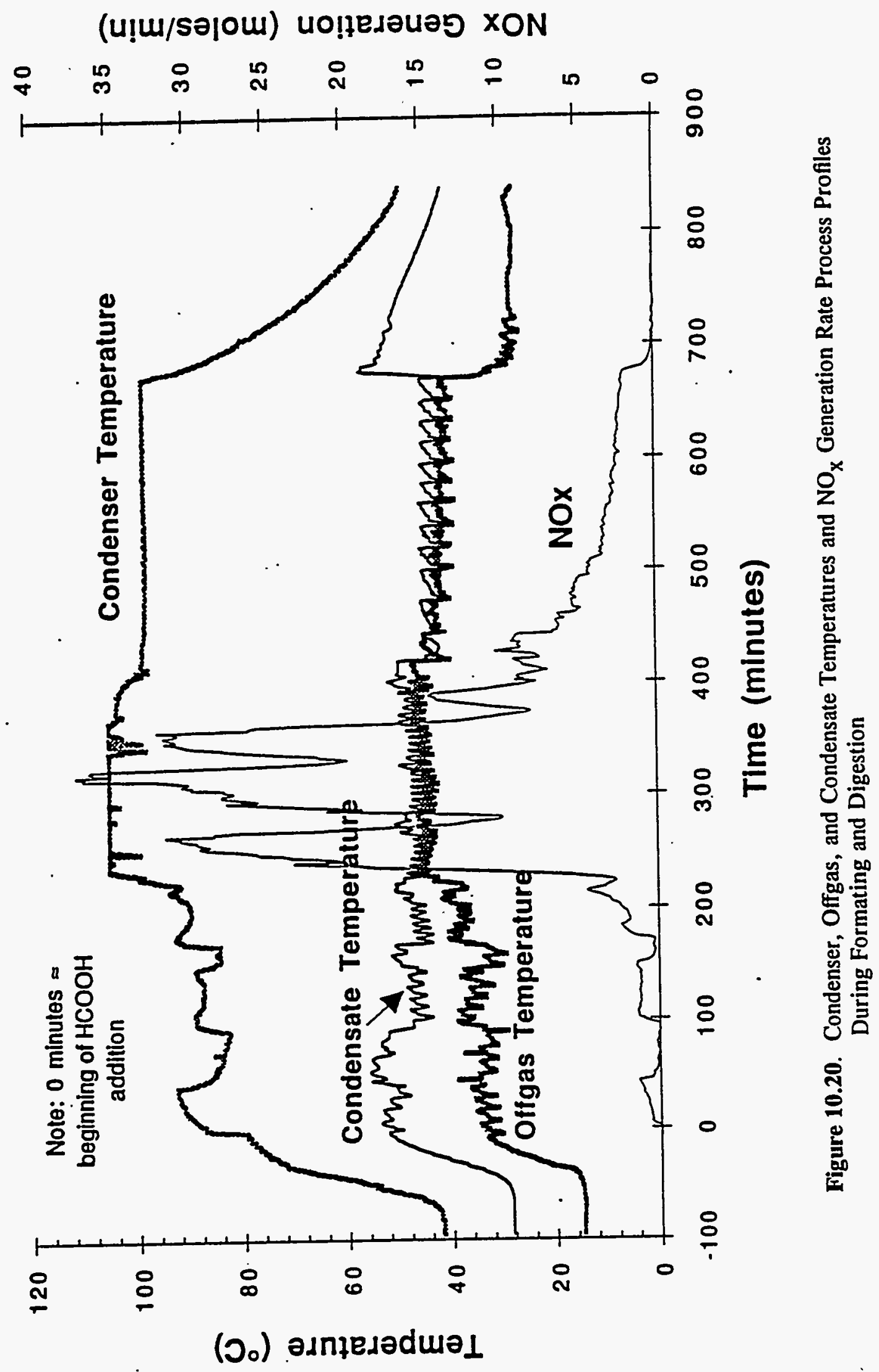

10.25 
The rapid increase in the condensate temperature is due to the heating effect experienced by the condenser separator unit and the condensate exit pipe, not to the condenser's inability to cool the condensate sufficiently. During testing, it was observed that at high condensate generation flow rates $(\approx 2$ to $4 \mathrm{gpm}$ ) the condensate temperature did not noticeably increase because the condensate did not spend a lot of time in the piping. At low condensate flow rates ( $\approx<1$ to $2 \mathrm{gpm}$ ) the temperature of the condensate increased significantly $\left(\approx 18^{\circ} \mathrm{C}\right)$.

The condensate exit pipe bends close to the SRAT. The walls of the SRAT are at $\approx 90^{\circ} \mathrm{C}$ during formating/digestion. Radiant heat from the SRAT can heat the condensate piping and subsequently the condensate that exits from the condenser. Also, a certain amount of reheating occurs in the condenser because the process vapor and condensate come in contact with the same walls. Figure 10.21 shows the relationship between condensate flow rate and condensate temperatures.

The condenser temperature increased from $\approx 85^{\circ} \mathrm{C}$ to greater than $105^{\circ} \mathrm{C}$ during formic acid addition. The exothermic $\mathrm{NO} \rightarrow \mathrm{NO}_{2}$ conversion is expected to cause condenser temperature to increase. Calculations performed before testing indicated that the condenser temperature would not increase past $105^{\circ} \mathrm{C}$. Therefore, the temperature equipment was set for reading the maximum temperature of $105^{\circ} \mathrm{C}$. In future testing, the maximum temperature setting will be set $>105^{\circ} \mathrm{C}$ to determine if the maximum temperature is $>105^{\circ} \mathrm{C}$.

\subsubsection{Tank Condenser Scrubbing Efficiency}

From Figure 10.22, it can be seen that $95 \%$ of the combined moles of nitrite and nitrate, detected in the condensate, are nitrate. This is consistent with the following reactions:

$$
\begin{gathered}
3 \mathrm{HNO}_{2} \rightarrow \mathrm{H}^{+}+\mathrm{NO}_{3}^{-}+2 \mathrm{NO}+\mathrm{H}_{2} \mathrm{O} \\
\mathrm{HNO}_{2(\mathrm{ag})} \rightarrow \mathrm{NO}_{2}^{-}(\mathrm{ag})
\end{gathered}
$$

Approximately $27 \%$ of the nitrogen generated as NOx was detected in the condensate as nitrate and nitrite. The total NOx value used to calculate the $27 \%$ included the 520 moles of NOx from the scaleup of the offgas system condensate.

\subsubsection{NOx Scrubbing by the Submerged Bed Scrubber during PSCM 23 and LFCM 8}

About 1 vol\% of $\mathrm{NO}_{\mathrm{x}}$ was scrubbed by the Submerged Bed Scrubber (SBS) during pilot-scale ceramic melter (PSCM)-run number 23. The low removal of $\mathrm{NO}_{\mathrm{x}}$ from the offgas stream was attributed to the fact that the $\mathrm{NO} / \mathrm{NO}_{2}$ ratio was estimated to be $>4$. 


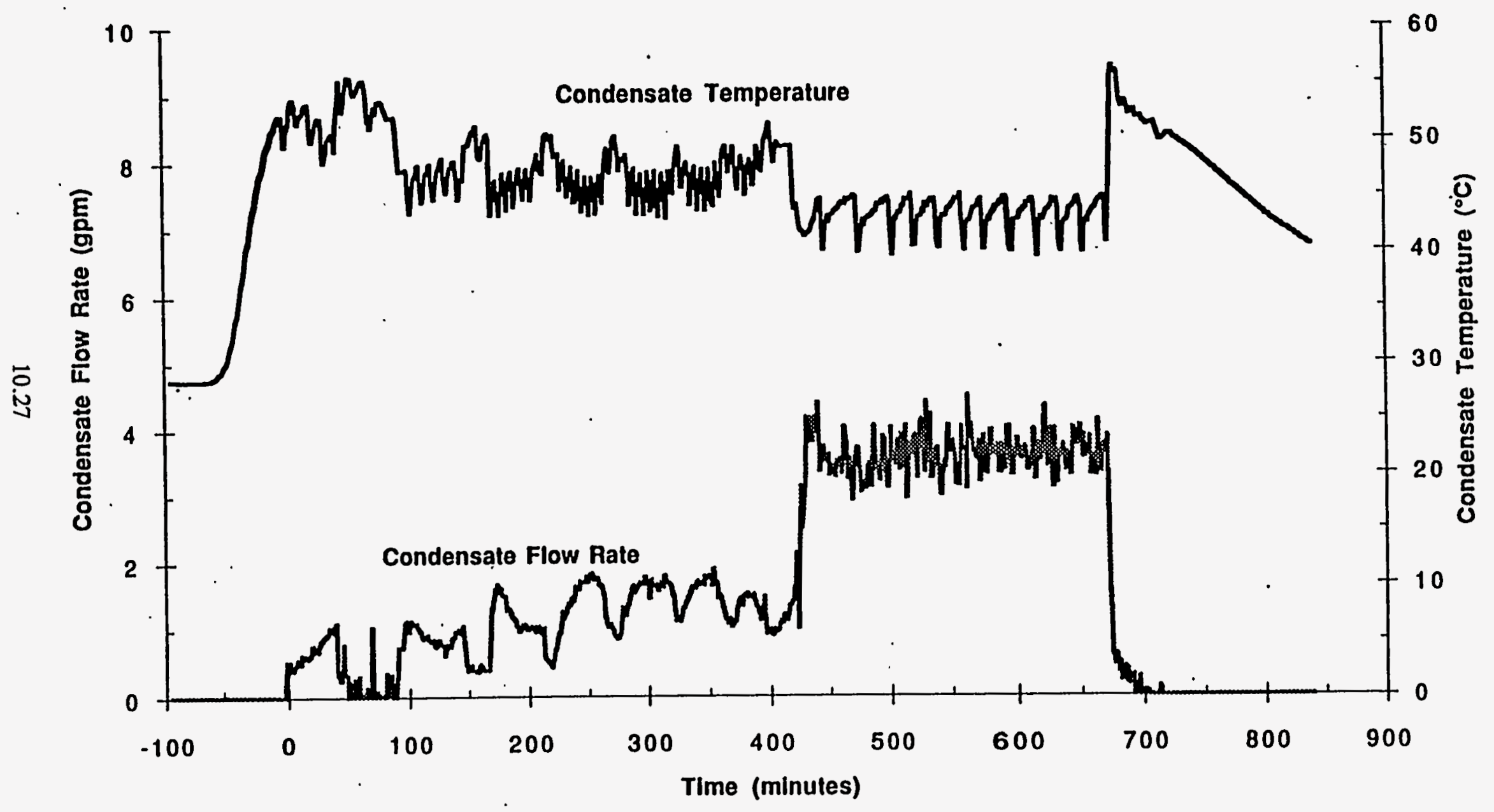

Figure 10.21. Condensate, Temperature and Condensate Flow-Rate Process Profiles During Formating and Digestion 


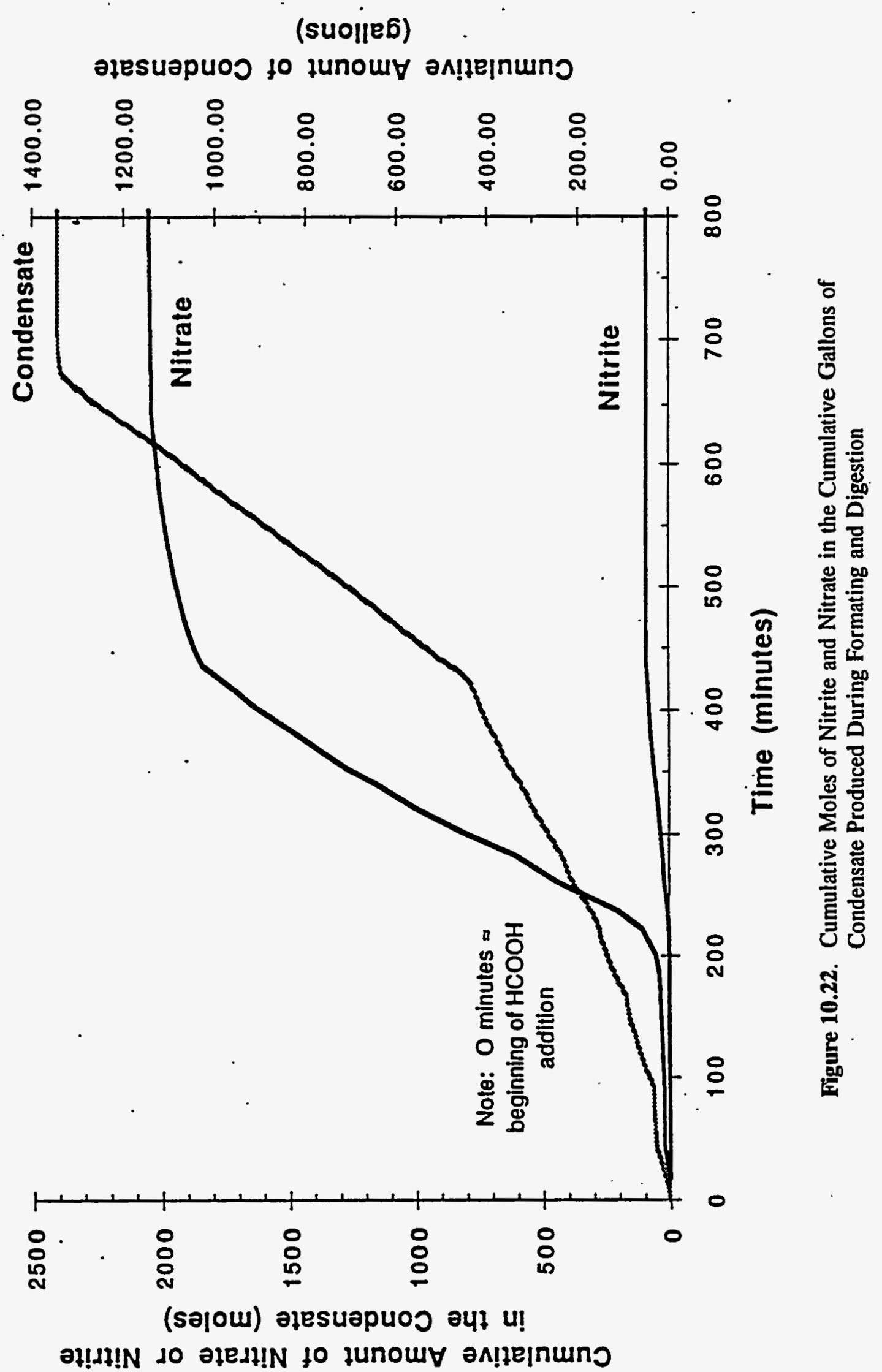




\subsubsection{Conclusions and Recommendations}

The data presented are based on one full-scale feed preparation test series.

Surges in offgas generation caused pressure spikes that resulted in tripping the automatic safety interlocks. It may be necessary to lower the tank vacuum or to add $\mathrm{HCOOH}$ at a lower rate to prevent safety interlock activation.

Ninety-two percent of the initial nitrogen present in the slurry was accounted for in the mass balance calculation. Uncertainty in the analytical measurements, offgas measurements, and in the offgas system condensate calculations contributed to the error in the mass balance.

A negligible amount of $\mathrm{NH}_{3}$ (bdl) and $\mathrm{H}_{2}(\approx 11$ moles) were produced during testing. The amounts of $\mathrm{NH}_{3}$ and $\mathrm{H}_{2}$ were expected to be low because the NCAW simulant did not contain noble metals. Noble metals are catalysts for the decomposition of $\mathrm{HCOOH}$ to produce $\mathrm{H}_{2}$ and $\mathrm{CO}_{2}$. A correlation between $\mathrm{NH}_{3}$ and noble metals (and/or $\mathrm{H}_{2}$ ) has also been theorized.

While 7400 gal of NCAW simulant without noble metals was formatted and digested, 5228 moles of $\mathrm{NO}_{\mathrm{x}}$ were produced with a maximum generation rate for $\mathrm{NO}_{\mathrm{x}}$ of $37 \mathrm{moles} / \mathrm{min}$. These numbers are expected to be 10 to $15 \%$ low due to the effect of $\mathrm{NO}_{2}$ stripped by the offgas system condensate. Discontinuous $\mathrm{HCOOH}$ addition rate may affect the reported maximum and minimum offgas generation rate for a $1.2 \mathrm{gpm} \mathrm{HCOOH}$ addition rate.

It is recommended that a full-scale formating test be performed with continuous formic acid addition to determine offgas generation characteristics.

Two reactions are predicted to produce $\mathrm{NO}_{x}$ in the SRAT:

$$
2 \mathrm{NaNO}_{2}+3 \mathrm{HCOOH} \rightarrow \underset{\text { (nitrite reduction by } \mathrm{HCOOH} \text { ) }}{2 \mathrm{NO}}+\mathrm{CO}_{2}+2 \mathrm{NaCOOH}+2 \mathrm{H}_{2}
$$

$$
3 \mathrm{HNO}_{2} \rightarrow 2 \mathrm{NO}+\mathrm{NO}_{3}^{-}+\mathrm{H}^{+}+\mathrm{H}_{2} \mathrm{O} \text { (disproportionation of nitrous acid) }
$$

Calculation by the carbon dioxide balance method showed that $\approx 22 \%$ of the $\mathrm{NO}_{\mathrm{X}}$ was from disproportionation of nitrous acid. The formate balance method showed $\approx 42 \%$ of the $\mathrm{NO}_{\mathrm{x}}$ from disproportionation. The calculations assumed all of the carbonate was destroyed and that none of the $\mathrm{MnO}_{2}$ was reduced $\mathrm{Mn}^{2+}$. If $80 \%$ of the $\mathrm{MnO}_{2}$ were assumed to be reduced to $\mathrm{Mn}^{2+}$, the results were $37 \%$ and $58 \%$, respectively, from the carbonate and formate balance methods. Uncertainty in analytical measurements as well as the fact that not everything is known about the slurry chemistry accounts for the range of numbers by different methods.

The NO $\rightarrow \mathrm{NO}_{2}$ conversion was estimated to be 45 to $94 \%$ complete at the point at which the offgas was measured. Offgas measurements should be representative of the reactions occurring in the 
tank vapor space and condenser based on calculations of offgas residence time. The range encompasses the uncertainty in the $\mathrm{NO}_{\mathrm{x}}$ generation values, the assumption that condensate nitrate and nitrite result from the reaction of $\mathrm{NO}_{2}$ with the condensate, the assumption that the increase slurry nitrate is (or is not) the result of $\mathrm{NO} \rightarrow \mathrm{NO}_{2} \rightarrow \mathrm{NO}_{3}{ }^{*}$, and the uncertainty in $\mathrm{N}_{2}$ and $\mathrm{O}_{2}$ in-leakage.

Condenser operation was successful in cooling the condensate to temperatures $50^{\circ} \mathrm{C}$ and below during periods of high $\mathrm{NO}_{\mathrm{x}}$ generation.

The condensate collection system design affected the condensate temperature. At low condensate generation rates $(<2 \mathrm{gpm})$, the condensate temperature increased above $50^{\circ} \mathrm{C}$. The increase in condensate temperature was probably caused by heat transfer through the condenser separator unit, which had process vapor (steam) on one side and condensate on the other side. It was also possible that external heating of the condensate exit pipe by the radiant heat from the SRAT might have occurred.

Approximately $27 \%$ of the nitrogen generated as $\mathrm{NO}_{\mathrm{x}}$ was present in the condensate as nitrate or nitrite. This assumes that $\mathrm{NO} \rightarrow \mathrm{NO}_{2} \rightarrow \mathrm{NO}_{2}^{-}$and $\mathrm{NO}_{3}{ }^{-}$in the condensate.

\subsection{Foaming Suppression (antifoaming agent)}

Suppression of foaming in the test tank by use of an antifoaming agent is discussed in this section.

\subsubsection{Background}

There has been a concern that foaming may be a serious problem during boiling. As a result, variables such as composition, agitator speed, temperature, and liquid level were examined for foaming influence. These effects were primarily measured during concentration, formating, and digestion of the NCAW-1 feed material. The condenser decontamination factors were determined through sampling and the foam level by an air-cooled, waterproof video camera positioned inside the tank. Additionally, tank pressure fluctuations recorded during the test also indicated foaming instances. At times that foaming was observed and/or anticipated, Dow Corning 544 Antifoam $^{\oplus}$ agent was added to the vessel. The effectiveness of this antifoam agent was also evaluated.

Full-scale testing of the Defense Waste Processing Facility (DWPF) Slurry Receipt and Adjustment Tank and Slurry Mix Evaporator (SRAT/SME) was conducted at the Savannah River Laboratory (SRL), in Aiken, South Carolina. During Run \#4 of the full-scale SRAT/SME, in February 1987, a high concentration of solids was observed in the condensate. 'Difficulties were also encountered in maintaining the vessel vacuum. At the time, the cause of the entrainment was unknown, and the only way to reduce the solids-carryover and to maintain the vacuum was to reduce the steam flow rate. The conditions of the run were reproduced in small-scale glassware, and the mechanism of the solids carryover was identified as foaming.

Several antifoaming agents were tested at SRL on a laboratory scale, and three were identified for testing in the full-scale SRAT/SME. Dow Corning 544 Antifoam $^{\oplus}$ has shown the greatest success in . the full-scale SRAT/SME testing and is currently the recommended antifoam for the DWPF. 
The following conclusions resulted from the DWPF SRAT/SME \#6 test at Savannah River Laboratory (TNX):

1. Dow Corning 544 Antifoam $^{\oplus}$ can effectively reduce foaming occurrences.

2. The antifoam agent appears to have a finite lifetime of about $24 \mathrm{~h}$.

3. The antifoam agent loses its effectiveness even when the boiling sludge remained on total reflux; i.e., the antifoam agent is not being steam stripped.

4. Antifoam agent concentrations as low as $10 \mathrm{ppm}$ reduced the foam layer; however, it appeared that a higher concentration of $27 \mathrm{ppm}$ reduced the foam layer even better.

5. Without fresh antifoam, foaming occurred in both the SRAT and SME cycles.

From the Savannah River SRAT/SME testing, DWPF recommendations were as follows:

1. Recommended concentration of antifoam is $25 \mathrm{ppm}$ active ingredient (the manufacturer suggests 10 to $100 \mathrm{ppm})$.

2. Minimum. recommended dilution factor is $10 \mathrm{X}$. During makeup, the weight ratio of water to antifoam is $10: 1$ (9.1 wt\% antifoam agent and $90.9 \mathrm{wt} \%$ water):

3. The antifoam agent can be added to either a hot or cold SRAT or SME; higher temperatures are preferred.

4. Periodic additions of antifoam agent are necessary; antifoam 544 must be added every $24 \mathrm{~h}$.

\subsubsection{Testing Approach}

During testing at which the contents of the test vessel (HB-15) were either concentrated or formated and digested, an in-tank camera was used to monitor for a foam layer. Additionally, the following tank conditions were recorded: the HB-15 condenser pressure, HB-15 temperature, heating coil steam flowrate, HB-15 agitator speed, and HB-15 tank weight. The pressure in HB-15 was usually set between -5 and -15 inches of water throughout testing.

For decontamination factors the off-gas and condensate flow-rates from the condenser were measured. In addition, samples from the condensate line were taken intermittently during testing to monitor solids carryover. Condensate line samples were analyzed for wt\% solids by drying the samples at $105^{\circ} \mathrm{C}$. The off-gas from the HB-15 condenser was isokinetically sampled, and any aerosols were collected on a filter. 


\subsubsection{Results}

Testing results are discussed below.

\subsubsection{DWPF Testing (Background)}

DWPF Laboratory Testing Following SRAT/SME Run \#4. Boiling of the initial caustic siudge and the formatted waste sludge produced an unstable froth on the liquid surface. It was not until the precipitate hydrolysis aqueous (PHA) stream was added that a fairly stable foam layer grew that filled the entire foam space of the vessel and carried the liquid and sludge solids through the condenser and into the condensate.

DWPF SRAT/SME Run \#5. The as received, alkaline, waste simulant slurry was frothy when the steam was incrementally raised from $2100 \mathrm{lb} / \mathrm{h}$ to $4800 \mathrm{lb} / \mathrm{h}$, but there was no severe foaming observed (foamed only slightly $\sim 6$ in.). However, formatted sludge foamed significantly at steam rates above $4000 \mathrm{lb} / \mathrm{h}$ (i.e., the foam layer rose to about $3 \mathrm{ft}$ above the liquid surface when the steam flow was raised from $2100 \mathrm{lb} / \mathrm{h}$ to $5100 \mathrm{lb} / \mathrm{h}$ ), but the condensate remained relatively clear. The PHA additions were accompanied by severe foam and muddy condensate at steam rates as low as $2000 \mathrm{lb} / \mathrm{h}$.

DWPF, Lifetime of 544 Antifoam ${ }^{\otimes} .9000$ gal of dilute SME material was concentrated and antifoam agent was added because of foaming. During a 24 -h period, the slurry was concentrated and cooled down. The foam layer returned after the 24-h period. DWPF engineers were unsure of one of the factors that contributed to the loss of effectiveness.

A controlled experiment was then performed to determine whether or not the antifoam was being steam-stripped. The last of 544 antifoam was added at a higher concentration ( $27 \mathrm{ppm}$ ) and was added to the boiling slurry to eliminate concerns about the effect of cooler temperatures. In addition, the slurry was boiled on total refiux to eliminate the concern of losing the antifoam agent with the condensate (steam-stripping). After $25 \mathrm{~h}$, the sludge surface was covered with a significant amount of foam. A slight loss in vacuum was observed shortly before the foaming. The onset of foaming occurred very quickly. Two possible explanations for the finite lifetime of the antifoam are 1) the antifoam is decomposing, and 2) the antifoam is being adsorbed onto the solids in the slurry.

\subsubsection{HWVP NCAW 1 (SIPT 2) Testing}

Observations from SIPT 2 testing follow. Table 10.6 shows portions of the test when foaming was observed and when antifoam was added.

\subsubsection{High-Tank-Level (7800 gal) Dilute Waste Simulant}

Evaporator/Condenser Testing. During this testing activity (January 6, 1993) the contents of HB-15 ( $4.5 \mathrm{wt} \%$ solids) were brought to a boil at approximately $99^{\circ} \mathrm{C}$ (measured). Figure 10.23 shows the process variables pertaining to tank foaming superimposed. The HB- 15 heating-coil flow rate was varied from approximately $5000 \mathrm{lb} / \mathrm{h}$ to $4400 \mathrm{lb} / \mathrm{h}$ to $3200 \mathrm{lb} / \mathrm{h}$ steam (measured). The agitator speed in Tank HB-15 also varied from $85 \mathrm{mpm}$ to $45 \mathrm{rpm}$ to $127 \mathrm{rpm}$ at a measured steam flow-rate of $4300 \mathrm{lb} / \mathrm{h}$. The pressure set-point in the HB-15 condenser was set to 10 inches of water vacuum. 
Table 10.6. Foaming Matrix for SIPT 2 Testing

\begin{tabular}{|c|c|c|c|c|}
\hline Tank Level (gal) & Composition & Test & Foam? & Antifoam? \\
\hline 1. High $(7800)$ & Dilute waste simulant & $\begin{array}{l}\text { Evaporator/condenser testing } \\
\text { Feed concentration }\end{array}$ & $\begin{array}{l}\text { yes } \\
\text { yes }\end{array}$ & $\begin{array}{l}\text { no } \\
\text { yes }\end{array}$ \\
\hline 2. Low (5700) & Concentrated waste simulant & $\begin{array}{l}\text { Feed concentration after feed make-up } \\
\text { Evaporator/condenser testing }\end{array}$ & $\begin{array}{l}\text { no } \\
\text { no }\end{array}$ & $\begin{array}{l}\text { yes } \\
\text { no }\end{array}$ \\
\hline 3. High $(7800)$ & Concentrated waste simulant & Feed concentration & yes & no \\
\hline 4. Low $(5700)$ & Formatted waste simulant & $\begin{array}{l}\text { Formic acid addition and digestion } \\
\text { Feed concentration before recycle } \\
\text { addition }\end{array}$ & $\begin{array}{l}\text { yes } \\
\text { yes }\end{array}$ & $\begin{array}{l}\text { yes } \\
\text { no }\end{array}$ \\
\hline 5. Low $(6200)$ & Melter feed & $\begin{array}{l}\text { Feed concentration before frit addition } \\
\text { Frit addition }\end{array}$ & $\begin{array}{l}\text { no } \\
\text { yes }\end{array}$ & $\begin{array}{l}\text { no } \\
\text { no }\end{array}$ \\
\hline
\end{tabular}

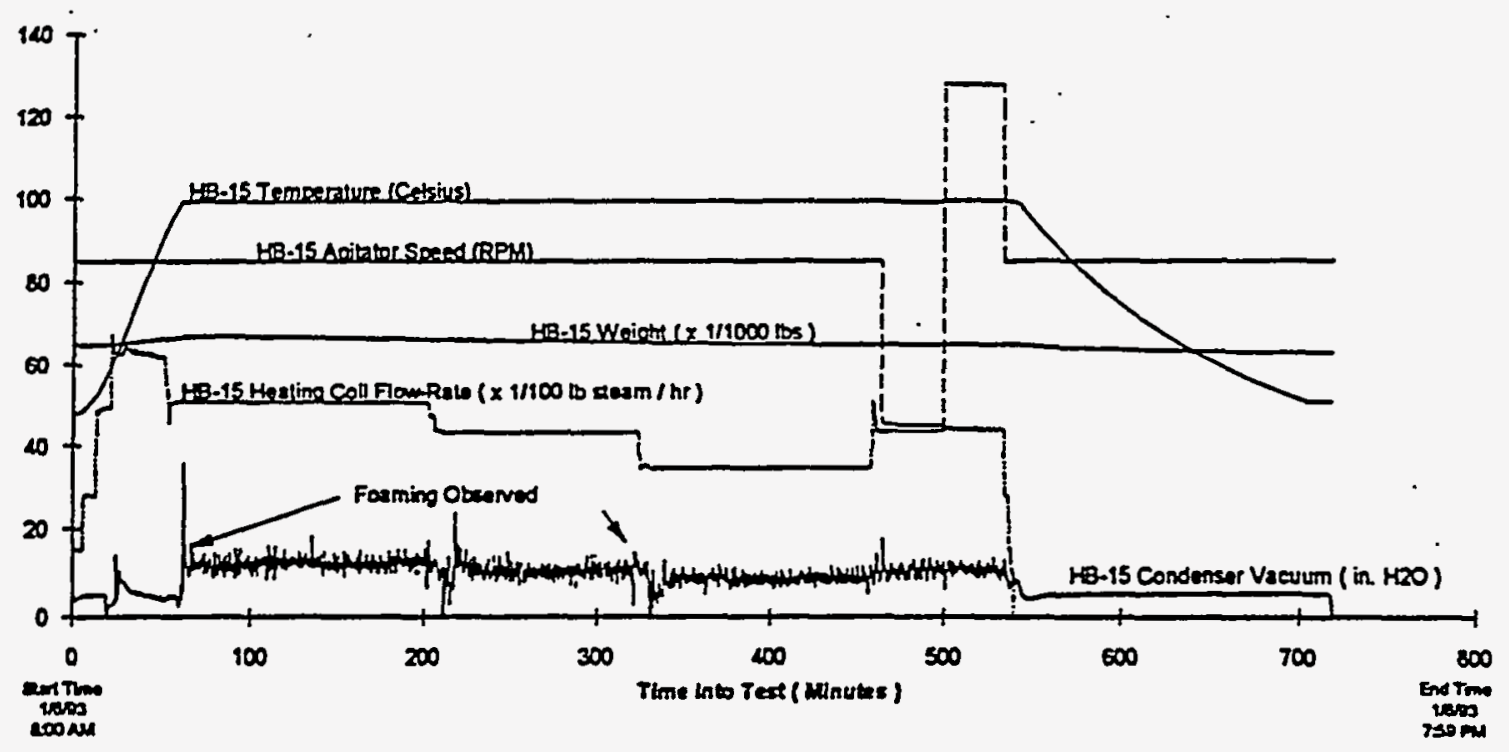

Figure 10.23. High-Tank-Level (7800 gal) Dilute Waste-Simulant Evaporator and Condenser Testing 
Foaming was observed in the test between 84 to 339 minutes into the test. The measured steam flow rates in the heat coils were $5000 \mathrm{lb} / \mathrm{h}$ and $4400 \mathrm{lb} / \mathrm{h}$ (actual steam flow rates are approximately $6000 \mathrm{lb} / \mathrm{h}$ and $5200 \mathrm{lb} / \mathrm{h}$, respectively). The agitator speed was held constant at $85 \mathrm{rpm}$ during this time. A foam layer as thick as $2 \mathrm{ft}$ was observed during this period.

After 320 minutes, the measured steam flow rate was reduced to $3500 \mathrm{lb} / \mathrm{h}(4200 \mathrm{lb} / \mathrm{h}$ actual), and the foaming in the tank totally subsided within 30 minutes. The agitator speed was kept constant at $85 \mathrm{rpm}$ during this time.

The steam flow was then increased to $4400 \mathrm{lb} / \mathrm{h}(5200 \mathrm{lb} / \mathrm{h}$ actual $)$ and the agitator speed was changed to $45 \mathrm{rpm}$ and to $127 \mathrm{rpm}$. There were no foaming problems observed at the higher steam flow rate and at the two different agitator speeds.

Condensate samples (Appendix AC, samples SIPT 2-8.1.10 - SIPT 2-8.1.23) taken during this period were analyzed for wt $\%$ solids. However, the weight percent solids in the condensate samples were under the detection limits of the analytical method.

Waste-Simulant Concentration. The contents of HB-15 were concentrated between January 13, 1993, to January 15, 1993 ( -15.5 wt\% solids) (shown in Figures 10.24 to 10.26). During this concentration step, the measured heating coil flow rate was between $3300 \mathrm{lb} / \mathrm{h}$ and $4800 \mathrm{lb} / \mathrm{h}$ steam (measured). The agitator speed was held constant at $85 \mathrm{rpm}$. Dow Corning 544 Antifoam $^{\oplus}$ compound was $^{2}$ added on all 3 days of this test portion due to foaming occurrences.

On the first day of feed concentration (January 13, 1993, see Figure 10.24), foaming was observed. The tank temperature was raised to $90^{\circ} \mathrm{C}$ at which point the actual steam flow was reduced to $5800 \mathrm{lb} / \mathrm{h}(4700 \mathrm{lb} / \mathrm{h}$ measured) while heating the test vessel contents to boiling. When the test vessel contents reachèd approximately $98^{\circ} \mathrm{C}$, the measured steam flow was reduced to $2800 \mathrm{lb} / \mathrm{h}$. Less than 2 minutes later, the slurry foamed until the camera was covered and/or submerged in foam. The steam was immediately turned off and the foam began to subside within the next 30 seconds. Over a period of the next 4 minutes, the steam flow (measured) was increased from $0 \mathrm{lb} / \mathrm{h}$ to $1500 \mathrm{lb} / \mathrm{h}$ to $2800 \mathrm{lb} / \mathrm{h}$. Two minutes later, the slurry foamed again. The steam flow (measured) was immediately reduced to $1500 \mathrm{lb} / \mathrm{h}$ and the foam subsided. Over a period of the next 20 minutes, the steam flow (measured) was increased from $1500 \mathrm{lb} / \mathrm{h}$ to $2200 \mathrm{lb} / \mathrm{h}$ to $2800 \mathrm{lb} / \mathrm{h}$ to $3800 \mathrm{lb} / \mathrm{h}$.

The slurry foamed after 10 minutes, and the steam flow (measured) was decreased to $2200 \mathrm{lb} / \mathrm{h}$. Four minutes after the steam flow change, the foam level in the tank was just below the camera and did not appear to be going down. Five minutes later the in-tank camera failed, and the steam flow was shut off. Before testing resumed, 77 pounds of $9.1 \mathrm{wt} \%$ Dow Corning 544 Antifoam $^{\star}$ and $90.9 \mathrm{wt} \%$ water was added to the tank. Since the camera had failed, visual reporting of foaming could not occur. The tank contents were then concentrated with a heating-coil flow rate of $3300 \mathrm{lb} / \mathrm{h}$ and $4800 \mathrm{lb} / \mathrm{h}$ steam (measured). 


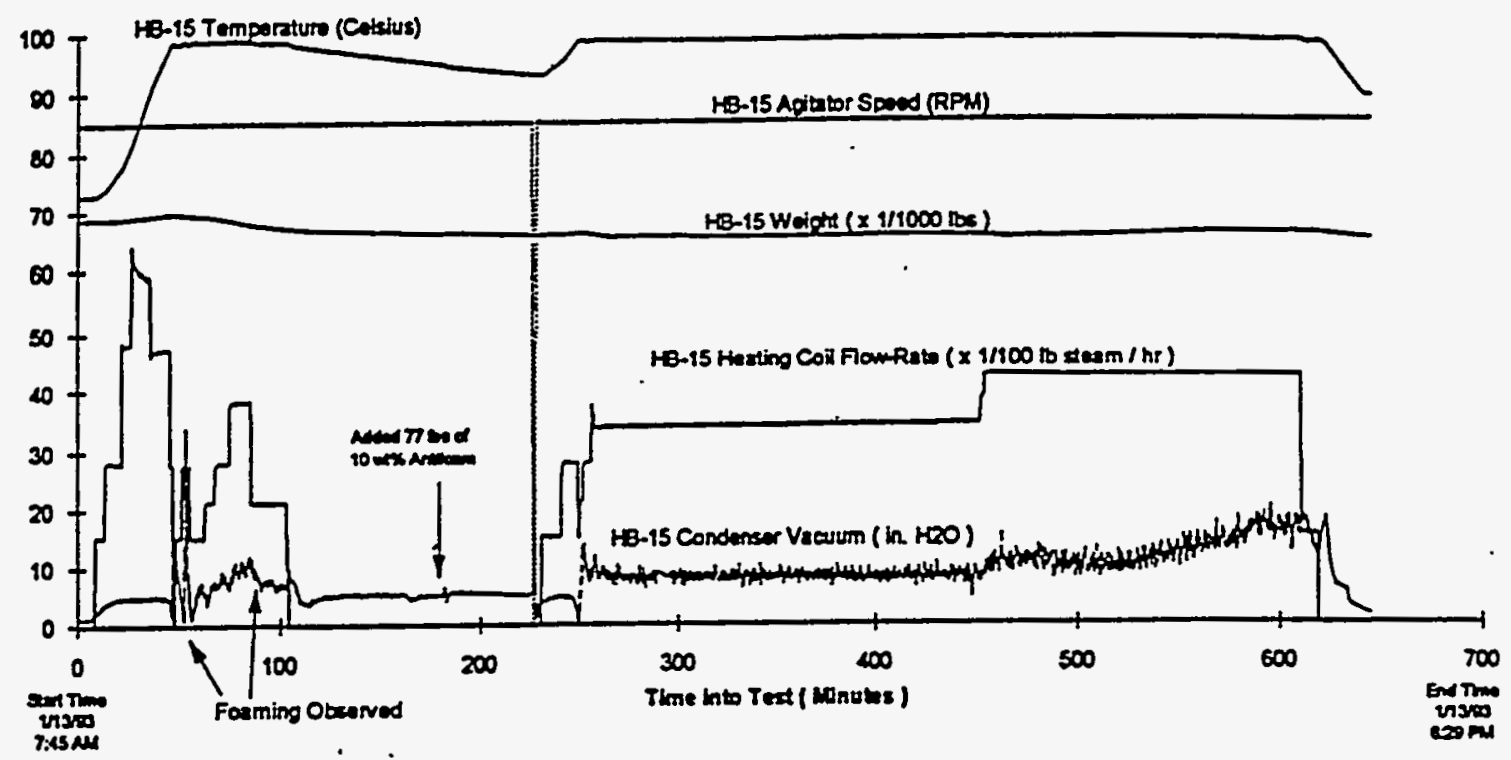

Figure 10.24. High-Tank-Level (7800 gal) Dilute Waste-Simulant Feed Concentration, January 13, 1993

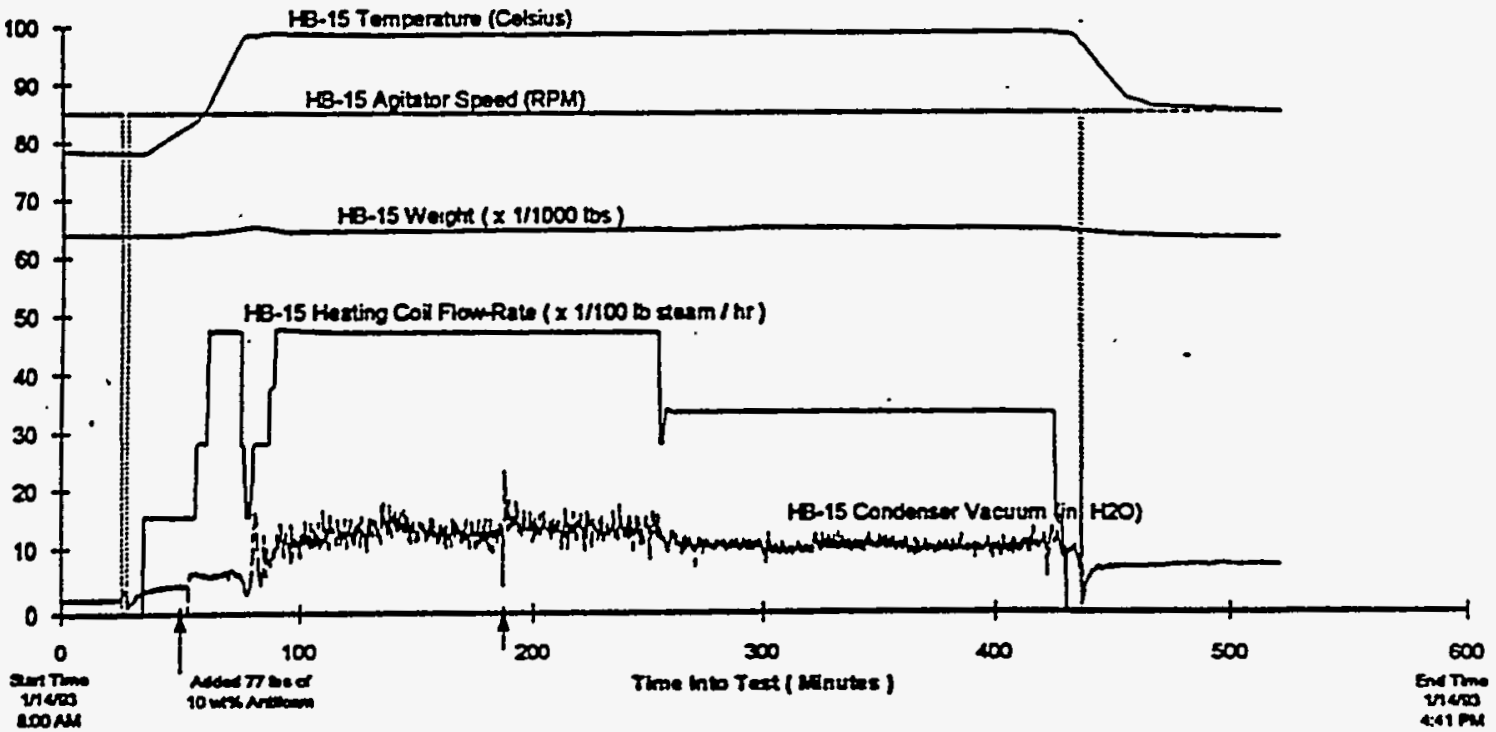

Figure 10.25. High-Tank-Level (7800 gal) Dilute Waste-Simulant Feed Concentration, January 14, 1993 


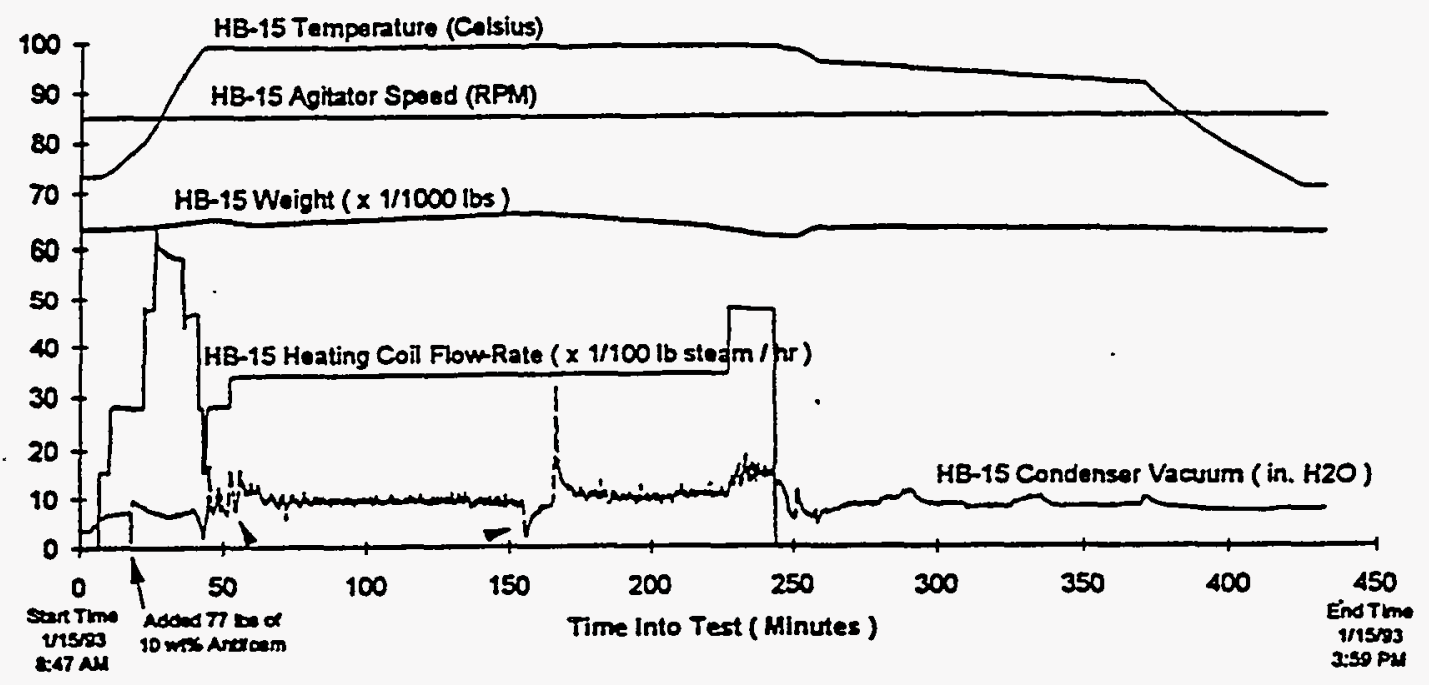

Figure 10.26. High-Tank-Level (7800 gal) Dilute Waste-Simulant Feed Concentration, January 15, 1993

Over the next couple of days of feed concentration, foaming may have occurred, but the camera was not functioning. The heating coil flow rate on both days of concentration were between $3400 \mathrm{lb} / \mathrm{h}$ and $4800 \mathrm{lb} / \mathrm{h}$ steam (measured). Seventy-seven pounds of $9.1 \mathrm{wt} \%$ antifoam was also added on the second and third day of feed concentration. Arrows in Figures 10.25 and 10.26 indicate when Dow Corning 544 Antifoam $^{\oplus}$ was added and show pressure fluctuations that may have resulted from foaming. It was believed that foaming did occur because the HB-15 condenser pressure fluctuated and spiked several times during the test. Notice in Figure 10.25 that the magnitude of the pressure fluctuations at the lower heating-coil flow rate $(\sim 3400 \mathrm{lb} / \mathrm{h}$ steam) was less than at the high steam flow rate.

Condensate samples (Appendix AC, samples SIPT.2-9.1.1 - SIPT 2-9.5.10) taken during this period were analyzed for $w t \%$ solids. However, the $w t \%$ solids in these condensate samples were below detection limits.

\subsubsection{Low-Level (5700 gal) Concentrated Waste Simulant}

Waste-Simulant Concentration from $(7800$ gal to 5700 gal). During this portion of the test (January 23, 1993, shown in Figure 10.27), the contents of the tank were concentrated from 7800 gal to 5700 gal. During this concentration step, the heating coil flow rate was $4800 \mathrm{lb} / \mathrm{h}$ steam (measured). 77 pounds of $9.1 \mathrm{wt} \%$ antifoam was added before HB- 15 reached boiling temperature. There was no foaming observed. However, there were several pressurization spikes (arrows in Figure 10.27) which could have been the result of small foaming occurrences.

Condensate samples (Appendix AC, samples SIPT 2-9.1.1 - SIPT 2-9.5.10) taken during this period were analyzed for wt\% solids. However, as in the previous tests, the wt\% solids in these condensate samples were below detection limits. 


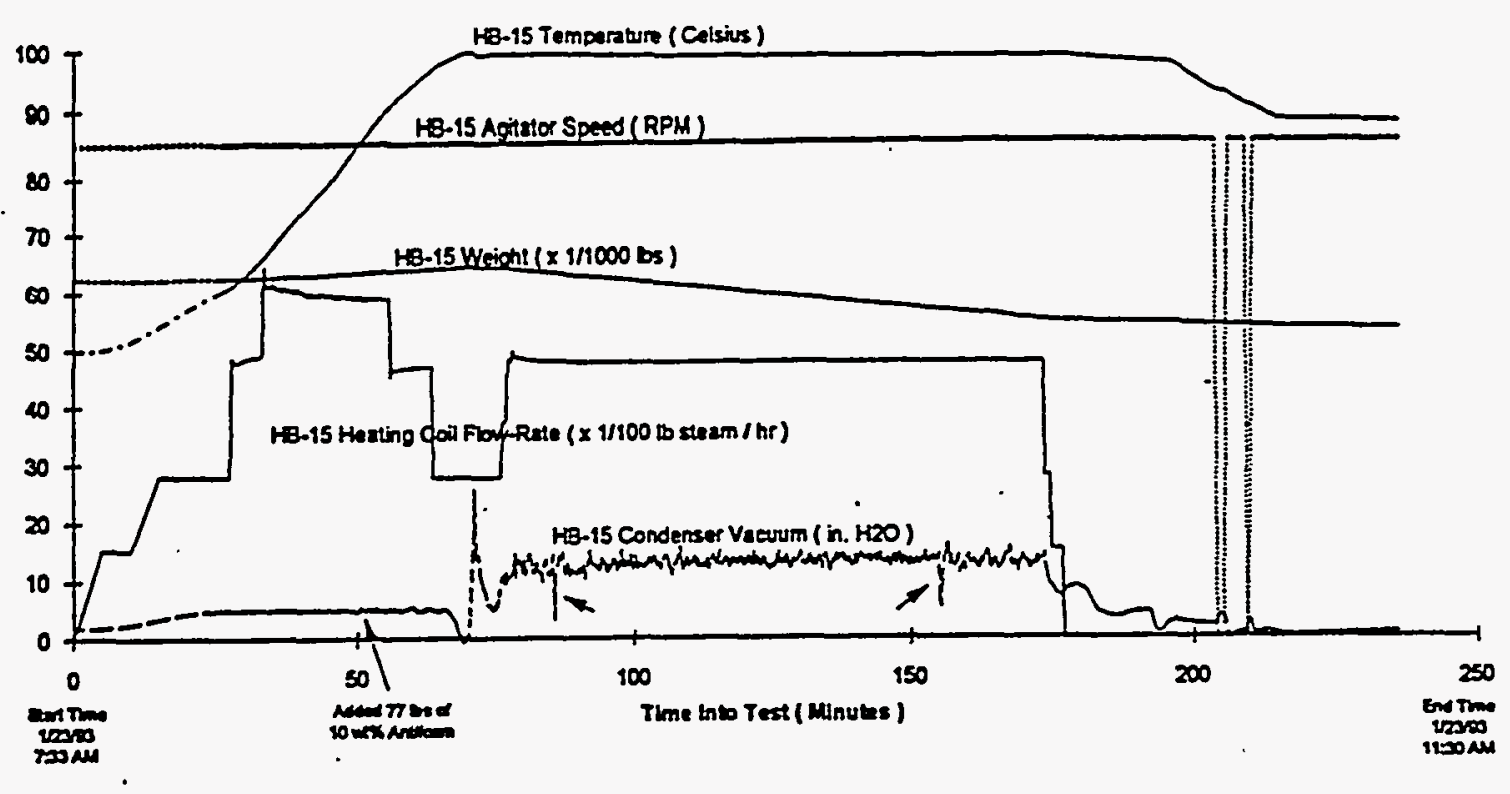

Figure 10.27. High-Tank-Level (7800 gal) Dilute Waste-Simulant Feed Concentration to $5700 \mathrm{Gal}$

Evaporator and Condenser Testing. During this test (January 28, 1993, shown in Figure 10.28), the contents of HB-15 were brought to a boil. The measured steam flow rate to the heating coils was varied from $4900 \mathrm{lb} / \mathrm{h}, 4200 \mathrm{lb} / \mathrm{h}$, and $3300 \mathrm{lb} / \mathrm{h}$. The HB-15 agitator speed also varied from $85 \mathrm{rpm}$, $45 \mathrm{rpm}$, and $125 \mathrm{rpm}$ at a steam flow rate (actual) of $5200 \mathrm{lb} / \mathrm{h}(4200 \mathrm{lb} / \mathrm{h}$, measured). No foaming observations were made at the highest steam flow rate $(5900 \mathrm{lb} / \mathrm{h}$ actual, $4900 \mathrm{lb} / \mathrm{h}$ measured). Additionally, no foaming was observed during variation of the HB-15 agitator speed. However, there were several small pressurization spikes (arrows in Figure 10.28) which may have been the result of foaming.

Condensate samples (Appendix AC, samples SIPT 2-15.1.1 - SIPT 2-15.1.21) taken during this period were analyzed for wt $\%$ solids. Once again, the wt\% solids in these condensate samples were below detection limits.

\subsubsection{High-Tank-Level (7800 gal) Concentrated Waste Simulant}

Waste-Simulant Concentration Before Formic Acid Addition. During this portion of the test (February 2, 1993, shown in Figure 10.29), the contents of HB-15 were concentrated at a heating coil flow rate between 3300 and $4800 \mathrm{lb} / \mathrm{h}$ steam (measured). The tank pressure fluctuated as the slurry foamed. Foam would form, boil up, and then collapse. This cycle repeated itself. Several pressurization spikes (arrows in Figure 10.29) were recorded which coincided with this foaming. No notes were made as to the height of the foam level. As the heating-coil flow rate decreased, the magnitude of tank pressure fluctuations also decreased. 


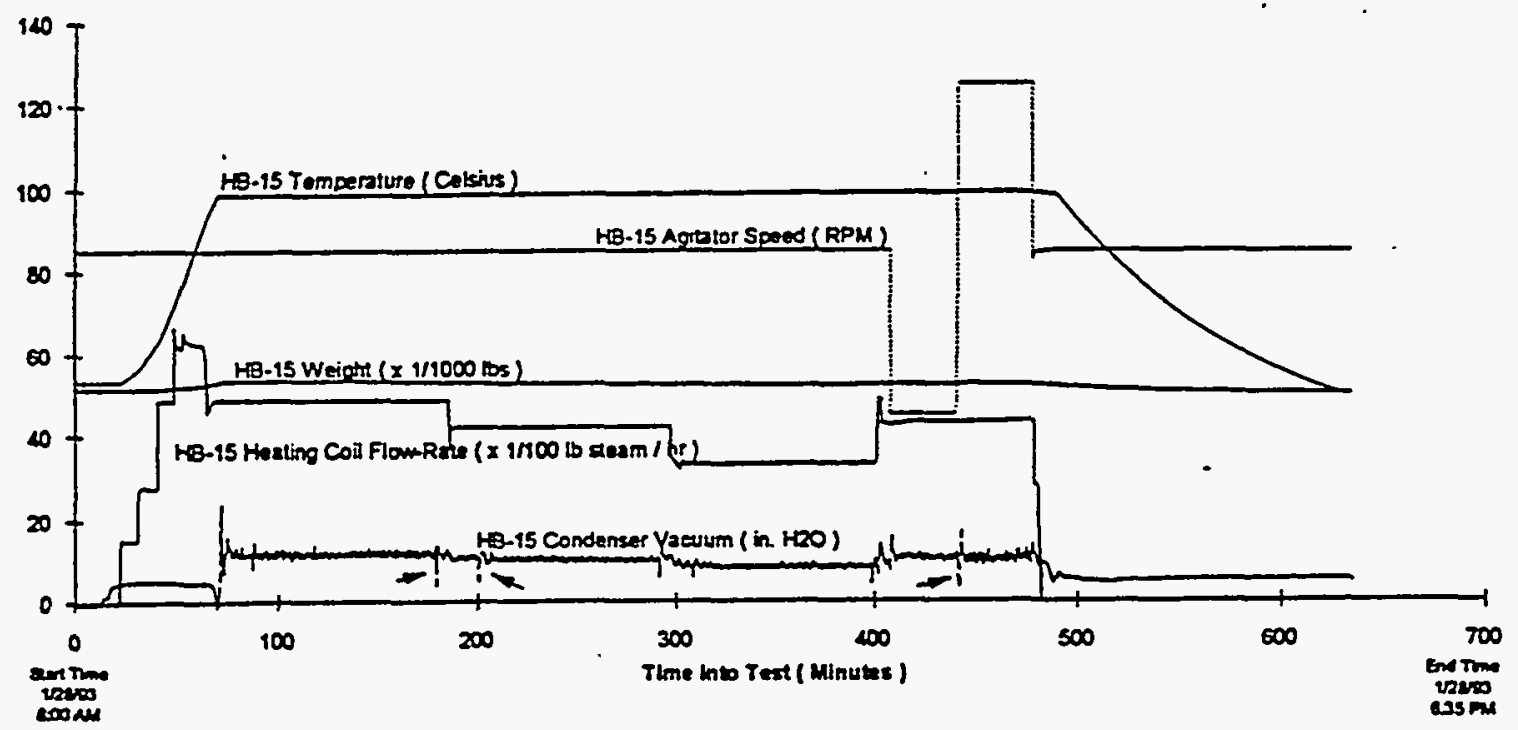

Figure 10.28. Low-Tank-Level (5700 gal) Concentrated Waste-Simulant Evaporator and Condenser Testing

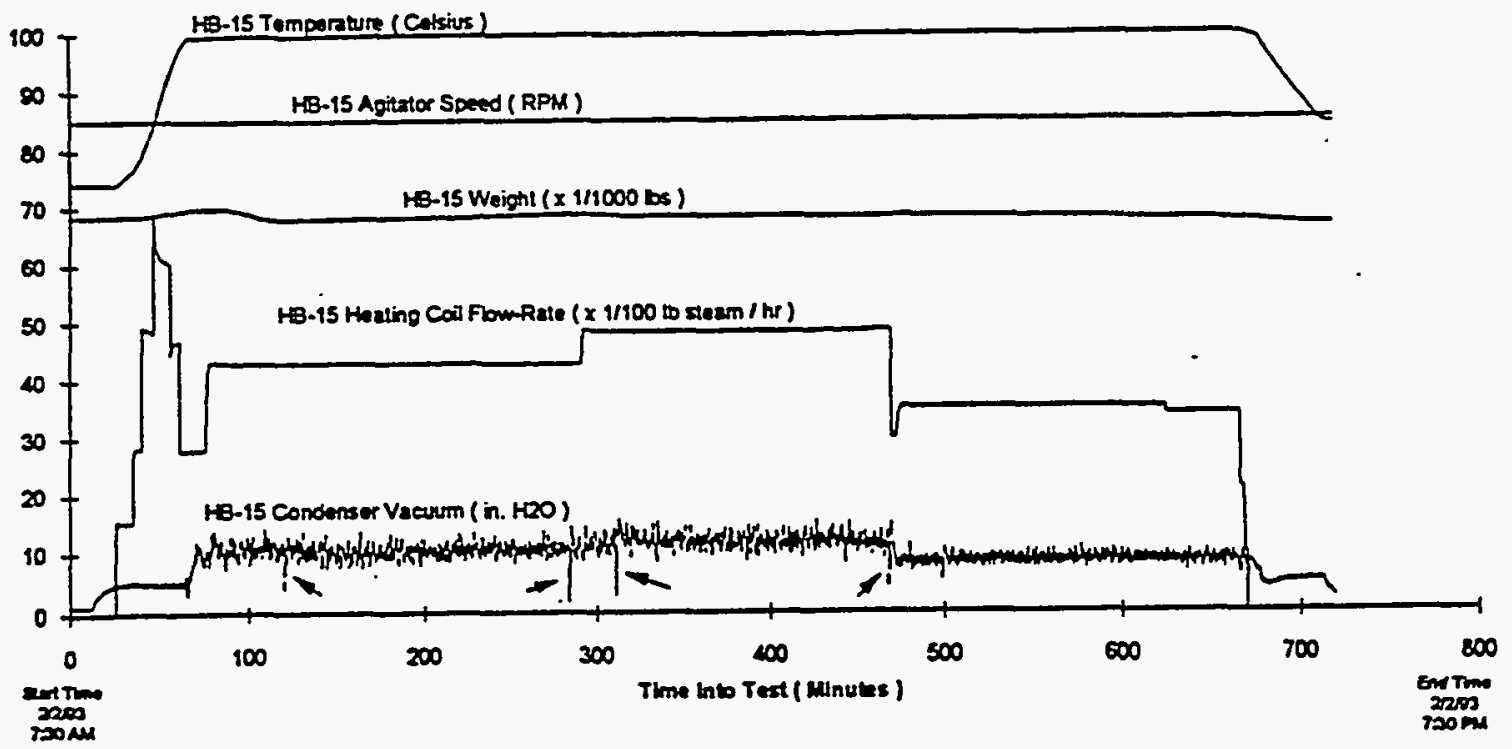

Figure 10.29. High-Tank-Level (7800 gal) Concentrated Waste-Simulant Feed Concentration 
Condensate samples (Appendix AC, samples SIPT 2-16.2.4 - SIPT 2-16.4.7) taken during this period were analyzed for wt\% solids. Again, the wt\% solids in these condensate samples were below detection limits.

\subsubsection{Formatted Waste Simulant $(7400 \mathrm{gal})$}

Formic Acid Addition and Digestion. During this portion of the test (March 10, 1993, and March 11, 1993, shown in Figure 10.30) antifoam was added while raising the tank temperature near boiling $\left(95^{\circ} \mathrm{C}\right)$. Thirty-two hundred pounds ( $\left.7 \mathrm{drums}\right)$ of formic acid were added to the tank, and the tank contents were digested at approximately $100^{\circ} \mathrm{C}$. The formic acid addition and digestion step lasted approximately $12 \mathrm{~h}$. The measured steam flow rate to the HB-15 heating coils was between $1600 \mathrm{lb} / \mathrm{h}$ and $2800 \mathrm{lb} / \mathrm{h}$ during this test. Very slight foaming occurred when formic acid addition started (one in Figure 10.30), then the foaming began to subside to little or no foaming. After about 15 minutes, the camera lens was fouled up; this made foaming very difficult to detect. After completion of the first drum, the pictures began clearing. No foaming was observed at that time. As the second formic acid drum (two in Figure 10.30) was added, a small visible foam layer was observed. While adding the rest of formic acid drums to the tank, the surface bubbled as though it was boiling. There were several pressurization spikes (arrows in Figure 10.30) that may have been the result of foaming, but overall the pressure remained relatively stable throughout rest of the test.

Condensate samples (Appendix AC, samples SIPT 2-21.0.1 - SIPT 2-21.0.21) taken during this period were analyzed for wt\% solids. However, the wt\% solids in these condensate samples were below detection limits.

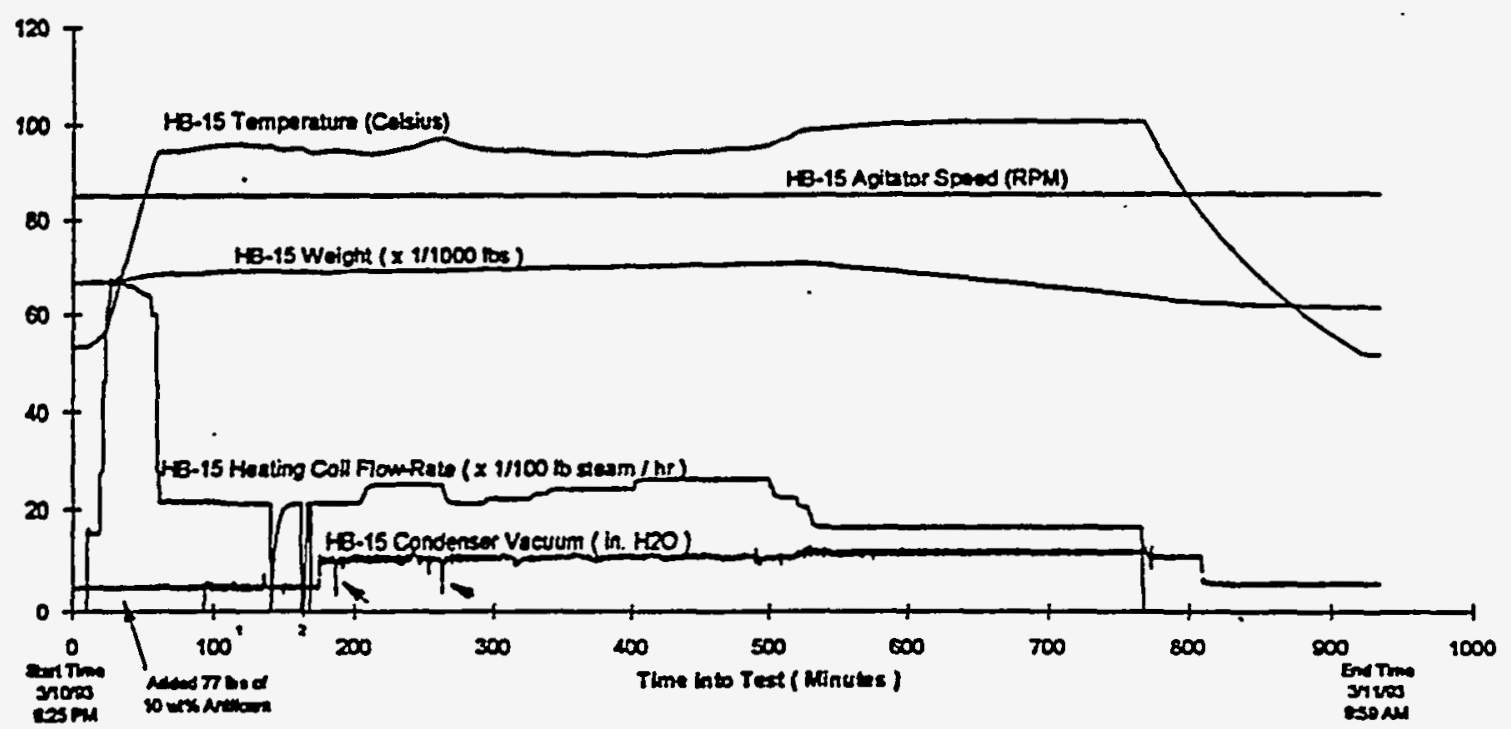

Figure 10.30. Formatted Waste Simulant (7400 gal) Formic Acid Addition 
Formatted Waste Concentration Before Recycle Addition. During this portion of the test (March 23, 1993, shown in Figure 10.31), the tank contents were concentrated for the upcoming melter recycle addition. No antifoam was added and the tank contents were concentrated at a heating coil flow rate of approximately $3800 \mathrm{lb} / \mathrm{h}$ steam (measured). As the test vessel neared boiling $\left(100^{\circ} \mathrm{C}\right)$, the steam flow (measured) was reduced from $6300 \mathrm{lb} / \mathrm{h}$ to $4500 \mathrm{lb} / \mathrm{h}$ to $2700 \mathrm{lb} / \mathrm{h}$ to $1500 \mathrm{lb} / \mathrm{h}$. At $1500 \mathrm{lb} / \mathrm{h}$ steam fiow (measured), a stable foam layer was observed. The steam flow (measured) was then increased to $2000 \mathrm{lb} / \mathrm{h}$. The foam level began rising slowly and stabilized at about 3 to 4 inches higher than achieved at the $1500 \mathrm{lb} / \mathrm{h}$ steam flow (measured). The steam flow (measured) was further increased to $2700 \mathrm{lb} / \mathrm{h}$. The foam layer increased, stabilizing to 4 to 5 inches above the previous level. The tank contents were finally concentrated at a heating coil flow rate of $3800 \mathrm{lb} / \mathrm{h}$ (measured). The foam appeared to be surging. Five minutes later, the foam was still surging. Visibility became very poor as the camera was fouled.

Condensate samples (Appendix AC, samples SIPT 2-24.1.1 - SIPT 2-24.1.9) taken during this period were analyzed for wt\% solids. However, the wt\% solids in these condensate samples were below detection limits.

Samples were also taken from the condensate receipt tank (HB-14); the condensate samples were brown and had approximately $0.4 \mathrm{wt} \%$ solids. It might have been possible that some of the foam had spilled over through the flow line into the tank and this was not measured because the sampling rate of the condensate was not fast enough.

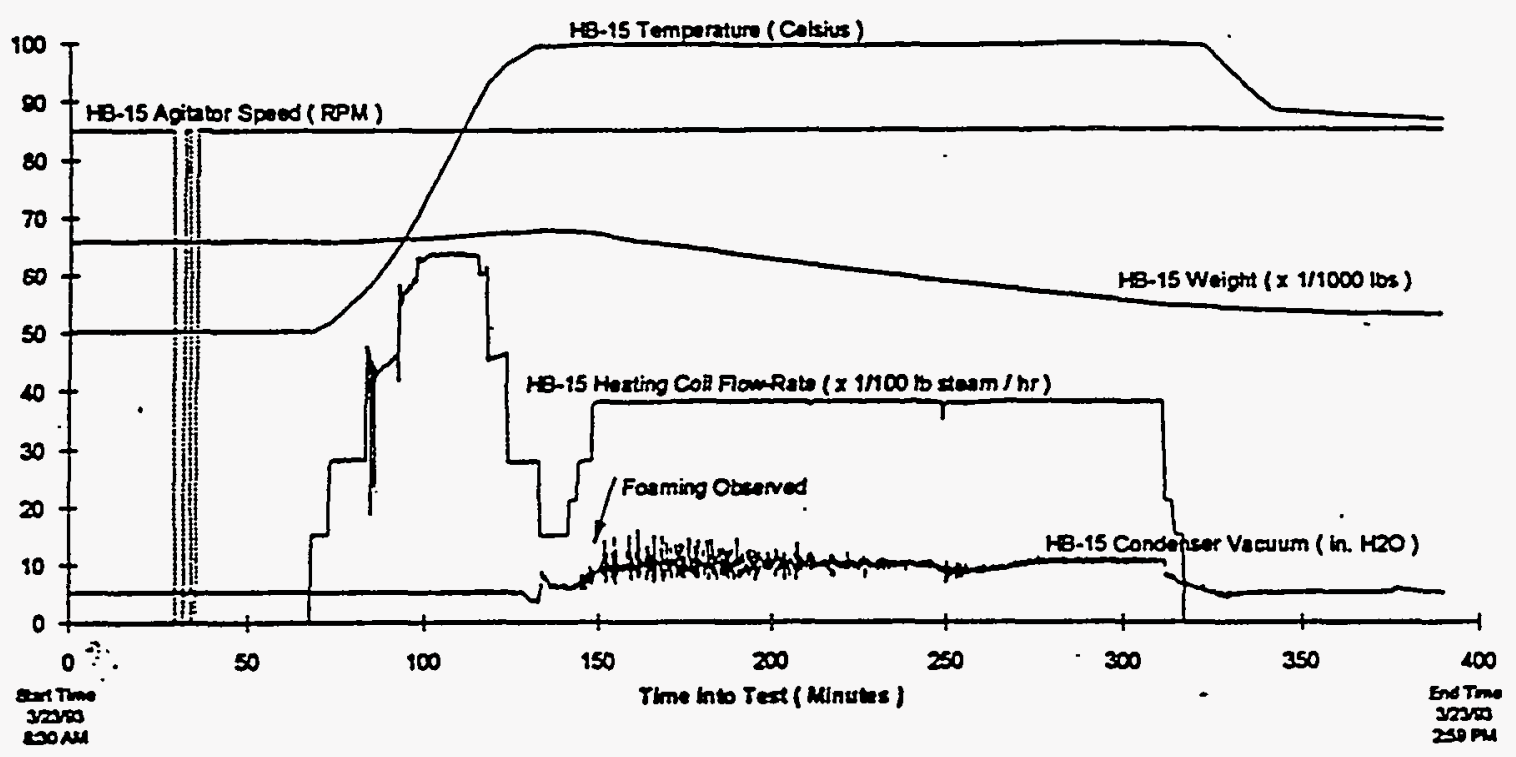

Figure 10.31. Formatted Waste Simulant $(7400 \mathrm{gal})$ Feed Concentration Before Recycle Addition Formatted Waste Concentration Before Recycle Addition 


\subsubsection{Formatted Melter-Feed Waste and Recycle Waste Simulant (6200 gal)}

Formatted/Recycled Waste Simulant Concentration Before Frit Addition. During this portion of the test (April 2, 1993, shown in Figure 10.32) the volume in HB-15 was concentrated by boiling at a heating coil flow rate of approximately $3600 \mathrm{lb} / \mathrm{h}$ steam (measured). No antifoam was added for this concentration. The pressure fluctuated erratically in the first 75 minutes after boiling and then stabilized. The pressure fluctuations may have been the result of fọaming.

Condensate samples (Appendix AC, samples SIPT 2-25.2.1 - SIPT 2-25.2.5) taken during this period were analyzed for wt\% solids. The wit\% solids in these condensate samples had approximately 0 wt\% solids.

Frit Addition. During this portion of testing (April 6, 1993, shown in Figure 10.33), 21,000 lb of frit was added to the feed preparation tank (HB-15). Tank HB- 15 temperature was raised to $95^{\circ} \mathrm{C}$ and $23 \mathrm{gal}$ of formic were added to the tank. The contents were then heated to boiling for $2 \mathrm{~h}$. Foaming was observed in Tank HB-15 just before the contents reached boiling temperature. After $2 \mathrm{~h}$, the steam fiow was suspended, and the tank temperature was allowed to fall.

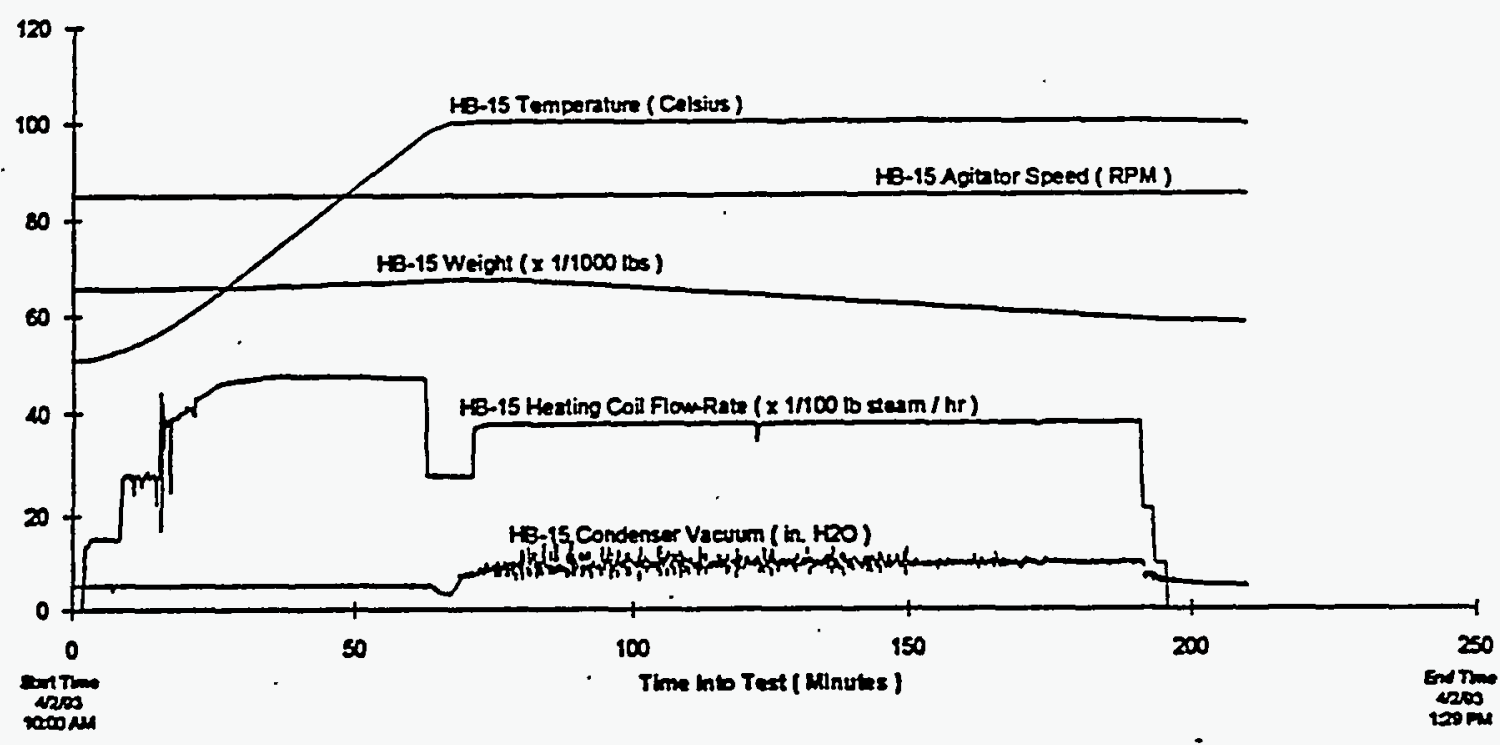

Figure 10.32. Meiter-Feed Waste and Recycle Simulant (6200 gal) Concentration Before Frit Addition 


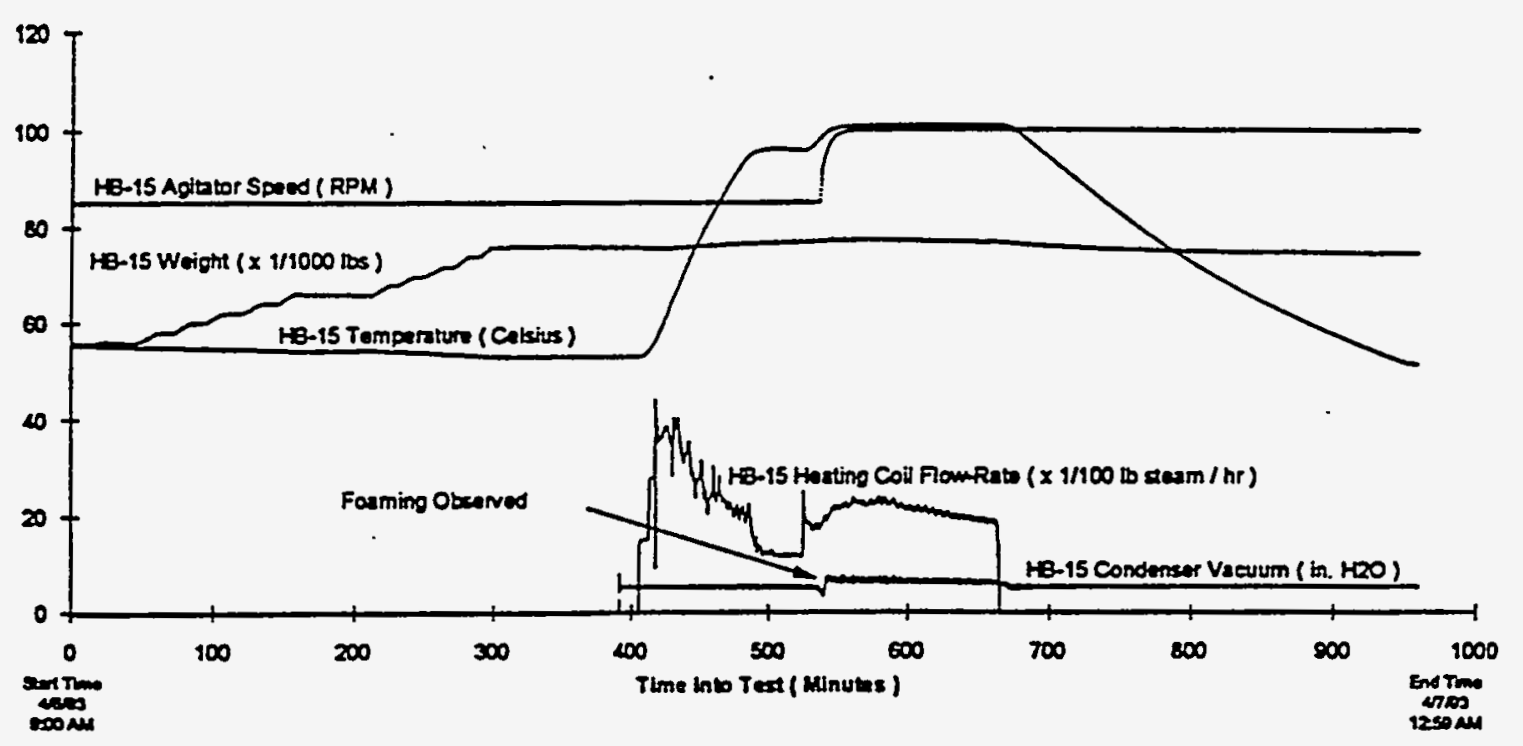

Figure 10.33. Melter-Feed Waste and Recycle Simulant (6200 gal) Frit Addition

\subsubsection{Laboratory Scale Tests}

Laboratory-scale tests of NCAW melter feed were also boiled to study foaming behavior. While boiling the first batch of melter feed, foaming was observed every time the temperature was increased from $100^{\circ} \mathrm{C}$ to $101^{\circ} \mathrm{C}$. It appeared to be a result of the transition to boiling because once the temperature of the slurry reached $101^{\circ} \mathrm{C}$ or higher, boiling was achieved, and foaming was non-existent.

During the second batch, it was observed that when the slurry was near the transition to boiling, very small changes in agitator speed could promote or dissipate foaming (i.e., increases in agitator speed would promote foaming, decreases in agitator speed would dissipate foaming). As condensate collection neared the desired level, the vacuum on the system was eliminated to slow down the rate at which the condensate was being generated. When the vacuum was eliminated, foaming was observed. The foam built up slowly to the one inch level in the vessel. When the vacuum was turned back on, the foam quickly dissipated. When the vacuum was removed, foaming increased slowly again. The tank vacuum was maintained around -0.5 in. of water vacuum.

During the third laboratory-scale study, foaming was also observed as the slurry came to a boil.

\subsubsection{Discussion}

Foaming was usually observed when first bringing the NCAW'waste simulant up to a boil. After subsequently reducing the heating of the tank, foaming was usually controlled or dissipated. Pressurization fluctuations in the tank vacuum may have been the result of foaming or may have mitigated the production of foam. The magnitude of the pressure fluctuations in the tank could be lessened by decreasing the heating-coil flow rate. The foaming in the tank contents (before frit addition) may have 
been stabilized by the fine solids suspended in the simulant 1,2,3. Except for damaging the in-tank camera, foaming occurrences did not interfere with either concentration or formating and digestion operations.

Decontamination factors in the condenser were to be calculated to satisfy data requests. Condensate from the condenser flowed through a line and was stored in a collection tank (HB-14). Grab samples from the condensate line were taken periodically during the testing. These grab samples were tested for $w t \%$ solids by drying the samples at $105^{\circ} \mathrm{C}$. Testing of these grab samples indicated that the solids composition were lower than analytic detection limits in most cases. Because most of the solids entrained in the aerosol should have been scrubbed in the condensate, it is believed that the sampling method of the condensate line was inadequate. A better method of sampling the condensate line would have been to install a filter in the line that would accumulate the solids over a period of time for each test. The inadequacy of the sampling methods was especially apparent from analyzing the samples taken from the condensate collection tank (HB-14). Although condensate line samples contained undetectable solids concentrations, condensate collection tank samples (SIPT 2-24.1.10 - SIPT 2-24.1.12) contained $0.4 \mathrm{wt} \%$ solids. Because of the lack of solids data in the condensate line, solids decontamination factors could not be calculated. However, for the sampling technique used, it appeared that aerosol solids affecting condenser performance was not an issue.

During formating and digestion, Dow Corning 544 Antifoam $^{\oplus}$ was added specifically to control foaming. In addition, the steam flow rate to the tank was lower (measured approximately 2800 to $1600 \mathrm{lb} / \mathrm{h}$ steam) than concentrating tests (measured approximately 3300 to $4800 \mathrm{lb} / \mathrm{h}$ steam). The combination of a lower heating rate and the addition of antifoam successfully controlled foaming and pressure fluctuations in the tank.

Feed concentration of the formatted feed (before recycle addition) had more robust foaming occurrences than the formating and digestion step. This was because the heating rate was higher (measured approximately $3600 \mathrm{lb} / \mathrm{h}$ steam) and that no Dow Corning 544 Antifoam $^{\star}$ was added. Effects of agitation rate and concentration on foaming were not evaluated.

\subsubsection{Conclusions and Recommendations}

The following conclusions and recommendations resulted from the test results and observations:

- Foaming did occur but not to the extent that concentration, formating, and digestion operations were hampered. Foaming was only encountered at higher heating rates and could be controlled by either lowering the heating rate or by adding Dow Corning 544 Antifoam ${ }^{\otimes}$.

- The magnitude of the tank pressure fluctuations increased with increasing heating-coil flow rate. The tank pressure fluctuations could be controlled by lowering the steam flow in the heating coils.

- Solids concentrations were so low in the condensate line that intermittent line sampling methods were inadequate for determining the solids composition in the condensate line. Therefore, solids decontamination factors were not calculated. If these smaller concentrations of solids are still a concern, the condensate line could be sampled with an in-line filter so that solids can be accumulated over longer periods of time. 
- A combination of a lower heating rate and the addition of Dow Corning 544 Antifoam ${ }^{\otimes}$ effectively controls foaming and tank pressure fluctuations.

\subsection{Silver Coating of Feed-Preparation System Components During Testing}

The deposition of silver on testing components are discussed in this section.

\subsubsection{Testing Observations}

After the feed preparation testing was completed, the agitator, cooling coils, and the main transfer pump were removed from the FPTS tank for maintenance and testing purposes. While inspecting the agitator blades, a shiny metallic buildup was noted on each of the blades. One such buildup is shown in Figure 10.34.

As seen from this figure, a razor knife could be used to scrape (or peel) sections of the buildup off of the blades. One of these scrapings was submitted for Inductively Coupled Plasma (ICP) analysis. The results of this analysis showed the material to be comprised of over $99 \%$ (by weight) metallic silver. Similar scrapings were taken from buildups noticed on the lower portions of the tank cooling coils and from the outside of the lower prime/suction lines of the transfer pump (see Figure 10.35). These samples proved to be essentially pure silver as well.

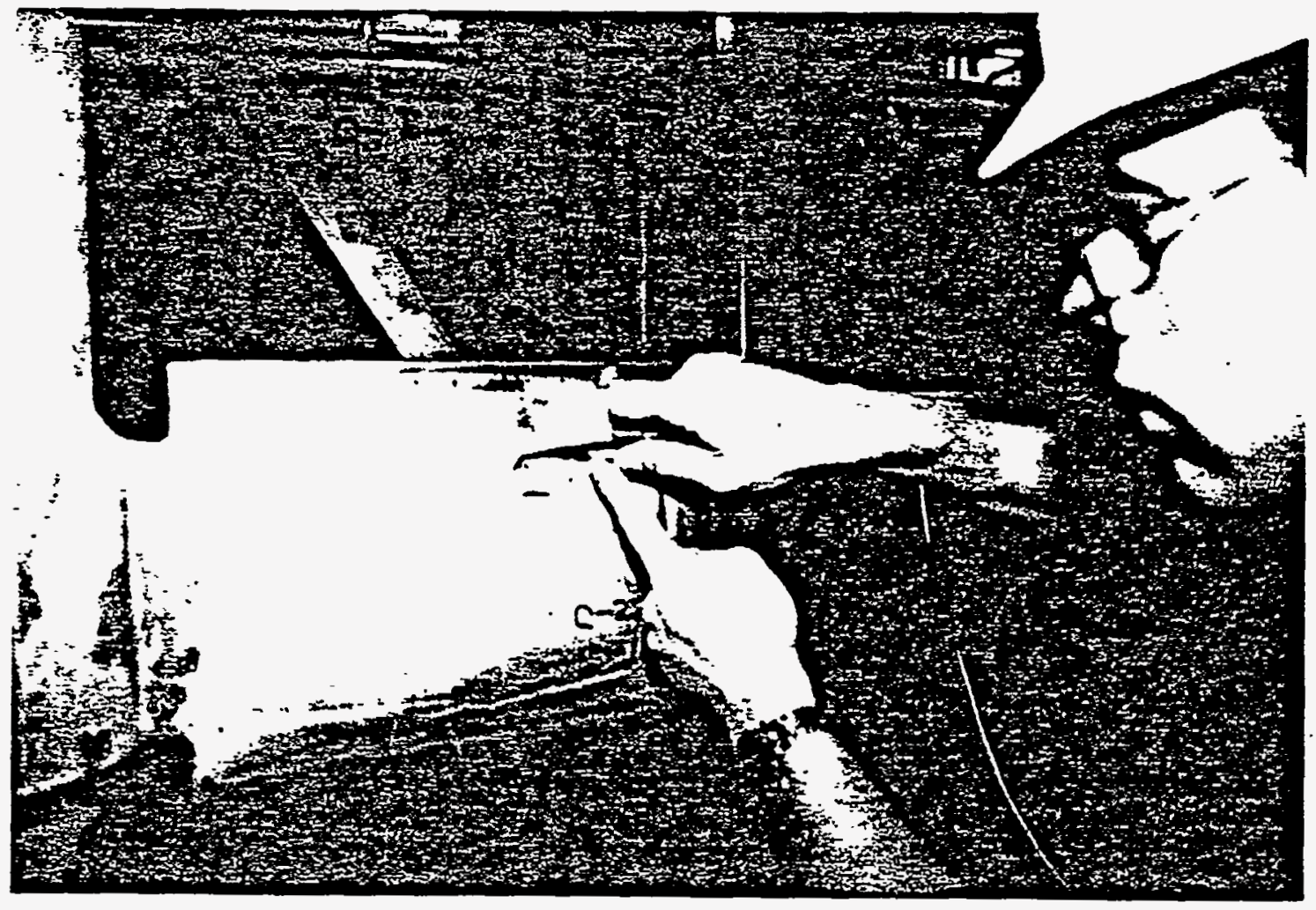

Figure 10.34. Observed Silver Buildup on the Flat-Bladed Impeller 


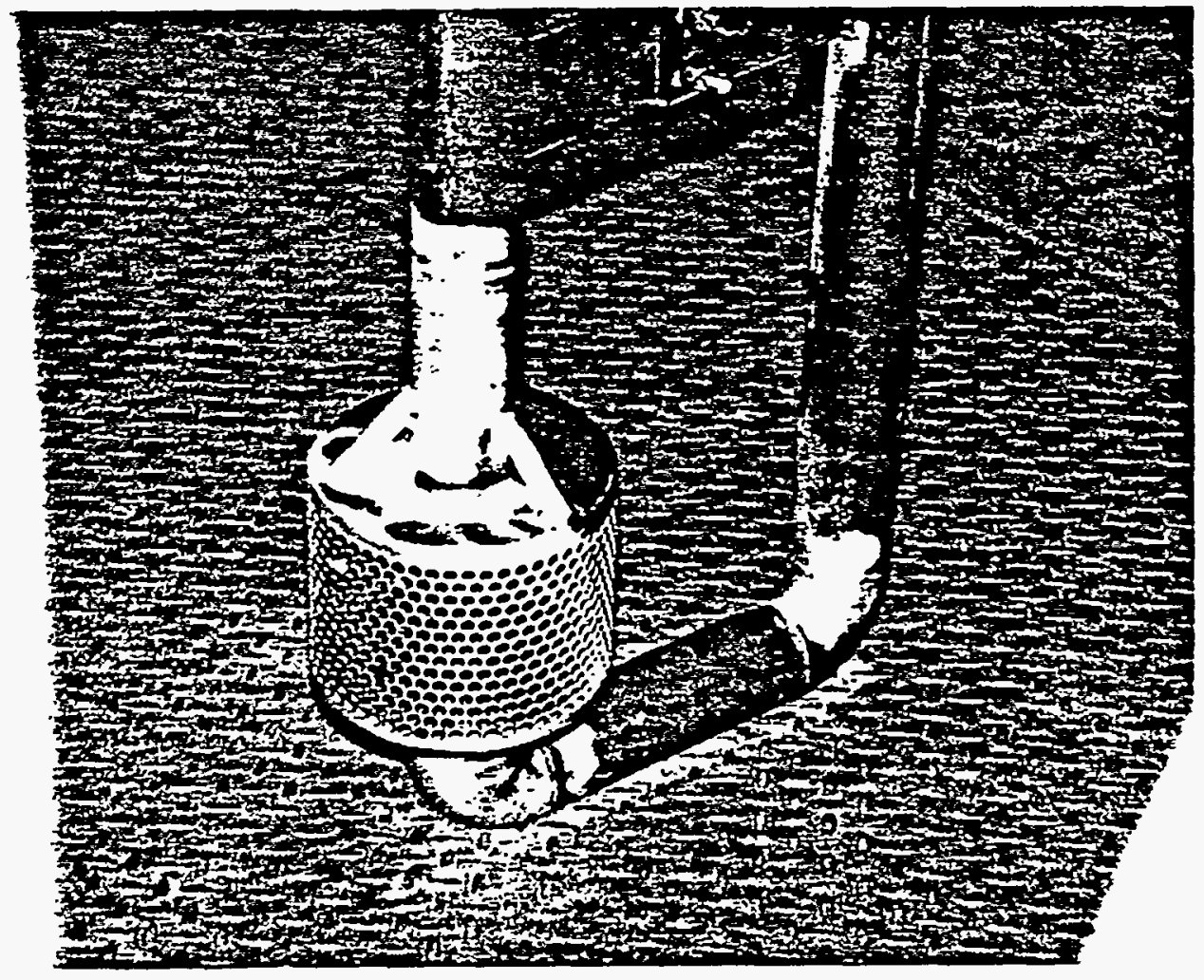

Figure 10.35. Observed Silver Buildup on the Transfer-Pump Intake Section

Figure 10.36 shows a schematic of the feed-preparation tank and internal components along with the areas of observed silver buildup circled. As seen in this figure, all of the silver coatings that were observed occurred in the highly agitated areas within the tank. These areas were mostly around the lower radial agitator impeller. The agitator blades were the first and the largest finding of the accumulated silver. These accumulations were found only on the front impacting sides of the blades. The lower inside portions of the heating and cooling coils, where the slurry is thrown away from the radial impeller, also had silver accumulations. Finally, silver was observed on the transfer pump intake, where the slurry impacted the screen surrounding the intake line. Internal transfer pump impeller samples showed no silver accumulations, suggesting that the silver coating occurred before melter feeding.

\subsubsection{Silver Mass Balance}

Over the duration of the SIPT testing, many samples were taken to verify concèntration and chemical makeup at each of the feed preparation stages. These melter feed preparation stages are listed as follows:

1. Concentrate the simulant to an appropriate solids loading.

2. Add formic acid and "digest" at elevated temperatures for a length of time.

3. Add the recycle stream components.

4. Add the fritted glass formers. 


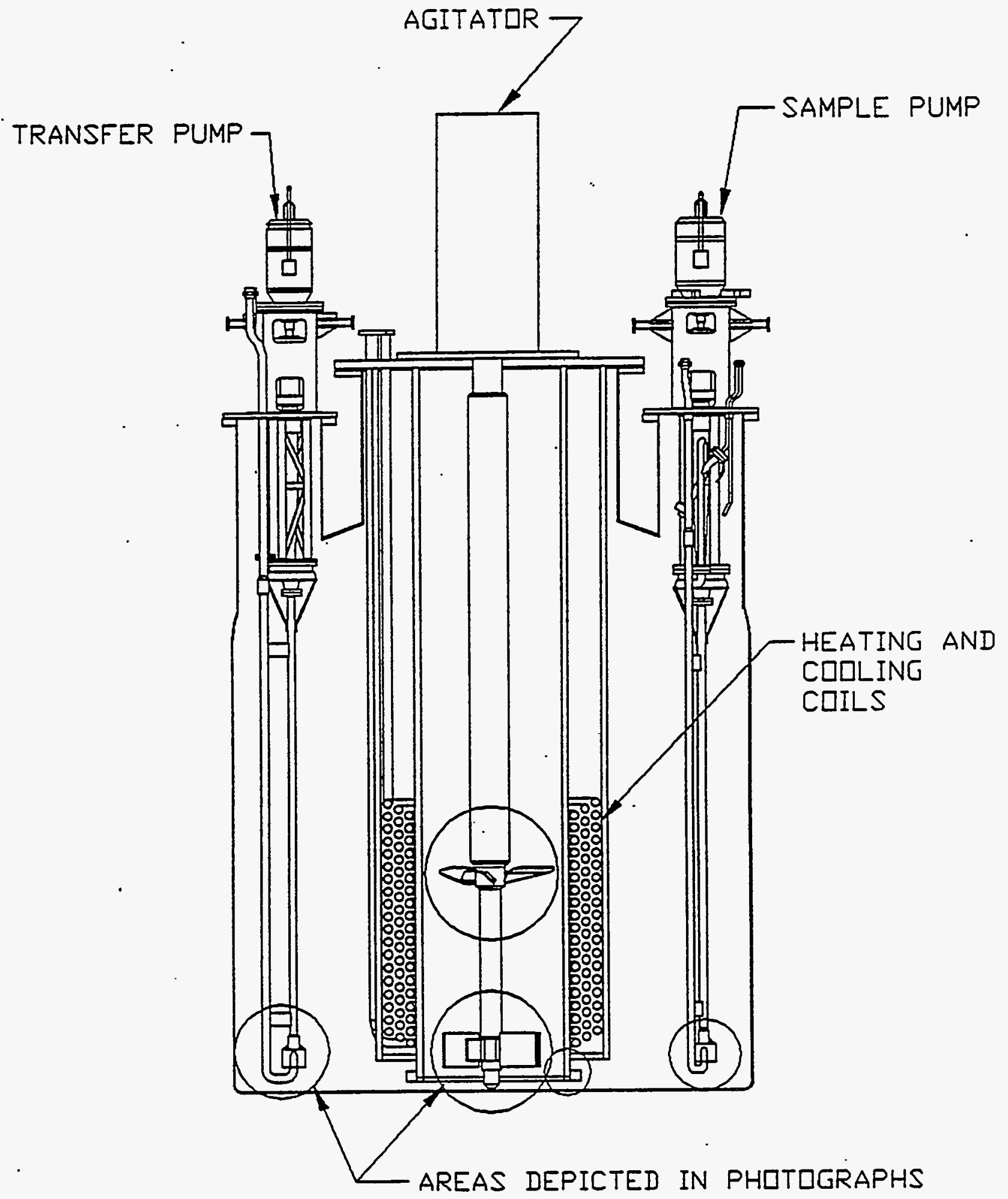

Figure 10.36. Schematic of Specified Regions of Observed Silver Buildup 
Samples taken during each feed-preparation stage were analyzed with ICP for elemental concentration. The NCAW waste simulant used all non-radioactive materials and also excluded the noble metals $(\mathrm{Ru}, \mathrm{Rh}$, and $\mathrm{Pd}$ ). Silver was only present in the waste simulant (as a nitrate) and not added to during any of the other feed preparation stages. Therefore, to quantify the amount of silver reduced during feed preparation, the mass of silver was referenced to other elements which were also only present in the waste simulant and not added to later, during the recycle and frit additions. These elements included lead, neodymium, and lanthanum. This calculational approach was used since the stand alone silver concentrations are dependent on the amount of solids present in the slurry along with the tank volume for each preparation stage, both of which add error to the reported concentrations. The resulting equation used to calculate the decreases in silver is given as follows (with $\mathrm{Nd}$ as the example reference element):

$$
\text { \% Decrease in } \mathrm{Ag}=100 *\left[\frac{\left[\frac{\text { Conc. } \mathrm{Ag}_{\text {Waste Simulant }}}{\text { Conc. } \mathrm{Nd}_{\text {Waste Simulant }}}-\frac{\text { Conc. } \mathrm{Ag}_{\text {After Step } \mathrm{X}}}{\text { Conc. } \mathrm{Nd}_{\text {After Step } \mathrm{X}}}\right]}{\left[\frac{\text { Conc. } \mathrm{Ag} \mathrm{W}_{\text {aste Simulant }}}{\text { Conc. } \mathrm{Nd}_{\text {Waste Simulant }}}\right]}\right]
$$

Table 10.7 shows the concentrations of silver and the reference elements in each of the main feed preparation stages. Additionally, the silver losses calculated with the above equation are shown at the right side of the table.

The data in Table 10.7 shows that the most significant decrease in silver occurred after formic acid was added and digested. The average loss of silver after this step was around $20 \%$. This value did not change drastically in the next two steps; the small deviations were most likely due to ICP interferences from concentration changes and the newly added recycle and frit materials.

\subsubsection{Conclusions}

Electrochemical plating was originally thought to be a potential mechanism for the silver accumulations. The fact that the tank was constructed with Carpenter-20 alloy and the agitator, coils, and pumps with $304 \mathrm{~L}$ stainless steel was thought to be the driving force behind the plating. However, since the silver mass balance showed a drastic reduction in silver concentration after formating, and not a gradual decrease with time, electrochemical plating was discounted as being the primary means for the observed accumulations.

The most likely scenario for causing the silver accumulations in the tank is that the silver in the waste simulant reduced to its metallic form during formating and digestion. Once these reduced metallic silver nodules were impacted by the tank impellers, or were thrown to impact the coils or 
Table 10.7. Calculated Decrease in Silver from the Waste Simulant During Feed Preparation

\begin{tabular}{|c|c|c|c|c|c|c|c|c|}
\hline & \multicolumn{4}{|c|}{ Mersured Concentrations (wt\%) } & \multicolumn{4}{|c|}{ Total Silver Decrease (wt $\%$ ) } \\
\hline & $\mathrm{Ag}$ & $\mathrm{Pb}$ & Nd & La & $\mathrm{Pb}$ Basis & Nd Basis & La Basis & Average \\
\hline Concentrated Waste Simulant & 0.01 & 0.08 & 0.38 & 0.08 & & & & \\
\hline Formatted Waste Simulant & 0.01 & 0.09 & 0.41 & 0.09 & 23.8 & 22.0 & 19.4 & 21.7 \\
\hline After Recycle Addition & 0.01 & 0.08 & 0.40 & 0.09 & 24.0 & 27.9 & 26.7 & 26.2 \\
\hline Melter Feed & 0.01 & 0.08 & 0.35 & 0.07 & 19.1 & 18.3 & 15.8 & 17.7 \\
\hline
\end{tabular}

other tank components, they stuck to those impact points and remained throughout the rest of the testing. This would explain the accumulations of silver only in the high velocity wear areas of the system components. Based on the amount of observed silver reduction, the reduction of noble metais certainly seems likely if those elements were also present in the waste.

\subsection{Comparison of Bench-Scale and Full-Scale Formating and Digestion Process Behavior}

A bench-scale simulation of the full-scale SIPT was performed. The data contains results produced during the formating and digestion of NCAW simulant without noble metais with the same composition as used in the full-scale test.

The full-scale simulation of the SIPT test differed from previous bench-scale tests (Test No. $1.16-2)^{(a)}$ because the $\mathrm{HCOOH}$ was added in seven batch additions as opposed to continuously and at a slower equivalent rate of $\sim 1.2 \mathrm{gpm}$. The formic acid addition rate during previous bench-scale tests has been an equivalent of $-2 \mathrm{gpm}$ in full-scale. In the full-scale SIPT the formic acid was added from 55 gal drums, so a time lag occurred between drum changes. During these time intervals, offgas generation rates, $\mathrm{pH}$, and temperature were affected. The full-scale test also differed from previous bench-scale tests $^{(b)}$ in that condensate refiuxed back into the test vessel during formating. The condensate from bench-scale testing refluxed (when not taking samples) during formating and collected during digestion.

(a) Smith, H. D., K. D. Wiemers, M. H. Langowski, M. R. Powell, and D. E. Larson. September 1993. Evaluation of HWVP Feed Preparation Chemistry for an NCAW Simulant - Fiscal Year 1992: Evaluation of Offgas Generation and Ammonia Formation. Technical Report to Westinghouse Hanford Company, Milestone PHTD-C93-03.02b, Pacific Northwest Laboratory, Richland, Washington.

(b) Wiemers, K. D., M. H. Langowski, M. R. Powell, and D. E. Larson. 1993. Evaluation of HWVP Feed Preparation Chemistry for an NCAW Feed Simulant - Fiscal Year 1991: Evaluation of Offgas Generation, Reductant Requirements, and HWVP NCAW Feed Simulant. Technical Report to Westinghouse Hanford Company, PHTD-C91-03.02C, Pacific Northwest Laboratory, Richland, Washington. 


\subsubsection{Testing Approach}

The bench-scale feed-preparation test was designed to duplicate the full-scale SIPT process test. The bench-scale test formating time schedule closely followed the SIPT while the total amount of formic acid added and the addition rate were scaled down based on total volume. The $7400 \mathrm{gal}$ (28012L) of NCAW simulant used in the SIPT test were scaled down to $1.5 \mathrm{~L}$ in the bench-scale test at $-140 \mathrm{~g}$ waste oxides (gwo) per liter.

A summary of the bench-scale key test variables are listed in Table 10.8. Full-scale variables are shown for comparison. Table 10.9 indicates the formating equipment physical differences between full-scale and bench-scale.

Table 10.8. Summary of Test Variables

\begin{tabular}{|c|c|c|}
\hline & Bench-Scale & Full-Scale \\
\hline Pre-Formating Slurry Volume & $1.5 \mathrm{~L}$ & $28012 \mathrm{~L}$ \\
\hline $\begin{array}{l}\text { Pre-Formating } \mathrm{pH}\left(\text { at } 95^{\circ} \mathrm{C} \text { ) }\right. \\
\text { Post-Formating } \mathrm{pH} \\
\text { Test pH Range }\end{array}$ & $\begin{array}{l}9.35 \\
5.78 \\
4.32 \text { to } 9.35\end{array}$ & $\begin{array}{l}9 \\
5.5 \\
4.5 \text { to } 9\end{array}$ \\
\hline Amount of $90 \mathrm{wt} \%$ Formic Acid & $64.73 \mathrm{~mL}$ & $1213.2 \mathrm{~L}$ \\
\hline $\begin{array}{l}\text { Formic Acid Addition Rate } \\
\text { Normalized Target Rate }\end{array}$ & $\begin{array}{l}0.25 \mathrm{~mL} / \mathrm{min} \\
0.243 \mathrm{~mL} / \mathrm{min}\end{array}$ & $\begin{array}{l}\text { 4.54 Lpm per drum } \\
\text { 3.03 Lpm over test }\end{array}$ \\
\hline Lag time between batch additions & 8 to $30 \mathrm{~min}$ & 8 to $30 \mathrm{~min}$ \\
\hline $\begin{array}{l}\text { HCOOH addition line flush water; } \\
\text { total added }\end{array}$ & $\begin{array}{l}2 \text { to } 3 \mathrm{~mL} \\
\sim 17.5 \mathrm{~mL} \text { total }\end{array}$ & $\begin{array}{l}5 \text { to } 10 \mathrm{~L} \\
-37 \text { to } 75 \mathrm{~L} \text { total }\end{array}$ \\
\hline Formating Temperature & $95^{\circ} \mathrm{C} \pm 3^{\circ} \mathrm{C}$ & $95^{\circ} \mathrm{C} \pm 2.6^{\circ} \mathrm{C}$ \\
\hline Digestion Temperature & $100^{\circ} \mathrm{C} \pm 3^{\circ} \mathrm{C}$ & $100^{\circ} \mathrm{C} \pm 1.3^{\circ} \mathrm{C}$ \\
\hline $\begin{array}{l}\text { Test Phase Schedules: } \\
\text { HCOOH addition } \\
\text { Heated up to } 100^{\circ} \mathrm{C} \\
\text { Digestion }\end{array}$ & $\begin{array}{l}0 \text { to } 390 \mathrm{~min} \\
415 \text { to } 445 \mathrm{~min} \\
445 \text { to } 681 \mathrm{~min}\end{array}$ & $\begin{array}{r}0 \text { to } 394 \mathrm{~min} \\
405 \text { to } 434 \mathrm{~min} \\
430 \text { to } 672 \mathrm{~min}\end{array}$ \\
\hline
\end{tabular}

Note: A brief temperature drop to $87^{\circ} \mathrm{C}$ during digestion was caused by the addition of water to bring the slurry volume up which had decreased due to a series of leaks digestion. 
Table 10.9. Formating Equipment/Test Condition Differences Between Full-Scale and Bench-Scale Tests

Batch Size

Sweep Gas/Dilution Gas

Total Carrier Gas Flow Rate

Vessel Geometry (Head

Space/Slurry Volume Ratio)

Slurry Surface Area/Slurry

Volume Ratio

Stirrer (Mixing)

Temperature Control

Analyzers
Full-Scale

Full-Scale

28012 L

-5 in. $\mathrm{H}_{2} \mathrm{O}$ vacuum

$115 \mathrm{ACFM}^{(\mathrm{a})}$

0.606

$35.0 \mathrm{~m}^{-1}$

HB-15 Agitator ( $~ 85 \mathrm{rpm})$

Heating Coils (immersed in slurry)

GC

Chemiluminescence

(NO/NO ${ }_{x}$ )

IR Detectors

Mass Spectrometer
Bench-Scale

$1.5 \mathrm{~L}$

0.2\% He in an Argon mixture pushed over surface

$1.95 \operatorname{slpm}^{(b)}$

0.33

$17.0 \mathrm{~m}^{-1}$

Propeller/Rod Agitator

Heating Mantle (no contact with slurry)

GC

Chemiluminescence

(NO/NO $)$

(a) ACFM - Actual cubic feet per minute.

(b) slpm - Standard liter per minute.

One and one half liters of NCAW simulant (from the same batch that was used for the SIPT) at $\sim 140 \mathrm{gwo} / \mathrm{L}$ were heated to $95^{\circ} \mathrm{C} \pm 3^{\circ} \mathrm{C}$ in the test vessel. A volume normalized amount $(10.0 \mathrm{~mL})$ of Dow Corning anti-foam ${ }^{\oplus}$ agent was added to the test vessel to duplicate full-scale testing. Sixty five $\mathrm{mL}$ of $90 \mathrm{wt} \%$ formic acid was added at an average rate of $0.24 \mathrm{~mL} / \mathrm{min}$. Both the addition rate and the volume of $90 \mathrm{wt} \%$ formic acid had been volume normalized to correlate with full-scale conditions. The $\mathrm{HCOOH}$ acid was added in seven batch additions with time lapses varying between 8 and $30 \mathrm{~min}$. The time lapses were included to simulate lapses which occurred during full-scale testing. During bench-scale testing, deionized water was added during the time lapses to simulate the rinse water additions. The $\mathrm{HCOOH}$ addition rate and cumulative $\mathrm{HCOOH}$ added are shown in Figures 10.37 and 10.38 for bench-scale and full-scale, respectively. The actual amount of HCOOH added during the pilot-scale test was 320.5 gal. Figure 10.37 shows the cumulative formic acid added to the full-scale system is approximately $330 \mathrm{~g}$. This value includes flush water added between drum 


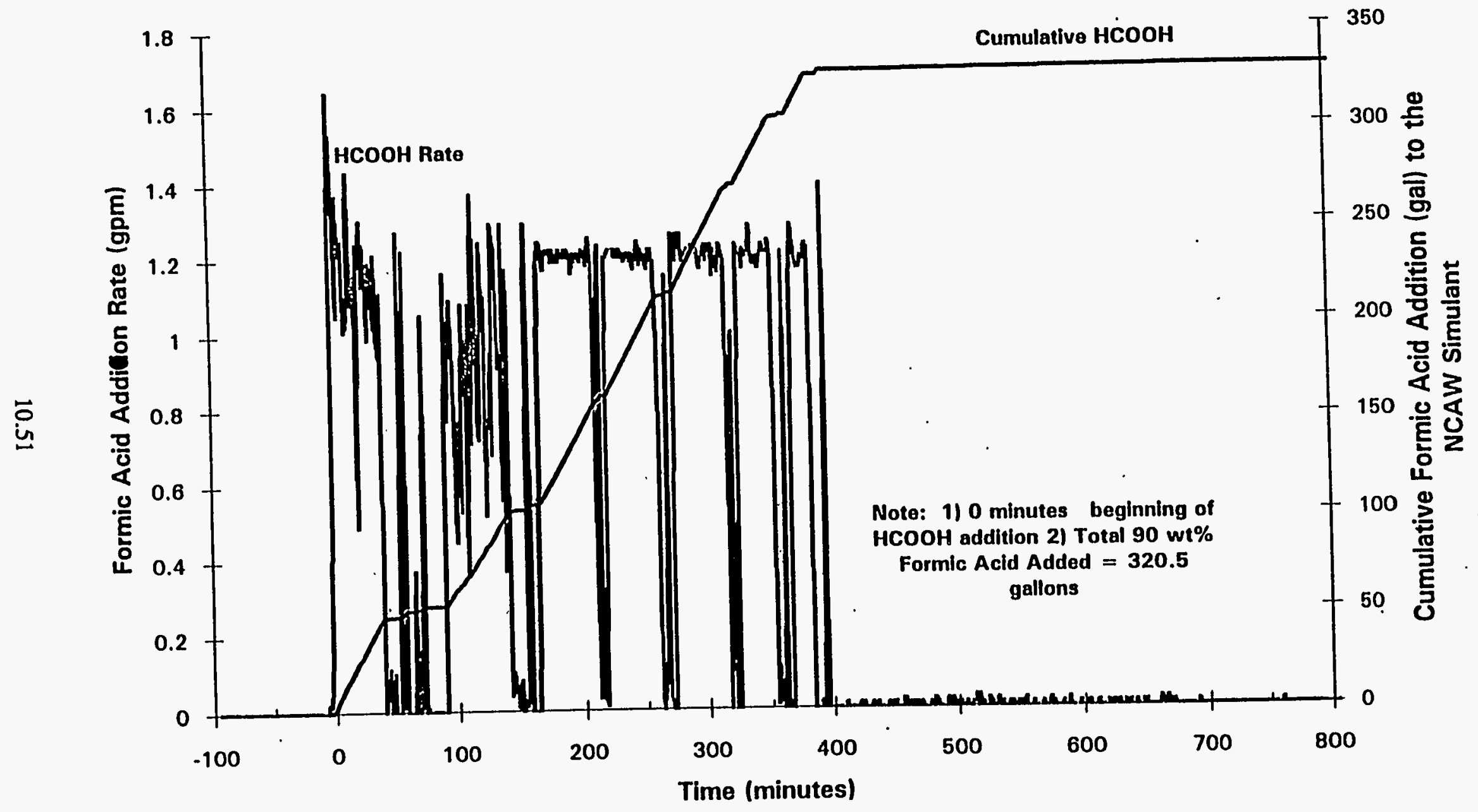

Figure 10.37. SIPT Formic Acid Addition Rate and Amount as a Function of Process Time 


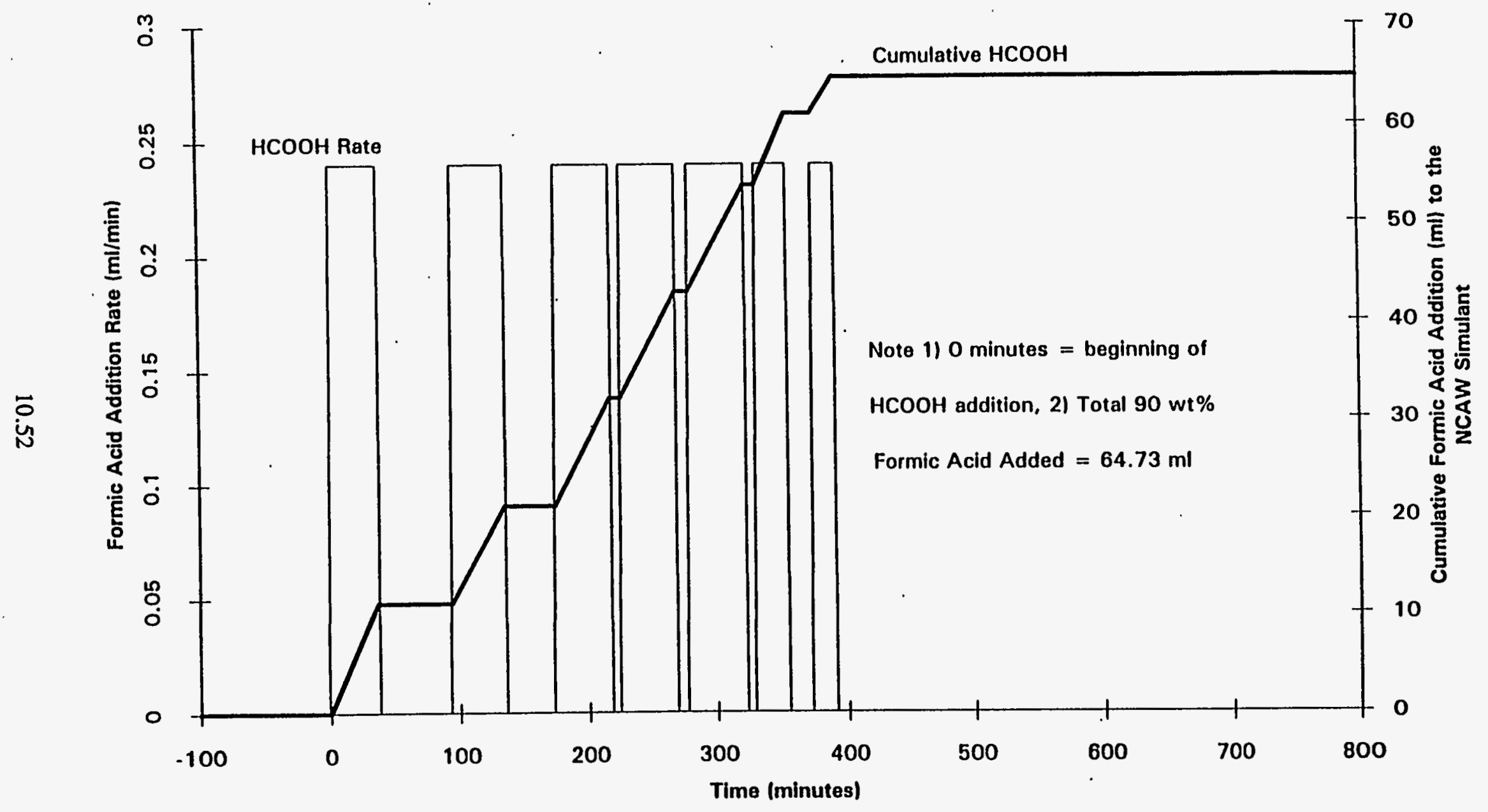

Figure 10.38. Bench-Scale: Formic Acid Addition Rate and Amount as a Function of Process Time 
additions. A comparison (normalized to a one liter batch at $140 \mathrm{gwo} / \mathrm{L}$ ) of the cumulative $\mathrm{HCOOH}$ added for bench-scale and full-scale (SIPT) is shown in Figure 10.39.

The temperature and $\mathrm{pH}$ profiles during formic acid addition and digestion are shown in Figures 10.40 and 10.41 , respectively. These temperature and $\mathrm{pH}$ profiles for the bench-scale simulation are compared to the results produced during the full-scale SIPT test.

The smaller volume of slurry and mixing efficiency of bench-scale testing resulted in greater temperature fluctuations throughout the test and a more rapid temperature drop after the set point was lowered to $50^{\circ} \mathrm{C}$. The condensate refluxed (when not taking samples) during formating and collected during digestion. After formating, the slurry (in both experiments) was heated to $100^{\circ} \mathrm{C}$ and boiled/digested for 4 hours. Following digestion, the slurry was cooled $50^{\circ} \mathrm{C}$.

The bench-scale $\mathrm{pH}$ in Figure 10.41 closely follows the full-scale $\mathrm{pH}$, but tends to respond quicker (i.e., pH drops faster) to formic acid additions during formating. This is probably due to better mixing in the smaller vessel. It is also possible that the $\mathrm{HCOOH}$ used in bench-scale may have been siightly more concentrated than that used in full-scale. The $\mathrm{pH}$ rises and falls due to formic acid addition stops and starts, respectively. The slurry was thus observed to exhibit a buffering phenomenon when formic acid addition was interrupted. After digestion was completed and the temperature set point was decreased to $50^{\circ} \mathrm{C}$, the bench-scale $\mathrm{pH}$ rose significantly faster than the full-scale $\mathrm{pH}$. This corresponds directly to the difference in cooling rates seen during this same time period.

The bench-scale test used Ar as the sweep gas, so that data generated would be compatible and comparable with previous bench-scale data. Had air been used as the sweep gas, it is believed that the condensate generated would have contained significant nitrate and/or nitrite. However, the amount of condensate, and any nitrate or nitrite contained in the condensate, would probably not be scalable because the condenser arrangement is different for full-scale than it is with bench-scale.

Steam leaks developed in the seals of the reaction vessel after $500 \mathrm{~min}$ and for the remainder of the bench-scale test. Because the reaction vessel was under positive pressure, air was. not introduced into the sample. However, the leaks did cause premature drying of the sample necessitating multiple additions of deionized water. At the time the leaks occurred, the majority of the offgas had been generated, and the impact to offgas was estimated to be minimal ( $<5 \%)$.

Two major variances from the SIPT procedures were used for the bench-scale off-gas testing. First, Argon was used as a sweep gas for the bench-scale test. In the full-scale testing, air was used as the sweep gas. The second variance was that the bench-scale apparatus was equipped with two condensers, while the full-scale setup used one condenser which was of a different design than the benchscale condensers. Both of these changes affect the total amount $\mathrm{NO}_{\mathrm{x}}$ measured in the offgas but should not affect a nitrogen mass balance. The formic acid reaction with $\mathrm{NaNO}_{2}$ in the slurry generates $\mathrm{NO}$ (Reaction 10.1) (a) which reacts with $\mathrm{O}_{2}$ to form $\mathrm{NO}_{2}$ (Reaction 10.2). The $\mathrm{O}_{2}$ is present in much larger quantities if air is used as the sweep gas versus argon. The $\mathrm{NO}_{2}$ that is produced in the reaction

(a) NO is also produced by disproportionation according to $3 \mathrm{HNO}_{2} \rightarrow \mathrm{H}^{+}+\mathrm{NO}_{3}^{+}+2 \mathrm{NO}+\mathrm{H}_{2} \mathrm{O}$. 


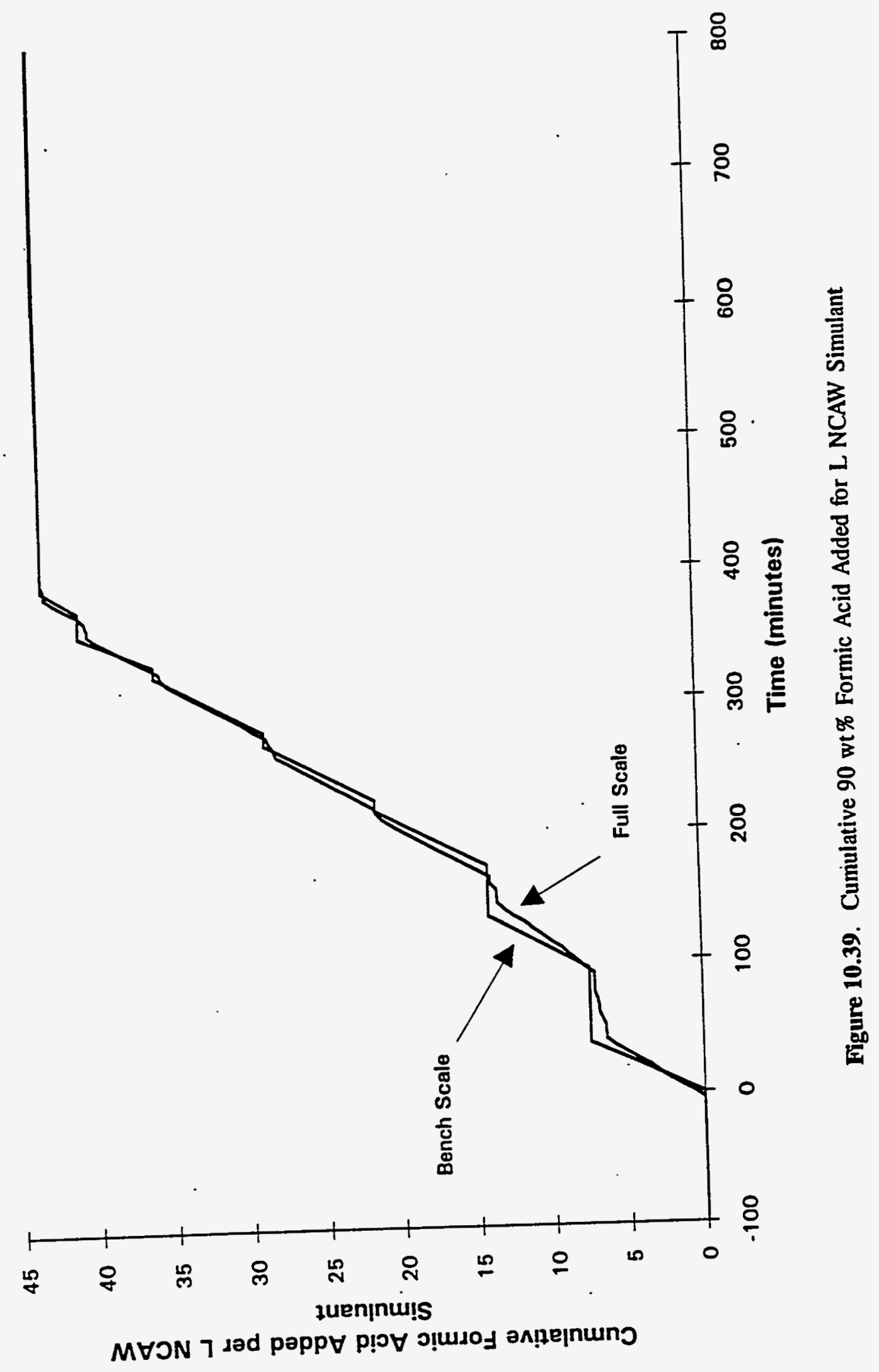




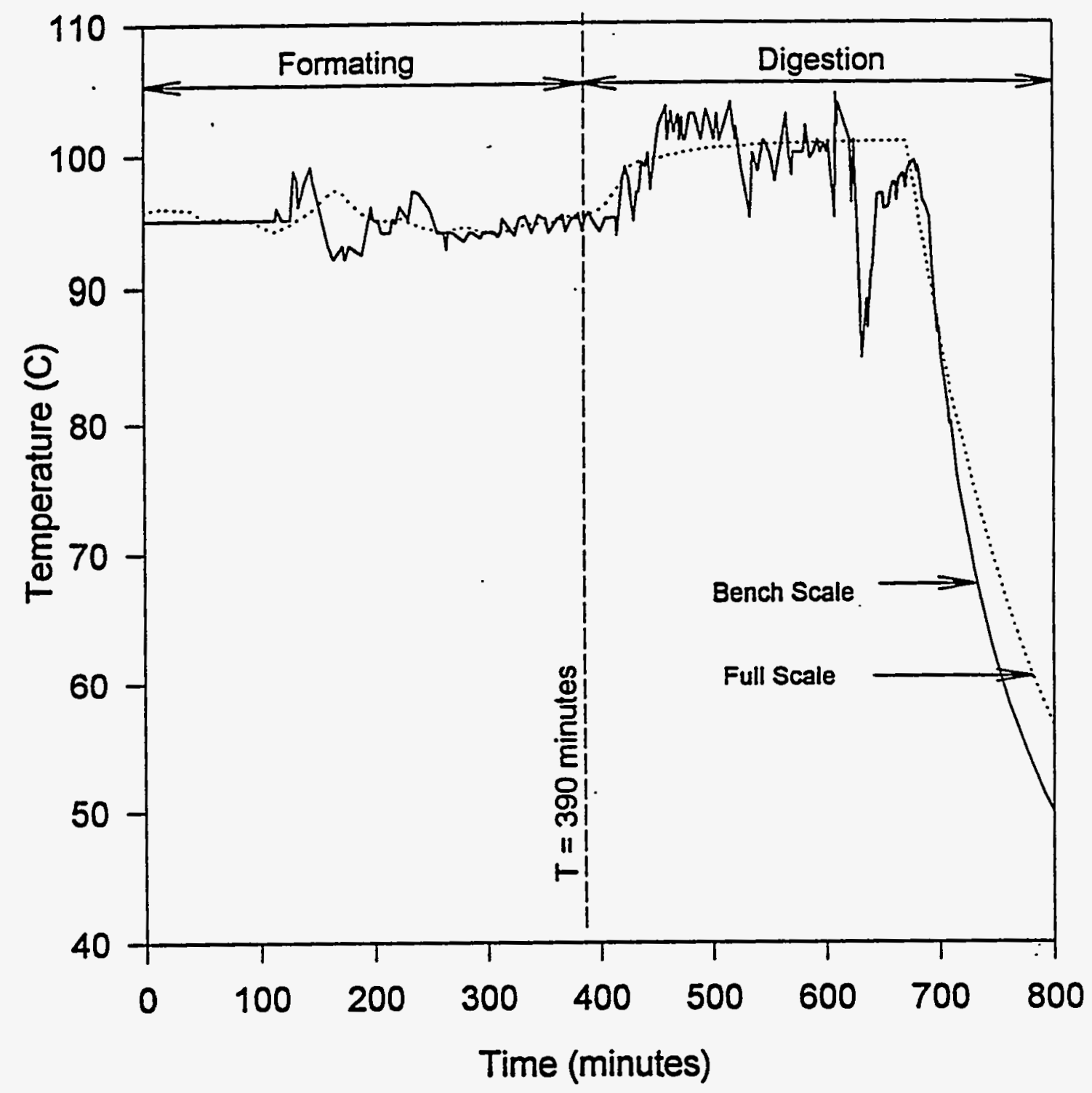

Figure 10.40. Time Versus Temperature (during formating and digestion)

with $\mathrm{O}_{2}$ subsequently reacts with water to form nitrous acid $\left(\mathrm{HNO}_{2}\right)$ which is soluble and collected in the condensate. Therefore, in a high oxygen environment, the amount of $\mathrm{NO}_{\mathrm{x}}$ in the offgas will be reduced as the nitrate or nitrite in the condensate is increased.

$$
2 \mathrm{NaNO}_{2}+3 \mathrm{HCOOH} \rightarrow 2 \mathrm{NO}+\mathrm{CO}_{2}+2 \mathrm{NaCOOH}+2 \mathrm{H}_{2} \mathrm{O} \text { (Hsu 1990) }
$$




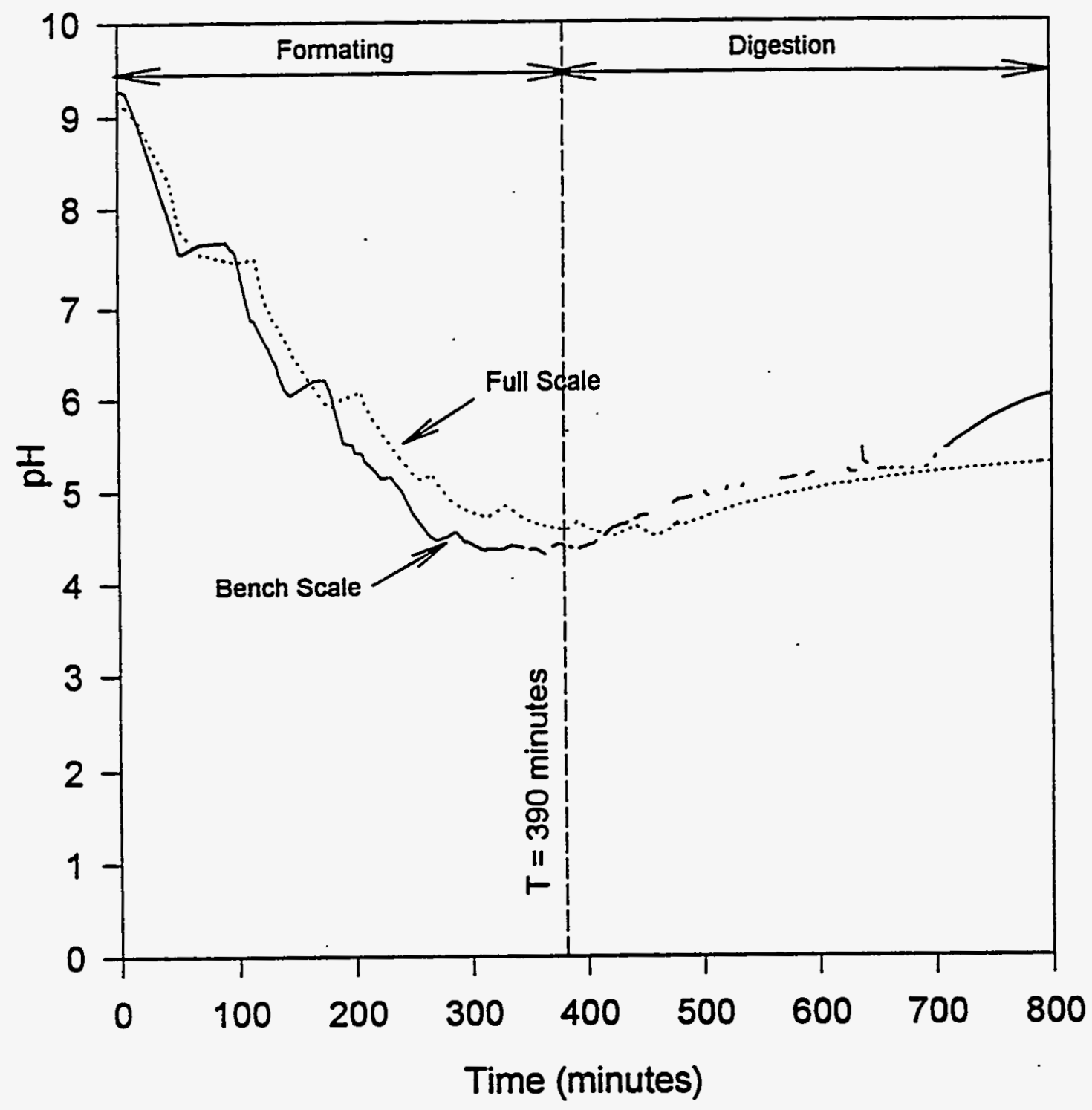

Figure 10.41. Time Versus $\mathrm{pH}$ (during formating and digestion)

$$
\mathrm{NO}+0.5 \mathrm{O}_{2} \rightarrow \mathrm{NO}_{2} \quad \text { (Weimers 1991) }
$$

\subsubsection{Results and Discussion}

A comparison of the results for full-scale and bench-scale testing is provided below. 


\subsubsection{Nitrogen Mass Balance}

A nitrogen mass balance for both full-scale and bench-scale testing is shown in Table 10.10. The initial nitrogen in the slurry is determined from the nitrate and nitrite found in a chemical analysis of the NCAW simulant. The final nitrogen value in solutions is a combination of nitrate and nitrite remaining in the final slurry volume, nitrate and nitrate measured in the condensate samples, and determinations to account for slurry losses that occurred during sampling.

The $\mathrm{N}_{2} \mathrm{O}$ and $\mathrm{NO}_{x}$ in the offgas are also accounted for in the nitrogen mass balance. The estimated $\mathrm{N}_{2} \mathrm{O}$ and $\mathrm{NO}_{x}$ produced after digestion and scale-up from offgas system condensate were not applicable in the bench-scale testing: the offgas system condensate from the full-scale system resulted from the offgas measurement system configuration, which was different for bench-scale. The estimated $\mathrm{N}_{2} \mathrm{O}$ and $\mathrm{NO}_{\mathrm{x}}$ were the result of slurry samples from full-scale being taken 4 days after the end of digestion. During the 4-day delay some $\mathrm{N}_{2} \mathrm{O}$ and $\mathrm{NO}_{\mathrm{x}}$ was still being generated by the slurry. The estimated amount accounts for this offgas. Bench-scale slurry samples were removed immediately after digestion so there was no 4-day $\mathrm{N}_{2} \mathrm{O}$ and $\mathrm{NO}_{x}$ estimation. Ninety-seven percent of the nitrogen was accounted for in the bench-scale mass balance. Sources of uncertainty include a $\sim 5 \%$ uncertainty in analytical results and $\dot{a} \sim 5 \%$ uncertainty in offgas measurements.

\subsubsection{Peak Generation Rates}

Bench-scale and full-scale $\mathrm{NO}_{\mathrm{x}}$ peak generation rates occur at similar times, which correlate to the starts and stoppages of $\mathrm{HCOOH}$. This shows that the addition of $\mathrm{HCOOH}$ strongly affects offgas generation rate. Peak generation rates are affected by several factors other than $\mathrm{HCOOH}$ addition rate. These factors include slurry temperature, concentration of $\mathrm{HCOOH}, \mathrm{pH}$, slurry composition, mixing of the slurry, and localized heating of the slurry. The $\mathrm{NO}_{x}$ peak generation rate for bench-scale and fullscale tests was comparable and within $11.95 \%$ as shown in Table 10.10 . The $\mathrm{N}_{2} \mathrm{O}$ peak generation

Table 10.10. Nitrogen Mass Balance

\begin{tabular}{|c|c|c|c|c|}
\hline \multirow[b]{2}{*}{$\cdot$} & \multicolumn{2}{|c|}{ Full-Scale } & \multicolumn{2}{|c|}{ Bench-Scale } \\
\hline & $\begin{array}{l}\text { Actual } \\
\text { (moles) }\end{array}$ & $\begin{array}{c}\text { Normalized } \\
\text { Vessel Volume } \\
(\mathrm{mol} / \mathrm{L})\end{array}$ & $\begin{array}{l}\text { Actual } \\
\text { (moles) }\end{array}$ & $\begin{array}{c}\text { Normalized } \\
\text { Vessel Volume } \\
(\mathrm{mol} / \mathrm{L})\end{array}$ \\
\hline initial nitrogen in slurry (moles) & 17744 & 6.334E-1 & 0.9153 & $6.102 E-1$ \\
\hline final nitrogen in slurry (moles) & 8895 & $3.175 E-1$ & 0.4528 & $3.019 \mathrm{E}-1$ \\
\hline $\mathrm{N}_{2} \mathrm{O}$ and $\mathrm{NO}_{x}$ offgas nitrogen (moles) & 6148 & $2.195 E-1$ & 0.4340 & $2.893 E-1$ \\
\hline nitrogen in condensate (moles) & 345 & $1.232 E-2$ & $9.8977 \mathrm{E}-4$ & $6.599 \mathrm{E}-4$ \\
\hline estimated $\mathrm{NO}_{x}$ produced after digestion* & 180 & $6.426 \mathrm{E}-3$ & - & - \\
\hline estimated $\mathrm{N}_{2} \mathrm{O}$ produced after digestion* & 169 & $6.033 E-3$ & - & - \\
\hline scale up from offgas system condensate & 520 & $1.856 \mathrm{E}-2$ & - & - \\
\hline $\mathrm{NH}_{3}$ in slurry & - & - & - & - \\
\hline \% nitrogen accounted for by mass balance & $92 \%$ & $92 \%$ & $97 \%$ & $97 \%$ \\
\hline
\end{tabular}


rates differed by $59 \%$. Less $\mathrm{N}_{2} \mathrm{O}$ was generated during the bench-scale test due to the steeper decrease in $\mathrm{pH}$ experienced during the test. The steeper decrease in $\mathrm{pH}$ was attributed to better mixing conditions in the bench-scale test. Acid conditions favor $\mathrm{NO}_{x}$ generation over $\mathrm{N}_{2} \mathrm{O}$ generation (Langowski 1993). Less $\mathrm{N}_{2} \mathrm{O}$ may contribute to the peak generation rate being less for bench-scale test. Additionally, given the fact that $\mathrm{N}_{2} \mathrm{O}$ generation rates are two orders of magnitude lower than $\mathrm{CO}_{2}$ or $\mathrm{NO}_{\mathrm{x}}$ generation rates, the difference is not as significant. The difference in $\mathrm{CO}_{2}$ generation rate of $-31 \%$ is not readily explained from the data but is attributed to the difficulty in strictly controlling all the relevant factors during testing.

\subsubsection{Nitrogen and Carbon Dioxide Offgas}

The $\mathrm{NO}_{\mathrm{x}}$ and $\mathrm{N}_{2} \mathrm{O}$ generation as a function of time during formating and digestion and the cumulative nitrogen generated during this same time period is shown in Figures 10.42 and 10.43 . Total amounts are listed in Table 10.11 along with the total amount of $\mathrm{CO}_{2}$.

The cumulative nitrogen generated and measured in the offgas during formating and digestion is a combination of the $\mathrm{NO}_{x}$ and $\mathrm{N}_{2} \mathrm{O}$. A comparison plot of this data is shown in Figure 10.43. The difference between the two graphs becomes more visible after $350 \mathrm{~min}$. This corresponds to when the bench-scale $\mathrm{NO}_{x}$ generation rate is higher than the full-scale $\mathrm{NO}_{x}$ generation (Figure 10.42). Additionally, a significant portion of the $\mathrm{NO}_{\mathrm{x}}$ was removed by the condensate during full-scale testing after $350 \mathrm{~min}$.

This contributes to the difference. The total $\mathrm{NO}_{\mathrm{x}}$ measured in the offgas, shown in Table 10.12 , is much less $(30 \%)$ for full-scale than bench-scale.

Figure 10.44 shows the cumulative $\mathrm{CO}_{2}$ produced and the generation rate as a function of time during formating and digestion. The peaks correspond to the start and stoppages of $\mathrm{HCOOH}$ addition. Total amounts for $\mathrm{N}_{2} \mathrm{O}$ and $\mathrm{CO}_{2}$ differed by $45 \%$ and $14 \%$, respectively. More $\mathrm{N}_{2} \mathrm{O}$ was generated during the full-scale test which produced more $\mathrm{CO}_{2}$ according to the reaction shown below. $\mathrm{N}_{2} \mathrm{O}$ generation is favored in less acidic conditions (Langowski 1993). As shown in Figure 10.41, the slurry $\mathrm{pH}$ did not drop as quickly during full-scale testing. The generation of more $\mathrm{CO}_{2}$ offgas during the full-scale test could be due to full-scale use of localized heating coils versus an indirect heating mantle. This could increase the amount of offgases produced by allowing direct heating of the slurry.

$$
2 \mathrm{NaNO}_{2}+4 \mathrm{HCOOH} \Rightarrow \mathrm{N}_{2} \mathrm{O}+2 \mathrm{CO}_{2}+2 \mathrm{NaCOOH}+3 \mathrm{H}_{2} \mathrm{O} \text { (Weimers 1993) }
$$

\subsubsection{Rheological Properties}

The bench-scale melter-feed viscosity data was obtained with a Haake M5 measuring system with a MVII sensor and cup. All samples were taken and tested at $50^{\circ} \mathrm{C}$. The compositions were the same as for the full-scale tests.

The rheograms were generated by increasing the shear rate from 0 to $441 \mathrm{~s}^{-1}$ in $2 \mathrm{~min}$ and then decreasing the shear rate to 0 in $2 \mathrm{~min}$. When there is a difference between the up curve and the down curve it is called a hysteresis. A hysteresis usually indicates dilatant or thixotropic behavior in the 
(Normalized to 1 Liter NCAW Simulant @ 140gWO/L)

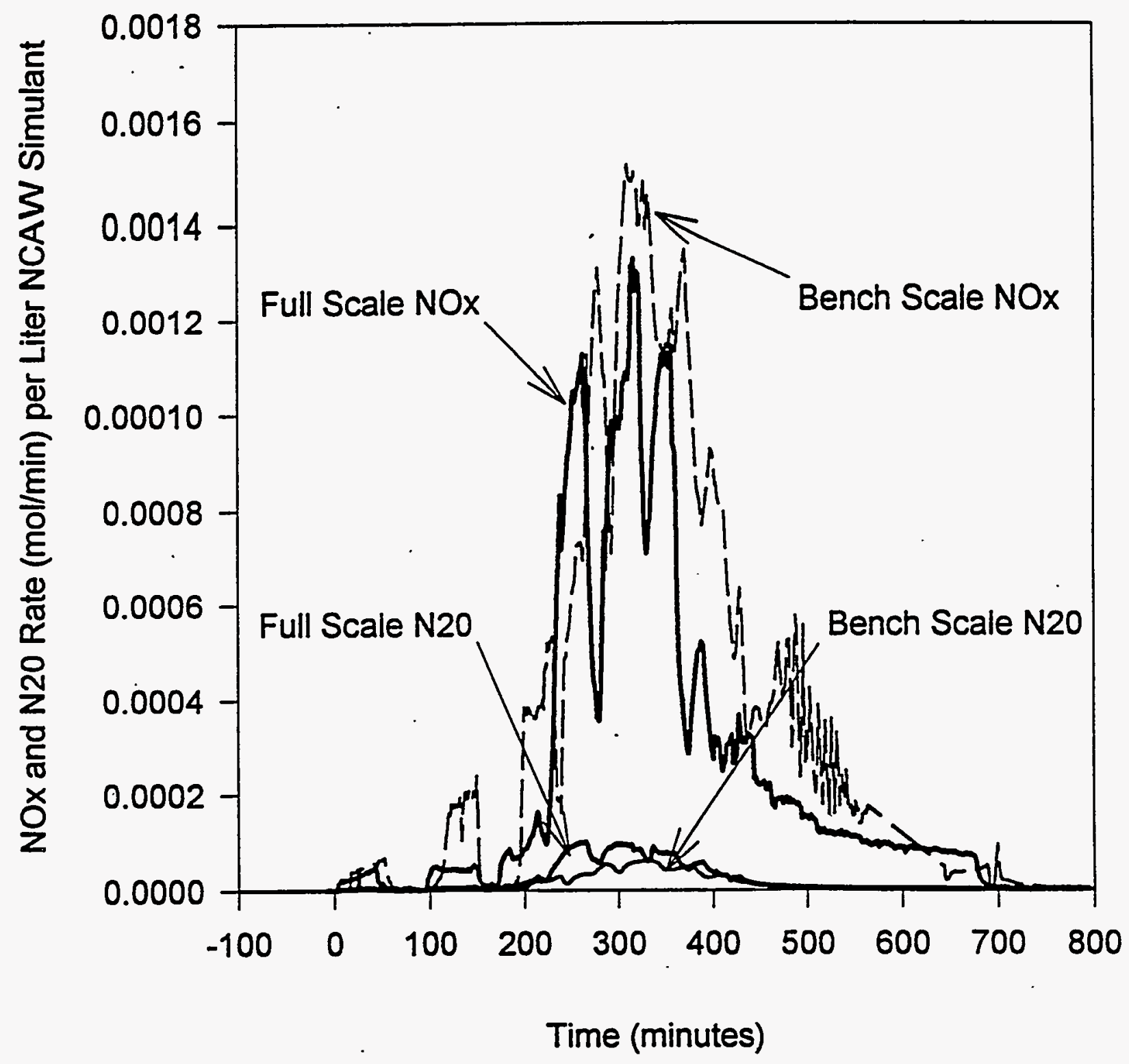

Figure 10.42. $\mathrm{NO}_{\mathrm{x}}$ and $\mathrm{N}_{2} \mathrm{O}$ Generation Versus Time 


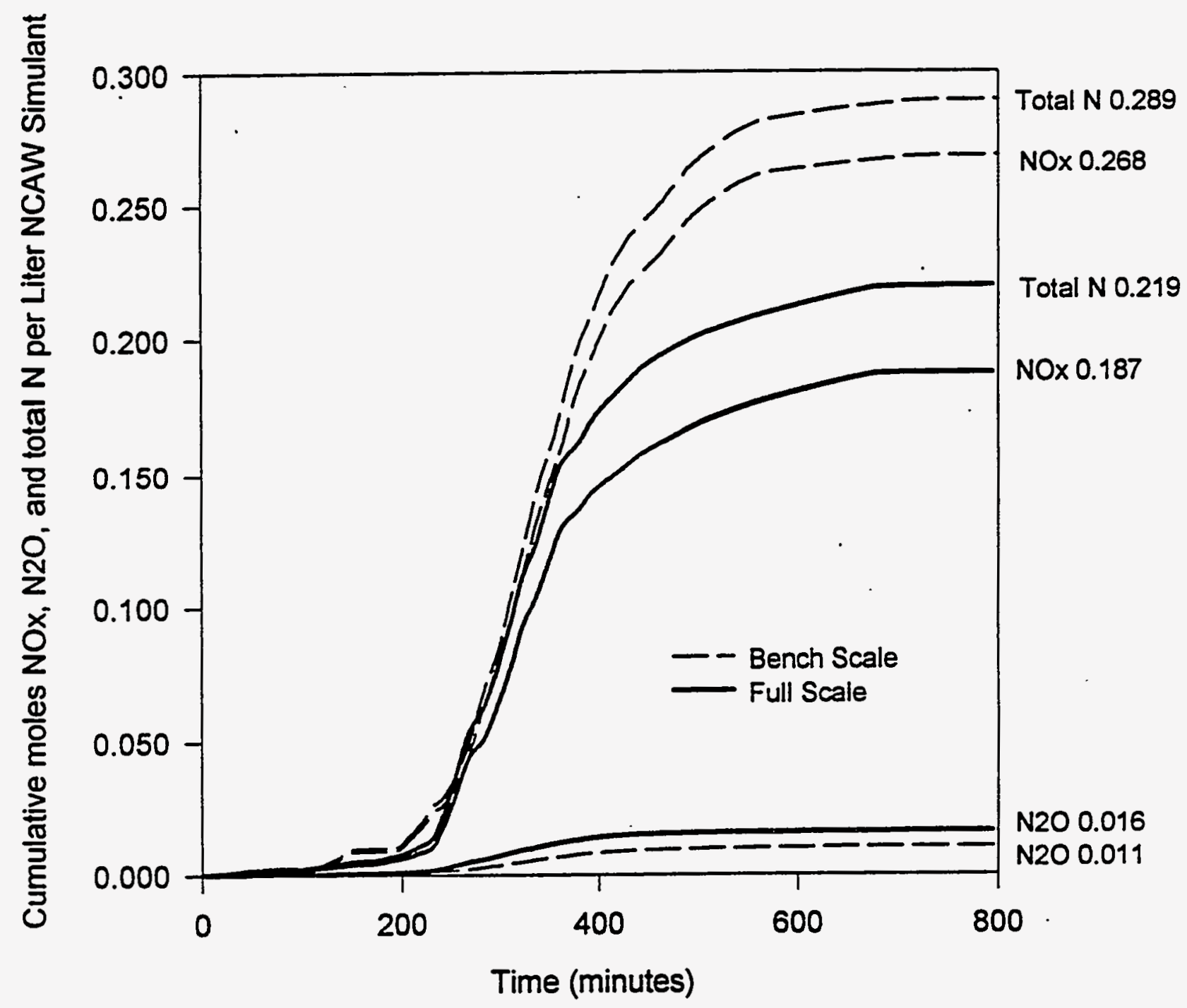

Figure 10.43. Graph of Measured Offgases Produced 
Table 10.11. Peak Generation Rates and Total Offgas

\begin{tabular}{|c|c|c|c|}
\hline & $(\mathrm{mol} / \mathrm{min} / \mathrm{L}$ & neration $R$ & $40 \mathrm{gwo} / \mathrm{L}$ ) \\
\hline & $\mathrm{NO}_{\mathrm{x}}$ & $\overline{\mathrm{N}_{2} \mathrm{O}}$ & $\mathrm{CO}_{2}$ \\
\hline nch-scale & $1.506 \mathrm{E}-3$ & $6.27 \mathrm{E}-5$ & $2.453 \mathrm{E}-3$ \\
\hline full-scale & $1.326 \mathrm{E}-3$ & $9.96 \mathrm{E}-5$ & $1.700 \mathrm{E}-3$ \\
\hline \% difference & -11.95 & 58.85 & -30.70 \\
\hline
\end{tabular}

Table 10.12. Total Offgas

Total Offgas Generated

(mol/L NCAW Simulant at $140 \mathrm{gwo} / \mathrm{L}$ )

\begin{tabular}{|c|c|c|}
\hline $\mathrm{NO}_{\mathrm{x}}$ & $\mathrm{N}_{2} \mathrm{O}$ & $\mathrm{CO}_{2}$ \\
\hline 0.268 & 0.011 & 0.279 \\
\hline 0.187 & 0.016 & 0.319 \\
\hline-30.22 & 45.46 & 14.34 \\
\hline
\end{tabular}

fluid. The melter-feed rheograms show a thixotropic hysteresis. The melter feed has a yield pseudoplastic flow behavior. Theoretically, the yield stress or yield point is the minimum amount of stress required to initiate fluid movement and begin flow. For the melter-feed rheograms the yield stress is defined as the stress value on the graph where the slope changes from near-vertical to nearhorizontal. A Bingham curve fit is used to extrapolate this intersection back to the shear stress axis to obtain a yield stress value. The yield stresses reported in this document are both rate and stress dependent and, therefore, not true theoretical yield points. However, they are a valid indication of the stress that would be required to restart flow in a tank or pipes if this material were allowed to set for a length of time.

The aging effects can be seen when the.rheograms from different process times are overlaid. A composite of the bench-scale rheograms is presented in Figure 10.45. The process points tested were pre-boil, after boil, 1 hour after boil, 24 hours after boil, and 4 weeks after boil. The yield points increase with time, with the exception between the 1-hour and the 24-hour measurement. This measurement was believed to have been compromised by a transfer of the test material to a separate reaction vessel soon after the 1-hour sample was pulled. It is believed that the feed was diluted slightly at this point, but this cannot be verified due to analytical problems encountered with the samples taken after this point. 


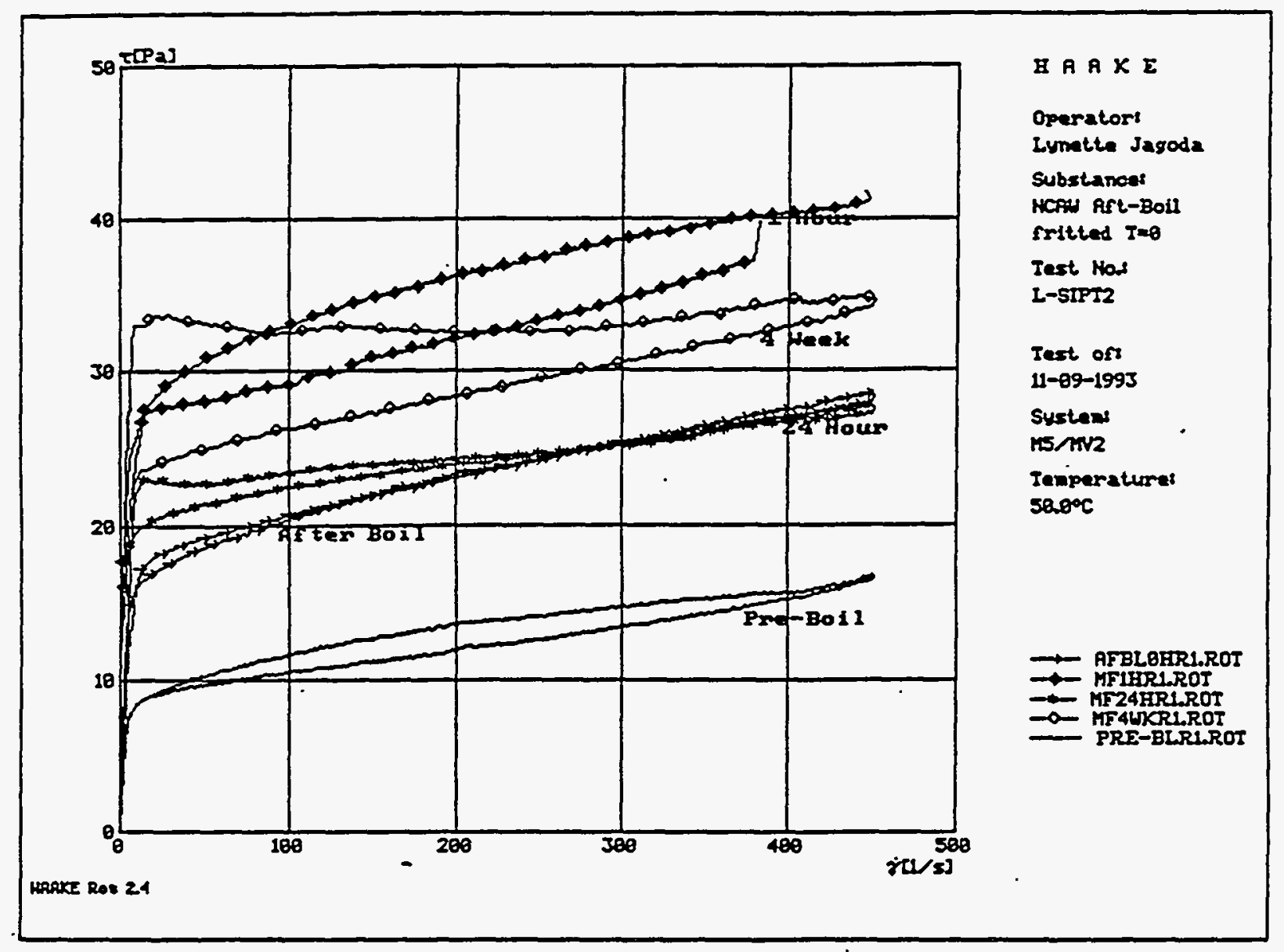

Figure 10.44. Shear Stress Versus Shear Rate for Bench-Scale at Various Times

A comparison overlay between full-scale and bench-scale rheology data for the two common points, 24 hours and 4 weeks, is shown in Figure 10.45. The yield points on the 24-hour rheograms are within $5 \%$ of each other. At the 4 -week point, the rheograms are within $10 \%$ of each other. The accuracy of the rheology instrumentation is $\pm 3 \%$. Additional sources of error lie potential variations of other parameters. Analysis of the full-scale test data revealed a strong correlation between the total oxide concentration and the yield point. It was also shown that $\mathrm{pH}$ can have an effect on the yield stress in NCAW-1 melter-feed simulant used for these tests. Because of problems with the analytical measurements on the full-scale samples at the $24-\mathrm{h}$ and 4 -week points it cannot be established that the total oxides and the $\mathrm{pH}$ measurements had remained constant. 


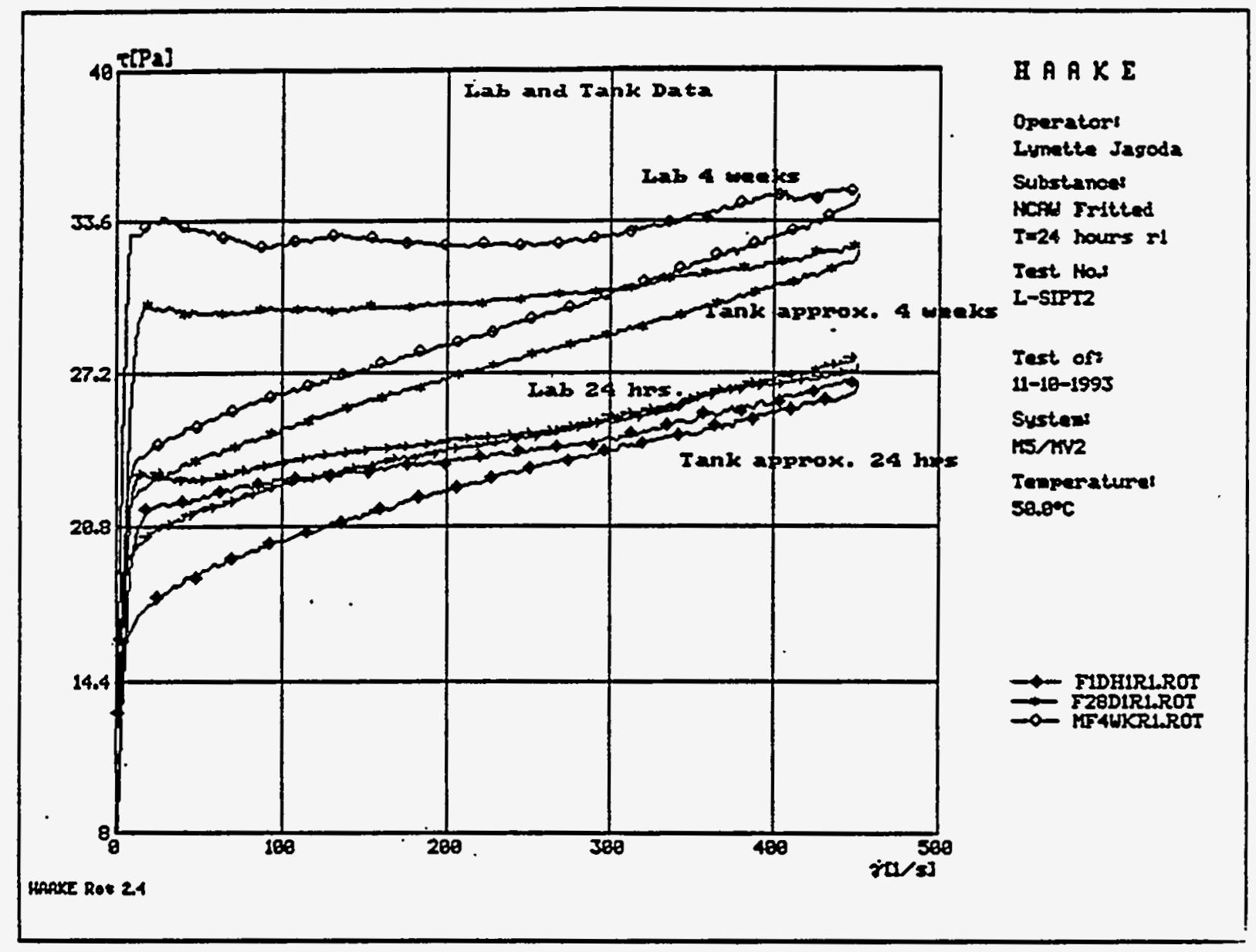

Figure 10.45. Shear Stress Versus Shear Rate for Pilot Scale (Tank) and Bench-Scale (Lab) at 2: hours and 4 weeks

Based on previous data it is estimated that variations of these parameters could increase the potential range of error to $\pm 15 \%$. The reproducibility of the effect itself was successful, and the magnitude of the effect was within a reasonable range of error when all the pertinent factors are considered.

The data generated in this testing supports the concept that rheological data from bench-scale work is comparable to the full-scale for melter-feed testing.

\subsubsection{Conclusions and Recommendations}

The following conclusions resulted from the test:

1. Peak gas generation rate corresponds to the start and stoppage of $\mathrm{HCOOH}$ acid addition. A series of peaks differed from those in previous bench-scale tests under continuous addition of $\mathrm{HCOOH}$. 
2. The $\mathrm{pH}$ dropped quicker during bench-scale formic acid additions than in full-scale and is most likely due to better mixing.

3. The peak generation rate of $\mathrm{NO}_{\mathrm{x}}$ during bench-scale testing is within $12 \%$ of full-scale data. The total amount of $\mathrm{CO}_{2}$ produced in bench-scale is within $15 \%$ of full-scale.

4. The smaller amount of $\mathrm{NO}_{\mathrm{x}}$ measured in the offgas in the full-scale test (compared to bench scale) is accounted for by the removal of nitrate and nitrite by the condensate during full-scale. The bench-scale test was run with $\mathrm{Ar}$ which did not react with $\mathrm{NO}_{\mathrm{x}}$ to produce $\mathrm{NO}_{2}$. Significantly less nitrate was present in bench-scale condensate.

5. The nitrogen mass balance was able to account for $97 \%$ of the nitrogen during bench scale.

6. Bench-scale rheology data is reasonably representative of full-scale.

The following recommendations are provided.

When considering scaling up bench-scale data conditions, such as temperature, $\mathrm{pH}, \mathrm{HCOOH}$ concentration, $\mathrm{HCOOH}$ addition rate, and slurry, composition must be carefully controlled to minimize differences in peak gas generation rates and total amounts of offgas. Concerning total amounts of $\mathrm{NO}_{x}$, bench-scale tests run in Ar represent the worst case where most of the $\mathrm{NO}_{\mathrm{x}}$ generated ends up in the offgas. However, it is important to note that bench-scale tests will not produce the worst case if a significant amount of slurry is removed through sampling during formating and digestion. This is because $\mathrm{NaNO}_{2}$ is removed and is therefore not present to react with $\mathrm{HCOOH}$. Sampling during formating and digestion of bench-scale testing should be minimized if offgas generation and amounts are to be scaled. Alternatively, as long as full-scale tests are run with air a significant portion of the $\mathrm{NO}_{\mathrm{x}}$ will be removed by the condensate provided a sufficient amount of condensate is generated.

Peak generation rate is a more complicated issue than which bench-scale tests may or may not generate the worst case. This is because peak generation rate is affected by many factors that have not been fully characterized. Also, the full-scale conditions may not be entirely known in advance in order to be incorporated during bench-scale tests. This makes scale-up predictions more difficult. 


\subsection{References}

Berkman and Egloff. 1941. Emulsions and Foams. pp. 112-152. Reinhold, New York.

Bikerman. 1975. Foams. Springer-Verlag, New York.

Crane. 1965. Flow of Fluids Through Valves, Fittings, and Pipe, Technical Paper No. 410, Crane Co., 4100 S. Kedzie Avenue, Chicago.

Govier, G. W. and K. Aziz. 1987. The Flow of Complex.Mixtures in Pipes. Robert E. Kreiger Publishing Company, Malabar, Florida.

Green. 1984. Perrys Chemical Engineers' Handbook. pp. 18-57 to 18-60. New York.

Holland, F. A. and F. S. Chapman. 1966. Pumping of Liquids. Reinhold Publishing Corporation, New York.

Holman, J. P. 1972. Heat Transfer, 3rd Edition, McGraw-Hill Book Company, New York.

Kern, D. Q. 1950. Process Heat Transfer. Mcgraw-Hill Book Company, New York.

Kruger, O. L. 1989. Hanford Waste Vitrification Plant Applied Technology Plan. WHC-EP-0224, Westinghouse Hanford Company, Richland, Washington.

Kruger, O. L. 1990. Hanford Whste.Vitrification Plant Applied Technology Plan. WHC-EP-0350. Westinghouse Hanford Company, Richland, Washington.

Rohsenow, W. M. and J. P. Hartnett. 1973. A Handbook of Heat Transfer, Mcgraw-Hill Book Company, New York.

Skelland, A.H.P. 1967. Non-Newtonian Flow and Heat Transfer. John Wiley \& Sons, Inc., New York.

Welty, J. R., C. E. Wicks, and R. E. Wilson. 1976. Fundamentals of Momentum, Heat, and Mass Transfer. 2nd Edition. John Wiley and Sons, New York. 
Appendix A

Equipment Description Figures 
- HWVP Feed Preparation Test Vessel Outline Drawing

- HWVP Feed Preparation Test Vessel Internals and Mercury Trough

- HWVP Feed Preparation Test Vessel Nozzles and Connections Details

- HWVP Feed Preparation Test Vessel Center Coil Assembly

- HWVP Feed Preparation Test System Condenser

- Philadelphia Mixers Outline Dimension Sheet

- Elevation of $2 \times 2 \times 11$ in. Vertical Cantilever Shaft Slurry Pump

- HWVP Feed Preparation Delivery Systems (P \& ID)

- HWVP Feed Preparation Test System Strainer Detail

- Melter Feed Piping Isometric

- HWVP Feed Line Restrictor Detail

- Melter Feed Piping Isometric (Rev)

- Elevation of 1-1/2 $22 \times 11$ in. Vertical Cantilever Shaft Slurry Pump

- Hydragard Sample Station Assembly

- Auxiliary Sample Station

- HWVP Feed Preparation Test System Thermowell Detail

- HWVP Feed Preparation Slurry Test Loop

- Three Sensor Bubbler Assembiy

- Cross-Section of Holledge Sensor

- Holledge Bubbler Assembly

- Offgas Characterization System (part 1)

- Offgas Characterization System (part 2)

- Schematic of Holledge Level Detection System

- CD-1000 Off Gas and Condensate Lines
Drawing Number D-10183-1

Drawing Number D-10183-2

Drawing Number D-10183-3

Drawing Number D-10183-4

Drawing Number M-4636

Drawing Number 90EUZ0631-1

Drawing Number M46313

Drawing Number SK-3-27797

Drawing Number SK-3-27814

Drawing Number FPTS-9103

Drawing Number SK-3-27815

Drawing Number FPTS-9103A

Drawing Number M46315

Drawing Number SK-3-28257

Drawing Number Figure B-4

Drawing Number SK-3-28256

Drawing Number FPTS 91-06

Rev 0

Drawing Number W752204

Drawing Number Figure 2

Drawing Number FPTS-91-01

Drawing Number Figure 4.2a

Drawing Number Figure 4.2b

Drawing Number Figure 1

Drawing Number Figure A.1 


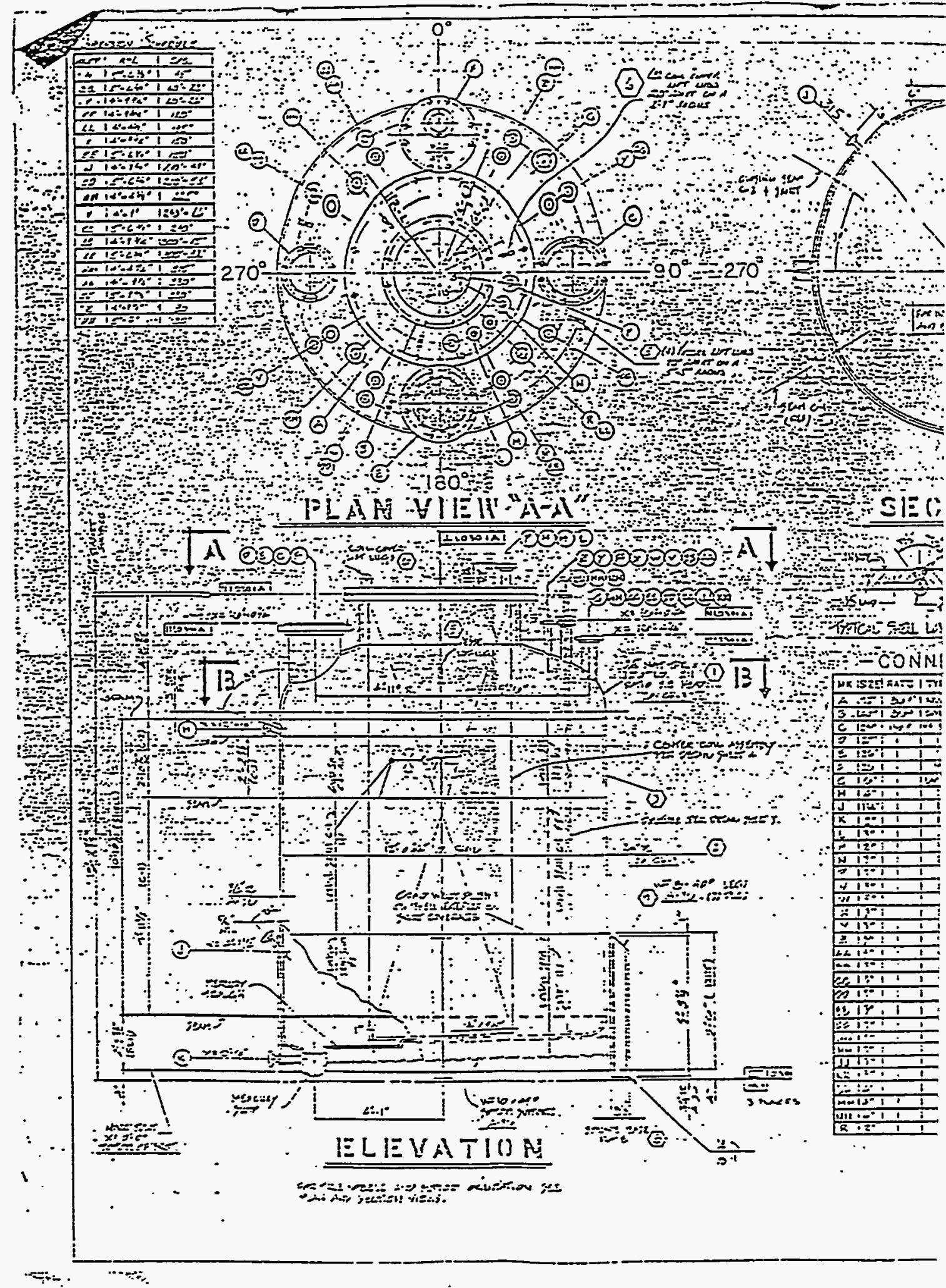

Figure A.1. HWVP Feed Prep 


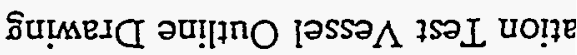

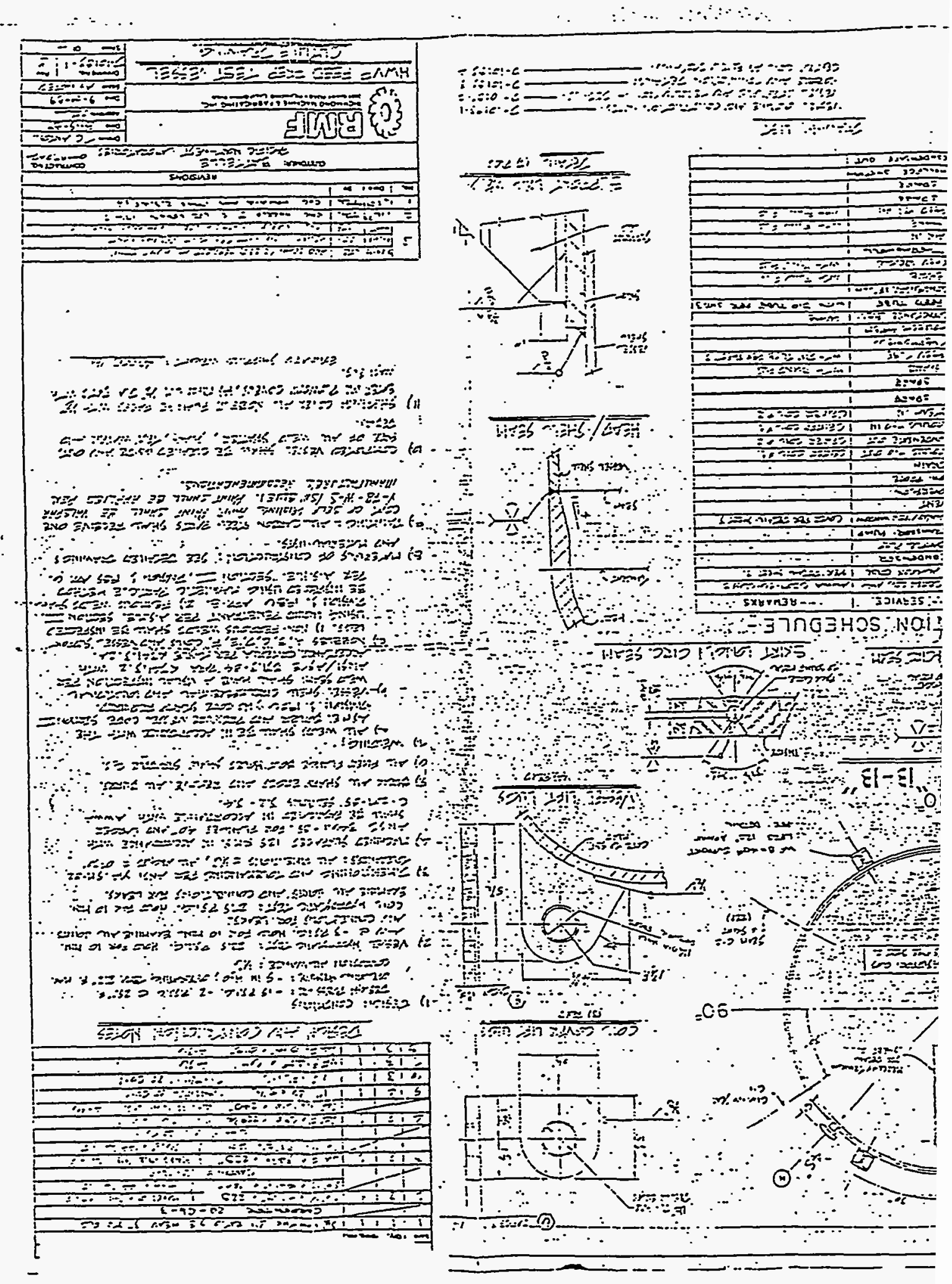




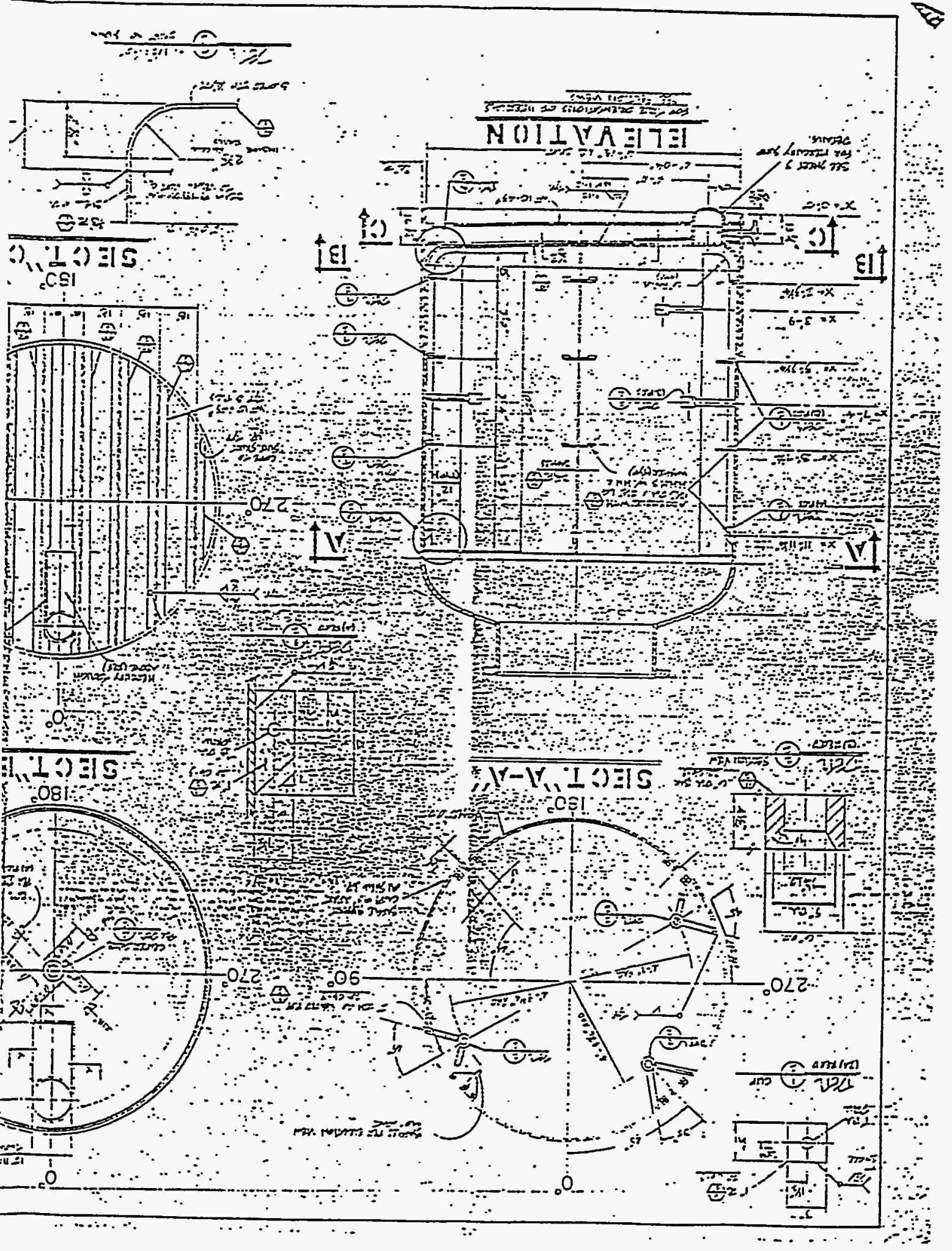




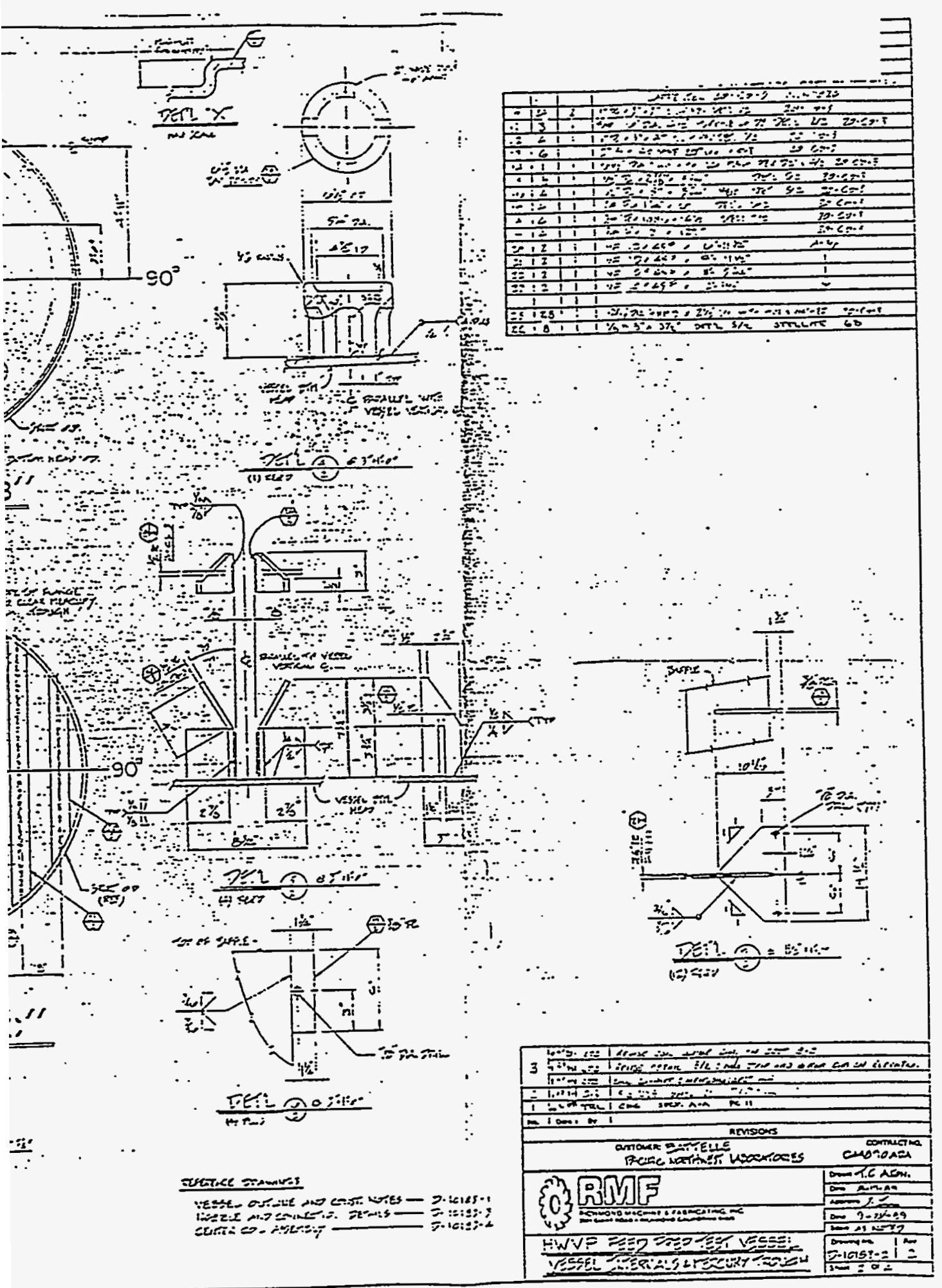

Vessel Internals and Mercury Trough 


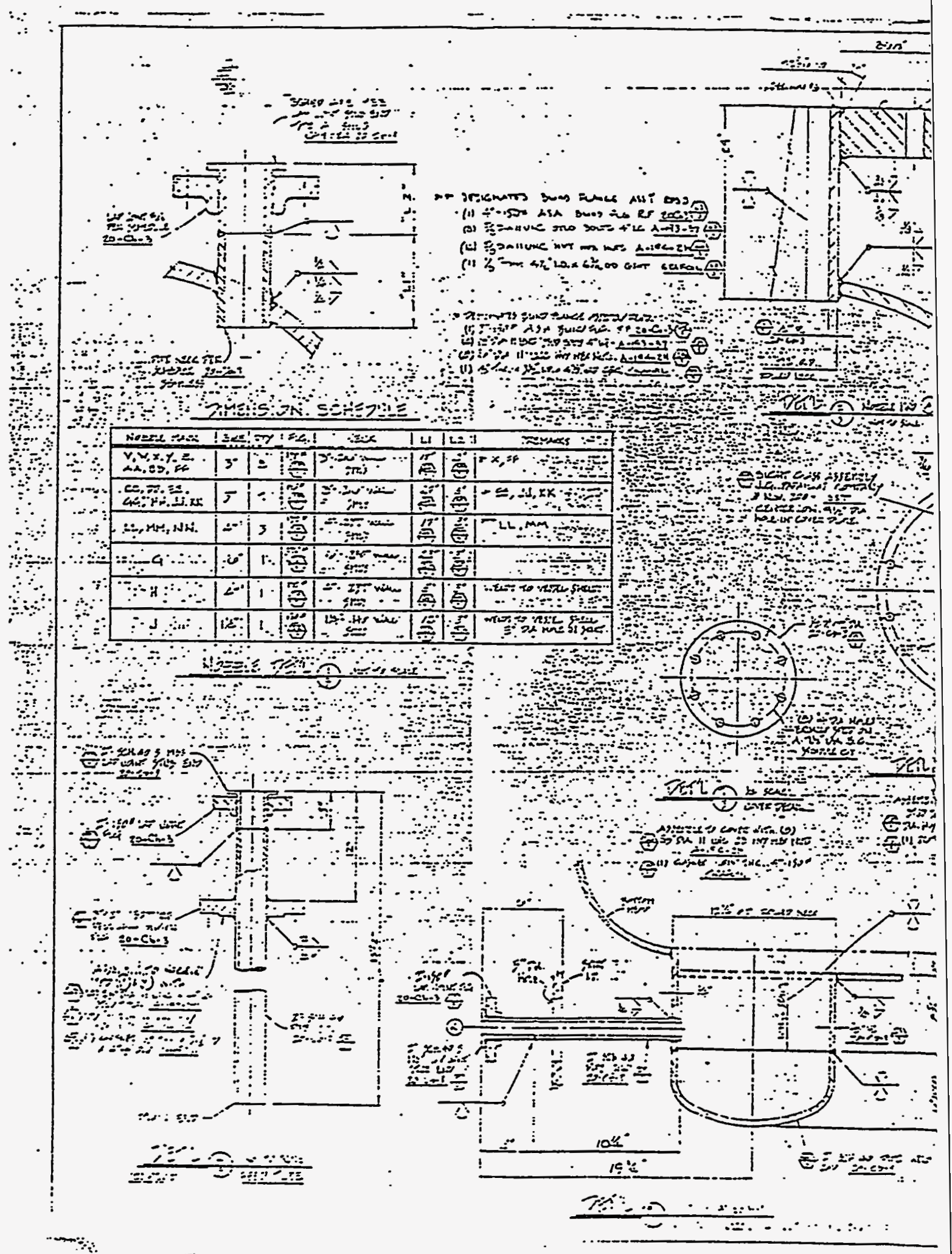

Figure A.3. HWVP Feed Preparation Tes 


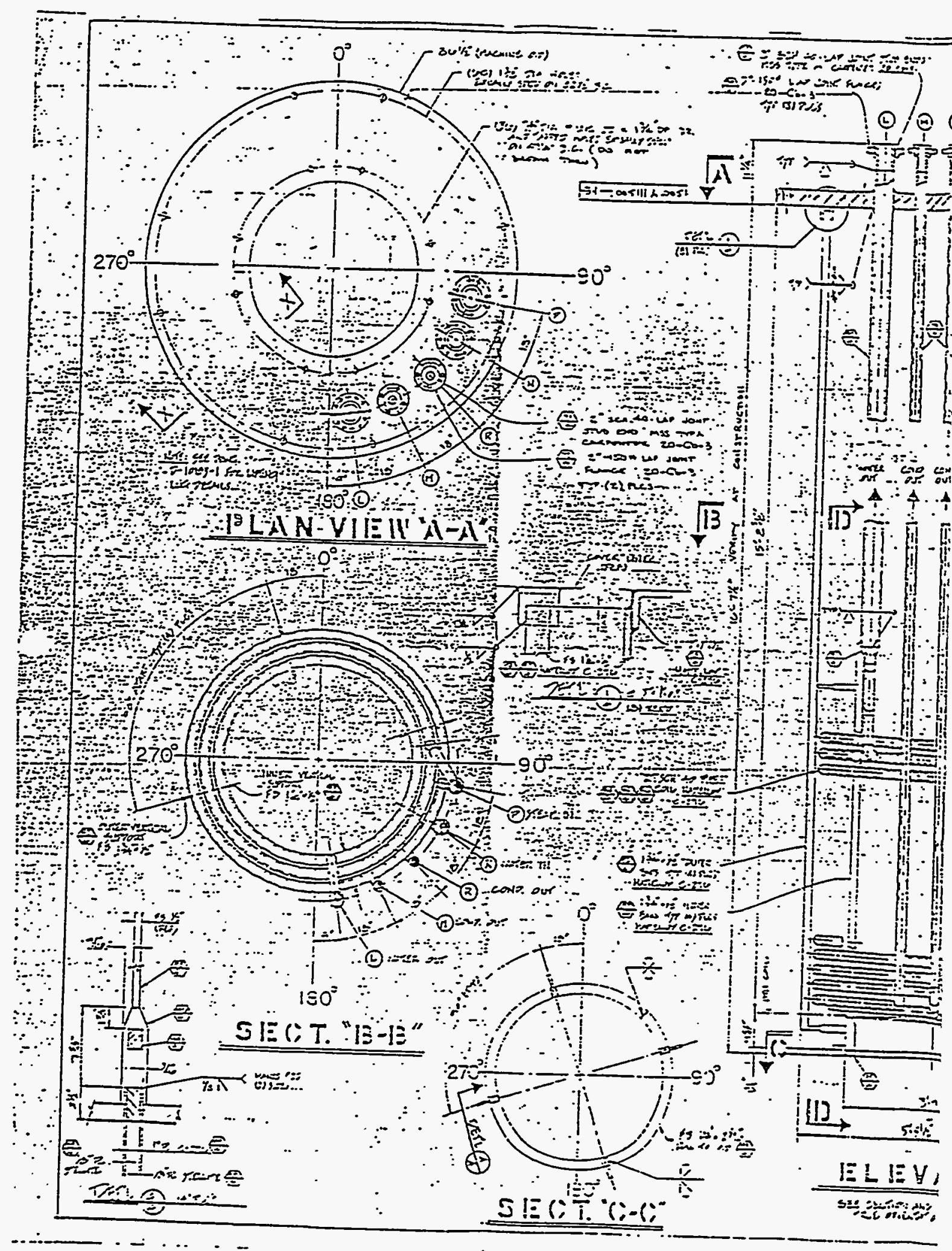

Figure A.4. HWVP Feed Preparatio: 


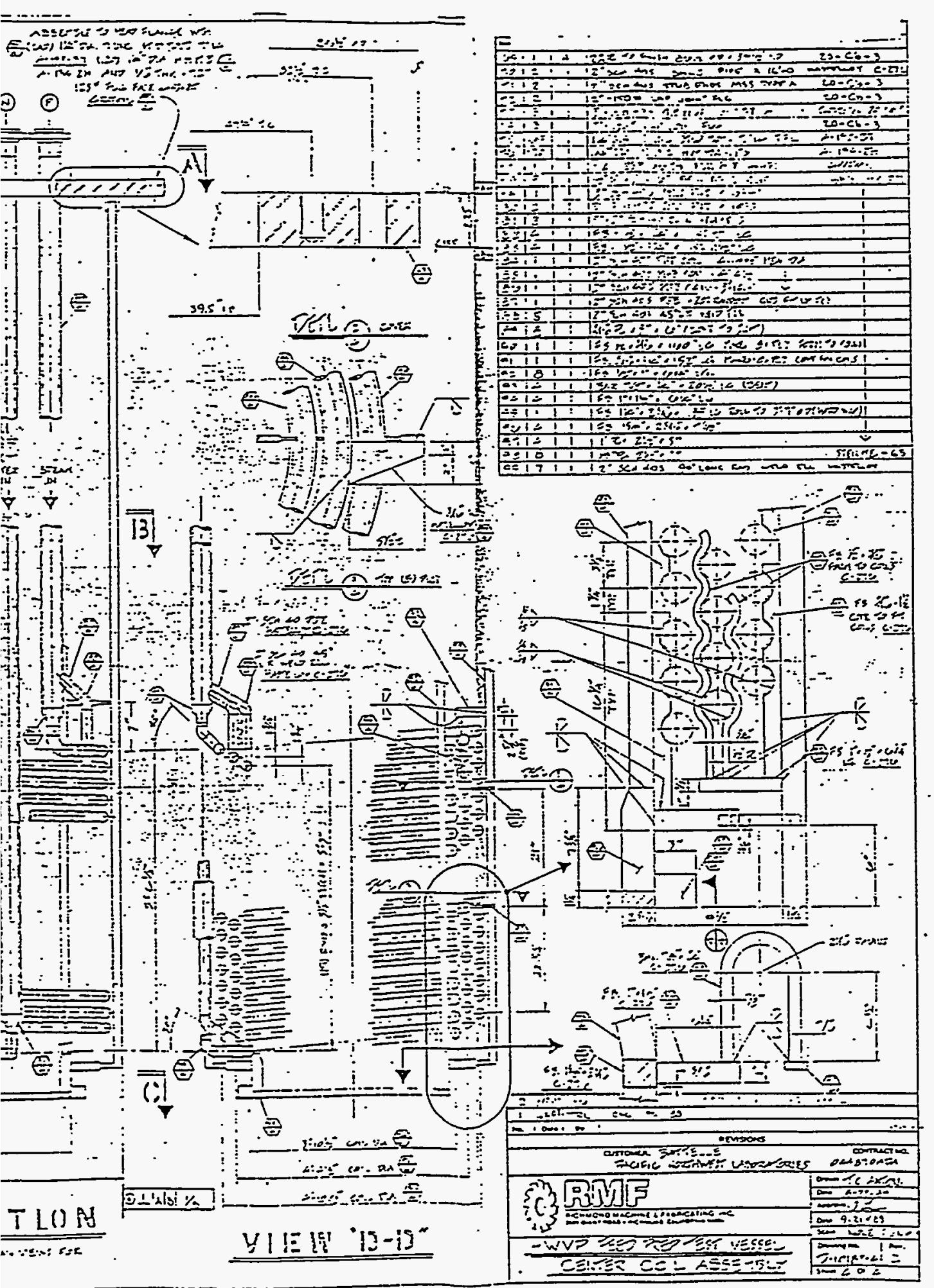

Test Vessel Center Coil Assembly 


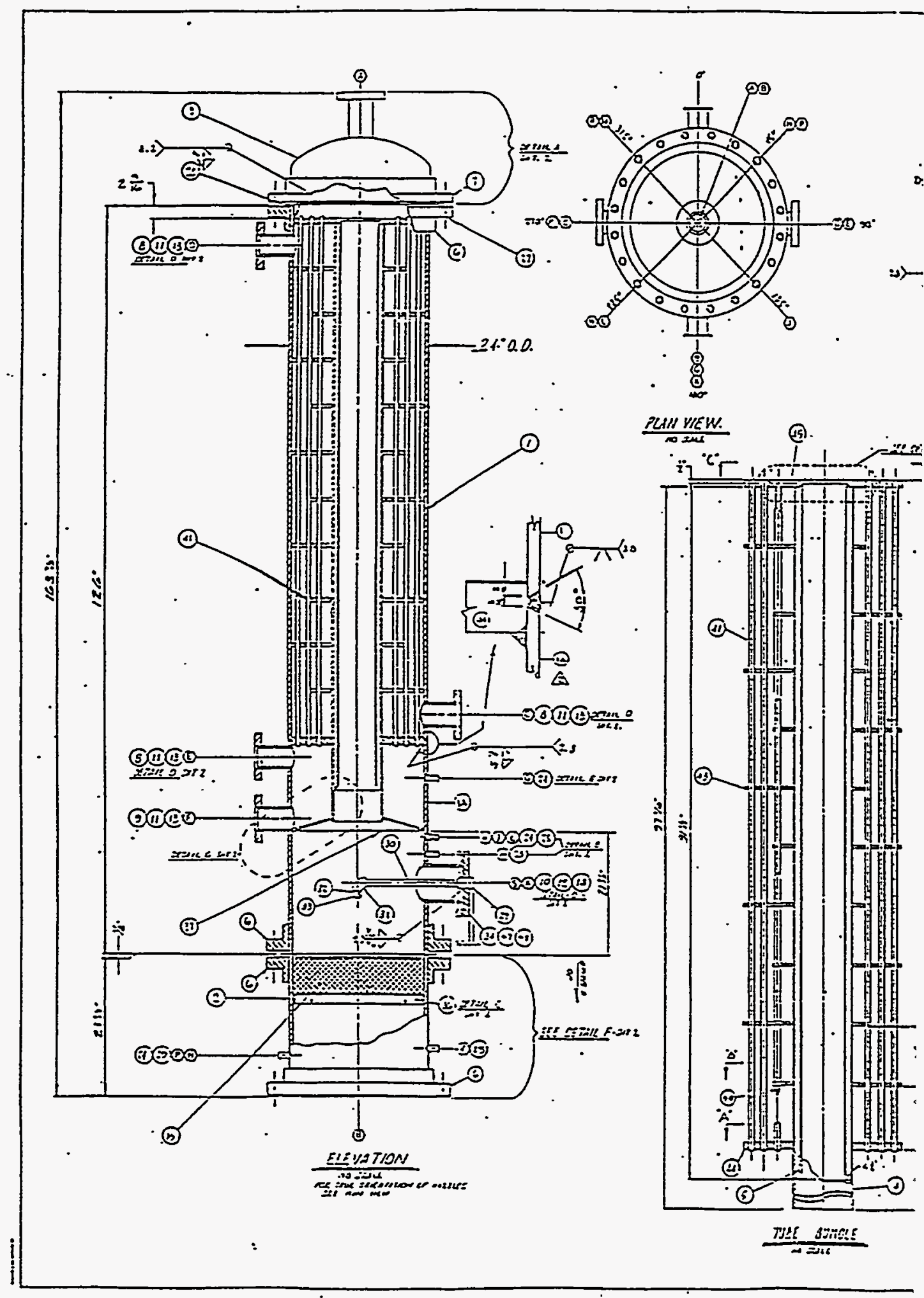

Figure A.5. HWVP Feed PreI 


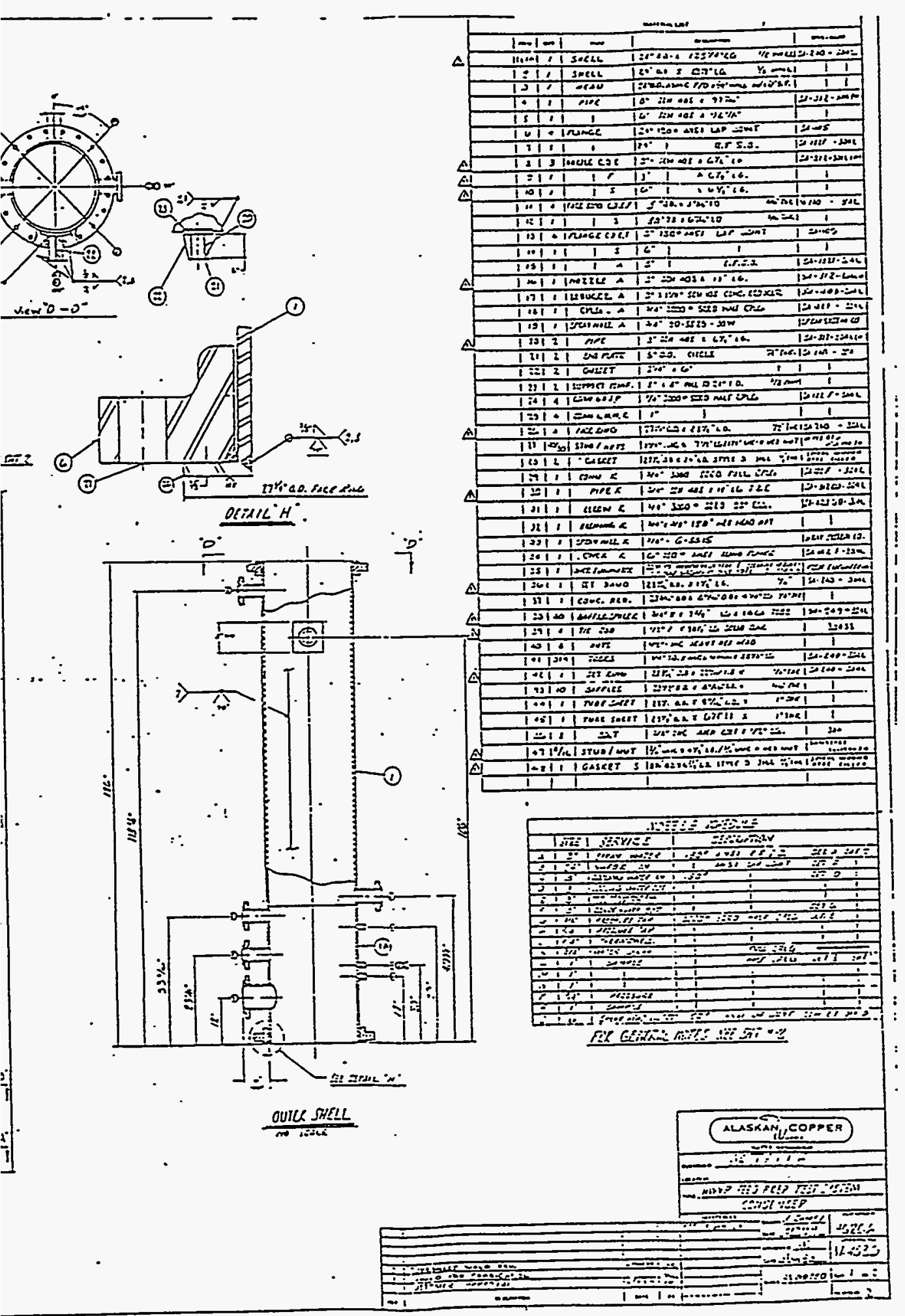

ration Test System Condenser 


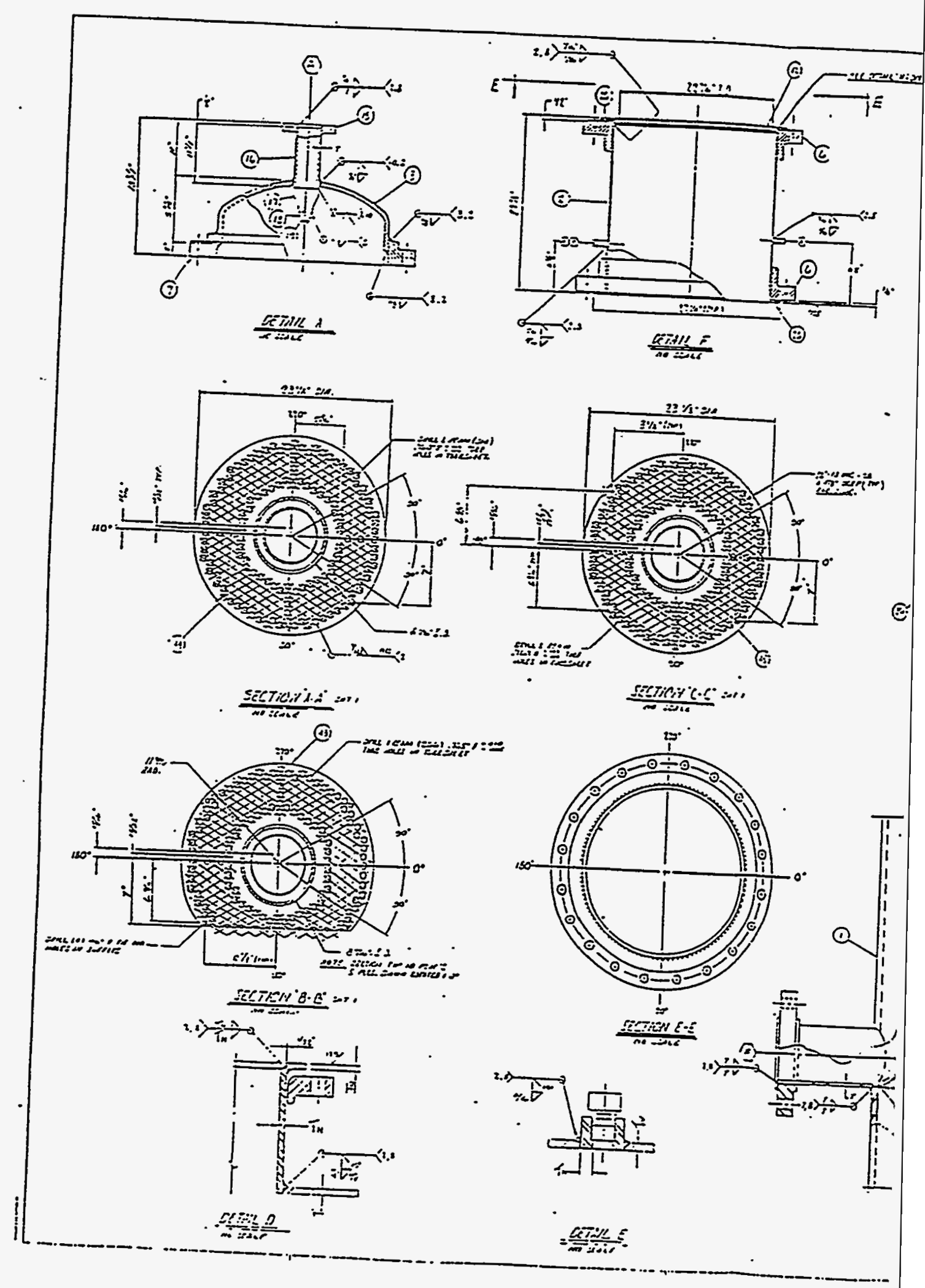

Figure A.S 


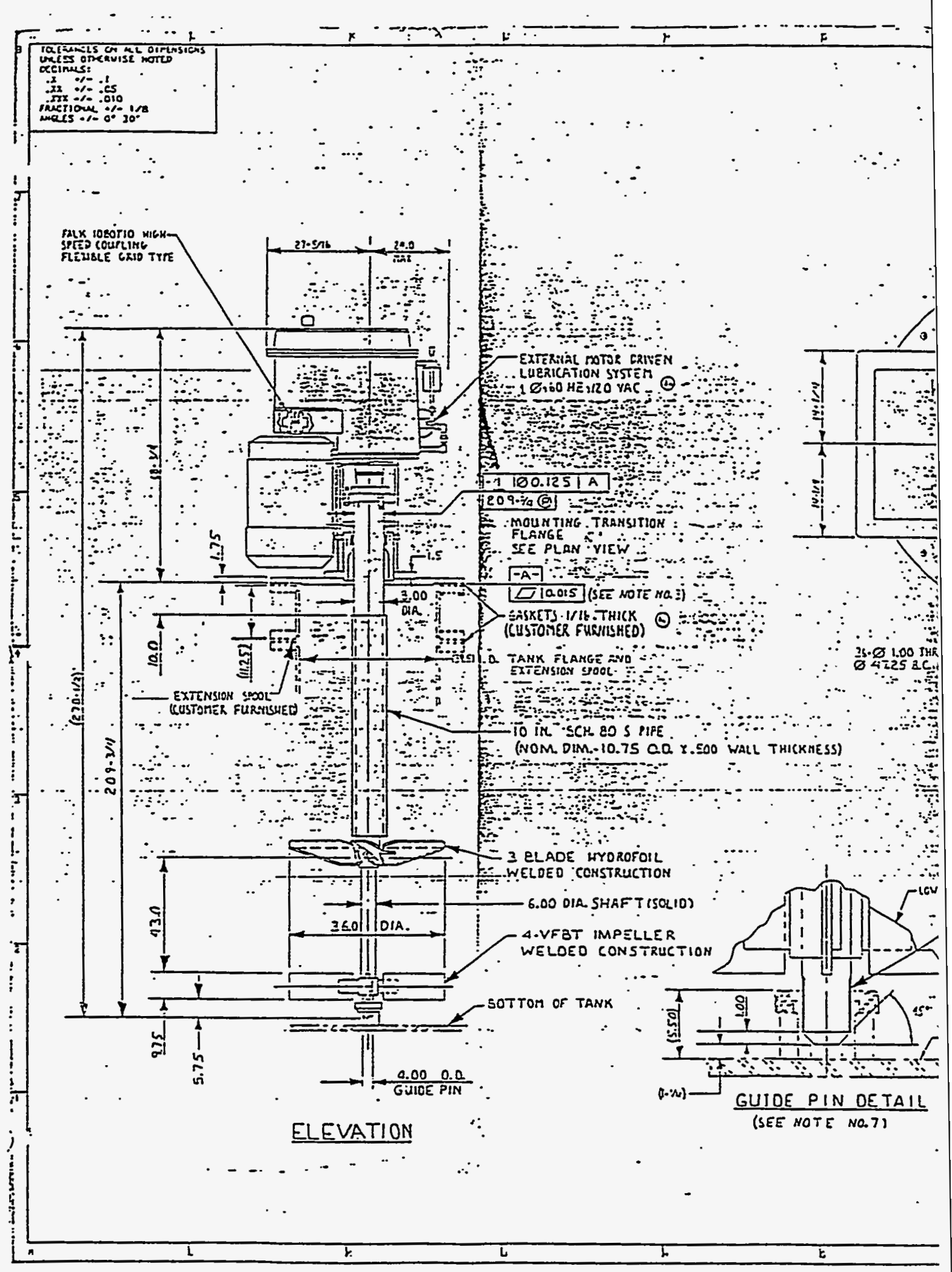

Figure A.6. Philadelphia Mixi 


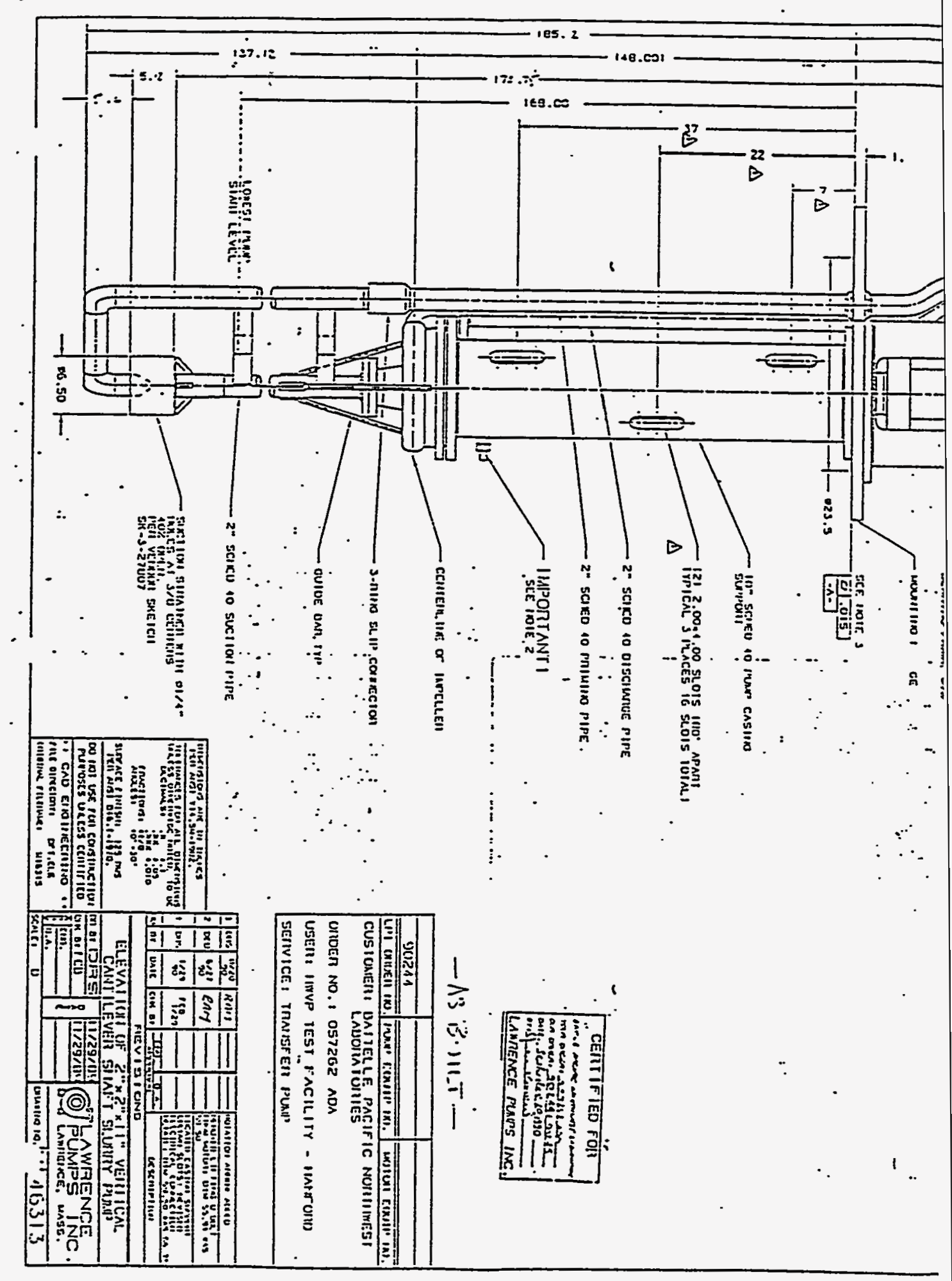

Figure A.7. Elevation of $2 \times 2 \times 11$ in. 


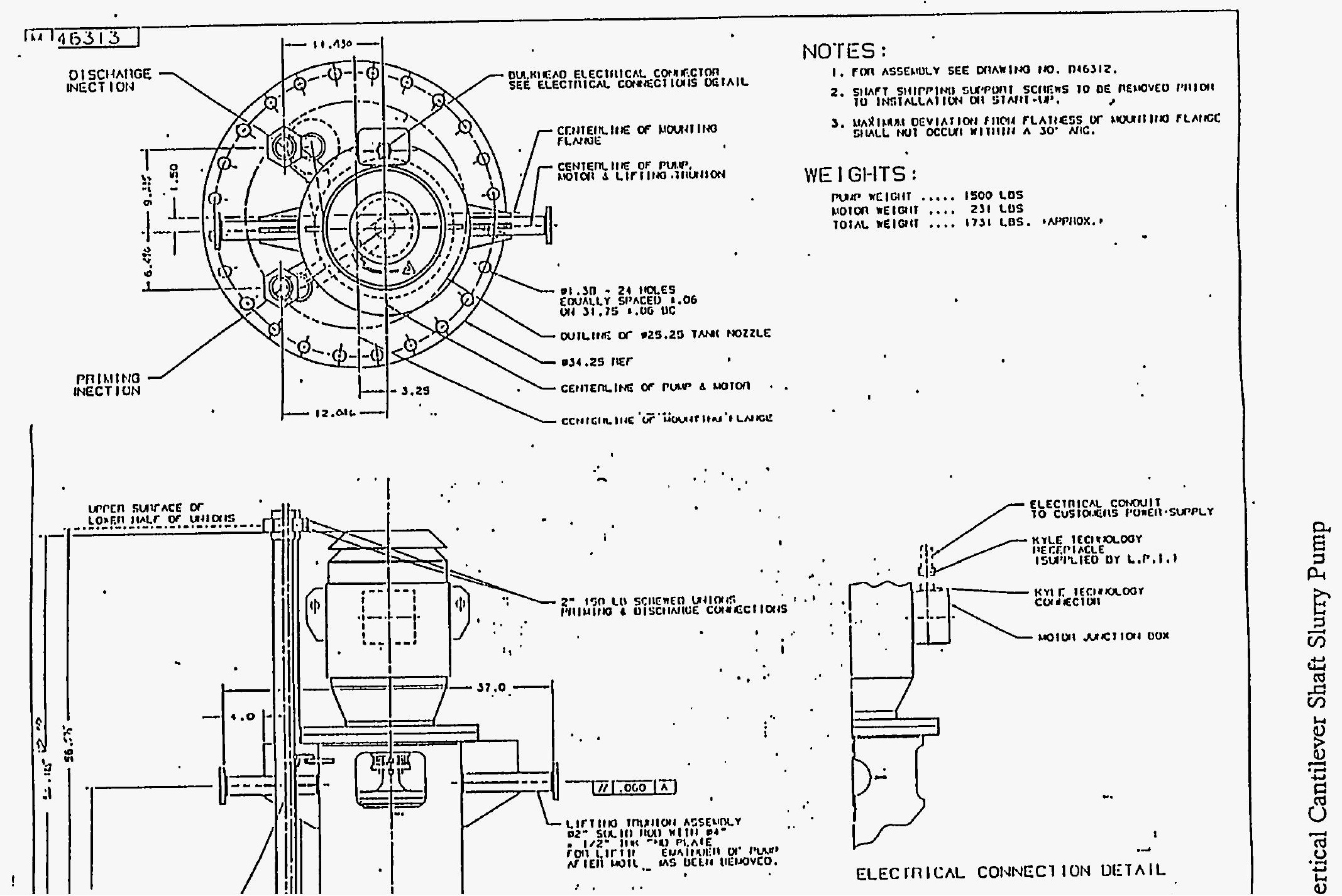




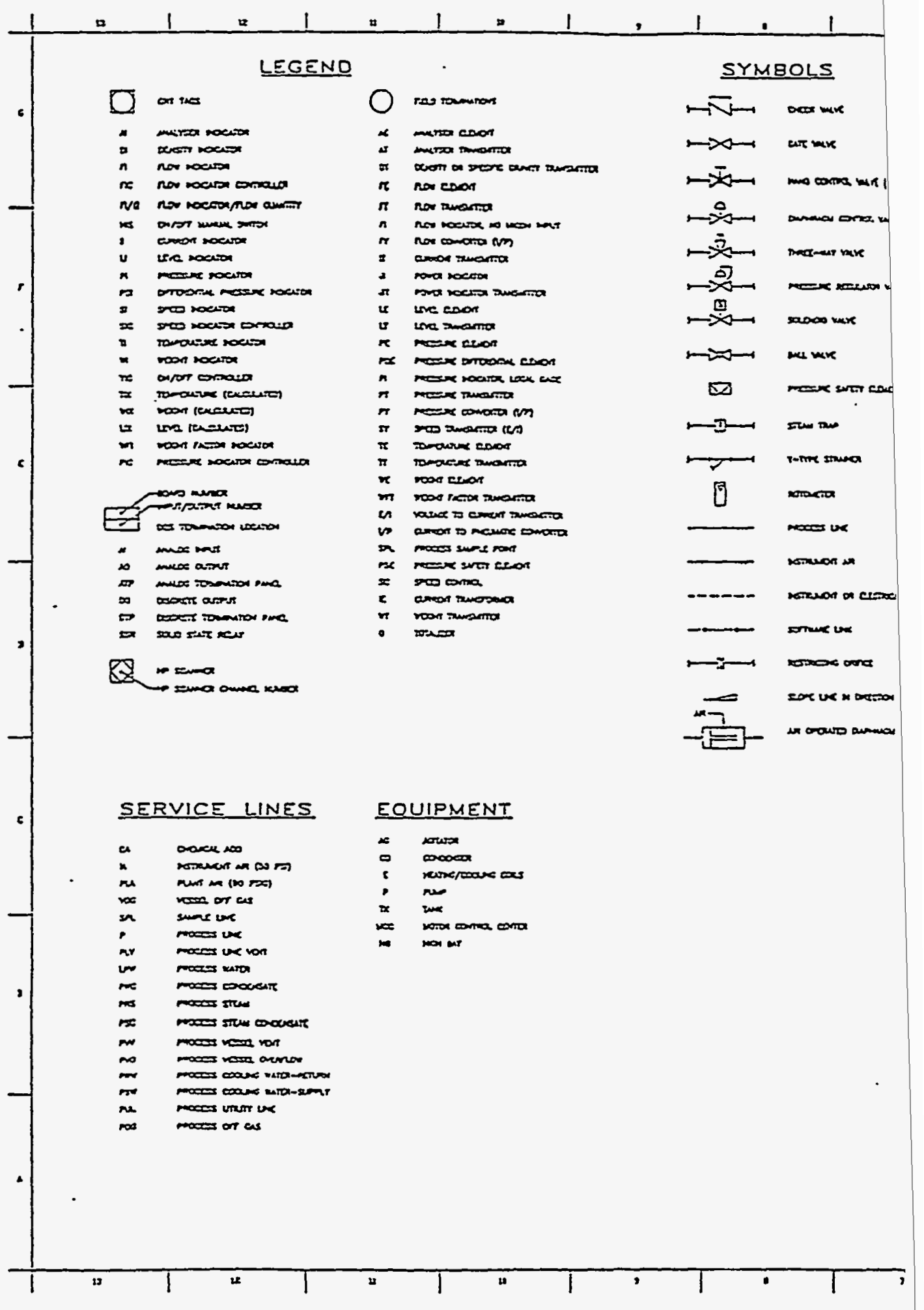

Figure A.8. HWVP Feed Prepar 


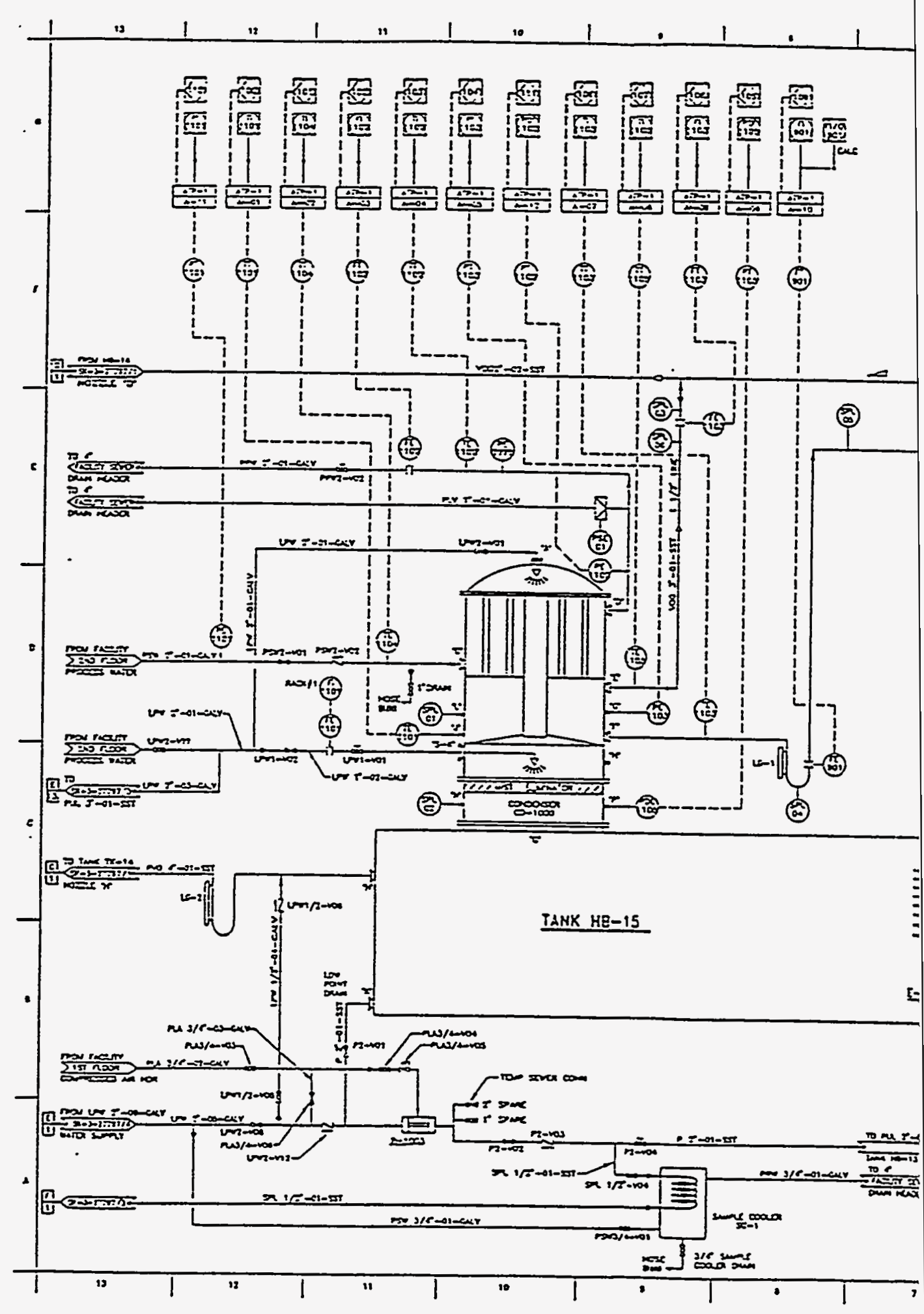

Figure A.8 


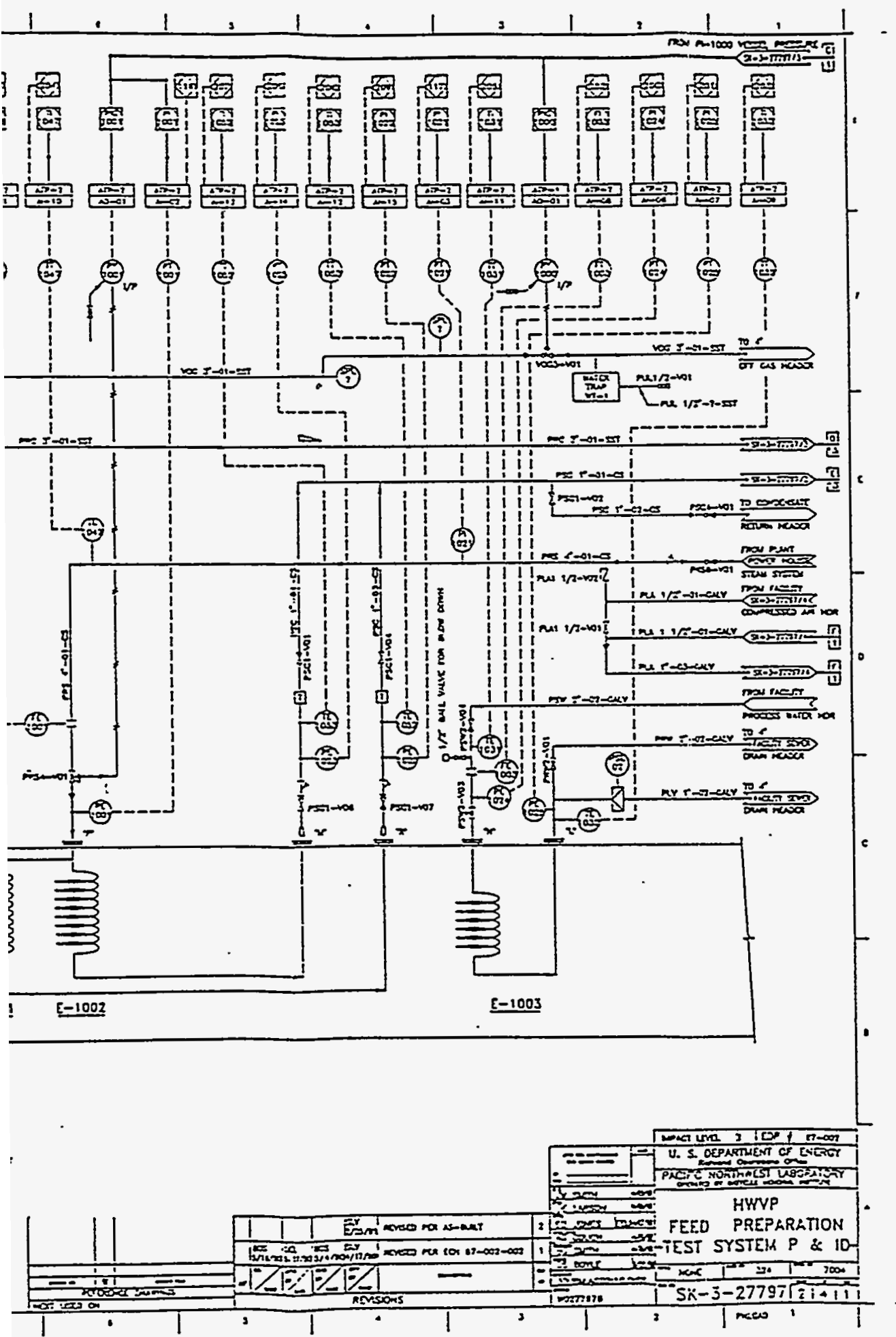

(contd) 


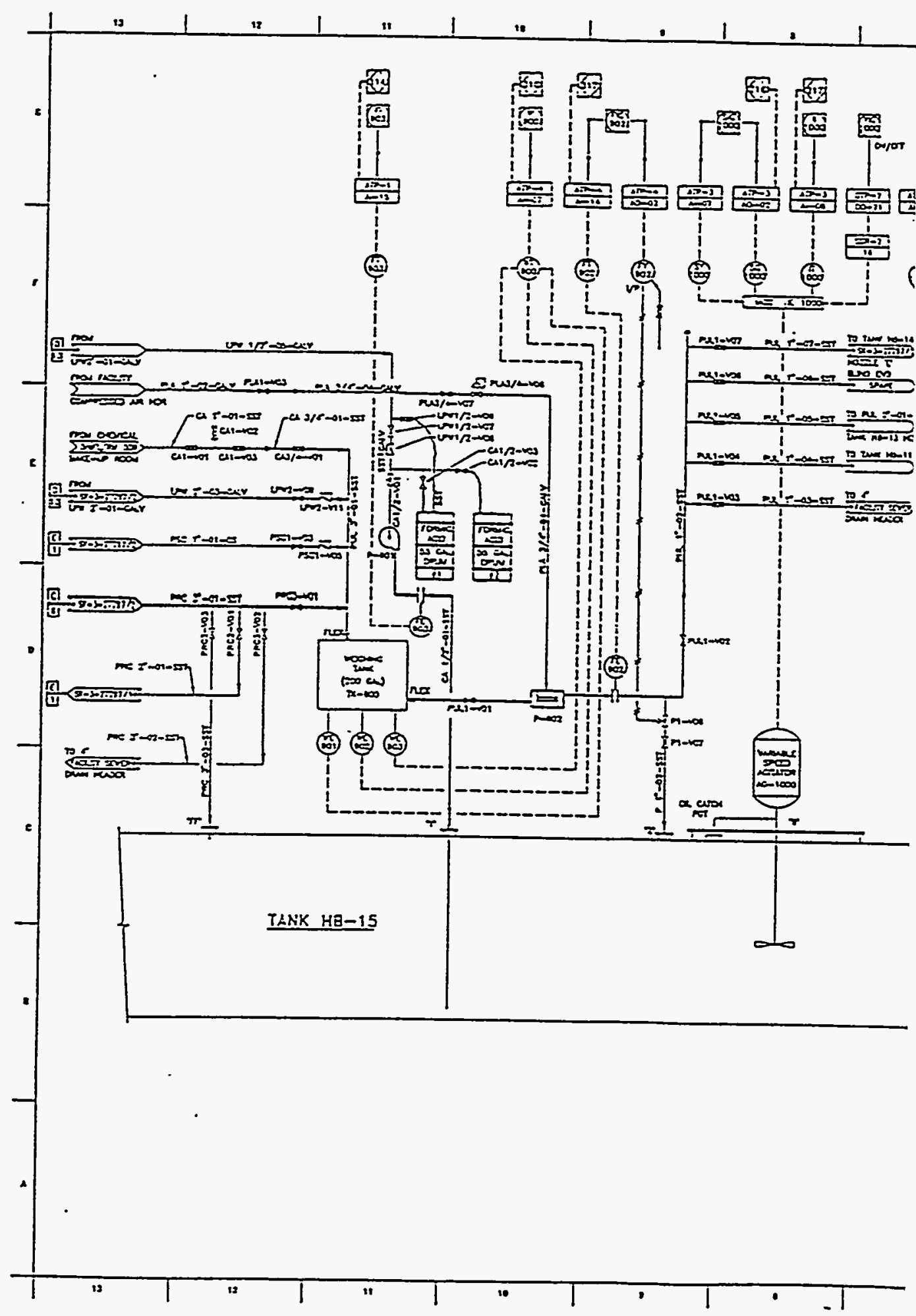

Figure A.8 


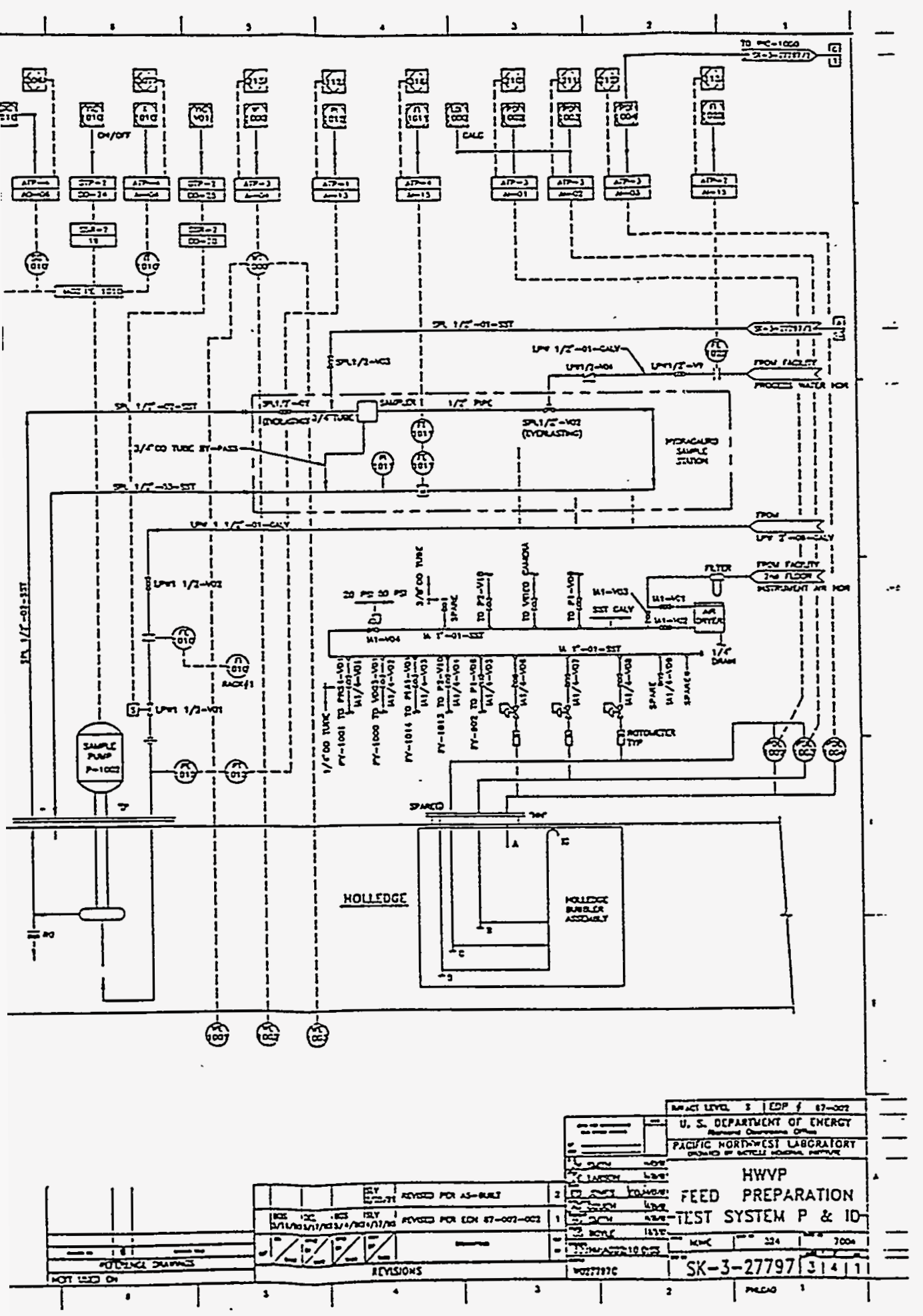

(contd) 

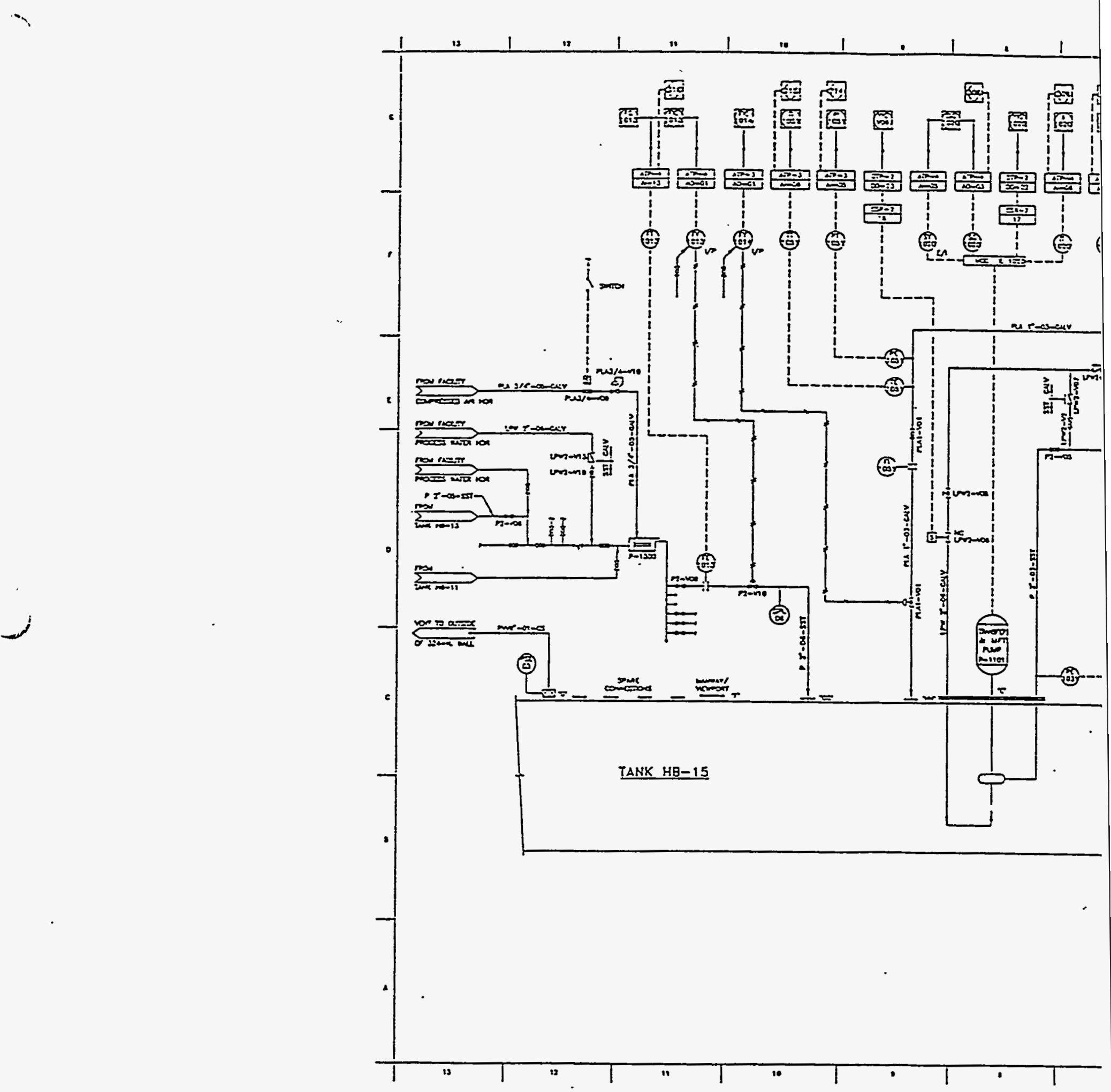

Figure A. 


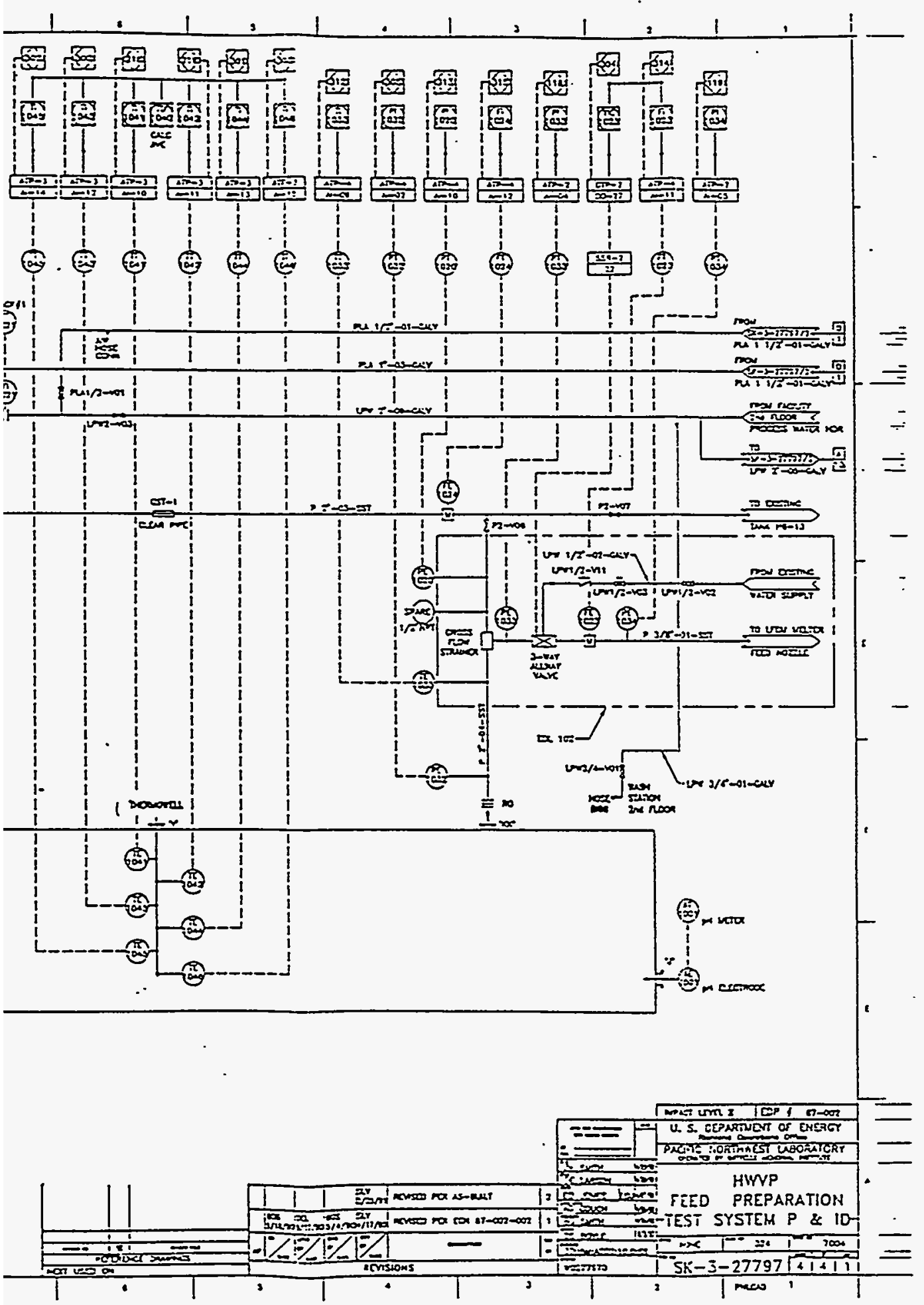

(contd) 


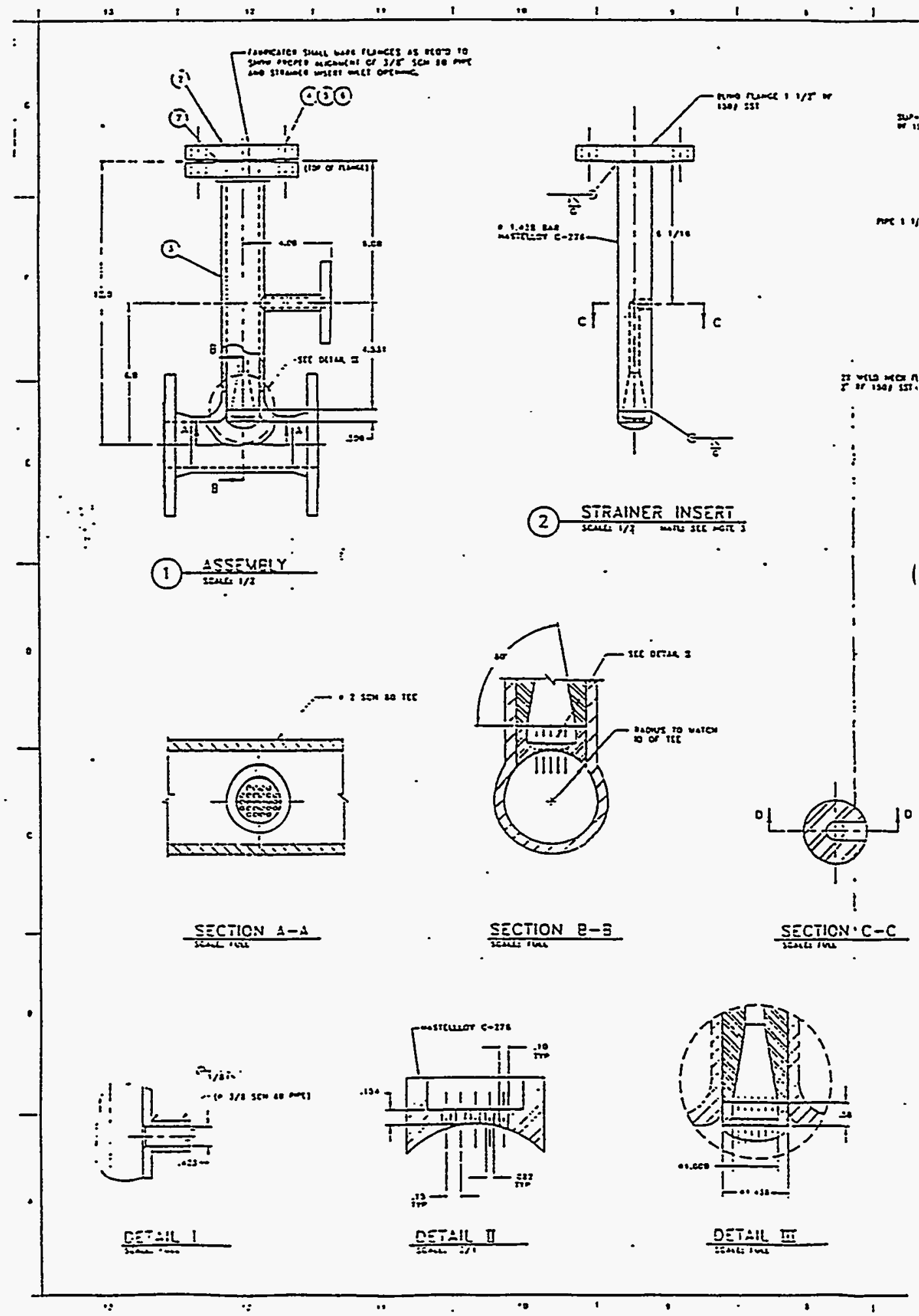

Figure A.9. HWVP Feed Prep. 


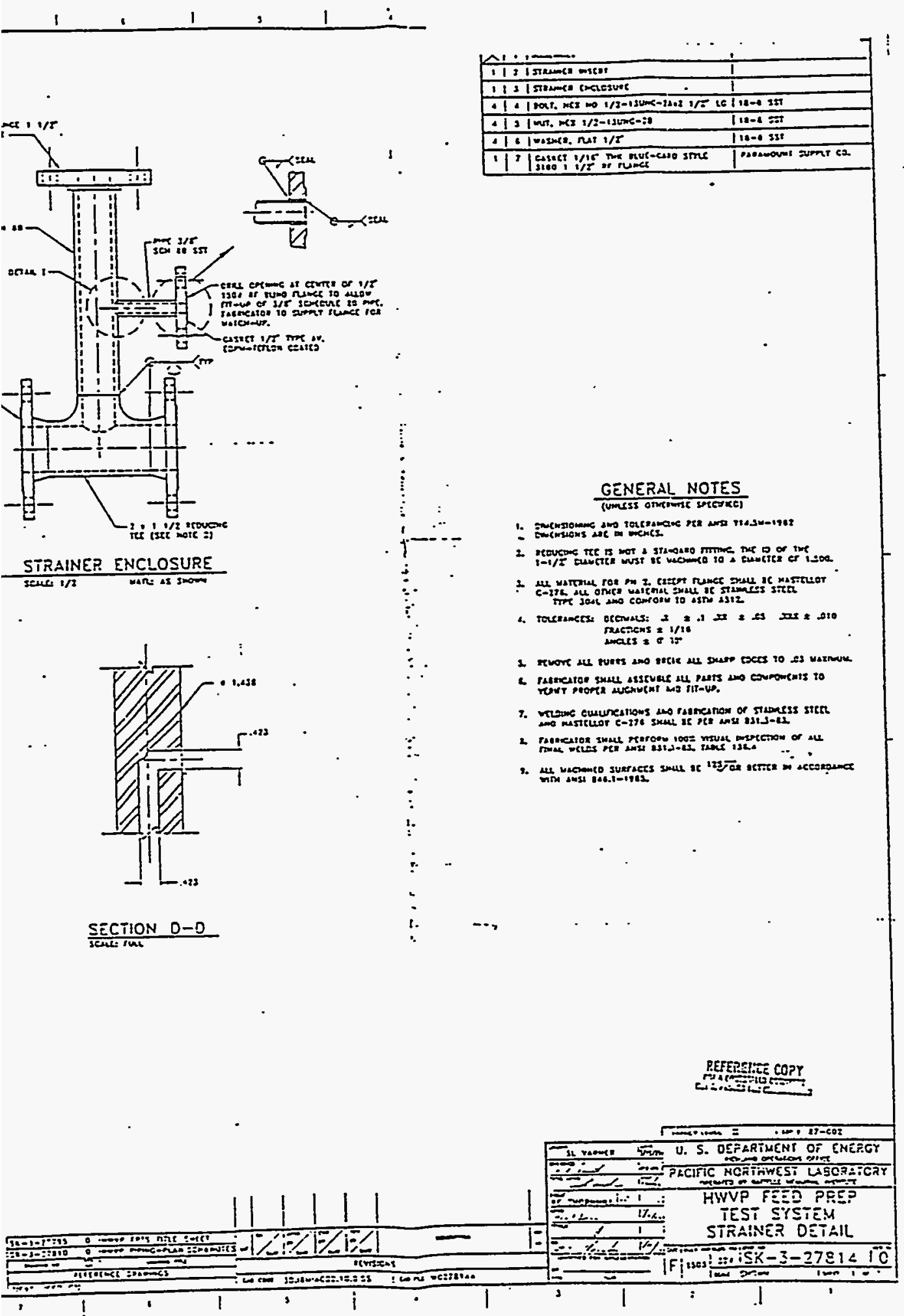

ation Test System Strainer Detail 


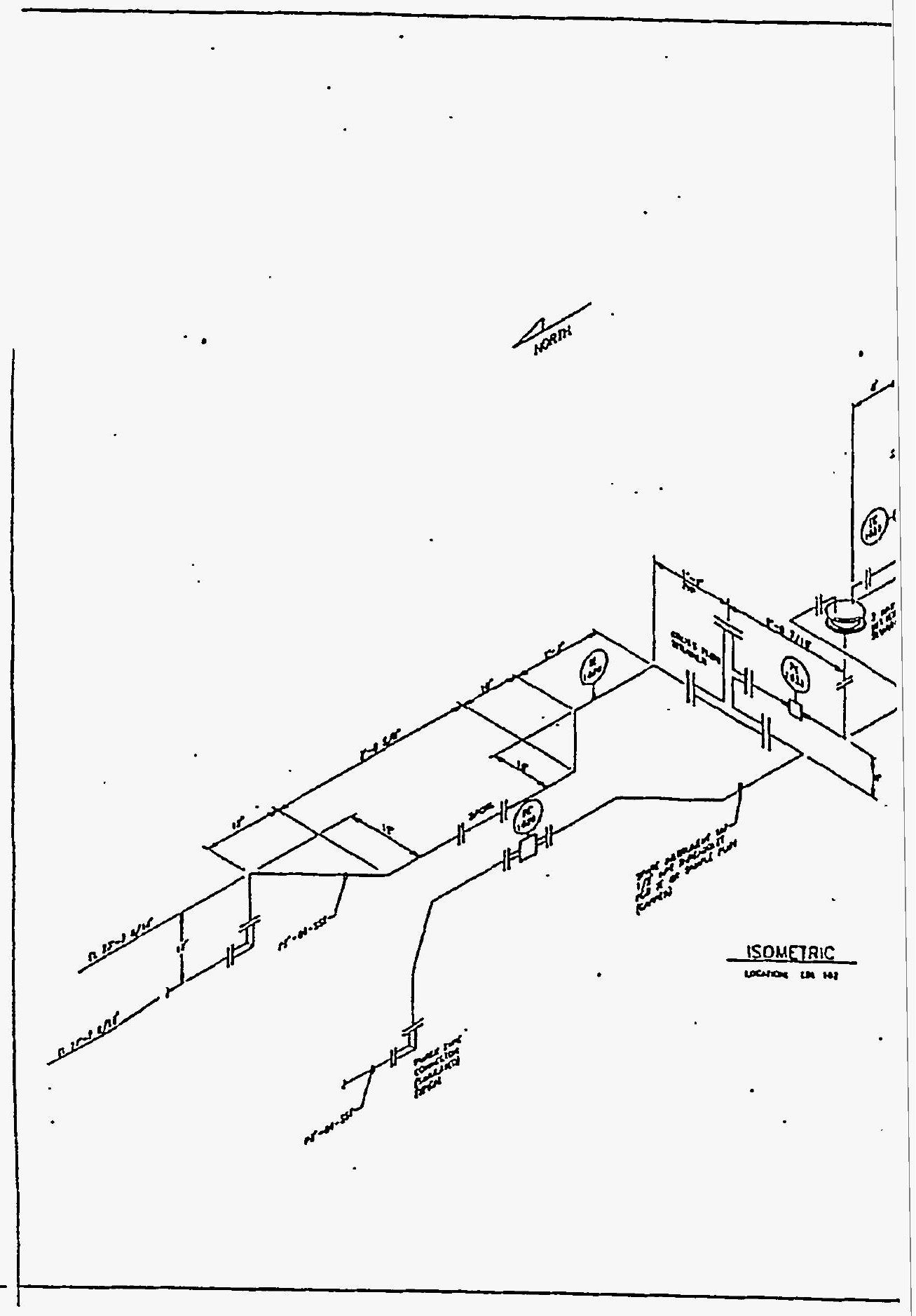

Figure A.10. Melter F 


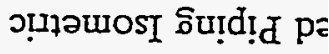

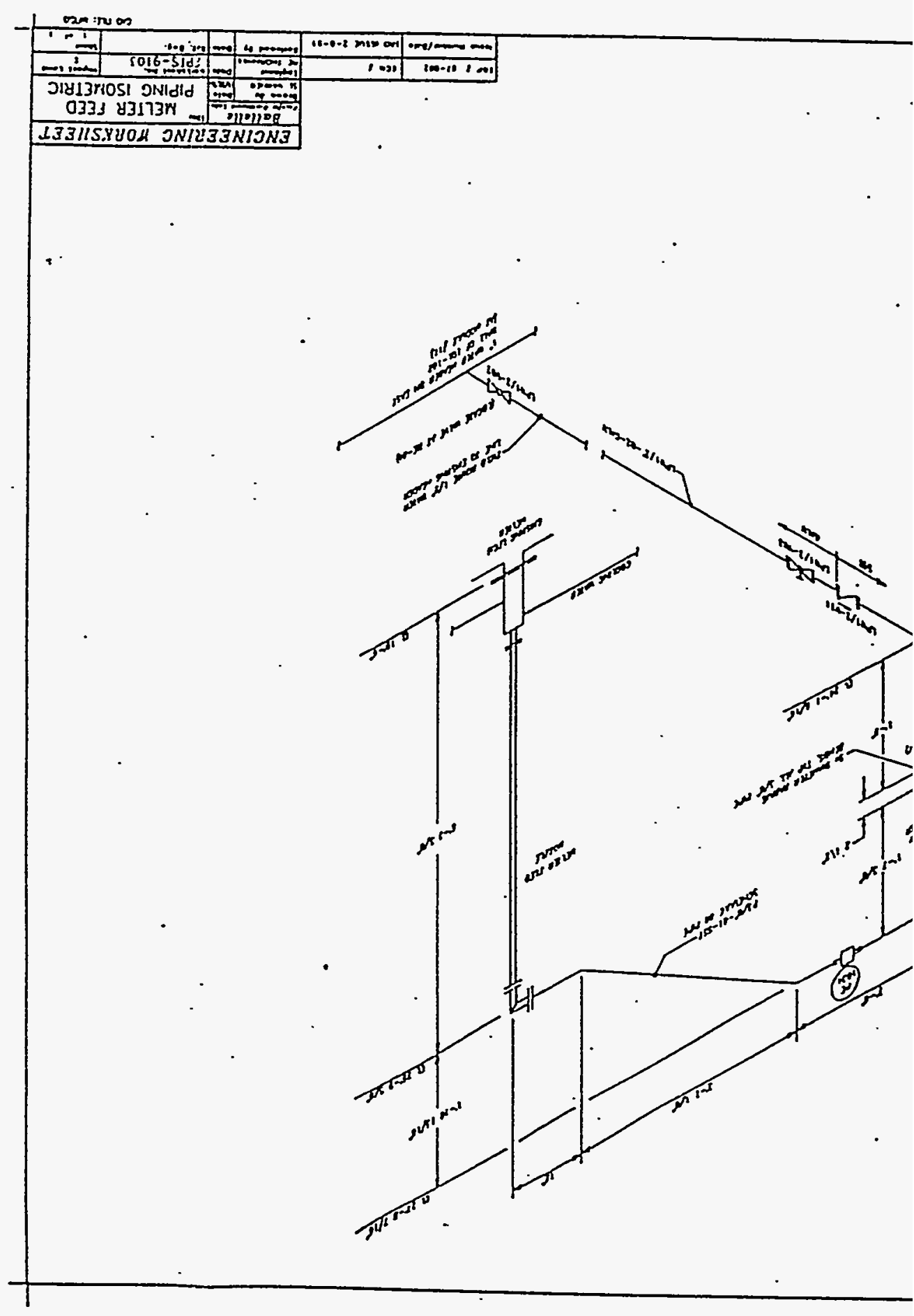




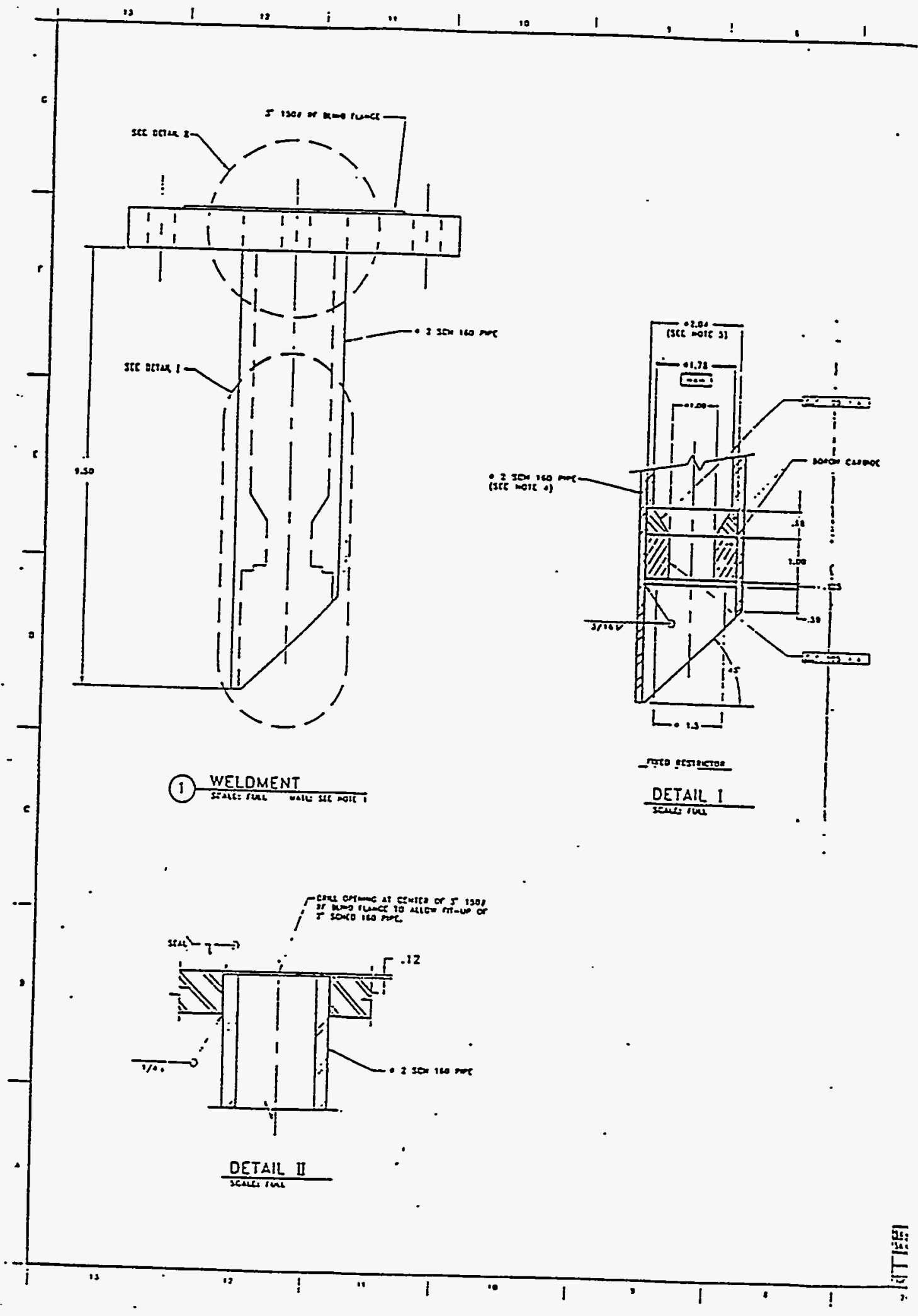

Figure A.11. HWVP Fee 


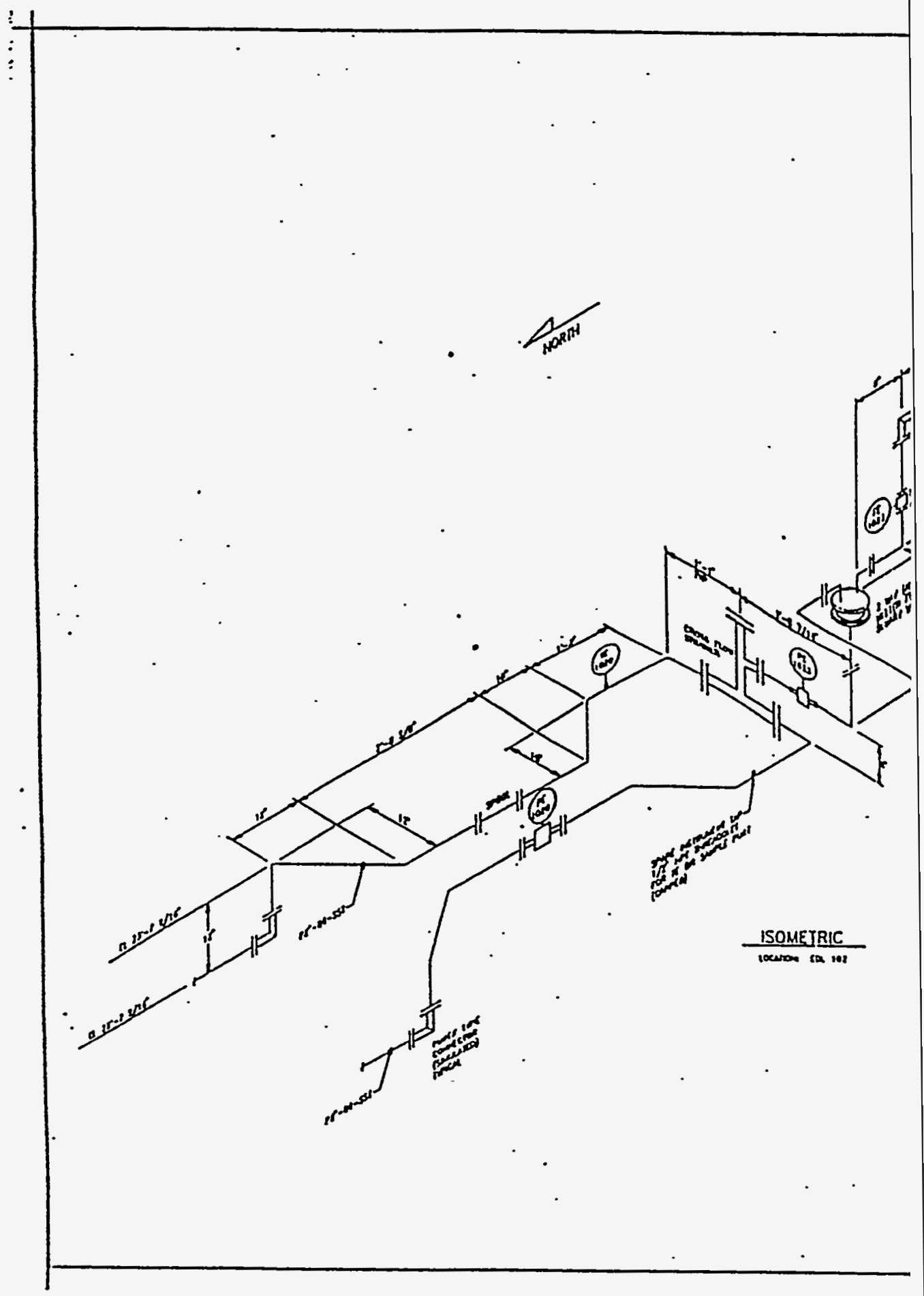

Figure A.12. Melter $\mathrm{Fe}$ 


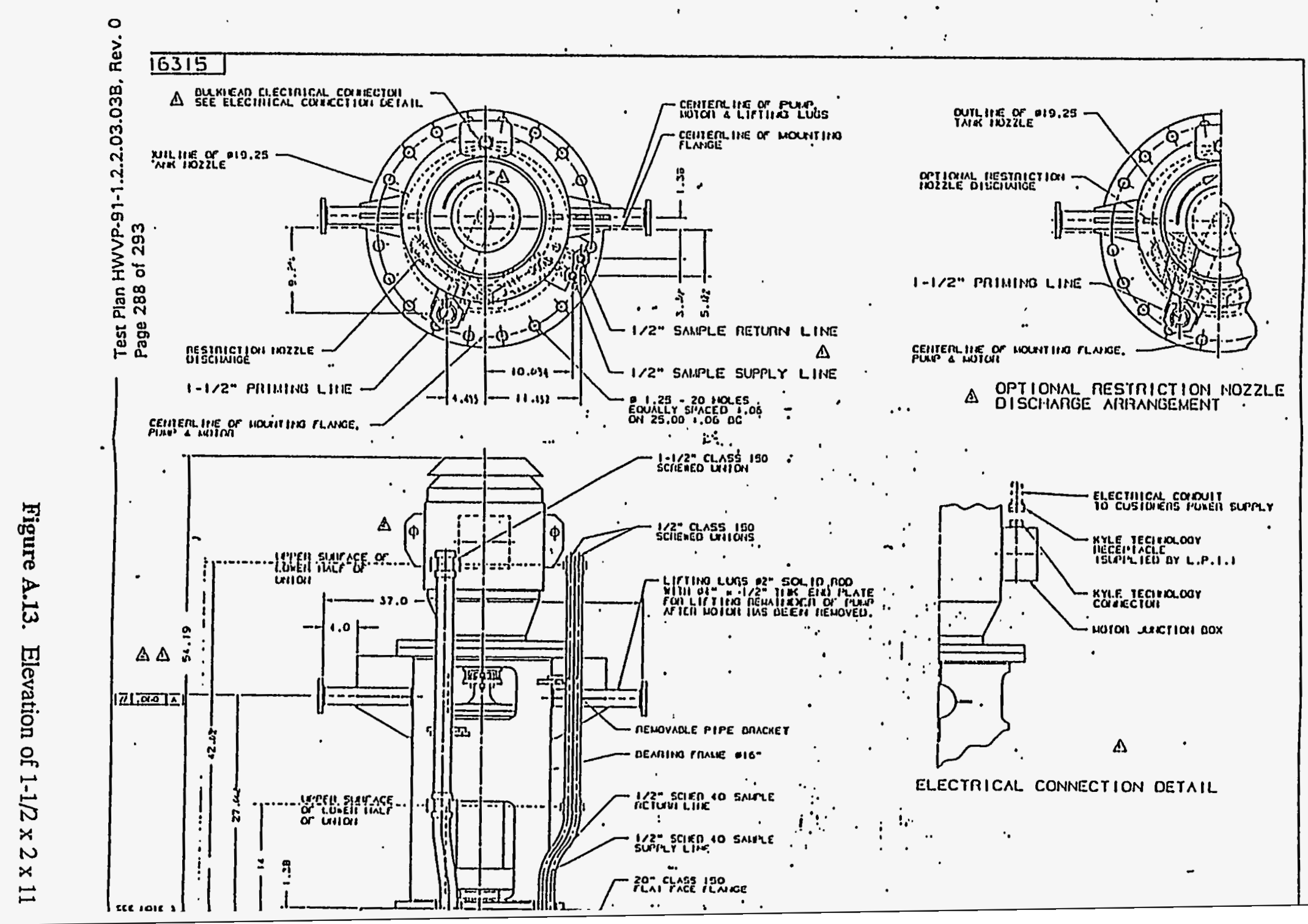




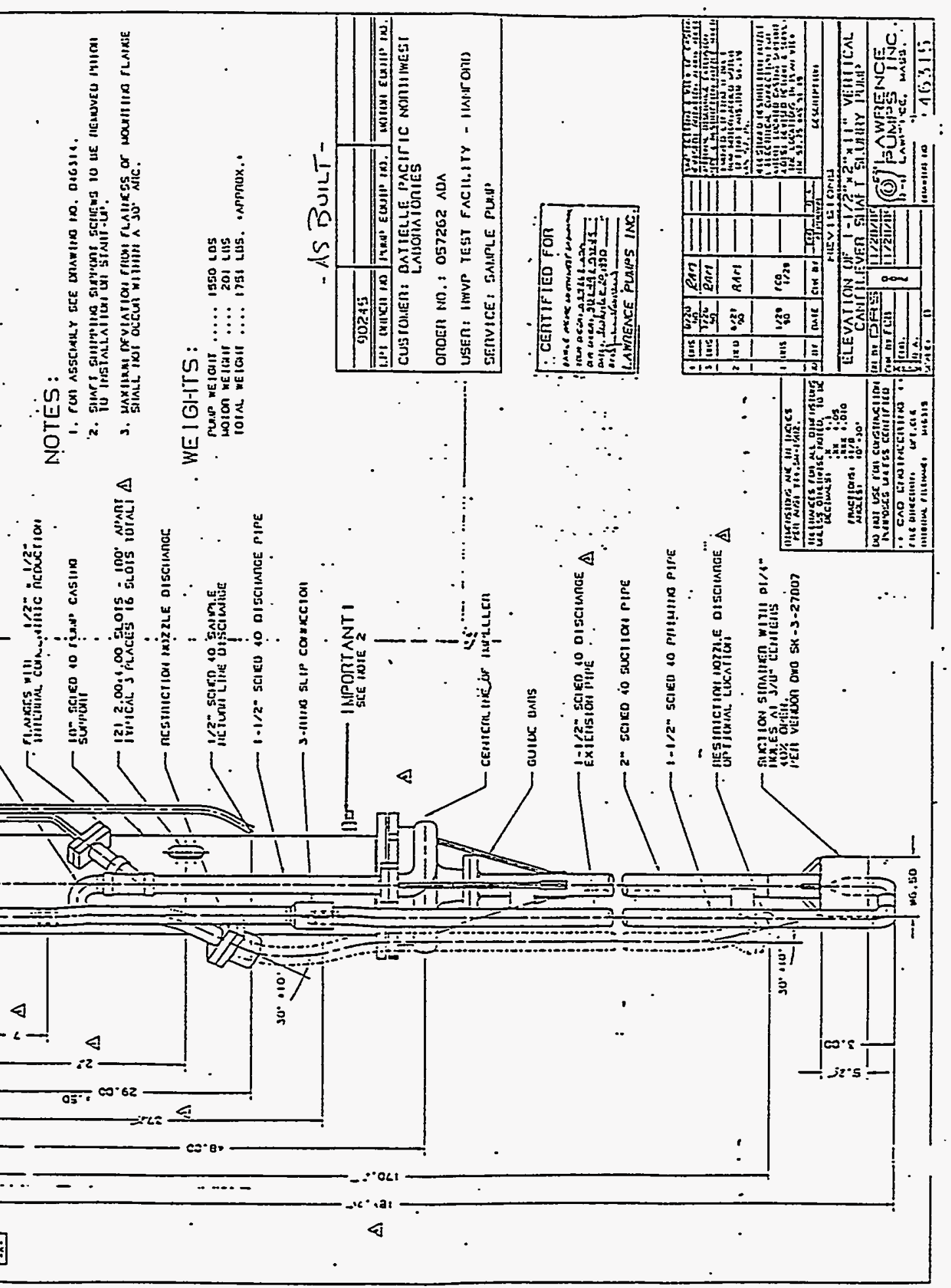

. Vertical Cantilever Shaft Slurry Pump 


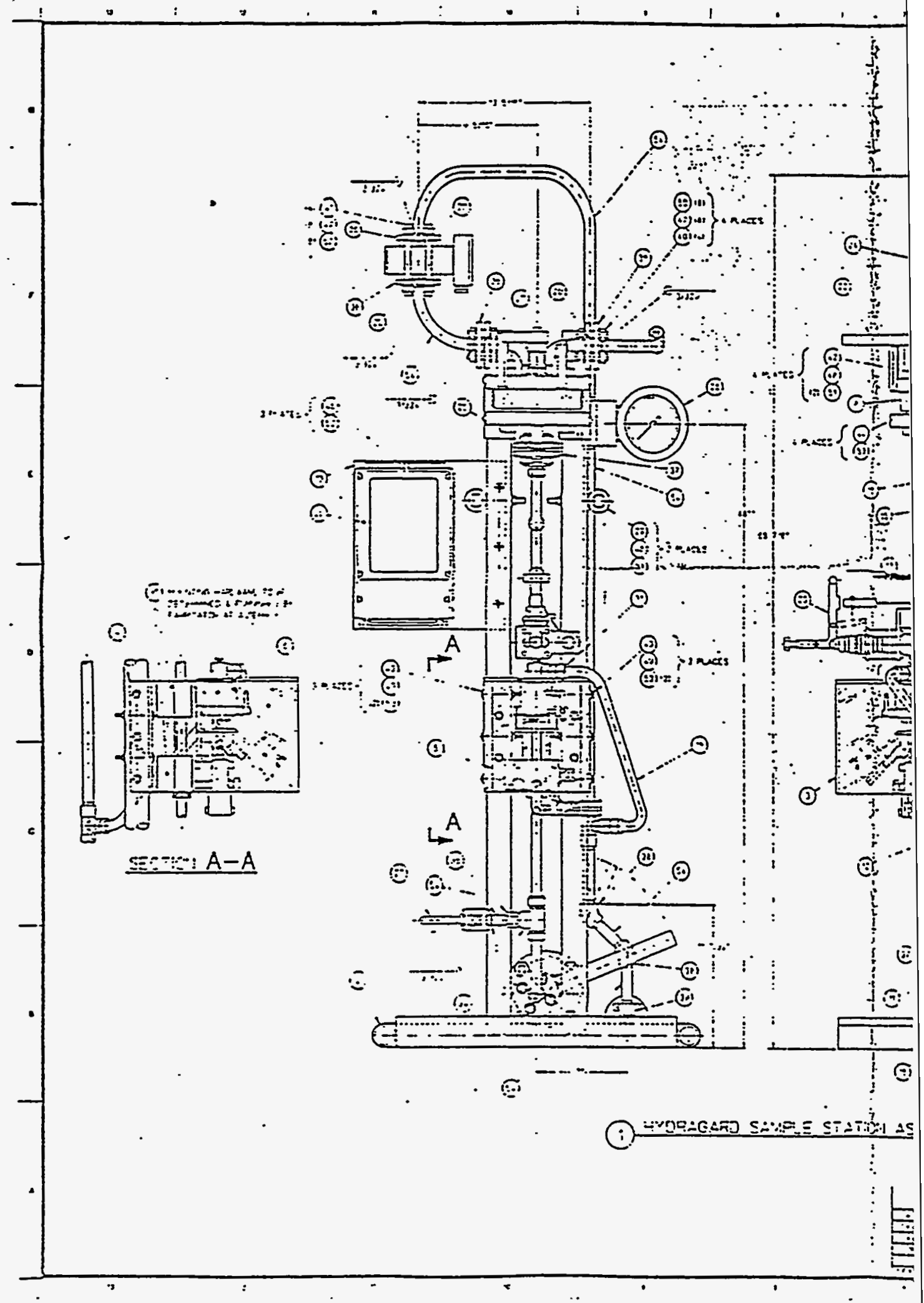

Figure A.14. Hydragard 


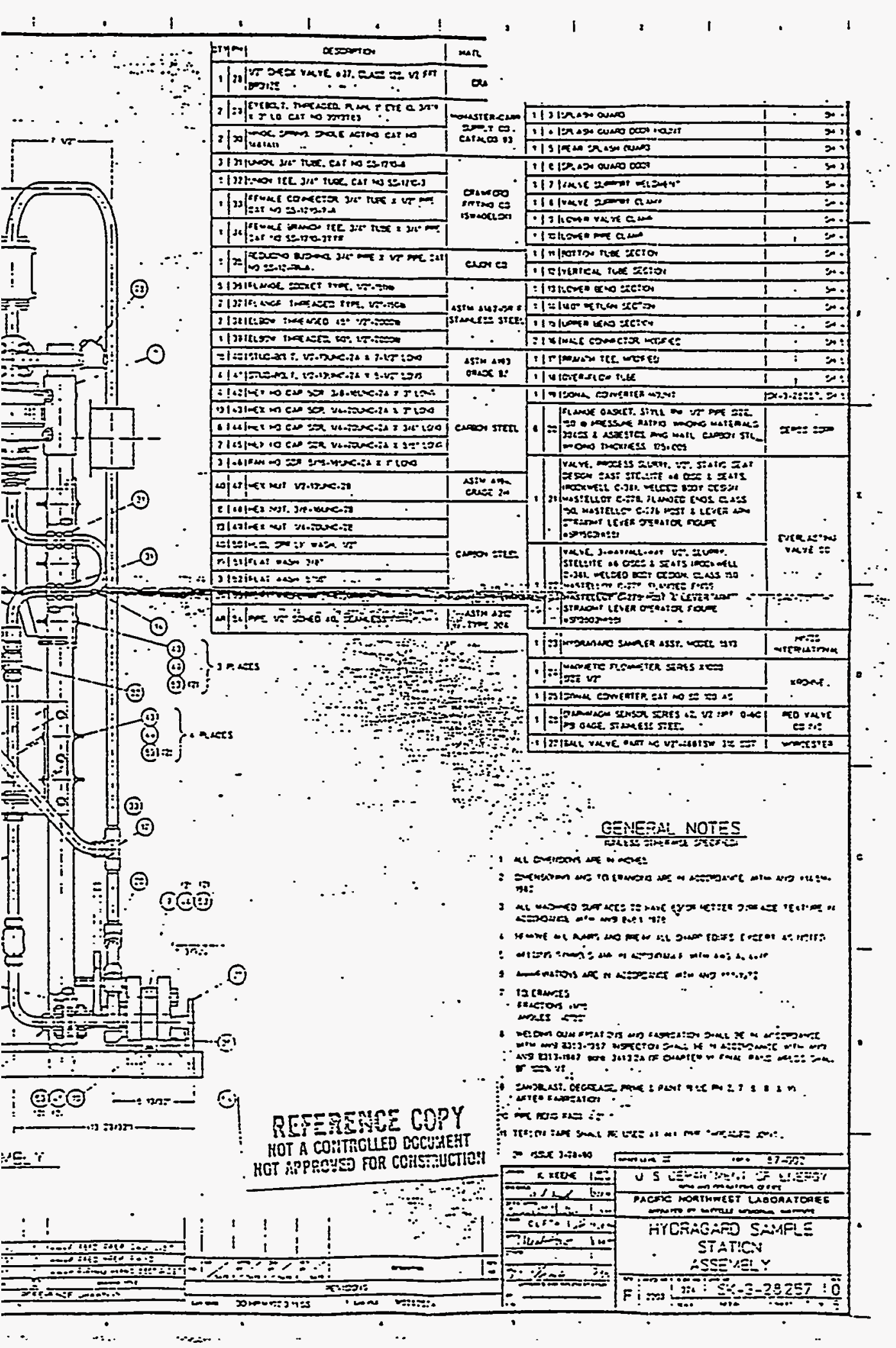

mple Station Assembly 


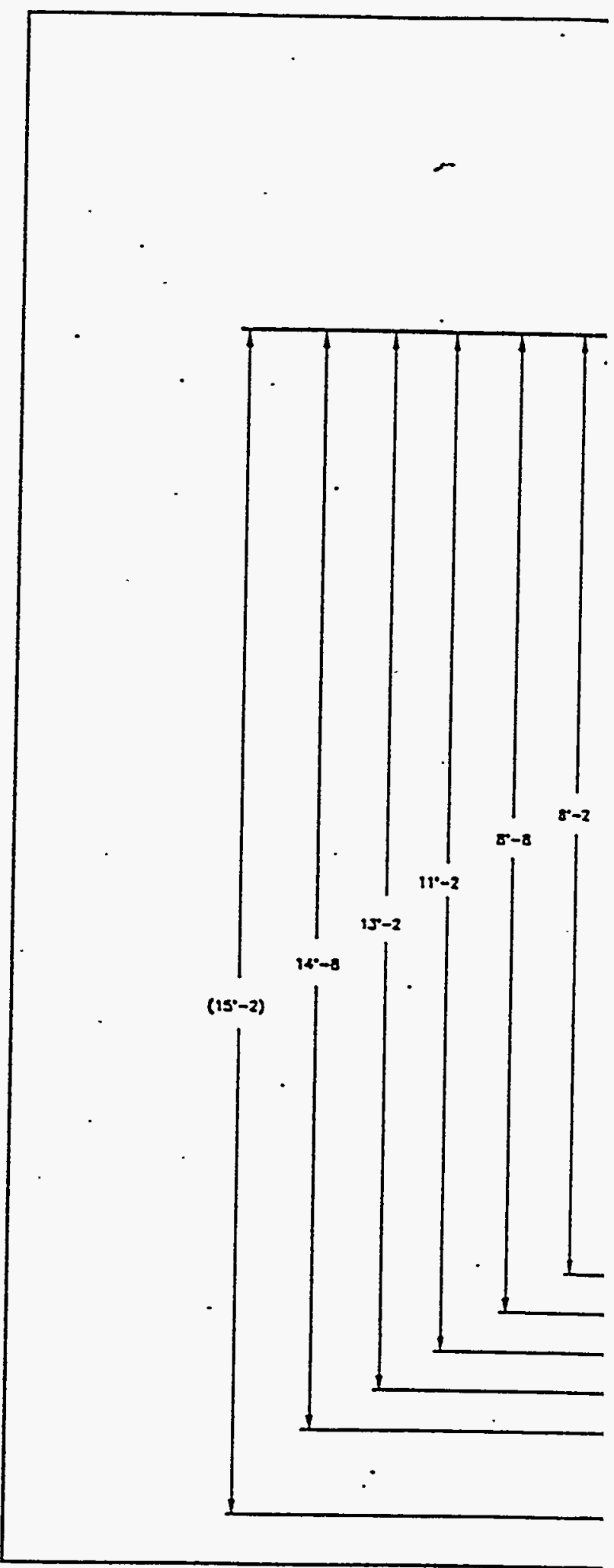

Figure A.15. Auxilia 


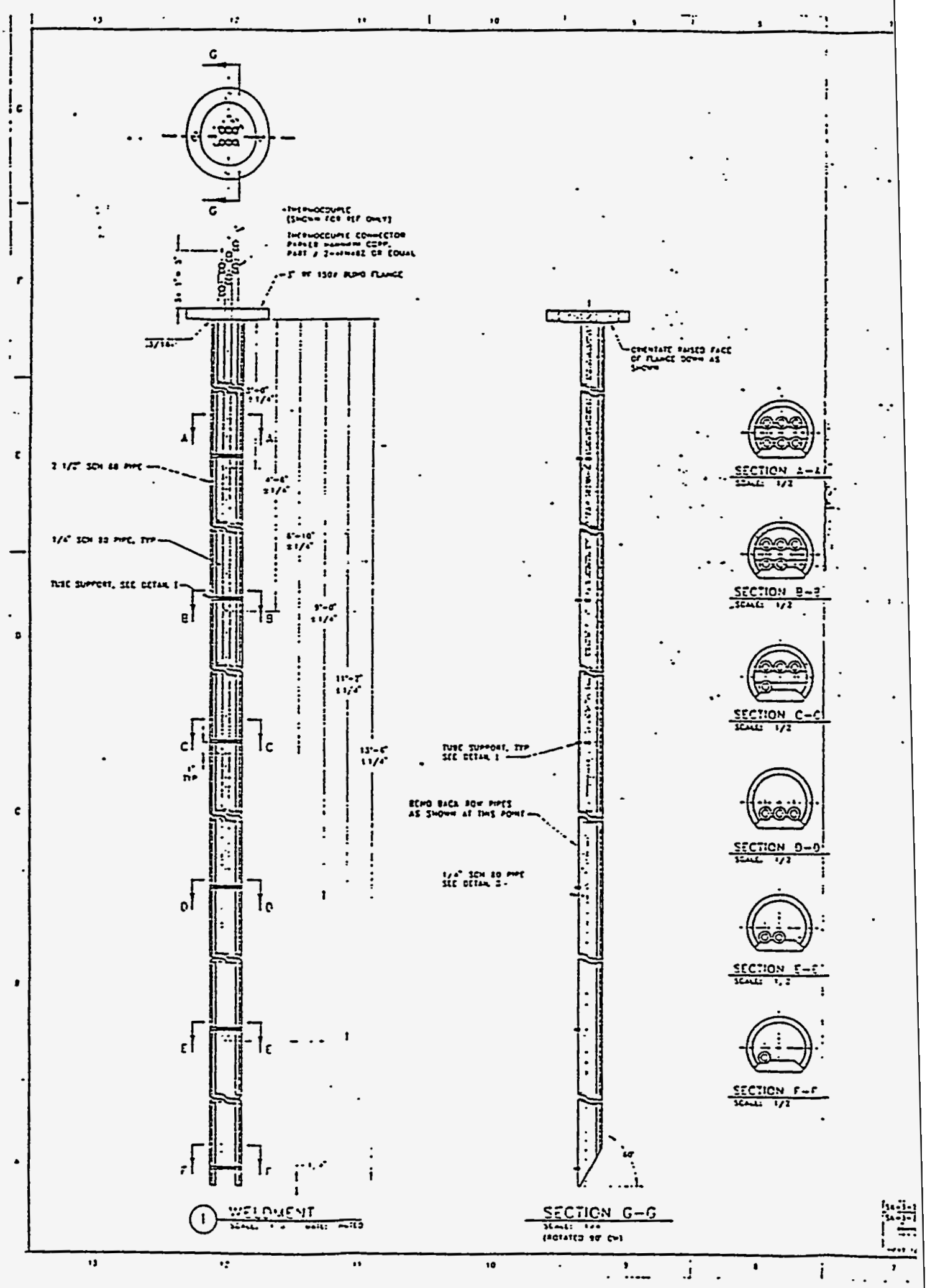

Figure A.16. HWVP Feed Preparati 


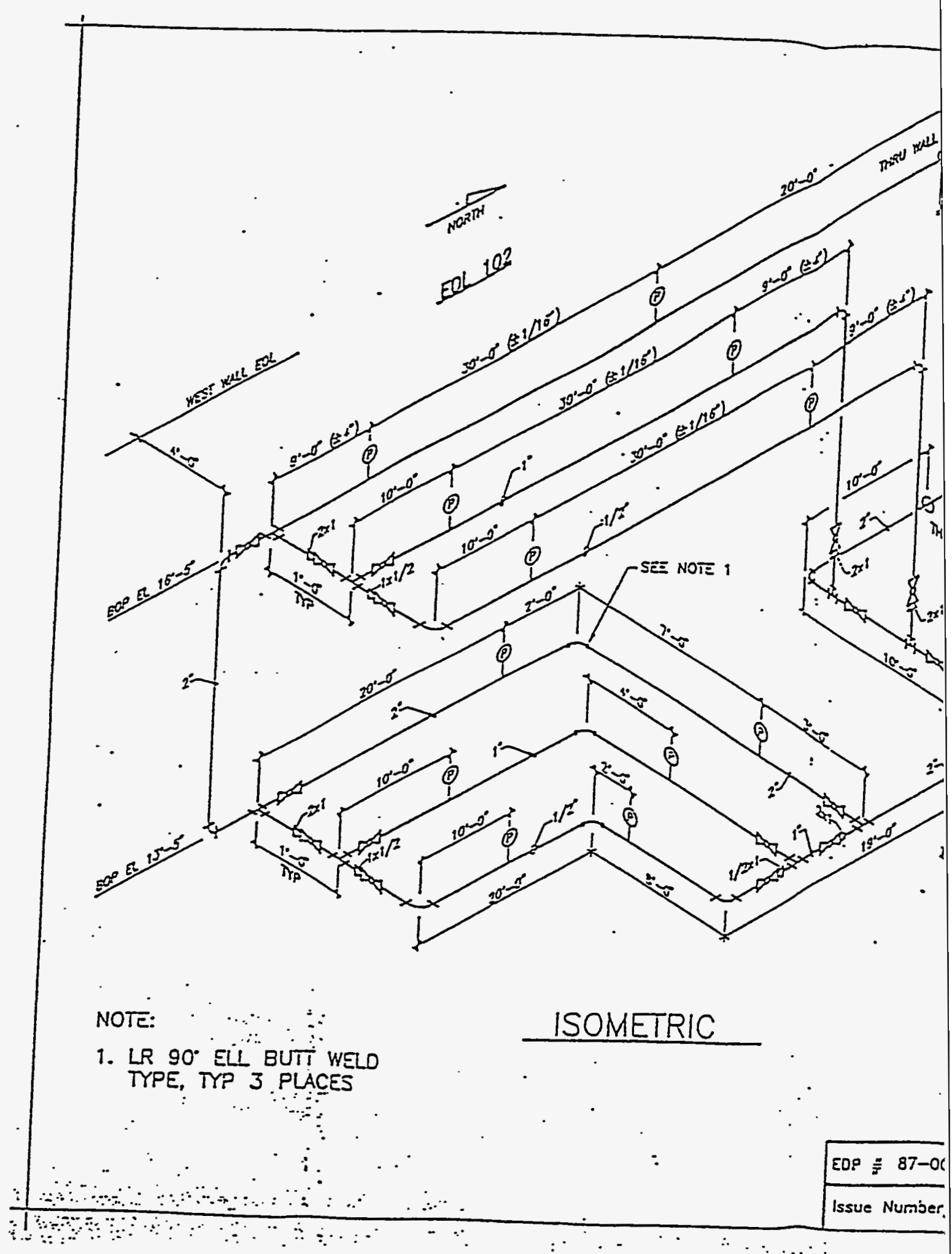

Figure A.17. HWVP Feed Pre 


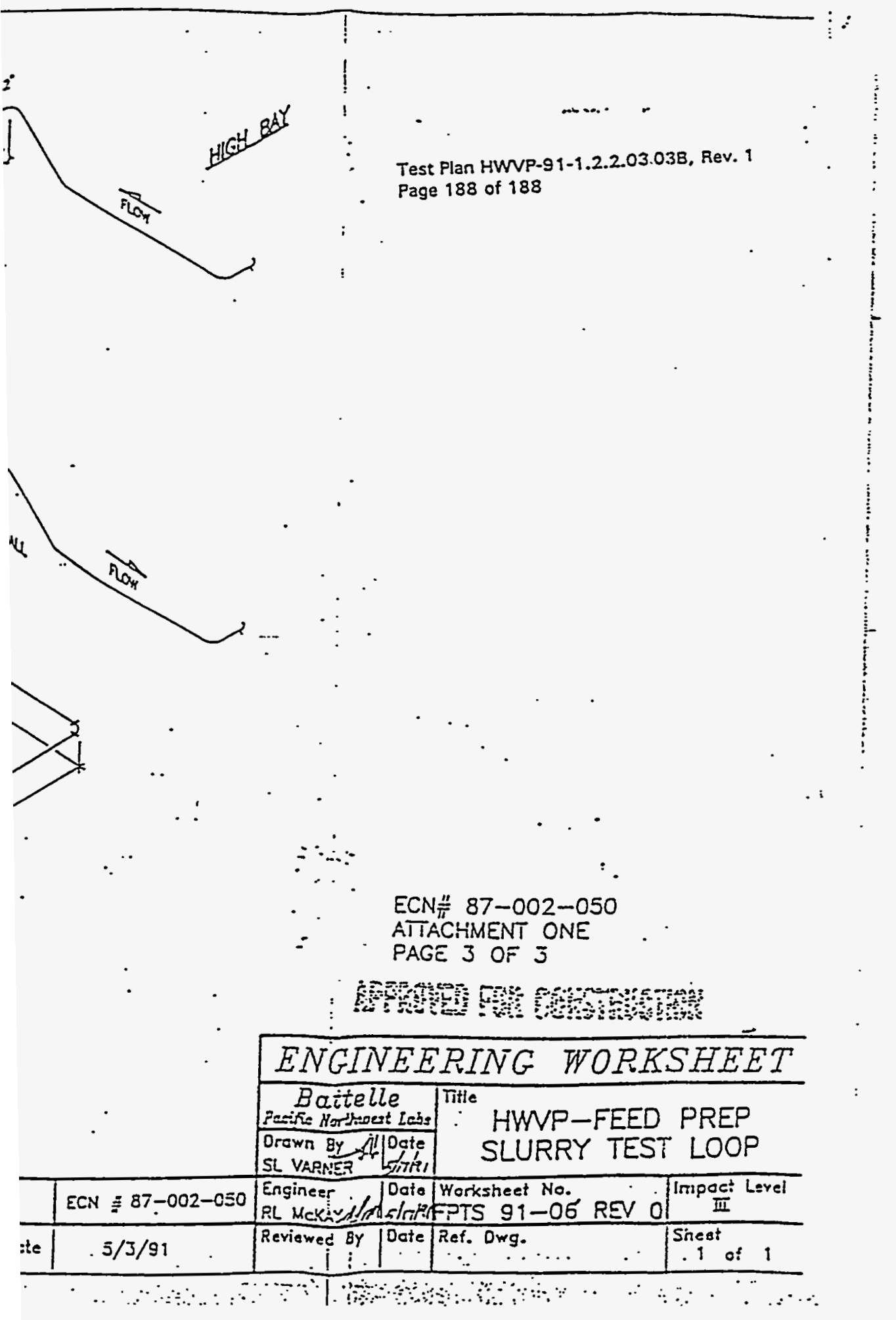

Iration Slurry Test Loop 


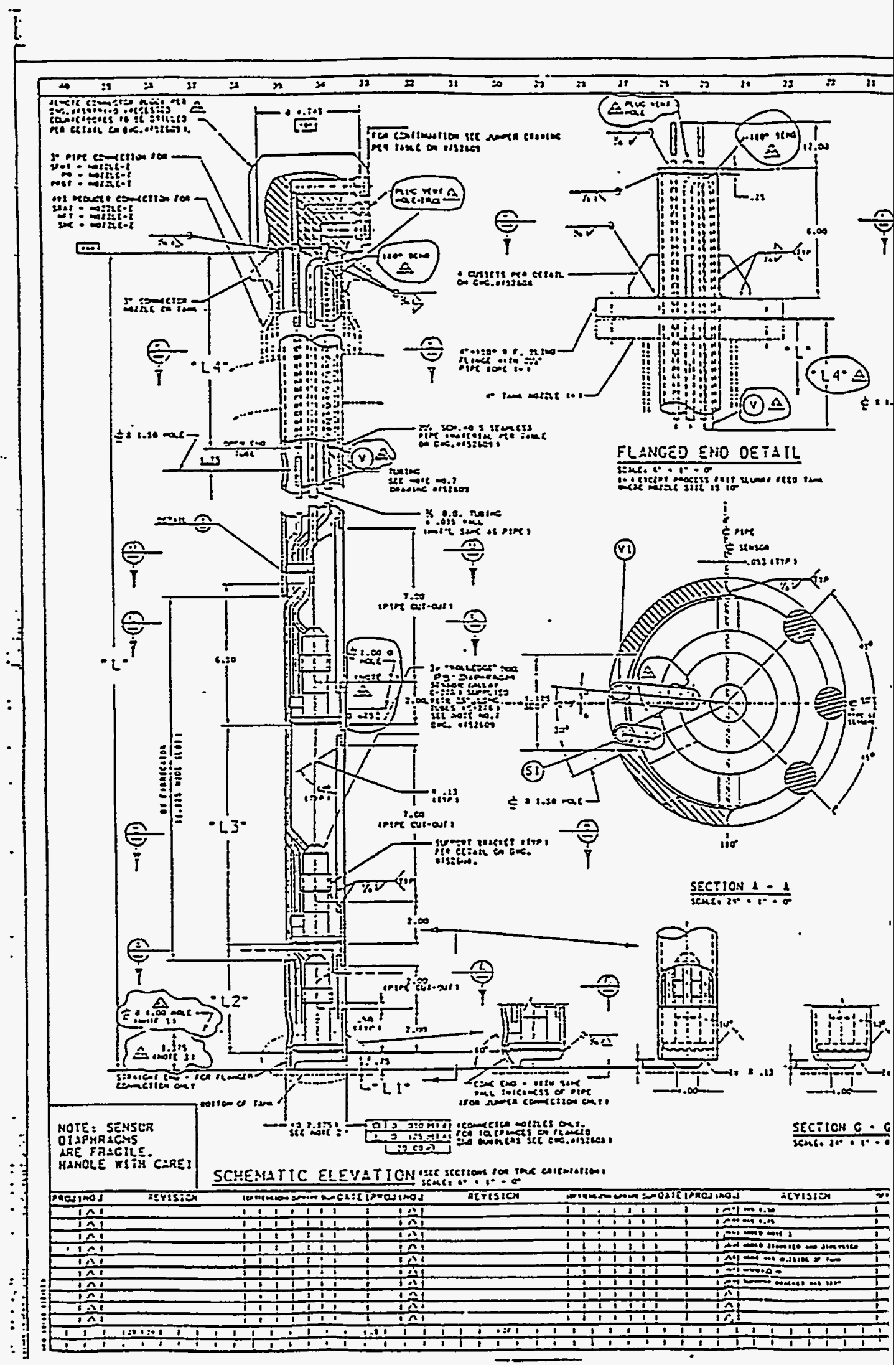

Figure A.18. Three Se 


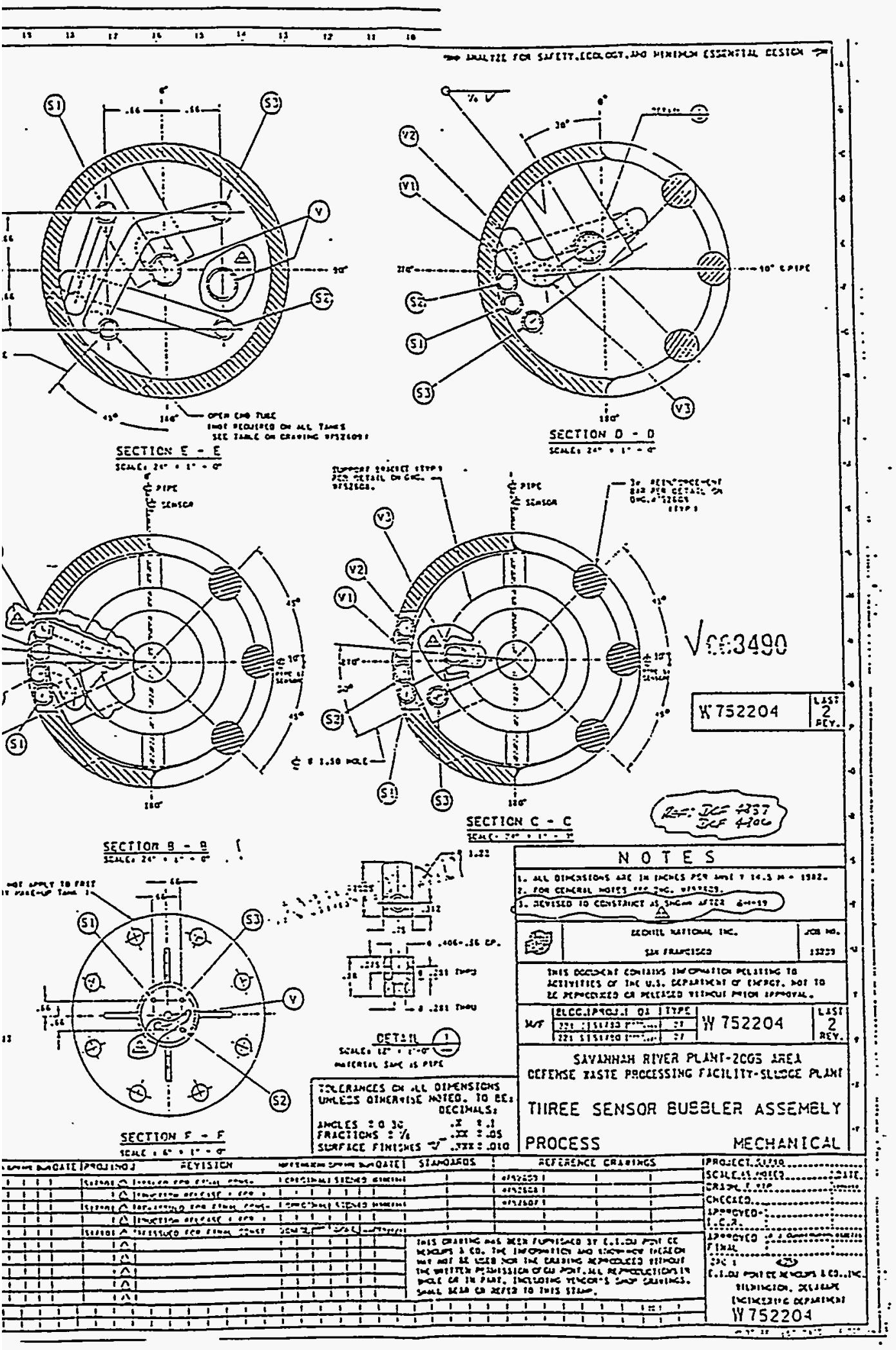

or Bubbler Assembly 


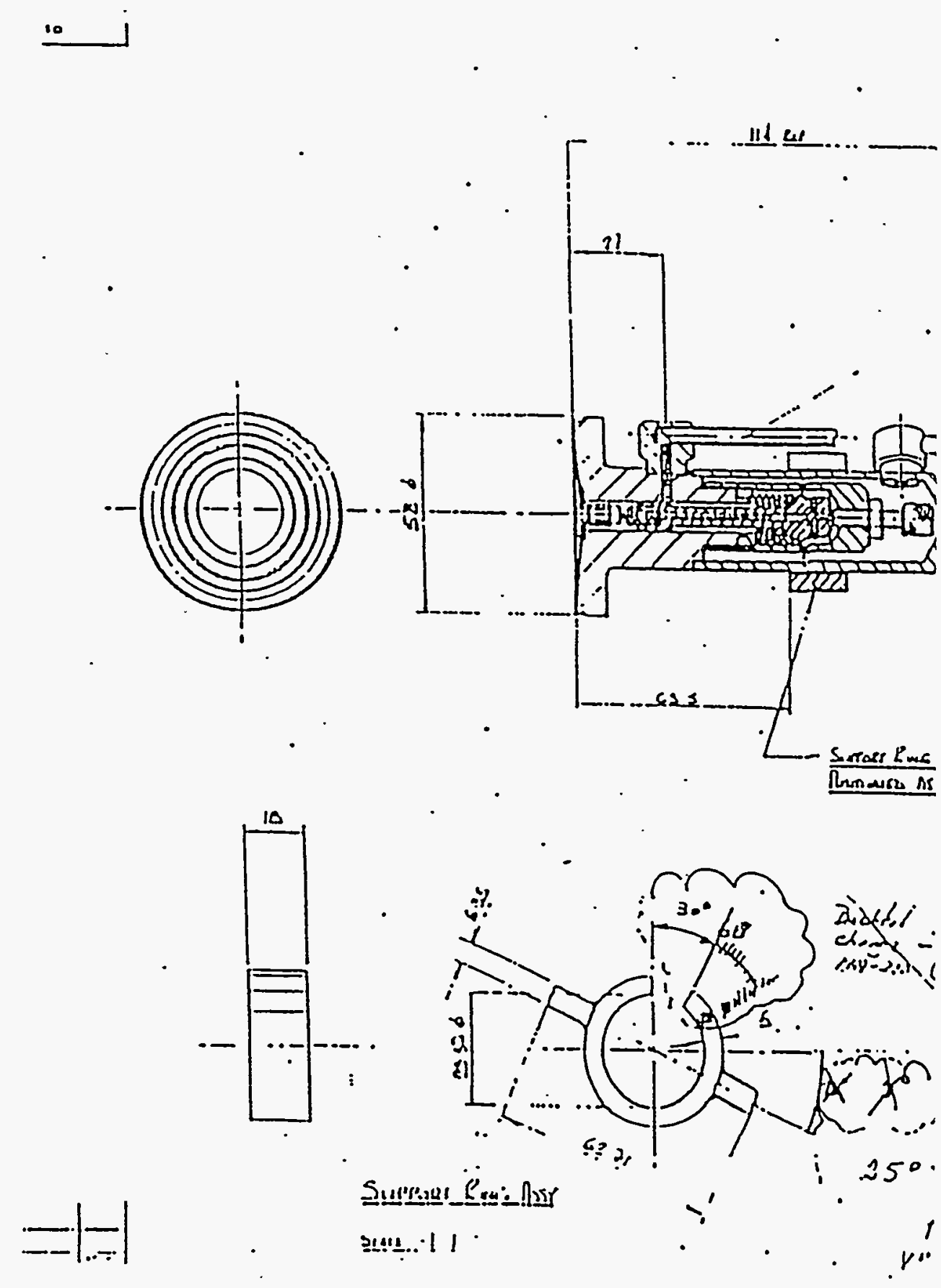

Figure A.19. Cross-Secti 


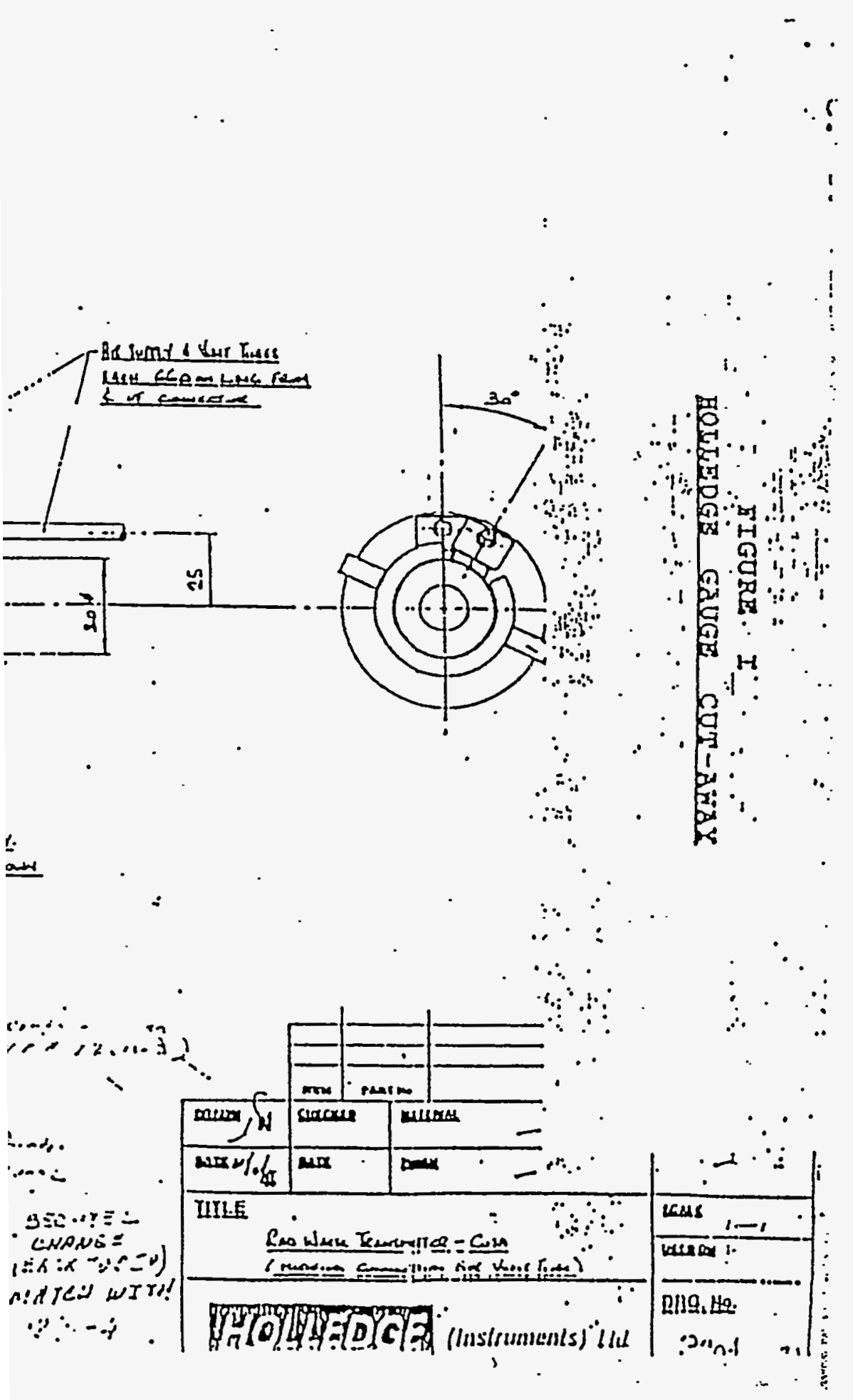

of Holledge Sensor 


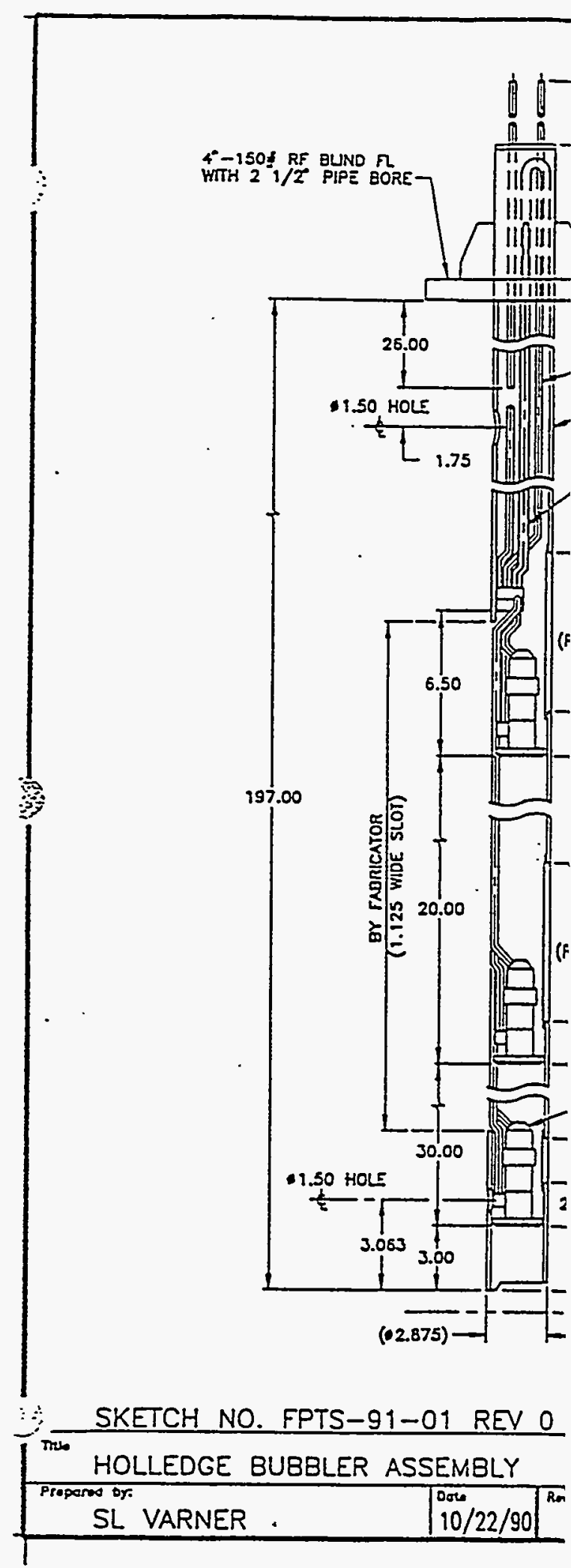

Figure A.20. Holled! 


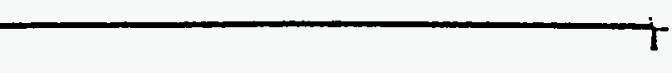

-

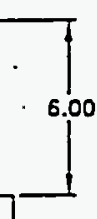

$-1 / 2$ OD TUEING $\times .035$ WALL TP

$21 / 2 \operatorname{sen} 40 \mathrm{~S}$ SEMLESS PIPE

3/8 O0 TUBING $\times .035$ WALL

7.00

1.00

cur our)

100

T

2.00

2.00

I SENSOR DUPHRAM. TRP

1

2.00 (PIPE CUT OUT)

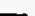

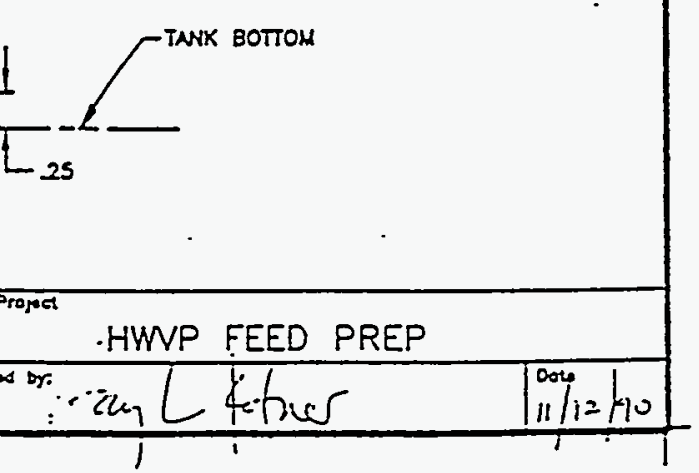

Bubbler Assembly 


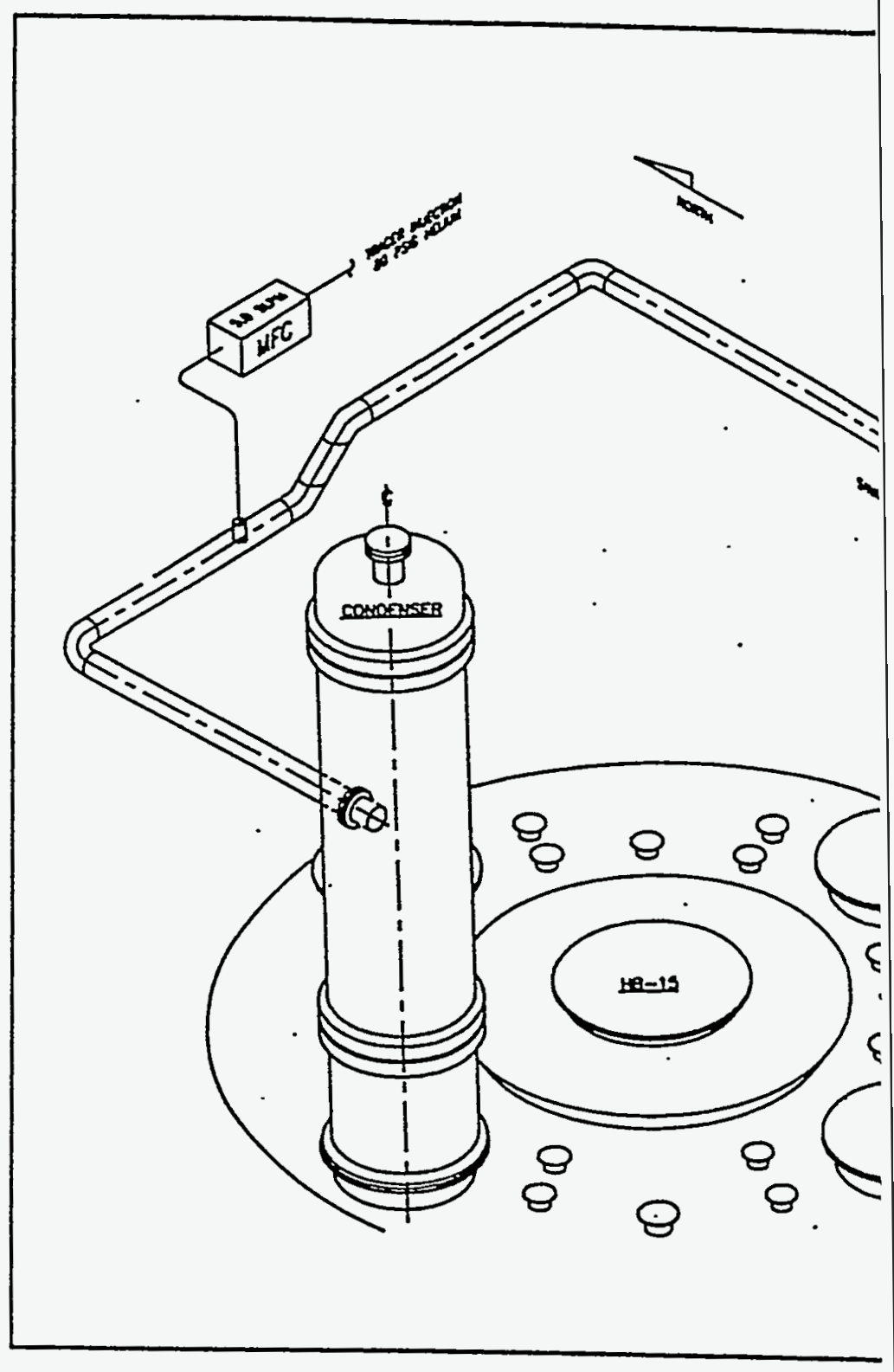

Figure A.21. Offgas Characl 


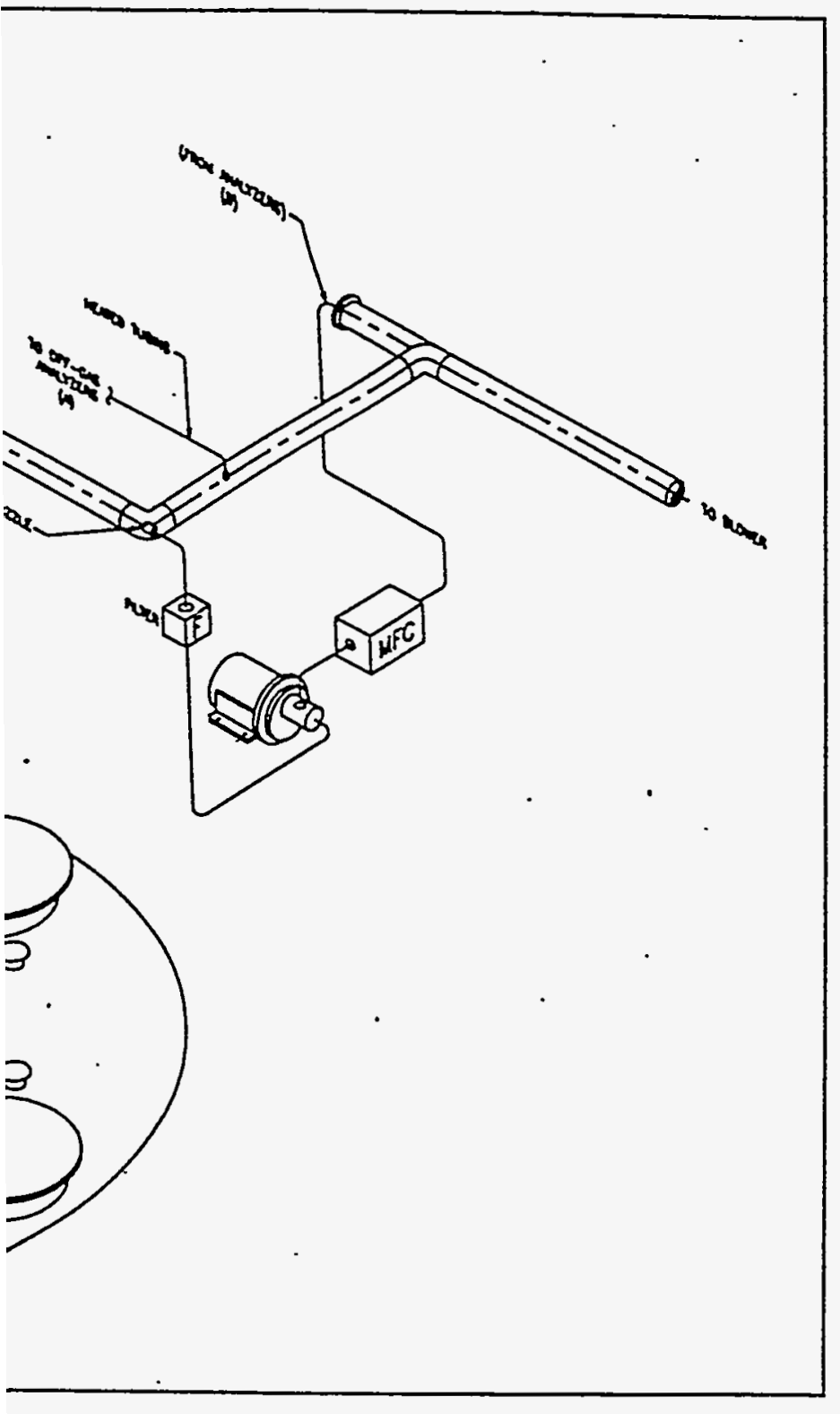

ization System (part 1) 


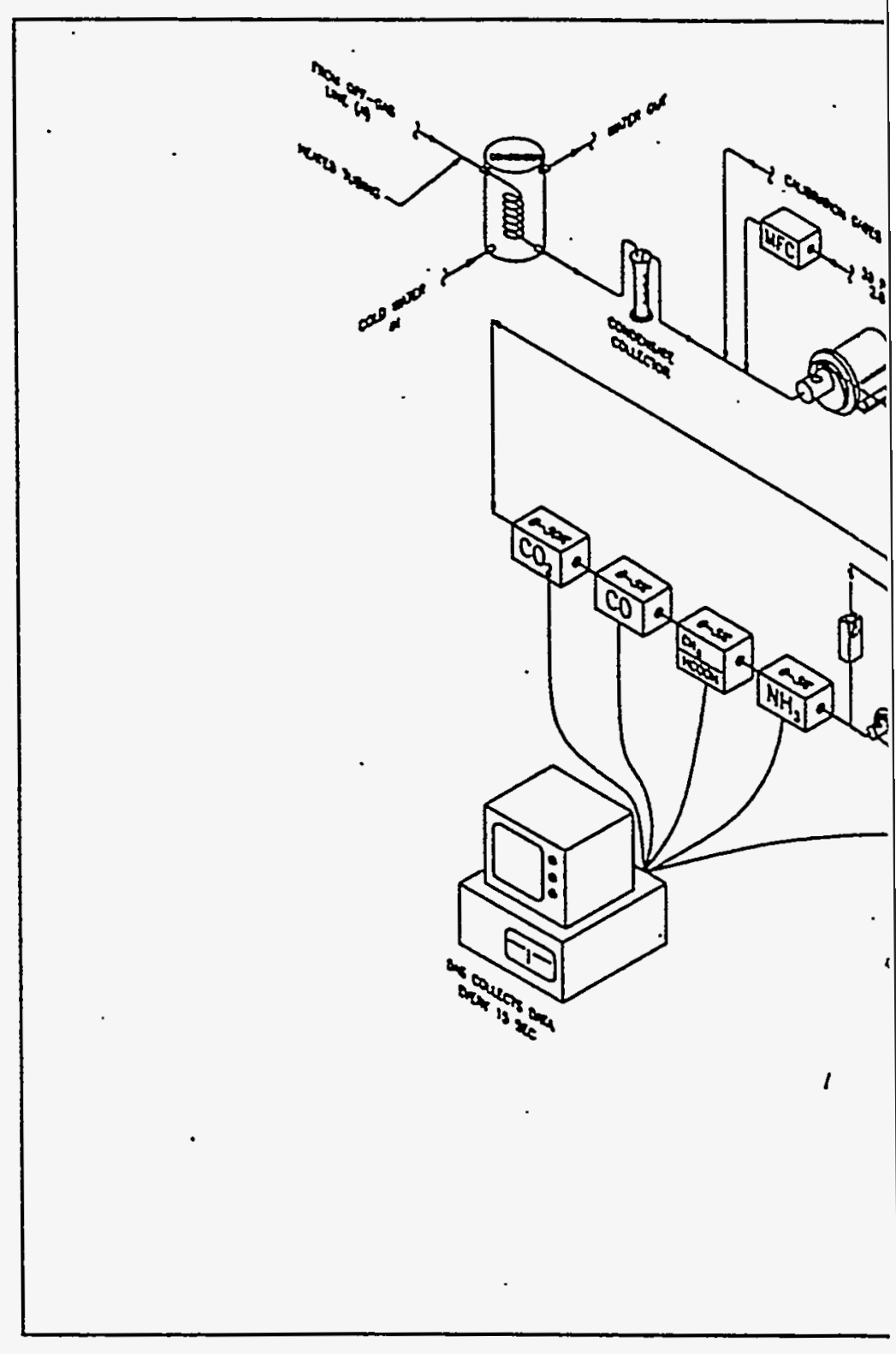

Figure A.22. Offgas Charac 


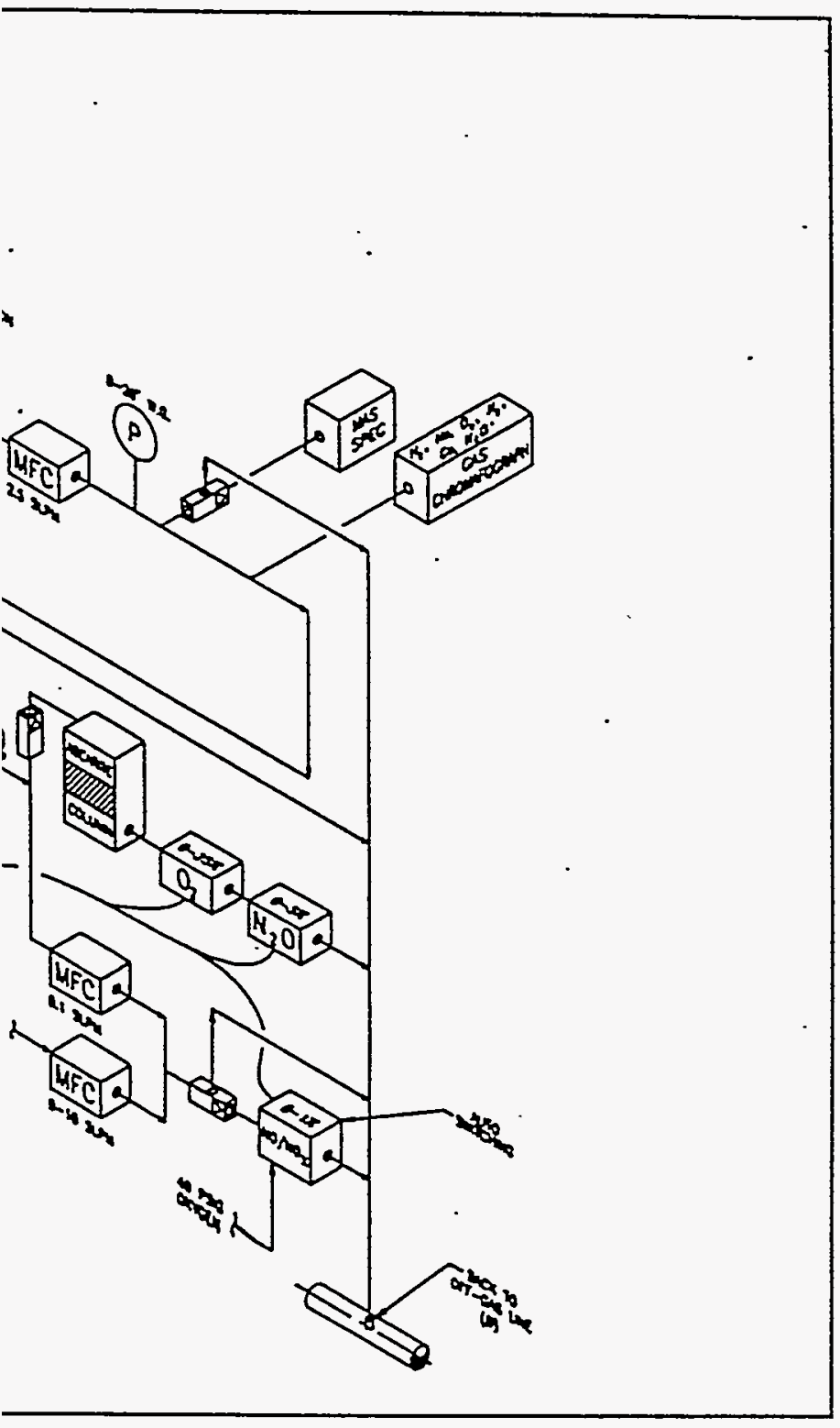

rization System (part 2) 


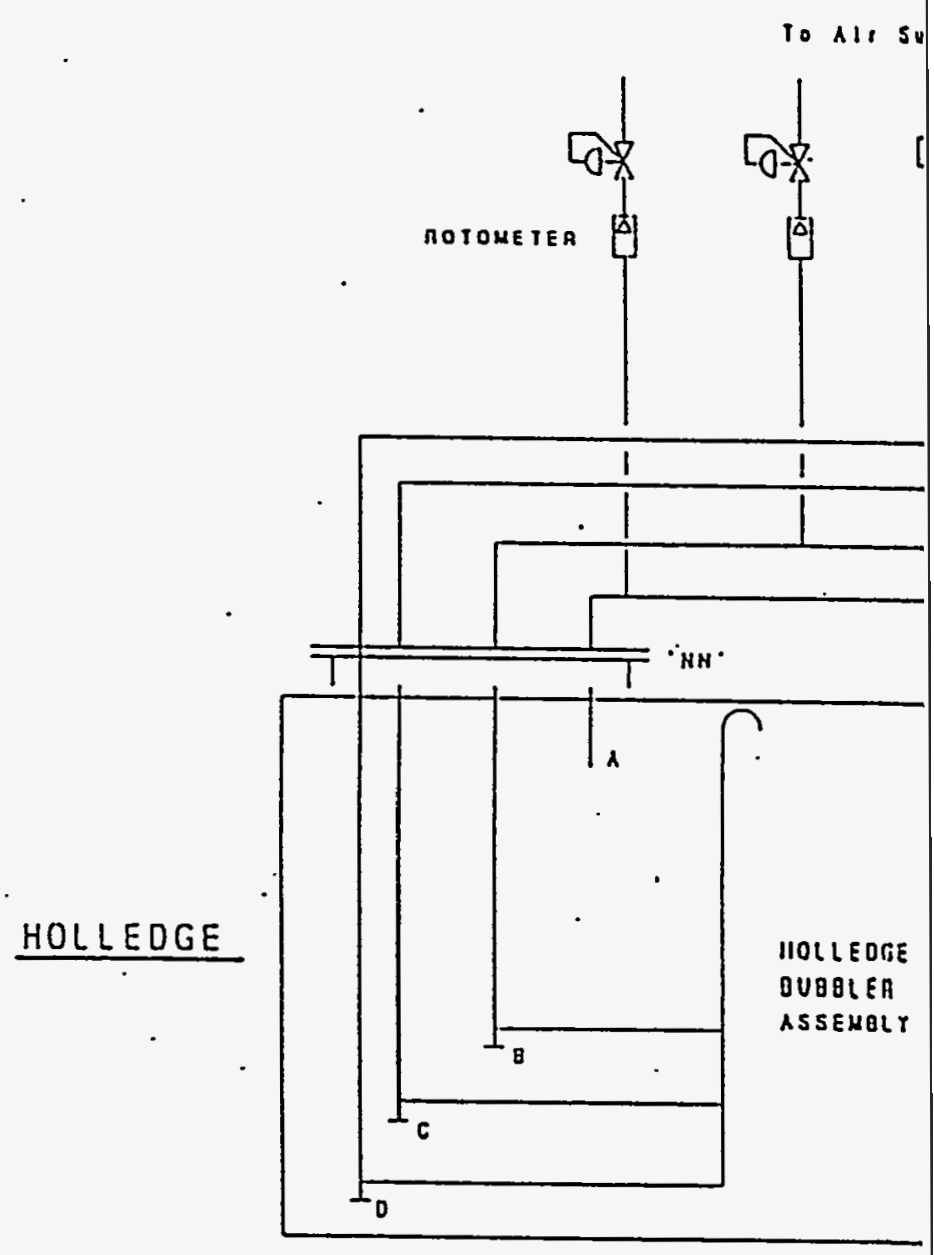

Figure A.23. Schematic of Holl 


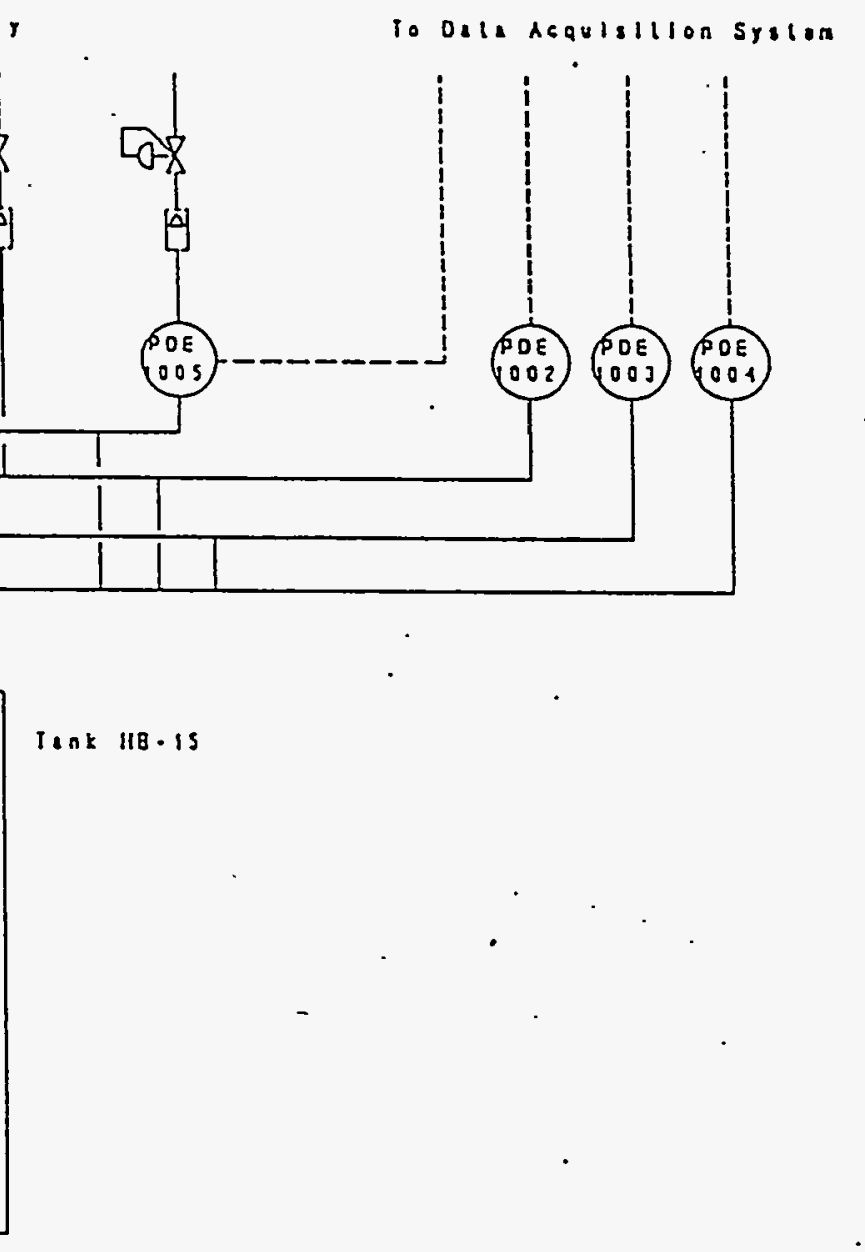

ge Level Relection System 
sิ: Battelle

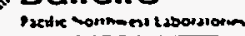

ENGINEERING

\begin{tabular}{|c|c|c|}
\hline Prepareo By. & Brian Hatedell & $2 / 22 / 92^{\text {proiees }} \leq$ \\
\hline 'Subjea: & Fioure $A-1$ & $C D-1000$ of \\
\hline
\end{tabular}

- Location of condensate and

- Condensate level required to ov

Both Lims are 3 ", Schedut 40 $O D=35^{\circ}$

thicknrss $=0.216$

ID $=3.5-2(0.216)=3.068$

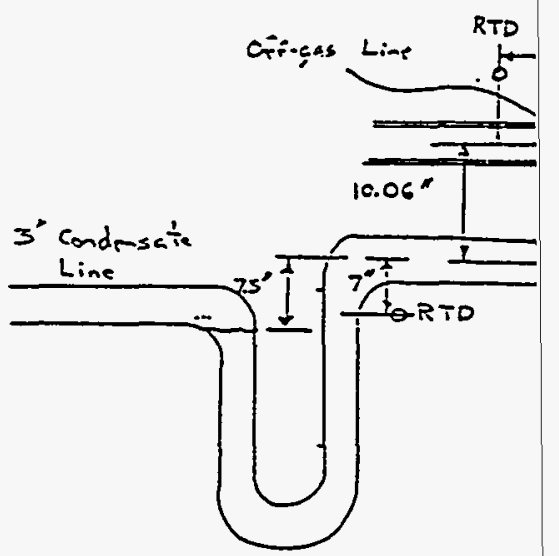

Lm $=$ Maximis height $0 \div$ Sof anse.

•
$L_{m}=10.05-\frac{3.063}{2}=3.526$ 2
Condensate level reauired to off-gas line

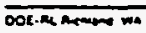

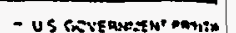

Figure A.24. CD-1000 Off ( 

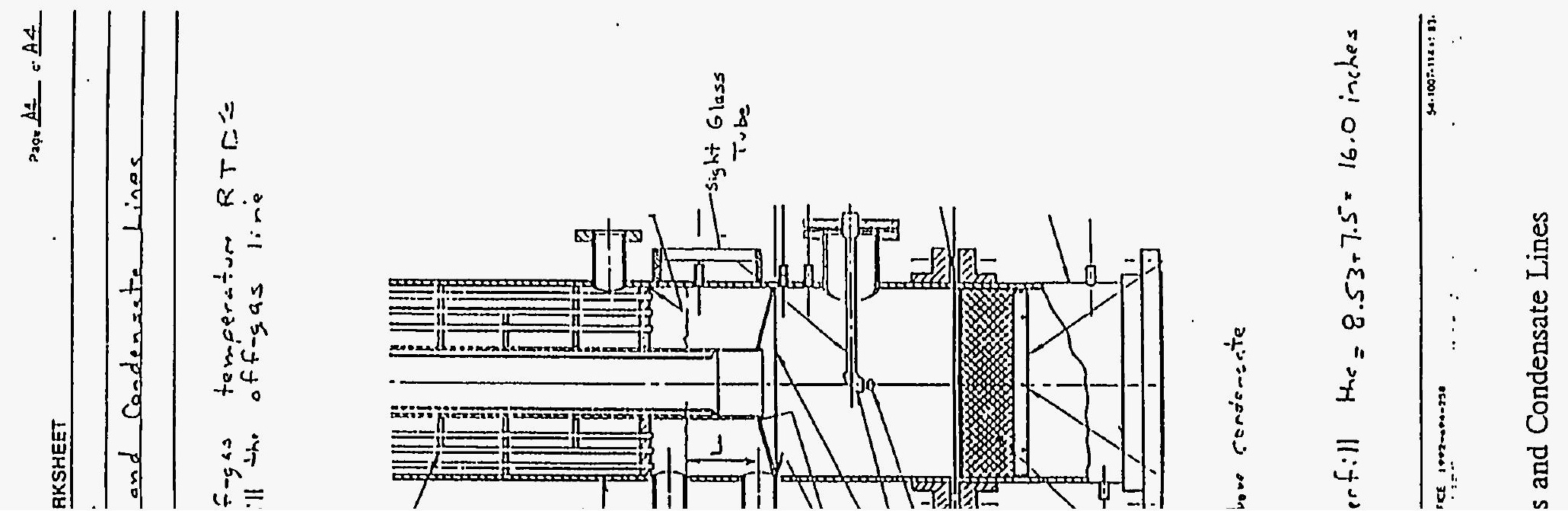
Appendix B

Chemical Compositions-Calculated Target Compositions for Each Simulant 
Table B.1. NCAW Feed Simulant (Batch 1)

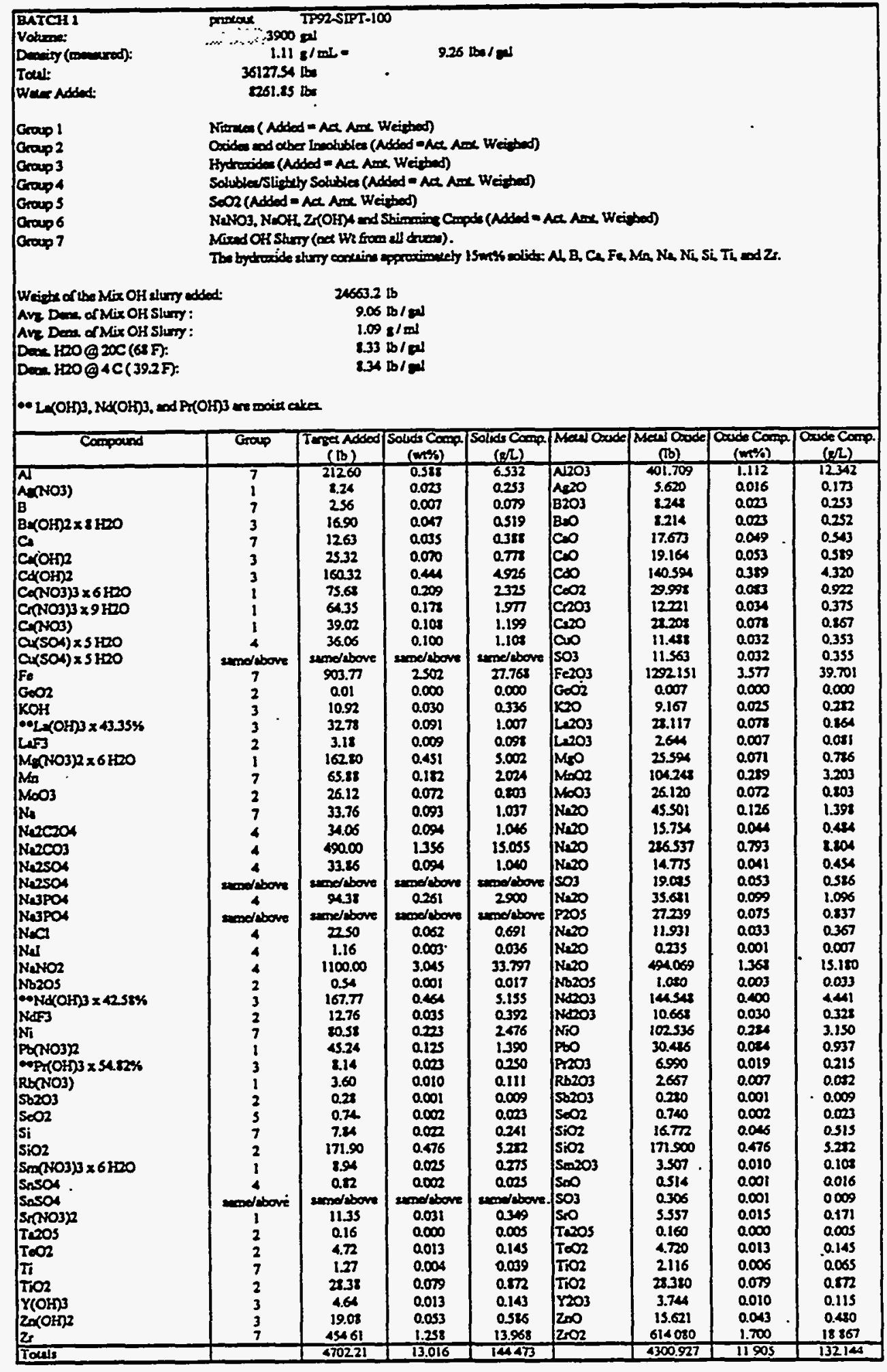

B. 1 
Table B.2. NCAW Feed Simulant (Batch 2)

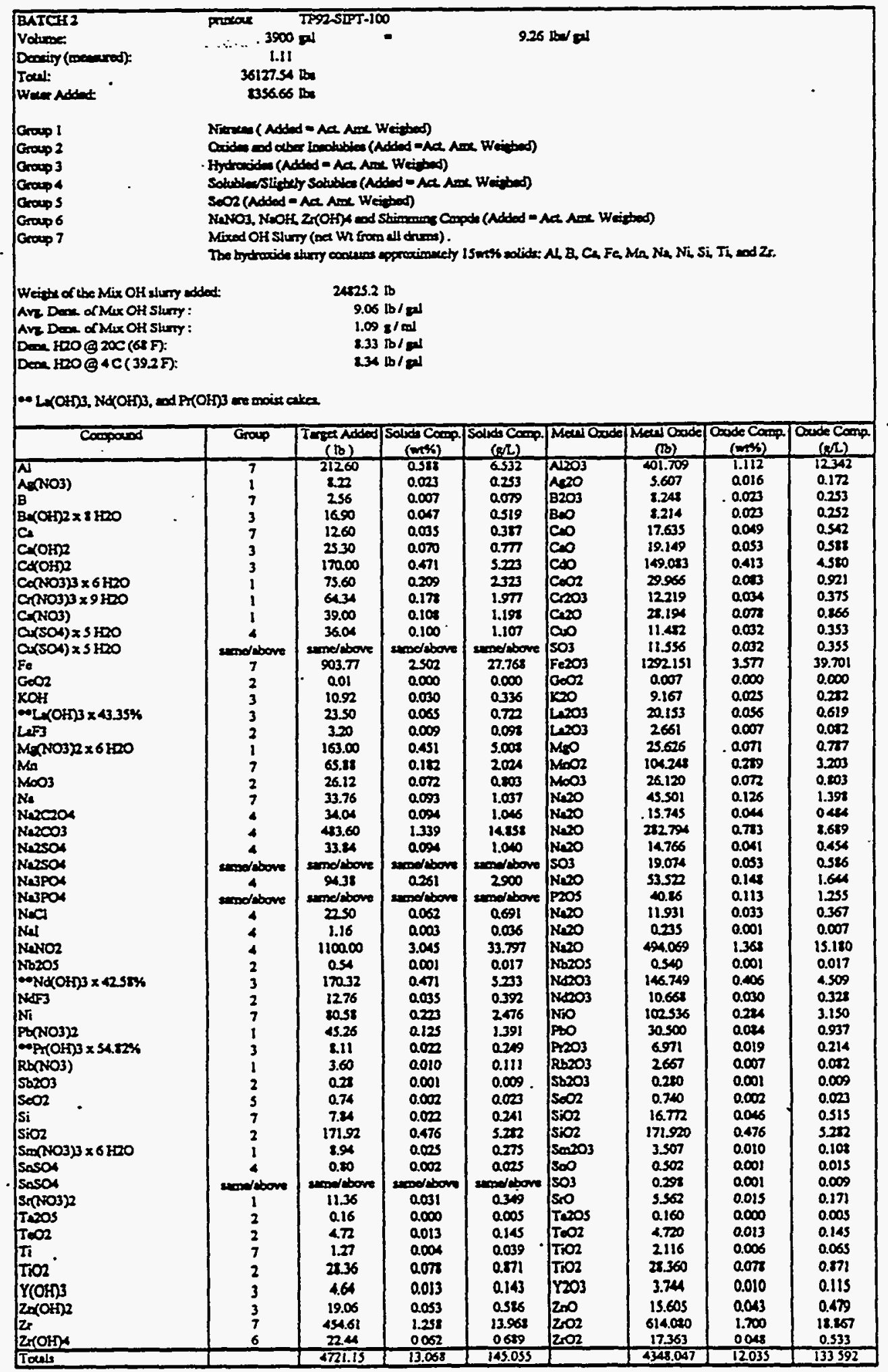


Table B.3. Low-Level Dilute Waste Simulant

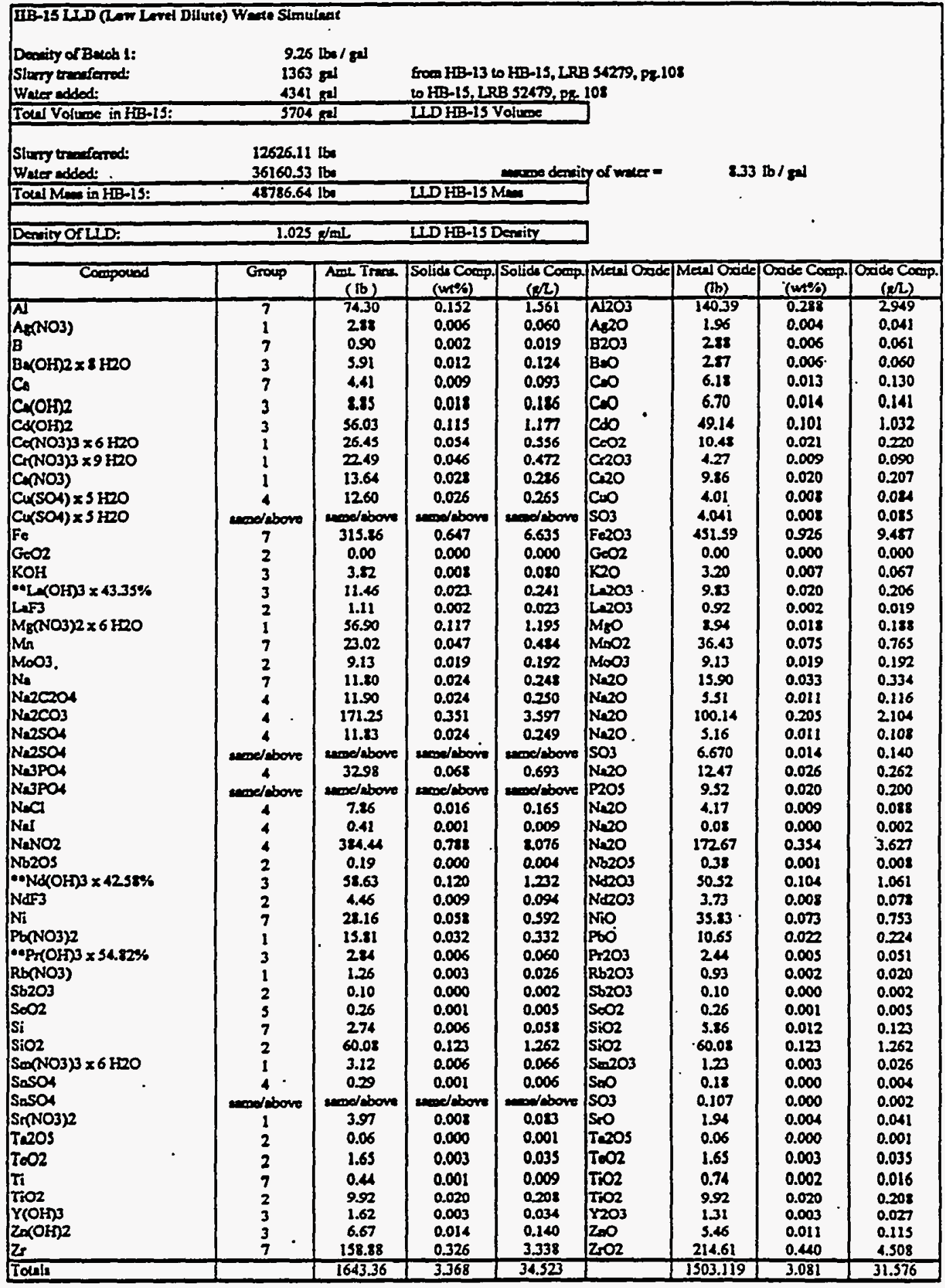


Table B.4. High-Level Dilute Waste Simulant

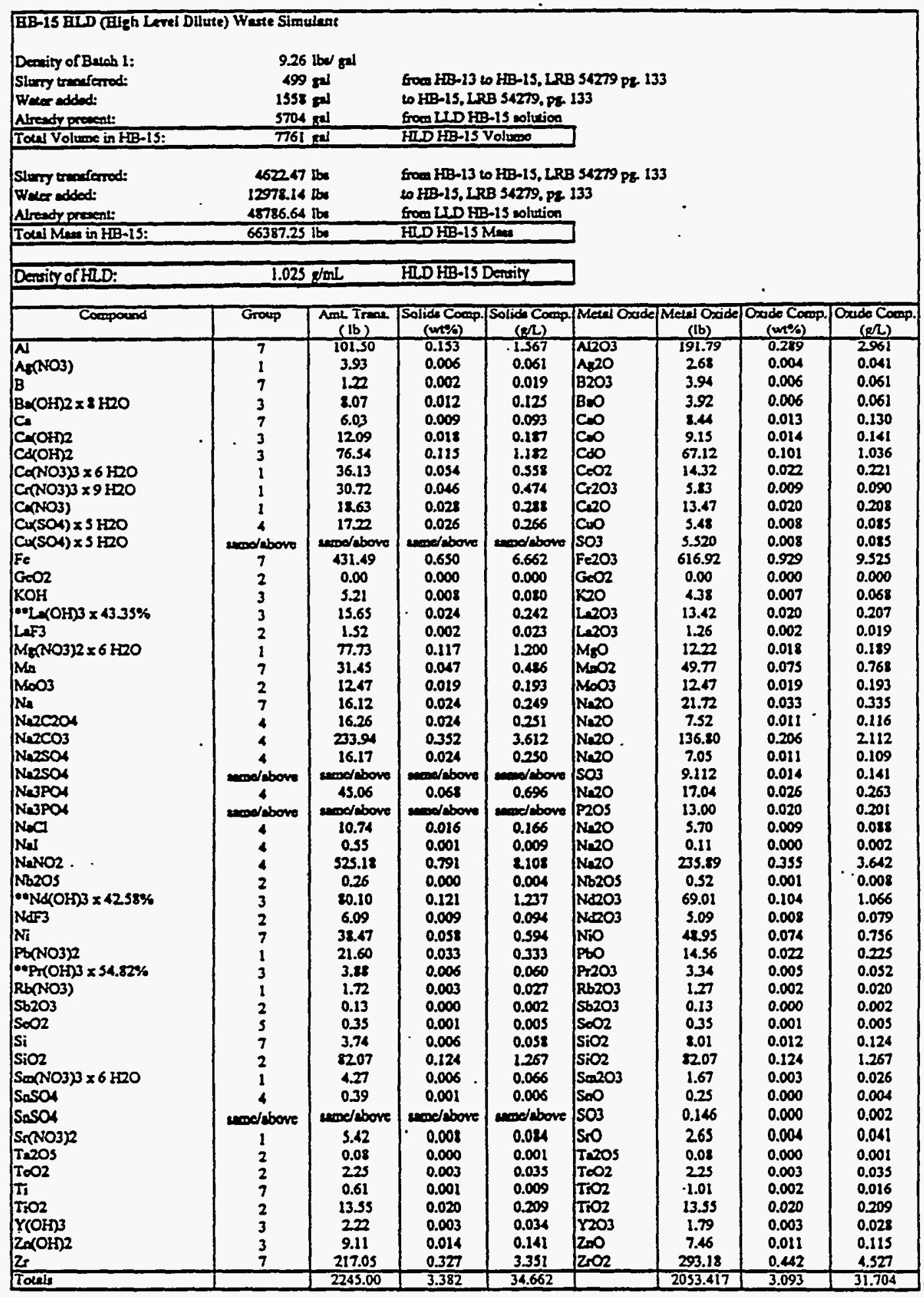


Table B.5. Low-Level Concentrated Waste Simulant

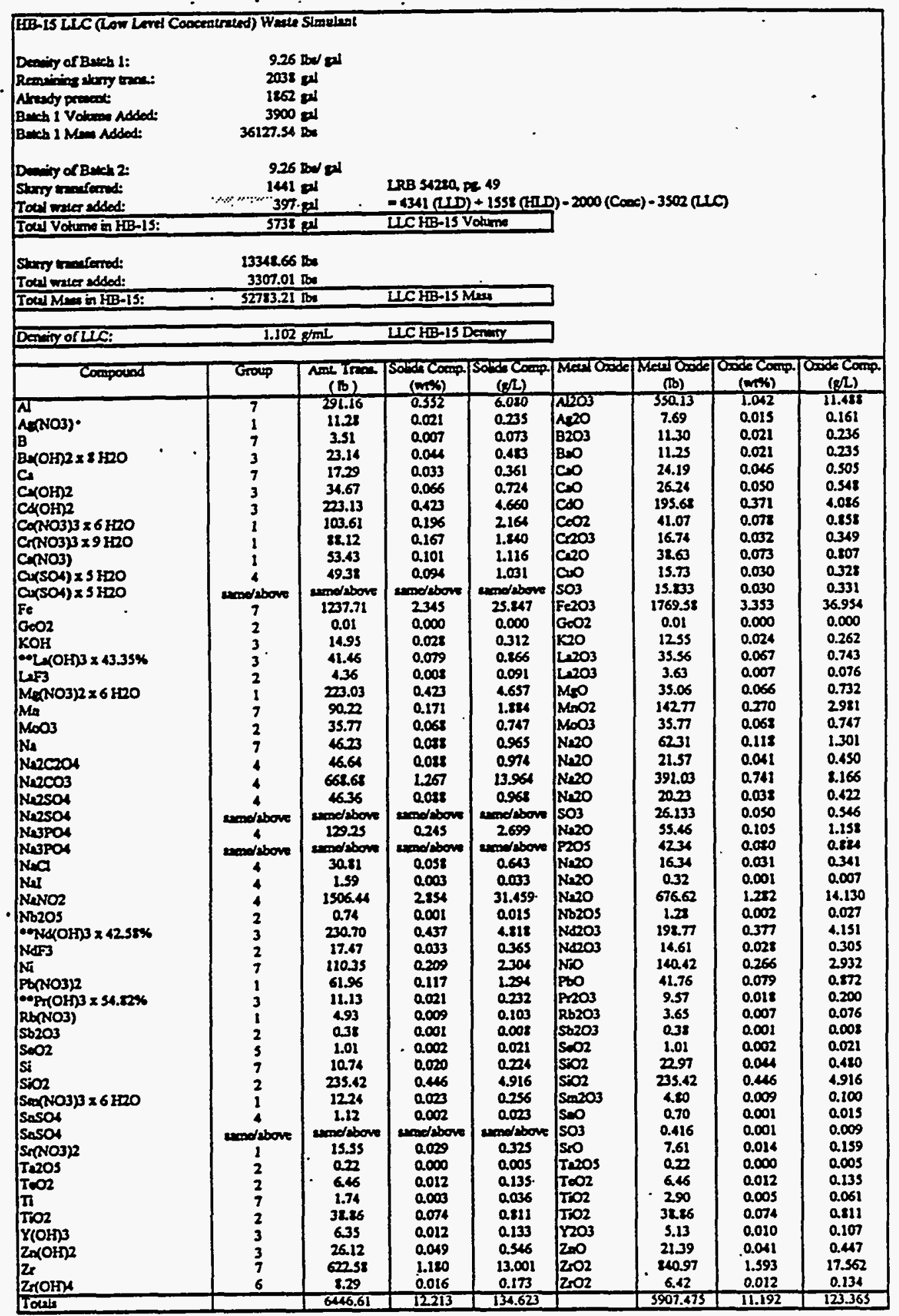


Table B.6. High-Level Concentrated Waste Simulant

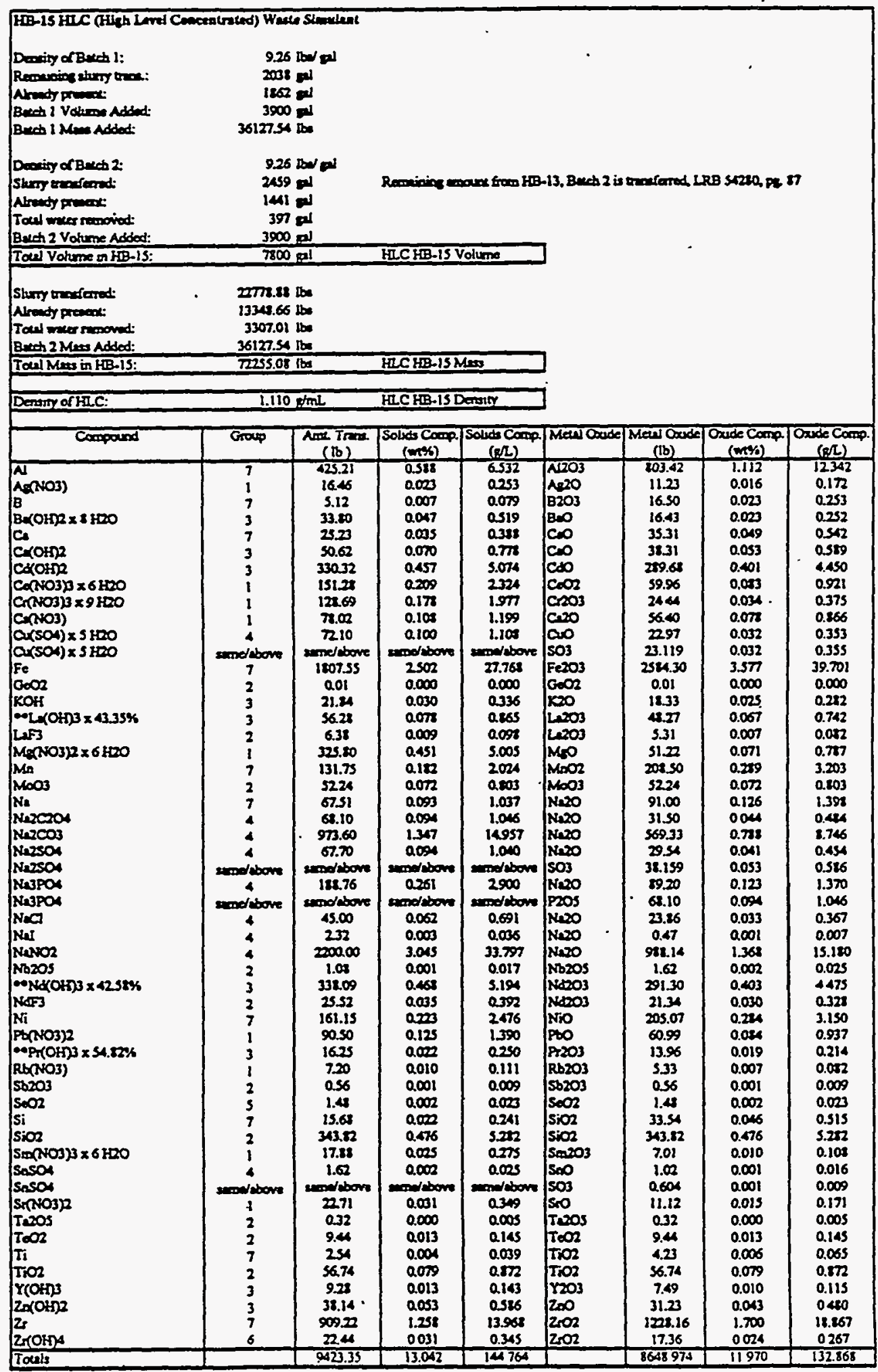


Table B.7. Formated Waste Simulant

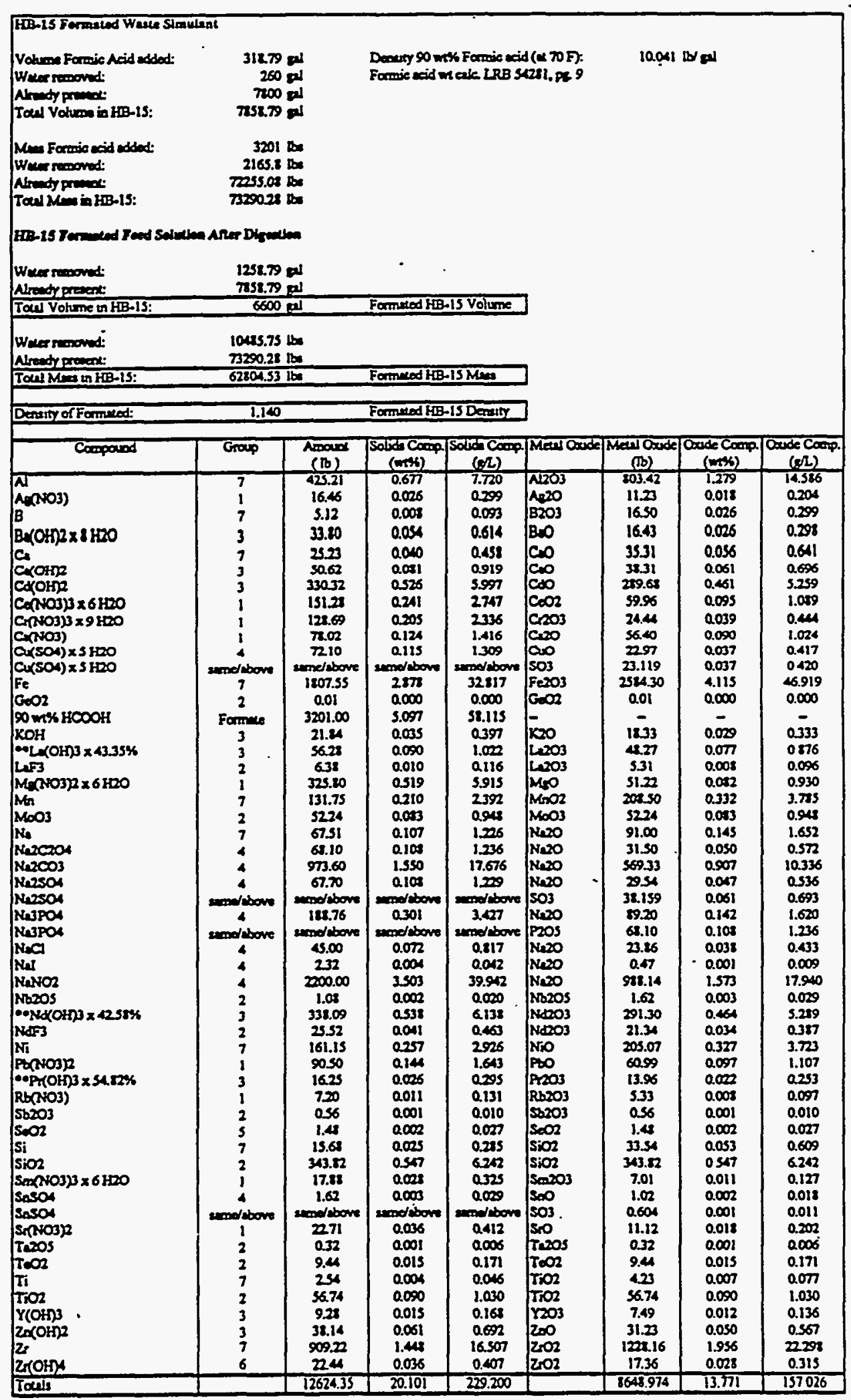


Table B.8. Recycle Waste Simulant

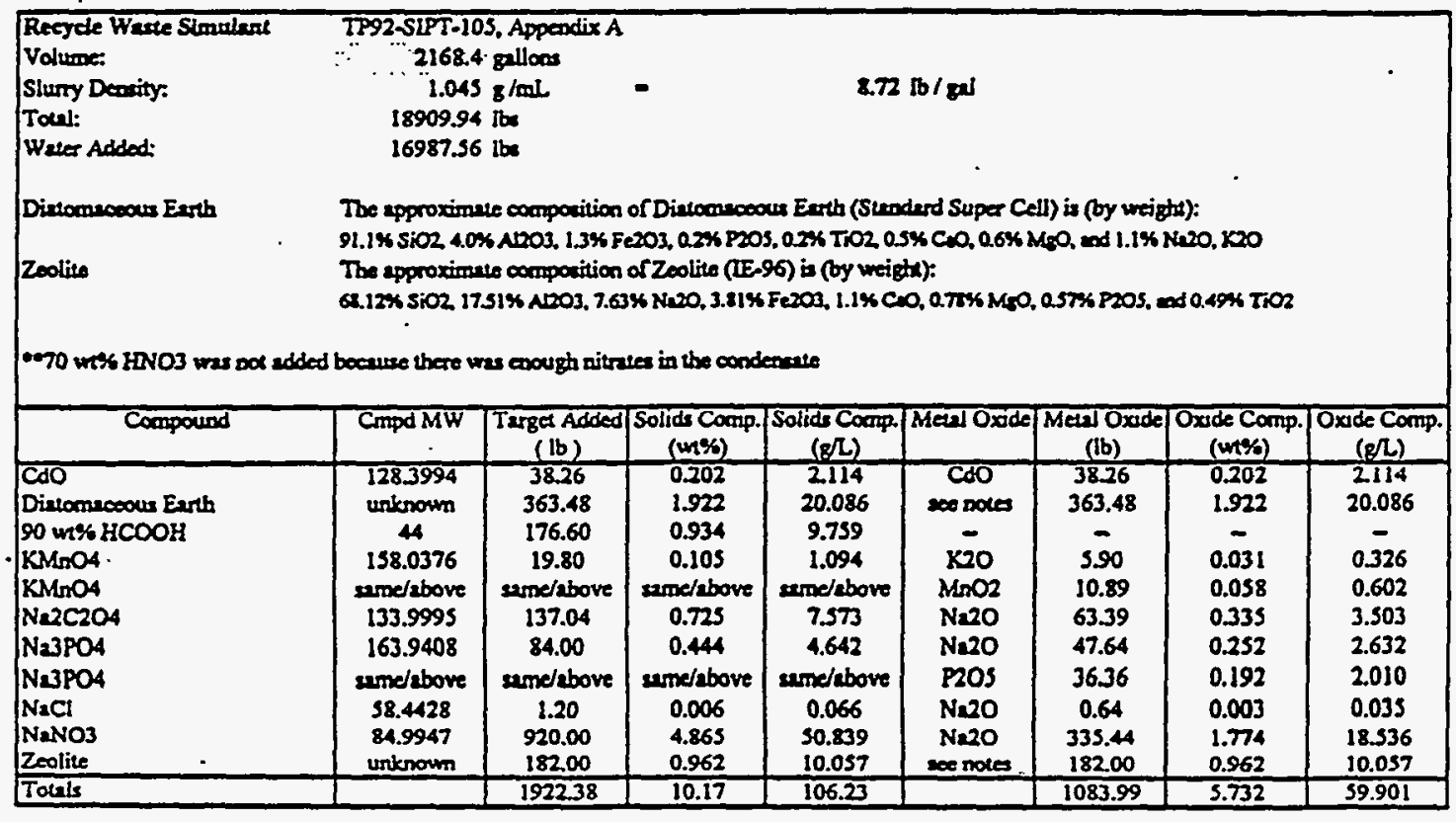


Table B.9. Formated Waste Simulant with Recycle

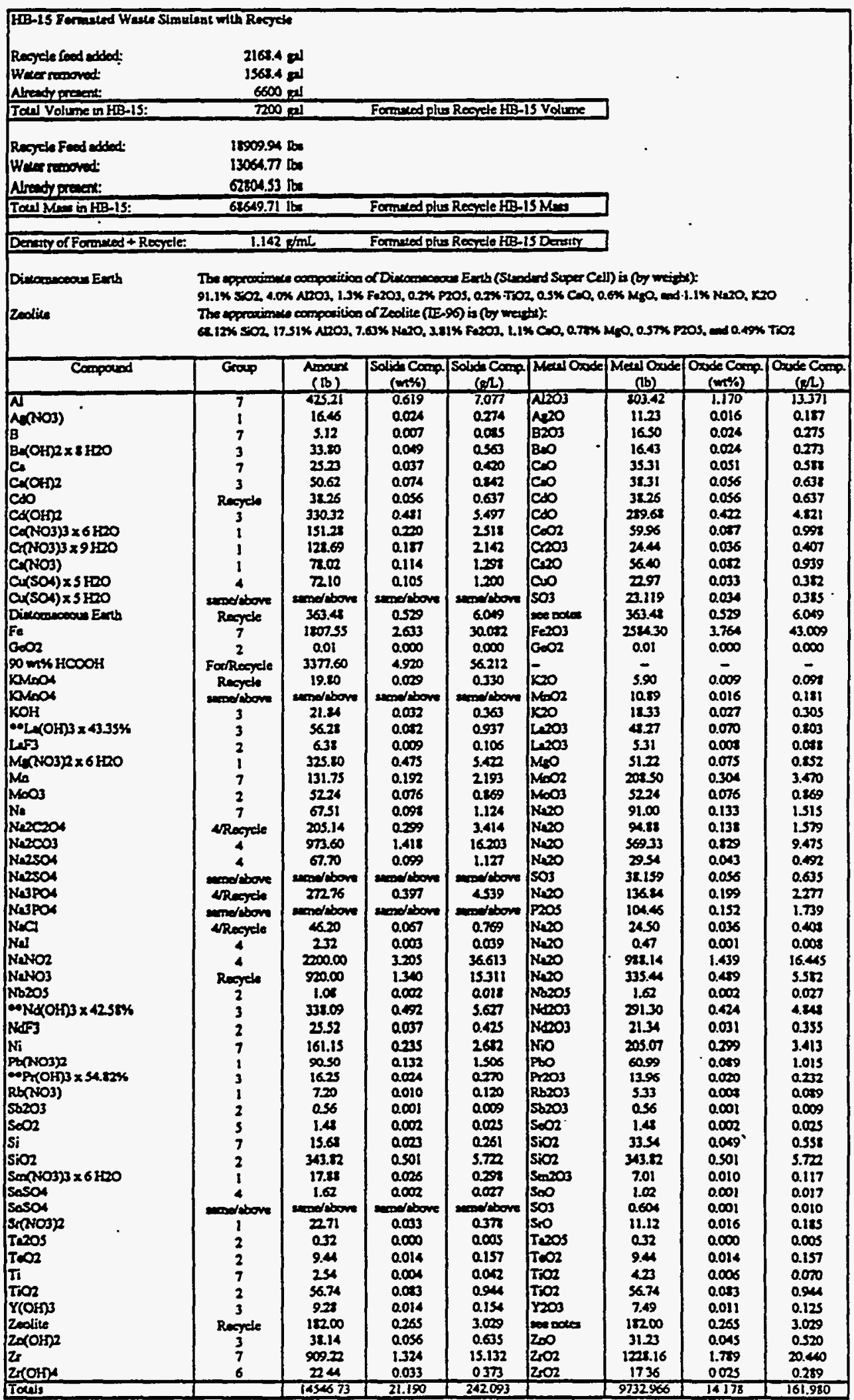

B.9 
Table B.10. Process Frit

\begin{tabular}{|c|c|c|c|c|c|c|c|}
\hline \multicolumn{8}{|l|}{ PROCESS FRTI } \\
\hline $\begin{array}{l}\text { Miem of frit eddiad: } \\
\text { Decrity of frit: } \\
\text { Volume of frit addod: }\end{array}$ & $\begin{array}{r}20800 \\
22.07 \\
242.4558224\end{array}$ & $\begin{array}{l}\text { Ibe } \\
\text { balgal } \\
\text { gallow }\end{array}$ & LRB 54281, I & PE. 55 & & & \\
\hline $\begin{array}{l}\text { Physical propertles: } \\
\text { Purticle xize: } \\
\text { Bulk density: } \\
\text { Specilie deasity: } \\
\text { Angle of repose: }\end{array}$ & $\begin{array}{r}20 \text { w0 } 200 \text { math } \\
70 \text { to } 94 \\
15510157 \\
301043 \text { deprose }\end{array}$ & $\begin{array}{l}\text { Db/e3 } \\
\text { lb/f3 }\end{array}$ & & & & - & \\
\hline $\begin{array}{c}\text { Cospousd } \\
\text { (FY 1991 Frit) }\end{array}$ & $\begin{array}{l}\text { Iarget Added } \\
\text { (Ib) }\end{array}$ & $\begin{array}{l}\text { Solids Cornt } \\
\text { (wt\%) }\end{array}$ & $\begin{array}{c}\text { Solide contup. } \\
(8 / L)\end{array}$ & Meal Oxde & $\begin{array}{c}\text { Mealoxide } \\
\text { (tb) }\end{array}$ & $\begin{array}{c}\text { Oxde Conpl } \\
(\mathrm{m} \%)\end{array}$ & $\begin{array}{l}\text { Oxode Comp. } \\
(2 / L)\end{array}$ \\
\hline $\begin{array}{l}\mathrm{SiO2} \\
\mathrm{B2O3} \\
\mathrm{LiO2}\end{array}$ & $\begin{array}{l}15184.00 \\
4160.00 \\
1456.00\end{array}$ & $\begin{array}{c}73.000 \\
20.000 \\
7.000 \\
\end{array}$ & \begin{tabular}{|l|}
1930.523 \\
528.910 \\
185.119 \\
\end{tabular} & $\begin{array}{l}\mathrm{S} 102 \\
\mathrm{B2O} 3 \\
\mathrm{LiO} 2\end{array}$ & $\begin{array}{l}15184.00 \\
4160.00 \\
1436.00 \\
\end{array}$ & \begin{tabular}{c|}
73.000 \\
20.000 \\
7.000 \\
\end{tabular} & $\begin{array}{l}1930.523 \\
528.910 \\
185.119 \\
\end{array}$ \\
\hline Tolels & 20800.00 & 100.00 & 2644.552 & & 20800.00 & 100.000 & 2644.532 \\
\hline
\end{tabular}


Table B.11. Melter Feed Waste Simulant

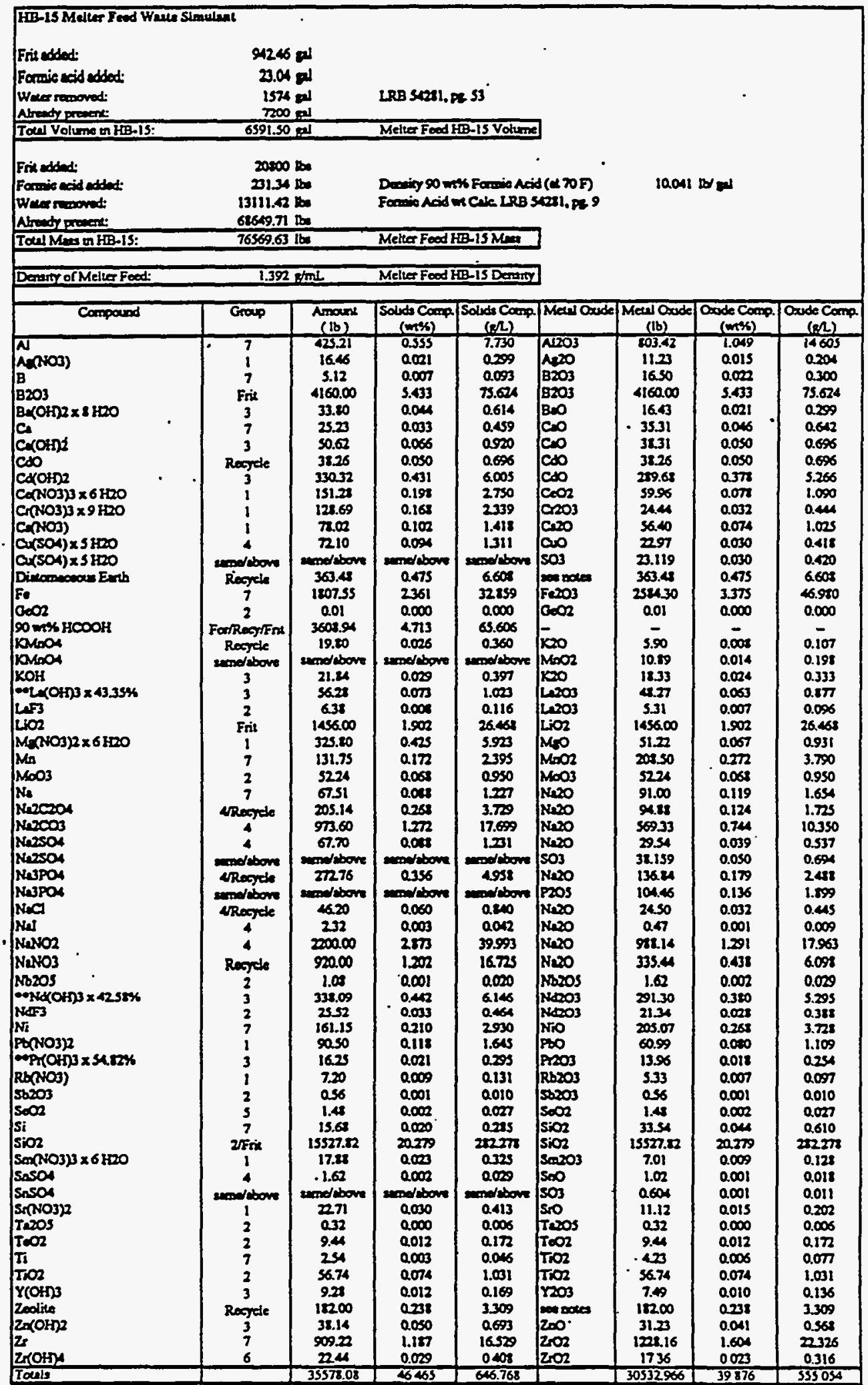

B. 11 


\section{Appendix C}

Chemical Compositions - Comparison of Target Compositions to Measured Compositions for Each Simulant 
Table C.1. NCAW Feed Simulant (Batch 1)

Comparison of Oxide Compositions (Target vs. Measured)

\begin{tabular}{|c|c|c|c|c|}
\hline Element & Metal Oxide & $\begin{array}{c}\text { Target } \\
\text { Composition* } \\
\text { (wt\%) }\end{array}$ & $\begin{array}{l}\text { Average Measured } \\
\text { Composition } \\
\text { (wt\%) }\end{array}$ & $\begin{array}{c}\text { Percent } \\
\text { Difference* } \\
(\%)\end{array}$ \\
\hline $\mathrm{Ag}$ & Ag2O & 0.016 & 0.010 & 40.625 \\
\hline Al & $\mathrm{A} 12 \mathrm{O} 3$ & 1.112 & 0.997 & 10.387 \\
\hline $\mathbf{B}$ & $\mathrm{B} 2 \mathrm{O} 3$ & 0.023 & 0.004 & 84.058 \\
\hline $\mathrm{Ba}$ & $\mathrm{BaO}$ & 0.023 & 0.022 & 5.072 \\
\hline $\mathrm{Ca}$ & $\mathrm{CaO}$ & 0.102 & 0.108 & 6.046 \\
\hline Cd & $\mathrm{CdO}$ & 0.389 & 0.370 & 4.884 \\
\hline Ce & $\mathrm{CeO} 2$ & 0.083 & 0.072 & 12.851 \\
\hline $\mathrm{Cr}$ & $\mathrm{Cr} 2 \mathrm{O} 3$ & 0.034 & 0.037 & 9.314 \\
\hline $\mathrm{Cu}$ & $\mathrm{CuO}$ & 0.032 & 0.032 & 1.042 \\
\hline Fe & $\mathrm{Fe} 2 \mathrm{O} 3$ & 3.577 & 3.499 & 2.181 \\
\hline $\mathrm{K}$ & $\mathrm{K} 20$ & 0.025 & not detected & - \\
\hline $\mathrm{Ia}$ & $\mathrm{La} 2 \mathrm{O} 3$ & 0.085 & 0.096 & 13.333 \\
\hline $\mathrm{Mg}$ & $\mathrm{MgO}$ & 0.071 & 0.078 & 10.094 \\
\hline Mn & $\mathrm{MnO} 2$ & 0.289 & 0.272 & 5.767 \\
\hline Mo & $\mathrm{M} \infty 3$ & 0.072 & 0.074 & 3.241 \\
\hline $\mathrm{Na}$ & $\mathrm{Na} 2 \mathrm{O}$ & 2.505 & 2.220 & 11.391 \\
\hline Nd & $\mathrm{Nd2O}$ & 0.43 & 0.408 & 5.155 \\
\hline $\mathrm{Ni}$ & NiO & 0.284 & 0.275 & 3.169 \\
\hline $\mathbf{P}$ & P2O5 & 0.075 & 0.121 & 61.333 \\
\hline $\mathrm{Pb}$ & $\mathrm{PbO}$ & 0.084 & 0.086 & 2.381 \\
\hline $\mathbf{S}$ & $\mathrm{SO} 3$ & 0.086 & 0.103 & 19.186 \\
\hline $\mathrm{Si}$ & $\mathrm{SiO}_{2}$ & 0.522 & 0.502 & 3.799 \\
\hline $\mathrm{Sn}$ & $\mathrm{SnO}$ & 0.001 & not detected & - \\
\hline Sr & SrO & 0.015 & 0.015 & 1.111 \\
\hline Te & $\mathrm{TeO} 2$ & 0.013 & 0.013 & 0.000 \\
\hline $\mathrm{Ti}$ & $\mathrm{THO} 2$ & 0.085 & 0.083 & 1.961 \\
\hline $\mathrm{Y}$ & $\mathrm{Y} 2 \mathrm{O} 3$ & 0.01 & 0.010 & .1 .667 \\
\hline $\mathrm{Zn}$ & $\mathrm{ZnO}$ & 0.043 & 0.039 & 10.465 \\
\hline $2 r$ & $\mathrm{ZrO2}$ & 1.7 & 1.614 & 5.039 \\
\hline
\end{tabular}

C. 1 
Table C.2. NCAW Feed Simulant (Batch 2)

Comparison of Oxide Compositions (Target vs. Measured)

\begin{tabular}{|c|c|c|c|c|}
\hline Element & Metal Oxide & $\begin{array}{c}\text { Target } \\
\text { Composition* } \\
\text { (wr\%) }\end{array}$ & $\begin{array}{l}\text { Average Measured } \\
\text { Composition } \\
\text { (wt\%) }\end{array}$ & $\begin{array}{c}\text { Percent } \\
\text { Difference* } \\
(\%)\end{array}$ \\
\hline Ag & $A 820$ & 0.016 & 0.030 & 93.308 \\
\hline Al & $\mathrm{Al} 2 \mathrm{O} 3$ & 1.112 & 1.235 & 11.069 \\
\hline$B$ & $\mathrm{~B} 2 \mathrm{O} 3$ & 0.023 & 0.030 & 31.404 \\
\hline $\mathrm{Ba}$ & $\mathrm{BaO}$ & 0.023 & 0.030 & 31.943 \\
\hline $\mathrm{Ca}$ & $\mathrm{CaO}$ & 0.102 & 0.130 & 27.451 \\
\hline $\mathrm{Cd}$ & $\mathrm{CdO}$ & 0.413 & 0.450 & 9.050 \\
\hline $\mathrm{Cr}$ & $\mathrm{Cr} 2 \mathrm{O} 3$ & 0.034 & 0.040 & 18.264 \\
\hline $\mathrm{Cu}$ & $\mathrm{CuO}$ & 0.032 & 0.040 & 25.861 \\
\hline Fe & $\mathrm{Fe} 2 \mathrm{O} 3$ & 3.577 & 3.575 & 0.046 \\
\hline $\mathbf{K}$ & $\times 20$ & 0.025 & not detected & $\cdots$ \\
\hline Mg & $\mathrm{MgO}$. & 0.071 & 0.075 & 5.737 \\
\hline $\mathrm{Mn}$ & $\mathrm{MnO} 2$ & 0.289 & 0.275 & 4.698 \\
\hline Mo & $\mathrm{MOO}_{3}$ & 0.072 & 0.070 & 3.180 \\
\hline $\mathrm{Na}$ & $\mathrm{Na} 2 \mathrm{O}$ & 2.543 & 2.945 & 15.808 \\
\hline $\mathrm{Ni}$ & $\mathrm{NiO}$ & 0.284 & 0.310 & 9.225 \\
\hline$P$ & P2OS & 0.113 & 0.080 & 29.263 \\
\hline $\mathrm{Pb}$ & $\mathrm{PbO}$ & 0.084 & 0.090 & 6.606 \\
\hline $\mathrm{Si}$ & $\mathrm{SiO} 2$ & 0.512 & 0.580 & 13.281 \\
\hline Sr & $\mathrm{SrO}$ & 0.015 & 0.020 & 29.905 \\
\hline $\mathrm{Ti}$ & $\mathrm{TiO}_{2}$ & 0.084 & 0.095 & 13.095 \\
\hline $\mathrm{Zn}$ & $2 \mathrm{nO}$ & 0.043 & 0.040 & 7.395 \\
\hline $\mathrm{Zr}$ & $\mathrm{ZrO2}$ & 1.748 & 1.920 & 9.840 \\
\hline
\end{tabular}


Table C.3. Low-Level Dilute Waste Simulant

Comparison of Oxide Compositions (Target vs. Measured)

\begin{tabular}{|c|c|c|c|c|}
\hline Element & Metal Oxide & $\begin{array}{c}\text { Target } \\
\text { Composition* } \\
\text { (wt\%) }\end{array}$ & $\begin{array}{l}\text { Average Measured } \\
\text { Composition } \\
\text { (wt\%) }\end{array}$ & $\begin{array}{c}\text { Percent } \\
\text { Difference* } \\
(\%)\end{array}$ \\
\hline $\mathrm{Ag}$ & $A \& 20$ & 0.004 & 0.002 & 50.000 \\
\hline Al & $\mathrm{A} 12 \mathrm{O} 3$ & 0.288 & 0.263 & 8.681 \\
\hline B & $\mathrm{B} 2 \mathrm{O} 3$ & 0.006 & 0.000 & 100.000 \\
\hline $\mathrm{Ba}$ & $\mathrm{BaO}$ & 0.006 & 0.006 & 1.964 \\
\hline $\mathrm{Ca}$ & $\mathrm{CaO}$ & 0.027 & 0.029 & 5.556 \\
\hline $\mathrm{Cd}$ & Cdo & 0.101 & 0.097 & 4.186 \\
\hline $\mathrm{Ce}$ & $\mathrm{CeO} 2$ & 0.021 & 0.019 & 13.911 \\
\hline $\mathrm{Cr}$ & $\mathrm{C} 22 \mathrm{O} 3$ & 0.009 & 0.010 & 8.513 \\
\hline $\mathrm{Cu}$ & $\mathrm{CuO}$ & 0.008 & 0.008 & 2.790 \\
\hline Fe & $\mathrm{Fe} 2 \mathrm{O} 3$ & 0.926 & 0.912 & 1.528 \\
\hline $\mathbf{x}$ & $\mathrm{K} 20$ & 0.007 & not detected & - \\
\hline La & $\mathrm{La}_{2} \mathrm{O} 3$ & 0.022 & 0.024 & 6.818 \\
\hline $\mathrm{Mg}_{\mathrm{g}}$ & $\mathrm{MgO}$ & 0.018 & 0.019 & 0.902 \\
\hline Mn & $\mathrm{MnO} 2$ & 0.075 & 0.071 & 4.926 \\
\hline Mo & $\mathrm{MoO} 3$ & 0.019 & 0.019 & 1.543 \\
\hline $\mathrm{Na}$ & $\mathrm{Na} 2 \mathrm{O}$ & 0.648 & 0.590 & 9.028 \\
\hline Nd & $\mathrm{Nd} 2 \mathrm{O} 3$ & 0.112 & 0.102 & 9.375 \\
\hline $\mathrm{Ni}$ & $\mathrm{NiO}$ & 0.073 & 0.070 & 5.381 \\
\hline$P$ & P2O5 & 0.020 & 0.034 & 71.682 \\
\hline $\mathrm{Pb}$ & $\mathrm{PbO}$ & 0.022 & 0.021 & 3.843 \\
\hline $\mathbf{S}$ & $\mathrm{SO} 3$ & 0.220 & 0.028 & 87.273 \\
\hline $\mathrm{Si}$ & $\mathrm{SiO} 2$ & 0.135 & 0.128 & 5.556 \\
\hline Sn & SnO & 0.000 & not detected & - \\
\hline Sr & $\mathrm{SrO}$ & 0.004 & 0.004 & 0.478 \\
\hline Te & $\mathrm{TeO} 2$ & 0.003 & 0.003 & 11.274 \\
\hline $\mathrm{Ti}$ & TiO2 & 0.022 & 0.022 & 2.273 \\
\hline $\mathbf{Y}$ & Y2O3 & 0.003 & 0.003 & 11.857 \\
\hline $\mathbf{Z n}$ & $\mathrm{ZnO}$ & 0.011 & 0.009 & 19.575 \\
\hline Zr & $2 \mathrm{SO} 2$ & 0.440 & 0.445 & 1.045 \\
\hline
\end{tabular}

C. 3 
Table C.4. High-Level Dilute Waste Simulant

Comparison of Oxide Compositions (Target vs. Measured)

\begin{tabular}{|c|c|c|c|c|}
\hline Element & Metsl Oxide & $\begin{array}{c}\text { Target } \\
\text { Composition* } \\
\text { (wt\%) }\end{array}$ & $\begin{array}{l}\text { Average Measured } \\
\text { Composition } \\
\text { (wt\%) }\end{array}$ & $\begin{array}{c}\text { Percent } \\
\text { Difference" } \\
(\%)\end{array}$ \\
\hline $\mathrm{Ag}$ & Ag2O & 0.004 & 0.003 & 25.779 \\
\hline Al & $\mathrm{Al} 2 \mathrm{O} 3$ & 0.289 & 0.268 & 7.233 \\
\hline B & $\mathrm{B} 2 \mathrm{O} 3$ & 0.006 & 0.002 & 74.712 \\
\hline $\mathrm{Ba}$ & $\mathrm{BaO}$ & 0.006 & 0.006 & 1.566 \\
\hline $\mathrm{Ca}$ & $\mathrm{CaO}$ & 0.027 & 0.031 & 14.815 \\
\hline $\mathrm{Cd}$ & $\mathrm{CdO}$ & 0.101 & 0.101 & 0.109 \\
\hline $\mathrm{Ce}$ & $\mathrm{CeO} 2$ & 0.022 & 0.021 & 4.977 \\
\hline $\mathrm{Cr}$ & $\mathrm{Cr} 2 \mathrm{O} 3$ & 0.009 & 0.011 & 19.467 \\
\hline $\mathrm{Cu}$ & CuO. & 0.008 & 0.009 & 8.934 \\
\hline $\mathrm{Fe}$ & $\mathrm{Fe} 2 \mathrm{O} 3$ & 0.929 & 0.957 & 2.984 \\
\hline $\mathrm{K}$ & K2O & 0.007 & not detected & - \\
\hline $\mathrm{La}$ & $\mathrm{La} 2 \mathrm{O} 3$ & 0.022 & 0.025 & 13.636 \\
\hline $\mathrm{Mg}$ & $\mathrm{MgO}$ & 0.018 & 0.024 & 27.672 \\
\hline $\mathrm{Mn}$ & $\mathrm{MnO} 2$ & 0.075 & 0.075 & 0.629 \\
\hline Mo & $\mathrm{M} \infty 3$ & 0.019 & 0.021 & 9.132 \\
\hline $\mathrm{Na}$ & $\mathrm{Na} 2 \mathrm{O}$ & 0.650 & 0.609 & 6.308 \\
\hline Nd & $\mathrm{Nd2O} 3$ & 0.112 & 0.109 & 3.125 \\
\hline $\mathrm{Ni}$ & $\mathrm{NiO}$ & 0.074 & 0.075 & 1.030 \\
\hline $\mathrm{P}$ & P2O5 & 0.020 & 0.034 & 71.011 \\
\hline $\mathrm{Pb}$ & $\mathrm{PbO}$ & 0.022 & 0.025 & 11.745 \\
\hline $\mathbf{s}$ & SO3 & 0.022 & 0.030 & 36.364 \\
\hline $\mathrm{Si}$ & $\mathrm{SiO} 2$ & 0.136 & 0.135 & 0.735 \\
\hline $\mathrm{Sn}$ & $\mathrm{SnO}$ & 0.000 & not detcted & - \\
\hline $\mathrm{Sr}_{\mathrm{r}}$ & SrO & 0.004 & 0.004 & 0.085 \\
\hline $\mathrm{Te}$ & $\mathrm{TeO} 2$ & 0.003 & 0.004 & 17.839 \\
\hline $\mathrm{Ti}$ & $\mathrm{TiO} 2$ & 0.022 & 0.023 & 2.273 \\
\hline$Y$ & Y2O3 & 0.003 & 0.003 & 11.420 \\
\hline $\mathrm{Zn}$ & $\mathrm{ZnO}$ & 0.011 & 0.011 & 6.537 \\
\hline $\mathrm{Z}$ & 2502 & 0.442 & 0.446 & 0.990 \\
\hline
\end{tabular}


Table C.5. Low-Level Concentrated Waste Simulant

Comparison of Oxide Compositions (Target vs. Measured)

\begin{tabular}{|c|c|c|c|c|}
\hline Element & Metal Oxide & $\begin{array}{c}\text { Target } \\
\text { Composition } \\
\text { (wit\%) }\end{array}$ & $\begin{array}{l}\text { Average Measured } \\
\text { Composition } \\
\text { (w\%\%) }\end{array}$ & $\begin{array}{c}\text { Percent } \\
\text { Difference* } \\
(\%)\end{array}$ \\
\hline $\mathrm{Ag}$ & $A B 2 O$ & 0.015 & 0.010 & 31.379 \\
\hline Al & $\mathrm{Al}_{2} \mathrm{O} 3$ & 1.042 & 0.980 & 5.973 \\
\hline B & $\mathrm{B} 2 \mathrm{O} 3$ & 0.021 & 0.005 & 76.635 \\
\hline $\mathrm{Ba}$ & $\mathrm{BaO}$ & 0.021 & 0.020 & 6.158 \\
\hline $\mathrm{Ca}$ & $\mathrm{CaO}$ & 0.096 & 0.100 & 4.167 \\
\hline $\mathrm{Cd}$ & CdO & 0.371 & 0.350 & 5.589 \\
\hline Ce & $\mathrm{CeO} 2$ & 0.078 & 0.065 & 16.462 \\
\hline $\mathrm{Cr}$ & $\mathrm{Cr} 2 \mathrm{O} 3$ & 0.032 & 0.030 & 5.384 \\
\hline $\mathrm{Cu}$ & $\mathrm{CuO}$ & 0.030 & 0.030 & 0.664 \\
\hline $\mathrm{Fe}$ & $\mathrm{Fe} 2 \mathrm{O} 3$ & 3.353 & 3.310 & 1.269 \\
\hline $\mathrm{K}$ & $\mathrm{K} 2 \mathrm{O}$ & 0.024 & not detected & - \\
\hline La & $\mathrm{La}_{2} \mathrm{O} 3$ & 0.074 & 0.085 & 14.865 \\
\hline $\mathrm{Mg}$ & $\mathrm{MgO}$ & 0.066 & 0.075 & 12.905 \\
\hline Mn & $\mathrm{MnO} 2$ & 0.270 & 0.255 & 5.722 \\
\hline Mo & $\mathrm{MoO} 3$ & 0.068 & 0.070 & 3.291 \\
\hline $\mathrm{Ne}$ & $\mathrm{Na} 2 \mathrm{O}$ & 2.357 & 2.190 & 7.085 \\
\hline Nd & $\mathrm{Nd} 2 \mathrm{O} 3$ & 0.405 & 0.390 & 3.704 \\
\hline $\mathrm{Ni}$ & $\mathrm{NiO}$ & 0.266 & 0.245 & 7.907 \\
\hline $\mathbf{P}$ & P2OS & 0.080 & 0.125 & 55.847 \\
\hline $\mathrm{Pb}$ & $\mathrm{PbO}$ & 0.079 & 0.075 & 5.193 \\
\hline $\mathbf{S}$ & $\mathrm{SO} 3$ & 0.081 & 0.095 & 17.284 \\
\hline $\mathrm{Si}$ & $\mathrm{SiO} 2$ & 0.490 & 0.580 & 18.367 \\
\hline $\mathrm{Sn}$ & $\mathrm{SnO}$ & 0.001 & not detected & - \\
\hline Sr & SrO & 0.014 & $0.010^{\circ}$ & 30.661 \\
\hline Te & $\mathrm{TeO} 2$ & 0.012 & 0.010 & 18.343 \\
\hline $\mathrm{Ti}$ & $\mathrm{TiO} 2$ & 0.079 & 0.085 & 7.595 \\
\hline$Y$ & $\mathrm{Y} 2 \mathrm{O} 3$ & 0.010 & 0.010 & 2.947 \\
\hline $\mathrm{Zn}$ & $\mathrm{ZnO}$ & 0.041 & 0.040 & 2.515 \\
\hline $\mathrm{Zs}$ & $2 \mathrm{rO} 2$ & 1.605 & 1.625 & 1.246 \\
\hline
\end{tabular}


Table C.6. High-Level Concentrated Waste Simulant

Comparison of Oxide Compositions (Target vs. Measured)

\begin{tabular}{|c|c|c|c|c|}
\hline Element & Metal Oxide & $\begin{array}{c}\text { Target } \\
\text { Composition* } \\
\text { (wt\%) }\end{array}$ & $\begin{array}{l}\text { Average Measured } \\
\text { Composition } \\
\text { (wt\%) }\end{array}$ & $\begin{array}{c}\text { Percent } \\
\text { Difference* } \\
(\%)\end{array}$ \\
\hline Ag & Ag2O & 0.016 & 0.020 & 28.715 \\
\hline $\mathrm{Al}$ & $\mathrm{Al}_{2} \mathrm{O} 3$ & 1.112 & 0.915 & 17.710 \\
\hline B & $\mathrm{B} 2 \mathrm{O} 3$ & 0.023 & 0.060 & 162.808 \\
\hline $\mathrm{Ba}$ & $\mathrm{BaO}$ & 0.023 & 0.020 & 12.038 \\
\hline $\mathrm{Ca}$ & $\mathrm{CaO}$ & 0.102 & 0.110 & 7.843 \\
\hline $\mathrm{cd}$ & $\mathrm{CdO}$ & 0.401 & 0.355 & 11.451 \\
\hline $\mathrm{Cr}$ & $\mathrm{Cr} 2 \mathrm{O} 3$ & 0.034 & 0.030 & 11.309 \\
\hline $\mathrm{Cu}$ & $\mathrm{CuO}$ & 0.032 & 0.030 & 5.631 . \\
\hline Fe & $\mathrm{Fe} 2 \mathrm{O} 3$ & 3.577 & 2.765 & 22.693 \\
\hline $\mathbf{K}$ & $\mathrm{K} 20$ & 0.025 & not detected & - \\
\hline$M B$ & $\mathrm{MgO}$ & 0.071 & 0.050 & 29.466 \\
\hline Mn & $\mathrm{MnO} 2$ & 0.289 & 0.250 & 13.361 \\
\hline Mo & $\mathrm{MoO} 3$ & 0.072 & 0.060 & 17.012 \\
\hline $\mathrm{Na}$ & $\mathrm{Na2O}$ & 2.523 & 2.220 & 12.010 \\
\hline $\mathrm{NI}$ & $\mathrm{NiO}$ & 0.284 & 0.250 & 11.915 \\
\hline $\mathbf{P}$ & P2OS & 0.094 & 0.065 & 31.031 \\
\hline $\mathrm{Pb}$ & $\mathrm{PbO}$ & 0.084 & 0.070 & 17.066 \\
\hline $\mathrm{Si}$ & $\mathrm{SiO} 2$ & 0.522 & 0.455 & 12.835 \\
\hline Sr & SrO & 0.015 & 0.010 & 33.333 \\
\hline $\mathrm{Ti}$ & $\mathrm{TiO}_{2}$ & 0.085 & 0.070 & 17.647 \\
\hline $\mathrm{Zn}$ & $\mathrm{ZnO}$ & 0.043 & 0.040 & 7.444 \\
\hline $\mathrm{Zs}$ & $\mathrm{ZrO2}$ & 1.724 & 1.520 & $11.833^{\circ}$ \\
\hline
\end{tabular}


Table C.7. Formated Waste Simulant

Comparison of Oxide Compositions (Target vs. Measured)

\begin{tabular}{|c|c|c|c|c|}
\hline Element & Metal.Oxide & $\begin{array}{c}\text { Target } \\
\text { Composition* } \\
\text { (wt\%) }\end{array}$ & $\begin{array}{l}\text { Average Measured } \\
\text { Composition } \\
\text { (wt\%) }\end{array}$ & $\begin{array}{c}\text { Percent } \\
\text { Difference* } \\
\text { (\%) }\end{array}$ \\
\hline $\mathrm{Ag}$ & $A_{82 O}$ & 0.018 & 0.011 & 39.864 \\
\hline Al & $\mathrm{Al}_{2} \mathrm{O} 3$ & 1.279 & 1.170 & 8.559 \\
\hline$B$ & $\mathrm{~B} 2 \mathrm{O} 3$ & 0.026 & 0.003 & 90.482 \\
\hline $\mathrm{Ba}$ & $\mathrm{BaO}$ & 0.026 & 0.026 & 0.606 \\
\hline $\mathrm{Ca}$ & $\mathrm{CaO}$ & 0.117 & 0.129 & 10.256 \\
\hline $\mathrm{Cd}$ & $\mathrm{CdO}$ & 0.461 & 0.430 & 6.826 \\
\hline $\mathrm{Ce}_{\mathrm{e}}$ & $\mathrm{CeO} 2$ & 0.095 & 0.083 & 13.592 \\
\hline $\mathrm{Cr}$ & $\mathrm{Cr} 2 \mathrm{O} 3$ & 0.039 & 0.042 & 7.927 \\
\hline $\mathrm{Cu}$ & $\mathrm{CuO}$ & 0.037 & 0.037 & 1.166 . \\
\hline Fe & $\mathrm{Fe} 2 \mathrm{O} 3$ & 4.115 & 3.985 & 3.149 \\
\hline $\mathrm{K}$ & $\mathrm{K} 20$ & 0.029 & not detected & - \\
\hline La & $\mathrm{La} 2 \mathrm{O} 3$ & 0.085 & 0.101 & 19.118 \\
\hline Mg & $\mathrm{MgO}$ & 0.082 & 0.081 & 0.986 \\
\hline Mn & $\mathrm{MnO} 2$ & 0.332 & 0.315 & 5.264 \\
\hline Mo & $\mathrm{MOO3}$ & 0.083 & 0.084 & 0.687 \\
\hline $\mathrm{Na}$ & $\mathrm{Na} 2 \mathrm{O}$ & 2.903 & 2.182 & 24.836 \\
\hline Nd & $\mathrm{Nd} 2 \mathrm{O} 3$ & 0.498 & 0.480 & .3 .614 \\
\hline $\mathrm{Ni}$ & $\mathrm{NiO}$ & 0.327 & 0.306 & 6.286 \\
\hline $\mathbf{P}$ & P2O5 & 0.108 & 0.070 & 35.441 \\
\hline $\mathrm{Pb}$ & $\mathrm{PbO}$ & 0.097 & 0.096 & 1.395 \\
\hline $\mathbf{s}$ & $\mathrm{SO} 3$ & 0.099 & 0.115 & 15.909 \\
\hline $\mathrm{Si}$ & $\mathrm{SiO} 2$ & 0.600 & 0.566 & 5.708 \\
\hline Sn & $\mathrm{SnO}$ & 0.002 & not detected & - \\
\hline Sr & SrO & 0.018 & 0.017 & 2.569 \\
\hline Te & $\mathrm{TeO} 2$ & 0.015 & 0.018 & 21.418 \\
\hline$\underline{T i}$ & $\mathrm{TiO} 2$ & 0.097 & 0.095 & 2.320 \\
\hline$\dot{Y}$ & Y2O3 & 0.012 & 0.012 & 2.748 \\
\hline $\mathrm{Zn}$ & $\mathrm{ZnO}$ & 0.050 & 0.046 & 7.985 \\
\hline $\mathrm{Zr}$ & $\mathrm{ZrO} 2$ & 1.984 & 1.866 & 5.973 \\
\hline
\end{tabular}


Table C.8. Recycle Waste Simulant

Comparison of Oxide Compositions (Target vs. Measured)

\begin{tabular}{|c|c|c|c|c|}
\hline Element & Metal Oxide & $\begin{array}{c}\text { Target } \\
\text { Composition* } \\
\text { (wt\%) }\end{array}$ & $\begin{array}{c}\text { Average Measured } \\
\text { Composition } \\
\text { (wt\%) }\end{array}$ & $\begin{array}{c}\text { Percent } \\
\text { Difference* } \\
(\%)\end{array}$ \\
\hline $\mathrm{Al}$ & $\mathrm{Al} 2 \mathrm{O} 3$ & 0.250 & 0.265 & 6.000 \\
$\mathrm{Ca}$ & $\mathrm{CaO}$ & 0.020 & 0.030 & 50.000 \\
$\mathrm{Cd}$ & $\mathrm{CdO}$ & 0.202 & 0.215 & 6.263 \\
$\mathrm{Fe}$ & $\mathrm{Fe} 2 \mathrm{O} 3$ & 0.060 & 0.230 & 283.333 \\
$\mathrm{~K}$ & $\mathrm{~K} 20$ & 0.141 & not detected & - \\
$\mathrm{Mg}$ & $\mathrm{MgO}$ & 0.020 & 0.025 & 25.000 \\
$\mathrm{Mn}$ & $\mathrm{MnO2}$ & 0.058 & 0.070 & 21.529 \\
$\mathrm{Na}$ & $\mathrm{Na2O}$ & 2.543 & 2.120 & 16.634 \\
$\mathrm{P}$ & $\mathrm{P} 205$ & 0.202 & 0.170 & 15.842 \\
$\mathrm{Si}$ & $\mathrm{SiO}$ & 2.407 & 2.175 & 9.639 \\
$\mathrm{Ti}$ & $\mathrm{TiO} 2$ & 0.009 & 0.010 & 11.111 \\
\hline
\end{tabular}


Table C.9. Formated Waste Simulant with Recycie

Comparison of Oxide Compositions (Target vs. Measured)

\begin{tabular}{|c|c|c|c|c|}
\hline $\begin{array}{c}\text { Element } \\
.\end{array}$ & Metal Oxide & $\begin{array}{c}\text { Target } \\
\text { Composition* } \\
\text { (wt\%) }\end{array}$ & $\begin{array}{l}\text { Average Measured } \\
\text { Composition } \\
\text { (wt\%) }\end{array}$ & $\begin{array}{c}\text { Percent } \\
\text { Difference* } \\
(\%)\end{array}$ \\
\hline Ag & Ag2O & 0.016 & 0.010 & 38.854 \\
\hline Al & $\mathrm{Al} 2 \mathrm{O} 3$ & 1.237 & 1.165 & 5.821 \\
\hline B & $\mathrm{B} 2 \mathrm{O} 3$ & 0.024 & 0.005 & 79.192 \\
\hline $\mathrm{Ba}$ & $\mathrm{BaO}$ & 0.024 & 0.020 & 16.427 \\
\hline $\mathrm{Ca}$ & $\mathrm{CaO}$ & 0.113 & 0.115 & 1.770 \\
\hline Cd & $\mathrm{CdO}$ & 0.478 & 0.460 & 3.766 \\
\hline $\mathrm{Cr}$ & $\mathrm{Cr} 2 \mathrm{O} 3$ & 0.036 & 0.040 & 12.354 \\
\hline $\mathrm{Cu}$ & $\mathrm{CuO}$ & .0 .033 & 0.035 & 4.604 \\
\hline $\mathrm{Fe}$ & $\mathrm{Fe} 2 \mathrm{O} 3$ & 3.781 & 3.795 & 0.370 \\
\hline $\mathrm{K}$ & $\mathrm{K} 2 \mathrm{O}^{\circ}$ & 0.038 & 0.040 & 5.263 \\
\hline Mg & $\mathrm{MgO}$ & 0.080 & 0.090 & 12.500 \\
\hline Mn & $\mathrm{MnO} 2$ & 0.320 & 0.310 & 3.125 \\
\hline Mo & $\mathrm{M} \infty \mathrm{O}$ & 0.076 & 0.080 & 5.130 \\
\hline $\mathrm{Na}$ & $\mathrm{Na} 2 \mathrm{O}$ & 3.330 & 2.660 & 20.120 \\
\hline $\mathrm{Ni}$ & $\mathrm{NiO}$ & 0.299 & 0.285 & 4.594 \\
\hline$P$ & P2OS & 0.155 & 0.120 & 22.581 \\
\hline $\mathrm{Pb}$ & $\mathrm{PbO}$ & 0.089 & 0.090 & 1.309 \\
\hline Si & $\mathrm{SiO} 2$ & 1.213 & 1.135 & 6.430 \\
\hline $\mathrm{Sr}$ & SrO & 0.016 & 0.020 & 23.477 \\
\hline $\mathrm{Ti}$ & $\mathrm{TiO} 2$ & 0.091 & 0.090 & 1.099 \\
\hline $\mathrm{zn}$ & $\mathrm{ZnO}$ & 0.045 & 0.045 & 1.070 \\
\hline $2 x$ & $\mathrm{ZxO2}$ & 1.814 & 1.785 & 1.599 \\
\hline
\end{tabular}

C.9 
Table C.10. Melter Feed Waste Simulant Comparison of Oxide Compositions (Target vs. Measured)

\begin{tabular}{|c|c|c|c|c|}
\hline Element & Metal Oxide & $\begin{array}{c}\text { Target } \\
\text { Composition } \\
\text { (wt\%) }\end{array}$ & $\begin{array}{l}\text { Average Measured } \\
\text { Composition } \\
\text { (wt\%) }\end{array}$ & $\begin{array}{c}\text { Percent } \\
\text { Difference* } \\
(\%) \\
\end{array}$ \\
\hline As & Ag2O & 0.015 & 0.016 & 9.121 \\
\hline Al & $\mathrm{A} 12 \mathrm{O} 3$ & 1.295 & 1.105 & 14.672 \\
\hline B & $\mathrm{B} 2 \mathrm{O} 3$ & 5.455 & 4.837 & 11.329 \\
\hline $\mathrm{Ba}$ & $\mathrm{BaO}$ & 0.021 & 0.023 & 7.197 \\
\hline $\mathrm{Ca}$ & $\mathrm{CaO}$ & 0.116 & 0.115 & 0.862 \\
\hline $\mathrm{Cd}$ & $\mathrm{CdO}$ & 0.428 & 0.402 & 6.075 \\
\hline $\mathrm{Ce}$ & $\mathrm{CeO} 2$ & 0.078 & 0.097 & 23.861 \\
\hline Cr & $\mathrm{Cr} 2 \mathrm{O} 3$ & 0.032 & 0.038 & 19.051 \\
\hline $\mathrm{Cu}$ & $\mathrm{CuO}$ & 0.030 & 0.031 & 3.338 \\
\hline Fe & $\mathrm{Fe} 2 \mathrm{O} 3$ & 3.437 & 3.293 & 4.190 \\
\hline $\mathbf{K}$ & $\mathrm{K} 2 \mathrm{O}$ & 0.042 & not detected & - \\
\hline $\mathrm{La}$ & $\mathrm{L} 82 \mathrm{O} 3$ & 0.070 & 0.088 & 25.714 \\
\hline $\mathrm{Li}$ & $\mathrm{LiO} 2$ & 1.902 & 1.717 & 9.705 \\
\hline $\mathrm{MB}_{8}$ & $\mathrm{MgO}$ & 0.087 & 0.103 & 18.391 \\
\hline Mn & $\mathrm{MnO} 2$ & 0.286 & 0.269 & 5.944 \\
\hline Mo & $\mathrm{MoO3}$ & 0.068 & 0.071 & 4.067 \\
\hline $\mathrm{Na}$ & $\mathrm{Na} 2 \mathrm{O}$ & 3.049 & 2.792 & 8.429 \\
\hline Nd & $\mathrm{Na} 2 \mathrm{O} 3$ & 0.408 & 0.414 & 1.471 \\
\hline$\sqrt{2}$ & $\mathrm{NiO}$ & 0.268 & 0.261 & 2.548 \\
\hline P & P2O5 & 0.146 & 0.174 & 19.178 \\
\hline $\mathrm{Pb}$ & $\mathrm{PbO}$ & 0.080 & 0.094 & 18.019 \\
\hline$S$ & $\mathrm{SO}$ & 0.081 & 0.128 & 58.025 \\
\hline $\mathrm{Si}$ & $\mathrm{SiO}_{2}$ & 22.730 & 20.260 & 10.867 \\
\hline Sn & $\mathrm{SnO}$ & 0.001 & not detected & - \\
\hline Sr & SrO & 0.015 & 0.014 & 3.594 \\
\hline Te & TeO2 & 0.012 & 0.026 & 110.891 \\
\hline $\mathrm{Ti}$ & $\mathrm{TiO} 2$ & 0.088 & 0.094 & 6.818 \\
\hline$Y$ & Y2O3 & 0.010 & 0.010 & 2.259 \\
\hline $\mathrm{Zn}$ & $\mathrm{ZnO}$ & 0.041 & 0.051 & 25.056 \\
\hline Zr & $\mathrm{ZrO2}$ & 1.627 & 1.525 & 6.269 \\
\hline
\end{tabular}




\section{Appendix D}

Rheological Properties-Rheograms and Settling Rates 
Table D.1. Settling Rates for Different Simulants

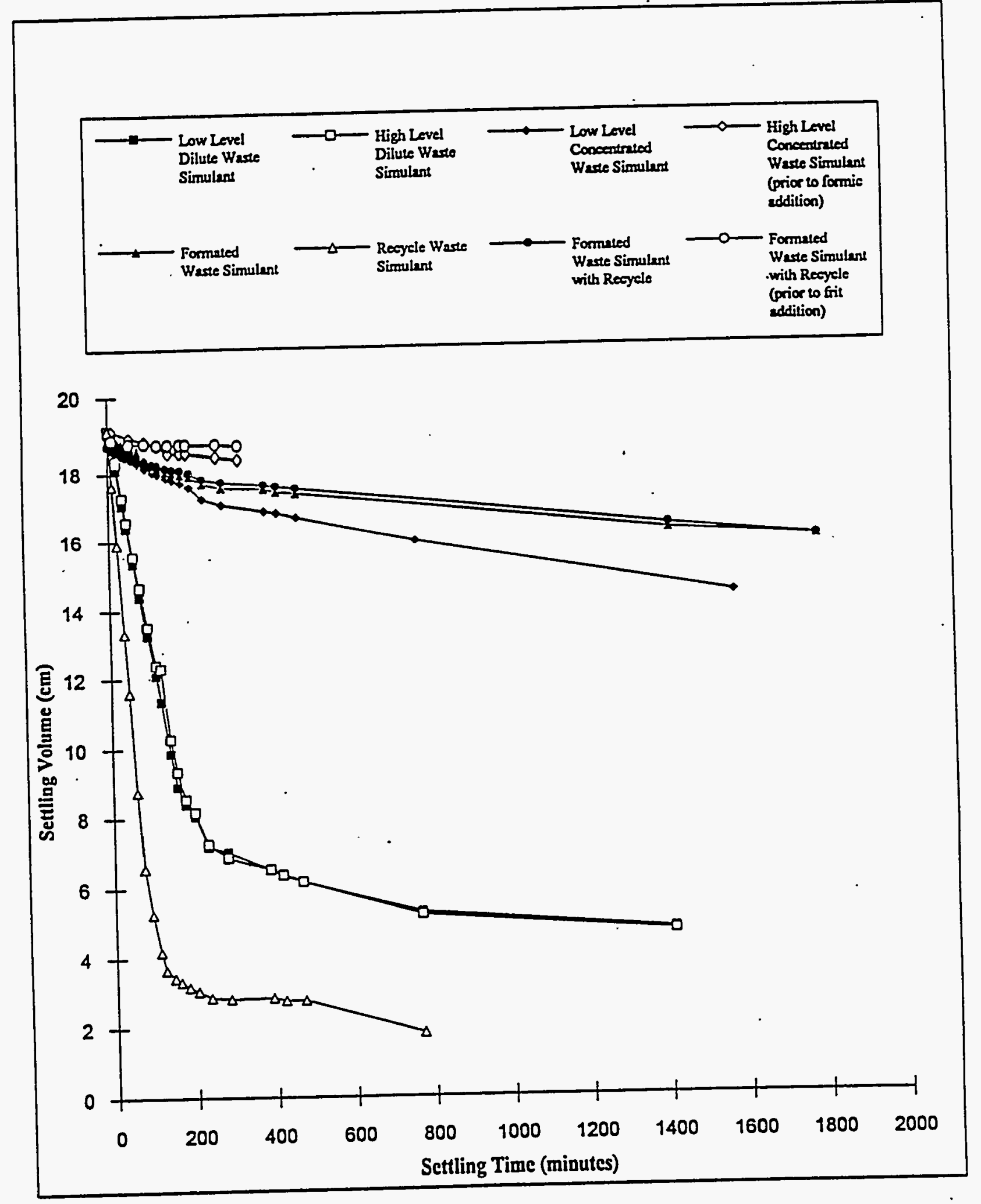

D. 1 
Table D.2. Settling Data

\begin{tabular}{|c|c|c|c|c|c|c|c|}
\hline 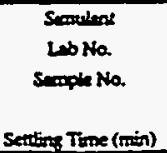 & $\begin{array}{c}\text { Low Lord Dliute } \\
1263-93 \\
1.41 \\
\text { Sating Votume (Er) }\end{array}$ & $\begin{array}{l}\text { Sumiant } \\
\text { LubNa. } \\
\text { Serpie Na. } \\
\text { Setting Time (min) }\end{array}$ & $\begin{array}{c}\text { Hugh Leved Dute } \\
1265-93 \\
\text { S.e1 } \\
\text { Seting Vohme (cm) }\end{array}$ & 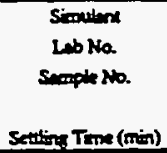 & $\begin{array}{c}\text { Low Loved Coneensund } \\
1262.93 \\
123.7\end{array}$ & $\begin{array}{l}\text { Serreviens } \\
\text { Leb No. } \\
\text { Sumple No. } \\
\text { Setting Trme (min) }\end{array}$ & 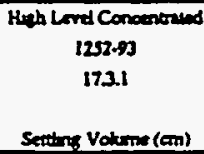 \\
\hline 0 & $120 \operatorname{sins}$ & 0 & 19.05 & 0 & 19.05 & 10 & 19.05 \\
\hline 10 & 127202 & 10 & 12014 & 10 & itessts & si & ievess \\
\hline 20 & 180075 & 20 & inses & 20 & 15.7cues & $\boldsymbol{x}$ & $12 x+a s$ \\
\hline 3 & 17.0075 & 34 & 17293 & 34 & 18009 & 122 & Inces \\
\hline 4 & 1630 & $\mu$ & 16.5735 & 4 & 1Rs356s & 150 & Iearts \\
\hline 9 & 1530525 & $s 9$ & 15sea & 9 & 1230025 & 17 & Itams \\
\hline 94 & 107275 & 74 & 14.coses & 74 & $12 \pi$ & 195 & isms \\
\hline 9 & 132975 & 91 & 135255 . & 91 & 121346s & 270 & 18003 \\
\hline III & $1207 \mathrm{~m}$ & uI & $123 \times 25$ & III & izansess & 325 & |ETS| \\
\hline 122 & 1135 & 127 & 1225725 & 122 & $17 \operatorname{sen}$ & & \\
\hline is & 92679 & is & 10287 & 14 & 17240 & & \\
\hline 199 & turas & 198 & 9306 & 158 & 17.7927 & & \\
\hline 17 & 130 & 178 & 2534 & .179 & 17.7165 & & \\
\hline 202 & 20091 & 202 & Itsu & 202 & 1750015 & & \\
\hline 24 & 7.100 & $\mathbf{2 4}$ & 7299 & $\mathbf{m}$ & 17.2212 & & \\
\hline 20 & 70104 & 200 & cess: & 20 & 17.0ms & & \\
\hline 300 & (SISI & 30 & GISI & 30 & 16.8525 & & \\
\hline$\infty$ & C.3*17s & $\infty$ & $6 \times 527$ & $\infty$ & 162021 & & \\
\hline$\$ 0$ & c.17n & 40 & a.ro & 40 & 16.6075 & & \\
\hline 700 & $\begin{array}{l}32950 \\
4.7625\end{array}$ & $m$ & 5.2197 & $\pi$ & 159009. & & \\
\hline Servelexp & Formelod & senesinst & Reryes & Sementex & Focmened weth Rogrile & Swroulent & Prox 60 Fint Adderon \\
\hline Lablia. & 125493 & Lebra. & 12563 & Lona. & 122993 & Lab No. & $1260-93$ \\
\hline sempie tia. & 219.6 & Seaple No. & 2421 & somian No. & $\mathbf{2 6 . 1}$ & Sampis No. & 252.1 \\
\hline Secting Terne (non) & Seting Volume (on) & Settin Time (min) & Scturg Volume (am) & Setting Tme (mis) & Sewing Voturne (m) & Sectling Trne (min) & Senting Voturne (cm) \\
\hline 0 & 1esess & 0 & 19,05 & 0 & 18.669 & 10 & iccozas \\
\hline 10 & $12 \pi \pi 0$ & 10 & 17.02123 & 10 & Iseses & si & |187071 \\
\hline 20 & 12760 & 20 & 1590573 & 20 & $185 s+7$ & 91 & |R7071 \\
\hline 34 & 127071 & 3 & 13.335 & 3 & 18.rns & 12 & 15.609 \\
\hline$\mu$ & - ILEA & 4 & II.cos & 4 & Ixum & 150 & 12669 \\
\hline so & IEsT37s & 9 & 2700 & so & 183035 & 179 & 12669 \\
\hline 74 & 1essin & 74 & astms & 14 & 123261 & 195 & iscose \\
\hline $9 t$ & Iesesis & 91 & s.moes & 91 & 1220 & 270 & 18668 \\
\hline$m$ & Itr2300s & 111 & 4191 & III & 182000 & 325 & 12.000 \\
\hline 12 & 12.1737 & 122 & 30576 & 122 & 18:1975 & & • \\
\hline 14 & 120ses & 14 & 300 & 14 & 1813s & & \\
\hline 159 & 180013 & 159 & 33187 & 190 & iscons & & \\
\hline 179 & 1756415 & 179 & 11023 & 179 & isorres & & \\
\hline 200 & 17507 & 202 & 104 & 202 & Inoons & & \\
\hline 24 & 27.574 & 24 & 20575 & 23 & 17s11175 & & \\
\hline 20 & 17 sesos & 20 & $2 \pi 1 \times 4$ & 20 & i7.71s & & \\
\hline 300 & 1750095 & 390 & 2000 & 30 & 17.6212 & & \\
\hline$\infty$ & 17.4117 & $\infty 0$ & 27605 & $\infty$ & 17 sul & & \\
\hline 40 & 173545 & 40 & 27005 & 100 & 1750 ses & & \\
\hline 1410 & 162655 & $m$ & 120075 & 1410 & 1630 & & \\
\hline $17 \pi 0$ & 16.002 & & & 170 & 16.002 & & \\
\hline
\end{tabular}


Table D.3. Low-Level Dilute Waste Simulant

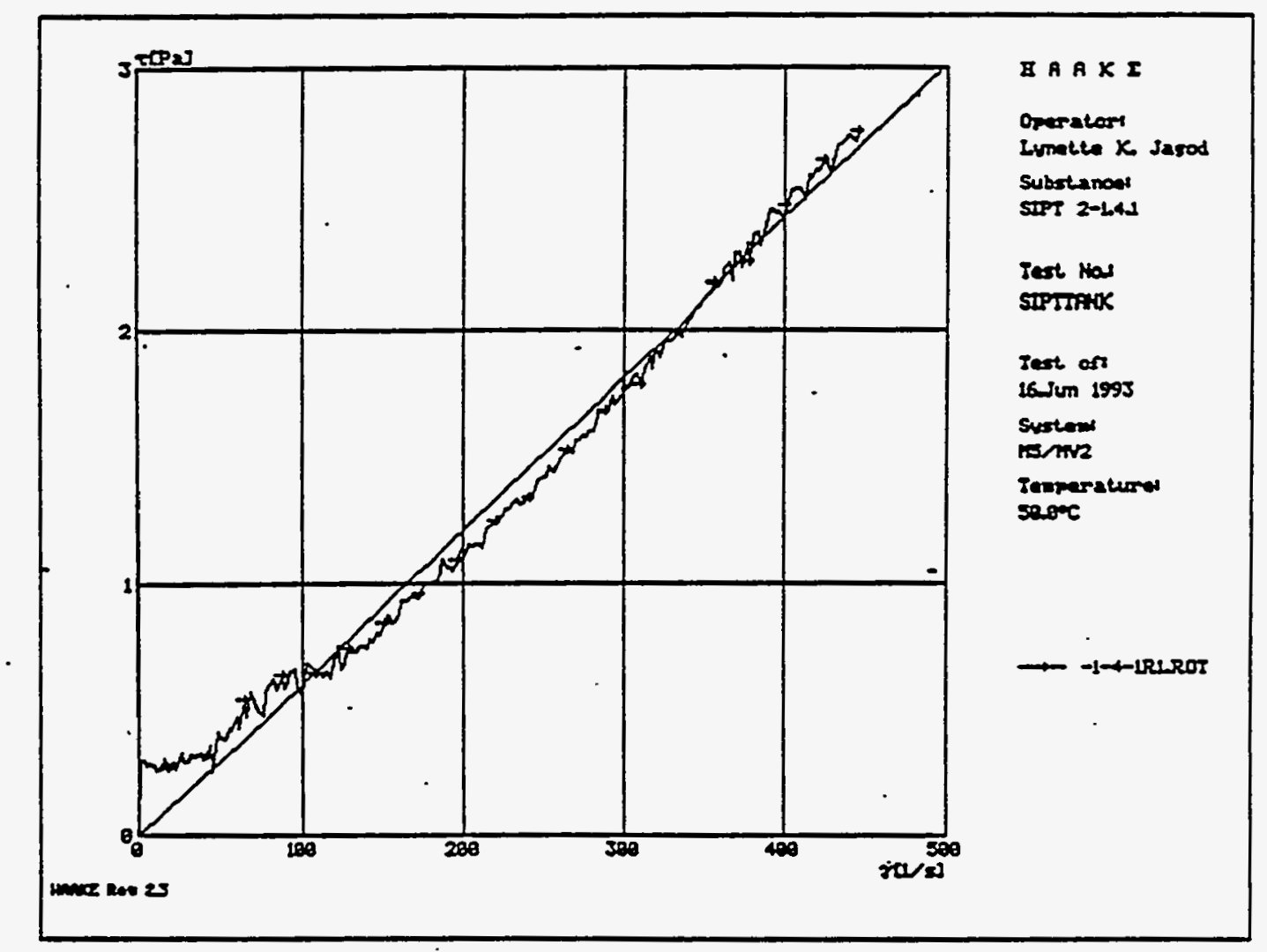

Low Level Dilute Waste Simulant

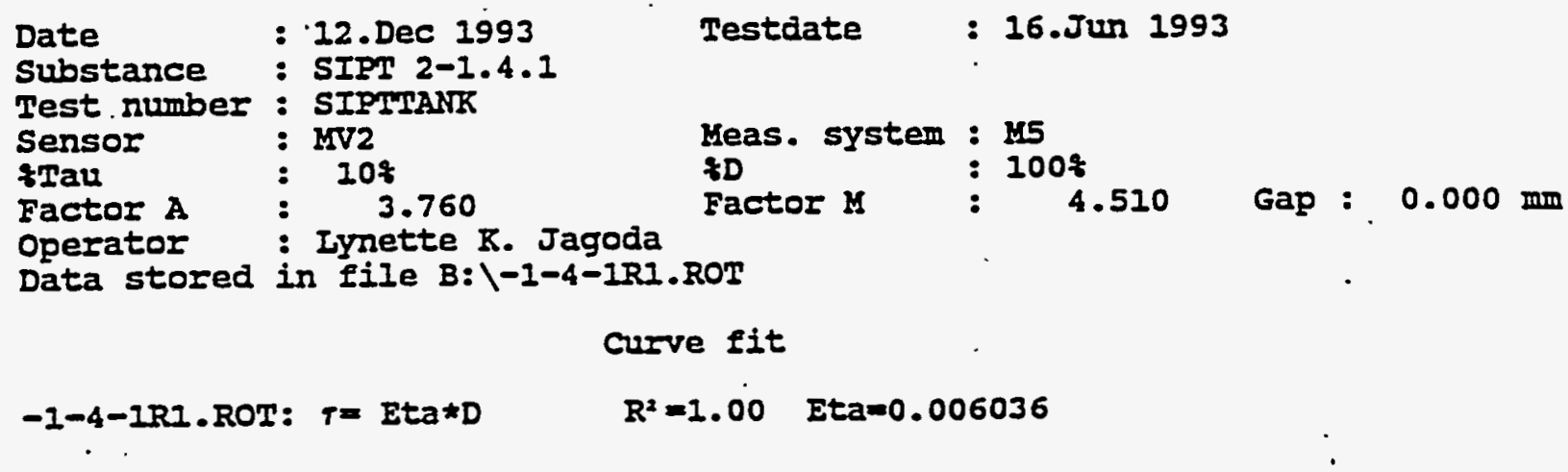

D.3 
Table D.4. High-Level Dilute Waste Simulant

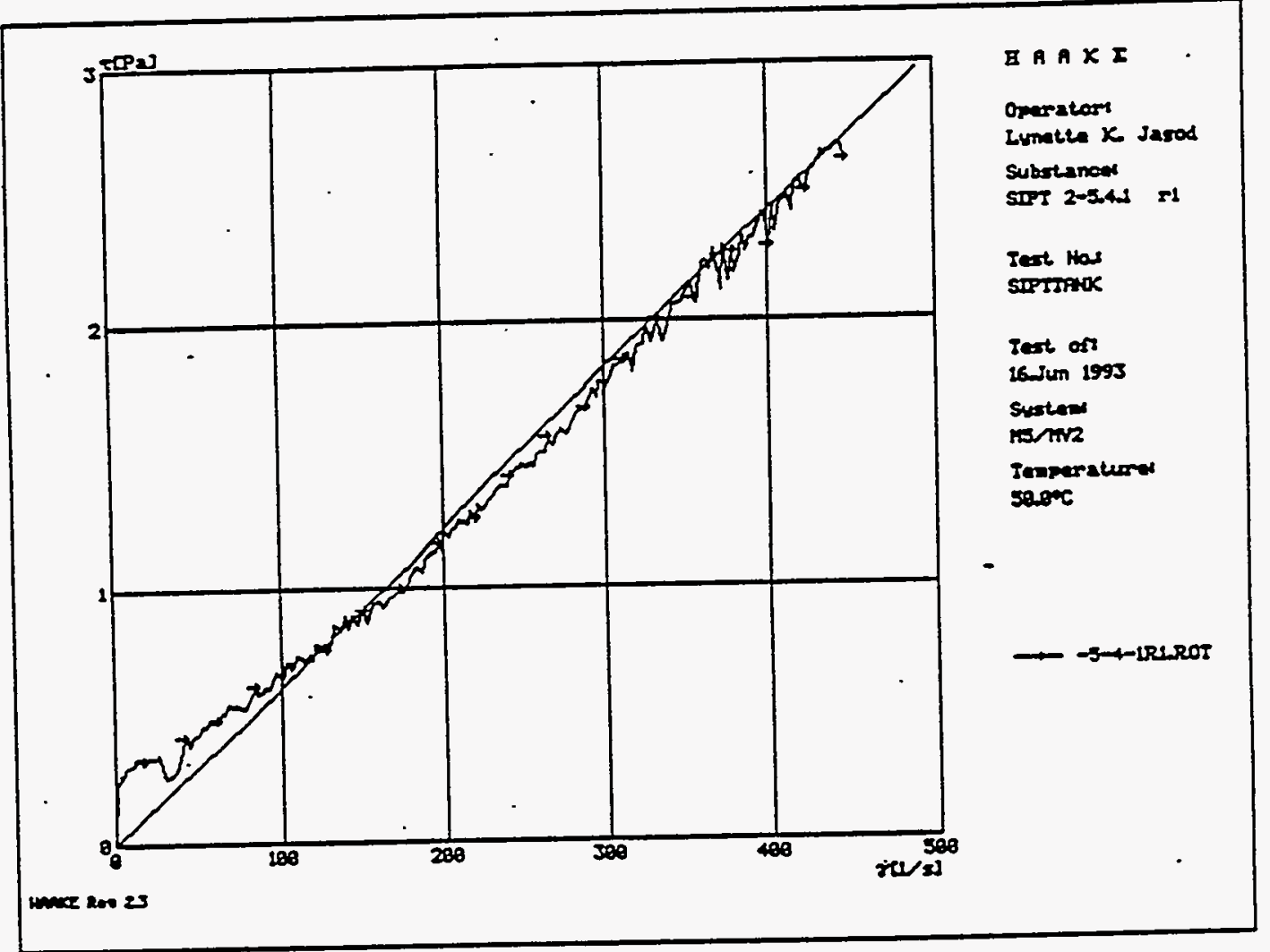

Bigh Level Dilute Waste Simulant

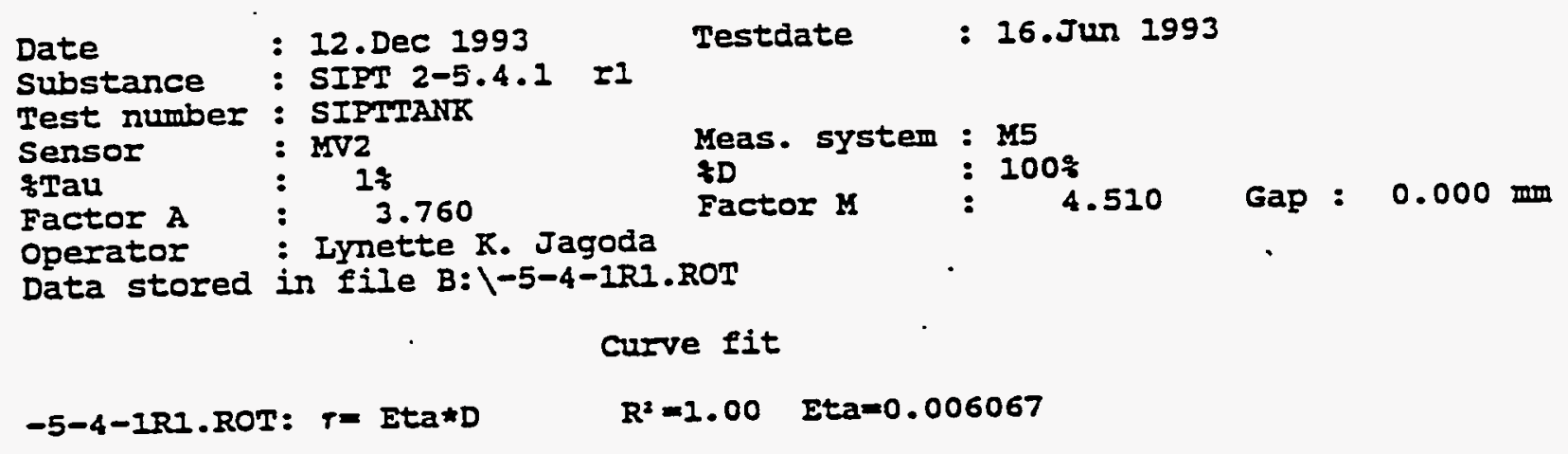

D. 4 
Table D.5. Low-Level Concentrated Waste Simulant

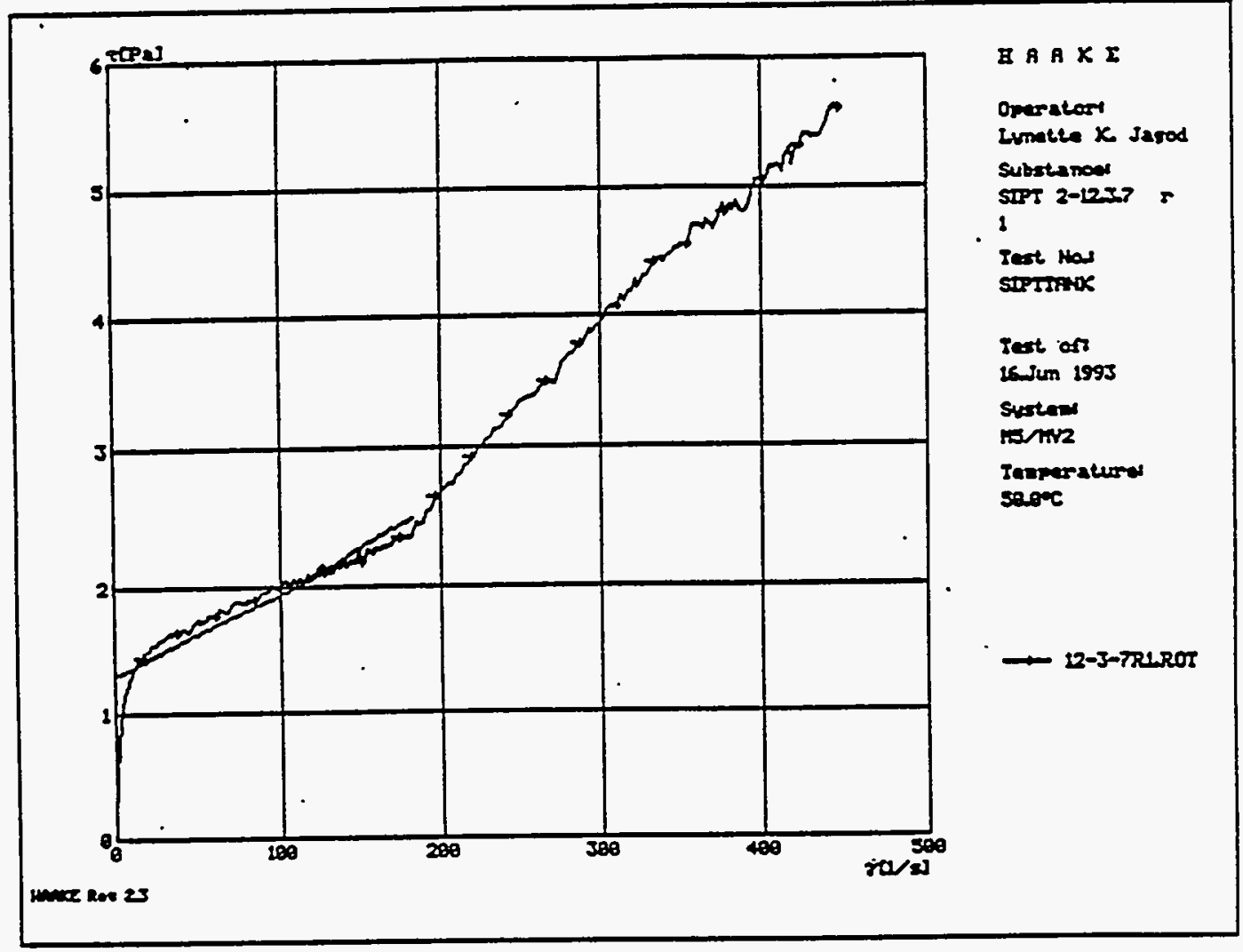

Low Level Concentrated Waste Simulant

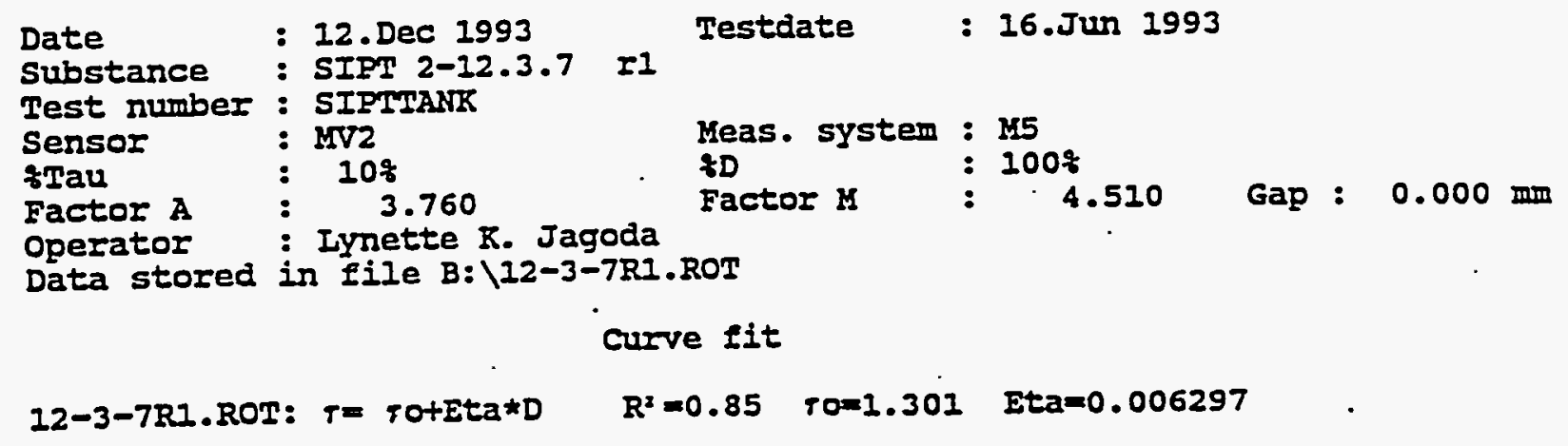


Table D.6. High-Level Concentrated Waste Simulant

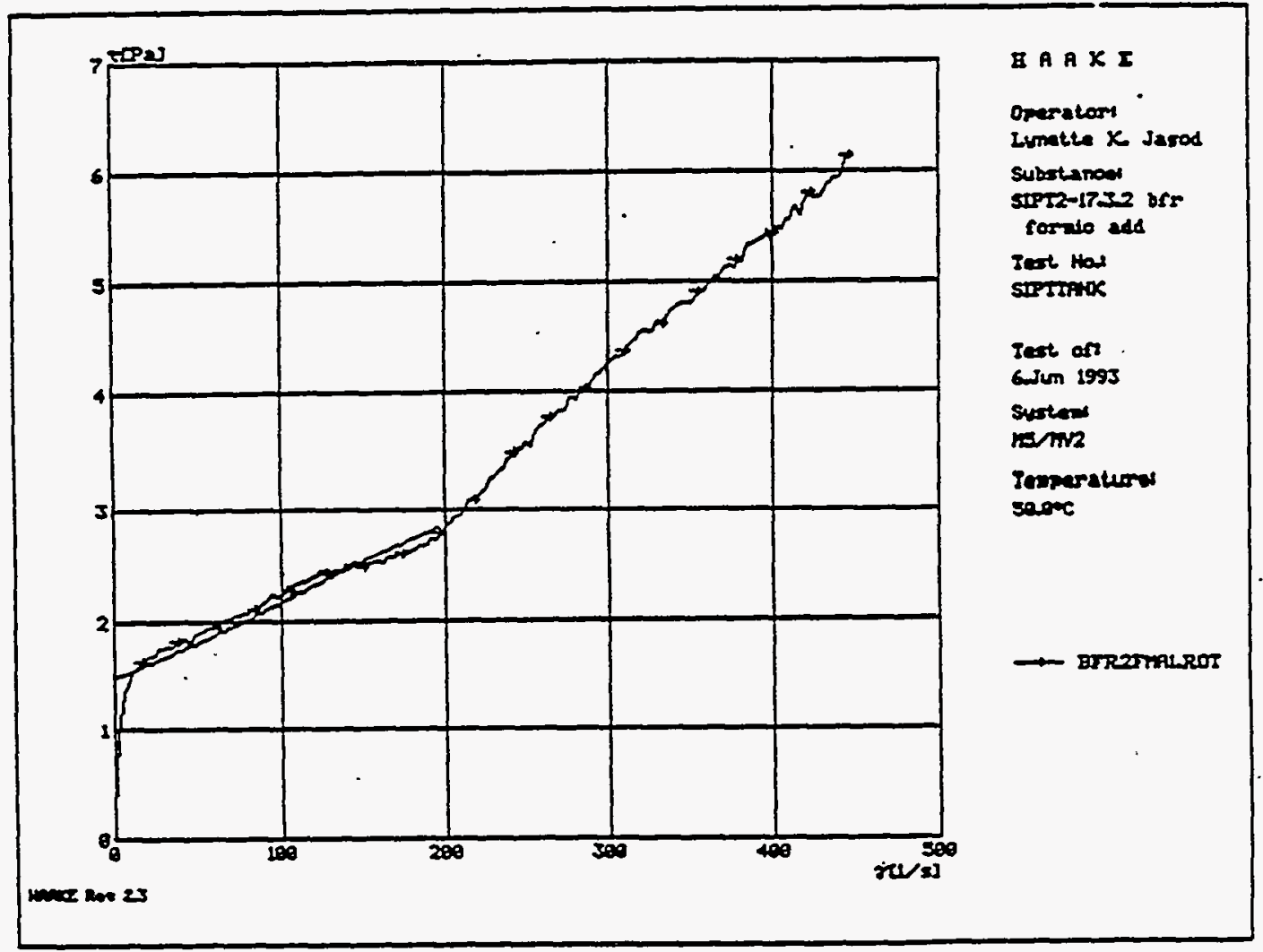

High Level Concentrated Waste Simulant (prior to formic acid addition)

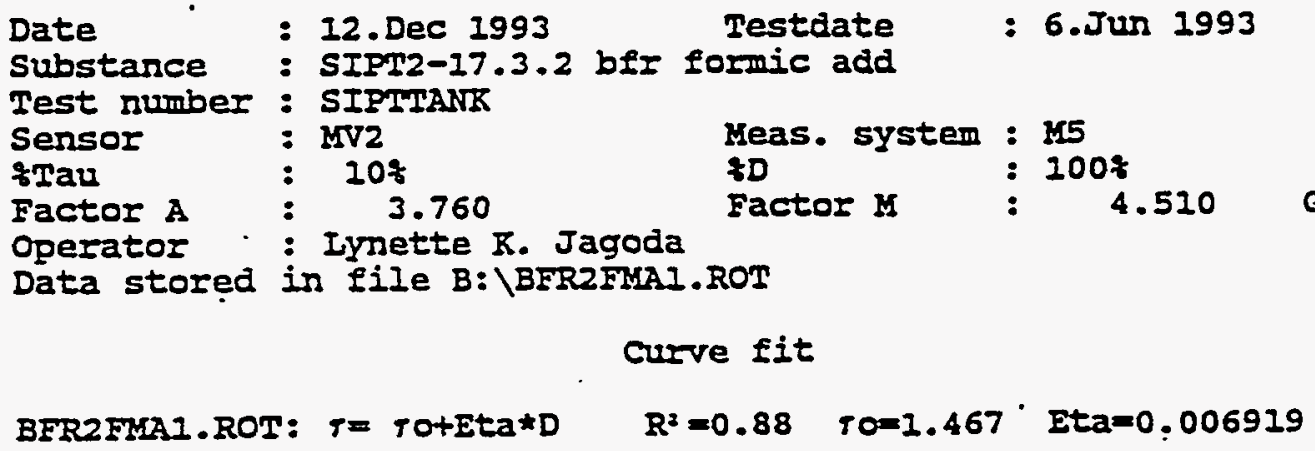


Table D.7. Formated Waste Simulant

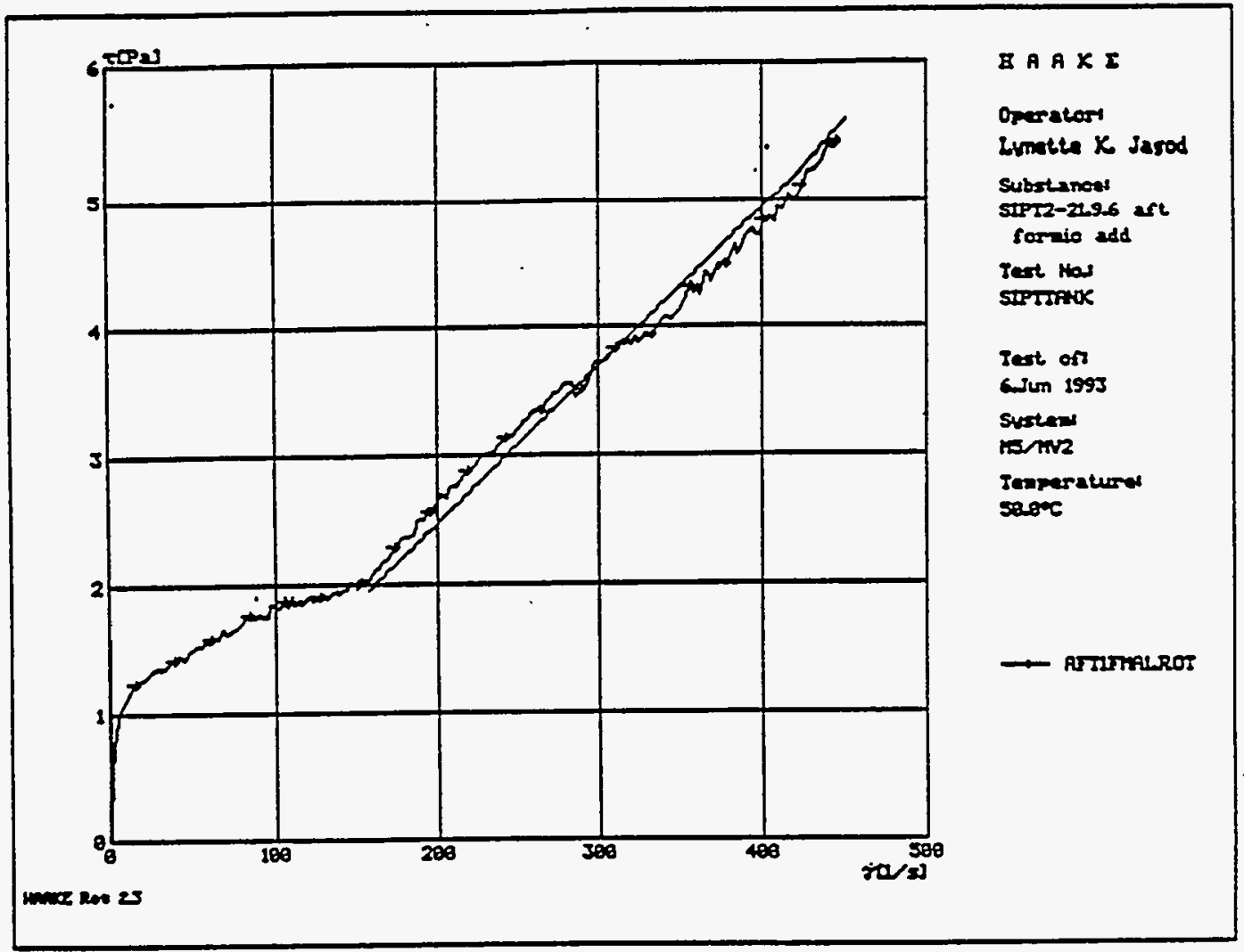

Formated Waste Simulant

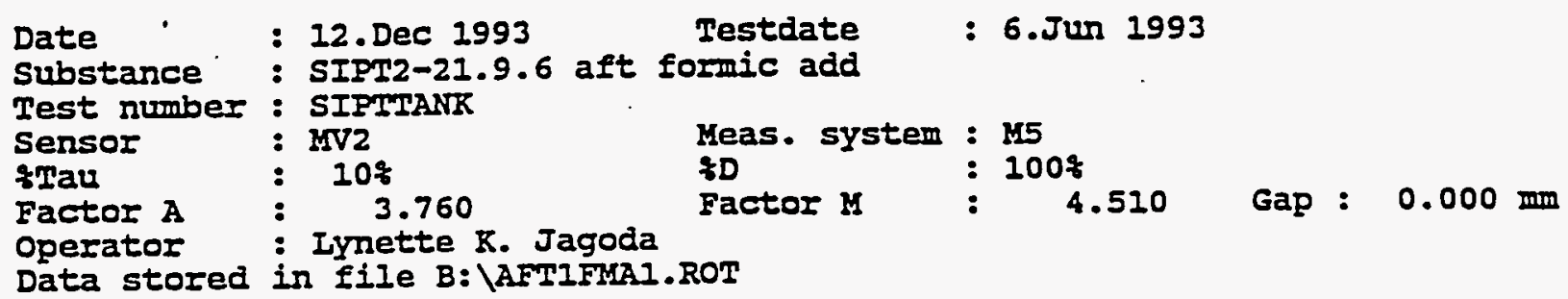

\section{Curve fit}

AFTIFMAI.ROT: $T=T O+E t a * D \quad R^{2}=0.88$ TO=1.105. Eta=0.00665

D.7 
Table D.8. Recycle Waste Simulant

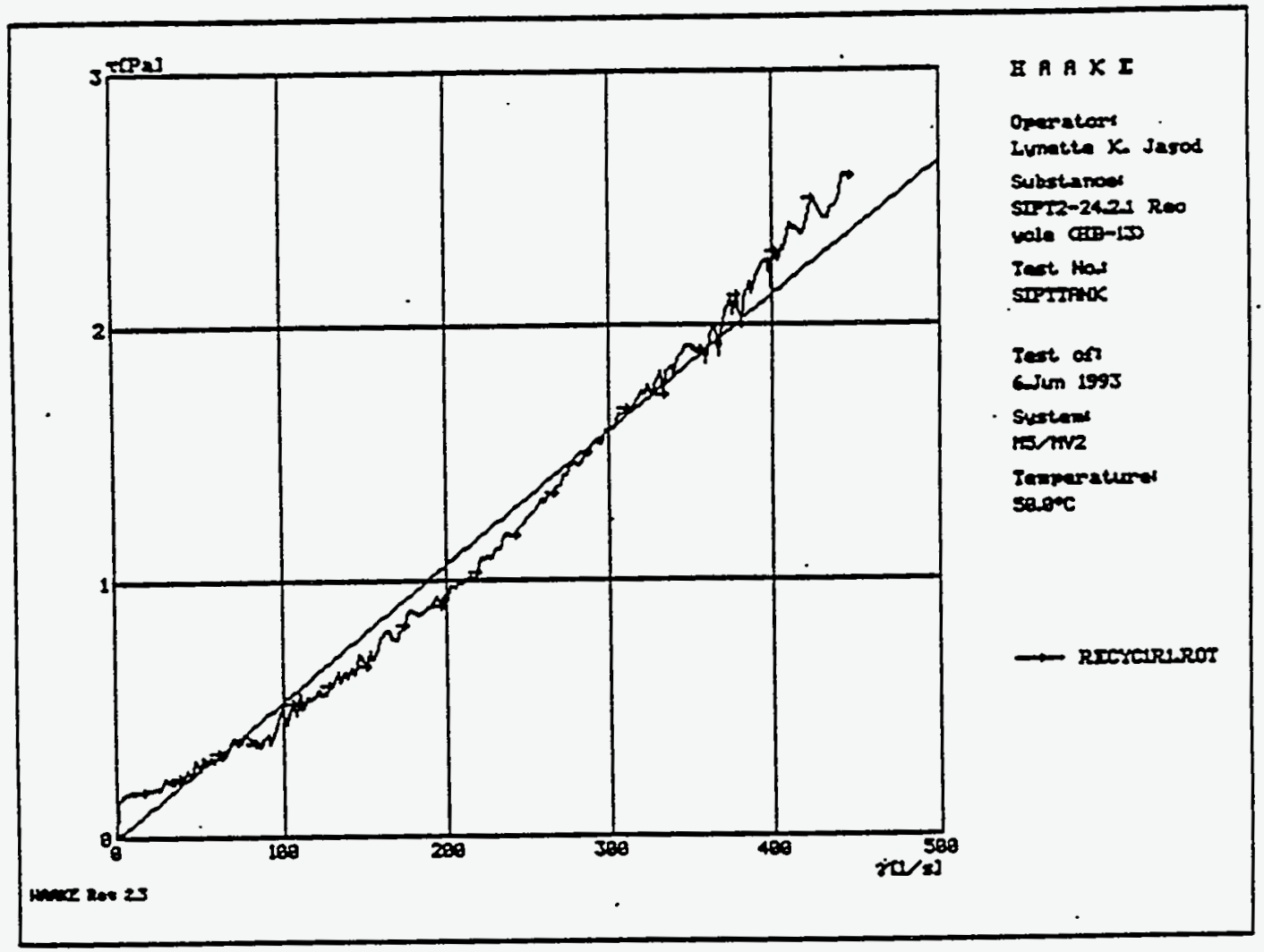

Recycle Waste Simulant

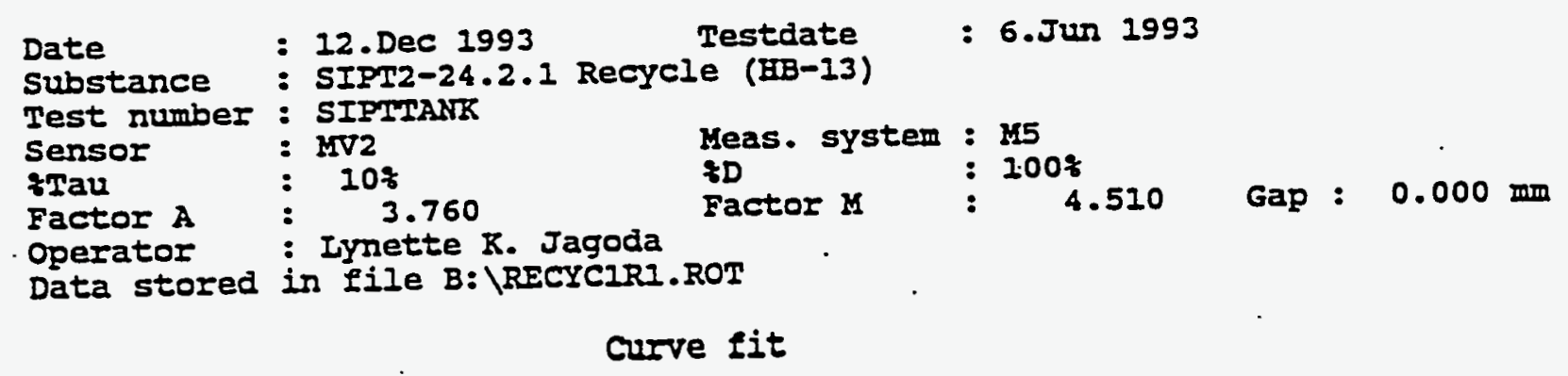

RECYCIRI.ROT: T= Eta*D

$R^{2}=1.00 \quad E t a=0.005289$ 
Table D.9. Formated Waste Simulant with Recycle

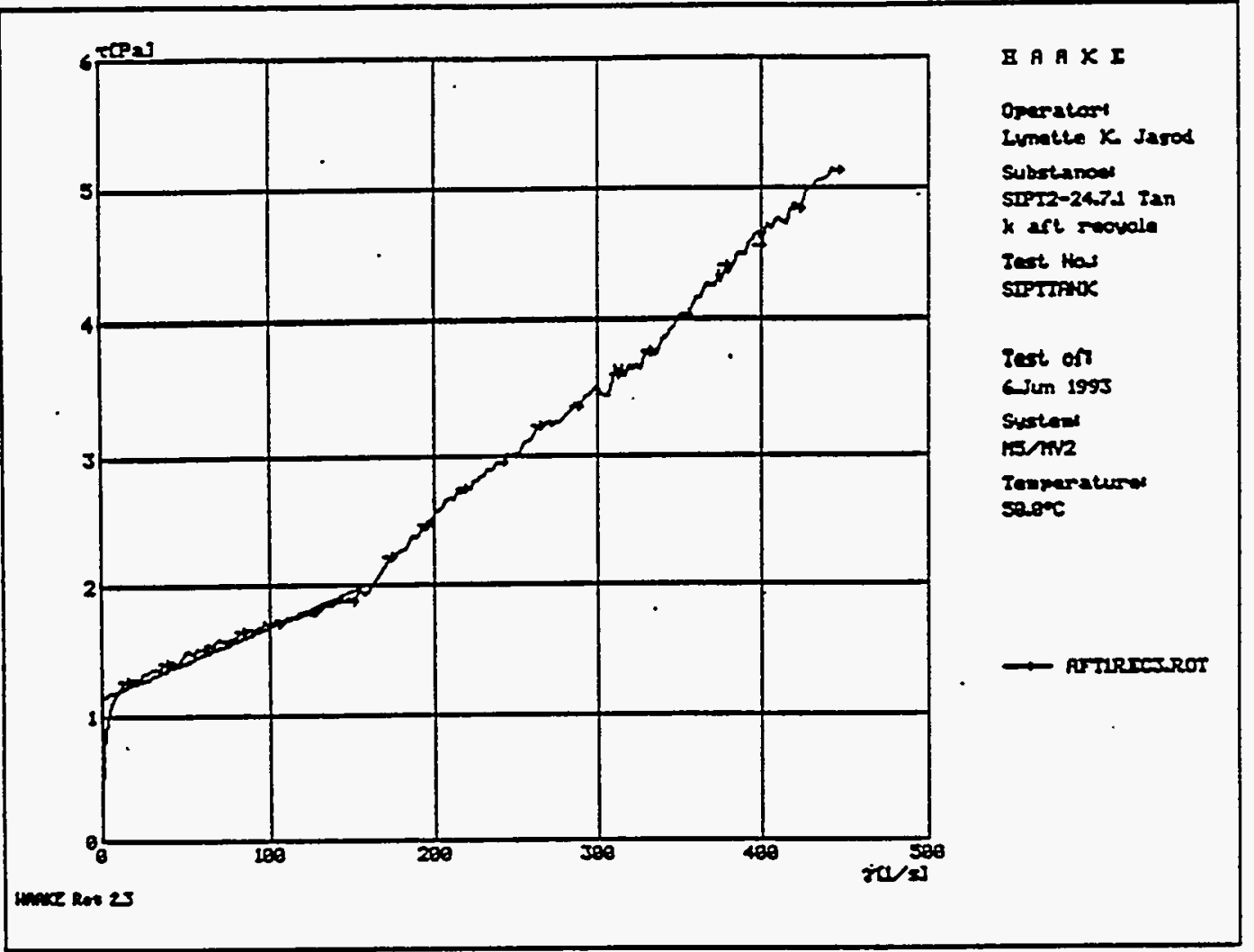

Formated Waste Simulant with Recycle

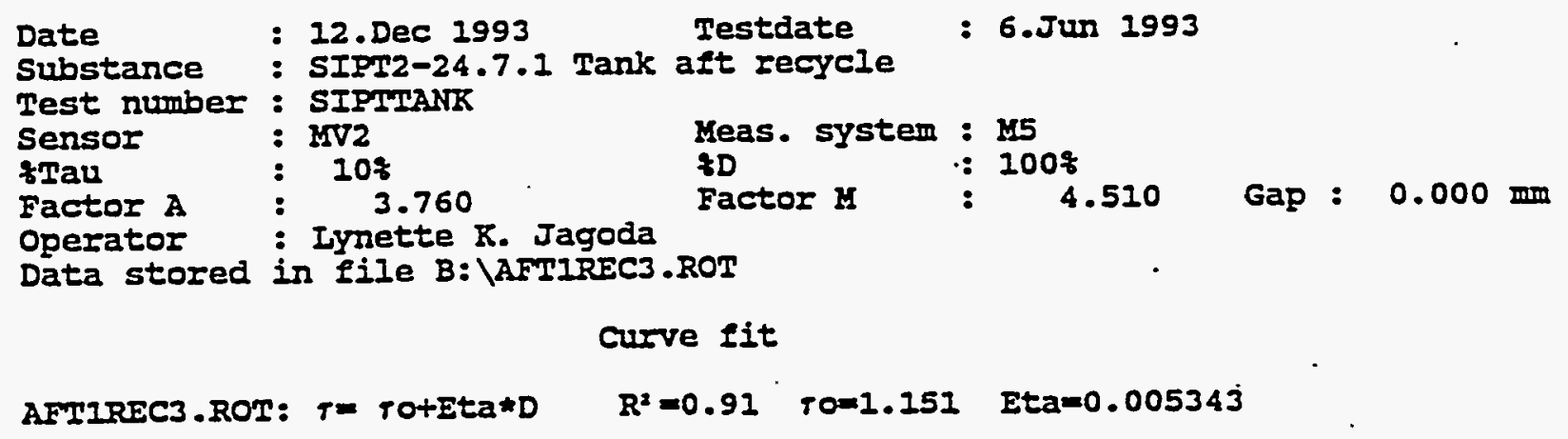

D. 9 
Table D.10. Formated Waste Simulant with Recycie (prior to frit addition)

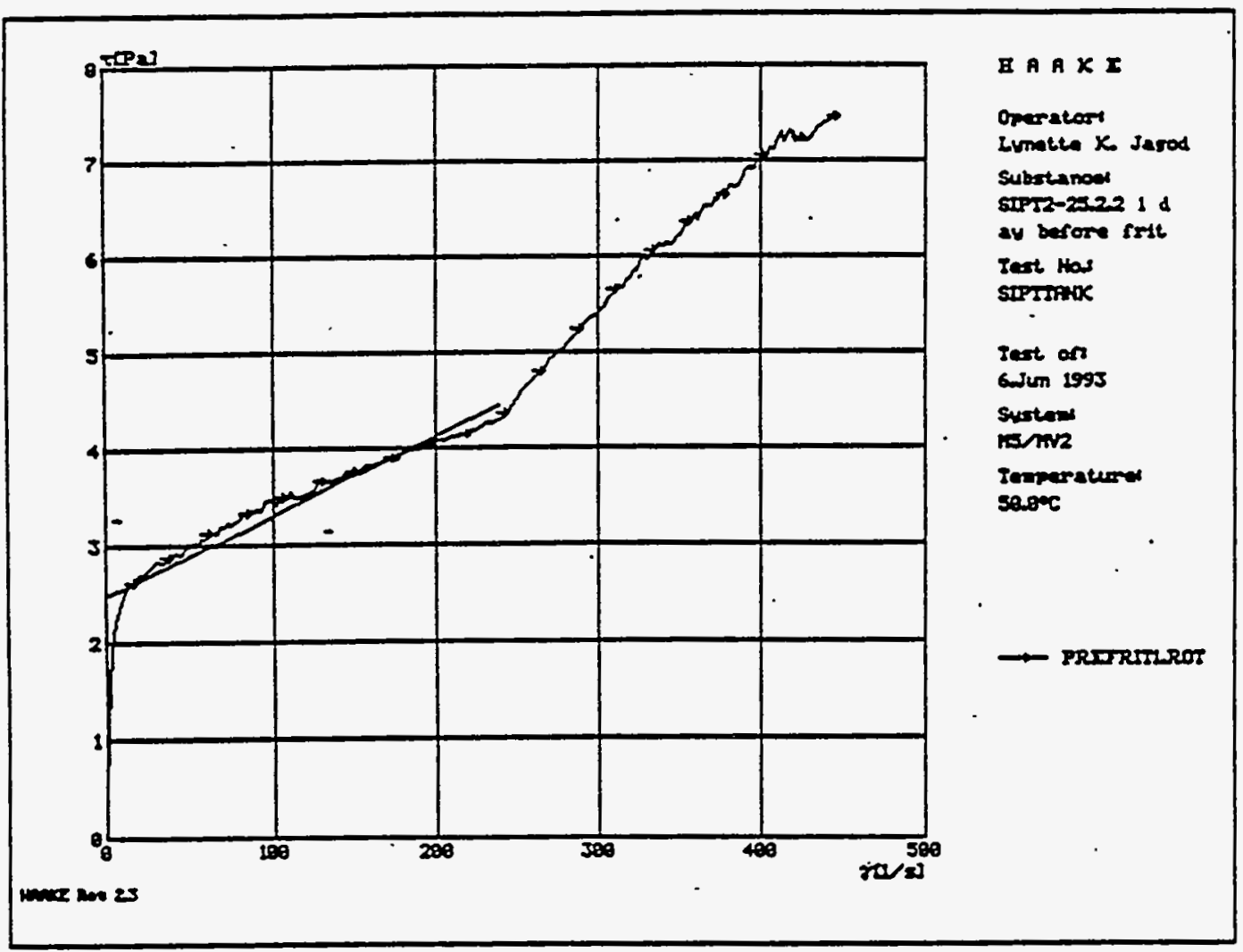

Formated Waste Simulant with Recycle (prior to frit addition)

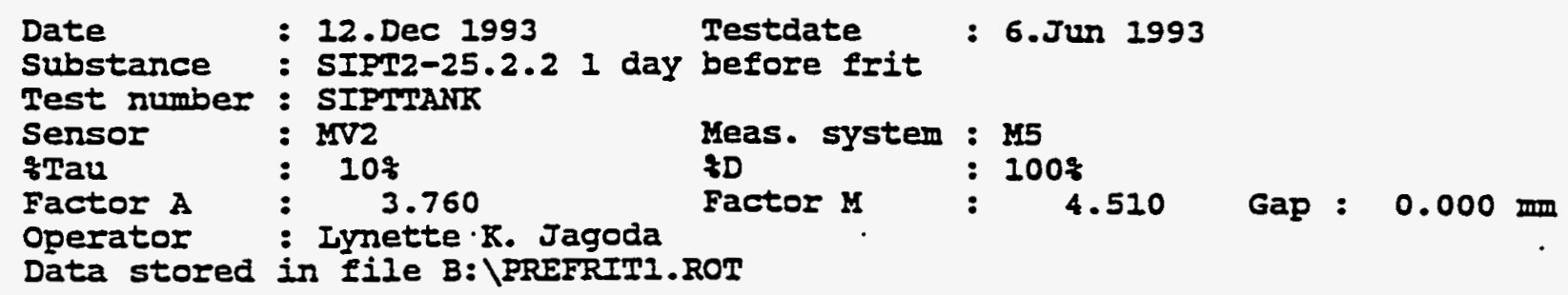

curve fit

PREFRITI.ROT: $T=T O+E t a \neq D \quad R^{2}=0.89 \quad T 0=2.488 \quad E t a=0.008135$ 
Table D.11. Melter Feed Waste Simulant (first day)

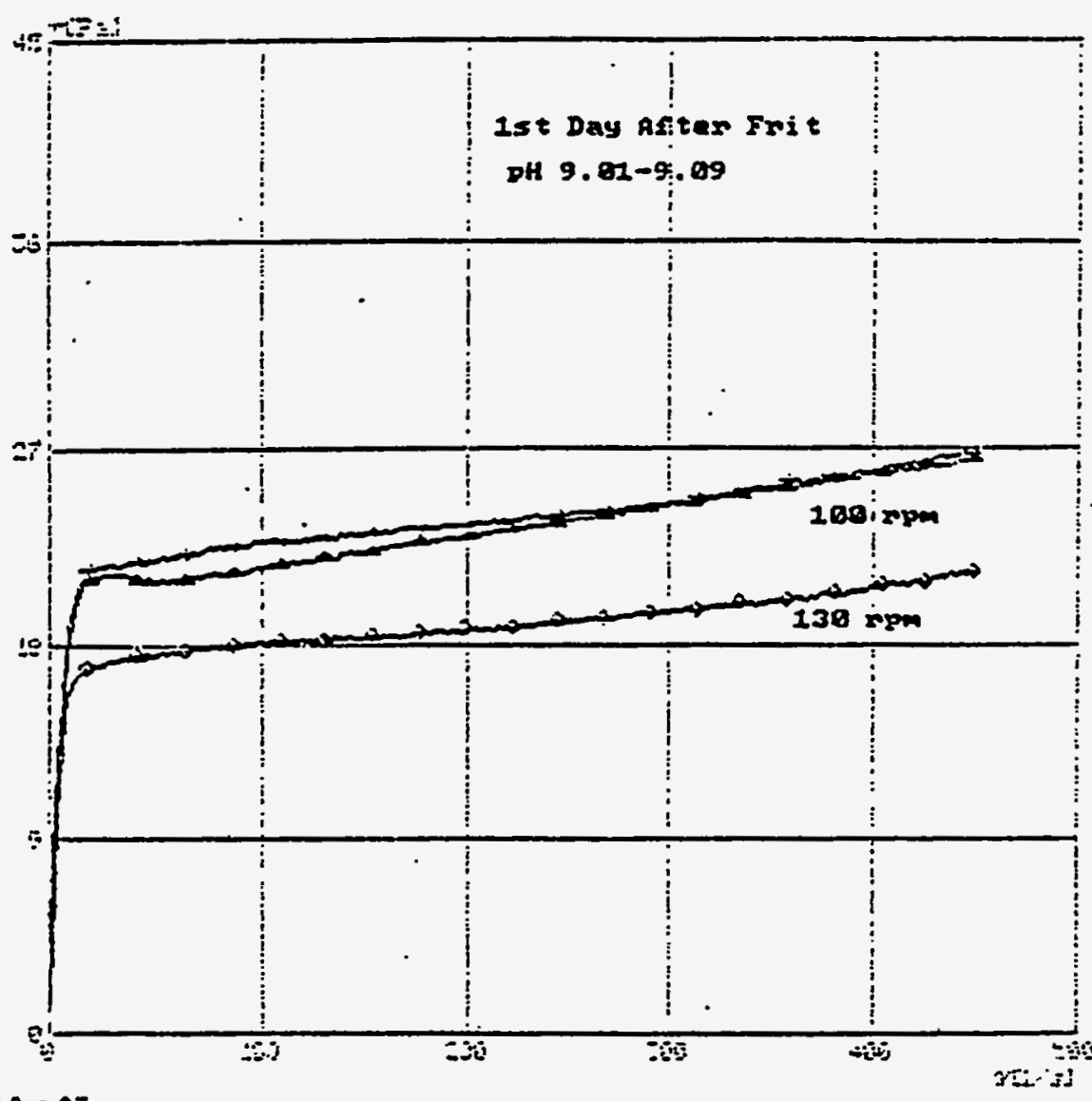

ะคคห

Operstor:

Lynatie Jareda

Sultstanse:

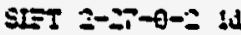
art-it $100 r$ rom

Test, Ho:

SIF TמAMR

Tert or:

FApr 1953

systent

Me.me

Tapparature:

sopor

$\rightarrow$ FDELPLPO

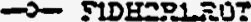

- FLESR: $30 \%$

HaRAKE Ros 25

D.11 
Table D.12. Melter Feed Waste Simulant (daily progress)

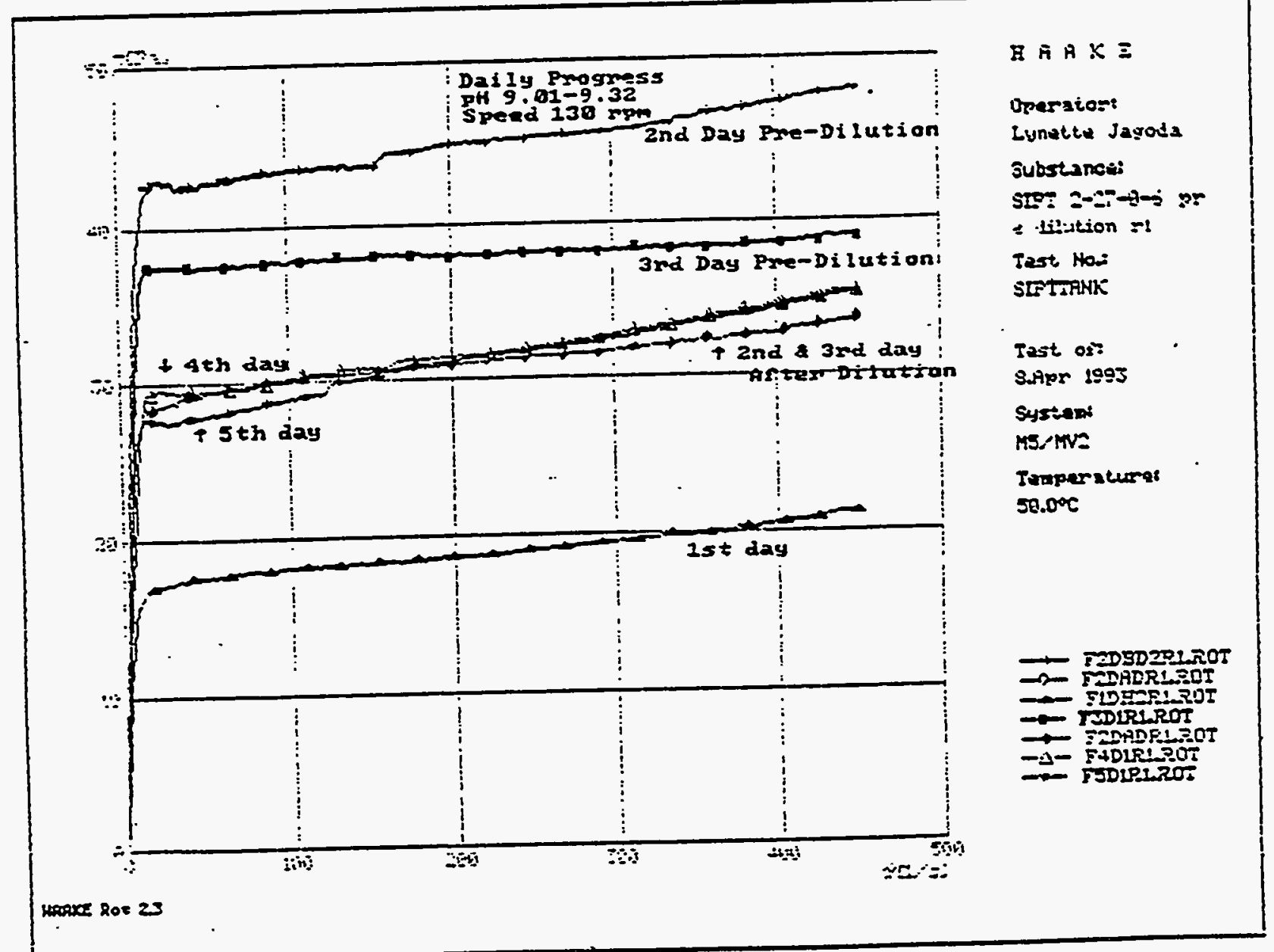

D. 12 
Table D.13. Meiter Feed Waste Simulant $\left(25^{\circ} \mathrm{C}\right.$ and $\left.50^{\circ} \mathrm{C}\right)$

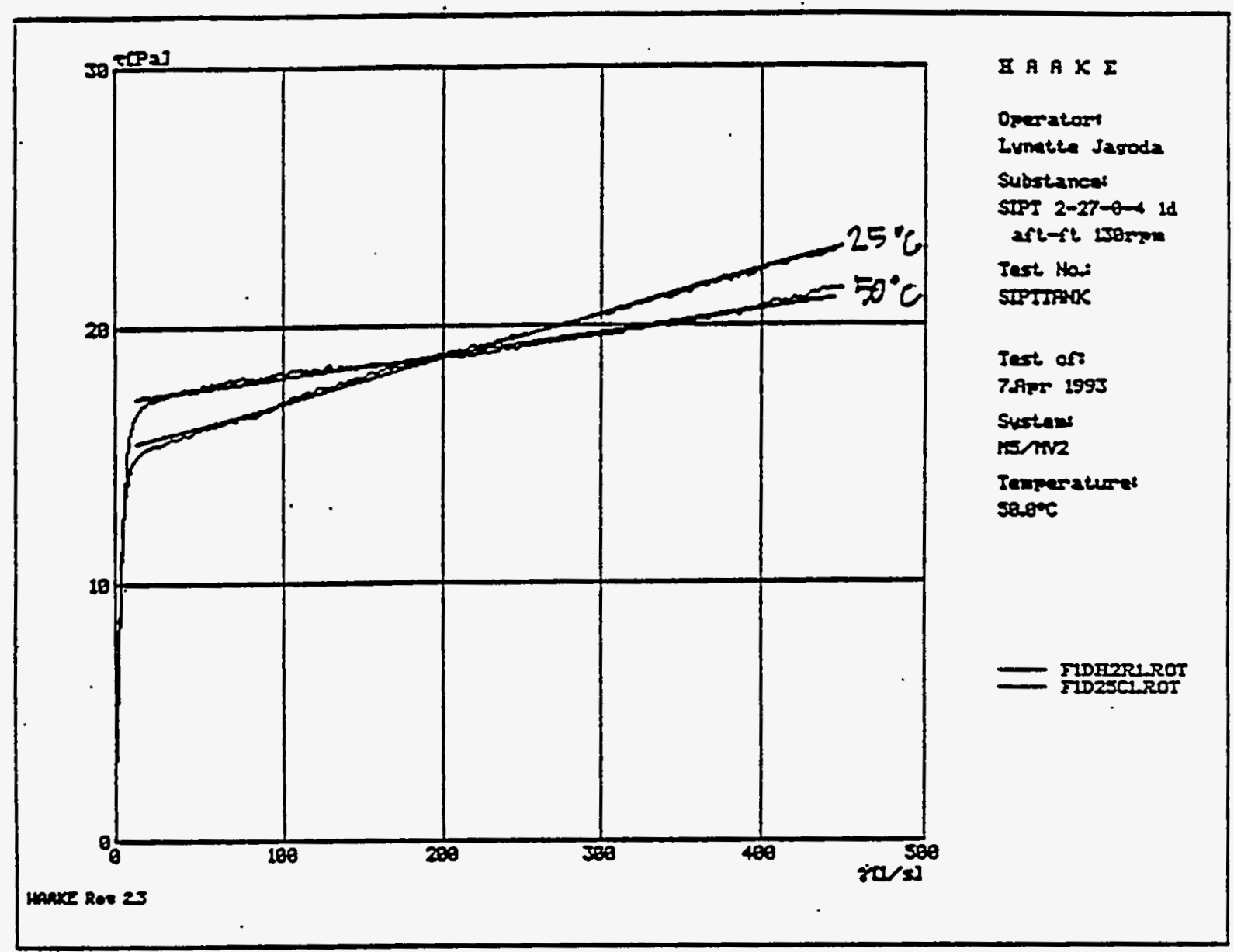

D. 13 
Table D.14. General Hysteresis Effect
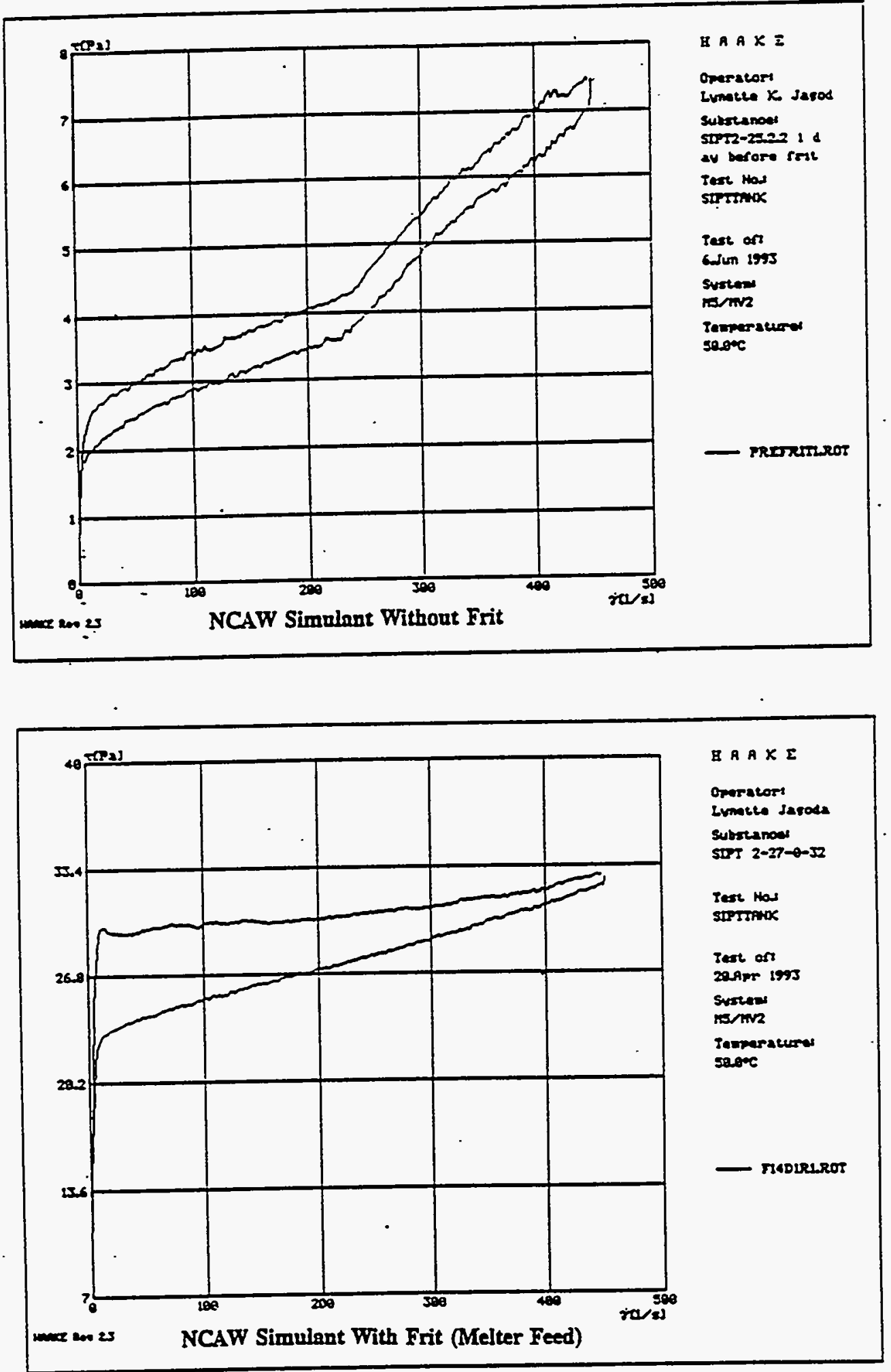

D. 14 
Appendix E

\section{FY 1992 Frit Study Data}


Date October 21, 1992

To I. Jagoda

From E. D. Jenson

Subject CRYSTALS FROM LI B SIO3 SLURRY

SUMMARY

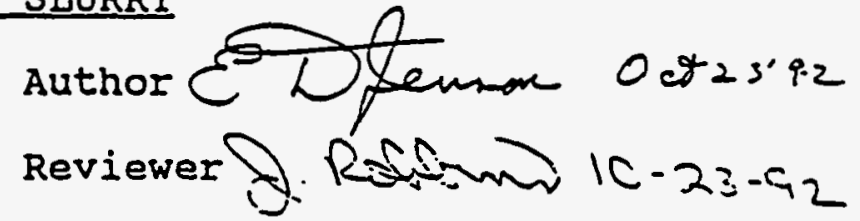

Samples of Li B SiO3 slurry and crystals forming on the slurry have been analyzed using X-ray Diffraction (XRD). The crystals were identified as $\mathrm{Li2} \mathrm{B2O4} \bullet 16 \mathrm{H} 20$. No indication of any additional phases was found.

RESULTS AND DATA

The crystals forming on the surface of the $\mathrm{Li}$ B SiO3 slurry were removed and examined as a thin sample on a glass slide. The crystals were crushed in place on the slide, since removing enough to crush as a bulk sample also removed some slurry and the whole mass liquified on crushing. Examination of the slurry itself showed the same phase present, and no others. Drying the sample, (effectively recovering the frit), gave no significant XRD spectrum.

A plot of the raw data from the crystals is given in figure 1. The sharp spikes are the diffraction peaks from the crystalline phase, while the broad, slowly changing baseline; is from the glass slide used as mount. Figure 2 shows the background subtracted spectrum in the top half of the plot, with a "stick figure" representation of the known pattern of Li2 B2O4 - $16 \mathrm{H} 20$ underneath. The pattern of peak positions between the two representations is practically identical, indicating a very good identification. The pattern of peak intensities varies somewhat from the known values. This is an artifact resulting from the method of preparation. Normally the samples are ground to pass a 20 mesh sieve, giving many small crystallites with random orientation. Since these crystals were crushed in place on the glass slide, the particle size is much greater than 200 mesh and the requirement for random orientation of the crystallites is not met, leading to the variation of peak intensity, but not peak position. 
L. Jagoda

October 21, 1992

The abbreviations on the accompanying plots are as follows:

FN = File name.

ID = Sample identification or comments.

Date = Date the run was started.

Time = Time the run was started.

$\mathrm{PT}=$ Point count time. Counting time in seconds at each step.

step = Angular step size, degrees 2-theta.

WL $=$ Wavelength of the $x$-rays used.

The horizontal axis is 2 -theta and the vertical axis is count rate (counts/seconds).

\section{EXPERIMENTAL}

The instrument used was the scintag Pad $\mathrm{V} x$-ray diffractometer located in room 409 of the 325 building, property tag number w24321. The range of 2-theta was 5 to 65 degrees with counting time of 5 seconds. Step size was 0.02 degrees two theta. x-ray tube conditions were $45 \mathrm{Kv}$ and $40 \mathrm{ma}$. The tube anode was copper, with the $K \propto$ line utilized. The instrument was operated in the theta/2-theta mode.

A background subtracted file was prepared to eliminate the. unwanted background in the XRD spectrum, and thereby enhance the peak intensity over the new background. As part of this routine, the contribution of the $K \propto 2$ peak was subtracted out.

The Scintag Peak Finder routine was used to locate the majority of peaks in the spectrum. Usually, unidentified peaks remain in the data, as well as peaks being identified which are not real. operator override is used to eliminate false peaks, and add those which were missed. A peak deconvolution routine is used to define peak locations of peaks which are obviously overlapping each other.

Phases were identified using the Scintag Search/Match routine XDS5. The ICDD (International Centre for Diffraction Data) data base, through set number 41 , was used for peak position and pattern data. The Search/Match routine identifies phases meeting all defined parameters. This usually includes phases which are not present, and must be eliminated by the operator. The final decision of phases present is made by the operator. Elements assumed to be present were $\mathrm{Li}, \mathrm{B}$ and $\mathrm{Si}$.

\section{QA STATEMENT}

Work was performed to procedure HTA-3-3, Rev 4, Solids Analysis: $x$-ray Diffraction. Calibration data are in LRB BNW 52334. Test 
L. Jagoda.

October 21, 1992

Work was performed to procedure HTA-3-3, Rev 4, Solids Analysis: X-ray Diffraction. Calibration data are in IRB BNW 52334. Test parameters are in LRB BNW 54656. ALO login numbers 93-00643 and 93-00644 apply to these samples. Daily calibration checks showed the instrument to be within calibration limits at all times. Training records of the operator, E. D. Jenson, are on file in the Aralytical Chemistry Iaboratory office. 


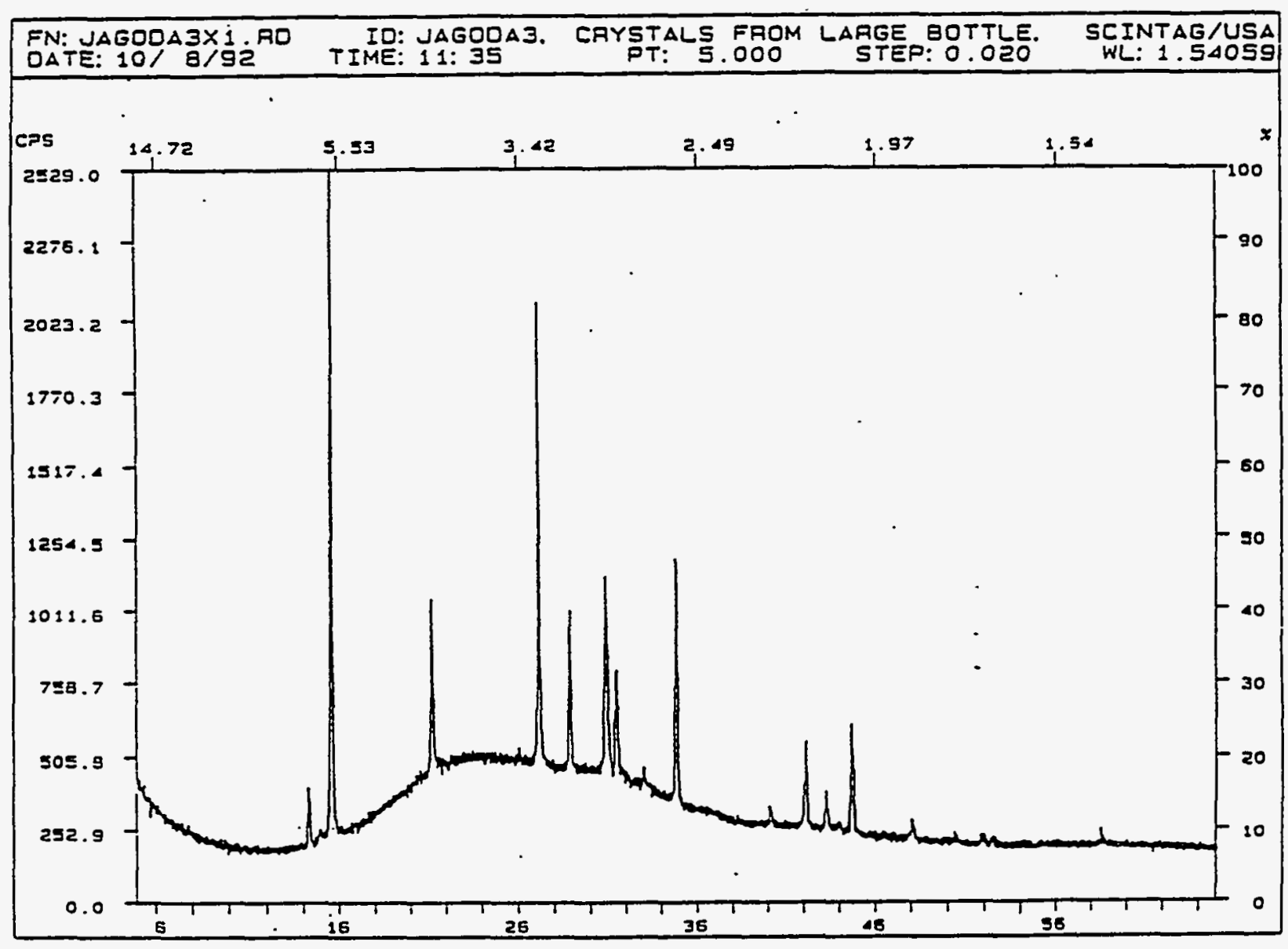

Figure E.1. Plot of Raw XRD Data from Crystals Forming in $\mathrm{Li} \mathrm{B} \mathrm{SiO}_{3}$ Slurry 


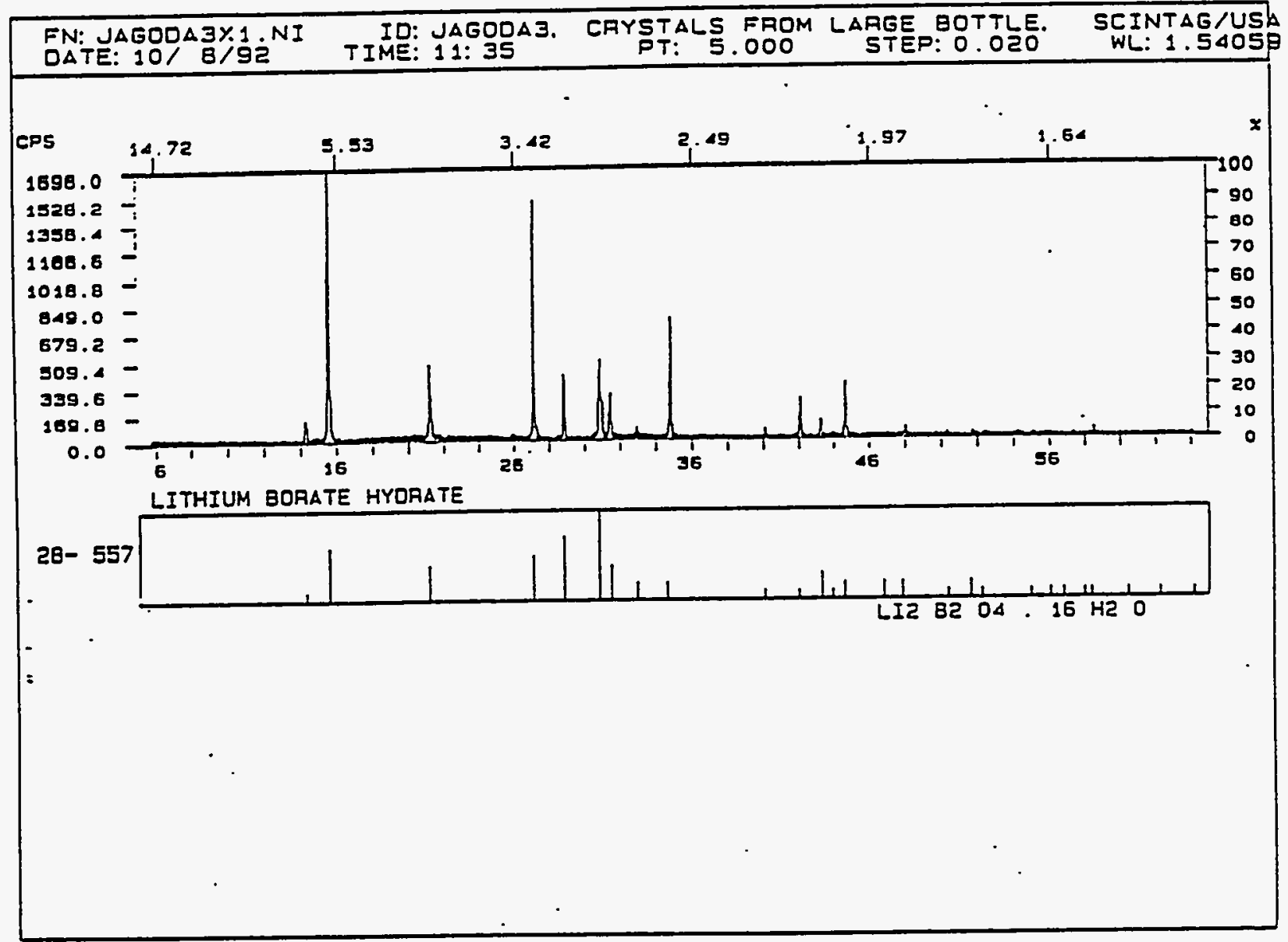

Figure E.2. Background Subtracted XRD Data from Crystals in $\mathrm{Li} \mathrm{B} \mathrm{SiO}_{3}$ Slurry. "Stick figure" representation of known pattern for $\mathrm{Li}_{2} \mathrm{~B} 204 \bullet 16 \mathrm{H} 2 \mathrm{O}$ is shown. 
AOYAKCE IMOROANIC AWLITSIS CROUP

AWTICH CHEISTRY LABORTORT, WATERINS \& CHEICN SCIEICES CETTER

BATELIE, PACIFIC NORTHEST LABORTORT, RICHUNO, TA

IOH CHROMUTOGRAPH, PH COMOUCTIVITY, \& CAREOK ARACYIICA RESULTS

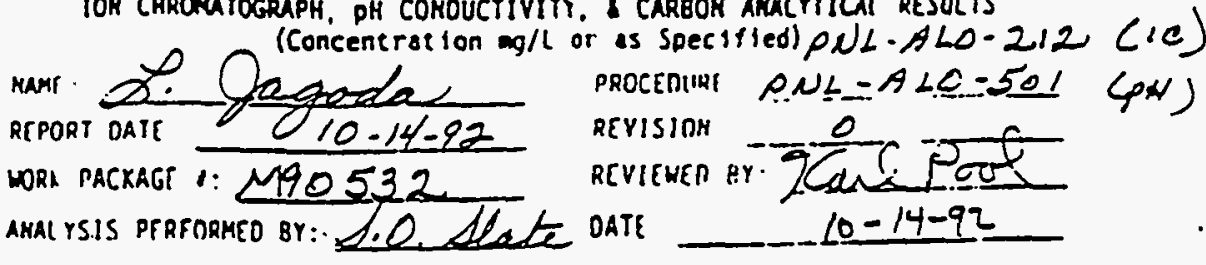

AMALYTICAI COUIPMENT. DIONEX SERIES $4000 \mathrm{i}$ ICH CHROMATOGRAPH (HBJ7427)

ORIOH DH METER. MODEL SOI (S/N 42707)

IERTEX-OOKRMANK MODEL OC-BO TOC AMALYZER (WA $17240 Z$ \& 12403)

YELLON SPRINGS. INC. CONDUCTIVITY BRIOGE MODEL 32 (S/N 2404$)$

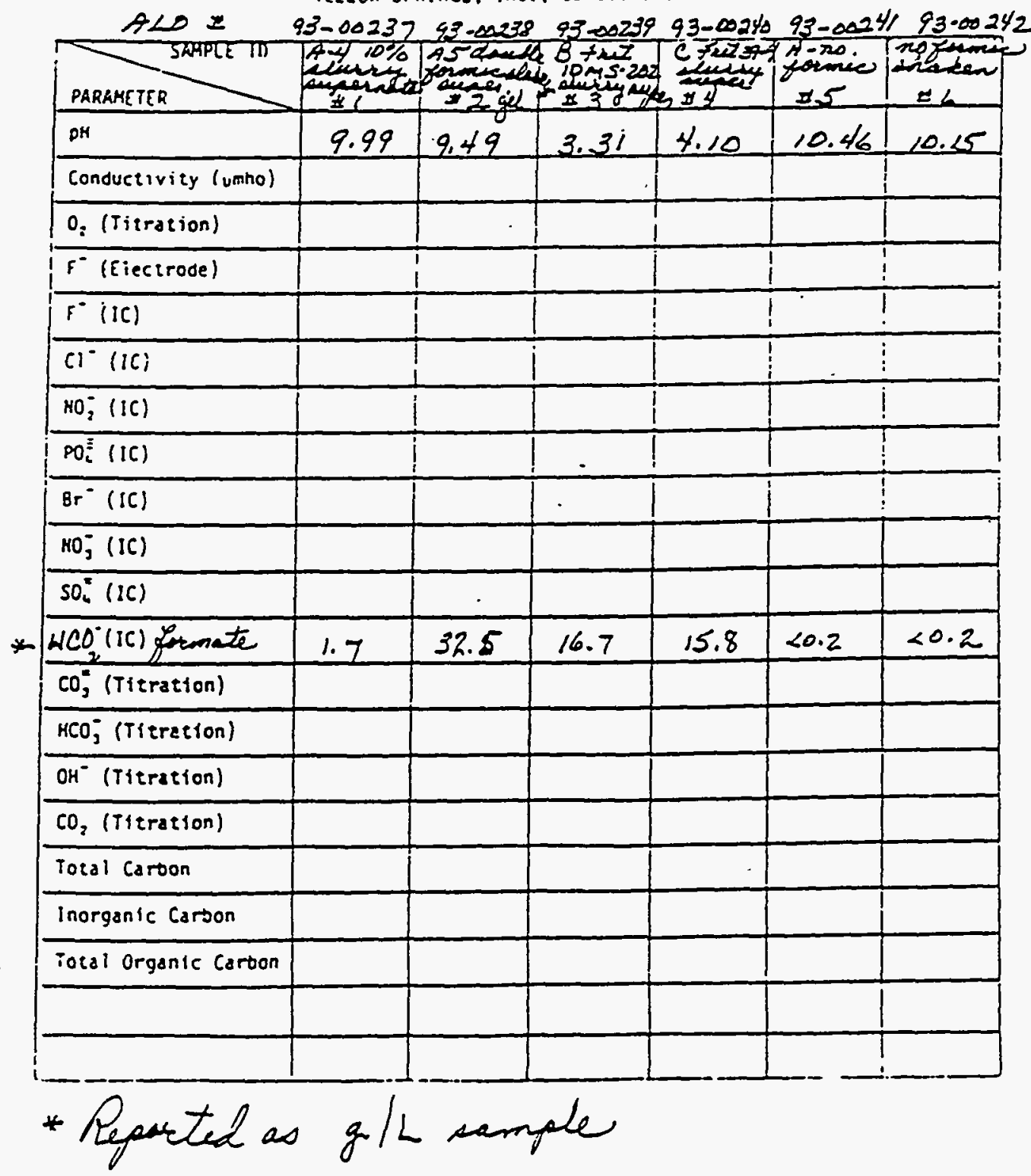




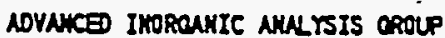

AWRTICN CHEISTRY LABRATORT, MATERINLS \& CHBITCL SCIEICES CEITER BATTELE, PACIFIC NORTHEEST UAORUTORT, RICHUND. IA

ION CHROMUTOGRAPH, PH COKOUCTIYITY, CARBOH AKALYIICAL RESUL TS

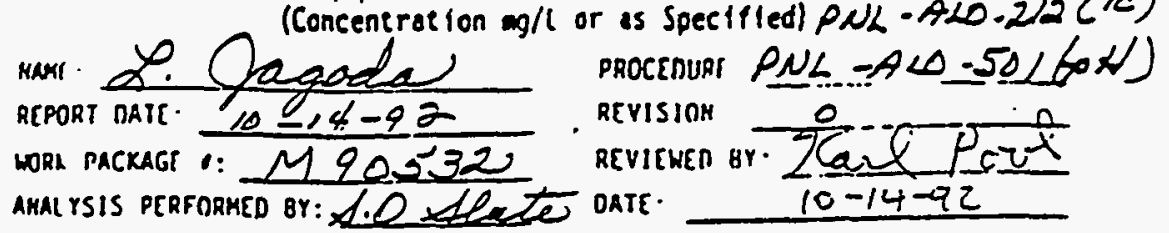

AKALYTICAI COUIPMENT: DIONEX SERIES 4000i IOH CHROMATOGRAPH (WB37427)

ORION OH METER, MOOEL SOI (S/H 42707)

XERTEX-DOHRMANH MODEL DC-80 TOC AKATYZER (WA 172402 \& 22403)

YELLOK SPRIKGS. IHC.: COHOUCTIVITY BRIDGE MOOEL 32 (5/W 2404)

ALO II $93-00243$ 23-2024/4 $93-0245$

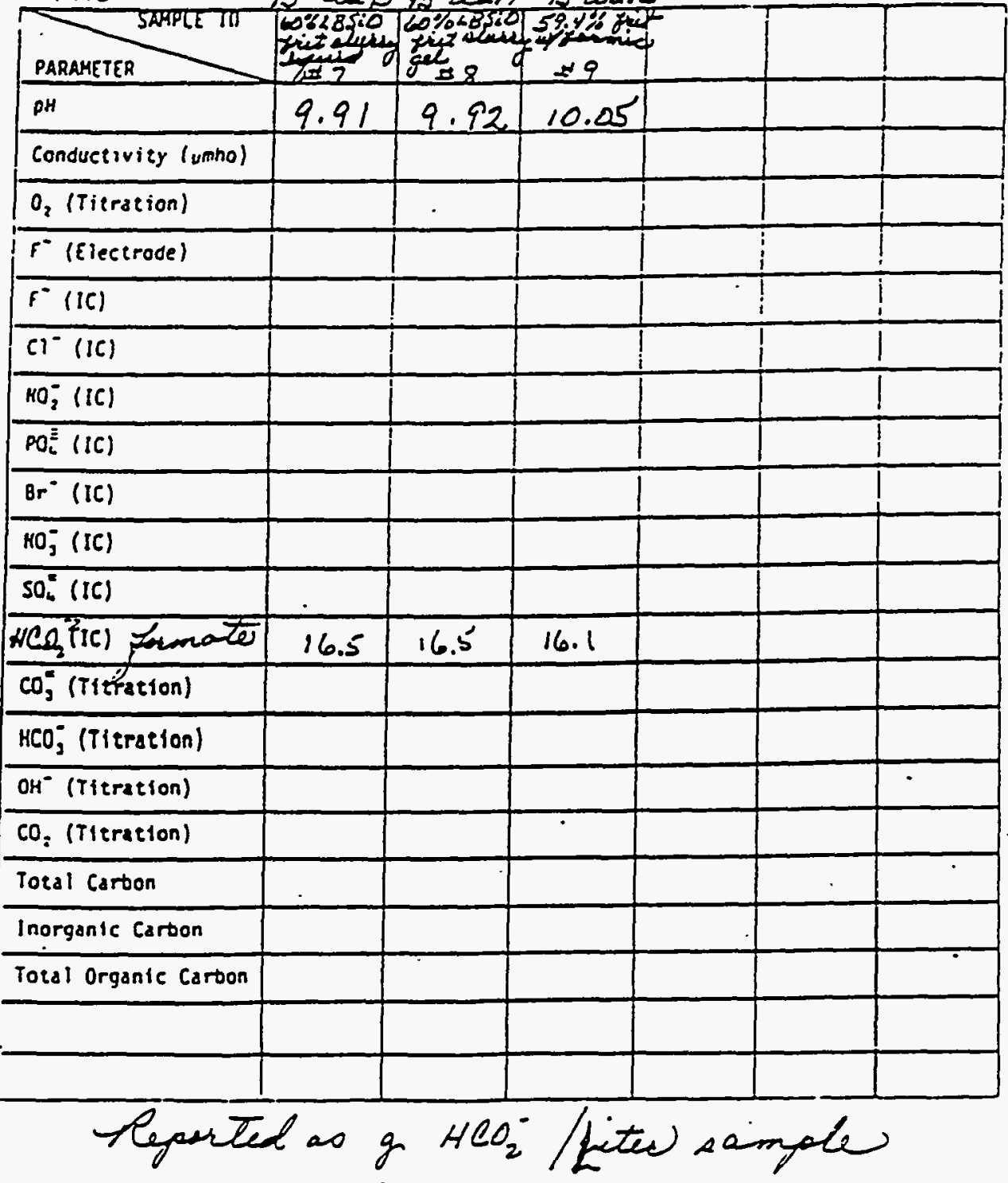

E.7 


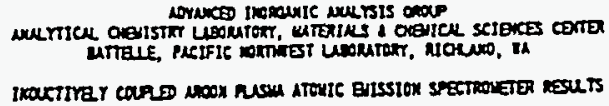

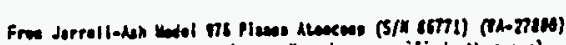

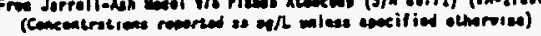

mi: D. Oagha

rens ant: 20 - 2092

were oror: $1: \mathrm{NaO532}$

moxtout. PNA-ALO-211

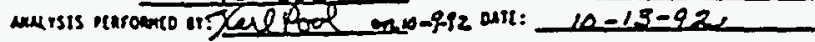
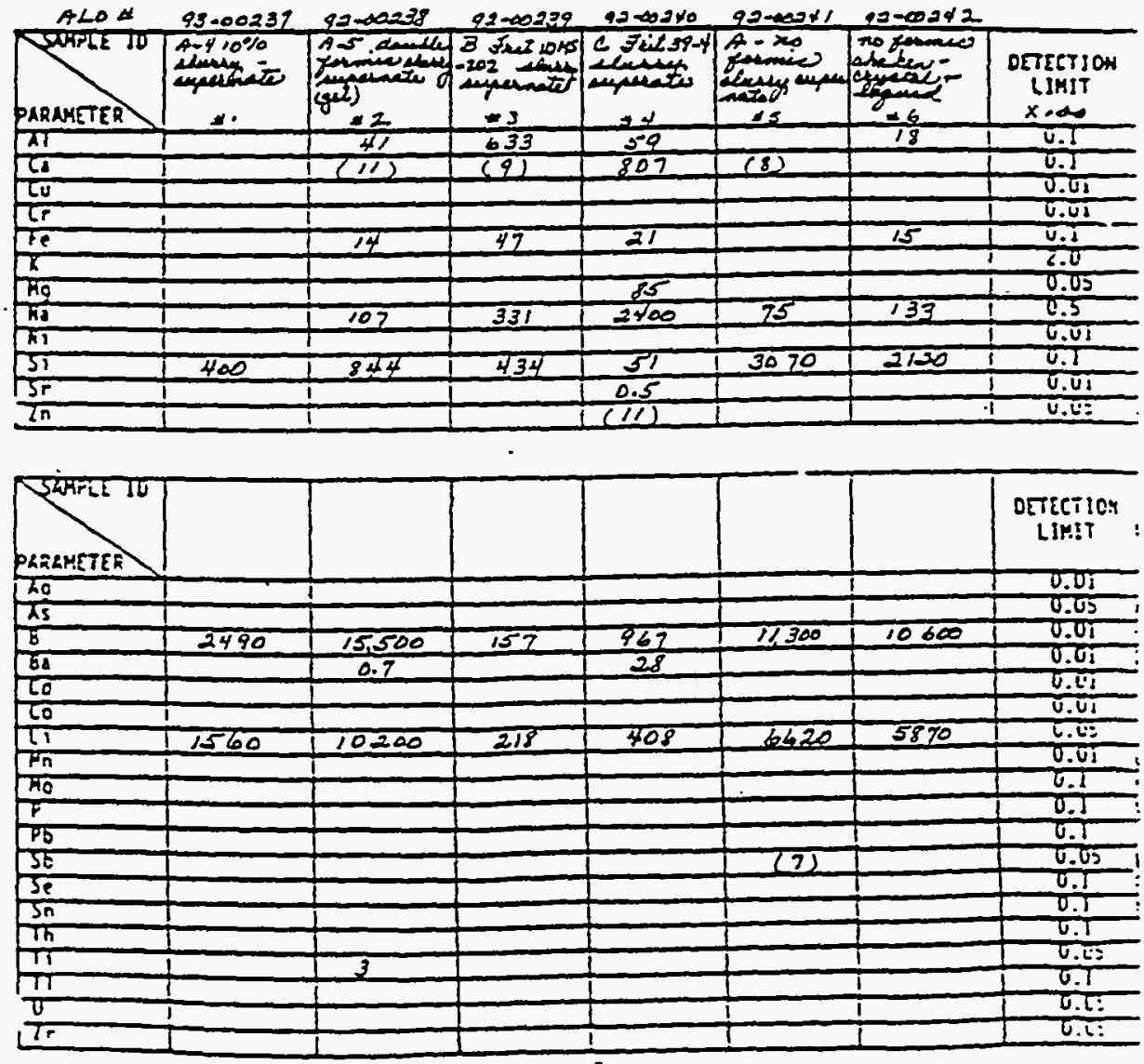


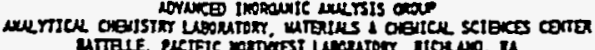

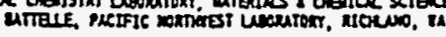

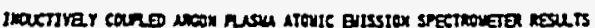

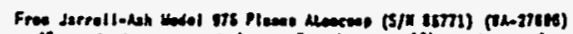

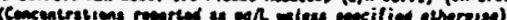

ur: 2 Q Q anda

unir ait: $10-13-92$

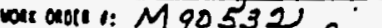

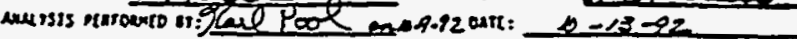
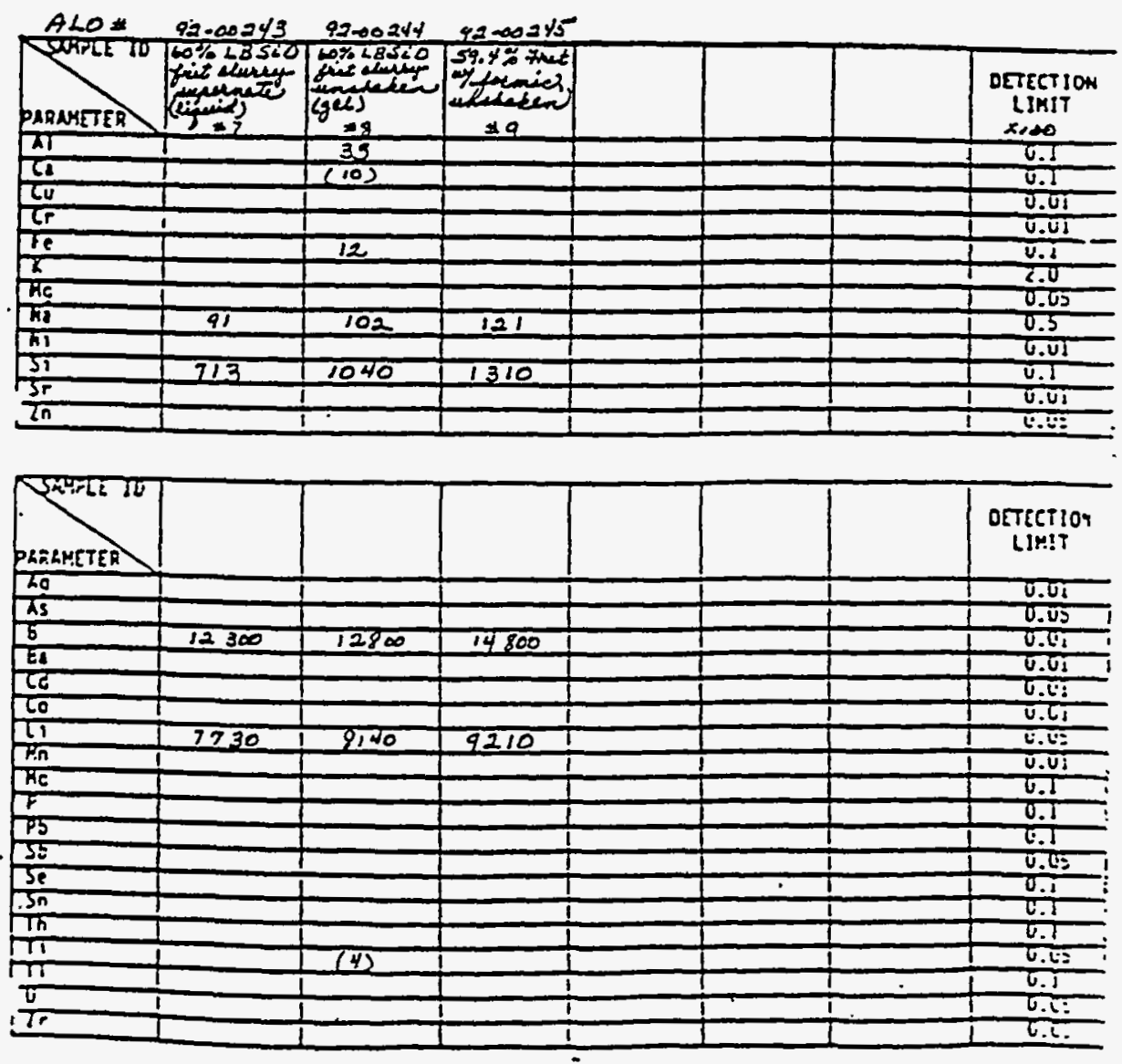

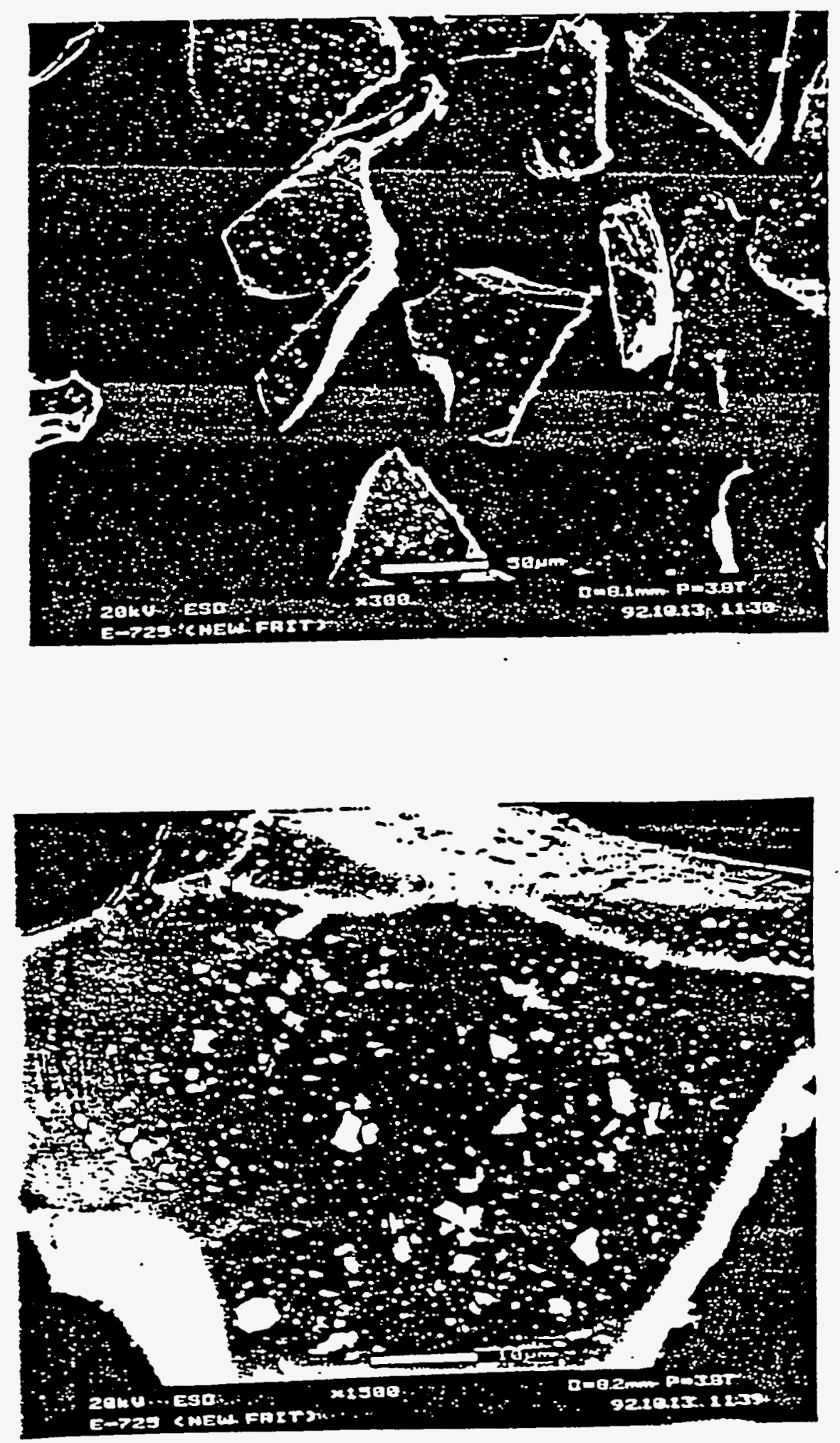

Figure E.3. Dry Frit - Unmodified 

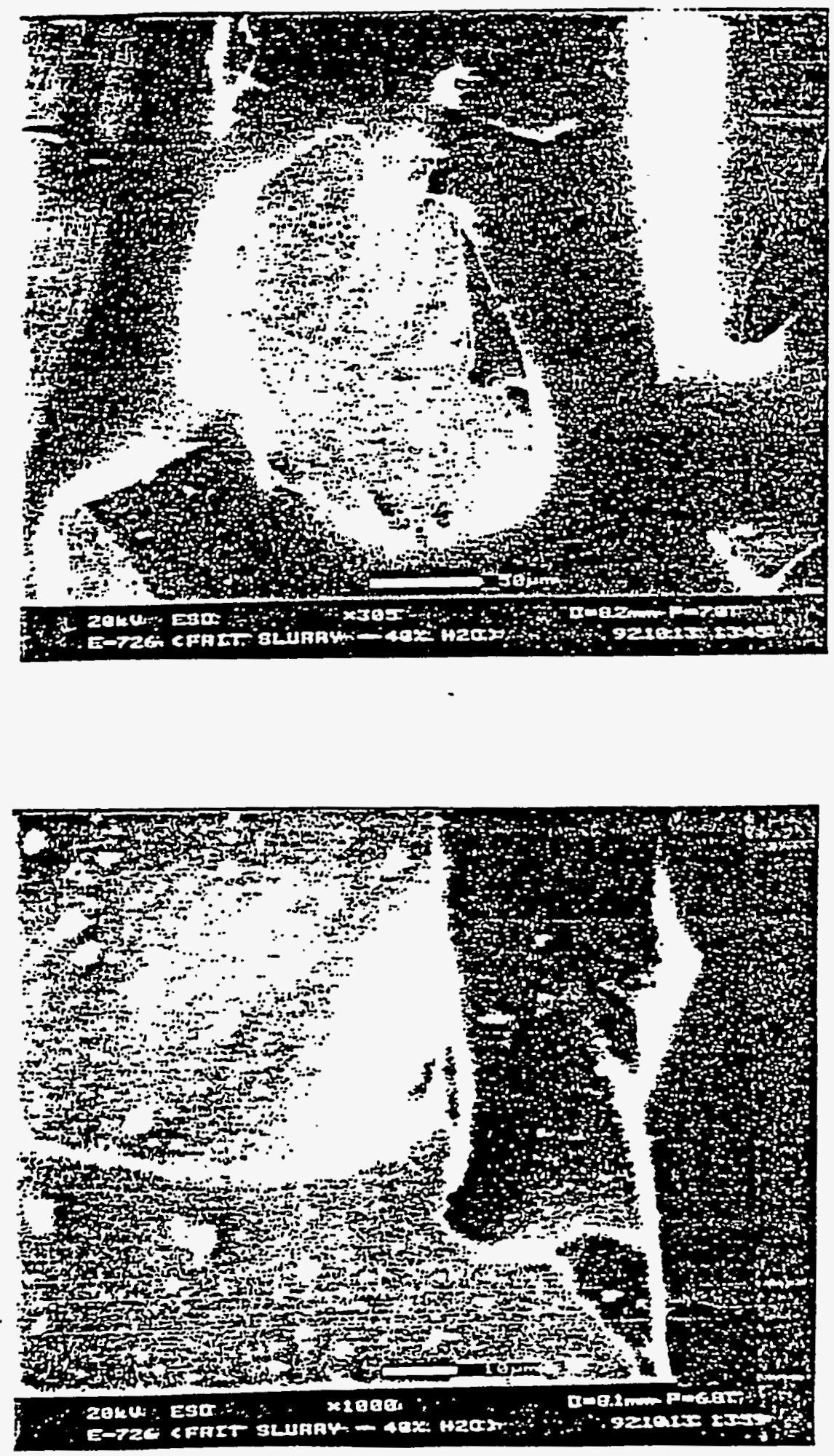

Figure E.4. Frit Aged in $\mathrm{H}_{2} \mathrm{O}$ (Still wet) 


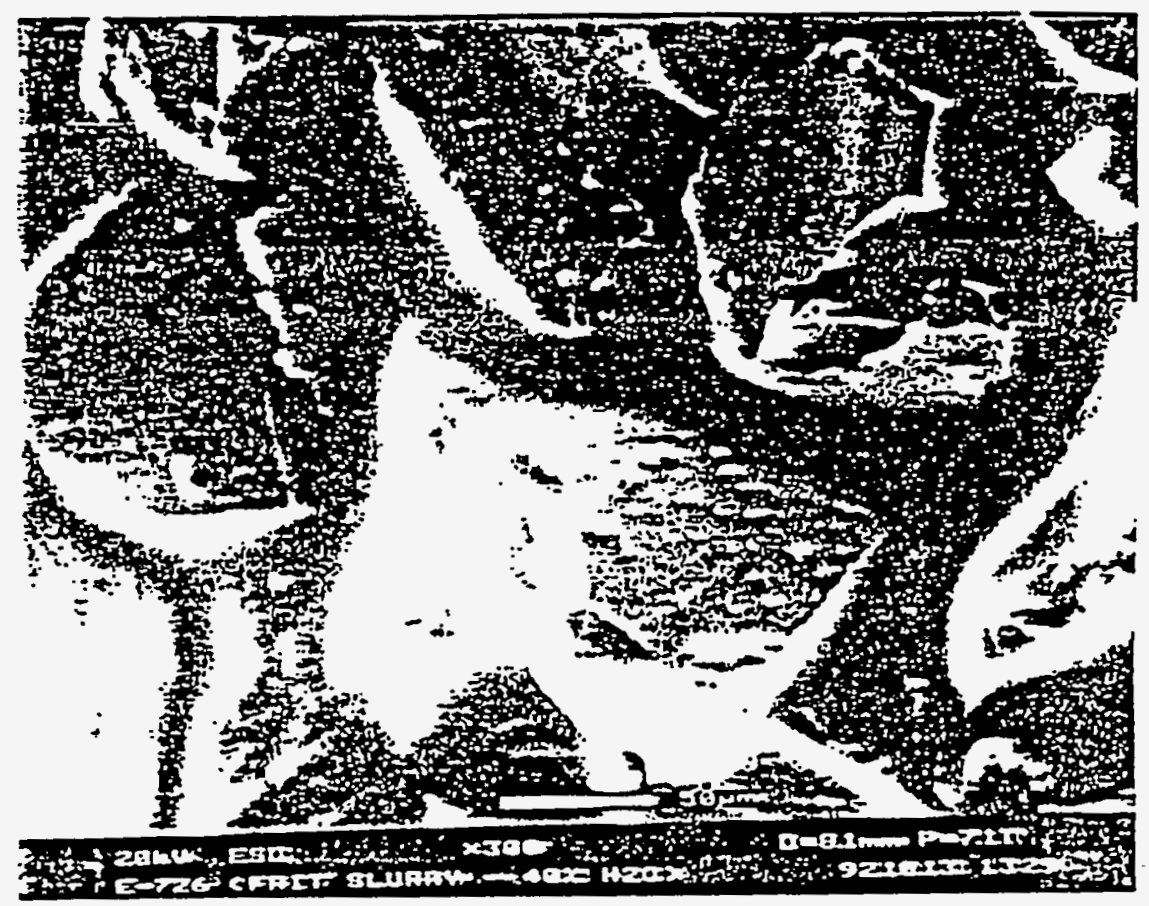

\section{Evidence of Dissolution}

Figure E.5. Frit Aged in $\mathrm{H}_{2} \mathrm{O}$ (Still wet) 

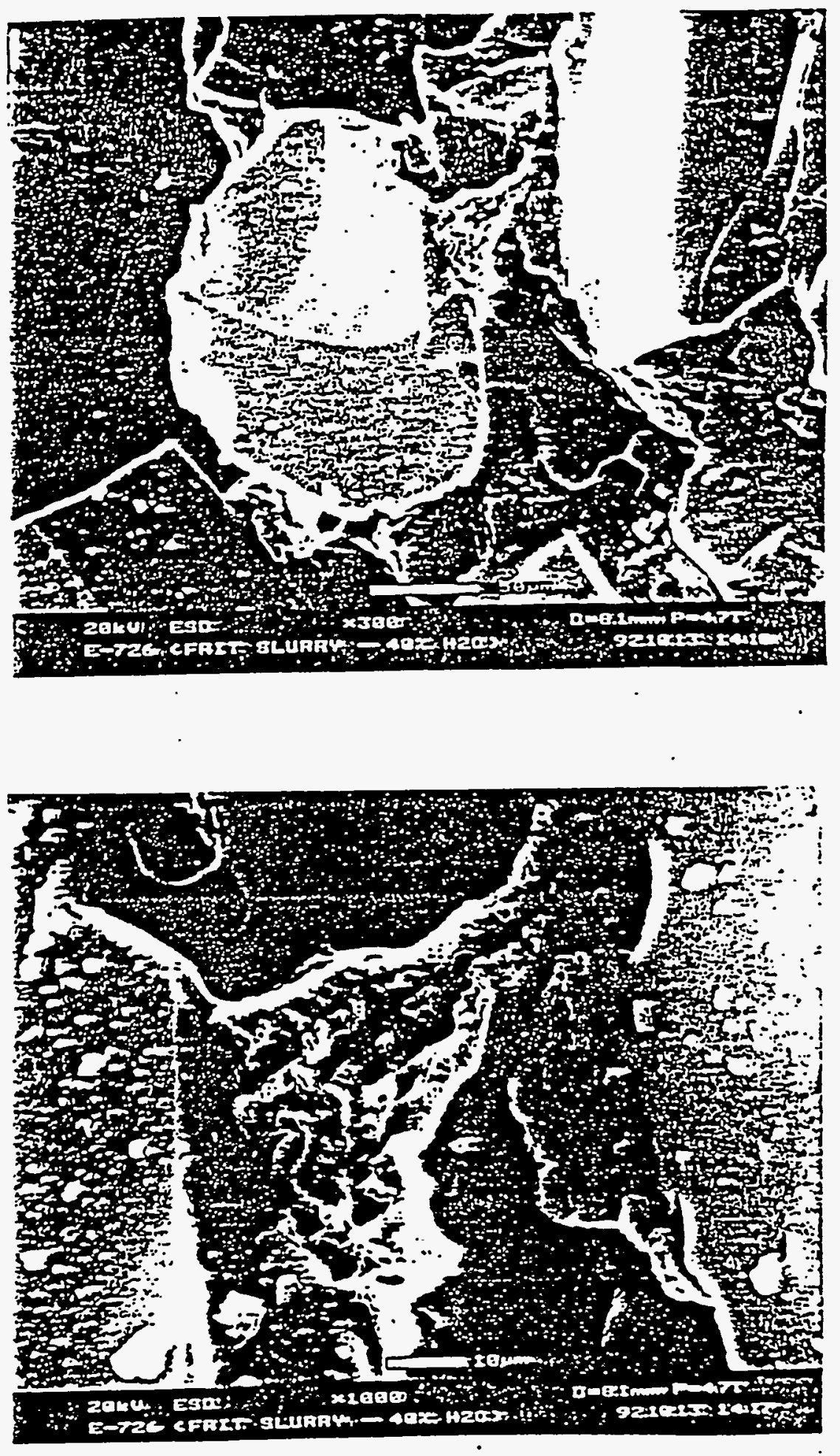

Figure E.6. Frit Aged in $\mathrm{H}_{2} \mathrm{O}$ (Dried) 


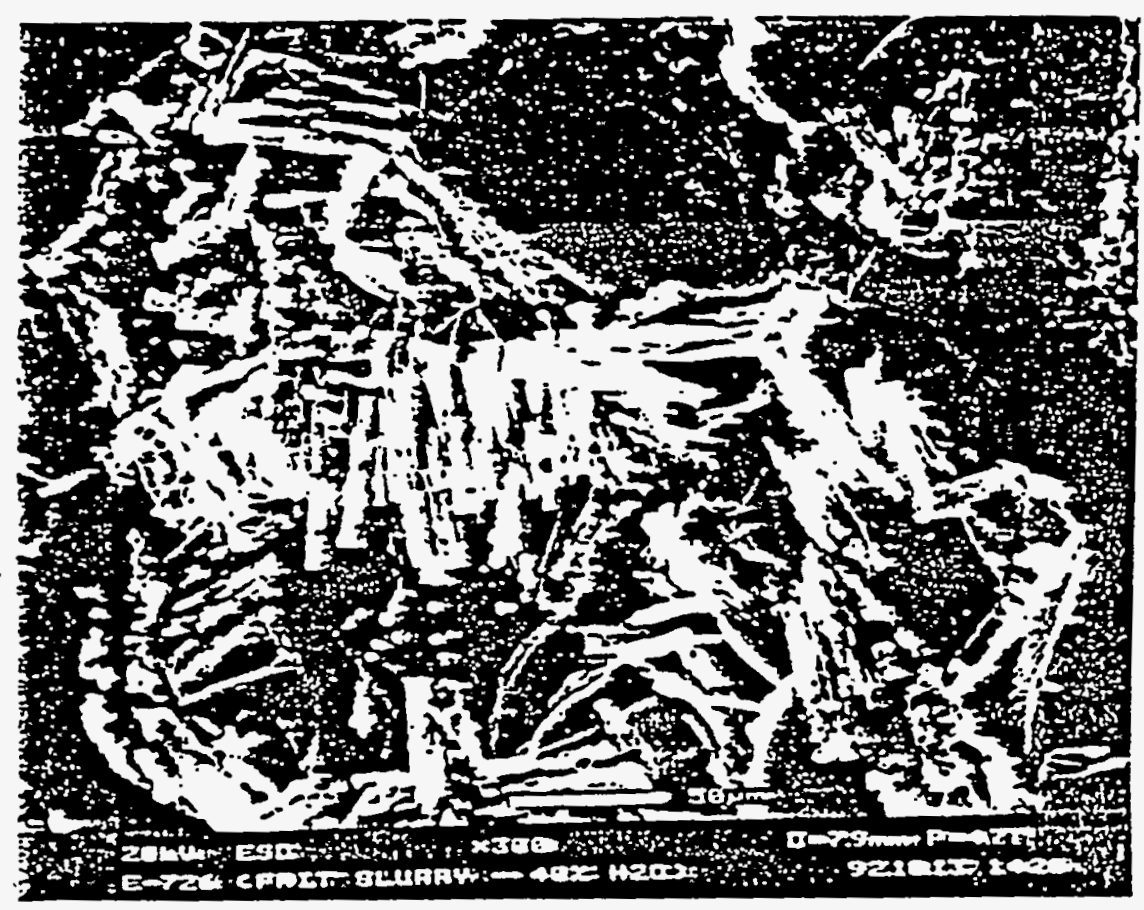

\section{Lithium Borate Hydrate Crystals}

Figure E.7. Frit Aged in $\mathrm{H}_{2} \mathrm{O}$ (Dried) 


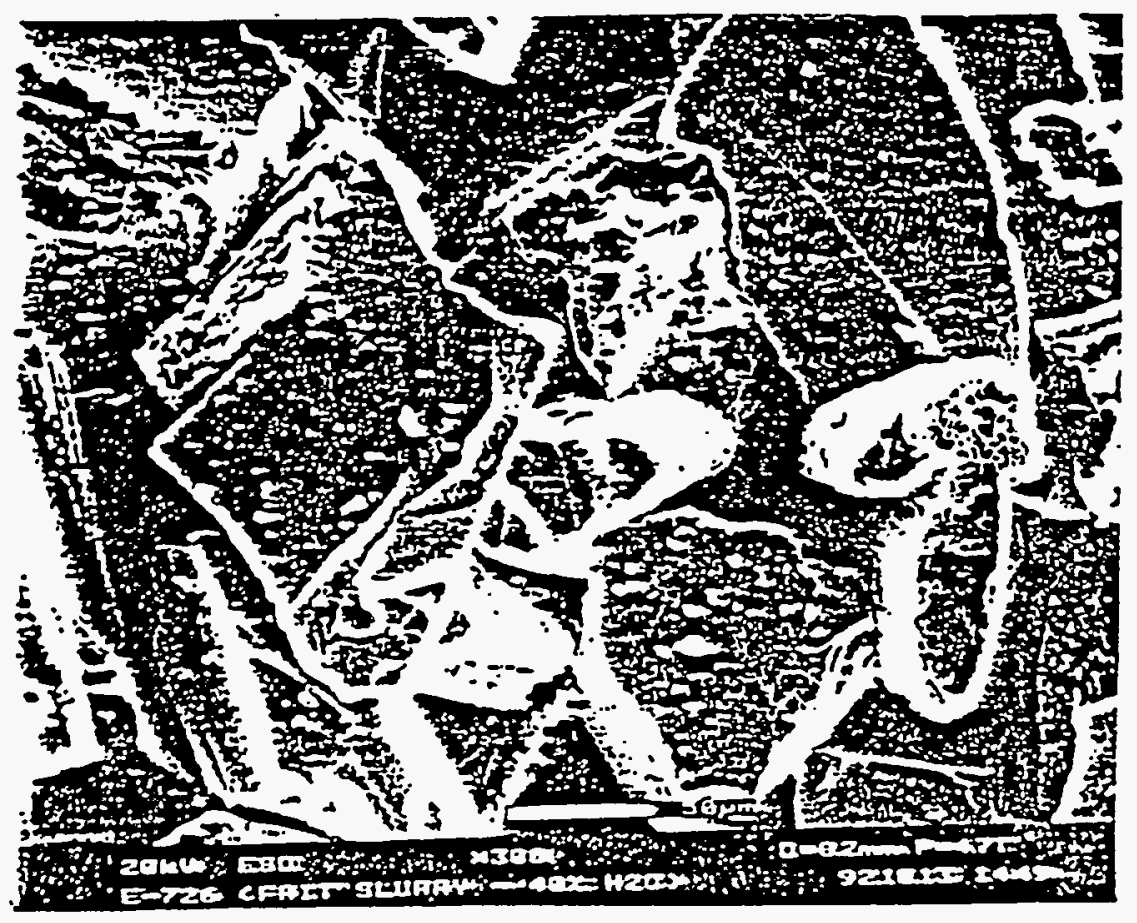

Figure E.8. Frit Aged in $\mathrm{H}_{2} \mathrm{O}$ (Dried) 

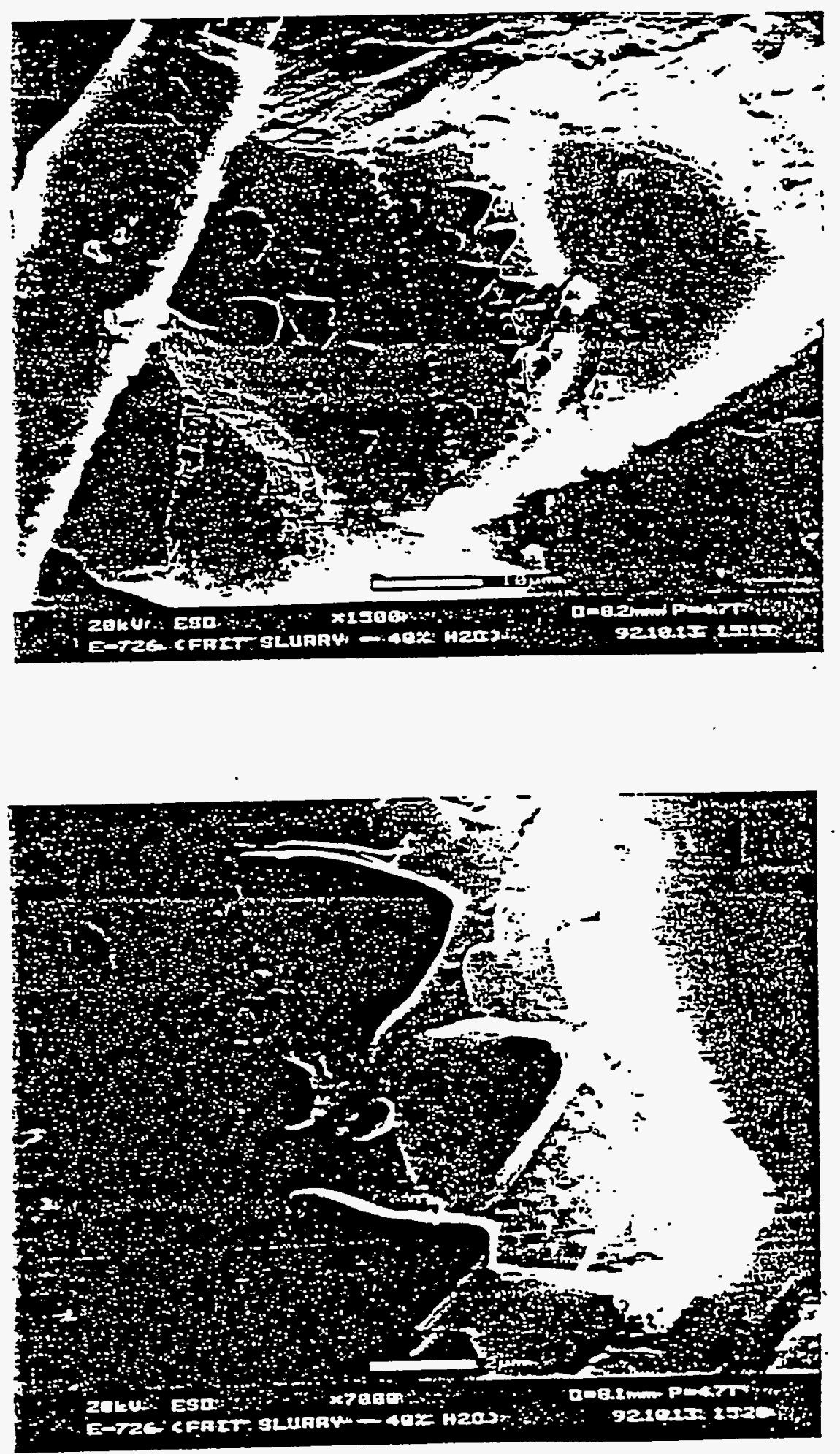

Figure E.9. Frit Aged in $\mathrm{H}_{2} \mathrm{O}$ (Dried) 


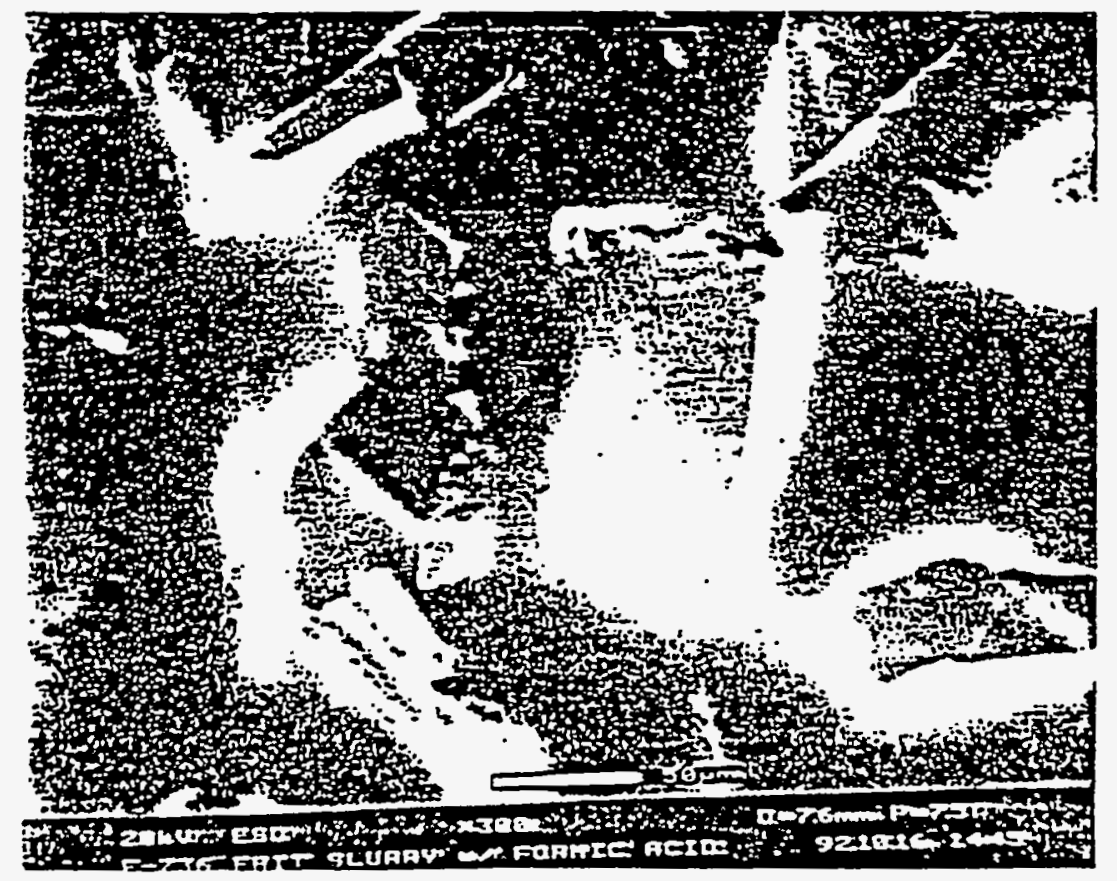

Figure E.10. Frit Aged in 0.6\% Formic Acid Solution (Wet)

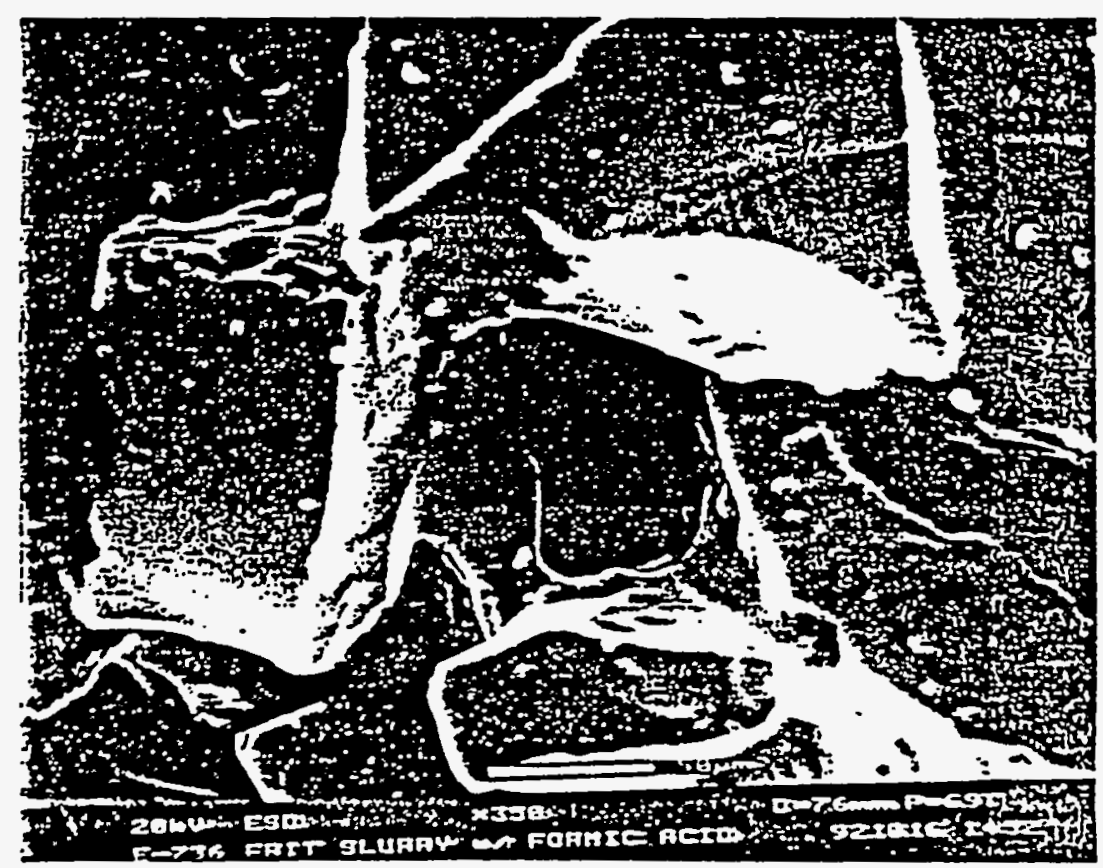

Figure E.11. Frit Aged in 0.6\% Formic Açid Solution (Partially Dried) 


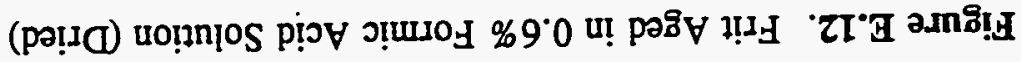
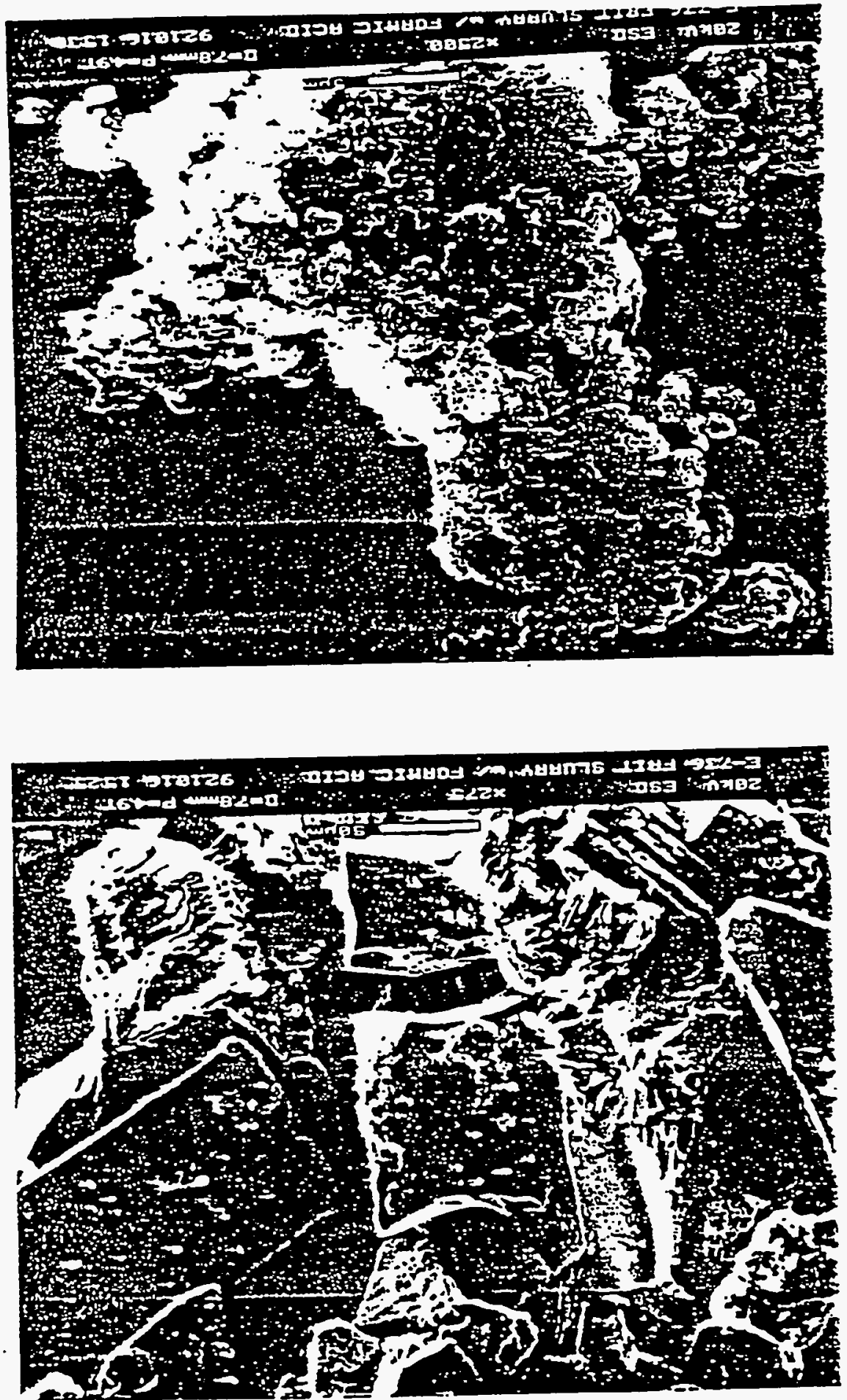


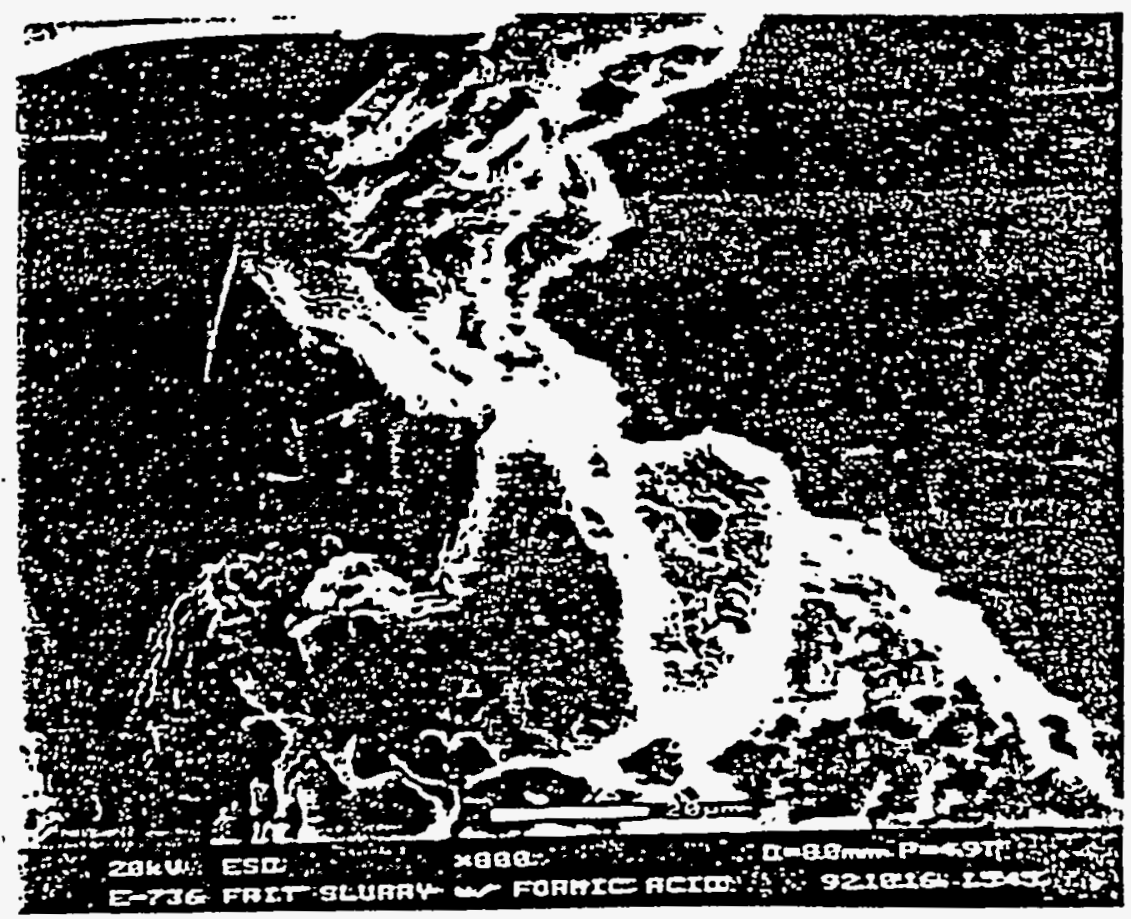

Figure E.13. Frit Aged in 0.6\% Formic Acid Solution (Dried)

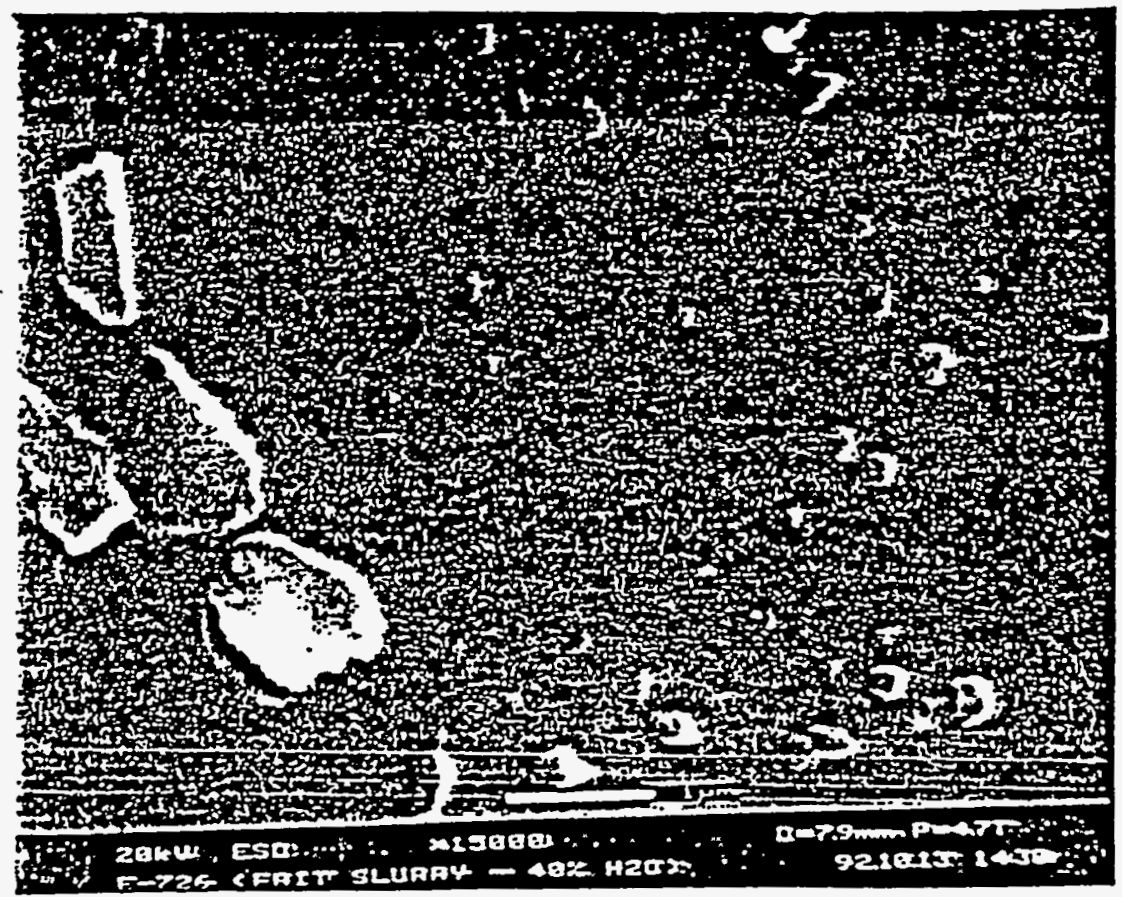

Figure E.14. Frit Aged in $\mathrm{H}_{2} \mathrm{O}$ Magnified Surface $\mathrm{X} 15000$ (Dried) 


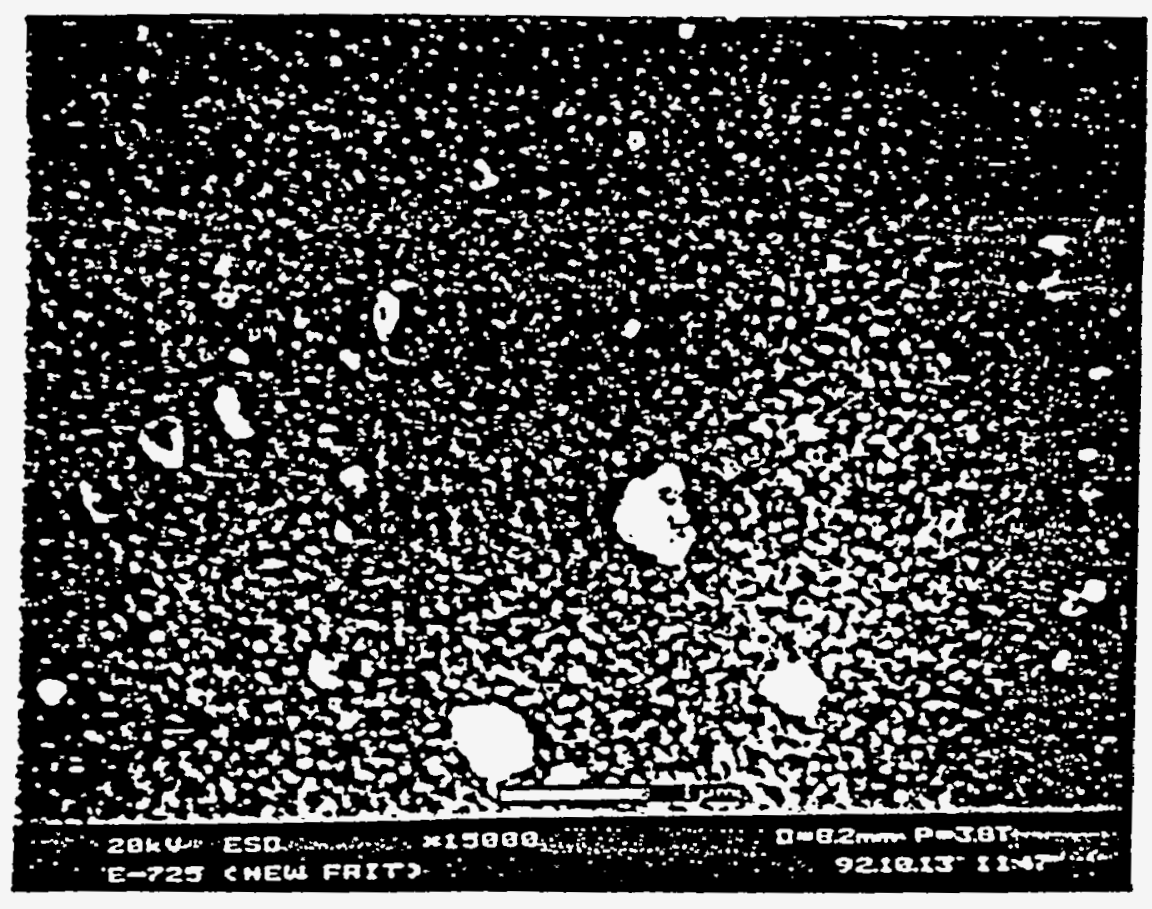

Figure E.15. Dry Frit - Unmodified Magnified Surface X 15000 (Dried)

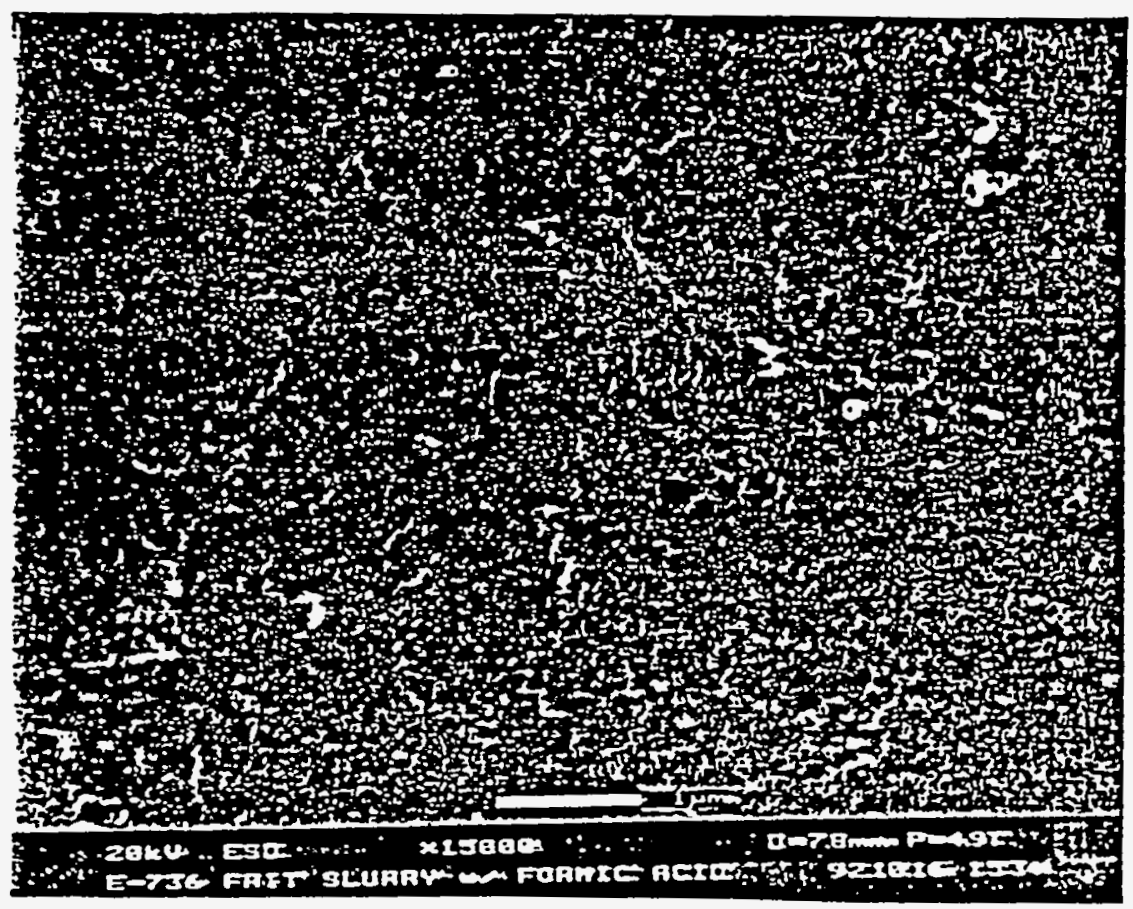

Figure E.16. Frit Aged in 0.6\% Formic Acid Magnified Surface X 15000 (Dried) 
Appendix F

Rheogram Overlays and Summary Data 


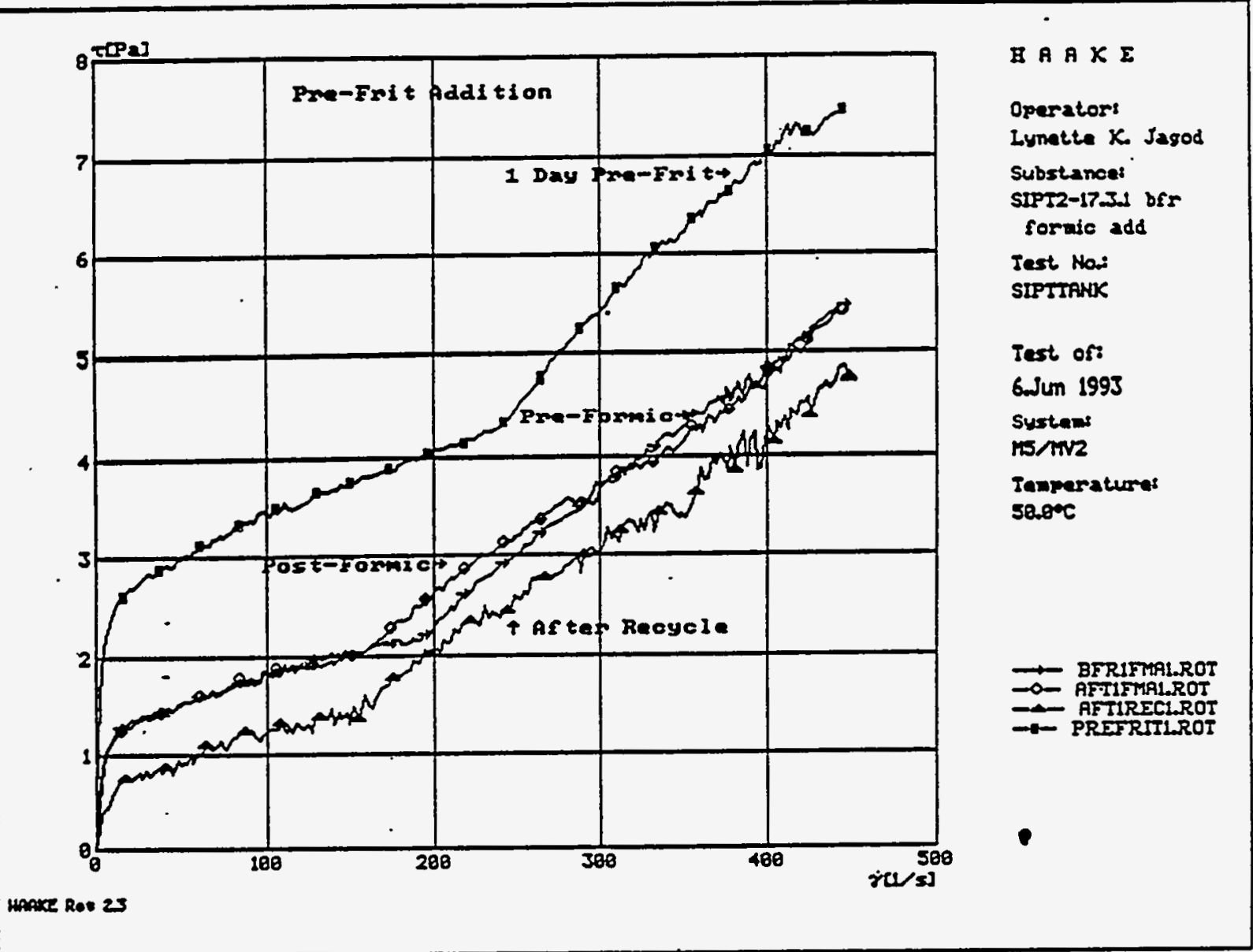

Figure F.1. Shear Stress Versus Shear Rate (up only) Full Scale Tank Data (HB-15) Pre-Frit Addition 


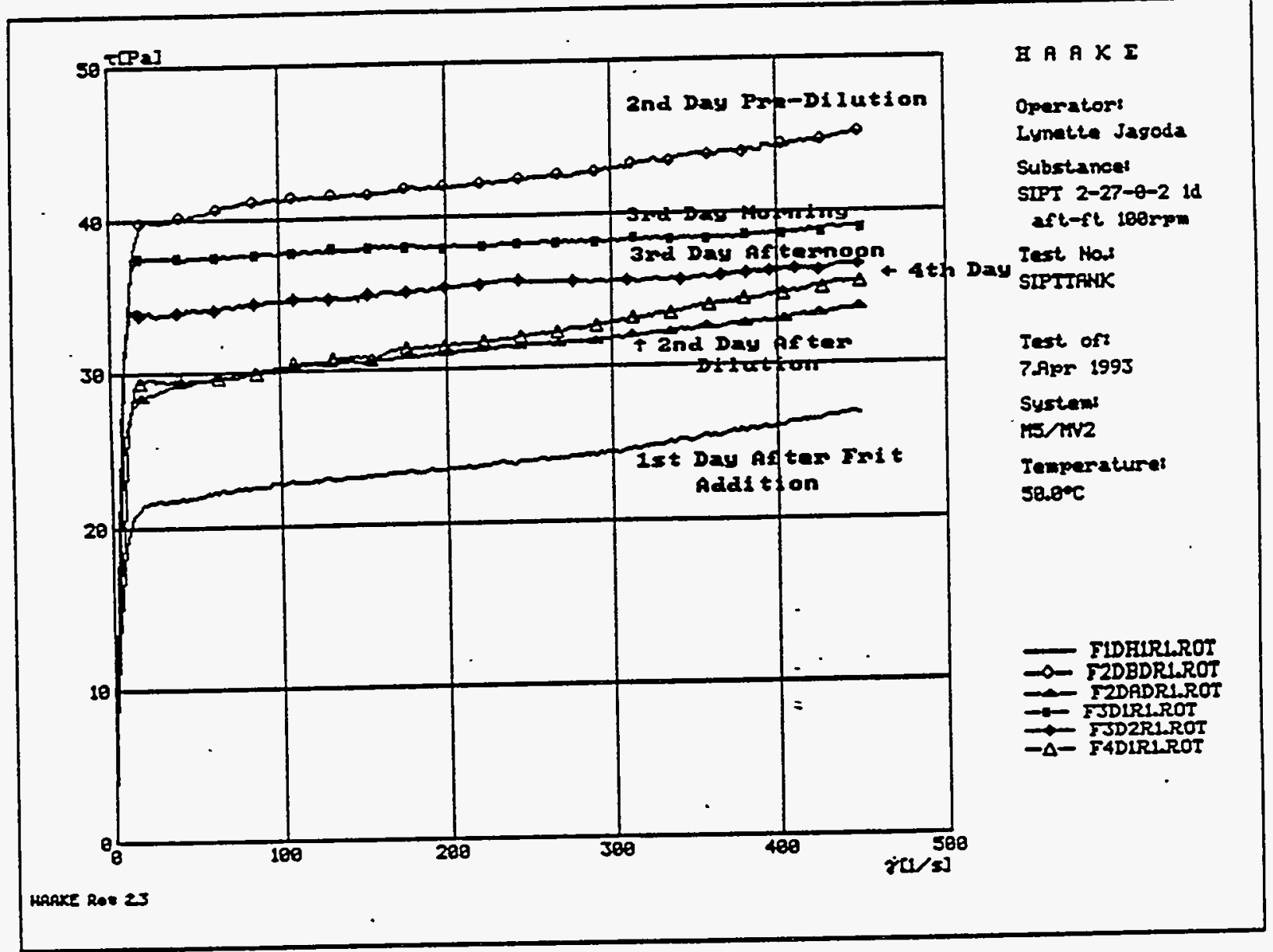

Figure F.2. Shear Stress Versus Shear Rate (up only) Full Scale Tank Data (HB-15) Dilution Effects 


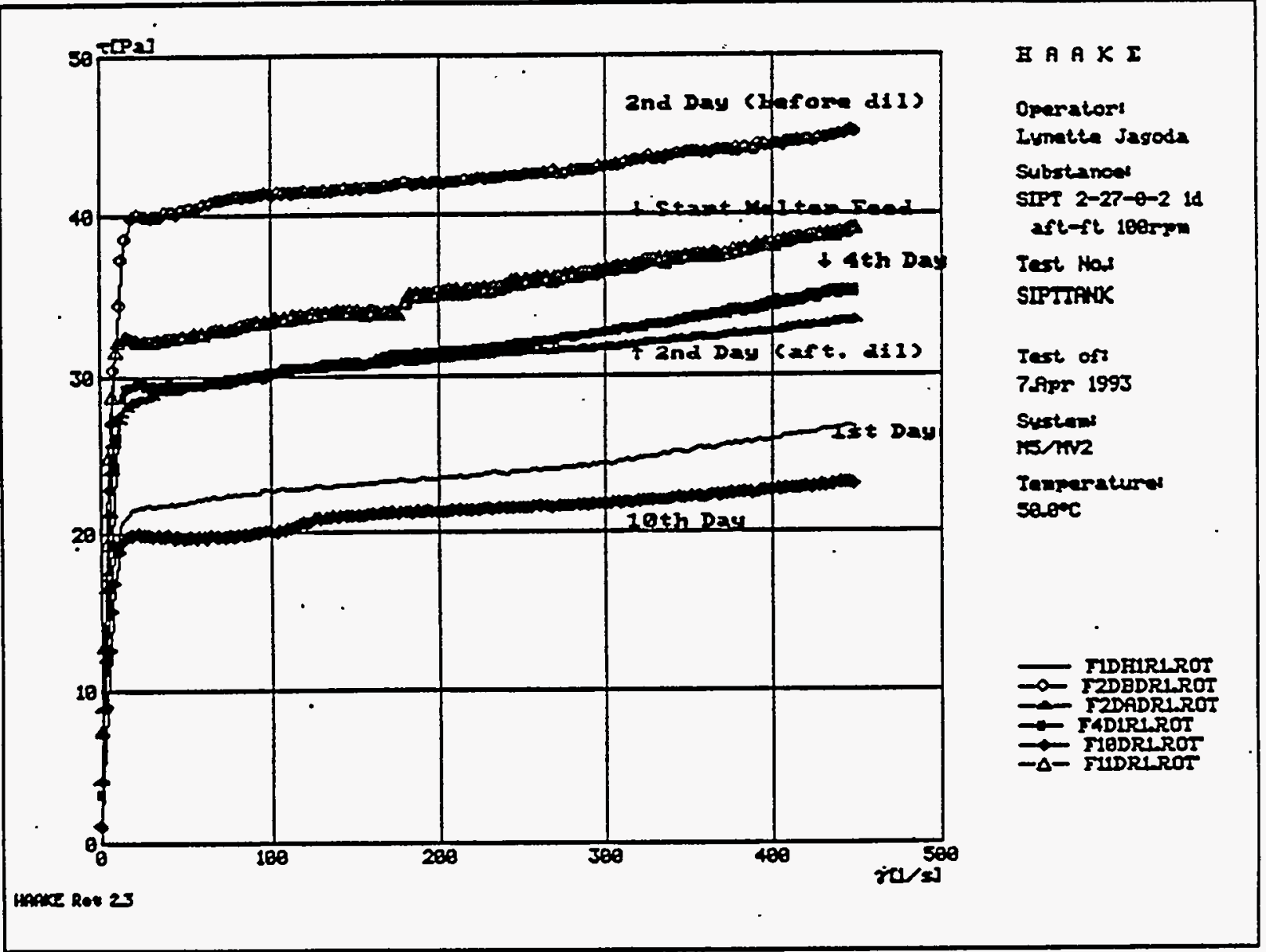

Figure F.3. Shear Stress Versus Shear Rate (up only) Full Scale Tank Data (HB-15) from First Day After Frit Addition Until Start of Melter Feed 


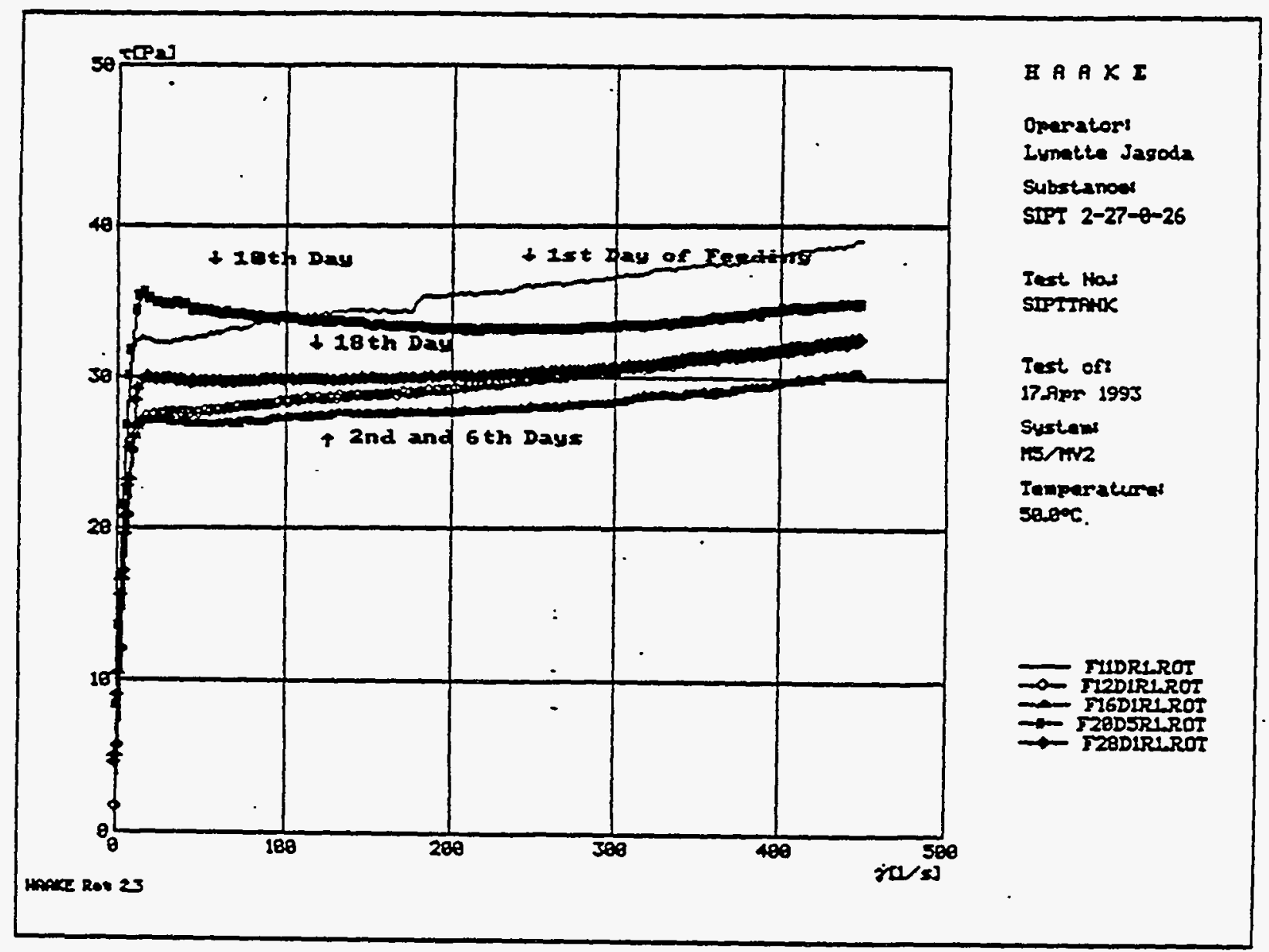

Figure F.4. Shear Stress Versus Shear Rate (up only) Full Scale Tank Data (HB-15) from Start of Melter Feed Until Transfer to Tank Data HB-13 


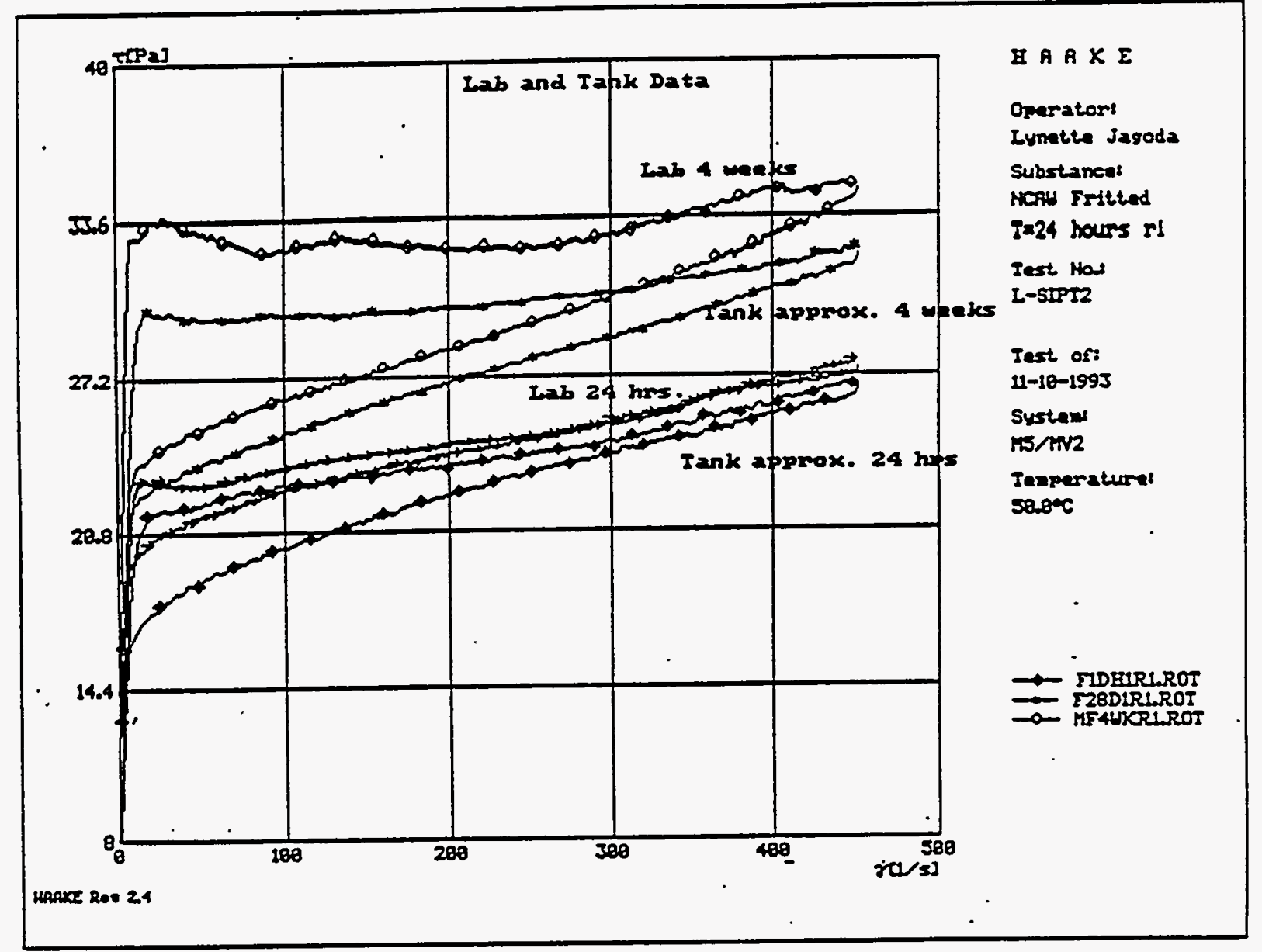

Figure F.5. Shear Stress Versus Shear Rate (up only) Full Scale Tank Data (HB-15) and Bench Scale (Lab) at 24 Hours and 4 Weeks 


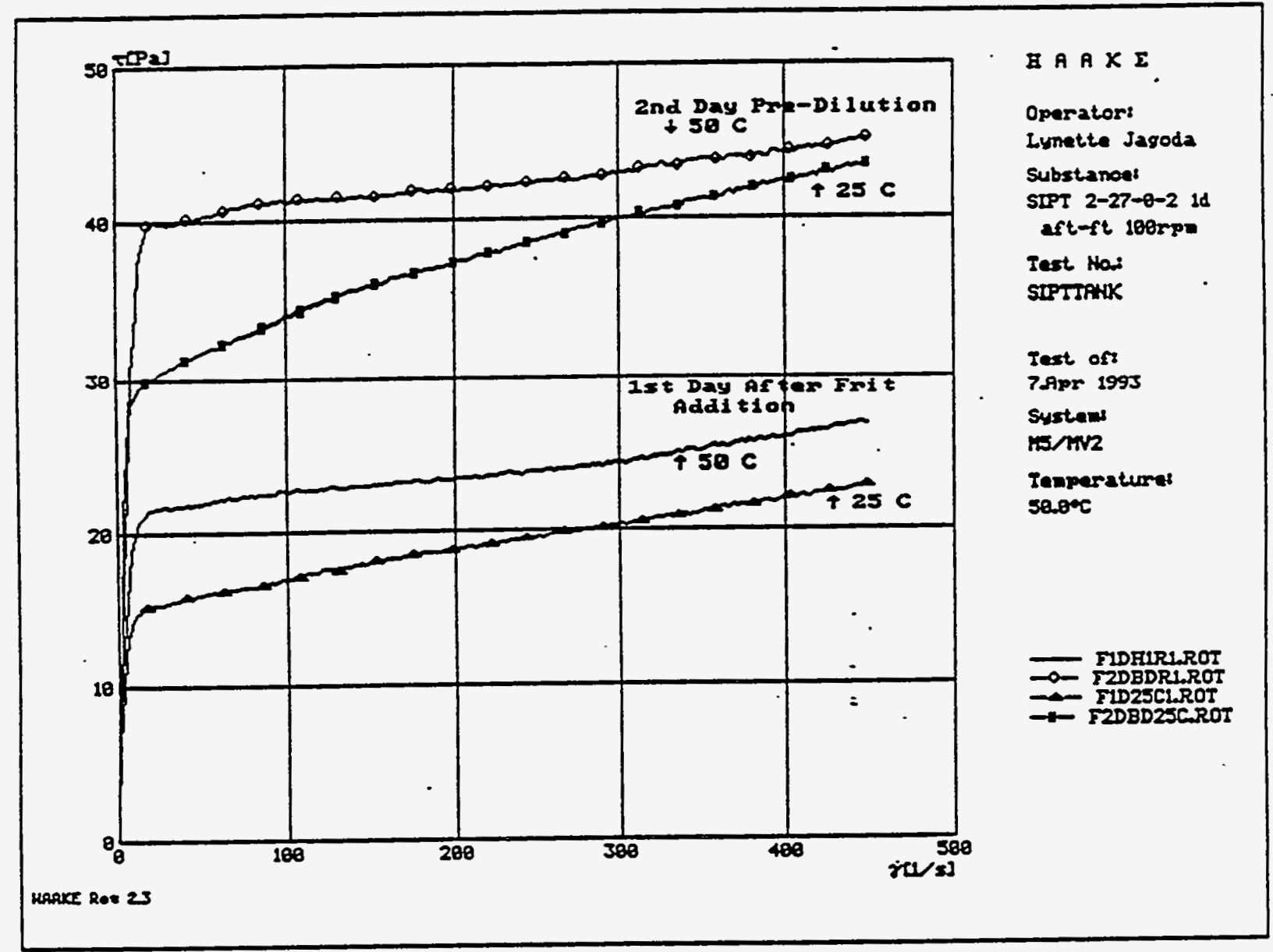

Figure F.6. Shear Stress Versus Shear Rate (up only) Full Scale Tank Data (HB-15) Temperature Effects 


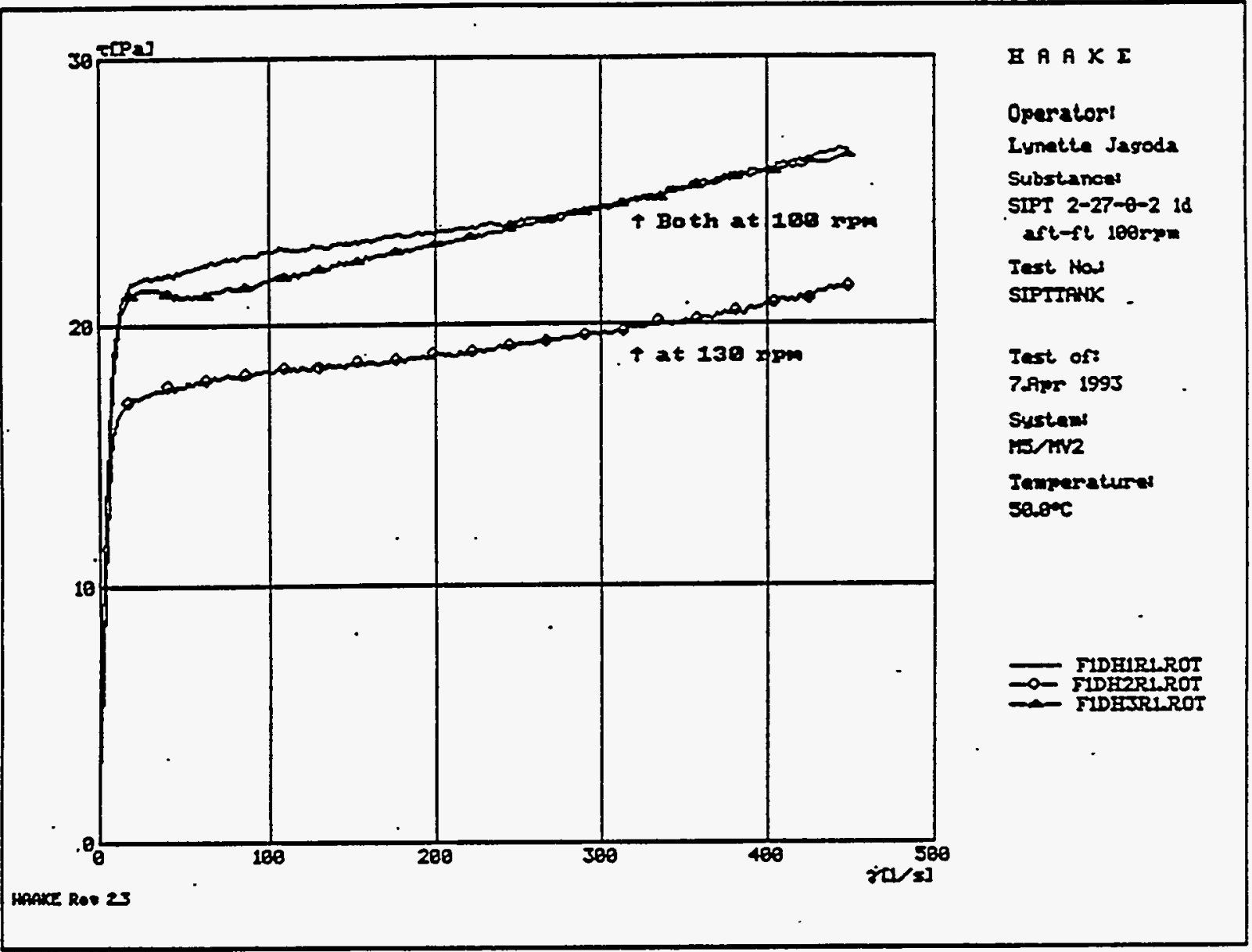

Figure F.7. Shear Stress Versus Shear Rate (up only) Full Scale Tank Data (HB-15) Shear Effects-In Tank 


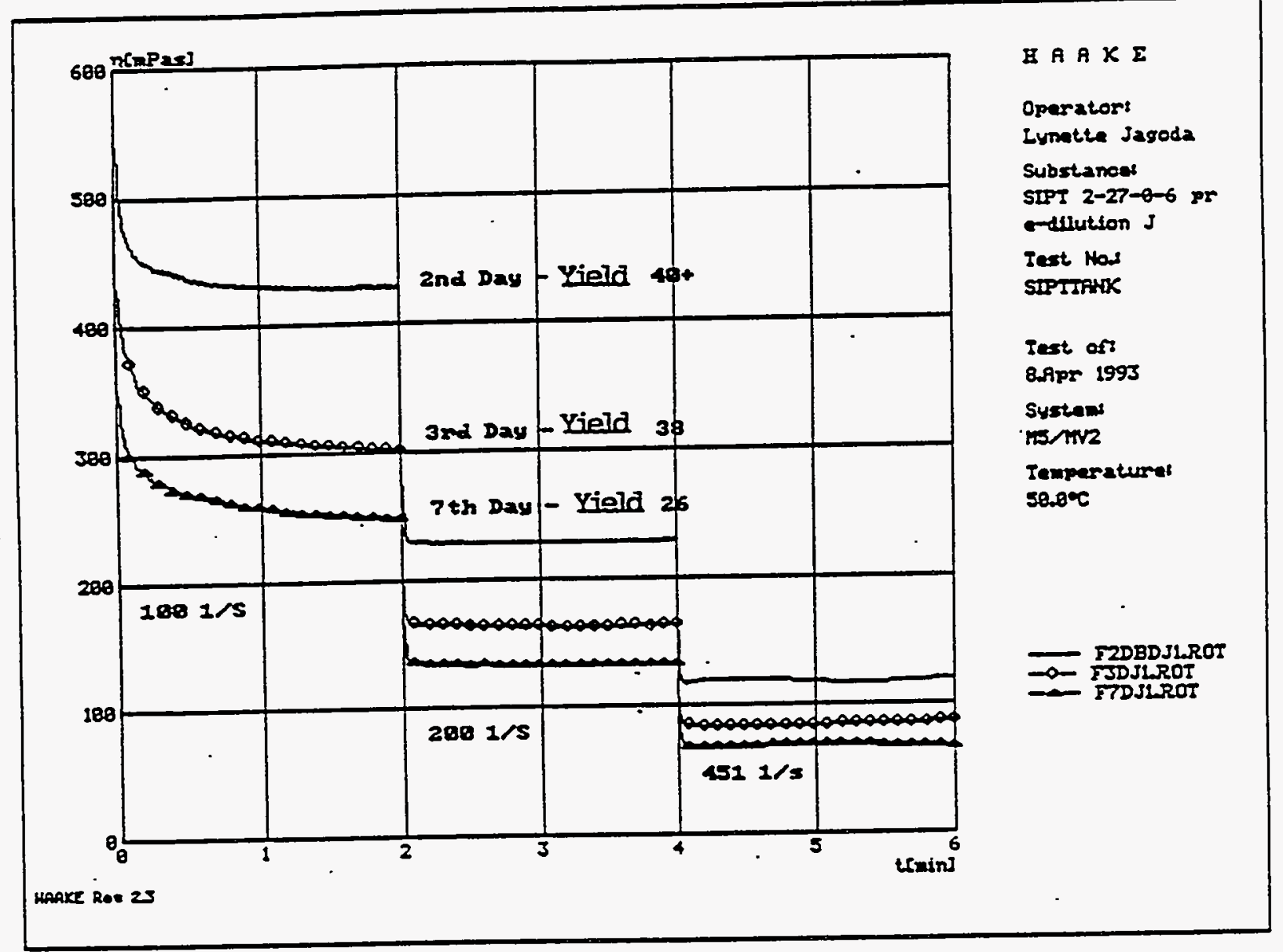

Figure F.8. Viscosity V.ersus Time (up only) Full Scale Tank Data (HB-15) Jump Measurement Evaluation of Thixotrophy 


\section{Appendix G}

\section{Tank Design Calculations}




\title{
Design Calculations
}

\section{CALC-SIPT-002, Rev. 0}

\author{
For \\ Slurry-Integrated Pefformance Testing \\ $6 / 793$
}

HB-15 Coil Heat Transfer Coefficients

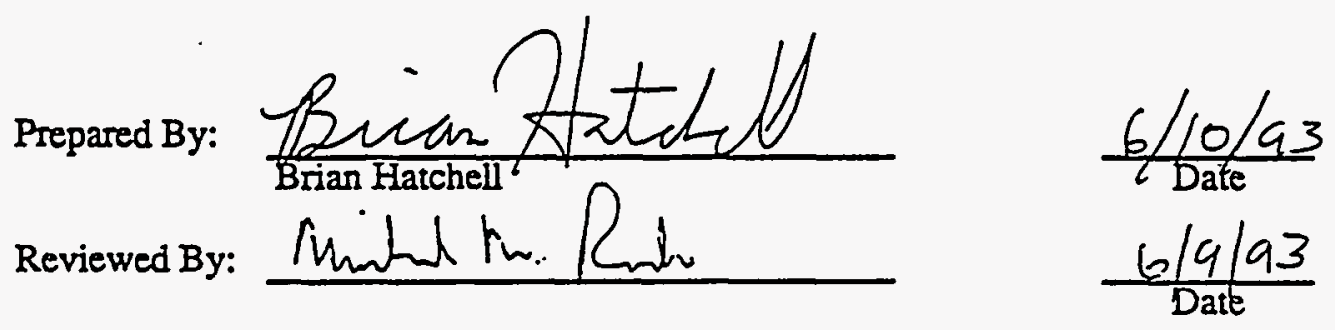

G.1 
CALC-SIPT-002, REV. 0 Page 2 of 22

Index to Calculations

$\begin{array}{ll}\text { 1.0 } & \text { Introduction } \\ 2.0 & \text { Data } \\ 3.0 & \text { Overall Heat Transfer. Coefficient } \\ 4.0 & \text { Heat Transfer Coefficient - Transient Cooling } \\ 4.1 & \text { Test Conditions - Transient Cooling } \\ 4.2 & \text { Vessel Side Heat Transfer Coefficient - Transient Cooling } \\ 4.3 & \text { Tube Side Heat Transfer Coefficient - Transient Cooling } \\ 4.4 & \text { Fouling Factors - Transient Cooling } \\ 4.5 & \text { Overall Predicted Heat Transfer Coefficient - Transient Cooling } \\ 4.6 & \text { Overall Experimental Heat Transfer Coefficient - Transient Cooling } \\ 4.7 & \text { Comparison of Predicted and Actual Heat Transfer Coefficient - Transient Cooling } \\ 5.0 & \text { Heat Transfer Coefficient - Transient Heating } \\ 5.1 & \text { Test Conditions - Transient Heating } \\ 5.2 & \text { Vessel Side Heat Transfer Coefficient - Transient Heating } \\ 5.3 & \text { Tube Side Heat Transfer Coefficient - Transient Heating } \\ 5.4 & \text { Fouling Factors - Transient Heating } \\ 5.5 & \text { Overall Predicted Heat Transfer Coefficient - Transient Heating } \\ 5.6 & \text { Overall Experimental Heat Transfer Coefficient - Transient Heating } \\ 5.7 & \text { Comparison of Predicted and Actual Heat Transfer Coefficient - Transient Heating } \\ 6.0 & \text { Heat Transfer Coefficient - Boiling } \\ 6.1 & \text { Test Conditions - Boiling } \\ 6.2 & \text { Vessel Side Heat Transfer Coefficient - Boiling } \\ 6.3 & \text { Tube Side Heat Transfer Coefficient - Boiling } \\ 6.4 & \text { Fouling Factors - Boiling } \\ 6.5 & \text { Overall Predicted Heat Transfer Coefficient - Boiling } \\ 6.6 & \text { Overall Experimental Heat Transfer Coefficient - Boiling } \\ 6.7 & \text { Comparison of Predicted and Actual Heat Transfer Coefficient - Boiling } \\ 7.0 & \text { References }\end{array}$

\subsection{Introduction}

The following calculations determine the overall heat transfer coefficients for the coils in the test vessel (HB-15) during transient batch heating, boiling, and transient batch cooling. The overall heat transfer coefficient $(U)$ is the inverse of all resistances between the steam (and cooling water) and the process side. The resistances include:

1) Coil side convective heat transfer coefficient

2) Fouling factor inside the tube

3) Resistance of the tube wall

4) Fouling factor outside the tube wall

5) Process side heat transfer coefficient 
The quantities are calculated for each process condition and combined to calculate the overall predicted heat transfer coefficient during heating, boiling, and cooling. The calculations rely on actual process data for material property evaluation, agitator speed, etc. The calculations assume water as the process liquid, since properties are well defined for water. Following the calculations is a derivation of the actual heat transfer coefficients during water testings.

\subsection{Data}

Heat Transfer Area:

Cooling Coil Outside Area, Ac: Heating Coils Outside Area, Ah:
$144.00 \mathrm{ft}^{\wedge} 2$

$343.00 \mathrm{ft}^{\wedge} 2$
Ref 1,pg 67

Ref 1, pg 67

Coil Properties: 2" SCH 40 Pipe Coil, Hastalloy C-276

Ref 6, Sheet 4

Conductivity, $\mathrm{K}$ tube $\quad 6.03$

6.24

6.46

Outside Diameter, Do Inside Diameter, $\mathrm{Di}$

\subsection{5 in}

2.067 in

Inside Area, $\mathrm{Ai}=(\pi / 4) * \mathrm{Di}^{\wedge} 2=$

$\pi=$

Vessel Dimensions

Vessel Inside Diameter, Dj

Vessel Paddle Diameter, L
$12.000 \mathrm{ft}$

$3.000 \mathrm{ft}$

\begin{abstract}
Btu/hr ft^2 $2^{\circ} \mathrm{F}$ at $125^{\circ} \mathrm{F} \quad$ Per Ref
$\mathrm{Btu} / \mathrm{hr} \mathrm{ft}^{\wedge} 2^{\circ} \mathrm{F}$ at $168^{\circ} \mathrm{F} \quad 7, \mathrm{pg} 155$

$\mathrm{Btu} / \mathrm{hr} \mathrm{ft} \wedge 2^{\circ} \mathrm{F}$ at $212^{\circ} \mathrm{F}$
\end{abstract}

$0.198 \mathrm{ft}$

$0.172 \mathrm{ft}$

$\mathrm{ft}^{\wedge} \mathbf{2}$
0.0233

$=$

0.0233 


\subsection{Overall Heat Transfer Coefficient}

The overall coil heat transfer coefficient is determined according to the following equations.

$$
\begin{array}{lr}
\frac{1}{U_{D}}=\frac{1}{h_{i 0}}+\frac{1}{h_{0}}+R+f_{i}+f_{0} & \text { Ref.2 pg } 106 \text { (1) } \\
h_{i 0}=h_{i} \frac{D_{i}}{D_{0}} & \text { Ref.2pg } 86 \text { (2) } \\
R=\frac{2.3 D_{0}}{2 K_{\text {ubbo }}} \log \left(\frac{D_{0}}{D_{i}}\right) & \text { Ref. } 2 \text { pg } 86(3) \\
\frac{1}{U_{c}}=\frac{1}{h_{10}}+\frac{1}{h_{0}}+R & \text { Ref. 2,pg } 86
\end{array}
$$

$$
\begin{aligned}
& \text { Where: } \quad h_{10}=\text { Tube side heat transfer coefficient based on outside area } \\
& h_{1}=\text { Tube side heat tansfer coefficient based on inside area } \\
& f_{i}=\text { Tube side fouling factor } \\
& f_{0} \quad=\quad \text { Vessel side fouling factor } \\
& \mathrm{R}=\text { Resistance through the tube wall } \\
& \mathrm{h}_{0}=\text { Vessel side heat transfer coefficient } \\
& \mathrm{K}_{\mathrm{mbe}}=\text { Tube conductivity } \\
& U_{D}=\text { Overall heat transfer coefficient (dirty) } \\
& \mathrm{U}_{\mathrm{C}}=\text { Overall heat transfer coefficient (clean) } \\
& D_{i}=\text { Inside diameter of tube } \\
& D_{0}=\text { Outside diameter of tube }
\end{aligned}
$$

The clean heat transfer coefficient (Uc) does not include fouling factors, and thus represents the predicted heat transfer coefficient for a new component. The dirty heat transfer coefficient (Ud) accounts for fouling equivalent to approximateiy one year of continuous service. 


\subsection{Heat Transfer Coefficient - Transient Cooling}

Cooling water is supplied to the test vessel cooling coils after the completion of the evaporation process to cool the liquid from boiling to $125^{\circ} \mathrm{F}$. The following calculations show the prediction of the heat transfer coefficient between the process liquid and the cooling water. The overail heat transfer coefficient is evaluated using data at three process temperatures: $125^{\circ} \mathrm{F}, 168.5^{\circ} \mathrm{F}$, and $212^{\circ} \mathrm{F}$.

\subsection{Test Conditions - Transient Cooling}

Use test data from TST019

$5 / 7 / 92$

See SIPT Test Data Log
Time, Start Cool

Time, End Cool

Elapsed Time

Process Start Temp

Process End Temp

Water Flow

Water Flow

Average Water Inlet Temp

Average Water Outlet Temp

Process Liquid Weight
$3: 37: 50$

5:15:50

$1.63 \mathrm{hrs}$

$207.61^{\circ} \mathrm{F}$

$125.57^{\circ} \mathrm{F}$.

$121.71 \mathrm{gpm}$

$60,905 \mathrm{lb} / \mathrm{hr}$

$75.52^{\circ} \mathrm{F}$

$115.48{ }^{\circ} \mathrm{F}$

$44,572 \mathrm{lb}$

\begin{tabular}{|l|c|c|c|}
\cline { 2 - 4 } Cooling water temperatures: & $\begin{array}{c}\text { Process @ } \\
207.6^{\circ} \mathrm{F}\end{array}$ & $\begin{array}{c}\text { Process @ } \\
167.7^{\circ} \mathrm{F}\end{array}$ & \begin{tabular}{c} 
Process @ $125.6^{\circ} \mathrm{F}$ \\
\hline Cooling water inlet temp, $\mathrm{F}$
\end{tabular} \\
\hline & 75.99 & 73.83 & 75.22 \\
Cooling water outlet temp, $\mathrm{F}$ & 143.35 & 119.21 & 98.42 \\
\hline
\end{tabular}

* Instantaneous cooling water temperatures at the specified process temperature, from TST019.

\subsection{Vessel Side Hieat Transfer Coefficient - Transient Cooling}

For a submerged tube coil subjected to mechanical agitation by a paddle, Reference 2 offers the following comelation for the vessel side heat transfer coefficient:

$\frac{\mathrm{h}_{0} \mathrm{D}_{1}}{\mathrm{k}}=0.87\left(\frac{\mathrm{L}^{2} \mathrm{~N} \rho}{\mu}\right)^{2 / 3}\left(\frac{c \mu}{\mathrm{k}}\right)^{1 / 3}\left(\frac{\mu}{\mu_{w}}\right)^{0.14}$ Ref. 2, pg. 722

Where: $\quad h_{0}=$ heat transfer coefficient, Btu/hr $-\mathrm{ft}^{2 \circ} \mathrm{F}$

$\mathrm{D}_{\mathrm{j}}=$ vessel diameter, $\mathrm{ft}$

$\mathrm{k}=$ process conductivity at bulk temperature, $\mathrm{Btu} / \mathrm{hr}-\mathrm{ft}^{\circ} \mathrm{F}$

$\mathrm{L}=$ blade diameter, $\mathrm{ft}$

$\mathrm{N}=$ agitator speed, rev/hr

$\rho=$ process density at bulk temperature, $\mathrm{lb} / \mathrm{ft}^{3}$

$c=$ process specific heat at bulk temperature, $\mathrm{Bt} / \mathrm{l} / \mathrm{b}^{\circ} \mathrm{F}$

$\mu=$ process viscosity at bulk temperature, $\mathrm{lb} / \mathrm{ft}-\mathrm{hr}$

$\mu_{w}=$ process viscosity at wall temperaure, $\mathrm{lb} / \mathrm{ft}-\mathrm{hr}$ 
CALC-SIPT-002, REV. 0 Page 6 of 22

perties of Water at $\mathrm{Tb}$

Ref 5,pg 750

\begin{tabular}{|l|l|l|l|l|}
\cline { 2 - 5 } \multicolumn{1}{c|}{} & $\begin{array}{l}\text { Process @ } \\
207.6^{\circ} \mathrm{F}\end{array}$ & $\begin{array}{l}\text { Process @ } \\
167.7^{\circ} \mathrm{F}\end{array}$ & $\begin{array}{l}\text { Process } \\
125.6^{\circ} \mathrm{F}\end{array}$ & \\
\hline $\mathrm{k}$ & 0.393 & 0.386 & 0.374 & $\mathrm{Btu} / \mathrm{hr} \mathrm{ft} \mathrm{F}$ \\
$\rho$ & 59.918 & 60.875 & 61.690 & $\mathrm{lb} / \mathrm{ft} \wedge 3$ \\
$\mu$ & 0.716 & 0.937 & 1.339 & $\mathrm{lb} / \mathrm{ft} \mathrm{hr}$ \\
$\mathrm{c}$ & 1.010 & 1.000 & 1.000 & $\mathrm{Btu} / \mathrm{lb} \mathrm{F}$ \\
\hline
\end{tabular}

Agitator Speed

N

$85.00 \mathrm{rpm}$

$5100.00 \mathrm{rev} / \mathrm{hr}$

For water,

$\left(\frac{\mu}{\mu_{\pi}}\right)^{0.54}=$

1.00

Approximately, per Ref. 2, pg. 723

Solve for ho

\begin{tabular}{|c|c|}
\cline { 2 - 2 } \multicolumn{1}{c|}{} & $\begin{array}{c}\text { Process } \\
207.6^{\circ}\end{array}$ \\
\hline ho & 855.46 \\
\hline & Heat Transfer Coefficien \\
\hline $0.027 \operatorname{Re}_{d}^{0.8} \operatorname{Pr}^{1 / 3}\left(\frac{\mu}{\mu_{w}}\right)^{0.14}$
\end{tabular}

\begin{tabular}{l|l}
\hline $\begin{array}{c}\text { Process @ } \\
167.7^{\circ} \mathrm{F}\end{array}$ & $\begin{array}{c}\text { P } \\
779.47\end{array}$ \\
\hline ransient Cooling \\
Ref. 4, pg 178
\end{tabular}

Process@ $125.6^{\circ} \mathrm{F}$

$683.02 \mathrm{Btu} / \mathrm{hr} \mathrm{ft}^{\wedge} 2 \mathrm{~F}$

\subsection{Tube Side Heat Transfer Coefficient - Transient Cooling}

The film coefficient for fully developed turbulent pipe flow may be found by:

$\mathrm{Nu}=0.027 \operatorname{Re}_{\Delta}^{0.8} \operatorname{Pr}^{1 / 3}\left(\frac{\mu}{\mu_{w}}\right)^{0.34} \quad \operatorname{Ref.} 4, \mathrm{pg} 178$

Where: $\quad \mathrm{Nu}=\cdot$ Nusselt Number $=h_{1} D_{1} / \mathrm{k}$, Ref. $4, \mathrm{pg} 182$

$\operatorname{Re}_{4}=$ Reynolds Number

Pr $=$ Prandit Number

$\mu \quad=\quad$ process viscosity at bulk temperature

$\mu_{w} \quad=\quad$ process viscosity at wall temperature

$D_{1}=$ Inside diameter of pipe

$\mathrm{k}=$ conductivity of fluid

Representative tube side water temperature \begin{tabular}{|c|c|c|}
\hline $\begin{array}{c}\text { Process @ } \\
207.6^{\circ} \mathrm{F}\end{array}$ & $\begin{array}{c}\text { Process @ } \\
167.7^{\circ} \mathrm{F}\end{array}$ & $\begin{array}{c}\text { Process @ } \\
125.6^{\circ} \mathrm{F}\end{array}$ \\
\hline 109.67 & 96.52 & 86.82 \\
\hline
\end{tabular} (average inlet and outlet temps provided above)

Properties of Water at average Temp Ref 5,pg 750

\begin{tabular}{|c|c|c|c|c|}
\hline $\mathrm{k}$ & 0.368 & 0.362 & 0.357 & Btu / hr ft ${ }^{\circ} \mathrm{F}$ \\
$\rho$ & 61.945 & 62.117 & 62.166 & $\mathrm{Ib} / \mathrm{ft}^{\wedge} 3$ \\
$\mu$ & 1.532 & 1.724 & 1.934 & $\mathrm{lb} / \mathrm{ft} \mathrm{hr}$ \\
$\mathrm{c}$ & 1.000 & 0.999 & 0.999 & $\mathrm{Btu} / \mathrm{lb}{ }^{\circ} \mathrm{F}$ \\
$\mathrm{PI}$ & 4.164 & 4.750 & 5.419 & Prandlt \# \\
\hline
\end{tabular}


Ave. Cooling Water Flow $=121.63 \quad \mathrm{gpm}=$

$\begin{array}{ll}\text { gpm }= & 975.55 \\ 60430.90 & \mathrm{lb} / \mathrm{hr}\end{array}$

$\mathrm{ft}^{\wedge} 3 / \mathrm{hr} \quad$ from TST019

Mass Flow, MDOT = density*flow =

Flow Speed, $u=($ MDOT $/$ density * Ai $)=41864.19 \mathrm{ft} / \mathrm{hr}$ Assume constant density of water (it changes very little)

Calculate Reynold's number.

$\operatorname{Re}_{d}=\frac{\rho u D_{i}}{\mu} \quad$ Ref. 2, pg. 29

\begin{tabular}{|c|c|c|c|}
\cline { 2 - 4 } \multicolumn{1}{c|}{} & $\begin{array}{c}\text { Process @ } \\
207.6^{\circ} \mathrm{F}\end{array}$ & $\begin{array}{c}\text { Process @ } \\
167.7 \mathrm{~F}^{\circ}\end{array}$ & $\begin{array}{c}\text { Process @ } \\
125.6^{\circ} \mathrm{F}\end{array}$ \\
\hline Red $=$ & 291,614 & 259,823 & 231,852 \\
\hline
\end{tabular}

Regions $R e_{d}<2300 \quad$ Laminar Reference 2, pg. 29

We are well into the turbulent zone.

For Water,

$$
\begin{array}{llll}
\left(\frac{\mu_{B}}{\mu_{\mathrm{w}}}\right)^{0.14} & = & 1.00 & \text { Approximately } \\
\mathrm{Nu}= & \mathrm{h} \mathrm{Di} / \mathrm{k} & \text { Ref. 4,pg } 182
\end{array}
$$

\begin{tabular}{|c|c|c|c|c|}
\hline & $\begin{array}{l}\text { Process@ } \\
-207.6^{\circ} \mathrm{F}\end{array}$ & $\begin{array}{c}\text { Process@ } \\
167.7^{\circ} \mathrm{F}\end{array}$ & $\begin{array}{c}\text { Process@@ } \\
125.6^{\circ} \mathrm{F}\end{array}$ & \\
\hline $\begin{array}{l}\mathrm{Nu}= \\
\mathrm{hi}=\end{array}$ & $\begin{array}{l}1,023 \\
2,183\end{array}$ & $\begin{array}{c}974 \\
2,048\end{array}$ & $\begin{array}{c}929 \\
1,925\end{array}$ & $\mathrm{Btu} / \mathrm{hr} f \mathrm{t}^{\wedge} 2^{\circ} \mathrm{F}$ \\
\hline
\end{tabular}

Solve for hi:

This is based on inside area. All calculations are referenced to outside area.

hio $=(\mathrm{Di} / \mathrm{Do}) *$ hi $=$

\begin{tabular}{|l|l|l|l|}
\hline 1,900 & 1,782 & 1,675 & $\mathrm{Btu}_{\mathrm{hrft}} \mathbf{2}^{\circ} \mathrm{F}$ \\
\hline
\end{tabular}

Ref. 2,pg 105

4.4 Fouling Factors - Transient Cooling

$\mathrm{fi}=\quad 0.001 \quad$ City Water, below $125 \mathrm{~F}$ Ref.5, pg 425

fo $=\quad 0.002 \quad$ City Water, above $125 \mathrm{~F}$

\subsection{Overall Predicted Heat Transfer Coefficient - Transient Cooling}

Use Eq. 3 to calculate $R$ Use Eq. 4 to calculate Uc Use Eq. 2 to evaluate Ud:

\begin{tabular}{|c|c|c|c|l|}
\cline { 2 - 5 } \multicolumn{1}{c|}{} & $\begin{array}{c}\text { Process @ } \\
207.6^{\circ} \mathrm{F}\end{array}$ & $\begin{array}{c}\text { Process @ } \\
167.7^{\circ} \mathrm{F}\end{array}$ & $\begin{array}{c}\text { Process @ } \\
125.6^{\circ} \mathrm{F}\end{array}$ & \\
\hline $\mathrm{R}$ & 0.0021 & 0.0022 & 0.0023 & \\
$\mathrm{Uc}$ & 261.7 & 247.3 & 230.4 & $\mathrm{Btu} / \mathrm{hrf} \wedge 2^{\circ} \mathrm{F}$ \\
$\mathrm{Ud}$ & 146.6 & 142.0 & 136.2 & $\mathrm{Btu} / \mathrm{hrft}^{\wedge} 2^{\circ} \mathrm{F}$ \\
\hline
\end{tabular}

\subsection{Overall Experimental Heat Transfer Coefficient - Transient Cooling}

The following calculations document the actual heat transfer coefficient between the cooling water and the process liquid duing the cooling process. A correlation for a coil-in-tank vessel, 
nonisothermal cooling medium is used to calculate $U$, based on actual test conditions

Assumptions: $\mathrm{U}$ is constant

Cooling water flow is constant

Specific heats are constant

Heating or cooling medium has a constant inlet temperature

Agitation produces a uniform batch fluid temperature

No partial phase changes occur

Heat loss from the tank are negligible (may not be reasonable at high temperatures)

$$
\begin{array}{ll}
\ln \left(\frac{T_{1}-t_{1}}{T_{2}-t_{1}}\right)=\frac{w C}{M C}\left(\frac{e^{\text {UMr }}-1}{e^{U M C}}\right) \Theta \quad \text { Ref. } 2, p g .628 \\
\text { Where: } \quad t_{1}=\text { inlet water temperature } \\
T_{1}=\text { initial process temperature } \\
T_{2}=\text { final process temperature } \\
\theta=\text { cooling time } \\
w=\text { water flow } \\
C=\text { specific heat of cooling water } \\
M=\text { mass of process liquid } \\
C=\text { specific heat of process }
\end{array}
$$

$\begin{array}{ll}\text { Use test data from TST019 } & \text { Time, Start Cool } \\ & \text { Time, End Cool } \\ & \text { Elapsed Time, } \theta \\ & \text { Start Temp, T1 } \\ \text { End Temp, T2 } \\ \text { Water Flow } \\ \text { Water Flow, w } \\ \text { Average Water Inlet Temp, t1 } \\ \text { Average Water Exit Temp } \\ \text { Process Weight, M }\end{array}$

$\mathrm{C}($ water $)=$ $c=$
1.00 1.00
$\mathrm{Bru} / \mathrm{lb} \mathrm{F}$ $\mathrm{Btu} / \mathrm{lb} \mathrm{F}$
$3: 37: 50$

5:15:50

$1.63 \mathrm{hrs}$ $207.61 \mathrm{degF}$ $125.57 \mathrm{degF}$ $121.71 \mathrm{gpm}$ $60,905 \mathrm{lb} / \mathrm{hr}$ $75.52 \mathrm{degF}$ $115.48 \mathrm{degF}$ $44,572 \mathrm{lb}$

Ref. 5, pg. 750

Equation 8 cannot be used to solve for $U$ directly, so I will iterate on $U$ unil the equality in satisfied.

$$
\begin{array}{ccc}
U= & 241.35 & \mathrm{Btu} / \mathrm{hr} \mathrm{F}_{\mathrm{t}} \wedge 2 \mathrm{~F} \\
\mathrm{UA} / \mathrm{wc}= & 0.57
\end{array}
$$

Left Hand Side, Eq. 6: $0.9705 \quad \sqrt{ }$ 
nonisothermal cooling medium is used to calculate $U$, based on actual test conditions

Assumptions: $U$ is constant

Cooling water flow is constant

Specific heats are constant.

Heating or cooling medium has a constant inlet temperature

Agitation produces a uniform batch fluid temperature

No partial phase changes $\alpha c c u r$

Heat loss from thic tank are negligible (may not be rcasonable at high tempcratures)

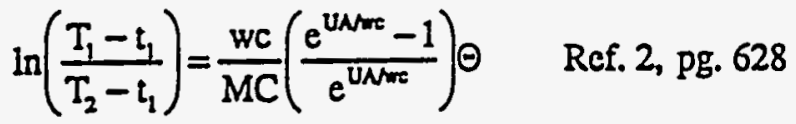

$$
\begin{aligned}
& \text { Where: } t_{1}=\text { inlet watcr temperature } \\
& T_{1}=\text { initial process temperature } \\
& \mathrm{T}_{2}=\text { final process tempcrature } \\
& \theta=\text { cooling time } \\
& w=\text { water flow } \\
& c=\text { specific heat of cooling water } \\
& M=\text { mass of process liquid } \\
& C=\text { specific heat of process }
\end{aligned}
$$

Use test data from TST019

Time, End Cool
Elapsed Time, $\quad$ Start Temp, T1
End Temp, T2
Water Flow
Water Flow, w
Average Water Inlet Temp, $\mathrm{t1}$
Average Water Exit Temp
Process Weight, M
1.00
Btu / lb F
1.00 .
Btu / lb F

$c=$

Equation 8 cannot be used to solve for $U$ direetly, so I will iterate on $U$ unil the equality in satisfied.

$$
\begin{array}{ccc}
\mathrm{U}= & 241.35 & \mathrm{Btu} / \mathrm{hr} \mathrm{Ft}^{\wedge} 2 \mathrm{~F} \\
\mathrm{UA} / \mathrm{wc}=\cdot \quad 0.57 &
\end{array}
$$

Left Hand Side, Eq. 6: $\quad 0.9705$

Right Hand Side, Eq. 6: 0.9705

$3: 37: 50$

5:15:50

$1.63 \mathrm{hrs}$

$207.61 \mathrm{deg} F$

$125.57 \mathrm{degF}$

$121.71 \mathrm{gpm}$

$60,905 \mathrm{lb} / \mathrm{hr}$

75.52 degF

$115.48 \mathrm{deg} F$

$44,572 \mathrm{lb}$

Ref. 5, pg. 750 
The instantaneous transient cooling heat transfer coefficient is evaluated below to determine how the coefficient varies with vessel temperature. A small time segment is used for each data point (1 minute), so that the temperature of the cooling water inlet and exit and the vessel process temperature are essentially constant. The same test data is used for the evaluation (TST019). Fouricr's law is used to determine the overall heat transfer coefficient. A log-mean temperature difference between the cooling water and the process liquid is used for $\Delta T$.

$$
\begin{aligned}
& Q=\mathrm{UA} \Delta \mathrm{T} \operatorname{Ref} 2 ; \mathrm{pg} 86 \\
& \Delta \mathrm{T}=\frac{\Delta \mathrm{t}_{2}-\Delta \mathrm{t}_{1}}{\ln \left(\Delta \mathrm{t}_{2} / \Delta \mathrm{t}_{1}\right)} \quad \text { Ref } 2, \mathrm{pg} 42 \\
& \text { Where } Q=\text { Heat transfered through coils } \\
& U=\text { Instantaneous heat transfer cocfficient } \\
& \mathrm{A}=\text { Cooling coil outside area } \\
& \Delta \mathrm{T}=\log \text { Mean Temperature Difference between } \\
& \text { Cooling water and process } \\
& \Delta t_{1}=\text { The higher temperature of the hot fluid }(-) \text { the } \\
& \text { higher temperature of the cold liquid } \\
& \Delta t_{2}=\text { The lower temperature of the hot fluid }(-) \text { the } \\
& \text { lower temperature of the cold liquid }
\end{aligned}
$$

$Q$ is determined from the cooling water change in temperature, i.e.:

$$
\mathrm{Q}=\mathrm{MDOT} * \mathrm{Cp} \Delta \mathrm{t} \quad \begin{aligned}
& \mathrm{Cp}=\text { specific heat of cooling water }=1 \mathrm{Btu} / \mathrm{lb}{ }^{\circ} \mathrm{F} \\
& \Delta \mathrm{t}=\text { tcmperature rise of cooling water }
\end{aligned}
$$

Average cooling water temperature throughout cooling process in
$T$ (ave, cooling water) $=$
95.50
${ }^{\circ} \mathrm{F}$
per TSTO19

Density of water at this temperature $=$

62.12

$\mathrm{lb} / \mathrm{ft}^{\wedge} 3$

Ref. 5, pg 750

Weight per gallon $=$

8.30

$\mathrm{lb} / \mathrm{gal}$

MDOT $=$ Flow rate $\mathrm{GPM} *(8.30 \mathrm{lb} / \mathrm{gal}) * .(60 \mathrm{~min} / \mathrm{Hr})$

The transient cooling heat transfer coefficient is plotted versus process temperature in the following graph. The periodic fluxuations are caused by the control limits of the cooling tower. Note that the $\mathrm{Q}$ imbedded in the instantaneous heat transfer coefficient is based on the change in enthalpy of the cooling. water. It neglects the heat input by the agitator and heat losses from the tank. The overall heat transfer coefficient, which was calculated to be $241 \mathrm{Bht} / \mathrm{Hiff} \mathrm{A}^{\wedge}{ }^{\circ} \mathrm{F}$, is based on the change in enthalpy of the process over time. For this reason, the instantanous heat transfer cocfficient is somewhat different than the overall. 


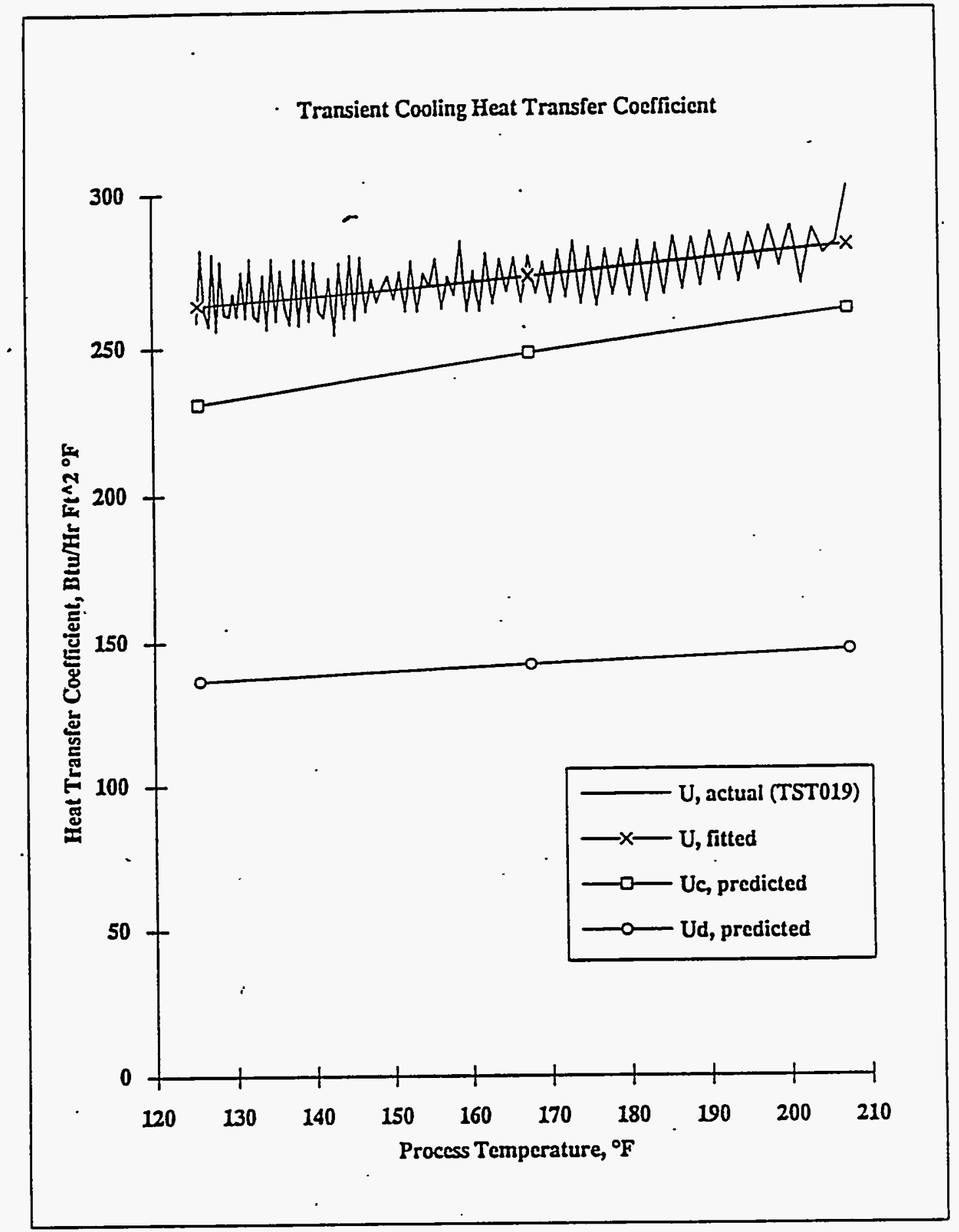

G.11 
A process temperature versus transient cooling heat transfer coefficient was fit through the data.

$$
\begin{array}{cc}
m & b \\
0.21 & 238.68
\end{array}
$$

Units of $m \quad\left(B t u / h r \mathrm{ft}^{\wedge} 2^{\circ} \mathrm{F}\right) / \mathrm{F}$

Units of $\mathrm{b} \quad \mathrm{Btw} / \mathrm{hr} \mathrm{ft}^{\wedge} 2^{\circ} \mathrm{F}$

$$
\mathrm{U}=\mathrm{mT}+\mathrm{b} \quad \text { where } \mathrm{T}=\text { process temperature, }{ }^{\circ} \mathrm{F}
$$

\begin{tabular}{|c|c|c|c|}
\cline { 2 - 4 } \multicolumn{1}{c|}{} & $\begin{array}{c}\text { Process @ } \\
207.6^{\circ} \mathrm{F}\end{array}$ & $\begin{array}{c}\text { Process @ } \\
167.7^{\circ} \mathrm{F}\end{array}$ & $\begin{array}{c}\text { Process @ } \\
125.6^{\circ} \mathrm{F}\end{array}$ \\
\hline $\mathrm{U}$ & 281.4 & 273.2 & 264.6 \\
\hline
\end{tabular}

This is also shown in the previous plot.

\subsection{Comparison of Predicted and Actual Heat Transfer Coefficient - Transient Cooling}

The predicted, actual overall, and actual instantanous transient cooling heat transfer coefficients are summarized below.

\begin{tabular}{|c|c|c|c|l|}
\cline { 2 - 5 } \multicolumn{1}{c|}{} & $\begin{array}{c}\text { Proccss @ } \\
207.6^{\circ} \mathrm{F}\end{array}$ & $\begin{array}{c}\text { Process @ } \\
167.7^{\circ} \mathrm{F}\end{array}$ & $\begin{array}{c}\text { Process @ } \\
125.6^{\circ} \mathrm{F}\end{array}$ & \multicolumn{1}{c|}{ Comments } \\
\hline Uc, predicted & 261.7 & 247.3 & 230.4 & Predicted \\
Ud, predicted & 146.6 & 142.0 & 136.2 & Predicted \\
\hline U, actual & 241.4 & 241.4 & 241.4 & Actual, overall \\
U, actual & 281.4 & 273.2 & 264.6 & Instantaneous, using linear curve fit \\
\hline U, design & 70.0 & 70.0 & 70.0 & Used by Fluor Danicl \\
\hline
\end{tabular}

The instantaneous heat transfer coefficient is a better indication of heat transfer, since it is based on the actual heat transfer through the coils, and does not include heat losses from the tank and agitator heat input. Since the overall heat transfer coefficient is effected by tank heat loss, it is somewhat lower than the instantaneous heat transfer coefficient. The instantancous cooiing heat uansfer coefficient was slightly higher than the predicted clean heat transfer coefficient Uc, which is somewhat surprising, but not alarming considering the accuracy of the correlations. The coils are relatively new and it is expected that the cooling heat transfer coefficient will decrease with time to the diry value Ud.

\subsection{Heat Transfer Coefficient - Transient Heating}

Steam flowing through the heating coils is used to heat the process liquid from an initial batch temperature of $125^{\circ} \mathrm{F}$ to boiling. The following calculations predict the overall heat transfer coefficient between the steam and the process liquid. The overall heat transfer cocfficient is evaluated using data at three process temperatures: $125^{\circ} \mathrm{F}, 168.5^{\circ} \mathrm{F}$, and $212^{\circ} \mathrm{F}$.

\section{5,1 Test Conditions - Transient Heating}

Transient conditions taken from

TST019, 5//92 


$\begin{array}{lccl}\text { Time, Start Heating } & \text { 10:06 AM } & \\ \text { Time, End Heating } & 11: 16 \mathrm{AM} & \\ \text { Elapsed Time, hrs } & 1.17 & \mathrm{hrs} \\ \text { Steam Temp } & 349.86 & \text { oF } \\ \text { Steam Pressure } & 133.67 & \text { psia } \\ \text { Steam Tsat } & 349.47 & \text { of } \\ \text { Slurry Mass } & 68109.77 & \mathrm{jb} \\ \text { Starting Slury Temp } & 124.92 & \text { of } \\ \text { Ending Slurry Temp } & 208.66 & \text { of } \\ \text { Process cp } & 1.00 & \text { Btu/lb\% }\end{array}$

I will caiculate the transient cooling heat transfer coefficient at the same temperatures as transient cooling: $207.6,167.7$, and $125.6^{\circ} \mathrm{F}$.

\subsection{Vessel Side Heat Transfer Coefficient - Transicnt Heating}

The situation is identical to transicnt cooling. The resulting outside heat transfer coefficients are repeat below.

Solve for ho

\begin{tabular}{|l|c|c|c|c|}
\cline { 2 - 5 } \multicolumn{1}{c|}{} & $\begin{array}{c}\text { Process @ } \\
207.6^{\circ} \mathrm{F}\end{array}$ & $\begin{array}{c}\text { Process @ } \\
167.7^{\circ} \mathrm{F}\end{array}$ & $\begin{array}{c}\text { Process @ } \\
125.6^{\circ} \mathrm{F}\end{array}$ & \\
\hline ho & 855.46 & 779.47 & 683.02 & But $/ \mathrm{hr} \mathrm{fr}^{\wedge} 2^{\circ} \mathrm{F}$ \\
\hline
\end{tabular}

\subsection{Tube Side Heat Transfer Coefficient - Transient Heating}

It is customary to adopt a conventional and conservative value for the film cocfficient of condensing steam, since it is never controlling, rather than obtain one by calculation.

For air-free steam, a value of 1500 btu/Hr $\mathrm{f} \wedge^{\wedge} 2^{\circ} \mathrm{F}$ will be used (see Ref. 2, page 164).

hio $=\quad 1500.00 \quad \mathrm{Btu} / \mathrm{H} \mathrm{Fr}^{\wedge} 2^{\circ} \mathrm{F}$

\subsection{Fouling Factors - Transicnt Heating}

$\begin{array}{lll}\mathrm{fi}= & 0.0005 & \text { Stcam, non-oil-bearing } \\ \mathrm{fo}= & 0.002 & \text { City Water, above 125 F }\end{array}$ Ref.5, pg 425

\subsection{Overall Predicted Heat Transfer Coefficient - Transient Heating}

-Use Eq. 3 to calculate R Use Eq. 4 to calculate Uc Use Eq. 2 to evaluate Ud:

\begin{tabular}{|c|c|c|c|}
\cline { 2 - 4 } \multicolumn{1}{c|}{} & $\begin{array}{c}\text { Proccss @ } \\
207.6^{\circ} \mathrm{F}\end{array}$ & $\begin{array}{c}\text { Process @ } \\
167.7{ }^{\circ} \mathrm{F}\end{array}$ & $\begin{array}{c}\text { Process @ } \\
125.6^{\circ} \mathrm{F}\end{array}$ \\
\hline $\mathrm{R}$ & 0.0021 & 0.0022 & 0.0023 \\
$\mathrm{Uc}$ & 252.5 & 241.0 & 226.8 \\
$\mathrm{Ud}$ & 154.8 & 150.4 & 144.7 \\
$\mathrm{~N}$ & $\mathrm{Btu} / \mathrm{hr} \mathrm{f} \mathrm{t}^{\wedge} 2 \mathrm{~F}$ \\
$\mathrm{Btu} / \mathrm{hr} \mathrm{ft}^{\wedge} 2 \mathrm{~F}$
\end{tabular}

\subsection{Overall Experimental Heat Transfer Coefficient - Transient Heating}

The following calculations determine the actual heat transfer coefficient between the steam and the process liquid duing the heating process. A correlation for a coil-in-tank vessel, isothermal heating medium is used to calculate $U$, based on actual test conditions 
Assumptions: $\mathrm{U}$ is constant

Steam flow is constant

Specific heat of process is constant throughout heating process

Heating medium has a constant inlet temperature

Agitation produces a uniform batch fluid temperature

Isothermal heating mediun

No partial phase changes occur

Heat loss from the tank are negligible

Heat due to sub-cooling of the stearn condensate is neglected

$\ln \left(\frac{T_{1}-t_{1}}{T_{1}-t_{2}}\right)=\frac{U A \Theta}{M c} \quad$ Ref. 2, pg. 627

Where: $\quad T_{1}=$ isothermal medium temperature

$t_{1}=$ initial process temperature

$t_{2}=$ final process temperature

$\Theta=$ heating time

$c=$ specific heat of process

$M=$ mass of process liquid

A $=$ heat transfer area

Using test conditions for heating during TSTO19:

$\begin{array}{ccl}\mathrm{T} 1= & 349.47 & { }^{\circ} \mathrm{F} \\ \mathrm{t} 1= & 124.92 & { }^{\circ} \mathrm{F} \\ \mathrm{L}= & 208.66 & { }^{\circ} \mathrm{F} \\ \mathrm{C}= & 1.00 & \mathrm{Btu} / \mathrm{lb} \mathrm{b}^{\circ} \mathrm{F} \\ \mathrm{M}= & 68,110 & \\ & & \\ & & \end{array}$

Solve for $\mathrm{U} \quad 79.44 \quad \mathrm{Btw} / \mathrm{HrFt}^{\wedge} 2^{\circ} \mathrm{F}$

The instantaneous heating heat transfer coefficient is evaluated below to determine how the coefficient varies with vessel temperature. A small time segment is used for each data point (1minute), so that the temperature of the steam condensate temperature and the vessel process temperature are essentially constant. The same test data is used for the evaluation (TSTO19). $Q$ is determined from the heat of condensation of the steam, plus any subcooling of the condensate.

$$
\begin{array}{ll}
\mathrm{Q}=\mathrm{MDOT} *(\mathrm{Cp} \Delta \mathrm{t}+\mathrm{hfg}) & \mathrm{Cp}=\text { specific heat of steam condensate }=1 \mathrm{Btu} / \mathrm{lb}{ }^{\circ \mathrm{F}} \\
& \Delta \mathrm{t}=\mathrm{temperature} \text { drop of condensate } \\
& \text { hfg = heat of vaporization of the steam } \\
& \mathrm{MDOT}=\text { mass flow of steam }
\end{array}
$$

The transient heating heat transfer coefficient is plotted versus process temperature in the following graph. Note that the $Q$ neglects the heat input by the agitator and heat losses from the tank. The instantaneous heat transfer coefficient is determined from Fourier's $L a w, Q=U A \Delta T$, where $\Delta T$ is logmean temperature difference between the steam and the process liquid. 


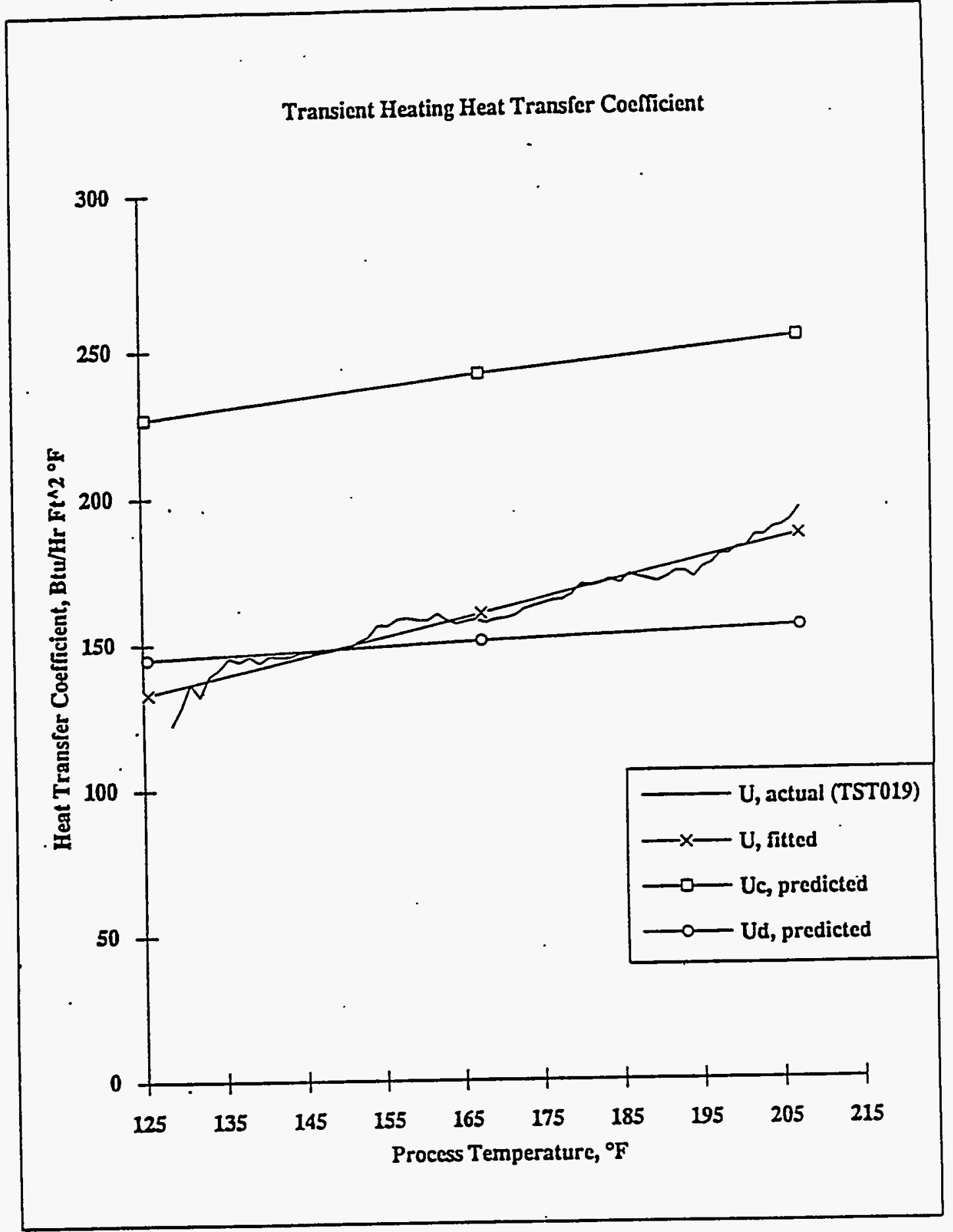

G.15 
A process temperature versus transient heating heat transfer coefficient was fit through the data.

$$
\begin{array}{cc}
\text { m } & \text { b } \\
0.64 & 52.15
\end{array}
$$

Units of $\mathrm{m} \quad\left(\mathrm{Btw} / \mathrm{hr} \mathrm{ft}^{\wedge} 2^{\circ} \mathrm{F}\right) / \mathrm{FF}$.

Units of $b \quad B t u / h r \mathrm{ft}^{\wedge} 2^{\circ} \mathrm{F}$

$$
\mathrm{U}=\mathrm{m} \mathrm{m}+\mathrm{b} \quad \text { where } \mathrm{T}=\text { process temperature, }{ }^{\circ} \mathrm{F}
$$

\begin{tabular}{|c|c|c|c|}
\cline { 2 - 4 } \multicolumn{1}{c|}{} & $\begin{array}{c}\text { Process @ } \\
207.6^{\circ} \mathrm{F}\end{array}$ & $\begin{array}{c}\text { Process @ } \\
167.7^{\circ} \mathrm{F}\end{array}$ & $\begin{array}{c}\text { Process @ } \\
125.6^{\circ} \mathrm{F}\end{array}$ \\
\hline $\mathrm{U}$ & 185.5 & $159.9^{\circ}$ & 132.8 \\
\hline
\end{tabular}

This is also shown in the previous plot.

\subsection{Comparison of Predicted and Actual Heat Transfer Coefficient - Transient Heating}

\begin{tabular}{|c|c|c|c|l|}
\cline { 2 - 5 } \multicolumn{1}{c|}{} & $\begin{array}{c}\text { Process @ } \\
207.6^{\circ} \mathrm{F}\end{array}$ & $\begin{array}{c}\text { Process @ } \\
167.7^{\circ} \mathrm{F}\end{array}$ & $\begin{array}{c}\text { Process @ } \\
125.6^{\circ} \mathrm{F}\end{array}$ & \multicolumn{1}{c|}{ Comments } \\
\hline Uc, predicted & 252.5 & 241.0 & 226.8 & Predicted \\
Ud, predicted & 154.8 & 150.4 & 144.7 & Predicted \\
\hline U, actual & 79.4 & 79.4 & 79.4 & Actual, ovcrall, using cquation 11 \\
U, actual & 185.5 & 159.9 & 132.8 & Actual, using linear curve fit \\
\hline U. design & 120.0 & 120.0 & 120.0 & Used by Fluor Daniel \\
\hline
\end{tabular}

The equation used to predict the overall transicnt heating heat transfer coefficient (Equation 11) appears inadequate for this situation. The primary reason for this is that Equation 11 assumes an isothermal heating medium. Even though the steam condenses at a constant temperature, a large amount of heat is transferred by subcooling the condensate. The result is that Equation 11 severely underpredicts the heat transfer coefficient. The actual heating heat transfer coefticient (using instantancous values) is only slightly above the predicted dirty (Ud) heat transfer coefficient. The reason for this is that, during water processing, the coils are oversurface, meaning that there is excess surface area for the application. This is supported by the fact that the steam condensate temperature (exit) is only slighly above the process icmperature during heat up (see the following plot of steam condensate temperature versus process temperature during heatup), indicating that essentially all available heat is extracted from the steam. Opcrating the stcam coils at higher steam flows would eliminate this situation. 
Steam condensate temperature minus process temperature

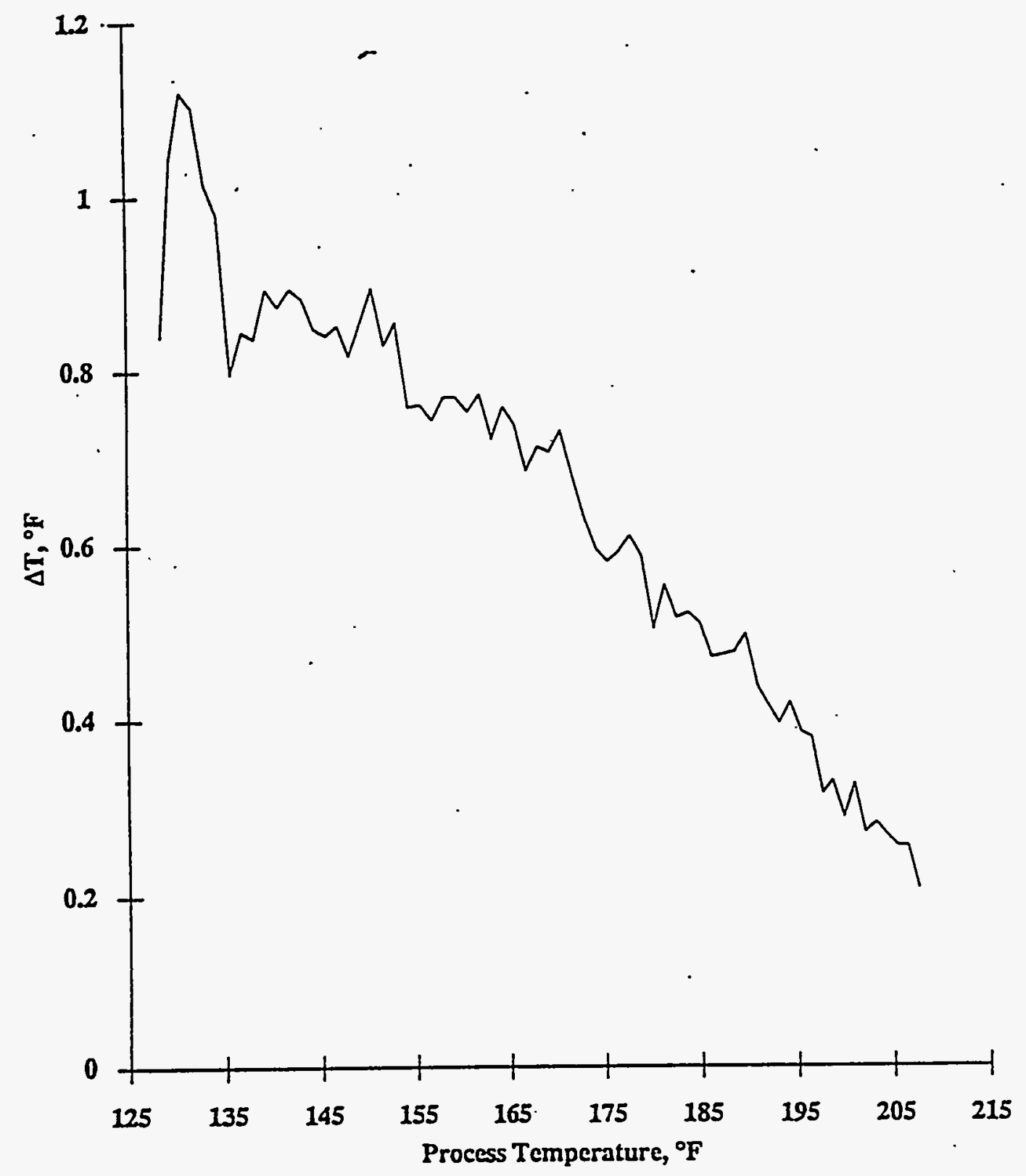

G. 17 


\subsection{Heat Transfer Coefficient - Boiling}

Steam flowing through the steam coils is used to evaporate the process liquid. The following calculations predict the overall heat transfer cocfficient between the steam and process liquid. Actual test data is used for property evaluation, flow rates, etc. The effect of boiling on the heat transfer coefficient will not be considered. Boiling heat transfer can be divided into different regions of behavior: natural convection, nucleate boiling, transitional boiling, and film boiling (sec Reference 3, pg. 387), depending on the amount of heat flux between the liquid and the heat transfer surface. Boiling in the test vessel will oceur in the nucicate, transitional, or film boiling regime: In general, boiling increases the heat transfer of a process if the boiling occurs in the nucleate or film boiling regime. During transitional boiling, however, the heat transfer surface is enguifed in a layer of vapor. This layer of vapor acts as insulation and can decrease the heat transfer.

Heat transfer in the tank will be a combination of forced convection by agitation and boiling heat transfer. Due to the complexities involved in calculating a boiling heat transfer coefficient, the cffect of boiling will be ignored, and a heat transfer cocfficient based only on forced convection will be calculated. The results will be compared to actual test data to validate this simplification.

The situation is therefore identical to transient heating, so the same equations will be used here.

\subsection{Test Conditions - Boiling}

Using data from TSTO29

$\begin{array}{lcl}\text { Time Start } & 11: 13 & \\ \text { Time End } & 11: 43 & \\ \text { Elapsed Time } & 30.00 & \mathrm{~min} \\ \text { Stcam Header Pressure } & 127.32 & \mathrm{psia} \\ \text { Steam Flow, mdot } & 5758.48 & \mathrm{lb} / \mathrm{hr} \\ \text { Sicam Tin } & 345.11 & { }^{\circ} \mathrm{F} \\ \text { Steam Pin } & 125.78 & \mathrm{psia} \\ \text { Steam Condensate Tout } & 213.49 & { }^{\circ} \mathrm{F} \\ \text { Evaporation Rate: } & 10.18 & \mathrm{gpm} \\ \text { Average Process Temp } & 211.08 & { }_{\mathrm{o}} \mathrm{F}\end{array}$

\subsection{Vessel Side Heat Transfer Coefficient - Boiling}

Properties of Water at Tb Ref 5, pg 750

Agitator Speed

For water,

\begin{tabular}{|c|l|l|}
\cline { 2 - 3 } \multicolumn{1}{c|}{} & $\begin{array}{l}\text { Process @ } \\
211.08 \text { of }\end{array}$ & \\
\hline $\mathrm{k}$ & 0.393 & $\mathrm{Btu} / \mathrm{hr} \mathrm{ftF}$ \\
$\mathrm{\rho}$ & 59.834 & $\mathrm{lb} / \mathrm{ft} \wedge 3$ \\
$\mu$ & 0.705 & $\mathrm{lb} / \mathrm{ft} \mathrm{hr}$ \\
$c$ & 1.010 & $\mathrm{Btu} / \mathrm{lb} \mathrm{F}$ \\
\hline
\end{tabular}

N

$85.00 \mathrm{rpm}$

$5100.00 \mathrm{rev} / \mathrm{hr}$
$\left(\frac{\mu}{\mu_{w}}\right)^{0.14}$
$=$
1.00
approximately 
\begin{tabular}{l|l|r|}
\cline { 2 - 2 } \multicolumn{1}{l|}{} & $\begin{array}{r}\text { Process @ } \\
207.6^{\circ} \mathrm{F}\end{array}$ \\
\cline { 2 - 3 } $\begin{array}{l}\text { Use Eq. } 5 \text { to } \\
\text { solve for ho }\end{array}$ & ho & 859.58 \\
\hline
\end{tabular}

\subsection{Tube Side Heat Transfer Coefficient - Boiling}

It is customary to adopt a conventional and conservative value for the film coefficient of condensing steam, since it is never the controlling factor, rather than obtain one by calculation. For air-frce steam, a value of $1500 \mathrm{btu} / \mathrm{Hr} \mathrm{ft}^{\wedge} 2^{\circ} \mathrm{F}$ will be used (see Ref. 2, page 164).

hio $=\quad 1500.00 \quad \mathrm{Btu} / \mathrm{Hr} \mathrm{FL}^{\wedge} 2^{\circ} \mathrm{F}$

\subsection{Fouling Factors - Boiling}

$\begin{array}{llll}\mathrm{fl}= & 0.0005 & \text { Steam, non-oil-bearing } & \text { Ref.5, pg } 425 \\ \mathrm{fo}= & 0.002 & \text { City Water, above 125 F }\end{array}$

\subsection{Overall Predicted Heat Transfer Coefficient - Boiling}

Use Eq. 3 to calculate $R$ Use Eq. 4 to calculate Uc Use Eq. 2 to evaluate Ud:

\begin{tabular}{|c|c|c|}
\hline$R$ & 0.0021 & \\
Uc & 252.8 & Btu/hr ft^2${ }^{\circ} \mathrm{F}$ \\
Ud & 154.9 & Btu/hr ff^2${ }^{\circ} \mathrm{F}$ \\
\hline
\end{tabular}

\subsection{Overall Experimental Heat Transfer Coefficient - Boiling}

Fourier's Law will be used to detcrmine the overall heat transfer coefficient between the tube side and the vessel side:

$$
\mathrm{Q}=\mathrm{U} \text { Ah } \Delta t \quad \text { Ref. 2, pg. } 86
$$

Where: $\quad U=$ boiling overall heat transfer coefficient

$\mathrm{Ah}=$ outside heat transfer area of the coils.

$\Delta t=L o g-m e a n$ Temperature difference between tube side fluid and process liquid.

Two cases are considered: Case 1: steam enters at saturation temperature

Case 1:

Case 2: steam cnters at a superheated condition

$Q$ is determined from the change in enthalpy of the tube side steam. At maximum evaporation, the steam enters at essentially the saturation temperature. The steam condenses and is subcooled below the saturation temperature. Therefore,

$$
Q=q(\text { condense })+q(\text { subcool })
$$

To calculate the wcighted temperature difference $\Delta t$, it is first necessary to calculate separately the temperature difference between the steam and the vessel liquid (this is constant) and the log-mean temperature difference between the stcam condensate and the vessel liquid. These temperature differences are then weighted by the amount of energy transferred in each 
phase to determine the overall, weighted temperature difference.

Using data from ISTO29

$\begin{array}{lcl}\text { Time Start } & 11: 13 & \\ \text { Time End } & 11: 43 & \\ \text { Elapsed Time } & 30.00 & \mathrm{~min} \\ \text { Steam Header Pressure } & 127.32 & \mathrm{psia} \\ \text { Steam Flow, mdot } & 5758.48 & \mathrm{Ib} / \mathrm{hr} \\ \text { Steam Tin } & 345.11 & { }_{\mathrm{F}} \\ \text { Steam Pin } & 125.78 & \mathrm{psia} \\ \text { Steam Condensate Tout } & 213.49 & \mathrm{o}_{\mathrm{F}} \\ \text { Evaporation Rate: } & 10.18 & \mathrm{gpm} \\ \text { Average Process Temp } & 211.08 & \mathrm{o}_{\mathrm{F}}\end{array}$

Saturation temperature, $T s=344.80^{\circ} \mathrm{F} \quad$ Very close to Tin

Ref.8, pg860 desuperheating ignored

heat of vaporization, $\mathrm{hfg}=875.61 \quad \mathrm{btu} / \mathrm{lb} \quad$ Ref. 8, pg. 861 (at Tsat) $q($ cond $)=$ mdot $*$ hfg $=$ 5.042E+06. Bru / hr

$q($ subcool $)=$ mass flow of steam $*$ temperature drop $=\operatorname{mdot}($ Tsat - Tout $)$ $q($ subcool $)=7.561 \mathrm{E}+05 \mathrm{Btu} / \mathrm{hr}$

Total Heat Lost from steam $=Q=\quad 5.798 E+06 \mathrm{Btu} / \mathrm{Hs}$

Now, calculate temperature difference during condensing and subcooling phases:

Condensation, $\Delta t c$

\begin{tabular}{|c|c|c|c|}
\hline Hot Fluid & & Cold Fluid & $\Delta t$ \\
\hline $\begin{array}{l}344.80 \\
344.80\end{array}$ & $\begin{array}{l}\text { High } \\
\text { Low }\end{array}$ & $\begin{array}{l}211.08 \\
211.08\end{array}$ & $\begin{array}{l}133.72 \\
133.72\end{array}$ \\
\hline $\begin{array}{c}\Delta t c= \\
q(\text { cond }) / \Delta t s=\end{array}$ & $133.72^{\circ} \mathrm{F}$ & 37706.23 & $\mathrm{Btu} / \mathrm{hr}{ }^{\circ} \mathrm{F}$ \\
\hline
\end{tabular}

\begin{tabular}{|c|c|c|c|}
\hline Hot Fluid & & Cold Fluid & $\Delta t$ \\
\hline 344.80 & High & 211.08 & 133.72 \\
213.49 & Low & 211.08 & 2.41 \\
\hline
\end{tabular}

LMID = Logorithmic mean temperature difference $\Delta t s=\mathrm{LMTD}=(\Delta t$ (high) $-\Delta t($ low $)) / \ln (\Delta \mathrm{t}(\mathrm{high}) / \Delta \mathrm{t}(\mathrm{low})) \quad$ Ref.2, pg. 42 $\Delta t s=$ $32.71^{\circ} \mathrm{F}$

$\mathrm{q}($ subcool $) / \Delta \mathrm{ts}=\quad 23120.06 \mathrm{Btu} / \mathrm{hr}{ }^{\circ} \mathrm{F}$

Calculate weighted temperature difference per Reference 2, pg. 291. 
$\begin{aligned} \Delta t(\text { weighted }) & =Q /((q / \Delta t) c+(q / \Delta t) s) \quad \text { Ref. 2,pg. } 291 \\ & =95.33^{\circ} \mathrm{F}\end{aligned}$

Calculate overall heat transfer coefficient using Fourier's Law (Eq. 8):

$\mathrm{U}=\mathrm{Q} / \mathrm{Ah} \Delta \mathrm{t}=177.3 \quad \mathrm{Btu} / \mathrm{hr} \mathrm{ft}^{\wedge} 2^{\circ} \mathrm{F}$

For lower evaporation rates, a valve is used to reduce the pressure and flow of the incoming steam. This reduces the saturation semperature of the steam, and results is superheated steam at the inlet. For this situation,

$$
Q=q(\text { desuperheat })+q(\text { condense })+q(\text { subcool })
$$

Using data from TSTO29

$\begin{array}{lcl}\text { Time Start } & 14: 26 & \\ \text { Time End } & 14: 56 & \\ \text { Elapsed Time } & 30.00 & \mathrm{~min} \\ \text { Steam Header Pressure } & 130.08 & \mathrm{psia} \\ \text { Steam Flow, mọot } & 1429.01 & \mathrm{lb} / \mathrm{hr} \\ \text { Steam Tin } & 346.73 & \circ \mathrm{oF} \\ \text { Steam Pin } & 34.37 & \mathrm{psia} \\ \text { Steam Condensate Tout } & 209.30 & { }^{\circ} \mathrm{F} \\ \text { Evaporation Rate: } & 2.45 & \mathrm{gpm} \\ \text { Average Process Temp } & 209.80 & \mathrm{oF}\end{array}$

Saturation temperature, $\mathrm{Ts}=258.17^{\circ} \mathrm{F}$

Ref.8, pg860

Average of $\mathrm{Ts}$ and $\mathrm{Tin}=302.45^{\circ} \mathrm{F}$

Steam vapor specific heat at $\mathrm{Tin}=$

$q($ desuperheat $)=$ mdot * $c($ Tin - Tsat $)=$

heat of vaporization, $\mathrm{hfg}=940.07$

(at Tsat)

$q($ cond $)=$ mdot $*$ hfg $=$
Substantially lower than Tin desuperheating must be considered

$0.48 \quad$ Btu $/ \mathrm{lb}^{\circ} \mathrm{F} \quad$ Ref. 5, pg 735

Btu / hr

btu / lb Ref. 8, pg. 861

1.343E+06 Btu/hr

$\mathrm{q}($ subcool $)=$ mass flow of steam * temperature drop = mdot(Tsat - Tout)

$q($ subcool $)=6.984 \mathrm{E}+04 \mathrm{Btu} / \mathrm{hr}$

Total Heat Lost from stcam $=Q=\quad 1.474 \mathrm{E}+06 \mathrm{Btu} / \mathrm{Hr}$

Now, calculate temperature difference during desuperheating, condensing, and subcooling phases:

Desuperheat, $\Delta$ tsub

\begin{tabular}{|c|c|c|c|}
\hline Hot Fluid & & Cold Fluid & $\Delta t$ \\
\hline 346.73 & High & 209.80 & 136.92 \\
258.17 & Low & 209.80 & 48.37 \\
\hline
\end{tabular}

$\triangle$ tsub $=\mathrm{LMTD}=85.10^{\circ} \mathrm{F}$

$\mathrm{q}$ (desuperheat) $/ \Delta \mathrm{tsub}=716.44 \quad \mathrm{Btu} / \mathrm{hr}{ }^{\circ} \mathrm{F}$ 
Condensation, $\Delta \mathrm{tc}$

\begin{tabular}{|c|c|c|c|}
\hline Hot Fluid & & Cold Fluid & $\Delta t$ \\
\hline 258.17 & High & 209.80 & 48.37 \\
\hline 258.17 & Low & 209.80 & 48.37 \\
\hline $\begin{array}{c}\Delta t \mathfrak{C}= \\
q(\text { cond }) / \Delta t s=\end{array}$ & $48.37^{\circ} \mathrm{F}$ & 27774.18 & $\mathrm{Btu} / \mathrm{hr}{ }^{\circ} \mathrm{F}$ \\
\hline
\end{tabular}

\begin{tabular}{|c|c|c|c|}
\hline Hot Fluid & & Cold Fluid & $\Delta t$ \\
\hline 258.17 & High & 209.00 & 49.17 \\
209.30 & Low & 209.00 & 0.30 \\
\hline
\end{tabular}

$$
\begin{aligned}
& \Delta t s=\mathrm{LMTD}=(\Delta t(\text { high })-\Delta t(\text { low })) / \ln (\Delta t \text { (high) } / \Delta t \text { (low) }) \quad \text { Ref.2, pg. } 42 \\
& \Delta t s=\quad 9.57^{\circ} \mathrm{F} \\
& \mathrm{q}(\mathrm{subco01}) / \Delta \mathrm{ts}=\quad 7298.65 \quad \mathrm{Bra} / \mathrm{hr}{ }^{\circ} \mathrm{F}
\end{aligned}
$$

Calculate weighted temperature difference per Reference 2, pg. 291.

$$
\begin{array}{rlrl}
\Delta t(\text { weighted }) & =Q /((q / \Delta t) \text { desuper }+(\mathrm{q} / \Delta t) c+(q / \Delta t) s) & \text { Ref. 2, pg. } 291 \\
& =41.19{ }^{\circ} \mathrm{F}
\end{array}
$$

Calculate overall heat transfer coefficient using Fourier's Law (Eq. 8):

$\mathrm{U}=\mathrm{Q} / \mathrm{Ah} \Delta \mathrm{t}=104.3 \quad \mathrm{Btu} / \mathrm{hr} \mathrm{ft} \wedge 2^{\circ} \mathrm{F}$

6.7 Comparison of Predicted and Actual Heat Transfer Coefficient - Boiling

At $10 \mathrm{gpm}$ evaporation, the following table summarized the boiling heat transfer coefficients:

\begin{tabular}{c|c|c|} 
Predicted & $\mathrm{R}$ & 0.0021 \\
Predicted & $\mathrm{Uc}$ & 253 \\
Actual & $\mathrm{Ud}$ & 155 \\
$\mathrm{U}$ & 177 \\
\hline
\end{tabular}

The actual heat transfer coefficient, is bracketed by the predicted clean and dirty heat transfer coefficient. Note that no boiling effects were considered in the derivation of the predicted heat transfer coefficient. In fact, boiling may actually reduce the heat transfer coefficient. During heating, the actual heat transfer coefficient was 185.5 (at a process temperature of $207.5^{\circ} \mathrm{F}$ ), which is actually above the boiling heat transfer coefficient calculated here. Possible reasons for this are: 1) vapor binding during the boiling process may reduce the heat transfer coefficeint and 2) bubbles formed during boiling at the top of the process liquid may reduce the actual heat transfer area. 


\section{Z.0 References}

1) R.L. McKay, et. al., April 21, 1992, Test Plan for Slurry-Integrated Performance Testing (SIPT), Hanford Waste Vitrification Program, Test Plan No. HWVP-91-1.2.2.03.03B, Revision 1, Prepared by Pacific Northwest Laboratory.

2) Kern, D.Q., 1950, Process Heat Transfer, Mcgraw-Hill Book Company, New York.

3) Lienhard, J.H., 1981, A Heat Tránsfer Textbook, Prentice-Hall, Inc, New Jersey.

4) Holman, J.P., 1972, Heat Transfer, 3rd Edition, Mcgraw-Hill Book Company, New York.

5) Welty, J.R., Wicks, C.E., and Wilson, R.E., 1976, Fundamentals of Momentum, Heat, and Mass Transfer, 2nd Edition, John Wiley adn Sons, New York.

6) Richmond Machine and Fabrication, Inc., HWVP Feed Prep Test Vessel Drawing D-10183.

7) 1980, Metals Handbook, 9th Edition, Volume 3, American Society for Metals, Metals Park, Ohio.

8) Wark, K, 1977, Thermodynamics, Mcgraw-Hill Book Company, New York. 


\section{CALC-SIPT-003, REV. 0 Page 1 of 10}

\section{Design Calculations}

CALC-SIPT-003, Rev. 0

For

Slurry-Integrated Performance Testing

$4 / 8 / 93$

HB-15 Tank Heat Loss (Experimental)

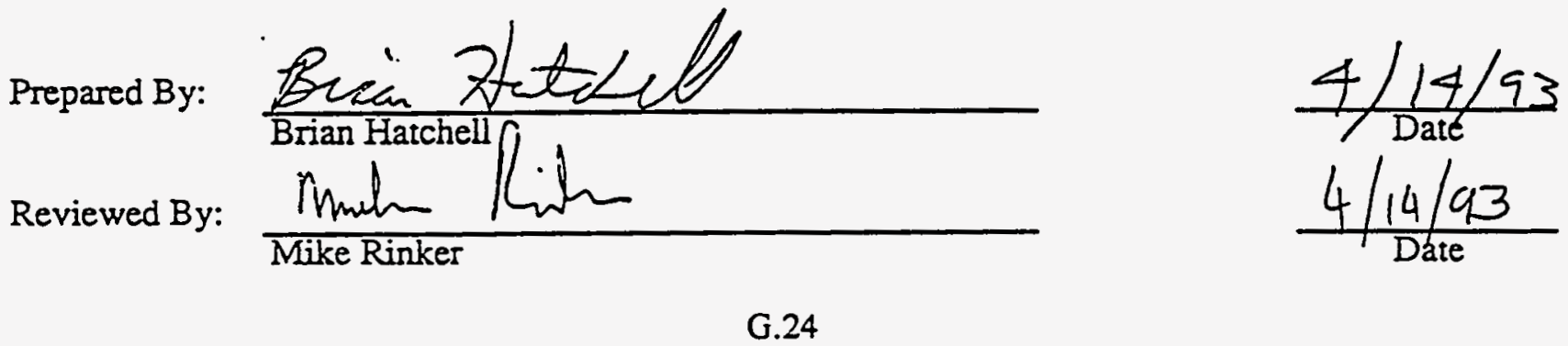




\subsection{Introduction}

A test was conducted to experimentally determine the heat loss from the HB-15 test vessel. At the conclusion of a boiling test with process water, the equipment (agitator, steam flow, condenser cooling water flow) was shut down as quickly as safety procedures would allow. A minimun vacuum was maintained in the tank by the blower ( -2 inches water). The tank was allowed to cool for an extended period of time to determine the heat loss from the tank to the environement. The temperature of the process and temperature of the high bay ambient was measured and recorded every 5 minutes.

Tank heat loss is important for two reasons: 1) tank heat loss increases the amount of plant steam required to heat and concentrate the process and 2) tank heat loss must be removed by the plant HVAC to maintain a constant plant temperature.

2.0Data

Vessel Dimensions

$\begin{array}{lc}\text { Inside Diameter } & 144.75 \text { in } \\ \text { Length (cylindrical) } & 145.75 \text { in } \\ \text { Thickness (cylindrical and bottom } & 0.38 \text { in } \\ \text { Thickness (top) } & 0.75 \text { in } \\ \text { Skirt length } & 66.00 \text { in } \\ \text { Skirt Thickness } & 0.75 \text { in }\end{array}$

For Water

$\begin{array}{lccc} & 125.00^{\circ} \mathrm{F} & 167.50^{\circ} \mathrm{F} & 210.00^{\circ} \mathrm{F} \\ \text { Cp, Btu/lb. } \mathrm{F} & 1.000^{\circ} & 1.000^{\circ} & 1.010^{\circ}\end{array}$

For A-36

$\begin{array}{cc}\mathrm{Cp}, \mathrm{Btw} / \mathrm{hb} \mathrm{o}^{\circ \mathrm{F}} & 0.112 \\ \mathrm{~K}, \mathrm{Btu} / \mathrm{hr} \mathrm{ft}{ }^{\circ} \mathrm{F} & 30.97 \\ \text { density, } \mathrm{lb} / \mathrm{ft} \mathrm{f}^{\wedge} \mathrm{O} & 0.29\end{array}$

$167.50^{\circ} \mathrm{F}$

0.115

30.49

0.29

Ref. 6

For Carpenter 20-Cb-3

$\mathrm{Cp}, \mathrm{Bta} / \mathrm{b} \mathrm{b}^{\circ} \mathrm{F}$

$125.00^{\circ} \mathrm{F}$

$\mathrm{K}$, Btu/hr ft ${ }^{\circ} \mathrm{F}$

0.109

6.72

density, $\mathrm{lb} / \mathrm{ft}^{\wedge} 3$

0.29

$167.50^{\circ} \mathrm{F}$

0.111

$210.00^{\circ} \mathrm{F}$

0.118

30.02

0.29

Ref. 5, pg 750

6.98

0.29

$210.00^{\circ} \mathrm{F}$

0.113

7.25

0.29

Ref.2, pg 799

Ref.2, pg 799

Ref.2, pg 799

$\pi=\quad 3.1416$ 


\subsection{Resuits}

The follow is a plot of the process and ambient temperatures versus time during the cool-down process. The process temperature is an average of the thermowell temperatures TI-1041 to TI-1046 (neglecting the transducers that were above water level). The ambient temperature was measured by TI-0100.

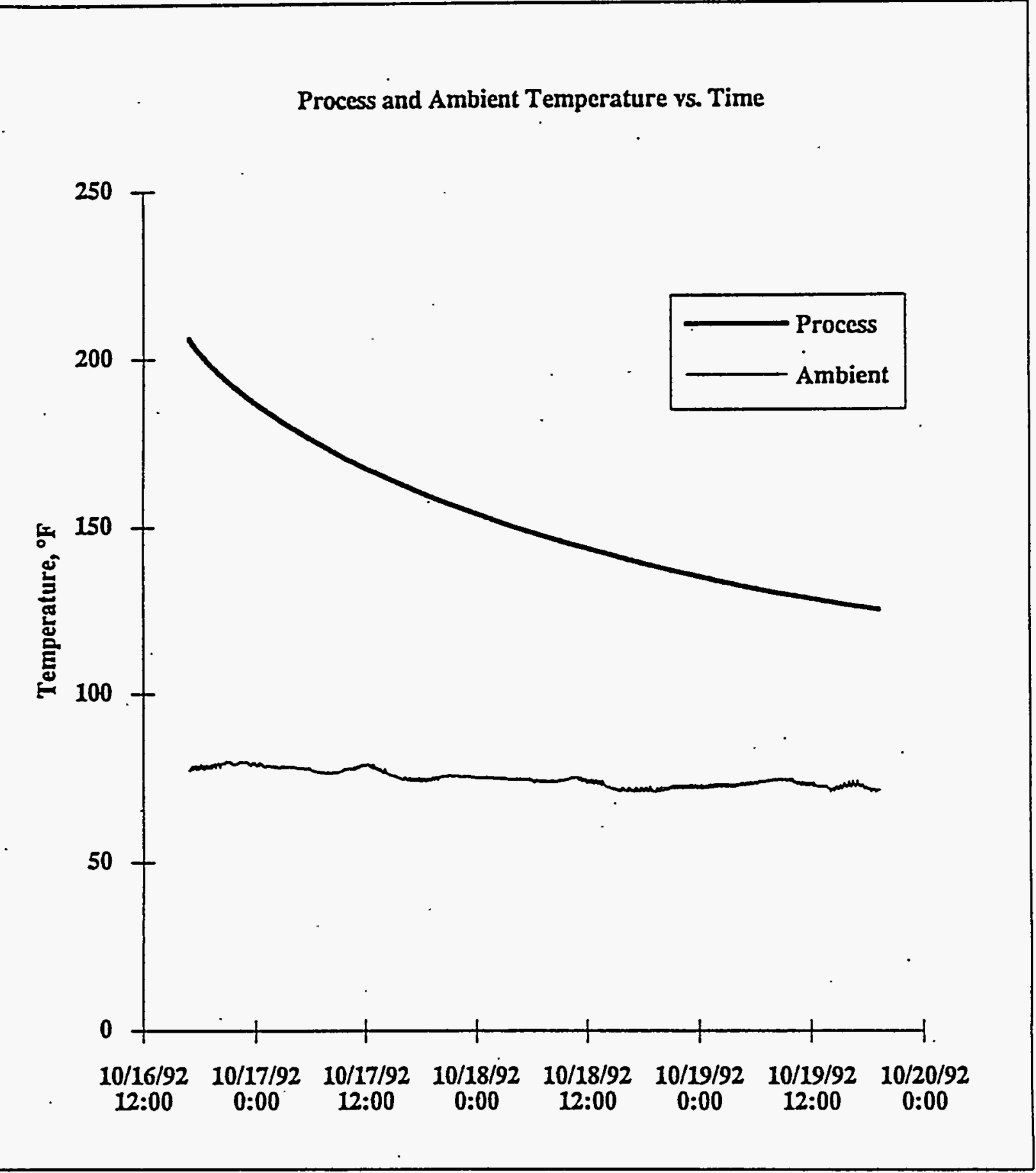




\subsection{Determining Heat Loss From Tcst Data}

Analysis Assumptions:

1) No heat is lost through off-gas (this assumption is verified later)

2) For any increment of time, the temperature drop of the entire vessel (water and tank)

is equal. The water in the tank is the most significant thermal mass in the system.

Even though the agitator was turned off, the water should be at a fairly uniform

temperature.

Overall Results:

Starting Process Temperature

Ending Process Temperature

Starting Time

Ending Time

Average Ambient Temperature

Mass of Process Water in Tank

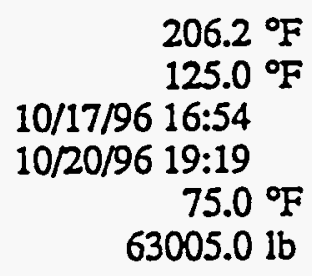

$206.2^{\circ} \mathrm{F}$

$16: 54$

$75.0^{\circ} \mathrm{F}$

$63005.0 \mathrm{ib}$

Determine Mass of Shell

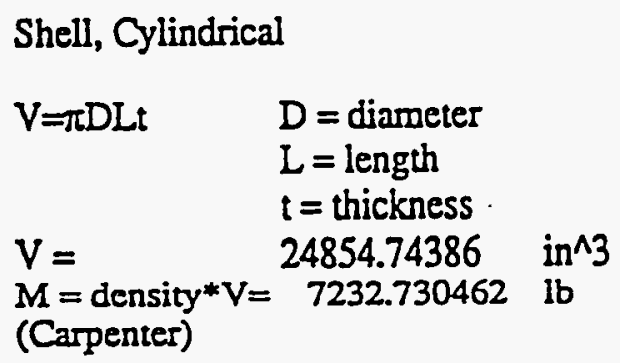

Shell Bottom

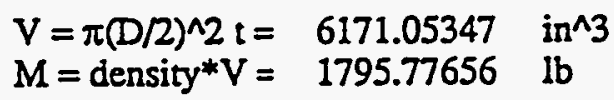

Shell Top: assume entire head is a 2:1 ratio elliptical head, ignore flanges
$\mathrm{V}=.95 * \mathrm{D}^{\wedge} 2 * \mathrm{t}=$
$\dot{M}=$ density $* V=4344.251927 \quad$ lb
Total weight of shell
$13372.75895 \quad \mathrm{lb}$
Skirt

$$
\begin{array}{lll}
V=\pi D L_{t}= & 22509.9567 & \text { in^3 } \\
M=\text { density *V } & 6415.33766 & \mathrm{lb}
\end{array}
$$

Using the assumptions stated above,
$Q=$
$(\mathrm{MCp}+$
$\mathrm{MCp}+$
Tank Shell
M Cp )
Tank Skirt
* $(\Delta \mathrm{T} / \Delta$ time $)$ 
Where: $\Delta T=$ temperature drop in incremental time

$$
\begin{aligned}
& \text {. } \Delta \mathrm{t}=\text { elapsed time }=\quad 5.00 \mathrm{~min} \quad 0.083 \mathrm{hr} \\
& Q=\quad(63005.00+3891.47+1828.37) \frac{\Delta T}{0.083 \mathrm{hr}} \\
& \mathrm{Q}(\text { in } \mathrm{Btu} / \mathrm{Hr})=\quad 824698.13 * \Delta \mathrm{T}^{\circ} \mathrm{F}
\end{aligned}
$$

This equation was used to solve for $Q$ during every time interval. The resulting $Q$ is plotted versus . process temperature.

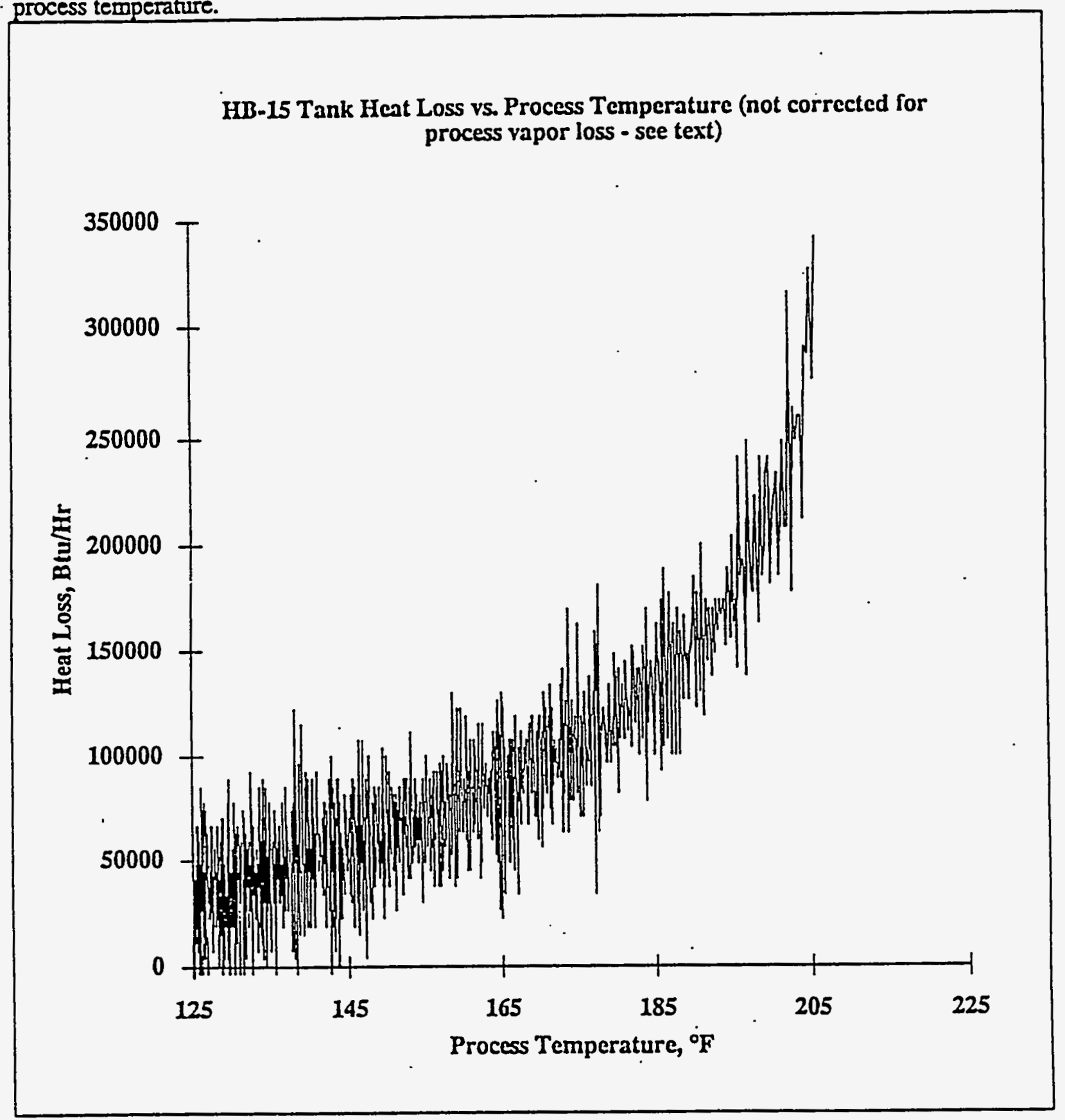


The heat loss versus process temperature plot has a fair amount of scatter. Linear interpolation is used to determine the heat loss at a process temperature of $206^{\circ} \mathrm{F}$, the maximum process temperature during the test. The data from $200^{\circ} \mathrm{F}$ to $206^{\circ} \mathrm{F}$ is shown below.

\begin{tabular}{|c|c|c|c|}
\hline Time & $\begin{array}{c}\text { Process Temp } \\
{ }^{\circ} \mathrm{F}\end{array}$ & $\begin{array}{c}\text { Heat Loss } \\
\mathrm{Btu} / \mathrm{Hr}\end{array}$ & \\
\hline 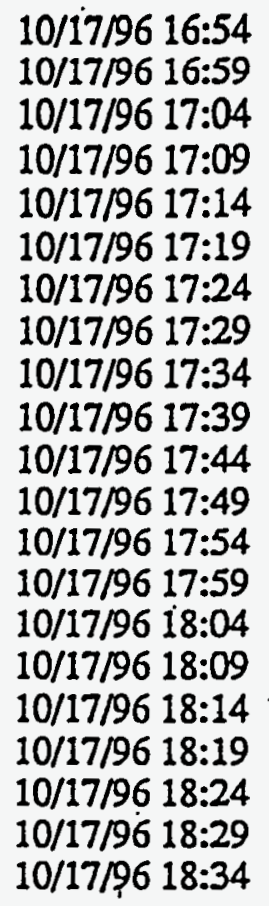 & $\begin{array}{l}206.24 \\
205.82 \\
205.49 \\
205.09 \\
204.75 \\
204.40 \\
204.14 \\
203.82 \\
203.51 \\
203.21 \\
202.89 \\
202.67 \\
202.29 \\
202.04 \\
201.79 \\
201.48 \\
201.23 \\
201.01 \\
200.72 \\
200.45 \\
200.19\end{array}$ & $\begin{array}{r}-341425.03 \\
274624.48 \\
326580.46 \\
285757.90 \\
289469.04 \\
211535.07 \\
259779.91 \\
259779.91 \\
248646.49 \\
263491.05 \\
178134.80 \\
315447.03 \\
207823.93 \\
207823.93 \\
248646.49 \\
207823.93 \\
185557.08 \\
233801.92 \\
222668.50 \\
215246.21\end{array}$ & Where Heat Loss $=M *$ Process Temp $+b$ \\
\hline$r^{\circ}$ & & & \\
\hline Heat Loss at 206 & & 306366.42 & $\mathrm{Btu} / \mathrm{Hr}$ \\
\hline
\end{tabular}

This is a very high heat loss, and apparently a large amount of heat is lost through the vaporization of water, even at $206^{\circ} \mathrm{F}$. During the test, the condenser cooling water flow was $350 \mathrm{gpm}$, so any process vapors that were swept up into the condenser should appear as condensate. The following is a plot of the condensate flow versus average process temperature. 


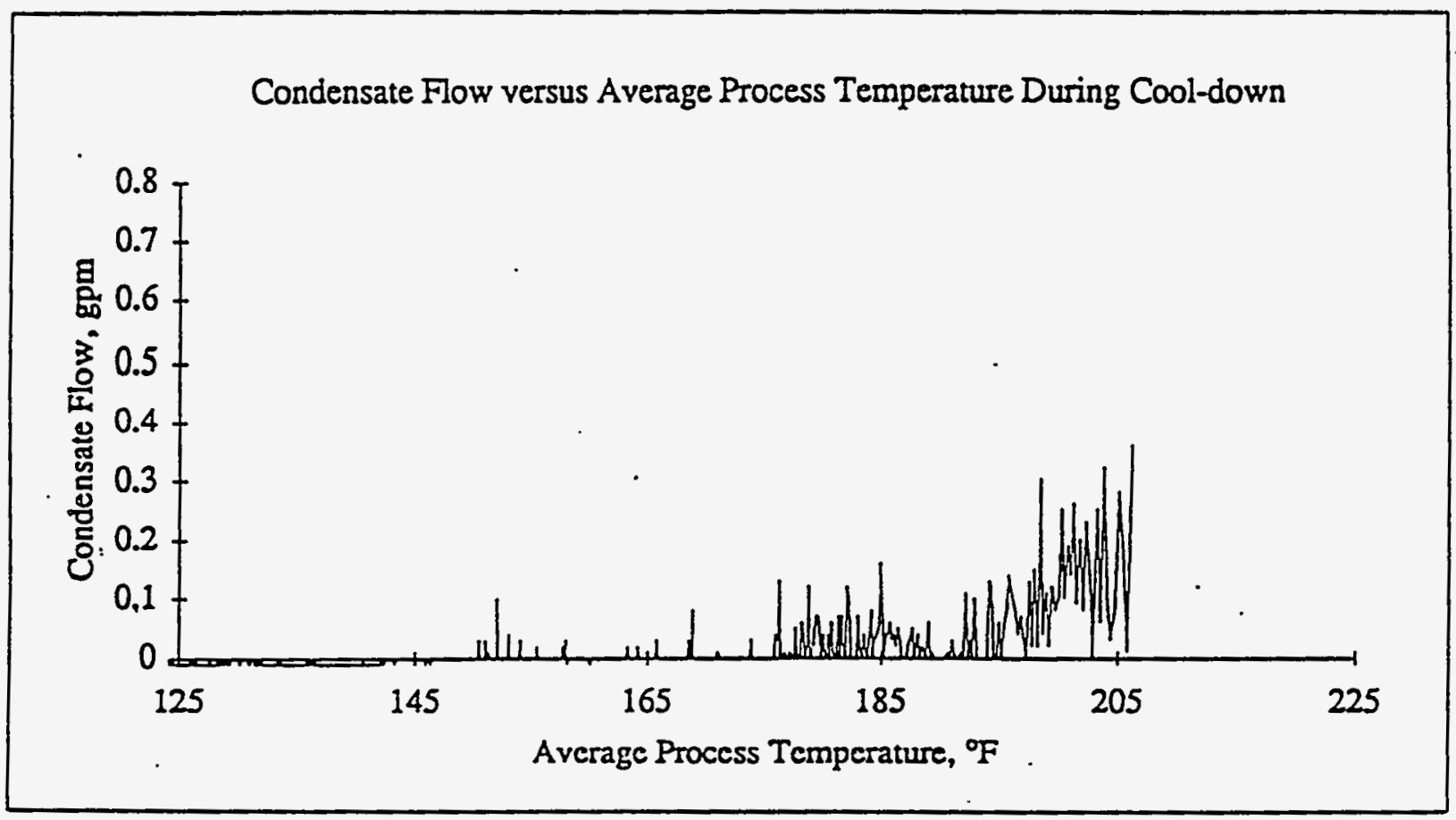

Obviously, a significant amount of heat loss is due to evaporation. I will correct the heat loss for this loss in overheat vapors by determining the amount of heat lost due to evaporation.

Data has some scatter. I will averge four data points.

\begin{tabular}{ccccc} 
Time & $\begin{array}{c}\text { Process Temp } \\
{ }^{\circ} \mathrm{F}\end{array}$ & $\begin{array}{c}\text { Condendate } \\
\text { Flow, gpm }\end{array}$ & $\begin{array}{c}\text { Condensate } \\
\text { Temp, }{ }^{\circ} \mathrm{C}\end{array}$ & $\begin{array}{c}\text { Condensate } \\
\text { Temp, }{ }^{\circ} \mathrm{F}\end{array}$ \\
\hline $10 / 17 / 9616: 54$ & 206.24 & 0.36 & 44.53 & 112.15 \\
$10 / 17 / 9616: 59$ & 205.82 & 0.01 & 45.32 & 113.58 \\
$10 / 17 / 9617: 04$ & 205.49 & 0.17 & 46.92 & 116.46 \\
$10 / 17 / 9617: 09$ & 205.09 & 0.28 & 48.58 & 119.44 \\
\cline { 3 - 5 } & & 0.205 & 46.338 & 115.408 \\
& & &
\end{tabular}

Specific volume of water at condensate temp= Density of water at condensate temp=

Mass flow of condensate, mdot=

Heat of Vaporization (Hfg) at $206^{\circ} \mathrm{F}=$

Total heat due to evaporating vapors $=\operatorname{mdot} * \mathrm{Hfg}=$

The heat of evaporation is subtracted from the total measured heat loss calculated above:

Heat loss from tank at $206^{\circ} \mathrm{F}$ due to radiation and convection

Qloss =

$207433.93 \mathrm{Btw} / \mathrm{hr}$

(at $206^{\circ} \mathrm{F}$ ) 
Linear Interpolation is also used to determine the heat loss at $167^{\circ} \mathrm{F}$ by fitting a line to the data above and below $167^{\circ} \mathrm{F}$.

\begin{tabular}{|c|c|c|c|c|}
\hline Time & $\begin{array}{c}\text { Process Temp } \\
{ }^{\circ} \mathrm{F}\end{array}$ & $\begin{array}{c}\text { Heat Loss } \\
\text { Btu/Hr }\end{array}$ & & \\
\hline 33894.49 & 168.03 & 103911.96 & & \\
\hline 33894.49 & 167.93 & 81645.11 & & \\
\hline 33894.49 & 167.83 & 85356.26 & & \\
\hline 33894.50 & 167.69 & 111334.25 & & \\
\hline 33894.50 & 167.61 & 66800.55 & & \\
\hline 33894.50 & 167.50 & 89067.40 & Linear Curve Fit: & \\
\hline 33894.51 & 167.38 & 103911.96 & & \\
\hline 33894.51 & 167.28 & 77933.97 & $\mathrm{~m},(\mathrm{Btu} / \mathrm{Hr}) /{ }^{\circ} \mathrm{F}$ & b, Btu/Hir \\
\hline 33894.51 & 167.18 & 81645.11 & 7345.04 & -1144242.81 \\
\hline 33894.52 & 167.14 & 33400.27 & & \\
\hline 33894.52 & 167.04 & 85356.26 & & \\
\hline 33894.52 & 166.90 & 118756.53 & & \\
\hline 33894.53 & 166.79 & 89067.40 & & \\
\hline 33894.53 & 166.71 & 66800.55 & & \\
\hline 33894.53 & 166.65 & 44533.70 & & \\
\hline 33894.54 & 166.52 & 107623.11 & & \\
\hline 33894.54 & 166.45 & 59378.27 & & \\
\hline 33894.55 & 166.37 & 70511.69 & & \\
\hline 33894.55 & 166.24 & 100200.82 & & \\
\hline 33894.55 & 166.11 & 107623.11 & & \\
\hline 33894.56 & 166.06 & 48244.84 & & \\
\hline \multicolumn{2}{|c|}{ Heat Loss at $167^{\circ} \mathrm{F}$} & 82379.20 & $\mathrm{Btu} / \mathrm{Hr}$ & \\
\hline
\end{tabular}

The condensate flow at this temperature is neglible, so no correction is made for process evaporation. 
Linear Interpolation is also used to determine the heat loss at $125^{\circ} \mathrm{F}$ by fitting a line to the data above and below $125^{\circ} \mathrm{F}$.

\begin{tabular}{|c|c|c|c|}
\hline Time & $\begin{array}{c}\text { Process Temp } \\
{ }^{\circ} \mathrm{F}\end{array}$ & $\begin{array}{c}\text { Heat Loss } \\
\mathrm{Bu} / \mathrm{Hr}\end{array}$ & \\
\hline $10 / 20 / 9618: 29$ & 125.35 & 48244.84 & 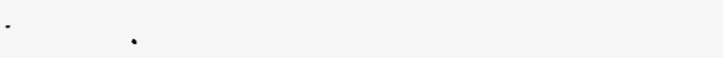 \\
\hline $10 / 20 / 9618: 34$ & 125.33 & 18555.71 & \\
\hline $10 / 20 / 9618: 39$ & 125.29 & 29689.13 & \\
\hline $10 / 20 / 9618: 44$ & 125.28 & 11133.42 & \\
\hline 10/20/96 18:49 & 125.23 & 40822.56 & \\
\hline 10/20/96 18:54 & 125.19 & 37111.42 & Linear Curve Fit: \\
\hline 10/20/96 18:59 & 125.16 & 18555.71 & \\
\hline 10/20/96 19:04 & 125.11 & 48244.84 & $\mathrm{~m},(\mathrm{Bru} / \mathrm{Hr}) /{ }^{\circ} \mathrm{F} \quad \mathrm{b}, \mathrm{Btu} / \mathrm{Hr}$ \\
\hline $10 / 20 / 9619: 09$ & 125.07 & 29689.13 & $1711.12 \quad-181505.88$ \\
\hline $10 / 20 / 9619: 14$ & 125.02 & 44533.70 & \\
\hline $10 / 20 / 9619: 19$ & 124.97 & 40822.56 & Where Heat Loss $=M *$ Process Temp $+b$ \\
\hline $10 / 20 / 9619: 24$ & 124.91 & 44533.70 & \\
\hline 10/20/96 19:29 & 124.88 & 22266.85 & \\
\hline $10 / 20 / 9619: 34$ & 124.84 & 37111.42 & \\
\hline $10 / 20 / 9619: 39$ & 124.80 & 33400.27 & \\
\hline $10 / 20 / 9619: 44$ & 124.76 & 33400.27 & \\
\hline $10 / 20 / 9619: 49$ & 124.73 & 22266.85 & \\
\hline $10 / 20 / 9619: 54$ & 124.69 & 33400.27 & \\
\hline $10 / 20 / 9619: 59$ & 124.64 & 44533.70 & \\
\hline 10/20/96 20:04 & 124.62 & 11133.42 & \\
\hline $10 / 20 / 9620: 09$ & 124.59 & 29689.13 & \\
\hline
\end{tabular}

Heat Loss at $125^{\circ} \mathrm{F}$ : $\quad 32384.32 \quad \mathrm{Btu} / \mathrm{Hr}$

The condensate flow at this temperature is neglible, so no correction is made for process evaporation.

Summary:

\begin{tabular}{|c|c|}
\hline $\begin{array}{c}\text { Process Temp } \\
\text { of }\end{array}$ & $\begin{array}{c}\text { Heat Loss } \\
\mathrm{Bru} / \mathrm{Hr}\end{array}$ \\
\hline 206.00 & 207433.93 \\
167.00 & 82379.20 \\
125.00 & 32384.32 \\
\hline
\end{tabular}

The heat loss at boiling should be very close to the heat loss at $206^{\circ} \mathrm{F}$. 


\section{References:}

1) RL. McKay, et. al., April 21, 1992, Test Plan for Slurry-Integrated Performance Testing (SIPT), Hanford Waste Vitrification Program, Test Plan No. HWVP-91-1.2.2.03.03B, Revision 1, Prepared by Pacific Northwest Laboratory.

2) Kern, D.Q., 1950, Process Heat T.ransfer, Mcgraw-Hill Book Company, New York.

3) Lienhard, J.H., 1981, A Heat Transfer Textbook, Prentice-Hall, Inc, New Jersey.

4) Holman, JP., 1972, Heat Transfer, 3rd Edition, Mcgraw-Hill Book Company, New York.

5) Welty, J.R., Wicks, C.E., and Wiison, R.E., 1976, Fundamentals of Momentum, Heat, and Mass Iransfer, 2nd Edition, John Wiley adn Sons, New York.

6) Richmond Machine and Fabrication, Inc., HWVP Feed Prep Test Vessel Drawing D-10183.

7) 1980, Metals Handbook, 9th Edition, Volume 3, American Society for Metals, Metals Park, Ohio.

8) Wark, 1977, Thermodynamics, 3rd Edition, Mcgraw-Hill Book Company, New York. 
Design Calculations

CALC-SIPT-007, Rev. 1

For

Slurry-Integrated Performance Testing

$8 / 18 / 93$

Agitator Heat Input

Prepared By: Monica Beckete

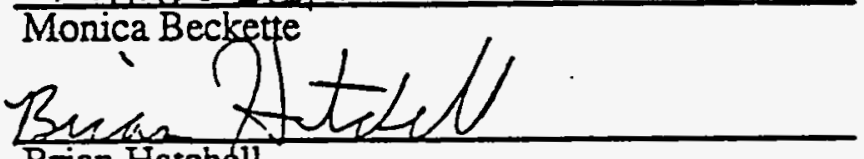

$\frac{9 / 4 / 93}{\text { Date }}$ Brian Harchell

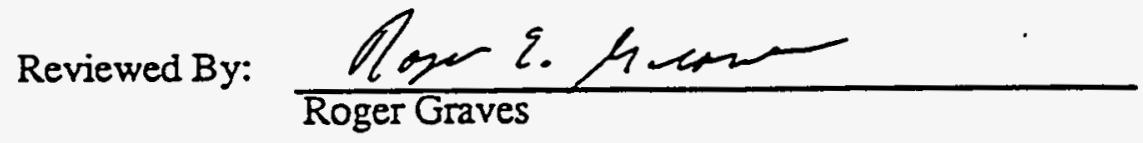

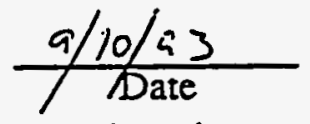

$\frac{9 / 29 / 30}{\text { Date }}$

\section{G.34}


PURPOSE In addition to mixing the contents of the test vessel (HB-15), the agitator will also transmit frictional heating to the process liquid. The purpose of this calculation is to correlate the motor shaft output power with the latent heat increase of the process liquid. Three different agitator speeds $(45,85$, and $130 \mathrm{rpm})$ were investigated.

PROCEDURE The agitator heating tests were conducted on two days: 4/8/92 (45 and $85 \mathrm{rpm}$ ) and $4 / 19 / 92(130 \mathrm{rpm})$. The tank was filled with approximately $45000 \mathrm{lbs}$ (5400 gallons) of water. After the temperature in the tank reached steady state, the agitator was operated at a constant speed for several hours. The temperature rise of the process water was then used to determine agitator heat input.

TEMPERATURE PLOTS

ENERGY BALANCE
Plots of the thermowell temperatures (TI1041-T11046) versus time are shown in Figures 1 ( 45 and $85 \mathrm{mpm})$ and $2(130 \mathrm{pm})$. Referring to these figures, it is apparent that TI1041-TI1043 were above the water level, and that TI1044 was erratic. TH1045 and T11046 were averaged to determine the temperature rise in the tank.

All data is taken from TST001.XIS (day 1) and TST002.XIS (day 2)

See SIPT Test Log.

If heat loss from the tank is neglected (this is a good assumption, since the temperature difference between the tank and ambient is small), the heat input to the process can be found by:

$$
\mathrm{Q}=\mathrm{m} C \mathrm{p} \Delta \mathrm{T} / \Delta \mathrm{t}
$$

Where:

$$
\begin{aligned}
& m=\text { Mass of water } \\
& C p=\text { Specific Heat of Water } \\
& \Delta T=\text { Temperature rise of water } \\
& \Delta t=\text { time interval }
\end{aligned}
$$

For water at ambient temperature, $\mathrm{Cp}=1 \mathrm{Btu} / \mathrm{bm}{ }^{\circ} \mathrm{F}$ per Ref $1, \mathrm{pg} 750$.

Figures 3 and 4 show the average of TI-1045 and TI-1046. A straight line was fit through the points using linear regression. The slopes of the fitted lines were found to be:

$$
\begin{array}{llll}
{ }^{\circ} \mathrm{F}=(5 / 9)^{\circ} \mathrm{C} & & & \\
45 \mathrm{ppm} & \Delta \mathrm{T} / \Delta \mathrm{t}= & 0.234^{\circ} \mathrm{C} / \text { day } & 0.0176^{\circ} \mathrm{F} / \mathrm{hr} \\
85 \mathrm{rpm} & \Delta \mathrm{T} / \Delta \mathrm{t}= & 6.840^{\circ} \mathrm{C} / \text { day } & 0.5130^{\circ} \mathrm{F} / \mathrm{hr} \\
130 \mathrm{ppm} & \Delta \mathrm{T} / \Delta \mathrm{t}= & 22.210^{\circ} \mathrm{C} / \text { day } & 1.6658^{\circ} \mathrm{F} / \mathrm{hr}
\end{array}
$$

WEIGHT The weight of the HB-15 tank was fairly constant throughout the tests (Figures 5 and 6) but did fluctuate due to thermal expansion of piping caused by changes in ambient temperatures. I'll use $45000 \mathrm{lb}$ as a representative weight for all tests.

$$
\text { G.35 }
$$




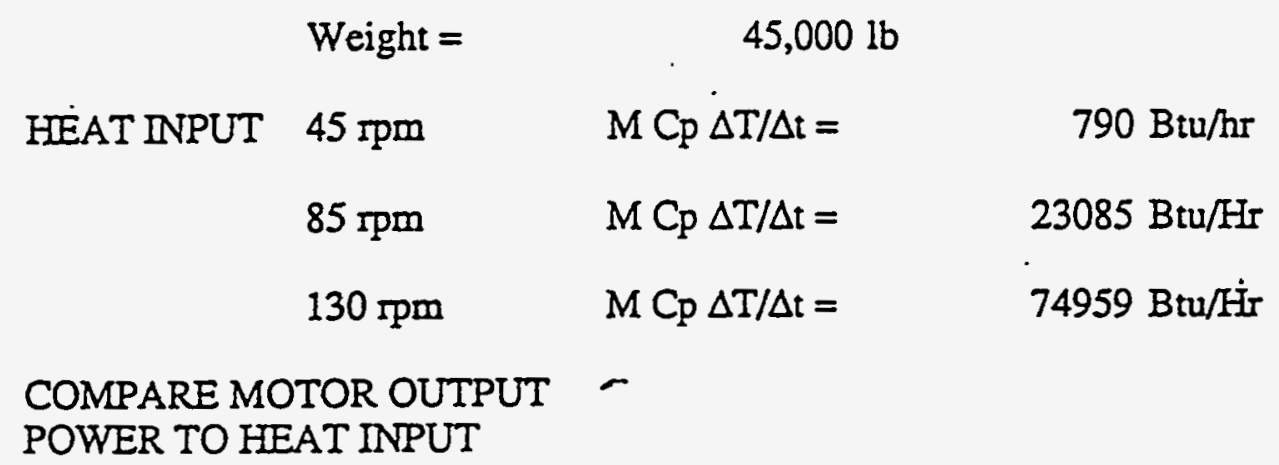

Power consumed by a three phase motor can be found by:

$P_{\text {Loeal }}=\sqrt{3} V_{L} I_{L} \times p f \quad$ Ref. 2, pg. $115 \quad$ Eq. (2)

Where:

$P_{\text {tow }}=$ Power into balanced three phase system

$\mathrm{V}_{\mathrm{L}}=$ Line Voltage

$I_{2}=$ Line Current

pf $=$ power factor

To find the output power of the motor, the power input is multiplied by the efficiency:

$P_{\text {out }}=P_{\text {tous }} \times \eta$

Ref. 2, pg 25

Eq. (3)

Where:

$$
\eta=\text { Efficiency }
$$

The Reliance data sheet for the $100 \mathrm{hp}$ agitator motor is attached (see page 15). The motor start/operating frequency of 6-60 HZ comesponds to a motor shaft speed of 178.5-1785 Ipm and an agitator shaft speed of $14-140 \mathrm{~mm}$. The performance table was used to relate the measured current to the horsepower. Note that motor performance data is only available at $1785 \mathrm{spm}$; at lower speeds, the frictional losses will be less.

To use this data, a polynomial curve was fit through the current versus horsepower points using Slidewrite to create an equation that related horsepower as a function of current. This data fitting procedure resulted in the following equation:

$\mathrm{HP}=-81.497845+3.336728 * \mathrm{I}-0.023814 * I^{\wedge} 2+0.000075 * I^{\wedge} 3$

Once the horsepower was calculated, power out from the motor was found by converting horspower to $\mathrm{Btu} / \mathrm{hr}$ as follows:

$1 \mathrm{HP}=(42.4 \mathrm{Btu} / \mathrm{min}) *(60 \mathrm{~min} / \mathrm{hr})=2544 \mathrm{Btu} / \mathrm{hr}$ 
The motor operates at a constant voltage of 460 Volts. Different speeds are achieved by varying the voltage frequency. The current to the agitator is recorded in DAS data II-1000. The agitator speed (SI1000 ) and current draw is plotted in Figures 7 and 8. The average current during the test segments was used to calculate the horsepower using Equation 4 . The following table compares the power out of the motor calculated using Equation 4 with the heating rate calculated from the temperature rise of the process.

\begin{tabular}{|c|c|c|c|c|}
\hline Equation 4 & $\begin{array}{l}\text { Agitator Shaft Speed, rpm } \\
\text { Motor Shaft Speed, rpm } \\
\text { I, amps } \\
\text { V, volts } \\
\text { Power out of motor, HP } \\
\text { Power out of motor, Btu/hr } \\
\text { Power into process, Btu/Hr }\end{array}$ & $\begin{array}{c}45.00 \\
573.75 \\
24.50 \\
460.00 \\
0.00 \\
0 \\
790\end{array}$ & $\begin{array}{c}85.00 \\
1083.75 \\
33.79 \\
460.00 \\
6.95 \\
17690 \\
23085\end{array}$ & $\begin{array}{c}130.00 \\
1657.50 \\
55.80 \\
460.00 \\
43.57 \\
110852 \\
74959\end{array}$ \\
\hline
\end{tabular}

\section{RESULTS}

The horspower for the $45 \mathrm{rpm}$ case was set to zero, since the calculated horspower was negative. This is indicative of the fact that the motor shaft speed is much less than $1785 \mathrm{rpm}$ (the motor speed used to establish the performance curves). Frictional losses are lower at $45 \mathrm{mpm}$, so shaft output would be higher. The method is therefore not accurate at $45 \mathrm{rpm}$. For the $85 \mathrm{rpm}$ case, the equation again underpredicts the motor power out, since the motor speed is again less than $1785 \mathrm{rpm}$. This may explain the fact that the power out of the agitator motor, based on Equation 4, is somewhat lower than the power into the process water, which was calculated from the temperature rise. For the $130 \mathrm{rpm}$ case, Equation 4 should be reasonably accurate; here, the power out of the motor is greater than the power into the process, which is probably due to other energy losses.

For energy balance calculations, Equation 4 will be used to determine the power out of the agitator motor regardless of agitator speed. If the calculated power is less than zero, it will be set to zero. This method is only accurate at higher speeds, but since the power draw at low speeds is small, from an energy balance standpoint, this is acceptable.

REFERENCES 1) Welty, Wicks, and Wilson, Fundamentals of Momentum, Heat, and Mass Transfer, John Wiley and Sons, 1976.

2) Mcpherson, G., An Introduction to Electrical Machines and Transformers, John Wiley and Sons, 1981. 


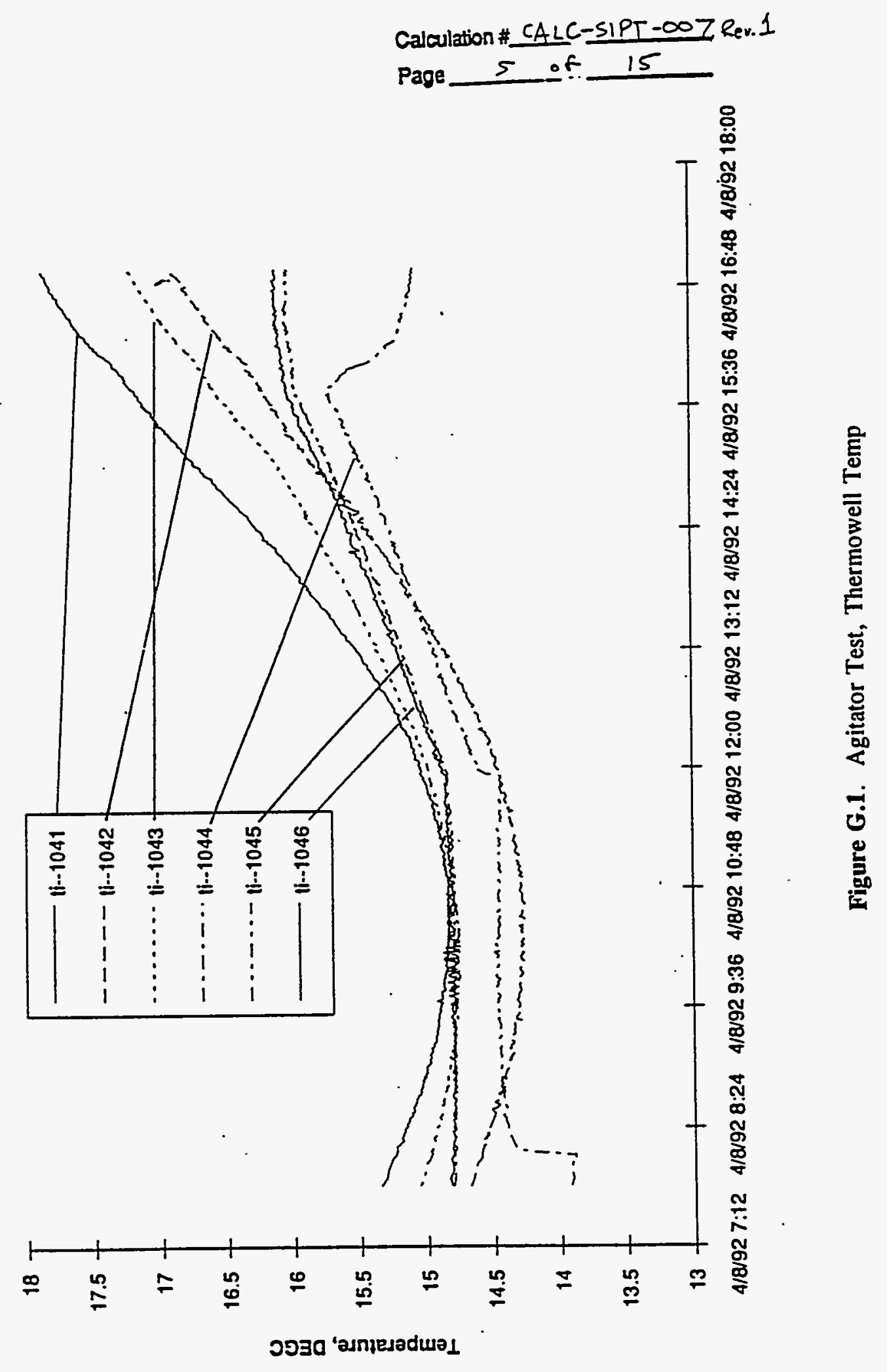




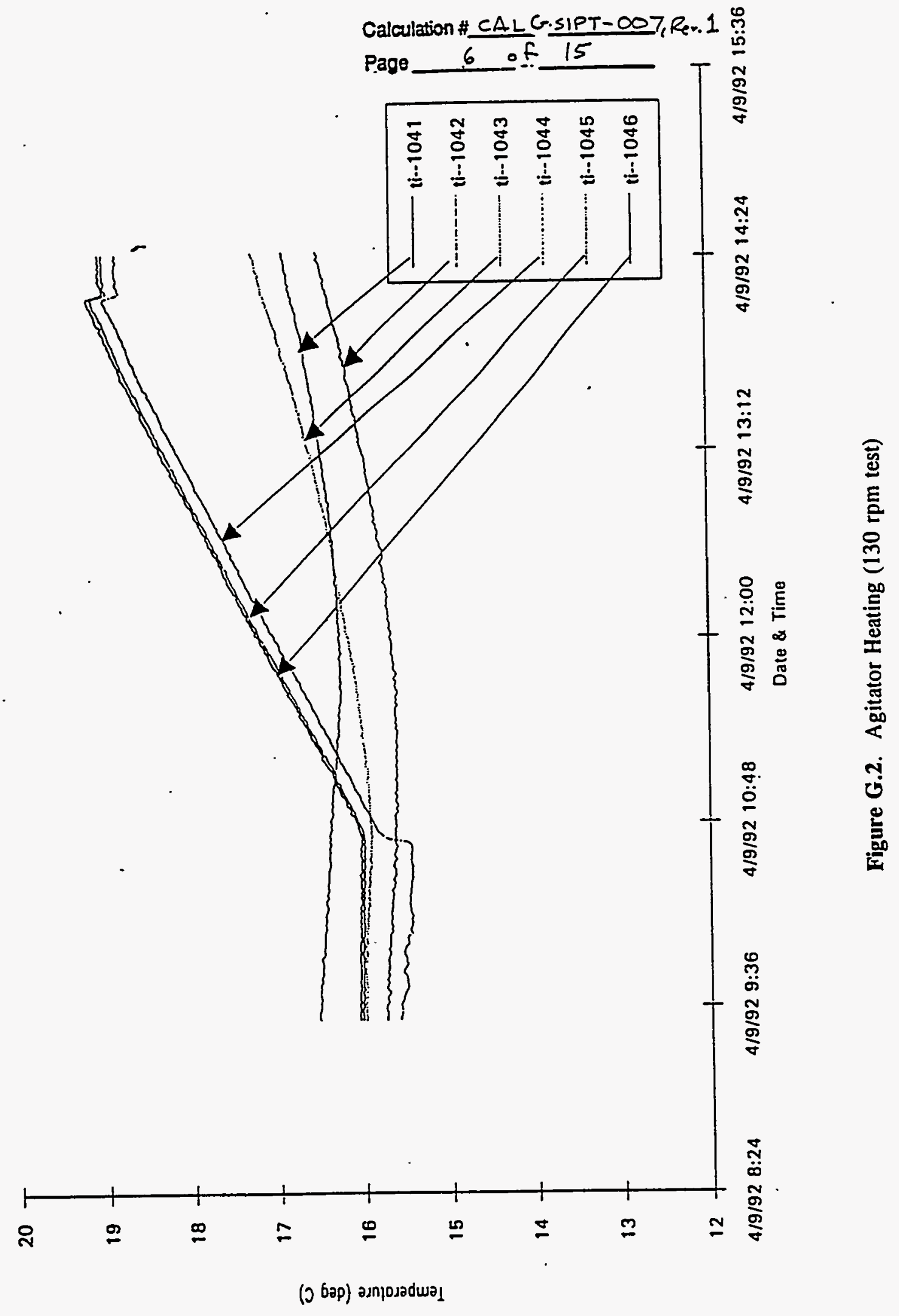




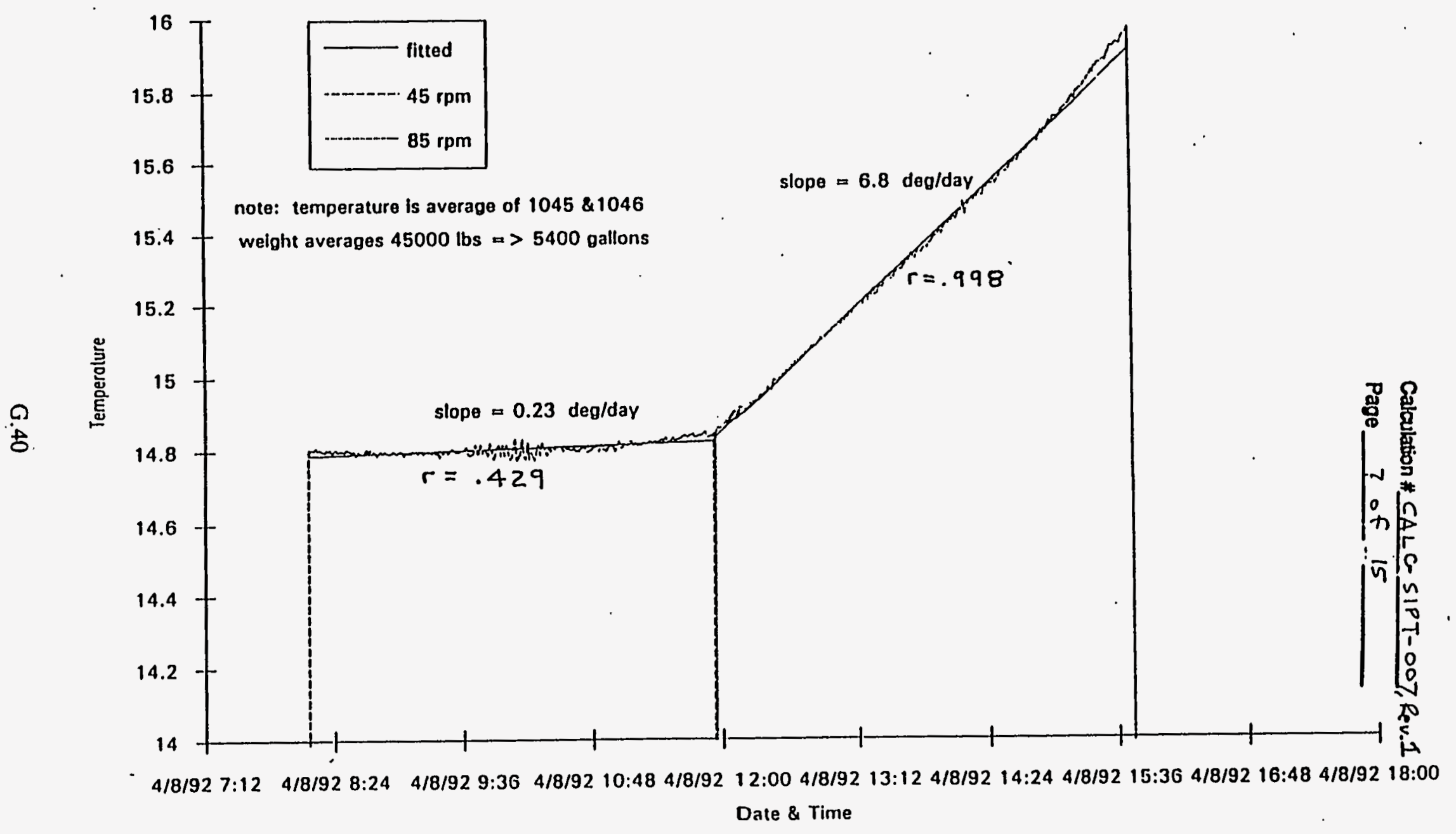

Figure G.3. Agitator Heating - Fitted Curves 


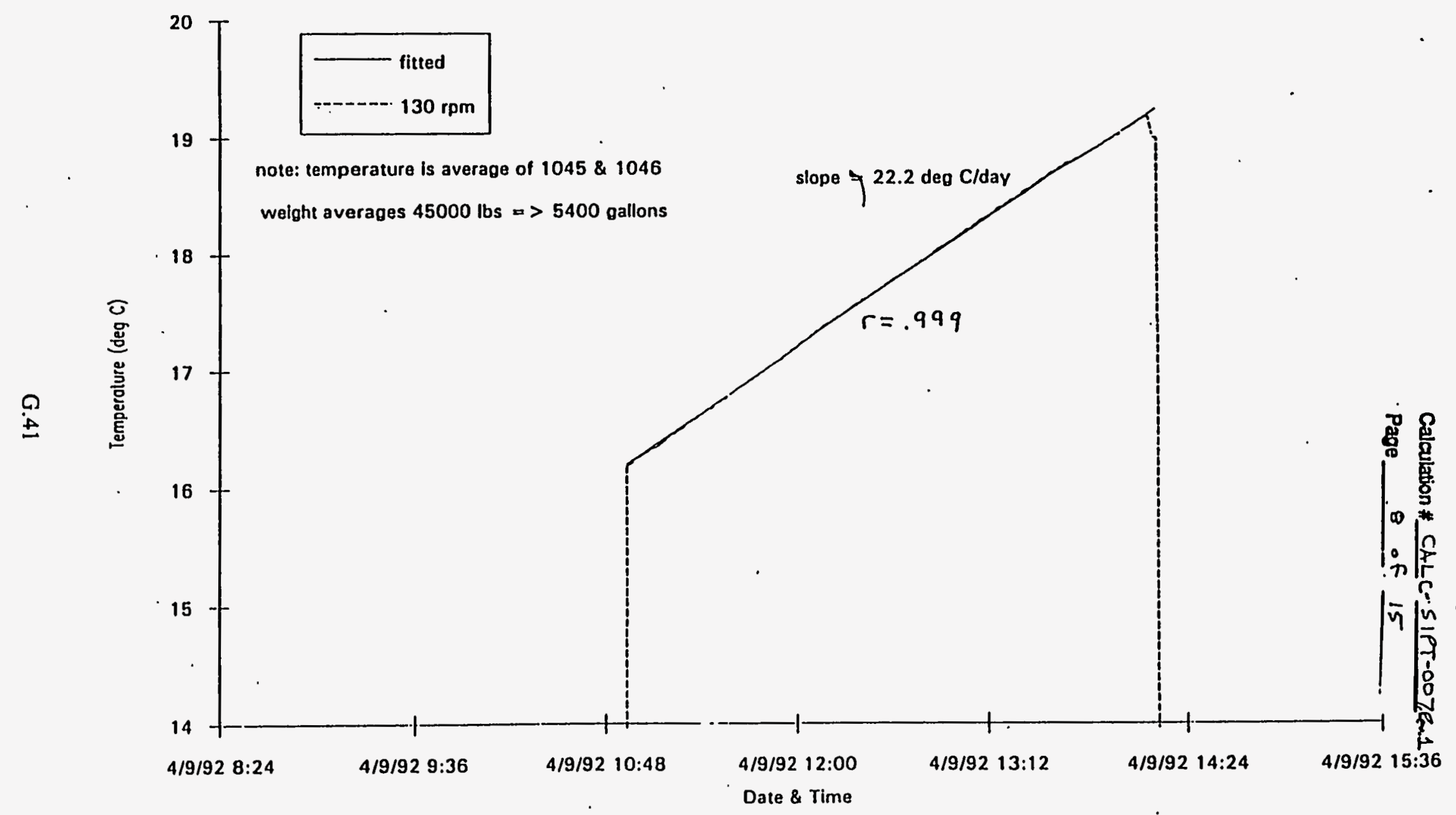

Figure G.4. Agitator Heating - Fitted Curve 


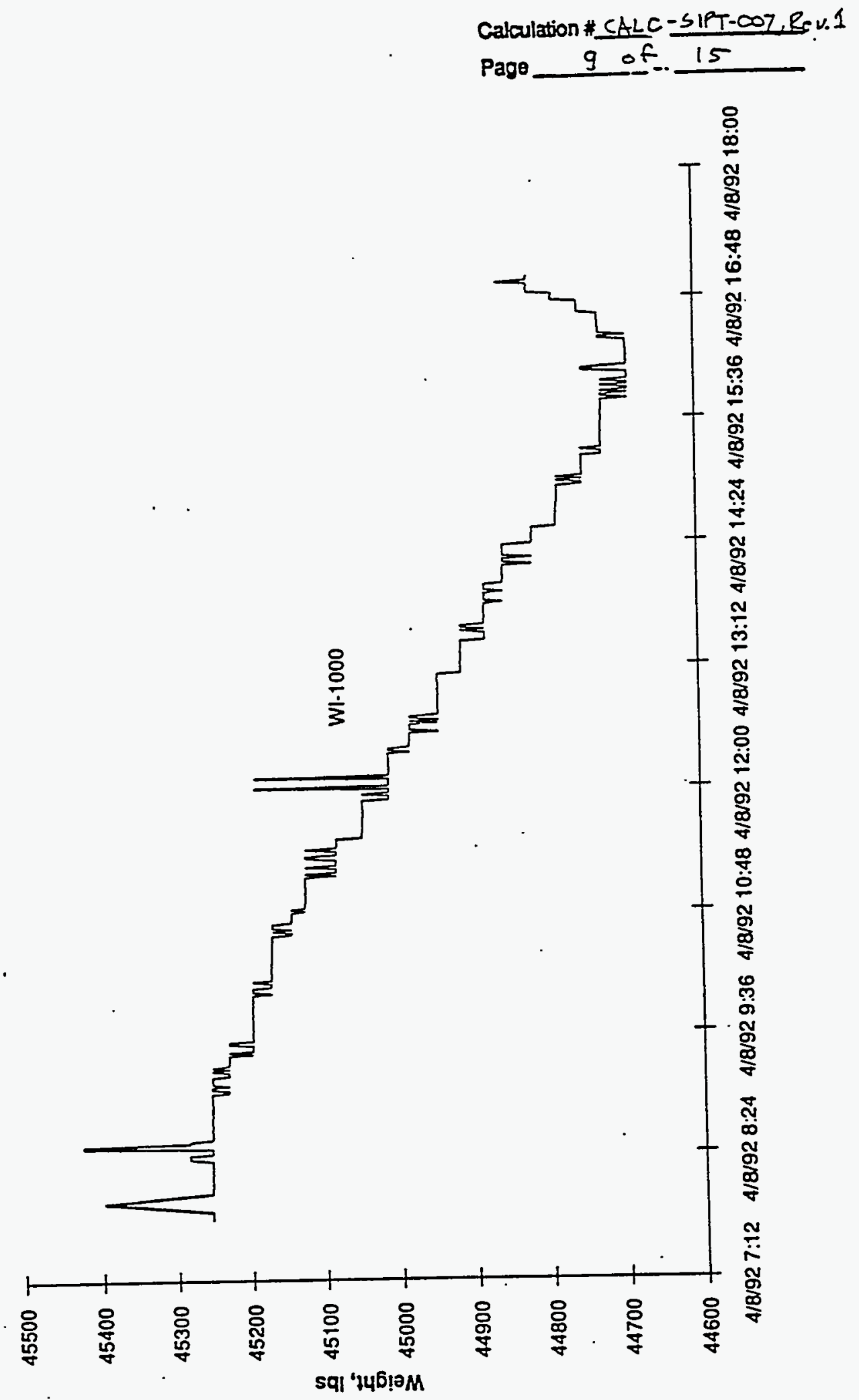

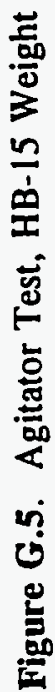

G.42 


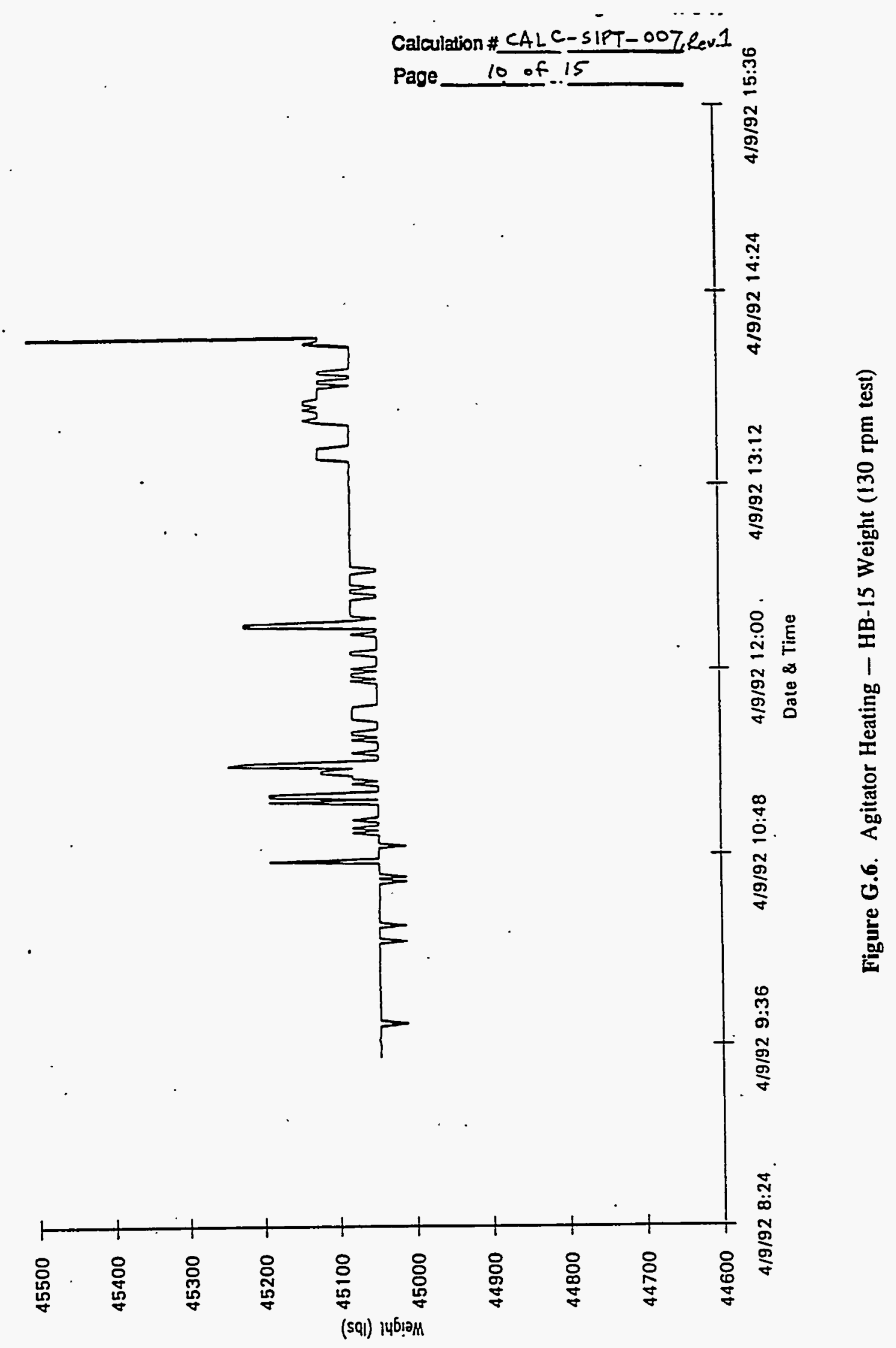

G.43 


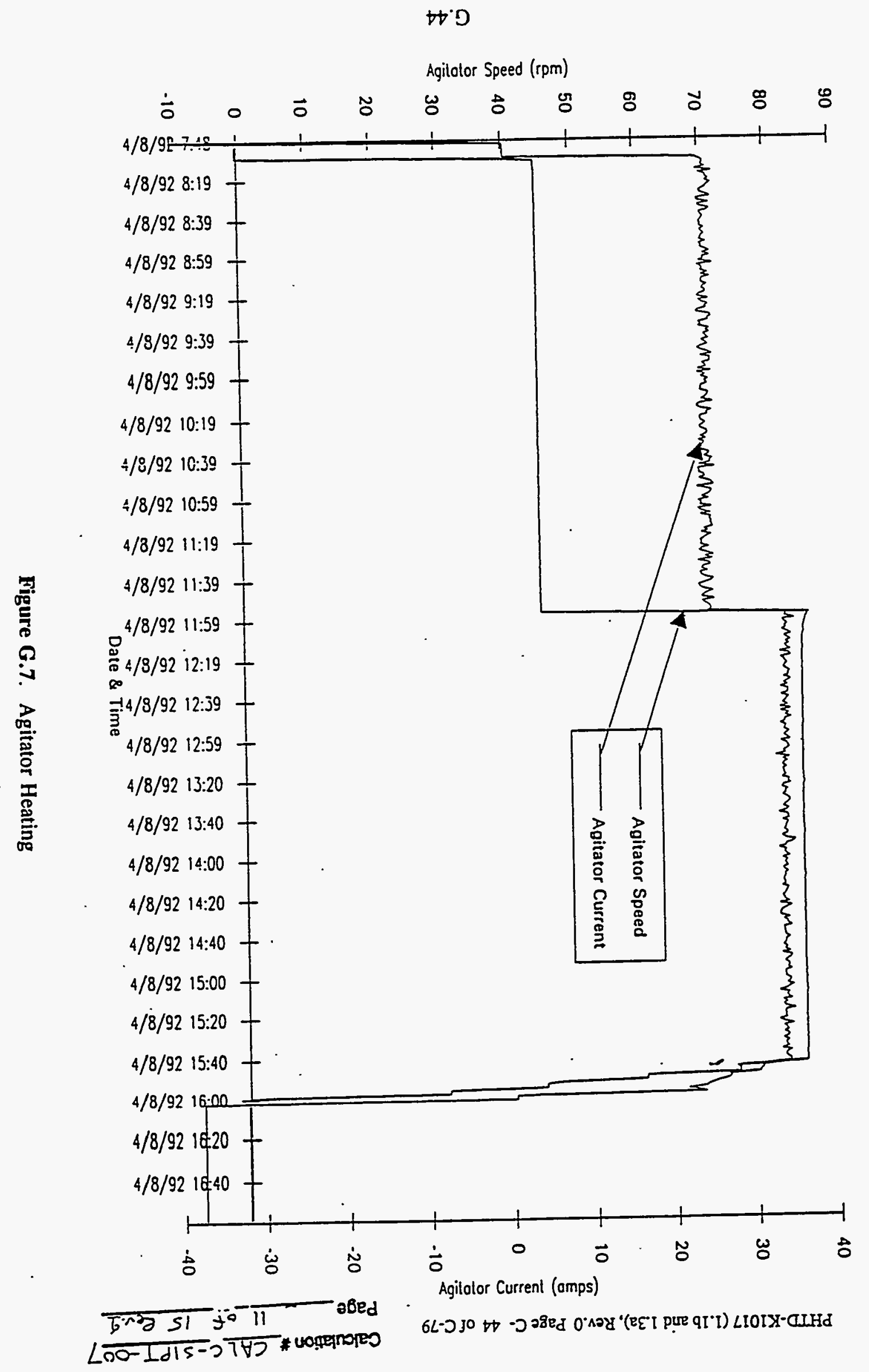




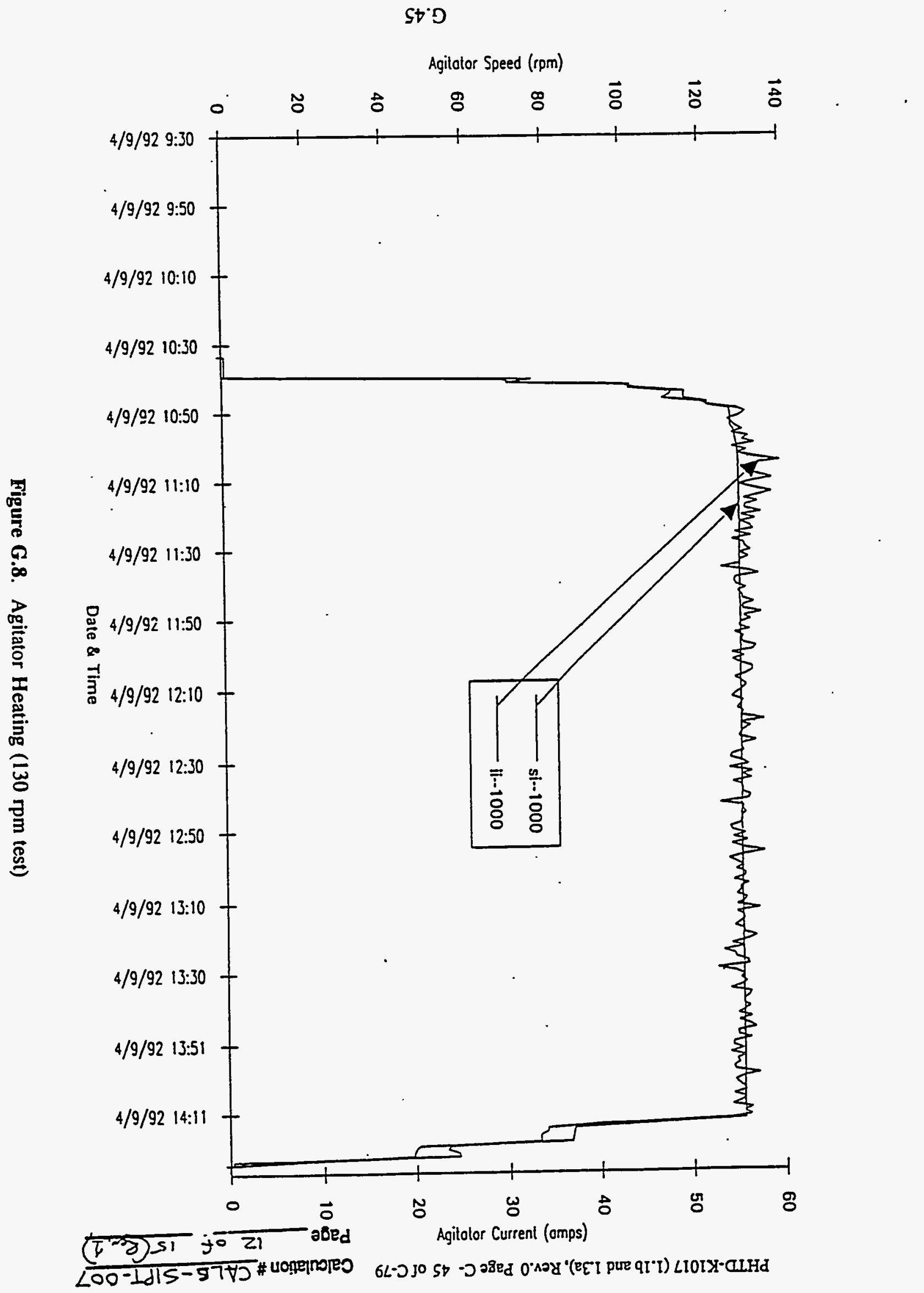




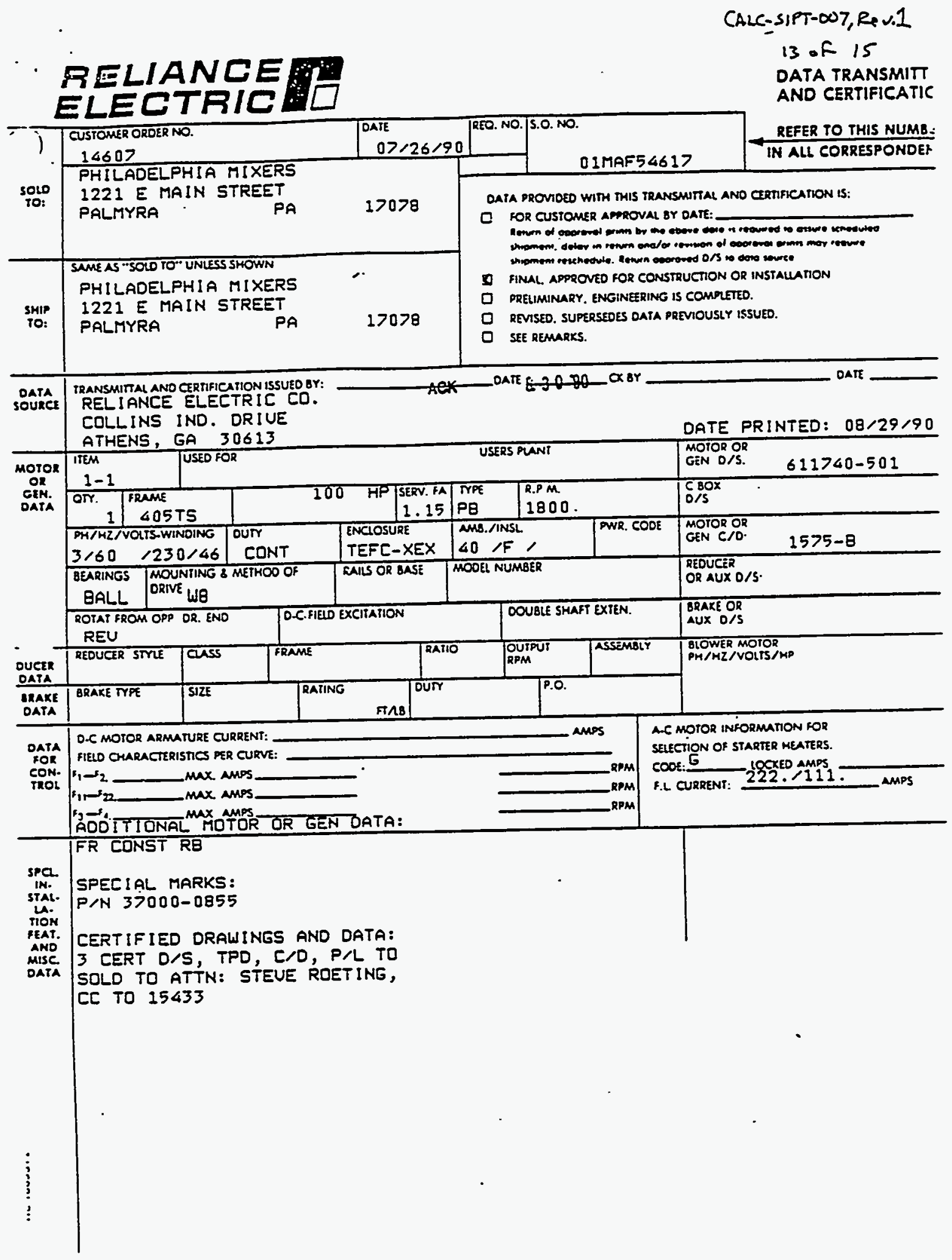


CALC-SIPT-OOT,ReV. $1 \quad 14$ of is

\begin{tabular}{|c|c|c|c|c|c|c|}
\hline $\begin{array}{l}\text { i REL. } \\
\text { S.O. }\end{array}$ & FRAME & HP & TYPE & $\begin{array}{l}\text { PHASEI } \\
\text { HERTZ }\end{array}$ & RPM & VOLTS \\
\hline IMAF54617 & 405TS & 100 & $P$ & $3 / 60$ & 1785 & $230 / 460$ \\
\hline AMPS & DUTY & $\begin{array}{l}\text { AMBOC/ } \\
\text { INSUL. }\end{array}$ & S.F. & $\begin{array}{c}\text { NEMA } \\
\text { OESIGH }\end{array}$ & $\begin{array}{l}\text { CODE } \\
\text { LETTER }\end{array}$ & ENCL. \\
\hline $222 / 111$ & CONT & $40 / F$ & 1.15 & B & G & TEFC-XEX \\
\hline E/S & \multicolumn{2}{|l|}{ ROTOR } & $\begin{array}{l}\text { TEST } \\
\text { s.o. }\end{array}$ & $\begin{array}{l}\text { TEST } \\
\text { OATE }\end{array}$ & \multicolumn{2}{|c|}{$\begin{array}{l}\text { STATOR RES. } 025^{\circ} \mathrm{C} \\
\text { OHMS (BETYEEN LINES }\end{array}$} \\
\hline 596830 & \multicolumn{2}{|c|}{ 418142-031-ME } & - & -- & \multicolumn{2}{|c|}{$.0123 / .0492$} \\
\hline \multicolumn{7}{|c|}{ A PERForMUACE } \\
\hline LOAD & HP & AMPERES & \multicolumn{2}{|c|}{ RPM } & POWER FACTOR & $\frac{x}{x}$ \\
\hline HO LOAD & 0 & 31.4 & \multicolumn{2}{|c|}{1800} & 5.04 & 0 \\
\hline $1 / 4$ & 25.0 & 41.5 & \multicolumn{2}{|c|}{1796} & 60.8 & 93.0 \\
\hline $2 / 4$ & 50.0 & 61.5 & \multicolumn{2}{|c|}{1792} & 79.9 & 95.3 \\
\hline $3 / 4$ & 74.9 & 85.3 & \multicolumn{2}{|c|}{1788} & 86.0 & 95.7 \\
\hline $4 / 4$ & 99.9 & 111 & \multicolumn{2}{|c|}{1783} & 88.1 & 95.4 \\
\hline $5 / 4$ & 125 & 140 & & & 88.3 & 94.9 \\
\hline & & SPEED & rOROUE & & & \\
\hline & & RPM & & & $\begin{array}{l}\text { TORQUE } \\
\text { LB.-FT. }\end{array}$ & AMPERES \\
\hline LOCXED ROTOR & & 0 & & & 438 & 715 \\
\hline I PULL UP & & 700 & & & 380 & 665 \\
\hline BREAKDOWH & & 1722 & & & 675 & 388 \\
\hline FULL LOAD & & 1783 & & & 294 & 111 \\
\hline
\end{tabular}

MMPERES SHOWH FOR 460. YOLT COMHECTION. IF OTHER VOLTAQE COHMECTIONS ARE AYAILABLE. THE AMPERES WILL YARY INYERSELY WITH THE AATED YOLTAGE

REMARXS، TYPICAL DATA

XE MOTOR- TYPICAL DATA - NEM NOM. EFF. 95.4 PCT. 1 GUARAKTEED MIN EFF. 95.0 PCT.

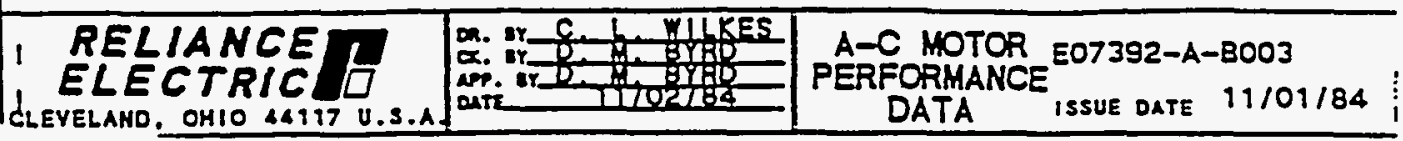


CALC-SIPT- -007, LVV. 1

15 of 15

\section{Typical 100 HP Motor Performance Curves}

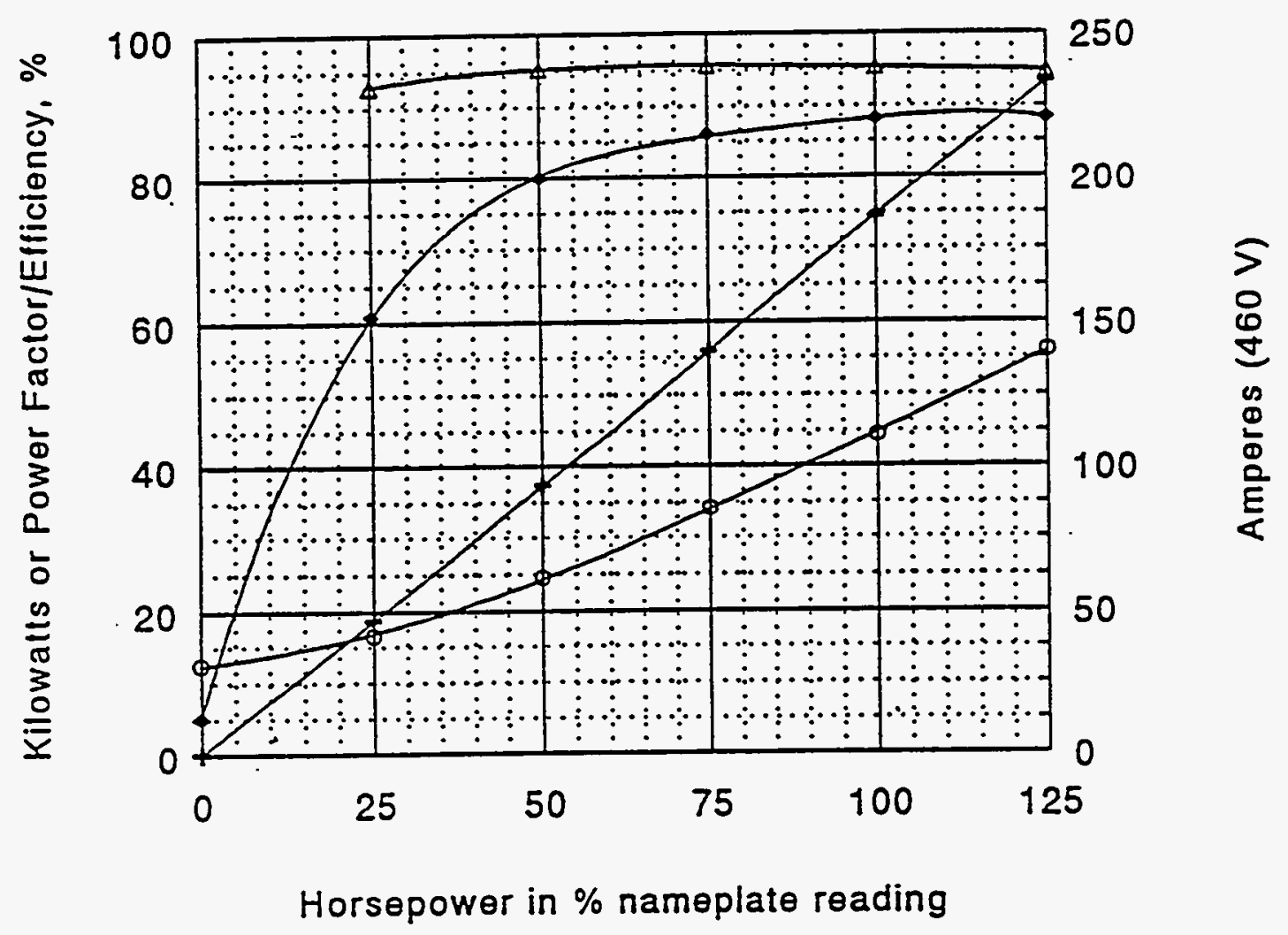

- \%PF $\triangle$ E Eff 0 Amps $+\mathrm{KW}$ 
Design Mode1

CALC-SIPT-011, Rev.0

For

Slurry-Integrated Performance Testing

July 12, 1993

HB-15 Tank Heat Loss (Analytical)
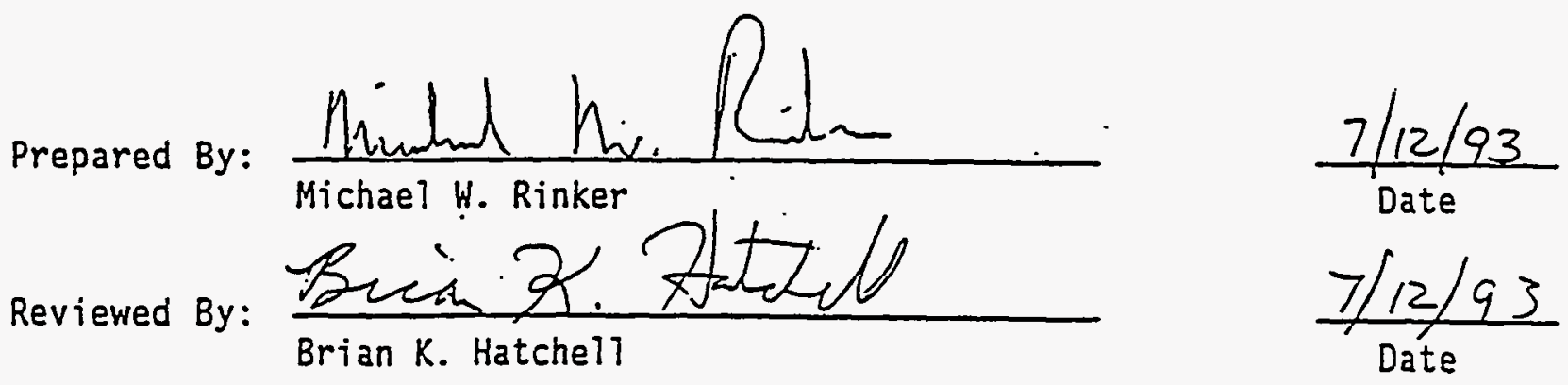

G.49 


\subsection{Introduction and Conclusions}

A computational thermal analysis was conducted to analytically determine both the heat loss from the HB-15 test vessel and the temperature distribution on the vessel. The results of the computer model were compared to calculations performed by Fluor Daniel (1), to experimental results by PNL $^{(2)}$, and to results of data reduction analysis.by PNL (3). Six cases of the thermal model were run using the ANSYS computer program ${ }^{(4)}$. The six cases were used to examine steady state heat loss in the tank and temperature distributions on the tank due to the combined effects of radiation, convection, and conduction. The differences in the cases were for changes in convection coefficient assumptions and for changes in fluid temperatures inside the tank.

The first three cases assumed a convection model based upon natural convection. The other three cases contained convection models based upon forced convection. The three temperature conditions analyzed for both the natural and forced convection cases were $50^{\circ} \mathrm{C}, 75^{\circ} \mathrm{C}$, and $100^{\circ} \mathrm{C}$. This corresponds to temperatures of the water inside the tank at particular times during the experiment.

Several conclusions have been drawn from this analysis:

1) The Fluor Daniel calculation for heat loss was low in comparison to the analytical natural convection model for two reasons. The first was because Fluor Daniel assumed that the tank bottom was insulated, and it is not. The second reason is because fluor Daniel assumed that the ambient temperature was 104 of while in fact the ambient temperature was $62 \circ \mathrm{F}$.

2) Results also show that the convective heat transfer coefficient is higher than can be calculated through the use of natural convection correlations.

3) For the lower tank temperatures of $50^{\circ} \mathrm{C}$ and $75^{\circ} \mathrm{C}$, the forced convection analytical model was able to reasonably predict the tank heat loss and temperature distribution.

4) At higher temperatures, the forced convection analytical model was not able to accurately predict tank heat loss, but the temperature prediction was reasonable. There are other mechanisms of heat loss in the tank that have not been accounted for in the model.

The remainder of this report provides detaits as to the description of the model, the modeling parameters that were used, results, discussions of results, and a list of references. An appendix is also included which contains the ANSYS input for one case of the model, a sketch of the idealized tank, and various detailed model plots. 


\subsection{Model Description}

The geometry. of the tank was idealized such that a simple axisymmetric model could be generated. This included assuming that the tank bottom was horizontal rather than on a slope. Also, the large I-beams underneath the tank were not included in the analysis. There are several pipe penetrations on the head of the tank. These were not included in the model. The penetration for the agitator in the center of the tank was included in the model. A fold-out sketch is in the Appendix which shows the idealization of the tank. It should be noted that the skirt, the insulation, and the top flange were included in the model as well as the tank bottom, cylinder, and elliptical head. Figure 1 is a plot of the tank model.

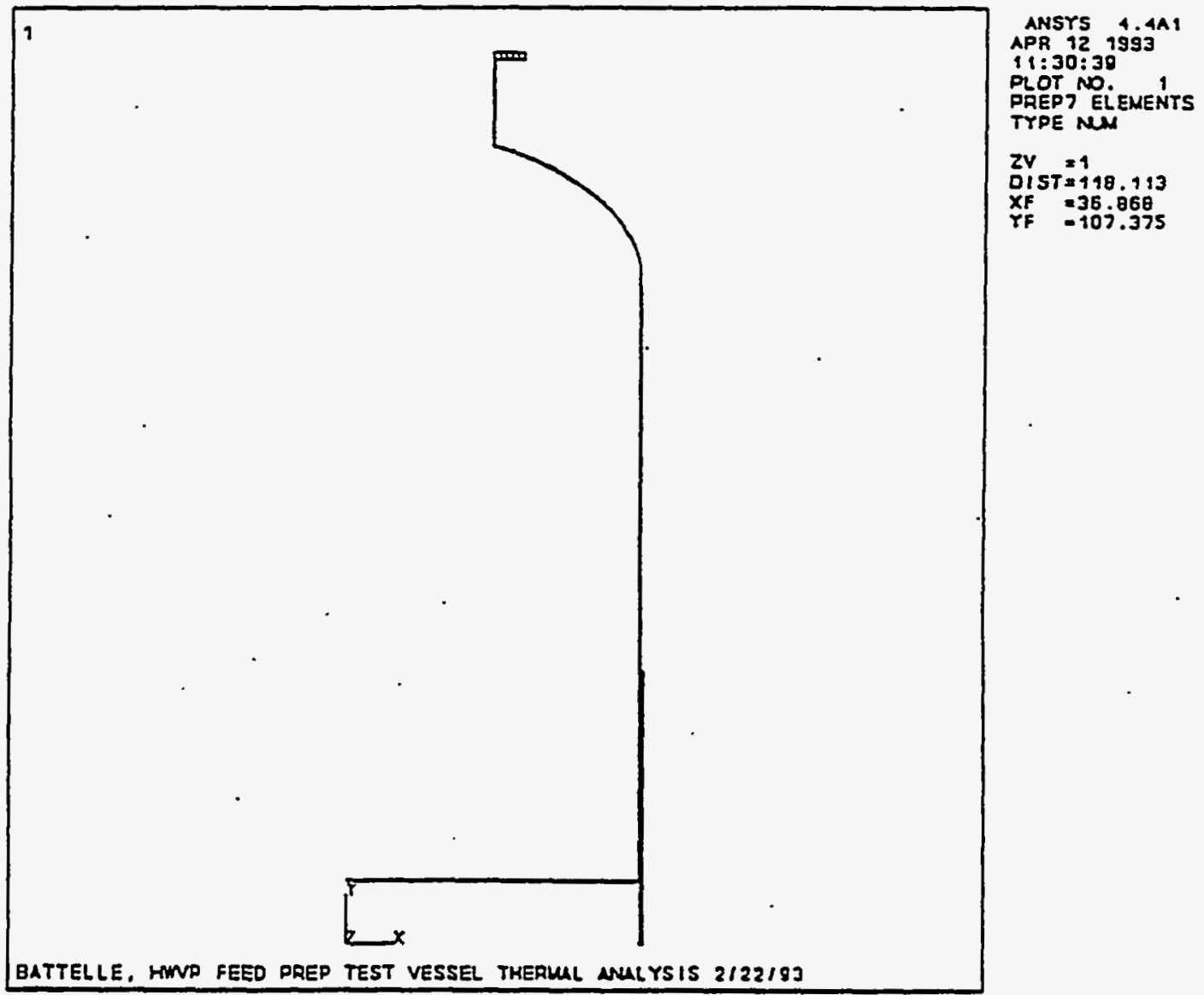

Figure 1 Analytical Model

Detailed plots of the various tank components that show where the individual elements are located are in the Appendix. In order for the elements to be easily seen, the plots have been expanded in either the horizontal or vertical directions as required. 
3.0 Model Parameters

The anaTysis consisted of conduction, radiation, and convection. ANSYS requires various parameters for the elements in order to perform the heat transfer calculations.

The data used for the analysis is given in Table 1 below.

Tank Data

\begin{tabular}{|c|c|c|c|c|}
\hline \multicolumn{5}{|c|}{ Cylinder $\quad$ Carpenter $20-\mathrm{Cb}-3$} \\
\hline $\begin{array}{l}\text { K, Btu/hr ft of } \\
\text { Emissivity } \\
\mathrm{H}_{f} \text { (Natural), Btu/hr } \mathrm{ft}^{2} \text { of } \\
\mathrm{H}_{\mathrm{f}} \text { (forced), Btu/hr } \mathrm{ft}^{2} \text { of }\end{array}$ & $\begin{array}{c}50{ }^{\circ} \mathrm{C} \\
6.72 \\
.5 \\
\text { Table } 2 \\
1.152\end{array}$ & $\begin{array}{c}75{ }^{\circ} \mathrm{C} \\
6.98^{\circ} \\
.5 \\
\text { Table } 2 \\
1.440\end{array}$ & $\begin{array}{l}100{ }^{\circ} \mathrm{C} \\
7.25 \\
.5 \\
\text { Table } 2 \\
1.440\end{array}$ & $\begin{array}{l}\text { Source } \\
(3) \\
(7) \\
(5) \\
\text { eng est }\end{array}$ \\
\hline \multicolumn{5}{|c|}{ Carpenter $20-\mathrm{Cb}-3$} \\
\hline $\begin{array}{l}\text { K, Btu/hr ft of } \\
\text { Emissivity } \\
H_{f} \text { (Natural), Btu/hr } \mathrm{ft}^{2} \text { of } \\
H_{f} \text { (forced), Btu/hr } \mathrm{ft}^{2} \text { of }\end{array}$ & $\begin{array}{c}50{ }^{\circ} \mathrm{C} \\
6.72 \\
.5 \\
\text { Table } 2 \\
1.152\end{array}$ & $\begin{array}{c}75^{\circ} \mathrm{C} \\
6.98 \\
.5 \\
\text { Table } 2 \\
1.440\end{array}$ & $\begin{array}{l}100^{\circ} \mathrm{C} \\
7.25 \\
.5 \\
\text { Table } 2 \\
1.440\end{array}$ & $\begin{array}{l}\text { Source } \\
(3) \\
(7) \\
(5) \\
\text { eng est }\end{array}$ \\
\hline \multicolumn{5}{|c|}{ Tank Head Carpenter 20-Cb-3 } \\
\hline $\begin{array}{l}\text { K, Btu/hr ft of } \\
\text { Emissivity } \\
H_{f} \text { (Natural), Btu/hr } \mathrm{ft}^{2} \text { of } \\
\mathrm{H}_{\mathrm{f}} \text { (forced), Btu/hr } \mathrm{ft}^{2} \circ \mathrm{F}\end{array}$ & $\begin{array}{c}50{ }^{\circ} \mathrm{C} \\
6.72 \\
.5 \\
\text { Table } 2 \\
1.152\end{array}$ & $\begin{array}{c}75{ }^{\circ} \mathrm{C} \\
6.98 \\
.5 \\
\text { Table } 2 \\
1.440\end{array}$ & $\begin{array}{l}1000^{\circ} \mathrm{C} \\
7.25 \\
.5 \\
\text { Table } 2 \\
1.440\end{array}$ & $\begin{array}{l}\text { Source } \\
(3) \\
(7) \\
(5) \\
\text { eng est }\end{array}$ \\
\hline \multicolumn{5}{|c|}{ Skirt $A-36$ Steel } \\
\hline $\begin{array}{l}\mathrm{K}, \text { Btu/hr ft of } \\
\text { Emissivity } \\
H_{f} \text { (Natural), Btu/hr } \mathrm{ft}^{2} \text { of } \\
H_{f} \text { (forced), Btu/hr } \mathrm{ft}^{2} \text { of }\end{array}$ & $\begin{array}{l}50 \circ \mathrm{C} \\
30.97 \\
.5 \\
\text { Table } 2 \\
1.152\end{array}$ & $\begin{array}{l}75 \circ^{\circ} \mathrm{C} \\
30.49 \\
.5 \\
\text { Table } 2 \\
1.440\end{array}$ & $\begin{array}{l}100{ }^{\circ} \mathrm{C} \\
30.02 \\
.5 \\
\text { Table } 2 \\
1.440\end{array}$ & $\begin{array}{c}\text { Source } \\
(3) \\
(7) \\
(5) \\
\text { eng est }\end{array}$ \\
\hline \multicolumn{5}{|l|}{ Insulation } \\
\hline $\begin{array}{l}\mathrm{K}, \text { Btu/hr ft of } \\
\text { Emissivity } \\
H_{f} \text { (Natural), Btu/hr } \mathrm{ft}^{2} \text { of } \\
\mathrm{H}_{\mathrm{f}} \text { (forced), Btu/hr } \mathrm{ft}^{2} \text { of }\end{array}$ & $\begin{array}{c}50{ }^{\circ} \mathrm{C} \\
0.01304 \\
.5 \\
\text { Table } 2 . \\
1.152\end{array}$ & $\begin{array}{c}75{ }^{\circ} \mathrm{C} \\
0.01304 \\
.5 \\
\text { Table } 2 \\
1.440\end{array}$ & $\begin{array}{c}100{ }^{\circ} \mathrm{C} \\
0.01304 \\
.5 \\
\text { Table } 2 \\
1.440\end{array}$ & $\begin{array}{c}\text { Source } \\
(6) \\
(7) \\
(5) \\
\text { eng est }\end{array}$ \\
\hline
\end{tabular}

Table 1 - Model physical properties 
The $H_{f}$ for natural convection given as a function of geometry and of the temperature difference $(\Delta T)$ between the tank and ambient is provided in Table 2 below 5 .

\begin{tabular}{|c|cc|}
\hline Surface & \multicolumn{2}{|c|}{ Turbulent Convection } \\
\hline Vertical planes or cylinders, $h_{f}$ & $0.19(\Delta T)^{1 / 3}$ & Btu/hr $\mathrm{ft}^{2}$ of \\
Heated plates facing upward, $h_{f}$ & $0.22(\Delta T)^{1 / 3}$ & Btu/hr $\mathrm{ft}^{2}$ of \\
Heated plates facing downward, $h_{f}$ & $0.12(\Delta T / L)^{1 / 4}$ & Btu/hr $\mathrm{ft}^{2}$ of \\
\hline
\end{tabular}

Table 2 - Turbulent natural convection coefficients

The $H_{f}$ for forced convection was given as an "engineering estimate" in Table 1. It was based upon trial and error. Attempts were made at matching both the recorded temperature distribution and the measured heat loss. It was found that while either one of the two items was easily matched, it was not possible to match both items. The section on discussion of results discusses this further.

There was a comparison made between the $H_{f}$ for the natural convection and the forced convection. The model results indicated that for the boiling water case, $H_{f}$ for the natural convection varied from $.374 \mathrm{Btu} / \mathrm{hr} \mathrm{ft}^{2}$ of to 1.08 $\mathrm{Btu} / \mathrm{hr} \mathrm{ft}^{2} \mathrm{oF}$. The forced convection term used for the case of boiling water was $1.440 \mathrm{Btu} / \mathrm{hr} \mathrm{ft}^{2}$ of as given in Table 1 . It was expected that the forced convection terms would be somewhat higher than the natural convection terms. 


\subsection{Results}

There were two items of particular interest in the analysis of the HB-15 tank. These items are the temperature distribution on the outside of the tank and the heat loss rate of the tank. The temperature distribution top of the tank head and on the surface of the insulation on the skirt of the tank was measured directly $(2)$ during the experiment. The heat loss from the tank was based upon experimental data that was reduced to actual heat loss through the use of spreadsheet and hand calculations ${ }^{(3)}$. Also, the heat loss of the tank was theoretically calculated by Fluor Daniel ${ }_{1}$. for the case of boiling water in the tank.

Tables 3,4 , and 5 contain the data at the points in which actual temperatures were recorded as well as the predicted temperature values. There were three sites of six discrete points at which the temperatures were recorded ${ }^{(2)}$. The three sites were spaced approximately 120 degrees apart. The six locations at each site started near the bottom of the tank and ended approximateiy five inches from the top of the skirt. The three recorded temperatures were averaged since the analytical model was axisymmetric. The $y$-location in the tables is the distance from the measurement point to the ground. The closest node listed in the tables is the closest node point in the model to the corresponding $y$-location. In all cases the closest node was less than $0.25 "$ from the location of measurement. The top temperature is measured on the elliptical head near the camera port. The top node of the model is where the flange on the top of the head come together.

\begin{tabular}{|c|c|c|c|c|c|}
\hline Hater temp. $=122{ }^{\circ} \mathrm{F}\left(50{ }^{\circ} \mathrm{C}\right)$ & \multicolumn{3}{|c|}{ Ambient temp. $=71{ }^{\circ} \mathrm{F}$} \\
\hline Location & $\begin{array}{c}\text { Y-location } \\
\text { (in) }\end{array}$ & $\begin{array}{c}\text { Nearest } \\
\text { Node }\end{array}$ & \multicolumn{3}{|c|}{ Temperature $\left({ }^{\circ} \mathrm{F}\right)$} \\
\cline { 4 - 6 } & & & $\begin{array}{c}\text { Experimental } \\
\text { Average }\end{array}$ & $\begin{array}{c}\text { Natural } \\
\text { Convection }\end{array}$ & $\begin{array}{c}\text { Forced } \\
\text { Convection }\end{array}$ \\
\hline 1 & 60.750 & 256 & 89.0 & 91.37 & 86.03 \\
3 & 51.725 & 238 & 86.0 & 91.37 & 86.03 \\
5 & 42.700 & 220 & 85.7 & 91.37 & 86.03 \\
7 & 33.675 & 202 & 84.7 & 91.37 & 86.03 \\
9 & 24.650 & 184 & 83.9 & 91.37 & 86.03 \\
11 & 15.625 & 166 & 81.4 & 90.34 & 85.01 \\
Top & 190.75 & 1623 & 98.2 & 107.80 & 107.7 \\
\hline
\end{tabular}

Table 3 Results at $T=50^{\circ} \mathrm{C}$ 


\begin{tabular}{|c|c|c|c|c|c|}
\hline \multicolumn{2}{|c|}{ Hater temp. $=167$ of $\left(75{ }^{\circ} \mathrm{C}\right)$} & \multicolumn{3}{|c|}{ Ambient temp. $=67{ }^{\circ} \mathrm{F}$} \\
\hline Location & $\begin{array}{c}\text { Y-Tocation } \\
\text { (in) }\end{array}$ & $\begin{array}{l}\text { Nearest } \\
\text { Node }\end{array}$ & \multicolumn{3}{|c|}{ Temperature ( $\mathrm{o}$ ) } \\
\cline { 3 - 6 } & & - & $\begin{array}{c}\text { Experimental } \\
\text { Average }\end{array}$ & $\begin{array}{c}\text { Natural } \\
\text { Convection }\end{array}$ & $\begin{array}{c}\text { Forced } \\
\text { Convection }\end{array}$ \\
\hline 1 & 60.750 & 256 & 105.6 & 106.1 & 95.60 \\
3 & 51.725 & 238 & 98.7 & 106.1 & 95.60 \\
5 & 42.700 & 220 & 96.3 & 106.0 & 95.60 \\
7 & 33.675 & 202 & 94.3 & 106.1 & 95.60 \\
9 & 24.650 & 184 & 92.6 & 106.1 & 95.60 \\
11 & 15.625 & 166 & 88.3 & 104.1 & 93.70 \\
Top & 190.75 & 1623 & 149.0 & 154.4 & 154.0 \\
\hline
\end{tabular}

Table 4 Results at $T=75^{\circ} \mathrm{C}$

\begin{tabular}{|c|c|c|c|c|c|}
\hline \multicolumn{2}{|c|}{ Water temp. $=212 \circ \mathrm{of}\left(100{ }^{\circ} \mathrm{C}\right)$} & \multicolumn{3}{|c|}{ Ambient temp. $=62{ }^{\circ} \mathrm{F}$} \\
\hline Location & $\begin{array}{c}\text { Y-location } \\
\text { (in) }\end{array}$ & $\begin{array}{c}\text { Nearest } \\
\text { Node }\end{array}$ & \multicolumn{3}{|c|}{ Temperature (oF) } \\
\cline { 3 - 6 } & & & $\begin{array}{c}\text { Experimental } \\
\text { Average }\end{array}$ & $\begin{array}{c}\text { Natural } \\
\text { Convection }\end{array}$ & $\begin{array}{c}\text { Forced } \\
\text { Convection }\end{array}$ \\
\hline 1 & 60.750 & 256 & 111.1 & 124.9 & 106.6 \\
3 & 51.725 & 238 & 102.9 & 124.9 & 106.6 \\
5 & 42.700 & 220 & 99.9 & 124.9 & 106.6 \\
7 & 33.675 & 202 & 99.9 & 124.9 & 106.6 \\
9 & 24.650 & 184 & 97.7 & 124.9 & 106.6 \\
11 & 15.625 & 166 & 92.5 & 122.3 & 103.9 \\
Top & 190.75 & 1623 & 197.6 & 197.1 & 196.9 \\
\hline
\end{tabular}

Table 5 Results at $T=100^{\circ} \mathrm{C}$

Table 6 contains the heat loss rates that were based upon experimental measurements as well as analytically derived heat loss rates. The table contains the heat loss rates for all three-temperatures. 


\begin{tabular}{|c|c|c|c|c|}
\hline $\begin{array}{l}\text { Water } \\
\text { Temp. } \\
\text { (०F) }\end{array}$ & \multicolumn{4}{|c|}{ Heat Loss Rate } \\
\cline { 2 - 5 } & $\begin{array}{c}\text { Fluor Daniel } \\
\text { Calculation } \\
\text { (Btu/hr) }\end{array}$ & $\begin{array}{c}\text { Experimental } \\
\text { (Btu/hr) }\end{array}$ & $\begin{array}{c}\text { Analytical } \\
\text { Natura } \\
\text { Convect } \\
\text { (Btu/hr) }\end{array}$ & $\begin{array}{c}\text { Analytical } \\
\text { Forced } \\
\text { Convection } \\
\text { (Btu/hr) }\end{array}$ \\
\hline 122 & - NA- & 32,384 & 24,553 & 34,590 \\
167 & $-N A-$ & 82,379 & 57,617 & 81,866 \\
212 & 54,130 & 207,434 & 88,308 & 125,519 \\
\hline
\end{tabular}

Table 6 Tank Heat Loss Rates 


\subsection{Discussion of Results}

Natural convection analytical model compared to Fluor Daniel calculations

The results that appear in Table 6 show that the natural convection analytical model did not agree with the Fluor Daniel calculations. There are several reasons for this. First, -Fluor Daniel assumed that there was insulation on the bottom of the tank ${ }^{(1)}$. There is no insulation under the tank at this time. Second, it was discovered that there is a duct underneath the tank which would tend to increase the convective heat loss. Third the Fluor calculations assumed that the ambient temperature was $104{ }^{\circ} \mathrm{F}^{(1)}$. The actual ambient temperature during the experiment was $62 \circ \mathrm{F}^{(2)}$. The combination of these items could easily account for the approximately 35,000 Btu/hr difference between the Fluor Daniel calculation of 54,130 Btu/hr and the analytical model prediction of $88,308 \mathrm{Btu} / \mathrm{hr}$.

Natural Convection analytical model compared to experimental results

The comparison of the natural convection analytical model to the experimental results, seen in Table 6 , showed that the analytical model under-predicted the heat loss in the tank. The differences between the predicted values and the experimental values became more pronounced for $100^{\circ} \mathrm{C}$ case. There were two hypotheses for this trend. One hypothesis was that forced convection rather than natural convection was causing the under-prediction. Upon visual examination of the Building 325 where the tank resides, it was determined that there was considerable air flow around and under the tank partially due to a duct underneath the tank. A second potential hypothesis was that there is additional heat loss that was not accounted for. For example it was determined that the evaporation of process vapors was responsible for an excess of $100,000 \mathrm{Btu} / \mathrm{hr}$ loss ${ }^{(3)}$. There could be additional sources of heat loss that stili have not been accounted for.

\section{Forced Convection analytical model compared to experimental results}

The first hypothesis which stated that forced convection would show a higher heat loss is discussed next. There was no data about the velocity or condition of the air at the time of the experiment, so the forced convection terms we're assumed to be constant along the tank. Successive trial and error attempts were made to try to match both the tank heat loss and the temperature distribution along the side of the tank. As seen in Tabie 6 for the fluid temperature of $50^{\circ} \mathrm{C}$, the forced convection model over-predicted the experimental results by approximateiy $2,000 \mathrm{Btu} / \mathrm{hr}$ which is about a $7 \%$ difference. The temperature distribution from the forced convection model, shown in Table 3, fell within the range of the experimental results. As seen in Table 6 for a fluid temperature of $75^{\circ} \mathrm{C}$, the forced convection model under-predicted the experimental results by approximately $500 \mathrm{Btu} / \mathrm{hr}$ which is less than a $1 \%$ difference. The temperature distribution, shown in Table 4 , fell within the range of the experimental results. As seen in Table 6 for a fluid temperature of approximately $100^{\circ} \mathrm{C}$, the forced convection model underpredicted the experimental results by approximately $82,000 \mathrm{Btu} / \mathrm{hr}$ which is approximately a $40 \%$ difference. The temperature distribution from the forced model was within the range of experimental results. The ability to match the temperature distribution but not the heat loss for the $100^{\circ} \mathrm{C}$ case lends 
credence to the hypothesis that there are additional heat loss sources that the model cannot predict. 


\section{References}

1) Fluor Daniel calculations, pp 10 - 27, Heat Gain to HVAC, contract no. 845724, CHBS 3212 and 3214, MF-0029, October 23, 1989, Prepared by Fluor Daniel.

2) PNL Laboratory Record,Book no. 54277, SIPT project no. 16706, Condenser Testing, pp 111 - 132, January 31, 1992, Prepared by the Pacific Northwest Laboratory.

3) B.K. Hatchell, April 8;, 1993, CALC-SIPT-003, REV.0, Design Calculations, for STurry-Integrated Performance Testing (SIPT), HB-15 Tank Heat Loss (Experimental).

4) G.J. DeSalvo and R.H. Gorman, ANSYS Engineering Analysis System, Revision 4.4a, May 1, 1989, Swanson Analysis Systems, INC.

5) Holman, J.P., Heat Transfer, Third Edition, McGraw Hill, New York.

6) Fluor Daniel Tech Need Sheets, Item 1.3A 


\section{Appendix}

\section{Listing of ANSYS input}

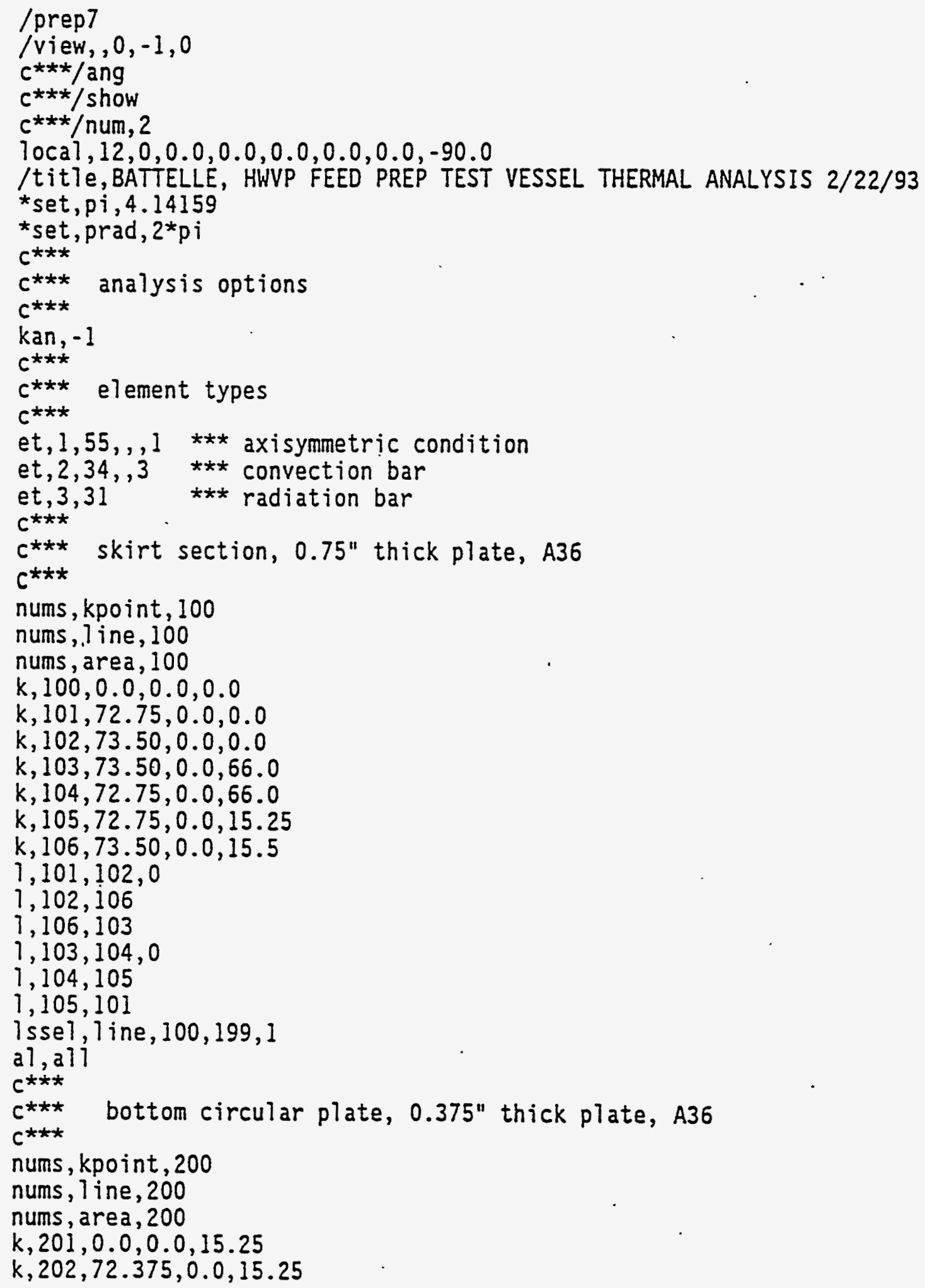




$$
k, 203,72.375,0.0,15.625
$$

$k, 204,0.0,0.0,15.625$

$1,201,202$

$1,202,203,0$

$1,203,204$

$1,204,201,0$

-1 ssel, line, 200, 299, 1

a], a 17

c**t

$c^{\star \star *}$ cylindrical shell, part 1, 0.375" thick, contact with skirt, $A 36$

$c^{\star \star \star}$

nums, kpoint, 300

nums, line, 300

nums, area, 300

$k, 301,72.375,0.0,66.0$

$1,104,301,0$

], 301,203

$1,202,105,0$

lssel, Tine, $300,399,1$

lsas, Tine, 201

Isas, 7 ine, 104

a) all

c***

$c^{\star * *}$ cylindrical shell, part $2,0.375^{\prime \prime}$ thick, insulated portion, A36

$c^{\star * *}$

nums, kpoint, 400

nums, 7 ine, 400

nums, area, 400

$k, 401,72.75,0.0,159.0$

$k, 402,72.375,0.0,159.0$

$1,104,401$

$1,401,402,0$

$1,402,301$

Issel, 1ine, $400,499,1$

isas, 7 ine, 300

a], a7?

$c^{\star \star \star \star}$

$c^{\star \star *}$ cylindrical shell, part $3,0.375^{n}$ thick, uninsulated portion, A36

$c * \star \star$

nums, kpoint, 500

nums, line, 500

nums, area, 500

$k, 501,72.75,0.0,161.0$

$k, 502,72.375,0.0,161.0$

$1,401,501$

$1,501,502,0$

$1,502,402$

lssel, 1 ine $, 500,599,1$

lsas, 7 ine, 401

al , al1

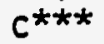

$c^{\star \star \star}$ elliptical dome, $0.75^{\prime \prime}$ thick $2: 1$ s.e. A36, uninsulated

G.61 


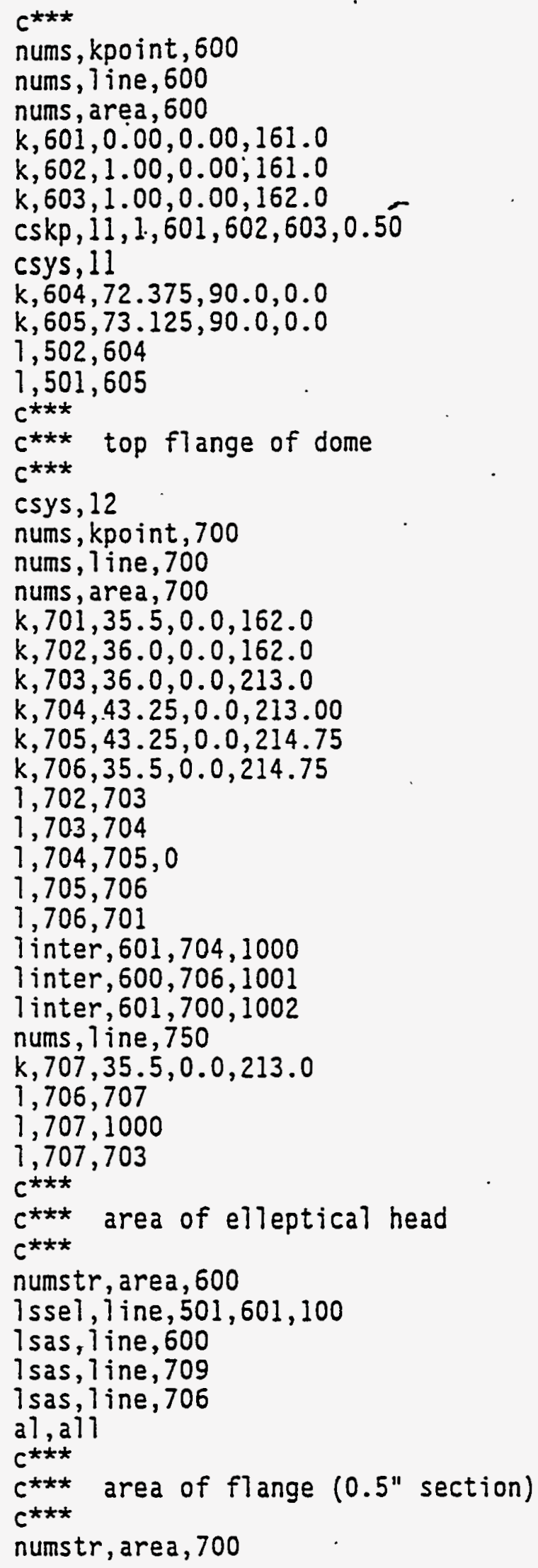


CALC-SIPT-011, REV. 0

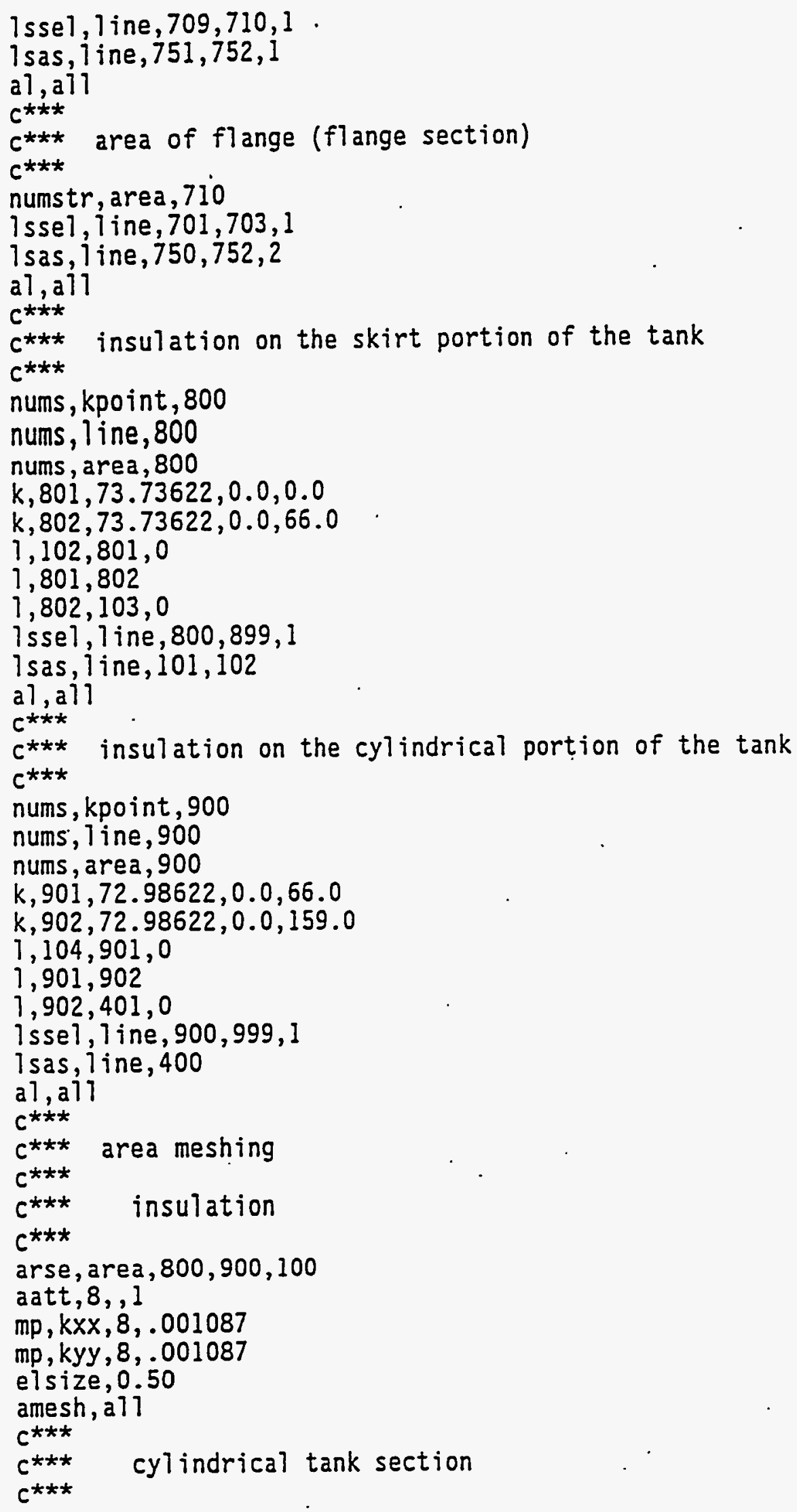




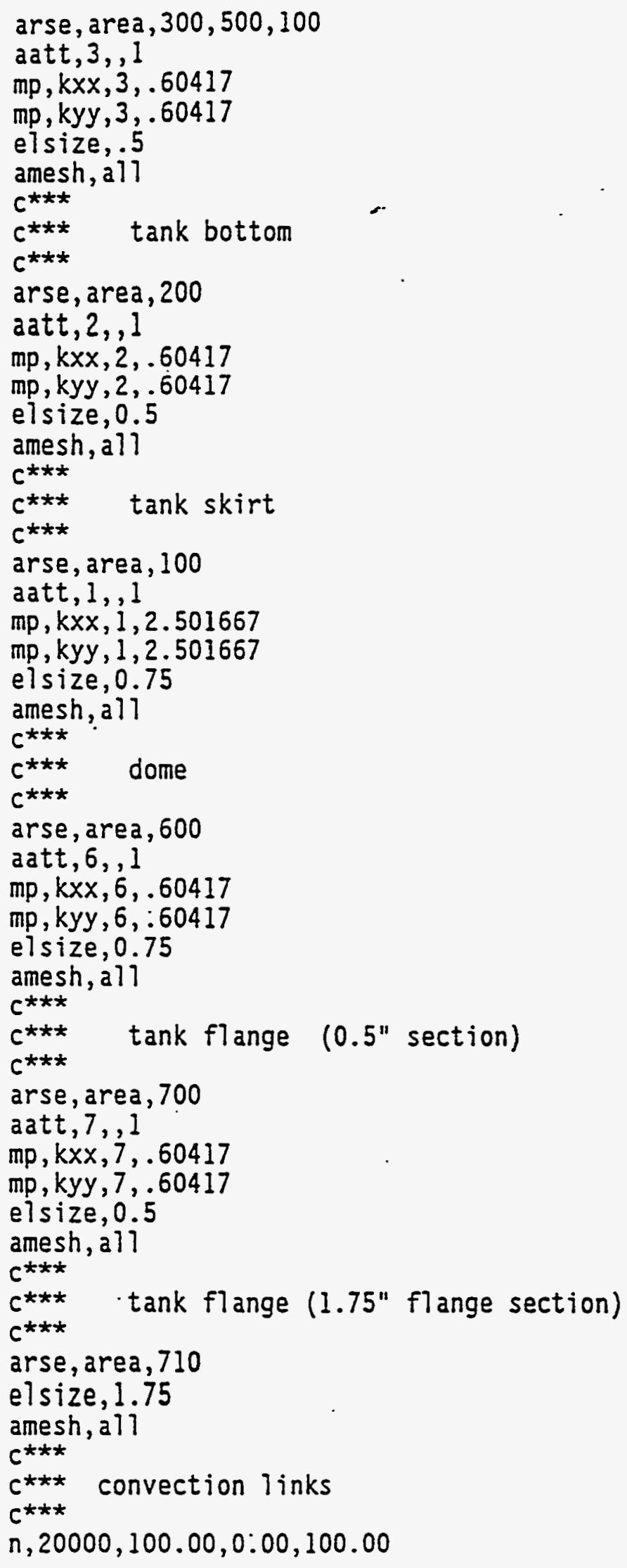


$c^{* * *}$ bottom of tank

numstr, elem, 20000

type, 2

mat, 20

mp, hf , 20,0.12/144

*set, en, 0.25

*set, $c c, 0.0$

$c^{\star \star \star \star}$

$c^{\star * *}$ first node at $r=0.0$

$c * \star \star$

*set, nod, 1040

*set, Ten, . 499138/2

*set, rad, ten $/ 2$

$r, 2000,1$ en*rad, en, $c c$

real, 2000

$e$, nod, 20000

$c * \star \star$

c*** middle noḍes

$c * \star *$

*set, node, 1040

*set, 1en, 0.499138

*set, inc, 1

$: 1 \mathrm{ab}$

*get, rad, nx, nodtinc

' $r, 2000+i n c$, rad*len, en, $c c$

real, 2000+ine

e, nodtinc, 20000

* set, inc, inct 1

*if, inc, 1e, 144,: $7 a b$

$c^{* * *}$

c*** last node

$c * \star *$

*set, nod, 743

*get, rad, nx, nod

* set, rad, rad- (len/4)

$r, 2000+i n c, \mathrm{rad}^{*}$ len/2, en, cc

real, $2000+i n c$

e, nod, 20000

$c * \star \star$

$c^{\star \star *}$
$c^{\star \star *}$

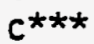

numstr, elem, 21000

type, 2

mat, 21

$m p, h f, 21,0.19 / 144$

*set, nod, 134

* get, rad, nx, nod

* set, len, 0.50

*set, inc, 1

* set, en, 0.33

*set, cc, 0.0 
CALC-SIPT-011, REV. 0

$r, 2100, \mathrm{rad}^{*} 1 \mathrm{en} / 2$, en, cc

rea], 2100

$e$, nod, 20000

$e, n o d+1,20000$

$r, 2101$, rad*len, en, $c c^{*}$

real, 2101

$e, \operatorname{nod}+2,20000$

rp 131,1

$c^{* \star \star *}$

$c^{* * *}$ insulation over tank

$c * \star \star *$

numstr, elem, 22000

type, 2

mat, 22

mp , hf , 22, 0.19/144

*set, nod, 454

* get, rad, nx, nod

*set, 7 en, 0.5

* set, inc, 1

* set, en, 0.33

* set, cc, 0.0

$r, 2200, \mathrm{rad}^{*} \mathrm{len} / 2$, en, cc

real , 2200

$e$, nod, 20000

$e, n o d+1,20000$

$\left.r, 2201, \mathrm{rad}^{*}\right]$ en, en, $c c$

real, 2201

e, nod $+2,20000$

rp 185, 1

$c^{* \star *}$

$c^{\star \star *}$ uninsulated tank cylinder

$c^{\star \star \star}$

numstr, elem, 23000

type, 2

mat, 23

$\mathrm{mp}, \mathrm{hf}, 23,0.19 / 144$

* set, nod, 268

* get, rad, nx, nod

* set, Ten, 0.5

* set, inc, 1

* set, en, 0.33

* set, $c c, 0.0$

$r, 2300, \mathrm{rad}^{*}$ len/2, en, cc

real, 2300

e, nod, 20000

* set, nod, 1036

$e$, nod, 20000

$r, 2301, r a d * 7 e n, e n, c c$

real, 2301

e, nodtl, 20000

rp3,1

$c * \star *$ 
CALC-SIPT-011, REV. 0

$c^{\star \star \star \star}$ dome portion of tank

$c^{\star \star \star \star}$

type, 2

numstr, e em, 24000

mat, 24

mp, hf, 24, 0.22/144

*set, en, 0.33

*set, cc, 0.0

$c^{\star \star * *}$

$c * \star$ beginning of dome

$c * \star \star *$

*set, nod, 1036

*get, rad, nx, nod

*set, len, 0.75

$r, 2400, \mathrm{rad}^{*} 1 \mathrm{en} / 2$, en, cc

real, 2400

e, nod, 20000

$c^{\star \star \star *}$

$c^{* * *}$

*set, nod, 1554

*set, inc, 1

*get, rad, nx, nod

$\left.r, 2400+i n c, \mathrm{rad}^{*}\right] \mathrm{en} / 2$, en, cc

real, 2400+ine

e, nod, 20000

$c * \star \star$

$c^{* * *}$ rest of dome

$c * * *$

$: 1$ a 4

*get, rad, nx, nodtinc

$\left.r, 2401+i n c, \mathrm{rad}^{*}\right]$ en, en, cc

real, 2401+inc

e, nod +inc, 20000

*set, inc, inc +1

*if, inc, 7e, 69, : ?a4

$c * \star \star *$

$c^{* * *}$ inside of skirt below tank bottom

$c * * \star$

numstr, elem, 25000

type, 2

mat, 25

mp, hf , 25, 0.19/144

*set, en, 0.33

*set, cc, 0.0

*set, nod, 641

*get, rad, nx, nod

*set, 7 en, 0.70

$\left.r, 2500, \mathrm{rad}^{*}\right] \mathrm{en} / 2$, en, $c c$

real, 2500

e, nod, 20000

*set, nod, 1330

e, nod, 20000 
CALC-SIPT-011, REV.0

$r, 2501, \mathrm{rad}^{*} 1 \mathrm{en}, \mathrm{en}, \mathrm{cc}$

real, 2501

$e$, nod $+1,20000$

rp20,1.

$c * \star \star$

$c^{\star \star \star *}$

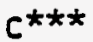

type, 2

numstr, elem, 26000

mat, 26

mp, hf , 25, 0.19/144

*set, en, . 33

*set, $c c, 0.0$

* set, nod, 1554

*get, rad, nx, nod

* set, len, .50

$\left.r, 2600, \mathrm{rad}^{*}\right] \mathrm{en} / 2$, en, cc

real, 2600

$e$, nod, 20000

*set, nod, 1655

e, nod, 20000

$r, 2601$, rad $^{*}$ len, en, $c c$

real , 2601

$e$, nodt 1,20000

$\operatorname{rp} 40,1$

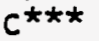

$c^{* * *}$ flange portion of flange

$c^{\star \star \star}$

numstr, e em, 27000

mat, 27

$\mathrm{mp}, \mathrm{hf}, 27,0.12 / 144$

*set, en, 0.25

* set, cc, 0.0

* set, nod, 1665

* set, inc, 1

*get, rad, nx, nod

* set, Ten, 1.45

$r, 2700,(\mathrm{rad}+1 \mathrm{en} / 2) * 7$ en, en, cc

real, 2700

$e$, nod, 20000

*set, nod, 1706

* get, rad, nx, nod

$r, 2700$ tinc, $(\mathrm{rad}-1 \mathrm{en} / 2)^{*}$ len, en, cc

real, $2700+i n c$

$e$, nod, 20000

$: 1 a 6$

*get, rad, nx, nodtinc

$r, 2700+1+i n c, \mathrm{rad}^{*} 7 \mathrm{en}, \mathrm{en}, c c$

real, $2700+1+i n c$

$e$, nodtine, 20000

* set, inc, inct 1

*if, inc, $7 e, 4,: 1$ a 6 


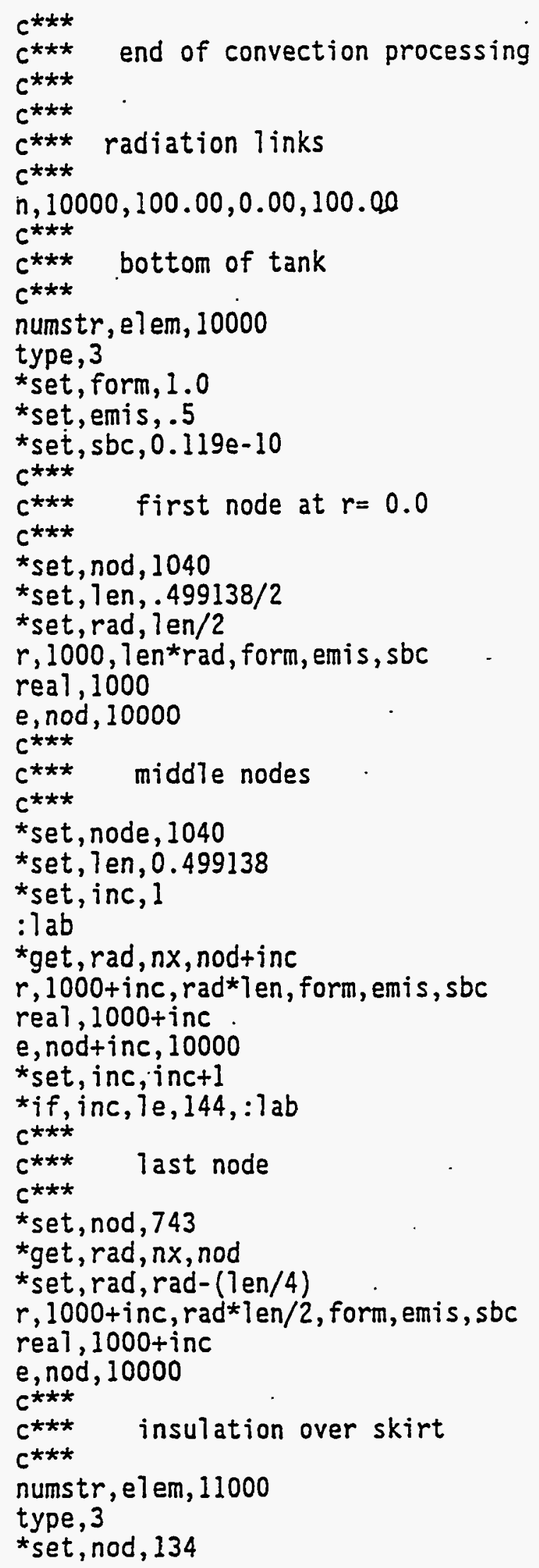


*get, rad, nx, nod

* set, Ten, 0.50

*set, inc, 1

*set, form, 1.0

* set, emis, 0.5

* set, sbc, $0.119 \mathrm{e}-10$

$r, 1100, \mathrm{rad}^{*} 7 \mathrm{en} / 2$, form, emjs, sbc

real, 1100

$e, \operatorname{nod}, 10000$

$e, n o d+1,10000$

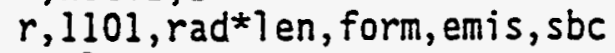

real, 1101

e, nod $+2,10000$

rpl31,1

$c^{* * *}$

c*** insulation over tank

$c^{* * *}$

numstr, elem, 12000

type, 3

*set, nod, 454

*get, rad, nx, nod

*set, 7 en, 0.5

*set, ine, 1

*set, form, 1.0

*set, emis, 0.5

*set, sbc, $0.119 \mathrm{e}-10$

$r, 1200$, rad*len/2, form, emis, sbc

rea], 1200

e, nod, 10000

$e, \operatorname{nod}+1,10000$

$r, 1201, \mathrm{rad}^{*} 7 \mathrm{en}$, form, emis, sbc

real, 1201

$e$, nodt2, 10000

rpl85, 1

$c^{\star \star \star \star}$

$c^{* * *}$ uninsulated tank cylinder

$c^{\star \star \star}$

numstr, elem, 13000

type, 3

*set, nod, 268

*get, rad, nx, nod

*set, len, 0.5

*set, inc, 1

*set, form, 1.0

* set, emis, 0.5

*set, sbc, 0.119e-10

$r, 1300, \mathrm{rad}^{*} 1 \mathrm{en} / 2$, form, emis, sbc

rea], 1300

e, nod, 10000

* set, nod, 1036

$e$, nod, 10000

$r, 1301, \mathrm{rad}^{*}$ len, form, emis, sbe 


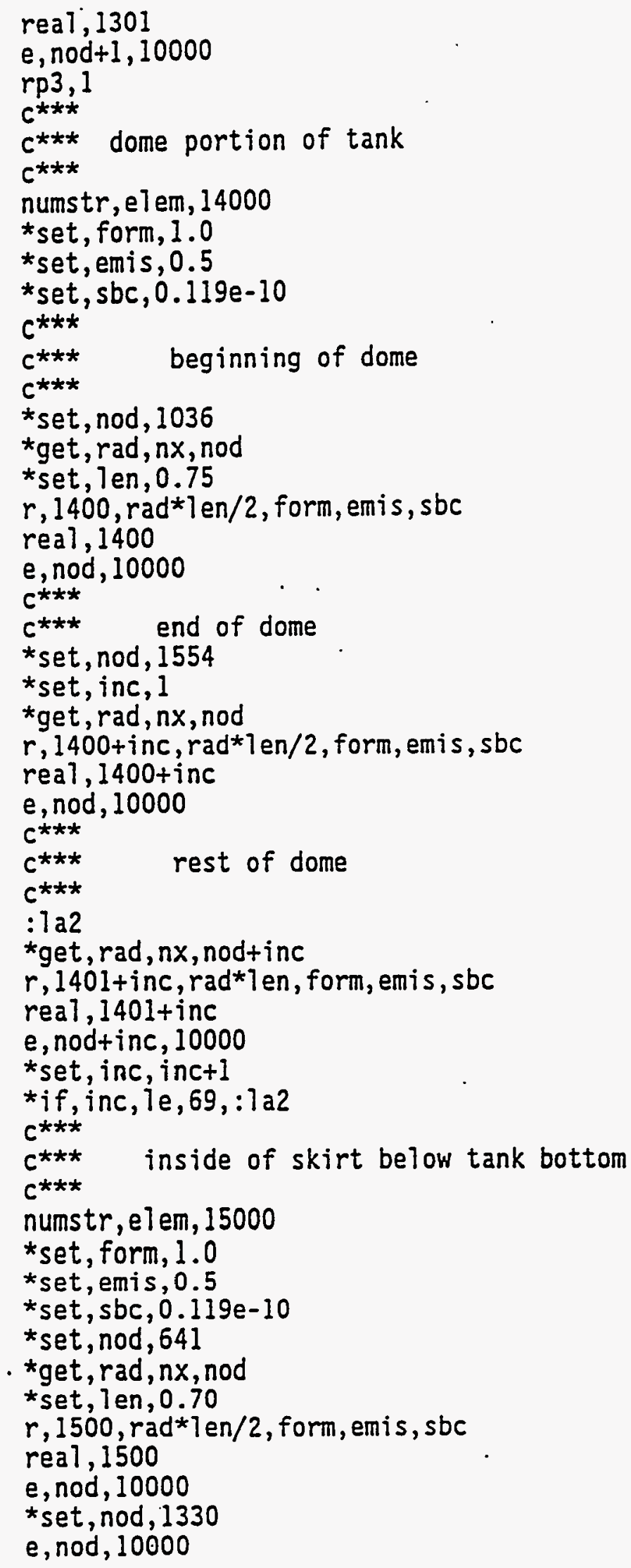


CALC-SIPT-011, REV.0

$\left.r, 1501, \mathrm{rad}^{\star}\right]$ en, form, emis, sbc

real, 1501

e, nod $+1,10000$

rp20,1

$c * \star *$

$c^{\star \star \star}$ outside portion of flange (.5" section)

$c^{\star \star \star \star}$

numstr, el em, 16000

*set, form, 1.0

*set, emis, 0.5

*set, sbc, $0.119 \mathrm{e}-10$

* set, nod, 1554

* get, rad, nx, nod

*set, len, .50

$r, 1600, \mathrm{rad}^{*} \mathrm{en} / 2$, form, emis, sbc

real , 1600

e, nod, 10000

*set, nod, 1665

$e$, nod, 10000

$r, 1601, \mathrm{rad}^{*}$ len, form, emis, sbc

real, 1601

e, nod +1, 10000

rp40,1

$c^{\star * *}$

$c^{\star \star *}$ flange portion of flange

$c^{\star \star \star}$

numstr, el em, 17000

*set, form, 1.0

*set, emis, 0.5

*set, sbc, $0.119 e-10$

*set, nod, 1665

*set, ine, 1

* get, rad, nx, nod

*set, len, 1.45

$r, 1700,(\mathrm{rad}+1 \mathrm{en} / 2) \star 1 e n$, form, emis, sbc

rea], 1700

e, nod, 10000

*set, nod, 1706

* get, rad, nx, nod

r, 1700+inc, (rad-len/2)*len, form, emis, sbc

real, $1700+i n c$

$e$, nod, 10000

$: 125$

*get, rad, $\mathrm{nx}$, nodtinc

$r, 1700+1+i n c, \mathrm{rad}^{*}$ en, form, emis, sbc

real, $1700+1+i n c$

e, nodtinc, 10000

*set, inc, inc +1

*if, inc, ie, $4,: 1 a 5$

$c * * *$

$C^{\star \star \star \star}$

$c^{\star \star *}$ 
CALC-SIPT-0I1, REV. 0

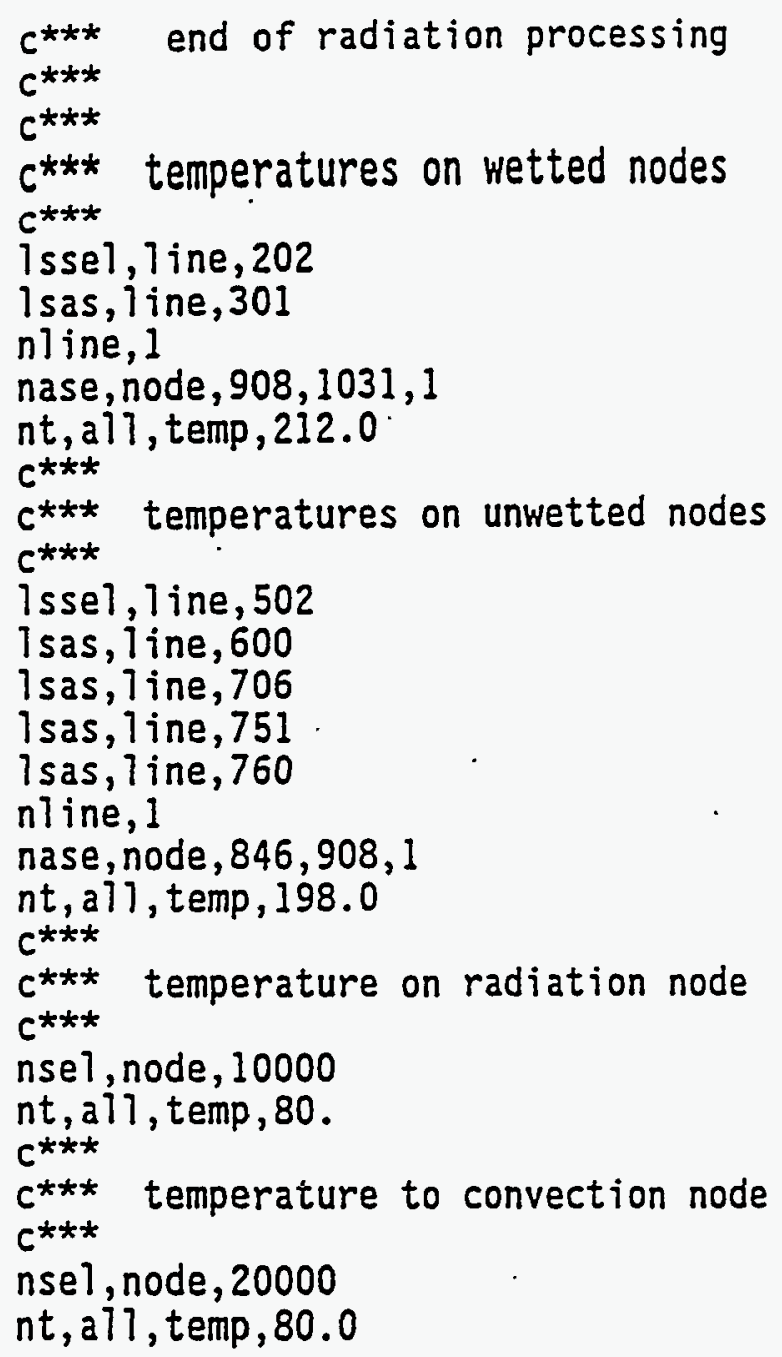




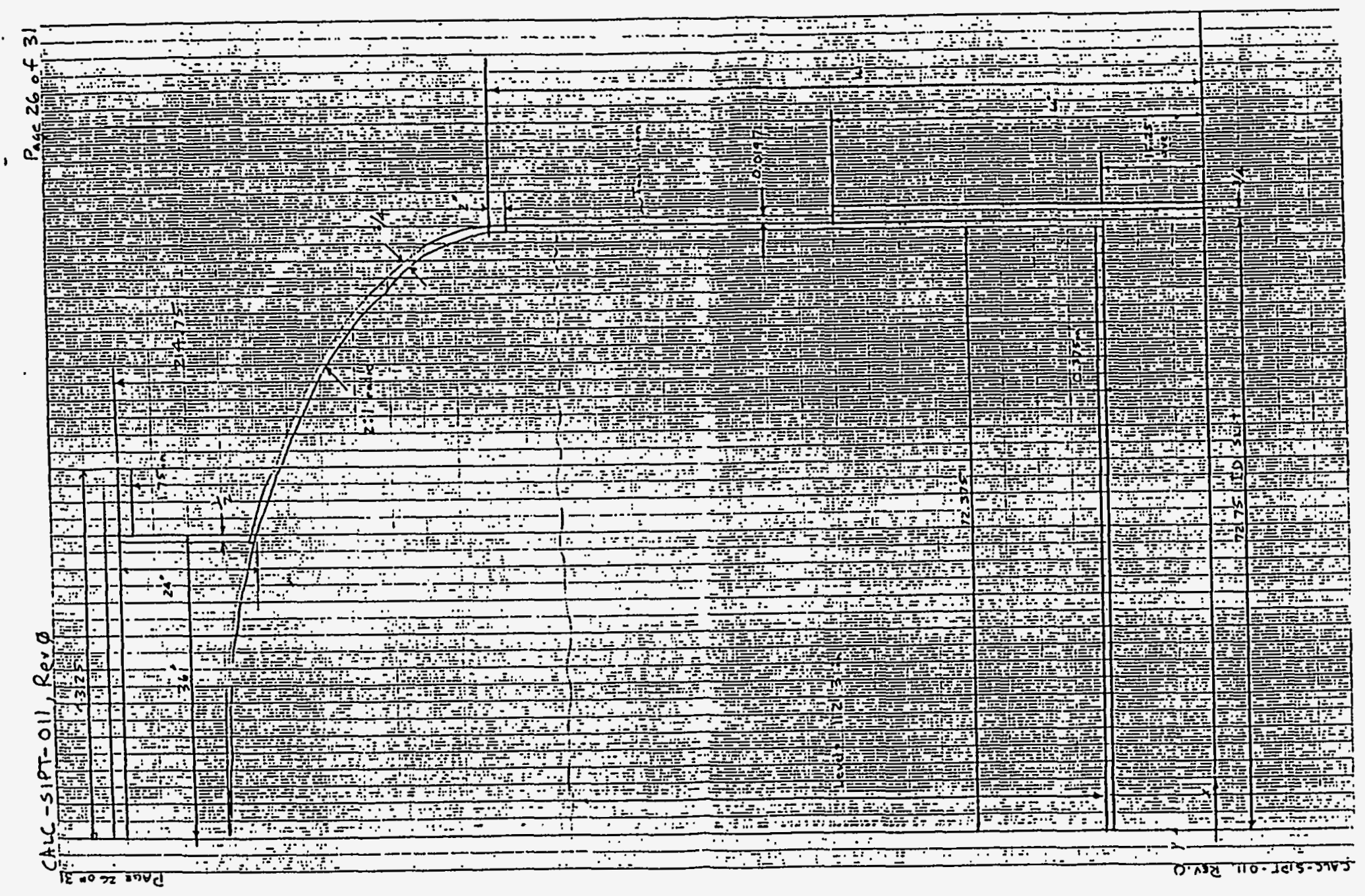




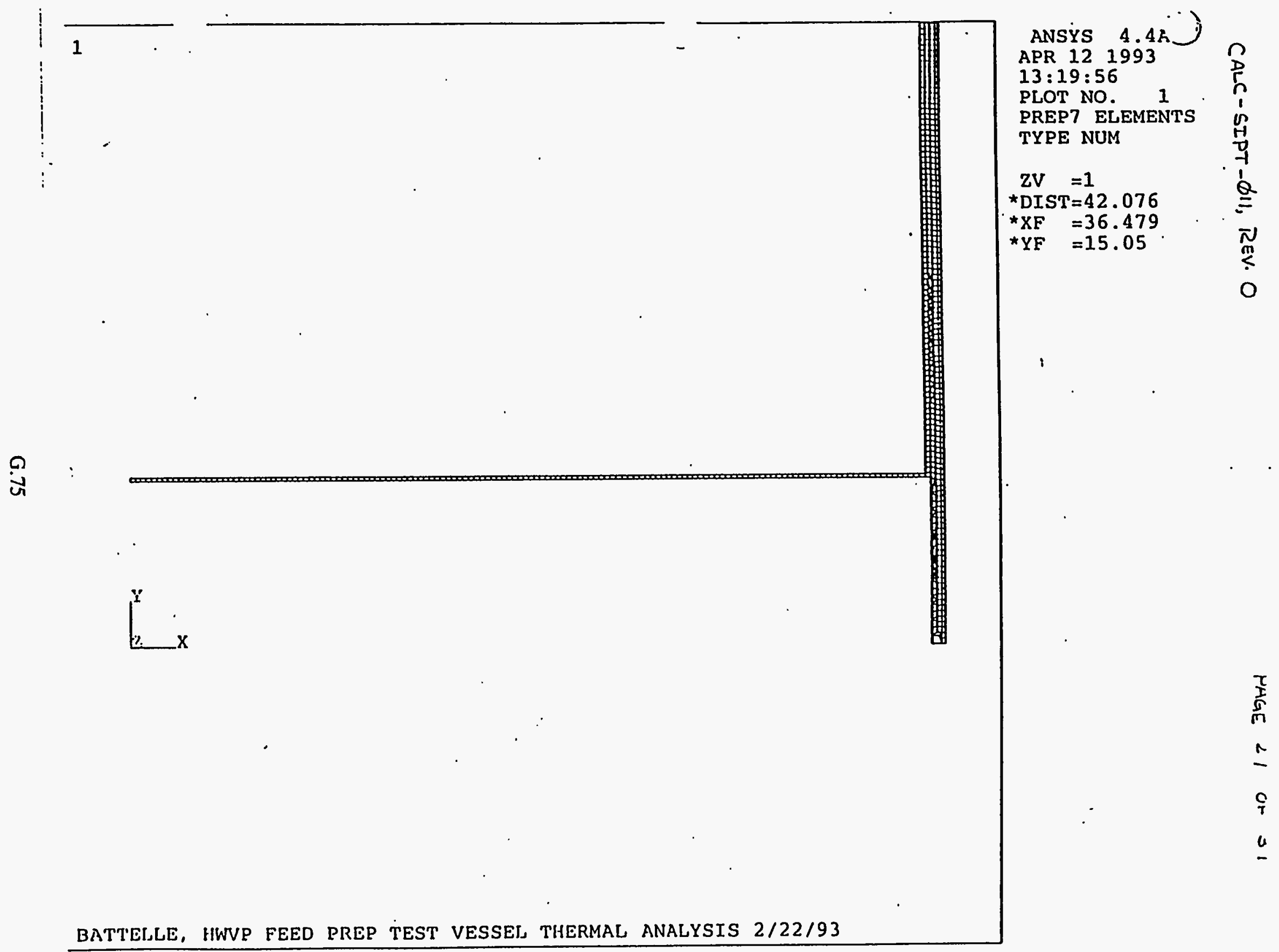


CALC - SIPT - $\emptyset I I$, REV.O

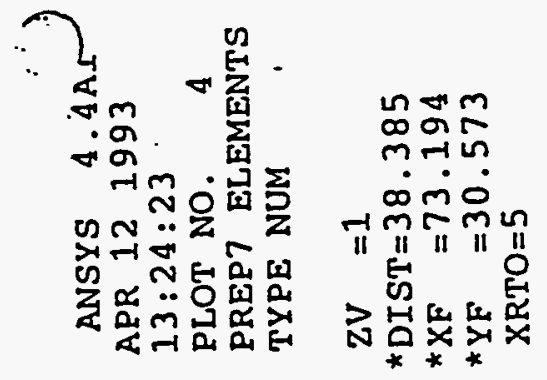

HAGE 29 OF 31
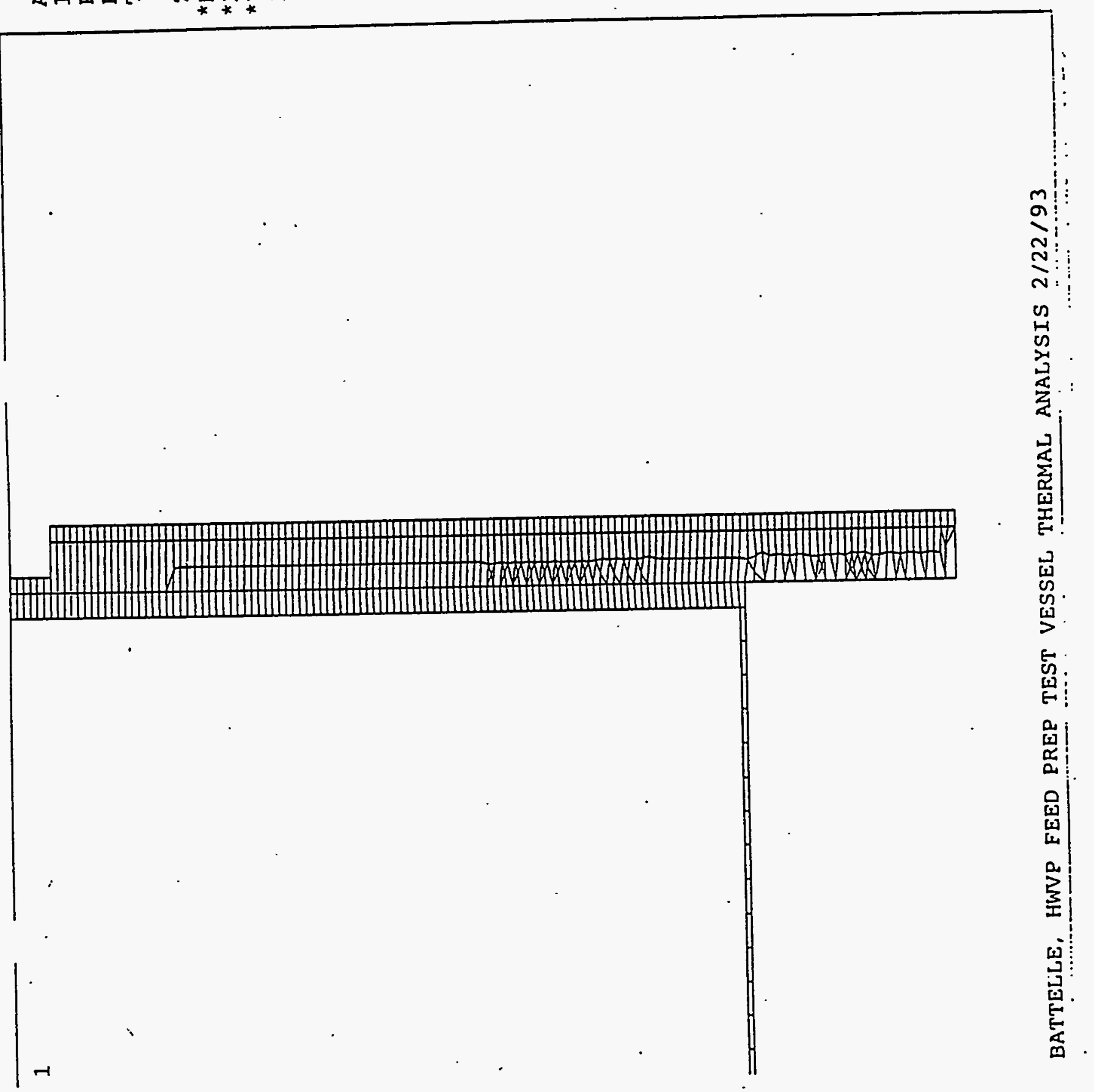

G.76 
$C A L C-S I P T-D I I, R E V . O$

PAGE 29 OF 31
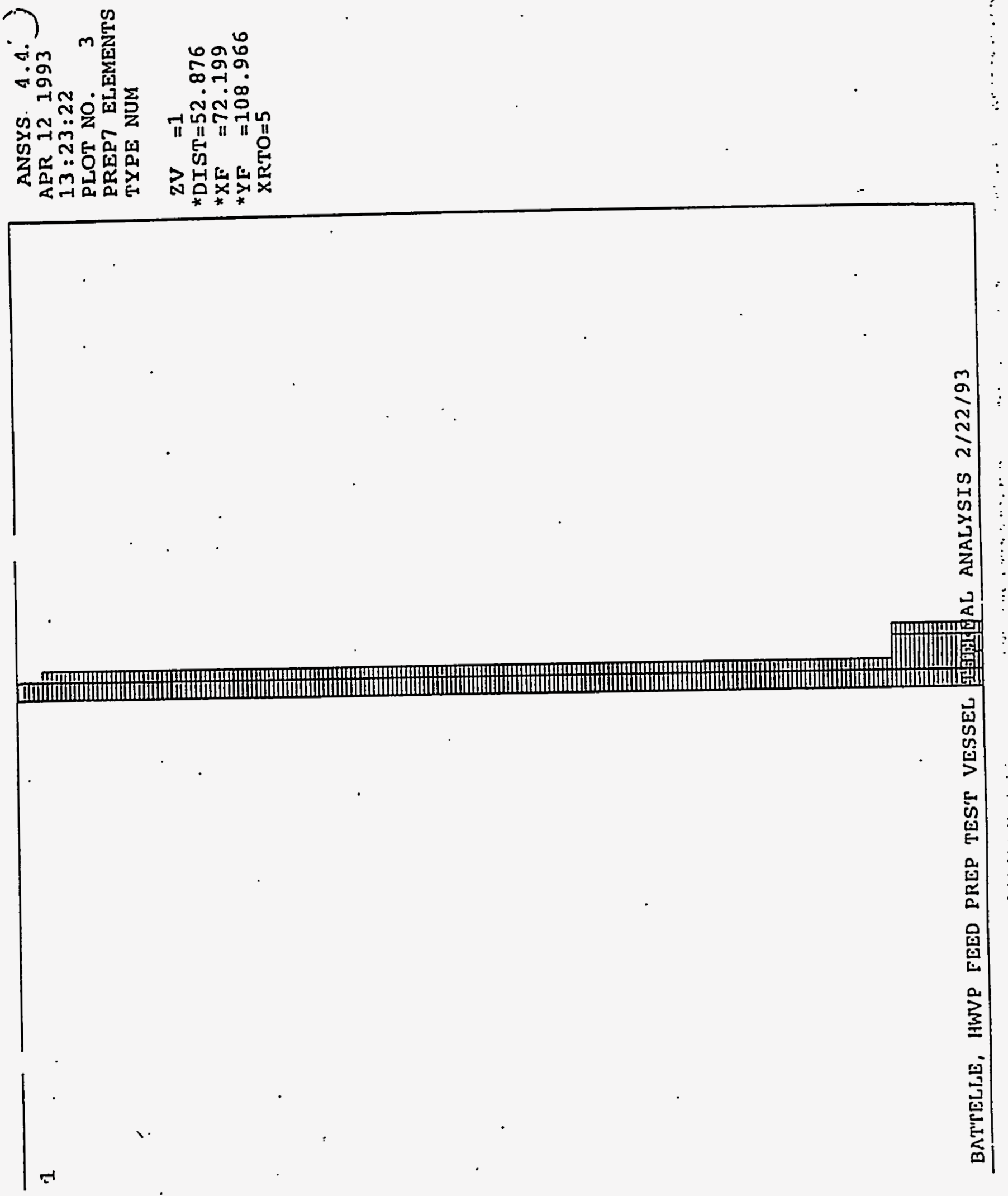

G.77 


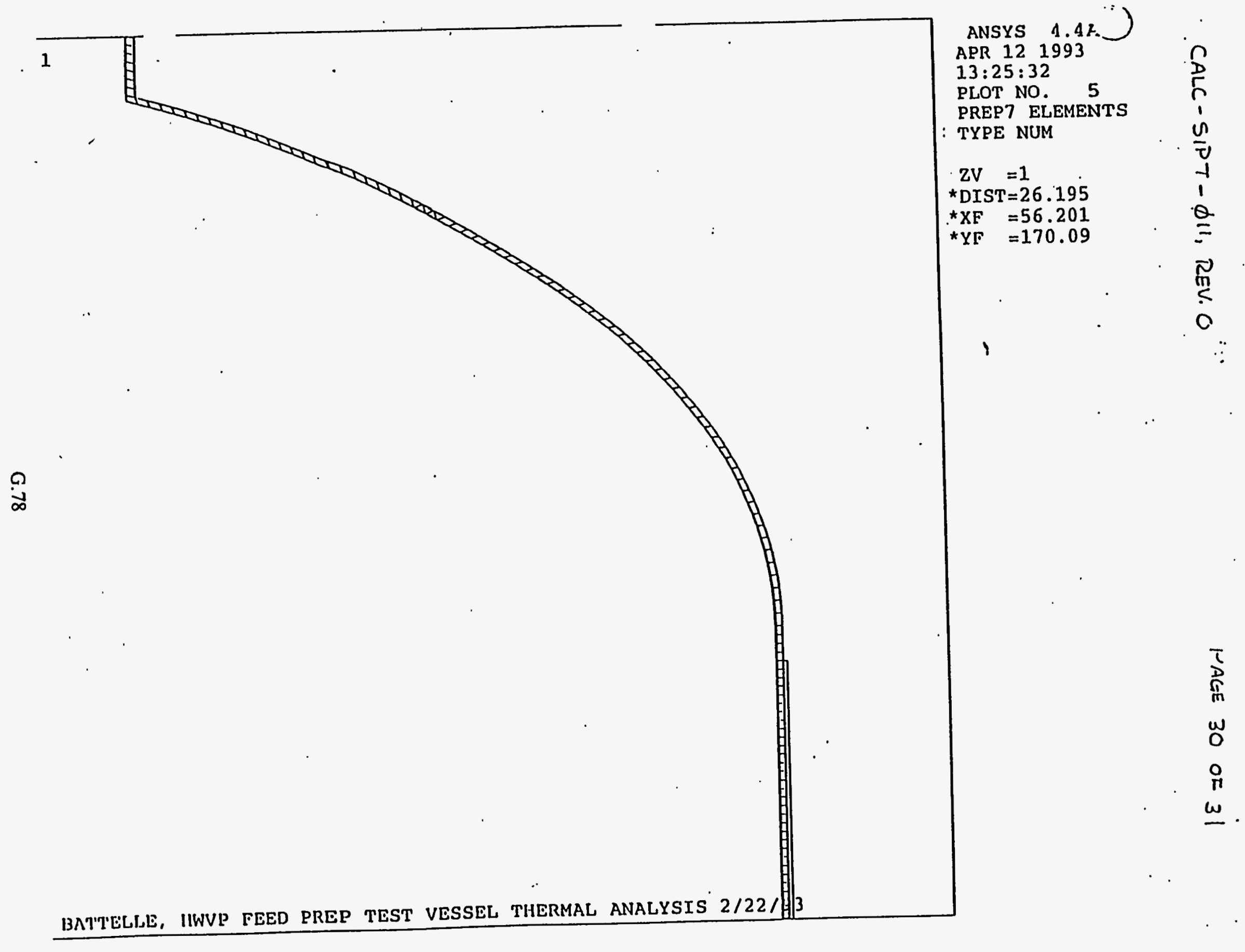




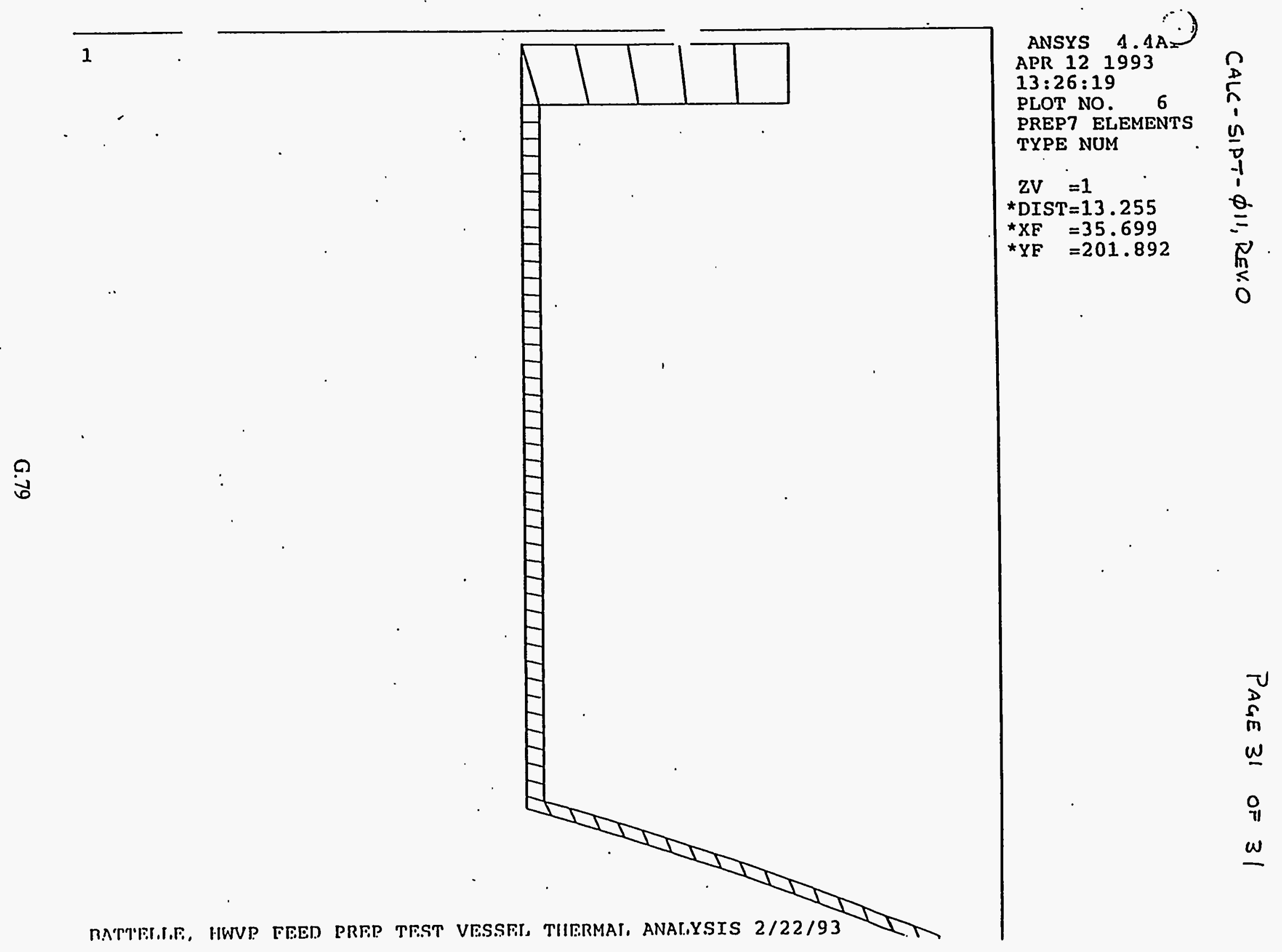


Appendix H

\section{Evaporator Performance Graphs}



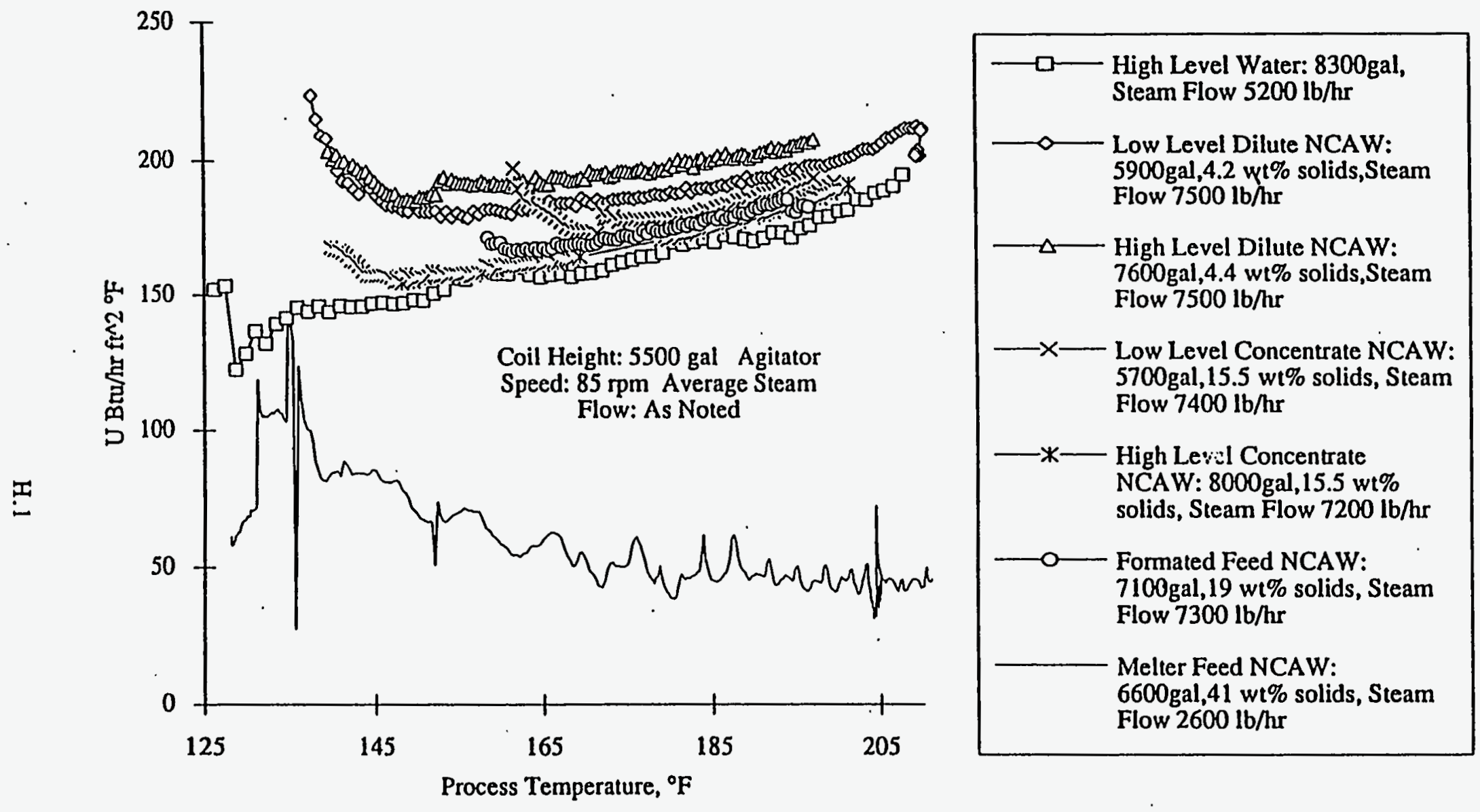

Figure H.1. U Heating Versus Process Temperature, Feed Preparation Cycle - NCAWI 

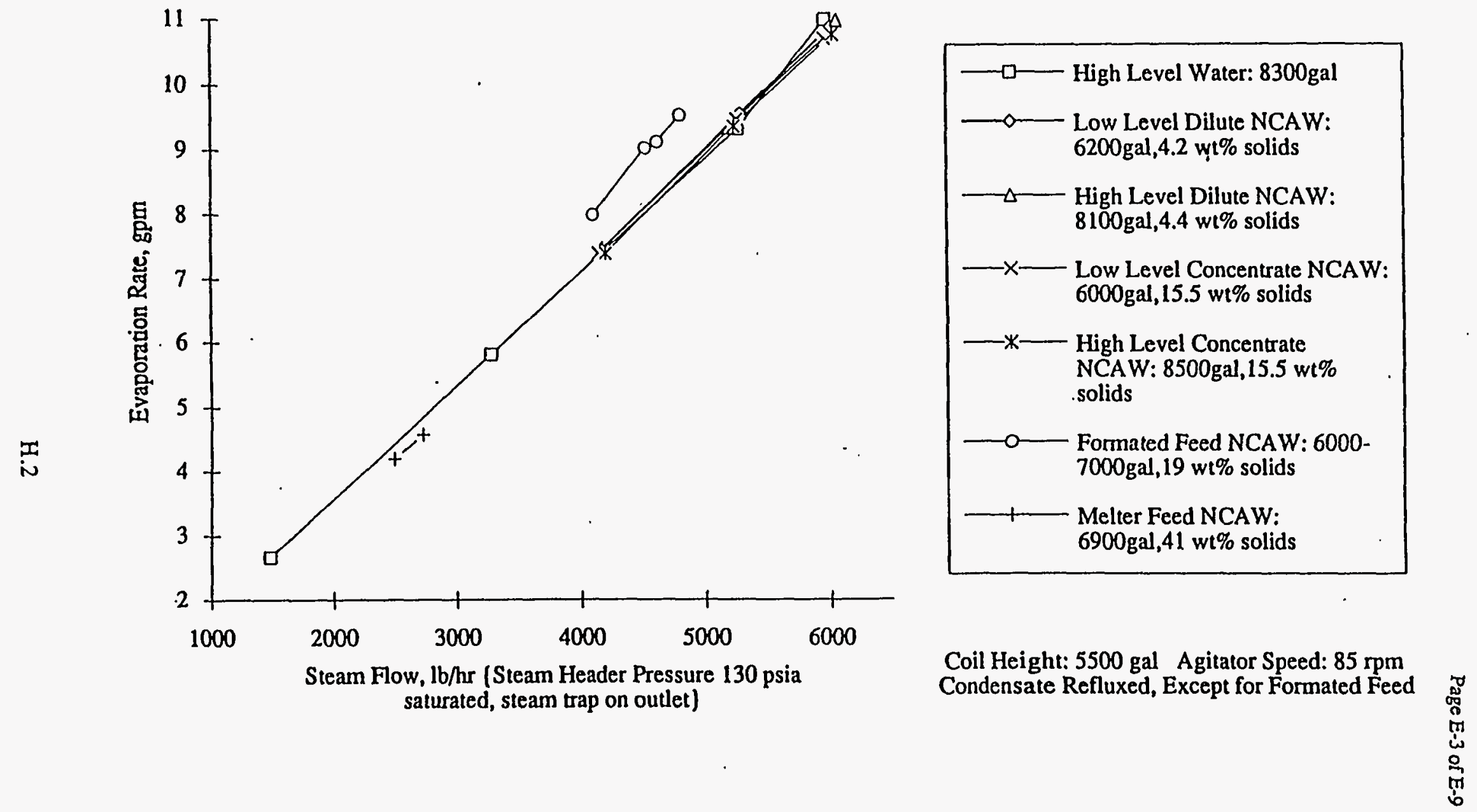

Figure H.2. Evaporation Rate Versus Steam Flow, Feed Preparation Cycle - NCAWI 

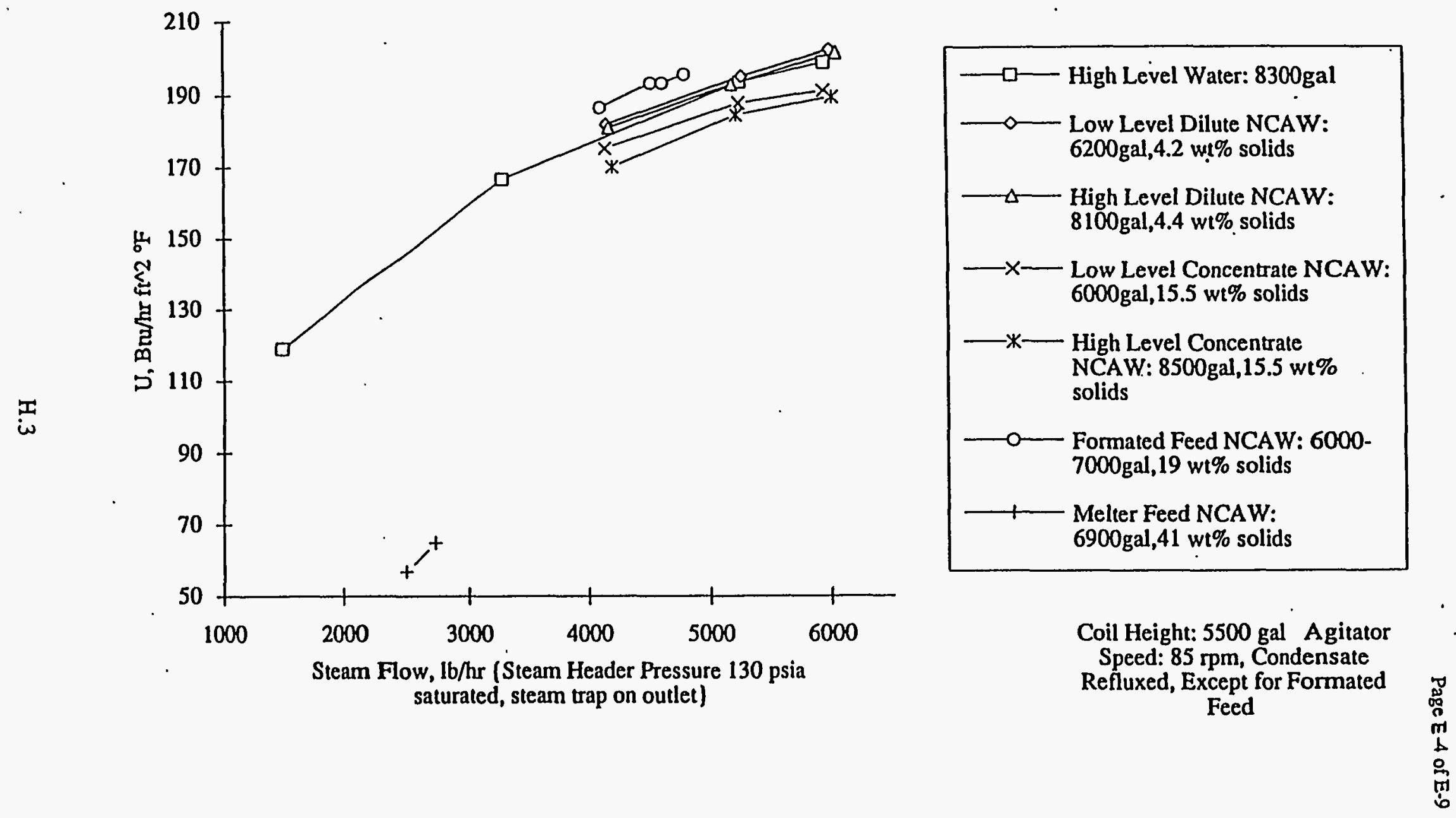

Figure H.3. U Boiling Versus Steam Flow, Feed Preparation Cycle - NCAW1 

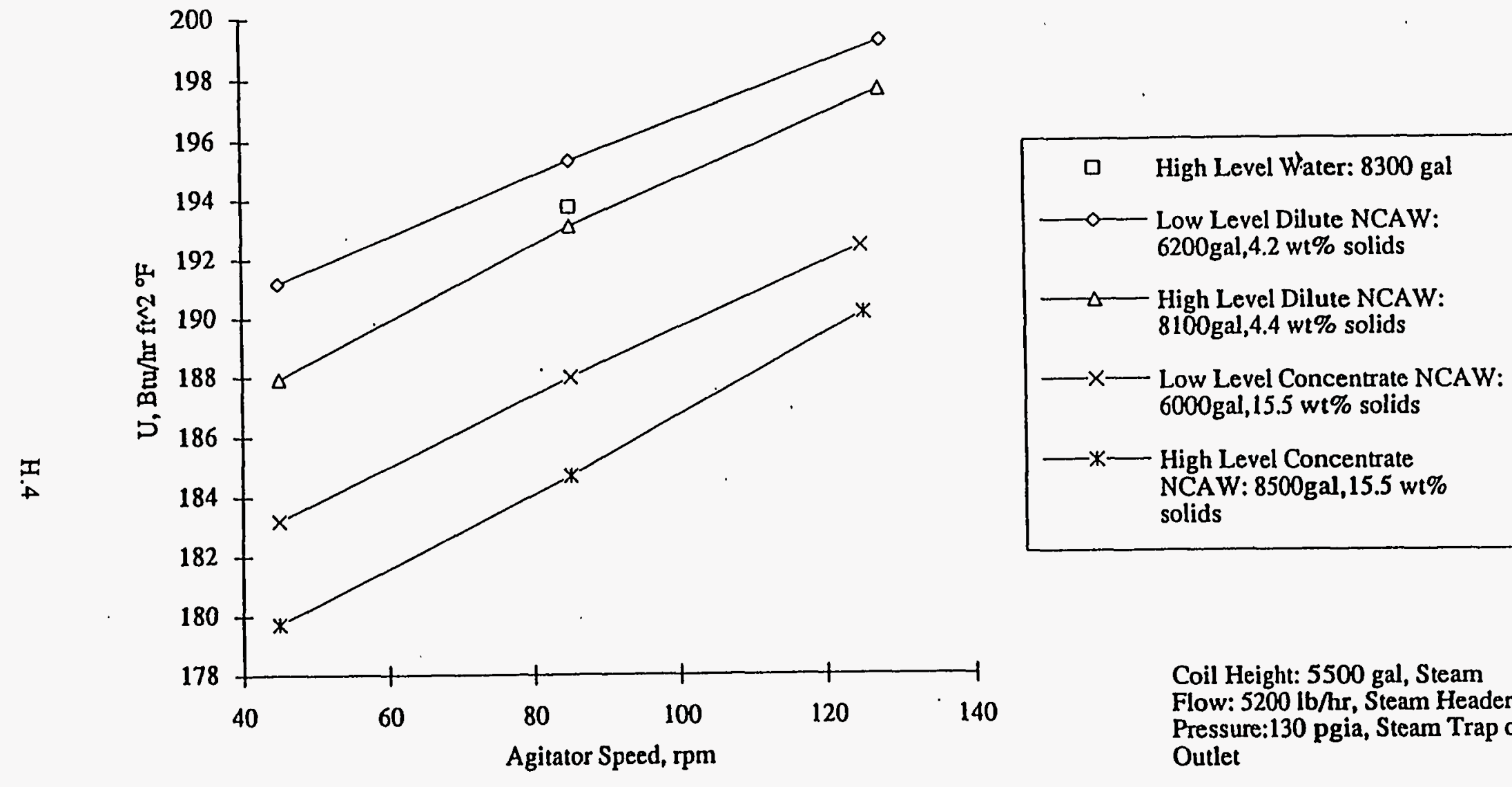

Coil Height: 5500 gal, Steam

Flow: $5200 \mathrm{lb} / \mathrm{hr}$, Steam Header Pressure:130 pgia, Steam Trap on Outlet

Figure H.4. U Boiling Versus Agitator Speed, Feed Preparation Cycle - NCAW1 

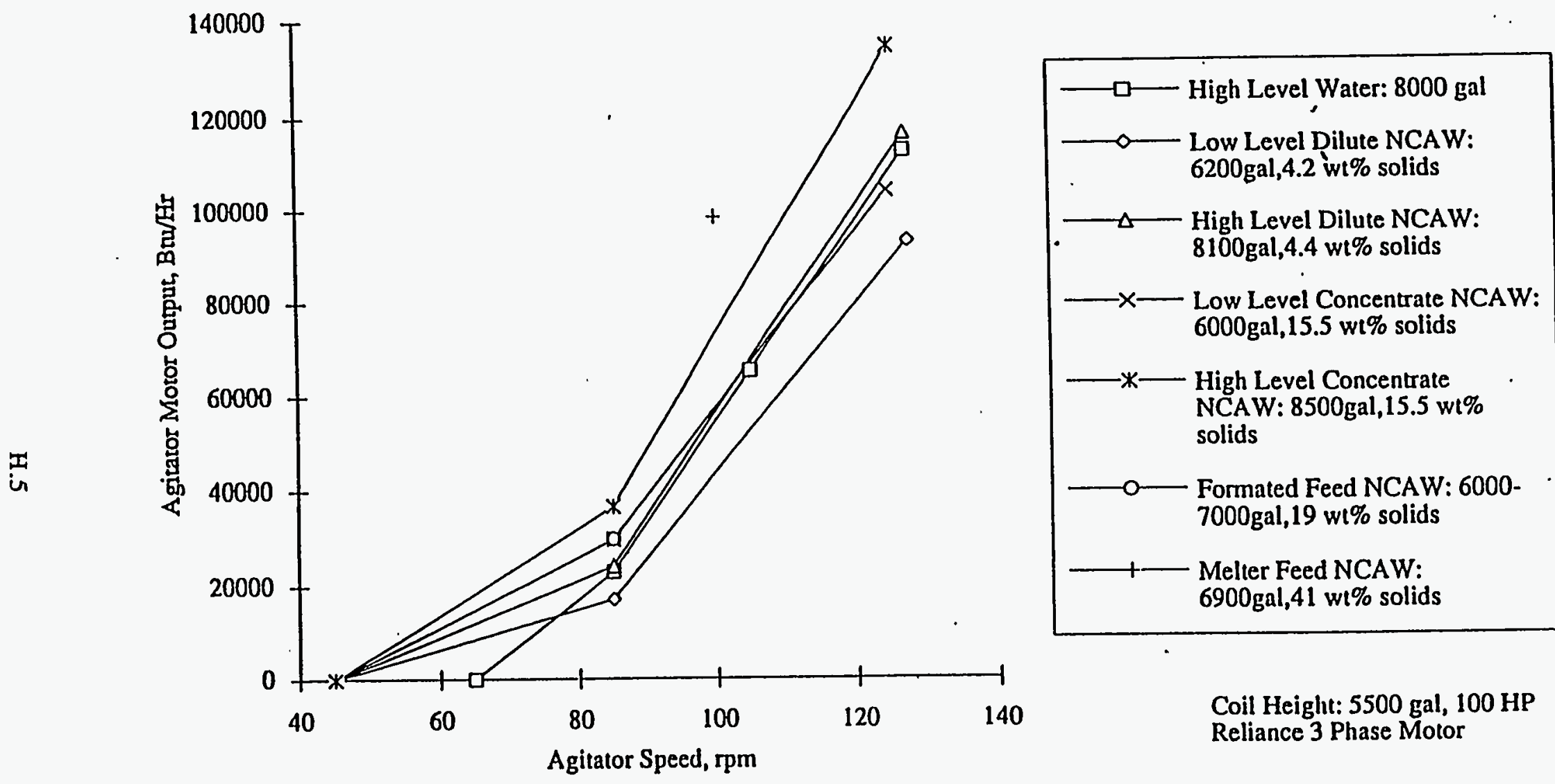

Figure H.5. Agitator Heating Versus Agitator Speed, Feed Preparation Cycle - NCAW1 

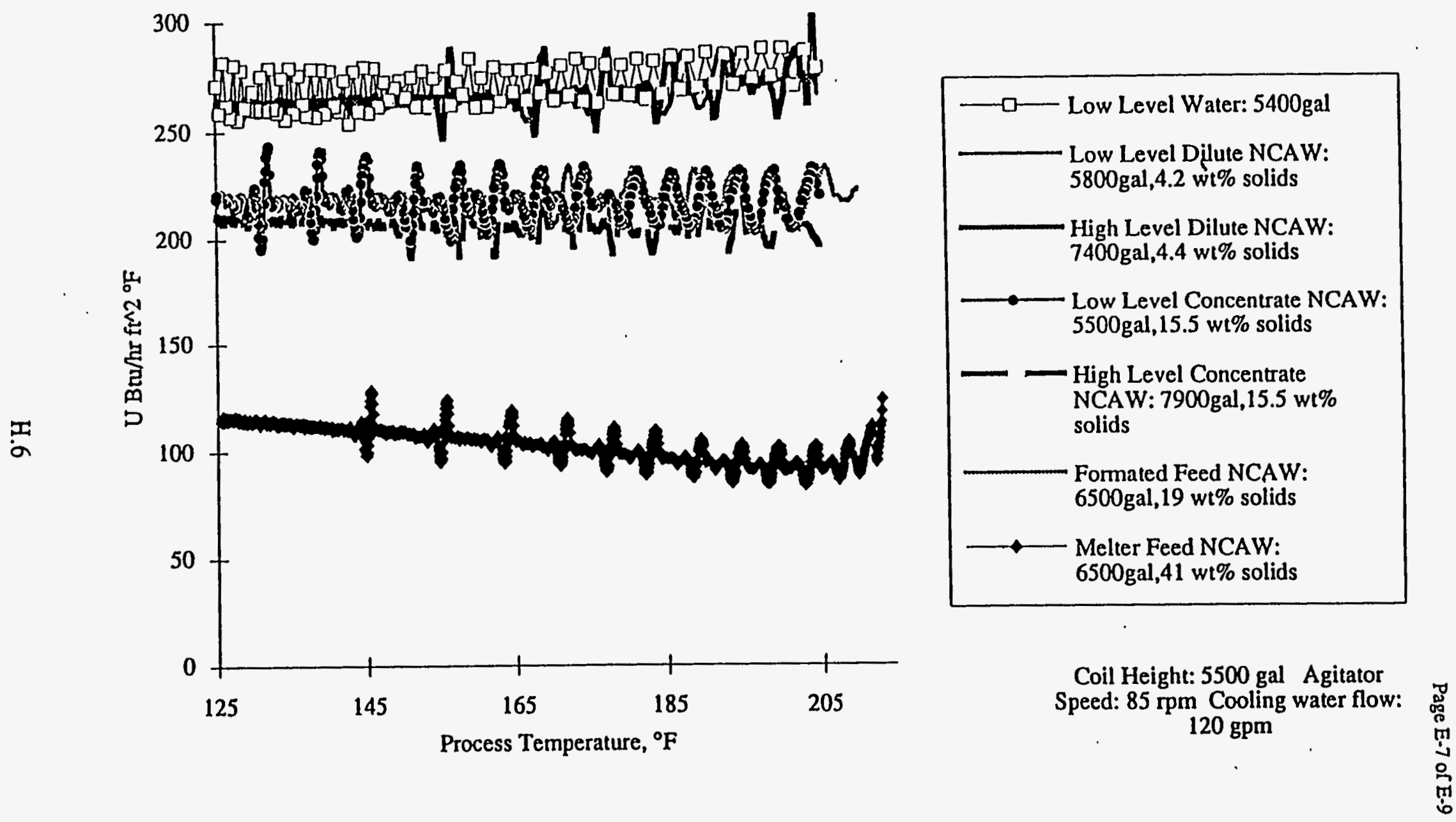

Figure H.6. U Cooling Versus Process Temperature, Feed Preparation Cycle 


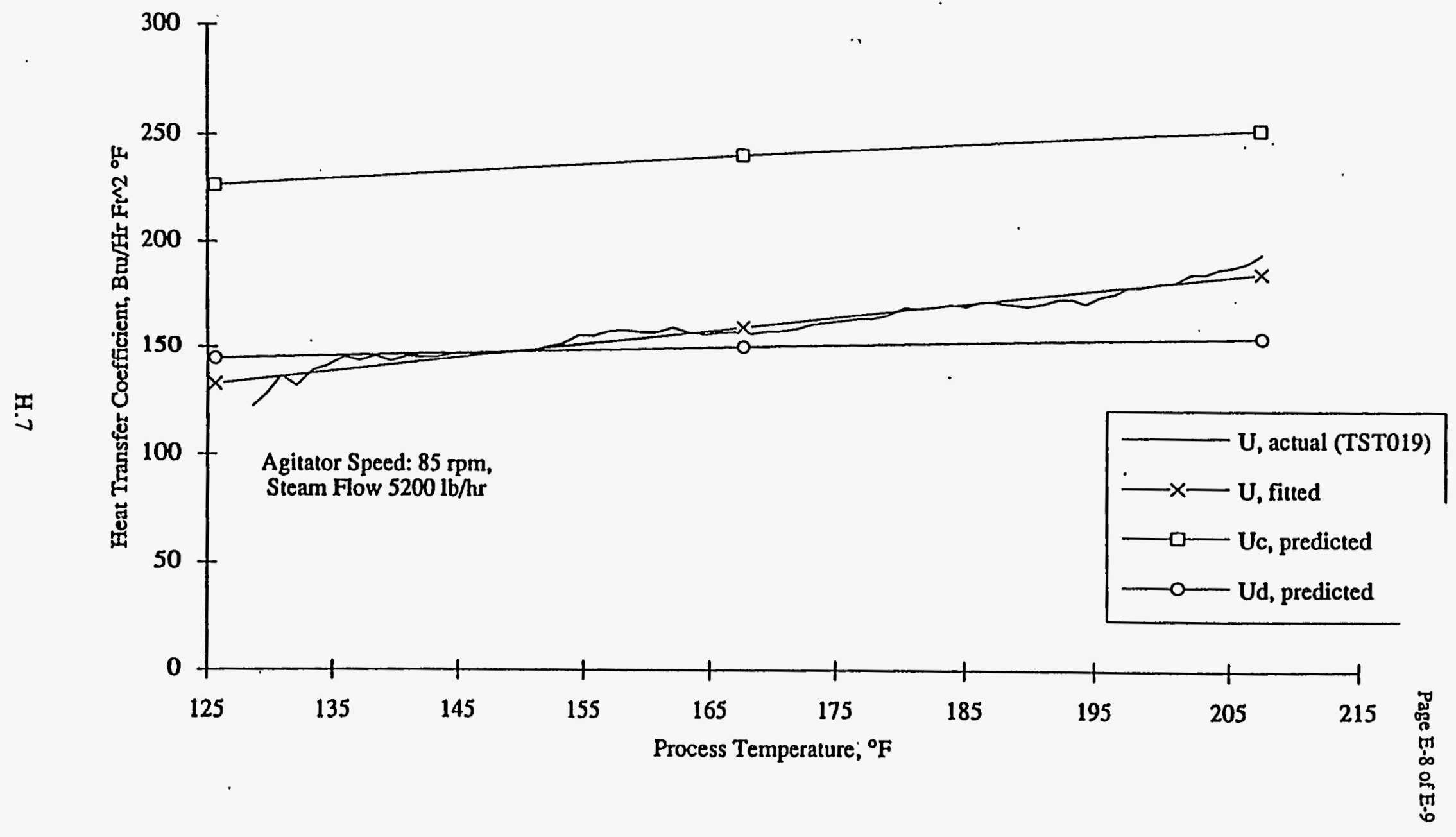

Figure H.7. Transient Heating Heat Transfer Coefficient - Water 
Page E-9 of E-9

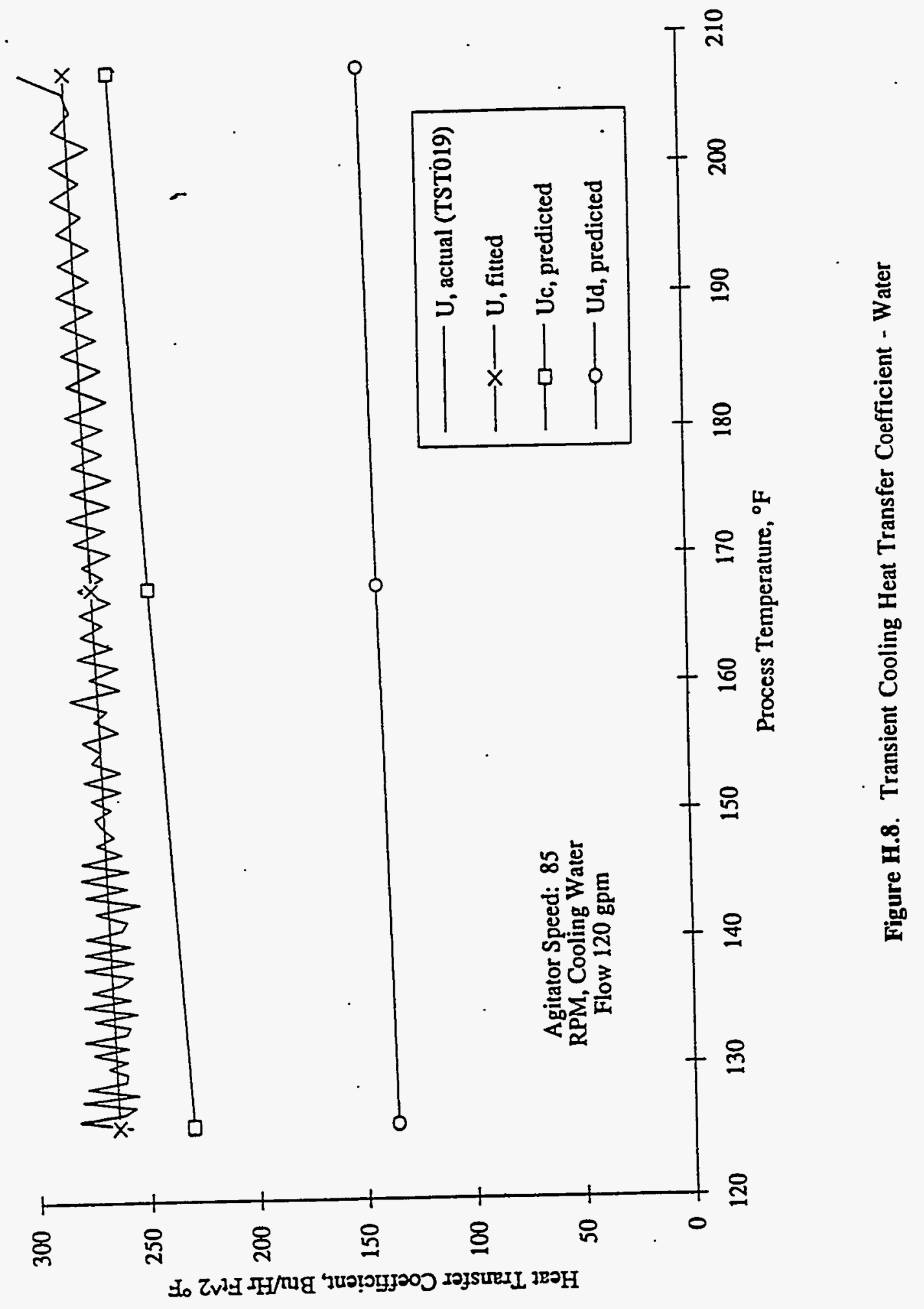




\section{Appendix I}

\section{Tank Heat Transfer Test Summary Tables}


Page D-2 of D-9

\begin{tabular}{|c|c|c|c|c|c|c|}
\hline & Test TST019 & \multicolumn{3}{|c|}{ Evaporator Heat Transfer Calculations } & \multicolumn{2}{|r|}{ v3 } \\
\hline & Start Time & $12: 00$ & $12: 55$ & $13: 20$ & $13: 50$ & $14: 25$ \\
\hline & End Time & $12: 29$ & $13: 19$ & $13: 49$ & $14: 23$ & $15: 28$ \\
\hline & Elapsed Time, min & 29.00 & 24.00 & 29.00 & 33.00 & 63.00 \\
\hline \multirow{10}{*}{ 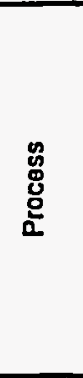 } & Starting Volume, gal & 8197.33 & 7554.30 & 7256.09 & 6880.53 & 6474.46 \\
\hline & Ending Volume, gal & 7858.77 & 7271.22 & 6919.75 & 6497.80 & 5749.48 \\
\hline & Level Change (PDI-1002), gpm & NA & NA. & NA & NA & NA \\
\hline & Level Change (PDI-1003), gpm & NA & NA & NA & NA & NA \\
\hline & Ave. Level Change, gpm ,. & NA & NA & NA & NA & NA \\
\hline & Ave. Temp, ${ }^{\circ} \mathrm{F}$ & 210.65 & 210.93 & 210.34 & 209.65 & 209.34 \\
\hline & Headspace Pressure, psia & NA & NA & NA & NA & NA \\
\hline & Evaporation, Blu/Hr & $5.005 E+06$ & $4.950 E+06$ & $5.036 E+06$ & $4.824 E+06$ & $4.610 E+06$ \\
\hline & Reheat, Btu/Hr & $0.000 E+00$ & $0.000 E+00$ & $0.000 E+00$ & $0.000 E+00$ & $0.000 E+00$ \\
\hline & Tolal Heat, Btu/Hr & $5.005 E+06$ & $4.950 E+06$ & $5.036 E+06$ & $4.824 E+06$ & $4.610 E+06$ \\
\hline \multirow{5}{*}{ 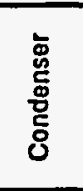 } & Condensate Flow (1), gpm & 10.40 & 10.28 & 10.46 & 10.02 & 9.58 \\
\hline & Condensate Flow (2), gpm & NA & NA & NA & NA & NA \\
\hline & Evaporation Rate, gpm & 10.40 & 10.28 & 10.46 & 10.02 & 9.58 \\
\hline & Condensate Temp, ${ }^{\circ} \mathrm{F}$ & 113.13 & 114.96 & 116.11 & 117.26 & 118.87 \\
\hline & OH-gas Flow, SCFM & 64.96 & 60.35 & 64.15 & 59.71 & 56.70 \\
\hline \multirow{14}{*}{ 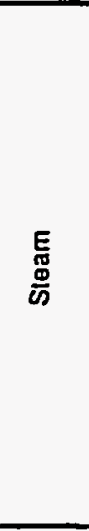 } & Flow. Lb/Hr & 5260.89 & 5237.19 & 5220.43 & 5233.02 & 5057.99 \\
\hline & Header Pressure, psia & 135.41 & 135.77 & 135.53 & 135.86 & 135.79 \\
\hline & Pin, psia & 134.12 & 134.50 & 134.27 & 134.60 & 130.50 \\
\hline & $\operatorname{Tin},{ }^{\circ} \mathrm{F}$ & 349.81 & 350.03 & 349.88 & 350.03 & 349.98 \\
\hline & Tsat at Pin. ${ }^{\circ} \mathrm{F}$ & 349.72 & 349.94 & 349.81 & 350.00 & 347.66 \\
\hline & Vapor $\mathrm{Cp}$ at Tsat, Blu/Lb ${ }^{\circ} \mathrm{F}$ & 0.48 & 0.48 & 0.48 & 0.48 & 0.48 \\
\hline & hig at Tsal, Btu/Lb & 871.52 & 871.34 & 871.45 & 871.29 & 873.26 \\
\hline & Condensate Pout, psia & 125.10 & 125.59 & 125.37 & 125.74 & 121.68 \\
\hline & Condensate Tout, ${ }^{\circ} \mathrm{F}$ & 212.50 & 212.16 & 211.99 & 211.71 & 211.33 \\
\hline & Coil Pressure Drop, psi & 9.02 & 8.91 & 8.90 & 8.86 & 8.82 \\
\hline & Desuperheat Heat, Btu/Hr & $2.304 E+02$ & $2.405 E+02$ & $1.791 E+02$ & $9.311 E+01$ & $5.658 E+03$ \\
\hline & Condense Heat, Btu/Hr & $4.585 E+06$ & $4.563 E+06$ & $4.549 E+06$ & $4.559 E+06$ & 4.417E+06 \\
\hline & Subcool Heat, Btu/Hr. & $7.219 E+05$ & $7.216 E+05$ & $7.195 E+05$ & 7.237E+05 & $6.895 E+05$ \\
\hline & Total Heat. Btu/Hr & $5.307 E+06$ & $5.285 E+06$ & $5.269 E+06$ & $5.283 E+06$ & $5.112 E+06$ \\
\hline \multirow{5}{*}{ 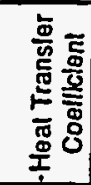 } & Desuperheat LMTD, ${ }^{\circ} \mathrm{F}$ & 139.12 & 139.06 & 139.50 & 140.37 & 139.47 \\
\hline & Condensation $\Delta t$, ${ }^{\circ} \mathrm{F}$ & 139.07 & 139.01 & 139.47 & 140.35 & 138.31 \\
\hline & Subcool LMTD. ${ }^{\circ} \mathrm{F}$ & 31.77 & 29.14 & 31.05 & 32.75 & 32.15 \\
\hline & Weighted $\Delta l,{ }^{\circ} \mathrm{F}$ & 95.29 & 91.78 & 94.44 & 96.79 & 95.69 \\
\hline & Boiling U, Blu/Hr $\mathrm{ft}^{\wedge} 2^{\circ} \mathrm{F}$ & 162.37 & $167.90^{\circ}$ & 162.67 & 159.14 & 155.75 \\
\hline \multirow{5}{*}{$\frac{\text { 喕 }}{\text { 要 }}$} & Speed, rpm & 85.01 & 85.02 & 85.04 & 85.02 & 85.06 \\
\hline & Current, Amps & 34.88 & 34.50 & 34.61 & 34.38 & 34.19 \\
\hline & Voltages, Volts & 460.00 & 460.00 & 460.00 & 460.00 & 460.00 \\
\hline & Motor Horsepower & 9.10 & 8.36 & 8.58 & 8.11 & 7.74 \\
\hline & Agitator Pout, Blu/trs & 23.146 & 21,274 & 21,822 & 20,629 & 19.701 \\
\hline \multirow{4}{*}{ 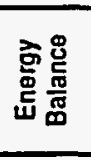 } & Tank Losses, Blu/Hr & 207000 & 207000 & 207000 & 207000 & 207000 \\
\hline & Total Heal in, Blu/Hr & $5.330 E+06$ & $5.306 E+06$ & $5.291 E+06$ & $5.304 E+06$ & $5.132 E+06$ \\
\hline & Total Heat Out, Blu/Hr & $5.212 E+06$ & $5.157 E+06$ & $5.243 E+06$ & $5.031 E+06$ & $4.817 E+06$ \\
\hline & $\%$ Difference & 2.22 & 2.82 & 0.91 & 5.14 & 6.14 \\
\hline
\end{tabular}

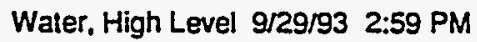


Page D-3 of D-9

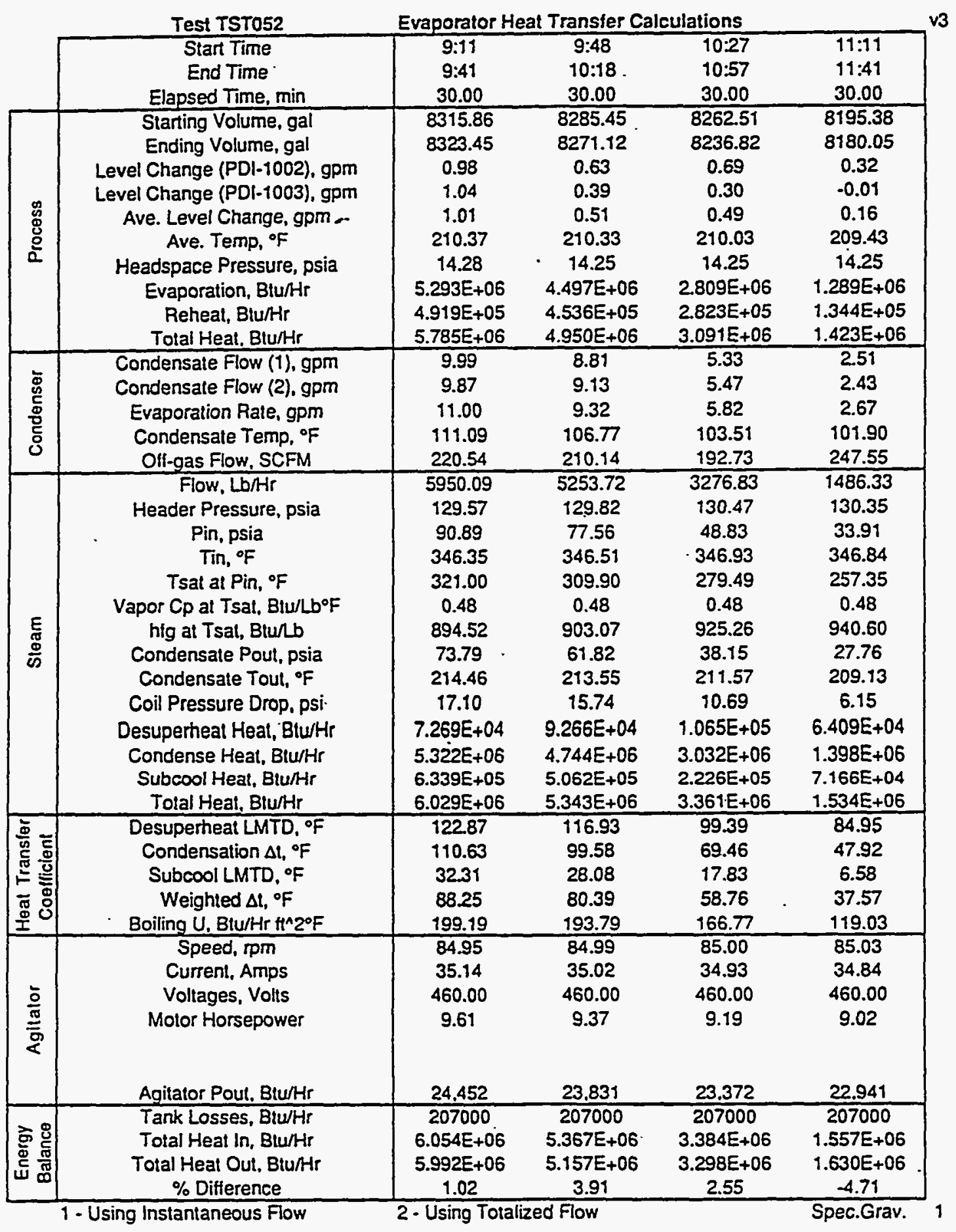

Water, High Level 9/29/93 3:05 PM 


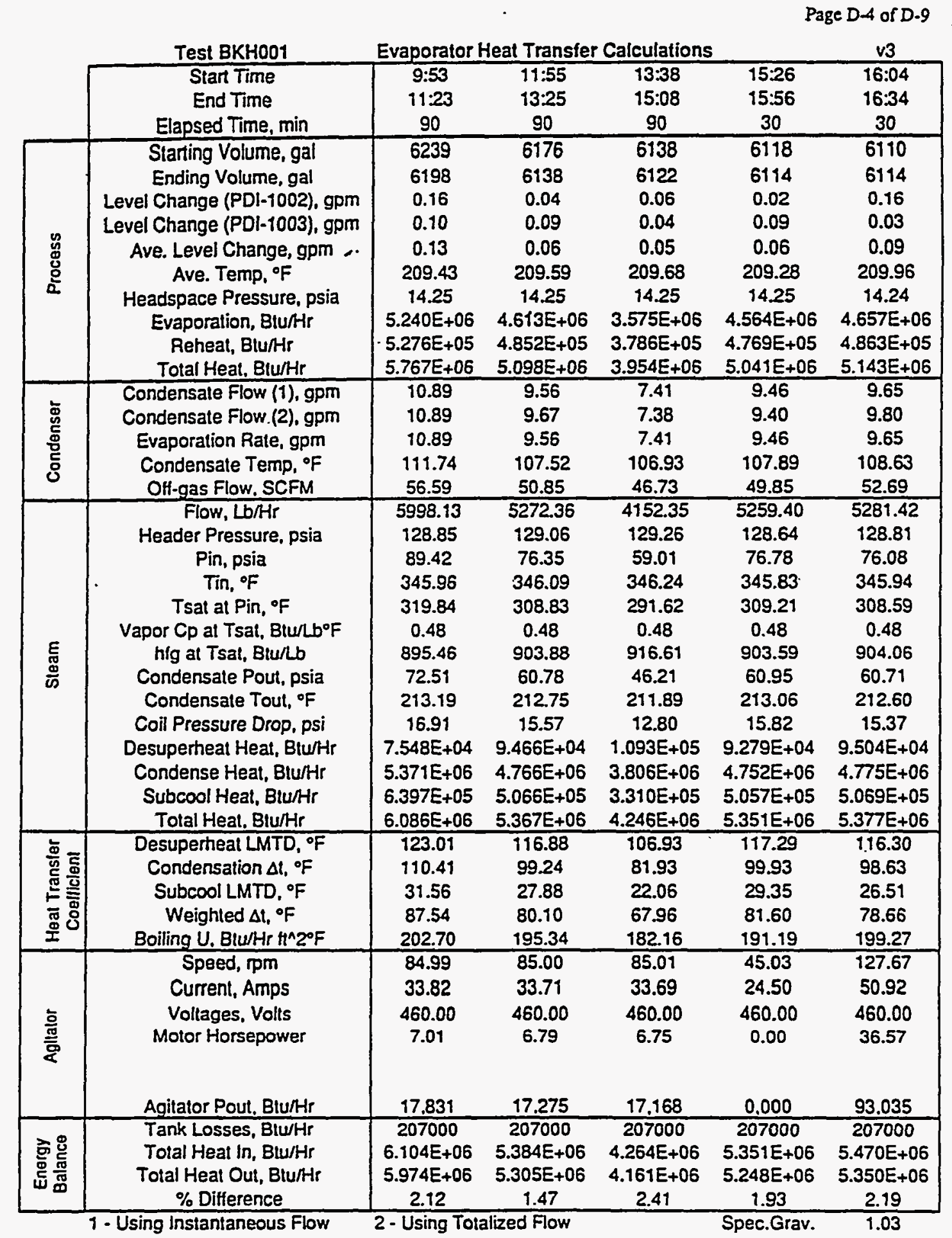

NCAW1 Low Level Dilute 9/29/93 3:07 PM 
Page D.5 of D.9

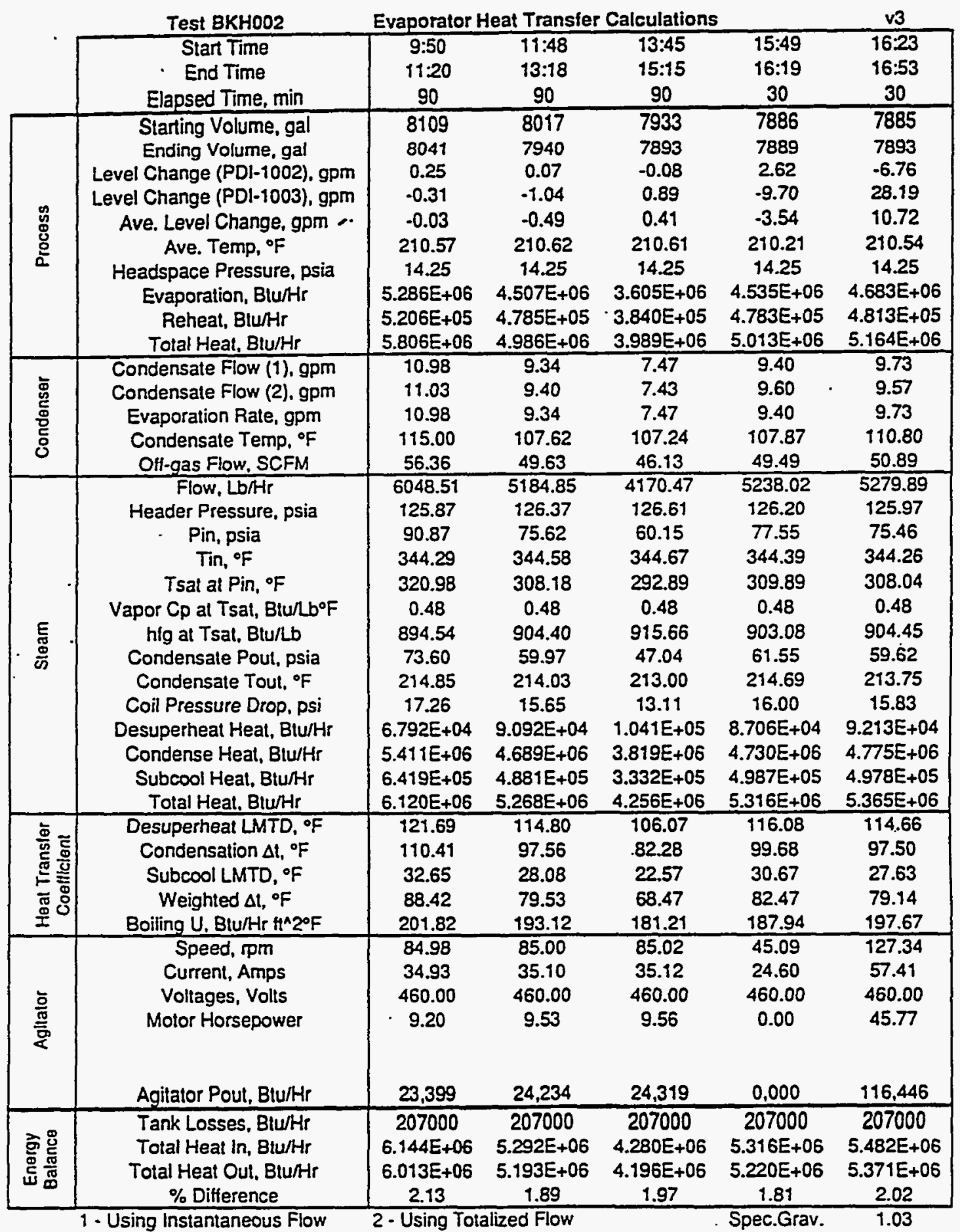

NCAW1 High Level Dilute 9/29/93 3:21 PM 
Page D-6 of D-9

\begin{tabular}{|c|c|c|c|c|c|c|}
\hline & Test BKHOO3 & \multicolumn{3}{|c|}{ Evaporator Heat Transfer Calculations } & \multicolumn{2}{|r|}{ v3 } \\
\hline & Start Time & $9: 28$ & $11: 20$ & $13: 08$ & $14: 50$ & $15: 27$ \\
\hline & End Time & $10: 59$ & $12: 52$ & $14: 39$ & $15: 20$ & $15: 57$ \\
\hline & Elapsed Time, min & 91 & 92 & 91 & 30 & 30 \\
\hline \multirow{10}{*}{ 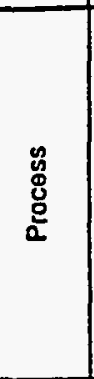 } & Starting Volume, gal & 6023 & 5965 & 5908 & 5901 & 5943 \\
\hline & Ending Volume, gal & 5983 & 5908 & 5897 & 5912 & 5894 \\
\hline & Level Change (PDI-1002), gpm & 0.41 & -0.24 & 0.15 & -2.00 & -0.01 \\
\hline & Level Change (PDI-1003), gpm & 0.38 & -0.50 & 0.88 & -1.48 & -1.82 \\
\hline & Ave. Level Change, gpm ,. & 0.39 & -0.37 & 0.52 & -1.74 & -0.92 \\
\hline & Ave. Temp, ${ }^{\circ} \mathrm{F}$ & 210.43 & 211.05 & 211.28 & 210.99 & 211.51 \\
\hline & Headspace Pressure, psia & 14.25 & 14.26 & 14.25 & 14.25 & 14.26 \\
\hline & Evaporation, Btu/Hr & 5.167E+06 & $4.570 E+06$ & $3.570 E+06$ & $4.676 E+06$ & 4.738E+06 \\
\hline & Reheal, Blu/Hr & $5.423 E+05$ & $4.948 E+05$ & $3.894 E+05$ & $5.043 E+05$ & $5.101 E+05$ \\
\hline & Total Heal, Btu/Hr & $5.709 E+06$ & $5.065 E+06$ & $3.959 E+06$ & $5.181 E+06$ & $5.249 E+06$ \\
\hline \multirow{5}{*}{ 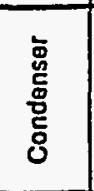 } & Condensate Flow (1), gpm & 10.71 & 9.47 & 7.40 & 9.69 & 9.82 \\
\hline & Condensate Flow (2), gpm & 10.74 & 9.41 & 7.31 & 8.43 & 9.67 \\
\hline & Evaporation Rate, gpm & 10.71 & 9.47 & 7.40 & 9.69 & 9.82 \\
\hline & Condensale Temp, ${ }^{\circ} \mathrm{F}$ & 108.60 & 106.00 & 105.44 & 106.36 & 107.05 \\
\hline & Off-gas Flow, SCFM & 40.27 & 36.70 & 33.66 & 37.78 & 36.64 \\
\hline \multirow{14}{*}{$\begin{array}{l}E \\
\text { E } \\
\text { ळ }\end{array}$} & Flow, Lb/Hr & 5946.43 & 5244.77 & 4140.09 & 5324.88 & 5334.84 \\
\hline & Header Pressure, psia & . 128.82 & 131.52 & 131.71 & 130.43 & 129.95 \\
\hline & Pin, psia & 91.96 & 78.81 & 61.77 & 82.11 & 81.14 \\
\hline & Tin, of & 345.97 & 347.53 & 347.65 & 346.90 & 346.62 \\
\hline & Tsat at Pin, ${ }^{\circ} \mathrm{F}$ & 321.82 & 311.01 & 294.60 & 313.85 & 313.03 \\
\hline & Vapor Cp at Tsat, Btu/Lb ${ }^{\circ} F$ & 0.48 & 0.48 & 0.48 & 0.48 & 0.48 \\
\hline & hig at Tsat, Btu/Lb & 893.88 & 903.22 & 914.40 & 900.04 & 900.67 \\
\hline & Condensate Pout, psia & 74.57 & 62.71 & 48.19 & 66.12 & 64.88 \\
\hline & Condensate Tout, ${ }^{\circ} \mathrm{F}$ & 216.44 & 215.52 & 214.31 & 216.57 & 215.02 \\
\hline & Coil Pressure Drop, psi & 17.39 & 16.10 & 13.58 & 15.99 & 16.26 \\
\hline & Desupertieat Heat, Btu/Hr & $6.920 E+04$ & $9.228 E+04$ & $1.058 E+05$ & $8.479 E+04$ & $8.633 E+04$ \\
\hline & Condense Heal, Btu/Hr & $5.315 E+06$ & $4.737 E+06$ & $3.786 E+06$ & $4.793 E+06$ & $4.805 E+06$ \\
\hline & Subcool Heat, Blu/Hr & $6.267 E+05$ & $5.008 E+05$ & $3.324 E+05$ & $5.180 E+05$ & $5.229 E+05$ \\
\hline & Total Heat. Blu/Hr & $6.011 E+06$ & $5.330 E+06$ & $4.224 E+06$ & $5.395 E+06$ & $5.414 E+06$ \\
\hline \multirow{5}{*}{ 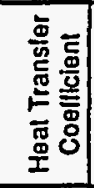 } & Desuperheat LMTD, ${ }^{\circ} \mathrm{F}$ & 123.07 & 117.27 & 107.67 & 118.61 & 1.17 .52 \\
\hline & Condensation $\Delta t$, ${ }^{\circ} \mathrm{F}$ & 111.39 & 99.96 & 83.31 & 102.86 & 101.52 \\
\hline & Subcool LMTD, of & 36.08 & 30.72 & 24.21 & 33.37 & 29.14 \\
\hline & Weighted $\Delta t .^{\circ} \mathrm{F}$ & 91.56 & 82.67 & 70.22 & 85.87 & 82.02 \\
\hline & Boiling U. Blu/Hr $\mathrm{H}^{\wedge} 2^{\circ} \mathrm{F}$ & 191.40 & 187.99 & 175.36 & 183.19 & 192.44 \\
\hline \multirow{5}{*}{ 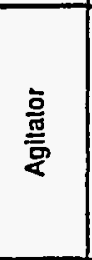 } & Speed, $\mathrm{pm}$ & 85.01 & 85.02 & 85.03 & 45.04 & 124.84 \\
\hline & Current, Amps & 36.22 & 36.24 & 36.17 & 25.01 & 53.86 \\
\hline & Voltages, Votts & 460.00 & 460.00 & 460.00 & 460.00 & 460.00 \\
\hline & Motor Horsepower & 11.68 & 11.72 & 11.59 & 0.00 & 40.86 \\
\hline & Agitator Pout, Blu/Hr & 29.718 & 29.824 & 29.492 & 0.000 & 103,951 \\
\hline \multirow{5}{*}{ 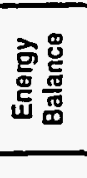 } & Tank Losses, Btu/Hr & 207000 & 207000 & 207000 & 207000 & 207000 \\
\hline & Total Heal in, Blu/Hr & $6.041 E+06$ & $5.360 E+06$ & $4.253 E+06$ & $5.395 E+06$ & $5.518 E+06$ \\
\hline & Total Heat Out, Blu/Hr & $5.916 E+06$ & $5.272 E+06$ & $4.166 E+06$ & $5.388 E+06$ & $5.456 E+06$ \\
\hline & $\%$ Difference & 2.06 & 1.64 & 2.06 & 0.15 & 1.13 \\
\hline & 1 - Using Instantaneous Flow & 2. Using Tol & zed Flow & & Spec.Grav. & 1.11 \\
\hline
\end{tabular}

NCAW1 Low Level Concentrate 9/29/93 3:10 PM 
Page D-7 of D-9

\begin{tabular}{|c|c|c|c|c|c|c|}
\hline & Test BKHOO4 & \multicolumn{3}{|c|}{ Evaporator Heat Transfer Calculations } & \multicolumn{2}{|r|}{ v3 } \\
\hline & Start Time & $14: 57$ & $10: 48$ & $8: 53$ & $12: 30$ & $13: 06$ \\
\hline & End Time & $16: 28$ & $12: 20$ & $10: 24$ & 13:00 & $13: 36$ \\
\hline & Elapsed Time, min & 91 & 92 & 91 & 30 & 30 \\
\hline \multirow{10}{*}{$\begin{array}{l}\text { : } \\
\text { : } \\
0 \\
0\end{array}$} & Starting Volume, gal & 8505 & 8428 & 8450 & 8383 & 8373 \\
\hline & Ending Volume, gal & 8469 & 8390 & 8432 & 8373 & 8362 \\
\hline & Level Change (PDI-1002), gpm & 4.38 & 0.14 & -0.14 & -0.07 & 0.11 \\
\hline & Level Change (PDI-1003), gpm & 0.67 & 0.17 & -0.30 & -1.40 & 5.33 \\
\hline & Ave. Level Change, gpm & 2.53 & 0.15 & -0.22 & -0.73 & 2.72 \\
\hline & Ave. Temp, ${ }^{\circ} \mathrm{F}$ & 211.46 & 211.78 & 211.46 & 211.60 & 211.86 \\
\hline & Headspace Pressure, psia & 14.25 & 14.25 & 14.26 & 14.25 & 14.26 \\
\hline & Evaporation, Bturtir & $5.181 E+06$ & $4.518 E+06$ & $3.569 E+06$ & $4.504 E+06$ & $4.633 E+06$ \\
\hline & Reheat, Btu/Hr & $5.407 E+05$ & $5.021 E+05$ & $3.971 E+05$ & $4.998 E+05$ & $5.136 E+05$ \\
\hline & Total Heat. Blu/Hr & $5.722 E+06$ & $5.021 E+06$ & $3.966 E+06$ & $5.004 E+06$ & $5.147 E+06$ \\
\hline \multirow{5}{*}{ 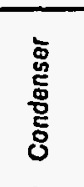 } & Condensate Flow (1), gpm & 10.77 & 9.36 & 7.40 & 9.34 & 9.60 \\
\hline & Condensate Flow (2), gpm & 10.81 & 9.43 & 7.37 & 9.37 & 9.60 \\
\hline & Evaporation Rate, gpm & 10.77 & 9.36 & 7.40 & 9.34 & 9.60 \\
\hline & Condensate Temp. ${ }^{\circ} \mathrm{F}$ & 110.20 & 103.95 & 103.51 & 103.94 & 104.30 \\
\hline & OH-gas Flow, SCFM & 39.79 & 35.42 & 32.55 & 35.56 & 35.32 \\
\hline \multirow{14}{*}{ 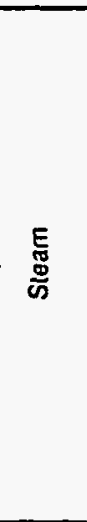 } & Flow, Lb/Hr & 6011.31 & 5222.61 & 4199.01 & 5236.00 & 5229.21 \\
\hline & Header Pressure, psia & 128.97 & 130.72 & 132.11 & 131.15 & 130.44 \\
\hline & Pin, psia & 93.40 & 78.25 & 62.55 & 78.91 & 77.78 \\
\hline & Tin, ${ }^{\circ} F$ & 346.08 & 347.07 & 347.92 & 347.32 & 346.91 \\
\hline & Tsat at Pin, of & 322.93 & 310.52 & 295.42 & 311.10 & 310.10 \\
\hline & Vapor $\mathrm{Cp}$ at Tsat, Btu/Lb॰F & 0.48 & 0.48 & 0.48 & 0.48 & 0.48 \\
\hline & hig at Tsat. Btu/Lb & 893.01 & 902.60 & 913.79 & 902.15 & 902.92 \\
\hline & Condensate Pout. psia & 75.49 & 61.66 & 48.34 & 62.50 & 61.26 \\
\hline & Condensale Tout, ${ }^{\circ} \mathrm{F}$ & 218.77 & 217.57 & 216.62 & 219.31 & 216.16 \\
\hline & Coil Pressure Drop, psi & 17.91 & 16.59 & 14.21 & 16.41 & 16.53 \\
\hline & Desuperheat Heat, Blu/Hr & $6.704 E+04$ & $9.198 E+04$ & $1.062 E+05$ & $9.138 E+04$ & $9.275 E+04$ \\
\hline & Condense Heat, Btu/Hr & $5.368 E+06$ & $4.714 E+06$ & $3.837 E+06$ & $4.724 E+06$ & $4.722 E+06$ \\
\hline & Subcool Heat, Btu/Hr & $6.261 E+05$ & $4.854 E+05$ & $3.309 E+05$ & $4.806 E+05$ & $4.912 E+05$ \\
\hline & Total Heat, Blurtir & $6.061 E+06$ & $5.291 E+06$ & 4.274E+06 & $5.296 E+06$ & $5.306 \mathrm{E}+06$ \\
\hline \multirow{5}{*}{ 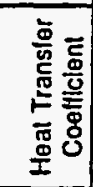 } & Desuperheat LMTD, ${ }^{\circ} \mathrm{F}$ & 122.68 & 116.06 & 108.09 & 116.68 & 115.67 \\
\hline & Condensation $\Delta t$, of & 111.47 & 98.74 & 83.95 & 99.51 & 98.24 \\
\hline & Subcool LMTD, ${ }^{\circ} \mathrm{F}$ & 38.23 & 32.77 & 28.24 & 35.89 & 30.03 \\
\hline & Weighted $\Delta t$ of $^{\circ} \mathrm{F}$ & 93.14 & 83.53 & 73.18 & 85.90 & 81.35 \\
\hline & Boiling U. Btu/Hr $t^{\wedge} 2^{\circ} F$ & 189.74 & 184.68 & 170.27 & 179.73 & 190.15 \\
\hline \multirow{5}{*}{ 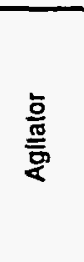 } & Speed, rpm & 84.99 & 85.02 & 85.01 & 45.04 & 125.10 \\
\hline & Current, Amps & 37.47 & 37.68 & 37.58 & 25.02 & 62.99 \\
\hline & Voltages, Volts & 460.00 & 460.00 & 460.00 & 460.00 & 460.00 \\
\hline & Motor Horsepower & 14.05 & 14.43 & 14.24 & 0.00 & 52.94 \\
\hline & Agitator Pout, Btu/Hr & 35,738 & 36.719 & 36.232 & 0,000 & 134.672 \\
\hline \multirow{5}{*}{ 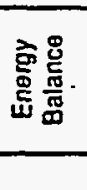 } & Tank Losses, Blu/Hr & 207000 & 207000 & 207000 & 207000 & 207000 \\
\hline & Total Heal In, Blu/Hr & $6.097 E+0.06$ & $5.328 E+06$ & $4.310 E+06$ & $5.296 E+06$ & $5.440 E+06$ \\
\hline & Total Heat Out, Btu/Hr & $5.929 E+06$ & $5.228 E+06$ & $4.173 E+06$ & $5.211 E+06$ & $5.354 E+06$ \\
\hline & $\%$ Difference & 2.76 & 1.89 & 3.18 & 1.60 & 1.59 \\
\hline & 1 - Using Instantaneous Flow & - Using To & zed Flow & & Spec.Grav. & 1.11 \\
\hline
\end{tabular}

NCAW1 High Level Concentrate 9/29/93 4:13 PM 
Page D-8 of D-9

\begin{tabular}{|c|c|c|c|c|c|}
\hline & Test RYC001 & Evaporator $\mathrm{H}$ & leat Transfer & Calculations & v3 \\
\hline & Slant Time & $11: 38$ & $12: 08$ & $12: 38$ & $12: 58$ \\
\hline & End Time & $12: 08$ & $12: 38$ & $12: 58$ & $13: 38$ \\
\hline & Elapsed Time, $\min$ & 30 & 30 & 20 & 40 \\
\hline \multirow{10}{*}{$\begin{array}{l}\text { : } \\
8 \\
8 \\
0\end{array}$} & Slarting Volume, gal & 7065 & 6793 & 6540 & 6384 \\
\hline & Ending Volume, gal & 6793 & 6540 & 6384 & 6088 \\
\hline & Level Change (PDl-1002), gpm & 7.29 & 7.07 & -2.94 & 3.40 \\
\hline & Level Change (PDI-1003), gpm & 243 & 17.57 & 6.55 & 6.62 \\
\hline & Ave. Level Change, gpm & 4.86 & 12.32 & 1.80 & 5.01 \\
\hline & Ave. Temp, ${ }^{\circ} \mathrm{F}$ & 212.29 & 212.41 & 212.44 & 212.81 \\
\hline & Headspace Pressure, psia & 14.25 & 14.25 & 14.25 & 14.25 \\
\hline & Evaporation, Blu/Hr & $4.404 E+06$ & 4.357E+06 & $3.859 E+06$ & 4.603E+06 \\
\hline & Reheat, Btu/Hr & $0.000 E+00$ & $0.000 E+00$ & $0.000 E+00$ & $0.000 E+00$ \\
\hline & - Total Heat. Btu/Hr & $4.404 E+06$ & 4.357E+06 & $3.859 E+06$ & $4.603 E+06$ \\
\hline \multirow{5}{*}{ 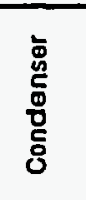 } & Condensate Flow (1), gpm & 9.13 & 9.03 & 8.00 & 9.54 \\
\hline & Condensate Flow (2), gpm & 9.57 & 8.37 & 8.00 & 9.55 \\
\hline & Evaporation Rate, gpm & 9.13 & 9.03 & 8.00 & 9.54 \\
\hline & Condensate Temp, ${ }^{\circ} \mathrm{F}$ & 107.81 & 107.32 & 105.43 & 107.41 \\
\hline & Off-gas Flow, SCFM & 78.90 & 75.72 & 66.97 & 76.60 \\
\hline \multirow{14}{*}{$\begin{array}{l}\text { E } \\
\text { कू }\end{array}$} & Flow, Lb/Hr & 4612.11 & 4518.95 & 4096.88 & 4794.60 \\
\hline & Header Pressure, psia & 127.36 & 124.67 & 111.70 & 132.19 \\
\hline & Pin, psia & 58.74 & 57.44 & 53.37 & 60.91 \\
\hline & Tin, ${ }^{\circ} \mathrm{F}$ & 344.97 & 343.39 & 334.96 & 347.72 \\
\hline & Tsal at $\mathrm{Pin},{ }^{\circ} \mathrm{F}$ & 291.31 & 289.85 & 285.12 & 293.69 \\
\hline & Vapor Cp at Tsat, Blu/LboF & 0.48 & 0.48 & 0.48 & 0.48 \\
\hline & hig at Tsat, Btunb & 916.83 & 917.91 & 921.26 & 915.07 \\
\hline & Condensate Pout. psia & 40.41 & 39.67 & 38.05 & 41.75 \\
\hline & Condensate Tout, ${ }^{\circ} \mathrm{F}$ & 218.49 & 218.29 & 217.29 & 219.79 \\
\hline & Coil Pressure Drop, psi & 18.33 & 17.76 & 15.32 & 19.16 \\
\hline & Desuperheat Heat, Btu/Hr & $1.192 E+05$ & $1.166 E+05$ & $9.839 E+04$ & $1.248 E+05$ \\
\hline & Condense Heat, Btu/Hr & $4.229 E+06$ & $4.148 E+06$ & $3.774 E+06$ & $4.387 E+06$ \\
\hline & Subcool Heat, Blu/Hr & $3.358 E+05$ & $3.234 E+05$ & $2.779 E+05$ & $3.543 E+05$ \\
\hline & Total Heat. Blu/Hr & $4.684 E+06$ & $4.588 E+06$ & $4.151 E+06$ & $4.867 E+06$ \\
\hline \multirow{5}{*}{ 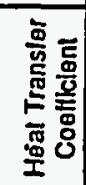 } & Desuperheat LMTD, ${ }^{\circ} \mathrm{F}$ & 103.55 & 101.87 & 95.44 & 105.60 \\
\hline & Condensation $\Delta t,{ }^{\circ} \mathrm{F}$ & 79.02 & 77.44 & 72.68 & 80.88 \\
\hline & Subcool LMTD, ${ }^{\circ} \mathrm{F}$ & 28.62 & 27.76 & 25.05 & 30.16 \\
\hline & Weighted $\Delta t{ }^{\circ} \mathrm{F}$ & 70.54 & 69.14 & 64.80 & 72.44 \\
\hline & Boiling U, Blu/Hr $/ t^{\wedge} 2^{\circ} \mathrm{F}$ & 193.58 & 193.47 & 186.74 & 195.85 \\
\hline \multirow{5}{*}{$\frac{\text { 亭 }}{\frac{\bar{c}}{8}}$} & Speed, rpm & 85.02 & 85.03 & 85.02 & 85.08 \\
\hline & Current, Amps & 36.26 & 36.19 & 36.31 & 36.55 \\
\hline & Voltages, Volts & 460.00 & 460.00 & 460.00 & 460.00 \\
\hline & Motor Horsepower & 11.75 & 11.63 & 11.85 & 12.31 \\
\hline & Agitator Pout, Btu/Hr & 29,899 & 29.582 & 30.134 & 31,321 \\
\hline \multirow{4}{*}{ 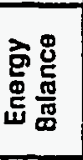 } & Tank Losses, Btu/Hr & 207000 & 207000 & 207000 & 207000 \\
\hline & Total Heat In, Btu/Hr & $4.714 E+06$ & $4.618 E+06$ & $4.181 E+06$ & $4.898 E+06$ \\
\hline & Total Heat Out, Blu/Hr & $4.611 E+06$ & $4.564 E+06$ & $4.066 E+06$ & $4.810 E+06$ \\
\hline & $\begin{array}{c}\% \text { Difference } \\
\text { - Using Instantaneous Flow }\end{array}$ & $\frac{2.17}{2-\text { Using Tota }}$ & $\frac{1.16}{\text { lized Flow }}$ & $\frac{2.74}{\text { Spec.Grav. }}$ & $\frac{1.78}{1.13}$ \\
\hline
\end{tabular}

NCAW1 Recycle 9/29/93 4:17 PM 
Test FRTO02

Evaporator Heat Transfer Calculations

v3

\begin{tabular}{|c|c|c|c|}
\hline & Test FRT002 & Evaporator H & eat Transfer \\
\hline & Start Time & $18: 15$ & $19: 00$ \\
\hline & End Time & $19: 00$ & $19: 45$ \\
\hline & Elapsed Time, min & 45.00 & 45.00 \\
\hline \multirow{10}{*}{ 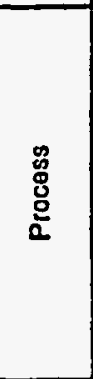 } & Starting Volume, gal & 6904 & 6894 \\
\hline & Ending Volume, gal & 6894 & 6879 \\
\hline & Level Change (PDl-1002), gpm & 6.42 & 1.42 \\
\hline & Level Change (PDI-1003), gpm & 0.69 & 0.83 \\
\hline & Ave. Level Change, gpm & 3.56 & 1.13 \\
\hline & Ave. Temp, ${ }^{\circ} \mathrm{F}$ & 213.98 & 214.11 \\
\hline & Headspace Pressure, psia & 14.25 & $\cdot 14.25$ \\
\hline & Evaporation, BtunHr & $2.210 E+06$ & $2.028 E+06$ \\
\hline & Reheat, Btu/Hr & $2.410 E+05$ & $2.198 E+05$ \\
\hline & Total Heat, Btu/Hr & $2.451 E+06$ & $2.247 E+06$ \\
\hline \multirow{5}{*}{ 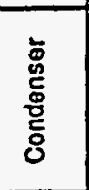 } & Condensate Flow (1), gpm & 4.58 & 4.20 \\
\hline & Condensate Flow (2), gpm. & NA & NA \\
\hline & Evaporation Rate. gpm & 4.58 & 4.20 \\
\hline & Condensale Temp, ${ }^{\circ} \mathrm{F}$ & 108.17 & 108.92 \\
\hline & OH-gas Flow, SCFM & 38.44 & 37.86 \\
\hline \multirow{13}{*}{$\begin{array}{l}\text { E్ } \\
\text { ळ }\end{array}$} & Flow, Lb/Hr & 2719.69 & 2482.07 \\
\hline & Header Pressure, psia & 127.29 & 127.48 \\
\hline & Pin, psia & 99.71 & 105.53 \\
\hline & Tin, of & 345.00 & 345.10 \\
\hline & Tsat al Pin, ${ }^{\circ} \mathrm{F}$ & 327.65 & 331.71 \\
\hline & Vapor Cp at Tsat, Blullbo $F$ & 0.48 & 0.48 \\
\hline & hig at Tsat, Bturh & 889.33 & 886.13 \\
\hline & Condensate Pout, psia & 91.74 & 98.34 \\
\hline & Condensate Tout, ${ }^{\circ} \mathrm{F}$ & 298.41 & 304.28 \\
\hline & Coil Pressure Drop. psi & 7.97 & 7.19 \\
\hline & Desuperheat Heat, Blu/Hr & $2.275 E+04$ & $1.601 E+04$ \\
\hline & Condense Heal, Btu/Hr & $2.419 E+06$ & $2.199 E+06$ \\
\hline & Subcool Heat, Blu/Hr & $7.951 E+04$ & $\begin{array}{l}6.808 E+04 \\
2.284 E+06\end{array}$ \\
\hline \multirow{5}{*}{ 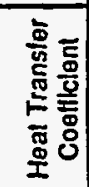 } & Desuperineal LMTD, ${ }^{\circ} \mathrm{F}$ & 122.14 & 124.17 \\
\hline & Condensation $\Delta t$, of & 113.67 & 117.60 \\
\hline & Subcool LMTD, ' $F$ & 98.33 & 103.28 \\
\hline & Weighted $\Delta t,{ }^{\circ} \mathrm{F}$ & 113.18 & 117.16 \\
\hline & Boiling U, Blu/Hr $f^{\wedge} 2^{\circ} F$ & 64.94 & 56.83 \\
\hline \multirow{5}{*}{$\frac{\frac{\grave{D}}{\bar{D}}}{\frac{\overline{D g}}{<}}$} & Speed, ipm & 99.95 & 99.99 \\
\hline & Current, Amps & 52.37 & 52.77 \\
\hline & Voltages, Volts & 460.00 & 460.00 \\
\hline & Motor Horsepower & 38.71 & 39.29 \\
\hline & Agitator Pout, Btu/Hr & 98,474 & 99,950 \\
\hline \multirow{3}{*}{ 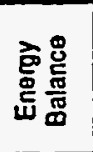 } & Tank Losses, Bluthl & 207000 & 207000 \\
\hline & Total Heat in, Btu/Hr & $2619 E+06$ & $2.383 E+06$ \\
\hline & $\begin{array}{c}\text { Total Heal Out, Btu/Hr } \\
\% \text { Difference }\end{array}$ & $\begin{array}{c}2.658 E+06 \\
-1.47\end{array}$ & $\begin{array}{c}2.454 E+06 \\
-298\end{array}$ \\
\hline & \%o Uinerence & $\frac{-1.47}{2-\text { Using Tot: }}$ & lized Flow \\
\hline
\end{tabular}

Spec.Grav. $\quad 1.4$ 
Appendix J

Homogeneity/Sampling Data Tables 
Homogeneity (Percent Oxides Data) as a Function of Agitator Speed

Test 1: Low Level Dilute Slumy - 5700 Gallons

\begin{tabular}{|c|c|c|c|c|c|c|c|c|}
\hline $\begin{array}{l}\text { Agtrator } \\
\text { Speed. } \mathrm{pm}\end{array}$ & $\begin{array}{c}\text { of } \\
\text { Samples }\end{array}$ & $\begin{array}{l}\text { Range of } \\
\text { Oxddes. wits }\end{array}$ & $\begin{array}{c}\text { Average } \\
\text { Oddes. } \\
\text { wrx }\end{array}$ & $\begin{array}{l}\text { Range of } \\
\text { Error, } \%\end{array}$ & $\begin{array}{l}\text { Average } \\
\text { Error, } \times\end{array}$ & $\begin{array}{l}\text { Stundard } \\
\text { Denterton }\end{array}$ & $\begin{array}{l}\text { Normalized } \\
\text { Standard } \\
\text { Devation, } x\end{array}$ & $\begin{array}{l}\text { Conthence } \\
\text { Level }\end{array}$ \\
\hline 45 & 21 & 2.97103 .06 & 3.03 & 0.06 to 2.04 & 0.42 & 0.0789 & 0.6224 & $399 \%$ \\
\hline 85 & 21 & 3.01 to 3.06 & 3.04 & 0.16100 .83 & 0.40 & 0.0147 & 0.4643 & $>998$ \\
\hline 130 & 21 & 3.04103 .09 & 3.05 & 0.14101 .17 & 0.32 & 0.0125 & 0.4086 & $299 \times$ \\
\hline Total & 63 & 2.97 to 3.09 & 3.04 & 0.05 to 2.04 & 0.30 & 0.0184 & 0.6042 & $>99 \times$ \\
\hline
\end{tabular}

Test 2: High Level Dilute Slumr - 7800 Gallons

\begin{tabular}{|c|c|c|c|c|c|c|c|c|}
\hline $\begin{array}{l}\text { Aghator } \\
\text { Speed, ipm }\end{array}$ & $\begin{array}{c}\text { of } \\
\text { Samples }\end{array}$ & $\begin{array}{l}\text { Range of } \\
\text { Oxdes, with }\end{array}$ & $\begin{array}{c}\text { Average } \\
\text { Oddes, } \\
\text { wrs }\end{array}$ & $\begin{array}{l}\text { Ringe of } \\
\text { Ertor, } \%\end{array}$ & $\begin{array}{l}\text { Avertage } \\
\text { Error, } \%\end{array}$ & $\begin{array}{l}\text { Stundard } \\
\text { Devation }\end{array}$ & $\begin{array}{l}\text { Normatered } \\
\text { Standied } \\
\text { Deviatlon, } 8\end{array}$ & $\begin{array}{l}\text { Conftence } \\
\text { Level }\end{array}$ \\
\hline 45 & 20 & 3.14 to 3.20 & 3.17 & 0.02 to 0.97 & 0.37 & 0.0141 & 0.4455 & $>99 \%$ \\
\hline 85 & 28 & 3.17 to 3.21 & 3.18 & 0.11800 .03 & 0.32 & 0.0125 & 0.3939 & $399 x$ \\
\hline 130 & 28 & 3.07 to 3.20 & 3.16 & 0.11 to 2.56 & 0.44 & 0.0226 & 0.7156 & $399 \times$ \\
\hline Total & 84 & 3.0210321 & 3.17 & 0.02102 .96 & 0.38 & 0.0180 & 0.5936 & $>99 x$ \\
\hline
\end{tabular}

Test 3: Low Level Concentrated Slurrv - 5700 Gallons

\begin{tabular}{|c|c|c|c|c|c|c|c|c|}
\hline $\begin{array}{l}\text { Agreator } \\
\text { Speed. rom }\end{array}$ & $\begin{array}{c}\text { of } \\
\text { Samples }\end{array}$ & $\begin{array}{l}\text { Range of } \\
\text { Oxddes. wix }\end{array}$ & $\begin{array}{l}\text { Average } \\
\text { Oddes. } \\
\text { msx. }\end{array}$ & $\begin{array}{l}\text { Renge of } \\
\text { Error, } \mathbf{x}\end{array}$ & $\begin{array}{l}\text { Average } \\
\text { Error. } \mathbf{x}\end{array}$ & $\begin{array}{l}\text { Standard } \\
\text { Devation }\end{array}$ & $\begin{array}{l}\text { Normulized } \\
\text { Standerd } \\
\text { Devation, } x\end{array}$ & $\begin{array}{c}\text { Comdence } \\
\text { Level }\end{array}$ \\
\hline 45 & 20 & 77.14 to 77.49 & 71.35 & 0.04 to 1.89 & 0.22 & 0.0513 & 0.4573 & $>99 x$ \\
\hline 05 & 28 & 17.35 to 17.56 & 17.43 & 0.07 to 1.75 & 0.34 & 0.0521 & 0.4558 & $299 \%$ \\
\hline 130 & 28 & 10.96 to 79.38 & 11.31 & 0.00 to 3.09 & 0.37 & 0.0771 & 0.6815 & $299 \%$ \\
\hline Total & $\mathbf{8}$ & 10.95 to 11.55 & 77.36 & 0.07 to 3.09 & 0.37 & 0.0783 & 0.6891 & $299 \%$ \\
\hline
\end{tabular}

Test 4: High Level Concentrated Slurry - 7800 Gallons

\begin{tabular}{|c|c|c|c|c|c|c|c|c|}
\hline $\begin{array}{l}\text { Aghator } \\
\text { Speed, rpm }\end{array}$ & $\begin{array}{c}\text { of } \\
\text { Samples }\end{array}$ & $\begin{array}{l}\text { Range of } \\
\text { Oxddes, wxo }\end{array}$ & $\begin{array}{c}\text { Average } \\
\text { Oddes. } \\
\text { wr\% }\end{array}$ & $\begin{array}{l}\text { Parge of } \\
\text { Eror, } x\end{array}$ & $\begin{array}{l}\text { Average } \\
\text { Error, } \mathbf{x}\end{array}$ & $\begin{array}{l}\text { Standard } \\
\text { Devation }\end{array}$ & $\begin{array}{l}\text { Normalbed } \\
\text { Standard } \\
\text { Devation, } \%\end{array}$ & $\begin{array}{l}\text { Conndence } \\
\text { Level }\end{array}$ \\
\hline 45 & 28 & 11.118011 .34 & 11.29 & 0.03 to 1.57 & 0.33 & 0.0533 & 0.4720 & $299 \times$ \\
\hline 85 & 28 & 11.20 to 11.37 & 17.32 & 0.02 to 1.09 & 0.20 & 0.0332 & 0.2930 & 2994 \\
\hline 130 & 28 & 11.27 to 11.35 & 11.31 & $0.02: 00.42$ & 0.16 & 0.0220 & 0.1945 & $>99 \%$ \\
\hline Total & 24 & T1.11 to 11.37 & 11.31 & 0.02 to 1.57 & 0.23 & 0.0408 & 0.3610 &, $99 x$ \\
\hline
\end{tabular}


Page E3 of E25

Test 5: Formated Slurry - 6500 Gallons

\begin{tabular}{|c|c|c|c|c|c|c|c|c|}
\hline $\begin{array}{l}\text { Agrutor } \\
\text { Speed, rpm }\end{array}$ & $\begin{array}{c}\text { of } \\
\text { simples }\end{array}$ & $\begin{array}{l}\text { Range of } \\
\text { Oxdes, } m x x\end{array}$ & $\begin{array}{c}\text { Average } \\
\text { Oddes. } \\
\text { wits }\end{array}$ & $\begin{array}{l}\text { Renge of } \\
\text { Ertor. } x\end{array}$ & $\begin{array}{l}\text { Average } \\
\text { Error. } \%\end{array}$ & $\begin{array}{l}\text { Standard } \\
\text { Oeviation }\end{array}$ & $\begin{array}{l}\text { Normalized } \\
\text { Standerd } \\
\text { Devintion, } \%\end{array}$ & $\begin{array}{l}\text { Confidence } \\
\text { Level }\end{array}$ \\
\hline 45 & 20 & 13.39 to 13.53 & 13.46 & 0.04 to 0.56 & 0.10 & 0.0301 & 0.2239 & $>99 \%$ \\
\hline 85 & 28 & 13.27 to 14.16 & 13.50 & 0.03 to 4.92 & 0.49 & 0.1415 & 1.0482 & $299 \times 6$ \\
\hline 130 & 20 & 13.38 to 13.54 & 13.40 & 0.01 to 0.73 & 0.18 & 0.0324 & 0.2407 & $299 \times$ \\
\hline Total & 84 & 13.27 to 14.16 & 13.40 & 0.01 to 4.92 & 0.28 & 0.0062 & 0.6390 & $299 \times$ \\
\hline
\end{tabular}

Test 6: Melter Feed Slumy - 7100 Gallons

\begin{tabular}{|c|c|c|c|c|c|c|c|c|}
\hline $\begin{array}{l}\text { Agrtutor } \\
\text { Speed, rpm }\end{array}$ & $\begin{array}{c}\text { of } \\
\text { samples }\end{array}$ & $\begin{array}{l}\text { Runge of } \\
\text { Oddes, wrx }\end{array}$ & $\begin{array}{l}\text { Average } \\
\text { Oxdes. } \\
\text { wrsts }\end{array}$ & $\begin{array}{l}\text { Range of } \\
\text { Eror. } \%\end{array}$ & $\begin{array}{l}\text { Average } \\
\text { Error. } \times\end{array}$ & $\begin{array}{l}\text { Standurd } \\
\text { Deviation }\end{array}$ & $\begin{array}{l}\text { Normattzed } \\
\text { Standard } \\
\text { Devlation, } x\end{array}$ & $\begin{array}{l}\text { Conidence } \\
\text { Level }\end{array}$ \\
\hline 130 & 28 & 38.65 to 39.84 & 39.21 & 0.02 to 7.60 & 0.47 & 0.2273. & 0.5797 & $>99 \times$ \\
\hline
\end{tabular}




\section{Homogeneity (Specific Gravity Data) as a Function of Agitator Speed}

Test 1: Low Level Dilute Slurry - 5700 Gallons

\begin{tabular}{|c|c|c|c|c|c|c|c|c|}
\hline $\begin{array}{l}\text { Agtutor } \\
\text { Speed, rpm }\end{array}$ & $\begin{array}{c}\text { of } \\
\text { Samples }\end{array}$ & $\begin{array}{c}\text { Range of } \\
\text { Speclic Gravty }\end{array}$ & $\begin{array}{c}\text { Average } \\
\text { Specinte } \\
\text { Gravty }\end{array}$ & $\begin{array}{l}\text { Range of } \\
\text { Enco, } x\end{array}$ & $\begin{array}{l}\text { Average } \\
\text { Error, } \times\end{array}$ & $\begin{array}{l}\text { Standard } \\
\text { Deviation }\end{array}$ & $\begin{array}{l}\text { Normaltzed } \\
\text { Stunderd } \\
\text { Devintion } \$\end{array}$ & $\begin{array}{c}\text { Comdence } \\
\text { Leved }\end{array}$ \\
\hline 45 & 28 & 1.02 to 1.05 & 1.04 & 0.40101 .45 & 0.55 & 0.0064 & 0.6164 & $>99 \times 6$ \\
\hline 85 & 20 & 1.03101 .05 & 1.03 & 0.42107 .52 & 0.50 & 0.0057 & 0.5510 & $>99 \%$ \\
\hline 130 & 20 & 1.03101 .04 & 1.03 & 0.21200 .76 & 0.33 & 0.0012 & 0.4050 & $>99 \times$ \\
\hline Total & 84 & 1.02101 .05 & 1.03 & 0.21101 .52 & 0.46 & 0.0055 & 0.5398 & $>99 \%$ \\
\hline
\end{tabular}

Test 2: High Level Dilute Silumy - 7800 Gallons

\begin{tabular}{|c|c|c|c|c|c|c|c|c|}
\hline $\begin{array}{l}\text { Aghtetor } \\
\text { Speed, rpm }\end{array}$ & $\begin{array}{c}\text { of } \\
\text { Samples }\end{array}$ & $\begin{array}{l}\text { Range of } \\
\text { Speetric Gravty }\end{array}$ & $\begin{array}{l}\text { Average } \\
\text { Spectic } \\
\text { Gravity }\end{array}$ & $\begin{array}{l}\text { Renge of } \\
\text { Eror, } \%\end{array}$ & $\begin{array}{l}\text { Average } \\
\text { Error. } \%\end{array}$ & $\begin{array}{l}\text { Standard } \\
\text { Deviation }\end{array}$ & $\begin{array}{c}\text { Normallzed } \\
\text { Standard } \\
\text { Devadon, } \times\end{array}$ & $\begin{array}{l}\text { Comidence } \\
\text { Level }\end{array}$ \\
\hline 45 & 28 & 1.02101 .05 & 1.04 & 0.42 to 1.52 & 0.54 & 0.0063 & 0.6121 & $299 \%$ \\
\hline 85 & 28 & 1.02 to 1.04 & 1.03 & 0 to 0.97 & 0.07 & 0.0027 & 0.2641 & s99\% \\
\hline 130 & 20 & 1.02 to 1.03 & 1.03 & 0.07 to 0.90 & 0.13 & 0.0025 & 0.2545 & $299 x$ \\
\hline Total & 84 & 1.02 to 1.05 & 1.03 & 0 to 1.52 & 0.25 & 0.0051 & 0.4953 & $>994$ \\
\hline
\end{tabular}

Test 3: Low Level Concentrated Slurry - 5700 Gallons

\begin{tabular}{|c|c|c|c|c|c|c|c|c|}
\hline $\begin{array}{l}\text { Agttaror } \\
\text { Speed. } \mathrm{pm}\end{array}$ & $\begin{array}{c}0 \text { of } \\
\text { Samples }\end{array}$ & $\begin{array}{l}\text { Range of } \\
\text { Spectile Gravtly }\end{array}$ & $\begin{array}{l}\text { Average } \\
\text { Spedife } \\
\text { Gravity }\end{array}$ & $\begin{array}{l}\text { Penge of } \\
\text { Error, } \mathbf{x}\end{array}$ & $\begin{array}{l}\text { Average } \\
\text { Enor. } \%\end{array}$ & $\begin{array}{l}\text { Standard } \\
\text { Deviation }\end{array}$ & $\begin{array}{l}\text { Normaltzed } \\
\text { Stundurd } \\
\text { Devation. } \%\end{array}$ & $\begin{array}{c}\text { Confidence } \\
\text { Level }\end{array}$ \\
\hline 45 & 28 & 1.00 to 1.12 & 1.10 & 0.13 to 9.21 & 9.17 & 0.0227 & 2.0628 & $299 \%$ \\
\hline 85 & 28 & 1.07 to 1.14 & 1.11 & 0.13 to 3.48 & 0.64 & 0.0718 & 1.0617 & $299 \times$ \\
\hline 130 & 28 & 7.10 to 7.12 & 1.11 & 0.29101 .19 & 0.40 & 0.0061 & 0.5530 & $>99 \times 6$ \\
\hline Toral & 84 & 1.00 20 7.14. & 1.11 & 0.13 to 9.21 & 0.75 & 0.0753 & 1.3857 & $599 \%$ \\
\hline
\end{tabular}

Test 4: High Level Concentrated Slurry - 7800 Gallons

\begin{tabular}{|c|c|c|c|c|c|c|c|c|}
\hline $\begin{array}{l}\text { Agltator } \\
\text { Speed. rpm }\end{array}$ & $\begin{array}{c}- \text { of } \\
\text { Samples }\end{array}$ & $\begin{array}{l}\text { Renge of } \\
\text { Speeline Gravmy }\end{array}$ & $\begin{array}{l}\text { Averege } \\
\text { Specthe } \\
\text { Gravty }\end{array}$ & $\begin{array}{l}\text { Range of } \\
\text { Error. } \%\end{array}$ & $\begin{array}{l}\text { Average } \\
\text { Enor, } x\end{array}$ & $\begin{array}{l}\text { Standira } \\
\text { Demition }\end{array}$ & $\begin{array}{l}\text { Normaltzed } \\
\text { Standard } \\
\text { Devatdon. \% }\end{array}$ & $\begin{array}{l}\text { Comdence } \\
\text { Lovel }\end{array}$ \\
\hline 45 & 28 & 0.95 to 1.12 & 1.10 & 0.07 to 13.58 & 1.86 & 0.0371 & 3.3758 & $>99 \times$ \\
\hline 05 & 28 & 1.09 to 1.12 & 1.11 & 0.19 to 1.62 & 0.48 & 0.0074 & 0.6662 & $\$ 99 \times$ \\
\hline 130 & 28 & 1.10 to 1.12 & 1.81 & 0.03 to 0.93 & 0.31 & 0.0058 & 0.5180 & $>99 \times$ \\
\hline Total & 84 & 0.95 to 7.72 & 1.11 & 0.03 to 13.58 & 0.89 & 0.0223 & 2.0202 & $>99 x$ \\
\hline
\end{tabular}


Page E5 of E25

Test 5: Formated Slumy - 6500 Gallons

\begin{tabular}{|c|c|c|c|c|c|c|c|c|}
\hline $\begin{array}{l}\text { Agrator } \\
\text { Speed, ipm }\end{array}$ & $\begin{array}{c}\text { of } \\
\text { Samples }\end{array}$ & $\begin{array}{c}\text { Range of } \\
\text { Spectite Gravity }\end{array}$ & $\begin{array}{l}\text { Average } \\
\text { Spectile } \\
\text { Gravily }\end{array}$ & $\begin{array}{l}\text { Renge of } \\
\text { Eror, } x\end{array}$ & $\begin{array}{l}\text { Average } \\
\text { Eror, } \%\end{array}$ & $\begin{array}{l}\text { Slandard } \\
\text { Deviation }\end{array}$ & $\begin{array}{l}\text { Normalaed } \\
\text { Standard } \\
\text { Deviation, } \times\end{array}$ & $\begin{array}{l}\text { Conndence } \\
\text { Level }\end{array}$ \\
\hline 45 & 20 & 7.20101 .14 & 1.13 & 0.03 to 2.69 & 0.43 & 0.0054 & 0.7474 & $299 \times$ \\
\hline 25 & 28 & 1.09 to 1.75 & 1.13 & 0.25103 .70 & 0.87 & 0.0136 & 1.1979 & $299 x$ \\
\hline 130 & 28 & 1.11 to 7.15 & 1.14 & 0.41 to 2.23 & 0.56 & 0.0079 & 0.6945 & $399 \times$ \\
\hline Total & 84 & 7.09 to 7.75 & 1.13 & 0.03 to 3.70 & 0.62 & 0.0704 & 0.9145 & $399 \times 6$ \\
\hline
\end{tabular}

Test 6: Melter Feed Slumy - 7100 Gallons

\begin{tabular}{|c|c|c|c|c|c|c|c|c|}
\hline $\begin{array}{l}\text { Agtrator } \\
\text { Speed, npm }\end{array}$ & $\begin{array}{c}\text { of } \\
\text { Samples }\end{array}$ & $\begin{array}{c}\text { Range of } \\
\text { Spectic Gravty }\end{array}$ & $\begin{array}{l}\text { Average } \\
\text { Specinc } \\
\text { Gravty }\end{array}$ & $\begin{array}{l}\text { Range of } \\
\text { Etor, } x\end{array}$ & $\begin{array}{l}\text { Average } \\
\text { Error, } x\end{array}$ & $\begin{array}{l}\text { Standard } \\
\text { Deviation }\end{array}$ & $\begin{array}{l}\text { Normatzed } \\
\text { Seanderd } \\
\text { Deviation. } \%\end{array}$ & $\begin{array}{l}\text { Conthdence } \\
\text { Level }\end{array}$ \\
\hline 130 & 20 & 1.30 to 1.40 & 1.34 & 0.03 to 4.51 & 0.84 & 0.0173 & 1.2929 & $>99 \times$ \\
\hline
\end{tabular}


Homogeneity (Percent Oxides Data) as a Function of Sampling Level

Test 1: Low Level Dilute Slumv - 5700 Gallons

\begin{tabular}{|c|c|c|c|c|c|c|c|c|}
\hline $\begin{array}{l}\text { Sample } \\
\text { Lecation }\end{array}$ & $\begin{array}{c}\text { of } \\
\text { Semples }\end{array}$ & $\begin{array}{l}\text { Rarige of } \\
\text { oddes, wrs }\end{array}$ & $\begin{array}{c}\text { Average } \\
\text { Oxdes. } \\
\text { wex }\end{array}$ & $\begin{array}{l}\text { Runge of } \\
\text { Error. } x\end{array}$ & $\begin{array}{l}\text { Average } \\
\text { Eror. } \%\end{array}$ & $\begin{array}{l}\text { Standerd } \\
\text { Devietion }\end{array}$ & $\begin{array}{l}\text { Mormalesed } \\
\text { Standerd } \\
\text { Deverten } \%\end{array}$ & $\begin{array}{l}\text { Comidence } \\
\text { Level }\end{array}$ \\
\hline Varve 1 & 21 & 2.97 to 3.07 & 304 & 0.06 to 2.36 & 0.43 & 0.0204 & 0.5706 & $399 x$ \\
\hline Valve 2 & 21 & 301 to 3.09 & 3.04 & 0.13 to 1.77 & 0.50 & 0.0207 & 0.6627 & $>99 \times$ \\
\hline Valve 3 & 21 & 301 to 3.06 & 3.04 & 0.17 to 1.10 & 0.37 & 0.0135 & 0.4449 & $299 x$ \\
\hline Total & 63 & 2.97103 .00 & $3: 04$ & 0.06 to 2.36 & 0.43 & 0.0183 & 0.6009 & $299 \times$ \\
\hline
\end{tabular}

Test 2: Hilgh Level Dilute Slumry - 7800 Gallons

\begin{tabular}{|c|c|c|c|c|c|c|c|c|}
\hline $\begin{array}{l}\text { Semple } \\
\text { Locution }\end{array}$ & $\begin{array}{c}\text { of } \\
\text { semples }\end{array}$ & $\begin{array}{l}\text { Penge of } \\
\text { Oxdes, wrs }\end{array}$ & $\begin{array}{c}\text { Average } \\
\text { Oxtdes. } \\
\text { wis. }\end{array}$ & $\begin{array}{l}\text { Renge of } \\
\text { Error, } x\end{array}$ & $\begin{array}{l}\text { Average } \\
\text { Error, } \%\end{array}$ & $\begin{array}{l}\text { Stancterd } \\
\text { Deviation }\end{array}$ & $\begin{array}{l}\text { Normaltzed } \\
\text { Standard } \\
\text { Devintion, } \%\end{array}$ & $\begin{array}{l}\text { Confidence } \\
\text { Level }\end{array}$ \\
\hline Hydragard & 21 & 3.07 to 3.21 & 3.18 & 0.04 to 3.42 & 0.58 & 0.0305 & 0.9600 & $>99 \%$ \\
\hline Varve 1 & 29 & 3.15103 .19 & 2.17 & 0.14200 .77 & 0.28 & 0.0108 & 0.3390 & $299 \%$ \\
\hline Vatve 5 & 21 & 3.15 to 3.20 & 3.17 & 0.02 to 0.93 & 0.35 & 0.0143 & 0.4514 & $>99 \times$ \\
\hline Valve 6 & 27 & 3.74 to 3.78 & 3.17 & 0.15 to 0.60 & 0.28 & 0.0100 & 0.3406 & $299 \%$ \\
\hline Total & 84 & 3.07 to 3.21 & 3.17 & 0.02103 .42 & 0.37 & 0.0188 & 0.5936 & 2994 \\
\hline
\end{tabular}

Test 3: Low Level Concentrated Slurry - 5700 Gallons

\begin{tabular}{|c|c|c|c|c|c|c|c|c|}
\hline $\begin{array}{l}\text { Sample } \\
\text { Location }\end{array}$ & $\begin{array}{c}\text { of } \\
\text { Samples }\end{array}$ & $\begin{array}{l}\text { Ainge of } \\
\text { odoes. wrss }\end{array}$ & $\begin{array}{c}\text { Average } \\
\text { Oddes. } \\
\text { wits }\end{array}$ & $\begin{array}{l}\text { Renge of } \\
\text { Enor. } x\end{array}$ & $\begin{array}{l}\text { Average } \\
\text { Eror, } \times\end{array}$ & $\begin{array}{l}\text { Stendard } \\
\text { Devation }\end{array}$ & $\begin{array}{l}\text { Normallzed } \\
\text { Standard } \\
\text { Devatton, } x\end{array}$ & $\begin{array}{c}\text { Confidence } \\
\text { Level }\end{array}$ \\
\hline Hydragard & 21 & 11.14 to 17.56 & - 11.39 & 0.13 to 2.23 & 0.71 & 0.7005 & 0.8823 & $299 x$ \\
\hline Valve 1 & 21 & 11.281011 .43 & 11.37 & 0.04 to 0.75 & 0.28 & 0.0393 & 0.3460 & $299 x$ \\
\hline Valve 2 & 21 & 31.991011 .42 & 11.35 & 0.004 to 1.41 & 0.34 & 0.0531 & 0.4674 & 2998 \\
\hline Valve 3 & 21 & 90.96 to 11.46 & 11.35 & 0.02 20 3.42 & 0.47 & 0.0977 & 0.8605 & $299 x$ \\
\hline Total & 84 & 10.96 to 11.56 & 11.36 & 0.004 to 3.42 & 0.45 & 0.0723 & 0.6891 & $399 x$ \\
\hline
\end{tabular}

Test 4: High Level Concentrated Slumy - 7800 Gallons

\begin{tabular}{|c|c|c|c|c|c|c|c|c|}
\hline $\begin{array}{l}\text { Semple } \\
\text { Location }\end{array}$ & $\begin{array}{c}\text { of } \\
\text { Samples }\end{array}$ & $\begin{array}{c}\text { Range of } \\
\text { addes, wish }\end{array}$ & $\begin{array}{c}\text { Average } \\
\text { Oddes. } \\
\text { was }\end{array}$ & $\begin{array}{l}\text { Renge of } \\
\text { Error. } \%\end{array}$ & $\begin{array}{l}\text { Average } \\
\text { Eror. } \mathbf{x}\end{array}$ & $\begin{array}{l}\text { Stunderd } \\
\text { Devintion }\end{array}$ & $\begin{array}{l}\text { Normaltzed } \\
\text { Standiard } \\
\text { Deviston. } x\end{array}$ & $\begin{array}{c}\text { Conindence } \\
\text { Level }\end{array}$ \\
\hline Hydragard & 21 & 11.17 to 11.34 & 11.27 & 0.008 to 1.43 & 0.40 & 0.0575 & 0.5103 & $299 \times$ \\
\hline Varve 1 & 21 & 17.28 to 71.35 & 17.32 & 0.008 to 0.36 & 0.13 & 0.0150 & 0.1574 & $>99 \times$ \\
\hline Vatve 5 & 21 & 11.26 to 11.36 & 37.32 & 0.03 to 0.50 & 0.23 & 0.0297 & 0.2626 & $>99 \times$ \\
\hline Valve 6 & 21 & 11.28 to 11.37 & 11.32 & 0.09 to 0.44 & 0.17 & 0.0228 & 0.2014 & $299 \times$ \\
\hline Totas & 84 & 11.11 to 11.37 & 11.31 & 0.000 to 1.43 & 0.23. & 0.0408 & 0.3610 & $299 \times$ \\
\hline
\end{tabular}


Test 5: Formated Slumy - 6500 Gallons

\begin{tabular}{|c|c|c|c|c|c|c|c|c|}
\hline $\begin{array}{l}\text { Sample } \\
\text { Leation }\end{array}$ & $\begin{array}{c}\text { of } \\
\text { Samples }\end{array}$ & $\begin{array}{l}\text { Runge of } \\
\text { Oddes, whs }\end{array}$ & $\begin{array}{c}\text { Average } \\
\text { Oxdes. } \\
\text { mos }\end{array}$ & $\begin{array}{l}\text { Range of } \\
\text { Error, } \%\end{array}$ & $\begin{array}{l}\text { Average } \\
\text { Error, } x\end{array}$ & $\begin{array}{l}\text { Standard } \\
\text { Devation }\end{array}$ & $\begin{array}{l}\text { Normullzed } \\
\text { Standard } \\
\text { Devintor. } \%\end{array}$ & $\begin{array}{l}\text { Comdence } \\
\text { Level }\end{array}$ \\
\hline Hydragard & 27 & 13.27 to 13.49 & 73.45 & 0.007 to 1.33 & 0.17 & 0.0438 & 0.3257 & $399 \times$ \\
\hline Varve 1 & 21 & 13.40 to 13.60 & 13.40 & 0.02 to 0.07 & 0.23 & 0.0425 & 0.3150 & $299 \%$ \\
\hline Vulve 4 & 21 & 13.39 to 13.55 & 13.47 & 0.02 10 0.62 & 0.22 & 0,0392 & 0.2906 & $399 \%$ \\
\hline Valve 5 & 21 & 13.38 to 14.16 & 13.50 & 0.007 to 4.90 & 0.50 & 0.1556 & 1.1526 & $299 \times$ \\
\hline Total & 84 & 13.27 to 14.16 & 13.40 & 0.007 to 4.90 & 0.28 & 0.0862 & 0.6398 & $299 \%$ \\
\hline
\end{tabular}

Test 6: Melter Feed Slurry - 7100 Gallons

\begin{tabular}{|c|c|c|c|c|c|c|c|c|}
\hline $\begin{array}{l}\text { Sample } \\
\text { Loeation }\end{array}$ & $\begin{array}{c}\text { of } \\
\text { Samples }\end{array}$ & $\begin{array}{l}\text { Pange of } \\
\text { Oxdes, mix }\end{array}$ & $\begin{array}{c}\text { Average } \\
\text { Oddes. } \\
\text { wox }\end{array}$ & $\begin{array}{l}\text { Range of } \\
\text { Error, } \%\end{array}$ & $\begin{array}{l}\text { Average } \\
\text { Eror. } \%\end{array}$ & $\begin{array}{l}\text { Seandard } \\
\text { Deviation }\end{array}$ & $\begin{array}{l}\text { Normalked } \\
\text { Stundard } \\
\text { Deviation, } \%\end{array}$ & $\begin{array}{c}\text { Comindence } \\
\text { Level }\end{array}$ \\
\hline Hydragard & 7 & 30.65 to 39.53 & 39.14 & 0.01 to 1.24 & 0.67 & 0.3232 & 0.0259 & $>99 \%$ \\
\hline Valve 1 & 7 & 39.18 to 39.84 & 39.34 & 0.01 to 1.26 & 0.36 & 0.2261 & 0.5747 & $299 \%$ \\
\hline Valve 4 & 7 & 38.92 to 39.35 & 39.17 & 0.03 10 0.63 & 0.27 & 0.1460 & 0.3728 & $299 \times 6$ \\
\hline Valve 5 & 7 & 39.00 to 39.45 & 39.20 & 0.04 to 0.52 & 0.31 & 0.1611 & 0.4110 & $299 \%$ \\
\hline Total & 28 & 38.65 to 39.84 & 39.21 & 0.01101 .26 & 0.40 & 0.2273 & 0.5797 & $>99 \times$ \\
\hline
\end{tabular}


Homogeneity (Specific Gravity Data) as a Function of Samoling Level

Test 1: Low Level Dilute Slumy - 5700 Gallons

\begin{tabular}{|c|c|c|c|c|c|c|c|c|}
\hline $\begin{array}{l}\text { Semple } \\
\text { Loestlon }\end{array}$ & $\begin{array}{c}\text { of } \\
\text { samples }\end{array}$ & $\begin{array}{c}\text { Range of } \\
\text { Spectic Gravty }\end{array}$ & $\begin{array}{c}\text { Avernge } \\
\text { Spectite } \\
\text { Gravty }\end{array}$ & $\begin{array}{l}\text { Renge of } \\
\text { Errer, } \%\end{array}$ & $\begin{array}{l}\text { Average } \\
\text { Error, } x\end{array}$ & $\begin{array}{l}\text { Standard } \\
\text { Devation }\end{array}$ & $\begin{array}{l}\text { Normeltzed } \\
\text { Stenderd } \\
\text { Deviation, } \times\end{array}$ & $\begin{array}{l}\text { Cortidence } \\
\text { Level }\end{array}$ \\
\hline Hydragard & 21 & 1.03 to 1.04 & 1.03 & 0.37800 .60 & 0.46 & 0.0050 & 0.4817 & $299 \%$ \\
\hline Vatve 1 & 21 & 1.03 to 1.05 & 1.03 & 0.46 to 1.47 & 0.53 & 0.0060 & 0.5810 & $299 \times$ \\
\hline Varve 2 & 21 & 1.03 to 1.04 & 1.03 & 0.37 to 0.60 & 0.46 & 0.0050 & 0.4817 & $299 x$ \\
\hline Vatre 3 & 21 & 1.02 to 1.05 & 1.03 & 0.20 to 1.66 & 0.49 & 0.0064 & 0.6235 & $.99 \%$ \\
\hline Total & 84 & 1.02 to 1.05 & 1.03 & 0.20101 .66 & 0.40 & 0.0055 & 0.5398 & 2995 \\
\hline
\end{tabular}

Test 2: High Level Dilute Slumy - 7800 Gallons

\begin{tabular}{|c|c|c|c|c|c|c|c|c|}
\hline $\begin{array}{l}\text { Sample } \\
\text { Loeation }\end{array}$ & $\begin{array}{c}\text { of } \\
\text { simples }\end{array}$ & $\begin{array}{l}\text { Range of } \\
\text { Specinc Gravty }\end{array}$ & $\begin{array}{l}\text { Averege } \\
\text { Speche } \\
\text { Gravty }\end{array}$ & $\begin{array}{l}\text { Renge of } \\
\text { Error, } x\end{array}$ & $\begin{array}{l}\text { Average } \\
\text { Eror, } x\end{array}$ & $\begin{array}{l}\text { Sernderd } \\
\text { Deviation }\end{array}$ & $\begin{array}{l}\text { Normittzed } \\
\text { Standard } \\
\text { Devation } \times\end{array}$ & $\begin{array}{c}\text { Confidence } \\
\text { Level }\end{array}$ \\
\hline Hydregard & 21 & 1.02101 .04 & 9.03 & 0.18 to 1.15 & 0.37 & 0.0051 & 0.4962 & $299 \times$ \\
\hline Valve 1 & 21 & 1.02801 .04 & 1.03 & 0.09 to 1.06 & 0.25 & 0.0044 & 0.4229 & $299 \times$ \\
\hline Vatve 5 & 21 & 1.03 to 1.05 & 2.03 & 020 to 1.66 & 0.42 & 0.0056 & 0.5432 & $299 \times$ \\
\hline Verve 6 & 21 & 1.02101 .04 & 1.03 & 0.09 to 1.06 & 0.33 & 0.0054 & 0.5228 & $299 \times 6$ \\
\hline Total & 84 & 1.02101 .05 & 1.03 & 0.09 to 1.65 & 0.35 & 0.0051 & 0.4953 & $299 \times$ \\
\hline
\end{tabular}

Test 3: Low Level Concentrated Siumy - 5700 Gallons

\begin{tabular}{|c|c|c|c|c|c|c|c|c|}
\hline $\begin{array}{l}\text { Sample } \\
\text { Location }\end{array}$ & $\begin{array}{c}\text { of } \\
\text { Sampies }\end{array}$ & $\begin{array}{c}\text { Range of } \\
\text { Speetne Grauty }\end{array}$ & $\begin{array}{l}\text { Average } \\
\text { Speetile } \\
\text { Gravity }\end{array}$ & $\begin{array}{l}\text { Renge of } \\
\text { Eror, } x\end{array}$ & $\begin{array}{l}\text { Average } \\
\text { Error, } \times\end{array}$ & $\begin{array}{l}\text { Sindard } \\
\text { Devaton }\end{array}$ & $\begin{array}{l}\text { Normalized } \\
\text { Sinndard } \\
\text { Devation. } \$\end{array}$ & $\begin{array}{c}\text { Confidence } \\
\text { Leved }\end{array}$ \\
\hline Hydregard & 21 & 1.07 to 1.14 & 1.11 & 0.34 to 3.27 & 0.00 & 0.0736 & 1.2285 & $.99 \%$ \\
\hline Valve 1 & 21 & 1.09 to 1.12 & 1.11 & 0.04 to 1.78 & 0.49 & 0.0001 & 0.7255 & $299 \%$ \\
\hline Valve 2 & 21 & 1.08 to 1.12 & 2.11 & 0.34102 .37 & 0.72 & 0.0102 & 0.9257 & $>99 \times$ \\
\hline Valve 3 & 27 & 1.00 to 1.12 & 1.10 & 0.04 to 9.13 & 0.99 & 0.0240 & 2.1701 & $>99 x$ \\
\hline Torel & 84 & 1.00 to 1.14 & i. 11 & 0.01 to 9.13 & $0 . \pi$ & 0.0153 & 1.3957 & $399 \times$ \\
\hline
\end{tabular}

Test 4: Hiah Level Concentrated Slumy - 7800 Gallons

\begin{tabular}{|c|c|c|c|c|c|c|c|c|}
\hline $\begin{array}{l}\text { Semple } \\
\text { Location }\end{array}$ & $\begin{array}{c}\text { of } \\
\text { Semples }\end{array}$ & $\begin{array}{c}\text { Pange of } \\
\text { Spectile Gravty }\end{array}$ & $\begin{array}{l}\text { Average } \\
\text { Spectic } \\
\text { Gravity }\end{array}$ & $\begin{array}{l}\text { Renge of } \\
\text { Eror, } x\end{array}$ & $\begin{array}{l}\text { Average } \\
\text { Error, } 2\end{array}$ & $\begin{array}{l}\text { Standard } \\
\text { Devation }\end{array}$ & $\begin{array}{l}\text { Normaltzed } \\
\text { Standard } \\
\text { Devation } \times\end{array}$ & $\begin{array}{l}\text { Confidence } \\
\text { Lovel }\end{array}$ \\
\hline Hydragard & 21 & 1.09801 .12 & 1.10 & 0.39 10 1.42 & 0.67 & 0.0008 & 0.7078 & $>99 x$ \\
\hline Valve I & 21 & 0.95107 .12 & 1.10 & 0.26 to 13.41 & 2.18 & 0.0479 & 3.6145 & $599 x$ \\
\hline Valve 5 & 21 & 1.00 to 1.12 & 1.17 & 0.13 to 2.03 & 0.51 & 0.0091 & 0.8720 & $>99 \times$ \\
\hline Varve 6 & 21 & 1.10 to 1.92 & 1.11 & 0.04100 .94 & 0.25 & 0.0050 & 0.4425 & $299 \times$ \\
\hline Total & 84 & 0.95 to 1.12 & 1.71 & 0.04 to 13.41 & 0.90 & 0.0223 & 2.0202 & $299 x$ \\
\hline
\end{tabular}


Test 5: Formated Slurry - 6500 Gallons

\begin{tabular}{|c|c|c|c|c|c|c|c|c|}
\hline $\begin{array}{l}\text { Sample } \\
\text { Loention }\end{array}$ & $\begin{array}{c}\text { of } \\
\text { semples }\end{array}$ & $\begin{array}{c}\text { Range of } \\
\text { Specinc Gravity }\end{array}$ & $\begin{array}{l}\text { Average } \\
\text { Speetfe } \\
\text { Graviny }\end{array}$ & $\begin{array}{l}\text { Range of } \\
\text { Enor, } \approx\end{array}$ & $\begin{array}{l}\text { Average } \\
\text { Error, } \% \text {. }\end{array}$ & $\begin{array}{l}\text { Standerd } \\
\text { Devation }\end{array}$ & $\begin{array}{l}\text { Normallzed } \\
\text { Stenderd } \\
\text { Devation } \%\end{array}$ & $\begin{array}{l}\text { Conmenes } \\
\text { Levet }\end{array}$ \\
\hline Hycregard & 21 & 1.09 to 1.14 & 9.13 & 0.42103 .13 & 0.81 & 0.0125 & 1.2109 & $299 x$ \\
\hline Vatve 1 & 21 & 1.13 to 1.15 & 1.14 & 0.13201 .00 & 0.43 & 0.0065 & 0.5753 & $299 \%$ \\
\hline Vatre 4 & 27 & 1.12 to 1.15 & 1.13 & 0.34 to 1.43 & 0.58 & 0.0031 & 0.7100 & 39976 \\
\hline Vatre 5 & 21 & 1.12 to 1.15 & 1.13 & 0.34 to 1.43 & 0.69 & 0.0092 & 0.8123 & $299 \times$ \\
\hline Total & 84 & 1.09101 .15 & 1.13 & 0.73 to 3.13 & 0.63 & 0.0104 & 0.9145 & $399 \times$ \\
\hline
\end{tabular}

Test 6: Melter Feed Slumy - 7100 Gallons

\begin{tabular}{|c|c|c|c|c|c|c|c|c|}
\hline $\begin{array}{c}\text { Semple } \\
\text { Loeation }\end{array}$ & $\begin{array}{c}\text { of } \\
\text { Samples }\end{array}$ & $\begin{array}{c}\text { Pange of } \\
\text { Spectic Grauty }\end{array}$ & $\begin{array}{l}\text { Average } \\
\text { Specinc } \\
\text { Gravity }\end{array}$ & $\begin{array}{l}\text { Fange of } \\
\text { Enor. } \%\end{array}$ & $\begin{array}{l}\text { Average } \\
\text { Error, } \%\end{array}$ & $\begin{array}{l}\text { Stendard } \\
\text { Deviation }\end{array}$ & $\begin{array}{l}\text { Normatzed } \\
\text { Stundard } \\
\text { Devation. } x\end{array}$ & $\begin{array}{c}\text { Contldence } \\
\text { Level }\end{array}$ \\
\hline Hydragard & 7 & 1.30 to 1.35 & 1.33 & 0.22 to 2.05 & 0.89 & 0.0160 & 1.2006 & $95 \%$ \\
\hline Vatve 1 & 7 & 1.32801 .35 & 1.34 & 0 to 1.49 & 0.43 & 0.09 & 0.7463 & $93 x$ \\
\hline Velve 4 & 7 & 9.34 to 1.40 & 1.35 & 0.32 to 3.30 & 0.96 & 0.0207 & 1.5205 & $95 \%$ \\
\hline Vatue 5 & 7 & 3.32101 .35 & 1.34 & 0.53 to 1.28 & 0.67 & 0.0197 & 0.6324 & $95 \%$ \\
\hline Total & 28 & 1.30101 .40 & 1.34 & 0 to 3.35 & 0.74 & 0.0173 & 1.2929 & $95 \%$ \\
\hline
\end{tabular}


Low Level Dilute Simulant

\begin{tabular}{|c|c|c|c|c|c|c|c|c|c|c|c|c|}
\hline RPM & Volume & Location & Number & Oxide & Avg. Ox & \% Error & Std. dev & Density & Avg. Den & क Error & Sid. dev & Ox Lood \\
\hline $\begin{array}{l}45 \\
45 \\
45 \\
45 \\
45 \\
45 \\
45\end{array}$ & $\begin{array}{l}5700 \\
5700 \\
5700 \\
5700 \\
5700 \\
5700 \\
5700\end{array}$ & $\begin{array}{l}\text { Hydragard } \\
\text { Hydragard } \\
\text { Hydragard } \\
\text { Hydragard } \\
\text { Hydragard } \\
\text { Hydragard } \\
\text { Hydragard }\end{array}$ & $\begin{array}{l}1 \\
2 \\
3 \\
4 \\
5 \\
6 \\
7\end{array}$ & & & & & $\begin{array}{l}1.03 \\
1.03 \\
1.03 \\
1.03 \\
1.03 \\
1.03 \\
1.04\end{array}$ & 1.031429 & $\begin{array}{l}0.4831 \\
0.4831 \\
0.4831 \\
0.4831 \\
0.4831 \\
0.4831 \\
0.4831\end{array}$ & 0.00378 & \\
\hline 45 & 5700 & Valve 1 & 8 & 297 & 3.03143 & 20418 & 0.02795 & 1.04 & 1.037143 & 0.4831 & 0.00488 & 30.888 \\
\hline 45 & 5700 & Valve 1. & 9 & -3.05 & & 0.5958 & & 1.04 & & 0.4831 & & 31.72 \\
\hline 45 & 5700 & Valve 1 & 10 & 3.04 & & 0.257 & & 1.03 & & 0.4831 & & 31.312 \\
\hline 45 & $57 \infty$ & Valve 1 & 11 & 3.04 & & 0.267 & & 1.04 & & 0.4831 & & 31.616 \\
\hline 45 & 5700 & Valve i & 12 & 3.05 & & 0.5968 & & 1.03 & & 0.4831 & & 31.415 \\
\hline 45 & 5700 & Valve 1 & 13 & 3.03 & & 0.0028 & & 9.04 & & 0.4839 & & 31.512 \\
\hline 45 & 5700 & Vatre 1 & 14 & 3.04 & & 0.257 & & 1.04 & & 0.4831 & & 31.616 \\
\hline$\frac{\pi}{45}$ & 5700 & Valvo 2 & 15 & 3.01 & 3.02286 & 0.7225 & 0.00756 & 1.04 & 1.037143 & 0.4831 & 0.00488 & 31.304 \\
\hline 45 & 5700 & Valve 2 & 16 & 3.02 & & 0.3926 & & 1.03 & & 0.4831 & & 31.106 \\
\hline 45 & 5700 & Valve 2 & 17 & 3.03 & & 0.0528 & & 1.04 & & 0.4831 & & 31.512 \\
\hline 45 & 5700 & Valve 2 & 18 & 3.03 & & 0.0528 & & 1.04 & & 0.4831 & & 31.512 \\
\hline 45 & 5700 & Valve 2 & 19 & 3.03 & & 0.0528 & & 1.03 & & 0.4831 & & 31.200 \\
\hline 45 & 5700 & Valve 2 & 20 & 3.02 & & 0.3926 & & 1.04 & & 0.4831 & & 31.408 \\
\hline 45 & 5700 & Valve 2 & 29 & 3.02 & & 0.3926 & & 1.04 & & 0.4831 & & 31.408 \\
\hline$\frac{40}{45}$ & 5700 & Valve 3 & 22 & 3.05 & 3.04143 & 0.5968 & 0.01215 & 1.03 & 1.034286 & 0.4831 & 0.00976 & 31.415 \\
\hline 45 & 5700 & Valve 3 & 23 & 3.03 & & 0.0528 & & 1.03 & & 0.4831 & & 31.209 \\
\hline 45 & 5700 & Valve 3 & 24 & 3.03 & & 0.0528 & & 1.04 & & 0.4831 & & 31.512 \\
\hline 45 & 5700 & Valve 3 & 25 & 3.06 & & 0.9267 & & 1.04 & & 0.4831 & & 31.824 \\
\hline 45 & 5700 & Valve 3 & 26 & 3.03 & & 0.0528 & & 1.05 & & 1.4493 & & 31.815 \\
\hline 45 & 5700. & Valve 3 & 27 & 3.05 & & 0.5968 & & 1.02 & & 1.4493 & & 31.11 \\
\hline 45 & 5700 & Vatue 3 & 28 & 3.04 & & 0.257 & & 1.03 & & 0.4891 & & 31.312 \\
\hline Totals & - & - & 21 & 3.0319 & 3.0319 & 0.4173 & 0.01887 & 1.035 & 1.035 & 0.5521 & 0.00538 & 31.41595 \\
\hline
\end{tabular}

Low Leved Dilute Simulant

\begin{tabular}{|c|c|c|c|c|c|c|c|c|c|c|c|c|}
\hline RPM & Volume & Location & Number & Oxide & Avg. Ox & \% Error & Sid. dev & Density & Avg. Den & क Emor & Std. der & Ox Load \\
\hline $\begin{array}{l}85 \\
85 \\
85 \\
85 \\
85 \\
85 \\
85\end{array}$ & $\begin{array}{l}5700 \\
5700 \\
5700 \\
5700 \\
5700 \\
5700 \\
5700\end{array}$ & $\begin{array}{l}\text { Hydragard } \\
\text { Hydragard } \\
\text { Hydragard } \\
\text { Hydragard } \\
\text { Hydragard } \\
\text { Hydragard } \\
\text { Hydragard }\end{array}$ & $\begin{array}{l}29 \\
30 \\
31 \\
32 \\
33 \\
34 \\
35\end{array}$ & & & & & $\begin{array}{l}1.03 \\
1.03 \\
1.03 \\
1.04 \\
1.04 \\
1.04 \\
1.04 \\
\end{array}$ & 1.035714 & $\begin{array}{l}0.4144 \\
0.4144 \\
0.4144 \\
0.5525 \\
0.5525 \\
0.5525 \\
0.5525\end{array}$ & 0.00535 & \\
\hline $\begin{array}{l}5 \\
85 \\
85 \\
85 \\
85 \\
85 \\
85\end{array}$ & $\begin{array}{l}5700 \\
5700 \\
5700 \\
5700 \\
5700 \\
5700 \\
5700 \\
\end{array}$ & $\begin{array}{l}\text { Valve } 1 \\
\text { Valve } 1 \\
\text { Valve } 1 \\
\text { Valve } 1 \\
\text { Vatre } 1 \\
\text { Valve } 1 \\
\text { Valve } 1\end{array}$ & $\begin{array}{l}36 \\
37 \\
38 \\
39 \\
40 \\
41 \\
42\end{array}$ & $\begin{array}{l}3.05 \\
3.02 \\
3.02 \\
3.05 \\
3.04 \\
3.04 \\
3.05\end{array}$ & 3.03857 & $\begin{array}{l}0.4864 \\
0.502 \\
0.502 \\
0.4864 \\
0.1569 \\
0.1569 \\
0.4864\end{array}$ & 0.01345 & $\begin{array}{l}1.05 \\
1.04 \\
1.03 \\
1.03 \\
1.03 \\
1.03 \\
1.04 \\
\end{array}$ & 1.035714 & $\begin{array}{l}1.5193 \\
0.5525 \\
0.4144 \\
0.4144 \\
0.4144 \\
0.4144 \\
0.5525 \\
\end{array}$ & 0.00787 & $\begin{array}{l}32.025 \\
31.408 \\
31.106 \\
31.415 \\
31.312 \\
31.312 \\
31.72 \\
\end{array}$ \\
\hline $\begin{array}{l}85 \\
85 \\
85 \\
85 \\
85 \\
85 \\
85\end{array}$ & $\begin{array}{l}5700 \\
5700 \\
5700 \\
5700 \\
5700 \\
5700 \\
5700\end{array}$ & $\begin{array}{l}\text { Valve } 2 \\
\text { Valve } 2 \\
\text { Valve } 2 \\
\text { Valve } 2 \\
\text { Valve } 2 \\
\text { Valve } 2 \\
\text { Valve } 2\end{array}$ & $\begin{array}{l}43 \\
44 \\
45 \\
46 \\
47 \\
48 \\
49\end{array}$ & $\begin{array}{l}3.03 \\
3.01 \\
3.01 \\
3.04 \\
3.03 \\
3.05 \\
3.04\end{array}$ & 3.03 & $\begin{array}{l}0.1726 \\
0.8315 \\
0.8315 \\
0.1569 \\
0.1726 \\
0.4864 \\
0.1569 \\
\end{array}$ & 0.01528 & $\begin{array}{l}1.03 \\
1.03 \\
1.04 \\
1.03 \\
1.03 \\
1.04 \\
1.03\end{array}$ & 1.032857 & $\begin{array}{l}0.4144 \\
0.4144 \\
0.5525 \\
0.4144 \\
0.4144 \\
0.5525 \\
0.4144\end{array}$ & 0.00488 & $\begin{array}{c}31.200 \\
31.003 \\
31.304 \\
31.312 \\
31.200 \\
31.72 \\
31.312 \\
\end{array}$ \\
\hline $\begin{array}{l}85 \\
85 \\
85 \\
85 \\
85 \\
85 \\
85\end{array}$ & $\begin{array}{l}57 \infty 0 \\
5700 \\
5700 \\
5700 \\
5700 \\
5700 \\
5700 \\
\end{array}$ & $\begin{array}{l}\text { Vatre } 3 \\
\text { Valve } 3 \\
\text { Vatre } 3 \\
\text { Valve } 3 \\
\text { Vatre } 3 \\
\text { Valve } 3 \\
\text { Valve } 3 \\
\end{array}$ & $\begin{array}{l}50 \\
51 \\
52 \\
53 \\
54 \\
55 \\
56 \\
\end{array}$ & $\begin{array}{l}3.03 \\
3.06 \\
3.01 \\
3.03 \\
3.04 \\
3.05 \\
3.04 \\
\end{array}$ & 3.03714 & $\begin{array}{l}0.1726 \\
0.8158 \\
0.8315 \\
0.1726 \\
0.1569 \\
0.4864 \\
0.1569 \\
\end{array}$ & 0.01604 & $\begin{array}{l}1.04 \\
1.03 \\
1.04 \\
1.03 \\
1.03 \\
1.03 \\
1.03 \\
\end{array}$ & 1.032857 & $\begin{array}{l}0.5525 \\
0.4144 \\
0.5525 \\
0.4144 \\
0.4144 \\
0.4144 \\
0.4144 \\
\end{array}$ & 0.00488 & $\begin{array}{l}31.512 \\
31.518 \\
31.304 \\
31.209 \\
31.312 \\
31.415 \\
31.312 \\
\end{array}$ \\
\hline Totals & - & - & 21 & 3.0352 & 3.03524 & 0.3989 & 0.0147 & 1.0343 & 1.034286 & 0.5032 & 0.00573 & 31.37852 \\
\hline
\end{tabular}


Low Level Dllute SImulant

\begin{tabular}{|c|c|c|c|c|c|c|c|c|c|c|c|c|}
\hline$\overline{R P M}$ & Volume & Location & Number & Oxide & Avg. $0 x$ & $\%$ Enor & Sid. dey & Density & Avg. Den & क Error & Sld. dev & Ox Load \\
\hline 130 & 5700 & Hydragard & 57 & & & & & 1.04 & 1.034286 & 0.7612 & 0.00535 & \\
\hline 130 & 5700 & Hydragard & 58 & & & & & 1.04 & & 0.7612 & & \\
\hline 130 & 5700 & Hydragard & 59 & & & & & 1.04 & & 0.7612 & & \\
\hline 130 & 5700 & Hydragard & $\infty$ & & & & & 1.03 & & 0.2076 & & \\
\hline 130 & 5700 & Hydragard & 61 & & & & & 1.03 & & 0.2076 & & \\
\hline 130 & 5700 & Hydragard & 62 & & & & & 1.03 & & 0.2076 & & \\
\hline 130 & 5700 & Hydragard & $\mathfrak{6}$ & & & & & 1.03 & & 0.2076 & & \\
\hline 130 & 5700 & Varve 1 & 64 & 3.05 & 3.05571 & 0.1403 & 0.00787 & 1.03 & 1.031429 & 0.2076 & 0.00378 & 31.415 \\
\hline 130 & 5700 & Valve 1 & 65 & 3.05 & & 0.1403 & & 1.00 & & 0.2076 & & 31.415 \\
\hline 130 & 5700 & Valve 1 & 66 & 3.05 & & 0.1403 & & 1.00 & & 0.2076 & & 31.415 \\
\hline 130 & 5700 & Valve 1 & 67 & 3.05 & & 0.1403 & & 1.08 & & 0.2076 & & 31.415 \\
\hline 130 & 5700 & Valve 1 & 68 & 3.06 & & 0.1879 & & 1.04 & & 0.7612 & & 31.824 \\
\hline 130 & 5700 & Vatve ? & $\infty$ & 3.07 & & 0.5145 & & 1.03 & - & 0.2076 & & 31.021 \\
\hline 130 & 5700 & Vatue 1 & 70 & 3.08 & & $0.187 !$ & & 1.03 & & 0.2076 & & 31.518 \\
\hline 130 & 5700 & Vahe 2 & 71 & 3.04 & 3.05571 & 0.4677 & 0.01902 & 1.03 & 1.031429 & 0.2076 & 0.00378 & 31.312 \\
\hline 130 & 5700 & Valve 2 & 72 & 3.09 & & 1.133 & & 1.03 & & 02076 & & 31.827 \\
\hline 130 & 5700 & Vatue 2 & 73 & 3.07 & & 0.5145 & . & 1.04 & & 0.7612 & & 31.928 \\
\hline 130 & 5700 & Valve 2 & 74 & 3.04 & & 0.4677 & & 1.03 & & 0.2076 & & 31.312 \\
\hline 130 & 5700 & Valve 2 & 75 & 3.04 & & 0.4677 & & 1.03 & & 0.2076 & . & 31.312 \\
\hline 130 & 5700 & Valve 2 & 76 & 3.06 & & 0.1871 & & 1.03 & & 0.2076 & & 39.518 \\
\hline 130 & 5700 & Vatue 2 & $\pi$ & 3.05 & & 0.1403 & & 1.03 & & 0.2076 & & 31.415 \\
\hline 130 & 5700 & Valve 3 & 78 & 3.04 & 3.05143 & 0.4677 & 0.009 & 1.04 & 1.031429 & 0.7612 & 0.00378 & 31.616 \\
\hline 130 & 5700 & Vatre 3 & 79 & 3.06 & & 0.1871 & & 1.03 & & 0.2076 & & 31.518 \\
\hline 130 & 5700 & Valve 3 & 80 & 3.05 & & 0.1403 & & 1.00 & & 0.2076 & & 31.415 \\
\hline 130 & 5700 & Vatre 3 & 81 & 3.06 & & 0.1871 & & 1.03 & & 0.2076 & & 31.518 \\
\hline 130 & 5700 & Varve 3 & 82 & 3.04 & & $0.46 \pi 7$ & & 1.03 & & 0.2076 & & 31.312. \\
\hline 130 & 5700 & Vahe 3 & 83 & 3.06 & & 0.1871 & & 1.03 & & 0.2076 & & 31.518 \\
\hline 130 & 5700 & Valve 3 & 84 & 3.05 & & 0.1403 & & 1.03 & & 0.2076 & & 31.415 \\
\hline Totals & - & - & 21 & 3.0543 & 3.05429 & 0.3163 & 0.01248 & 9.0321 & 1.032143 & 0.3262 & 0.00418 & 31.50281 \\
\hline Overall & - & - & (3) & 3.0405 & 3.04048 & 0.3775 & 0.01827 & 1.0338 & 1.03381 & 0.4605 & 0.00558 & 31.43243 \\
\hline
\end{tabular}

High Leved Dilute Simulant

\begin{tabular}{|c|c|c|c|c|c|c|c|c|c|c|c|c|}
\hline RPM & Volume & Location & Number & Oxjofe & Avg. Ox. & क Enror & Std. dev & Density & Avg. Den & $\%$ Error & Std.der & Ox. Load \\
\hline 45 & 7800 & Hydragard & 1 & 3.2 & 3.17857 & 0.9691 & 0.01464 & 1.04 & 1.037143 & 0.4138 & 0.00488 & 33.28 \\
\hline 45 & 7800 & .Hydragard & 2 & 3.18 & & 0.3381 & & 1.04 & & 0.4138 & & 33.072 \\
\hline 45 & 7800 & Hydragard & 3 & 3.18 & & 0.3381 & & 1.04 & & 0.4138 & & 33.072 \\
\hline 45 & 7800 & Hydragard & 4 & 3.18 & & 0.3381 & & 1.04 & & 0.4138 & & 33.072 \\
\hline 45 & 7800 & Hydragand & 5 & 3.15 & & 0.6085 & & 1.04 & & 0.4138 & & 32.76 \\
\hline 45 & 7800 & Hydragard & 6 & 3.18 & & 0.3381 & & 1.03 & & 0.5517 & & 32.754 \\
\hline 45 & 7800 & Hydragard & 7 & 3.18 & & 0.3381 & & 1.03 & & 0.5517 & & 32.754 \\
\hline 45 & 7800 & Vatue ? & 8 & 3.16 & 3.17286 & 0.293 & 0.01113 & 1.03 & 1.034286 & 0.5517 & 0.00535 & 32.548 \\
\hline 45 & 7800 & Vatue 1 & 9 & 3.18 & & 0.3381 & & 1.04 & & 0.4138 & & 33.072 \\
\hline 45 & 7800 & Valve 1 & 10 & 3.17 & & 0.0225 & & 1.04 & & 0.4138 & & 32.968 \\
\hline 45 & 7800 & Varve 1 & 11 & 3.18 & & 0.3381 & & 1.04 & & 0.4138 & & 33.072 \\
\hline 45 & 7800 & Valve 1 & 12 & 3.19 & & 0.6536 & & 1.03 & & 0.5517 & & 32.857 \\
\hline 45 & 7800 & Vatve 1 & 13 & 3.16 & & 0.293 & & 1.03 & & 0.5517 & & 32.548 \\
\hline 45 & 7800 & Vaive 1 & 14 & 3.17 & & 0.0225 & & 9.03 & & 0.5517 & & 32.651 \\
\hline 45 & 7800 & Vaive 5 & 15 & 3.17 & 3.17 & 0.0225 & 0.01155 & 1.04 & 1.037143 & 0.4138 & 0.00756 & 32968 \\
\hline 45 & 7800 & Valve 5 & 16 & 3.16 & & 0.293 & & 1.04 & & 0.4138 & & 32864 \\
\hline 45 & 7800 & Valve 5 & 17 & 3.18 & & 0.3381 & & 1.04 & & 0.4138 & & 33.072 \\
\hline 45 & 7800 & Valve 5 & 18 & 3.18 & & 0.3381 & & 1.05 & & 1.3793 & & 33.39 \\
\hline 45 & 7800 & Valve 5 & 19 & 3.15 & & 0.6085 & & 1.03 & & 0.5517 & & 32.445 \\
\hline 45 & 7800 & Valve 5 & 20 & 3.18 & & 0.3381 & & 1.00 & & 0.5517 & & 32754 \\
\hline 45 & 7800 & Value 5 & 21 & 3.17 & & 0.0225 & & 1.03 & & 0.5517 & & 32.651 \\
\hline 45 & 7800 & Valve 6 & 22 & 3.16 & 3.15571 & 0.293 & 0.00976 & 1.04 & 1.034286 & 0.4138 & 0.00787 & 32.864 \\
\hline 45 & 7800 & Valve 6 & 23 & 3.16 & & 0.293 & & 1.04 & & 0.4138 & & 32.864 \\
\hline 45 & 7800 & Valve 6 & 24 & 3.15 & & 0.6085 & & 1.04 & & 0.4138 & & 32.76 \\
\hline 45 & 7800 & Valve 6 & 25 & 3.17 & & 0.0225 & & 1.04 & & 0.4138 & & 32968 \\
\hline 45 & 7800 & Valve 6 & 26 & 3.15 & & 0.6085 & & 1.02 & & 1.5172 & & 32.13 \\
\hline 45 & 7800 & Valve 6 & 27 & 3.14 & & 0.924 & & 1.03 & & 0.5517 & & 32.342 \\
\hline 45 & 7800 & Valve 6 & 28 & 3.16 & & 0.293 & & 1.03 & & 0.5517 & & 32.548 \\
\hline Totals & - & - & 28 & 3.1693 & 3.16929 & 0.3654 & 0.01412 & 1.0357 & 1.035714 & 0.5419 & 0.00534 & 32.825 \\
\hline
\end{tabular}


High Leved Dilute Simulant

\begin{tabular}{|c|c|c|c|c|c|c|c|c|c|c|c|c|}
\hline RPM & Volume & Location & Number & Oxide & Avg. $O x$ & क Error & Std. dev & Density & Avg. Den & \% Error & Sid. der & Ox Load \\
\hline 85 & 7800 & Hydragard & 29 & 3.17 & 3.19571 & 0.4253 & 0.01512 & 1.03 & 1.028571 & 0 & 0.00378 & 32651 \\
\hline 85 & 7800 & Hydragard & 30 & 3.2 & & 0.516 & & $1.03^{\circ}$ & & 0 & & 32.96 \\
\hline 85 & 7800 & Hydragard & 31 & 3.21 & & 0.8302 & & 1.03 & & 0 & & 33.053 \\
\hline 85 & 7800 & Hydragard & 32 & 3.29 & & 0.8302 & & 1.03 & & 0 & & 33.053 \\
\hline 85 & 7800 & Hydragard & 33 & 3.2 & & 0.516 & & 1.03 & & 0 & & 32.96 \\
\hline 85 & 7800 & Hydragard & 34 & 3.2 & & 0.516 & & 1.03 & & 0 & & 32.96 \\
\hline 85 & 7800 & Hydragard & 35 & 3.18 & & 0.1122 & & 1.02 & & 0.9709 & & 32.436 \\
\hline 85 & 7800 & Valve 1 & 36 & 3.18 & 3.18143 & 0.1122 & 0.0009 & 1.03 & 1.03 & 0 & 0 & 32754 \\
\hline 85 & 7800 & Valve? & 37 & -3.18 & & 0.1122 & & 1.03 & & 0 & & 32.754 \\
\hline 85 & 7800 & Valve 1 & 38 & 3.17 & & 0.4253 & & 1.03 & & 0 & & 32651 \\
\hline 85 & 7800 & Valve 1 & 39 & 3.18 & & 0.1122 & & 1.03 & & 0 & & 32754 \\
\hline 85 & 7800 & Vatue 1 & 40 & 3.18 & & 0.1922 & & 1.03 & & 0 & & 32754 \\
\hline 85 & 7800 & Valve 1 & 41 & 3.19 & & 0.2019 & & 1.03 & & 0 & & 32857 \\
\hline 85 & 7800 & Valve 1 & 42 & 3.19 & & 0.2019 & & 1.03 & & 0 & & 32.857 \\
\hline 85 & 7800 & Valve 5 & 43 & 3.17 & 3.18286 & 0.4263 & 0.01113 & 1.03 & 1.031429 & 0 & 0.00378 & 32651 \\
\hline 85 & 7800 & Valve 5 & 44 & 3.17 & & 0.4263 & & 1.03 & & 0 & & 32651 \\
\hline 85 & 7800 & Valvé 5 & 45 & 3.19 & & 0.2019 & & 1.03 & & 0 & & 32.857 \\
\hline 85 & 7800 & Valve 5 & 46 & 3.18 & & 0.1122 & & 1.03 & & 0 & & 32754 \\
\hline 85 & 7800 & Valve 5 & 47 & 3.18 & & 0.1122 & & 1.03 & & 0 & & 32754 \\
\hline 85 & 7800 & Valve 5 & 48 & 32 & & 0.516 & - & 1.04 & & 0.9709 & & 33.28 \\
\hline 85 & 7800 & Valve 5 & 49 & 3.19 & & 0.2019 & & 1.03 & & 0 & & 32.857 \\
\hline 85 & 7800 & Valve 6 & 50 & 3.17 & 3.17429 & 0.4263 & 0.00535 & 1.03 & 1.03 & 0 & 0 & 32.651 \\
\hline 85 & 7800 & Valve 6 & 51 & 3.17 & & 0.4263 & & 1.03 & & 0 . & & 32.651 \\
\hline 85 & 7800 & Valve 6 & 52 & 3.18 & & 0.1122 & & 1.03 & & 0 & & 32754 \\
\hline 85 & 7800 & Vatre 6 & 53 & 3.17 & & 0.4263 & & 1.03 & & 0 & & 32.651 \\
\hline 85 & 7800 & Valve 6 & 54 & 3.18 & & 0.1122 & & 1.03 & & 0 & & 32754 \\
\hline 85 & 7800 & Valve 6 & 55 & 3.17 & & 0.4263 & & 1.03 & & 0 & & 32.651 \\
\hline 85 & 7800 & Valve 6 & 56 & 3.18 & & 0.1122 & & 1.03 & & 0 & & 32754 \\
\hline Tolals & - & - & 28 & 3.1836 & 3.18357 & 0.3237 & 0.01254 & 1.03 & 1.03 & 0.0693 & 0.00272 & 3279086 \\
\hline
\end{tabular}

High Level Dilute Simulant

\begin{tabular}{|c|c|c|c|c|c|c|c|c|c|c|c|c|}
\hline RPM & Volume & Location & Number & Oxide & Avg. Ox & XError & Std. dev & Density & Avg. Den & $\%$ Error & Std. dev & Ox Load \\
\hline 130 & 7800 & Hydragard & 57 & 3.2 & 3.16143 & 1.1515 & 0.04451 & 1.03 & 1.03 & 0.0694 & 0 & 32.96 \\
\hline 130 & 7800 & Hydragard & 58 & 3.19 & & 0.8354 & & 1.03 & & 0.0094 & & 32.857 \\
\hline 130 & 7800 & Hydragard & 59 & 3.17 & & 0.2032 & & 1.03 & & 0.0094 & & 32651 \\
\hline 130 & 7800 & Hydragard & 60 & 3.18 & & 0.5193 & & 1.03 & & 0.0094 & & 32754 \\
\hline 130 & 7800 & Hydragard & 61 & 3.07 & & 29578 & & 1.03 & & 0.0694 & & 31.621 \\
\hline 130 & 7800 & Hydragard & $\sigma 2$ & 3.14 & & 0.7451 & & 1.03 & & 0.0094 & . & 32.342 \\
\hline 130 & 7800 & Hydragard & 63 & 3.18 & & 0.5193 & & 1.03 & & 0.0694 & & 32.754 \\
\hline 130 & 7800 & Valve 1 & 64 & 3.18 & 3.16857 & 0.5193 & 0.01069 & 1.03 & 1.028574 & 0.0694 & 0.00378 & 32754 \\
\hline 130 & 7800 & Valve ? & 65 & 3.18 & & 0.5193 & & 1.03 & & 0.0094 & & 32754 \\
\hline 130 & 7800 & Valve 1 & 66 & 3.15 & & 0.429 & & 1.02 & & 0.9022 & & 32.13 \\
\hline 130 & 7800 & Valve ? & 67 & 3.17 & & 0.2032 & & 1.03 & & 0.0634 & & 32651 \\
\hline 130 & 7800 & Valve 1 & 68 & 3.17 & & 0.2032 & & 1.03 & & 0.0694 & & 32.651 \\
\hline 130 & 7800 & Valve? & $\infty$ & 3.16 & & 0.1129 & & 1.03 & & 0.0094 & & 32.548 \\
\hline 130 & 7800 & Valve 1 & 70 & 3.17 & & 0.2032 & & 1.03 & & 0.0094 & & 32.651 \\
\hline 130 & 7800 & Valve 5 & 71 & 3.17 & 3.15857 & 0.2032 & 0.009 & 1.03 & 1.03 & 0.0694 & 0 & 32.651 \\
\hline 130 & 7800 & Valve 5 & 72 & 3.17 & & 0.2032 & & 1.03 & & 0.0594 & & 32,651 \\
\hline 130 & 7800 & Valve 5 & 73 & 3.16 & & 0.1129 & & 1.03 & & 0.0004 & & 32.548 \\
\hline 130 & 7800 & Vatue 5 & 74 & 3.15 & & 0.429 & & 1.03 & & 0.0094 & & 32.445 \\
\hline 130 & 7800 & Valve 5 & 75 & 3.15 & & 0.429 & & 1.03 & & 0.0594 & & -32.445 \\
\hline 130 & 7800 & Valve 5 & 76 & 3.15 & & 0.429 & & 1.03 & & 0.0094 & & 32.445 \\
\hline 130 & 7800 & Valve 5 & 77 & 3.16 & & 0.1129 & & 1.03 & & 0.0094 & & 32.548 \\
\hline 130 & 7800 & Valve 6 & 78 & 3.18 & 3.16571 & 0.5193 & 0.00787 & 1.02 & 1.028571 & 0.9022 & 0.00378 & 32.436 \\
\hline 130 & 7800 & Valve 6 & 79 & 3.17 & & 0.2032 & & 1.03 & & 0.0694 & & 32.651 \\
\hline 130 & 7800 & Valve 6 & 80 & 3.16 & & 0.1129 & & 1.03 & & 0.0594 & & 32.548 \\
\hline 130 & 7800 & Valve 6 & 81 & 3.16 & & 0.1129 & & 1.03 & & 0.0694 & & 32.548 \\
\hline 130 & 7800 & Vatue 6 & 82 & 3.17 & & 0.2032 & & 1.03 & & 0.0094 & & 32.651 \\
\hline 130 & 7800 & Valve 6 & 83 & 3.16 & & 0.1129 & & 1.03 & & 0.0094 & & 32.548 \\
\hline 130 & 7800 & Valve 6 & 84 & 3.16 & & 0.1129 & - & 1.03 & & 0.0594 & & 32.548 \\
\hline Totals & - & - & 28 & $3.1 \sqrt[36]{6}$ & 3.16357 & 0.4435 & 0.02264 & 1.0293 & 1.029286 & 0.1289 & 0.00252 & 3255218 \\
\hline Overall & $=$ & $=$ & 84 & 3.1721 & 3.17214 & 0.3776 & 0.01883 & 1.0317 & 1.031657 & 0.2457 & 0.00511 & 32.72601 \\
\hline
\end{tabular}


Low Level Concentrated Simulant

\begin{tabular}{|c|c|c|c|c|c|c|c|c|c|c|c|c|}
\hline$R P M$ & Volume & Location & Number & Oxide & Avg. Ox & क Error & Std. dev & Density & Avg. Den & \% Error & Std. dev & Ox Load \\
\hline 45 & 5700 & Hydragard & 1 & 11.14 & 11.3443 & 1.8873 & 0.10374 & 1.1 & 1.108571 & 0.1297 & 0.009 & 122.54 \\
\hline 45 & 5700 & Hydragard & 2 & 11.34 & & 0.1258 & & 1.12 & & 1.6851 & & 127.008 \\
\hline 45 & 5700 & Hydragard & 3 & 11.38 & & 0.2265 & & 1.12 & & 1.6861 & & 127.456 \\
\hline 45 & 5700 & Hydragard & 4 & 91.36 & & 0.0503 & & 1.11 & & 0.7782 & & 126.096 \\
\hline 45 & 5700 & Hydragard & 5 & 11.49 & & 1.1953 & & 1.1 & & 0.1297 & & 126.39 \\
\hline 45 & 5700 & Hydragard & 6 & 11.35 & & 0.0377 & & 1.11 & & 0.7782 & & 125.985 \\
\hline 45 & 5700 & Hydragard & 7 & $\$ 1.35$ & & 0.037 & & 1.1 & & 0.1297 & & 124.85 \\
\hline 45 & 5700 & Vatre 1 & 8 & 11.37 & 11.3571 & 0.1384 & 0.01799 & 9.12 & 1.108571 & 1.6851 & 0.01215 & 127.344 \\
\hline 45 & 5700 & Vatre 1 & 9 & -11.36 & & 0.0503 & & 1.1 & & 0.1297 & & 124.96 \\
\hline 45 & 5700 & Vatre 1 & 10 & 11.35 & & $0.03 \pi$ & & 1.09 & & 1.0376 & & 123.715 \\
\hline 45 & 5700 & Valve 1 & 11 & 11.38 & & 0.2265 & & 1.11 & & 0.7782 & & 126.318 \\
\hline 45 & 5700 & Valve 1 & 12 & 11.37 & & 0.1384 & & 1.1 & & 0.1297 & & 125.07 \\
\hline 45 & 5700 & Valve ? & 13 & 11.33 & & 0.2139 & & 1.12 & & 1.6861 & & 126.896 \\
\hline 45 & 5700 & Valve : & 14 & 11.34 & & 0.1258 & & 1.12 & & 1.6861 & & 127.008 \\
\hline 45 & 5700 & Valve 2 & 15 & 91.37 & 11.3557 & 0.1384 & 0.01618 & 1.09 & 1.1 & 1.0376 & 0.01291 & 123.933 \\
\hline 45 & 5700 & Valve 2 & 16 & 11.35 & & 0.037 & & 1.11 & & 0.7782 & & 125.985 \\
\hline 45 & 5700 & Valve 2 & 17 & 11.34 & & 0.1258 & & 1.09 & & 1.0376 & & 123.606 \\
\hline 45 & 5700 & Vatve 2 & 18 & 11.37 & & 0.1384 & & 1.11 & & 0.7782 & & 128.207 \\
\hline 45 & 5700 & Valve 2 & 19 & 11.37 & & 0.1384 & & 1.11 & - & 0.7782 & & 126.207 \\
\hline 45 & 5700 & Valve 2 & 20 & 11.36 & & 0.0503 & & 1.08 & & 1.9455 & & 122688 \\
\hline 45 & 5700 & Valve 2 & 21 & 11.33 & & 0.2139 & & 1.11 & & 0.7782 & & 125.763 \\
\hline 45 & 5700 & Vatue 3 & 22 & 11.36 & 11.36 & 0.0503 & 0.01732 & 1.09 & 1.088571 & 1.0376 & 0.04018 & 123.824 \\
\hline 45 & 5700 & Vatue 3 & 23 & 11.33 & & 0.2139 & & 1.1 & & 0.1297 & & 124.63 \\
\hline 45 & 5700 & Valve 3 & 24 & 11.35 & & 0.037 & & 1.1 & & 0.1297 & & 124.85 \\
\hline 45 & 5700 & Valve 3 & 25 & 11.38 & & 0.2265 & & 1.12 & . & 1.6861 & & 127.456 \\
\hline 45 & 5700 & Valve 3 & 26. & 11.36 & & 0.0503 & & 1.1 & & 0.1297 & & 124.96 \\
\hline 45 & 5700 & Valve 3 & 27 & 11.38 & & 0.2265 & & 1.11 & & 0.7782 & & 126.318 \\
\hline 45 & 5700 & Valve 3 & 28 & 11.36 & & 0.0503 & & 1 & & 9.2088 & $\cdot$ & 113.6 \\
\hline Totals & - & - & 28 & 11.354 & 11.3543 & 0.2211 & 0.05124 & $\$ .1014$ & 1.101429 & 1.1673 & 0.02272 & 125.0594 \\
\hline
\end{tabular}

Low Level Concentrated Simulant

\begin{tabular}{|c|c|c|c|c|c|c|c|c|c|c|c|c|}
\hline RPM & Volume & Location & Number & Oxide & Avg. Ox & क Enror & Std, dey & Density & Avg. Den & \% Enror & Std. dev & $O x$ Losd \\
\hline 85 & 5700 & Hydragard & 29 & 11.45 & 11.5014 & 0.1844 & 0.05014 & 1.11 & 1.107143 & 0.1289 & 0.02215 & 127.095 \\
\hline 85 & 5700 & Hydragard & 30 & 11.5 & & 0.6219 & & 1.07 & & 3.4794 & & 123.05 \\
\hline 85 & 5700 & Hydragard & 31 & 19.51 & & 0.7094 & & 9.12 & & 1.0300 & & 128.912 \\
\hline 85 & 5700 & Hydragard & 32 & 11.56 & & 1.1468. & & 1.14 & & 2.8351 & & 131.784 \\
\hline 85 & 5700 & Hydragard & 33 & 11.53 & & 0.8843 & & 1.09 & & 1.6753 & & 125.677 \\
\hline 85 & 5700 & Hydragard & 34 & 11.42 & & 0.0781 & & 1.11 & & 0.1289 & & 126.762 \\
\hline 85 & 5700 & Hydragard & 35 & 11.54 & & 0.9718 & & 1.11 & & 0.1289 & & 128.094 \\
\hline 85 & 5700 & Valve ? & 36 & 11.4 & 11.4086 & 0.2531 & 0.01676 & 1.1 & 1.11 & 0.7732 & 0.00577 & 125.4 \\
\hline 85 & 5700 & Valve 1 & 37 & 11.42 & & 0.0781 & & 1.11 & & 0.1289 & & 126.752 \\
\hline 85 & 5700 & Valve 9 & 38 & 11.42 & & 0.0781 & & 1.11 & & 0.1289 & & $126.7 \sigma$ \\
\hline 85 & 5700 & Valve 1 & 39 & 11.4 & & 0.2531 & & 1.11 & & 0.1289 & & 126.54 \\
\hline 25 & 5700 & Valve 1 & 40 & $\$ 1.41$ & & 0.1656 & & 9.11 & & 0.1289 & & 126.651 \\
\hline 85 & 5700 & Valve 1 & 41 & $\$ 1.43$ & & 0.0094 & & 1.12 & & 1.0309 & & 128.016 \\
\hline 85 & 5700 & Vatue 1 & 42 & 11.38 & & 0.4281 & & 1.11 & & 0.1289 & & 126.318 \\
\hline 85 & 5700 & Valve 2 & 43 & 11.41 & 11.3971 & 0.1656 & 0.02059 & 1.1 & 1.11 & 0.7732 & 0.00816 & 125.51 \\
\hline 85 & 5700 & Valve 2 & 44 & 11.4 & & 0.2531 & & 1.11 & & 0.1289 & & 126.54 \\
\hline 85 & 5700 & Valve 2 & 45 & 11.41 & & 0.1656 & & 1.11 & & 0.1289 & & 126.651 \\
\hline 85 & 5700 & Valve 2 & 46 & 11.42 & & 0.0781 & & 1.91 & & 0.1289 & & 126.762 \\
\hline 85 & 5700 & Valve 2 & 47 & 11.4 & & 0.2531 & & 1.1 & & 0.7732 & & 125.4 \\
\hline 85 & 5700 & Valve 2 & $48^{\circ}$ & 11.36 & & 0.6031 & & 1.12 & & 1.0309 & & 127.232 \\
\hline 85 & 5700 & Valve 2 & 49 & 11.38 & & 0.4281 & & 9.12 & & 1.0309 & & 127.456 \\
\hline 85 & 5700 & Valve 3 & 50 & 11.41 & 11.4086 & 0.1656 & 0.02673 & 1.11 & 1.107143 & 0.1289 & 0.00488 & 126.651 \\
\hline 85 & 5700 & Valve 3 & 51 & 11.4 & & 0.2531 & & 1.1 & & 0.7732 & & 125.4 \\
\hline 85 & 5700 & Vatre 3 & 52 & 11.41 & & 0.1656 & & 1.11 & & 0.1289 & & $\{26.651$ \\
\hline 25 & 5700 & Valve 3 & 53 & 11.46 & & 0.2719 & & 1.11 & & 0.1289 & & 127,206 \\
\hline 85 & 5700 & Valve 3 & 54 & 11.4 & & 0.2531 & & 1.1 & & 0.7732 & & 125.4 \\
\hline 85 & 5700 & Valve 3 & 55 & 11.41 & & 0.1656 & & $\cdot 1.11$ & & 0.1289 & & 126.651 \\
\hline 85 & 5700 & Value 3 & 56 & 11.37 & & 0.5156 & & 1.11 & & 0.1289 & & 126.207 \\
\hline Totals & - & - & 28 & 11.429 & 11.4289 & 0.3428 & 0.05209 & 1.1086 & 1.108579 & 0.6443 & 0.01977 & 126.6979 \\
\hline
\end{tabular}


Low Level Concentrated SImulant

\begin{tabular}{|c|c|c|c|c|c|c|c|c|c|c|c|c|}
\hline RPM & Volume & Location & Number & Oxide & Avg. Ox & $\%$ Error & Sid. dev & Density & Avg. Den & \% Error & Sid. dev & Ox.Load \\
\hline 130 & 5700 & Hydragard & 57 & 11.34 & 11.3371 & 0.2716 & 0.01704 & 1.11 & 1.102857 & 0.2904 & 0.00488 & 125.874 \\
\hline 130 & 5700 & Hydragard & 58 & 11.3 & & 0.0821 & & 1.1 & & 0.6131 & & 124.3 \\
\hline 130 & 5700 & Hydragard & 59 & 11.35 & & 0.36 & & 1.1 & & 0.6131 & & 124.85 \\
\hline 130 & 5700 & Hydragard & 60 & 11.34 & & 0.2716 & & 1.11 & & 0.2004 & & 125.874 \\
\hline 130 & 5700 & Hydragard & 61 & 11.34 & - & 0.2716 & & 1.1 & & 0.6131 & & 124.74 \\
\hline 130 & 5700 & Hydragard & 62 & 11.35 & & 0.36 & & 1.1 & & 0.6131 & & 124.85 \\
\hline 130 & 5700 & Hydragard & 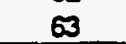 & $\$ 1.34$ & & 0.2716 & & 1.1 & & 0.6131 & & 124.74 \\
\hline 130 & 5700 & Valve 1 & 64 & 11.37 & $11 . \overline{3286}$ & 0.5359 & 0.02573 & 1.1 & 1.11 & 0.6131 & 0.00577 & 125.07 \\
\hline 130 & 5700 & Valve 1 & 65 & .11 .28 & & 0.259 & & 1.11 & & 0.2904 & & 125.208 \\
\hline 130 & 5700 & Value 1 & 65 & 11.33 & & 0.1832 & & 1.11 & & 0.2904 & & 125.763 \\
\hline 130 & 5700 & Valve 1 & 67 & 11.33 & & 0.1832 & & 1.11 & & 0.2004 & & 125.763 \\
\hline 130 & 5700 & Valve 1 & 68 & 11.33 & & 0.1832 & & 1.99 & & 0.2904 & & 125.763 \\
\hline 130 & 5700 & Valve 1 & $\infty$ & 11.34 & & 0.2716 & & 1.12 & & 1.1939 & & 127.008 \\
\hline 130 & 5700 & Varve 1 & 70 & 11.32 & & 0.0947 & $\cdot$ & 1.11 & & 0.2004 & & 125.652 \\
\hline 130 & 5700 & Valve 2 & 79 & 11.28 & 11295 & 0.259 & 0.05127 & 1.12 & 1.108571 & 1.1939 & 0.00699 & 126.336 \\
\hline 130 & 5700 & Valve 2 & 72 & 1.1 .33 & & 0.1832 & & 1.11 & & 0.2004 & & 125.763 \\
\hline 130 & 5700 & Valve 2 & 73 & 11.19 & & 1.0548 & & 1.11 & & 0.2904 & & 124.209 \\
\hline 130 & 5700 & Vatue 2 & 74 & 11.3 & & 0.0821 & & 1.1 & & 0.6131 & & 124.3 \\
\hline 130 & 5700 & Valve 2 & 75 & 11.3 & & 0.0821 & & 1.11 & & 0.2004 & & 125.43 \\
\hline 130 & 5700 & Vatue 2 & 76 & 11.33 & & 0.1832 & & 1.1 & & 0.6131 & & 124.63 \\
\hline 130 & 5700 & Valve 2 & $\pi$ & 11.34 & & 0.2716 & & 1.19 & & 0.2904 & & 125.874 \\
\hline 1.30 & 5700 & Valve 3 & 78 & 10.96 & 11.2757 & 3.0885 & 0.14223 & 1.1 & 1.105714 & 0.6131 & 0.00535 & 120.56 \\
\hline 130 & 5700 & Valve 3 & 79 & 11.33 & & 0.1832 & & 1.11 & & 0.2904 & & 125.763 \\
\hline 130 & 5700 & Valve 3 & 80 & 11.32 & & 0.0947 & & 1.11 & & 0.2004 & & 125.652 \\
\hline 130 & 5700 & Valve 3 & 81 & 11.38 & & 0.6253 & & 1.1 & & 0.6131 & & 125.18 \\
\hline 130 & 5700 & Valve 3 & 82 & 11.33 & & 0.1832 & & 1.11 & & 0.2004 & & 125.763 \\
\hline 130 & 5700 & Valve 3 & 83 & 11.28 & & 0.259 & & 1.11 & & 0.2904 & & 125.208 \\
\hline 130 & 5700 & Valve 3 & 84 & 11.33 & & 0.1832 & & 1.1 & & 0.6131 & & 124.63 \\
\hline Totals & - & - & 28 & 11.309 & 11.3093 & 0.369 & 0.07707 & 1.1068 & 1.106786 & 0.4817 & 0.00612 & 125.1698 \\
\hline Overall & - & - & 84 & 11.364 & 11.3642 & 0.311 & 0.07831 & 1.1056 & 1.105595 & 0.7645 & 0.01532 & 125.6423 \\
\hline
\end{tabular}

High Level Concentrated Simulant

\begin{tabular}{|c|c|c|c|c|c|c|c|c|c|c|c|c|}
\hline RPM & Volume & Location & Number & Oxide & Avg. Ox. & \% Error & Std. dev & Density & Avg. Den & \% Error & Std. dev & Ox Load \\
\hline 45 & 7800 & Hydragard & 1 & 1121 & 112271 & 0.6803 & 0.07274 & 1.12 & 1.108571 & 1.8843 & 0.01059 & 125.552 \\
\hline 45 & 7800 & Hydragard & 2 & 11.32 & & 0.2943 & & 1.11 & & 0.9747 & & 125.652 \\
\hline 45 & 7800 & Hydragard & 3 & 11.11 & & 1.5653 & & 1.12 & & 1.8843 & & 124.432 \\
\hline 45 & 7800 & Hydragard & 4 & 11.3 & & 0.1171 & & 1.11 & & 0.9747 & & 125.43 \\
\hline 45 & 7800 & Hydragard & 5 & 11.23 & & 0.5031 & & 1.09 & & 0.8447 & & 122.407 \\
\hline 45 & 7800 & Hydragard & 6 & 11.25 & & 0.3259 & - & 1.1 & & 0.065 & & 123.75 \\
\hline 45 & 7800 & Hydragard & 7 & 11.17 & & 1.0347 & & 1.11 & & 0.9747 & & 123.987 \\
\hline 45 & 7800 & Vatve 1 & 8 & 11.33 & 11.3129 & 0.3829 & 0.02059 & 1.09 & 1.07 & 0.8447 & 0.05708 & 123.497 \\
\hline 45 & 7800 & Valve 1 & 9 & 11.32 & & 0.2943 & & 0.95 & & 13.58 & & 107.54 \\
\hline 45 & 7800 & Valve 1 & 10 & 11.33 & & 0.3829 & & 1.11 & & 0.9747 & & 125.763 \\
\hline 45 & 7800 & Valve 1 & 11 & 11.31 & & 0.2057 & & 1.11 & & 0.9747 & & 125.541 \\
\hline 45 & 7800 & Valve 1 & 12 & 11.29 & & 0.0285 & & 1 & & 9.0318 & & 1129 \\
\hline 45 & 7800 & Valve 1 & 13 & 11.33 & & 0.3829 & & 1.11 & & 0.9747 & . & 125.763 \\
\hline 45 & 7800 & Vatve 1 & 14 & 1128 & & 0.0601 & & 1.12 & & 1.8843 & & 126.336 \\
\hline 45 & 7800 & Valve 5 & 15 & 11.3 & 11.295 & 0.1171 & 0.0282 & 1.12 & 1.108571 & 1.8843 & 0.01454 & 126.56 \\
\hline 45 & 7800 & Vatve 5 & 16 & 11.32 & & 0.2943 & & 1.1 & & 0.065 & & 124.52 \\
\hline 45 & 7800 & Vatve 5 & 17 & 11.28 & & 0.0601 & & 1.08 & & 1.7544 & & 121.824 \\
\hline 45 & 7800 & Valve 5 & 18 & 11.34 & & 0.4715 & & 1.12 & & 1.8843 & - & 127.008 \\
\hline 45 & 7800 & Valve 5 & 19 & 11.26 & & 0.2373 & & 1.11 & & 0.9747 & & 124.986 \\
\hline 45 & 7800 & Valve 5 & 20. & 11.3 & & 0.1171 & & 1.12 & & 1.8843 & & 126.56 \\
\hline 45 & 7800 & Valve 5 & 21 & 11.27 & & 0.1487 & & 1.11 & & 0.9747 & & 125.097 \\
\hline 45 & 7800 & Valve 6 & 22 & 11,31 & 11.3114 & 0.2057 & 0.02268 & 1.12 & 1.11 & 1.8843 & 0.00577 & 126.672 \\
\hline 45 & 7800 & Valve 6 & 23 & 11.3 & & 0.1171 & & 1.11 & & 0.9747 & & 125.43 \\
\hline 45 & 7800 & Valve 6 & 24 & 11.33 & & 0.3820 & & 1.11 & & 0.9747 & & 125.703 \\
\hline 45 & 7800 & Valve 6 & 25 & 1129 & & 0.0285 & & 1.11 & & 0.9747 & & 125.319 \\
\hline 45 & 7800 & Vaive 6 & 26 & 11.34 & & 0.4715 & & 1.1 & & 0.065 & & 124.74 \\
\hline 45 & 7800 & Valve 6 & 27 & 11.33 & & 0.3829 & & 1.11 & & 0.9747 & & 125.763 \\
\hline 45 & 7800 & Valve 6 & 28 & 11.28 & & 0.0601 & & 1.11 & & 0.9747 & & 125.208 \\
\hline Totals & - & - & 28 & 11.287 & 112868 & 0.3341 & 0.05327 & 1.0993 & 1.099286 & 1.8611 & 0.03711 & 124.0714 \\
\hline
\end{tabular}


High Level Concentrated Simulant

\begin{tabular}{|c|c|c|c|c|c|c|c|c|c|c|c|c|}
\hline RPM & Volume & Location & Number & Oxide & Avg. $O x$ & \% Error & Std. dev & Density & Avg. Den & $\%$ Error & Std. dev & Ox Load \\
\hline 85 & 7800 & Hydragard & 29 & 11.26 & 11.2914 & 0.552 & 0.04706 & 1.1 & 1.1 & 0.7092 & 0.00816 & 123.86 \\
\hline 85 & 7800 & Hydragard & 30 & 11.39 & & 0.1104 & & 1.1 & & 0.7092 & & 124.41 \\
\hline 85 & 7800 & Hydragard & 31 & 112 & & 1.0819 & & 1.1 & & 0.7092 & & 123.2 \\
\hline 85 & 7800 & Hydragard & 32 & 11.31 & & 0.1104 & & 1.09 & - & 1.6149 & & 123.279 \\
\hline 85 & 7800 & Hydragard & 33 & 11.3 & & 0.1987 & & 1.11 & & 0.1934 & & 125.43 \\
\hline 85 & 7800 & Hydragard & 34 & 11.32 & & 0.0221 & & 1.11 & & 0.1934 & & 125.652 \\
\hline 85 & 7800 & Hydragard & 35 & 11.34 & & 0.1546 & & 1.09 & & 1.6119 & & 123.606 \\
\hline 85 & 7800 & Vatve 1 & 36 & 11.35 & 11.3286 & 0.2429 & 0.02268 & 1.11 & 1.11 & 0.1934 & 0.00577 & 125.985 \\
\hline 85 & 7800 & Valve 1 & 37 & -11.33 & & 0.0552 & & 1.11 & & 0.1834 & & 125.763 \\
\hline 85 & 7800 & Valve 1 & 38 & 11.33 & & 0.0652 & & 1.91 & & 0.1934 & & 125.763 \\
\hline 85 & 7800 & Valve 1 & 39 & 11.34 & & 0.1546 & & 1.1 & & 0.7092 & & 124.74 \\
\hline 85 & 7800 & Vatue 1 & 40 & 11.34 & & 0.1546 & & 1.19 & & 0.1934 & & 125.874 \\
\hline 85 & 7800 & Valve i & 49 & 11.33 & & 0.0652 & & 1.11 & & 0.1934 & & 125.763 \\
\hline 85 & 7800 & Valve 1 & 42 & 11.28 & & 0.3754 & & 1.12 & & 1.0961 & & 126.336 \\
\hline 85 & 7800 & Valve 5 & 43 & 11.35 & 11.3357 & 0.2429 & 0.01902 & 1.11 & 1.112857 & 0.1934 & 0.00488 & 125.985 \\
\hline 85 & 7800 & Valve 5 & 44 & 11.36 & & 0.3312 & & 1.11 & & 0.1934 & & 126.096 \\
\hline 85 & 7800 & Valve 5 & 45 & 11.33 & & 0.0652 & & 1.11 & & 0.1934 & & 125.763 \\
\hline 85 & 7800 & Vatve 5 & 46 & 11.34 & & 0.1546 & & 1.19 & & 0.1934 & & 125.874 \\
\hline 85 & 7800 & Valve 5 & 47 & 11.34 & & 0.1546 & & 1.12 & & 1.0961 & & 127.008 \\
\hline 85 & 7800 & Valve 5 & 48 & 11.33 & & 0.0652 & & 1.11 & & 0.1934 & & 125.763 \\
\hline 85 & 7800 & Valve 5 & 49 & 11.3 & & 0.1987 & & 1.12 & & 1.0961 & & 126.56 \\
\hline 85 & 7800 & Valve 6 & 50 & 11.37 & 11.3343 & 0.4195 & 0.01813 & 1.11 & 1.108571 & 0.1934 & 0.00378 & 126.207 \\
\hline 85 & 7800 & Vatre 6 & 51 & 11.33 & & 0.0662 & & 1.11 & & 0.1934 & & 125.763 \\
\hline 85 & 7800 & Valve 6 & 52 & 11.33 & & 0.0662 & & 9.11 & & 0.1934 & & 125.763 \\
\hline 85 & 7800 & Valve 6 & 53 & 11.34 & & 0.1546 & & 1.1 & & 0.7092 & & 124.74 \\
\hline 85 & 7800 & Valve 6 & 54 & 11.33 & & 0.0662 & & 1.11 & & 0.1934 & & 125.763 \\
\hline 85 & 7800 & Valve 6 & 55 & 11.33 & & 0.0652 & & 1.11 & & 0.1934 & & 125.763 \\
\hline 85 & 7800 & Valve 6 & 56 & 11.31 & & 0.1104 & & 1.11 & & 0.1934 & & 125.541 \\
\hline Totals & 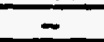 & 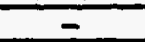 & 28 & 11.323 & 11.3225 & 0.1971 & 0.03318 & 1.1079 & 1.107857 & 0.4836 & 0.00738 & 125.4375 \\
\hline
\end{tabular}

High Level Concentrated Simulant

\begin{tabular}{|c|c|c|c|c|c|c|c|c|c|c|c|c|}
\hline RPM & Volume & Location & Number & Oxide & Avg. $0 x$. & $\%$ Entor & Std. dey & Density & Avg. Den & $\%$ Error & Std. dev & Ox Laad \\
\hline 130 & 7800 & Hydragard & 57 & 1129 & 11.2943 & 0.1957 & 0.01272 & 1.1 & 1.104286 & 0.9328 & 0.00535 & 124.19 \\
\hline 130 & 7800 & Hydragand & 58 & 1127 & & 0.3725 & & 1.1 & & 0.9328 & & 123.97 \\
\hline 130 & 7800 & Hydragard & 59 & 11.29 & & 0.1957 & & 1.11 & & 0.0322 & & 125.349 \\
\hline 130 & 7800 & Hydragard & $\infty$ & 11.3 & & 0.1073 & & 1.11 & & 0.0322 & & 125.43 \\
\hline 130 & 7800 & Hydragard & 69 & 11.3 & & 0.1073 & & 1.11 & & 0.0322 & & 125.43 \\
\hline 130 & 7800 & Hydragard & $\sigma 2$ & 11.3 & & 0.1073 & & 1.1 & & 0.9328 & & 124.3 \\
\hline 130 & 7800 & Hydragard & (3) & 11.31 & & 0.0189 & & 1.1 & & 0.9328 & & 124.41 \\
\hline 130 & 7800 & Valve ? & 64 & 11.34 & 11.3214 & 0.2453 & 0.01069 & 1.12 & 1.111429 & 0.8684 & 0.00378 & $127: 008$ \\
\hline 130 & 7800 & Valve 1 & 65 & 11.31 & & 0.0189 & & 1.11 & & 0.0322 & & 125.541 \\
\hline 130 & 7800 & Vahe? & 66 & 11.31 & & 0.0189 & & १.11 & & 0.0322 & & 125.541 \\
\hline 130 & 7800 & Valve 1 & 67 & 11.32 & & 0.0095 & & 1.11 & & 0.0322 & & 125.652 \\
\hline 130 & 7800 & Valve ? & 68 & 11.33 & & 0.1579 & & 1.11 & & 0.0322 & & 125.763 \\
\hline 130 & 7800 & Valve 1 & $\infty$ & 11.32 & & 0.0005 & & 1.11 & & 0.0322 & & 125.652 \\
\hline 130 & 7800 & Vatue 1 & 70 & 11.32 & & 0.0095 & & 1.11 & & 0.0322 & & 125.652 \\
\hline 130 & 7800 & Valve 5 & 71 & 11.36 & 11.3186 & 0.4231 & 0.02911 & 1.11 & 1.112857 & 0.0322 & 0.00488 & 126.096 \\
\hline 130 & 7800 & Valve 5 & 72 & 11.3 & & 0.1073 & & 1.12 & & 0.8684 & & 126.56 \\
\hline 130 & 7800 & Valve 5 & 73 & 11.34 & & 0.2463 & & 1.11 & & 0.0322 & & 125.874 \\
\hline 130 & 7800 & Vatve 5 & 74 & 11.20 & & 0.1957 & & 9.11 & & 0.0322 & & 125.319 \\
\hline 130 & 7800 & Valve 5 & 75 & 11.28 & & 0.2841 & & 1.11 & & 0.0322 & & 125208 \\
\hline 130 & 7800 & Valve 5 & 76 & 11.33 & & 0.1579 & & 1.11 & & 0.0322 & & $125.7 \approx 3$ \\
\hline 130 & 7800 & Valve 5 & $\pi$ & 11.33 & & 0.1579 & & 1.12 & & 0.8684 & & 126.896 \\
\hline 130 & 7800 & Valve 6 & 78 & 91.3 & 11.3143 & 0.7073 & 0.02299 & 1.11 & 1.112857 & 0.0322 & 0.00488 & 125.43 \\
\hline 130 & 7800 & Valve 6 & 79 & 11.33 & & 0.1579 & & 1.12 & & 0.8584 & & 126.896 \\
\hline 130 & 7800 & Valve 6 & 80 & 11.35 & & 0.3347 & & 1.11 & & 0.0322 & & 125.985 \\
\hline 130 & 7800 & Valve 6 & 81 & 11.31 & & 0.0189 & & 1.91 & & 0.0322 & & 125.541 \\
\hline 130 & 7800 & Vahe 6 & 82 & 11.29 & & 0.1957 & & 1.91 & & 0.0322 & & 125.319 \\
\hline 130 & 7800 & Valve 6 & 83 & 11.29 & & 0.1957 & & 1.91 & & 0.0322 & & 125.319 \\
\hline 130 & 7800 & Valve 6 & 84 & 11.33 & & 0.1579 & & 1.12 & & 0.8584 & & 126.896 \\
\hline Totals & - & - & 28 & 11.312 & 11.3121 & 0.1606 & 0.022 & 1.1104 & 1.110357 & 0.3102 & 0.00576 & 125.6057 \\
\hline Overall & $=$ & $=$ & 84 & 11.307 & 11.3071 & 0.2306 & 0.04082 & 1.1058 & 1.105833 & 0.885 & 0.02234 & 125,0382 \\
\hline
\end{tabular}


Formated Simulant

\begin{tabular}{|c|c|c|c|c|c|c|c|c|c|c|c|c|}
\hline RPM & Volume & Location & Number & Oxide & Avg. Ox & क Ertor & Std. dey & Density & Avg. Den & \% Error & Std. der & Ox Load \\
\hline 45 & 6500 & Hydragard & 1 & 13.47 & 13.46 & 0.1141 & 0.01633 & 1.1 & 1.127143 & 26856 & 0.01254 & 148.17 \\
\hline 45 & 6500 & Hydragard & 2 & 13.47 & & 0.1141 & & 1.13 & & 0.0316 & & 152219 \\
\hline 45 & 6500 & Hydragand & 3 & 13.44 & & 0.1088 & & 1.13 & & 0.0316 & & 151.872 \\
\hline 45 & 6500 & Hydragard & 4 & 13.48 & & 0.1885 & & 1.14 & & 0.8531 & & 153.672 \\
\hline 45 & 6500 & Hydragard & 5 & 13.44 & & 0.1088 & & 1.13 & & 0.0316 & & 151.872 \\
\hline 45 & 6500 & Hydragard & 6 & 13.45 & & 0.0345 & & 1.13 & & 0.0316 & & 151.985 \\
\hline 45 & 6500 & Hydragard & 7 & 13.47 & & 0.1141 & & 1.13 & & 0.0316 & & 152.211 \\
\hline 45 & 6500 & Valve 1 & 8 & 13.48 & 13.45 & 0.1885 & 0.02709 & 1.14 & 1.135714 & 0.8531 & 0.00535 & 153.672 \\
\hline 45 & 6500 & Valve 1 & 9 &. .13 .46 & & 0.0398 & & 1.14 & & 0.8531 & & 153.444 \\
\hline 45 & 6500 & Valve 1 & 10 & 13.48 & & 0.1885 & & 1.13 & & 0.0316 & & 152.324 \\
\hline 45 & 6500 & Valve 1 & 11 & 13.44 . & & 0.1088 & & 1.13 & & 0.0316 & & 151.872 \\
\hline 45 & 6500 & Valve? & 12 & 13.44 & & 0.1088 & & 1.13 & & 0.0316 & & 151.872 \\
\hline 45 & 6500 & Valve 1 & 13 & 13.45 & & 0.0345 & & 1.94 & & 0.8539 & & 153.33 \\
\hline 45 & 6500 & Vatue 1 & 14 & 13.4 & & 0.4061 & & 1.14 & & 0.8531 & & 15276 \\
\hline 45 & 6500 & Valve 4 & 15 & 13.42 & 13.4443 & 0.2575 & 0.0369 & 1.13 & 1.128571 & 0.0316 & 0.00378 & 151.646 \\
\hline 45 & 6500 & Valve 4 & 16 & 13.48 & & 0.1885 & & 1.13 & & 0.0316 & & 152.324 \\
\hline 45 & 6500 & Valve 4 & 17 & 13.39 & & 0.4805 & & 1.13 & & 0.0316 & & 151.307 \\
\hline 45 & 6500 & Valve 4 & $\cdot 18$ & 13.46 & & 0.0398 & & 1.13 & & 0.0316 & & 152008 \\
\hline 45 & 6500 & Valve 4 & 19 & 13.41 & & 0.3318 & & 1.93 & & 0.0316 & & 151.533 \\
\hline 45 & 6500 & Valve 4 & 20 & 13.48 & & 0.1885 & & 1.12 & & 0.9163 & & 150.976 \\
\hline 45 & 6500 & Valve 4 & 21 & 13.47 & & 0.1141 & & 1.13 & & 0.0316 & & 152211 \\
\hline 45 & 6500 & Value 5 & 22 & 13.45 & 13.4643 & 0.0345 & 0.03735 & 1.13 & 1.13 & 0.0316 & 0.00816 & 151.985 \\
\hline 45 & 6500 & Valve 5 & 23 & 13.49 & & 0.2528 & & 1.13 & & 0.0316 & & 152.437 \\
\hline 45 & 6500 & Valve 5 & 24 & 13.53 & & 0.5601 & & 1.14 & & 0.8531 & & 154.242 \\
\hline 45 & 6500 & Valve 5 & 25 & 13.47 & & 0.1141 & & 1.13 & & 0.0916 & & 152211 \\
\hline 45 & 6500 & Valve 5 & 26 & 13.42 & & 0.2575 & & 1.14 & & 0.8531 & & 152.988 \\
\hline 45 & 6500 & Vatue 5 & 27 & 13.43 & & 0.1832 & & 1.12. & & 0.9163 & & 150.416 \\
\hline 45 & 6500 & Value 5 & 28 & 13.46 & & 0.0398 & & 1.12 & & 0.9163 & & 150.752 \\
\hline Tolals & - & - & 28 & 13.455 & 13.4546 & 0.1754 & 0.03012 & 1.1304 & 1.130357 & 0.4265 & 0.00838 & 152.0855 \\
\hline
\end{tabular}

Formated Simulant

\begin{tabular}{|c|c|c|c|c|c|c|c|c|c|c|c|c|}
\hline RPM & Volume & Location & Number & Oxide & Avg. Ox & \% Error & Sid. dev & Density & Avg. Den & $\%$ Error & Std. der & Ox. Laad \\
\hline 85 & 6500 & Hydragard & 29 & 13.27 & 13.42 & 1.6725 & 0.06683 & 1.11 & 1.122857 & 20177 & 0.01704 & 147.297 \\
\hline 85 & 6500 & Hydragard & 30 & 13.44 & & 0.4128 & & 1.13 & & 0.2522 & & 151.872 \\
\hline 85 & 6500 & Hydragard & 31 & 13.45 & & 0.3387 & & 1.13 & & 0.2522 & & 151.985 \\
\hline 85 & 6500 & Hydragard & 32 & 13.45 & & 0.3387 & & 1.13 & & 0.2520 & & 151.985 \\
\hline 85 & 6500 & Hydragard & 33 & 13.44 & & 0.4128 & & 1.14 & & 0.6305 & & 153216 \\
\hline 85 & 6500 & Hydragard & 34 & 13.43 & & 0.4869 & & 1.09 & & 3.7831 & & 146.387 \\
\hline 85 & 6500 & Hydragard & 35 & 13.46 & & 0.2646 & & 1.13 & & 0.2522 & & 152.098 \\
\hline 85 & 6500 & Valve 1 & 36 & 13.47 & 13.5057 & 0.1905 & 0.04756 & 1.13 & 1.14 & 0.2522 & 0.01 & 152211 \\
\hline 85 & 6500 & Valve 1 & 37 & 13.45 & & 0.3387 & & 1.13 & & 0.2522 & & 151.985 \\
\hline 85 & 6500. & Valve 1 & 38 & 13.6 & & 0.7727 & & 1.13 & & 02522 & & 153.68 \\
\hline 85 & 6500 & Valve 1 & 39 & 13.5 & & 0.0318 & & 1.15 & & 1.5132 & & 155.25 \\
\hline 85 & 6500 & Valve 1 & 40 & 13.5 & & 0.0318 & & 1.15 & & 1.5132 & & 155.25 \\
\hline 85 & 6500 & Valve 1 & 41 & 13.5 & & 0.0318 & & 1.15 & & 1.5132 & & 155.25 \\
\hline 85 & 6500 & Vatve 1 & 42 & 13.52 & & 0.18 & & 1.14 & & 0.0305 & & 154.128 \\
\hline 85 & 6500 & Valve 4 & 43 & 13.47 & 13.4843 & 0.1905 & 0.03994 & 1.12 & 1.134286 & 1.1349 & 0.00976 & 150.864 \\
\hline 85 & 6500 & Valve 4 & 44 & 13.46 & & 0.2646 & & 1.13 & & 0.2522 & & 152008 \\
\hline 85 & 6500 & Vatre 4 & 45 & 13.45 & & 0.3387 & & 1.13 & & 0.2522 & & 151.985 \\
\hline 85 & 6500 & Valve 4 & 46 & 13.44 & & 0.4128 & & 1.13 & & 0.2522 & & 151.872 \\
\hline 85 & 6500 & Valve 4 & 47 & $13.5 !$ & & 0.1059 & & 1.15 & & 1.5132 & & 155.365 \\
\hline 85 & 6500 & Valve 4 & 48 & 13.51 & & 0.1059 & & 1.14 & & 0.6305 & & 154.014 \\
\hline 85 & 6500 & Valve 4 & 49 & 13.55 & & 0.4022 & & 1.14 & & 0.0305 & & 154.47 \\
\hline 85 & 6500 & Valve 5 & 50 & 13.45 & 13.5729 & 0.3387 & 0.26043 & 1.13 & 1.134286 & 0.2522 & 0.01272 & 151.985 \\
\hline 85 & 6500 & Valve 5 & 51 & 13.46 & & 0.2646 & & 1.12 & & 1.1340 & & 150.752 \\
\hline 85 & 6500 & Vatve 5 & 52 & 13.44 & & 0.4128 & & 1.13 & & 0.2522 & & 151.872 \\
\hline 85 & 6500 & Valve 5 & 53 & 14.16 & & 4.9222 & & 1.12 & & 1.1349 & & 158.552 \\
\hline 85 & 6500 & Valve 5 & 54 & 13.5 & & 0.0318 & & 1.15 & & 1.5132 & & 155.25 \\
\hline 85 & 6500 & Valve 5 & 55 & 13.48 & & 0.1164 & & 1.15 & & 1.5132 & & 155.02 \\
\hline 85 & 6500 & Valve 5 & 56 & 13.52 & & 0.18 & & 1.14 & & 0.0305 & & 154.128 \\
\hline Totals & - & - & 28 & 13.496 & 13.4957 & 0.4854 & 0.14146 & 1.1329 & 1.132857 & 0.8737 & 0.01357 & 1528879 \\
\hline
\end{tabular}


Formated Simulant

\begin{tabular}{|c|c|c|c|c|c|c|c|c|c|c|c|c|}
\hline$\overline{R P M}$ & Volume & Location & Number & Oxide & Avg. Ox & क ERTor & Sid. dev & Density & Avg. Den & $\%$ Error & Std. dev & Ox Lazd \\
\hline 130 & 6500 & Hydragard & 57 & 13.46 & 13.4571 & .0 .1351 & 0.01254 & 1.13 & 1.125714 & 0.4718 & 0.00787 & 152008 \\
\hline 130 & 6500 & Hydragard & 58 & 13.47 & & 0.0609 & & 1.12 & . & 1.3526 & & 150.854 \\
\hline 130 & 6500 & Hydragard & 59 & 13.49 & & 0.0874 & & 1.11 & & 2.2334 & & 149.739 \\
\hline 130 & 6500 & Hydragard & 60 & 13.46 & & 0.1351 & & 1.13 & & 0.4718 & & 152098 \\
\hline 130 & 6500 & Hydragard & 61 & 13.45 & & 0.2093 & & 1.13 & & 0.4718 & & 151.985 \\
\hline 130 & 500 & Hydragard & $\boldsymbol{2}$ & 13.47 & & 0.0609 & & 1.13. & & 0.4718 & & 152211 \\
\hline 130 & 6500 & Hydragard & 63 & 13.47 & & 0.0009 & & $1.13^{\circ}$ & & 0.4718 & & 152.211 \\
\hline 130 & 6500 & Valve 1 & 64 & 13.54 & 13.4943 & 0.4584 & 0.03101 & 1.14 & 1.14 & 0.4089 & 1.7E-08 & 154.356 \\
\hline 130 & 6500 & Valve 1 & 65 & .13 .52 & & 0.31 & & 1.94 & & 0.4089 & & 154.128 \\
\hline 130 & 6500 & Valve 1 & 66 & 13.49 & & 0.0874 & & 1.14 & & 0.4089 & & 153.786 \\
\hline 130 & 6500 & Valve 1 & 67 & 13.51 & & 0.2358 & & 1.14 & & 0.4089 & & 154.014 \\
\hline 130 & 6500 & Valve 1 & 68 & 13.45 & & 0.2050 & & 1.14 & & 0.4089 & & 153.33 \\
\hline 130 & 6500 & Valve 1 & $\infty$ & 13.48 & & 0.0132 & & 1.14 & & 0.4089 & & 153.672 \\
\hline 130 & 6500 & Vatre 1 & 70 & 13.47 & & 0.0509 & & 1.14 & & 0.4089 & & 153.558 \\
\hline 130 & 6500 & Vatre 4 & 71 & 13.52 & 13.4914 & 0.31 & 0.02545 & 1.14 & 1.138571 & 0.4089 & 0.0069 & 154.128 \\
\hline 130 & 6500 & Valve 4 & 72 & 13.59 & & 0.2358 & & 1.14 & & 0.4089 & & 154.014 \\
\hline 130 & 6500 & Vahe 4 & 73 & 13.5 & & 0.1616 & & 1.14 & & 0.4089 & & 153.9 \\
\hline 130 & 6500 & Valve 4 & 74 & 13.51 & & 0.2358 & & 1.13 & & 0.4718 & & 152.663 \\
\hline 130 & 6500 & Valve 4 & 75 & 13.47 & & 0.0609 & & 1.13 & & 0.4718 & & 152211 \\
\hline 130 & 6500 & Valvo 4 & 76 & 13.48 & & 0.0132 & & 1.14 & & 0.4089 & & 153.672 \\
\hline 130 & 6500 & Valve 4 & $\pi$ & 13.45 & & 0.2093 & & 1.15 & & 1.2897 & & 154.675 \\
\hline 130 & 6500 & Valve 5 & 78 & 13.49 & 13.46 & 0.0874 & 0.04397 & 1.14 & 1.137143 & 0.4089 & 0.00488 & 153.786 \\
\hline 130 & 6500 & Valve 5 & 79 & 13.49 & & 0.0874 & & 1.13 & & 0.4718 & & 152.437 \\
\hline 130 & 6500 & Vatve 5 & 80 & 13.47 & & 0.0009 & & 1.14 & & 0.4089 & & 153.558 \\
\hline 130 & 6500 & Valve 5 & 81 & 13.5 & . & 0.1616 & & 1.14 & & 0.4089 & & 153.9 \\
\hline 130 & 6500 & Valve 5 & 82 & 13.47 & & 0.0009 & & 1.13 & & 0.4718 & & 152.211 \\
\hline 130 & 6500 & Valve 5 & 83 & 13.38 & & 0.7287 & & 1.14 & & 0.4089 & & 152532 \\
\hline 130 & 6500 & Vatue 5 & 84 & 13.42 & & 0.4319 & & 1.14 & & 0.4089 & & 152.988 \\
\hline Totals & - & - & 28 & 13.478 & 13.4782 & 0.1775 & 0.03244 & 1.1354 & 1.135357 & 0.5595 & 0,00793 & 153.0259 \\
\hline Overall & - & $=$ & 84 & 13.476 & 13.4762 & 0.2794 & 0.08522 & 1.1329 & 1.132857 & 0.6199 & 0.01036 & 152.6664 \\
\hline
\end{tabular}

Melter Feed Simulant

\begin{tabular}{|c|c|c|c|c|c|c|c|c|c|c|c|c|}
\hline RPM & Volume & Location & Number & Oxide & Avg. Ox & $\%$ Entor & Std. der & Density & Avg. Den & $\%$ Error & Std. dev & Ox Load \\
\hline 130 & 7100 & Hydragard & 57 & 38.65 & 39.1357 & 1.4354 & 0.32321 & 1.3 & 1.327143 & 29592 & 0.01604 & 502.45 \\
\hline 130 & 7100 & Hydragand & 58 & 39.13 & & 0.2113 & & 1.34 & & 0.0267 & & 524.342 \\
\hline 130 & 7100 & Hyctragard & 59 & 38.87 & & 0.8743 & & 1.32 & & 1.4653 & & 513.084 \\
\hline 130 & 7100 & Hydragard & $\infty$ & 38.98 & & 0.5938 & & 1.35 & & 0.7731 & & 526.23 \\
\hline 130 & 7100 & Hydragard & 61 & 39.53 & & 0.8088 & & 1.33 & & 0.7198 & & 525.749 \\
\hline 130 & 7100 & Hydragard & 52 & 39.34 & & 0.3242 & & 1.32 & & 1.4653 & - & 519.288 \\
\hline 130 & 7100 & Hydragard & 63 & 39.45 & & 0.6048 & & 1.33 & & 0.7198 & & 524.685 \\
\hline 130 & 7100 & Vatue 1 & 64 & 39.18 & 39.3443 & 0.0838 & 0.22612 & 1.32 & 1.34 & 1.4653 & 0.01 & 517.176 \\
\hline 130 & 7100 & Valve 1 & 65 & 39.32 & & 0.2732 & & 1.35 & & 0.7731 & & 530.82 \\
\hline 130 & 7100 & Valve 1 & 66 & 39.24 & & 0.0002 & & 1.34 & & 0.0267 & & 525.816 \\
\hline 130 & 7100 & Valve 1 & 67 & 39.35 & & 0.3497 & & 1.34 & & 0.0267 & & 527.29 \\
\hline 130 & 7100 & Valve 1 & 68 & 39.22 & & 0.0182 & & 1.34 & & 0.0267 & & 525.548 \\
\hline 130 & 7100 & Valve 1 & $\mathscr{9}$ & 39.26 & & 0.1202 & & 1.35 & & 0.7731 & & 530.01 \\
\hline 130 & 7100 & Valve 1 & 70 & 39.84 & & 1.5093 & & 1.34 & & 0.0267 & & 533.856 \\
\hline 130 & 7100 & Valve 4 & 71 & 39.06 & 39.1671 & 0.3858 & 0.14603 & 1.34 & 1.354286 & 0.0267 & 0.0207 & 523.404 \\
\hline 130 & 7100 & Valve 4 & 72 & 38.92 & & 0.7468 & & 1.34 & & 0.0267 & & 521.528 \\
\hline 130 & 7100 & Valve 4 & 73 & 39.15 & & 0.1603 & & 1.35 & & 0.7731 & & 528.525 \\
\hline 130 & 7100 & Valve 4 & 74 & 39.2 & & 0.0328 & & 1.35 & & 0.7731 & & 529.2 \\
\hline 130 & 7100 & Valve 4 & 75 & 39.18 & & 0.0838 & & 1.35 & & 0.7731 & & 528.93 \\
\hline 130 & 7100 & Valve 4 & 76 & 39.35 & & 0.3497 & & 1.35 & & 0.7731 & & 531.225 \\
\hline 130 & 7100 & Value 4 & $\pi$ & 39.31 & & 0.2477 & & 1.4 & & 4.5055 & & 550.34 \\
\hline 130 & 7100 & Valve 5 & 78 & 39.17 & 39.2043 & 0.1093 & 0.16113 & 1.33 & 1.337143 & 0.7198 & 0.01113 & 520.961 \\
\hline 130 & 7100 & Vatve 5 & 79 & 39.19 & & 0.0583 & & 1.32 & & 1.4653 & & 517.308 \\
\hline 130 & 7100 & Varve 5 & 80 & 39.06 & & 0.3898 & & 1.34 & & 0.0267 & & 523.404 \\
\hline 130 & 7100 & Varve 5 & 81 & 39.18 & & 0.0838 & & 1.34 & & 0.0267 & & 525.012 \\
\hline 130 & 7100 & Varve 5 & 82 & 39.45 & & 0.6048 & & 1.35 & & 0.7731 & & 532.575 \\
\hline 130 & 7100 & Valve 5 & 83 & 39 & & 0.5428 & & 1.35 & & 0.7731 & & 526.5 \\
\hline 130 & 7100 & Vatue 5 & 84 & 39.38 & & 0.4262 & & 1.33 & & 0.7198 & & 523.754 \\
\hline Totals & - & - & 28 & 39.213 & 39.2129 & 0.414 & 0.2273 & 1.3396 & 1.339643 & 0.836 & 0.01732 & 525.3218 \\
\hline
\end{tabular}


Low Lever Dihte Simulart

\begin{tabular}{|c|c|c|c|c|c|c|c|c|c|c|c|c|}
\hline Location & volume & RPM & Number & oxode & Avo. $0 x$ & \% ErTo & Sto. der & Densiny & Ang. Den & \% Error & sid $\infty x$ & Ox Lood \\
\hline $\begin{array}{l}\text { Hydregard } \\
\text { Hydragard } \\
\text { Hydragard } \\
\text { Hydregard } \\
\text { Hydrigard } \\
\text { Hydrogend } \\
\text { Hydregard }\end{array}$ & $\begin{array}{l}\mathbf{5 7 0 0} \\
5700 \\
5700 \\
5700 \\
5700 \\
5700 . \\
5700 \\
\end{array}$ & $\begin{array}{l}45 \\
15 \\
45 \\
45 \\
45 \\
45 \\
15\end{array}$ & $\begin{array}{l}1 \\
2 \\
3 \\
1 \\
5 \\
6 \\
7\end{array}$ & & & & 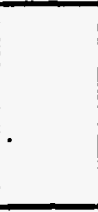 & $\begin{array}{l}1.03 \\
1.03 \\
1.03 \\
1.03 \\
1.03 \\
1.03 \\
1.04 \\
\end{array}$ & 1.03143 & $\begin{array}{l}0.3685 \\
0.3685 \\
0.3685 \\
0.3685 \\
0.3685 \\
0.3685 \\
0.5988\end{array}$ & 0.00378 & \\
\hline 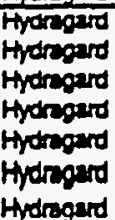 & $\begin{array}{l}5700 \\
5700 \\
5700 \\
5700 \\
5700 \\
5700 \\
5700\end{array}$ & $\begin{array}{l}85 \\
85 \\
85 \\
85 \\
85 \\
85 \\
85\end{array}$ & $\begin{array}{l}8 \\
9 \\
10 \\
11- \\
12 \\
13 \\
14\end{array}$ & & & & & $\begin{array}{l}1.03 \\
1.03 \\
1.03 \\
1.04 \\
1.04 \\
1.04 \\
1.04\end{array}$ & 9.03579 & $\begin{array}{l}0.3685 \\
0.3685 \\
0.3685 \\
0.5988 \\
0.5988 \\
0.5988 \\
0.5980\end{array}$ & 0.00535 & \\
\hline $\begin{array}{l}\text { Fydregand } \\
\text { Hydregard } \\
\text { Hydrogard } \\
\text { Hyoregard } \\
\text { Hydregard } \\
\text { Hydregard } \\
\text { Aydrogard }\end{array}$ & $\begin{array}{l}5700 \\
5700 \\
5700 \\
5700 \\
.5700 \\
5700 \\
5700\end{array}$ & $\begin{array}{l}130 \\
130 \\
130 \\
130 \\
130 \\
130 \\
130\end{array}$ & $\begin{array}{l}15 \\
16 \\
17 \\
10 \\
19 \\
20 \\
21\end{array}$ & & & & & $\begin{array}{l}1.04 \\
1.04 \\
1.04 \\
1.03 \\
1.03 \\
1.03 \\
1.03\end{array}$ & 1.03420 & $\begin{array}{l}0.5988 \\
0.5988 \\
0.5988 \\
0.3685 \\
0.3685 \\
0.3685 \\
0.3685\end{array}$ & 0.00535 & \\
\hline Touals & $-\infty$ & - & 0 & 0 & 0 & 0 & 0 & 1.0338 & 1.03381 & 0.4562 & 0.00498 & 0 \\
\hline
\end{tabular}

Low Level Dilute Simulant

\begin{tabular}{|c|c|c|c|c|c|c|c|c|c|c|c|c|}
\hline Lecalion & volume & RPM & Numbers & oxode & Avg. Ox & $\% \in \pi R$ & Sid. oev & Densiny & Avg. Den & \% Error & Sta dev & Ox Lasd \\
\hline Vave 1 & 5700 & 45 & 22 & 2.97 & 3.03143 & 2.3638 & 0.02795 & 1.04 & 1.03714 & 0.5062 & 0.00488 & 30.888 \\
\hline Valve 1 & 5700 & 45 & 23 & 3.05 & & 0.2661 & & 1.04 & & 0.5062 & & 31.72 \\
\hline Vave 1 & 5700 & 45 & 24 & 3.04 & & 0.0526 & & 1.03 & & 0.4602 & & 31.372 \\
\hline Vave 1 & 5700 & 15 & 25 & 3.04 & & 0.0026 & & 1.04 & & 0.5062 & & 31.676 \\
\hline Vave? & 5700 & 45 & 26 & 3.05 & & 0.2651 & & 1.03 & & 0.4602 & & 31.415 \\
\hline Valve 1 & 5700 & 45 & 27 & 3.03 & & 0.3914 & & 1.04 & & 0.5062 & & 31.512 \\
\hline Valve I & 5700 & 45 & 28 & 3.04 & & 0.0626 & & 1.04 & & 5062 & & 31.616 \\
\hline Vane 1 & & 85 & 29 & 3.05 & 3.03857 & 0.2661 & 0.01345 & 1.05 & 1.03571 & 4726 & 0.00787 & 32.025 \\
\hline Vave 1 & 5700 & 25 & 30 & 3.02 & & 0.7201 & & 1.04 & & 0.5002 & & 31.408 \\
\hline Vove? & 5700 & 85 & 31 & 3.02 & & 0.7201 & & 1.03 & & 0.4602 & & 31.106 \\
\hline Vane 1 & 5700 & 85 & 32 & 3.05 & & 0.2661 & & 1.03 & & 0.4602 & & 31.415 \\
\hline Vaive I & 5700 & 85 & 33 & 3.04 & & 0.0526 & & 1.03 & & 0.4602 & & 31.312 \\
\hline Vaine 1 & & 85 & 34 & 3.04 & & & & 1.03 & & 0.4602 & & 31.312 \\
\hline $\begin{array}{l}\text { Vane I } \\
\text { Vane }\end{array}$ & $\frac{5700}{5700}$ & $\frac{85}{130}$ & 36 & $\frac{3.05}{3.05}$ & 3.05571 & $\frac{0.2061}{0.2661}$ & 0.00787 & $\frac{1.06}{1.03}$ & 1.03143 & 0.46012 & 0.00378 & 31.415 \\
\hline Vave? & 57 & 130 & 37 & 3.05 & & 0.2661 & & 1.03 & & 0.4602 & & 31.415 \\
\hline Valve 1 & 5700 & 130 & 38 & 3.05 & & 0.2681 & & 1.03 & & 0.4602 & & 31.415 \\
\hline Valve 1 & & 130 & 39 & 3.05 & & & & 1.03 & & 0.4602 & & 31.415 \\
\hline Valve? & & 130 & 10 & 3.06 & & 0.5949 & & 1.04 & & 0.5052 & & 39.824 \\
\hline & & 130 & 41 & 3.07 & & & & 1.03 & & 0.46022 & & 31.621 \\
\hline & 5700 & 130 & 42 & 3.06 & & 0.5949 & & 1.03 & & 0.4602 & & 39.518 \\
\hline & & - & 21 & 3.0419 & 3.0419 & 0.4294 & 0.0204 & 9.0348 & 1.03476 & 0.5259 & 0.00602 & 31.4762 \\
\hline
\end{tabular}

Law Low Dilute Simuiart

\begin{tabular}{|c|c|c|c|c|c|c|c|c|c|c|c|c|}
\hline Location & volume & RPM & Number & Oode & $A \cup g . \alpha x$ & $\%$ Enox & Sid dor & Dersiny & A $v$ g Den & x ERO & Std. der & $O x \operatorname{Las} d$ \\
\hline $\begin{array}{l}\text { Vave } 2 \\
\text { Valve } 2 \\
\text { Vaim } 2 \\
\text { Vaine } 2 \\
\text { Vave } 2 \\
\text { Vaive } 2 \\
\text { Valve } 2\end{array}$ & $\begin{array}{l}5700 \\
5700 \\
5700 \\
5700 \\
5700 \\
5700 \\
5700\end{array}$ & $\begin{array}{l}15 \\
45 \\
45 \\
45 \\
45 \\
45 \\
45\end{array}$ & $\begin{array}{l}43 \\
4 \\
45 \\
48 \\
47 \\
40 \\
49\end{array}$ & $\begin{array}{l}3.01 \\
3.02 \\
3.03 \\
3.03 \\
3.03 \\
3.02 \\
3.02\end{array}$ & 3.02286 & $\begin{array}{l}0.8626 \\
0.5332 \\
0.2039 \\
0.2039 \\
0.2039 \\
0.53332 \\
0.5332\end{array}$ & 0.00756 & $\begin{array}{l}1.04 \\
1.03 \\
1.04 \\
1.04 \\
1.03 \\
1.04 \\
1.04\end{array}$ & 7.03714 & $\begin{array}{l}0.5988 \\
0.3685 \\
0.5988 \\
0.5988 \\
0.3645 \\
0.5988 \\
0.5988\end{array}$ & 0.00488 & $\begin{array}{l}31.304 \\
31.106 \\
31.512 \\
31.512 \\
31.209 \\
31.408 \\
31.408\end{array}$ \\
\hline $\begin{array}{l}\text { Vave } 2 \\
\text { Vaive } 2 \\
\text { Valve } 2 \\
\text { Vave } 2 \\
\text { Vave } 2 \\
\text { Vave } 2 \\
\text { Vave 2 }\end{array}$ & $\begin{array}{l}5700 \\
5700 \\
5700 \\
5700 \\
5700 \\
5700 \\
5700\end{array}$ & $\begin{array}{l}85 \\
85 \\
85 \\
85 \\
85 \\
85 \\
85 \\
\end{array}$ & $\begin{array}{l}50 \\
51 \\
52 \\
53 \\
54 \\
55 \\
56\end{array}$ & $\begin{array}{l}3.03 \\
3.01 \\
3.01 \\
3.04 \\
3.03 \\
3.05 \\
3.04\end{array}$ & 3.03 & $\begin{array}{l}0.2039 \\
0.8526 \\
0.8626 \\
0.1255 \\
0.2039 \\
0.4548 \\
0.1255\end{array}$ & 0.01528 & $\begin{array}{l}.03 \\
1.03 \\
1.04 \\
1.03 \\
1.03 \\
1.04 \\
1.03 \\
\end{array}$ & 1.03286 & $\begin{array}{l}0.3685 \\
0.3685 \\
0.5988 \\
0.3685 \\
0.3685 \\
0.5988 \\
0.3685\end{array}$ & 0.00488 & $\begin{array}{c}31.209 \\
31.003 \\
31.301 \\
31.312 \\
31.209 \\
31.72 \\
31.312\end{array}$ \\
\hline 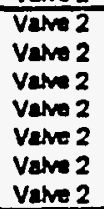 & $\begin{array}{l}5700 \\
5700 \\
5700 \\
5700 \\
5700 \\
5700 \\
5700\end{array}$ & $\begin{array}{l}130 \\
130 \\
130 \\
.130 \\
130 \\
130 \\
130\end{array}$ & $\begin{array}{l}57 \\
58 \\
59 \\
60 \\
61 \\
62 \\
63\end{array}$ & $\begin{array}{l}3.04 \\
3.09 \\
3.07 \\
3.04 \\
3.04 \\
3.06 \\
3.05\end{array}$ & 3.055779 & $\begin{array}{l}0.1255 \\
1.7723 \\
1.1136 \\
0.1255 \\
0.1255 \\
0.7842 \\
0.4548\end{array}$ & 0.01902 & $\begin{array}{l}1.03 \\
1.03 \\
1.04 \\
1.03 \\
1.03 \\
1.03 \\
1.03 \\
\end{array}$ & 1.03743 & $\begin{array}{l}0.3685 \\
0.3685 \\
0.5988 \\
0.3885 \\
0.3685 \\
0.3685 \\
0.3685\end{array}$ & 0.00378 & $\begin{array}{l}31.312 \\
31.027 \\
31.928 \\
31.312 \\
31.312 \\
31.518 \\
31.415\end{array}$ \\
\hline Toals & & & 21 & 3.0362 & 3.03619 & $\overline{0.4959}$ & 0.02012 & 1.0338 & 1.03389 & 0.4562 & 0.00498 & 37.3882 \\
\hline
\end{tabular}


Low Lond Dituse Simulart

\begin{tabular}{|c|c|c|c|c|c|c|c|c|c|c|c|c|}
\hline Location & Voume & RPM & Number & 0,006 & Avg. $O x$ & \% Error & sio. od & Densty & Avg. $D=n$ & xERror & Std. on & $O x \operatorname{Lag}$ \\
\hline Vave 3 & 5700 & 45 & 64 & 3.05 & 3.04143 & 0.2191 & 0.01215 & 1.03 & 1.03429 & 0.2766 & 0.00976 & 31.415 \\
\hline Vawe 3 & 5700 & 45 & 65 & 3.03 & & 0.4381 & & 1.00 & & 0.2768 & & 31.209 \\
\hline Veve 3 & 5700 & 15 & 65 & 3.03 & & 0.4381 & & 1.04 & & 0.6916 & & 31.512 \\
\hline Vale 3 & 5700 & 45 & 67 & 3.06 & & 0.5476 & & 1.04 & & 0.6916 & & 31.824 \\
\hline Veve 3 & 5700 & 25 & 68 & 3.003 & & 0.1399 & & 1.05 & & 1.6598 & & 31.845 \\
\hline Vave 3 & 5700 & 45 & 69 & 3.05 & & 0.2191 & & 1.02 & & 1.2440 & & 31.11 \\
\hline Vatwe 3 & 5700 & 45 & 70 & 3.04 & & 0.1095 & & 1.03 & & 0.2765 & & 31.312 \\
\hline Vave 3 & 5700 & 85 & 71 & 3.03 & 3.03794 & 0.4387 & 0.01604 & 1.04 & 1.03286 & 0.6916 & 0.00488 & 31.512 \\
\hline Vave 3 & 5700 & 85 & 72 & 3.06 & & 0.5476 & & 1.03 & & 0.2786 & & 31.518 \\
\hline Vare 3 & 5700 & 25 & 73 & 3.09 & & 1.0953 & & 1.04 & & 0.6918 & & 31.304 \\
\hline Vaive 3 & 5700 & 85 & 74. & 3.03 & & 0.4381 & & 1.00 & & 0.2768 & & 31.200 \\
\hline veres 3 & 5700 & 85 & $75^{\circ}$ & 3.04 & & 0.1095 & & 1.00 & & 0.2768 & & 31.312 \\
\hline Vewo 3 & 5700 & 85 & 76 & 3.05 & & 0.2191 & & 1.09 & & 0.2768 & & 31.495 \\
\hline Veroo 3 & 5700 & 85 & $\pi$ & 3.04 & & 0.1095 & & 1.03 & & 0.2768 & & 31.312 \\
\hline Vaw 3 & 5700 & 130 & 78 & 3.04 & 3.05143 & 0.1095 & 0.009 & 1.04 & 1.03143 & 0.6916 & 0.00378 & 31.616 \\
\hline value 3 & 5700 & 130 & 79 & 3.08 & & 0.5676 & & 1.00 & & 0.2788 & & 31.518 \\
\hline Vene 3 & 5700 & 130 & 80 & 3.05 & & 0.2191 & & 1.03 & & 0.2768 & & 31.495 \\
\hline Vale 3 & 5700 & 130 & 81 & 3.08 & & 0.5476 & & 1.09 & & 0.2768 & & 31.518 \\
\hline Veive 3 & 5700 & 130 & 82 & 3.04 & & 0.1095 & & 1.00 & & 0.2766 & & 31.312 \\
\hline Vasm 3 & 5700 & 130 & 03 & 3.06 & & 0.5476 & & 1.03 & & 0.2763 & & 31.518 \\
\hline Valve 3 & 5700 & 130 & 84 & 3.05 & & 0.2191 & & 1.03 & & 0.2768 & & 31.415 \\
\hline Toxats & - & - & 21 & 3.0433 & 3.04333 & 0.3651 & 0.01354 & 1.0329 & 1.03286 & 0.4874 & 0.00644 & 31.4329 \\
\hline Overall & - & $=$ & 63 & 3.0405 & 3.04048 & 0.4301 & 0.01827 & 1.0338 & 1.03381 & 0.4814 & 0.00558 & 31.4324 \\
\hline
\end{tabular}

High Level Dilute Simularts

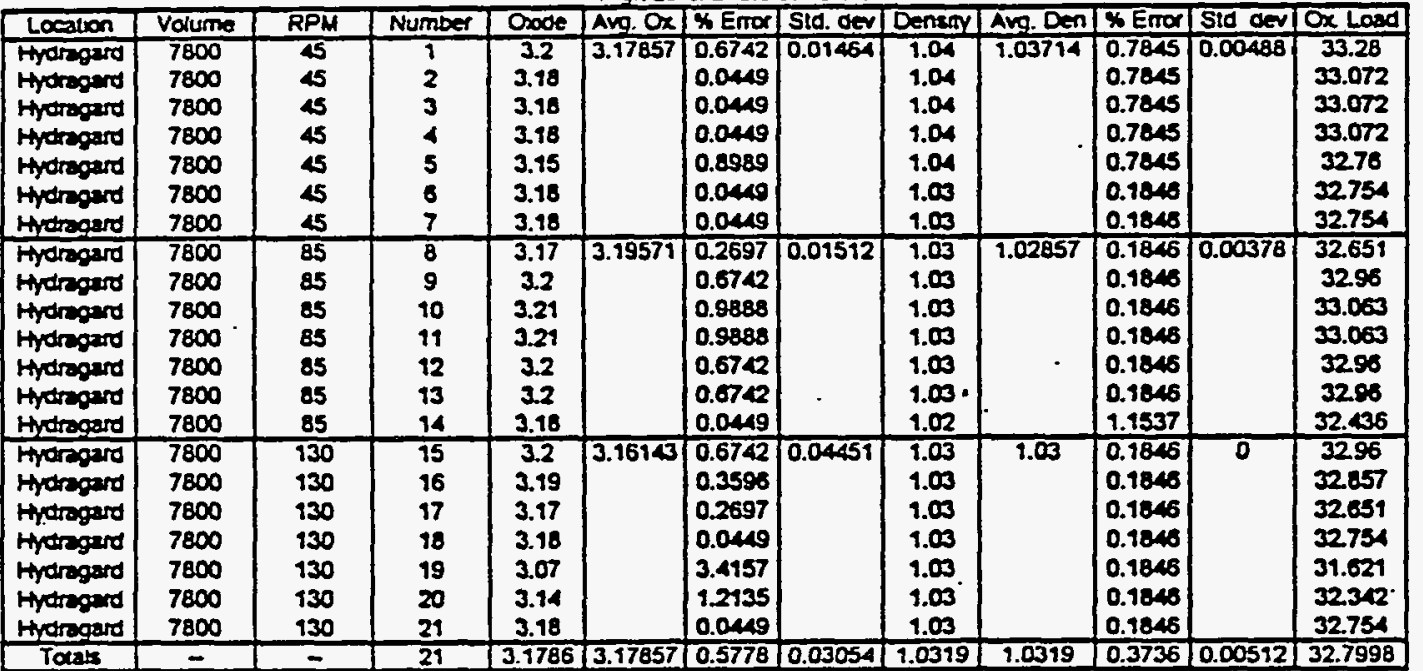

High Level Dihte Simutant

\begin{tabular}{|c|c|c|c|c|c|c|c|c|c|c|c|c|}
\hline Location & Volume & RPM & Number & Oxode & $A w . \alpha x$ & S Error & STo. don & Denasy & Ang.Den & $\%$ Enror & Std. oov & Do Laed \\
\hline Vene? & 7800 & 45 & 22 & 3.16 & 3.17286 & 0.45 & 0.07913 & 1.03 & 1.03429 & 0.0924 & 0.00535 & 32.548 \\
\hline Valve 1 & 7800 & 45 & 23 & 3.18 & & 0.18 & & 1.04 & & 0.8776 & & 33.072 \\
\hline Verve 1 & 7800 & 45 & 24 & 3.17 & & 0.135 & & 1.04 & & 0.8778 & & 32.968 \\
\hline Vave 1 & 7800 & 45 & 25 & 3.18 & & 0.18 & & 9.04 & & 0.8776 & & 33.072 \\
\hline Vawe 1 & 7800 & 45 & 26 & 3.19 & & 0.495 & & 1.00 & & 0.0924 & & 32.857 \\
\hline Velve? & 7800 & 45 & 27 & 3.16 & & 0.45 & & 1.00 & & 0.0924 & & 32.540 \\
\hline Velve? & 7800 & 45 & 28 & 3.17 & & 0.135 & & 1.03 & & 0.0924 & & 32.651 \\
\hline Vave I & 7800 & 85 & 29 & 3.18 & 3.18143 & 0.18 & 0.0069 & 1.03 & 1.03 & 0.0924 & 0 & 32.754 \\
\hline Veve? & 7800 & 85 & 30 & 3.18 & & 0.98 & & 1.03 & & 0.0024 & & 32.754 \\
\hline Vave 1 & 7800 & 85 & 31 & 3.17 & & 0.135 & & 1.03 & & 0.0924 & & 32.651 \\
\hline Valve 1 & 7800 & 85 & 32 & 3.18 & & 0.18 & & 1.03 & & 0.0024 & & 32.754 \\
\hline Valve? & 7800 & es & 33 & 3.18 & & 0.18 & & 1.00 & & 0.0924 & & 32.734 \\
\hline Vave? & 7800 & 85 & 34 & 3.19 & & 0.495 & & 1.03 & & 0.00224 & & 32.857 \\
\hline Vave 1 & 7800 & 85 & 35 & 3.19 & & 0.495 & & 1.03 & & 0.0924 & & 32.057 \\
\hline Vare 1 & 7800 & 130 & 36 & 3.18 & 3.16857 & 0.18 & 0.01069 & 9.03 & 1.02857 & 0.0924 & 0.00378 & 32.754 \\
\hline Vewe 1 & 7800 & 130 & 37 & 3.10 & & 0.18 & & 1.00 & & 0.0924 & & 32.754 \\
\hline velue 1 & 7800 & 130 & 38 & 3.15 & & 0.7651 & & 1.02 & & 1.0024 & & 3213 \\
\hline Veve 1 & 7800 & 130 & 39 & 3.17 & & 0.135 & & 1.03 & & 0.00924 & & 32.651 \\
\hline Valve 1 & 7800 & 130 & 40 & 3.17 & & 0.135 & & 1.03 & & 0.0024 & & 32.651 \\
\hline Vare? 1 & 7800 & 130 & 41 & 3.16 & & 0.45 & & 1.03 & & 0.0924 & & 32540 \\
\hline Valve 1 & 7800 & 130 & 12 & 3.17 & & 0.135 & & 1.03 & & 0.0924 & & 32.659 \\
\hline Tods & - & - & 21 & 3.1743 & 3.17429 & 0.2786 & 0.01076 & 1.031 & 1.03095 & 0.2507 & 10.00436 & 32.7255 \\
\hline
\end{tabular}


High Level Dihte Simulant

\begin{tabular}{|c|c|c|c|c|c|c|c|c|c|c|c|c|}
\hline Location & Volume & RPM & Number & Oxde & Avg. $O x$ & $x$ Enror & Std dev & Density & Avg. Den & X Entor & Sta der & Ox Loxd \\
\hline Vames & $\begin{array}{l}7800 \\
7800\end{array}$ & $\begin{array}{l}45 \\
45\end{array}$ & $\begin{array}{l}43 \\
4\end{array}$ & $\begin{array}{l}3.17 \\
3.16\end{array}$ & 3.17 & $\begin{array}{l}0.015 \\
0.3304\end{array}$ & 0.01155 & $\begin{array}{l}1.04 \\
1.04\end{array}$ & 1.03714 & $\begin{array}{l}0.6916 \\
0.6916\end{array}$ & 0.00756 & $\begin{array}{l}32.968 \\
32.864\end{array}$ \\
\hline $\begin{array}{l}\text { Valres } \\
\text { Vares }\end{array}$ & $\begin{array}{l}7800 \\
7800\end{array}$ & 45 & 45 & 3.18 . & & 0.3004 & & 1.04 & & 0.6916 & & 33.072 \\
\hline Vaves 5 & 7800 & 45 & 46 & 3.18 & & 0.3004 & & 1.05 & . & 1.6598 & & 33.39 \\
\hline Vare 5 & 7800 & 45 & 47 & 3.15 & & 0.6458 & & 1.03 & & 0.2768 & & 32.415 \\
\hline vave 5 & 7800 & 45 & 48 & 3.18 & & 0.3004 & & 1.00 & & 0.2768 & & 32754 \\
\hline Vake 5 & 7800 & 45 & 49 & 3.17 & & 0.015 & & 1.03 & & 0.2766 & & 32.651 \\
\hline Vanes & 7800 & 85 & 50 & 3.17 & 3.18286 & 0.015 & 0.07173 & 1.03 & 1.03143 & 0.2766 & 0.00378 & 32.651 \\
\hline Vaves & 7800 & 85 & 51 & 3.17 & & 0.015 & & 1.03 & & 0.2766 & & 32.651 \\
\hline Valus 5 & 7800 & 85 & 52 & 3.19 & & 0.6158 & & i.m & & 0.2768 & & 32857 \\
\hline Vem 5 & 7800 & 85 & 53 & 3.18 & & 0.3004 & & 1.03 & & 0.2760 & & 32.754 \\
\hline Vam 5 & 7800 & 85 & $54^{-2}$ & 3.18 & & 0.3004 & & 1.03 & & 0.2766 & & 32.751 \\
\hline Vawe 5 & 7800 & 85 & 55 & 3.2 & . & 0.9312 & & 1.04 & & 0.6916 & & 33.20 \\
\hline Vam 5 & 7800 & 85 & 56 & 3.19 & & 0.6158 & & 1.03 & & 0.2768 & & 32.857 \\
\hline Vams & 7800 & 130 & 57 & 3.17 & 3.15857 & 0.015 & 0.009 & 1.03 & 1.03 & 0.2766 & 0 & 32651 \\
\hline Valve 5 & 7800 & 130 & 58 & 3.17 & & 0.015 & & 1.03 & & 0.2766 & & 32.651 \\
\hline Varre 5 & 7800 & 130 & 59 & 3.16 & & 0.3304 & & 1.03 & & 0.2766 & & 32.548 \\
\hline Vave 5 & 7800 & 130 & 60 & 3.15 & & 0.6458 & & 1.03 & & 0.2766 & & 32445 \\
\hline Vawes & 7800 & 130 & 61 & 3.15 & & 0.6458 & & 1.03 & & 0.2768 & & 32.45 \\
\hline Valvos & 7800 & 130 & 62 & 3.15 & & 0.6458 & & 1.03 & & 0.2766 & & 32.45 \\
\hline Vates 5 & 7800 & 130 & 6 & 3.16 & & 0.3304 & & 1.03 & & 0.2766 & & 32.548 \\
\hline Totals & & - & 21 & 3.1705 & 3.17048 & 0.349 & 0.01431 & 1.0329 & 1.03286 & 0.4215 & 0.00561 & 32.7467 \\
\hline
\end{tabular}

Hioh Leret Dilute Stmulart

\begin{tabular}{|c|c|c|c|c|c|c|c|c|c|c|c|c|}
\hline Location & Volume & RPM & Number & Oxade & Avg $O x$ & \% Error & Std. dev & Densiy & Ang. Den & \% ERT & Sid der & Ox Lasd \\
\hline $\begin{array}{l}\text { Vare } 6 \\
\text { Vam } 6 \\
\text { Vam } 6 \\
\text { Vaw } 6 \\
\text { Vam } 6 \\
\text { Vam } 6 \\
\text { Vawe } 6\end{array}$ & $\begin{array}{l}7800 \\
7800 \\
7800 \\
7800 \\
7800 \\
7800 \\
7800\end{array}$ & $\begin{array}{l}45 \\
45 \\
45 \\
45 \\
45 \\
45 \\
45\end{array}$ & $\begin{array}{r}64 \\
65 \\
66 \\
67 \\
68 \\
69 \\
70\end{array}$ & $\begin{array}{l}3.16 \\
3.16 \\
3.15 \\
3.17 \\
3.15 \\
3.14 \\
3.16\end{array}$ & 3.1557 .1 & $\begin{array}{l}0.1655 \\
0.1655 \\
0.4814 \\
0.1504 \\
0.4894 \\
0.7974 \\
0.1655\end{array}$ & 0.00976 & $\begin{array}{l}1.04 \\
1.04 \\
1.04 \\
1.04 \\
1.02 \\
1.03 \\
1.03\end{array}$ & 1.03429 & $\begin{array}{l}0.8776 \\
0.8776 \\
0.8776 \\
0.8776 \\
1.0524 \\
0.0924 \\
0.0924 \\
\end{array}$ & 0.00787 & $\begin{array}{c}32.864 \\
32.864 \\
32.76 \\
32.968 \\
32.13 \\
32.342 \\
32.548\end{array}$ \\
\hline $\begin{array}{l}\text { Vare } 6 \\
\text { Vawe } 6 \\
\text { Vare } 6 \\
\text { Vare } 6 \\
\text { Vare } 6 \\
\text { Vare } 6 \\
\text { Vame } 6\end{array}$ & $\begin{array}{l}7800 \\
7800 \\
7800 \\
7800 \\
7800 \\
7800 \\
7800 \\
\end{array}$ & $\begin{array}{l}85 \\
85 \\
65 \\
85 \\
85 \\
85 \\
85\end{array}$ & $\begin{array}{l}71 \\
72 \\
73 \\
74 \\
75 \\
76 \\
77 \\
\end{array}$ & \begin{tabular}{l|}
3.17 \\
3.17 \\
3.18 \\
3.17 \\
3.18 \\
3.17 \\
3.18
\end{tabular} & 3.17429 & $\begin{array}{l}0.1504 \\
0.1504 \\
0.4664 \\
0.1504 \\
0.4664 \\
0.1504 \\
0.4654\end{array}$ & 0.00535 & $\begin{array}{l}1.03 \\
1.03 \\
1.03 \\
1.03 \\
1.03 \\
1.03 \\
1.03\end{array}$ & 1.03 & $\begin{array}{l}0.0924 \\
0.0924 \\
0.0924 \\
0.0924 \\
0.0924 \\
0.0924 \\
0.0924\end{array}$ & 0 & $\begin{array}{l}32.651 \\
32.651 \\
32.754 \\
32.651 \\
32.754 \\
32.651 \\
32.754\end{array}$ \\
\hline $\begin{array}{l}\text { Vame } 6 \\
\text { Vame } 6 \\
\text { Vale } 6 \\
\text { Vame } 6 \\
\text { Vame } 6 \\
\text { Vame } 6 \\
\text { Vame } 6\end{array}$ & $\begin{array}{l}7800 \\
7800 \\
7800 \\
7800 \\
7800 \\
7800 \\
7800\end{array}$ & $\begin{array}{l}130 \\
130 \\
130 \\
130 \\
130 \\
130 \\
130\end{array}$ & $\begin{array}{l}78 \\
79 \\
80 \\
81 \\
82 \\
83 \\
84\end{array}$ & $\begin{array}{l}3.18 \\
3.17 \\
3.16 \\
3.16 \\
3.17 \\
3.16 \\
3.16\end{array}$ & 3.16571 & $\begin{array}{l}0.4664 \\
0.1504 \\
0.1655 \\
0.1655 \\
0.1504 \\
0.1655 \\
0.1655\end{array}$ & 0.00787 & $\begin{array}{l}1.02 \\
1.03 \\
1.03 \\
1.03 \\
1.03 \\
1.03 \\
1.03\end{array}$ & 7.02857 & $\begin{array}{l}1.0624 \\
0.0924 \\
0.0924 \\
0.0924 \\
0.0924 \\
0.0924 \\
0.0924\end{array}$ & 0.00378 & $\begin{array}{l}32.436 \\
32.651 \\
32.548 \\
32.548 \\
32.651 \\
32.548 \\
32.548\end{array}$ \\
\hline Tocals & - & - & 21 & 3.1652 & 3.16524 & 0.278 & 0.01078 & 1.031 & 1.03095 & 0.3343 & 0.00539 & 32.632 \\
\hline Overall & $=$ & $=$ & 84 & 3.1721 & 3.17214 & 0.3709 & 0.01883 & 1.0317 & 1.03167 & 0.345 & 0.00511 & 32.726 \\
\hline
\end{tabular}

Low Level Concentrated Simutant

\begin{tabular}{|c|c|c|c|c|c|c|c|c|c|c|c|c|}
\hline Localion & Volume & RPM & Number & onde & Avg. $\mathrm{Ox}$ & * Error & Sta gev & Dernsyy & Avg. Den & X Error & Sta dev & Ox Losd \\
\hline $\begin{array}{l}\text { Hydragard } \\
\text { Hydrogard } \\
\text { Hydragard } \\
\text { Hydregard } \\
\text { Hydragard } \\
\text { Hydragard } \\
\text { Hydragard }\end{array}$ & $\begin{array}{l}5700 \\
5700 \\
5700 \\
5700 \\
5700 \\
5700 \\
5700\end{array}$ & $\begin{array}{l}45 \\
45 \\
45 \\
45 \\
45 \\
45 \\
45\end{array}$ & $\begin{array}{l}1 \\
2 \\
3 \\
4 \\
5 \\
6 \\
7\end{array}$ & $\begin{array}{l}11.14 \\
11.34 \\
11.38 \\
11.38 \\
11.49 \\
11.35 \\
11.35\end{array}$ & 11.3443 & $\begin{array}{c}2.2317 \\
0.4764 \\
0.1254 \\
0.3009 \\
0.04 \\
0.3887 \\
0.3887\end{array}$ & 0.70374 & $\begin{array}{l}1.1 \\
1.12 \\
1.12 \\
1.11 \\
1.1 \\
1.11 \\
1.1\end{array}$ & 1.10857 & $\begin{array}{l}0.5596 \\
1.2484 \\
1.2484 \\
0.3444 \\
0.5598 \\
0.3444 \\
0.5596\end{array}$ & 0.009 & $\begin{array}{c}122.54 \\
127.008 \\
127.456 \\
126.095 \\
126.39 \\
125.985 \\
124.85\end{array}$ \\
\hline $\begin{array}{l}\text { Hydragard } \\
\text { Hydregard } \\
\text { Hydragard } \\
\text { Hydragard } \\
\text { Hydregard } \\
\text { Hydragard } \\
\text { Hydregard }\end{array}$ & $\begin{array}{l}5700 \\
5700 \\
5700 \\
5700 \\
5700 \\
5700 \\
5700\end{array}$ & $\begin{array}{l}85 \\
85 \\
85 \\
85 \\
85 \\
85 \\
85\end{array}$ & $\begin{array}{c}8 \\
9 \\
10 \\
11 \\
12 \\
13 \\
14\end{array}$ & $\begin{array}{l}11.45 \\
11.5 \\
11.51 \\
11.56 \\
11.53 \\
11.42 \\
11.51\end{array}$ & 71.5014 & $\begin{array}{c}0.489 \\
0.5278 \\
1.0155 \\
1.4544 \\
1.1911 \\
0.2257 \\
1.2788\end{array}$ & 0.05014 & $\begin{array}{l}1.11 \\
1.07 \\
1.12 \\
1.14 \\
1.09 \\
1.11 \\
1.11\end{array}$ & 1.10794 & $\begin{array}{l}0.3444 \\
3.2718 \\
1.2484 \\
3.0564 \\
1.4038 \\
0.3444 \\
0.3444\end{array}$ & 0.02215 & $\begin{array}{c}127.095 \\
123.05 \\
128.912 \\
131.784 \\
125.677 \\
126.762 \\
128.094\end{array}$ \\
\hline $\begin{array}{l}\text { Hydragard } \\
\text { Hydregard } \\
\text { Hydrogard } \\
\text { Hydragard } \\
\text { Hydrogard } \\
\text { Hydrogard } \\
\text { Hydrogard }\end{array}$ & $\begin{array}{l}5700 \\
5700 \\
5700 \\
5700 \\
5700 \\
5700 \\
5700\end{array}$ & $\begin{array}{l}130 \\
130 \\
130 \\
130 \\
130 \\
130 \\
130\end{array}$ & $\begin{array}{l}15 \\
18 \\
17 \\
18 \\
19 \\
20 \\
21\end{array}$ & $\begin{array}{c}11.34 \\
11.3 \\
11.35 \\
11.34 \\
11.34 \\
11.35 \\
11.34\end{array}$ & 11.3371 & $\begin{array}{l}0.4764 \\
0.8275 \\
0.3887 \\
0.4764 \\
0.4764 \\
0.3887 \\
0.4764\end{array}$ & 0.01704 & $\begin{array}{l}1.11 \\
1.1 \\
1.1 \\
1.91 \\
1.1 \\
1.1 \\
1.1\end{array}$ & 1.10286 & $\begin{array}{l}0.3444 \\
0.5596 \\
0.5596 \\
0.3444 \\
0.5596 \\
0.5596 \\
0.5596\end{array}$ & 0.00488 & $\begin{array}{c}125.874 \\
124.3 \\
124.85 \\
125.874 \\
124.74 \\
124.85 \\
124.74\end{array}$ \\
\hline Totals & - & - & 21 & 11.39 & 11.394 & 0.7069 & 0.10053 & 1.1052 & 1.10519 & 0.8774 & 0.01359 & 126.044 \\
\hline
\end{tabular}


Low Level Concentrated Simulant

\begin{tabular}{|c|c|c|c|c|c|c|c|c|c|c|c|c|}
\hline Location & Volume & RPM & Number & Doce & Avg. $O x$ & SError & Std. dev & Densiy & Avg. Den & S Enor & Std dev & Ox Losd \\
\hline 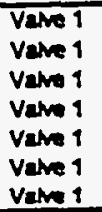 & $\begin{array}{l}5700 \\
5700 \\
5700 \\
5700 \\
5700 \\
5700 \\
5700\end{array}$ & $\begin{array}{l}45 \\
45 \\
45 \\
45 \\
45 \\
45 \\
45\end{array}$ & $\begin{array}{l}22 \\
23 \\
24 \\
25 \\
26 \\
27 \\
28\end{array}$ & $\begin{array}{l}11.37 \\
11.36 \\
11.35 \\
11.38 \\
11.37 \\
11.33 \\
11.34\end{array}$ & 11.3571 & $\begin{array}{l}0.0461 \\
0.0419 \\
0.1299 \\
0.1341 \\
0.0481 \\
0.3059 \\
0.2179 \\
\end{array}$ & 0.01799 & $\begin{array}{c}1.12 \\
1.1 \\
1.09 \\
1.11 \\
1.1 \\
1.12 \\
1.12 \\
\end{array}$ & 1.10857 & $\begin{array}{l}0.9442 \\
0.8584 \\
1.7597 \\
0.0429 \\
0.8584 \\
0.9442 \\
0.9442\end{array}$ & 0.01215 & $\begin{array}{c}127.344 \\
124.96 \\
123.715 \\
126.318 \\
125.07 \\
126.896 \\
127.008\end{array}$ \\
\hline 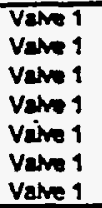 & $\begin{array}{l}5700 \\
5700 \\
5700 \\
5700 \\
5700 \\
5700 \\
5700 \\
\end{array}$ & $\begin{array}{l}85 \\
85 \\
85 \\
85 \\
85 \\
85 \\
85\end{array}$ & $\begin{array}{l}29 \\
30 \\
31 \\
32 \\
33 \\
34 \\
35\end{array}$ & $\begin{array}{c}11.4 \\
11.42 \\
11.42 \\
11.4 \\
11.41 \\
11.40 \\
11.38\end{array}$ & 71.4086 & $\begin{array}{c}0.3101 \\
0.486 \\
0.488 \\
0.3101 \\
0.3981 \\
0.574 \\
0.1341 \\
\end{array}$ & 0.01676 & $\begin{array}{l}1.1 \\
1.19 \\
1.11 \\
1.11 \\
1.11 \\
1.12 \\
1.11 \\
\end{array}$ & 1.11 & $\begin{array}{l}0.8584 \\
0.0429 \\
0.0429 \\
0.0429 \\
0.0429 \\
0.0442 \\
0.0429\end{array}$ & 0.00577 & $\begin{array}{c}125.4 \\
126.762 \\
126.762 \\
126.54 \\
126.051 \\
128.016 \\
120.318\end{array}$ \\
\hline $\begin{array}{l}\text { Vare } 1 \\
\text { Vam } 1 \\
\text { Vawe } 1 \\
\text { Vam } 1 \\
\text { Vam } 1 \\
\text { Vame } 1 \\
\text { Vame } 1\end{array}$ & $\begin{array}{l}5700 \\
5700 \\
5700 \\
5700 \\
5700 \\
5700 \\
5700 \\
\end{array}$ & $\begin{array}{l}130 \\
130 \\
130 \\
130 \\
130 \\
130 \\
130\end{array}$ & $\begin{array}{l}36 \\
37 \\
38 \\
39 \\
40 \\
41 \\
42\end{array}$ & $\begin{array}{l}11.37 \\
11.28 \\
11.33 \\
11.33 \\
11.33 \\
11.34 \\
11.32 \\
\end{array}$ & 11.3286 & $\begin{array}{l}0.0451 \\
0.7458 \\
0.3059 \\
0.3059 \\
0.3059 \\
0.2179 \\
0.3939 \\
\end{array}$ & 0.02673 & $\begin{array}{l}1.1 \\
1.11 \\
1.11 \\
1.11 \\
1.11 \\
1.12 \\
1.11 \\
\end{array}$ & 1.11 & $\begin{array}{l}0.8584 \\
0.0429 \\
0.0429 \\
0.0129 \\
0.0429 \\
0.9412 \\
0.0429\end{array}$ & 0.00577 & $\begin{array}{c}125.07 \\
125.208 \\
125.703 \\
125.703 \\
125.703 \\
127.008 \\
125.652\end{array}$ \\
\hline Tocais & - & - & 21 & 11.365 & 17.3648 & 0.2829 & 0.03932 & 1.1095 & 1.10952 & 0.4946 & 0.00805 & 126.095 \\
\hline
\end{tabular}

Law Level Concentrated Simutart

\begin{tabular}{|c|c|c|c|c|c|c|c|c|c|c|c|c|}
\hline Location & Volume & RPM & Number & Oxos & Avg. $O x$ & * Error & Std. dev & Deneny & Avg. Den & XErtor & Std dev & Ox Laad \\
\hline $\begin{array}{l}\text { Vare } 2 \\
\text { Vare } 2 \\
\text { Vawe } 2 \\
\text { Vawe } 2 \\
\text { Vawe } 2 \\
\text { Vare } 2 \\
\text { Vare } 2\end{array}$ & $\begin{array}{l}5700 \\
5700 \\
5700 \\
5700 \\
5700 \\
5700 \\
5700\end{array}$ & $\begin{array}{l}45 \\
45 \\
45 \\
45 \\
45 \\
45 \\
45\end{array}$ & $\begin{array}{l}43 \\
44 \\
45 \\
46 \\
47 \\
48 \\
49\end{array}$ & $\begin{array}{l}11.37 \\
11.35 \\
11.31 \\
11.37 \\
11.37 \\
11.36 \\
11.33\end{array}$ & 11.3557 & $\begin{array}{l}0.1804 \\
0.0042 \\
0.0839 \\
0.1804 \\
0.1804 \\
0.0923 \\
0.172 \\
\end{array}$ & 0.01618 & $\begin{array}{l}1.09 \\
1.11 \\
1.09 \\
1.11 \\
1.11- \\
1.08 \\
1.11 \\
\end{array}$ & 1.1 & $\begin{array}{l}1.4636 \\
0.3444 \\
1.4536 \\
0.3444 \\
0.3444 \\
23576 \\
0.3444\end{array}$ & 0.01291 & $\begin{array}{l}123.933 \\
125.985 \\
123.606 \\
126.207 \\
126.207 \\
122.688 \\
125.763\end{array}$ \\
\hline 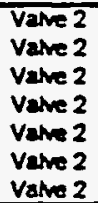 & $\begin{array}{l}5700 \\
5700 \\
5700 \\
5700 \\
5700 \\
5700 \\
5700\end{array}$ & $\begin{array}{l}85 \\
85 \\
85 \\
85 \\
85 \\
85 \\
85\end{array}$ & $\begin{array}{l}50 \\
51 \\
52 \\
53 \\
54 \\
55 \\
56\end{array}$ & $\begin{array}{c}11.41 \\
11.4 \\
11.41 \\
11.42 \\
11.4 \\
11.36 \\
71.38\end{array}$ & 11.3979 & $\begin{array}{l}0.5329 \\
0.4447 \\
0.5329 \\
0.621 \\
0.4447 \\
0.0923 \\
0.2845 \\
\end{array}$ & 0.02059 & $\begin{array}{l}1.1 \\
1.11 \\
1.11 \\
1.11 \\
1.1 \\
1.12 \\
1.12\end{array}$ & 1.18 & $\begin{array}{l}0.5596 \\
0.3444 \\
0.3444 \\
0.3444 \\
0.5596 \\
1.2484 \\
1.2484\end{array}$ & 0.00816 & $\begin{array}{c}125.51 \\
126.54 \\
126.051 \\
126.762 \\
125.4 \\
127.232 \\
127.456\end{array}$ \\
\hline $\begin{array}{l}\text { Vare } 2 \\
\text { Vare } 2 \\
\text { Vare } 2 \\
\text { Vatre } 2 \\
\text { Vatre } 2 \\
\text { Vare } 2 \\
\text { Vare } 2\end{array}$ & $\begin{array}{l}5700 \\
5700 \\
5700 \\
5700 \\
5700 \\
5700 \\
5700 \\
\end{array}$ & $\begin{array}{l}130 \\
130 \\
130 \\
130 \\
130 \\
130 \\
130\end{array}$ & $\begin{array}{l}57 \\
58 \\
59 \\
60 \\
61 \\
62 \\
63\end{array}$ & $\begin{array}{c}11.28 \\
11.33 \\
11.19 \\
11.3 \\
11.3 \\
11.33 \\
11.34\end{array}$ & 11.2957 & \begin{tabular}{|c|}
0.6126 \\
0.172 \\
1.4056 \\
0.4364 \\
0.4364 \\
0.172 \\
0.0839 \\
\end{tabular} & 0.05127 & $\begin{array}{l}1.12 \\
1.11 \\
1.11 \\
1.1 \\
1.11 \\
1.1 \\
1.11 \\
\end{array}$ & 1.10857 & $\begin{array}{l}1.2484 \\
0.3444 \\
0.3444 \\
0.5596 \\
0.3444 \\
0.5596 \\
0.3444 \\
\end{array}$ & 0.0069 & $\begin{array}{c}126.336 \\
125.763 \\
124.209 \\
124.3 \\
125.40 \\
124.63 \\
125.874\end{array}$ \\
\hline Tocats & - & - & 21 & 11.35 & 11.3495 & 0.3405 & 0.05305 & 1.1062 & 1.10619 & 0.7175 & 0.01024 & 125.547 \\
\hline
\end{tabular}

Low Level Concentrated Simutant

\begin{tabular}{|c|c|c|c|c|c|c|c|c|c|c|c|c|}
\hline Location & Votume & RPH & Number & Oxoe & Avg. Ox & \% Error & Std dev & Densty & Avg. Den & $\%$ Error & Sta dev & Ox Lood \\
\hline $\begin{array}{l}\text { Vare } 3 \\
\text { Vare } 3 \\
\text { Vave } 3 \\
\text { Vawe } 3 \\
\text { Vawe } 3 \\
\text { Vave } 3 \\
\text { Vawo } 3\end{array}$ & $\begin{array}{l}5700 \\
5700 \\
5700 \\
5700 \\
5700 \\
5700 \\
5700\end{array}$ & $\begin{array}{l}45 \\
45 \\
45 \\
45 \\
45 \\
15 \\
15\end{array}$ & $\begin{array}{l}64 \\
65 \\
66 \\
67 \\
68 \\
69 \\
70\end{array}$ & $\begin{array}{l}11.36 \\
11.33 \\
11.35 \\
11.38 \\
11.36 \\
11.38 \\
11.36\end{array}$ & 11.36 & $\begin{array}{l}0.1049 \\
0.1595 \\
0.0168 \\
0.2819 \\
0.1049 \\
0.2819 \\
0.1049\end{array}$ & 0.01732 & $\begin{array}{c}1.09 \\
1.1 \\
1.1 \\
1.12 \\
1.1 \\
1.11 \\
1\end{array}$ & 1.08857 & $\begin{array}{c}0.952 \\
0.0433 \\
0.0433 \\
1.7741 \\
0.0433 \\
0.8654 \\
9.1302\end{array}$ & 0.04018 & $\begin{array}{c}123.824 \\
124.63 \\
124.05 \\
127.456 \\
124.96 \\
126.318 \\
113.6\end{array}$ \\
\hline $\begin{array}{l}\text { Vare } 3 \\
\text { Vame } 3 \\
\text { Vawe } 3 \\
\text { Vame } 3 \\
\text { Vave } 3 \\
\text { Vave } 3 \\
\text { Vane } 3\end{array}$ & $\begin{array}{l}5700 \\
5700 \\
5700 \\
5700 \\
5700 \\
5700 \\
5700\end{array}$ & $\begin{array}{l}85 \\
85 \\
85 \\
85 \\
85 \\
85 \\
85\end{array}$ & $\begin{array}{l}71 \\
72 \\
73 \\
74 \\
75 \\
76 \\
\pi\end{array}$ & $\begin{array}{c}11.41 \\
11.4 \\
11.41 \\
11.46 \\
11.4 \\
11.41 \\
11.37\end{array}$ & 11.4086 & $\begin{array}{l}0.5455 \\
0.4574 \\
0.5455 \\
0.9861 \\
0.4574 \\
0.5455 \\
0.193\end{array}$ & 0.02673 & $\begin{array}{c}1.11 \\
1.1 \\
1.11 \\
1.11 \\
1.1 \\
1.11 \\
1.19\end{array}$ & 1.10714 & $\begin{array}{l}0.8654 \\
0.0633 \\
0.8654 \\
0.8654 \\
0.0433 \\
0.8654 \\
0.8654\end{array}$ & 0.00488 & $\begin{array}{c}126.651 \\
125.4 \\
126.651 \\
127.206 \\
125.4 . \\
126.651 \\
126.207\end{array}$ \\
\hline $\begin{array}{l}\text { Vane } 3 \\
\text { Vame } 3 \\
\text { Vame } 3 \\
\text { Vame } 3 \\
\text { Vane } 3 \\
\text { Vame } 3 \\
\text { Vane } 3\end{array}$ & $\begin{array}{l}5700 \\
5700 \\
5700 \\
5700 \\
5700 \\
5700 \\
5700\end{array}$ & $\begin{array}{l}130 \\
130 \\
130 \\
130 \\
130 \\
130 \\
130\end{array}$ & $\begin{array}{l}78 \\
79 \\
80 \\
81 \\
82 \\
83 \\
84\end{array}$ & $\begin{array}{l}10.96 \\
11.33 \\
11.32 \\
11.38 \\
11.33 \\
11.28 \\
11.33\end{array}$ & 11.2757 & $\begin{array}{l}3.4199 \\
0.1595 \\
0.2476 \\
0.2811 \\
0.1595 \\
0.6001 \\
0.1595\end{array}$ & 0.74223 & $\begin{array}{c}1.1 \\
1.11 \\
1.11 \\
1.1 \\
1.18 \\
1.11 \\
1.1\end{array}$ & 1.10579 & $\begin{array}{l}0.0433 \\
0.8654 \\
0.0654 \\
0.0433 \\
0.8654 \\
0.8654 \\
0.0433\end{array}$ & 0.00535 & $\begin{array}{c}120.56 \\
125.763 \\
125.652 \\
125.18 \\
125.763 \\
125.208 \\
124.63\end{array}$ \\
\hline Totals & - & $=$ & 21 & 17.348 & 11.3481 & 0.4672 & 0.09765 & 1.1005 & 1.10048 & 0.9932 & 0.02397 & 124.884 \\
\hline Overall & - & - & 84 & 11.364 & 11.3642 & 0.4494 & 0.07831 & 9.1056 & 1.1056 & 0.7706 & 0.01532 & 125.642 \\
\hline
\end{tabular}


High Level Concentrated Simulare

\begin{tabular}{|c|c|c|c|c|c|c|c|c|c|c|c|c|}
\hline Location & Volume & $R P M$ & Number & Oxace & Avo. $O x$ & * Enor & sid. $\alpha e$ & Density & Avg. Den & \% EnTor & sid $\mathrm{der}$ & Ox Laed \\
\hline $\begin{array}{l}\text { Hyangard } \\
\text { Hydregard } \\
\text { Hydrgard } \\
\text { Hydregard } \\
\text { Hydregard } \\
\text { Hydrgard } \\
\text { Hydregard }\end{array}$ & $\begin{array}{l}7800 \\
7800 \\
7800 \\
7800 \\
7800 \\
7800 \\
7800 \\
\end{array}$ & $\begin{array}{l}45 \\
45 \\
45 \\
45 \\
45 \\
45 \\
45\end{array}$ & $\begin{array}{l}1 \\
2 \\
3 \\
4 \\
5 \\
6 \\
7\end{array}$ & $\begin{array}{c}11.21 \\
11.32 \\
11.11 \\
11.3 \\
11.23 \\
11.25 \\
11.17 \\
\end{array}$ & 11.2271 & $\begin{array}{l}0.5408 \\
0.4352 \\
1.428 \\
0.2577 \\
0.3533 \\
0.1859 \\
0.8957 \\
\end{array}$ & 0.07274 & $\begin{array}{l}1.12 \\
1.11 \\
1.12 \\
1.11 \\
1.09 \\
1.1 \\
1.11 \\
\end{array}$ & 1.10857 & $\begin{array}{c}1.423 \\
0.5175 \\
1.423 \\
0.5175 \\
1.2937 \\
0.3881 \\
0.5175 \\
\end{array}$ & 0.01069 & $\begin{array}{c}125.552 \\
125.652 \\
124.432 \\
125.43 \\
122.407 \\
123.75 \\
123.987\end{array}$ \\
\hline $\begin{array}{l}\text { Hydregerd } \\
\text { Hydroged } \\
\text { Hydregerd } \\
\text { Hydregard } \\
\text { Hydrogerd } \\
\text { Hydregend } \\
\text { Hydrogard }\end{array}$ & $\begin{array}{l}7800 \\
7800 \\
7800 \\
7800 \\
7800 \\
7800 \\
7800\end{array}$ & $\begin{array}{l}85 \\
85 \\
85 \\
85 \\
85 \\
85 \\
85\end{array}$ & $\begin{array}{c}8 \\
9 \\
10 \\
11 \\
12 \\
13 \\
14\end{array}$ & $\begin{array}{c}11.26 \\
11.31 \\
11.2 \\
11.31 \\
11.3 \\
11.32 \\
11.31\end{array}$ & 11.2914 & $\begin{array}{l}0.0972 \\
0.3464 \\
0.6295 \\
0.3464 \\
0.2577 \\
0.4352 \\
0.6126\end{array}$ & 0.04706 & $\begin{array}{c}1.1 \\
1.1 \\
1.1 \\
1.09 \\
1.11 \\
1.11 \\
1.09\end{array}$ & 1.7 & $\begin{array}{l}0.3881 \\
0.3881 \\
0.3881 \\
1.2937 \\
0.5175 \\
0.5175 \\
1.2937 \\
\end{array}$ & 0.00876 & $\begin{array}{c}123.86 \\
124.41 \\
123.2 \\
123.279 \\
125.43 \\
125.652 \\
123.608\end{array}$ \\
\hline $\begin{array}{l}\text { Hydragard } \\
\text { Hydrogard } \\
\text { Hydrogand } \\
\text { Hydngard } \\
\text { Hydregard } \\
\text { Hydregend } \\
\text { Hydregard }\end{array}$ & $\begin{array}{l}7800 \\
7800 \\
7800 \\
7800 \\
7800 \\
7800 \\
7800 \\
\end{array}$ & $\begin{array}{l}130 \\
130 \\
130 \\
130 \\
130 \\
130 \\
130\end{array}$ & $\begin{array}{l}15 \\
16 \\
17 \\
18 \\
19 \\
20 \\
21\end{array}$ & $\begin{array}{c}11.29 \\
11.27 \\
11.29 \\
11.3 \\
11.3 \\
11.3 \\
11.31\end{array}$ & 11.2943 & $\begin{array}{l}0.169 \\
0.0084 \\
0.169 \\
0.2577 \\
0.2577 \\
0.2577 \\
0.3464 \\
\end{array}$ & $\begin{array}{c}0.01272 \\
.\end{array}$ & $\begin{array}{c}1.1 \\
1.1 \\
1.11 \\
1.11 \\
1.11 \\
1.1 \\
1.1 \\
\end{array}$ & 1.10429 & $\begin{array}{l}0.3889 \\
0.3881 \\
0.5175 \\
0.5175 \\
0.5175 \\
0.3881 \\
0.3881\end{array}$ & 0.00535 & $\begin{array}{c}124.19 \\
123.97 \\
125.319 \\
125.43 \\
125.43 \\
124.3 \\
124.41\end{array}$ \\
\hline Toris & - & - & 21 & 11.271 & 11.271 & 0.3951 & 0.05752 & 1.1043 & 1.10429 & 0.6653 & 0.0037 & 124.462 \\
\hline
\end{tabular}

High Level Concentrated Simulant

\begin{tabular}{|c|c|c|c|c|c|c|c|c|c|c|c|c|}
\hline Location & Voiume & RPM & Number & Oxde & Avg. $O x$ & $\%$ Error & Sto oev & Densay & Avg. Den & \% Error & SId. $\alpha$. & Ox Lasd \\
\hline $\begin{array}{l}\text { Vave } 1 \\
\text { Vane } 1 \\
\text { Vawe } 1 \\
\text { Vawe } 1 \\
\text { Vawe } 1 \\
\text { Vawe } 1 \\
\text { Vate } 1\end{array}$ & $\begin{array}{l}7800 \\
7800 \\
7800 \\
7800 \\
7800 \\
7800 \\
7800\end{array}$ & $\begin{array}{l}45 \\
45 \\
45 \\
45 \\
45 \\
45 \\
45\end{array}$ & $\begin{array}{l}22 \\
23 \\
24 \\
25 \\
26 \\
27 \\
28\end{array}$ & $\begin{array}{l}11.33 \\
11.32 \\
11.33 \\
11.31 \\
11.29 \\
11.33 \\
11.28\end{array}$ & 11.3129 & $\begin{array}{l}0.0799 \\
0.0084 \\
0.0799 \\
0.0967 \\
0.2734 \\
0.0799 \\
0.3617\end{array}$ & 0.02059 & $\begin{array}{c}1.09 \\
0.95 \\
1.11 \\
1.11 \\
1 \\
1.11 \\
1.12\end{array}$ & 1.07 & $\begin{array}{l}0.651 \\
13.411 \\
1.1719 \\
1.1719 \\
8.8542 \\
1.1719 \\
2.0833 \\
\end{array}$ & 0.06700 & $\begin{array}{c}123.497 \\
107.54 \\
125.763 \\
125.541 \\
112.9 \\
125.763 \\
126.336\end{array}$ \\
\hline 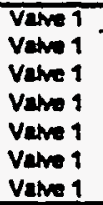 & $\begin{array}{l}7800 \\
7800 \\
7800 \\
7800 \\
7800 \\
7800 \\
7800\end{array}$ & $\begin{array}{l}85 \\
85 \\
85 \\
85 \\
85 \\
85 \\
85\end{array}$ & $\begin{array}{l}29 \\
30 \\
31 \\
32 \\
33 \\
34 \\
35\end{array}$ & $\begin{array}{l}11.35 \\
11.33 \\
11.33 \\
11.34 \\
11.34 \\
11.33 \\
11.28\end{array}$ & 11.3286 & $\begin{array}{l}0.2566 \\
0.0799 \\
0.0799 \\
0.1683 \\
0.1683 \\
0.0799 \\
0.3617\end{array}$ & 0.02268 & $\begin{array}{l}1.11 \\
1.11 \\
1.11 \\
1.1 \\
1.11 \\
1.11 \\
1.12\end{array}$ & 1.11 & $\begin{array}{l}1.1719 \\
1.1719 \\
1.1719 \\
0.2604 \\
1.1719 \\
1.1719 \\
2.0833\end{array}$ & 0.00577 & $\begin{array}{c}125.985 \\
125.763 \\
125.763 \\
124.74 \\
125.874 \\
125.763 \\
126.336 \\
\end{array}$ \\
\hline $\begin{array}{l}\text { Vawe I } \\
\text { Vare I } \\
\text { Vaive I } \\
\text { Vave } 1 \\
\text { Vave I } \\
\text { Vave I } \\
\text { Vave I }\end{array}$ & $\begin{array}{l}7800 \\
7800 \\
7800 \\
7800 \\
7800 \\
7800 \\
7800\end{array}$ & $\begin{array}{l}130 \\
130 \\
130 \\
130 \\
130 \\
130 \\
130\end{array}$ & $\begin{array}{l}36 \\
37 \\
38 \\
39 \\
40 \\
41 \\
42\end{array}$ & $\begin{array}{l}-11.34 \\
11.31 \\
11.31 \\
11.32 \\
11.33 \\
11.32 \\
11.32 \\
\end{array}$ & 11.3214 & $\begin{array}{l}0.1683 \\
0.0967 \\
0.0957 \\
0.0084 \\
0.0799 \\
0.0084 \\
0.0084\end{array}$ & 0.01069 & $\begin{array}{l}1.12 \\
1.11 \\
1.19 \\
1.11 \\
1.11 \\
1.11 \\
1.11\end{array}$ & 1.17143 & $\begin{array}{l}20833 \\
1.1719 \\
1.1719 \\
1.1719 \\
1.1719 \\
1.1719 \\
1.1719 \\
\end{array}$ & $\begin{array}{c}0.00378 \\
.\end{array}$ & $\begin{array}{l}127.008 \\
125.541 \\
125.541 \\
125.652 \\
125.763 \\
125.652 \\
125.652\end{array}$ \\
\hline Totals & $=$ & $=$ & 21 & 11.321 & 11.321 & 0.1258 & 0.01895 & 1.0971 & 1.09714 & 2.1825 & 0.04185 & 124.208 \\
\hline
\end{tabular}

High Leved Concertrated Simetant

\begin{tabular}{|c|c|c|c|c|c|c|c|c|c|c|c|c|}
\hline Localion & Volume & RPM & Number & Onose & Alg $\alpha x$ & \% Enror & Sid dev & Densty & Avg. Den & \% Emor & sid. $\mathbf{d o v}$ & $O x$ Losd \\
\hline 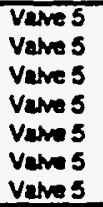 & $\begin{array}{l}7800 \\
7800 \\
7800 \\
7800 \\
7800 \\
7800 \\
7800 .\end{array}$ & $\begin{array}{l}45 \\
45 \\
45 \\
45 \\
45 \\
45 \\
45\end{array}$ & $\begin{array}{l}43 \\
44 \\
45 \\
46 \\
47 \\
48 \\
49\end{array}$ & $\begin{array}{c}11.3 \\
11.32 \\
11.28 \\
11.34 \\
11.26 \\
11.3 \\
11.27\end{array}$ & 11.2957 & $\begin{array}{l}0.1473 \\
0.0295 \\
0.324 \\
0.2062 \\
0.5007 \\
0.1473 \\
0.4124\end{array}$ & 0.0282 & $\begin{array}{l}1.12 \\
1.1 \\
1.08 \\
1.12 \\
1.11 \\
1.12 \\
1.11\end{array}$ & 1.10857 & $\begin{array}{l}0.7712 \\
1.0243 \\
2.8278 \\
0.7712 \\
0.1285 \\
0.7712 \\
0.1285\end{array}$ & 0.01464 & $\begin{array}{c}126.56 \\
124.52 \\
121.024 \\
127.008 \\
124.986 \\
128.56 \\
125.097\end{array}$ \\
\hline $\begin{array}{l}\text { Yame } 5 \\
\text { Vares } 5 \\
\text { Vares } 5 \\
\text { Yave } 5 \\
\text { Vawe } 5 \\
\text { Vawe } 5 \\
\text { Vate } 5\end{array}$ & $\begin{array}{l}7800 \\
7800 \\
7800 \\
7800 \\
7800 \\
7800 \\
7800\end{array}$ & $\begin{array}{l}85 \\
85 \\
85 \\
85 \\
85 \\
85 \\
85\end{array}$ & $\begin{array}{l}50 \\
51 \\
52 \\
53 \\
54 \\
55 \\
56\end{array}$ & $\begin{array}{l}11.35 \\
11.36 \\
11.33 \\
11.34 \\
11.34 \\
11.33 \\
11.3\end{array}$ & 11.3357 & $\begin{array}{l}0.2946 \\
0.3829 \\
0.1178 \\
0.2062 \\
0.2062 \\
0.1178 \\
0.1473 \\
\end{array}$ & $\begin{array}{c}0.01802 \\
.\end{array}$ & $\begin{array}{l}1.11 \\
1.11 \\
1.11 \\
1.11 \\
1.12 \\
1.11 \\
1.12 \\
\end{array}$ & 1.11286 & $\begin{array}{l}0.1285 \\
0.1285 \\
0.1285 \\
0.1285 \\
0.7712 \\
0.1285 \\
0.7712 \\
\end{array}$ & 0.00488 & $\begin{array}{c}125.985 \\
126.098 \\
125.763 \\
125.874 \\
127.008 \\
125.763 \\
125.56\end{array}$ \\
\hline $\begin{array}{l}\text { Vare } 5 \\
\text { Vare } 5 \\
\text { Vare } 5 \\
\text { Vave } 5 \\
\text { Vame } 5 \\
\text { Vame } 5 \\
\text { Vame } 5\end{array}$ & $\begin{array}{l}7800 \\
7800 \\
7800 \\
7800 \\
7800 \\
7800 \\
7800 \\
\end{array}$ & $\begin{array}{l}130 \\
130 \\
130 \\
130 \\
130 \\
130 \\
130 \\
\end{array}$ & $\begin{array}{l}57 \\
58 \\
59 \\
60 \\
61 \\
62 \\
63 \\
\end{array}$ & $\begin{array}{c}11.36 \\
11.3 \\
11.34 \\
11.29 \\
11.28 \\
11.33 \\
11.33 \\
\end{array}$ & 11.3186 & $\begin{array}{c}0.3829 \\
0.1473 \\
0.2002 \\
0.2356 \\
0.324 \\
0.1178 \\
0.1178 \\
\end{array}$ & 0.02911 & $\begin{array}{l}1.11 \\
1.12 \\
1.11 \\
1.11 \\
1.11 \\
1.11 \\
1.12\end{array}$ & 1.11286 & $\begin{array}{l}0.1285 \\
0.7712 \\
0.1285 \\
0.1285 \\
0.1285 \\
0.1285 \\
0.7792 \\
\end{array}$ & 0.00488 & $\begin{array}{c}126.096 \\
126.56 \\
125.874 \\
125.319 \\
125.208 \\
125.763 \\
126.896\end{array}$ \\
\hline Tolats & & - & 21 & 11.317 & 11.3167 & 0.2272 & 0.02972 & 1.1914 & 1.11743 & 0.5141 & 0.0091 & 125.777 \\
\hline
\end{tabular}


High Lever Concentrated Simulart

\begin{tabular}{|c|c|c|c|c|c|c|c|c|c|c|c|c|}
\hline Locainen & Yolume & RPM & Number & Ooose & Ang. $O x$ & \% Enror & Sid. der & Densy & Avg. Den & K Error & Std. $d x$ & Ox Load \\
\hline $\begin{array}{l}\text { Vare } 6 \\
\text { Vave } 6 \\
\text { Vave } 6 \\
\text { Vave } 6 \\
\text { Vave } 6 \\
\text { Vave } 6 \\
\text { Vave } 6\end{array}$ & $\begin{array}{l}7800 \\
7800 \\
7800 \\
7800 \\
7800 \\
7800 \\
7800\end{array}$ & $\begin{array}{l}45 \\
45 \\
45 \\
45 \\
45 \\
45 \\
45\end{array}$ & $\begin{array}{l}64 \\
65 \\
66 \\
67 \\
68 \\
69 \\
70\end{array}$ & $\begin{array}{c}11.31 \\
11.3 \\
11.33 \\
11.29 \\
11.34 \\
11.33 \\
11.28\end{array}$ & 11.3114 & $\begin{array}{l}0.0883 \\
0.1767 \\
0.0883 \\
0.265 \\
0.1767 \\
0.0883 \\
0.3534\end{array}$ & 0.02268 & $\begin{array}{c}1.12 \\
1.11 \\
1.11 \\
1.11 \\
1.1 \\
1.11 \\
1.11\end{array}$ & 1.11 & $\begin{array}{l}0.8576 \\
0.0429 \\
0.0429 \\
0.0429 \\
0.9434 \\
0.0429 \\
0.0429\end{array}$ & 0.00577 & $\begin{array}{c}126.672 \\
125.43 \\
125.763 \\
125.319 \\
124.74 \\
125.763 \\
125.200\end{array}$ \\
\hline $\begin{array}{l}\text { Vahe } 6 \\
\text { Vare } 6 \\
\text { Vave } 6 \\
\text { Vawe } 6 \\
\text { Vaive } 6 \\
\text { Vale } 6 \\
\text { Vale } 6\end{array}$ & $\begin{array}{l}7800 \\
7800 \\
7800 \\
7800 \\
7800 \\
7800 \\
7800\end{array}$ & $\begin{array}{l}85 \\
85 \\
85 \\
85 \\
85 \\
85 \\
85\end{array}$ & $\begin{array}{l}71 \\
72 \\
73 \\
74 \\
75 \\
76 \\
77\end{array}$ & $\begin{array}{l}11.37 \\
11.33 \\
11.33 \\
11.34 \\
11.33 \\
11.33 \\
11.31\end{array}$ & 71.3343 & $\begin{array}{l}0.4417 \\
0.0883 \\
0.0883 \\
0.1767 \\
0.0883 \\
0.0883 \\
0.0883\end{array}$ & 0.01813 & $\begin{array}{l}1.19 \\
1.11 \\
1.11 \\
1.1 \\
1.11 \\
1.19 \\
1.11\end{array}$ & 1.10857 & $\begin{array}{l}0.0429 \\
0.0429 \\
0.0429 \\
0.0434 \\
0.0429 \\
0.0429 \\
0.0429\end{array}$ & 0.00378 & $\begin{array}{c}126.207 \\
125.763 \\
125.763 \\
124.74 \\
125.763 \\
125.763 \\
125.541\end{array}$ \\
\hline $\begin{array}{l}\text { Vane } 6 \\
\text { Vawe } 6 \\
\text { Vame } 6 \\
\text { Vawe } 6 \\
\text { Vawe } 6 \\
\text { Vame } 6 \\
\text { Vame } 6\end{array}$ & $\begin{array}{l}7800 \\
7800 \\
7800 \\
7800 \\
7800 \\
7800 \\
7800\end{array}$ & $\begin{array}{l}130 \\
130 \\
130 \\
130 \\
130 \\
130 \\
130\end{array}$ & $\begin{array}{l}78 \\
79 \\
80 \\
81 \\
82 \\
83 \\
84\end{array}$ & $\begin{array}{c}11.3 \\
11.33 \\
11.35 \\
11.31 \\
11.29 \\
11.29 \\
11.33\end{array}$ & 11.3143 & $\begin{array}{c}0.1767 \\
0.0283 \\
0.265 \\
0.0883 \\
0.265 \\
0.265 \\
0.0883\end{array}$ & 0.02299 & $\begin{array}{l}1.11 \\
1.12 \\
1.19 \\
9.11 \\
1.11 \\
1.11 \\
1.12\end{array}$ & 1.11286 & $\begin{array}{l}0.0429 \\
0.6576 \\
0.0429 \\
0.0429 \\
0.0429 \\
0.0429 \\
0.0576\end{array}$ & 0.00488 & $\begin{array}{c}125.43 \\
120.890 \\
125.985 \\
125.541 \\
125.319 \\
125.319 \\
126.896\end{array}$ \\
\hline Tolats & - & - & 21 & 11.32 & 11.32 & 0.1683 & 0.0228 & 1.1105 & 1.11048 & 0.245 & 0.00498 & 125.706 \\
\hline Overall & - & $=$ & 84 & 11.307 & 11.3071 & 0.2291 & 0.04082 & 1.1058 & 1.10583 & 0.9018 & 0.02234 & 125.038 \\
\hline
\end{tabular}

Formated Simulant

\begin{tabular}{|c|c|c|c|c|c|c|c|c|c|c|c|c|}
\hline Location & Volume & RPM & Number & Oxace & Avg. $O x$ & S Emor & Std. der & Densiny & Avg. Den & $\%$ Error & Sid. der & $0 x$ Lax \\
\hline Hydregard & 6500 & 45 & 1 & 13.47 & 13.46 & 0.1558 & 0.01633 & 1.1 & 1.12714 & 2.2429 & 0.01254 & 148.17 \\
\hline Hydragard & 6500 & 45 & 2 & 13.47 & & 0.1558 & & 1.13 & & 0.4232 & & 152.211 \\
\hline Hodragard & 6500 & 45 & 3 & 13,4 & & 0.0673 & & 1.13 & & 0.4232 & & 151.872 \\
\hline Hydregard & 6500 & 45 & 4 & 13.40 & & 0.2301 & & 1.14 & & 1.3119 & & 153.672 \\
\hline Hydregard & 6500 & 15 & 5 & 13.44 & & 0.0673 & & 1.13 & & 0.4232 & & 151.872 \\
\hline Hyoragard & 6500 & 45 & 6 & 13.45 & & 0.0071 & & 1.13 & & 0.4232 & & 151.985 \\
\hline Horgoard & 6500 & 45 & 7 & 13.47 & & 0.1558 & & 1.13 & & 0.4232 & & 152.211 \\
\hline Hyoragard & 6500 & 85 & 8 & 13.27 & 13.42 & 1.3313 & 0.06683 & 1.31 & 1.12286 & 1.3542 & 0.01704 & 147.297 \\
\hline Hotrogard & 6500 & 85 & 9 & 13.44 & & 0.0673 & & 1.13 & & 0.4232 & & 151.872 \\
\hline Hydrogard & 6500 & 85 & 10 & 13.45 & & 0.0071 & & 1.13 & & 0.4232 & & 151.985 \\
\hline Hydregend & 6500 & 85 & 11 & 13.45 & & 0.0071 & & 1.13 & & 0.4232 & & 151.985 \\
\hline Hrdrgard & 6500 & 85 & 12 & 13.44 & & 0.0673 & & 1.94 & & 1.3119 & - & 153.216 \\
\hline Hrongard & 6500 & 85 & 13 & 13.43 & & 0.1416 & & 1.09 & & 3.1316 & & 146.387 \\
\hline Hodragard & 6500 & 85 & 14 & 13.46 & & 0.0814 & & 1.13 & & 0.4232 & & 152.098 \\
\hline Hyoragard & 6500 . & 130 & 15 & 13.46 & 13.4671 & 0.0814 & 0.01254 & 1.13 & 1.12571 & 0.4232 & 0.00787 & 152098 \\
\hline Hydragard & 6500 & 130 & 16 & 13.47 & & 0.1558 & & 1.12 & & 0.4655 & & 150.864 \\
\hline Hydragard & 6500 & 130 & 17 & 13.49 & & 0.3045 & & 1.11 & & 1.3542 & & 149.739 \\
\hline Hydragard & 6500 & 130 & 18 & 13.46 & & 0.0814 & & 1.13 & & 0.4232 & & 152.098 \\
\hline Hodregard & 6500 & 130 & 19 & 13.45 & & 0.0071 & & 1.13 & & 0.4232 & & 151.985 \\
\hline Hydragard & 6500 & 130 & 20 & 13.47 & & 0.1558 & & 1.13 & & 0.4232 & & 152211 \\
\hline Hydragaro & 0500 & 130 & 21 & 13.47 & & 0.1558 & & 1.13 & & 0.4232 & & 152.211 \\
\hline Totarts & - & - & 21 & 13.449 & 13.449 & 0.1659 & 0.04381 & 1.1252 & 1.12524 & 0.8141 & 0.0125 & 151.335 \\
\hline
\end{tabular}

Fomated Simulants

\begin{tabular}{|c|c|c|c|c|c|c|c|c|c|c|c|c|}
\hline Location & Volume & RPM & Number & Oode & Alg. $O x$ & Y Error & Sid. $\alpha$ & Densty & Avg. Den & KError & Sld. der & Ox Load \\
\hline $\begin{array}{l}\text { Vare } 1 \\
\text { Vare } 1 \\
\text { Vare } 1 \\
\text { Vare } 1 \\
\text { Vare } 1 \\
\text { Vane } 1 \\
\text { vave } 1\end{array}$ & $\begin{array}{l}6500 \\
6500 \\
6500 \\
6500 \\
6500 \\
6500 \\
6500\end{array}$ & $\begin{array}{l}45 \\
45 \\
45 \\
45 \\
45 \\
45 \\
45\end{array}$ & $\begin{array}{l}22 \\
23 \\
24 \\
25 \\
26 \\
27 \\
20\end{array}$ & $\begin{array}{l}13.48 \\
13.46 \\
13.48 \\
13.44 \\
13.44 \\
13.45 \\
134\end{array}$ & 13.45 & $\begin{array}{l}0.0247 \\
0.1731 \\
0.0247 \\
0.3214 \\
0.3214 \\
0.2472 \\
0.618\end{array}$ & 0.02769 & $\begin{array}{l}1.14 \\
1.14 \\
1.13 \\
1.13 \\
1.13 \\
1.14 \\
1.14\end{array}$ & 1.13571 & $\begin{array}{l}0.1255 \\
0.1255 \\
0.7528 \\
0.7528 \\
0.7528 \\
0.1255 \\
0.1255\end{array}$ & 0.00535 & $\begin{array}{c}153.672 \\
153.444 \\
152.324 \\
151.872 \\
151.872 \\
153.33 \\
152.76\end{array}$ \\
\hline $\begin{array}{l}\text { Vane } 1 \\
\text { Valve } 1 \\
\text { Vave } 1 \\
\text { Vate } 1 \\
\text { Valve } 1 \\
\text { Vatre } 1 \\
\text { Vare } 1\end{array}$ & $\begin{array}{l}6500 \\
6500 \\
6500 \\
6500 \\
6500 \\
6500 \\
6500\end{array}$ & $\begin{array}{l}85 \\
85 \\
85 \\
85 \\
85 \\
85 \\
85\end{array}$ & $\begin{array}{l}29 \\
30 \\
31 \\
32 \\
33 \\
34 \\
35\end{array}$ & $\begin{array}{c}13.47 \\
13.45 \\
13.6 \\
13.5 \\
13.5 \\
13.5 \\
13.52 \\
\end{array}$ & 13.5057 & $\begin{array}{l}0.0989 \\
0.2472 \\
0.8653 \\
0.1236 \\
0.1236 \\
0.1236 \\
0.2719\end{array}$ & 0.04756 & $\begin{array}{l}1.13 \\
1.13 \\
1.13 \\
1.15 \\
1.15 \\
1.15 \\
1.14\end{array}$ & 1.14 & $\begin{array}{l}0.7528 \\
0.7528 \\
0.7528 \\
1.0038 \\
1.0038 \\
1.0038 \\
0.1255\end{array}$ & 0.01 & $\begin{array}{c}152.211 \\
151.905 \\
153.68 \\
155.25 \\
155.25 \\
155.25 \\
154.128\end{array}$ \\
\hline $\begin{array}{l}\text { Vane } 1 \\
\text { Vale } 1 \\
\text { Vale } 1 \\
\text { Vate } 1 \\
\text { Vawe } 1 \\
\text { Vave } 1 \\
\text { Valve } 1\end{array}$ & $\begin{array}{l}6500 \\
6500 \\
6500 \\
6500 \\
6500 \\
6500 \\
6500\end{array}$ & $\begin{array}{l}130 \\
130 \\
130 \\
130 \\
130 \\
130 \\
130\end{array}$ & $\begin{array}{l}36 \\
37 \\
38 \\
39 \\
40 \\
41 \\
0\end{array}$ & $\begin{array}{l}13.54 \\
13.52 \\
13.49 \\
13.51 \\
13.45 \\
13.48 \\
13.47\end{array}$ & 13.4943 & $\begin{array}{l}0.1203 \\
0.2719 \\
0.0494 \\
0.1978 \\
0.2472 \\
0.0247 \\
0.0989\end{array}$ & 0.03701 & $\begin{array}{l}1.14 \\
1.14 \\
1.14 \\
1.14 \\
1.14 \\
1.14 \\
1.14\end{array}$ & 1.14 & $\begin{array}{l}0.1255 \\
0.1255 \\
0.1255 \\
0.1255 \\
0.1255 \\
0.1255 \\
0.1255\end{array}$ & 1.7E-08 & $\begin{array}{c}154.356 \\
154.128 \\
153.786 \\
154.014 \\
153.33 \\
153.672 \\
153.558\end{array}$ \\
\hline Totals & - & - & 21 & 13.483 & 13.4833 & 0.2331 & 0.04247 & 9.1386 & 1.13857 & 0.4302 & 0.00655 & 153.518 \\
\hline
\end{tabular}


Formated Simulart

\begin{tabular}{|c|c|c|c|c|c|c|c|c|c|c|c|c|}
\hline Location & Volume & RPM & Number & Oode & Avg. $\mathrm{Ox}$ & K Error & Std. der & Oensty & Avg. Den & \% Emox & Std. der & Ox Land \\
\hline $\begin{array}{l}\text { Vave } 4 \\
\text { Vare } 4 \\
\text { Vale } 4 \\
\text { Vave } 4 \\
\text { Vave } 4 \\
\text { Varo } 4 \\
\text { Vale } 4\end{array}$ & $\begin{array}{l}6500 \\
6500 \\
6500 \\
6500 \\
6500 \\
6500 \\
6500\end{array}$ & $\begin{array}{l}45 \\
45 \\
45 \\
45 \\
45 \\
45 \\
45\end{array}$ & $\begin{array}{l}43 \\
44 \\
45 \\
46 \\
47 \\
48 \\
49\end{array}$ & $\begin{array}{l}13.42 \\
13.48 \\
13.39 \\
13.46 \\
13.41 \\
13.48 \\
13.47 \\
\end{array}$ & 13.4443 & $\begin{array}{l}0.3958 \\
0.0495 \\
0.6185 \\
0.099 \\
0.4701 \\
0.0495 \\
0.0247\end{array}$ & 0.0369 & $\begin{array}{l}1.13 \\
1.13 \\
1.13 \\
1.13 \\
1.13 \\
1.12 \\
1.13 \\
\end{array}$ & 1.12857 & $\begin{array}{l}0.336 \\
0.336 \\
0.336 \\
0.336 \\
0.338 \\
1.218 \\
0.336 \\
\end{array}$ & 0.00378 & $\begin{array}{l}151.646 \\
152.324 \\
151.307 \\
152.098 \\
151.533 \\
150.976 \\
152211\end{array}$ \\
\hline 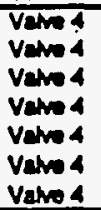 & $\begin{array}{l}6500 \\
6500 \\
6500 \\
6500 \\
6500 \\
6500 \\
6500\end{array}$ & $\begin{array}{l}85 \\
85 \\
85 \\
85 \\
85 \\
85 \\
85\end{array}$ & $\begin{array}{l}50 \\
51 \\
52 \\
53 \\
54 \\
55 \\
56\end{array}$ & $\begin{array}{l}13.47 \\
13.49 \\
13.45 \\
13.44 \\
13.51 \\
13.51 \\
13.55\end{array}$ & 13.4843 & $\begin{array}{c}0.0247 \\
0.099 \\
0.1732 \\
0.2474 \\
0.2721 \\
0.2721 \\
0.569 \\
\end{array}$ & 0.03994 & $\begin{array}{l}.12 \\
1.13 \\
1.13 \\
1.13 \\
1.15 \\
1.14 \\
1.14 \\
\end{array}$ & 1.73429 & $\begin{array}{l}1.218 \\
0.338 \\
0.338 \\
0.328 \\
1.428 \\
0.548 \\
0.548 \\
\end{array}$ & 0.00976 & $\begin{array}{l}150.864 \\
152.090 \\
151.885 \\
151.072 \\
155.385 \\
154.014 \\
154.47\end{array}$ \\
\hline $\begin{array}{l}\text { Vaw } 4 \\
\text { Vare } 4 \\
\text { Vame } 4 \\
\text { Vawe } 4 \\
\text { Vare } 4 \\
\text { Vame } 4 \\
\text { Valve } 4\end{array}$ & $\begin{array}{l}6500 \\
6500 \\
6500 \\
6500 \\
6500 \\
6500 \\
6500 \\
\end{array}$ & $\begin{array}{l}130 \\
130 \\
130 \\
130 \\
130 \\
130 \\
130 \\
\end{array}$ & $\begin{array}{l}57 \\
58 \\
59 \\
60 \\
61 \\
62 \\
63\end{array}$ & $\begin{array}{l}13.52 \\
13.51 \\
13.5 \\
13.51 \\
13.47 \\
13.48 \\
13.45\end{array}$ & 73.4914 & $\begin{array}{l}0.3464 \\
0.2729 \\
0.1979 \\
0.2721 \\
0.0247 \\
0.0495 \\
0.1732 \\
\end{array}$ & 0.02545 & $\begin{array}{l}1.14 \\
1.14 \\
1.14 \\
1.13 \\
1.13 \\
1.14 \\
1.15 \\
\end{array}$ & 1.73857 & $\begin{array}{l}0.546 \\
0.546 \\
0.546 \\
0.336 \\
0.336 \\
0.548 \\
1.428\end{array}$ & 0.0069 & $\begin{array}{c}154.128 \\
154.014 \\
153.9 \\
152.653 \\
152.211 \\
153.672 \\
154.675\end{array}$ \\
\hline Tocals & - & - & 21 & 13.473 & 13.4733 & 0.2238 & 0.03916 & 7.7338 & 1. 13381 & 0.584 & 0.00805 & 152.763 \\
\hline
\end{tabular}

Formated Simutart

\begin{tabular}{|c|c|c|c|c|c|c|c|c|c|c|c|c|}
\hline Location & Volume & RPM & Number & Oxoe & Avg. Ox & XERTr & Std. dev & Densiny & Avg. Den & \% Error & \multicolumn{2}{|c|}{ Std der $0 x$ Lasd } \\
\hline Varas & 6500 & 45 & 64 & 13.45 & 13.4643 & 0.3633 & 0.03735 & 1.13 & 1.13 & 0.336 & 0.00816 & 151.985 \\
\hline Vates & .6500 & 15 & 65 & 13.49 & & 0.067 & & 1.13 & & 0.338 & & 152.437 \\
\hline Vaves & 6500 & 45 & 68 & 13.50 & & 0.2293 & & 1.14 & & 0.548 & & 154.212 \\
\hline Vawes & 6500 & 45 & 67 & 13.47 & & 0.2152 & & 1.13 & & 0.336 & & 152.211 \\
\hline Vares & 6500 & 45 & 68 & 13.42 & & 0.5856 & & 1.14 & & 0.546 & & 152988 \\
\hline Vams & 6500 & 45 & 69 & 13.40 & & 0.5115 & & 1.12 & & 1.218 & & 150.416 \\
\hline Vaves & 6500 & 15 & 70 & 13.45 & & 0.2893 & & 1.12 & & 1.218 & & 150.752 \\
\hline Vane 5 & 6500 & 85 & 71 & 13.45 & 13.5729 & 0.3633 & 0.26043 & 1.13 & 1.13429 & 0.336 & 0.01272 & 151.985 \\
\hline Valves & 6500 & 85 & 72 & 13.45 & & 0.2893 & & 1.12 & & 1.218 & & $\begin{array}{l}150.752 \\
151.872\end{array}$ \\
\hline Vawe 5 & 6500 & 85 & 74 & $\begin{array}{l}13.44 \\
14.16\end{array}$ & & 1.8963 & & $\begin{array}{l}1.73 \\
1.12\end{array}$ & & $\begin{array}{l}0.336 \\
1.218\end{array}$ & & $\begin{array}{r}151.872 \\
158.592\end{array}$ \\
\hline Vates & 6500 & 85 & 75 & 13.5 & & 0.0071 & & 1.15 & & 1.428 & & 155.25 \\
\hline Vanes & 6500 & 25 & 76 & 13.48 & & 0.1411 & & 1.15 & & 1.428 & & 155.02 \\
\hline Vaves & 6500 & 85 & $\pi$ & 13.52 & & 0.1552 & & 1.14 & & 0.546 & & 154.128 \\
\hline Vave 5 & 6500 & 130 & 78 & 13.49 & 13.46 & 0.067 & 0.04397 & 1.14 & 1.13714 & 0.546 & 0.00488 & 153.786 \\
\hline Vaves & 6500 & 130 & 79 & 13.49 & & 0.067 & & 1.13 & & 0.336 & & 152.137 \\
\hline Vam 5 & 6500 & 130 & 80 & 13.47 & & 0.2152 & & 1.14 & & 0.546 & & 153.558 \\
\hline Vave 5 & 6500 & 130 & 81 & 13.5 & & 0.0071 & & 1.14 & & 0.548 & & 153.9 \\
\hline Vares & 6500 & 130 & 82 & 13.47 & & 0.2152 & & 1.13 & & 0.338 & & 152.211 \\
\hline Vames & 6500 & 130 & 83 & 13.38 & & 0.8819 & & 1.14 & & 0.546 & & 152.532 \\
\hline Vales 5 & 6500 & 130 & 84 & 13.42 & & 0.5858 & & 1.14 & & 0.548 & & 152.988 \\
\hline Tolats & - & - & 21 & 13.499 & 13.4 & 0.5043 & 0.15559 & 1.1338 & 1.13381 & 0.688 & 0.00921 & 153.05 \\
\hline Orerall & - & - & 84 & 13.476 & 13.4762 & 0.2818 & 0.08622 & 1.1329 & 1.73286 & 0.6291 & 0.01036 & 152.666 \\
\hline
\end{tabular}

Mether Feed Sirnulint

\begin{tabular}{|c|c|c|c|c|c|c|c|c|c|c|c|c|}
\hline Location & Volume & RPM & Number & Oxde & Avg. Ox & \% Enror & Std. dev & Density & Avg. Den & $\%$ Ertor & Std. dev & Ox Load \\
\hline $\begin{array}{l}\text { Hydragard } \\
\text { Hydragard } \\
\text { Hydragard } \\
\text { Hydragard } \\
\text { Hydregard } \\
\text { Hydregard } \\
\text { Hydregard }\end{array}$ & $\begin{array}{l}7100 \\
7100 \\
7100 \\
7100 \\
7100 \\
7100 \\
7100\end{array}$ & $\begin{array}{l}130 \\
130 \\
130 \\
130 \\
130 \\
130 \\
130\end{array}$ & $\begin{array}{l}15 \\
16 \\
17 \\
18 \\
19 \\
20 \\
21\end{array}$ & $\begin{array}{l}38.65 \\
39.13 \\
38.87 \\
38.98 \\
39.53 \\
39.34 \\
39.45\end{array}$ & 39.1357 & $\begin{array}{l}1.2411 \\
0.0146 \\
0.679 \\
0.3979 \\
1.0075 \\
0.522 \\
0.8031\end{array}$ & 0.32321 & $\begin{array}{l}1.3 \\
1.34 \\
1.32 \\
1.35 \\
1.33 \\
1.32 \\
1.33\end{array}$ & 1.32714 & $\begin{array}{l}2.0452 \\
0.9688 \\
0.5382 \\
1.7223 \\
0.2153 \\
0.5382 \\
0.2153\end{array}$ & 0.01604 & $\begin{array}{c}502.45 \\
524.342 \\
513.084 \\
526.23 \\
525.749 \\
519.280 \\
524.685\end{array}$ \\
\hline Tocais & - & - & $\frac{-1}{7}$ & 39.136 & 39.1357 & 0.6664 & 0.32321 & 9.3271 & 1.32714 & 0.8919 & 0.01604 & 519.404 \\
\hline
\end{tabular}

Meter Feed Simulark

\begin{tabular}{|c|c|c|c|c|c|c|c|c|c|c|c|c|}
\hline Location & Volume & RPM & Numoer & Ooode & Avg. $\alpha x$ & $x$ Error & Std. dev & Derany & Avg. Den & $\%$ Enror & Std dev & Ox Load \\
\hline $\begin{array}{l}\text { Vare } 1 \\
\text { Vew } 1 \\
\text { Vaw } 1 \\
\text { Vaw } 1 \\
\text { Vare } 1 \\
\text { Vave } 1 \\
\text { Vane } 1\end{array}$ & $\begin{array}{l}7100 \\
7100 \\
7100 \\
7100 \\
7100 \\
7100 \\
7100\end{array}$ & $\begin{array}{l}130 \\
130 \\
130 \\
130 \\
130 \\
130 \\
130\end{array}$ & $\begin{array}{l}36 \\
37 \\
38 \\
39 \\
40 \\
41 \\
42\end{array}$ & $\begin{array}{l}39.18 \\
39.32 \\
39.24 \\
39.35 \\
39.22 \\
39.26 \\
39.84\end{array}$ & 39.3443 & $\begin{array}{l}0.4176 \\
0.0617 \\
0.2651 \\
0.0145 \\
0.3159 \\
0.2142 \\
1.2599 \\
\end{array}$ & 0.22612 & $\begin{array}{l}1.32 \\
1.35 \\
1.34 \\
1.34 \\
1.34 \\
1.35 \\
1.34 \\
\end{array}$ & 1.34 & $\begin{array}{l}1.4925 \\
0.7463 \\
2 E-14 \\
2 E-14 \\
2 E-14 \\
0.7463 \\
2 E-14 \\
\end{array}$ & 0.01 & $\begin{array}{c}517.176 \\
530.82 \\
525.816 \\
527.29 \\
525.548 \\
530.01 \\
533.856\end{array}$ \\
\hline Touts & - & - & 7 & 39.344 & 39.3443 & 0.3641 & 0.22612 & 1.34 & 1.34 & 0.4264 & 0.01 & $\$ 27.217$ \\
\hline
\end{tabular}


Melle Feed Simulart

\begin{tabular}{|c|c|c|c|c|c|c|c|c|c|c|c|c|}
\hline Location & Volume & RPM & Number & oxode & Ang, ox & $\%$ Ema & Sid der & Deness & Avg. Den & \%Enx & sia oor & Ox Losd \\
\hline Venod & 7100 & 130 & 57 & 39.06 & 39.1671 & 0.2736 & 0.14503 & 9.34 & 1.35429 & 7.0549 & 0.0207 & 523.404 \\
\hline Vawe 4 & 7900 & 130 & 58 & 38.92 & & 0.631 & & 1.34 & & $1.054 \theta$ & & 521.528 \\
\hline Vatod & 7900 & 130 & 59 & 39.15 & & 0.0438 & & 1.35 & & 0.3165 & & 528.525 \\
\hline valued & 7900 & 130 & $\infty$ & 39.2 & & 0.0839 & & 1.35 & & 0.3165 & & 529.2 \\
\hline Velve 4 & 7100 & 130 & 61 & 39.18 & & 0.0328 & & 1.35 & • & 0.3165 & & 528.93 \\
\hline vale 4 & 7100 & 130 & 02 & 39.35 & & 0.4669 & & 1.35 & & 0.3165 & & 531.225 \\
\hline Vowed & 7900 & 130 & $\infty$ & 39.31 & & 0.3647 & & 1.4 & & 3.3755 & & 550.34 \\
\hline Tounts & - & - & 7 & 39.167 & 39.1671 & 0.2709 & 0.14503 & 1.3543 & 9.35429 & 0.9644 & 0.0207 & 530.45 \\
\hline
\end{tabular}

Mever Food Simulent

\begin{tabular}{|c|c|c|c|c|c|c|c|c|c|c|c|c|}
\hline Lecation & Votume & RPM & Number & 0000 & $A n g$ & $\%$ Enx & Sid dor & Densy & Ang. Den & \% EnT & sid. $\alpha$ & Ox Lood \\
\hline value 5 & 7100 & 130 & $78-$ & 39.17 & 39.2043 & 0.0875 & 0.16113 & 1.33 & 1.33714 & 0.5342 & 0.01113 & 520.061 \\
\hline Vaves & 7100 & 130 & 79 & 39.19 & & 0.0384 & & 1.32 & & 1.2821 & & 517.308 \\
\hline Vawes & 7100 & 130 & 80 & 39.06 & & 0.368 & & 1.34 & & 0.2137 & & 523.404 \\
\hline Venos 5 & 7900 & 130 & 81 & 39.18 & & 0.0819 & & 1.34 & & 0.2137 & & 525.012 \\
\hline & 7100 & 130 & 82 & 39.45 & & 0.6268 & & 1.35 & & 0.9615 & & 532.575 \\
\hline Varwes & 7100 & 130 & 23 & 39 & & 0.5211 & & 1.35 & & 0.9815 & & \\
\hline & 7100 & 130 & 84 & 39.38 & & 0.4482 & & 1.33 & & 0.5342 & & 523.754 \\
\hline To & - & - & 7 & 39.201 & $39.20 \times 3$ & 0.3071 & 0.161 & 1.3371 & 1.33794 & 0.6716 & & 524.216 \\
\hline & & - & 28 & 39.213 & & 0.4022 & 0.2273 & 1.3396 & 1.33964 & 0.7386 & 0.01732 & 525.322 \\
\hline
\end{tabular}




\section{Appendix K}

Solids Buildup Pictures 
Page F2 of F5
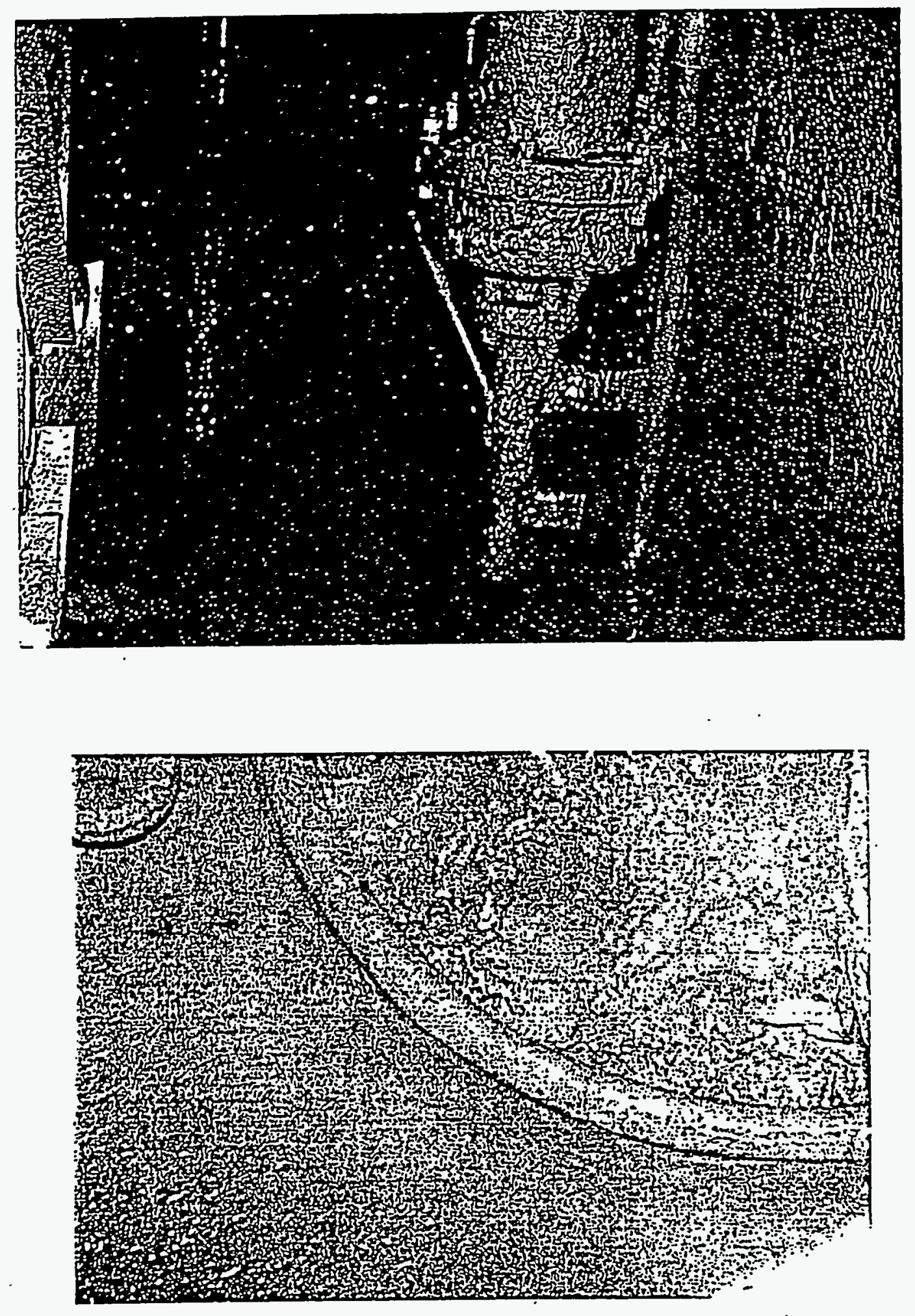

K.1 
Page F3 of F5
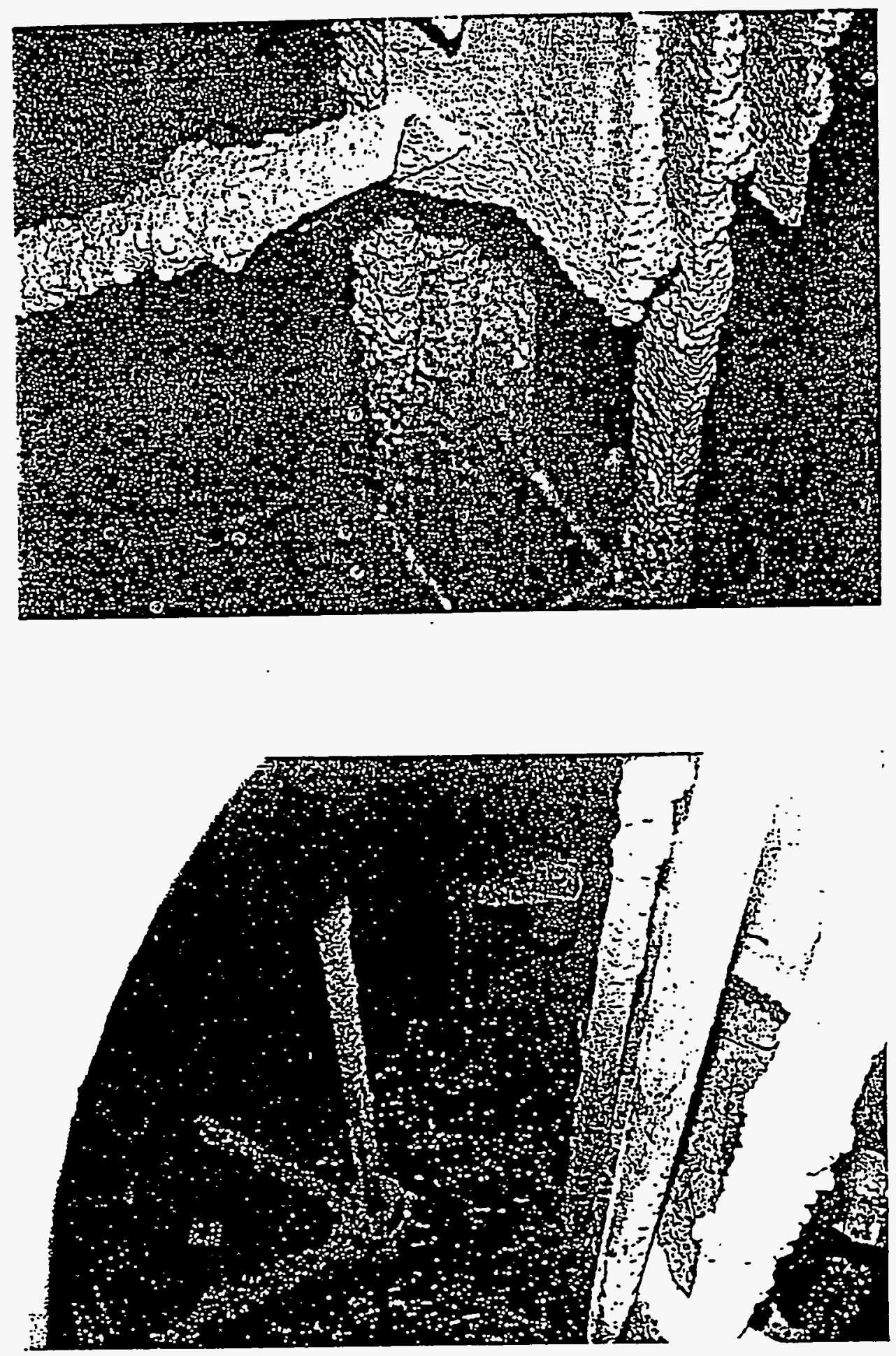
Page F4 of F5
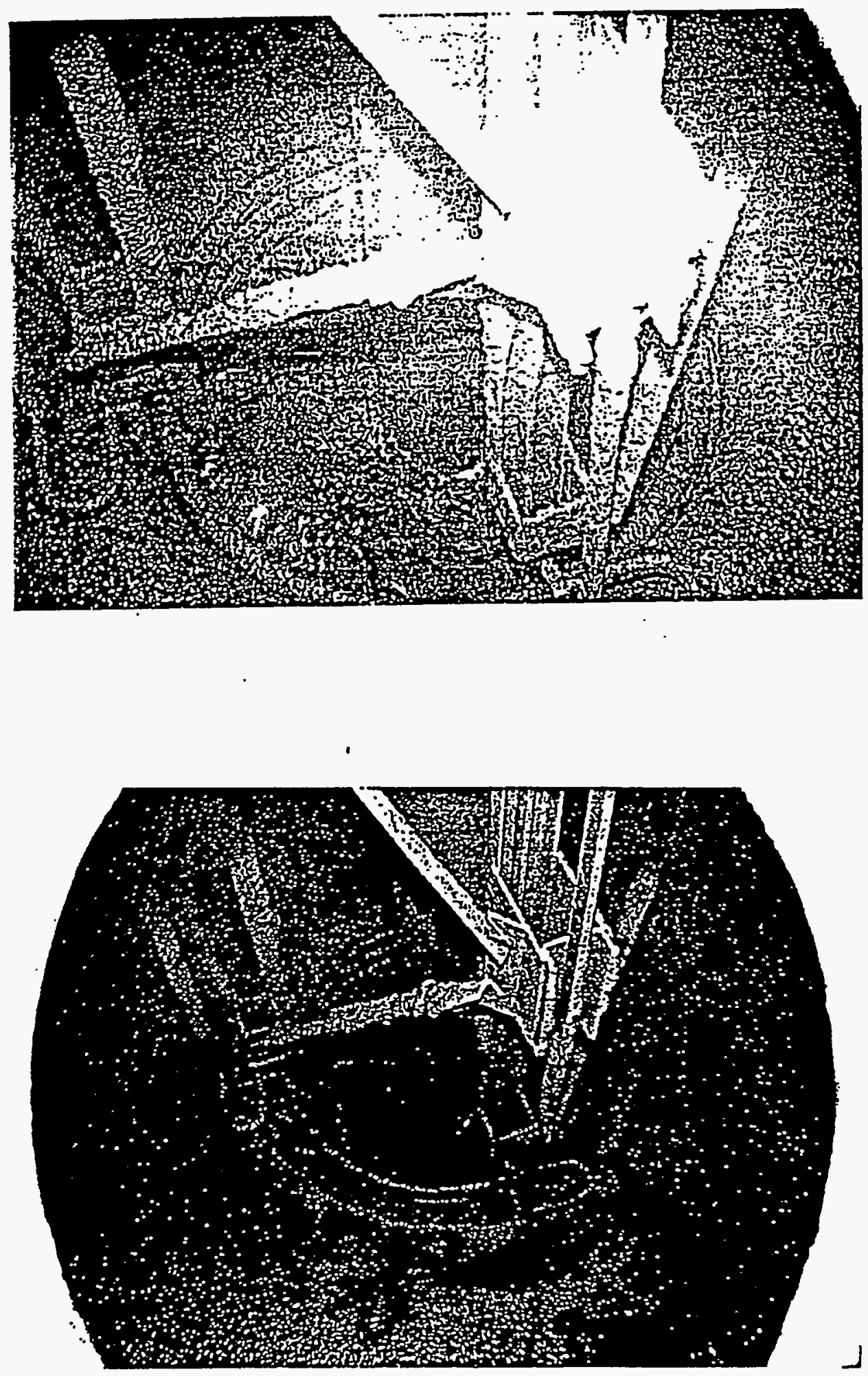

K.3 

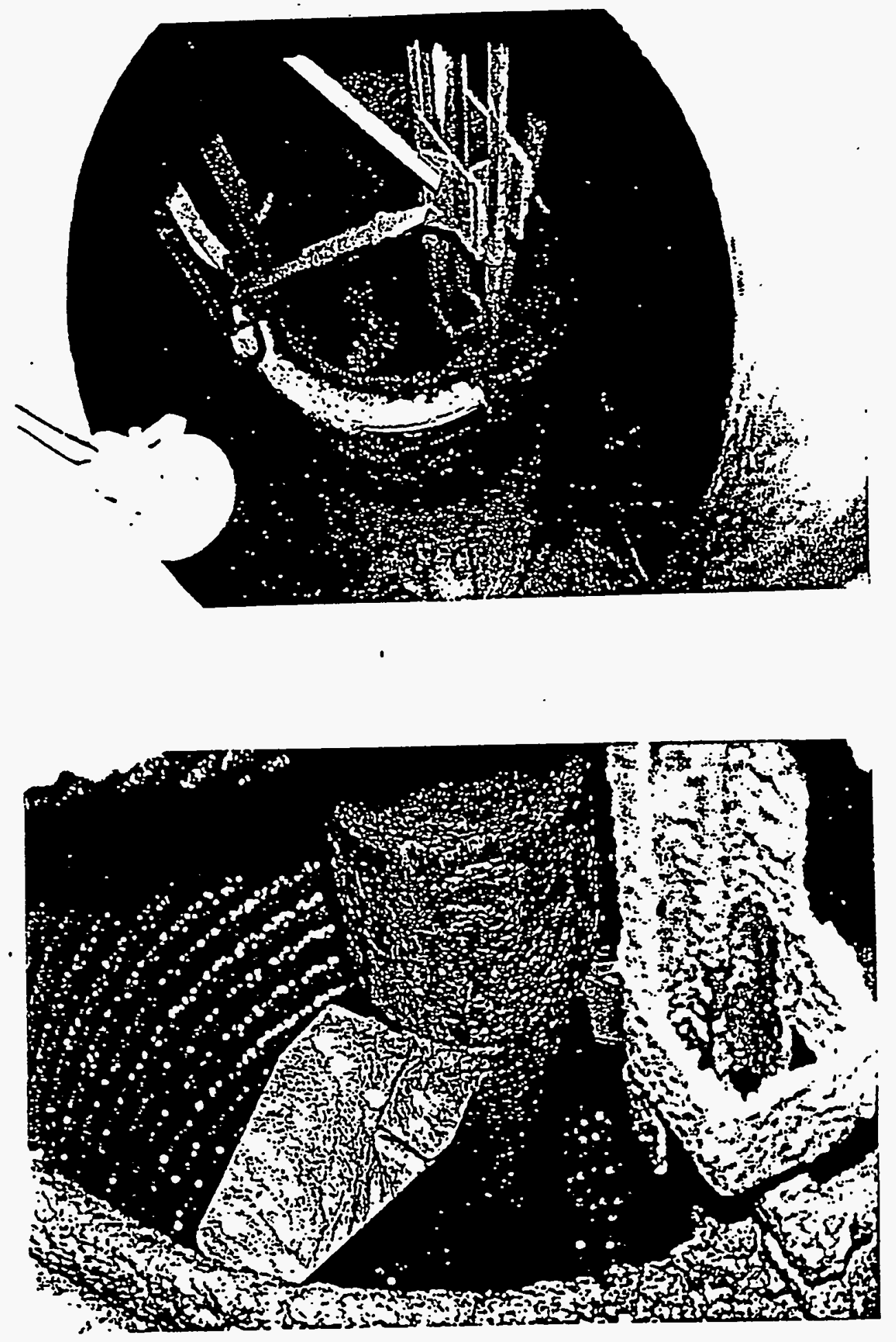
Appendix L

Condenser Design Calculations 


\section{Design Calcuiations}

\section{CALC-SIPT-006, Rev. 1}

For

Slurry-Integrated Performance Testing

$2 / 16 / 93$

\section{FPTS Condenser Analysis}

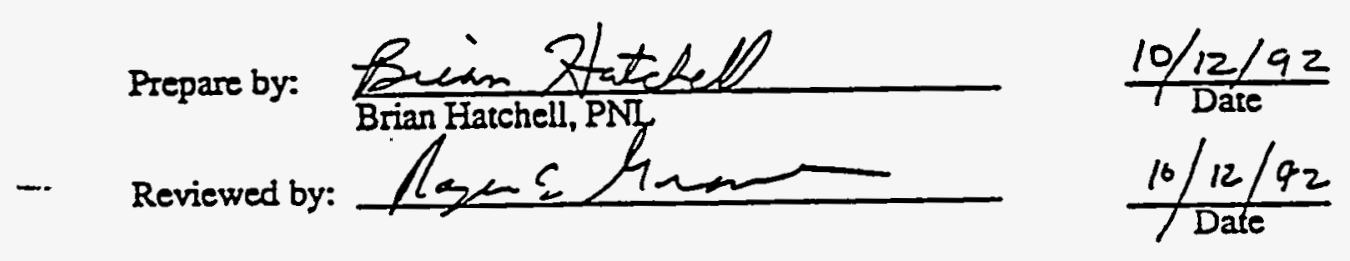

L. 1 


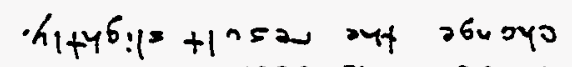
sill gray, if posn som arlon touscoo o

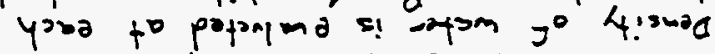

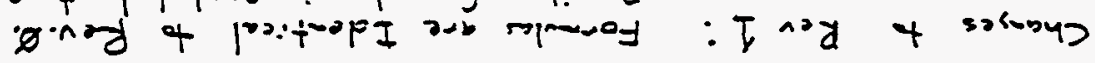

11

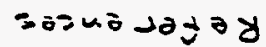

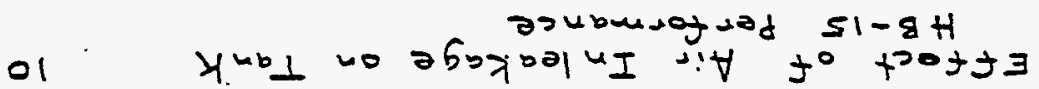

$$
\begin{aligned}
& \text { b sbb-jjo u! sitom to tuaomo 6u!tj!posd }
\end{aligned}
$$

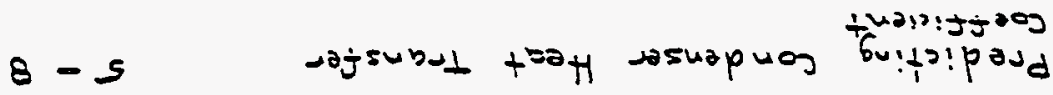

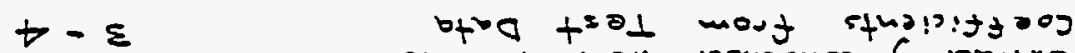

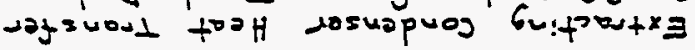
(5) $2 e^{d}$
ग+1 $x: \frac{1}{2+2}$

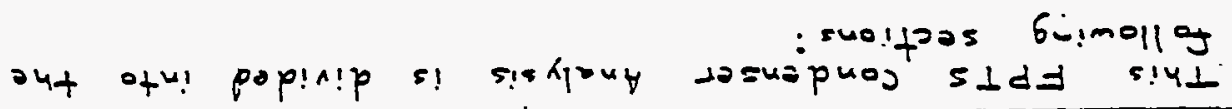

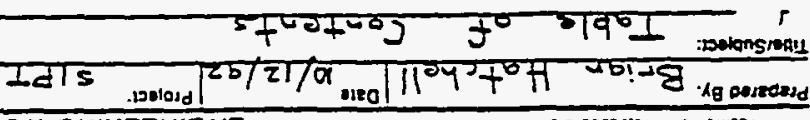
LBHSXYYOM ONIEEZNION3

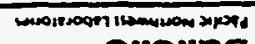




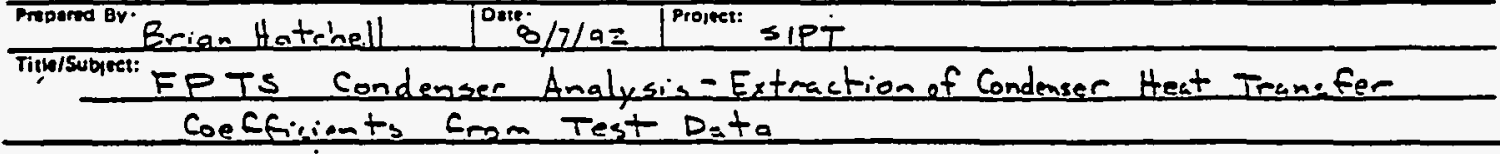

This calculation provides an example of how to extract $F$ for the enndenser from test conditions. The same technigue was incorporated into an Excel spreadsheot.

Process Conditions: Test Data averoged from TSTOza

$$
\begin{aligned}
& \text { steam Flow }-5758.5 \mathrm{lb} / \mathrm{hr} \\
& \text { Time } 11: 13-11: 43
\end{aligned}
$$$$
\text { Condensate Flow Rate }=9.575 \mathrm{gpm}
$$$$
\text { Vapor Temp In }=211.09 \text { \% }{ }^{*}
$$

Condenser Cooling Water Temp In $=76.16^{\circ} \mathrm{F}$

Condenser Cooling Water Temp Out $=129.86^{\circ} \mathrm{F}$

Condensute Temperatme $=110.45^{\circ} \mathrm{F}$

Condensor Cosling Water Ftow $=203.04 \mathrm{gpm}$

* This is the average thermo well temperature. TI- 1101 messures the

temperature at the condenser entrance, but this will include the

effect of air in the gas sweep. For this reason, therndynamic properties for process vapor will be evaluated at avercye therrowell.

Heat Tramefer Aran 313 Tubes, 14 BWG, $89^{\prime \prime}$ Lom, 3/4"

$00 \cdot 0.75 \mathrm{in}=0.0625 \mathrm{ft}, I 0=0.594 . \mathrm{m}=0.04867 \mathrm{ft}$

Outside surface area per foot $=0.1963, \mathrm{Ft}^{2} / \mathrm{f}+R_{2} f, 5, \mathrm{pg} 343$

Heat Tramsfor Area $=313 .(88 \mathrm{in})\left(\frac{\mathrm{Cl}}{\mathrm{Kin}}\right)\left(0.1963 \frac{\mathrm{CL}^{2}}{\mathrm{Cr}_{r}}\right)$

$$
=450.6 \quad t_{t}^{2}
$$

Process Condensete Mrss Flow Rate

$\rightarrow$ (wate) at condensate Tenp $=0.01617 \frac{\mathrm{G}_{7}}{16}$ Refl, pg 858

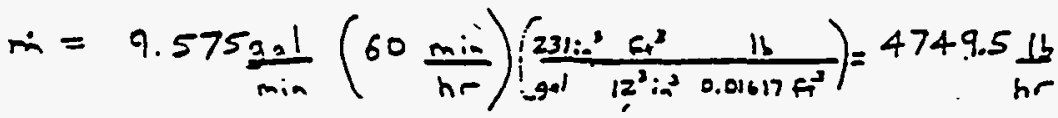

Heat Exchanas Vapor Condensation $\sum$ suboool

$$
\begin{aligned}
& \text { insg stean } \theta 211.09^{\circ} \mathrm{F}=970.9 \text { Btu/b Ret 1, pg A-12 } \\
& \text { condensing } g_{c}=4749.5 \frac{\mathrm{b}}{\mathrm{hr}}\left(970.7 \frac{\mathrm{etu}}{\mathrm{b}}\right)=4.611 \times 10^{6} \frac{\mathrm{et} . \mathrm{r}}{\mathrm{m}}
\end{aligned}
$$

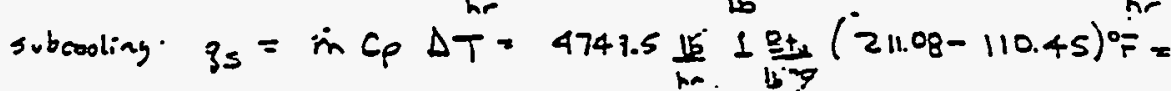

$$
\begin{aligned}
& =4.779 \times 10^{5} \mathrm{BL}
\end{aligned}
$$

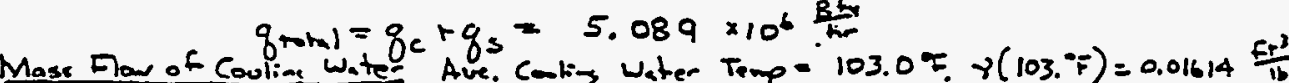

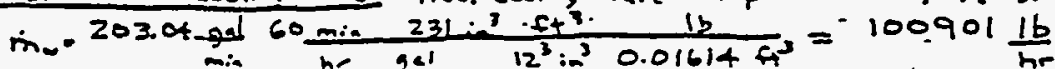




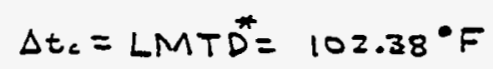

\begin{tabular}{|l|c|c|c|}
\hline Ho Fluid & \multicolumn{1}{|c|}{ Subeoling } \\
\hline Z11.08 & High & 84.16 & 126.92 \\
110.45 & Low & 76.16 & 34.29 \\
\hline
\end{tabular}

Condensing . $8 \mathrm{c} /$ Lte $=4.611 \times 10^{4} / 102.38=45038 \mathrm{Btu} / \mathrm{hm}$ F Subesuling $g_{s} / \Delta t_{s}=4.779 \times 10^{5} / 70.78=6752 \mathrm{Btu} / \mathrm{hr}{ }^{\circ} \mathrm{F}$ 51790 Ein/inrse

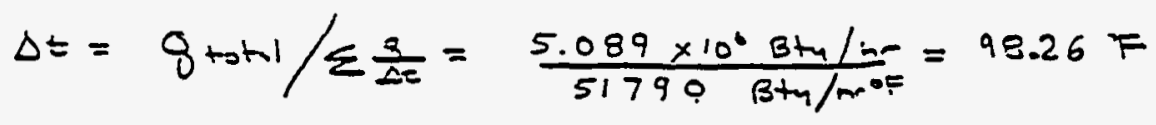$$
Q=\tau A \Delta t
$$$$
5.089 \times 10^{\circ} \frac{B+w}{h r}=T\left(453.694^{2}\right) 98.26^{\circ} \mathrm{F}
$$

$$
\tau=\frac{5.089 \times 10^{\circ}}{4506(93.26)}=114.94 \frac{26}{h_{r} F_{t}}=\text { of }
$$

The naxt section will predict the condenser overal heat transfer coefficienty based on the same set of

test conditions.

$$
\text { in }\left(\frac{\Delta t+16 n}{\Delta t+00}\right)
$$




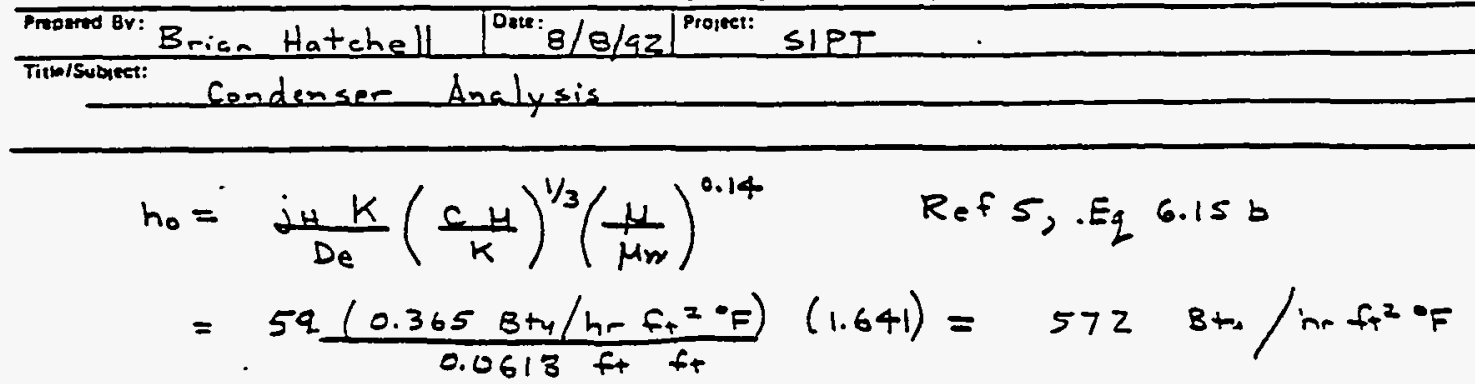

Hot Elvid: Tube Side, Condensino Water

condensation Inside Verticle Tubes-see Ref 5, pg $<70$

Quantities - $\quad t_{0}=t_{\text {man }}$

$t_{\text {- }}=$ Mean Temp of Cooling woter:

$t_{w}=t_{m}+\left(\frac{h_{i 0}}{h_{i_{0}}+h_{0}}\right)\left(T_{y}-t_{m}\right) \quad \operatorname{Ref} 5, E_{2} 5.31$

hos inside heat transfer eosflisict, besed on outside area.

- Assume hio $=950 \mathrm{Btu} / \mathrm{hr} \mathrm{fr}^{2} \mathrm{~F}$

$t_{m}=(76.16+129.86) / 2=103.01 \cdot F$

$t_{\omega}=103.01+\left(\frac{950}{950.5720^{\circ}}\right)(211.08-103.01)=170.5^{\circ} \mathrm{F}$

$t_{s}=\left(t_{w}+T_{v}\right) / z=(170.5+211.08) / z=190.8^{\circ} \mathrm{F}$

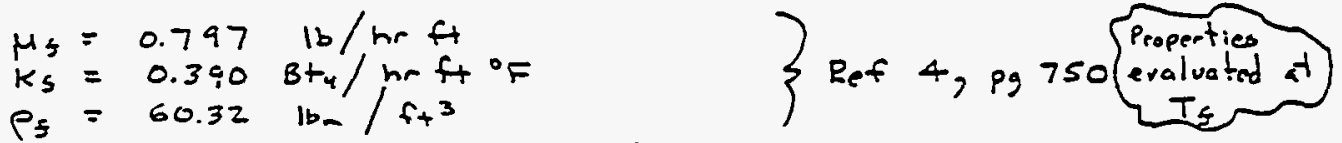

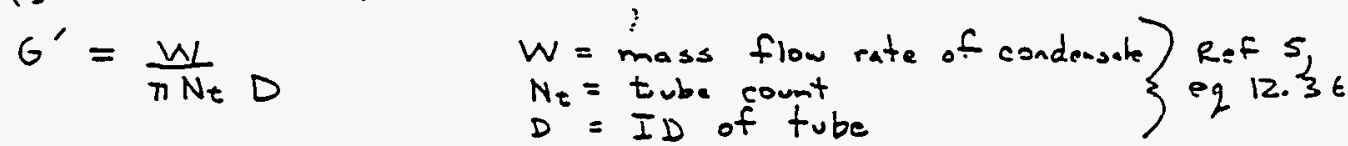

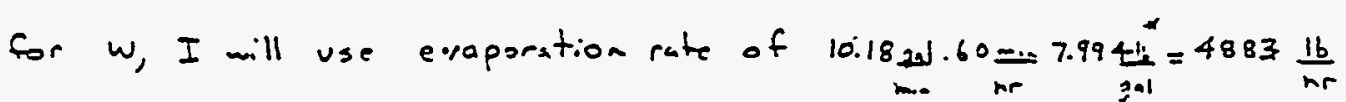

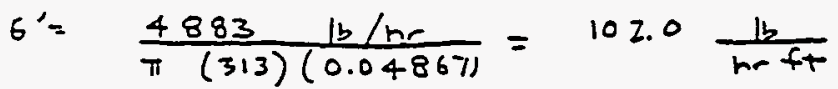

* $\rightarrow\left(\right.$ water at $\left.212^{\circ} \mathrm{F}\right)=0.1672^{\frac{84}{10}} \quad e_{e}=1, \rho 9858$

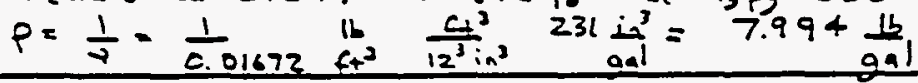




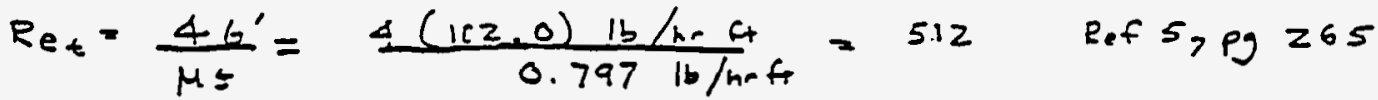

$\bar{h} \cdot\left(\frac{u_{1}^{2}}{k^{3}+\rho^{2}=g}\right)^{1 / 3}=0.23 \quad$ Res 5 , Fis 12.12 , pg 270

$\bar{h}=0.23\left(\frac{k_{s}^{3} \rho_{s}^{2} g}{\mu_{s}^{2}}\right)^{1 / 3} \quad g=32.17+\frac{\theta_{s e c}}{\sec ^{2}}\left(3600 \frac{\mathrm{sec}}{\mathrm{hr}}\right)^{2}=4.17 \times 10^{8} \frac{\mathrm{G}}{\mathrm{hr}}$

$\bar{h}=0.23\left(\frac{0.39^{3} 61.32^{2} 4.17 \times 10^{2}}{0.797^{2}}\right)^{1 / 3}=1200 \mathrm{Bth} / \mathrm{Ar} \mathrm{ft}^{2}$ of

- Znd Iteration, $n_{i_{0}}=1200 \mathrm{Bty} / \mathrm{hr}_{\mathrm{ft}}{ }^{2} \mathrm{~F}$

$$
\begin{aligned}
& \therefore \omega=103.01+\left(\frac{1200}{1200+572}\right)(211.08-103.01)=176.2 \% \mathrm{~F} \\
& E==(176.2+211.08) /==193.6 \cdot \mathrm{F}
\end{aligned}
$$

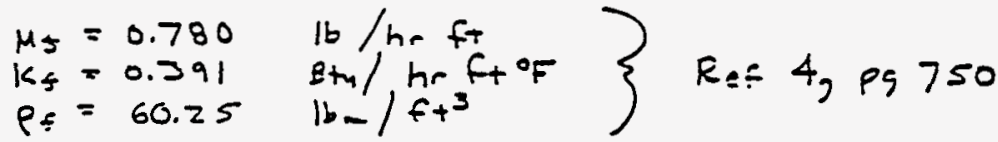

Ret $=4(102.0) / 0.78-523.1$

$\bar{n}\left(\frac{\mu_{s}^{2}}{k^{3} f_{5}-g}\right)^{1 / 2}=0.23=t i l$

$\bar{h}=1219 \quad B t_{4} / \mathrm{hr} \mathrm{ft}_{4}^{2}{ }^{\circ} \mathrm{F} \quad r$

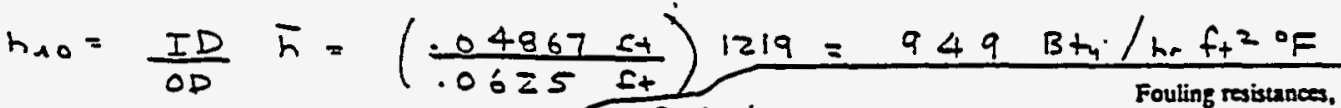

Fouling factors:

Condensecte Temoorature $>125^{\circ} \mathrm{F}$ [o. most of condenseer length. Condenser cooling water greuter than $125^{\circ} \mathrm{F}$ for port of condenser leagth.

$$
f_{i}=0.002
$$

$f_{0}=0.002$ (conservative)
Ref 4, Page 424: Fluid

Distilled water

Sea mater, below $125^{\circ} \mathrm{F}$

above $125^{\circ} \mathrm{F}$

Boiler feed water, treated

Cily or well water, below $125^{\circ} \mathrm{F}$

above $125^{\circ}$

Refrigerating liquids

Refrigerating vapors

Liquid gasoline, organic vapors

Fuel oil

Qvenching oil

Steam, non-oit-bearing

Industrial ait

hr $\mathrm{ft}^{2}$ F/Btu

0.0005

0.0005

0.001

0.001

0.001

0.002

0.001

0.001

0.0005

0.005

0.004

0.0005

0.002 


\begin{tabular}{|c|c|c|c|}
\hline Prnpared Bv & Brian Hatcinell & $1^{\text {onte }} 8 / 8 / 52$ & Proiret: SIPT \\
\hline
\end{tabular}

Overall Heat Transe- Coefficient

$\frac{1}{v}=\frac{1}{h_{i 0}}+\frac{1}{h_{0}}+\frac{2.3 D_{0}}{2 K_{i+b e}} \log \frac{D_{0}}{D_{i}}+f_{i}+f_{0} \quad \operatorname{Ref5,\rho g} 86$

$=\frac{1}{949}+\frac{1}{572.0}-\frac{2.30 .0625}{2(10)} \log \left(\frac{0.0625}{0.04867}\right)+.00 z+.002$

$\Rightarrow U=131.9 \mathrm{Bth} / \mathrm{hr} \mathrm{ft}{ }^{2}{ }^{\circ} \mathrm{F}$

Note that this value neglects the effect of noncondensibles.

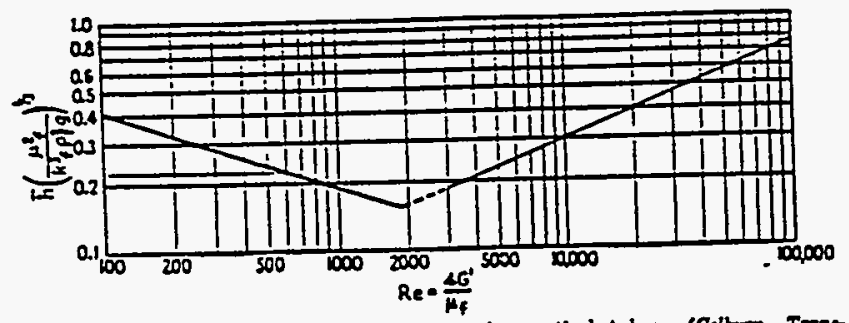

The.

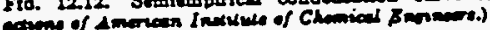
From Reference 5, pg 270 (used to determine.
$r_{1}$ for condensction inside tubes) 


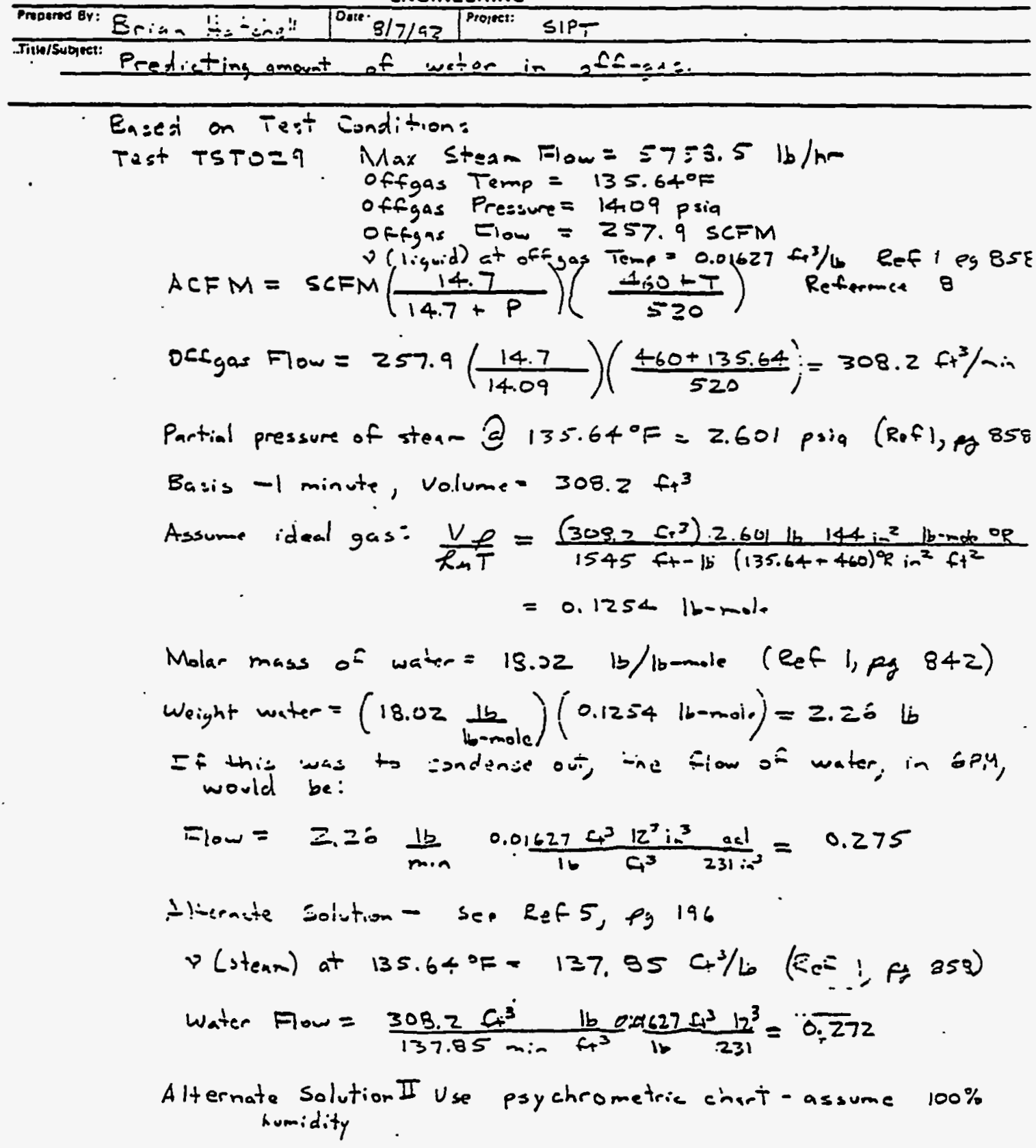




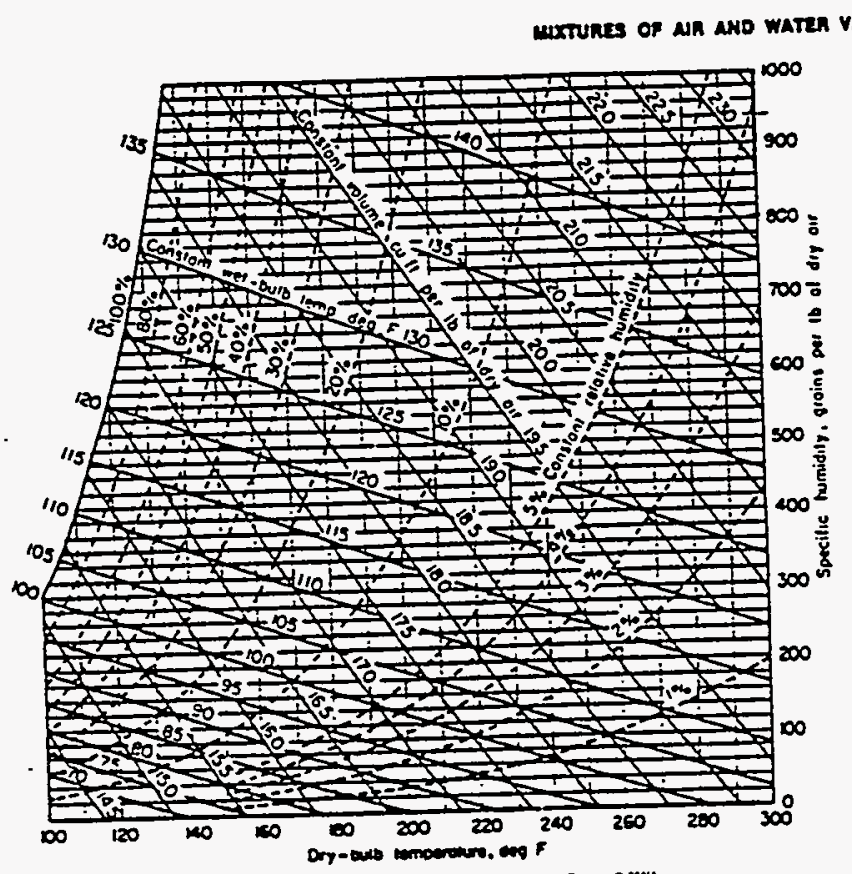

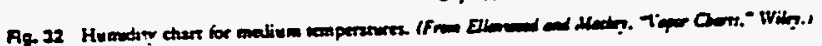

$135.6{ }^{\circ} \mathrm{F}$ and $100 \%$ humidity, specific humidity $=\frac{940 \text { gavianthe }}{16 \text { dry air }}$ This elout is based on a total pressure of 14.696 psid This is not
correct (prescure $=14.09$ psi) but using 14.696 psi should not introduce large errors.

$\rho_{\text {air }}=14.696-2.601=12.095 \rho \mathrm{si}\left(\begin{array}{c}144 \mathrm{in}^{2} \\ \mathrm{ft}^{2}\end{array}\right)=1741.7 \frac{\mathrm{lb}}{\mathrm{ft}^{2}}$

PV- NRuT $\quad R_{n}=1545$ F+ $\| / / b-m a=R \quad R_{e} f 1, P g 25$

$N=\frac{P V}{R_{a} T}=\frac{\left(1741.7 \frac{16}{f t^{2}}\right) 308.2 . \mathrm{ft}^{3}}{1545 \frac{\mathrm{b}}{16-m-l_{e} \cdot R}(135.6+460)^{\circ} \mathrm{R}}=0.5833 \mathrm{lb}$-mode 


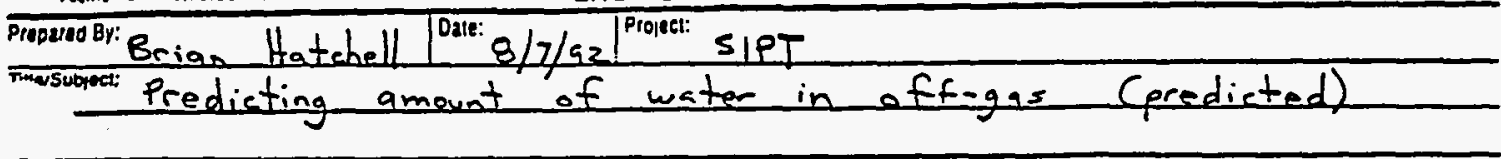

.. M-lar. Hass of water $=28.97 \frac{\mathrm{bb}}{\mathrm{b}-\text { le }} \quad R_{e} f$ 1, ig 842

Mass of air $=(0.5333 \mathrm{lb}$-mole $) 28.97 \frac{\mathrm{lb}}{16-m l_{c}}=16.90 \mathrm{lb}$ dry air

Mass of water $=\left(\frac{940 \text { grains } H_{2} O}{1 b_{\text {dry air }}}\right)(16.9 \mathrm{lb}$ dy air $)\left(\frac{1 b}{7000 \text { grain. }}\right)=227 \mathrm{bb}$

Volume of process water $=(2.27 \mathrm{Lb})\left(\frac{0.0162712^{3}}{231}\right)=0.276 \mathrm{GPM}$
per minute

$\Rightarrow$ All three methods give comparable results 


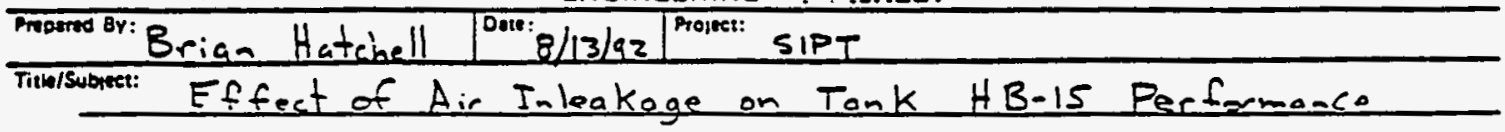

Purpose- Determina the amout of heat required to ineat the offgas from ambient conditions to the condensen tempenturs.

Est easis

- TST029. 11:13- 11:43 Averaye off-gas oir flow $=308.16$ min (ACFM) assume this is all air

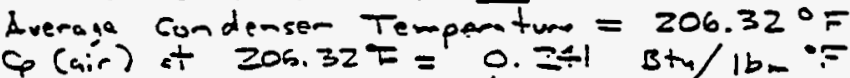
Average offesas Tempersturo $=13 \% 5.64$ of Average condeaser pressure $=14.09$ psij

Caloulate mass flow of air $a$ off-jas isinglition=:

$$
\begin{aligned}
& P_{\gamma}=\frac{R_{4} T}{M} \quad R_{e}=1 \text {, } \rho_{g} 25 \\
& M=28.97 \mathrm{lb}-/ 1 b_{0}-m_{0} 10 \quad R_{e}=1, p_{j} H-z
\end{aligned}
$$

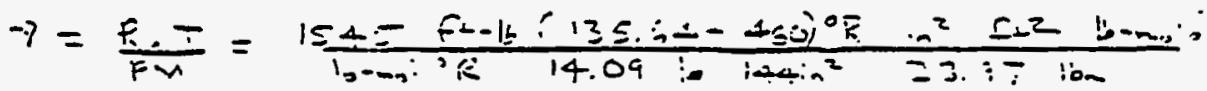

$$
\begin{aligned}
& =15.66=2 / 10 \\
& \dot{m}=\frac{309.16(\mathrm{ct} / \mathrm{mm})}{15.66\left(\mathrm{Ft}^{3} / \mathrm{b}\right.}=19.6 \mathrm{~s} \mathrm{lb} / \mathrm{min}
\end{aligned}
$$

Culculate heat requjerd to raise temperature $f$ gir Fror amoup-

to condenser temperntore. Adsume Anbies Temp $=80^{\circ} \mathrm{F}$.

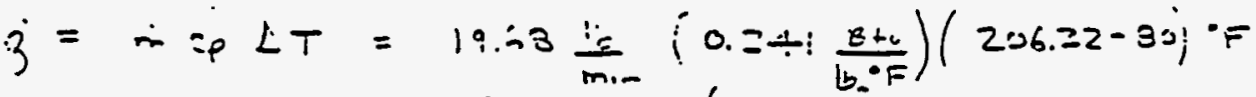

$$
\begin{aligned}
& \text { = 50,9i Btu/min }
\end{aligned}
$$

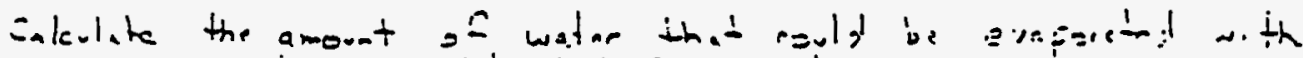

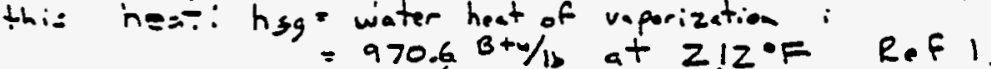

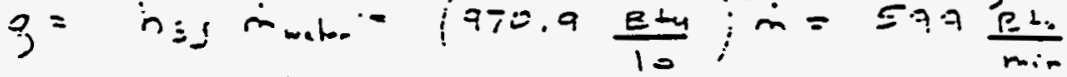

$$
\begin{aligned}
& \dot{m}=0.617 \mathrm{~b} / \mathrm{min} \text { Need to convest to volum. } c_{1 / 00}=\dot{V}
\end{aligned}
$$

Not. specific heat of water, $7=0.0167 \mathrm{f}+3 / 1=$

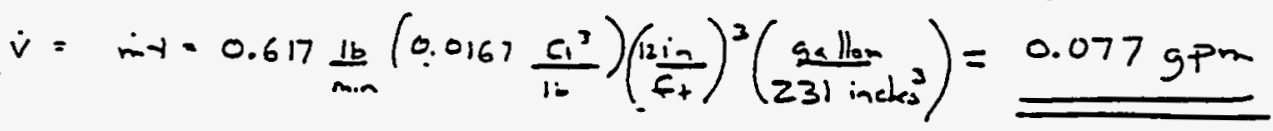


1) Wark, K., Themodiynamies 30d Edirion, Mcgraw-Hill Book Company, New York, 1977.

2) Lienhard, J.H. A.Hent Transfer Texibook, Prentice-Hall, Inc, New Jersey, 1981.

3) Holman, J.P., Heat Tmnsfer 3rd Edition, Megraw-Hill Book Company, New York, 1972.

4) Welty, J.R., Wicks, C.E, and Wilson, R.E. Eundamentals of Momenum. Heat.and.Mass Iransfer 2nd Edition, John Wiley and Sons, New York, Weliy, 1976.

5) Kern, D.Q. Brocess Hear Tmnsfer, Mcgraw-Hill Book Company, New York, 1950.

6) Rohsenow, W.M. and Harnett, J.P., A Handbook of Heal Transfer Mcgraw-Hill Book Company, New York, 1973.

7) Flour Daniel Preliminary Calculations for Hanford Waste Vitrification Plant - Feed Receipt. Feed Preparation, Radioactive Waste Collection and Treament, Melter Feed Calculations. Calculation 3210-MF-0013.

8.) PSE. Inc., Flow sensors Handbook, Flow Caleulations File No. $382-2$.

9) Slurry Integrated Performance Calculation CPD-01: sIPT Condenser Shell-side Pressure Drop. Performed by Pacific Norttwest Laboratory December 13, 1991.

10) Baumeixter, $T$ ot. al., Marks standard Hond book Es Mechamieal Engineer, $8 \pm$ Edition. MaGean Hill, New York, 1978. 
CALC-SIPT-009, REV. 1 PAGE 1 OF 38

\title{
Design Calculations \\ CALC-SIPT-009, Rev. 1
}

\author{
For \\ Slurry-Integrated Performance Testing \\ $2 / 16 / 93$
}

Data Conversion Methods

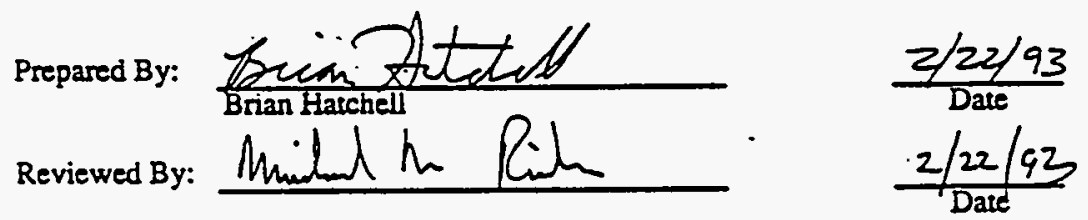

L. 14 
Index to Calcularions

1.0 Introduction

2.0 DAS Raw Data File used for Spreadsheet Verificarion

3.0 Heat Transfer Spreadsheet Results

4.0 Heat Transfer Spreadsheet Formulas

5.0 Formulas in Raw Data File

6.0 Evaporator and Condenser Heat Transfer Spreadsheet Verification

7.0 References.

1.e incroduction

This calculations provides verification of the spreadsheets used to report and summarize SIPT Heat Transfer quantities and calculation results. Included herein is an example raw data file, the spreadsheet results, spreadsheet formula printout, and formula verification. For each formula, a separate hand calculation is performed and the result is checked against the spreadsheet.

Note that three formulas are imbedded in the raw data spreadsheet, while the rest are contained in heat transfer summary spreadsheets. 
20 DAS Raw Data File used for spreadsheet Verification

The fllowing Microsoft Excel sprendsheet contains date in

the seme formet as the raw date. File. It is used only

for spreadsheet verification

\begin{tabular}{|c|c|c|c|c|c|c|c|c|}
\hline & 1 & $z$ & 3 & 4 & 5 & 6 & 7 & 8 \\
\hline & $\bar{A}$ & B & c & D & $E$ & $F$ & G & $\mathrm{H}$ \\
\hline 1 & timel & EI-1000 & $\overline{F I}-901$ & FI-1001 & FI-1003 & $\overline{F l}-1102$ & FI-1103 & $4-1000$ \\
\hline 2 & $12 / 18 / 9212: 40$ & 259.43 & 9.88 & 4910.94 & 0.04 & 356.17 & 452.05 & 34.71 \\
\hline 3 & $12 / 18 / 9212: 40$ & 259.46 & 7.82 & 4910.27 & 0.04 & 354.44 & 251.99 & 34.86 \\
\hline
\end{tabular}

\begin{tabular}{|c|c|c|c|c|c|c|c|c|}
\multicolumn{2}{c}{9} & 10 & \multicolumn{1}{c}{11} & 12 & 13 & 14 & 15 & 16 \\
\hline & 1 & $J$ & $K$ & $L$ & $M$ & $N$ & 0 & $P$ \\
\hline 1 & LI-1400 & PDI-1002 & PDI-1003 & PDI-1005 & PI-1001 & PI-1004 & PI-1021 & PI- 1022 \\
\hline 2 & -7.24 & 82.32 & 63.66 & 109.16 & 76.56 & 0.48 & 114.32 & 65.6 \\
\hline 3 & -3.02 & 82.31 & 63.655 & 108.36 & 76.62 & -0.71 & 114.32 & 65.62 \\
\hline
\end{tabular}

\begin{tabular}{|c|c|c|c|c|c|c|c|c|}
\hline & 17 & 18 & 19 & 20 & 21 & 22 & 23 & 24 \\
\hline & a & R & $\mathbf{S}$ & $T$ & U & $\mathbf{v}$ & $w$ & $x$ \\
\hline 1 & PI--1023 & $P I-1024$ & PI-1025 & PI-1101 & PI-1102 & PI-1103 & $51-1000$ & $I I-1031$ \\
\hline 2 & 53.28 & 5.42 & 5.92 & 28.45 & 23.35 & -8.66 & 84.88 & 65.8 \\
\hline$\overline{3}$ & 53.47 & 5.35 & 5.82 & 28.77 & 23.67 & -10.39 & 84.86 & 65.88 \\
\hline
\end{tabular}

\begin{tabular}{|c|c|c|c|c|c|c|c|c|}
\multicolumn{2}{c}{25} & 26 & 27 & 28 & 29 & 30 & 31 & 32 \\
\hline & $Y$ & $Z$ & AA & AB & AC & AD & AE & AF \\
\hline 1 & $\mathrm{TI}-1032$ & $\mathrm{TI}-1041$ & $\mathrm{TI}-1042$ & $\mathrm{TI}-1043$ & $\mathrm{TI}-1044$ & $\mathrm{~T}-1045$ & $\mathrm{TI}-1046$ & $\mathrm{TI}-1047$ \\
\hline 2 & 60.24 & 94.79 & 95.75 & 98.62 & 99.31 & 99.27 & 99.63 & 174.44 \\
\hline 3 & 59.71 & 95.28 & 96.04 & 98.6 & 99.26 & 99.26 & 99.61 & 174.44 \\
\hline
\end{tabular}

$\begin{array}{llllllll}33 & 34 & 35 & 36 & 37 & 28 & 39 & 40\end{array}$

\begin{tabular}{|c|c|c|c|c|c|c|c|c|}
\hline & AG & AH & Al & AJ & AK & AL & AM & AN \\
\hline 1 & $T 1-1052$ & $T I-1053$ & TI-1101 & TI-1102 & TI-1103 & TI-1104 & TI- 1105 & WI- 900 \\
\hline 2 & 100.85 & 102.51 & 96.46 & 44.43 & 46.34 & 26.27 & 53.05 & 164.75 \\
\hline 3 & 100.85 & 102.51 & 96.77 & 43.95 & 45.81 & 25.92 & 54.76 & 164.75 \\
\hline
\end{tabular}




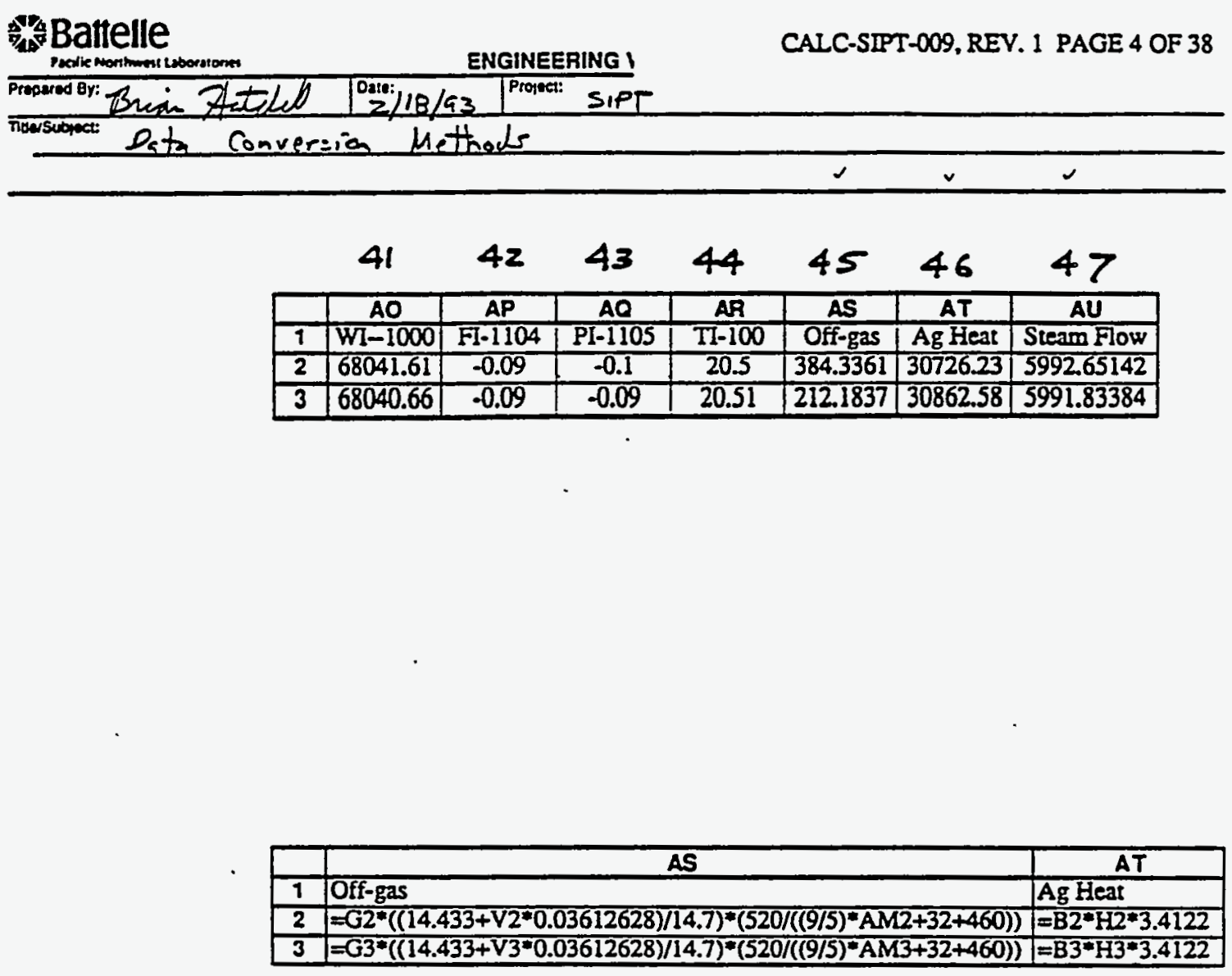

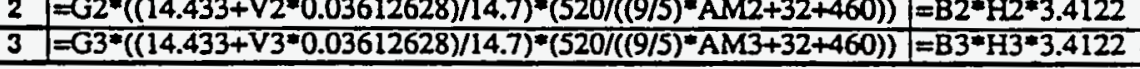

\begin{tabular}{|l|l|}
\hline & \multicolumn{1}{|c|}{ AU } \\
\hline 1 & Steam Flow \\
\hline 2 & $=\mathrm{D2} 2^{*}\left(4.26 /\left(-0.0273^{*}(02+14.433)+7.006\right)\right)$ \\
\hline 3 & $=\mathrm{D} 3^{*}\left(4.26 /\left(-0.0273^{*}(03+14.433)+7.006\right)\right)$ \\
\hline
\end{tabular}


CALC-SIPT-009, REV. 1 PÁGE 5 OF $38^{\circ}$

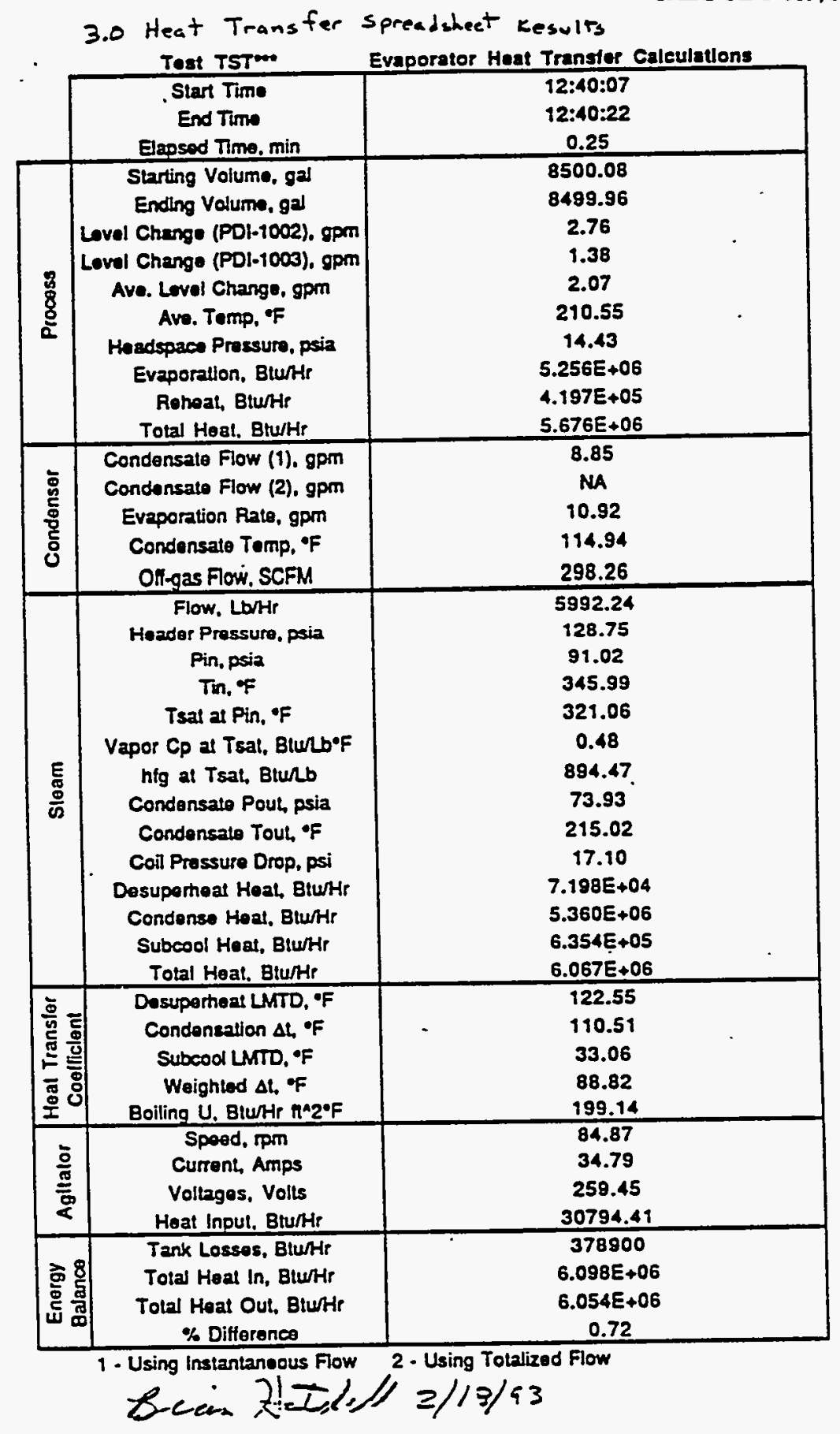


CALC-SIPT-009, REV. 1 PAGE 6 OF 38

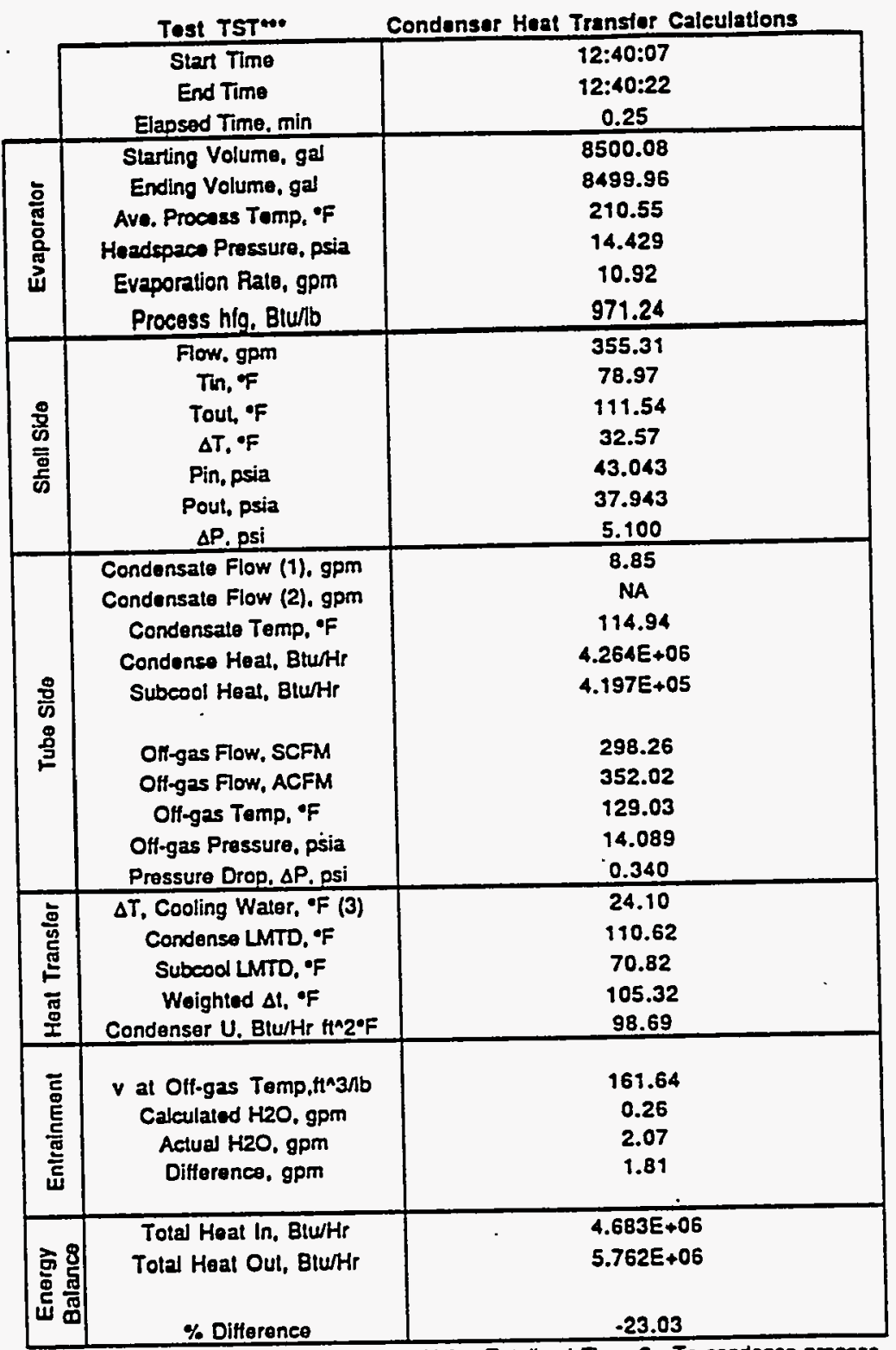

1 - Using Instantaneous Flow 2 - Using Totalized Flow 3 - To condense process

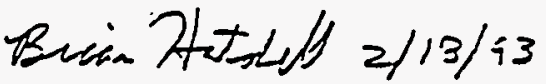


CALC-SIPT-009, REV. 1 PAGE T OF 38

Names:

FPP 14.43

BS 69.00

Density of water, per Wark. Thamodynamies, 3rd Edition, Megraw-Hill

Book Company. Now York. 1977, po. 858

\begin{tabular}{|c|c|c|c|}
\hline Temp. $0 \mathrm{~F}$ & $\begin{array}{c}\text { Spec Vol. } \\
\text { IIA3/lb }\end{array}$ & $\begin{array}{c}\text { Density } \\
\text { lb/ftA3 }\end{array}$ & $\begin{array}{c}\text { Density } \\
\text { lb/gal }\end{array}$ \\
\hline 50 & 0.01602 & 62.42 & 8.345 \\
55 & 0.01603 & 62.38 & 8.339 \\
60 & 0.01604 & 62.34 & 8.334 \\
65 & 0.01604 & 62.34 & 8.334 \\
70 & 0.01605 & 62.31 & 8.329 \\
75 & 0.01606 & 62.27 & 8.324 \\
80 & 0.01607 & 62.23 & 8.319 \\
85 & 0.01609 & 62.15 & 8.308 \\
90 & 0.0161 & 62.11 & 8.303 \\
155 & 0.01611 & 62.07 & 8.298 \\
100 & 0.01613 & 62.00 & 8.288 \\
1.10 & 0.01617 & 61.84 & 8.267 \\
120 & 0.01621 & 61.69 & 8.247 \\
130 & 0.01625 & 61.54 & 8.226 \\
140 & 0.01629 & 61.39 & 8.206 \\
150 & 0.01634 & 61.20 & 8.181 \\
160 & 0.0164 & 60.98 & 8.151 \\
170 & 0.01645 & 60.79 & 8.126 \\
180 & 0.01651 & 60.57 & 8.097 \\
190 & 0.01657 & 60.35 & 8.068 \\
200 & 0.01663 & 60.13 & 8.039 \\
210 & 0.0167 & 59.88 & 8.005 \\
212 & 0.01672 & 59.81 & 7.995 \\
220 & 0.01677 & 59.63 & 7.971 \\
\hline
\end{tabular}

Bsin Aitdll 2/19/93 


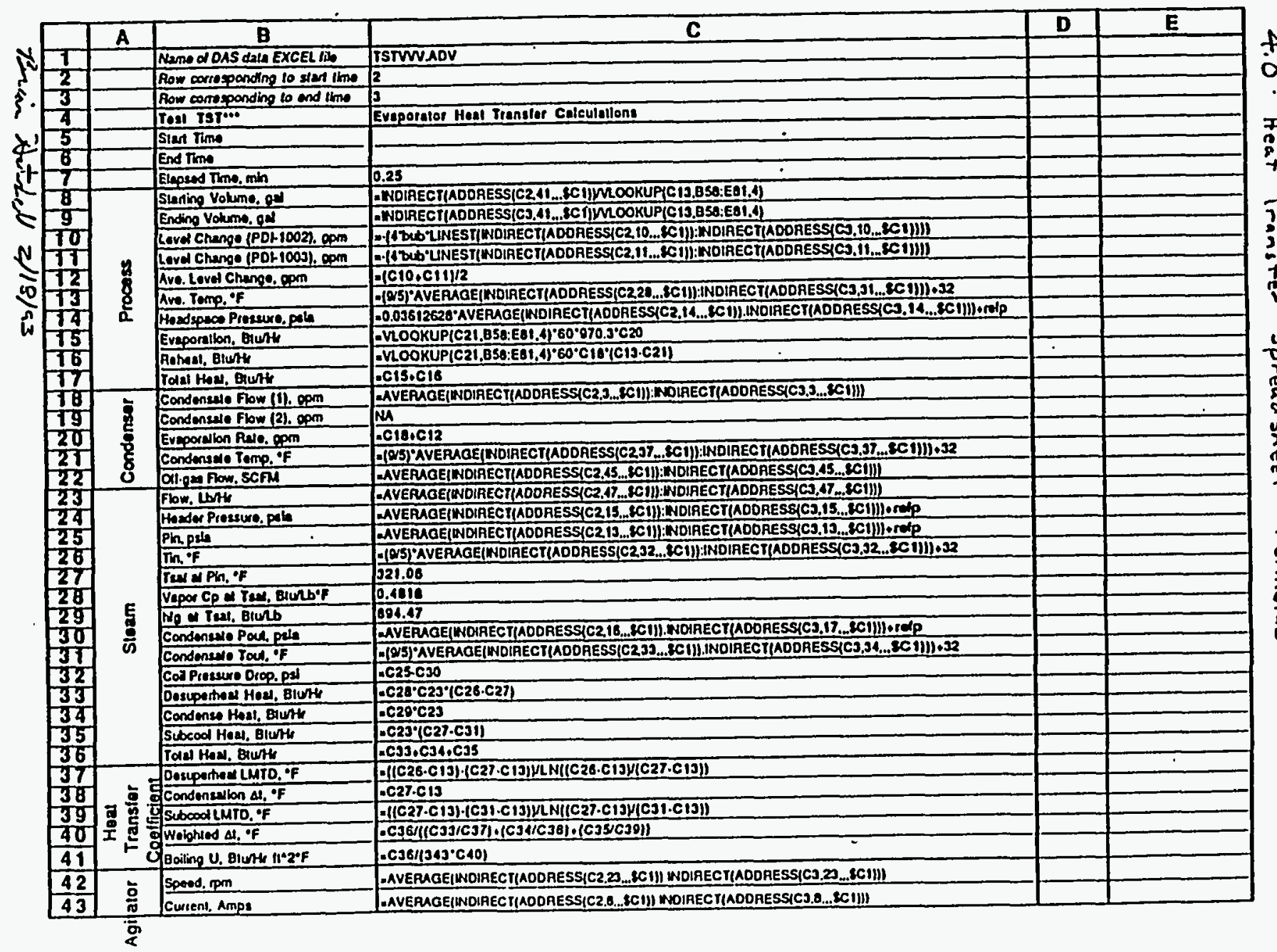




\begin{tabular}{|c|c|c|c|c|c|}
\hline & E- & B & C & D & E \\
\hline & 蓉 & Vothegen, Voht & 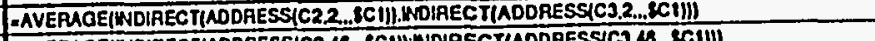 & & \\
\hline$\frac{45}{46}$ & ๔ & How hout Bilute & 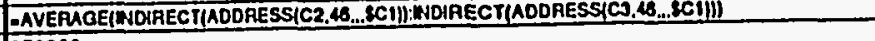 & & \\
\hline$\frac{46}{47}$ & 8 & Tent Loson, Blunth & 376900 & & \\
\hline $\begin{array}{l}47 \\
48\end{array}$ & 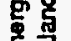 & 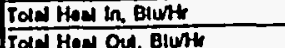 & $\frac{. C 38+C 45}{. C 17 . C 48}$ & - & \\
\hline$\frac{40}{49}$ & & $\begin{array}{l}\text { Tow How Oad, Blust } \\
x \text { Ditherences }\end{array}$ & $.100^{\circ}(C 47.048) / C 47$ & & \\
\hline 50 & & 1. Uthe haliententedur from & 2. Usho Tolellized Fow & & \\
\hline & & Hamen: & 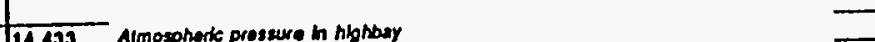 & & \\
\hline $\begin{array}{l}52 \\
53\end{array}$ & & $\frac{189}{180}$ & 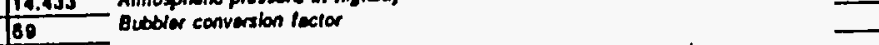 & 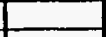 & \\
\hline & & & & & \\
\hline$\frac{55}{56}$ & & & & Densiliy & Densulity \\
\hline$\frac{56}{57}$ & & & Spect. Vo. & $18 / 11+3$ & $\mid 10 \mathrm{pal}$ \\
\hline $\begin{array}{l}57 \\
58 \\
\end{array}$ & & Tomp. of & $\frac{110310}{0.01602}$ & $=1 / 1051$ & $-050 \cdot 2311\left(12^{*} \cdot 3\right)$ \\
\hline$\frac{58}{59}$ & & $\frac{50}{35}$ & $\frac{0.01603}{0.0160}$ & $-1 / 1050$ & 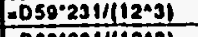 \\
\hline 60 & & 60 & 0.01604 & $\frac{-11060}{.1081}$ & 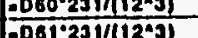 \\
\hline & & Bs & 0.01604 & .11608 & 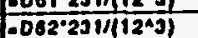 \\
\hline 62 & & 10 & 0.01605 & ICGs & 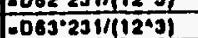 \\
\hline & & 73 & $\begin{array}{ll}0.01808 \\
0.08\end{array}$ & $=0,1004$ & $\frac{0}{.06\left(231 / 12^{4} 3\right)}$ \\
\hline 64 & & 10 & 0.01607 & actos & 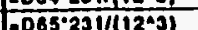 \\
\hline 65 & & B5 & 00.01800 & & 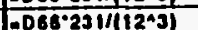 \\
\hline 66 & & 100 & 然161 & -11667 & $-087^{2} 231 /\left(12^{*} \cdot 3\right)$ \\
\hline 67 & & los & 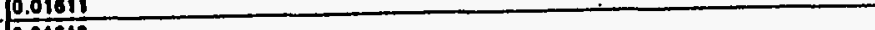 & -1/C86 & $=080^{\circ} 231 /\left(12^{\wedge} 0\right)$ \\
\hline 68$]$ & & 100 & 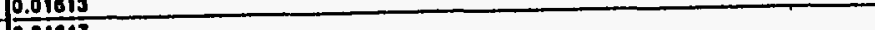 & $-1 / C 89$ & $.080^{2} 231 /\left(12^{\circ} 3\right)$ \\
\hline 69 & & 1110 & 然. & -11670 & $\left.-070.231 /\left[12^{4}\right]\right\}$ \\
\hline 70 & & 120 & 年 & 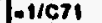 & $-071 \cdot 231 /(1249)$ \\
\hline 71 & & 1000 & (1.01690 & $-1 / 672$ & $-072^{\prime} 231 /\left(12^{\wedge} \cdot\right)$ \\
\hline $\mathbf{2} \mathbf{2}$ & & $\frac{140}{100}$ & to.01634 & $.1 / 1 / 673$ & $-0.073^{\prime} \cdot 231 /\left[12^{\circ} 3\right)$ \\
\hline 73 & & 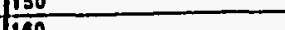 & 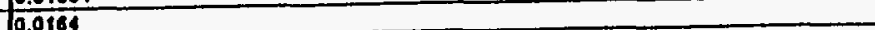 & $-1 / 1 / 674$ & {$\left[-074 \cdot 2311\left(12^{\wedge} 3\right)\right.$} \\
\hline$\frac{14}{75}$ & & $\frac{100}{170}$ & 101845 & $-1 / 1075$ & 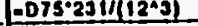 \\
\hline 76 & & (1) & 0.01651 & $=1 / 1078$ & $\left.-0070^{-23}\left(1 / 12^{*}\right]\right)$ \\
\hline 77 & & 100 & 0.01657 & |ll/677 & $=0777^{2}(23)\left(122^{*} 9\right)$ \\
\hline 4 & & $\frac{100}{200}+2>3$ & 0.01860 & Inen & $=070 \cdot 231 /\left(12^{3} \cdot 3\right)$ \\
\hline 79 & & $\frac{10}{210}$ & 0.0167 & Plores & $=070.231[1[12 \cdot 3]$ \\
\hline 8ण & & $\frac{12}{312}$ & 0.01672 & 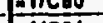 & \\
\hline 81 & & 220 & 0.01677 & & 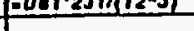 \\
\hline 82 & & & & 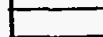 & \\
\hline$\frac{83}{84}$ & & Densily of waler, per & 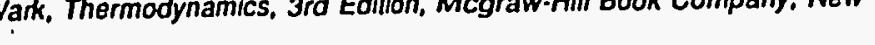 & E & \\
\hline 85 & & York, 197/, pg. 858 & & & \\
\hline
\end{tabular}


CALC-SIPT-009, REV. 1 PAGE 10 OF 38

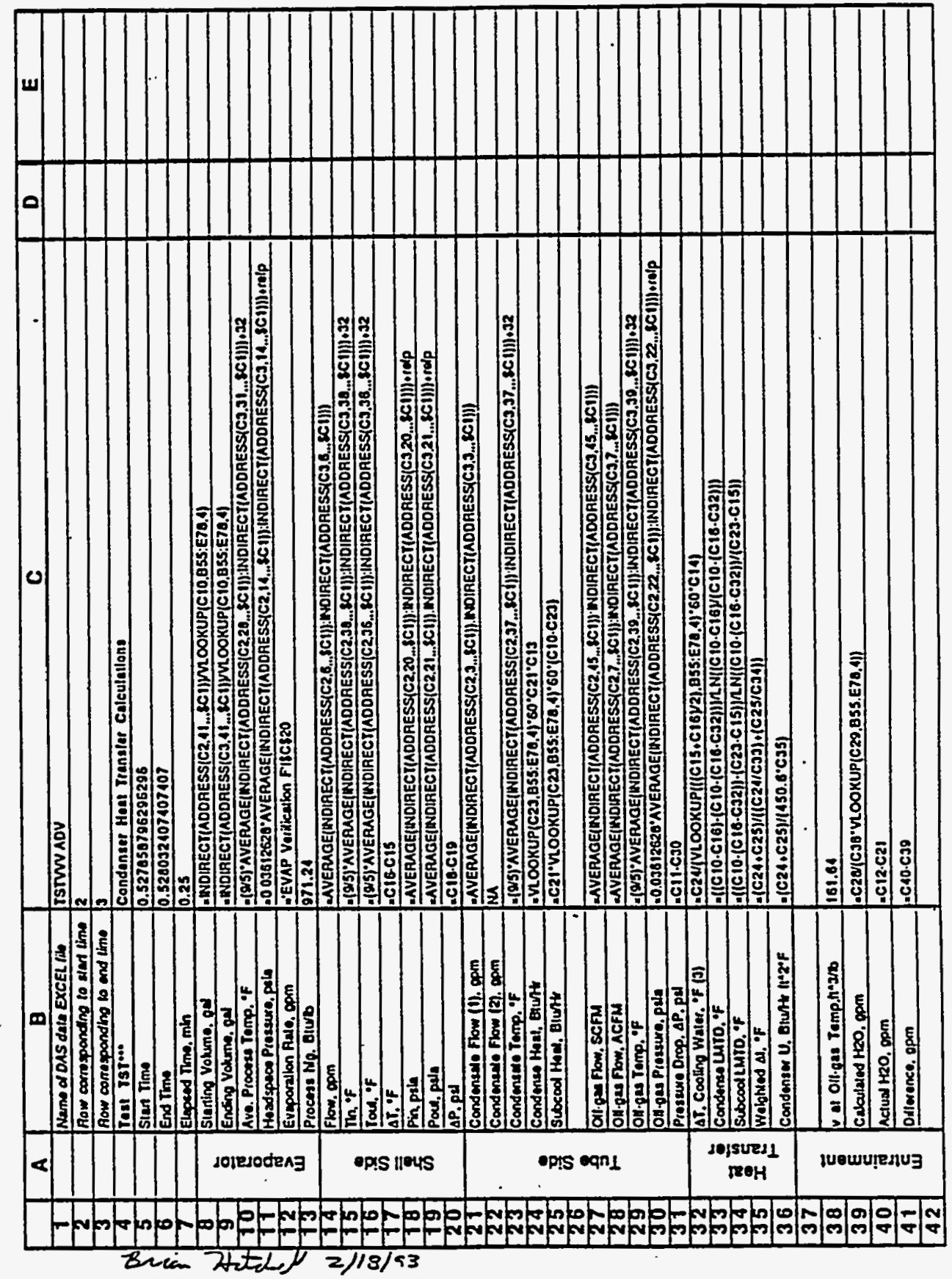




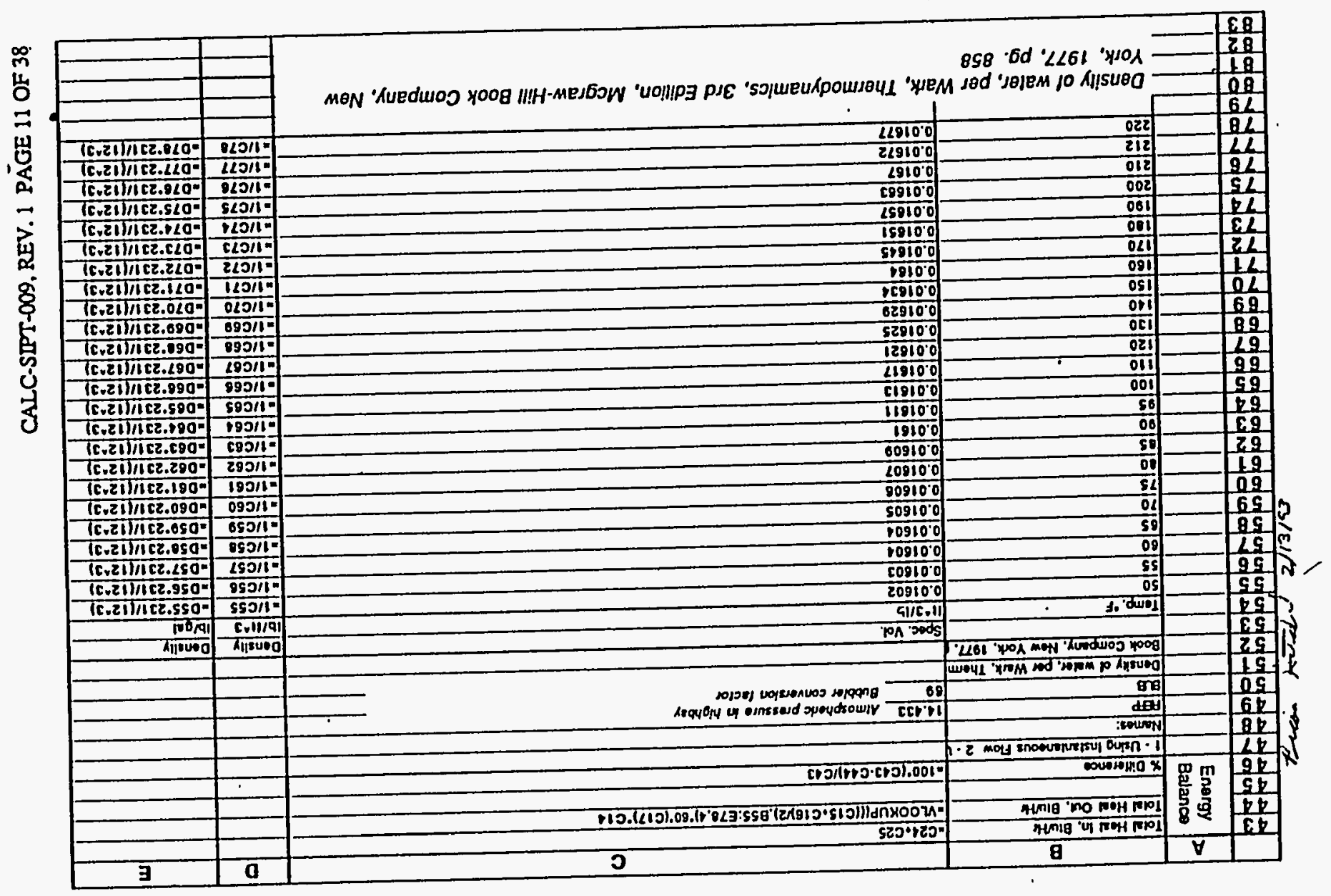




\subsection{Formulas in Raw Data. File Throe formulas are imbedded in} calculations: steam flow, offegas flow, and csitator heat input. These quantities are described below.

\section{Steam. Alw Conversion}

Description: - - .....

The flow meter used to measure the steam flow through E-1001/E-1002 coils of HB-15 (FT-1001 per Ref. 2) is a Fischer Porter Flow meter. It was calibrated to read in $1 b / h r$ at 33$)^{\circ} \mathrm{F}$ saturated steam (Ref. i). $\left.a^{\circ} \quad T=331^{\circ} \mathrm{F}, \quad \begin{array}{rl}P & =104.49 \mathrm{psiq} \\ \gamma & =4.2600 \mathrm{ft} / \mathrm{b}\end{array}\right\} \operatorname{Ref} 3, \mathrm{pg} 859$

If the stam enters the coils at a differso-i pressure, the flow meter reading will have to be adjustei, since the density of the stearn will be different. The flowmeter actually mecsures volumetric flow, rotmass flow.

$$
\text { Volumetric Flow } \begin{aligned}
& \dot{m} \nu \\
\dot{m} & =\text { mass flow } \\
r & =\text { specific volume }=1 / \rho
\end{aligned}
$$


Wusuover Data Conversion Methods

Procedure: 1) Determine pressure of incoming steam. (PI-1021)

This pressure is upsteam of flow meter per

Ref 4. Pressure is "gage"; add 14.433 Fi to

obts in stewn pressure in psia.

2) Determine the specific volume of steam ai

PI-1021 (psia) using Ref 3 (or other steam tables):

vactual in $\mathrm{ft}^{-3} / \mathrm{lb}$

3) Obtain actual stean flow as follow

$F I-1001$ = measured steur flow $(\mathrm{b} / \mathrm{hr})$

volumetric flow $\dot{v}=(F I-1001)\left(4.26 \frac{\mathrm{c}_{+}^{3}}{1 b}\right)$

$=4.26(\mathrm{FI-1001}) \frac{\mathrm{c}^{3}}{\mathrm{hr}}$

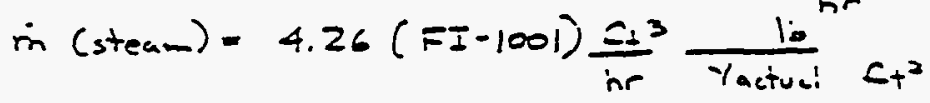

$$
=\frac{\Delta .26}{\text { Yaciua: }}==-100 i
$$

To fasilitain spreasesincet calalations, it was desirable

to automate the process by creating equations for

vactual vs. saturation pressure:

$$
\begin{aligned}
& \nu_{\text {actual }}=m p+b \quad m=\text { slope } \\
& \begin{array}{l}
P=\text { saturation pressur } \\
b=y \text { interespt }
\end{array}
\end{aligned}
$$

$p=120-130$ psia:

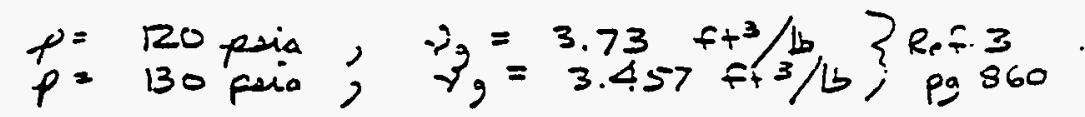

$m=$ slope $=\frac{3.457-3.73}{10}=-0.0273$

solve for b using data at 120 psin

$3.73=-0.0273(120)+b \Rightarrow b=7.006$

$\gamma_{\text {nctu. }}=-0.0273 p+7.006 ; p=120-130 \mathrm{poir}$ 


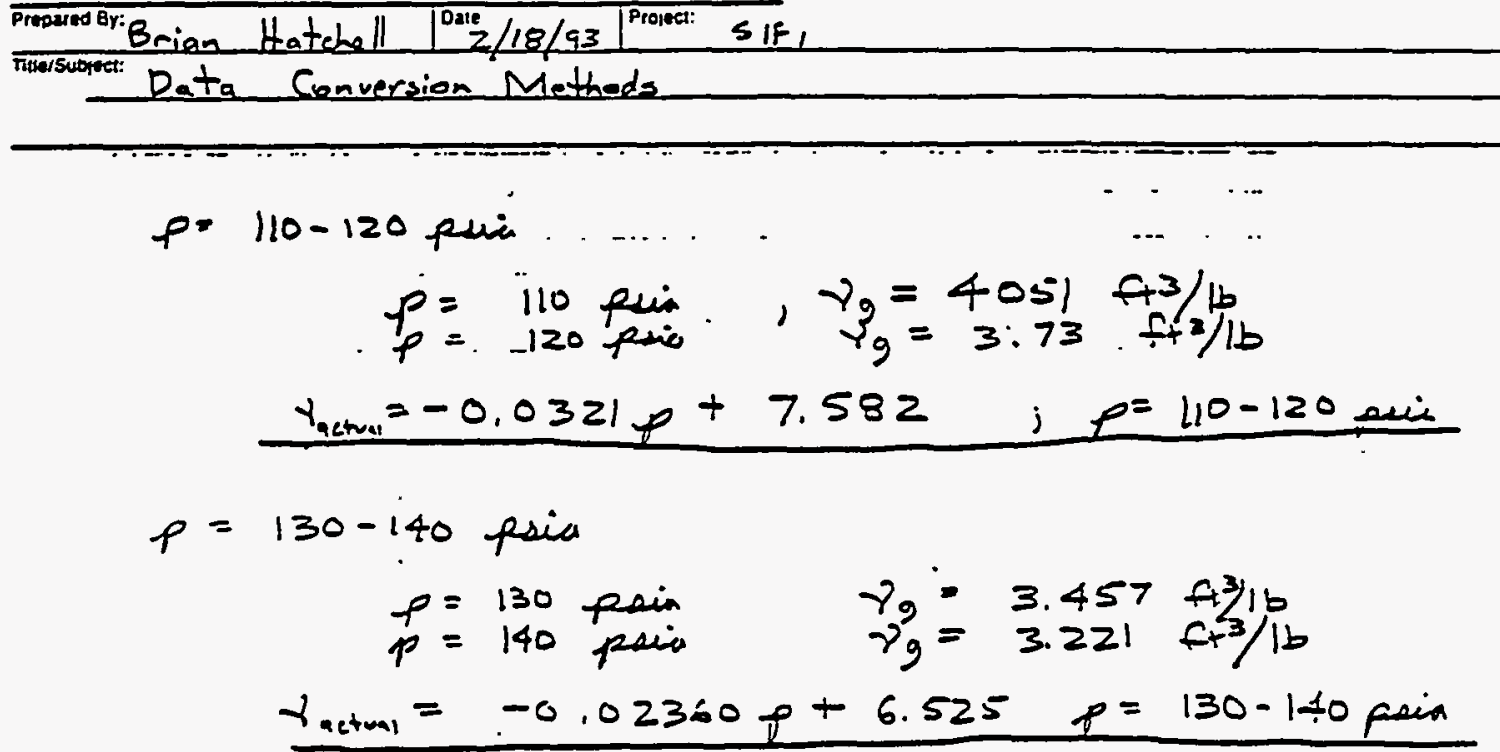

Verification: 1) Pressure of incoming stean= PI--1021 + 14.433 $=114.32+14433$

2) Since stem pressum is less than 130 and greater then 120 psia, used

$\gamma=-0.0273+7.006$ $=-0.0273(123.75)+7.006=3.4911 \frac{\mathrm{bb}}{\mathrm{f}^{3}}$

3) $\dot{m}=\left(\frac{4.26}{3.4911}\right) \mathrm{FI}-1001$ verify ist data point:

$\dot{m}=\frac{4.26}{3.4911}(4910.94)=5992.6 \frac{\mathrm{lb}}{\mathrm{h}}$ 
OEfogas Elou Conversion

Pescription: - . . . ..........

The following is the conversion used to convert differential pressure, obtaind using a pitot tube, to the rolumetris

flou rate of of $f-g a s$

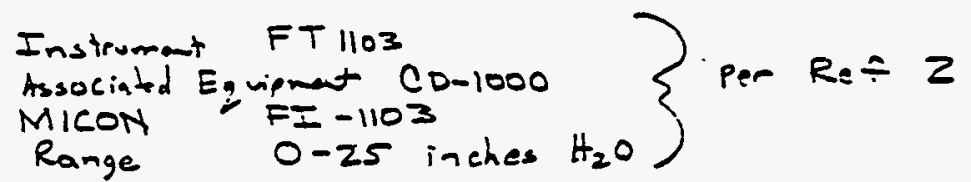

Air Yolume Flow Rate, $Q$, is derised as follows:

$$
\begin{aligned}
& y(\text { in SCFM })=K N D^{2} \sqrt{\frac{A_{0}}{A_{T}}} . \quad R_{e}=5, p_{3} 3 \\
& Q=y \cdot \sqrt{\Delta P}
\end{aligned}
$$

$K=$ Flow Coefficient $=0.65$ for a 3 "pipe Ref $5, p y 5$

$H=12 S .52$ (conrursion) tor $\Delta D_{\text {in incies } H_{2} O}=Q$ in SCFM

$D$ - off-gas $P$ ipe $I D=3.07$. inchew Re 6

$A_{p}=$ Absolute Pressurer, psia

$A_{T}=$ Aisolute Temp? OR

$Y=$ Inte-m ediate Result

$\Delta P=$ Pressum Differential of Flow sensor FI-110

$Q=$ Volvmetric ofegas Flov in sCFM

$0=$ gas Pressure $(P \equiv-1103)$ is mensured in inches water To ronvert incles wate to psig".

$P_{g}=P_{g} \Delta Z$

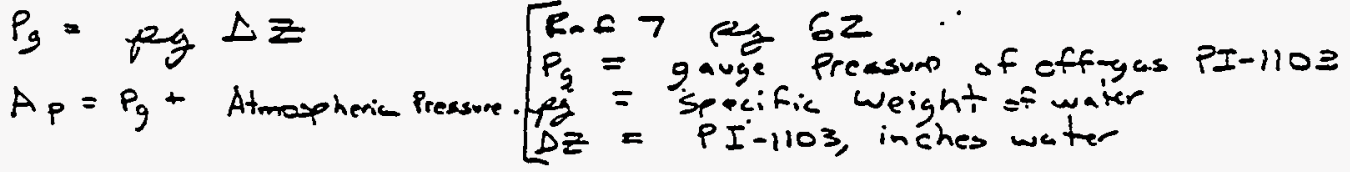

$$
f g(\text { water })=62.4 \mathrm{lb} / \mathrm{ft}^{3} \text { Ref } 7 \text {, fe } 62
$$

Atmospheric Pressure $=14.433$ at sos $t+$ elevetion

(approximately the sime $a=$ high bay) fer fos $=5$ pg:

$\therefore A_{p}=14.433 p$ sia $+62.4 \frac{f_{b}}{f_{t}^{3}}\left(\frac{. f t}{12 \text { in }}\right)^{3} \Delta z$ 
Bantelle

CALC-SIPT-009, REV. 1 PAGE 16 OF 38

Prepaid By:

ENGINEERING

Brian Hatekell [ Date $2 / 18 / 93$ [

Fularsuoneci Data Conversion inethods

$$
\begin{aligned}
& A_{P}=14.433 \mathrm{psi}+0.03611 \cdot(P I-1103) \\
& A_{T}=\text { Absolute Temp of Offgas, TI-1105. since TI-1105 } \\
& \begin{array}{l}
{ }^{\circ} F=\frac{a}{c}{ }^{\circ} C+32 \\
\text { iR }
\end{array} \\
& \therefore \quad A_{T}=\frac{9}{5}(T I-1105)-32+460
\end{aligned}
$$$$
\text { is in }{ }^{\circ} C \text {, we must first convert to }{ }^{\circ} \mathrm{F}, \text { and }
$$

Also, $F=-1103$ read -0.09 inches water, even when there is rio flow. To zens the sensor, a or is a dyed to the flow reading

$$
\begin{aligned}
& Q=K N D^{2} \sqrt{\frac{A_{Q}}{A T}} \sqrt{\Delta P} \\
& =0.65(129.52)(3.07)^{2} \sqrt{\frac{14.433+0.03611(P I-1103)}{\frac{g}{5}(T I-1105)+32+460}} \sqrt{\mathrm{FI11050.09}} \\
& =787.337 \sqrt{\frac{14.433+0.03611(P I-1103)}{\frac{0}{5}(T I-1105)+32+450}} \sqrt{F=1103+0.09} \\
& \text { (in SCFM) }
\end{aligned}
$$

To convert from SCFM to ACFM :

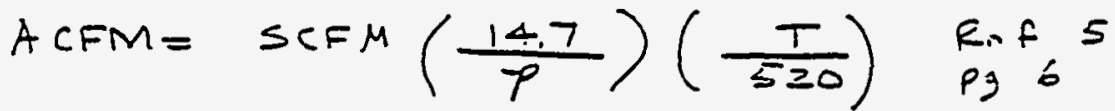

$$
\begin{aligned}
& \begin{array}{l}
P=\text { pacesure, in } P \text { sig } \\
T=\text { tempeatiore, in } O R
\end{array} \\
& \therefore \quad A C E M=\operatorname{SCFM} \cdot\left(\frac{147}{14.43 \cdot 3+0.53611(\cdot 9 \cdot-1103)}\right)\left(\frac{(a / 5) T I 7105-32+460}{520}\right. \text {, }
\end{aligned}
$$

The piton tube flow meter, was recently replaced with a turbine type flow meter, which measured flow in ACFM. In this case, the all conversion required is ACFM $\rightarrow$ SCAM

or in nevers wa

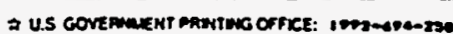

S4togr-tient

L.29 


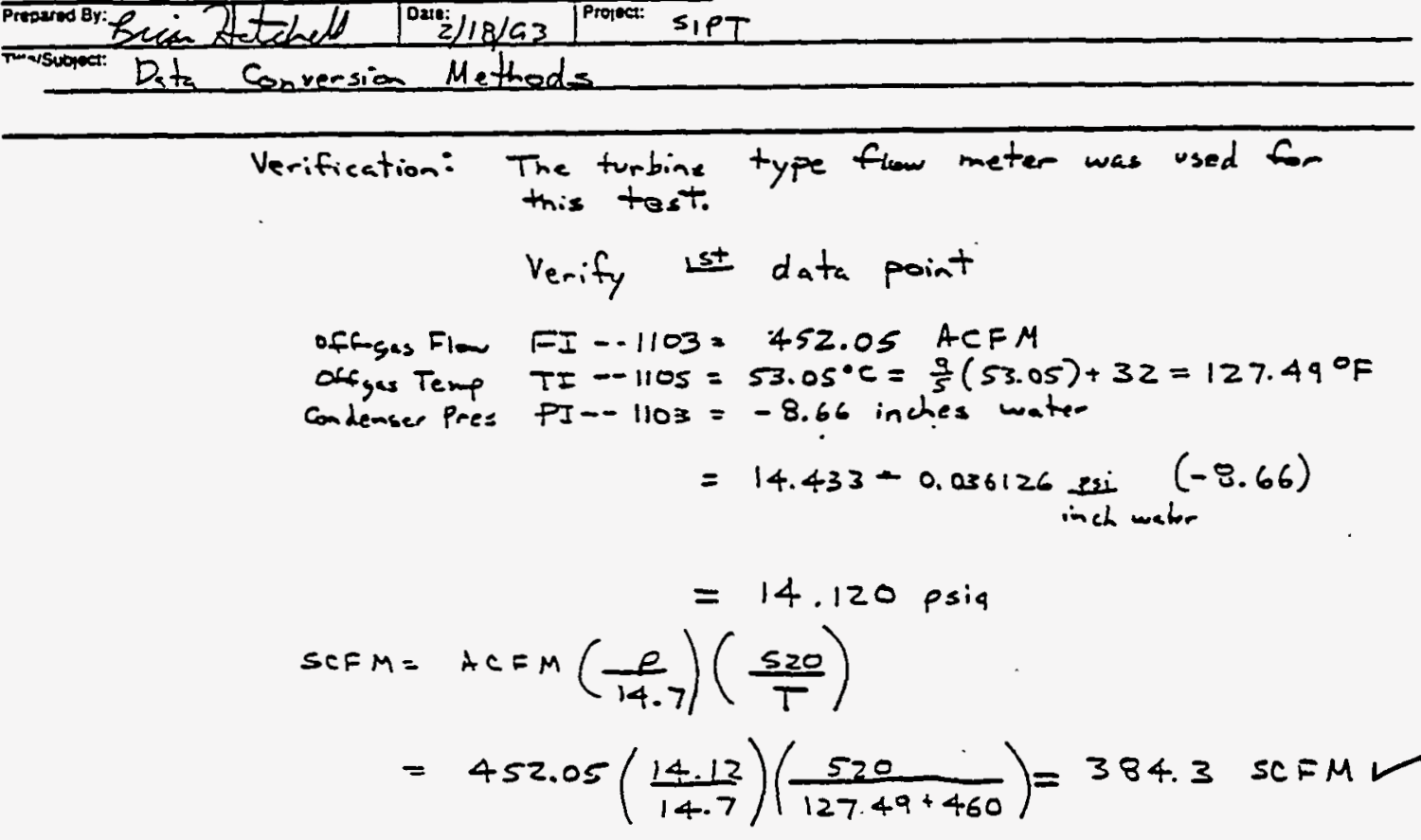

Heat Input by Agitator

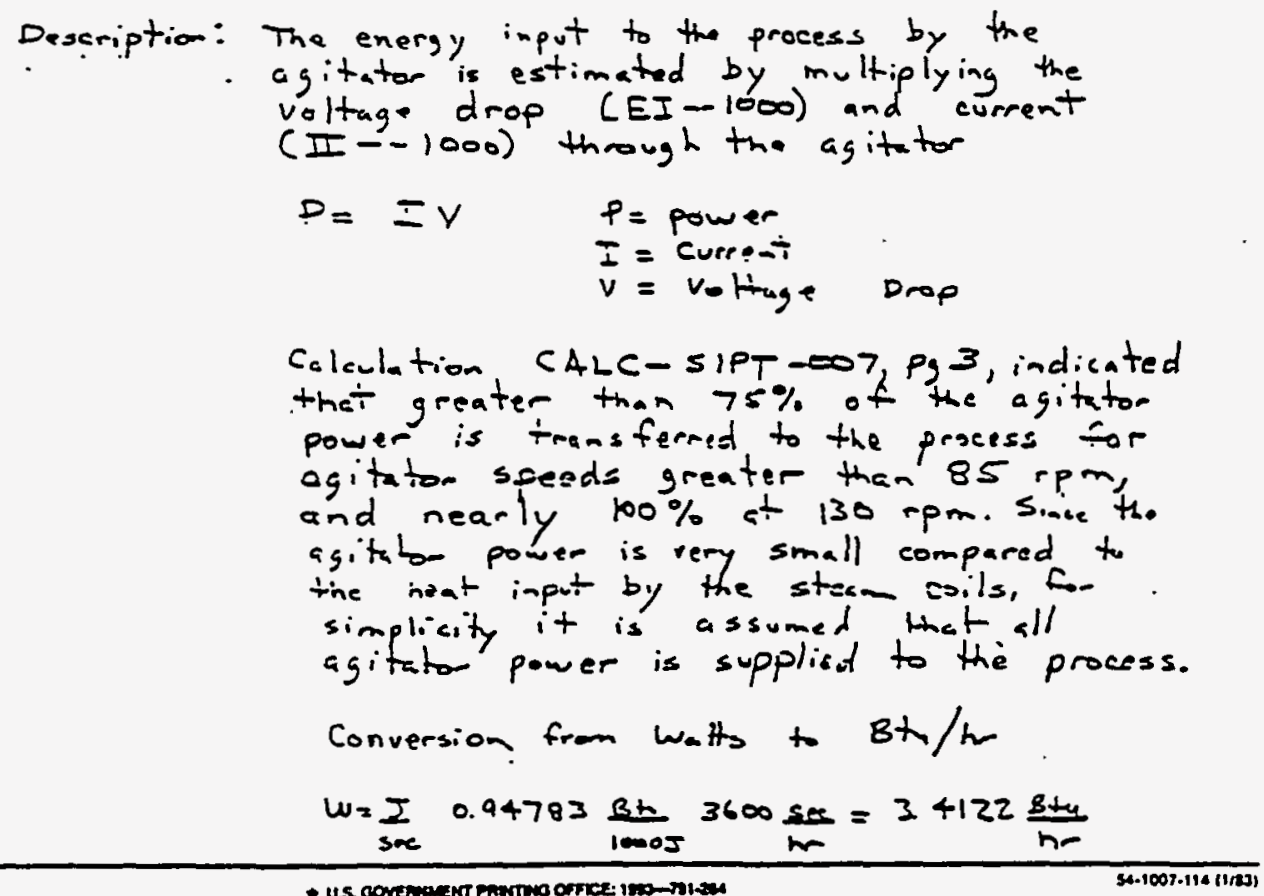




$$
\begin{aligned}
\text { Verification: } & \text { Using } 1 \text { st tata Poiat: } \\
& \text { EI }-1000=259.43 \mathrm{~V} \\
& I I-1000=34.71 \mathrm{~A} \\
& F=\left(3.4122 \frac{\mathrm{Btu} / \mathrm{hr}}{\mathrm{mm}}\right) 259.43 \vee(34.71 \mathrm{~A})=30726 \frac{\mathrm{Bty}}{\mathrm{hr}}
\end{aligned}
$$

6.0 Evaporator and Condenser Heat Tranxfe- Sprodsheet Verification

separate evaporator and condenser porformance spreadsheets were used to extract average proess info-metion from the raw data spresisheots and perform heat transfer, picssure $d r o p$, and energy balance calculations. Each spreadstect. is divided into segments of constant. evaporation rate, where process varicbles are essectially constant.

The spreadshests utilize the INDIRECT and ADDRESS function to access dat from the ruw data file, depending on the cortents of the starting and ending row celle

Also utilized is the VLOOKUP function to determine the density of water at a given temperature. Note that the function areesses the density at the temperatiure esual to cor just below) the given temperature. It does not inte-polate between dat points. 
Evaporator Hect Tramsfer Spreadsheet Verification

Date File The EXCEL file that contains the raw tost data Entered manually

startina Row the row number of the EXCEL raw datia file corresfonding to the start time of this test segment Entered manually

Endina Row The row number of the EXCEL raw data file corresponding to the end time of this test segmeat. Entered manually

sta-t Tix./End Time/Elapsed Time Timo span of this boiling segment determined from

starting Volume/ E-dian Volume Lavoratory record book.

Description: The volume of process liquid in $\mathrm{HB}-15$ is estimated using to weight of the tank, which mas beer calibreted to read 0 lb's for an e-pty tank (WI-1000)

To convert from lbs b gellows, the density of water is found from lookup toble for the average process temperature.

Verification: $\rho\left(\mathrm{H}_{2} \mathrm{O} . \mathrm{at} 210.55^{\circ} \mathrm{F}\right)=8.0048 \mathrm{~b} / \mathrm{gal}$ $W I 1000$ (start) $=68041.61 \mathrm{lb}$
$W \equiv 1000$ (end) $=68040.66 \mathrm{lb}$ starting $v_{\text {olume }}=68041.61 \mathrm{~b}\left(\frac{a_{c} l}{8.0048 \mathrm{bb}}\right)=8500.1 \mathrm{gal}$ Ending Volume $=68040.66 \mathrm{~b}\left(\frac{\mathrm{a.l}}{8.0048 \mathrm{bb}}\right)=8500.0 \mathrm{gal} \mathrm{r}$

Level Chanae (PDI-1002\&PDI-1003)

Description: PDI-100Z and PDI-1003 are used to measure tha process level in HB-15. If the process is wator, then these gouges read in inches of water. 
Volume change based on testing:

ID of $H B-15=12^{\prime} 3 / 4^{\prime \prime}=144.75 \mathrm{in}$

$\Longrightarrow$ Basis: disk of l" height

$v=1+\pi\left(\frac{D}{2}\right)^{2}=\operatorname{lin} \pi\left(\frac{144.75}{2}\right)^{2}=16456: 3$

$v=1645 \frac{5 \mathrm{in}^{3}}{\mathrm{in}}\left(\frac{\mathrm{gal}}{231 \mathrm{in}^{3}}\right)=71.2 \frac{\mathrm{gal}}{\mathrm{in}} \mathrm{H}_{2} \mathrm{O}$

Volume change besed on testing:

The above caleulation ignores pife,
coils, otc inside the tank. To determine inis effect, the change in dejth of the tank due to adding a known volume of water was measured. The level inside the tank was always above the bottom of the coils. The volume of water per inct depth was found to be 69 gal . Thus value is used in bubbler data conversion.

Over each boiling segment, the slope of the bubbler gauge recding vs timp curve was determined by filting a line through the data using the LINEST function. Knowing the chango in slope of the bubbler line, the change in volume per timo is determined.

Verification: Using PDI-100z:

Starting level $=82.32$ inches
Ending level $=82.31$ inches 
Note: data taken every is seconds

$$
\begin{aligned}
\text { slope } & =\frac{(82.32-82.31) \text { inchas } \frac{60 \text { see }}{15 \text { sec }}}{\text { min }} \\
& =0.04 \frac{\text { inches }}{\text { min }}
\end{aligned}
$$

Bubblar conversion factor (an ExCEL parameter called $B \cup B)=69 \mathrm{gal} / \mathrm{in}$

Level Change= $0.04 \frac{\text { in }}{\min } 69 \frac{\mathrm{agl}}{\mathrm{in}}=2.76 \mathrm{gpm}$

Average Level Change

Deseription: The bublle gavges exhibit a small amont of randor fluetuations. To obtain a. more stable result, the level cincinge determined from the two bubbler gauge: are averaged

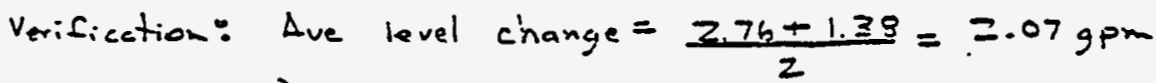
Ave Teme (Process)

Description: $T I-1041$ to $I I 1046$ measure process temperature in HB-15. Depending on the level in the tank, highe- (in elextion) gauges may be above the process ligvid. and are in effect measuring the headspace temperature. The head-pace temperatum is several degrees cooler than the process (avring boiling). To determine the average peoces temperature, oll thermo-well gauges bolow the headspace level are averaged.

Yerificotion: In test spreatshoet, $T=-10+$ \& $T=-1042$ are ebviously above the process, and are not ineluded in the averge.

$$
\begin{aligned}
& \text { To conert from }{ }^{\circ} \mathrm{C} \text { to of, use } \\
& \text { - } F=\frac{9}{5}{ }^{\circ} \mathrm{C}+32 \text { Re } 7, \mathrm{pg} 689
\end{aligned}
$$




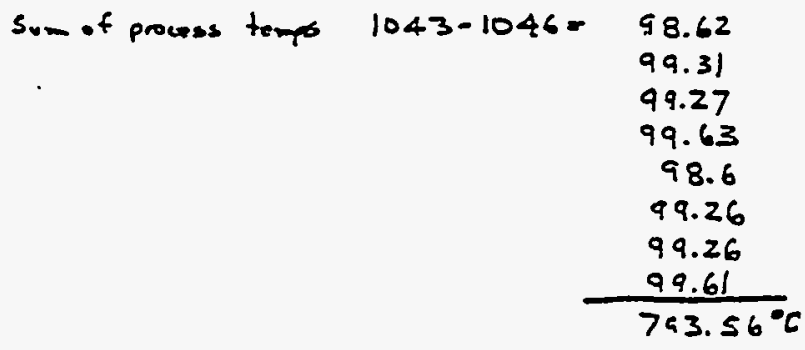

Average process temp $=\frac{0}{5}\left[\frac{7 a 3.56^{\circ} \mathrm{C}}{8}\right]+32=21055^{\circ} \mathrm{F}$

Headspace Pressure

Description: PI-1004 measure gauge pressure inside the tank. This quantity is arerages, and converted to absolute pressure

$\begin{gathered}\text { Verification: Headspace Pressure } \\ \text { (ave) }\end{gathered}=\frac{0.45-0.71}{2}=-0.115$ in water

$$
\begin{aligned}
& P g \quad=\rho g \Delta z \quad \operatorname{Ref} 7, \rho g 62 \\
& P_{g}=\text { gauge peessure } \\
& p g=\text { specific weight }=62.4 \mathrm{lb} / \mathrm{f} 3 \\
& P_{g}=62.4 \frac{\mathrm{lb}}{\mathrm{fr}^{3}}\left(\frac{\mathrm{Et}_{t}}{12 \mathrm{in}}\right)^{3} \Delta \equiv \\
& =0.03611 \Delta z
\end{aligned}
$$

A bsulute pressure in 324 Suilding Highioy

is 14.433 psi. This is named EEFP

in the EXCEL spreadsheet

$$
\begin{aligned}
\text { Headspace Pressure } & =14.433+0.03611(-0.115 \mathrm{in}) \\
& =14.43 \mathrm{psi}
\end{aligned}
$$


Evaporation Heat

Description: The heat required to eveporate the process at the process evaporation rate

$$
Q=h_{s g} \dot{v} \quad \begin{aligned}
h_{s g} & =\text { hat of vaporization } \\
\rho & =\text { density } \\
\nu & =\text { volumetric flow rate }
\end{aligned}
$$

Verification: $\rho$ at a verage condeneretemp $=8.2672 \mathrm{~b} / \mathrm{sal}$

use lookup table and $T_{2} 114.94^{\circ} \mathrm{F}$ conde-sate temp* evaporation rate $=10.92 \mathrm{gpm}$

hFs of water at $212^{\circ} \mathrm{F}=970.3 \frac{\mathrm{Bty}}{16}$ Ref $3 \mathrm{gg} 958$

$Q_{e}=970.3 \frac{\mathrm{Bth}}{\mathrm{bb}} \quad 8.2672 \frac{\mathrm{lb}}{\mathrm{ga} !} 10.92 \frac{\mathrm{gal}}{\mathrm{min}} 60 \frac{\mathrm{min}}{\mathrm{hr}}$

$=5.256 \times 10^{5} \mathrm{Bt} / \mathrm{Hr}$

* Note that the evcporotion rate is measured primarily with the condensate flow meter, although small corrections are made for entrainment.

Reheat

Deseription: The heat required to reheat condensate to boiling temporature during reflux

$Q_{p}=\varphi \dot{v}\left(T_{p}-T_{c}\right) \quad c_{p}=$ specific heat

$$
\begin{aligned}
& p=\text { density } \\
& i=\text { condensate flow rate } \\
& T_{p}=\text { Are prosess temp } \\
& T_{c}=\text { condensate terp }
\end{aligned}
$$

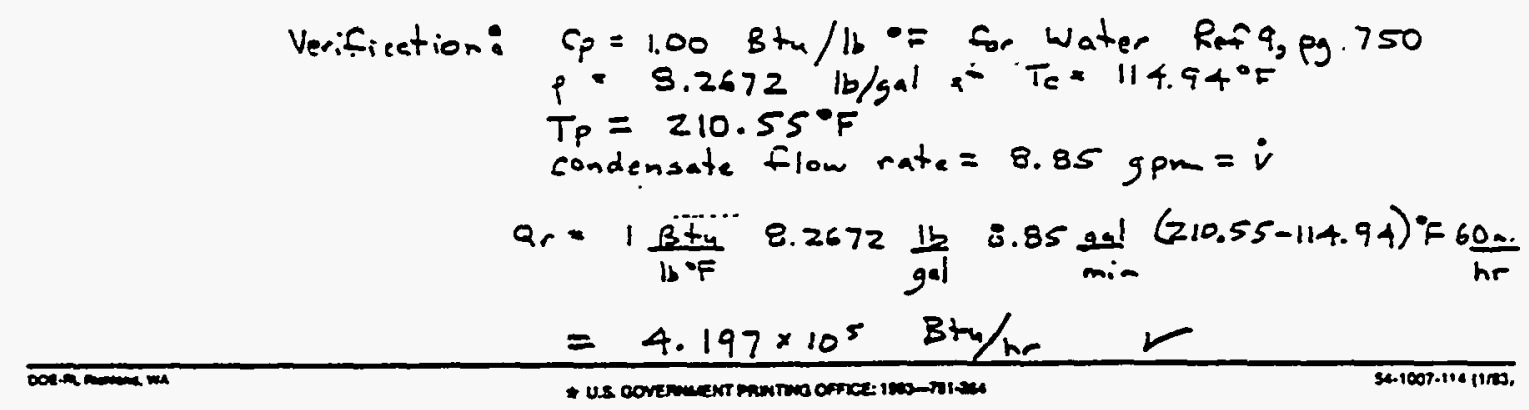




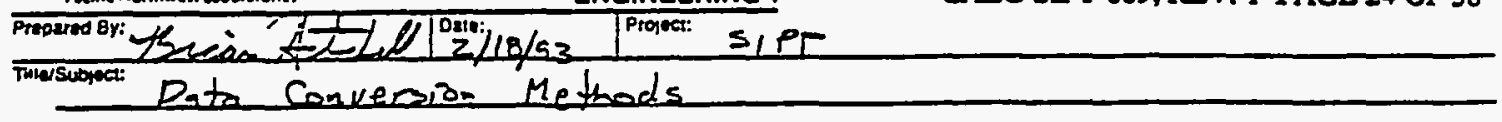

Total Hoat Total Heat = Evaporation + Rehat $=5.256110^{6}+.197 \times 6^{5}$ Condersete Elow (1) (2) $=5.676 \times 10^{\circ} \mathrm{et}$

Pescription: Condensate Flow is measured buth in terms of instantaneous flow $(F I-901)$ and totalized volume. through FI-Ga. During mat segmeats, the totalized flow is measured and recorded in the LRB. The toticlized flow is convertel

to an arenge flow by dividing the total volume through the flow meter by the elapsed time (this is done imanuallyj Conde-nte flow $(1)=$ Avenge of $F I \cdot 901$ over Condensate Flow $(2)=\frac{\text { time segment }}{\text { Total volume }}$ From

Verification: Condensate Flow $(1)=\frac{9.88+7.82}{2}$

$$
=8.55 \mathrm{gpr} r
$$

Evaporation Rote

Description: The evaporction rate is the rondensate fiow rate plus any wate- lost in condenser off-gas. During reflux, any level change in the tank is due to overhead entrainment, so

Evaporation $R_{a} t_{e}=$ condensate Flow Rate + Ave. Level. Cinange.

If the Ave. Level Change is negative Cdue

to minior instrument Suctuations) it is discurded, and the evcporation rate is equal to the condenset. flow rate.

Verification: Evaporation Rate $=3.85+2.07=10.92 \mathrm{gpm}$ Condensete Tere Description: Ave of TI-1103 over time segment,
converted to of 
Battelle

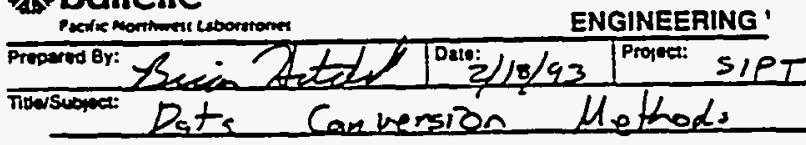

Verification: Condensate Temp $=\frac{46.34+45.81}{2}=46.075^{\circ} \mathrm{C}$

$$
=\frac{a}{5}\left(46.075^{\circ} \mathrm{C}\right)+32 \times 114.94^{\circ} \mathrm{F}
$$

Offers Flow

Description: Avenge of the offer flow, in SCFM, calculated in the raw data spreadsheet

$$
\begin{aligned}
& \text { Verification: off gas flow }=\frac{384.3361+212.1837}{2} \\
& =298.26 \text { SCuM }
\end{aligned}
$$

Stem Flow

Description: Average steam flow through HB-15, heating coils, calculated in the raw data epreadsinest

Verification: Steam Flow $=\frac{5992.65142+59918328=}{2}$

$$
=5992.24 \mathrm{lb} / \mathrm{hr}
$$

Header Pressure (steam)

Description: Average of $P I-1021$, converted to dissolute pressure

Verification: Header Pressure $=14.433$ psia $+\frac{114.32+114.32}{2}$

$$
=128.75 \text { psia } r
$$

Pin (Steam)

Description: Average of PI-1001, the coil stern supply pressure a filer the control valve

$$
\text { Verification: } \begin{aligned}
P_{\text {in }} & =14.433 \text { psia } \\
& =91.02 \text { psia }
\end{aligned}
$$

$\cos \cos \min$

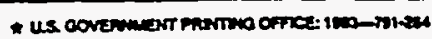

s4-1007-114 (1100)

L. 38 


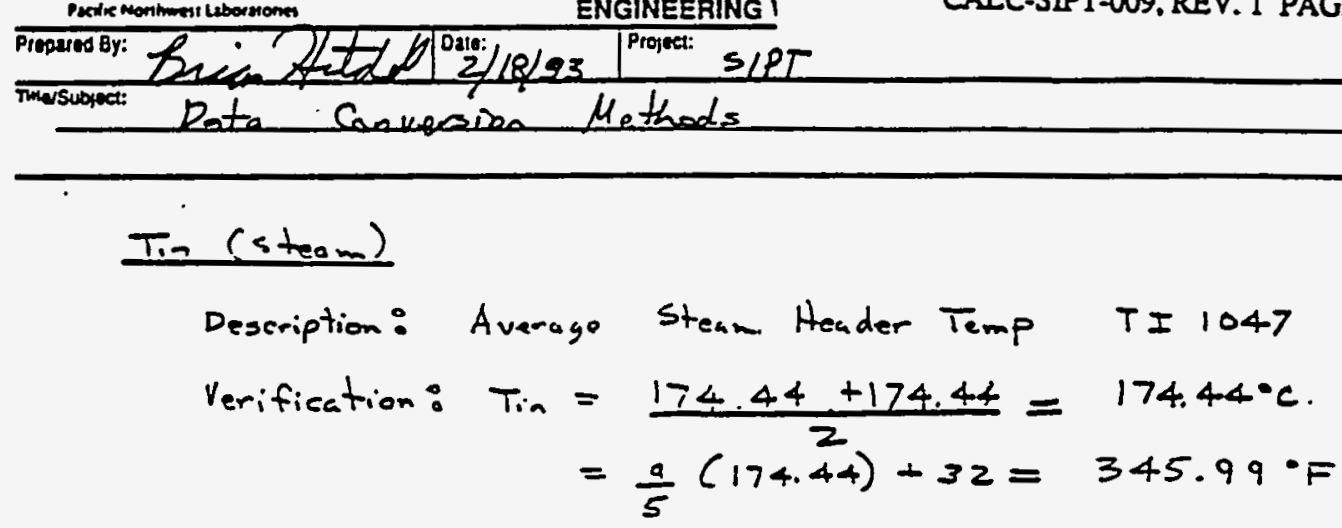

Tsat at Pin (steam)

Description: Stear saturation temperature at. Pin per

Verification: Entered manually

Vepor ce $a_{1} \div$ Ise- (steam)

Description: Specific hect of stenm at Tin, per Ref. $q$, pg 735

Verification: Entered manually

$h c ; a+T_{\text {set }}$ (stean)

Pescription: heat of raporization of saturated steam. at Tsat, per $\operatorname{Ref} 3$, pg 860

Yerification: Entered manually

Cendensete Pout (sten-)

Description: Coil stean condensate average pressure

$P=-1022$ and PI 1023

Verification: $\quad P_{\text {out }}=\frac{65.6+65.62+53.28+53.47}{4}$

$=59.4925$ psig

$P_{\text {out }}=59.4925+14.433=73.93$ psia $V$ 
Condensate Tout (stean)

Description: Coil steam sonde-sate averago temporature $T I-1052$ and $T J-1053$

Verification: $T_{0 . t}=\frac{100.85+100.35+102.51+102.51}{4}$ $=101.68^{\circ} \mathrm{C}$

$$
T_{\text {out }}=(9 / 5)\left(101.68^{\circ} \mathrm{C}\right)+32=215.02^{\circ} \mathrm{F}
$$

Ceil Pressure Drop (stern) Description: Pressure drop accross stean coils rafter
control value

Coil Pressure Drop $=$ Pin - Pout

Verification: Coil Pressure Erap $=91.02-73.93-17.1$ psiar Desuperheat Heat (steam)

Description: Heat to desuperheat stan from $T_{i n}$ to $T_{\text {sat }}$

$$
Q_{D S H}=c_{p} \dot{m}\left(T_{i n}-T_{\text {sat }}\right)
$$$$
\text { where } \dot{m}=\text { stean mass flow }
$$

Verification: $Q_{D S H}=0.4313 \frac{P L_{1}}{b_{b}} 5992.24 \frac{\mathrm{lb}}{\mathrm{hr}}(345.99-321.06)^{\circ}=$ $=7.197 \times 10^{4} \mathrm{BH} / \mathrm{hr} / \mathscr{r}$

Sondense Hect (ste.-)

Description: Heat to condense steam

$Q_{c}=b_{s g} \dot{m}$

Verification: $Q_{c}=894.47 \frac{\mathrm{sty}}{16} 5992.24 \frac{\mathrm{W}}{\mathrm{hr}}=5.360 \times 10^{6} \frac{\mathrm{Btu}}{\mathrm{nr}}$ 
Subeod Heat (steen)

Description: Heat to subeool coil condensate from Tsat to

$$
Q_{s c}=c_{p} \dot{m}\left(T_{\text {sat }}-T_{\text {out }}\right)
$$

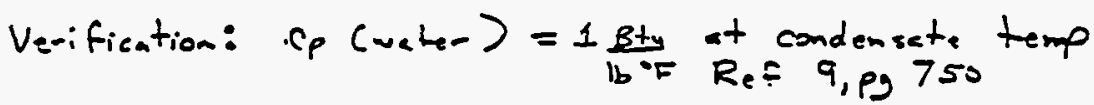

$$
\begin{aligned}
a_{s c} & =1.00 \frac{\mathrm{gtu}}{\mathrm{b} \cdot \mathrm{F}} 5992.24 \frac{\mathrm{lb}}{\mathrm{hr}}(321.06-215.02) \\
& =6.354 \times 10^{5} \frac{\mathrm{Btw}}{\mathrm{hr}}
\end{aligned}
$$

Total Heet (sten-)

$$
\begin{aligned}
& \begin{aligned}
\text { Description: Totel ineat ireisferrnd from steam to } \\
\text { process } Q_{\text {totel }}=Q_{0 S H}+Q_{C}+Q_{s e}
\end{aligned} \\
& \text { Verification: } \begin{aligned}
Q_{\text {tatii }} & =7.19 .7 \times 10^{4}+5.360 \times 10^{6}+6.354 \times 10^{5} \\
& =6.067 \times 10^{6} \mathrm{Bth} / \mathrm{Hm}
\end{aligned}
\end{aligned}
$$

Heat Trunsfer Coefeiciest

$$
\begin{aligned}
& \text { Description: computes the heat tranfer coefficient (V) } \\
& \text { between the frocess ind ine stear cail. } \\
& \text { See CALC-SIFT-002, Rev. O for theoretizal } \\
& \text { basis for the calculations. (Section 6.6) }
\end{aligned}
$$

Verification: Desuperhont LMTD

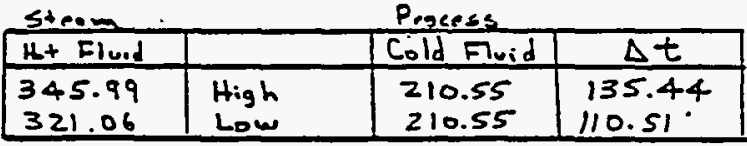

$$
\begin{aligned}
& \Delta t_{\text {DSH }}=\frac{\Delta t(\text { hiah })-\Delta t(\text { low })}{\ln \left(t^{2}\right)} \\
& \text { in } \Delta t \text { (nigi) } / \Delta t \text { (10n)) } \\
& =135.44-110.5 \\
& \ln \left(\frac{135.44}{110.51}\right) \\
& =122.55^{\circ} \mathrm{F}
\end{aligned}
$$




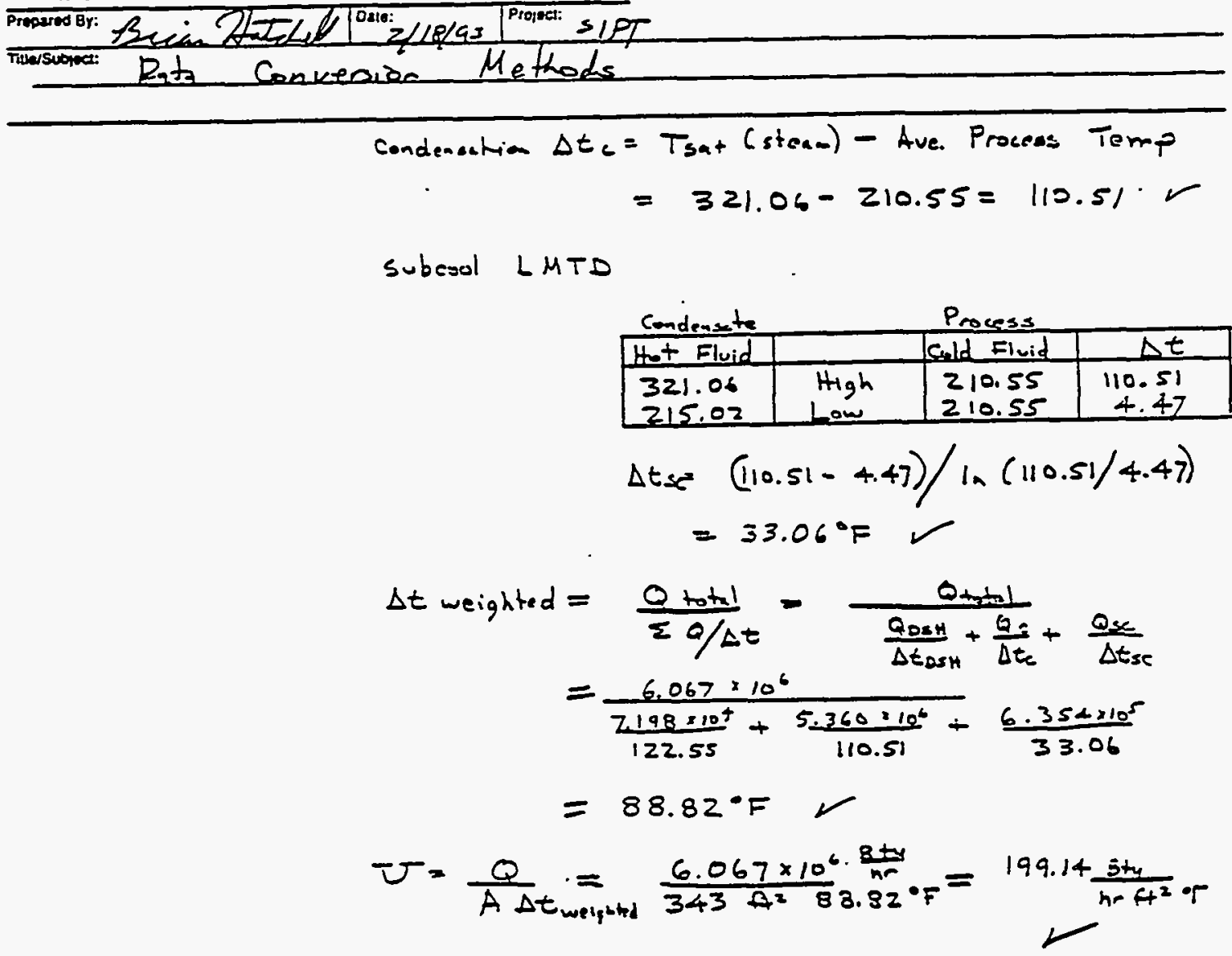

Agitator Speed

Description: Average agitator speed SI-1000

Verification: Agitator speed $=\frac{84.88+84.86}{2}=94.97 \mathrm{rpmr}$

Agitator Curreat

Description: Arerage agitator current II-1000

verification: Agitator Current $=\frac{34.71+34.86}{2}=34.79$ Amps $V$ 
Agitator Voltage

Description: 4uverage ogitator voltage EI-1000

Verificution: Agitator voltage $=\frac{259.43+259.46}{2}=259.45 \mathrm{r}$ roit

Agitutor Heat Inqut

Description: Average agitator hect input, calculated in the raw data spread sheet

Verifieation: Agitator Heat Input $=\frac{3072623+30362.58}{2}$

$$
=30794.41 \frac{\mathrm{Bty}}{\mathrm{Hr}} \mathrm{r}
$$

Energy Balance

Description: Computes energy balance for the corporstor.

Tank Losses - heat lost from the tank, determined experimentally and documented in

CALC-SIPT-003, RevQ

Total Heat $I_{n}=Q($ steam, tota $)+\cdots Q$ (ajithon)

Total Heat out $=Q$ (.Process) $)+Q$ (tank losses)

$\%$ bifference $=\frac{\text { Heat } I_{n}-\text { Heat Out }}{\text { Heat In }}=100 \%$

Verification: Tank Losses $=378900 \frac{8 \text { tw }}{\mathrm{Hr}}$ (Input manually)

Hent $I_{n}=6.067 \times 10^{6}+30794=6.098 \times 10^{6} \frac{\mathrm{Bt}}{\mathrm{Hr}}$

$r \mathrm{Hr}$

Heat out $=378900+5.676 \times 10^{6}=6.054 \times 10^{6} \frac{\mathrm{Bt}}{1 \mathrm{tr}} \mathrm{r}$

$\%$ Difference $=\frac{6.098 \times 10^{6}-6.054 \times 10^{6}}{6.099 \times 10^{6}} \times 100 \%$

$$
=0.72 \%
$$




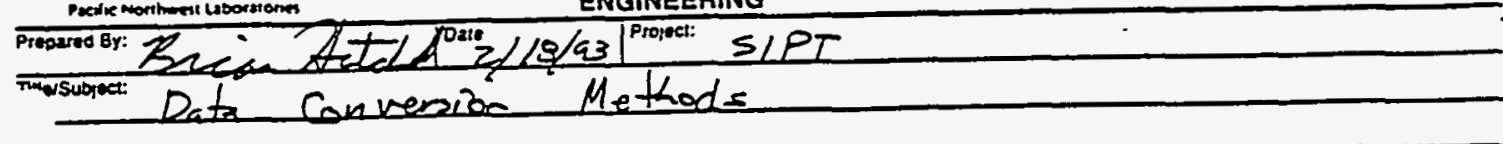

Condenser Heat Transfer Spreedshoet Verification

Note: The following quantities are identical to the same quantities in the evaporater spreadsicet, and are al ready verified:

... Start Time

End Time

Elapsed Time

Starting Volume

Ending Volume

Ave. Process Temp

Headspace Pressure

Evaporation Rate

Condensate Flow (1) \& (2)

Condensate theat

offyas Flow, SCEM

Pracess $h \in_{f}$

Description: Heat of vaporization of the process at the average provess temperature, essuming saturated conditions

Verification: Entered manually

Shell side Condenser Cooling Water Flow

Description: Flow = Condense- Cooling Wate- Flow = FI--1102

$T_{\text {in }}=T I--110 t$

TouT $=T I--1102$

$\Delta T=T_{\text {in }}-T_{\text {our }}$

$P_{\text {in }}=P I-. \|$ ol

$P_{\text {oug }}=P_{I} I-1102$

$\Delta P=P_{\text {IN }}-P_{\text {OUT }}$

Temperctures are converted from ${ }^{\circ} \mathrm{C}$ to $F$

Prossures are converted from $p=i g$ to $p=i a$

Verification: Flow $=\frac{\equiv 56.17+354.44}{2}=355.31 \mathrm{gpm}$ 


$$
\begin{aligned}
& T_{\text {in }}=\frac{9}{5}\left[\frac{26.27+25.92}{2} \cdot \mathrm{F}+32=78.97^{\circ} \mathrm{F}\right. \\
& T_{\text {out }}=\frac{9}{5}\left[\frac{44.43-43.95}{2}\right]+32=111.54^{\circ} \mathrm{F} \\
& \Delta T=111.54-78.97=32.57^{\circ} \mathrm{F} \\
& P_{\text {in }}=14.433+\left[\frac{28.45+20.77}{2}\right]=43.043 \text { psiq } \\
& P_{\text {out }}=14.433+\left[\frac{23.35+23.67}{2}\right]=37.943 \text { psiq } \\
& \Delta . P=43.043-37.943=5.100^{\circ} \text { Psiq }
\end{aligned}
$$

Condense Heet

Description: Heat to condense process vapors

$$
Q_{c}=\rho \dot{v} \text { hsg } \quad \begin{aligned}
\dot{V} & =\text { condensate flow rate } \\
\rho & =\text { density of water at } \\
& \text { condensate temp }
\end{aligned}
$$

Verification: $\quad \dot{v}=8.85 \mathrm{gpm}$

$$
\begin{aligned}
& \rho=8.2672 \frac{\mathrm{ll}}{54} \\
& Q_{c}=8.2672 \frac{16}{9.1} 8.95 \frac{\mathrm{aal}}{\mathrm{min}} \cdot 971.24 \frac{\mathrm{Bth}}{\mathrm{db}} \cdot 60 \frac{\mathrm{min}}{\mathrm{nr}} \\
& =4.264 \times 10^{6} \mathrm{Bt} / \mathrm{Hr}
\end{aligned}
$$

Subenol Heat

$$
\begin{aligned}
& \text { Description: Heat to subcool process } \\
& Q_{s}=\rho \dot{V}\left[T_{P},-T_{e}\right] \dot{s} \\
& \dot{v}=\text { condenseste flow rate } \\
& \rho=\text { density of water } \\
& \text { ot condensate } \\
& \text { temp (1ouk up } \\
& \text { table) } \\
& T_{p}=\text { Ave. Process Temp } \\
& T_{c}=\text { Condeneste Te } \rightarrow \\
& C_{p}=\text { specific Heat } \\
& \text { of Condensate }
\end{aligned}
$$




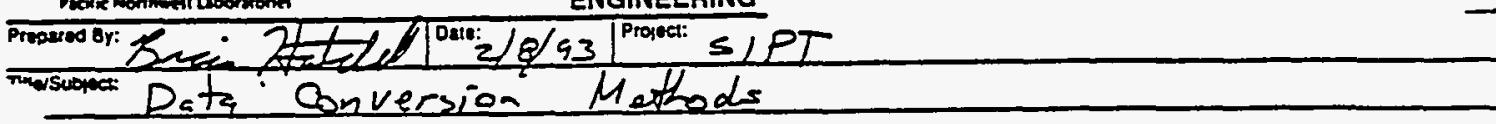

$$
\begin{aligned}
& \text { Verification: } \dot{v}=8.35 \mathrm{gpm} \\
& p=8.2622 \mathrm{~b} / \mathrm{gal} \\
& T_{p}=210.55^{\circ} \mathrm{F} \\
& T_{C}=114.94^{\circ} \mathrm{F} \\
& C_{p}=1.00 \text { Btw/bo Ref } 9, \lg 750 \\
& Q_{s}=3.35 \text { ten } 8.2672 \text { lb }[210.55-114.94]-7 \\
& \text { - } 1.00 \frac{8+y}{16.5}=4.197 \times 10^{5} \frac{B+y}{4 r}
\end{aligned}
$$

Ofraas Elow, ACFM

$$
\begin{aligned}
& \text { Descriptron: Offgas Flow expressed in } \mathrm{fr}^{3} / \mathrm{min} \\
& \text { ACF } M=\operatorname{SCF} M\left(\frac{14.7}{p}\right)\left(\frac{T}{520}\right) \text { Ref } 5, \mathrm{Pg}^{6} \\
& \begin{array}{l}
P=\text { Offgas Pressure. } \\
T=\text { Offgas Temfertur, oR }
\end{array} \\
& \text { Verification: } A C F M=293.26\left(\frac{14.7}{14.089}\right)\left(\frac{129.03+460}{520}\right) \\
& =352.51 \text { ACFM }
\end{aligned}
$$

Offges Tomp, Pressure

$$
\begin{aligned}
& \text { Description: Off-gas Temp TI-- } 1105 \\
& \text { off gas Pressure } \doteq \text { Condenser Pressure }=\text { PI- }-1103 \\
& \text { Temperature converted from } T \text { to }{ }^{\circ} \mathrm{F} \\
& \text { Pressure converted from incles wate- to psiq } \\
& \text { Verification: off-gas Temp }=\frac{8}{3}\left[\frac{53.05+54.76}{2}\right]+32 \\
& =129.03^{\circ} F \\
& \text { off-gas Pressure }=14.433+0.036 \frac{13 \text { psi }}{\text { inch water }}\left(\frac{-8.66-10.39}{2}\right) \\
& =14.089 \text { psig }
\end{aligned}
$$


Tube Side Pressure Drop

Description: Pressure Prop through condenser, determined by
Subtracting the headspace pressure from the subtracting the hea

$\begin{aligned} \text { Venfication: Tube side pressure drop } & =14.429-14.039 \\ & =0.340 \text { psia }\end{aligned}$

Heat Transfar Coefficient

Description: Computes the heat transfer coefficient (G) betwee- the process and the conde-ser cooling water. see CALC-SIPT-Dob for theoretical basis for calculations.

Verificotion: Ave. cooling wiater temp- $\frac{78.97+111.54}{2}$

$=92.255^{\circ} \mathrm{F}$

$P$ (water) at querage cosling water temp $=8.3031 \frac{\mathrm{lb}}{9 \mathrm{cl}}$ (lookup table)

$\dot{m}$ (cooling water) $=355.31 \frac{\mathrm{gal}}{\mathrm{min}} \frac{60-\mathrm{in}}{\mathrm{hr}} 8.3031 \frac{\mathrm{h}}{\mathrm{gal}}$

$$
=177010.5 \frac{16}{\mathrm{hr}}
$$

Dt cooling vater to $=\frac{O_{C}}{\text { condense process }}$

$$
Q_{c}=\text { Condunge Hect }
$$

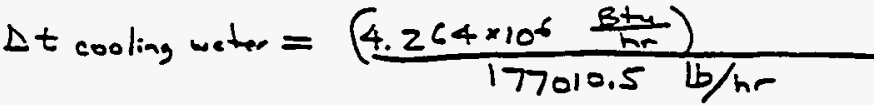

$$
=24.10^{\circ} \mathrm{F} .
$$

Codense LMTE.

\begin{tabular}{|c|c|c|c|}
\hline Aot Fluid & & Cold Fluid & $\Delta t$ \\
\hline 210.55 & High & 111.54 & 99.01 \\
Z10.55 & Low & $111.54-24.1$ & 123.11 \\
\hline
\end{tabular}


Subeol LMTD

\begin{tabular}{|c|c|c|c|}
\hline Hot Fluod & & Cld Eluid & $\Delta t$ \\
\hline $\begin{array}{l}210.55 \\
114.94\end{array}$ & $\begin{array}{l}\text { High } \\
\text { Low }\end{array}$ & $\begin{array}{c}111.54-24.1 \\
78.97\end{array}$ & $\begin{array}{r}123.11 \\
35.97\end{array}$ \\
\hline
\end{tabular}

$$
\Delta t_{s}=\frac{123.11-35.97}{\ln (123.11 / 35.97)}=70.82 \mathrm{Fr}
$$

weighted $\Delta t$

$$
\begin{aligned}
& \Delta t=\frac{Q_{c}+Q_{s}}{\frac{Q_{c}}{\Delta=c}+\frac{Q_{s}}{\Delta \dot{t}_{s}}} \\
& =\left(4.264 \times 10^{6}+4.197 \times 10^{5}\right) \frac{\text { Btr }}{\mathrm{Hr}} \\
& \frac{4.26+\times 10^{6} \frac{85}{16}}{110.62^{\circ} \mathrm{F}} \frac{4.197 \times 10^{5} \frac{04}{70.32}}{70.5} \\
& =105.32 \mathrm{~F} \\
& \tau=\frac{Q_{S}+Q_{C}}{A \Delta t \text { weighted }} \\
& =\frac{\left(4.264 \times 10^{6}+4.197 \times 10^{5}\right) \frac{\mathrm{et}}{\mathrm{Hr}}}{450.6 \mathrm{ft}^{2} 105.32^{\circ} \mathrm{F}} \\
& =98.69 \frac{B+4}{\mathrm{Hr} t^{2}} . \mathrm{F}
\end{aligned}
$$

Entrainment

Description: Computes the amoint of water in the offyes assuming the off gas is at $100 \%$ humidity.
This a mount of mater is subtracted from
the total wate- in offyas to deternine the
amount of liguid entrinment in off-gas. 


\section{Dats Conversion Metheds}

See CALC-SIPT-OOS for theoretical basis.

Verificction: $\rightarrow$ at off-gas temeenture - sfecific volume pe- Ref 3 , pq 750

Input manually

Calculated $H_{2} \mathrm{O}=\frac{O f(a) s \text { Fin in ACFM }}{\nabla \cdot P}$

$$
\begin{aligned}
p & =\text { density of water at } \\
& =8 f g a s \text { temp } \\
& =8.2468 \frac{1 b}{g a l}
\end{aligned}
$$

colculated $H_{2} \mathrm{O}=352.02 \mathrm{fH} / \mathrm{min}$

$$
\begin{aligned}
& 161.64^{\circ} \frac{\mathrm{c}^{2}}{b^{2}} 8.2468 \frac{\mathrm{b}}{9^{4}} \\
& =0.26 \mathrm{gpm}
\end{aligned}
$$

Actual $\mathrm{H}_{2} \mathrm{O}=$ Evaporation Rate- Condensate

$$
=10.92-8.85=207 \mathrm{gpm}
$$

$D_{i}$ iterence $=2.07-0.26=1.81 \mathrm{gPm}$

\section{Entay Bolance}

Description: Computes energy balance for the condensor Neglects hent losses.

Total Heat $I_{n}=$ Condense Heat t subead Heat

Total Heat out = Enezy Removed by
Condenser cooling water

$$
=\rho \dot{V} \leftarrow \Delta T
$$

where $\rho=$ dinsity of mater

$$
\dot{v}=\text { at average temp }
$$$$
\text { slow rate }
$$

$\Delta T=$ Temperature rise

$C_{7}$ \& water speeifir hect

$\%$ Difference $=$ Heat In - Heat Out $\times 100 \%$

Heat In 


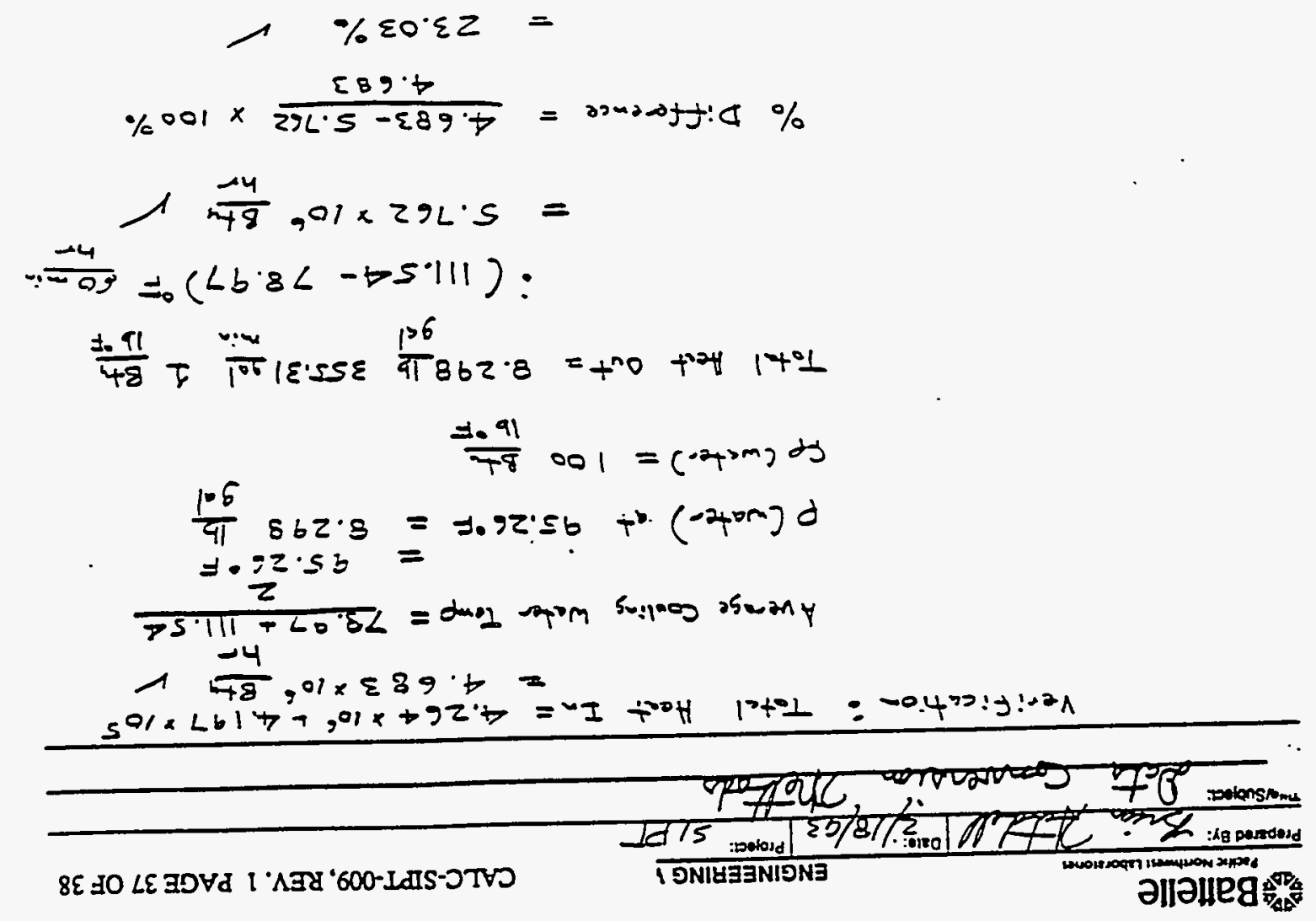


2) Slurry. Intiezrated Performance Testing Measurement and Test Equipment List

3) Thermodynamics, 3 ed Edition, 1977, McGraw-Hill Book Company) New York

4) HWYP Feed Preparation Test Sysiem $P E 1 D$

FNL Drawing $5 K-3-27797$

5) PSE. Ine Flou Sensors Handbook, Fow

6) Hwyp Feed Prep Test System Condenser Drawing, Aiaskan Copper wories Drawing M-4636

7) Fluid Mechanice 1979 , McGraw-Hill Boo'x Company

8) DDDP Item 1.26 - Effect of Non-Condensibles on Condenser Performance PHTD-91-03.036-K900 (i.z), Rer 0, September 1992

9) Eundamentals of Momentum, Heat, and Mass Transfer; 
CALC-SIPT-010, REV. 0 PÁGE 1 OF 18

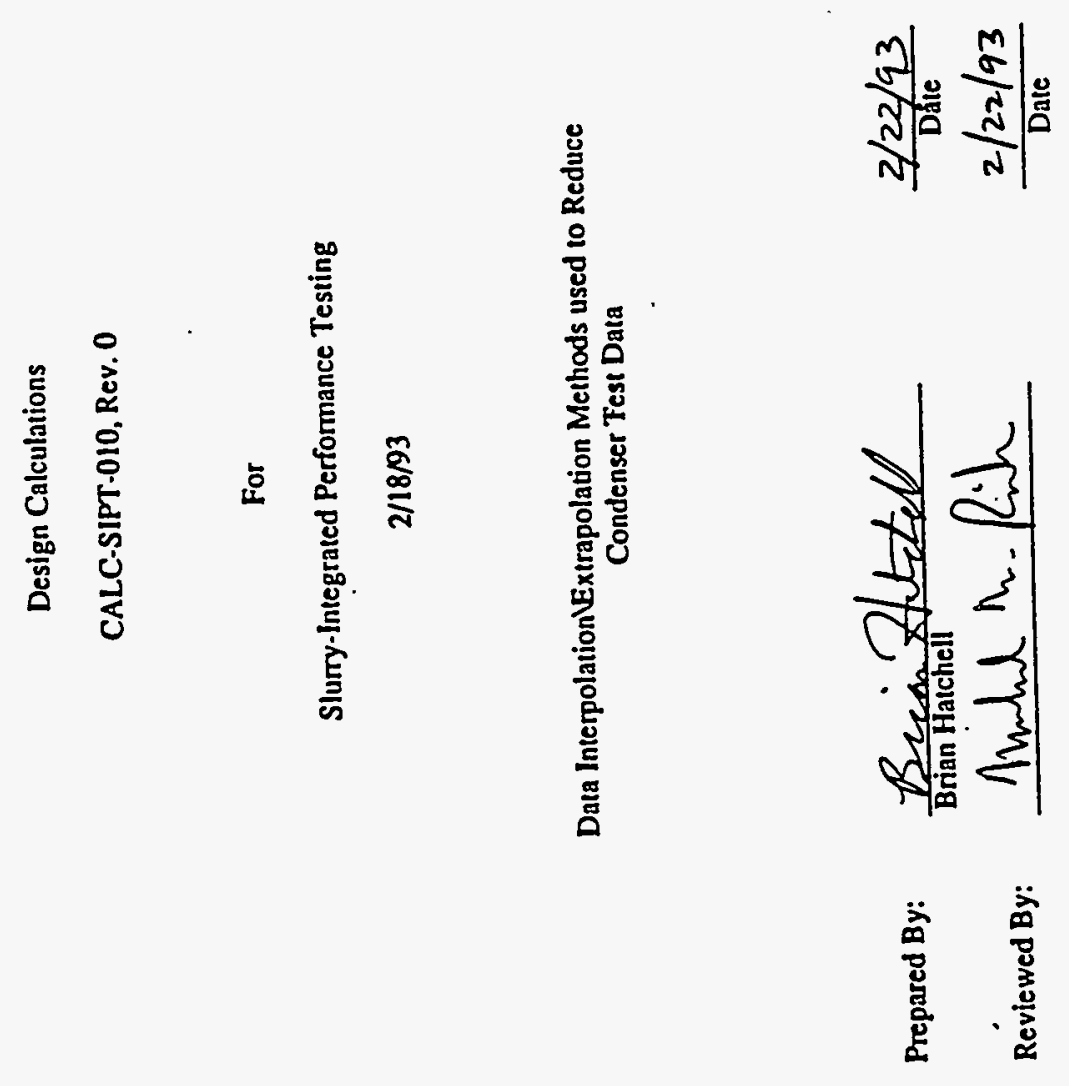


DATA INTERPOLATION/EXTRAPOLATION SPREADSHEET

The following table summarizes the evaporation rate-off-gas flow combinations, and associated parameters of interest. The data is extracted from the evaporator and condenser summary spreadsheets.

\begin{tabular}{|c|c|c|c|c|c|c|c|c|c|}
\hline Test & $\begin{array}{c}\text { Data } \\
\text { \# }\end{array}$ & $\begin{array}{c}\text { Evaporation } \\
\text { Rate, gpm }\end{array}$ & $\begin{array}{c}\text { Off-gas Flow } \\
\text { SCFM }\end{array}$ & $\begin{array}{c}\text { Water Lost in } \\
\text { off-gas, GPM }\end{array}$ & $\begin{array}{c}\text { Condensate } \\
\text { Flow, GPM }\end{array}$ & $\begin{array}{c}\text { Condenser U } \\
\text { Bu/hr ft^2 F }\end{array}$ & $\begin{array}{c}\text { Condensate } \\
\text { Temp, }{ }^{\circ} \text { F }\end{array}$ & $\begin{array}{c}\text { Off-gas Temp } \\
{ }^{\circ} \text { F }\end{array}$ & $\begin{array}{c}\text { Tube Side } \Delta \\
\text { psia }\end{array}$ \\
\hline TST053 & 1 & 2.63 & 51.44 & 0.00 & 2.63 & 27.09 & 110.25 & 104.88 & 0.025 \\
TST053 & 2 & 6.05 & 37.65 & 0.09 & 5.96 & 66.51 & 106.25 & 126.43 & 0.085 \\
TST053 & 3 & 9.44 & 27.36 & 0.00 & 9.44 & 110.80 & 108.64 & 142.46 & 0.202 \\
TST038 & 4 & 2.63 & 110.68 & 0.00 & 2.63 & 27.37 & 109.12 & 106.14 & 0.031 \\
TST038 & 5 & 5.91 & 107.92 & 0.00 & 5.91 & 66.00 & 106.04 & 124.71 & 0.092 \\
TST038 & 6 & 10.06 & 104.66 & 0.38 & 9.68 & 114.43 & 110.17 & 142.27 & 0.234 \\
TST038 & 7 & 10.36 & 111.06 & 0.00 & 10.36 & 124.04 & 113.91 & 146.40 & 0.262 \\
TST052 & 8 & 2.67 & 247.55 & 0.16 & 2.51 & 25.81 & 101.90 & 99.08 & 0.049 \\
TST052 & 9 & 5.82 & 192.73 & 0.49 & 5.33 & 58.45 & 103.51 & 113.54 & 0.117 \\
TST052 & 10 & 9.32 & 210.14 & 0.51 & 8.81 & 99.93 & 106.77 & 128.65 & 0.249 \\
TST052 & 11 & 11.00 & 220.54 & 1.01 & 9.99 & 114.14 & 111.09 & 134.00 & 0.291 \\
TST051 & 12 & 2.83 & 326.19 & 0.43 & 2.40 & 25.75 & 103.90 & 99.49 & 0.062 \\
TST051 & 13 & 5.99 & 348.05 & 0.63 & 5.36 & 60.19 & 104.99 & 112.09 & 0.153 \\
TST051 & 14 & 9.64 & 329.43 & 0.96 & 8.68 & 100.86 & 110.65 & 129.60 & 0.283 \\
TST051 & 15 & 10.85 & 279.94 & 1.52 & 9.33 & 110.84 & 115.52 & 136.51 & 0.314 \\
TST050 & 16 & 2.97 & 481.03 & 0.66 & 2.31 & 24.90 & 101.64 & 97.11 & 0.087. \\
TST050 & 17 & 6.10 & 451.07 & 0.89 & 5.20 & 58.07 & 104.01 & 109.98 & 0.168 \\
TST050 & 18 & 9.48 & 422.97 & 0.92 & 8.56 & 98.30 & 110.10 & 127.40 & 0.312 \\
TST050 & 19 & 10.76 & 332.25 & 2.33 & 8.44 & 99.46 & 115.51 & 132.77 & 0.332 \\
\hline
\end{tabular}

us 
CALC-SIPT-010, REV. 0 PAGE 3 OF 18
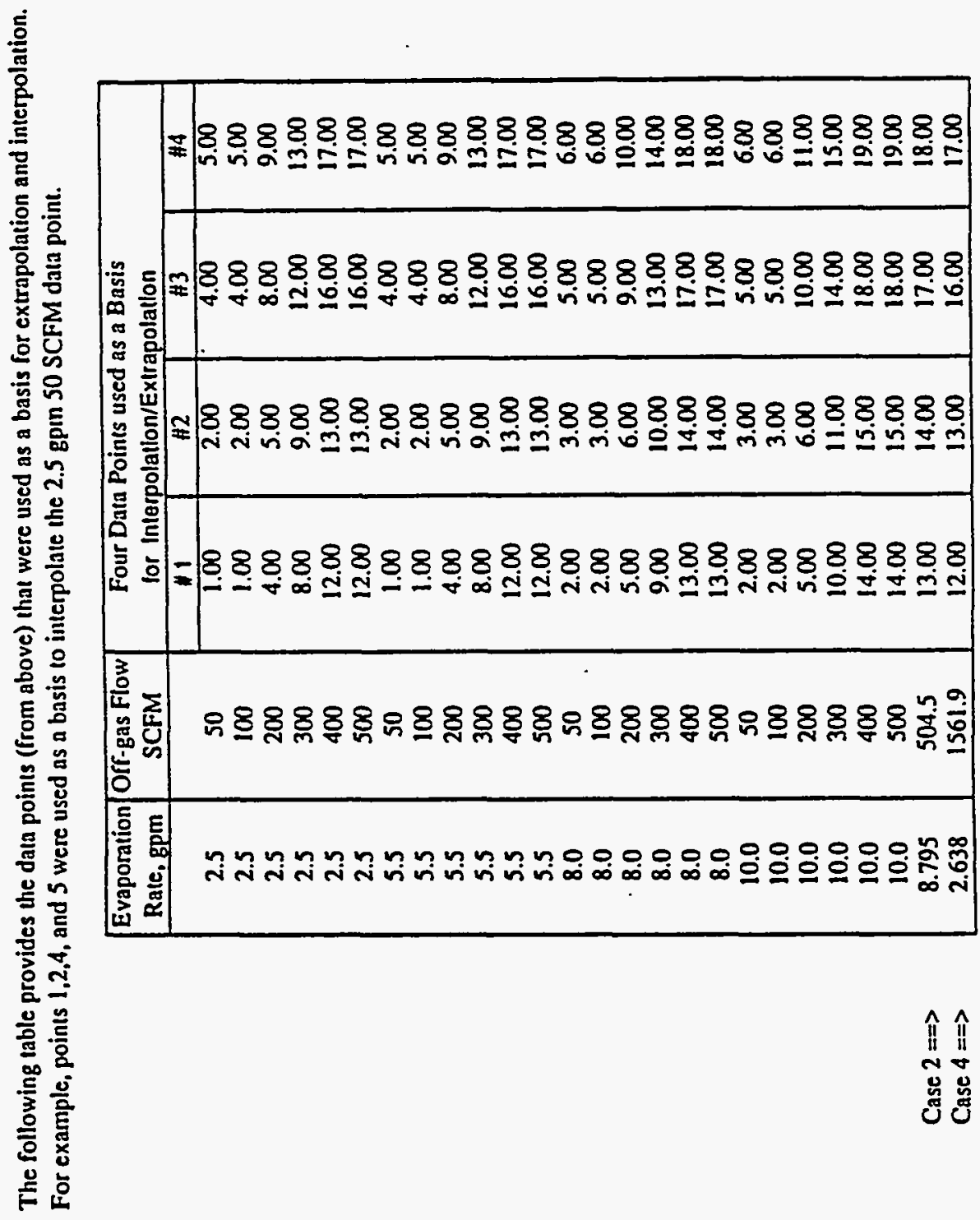
The following tables document the results of the interpolation/extrapolation using the 4 data points. The results are obtained by using the LINEST coinmand within Microsoft EXCEL.

\begin{tabular}{|c|c|c|c|c|c|c|c|c|c|}
\hline $\begin{array}{c}\text { Evaporation Rate } \\
\text { Off-gas Flow }\end{array}$ & $\begin{array}{l}2.5 \\
50 \\
\end{array}$ & $\begin{array}{c}\text { Evaporation } \\
\text { Rate, gpm }\end{array}$ & $\begin{array}{l}\text { Off-gas Flow } \\
\text { SCFM }\end{array}$ & $\begin{array}{l}\text { Water Lost in } \\
\text { off-gas, GPM }\end{array}$ & $\begin{array}{l}\text { Condensate } \\
\text { Flow, GPM }\end{array}$ & $\begin{array}{l}\text { Condenser U } \\
\text { Btu/hr fi^2 F }\end{array}$ & $\begin{array}{l}\text { Condensate } \\
\text { Temp. }{ }^{\circ} \mathrm{F}\end{array}$ & $\begin{array}{c}\text { Off-gas Temp } \\
{ }^{\circ} \mathrm{F}\end{array}$ & $\begin{array}{c}\text { Tube Side } \Delta \\
\text { psia }\end{array}$ \\
\hline Data Points & 1.00 & 2.63 & 51.44 & 0.0000 & 2.63 & 27.09 & 110.25 & 104.88 & 0.025 \\
\hline Used for & 2.00 & 6.05 & 37.65 & 0.0893 & 5.96 & 66.51 & 106.25 & 126.43 & 0.085 \\
\hline Interpolation/ & 4.00 & 2.63 & 110.68 & 0.0000 & 2.63 & 27.37 & 109.12 & 106.14 & 0.031 \\
\hline Extrapolation & 5.00 & 5.91 & 107.92 & 0.0000 & 5.91 & 66.00 & 106.04 & 124.71 & 0.092 \\
\hline \multirow{3}{*}{\multicolumn{4}{|c|}{ 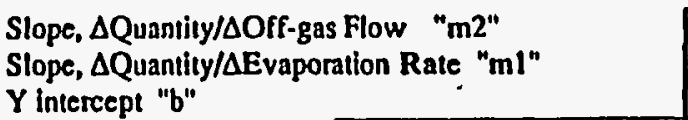 }} & .0000729 & 0.000720 & 0010011 & .0010778 & 0.000857 & 0.000126 \\
\hline & & & & 0.011759 & 0.988241 & 11.673532 & -1.086865 & 5.996806 & 0.018373 \\
\hline & & & & 0.0278 & .0 .0278 & -4.2816 & 113.4234 & 89.6585 & -0.0306 \\
\hline \multicolumn{2}{|c|}{ Interpolated Values $\Rightarrow$} & 2.5 & 50 & 0.02 & 2.48 & 25.40 & 110.17 & 104.69 & 0.022 \\
\hline
\end{tabular}

Verify with Hand Calculations (all other tables use the same formulas)

\begin{tabular}{|c|c|c|}
\hline Water Losi in & off-gas, GPM & $-0.000124(50 \mathrm{kcFm})+0.011759\left(2.5 g p^{2}\right)+0.0278=0.0207 \mathrm{~V}$ \\
\hline Condensace & Flow, GPM & $0.000724(50$ SCFM) $+0.988241(2.5 \mathrm{gPa})-0.0278=2.48 \mathrm{~V}$ \\
\hline Condenser U & Biu/hr $\mathfrak{l}^{\wedge} \mathbf{2} \mathbf{F}$ & $0.010011(50)+11.673532(2.5)-4.2816=25.4$ \\
\hline Condensate & Temp, ${ }^{\circ} \mathrm{F}$ & $-0.010778(50)-1.086865(2.5)+113.4234=110.17$ \\
\hline Off-gas Temp & ${ }^{\circ} \mathrm{F}$ & $0.000857(50)+5.996806(2.5)+89.6585=$ \\
\hline Tube S & psia & $0.000126(50)+0.018373(2.5)-0.0306=$ \\
\hline
\end{tabular}




\begin{tabular}{|c|c|c|c|c|c|c|c|c|c|}
\hline Evaporation Rale & 2.5 & Evaporation & Off-gas Flow & Water Lost in & Condensate & Condenser U & Condensate & Off-gas Temp & $\begin{array}{c}\text { Tube Side } \Delta \\
\text { psia }\end{array}$ \\
\hline Off-gas Flow & 100 & Raic, gpm & SCFM & off-gas, GPM & Flow, GPM & Btu/hr f $\mathfrak{t}^{\wedge} \mathbf{F}$ & Temp。 ${ }^{\circ} \mathrm{F}$ & ${ }^{\circ} \mathrm{F}$ & $\frac{\text { psia }}{0.025}$ \\
\hline Dala Points & 1 & 2.63 & 51.44 & 0.00 & 2.63 & 27.09 & 110.25 & 104.88 & 0.025 \\
\hline Used for & 2 & 6.05 & 37.65 & 0.09 & 5.96 & 66.51 & 106.25 & 126.43 & 0.085 \\
\hline Interpolation/ & 4 & 2.63 & 110.68 & 0.00 & 2.63 & 27.37 & 109.12 & 106.14 & 0.031 \\
\hline Extrapolation & 5 & 5.91 & 107.92 & 0.00 & 5.91 & 66.00 & 106.04 & 124.71 & 0.092 \\
\hline
\end{tabular}

Slope, $\Delta$ Quantity/dOff-gas Flow "m2"

Slope, $\Delta$ Quantity/ Evaporation Rate "ml"

$Y$ intercept " $b$ "

Interpolaied Values $\Rightarrow$

2.5

\begin{tabular}{|c|c|c|c|c|c|c|}
\hline & -0.0007 & 0.0007 & 0.0100 & -0.0108 & 0.0009 & 0.0001 \\
& 0.0118 & 0.9882 & 11.6735 & -1.0869 & 5.9968 & 0.0184 \\
& 0.0278 & -0.0278 & -4.2816 & 113.4234 & 89.6585 & -0.0306 \\
\hline 100 & -0.02 & 2.52 & 25.90 & 109.63 & 104.74 & 0.028 \\
\hline
\end{tabular}

\begin{tabular}{|c|c|c|c|c|c|c|c|c|c|}
\hline $\begin{array}{c}\text { Evaporation Rate } \\
\text { Off-gas Flow }\end{array}$ & $\begin{array}{l}2.5 \\
200\end{array}$ & $\begin{array}{l}\text { Evaporation } \\
\text { Rate, gpm }\end{array}$ & $\begin{array}{c}\text { Off-gas Flow } \\
\text { SCFM }\end{array}$ & $\begin{array}{l}\text { Water Lost in } \\
\text { off-gas, GPM }\end{array}$ & $\begin{array}{l}\text { Condensate } \\
\text { Flow, GPM }\end{array}$ & \begin{tabular}{|l|} 
Condenser U \\
Btu/hr ft^2 F
\end{tabular} & $\begin{array}{c}\text { Condensate } \\
\text { Temp, }{ }^{\circ} \mathrm{F}\end{array}$ & $\begin{array}{c}\text { Off-gas Temp } \\
{ }^{\circ} \mathrm{F}\end{array}$ & $\begin{array}{c}\text { Tube Side } \Delta \\
\text { psia }\end{array}$ \\
\hline Data Points & 4 & 2.63 & 110.68 & 0.00 & 2.63 & 27.37 & 109.12 & 106.14 & 0.031 \\
\hline Used for & 5 & 5.91 & 107.92 & 0.00 & 5.91 & 66.00 & 106.04 & 124.71 & 0.092 \\
\hline Interpolation/ & 8 & 2.67 & 247.55 & 0.16 & 2.51 & 25.81 & 101.90 & 99.08 & 0.049 \\
\hline Extrapolation & 9 & 5.82 & 192.73 & 0.49 & 5.33 & 58.45 & 103.51 & 113.54 & 0.117 \\
\hline
\end{tabular}

Slope, $\Delta$ Quantity/ $\Delta$ Off-gas Flow "m2" Slope, $\Delta$ Quantity/ $\Delta$ Evaporation Rate " $\mathrm{ml}$ " $Y$ intercept " $b$ "

Interpolated Values $\Rightarrow$

\begin{tabular}{|l|l|}
\hline 2.5 & 200 \\
\hline
\end{tabular}

\begin{tabular}{|c|c|c|c|c|c|c|}
\cline { 2 - 7 } & 0.0024 & -0.0024 & -0.0316 & -0.0465 & -0.0732 & 0.0002 \\
& 0.0723 & 0.9277 & 10.8195 & -0.6525 & 4.5069 & 0.0216 \\
& -0.5465 & 0.5465 & 3.5303 & 115.5851 & 103.7202 & -0.0490 \\
\hline 200 & 0.12 & 2.38 & 24.25 & 104.65 & 100.35 & $0.041^{\prime}$ \\
\hline
\end{tabular}

\begin{tabular}{|c|c|c|c|c|c|c|c|c|c|}
\hline $\begin{array}{c}\text { Evaporation Rate } \\
\text { Off-gas Flow }\end{array}$ & $\begin{array}{l}2.5 \\
300\end{array}$ & $\begin{array}{l}\text { Evaporation } \\
\text { Rate, gpm }\end{array}$ & \begin{tabular}{|} 
Off-gas Flow \\
SCFM
\end{tabular} & $\begin{array}{l}\text { Water Lost in } \\
\text { off-gas, GPM }\end{array}$ & $\begin{array}{l}\text { Condensale } \\
\text { Flow, GPM }\end{array}$ & $\begin{array}{l}\text { Condenser U } \\
\text { Btu/hr ft^2 F }\end{array}$ & $\begin{array}{c}\text { Condensate } \\
\text { Temp, }^{\circ} \mathrm{F}\end{array}$ & $\begin{array}{c}\text { Off-gas Temp } \\
{ }^{\circ} \mathrm{F}\end{array}$ & $\begin{array}{c}\text { Tube Side } \Delta \\
\text { psia }\end{array}$ \\
\hline Data Points & 8 & 2.67 & 247.55 & 0.16 & 2.51 & 25.81 & 101.90 & 99.08 & 0.049 \\
\hline Used for & 9 & 5.82 & 192.73 & 0.49 & 5.33 & 58.45 & 103.51 & 113.54 & 0.117 \\
\hline Interpolation/ & 12 & 2.83 & 326.19 & 0.43 & 2.40 & 25.75 & 103.90 & 99.49 & 0.062 \\
\hline Extrapolation & 13 & 5.99 & 348.05 & 0.63 & 5.36 & 60.19 & 104.99 & 112.09 & 0.153 \\
\hline
\end{tabular}




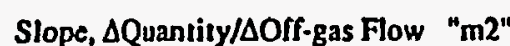

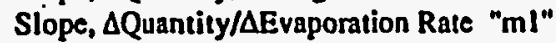
$Y$ intercept " $b$ "

Interpolated Values $\Rightarrow$

\begin{tabular}{l|l}
\hline 2.5 & 300 \\
\hline
\end{tabular}

\begin{tabular}{lll}
\hline 300 & \\
\hline
\end{tabular}

0.001
0.091
-0.33

-0.00
0.908
0.33

\begin{tabular}{|l|l|}
\hline .0013 & \\
0.9081 & 10.0 \\
\hline .3366 & -2.0 \\
\hline
\end{tabular}

\begin{tabular}{|l|}
\hline-0.0048 \\
10.6077 \\
-2.0220 \\
\hline
\end{tabular}

0.0121
0.4941
98.0606

-0.011
4.2339
90.995

0.0002

0.29

23.05

102.93

98.06

$-0.0691$

\begin{tabular}{|c|c|c|c|c|c|c|c|c|c|}
\hline $\begin{array}{c}\text { Evaporation Rale } \\
\text { Off-gas Flow }\end{array}$ & $\begin{array}{l}2.5 \\
400\end{array}$ & $\begin{array}{l}\text { Evaporation } \\
\text { Rate, gpm }\end{array}$ & $\begin{array}{c}\text { Off-gas Flow } \\
\text { SCFM }\end{array}$ & $\begin{array}{l}\text { Water Lost in } \\
\text { off-gas, GPM }\end{array}$ & $\begin{array}{l}\text { Condensate } \\
\text { Flow, GPM }\end{array}$ & $\begin{array}{l}\text { Condenser U } \\
\text { Btu/hr } \mathrm{fl}^{\wedge} 2 \mathrm{~F}\end{array}$ & \begin{tabular}{c|} 
Condensate \\
Temp, ${ }^{\circ} \mathrm{F}$
\end{tabular} & $\begin{array}{c}\text { Off-gas Temp } \\
{ }^{\circ} \mathrm{F}\end{array}$ & $\begin{array}{c}\text { Tube Side } \Delta \\
\text { psia }\end{array}$ \\
\hline Data Points & 12 & 2.83 & 326.19 & 0.43 & 2.40 & 25.75 & 103.90 & 99.49 & 0.062 \\
\hline Used for & 13 & 5.99 & 348.05 & 0.63 & 5.36 & 60.19 & 104.99 & 112.09 & 0.153 \\
\hline Interpolation/ & 16 & 2.97 & 481.03 & 0.66 & 2.31 & 24.90 & 101.64 & 97.11 & 0.087 \\
\hline Extrapolation & 17 & 6.10 & 451.07 & 0.89 & 5.20 & 58.07 & 104.01 & 109.98 & 0.168 \\
\hline
\end{tabular}

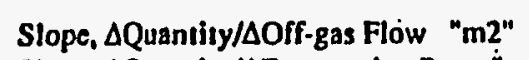

Slope, $\Delta$ Quantily/ $/$ Evaporation Rale " $\mathrm{ml}$ "

$Y$ intercept "b"

Interpolated Values $\Rightarrow$

\begin{tabular}{|l|l|}
\hline 2.5 & 4 \\
\hline
\end{tabular}

\begin{tabular}{|c|c|c|c|c|c|c|}
\hline & 0.0017 & -0.0017 & -0.0199 & -0.0135 & -0.0206 & 0.0001 \\
& 0.0714 & 0.9286 & 10.7312 & 0.5322 & 4.0255 & 0.0276 \\
& -0.3521 & 0.3521 & 2.2276 & 106.6854 & 94.9572 & -0.0594 \\
\hline 400 & 0.51 & 1.99 & 21.11 & 102.61 & 96.77 & 0.063 \\
\hline
\end{tabular}

\begin{tabular}{|c|c|c|c|c|c|c|c|c|c|}
\hline $\begin{array}{c}\text { Evaporation Rate } \\
\text { Off-gas Flow }\end{array}$ & $\begin{array}{l}2.5 \\
500\end{array}$ & $\begin{array}{l}\text { Evaporation } \\
\text { Rate, gpm }\end{array}$ & $\begin{array}{l}\text { Off-gas Flow } \\
\text { SCFM }\end{array}$ & $\begin{array}{l}\text { Water Lost in } \\
\text { off-gas, GPM }\end{array}$ & $\begin{array}{l}\text { Condensate } \\
\text { Flow, GPM }\end{array}$ & $\begin{array}{l}\text { Condenser U } \\
\text { Btu/hr f1^2 F }\end{array}$ & $\begin{array}{l}\text { Condensate } \\
\text { Temp, }{ }^{\circ} \mathbf{F}\end{array}$ & $\begin{array}{c}\text { Off-gas Temp } \\
\text { of }\end{array}$ & $\begin{array}{c}\text { Tube Side } \Delta \\
\text { psia }\end{array}$ \\
\hline Data Points & 12 & 2.83 & 326.19 & 0.43 & 2.40 & 25.75 & 103.90 & 99.49 & 0.062 \\
\hline Used for & 13 & 5.99 & 348.05 & 0.63 & 5.36 & 60.19 & 104.99 & 112.09 & 0.153 \\
\hline Interpolation & 16 & 2.97 & 481.03 & 0.66 & 2.31 & 24.90 & 101.64 & 97.11 & 0.087 \\
\hline Extrapolation & 17 & 6.10 & 451.07 & 0.89 & 5.20 & 58.07 & 104.01 & 109.98 & 0.168 \\
\hline
\end{tabular}

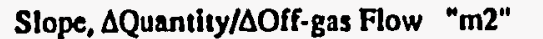
Slope, $\Delta Q$ Quantily/AEvaporation Rate " $\mathrm{ml}$ " $Y$ intercept "b"

Interpolated Values $\Rightarrow$

\begin{tabular}{|c|c|c|c|c|c|c|}
\cline { 2 - 7 } & 0.0017 & -0.0017 & -0.0199 & -0.0135 & -0.0206 & 0.0001 \\
& 0.0714 & 0.9286 & 10.7312 & 0.5322 & 4.0255 & 0.0276 \\
& -0.3521 & 0.3521 & 2.2276 & 106.6854 & 94.9572 & -0.0594 \\
\hline 500 & 0.68 & 1.82 & 19.13 & 101.25 & 94.71 & 0.076 \\
\hline
\end{tabular}




\begin{tabular}{|c|c|c|c|c|c|c|c|c|c|}
\hline $\begin{array}{l}\text { Evaporation Rale } \\
\text { Off-gas Flow }\end{array}$ & $\begin{array}{l}5.5 \\
50\end{array}$ & $\begin{array}{c}\text { Evaporation } \\
\text { Rate, gpm }\end{array}$ & $\begin{array}{c}\text { Orf-gas Flow } \\
\text { SCFM }\end{array}$ & $\begin{array}{l}\text { Water Lost in } \\
\text { off-gas, GPM }\end{array}$ & $\begin{array}{l}\text { Condensale } \\
\text { Flow, GPM }\end{array}$ & \begin{tabular}{|l} 
Condenser U \\
But $/ \mathrm{hr} \mathrm{f}^{\wedge} \wedge \mathrm{F}$
\end{tabular} & $\begin{array}{l}\text { Condensate } \\
\text { Temp, }{ }^{\circ} \mathrm{F}\end{array}$ & $\begin{array}{c}\text { Off-gas Temp } \\
{ }_{0} \mathrm{~F}\end{array}$ & $\begin{array}{c}\text { Tube Side } \Delta \\
\text { psia }\end{array}$ \\
\hline Dala Poinls & $\frac{1}{1}$ & 2.63 & 51.44 & 0.00 & 2.63 & 27.09 & 110.25 & 104.88 & 0.025 \\
\hline Used for & 2 & 6.05 & 37.65 & 0.09 & 5.96 & 66.51 & 106.25 & 126.43 & 0.085 \\
\hline Interpolation/ & 4 & 2.63 & 110.68 & 0.00 & 2.63 & 27.37 & 109.12 & 106.14 & 0.031 \\
\hline Extrapolation & 5 & 5.91 & 107.92 & 0.00 & 5.91 & 66.00 & 106.04 & 124.71 & 0.092 \\
\hline \multirow{3}{*}{\multicolumn{4}{|c|}{ 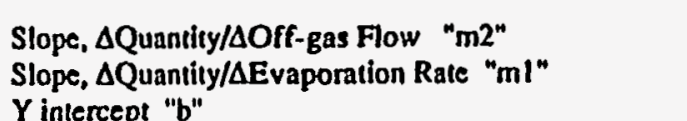 }} & & 00007 & 0.0100 & .00108 & 00009 & 00001 \\
\hline & & & & 0.0118 & 0.9882 & 11.6735 & -1.0869 & 5.9968 & 0.0184 \\
\hline & & & & 0.0278 & -0.0278 & .4 .2816 & 113.4234 & 89.6585 & -0.0306 \\
\hline Interpolated Values & & 5.5 & 50 & 0.06 & 5.44 & 60.42 & 106.91 & 122.68 & 0.077 \\
\hline
\end{tabular}

\begin{tabular}{|c|c|c|c|c|c|c|c|c|c|}
\hline $\begin{array}{c}\text { Evaporation Rate } \\
\text { Off-gas Flow }\end{array}$ & $\begin{array}{l}5.5 \\
100 \\
\end{array}$ & $\begin{array}{c}\text { Evsporalion } \\
\text { Rate, gpm }\end{array}$ & $\begin{array}{l}\text { Off-gas Flow } \\
\text { SCFM }\end{array}$ & $\begin{array}{l}\text { Water Lost in } \\
\text { off-gas, GPM }\end{array}$ & $\begin{array}{l}\text { Condensale } \\
\text { Flow, GPM }\end{array}$ & $\begin{array}{l}\text { Condenser U } \\
\text { Bru/hr ft^2 F }\end{array}$ & $\begin{array}{l}\text { Condensale } \\
\text { Temp. }{ }^{\circ} \mathrm{F}\end{array}$ & $\begin{array}{c}\text { Off-gas Temp } \\
\text { of }\end{array}$ & $\begin{array}{c}\text { Tube Side } \Delta \\
\text { psia }\end{array}$ \\
\hline Data Points & 1 & 2.63 & 51.44 & 0.00 & .2 .63 & 27.09 & 110.25 & 104.88 & 0.025 \\
\hline Used for & 2 & 6.05 & 37.65 & 0.09 & 5.96 & 66.51 & 106.25 & 126.43 & 0.085 \\
\hline Interpolation/ & 4 & 2.63 & 110.68 & 0.00 & 2.63 & 27.37 & 109.12 & 106.14 & 0.031 \\
\hline Extrapolation & 5 & 5.91 & 107.92 & 0.00 & 5.91 & 66.00 & 106.04 & 124.71 & 0.092 \\
\hline
\end{tabular}

Slope, $\Delta$ Quantity/AOrf-gas Flow "m2" Slope, $\Delta$ Quantity/AEvaporation Rate "ml" $Y$ intercept "b"

Interpolated Values $\Rightarrow>$

\begin{tabular}{|c|}
\hline \\
\hline
\end{tabular}

\begin{tabular}{|c|c|c|c|c|c|c|}
\hline \multicolumn{1}{c|}{} & -0.0007 & 0.0007 & 0.0100 & -0.0108 & 0.0009 & 0.0001 \\
& 0.0118 & 0.9882 & 11.6735 & -1.0869 & 5.9968 & 0.0184 \\
& 0.0278 & -0.0278 & -4.2816 & 113.4234 & 89.6585 & -0.0306 \\
\hline 100 & 0.02 & 5.48 & 60.92 & 106.37 & 122.73 & 0.083 \\
\hline
\end{tabular}

\begin{tabular}{|c|c|c|c|c|c|c|c|c|c|}
\hline $\begin{array}{c}\text { Evaporation Rate } \\
\text { Off-gas Flow }\end{array}$ & $\begin{array}{l}5.5 \\
200 \\
\end{array}$ & $\begin{array}{l}\text { Evaporation } \\
\text { Rate, gpm }\end{array}$ & $\begin{array}{c}\text { Off-gas Flow } \\
\text { SCFM }\end{array}$ & $\begin{array}{l}\text { Water Lost in } \\
\text { off-gas, OPM }\end{array}$ & $\begin{array}{l}\text { Condensate } \\
\text { Flow, GPM }\end{array}$ & $\begin{array}{l}\text { Condenser U } \\
\text { Btu/hr f^^2 F }\end{array}$ & $=\begin{array}{l}\text { Condensate } \\
\text { Temp. }{ }^{\circ} \mathbf{F}\end{array}$ & $\begin{array}{c}\text { Off-gas Temp } \\
{ }^{\circ} \mathbf{F}\end{array}$ & $\begin{array}{c}\text { Tube Side } \Delta \\
\text { psia }\end{array}$ \\
\hline Data Poinis & 4 & 2.63 & 110.68 & 0.00 & 2.63 & 27.37 & 109.12 & 106.14 & 0.031 \\
\hline Used for & $s$ & 5.91 & 107.92 & 0.00 & 5.91 & 66.00 & 106.04 & 124.71 & 0.092 \\
\hline Interpolation/ & 8 & 2.67 & 247.55 & 0.16 & 2.51 & 25.81 & 101.90 & 99.08 & 0.049 \\
\hline Extrapolation & 9 & 5.82 & 192.73 & 0.49 & 5.33 & 58.45 & 103.51 & 113.54 & 0.117 \\
\hline
\end{tabular}


Slope, $\Delta$ Quantily/ $\Delta$ Off-gas Flow "m2" Slope, $\Delta$ Quantily/ $\Delta$ Evaporation Rate "ml" $Y$ intercept " $b$ "

Interpolated Values $\Rightarrow$

5.5

\begin{tabular}{c|c|c|c|c}
\cline { 2 - 4 } & 0.0024 & -0.0024 & -0.0316 & \\
& 0.0723 & 0.9277 & 10.8195 & \\
& -0.5465 & 0.5465 & 3.5303 & 115 \\
\hline 200 & 0.34 & 5.16 & 56.71 & \\
\hline
\end{tabular}

-0.0465
-0.6525
115.5851

102.69

$-0.0732$

4.5069

103.7202

0.0002

0.0216

113.87

0.105

\begin{tabular}{|c|c|c|c|c|c|c|c|c|c|}
\hline $\begin{array}{c}\text { Evaporation Rate } \\
\text { Off-gas Flow }\end{array}$ & $\begin{array}{r}5.5 \\
300 \\
\end{array}$ & $\begin{array}{c}\text { Evapomition } \\
\text { Rate. gpm }\end{array}$ & $\begin{array}{l}\text { Off-gas Flow } \\
\text { SCFM }\end{array}$ & $\begin{array}{l}\text { Water Lost in } \\
\text { off-gas, GPM }\end{array}$ & $\begin{array}{l}\text { Condensate } \\
\text { Flow, GPM } \\
\end{array}$ & $\begin{array}{l}\text { Condenser U } \\
\text { Blu/hr ft^2 F }\end{array}$ & $\begin{array}{l}\text { Condensale } \\
\text { Temp. }{ }^{\circ} \mathrm{F}\end{array}$ & \begin{tabular}{|c|} 
Off-gas Temp \\
of
\end{tabular} & $\begin{array}{c}\text { Tube Side } \Delta \\
\text { psia }\end{array}$ \\
\hline Data Points & 8 & 2.67 & 247.55 & 0.16 & 2.51 & 25.81 & 101.90 & 99.08 & 0.049 \\
\hline Used for & 9 & 5.82 & 192.73 & 0.49 & 5.33 & 58.45 & 103.51 & 113.54 & 0.117 \\
\hline Interpolation/ & 12 & 2.83 & 326.19 & 0.43 & 2.40 & 25.75 & 103.90 & 99.49 & 0.062 \\
\hline Extrapolation & 13 & 5.99 & 348.05 & 0.63 & 5.36 & 60.19 & 104.99 & 112.09 & 0.153 \\
\hline
\end{tabular}

Slope, $\Delta$ Quantity/ $\Delta$ Off-gas Flow "m2" '

Slope, $\Delta$ Quantity/ $\Delta$ Evaporation Rate "ml"

$Y$ intercept "b"

Interpolated Values $\Rightarrow$

\begin{tabular}{|l|l|}
\hline 5.5 & 300 \\
\hline
\end{tabular}

\begin{tabular}{|c|c|c|c|c|c|c|}
\hline \multicolumn{1}{c|}{} & 0.0013 & -0.0013 & -0.0048 & 0.0121 & -0.0117 & 0.0002 \\
0.0919 & 0.9081 & 10.6077 & 0.4941 & 4.2339 & 0.0261 \\
& -0.3366 & 0.3366 & -2.0220 & 98.0606 & 90.9954 & -0.0691 \\
\hline 300 & 0.56 & 4.94 & 54.88 & 104.41 & 110.76 & 0.130 \\
\hline
\end{tabular}

\begin{tabular}{|c|c|c|c|c|c|c|c|c|c|}
\hline $\begin{array}{c}\text { Evaporation Rate } \\
\text { Off-gas Flow }\end{array}$ & $\begin{array}{l}5.5 \\
400\end{array}$ & $\begin{array}{l}\text { Evaporation } \\
\text { Rate, gpm }\end{array}$ & $\begin{array}{l}\text { Orf-gas Flow } \\
\text { SCFM }\end{array}$ & $\begin{array}{l}\text { Water Lost in } \\
\text { off-gas, GPM }\end{array}$ & $\begin{array}{l}\text { Condensale } \\
\text { Flow, GPM }\end{array}$ & \begin{tabular}{|l|} 
Condenser U \\
Btu/hr $\mathrm{ft}^{\wedge} 2 \mathrm{~F}$
\end{tabular} & $\begin{array}{c}\text { Condensate } \\
\text { Temp, }{ }^{\circ} \mathrm{F}\end{array}$ & $\begin{array}{c}\text { Off-gas Temp } \\
{ }^{\circ} \mathrm{F}\end{array}$ & $\begin{array}{c}\text { Tube Side } \Delta \\
\text { psia }\end{array}$ \\
\hline $\begin{array}{l}\text { Data Points } \\
\text { Used for } \\
\text { Interpolation/ } \\
\text { Extrapolation }\end{array}$ & $\begin{array}{l}12 \\
13 \\
16 \\
17\end{array}$ & $\begin{array}{l}2.83 \\
5.99 \\
2.97 \\
6.10\end{array}$ & \begin{tabular}{|l|}
326.19 \\
348.05 \\
481.03 \\
451.07
\end{tabular} & \begin{tabular}{|l|}
0.43 \\
0.63 \\
0.66 \\
0.89
\end{tabular} & $\begin{array}{l}2.40 \\
5.36 \\
2.31 \\
5.20\end{array}$ & \begin{tabular}{|l|}
25.75 \\
60.19 \\
24.90 \\
58.07
\end{tabular} & $\begin{array}{l}103.90 \\
104.99 \\
101.64 \\
104.01\end{array}$ & \begin{tabular}{|c|}
99.49 \\
112.09 \\
97.11 \\
109.98 \\
\end{tabular} & \begin{tabular}{|l|}
0.062 \\
0.153 \\
0.087 \\
0.168 \\
\end{tabular} \\
\hline
\end{tabular}

Slope, $\Delta$ Quantity/ $\Delta$ Off-gas Flow " $m 2$ "

Slope, $\Delta$ Quantity/ $\Delta$ Evaporation Rate "ml"

$Y$ intercept " $b$ "

Interpolaied Values $\Rightarrow$

\begin{tabular}{|l|l|}
\hline 5.5 & 400 \\
\hline
\end{tabular}

0.00
0.07
-0.3

\begin{tabular}{|c|c|c|c|c|}
\hline-0.0017 & -0.0199 & -0.0135 & -0.0206 & 0.0001 \\
0.9286 & 10.7312 & 0.5322 & 4.0255 & 0.0276 \\
0.3521 & 2.2276 & 106.6854 & 94.9572 & -0.0594 \\
\hline 4.78 & 53.31 & 104.20 & 108.85 & 0.146 \\
\hline
\end{tabular}

109.98

0.72 


\begin{tabular}{|c|c|c|c|c|c|c|c|c|c|}
\hline $\begin{array}{c}\text { Evaporation Rate } \\
\text { Off-gas Flow }\end{array}$ & $\begin{array}{c}5.5 \\
500\end{array}$ & $\begin{array}{c}\text { Evaporation } \\
\text { Rate, gpm }\end{array}$ & $\begin{array}{c}\text { Off-gas Flow Water Lost in } \\
\text { SCFM }\end{array}$ & $\begin{array}{c}\text { Condensate } \\
\text { off-gas, GPM }\end{array}$ & $\begin{array}{c}\text { Condenser U } \\
\text { Flow, GPM }\end{array}$ & $\begin{array}{c}\text { Condensate } \\
\text { Btu/hr f^^2 F }\end{array}$ & $\begin{array}{c}\text { Orf-gas Temp } \\
\text { Temp, }{ }^{\circ} \text { F }\end{array}$ & $\begin{array}{c}\text { Tube Side } \Delta \\
\text { of }\end{array}$ \\
\hline Data Points & 12 & 2.83 & 326.19 & 0.43 & 2.40 & 25.75 & 103.90 & 99.49 & 0.062 \\
Used for & 13 & 1.99 & 348.05 & 0.63 & 5.36 & 60.19 & 104.99 & 112.09 & 0.153 \\
Interpolation/ & 16 & 2.97 & 481.03 & 0.66 & 2.31 & 24.90 & 101.64 & 97.11 & 0.087 \\
Extrapolation & 17 & 6.10 & 451.07 & 0.89 & 5.20 & 58.07 & 104.01 & 109.98 & 0.168 \\
\hline
\end{tabular}

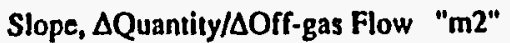
Slope, $\Delta$ Quantity/ EEvaporation Rate "ml" $Y$ intercept " $b$ "

Interpolated Values $\Rightarrow$

$$
5.5
$$

.

\begin{tabular}{l|l|l|}
\hline 0.0017 & -0.0017 & -0.019 \\
\hline
\end{tabular}

104.01

109.98

\begin{tabular}{|c|c|c|c|c|c|c|c|c|c|}
\hline $\begin{array}{c}\text { Evaporation Ratc } \\
\text { Off-gas Flow }\end{array}$ & $\begin{array}{c}8 \\
50\end{array}$ & $\begin{array}{l}\text { Evaporation } \\
\text { Rale, gpm }\end{array}$ & $\begin{array}{c}\text { Off-gas Flow } \\
\text { SCFM }\end{array}$ & $\begin{array}{l}\text { Water Lost in } \\
\text { off-gas, GPM }\end{array}$ & $\begin{array}{l}\text { Condensate } \\
\text { Flow, GPM }\end{array}$ & $\begin{array}{l}\text { Condenser U } \\
\text { Blu/hr ft^2 F }\end{array}$ & $\begin{array}{c}\text { Condensate } \\
\text { Temp. }^{\circ} \mathbf{F}\end{array}$ & $\begin{array}{c}\text { Off-gas Temp } \\
{ }^{\circ} \mathrm{F}\end{array}$ & $\begin{array}{c}\text { Tube Side } \Delta \\
\text { psia }\end{array}$ \\
\hline Data Points & 2 & $\cdot 6.05$ & 37.65 & 0.09 & 5.96 & 66.51 & 106.25 & 126.43 & 0.085 \\
\hline Used for & 3 & 9.44 & 27.36 & 0.00 & 9.44 & 110.80 & 108.64 & 142.46 & 0.202 \\
\hline Interpulationy & 5 & 5.91 & 107.92 & 0.00 & 5.91 & 66.00 & 106.04 & 124.71 & 0.092 \\
\hline Extrapolation & 6 & 10.06 & 104.66 & 0.38 & 9.68 & 114.43 & 110.17 & 142.27 & 0.234 \\
\hline \multirow{3}{*}{\multicolumn{4}{|c|}{ 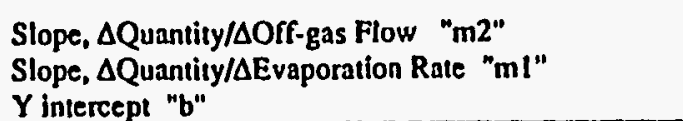 }} & 0.0020 & -0.0020 & -0.0213 & 0.0064 & -0.0282 & 0.0002 \\
\hline & & & & 0.0477 & 0.9523 & 12.1869 & 0.8890 & 4.3809 & 0.0345 \\
\hline & & & & -0.3954 & 0.3954 & -4.9513 & 100.3373 & 101.4611 & -0.1292 \\
\hline \multicolumn{2}{|c|}{ Interpolated Values $\Rightarrow$} & 8 & 50 & 0.09 & 7.91 & 91.48 & 107.77 & 135.10 & 0.155 \\
\hline
\end{tabular}

\begin{tabular}{|c|c|c|c|c|c|c|c|c|c|}
\hline $\begin{array}{c}\text { Evaporation Rate } \\
\text { Off-gas Flow }\end{array}$ & $\begin{array}{c}8 \\
100\end{array}$ & $\begin{array}{l}\text { Evaporalion } \\
\text { Rale, gpm }\end{array}$ & $\begin{array}{c}\text { Off-gas Flow } \\
\text { SCFM }\end{array}$ & $\begin{array}{l}\text { Water Lost in } \\
\text { off-gas, GPM }\end{array}$ & $\begin{array}{l}\text { Condensate } \\
\text { Flow, GPM }\end{array}$ & $\begin{array}{l}\text { Condenser U } \\
\text { Btu/hr fi^2 F }\end{array}$ & $\begin{array}{l}\text { Condensate } \\
\text { Temp. }{ }^{\circ} \mathrm{F}\end{array}$ & $\begin{array}{l}\text { Off-gas Temp } \\
{ }^{\circ} \mathrm{F}\end{array}$ & $\begin{array}{c}\text { Tube Side } \Delta \\
\text { psia }\end{array}$ \\
\hline Data Points & 2 & 6.05 & 37.65 & 0.09 & 5.96 & 66.51 & 106.25 & 126.43 & 0.085 \\
\hline Used for & 3 & 9.44 & 27.36 & 0.00 & 9.44 & 110.80 & 108,64 & 142.46 . & 0.202 \\
\hline Interpolation/ & 5 & 5.91 & 107.92 & 0.00 & 5.91 & 66.00 & 106.04 & 124.71 & 0.092 \\
\hline Extrapolation & 6 & 10.06 & 104.66 & 0.38 & 9.68 & 114.43 & 110.17 & 142.27 & 0.234 \\
\hline
\end{tabular}


Slope, $\Delta$ Quantily/ $\Delta$ Off-gas Flow "m2". Slope, $\Delta Q$ Quantily/AEvaporation Rale " $\mathrm{ml}$ " $Y$ intercept "b"

Interpolated Values $\Rightarrow$

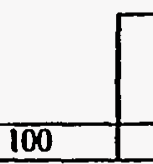

0.0020

0.0477

$-0.3954$

\begin{tabular}{|l|l|}
\hline-0.0020 & -0.0213 \\
\hline
\end{tabular}

\begin{tabular}{|c|}
\hline 0.0064 \\
0.8890 \\
100.3373 \\
\hline 108.09
\end{tabular}

$-0.0282$

$\mathbf{0 . 0 0 0 2}$

\begin{tabular}{lll}
4.3809 & 0.0345 \\
\hline
\end{tabular}

\begin{tabular}{l|r}
0.18 & 0.395 \\
\hline 0.8
\end{tabular}

\begin{tabular}{l|l}
0.9523 & -4.9513 \\
\hline 7.82 & 90.41
\end{tabular}

90.41

108.09

133.69

\begin{tabular}{|c|c|c|c|c|c|c|c|c|c|}
\hline $\begin{array}{c}\text { Evaporation Rate } \\
\text { Off-gas Flow }\end{array}$ & $\begin{array}{c}8 \\
200\end{array}$ & $\begin{array}{l}\text { Evaporation } \\
\text { Rate, gpm }\end{array}$ & $\begin{array}{c}\text { Off-gas Flow } \\
\text { SCFM }\end{array}$ & $\begin{array}{l}\text { Waler Lost in } \\
\text { off-gas, GPM }\end{array}$ & $\begin{array}{l}\text { Condensale } \\
\text { Flow, GPM }\end{array}$ & $\begin{array}{l}\text { Condenser U } \\
\text { Btu/he f(^2 F }\end{array}$ & $\begin{array}{l}\text { Condensale } \\
\text { Temp. }{ }^{\circ} \mathrm{F}\end{array}$ & $\begin{array}{c}\text { Off-gas Temp } \\
\text { of }\end{array}$ & $\begin{array}{c}\text { Tube Side } \Delta \\
\text { psia }\end{array}$ \\
\hline Data Points & 5 & 5.91 & 107.92 & 0.00 & 5.91 & 66.00 & 106.04 & 124.71 & 0.092 \\
\hline Used for & 6 & 10.06 & 104.66 & 0.38 & 9.68 & 114.43 & 110.17 & 142.27 & 0.234 \\
\hline Interpolation/ & 9 & 5.82 & 192.73 & 0.49 & 5.33 & 58.45 & 103.51 & 113.54 & 0.117 \\
\hline Extrapolation & 10 & 9.32 & 210.14 & 0.51 & 8.81 & 99.93 & 106.77 & 128.65 & 0.249 \\
\hline
\end{tabular}

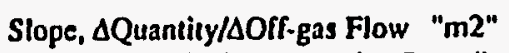
Slope, $\Delta Q$ Quantity/AEvaporation Rate " $\mathrm{ml}$ " $Y$ intercept "b" Interpolated Values $\Rightarrow$

\begin{tabular}{|c|c|}
\hline 8 & \\
\hline
\end{tabular}

200

\begin{tabular}{l|l}
0.0033 & \\
0.0504 &
\end{tabular}

\begin{tabular}{c|c}
0.003462 & 0.54 \\
\hline 0.51 & 7.49
\end{tabular}

\begin{tabular}{|c|c|c|c|c|}
\hline-0.0033 & -0.0626 & -0.0265 & -0.1091 & 0.0004 \\
0.9496 & 11.8505 & 1.0107 & 4.4467 & 0.0351 \\
0.5462 & 2.1339 & 102.8427 & 109.4853 & -0.1564 \\
\hline 7.49 & 84.42 & 105.62 & 123.24 & 0.198 \\
\hline
\end{tabular}

\begin{tabular}{|c|c|c|c|c|c|c|c|c|c|}
\hline $\begin{array}{c}\text { Evaporation Rate } \\
\text { Off-gas Flow }\end{array}$ & $\begin{array}{c}8 \\
300\end{array}$ & $\begin{array}{l}\text { Evaporation } \\
\text { Rate, gpm }\end{array}$ & \begin{tabular}{|c|} 
Off-gas Flow \\
SCFM
\end{tabular} & $\begin{array}{l}\text { Waler Lost in } \\
\text { off-gas, OPM }\end{array}$ & $\begin{array}{l}\text { Condensale } \\
\text { Flow, GPM } \\
\end{array}$ & $\begin{array}{l}\text { Condenser U } \\
\text { Btu/hr ft^2 F }\end{array}$ & \begin{tabular}{|c|} 
Condensate \\
Temp, ${ }^{\circ} \mathrm{F}$
\end{tabular} & $\begin{array}{c}\text { Off-gas Temp } \\
{ }^{\circ} \mathrm{F}\end{array}$ & $\begin{array}{c}\text { Tube Side } \Delta \\
\text { psin }\end{array}$ \\
\hline $\begin{array}{l}\text { Data Points } \\
\text { Used for } \\
\text { Interpolation/ } \\
\text { Extrapolation }\end{array}$ & $\begin{array}{l}9 \\
10 \\
13 \\
14\end{array}$ & $\begin{array}{l}5.82 \\
9.32 \\
5.99 \\
9.64 \\
\end{array}$ & \begin{tabular}{l|}
192.73 \\
210.14 \\
348.05 \\
329.43 \\
\end{tabular} & \begin{tabular}{|l|}
0.49 \\
0.51 \\
0.63 \\
0.96 \\
\end{tabular} & \begin{tabular}{|l|}
5.33 \\
8.81 \\
5.36 \\
8.68 \\
\end{tabular} & \begin{tabular}{|c|}
58.45 \\
99.93 \\
60.19 \\
100.86 \\
\end{tabular} & \begin{tabular}{l|}
103.51 \\
106.77 \\
104.99 \\
110.65 \\
\end{tabular} & \begin{tabular}{|l|}
113.54 \\
128.65 \\
112.09 \\
129.60 \\
\end{tabular} & \begin{tabular}{|l|}
0.117 \\
0.249 \\
0.153 \\
0.283 \\
\end{tabular} \\
\hline 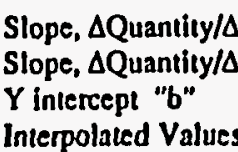 & $\begin{array}{l}\text { ff-gas } \\
\text { ivapor }\end{array}$ & $\begin{array}{l}\text { Flow "m2" } \\
\text { ation Rate "m }\end{array}$ & 300 & $\begin{array}{c}0.0019 \\
0.0507 \\
-0.2455 \\
0.72 \\
\end{array}$ & $\begin{array}{l}0.0019 \\
0.9493 \\
0.2455 \\
7.28 \\
\end{array}$ & $\begin{array}{c}-0.0092 \\
11.4771 \\
-5.9487 \\
83.12\end{array}$ & $\begin{array}{c}0.0160 \\
1.2621 \\
92.4621 \\
107.34 \\
\end{array}$ & $\begin{array}{c}-0.0105 \\
4.5659 \\
88.6829 \\
122.06 \\
\end{array}$ & $\begin{array}{r}0.0002 \\
0.0368 \\
-0.1338 \\
0.217 \\
\end{array}$ \\
\hline
\end{tabular}




\begin{tabular}{|c|c|c|c|c|c|c|c|c|c|}
\hline $\begin{array}{c}\text { Evaporation Rate } \\
\text { Off-gas Flow }\end{array}$ & $\begin{array}{r}8 \\
400 \\
\end{array}$ & $\begin{array}{l}\text { Evaporation } \\
\text { Rale, gpm }\end{array}$ & $\begin{array}{c}\text { Off-gas Flow } \\
\text { SCFM }\end{array}$ & $\begin{array}{l}\text { Waler Lost in } \\
\text { off-gas, GPM } \\
\end{array}$ & $\begin{array}{l}\text { Condensale } \\
\text { Flow, GPM } \\
\end{array}$ & $\begin{array}{l}\text { Condenser U } \\
\text { Btu/hr fi^2 F }\end{array}$ & $\begin{array}{l}\text { Condensale } \\
\text { Temp. }{ }^{\circ} \mathrm{F}\end{array}$ & \begin{tabular}{|c|}
$\begin{array}{c}\text { Off-gas Temp } \\
{ }^{\circ} \mathrm{F}\end{array}$ \\
\end{tabular} & \begin{tabular}{|c|} 
Tube Side $\Delta$ \\
psia
\end{tabular} \\
\hline Data Points & 13 & 5.99 & 348.05 & 0.63 & 5.36 & 60.19 & 104.99 & 112.09 & 0.153 \\
\hline Used for & 14 & 9.64 & 329.43 & 0.96 & 8.68 & 100.86 & 110.65 & 129.60 & 0.283 \\
\hline Interpolation/ & 17 & 6.10 & 451.07 & 0.89 & 5.20 & 58.07 & 104.01 & 109.98 & 0.168 \\
\hline Extrapolation & 18 & 9.48 & 422.97 & 0.92 & 8.56 & 98.30 & 110.10 & 127.40 & 0.312 \\
\hline
\end{tabular}

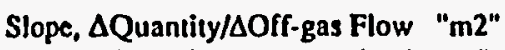
Slope, $\Delta$ Quantity/ Evaporation Rate " $\mathrm{ml}$ " $Y$ intercept "b"

Interpolated Values $\Rightarrow$

\begin{tabular}{|r|r|}
\hline 8 & 400 \\
\hline
\end{tabular}

\begin{tabular}{|c|c|c|c|c|c|c|}
\hline & 0.0012 & -0.0012 & -0.0213 & -0.0076 & -0.0209 & 0.0002 \\
& 0.0597 & 0.9403 & 11.3514 & 1.6173 & 4.8238 & 0.0403 \\
& -0.0896 & 0.0896 & -0.9164 & 97.7544 & 90.2582 & -0.1749 \\
\hline 400 & 0.88 & 7.12 & 81.37 & 107.67 & 120.48 & 0.240 \\
\hline
\end{tabular}

\begin{tabular}{|c|c|c|c|c|c|c|c|c|c|}
\hline $\begin{array}{c}\text { Evaporation Rate } \\
\text { Off-gas Flow }\end{array}$ & $\begin{array}{c}8 \\
500\end{array}$ & $\begin{array}{c}\text { Evaporation } \\
\text { Rate, gpm }\end{array}$ & $\begin{array}{l}\text { Off-gas Flow } \\
\text { SCFM }\end{array}$ & $\begin{array}{l}\text { Water Lost in } \\
\text { off-gas, GPM }\end{array}$ & $\begin{array}{l}\text { Condensale } \\
\text { Flow, GPM }\end{array}$ & $\begin{array}{l}\text { Condenser U } \\
\text { Btu/hr ft^2 F }\end{array}$ & $\begin{array}{l}\text { Condensate } \\
\text { Temp. }{ }^{\circ} \mathrm{F}\end{array}$ & $\begin{array}{c}\text { Off-gas Temp } \\
{ }^{\circ} \mathrm{F}\end{array}$ & $\begin{array}{c}\text { Tube Side } \Delta \\
\text { psia }\end{array}$ \\
\hline Data Points & 13 & 5.99 & 348.05 & 0.63 & 5.36 & 60.19 & 104.99 & 112.09 & 0.153 \\
\hline Used for & 14 & 9.64 & 329.43 & 0.96 & 8.68 & 100.86 & 110.65 & 129.60 & 0.283 \\
\hline Interpolation/ & 17 & 6.10 & 451.07 & 0.89 & 5.20 & 58.07 & 104.01 & 109.98 & 0.168 \\
\hline Extrapolation & 18 & 9.48 & 422.97 & 0.92 & 8.56 & 98.30 & 110.10 & 127.40 & 0.312 \\
\hline
\end{tabular}

Slope, $\Delta$ Quantity/dOff-gas Flow "m2" Slope, $\Delta$ Quantity/ Evaporation Rate "ml" $Y$ intercept " $b$ "

Interpolated Values $\Rightarrow$

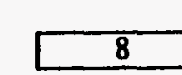

0.0012

$\begin{array}{r}0.56 \\ \hline\end{array}$

98.30

110.10

\begin{tabular}{|c|c|c|c|c|c|c|c|c|c|}
\hline Interpolated Values & & 8 & 500 & 1.00 & 7.00 & $79.24^{\circ}$ & 106.91 & 118.39 & 0.263 \\
\hline $\begin{array}{c}\text { Evaporation Rale } \\
\text { Off-gas Flow }\end{array}$ & $\begin{array}{l}10 \\
50\end{array}$ & $\begin{array}{c}\text { Evaporation } \\
\text { Rate, gpm }\end{array}$ & $\begin{array}{c}\text { Off-gas Flow } \\
\text { SCFM }\end{array}$ & $\begin{array}{l}\text { Water Lost in } \\
\text { off-gas, GPM }\end{array}$ & $\begin{array}{l}\text { Condensale } \\
\text { Flow, GPM }\end{array}$ & $\begin{array}{l}\text { Condenser U } \\
\text { Btu/hr f(t^2 F }\end{array}$ & $\begin{array}{l}\text { Condensate } \\
\text { Temp, }{ }^{\circ} \mathrm{F}\end{array}$ & $\begin{array}{c}\text { Off-gas Temp } \\
{ }^{\circ} \text { F }\end{array}$ & $\begin{array}{c}\text { Tube Side } \Delta \\
\text { psia }\end{array}$ \\
\hline Data Points & 2 & 6.05 & 37.65 & 0.09 & 5.96 & 66.51 & 106.25 & 126.43 & 0.085 \\
\hline Used for & 3 & 9.44 & 27.36 & 0.00 & 9.44 & 110.80 & 108.64 & 142.46 & 0.202 \\
\hline Interpolation/ & 5 & 5.91 & 107.92 & 0.00 & 5.91 & 66.00 & 106.04 & 124.71 & 0.092 \\
\hline Extrapolation & 6 & 10.06 & 104.66 & 0.38 & 9.68 & 114.43 & 110.17 & 142.27 & 0.234 \\
\hline
\end{tabular}




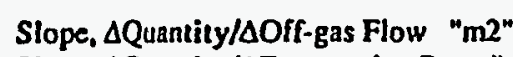

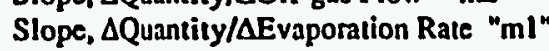
$Y$ intercept "b"

Inierpolated Values $=>$

\begin{tabular}{|c|c|}
\hline 10 & \\
\hline
\end{tabular}

\begin{tabular}{|c|c|c|c|c|c|c|}
\hline & 0.0020 & -0.0020 & -0.0213 & 0.0064 & -0.0282 & 0.0002 \\
& 0.0477 & 0.9523 & 12.1869 & 0.8890 & 4.3809 & 0.0345 \\
-0.3954 & 0.3954 & -4.9513 & 100.3373 & 101.4611 & -0.1292 \\
\hline 50 & 0.18 & 9.82 & 115.85 & 109.55 & 143.86 & 0.224 \\
\hline
\end{tabular}

\begin{tabular}{|c|c|c|c|c|c|c|c|c|c|}
\hline $\begin{array}{c}\text { Evaporation Rate } \\
\text { Off-gas Flow }\end{array}$ & $\begin{array}{c}10 \\
100\end{array}$ & $\begin{array}{l}\text { Evaporation } \\
\text { Rale, gpm }\end{array}$ & $\begin{array}{l}\text { Off-gas Flow } \\
\text { SCFM }\end{array}$ & $\begin{array}{l}\text { Water Lost in } \\
\text { off-gas, GPM }\end{array}$ & $\begin{array}{l}\text { Condensate } \\
\text { Flow, GPM }\end{array}$ & $\begin{array}{l}\text { Condenser U } \\
\text { Btu/hr ft^^2 F }\end{array}$ & $\begin{array}{l}\text { Condensate } \\
\text { Temp, }{ }^{\circ} \mathrm{F}\end{array}$ & \begin{tabular}{|c|} 
Off-gas Temp \\
${ }^{\circ} \mathrm{F}$
\end{tabular} & $\begin{array}{c}\text { Tube Side } \Delta \\
\text { psia }\end{array}$ \\
\hline Data Points & 2 & 6.05 & 37.65 & 0.09 & 5.96 & 66.51 & 106.25 & .126 .43 & 0.085 \\
\hline Used for & 3 & 9.44 & 27.36 & 0.00 & 9.44 & 110.80 & 108.64 & 142.46 & 0.202 \\
\hline Interpolation & 5 & 5.91 & 107.92 & 0.00 & 5.91 & 66.00 & 106.04 & 124.71 & 0.092 \\
\hline Extrapolation & 6 & 10.06 & 104.66 & 0.38 & 9.68 & 114.43 & 110.17 & 142.27 & 0.234 \\
\hline
\end{tabular}

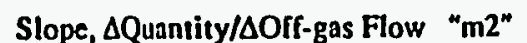

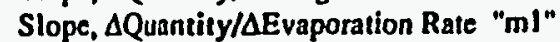

$Y$ intercept "b"

Interpolated Values $\Rightarrow$

\begin{tabular}{l|l}
\hline 10 & 100 \\
\hline
\end{tabular}

100

0.0020

0.0020

114.43

110.17

142.27

0.234

\begin{tabular}{|c|c|c|c|c|c|c|c|c|c|}
\hline $\begin{array}{c}\text { Evaporation Rate } \\
\text { Off-gas Flow }\end{array}$ & $\begin{array}{c}10 \\
200\end{array}$ & $\begin{array}{c}\text { Evaporation } \\
\text { Rate, gpm }\end{array}$ & $\begin{array}{l}\text { Off:gas Flow } \\
\text { SCFM }\end{array}$ & $\begin{array}{l}\text { Water Lost in } \\
\text { off-gas, GPM }\end{array}$ & $\begin{array}{l}\text { Condensate } \\
\text { Flow, GPM }\end{array}$ & \begin{tabular}{|l|} 
Condenser U \\
Btu/hr fı^2 F
\end{tabular} & $\begin{array}{l}\text { Condensate } \\
\text { Temp, }{ }^{\circ} \mathbf{F}\end{array}$ & $\begin{array}{c}\text { Off-gas Temp } \\
{ }^{\circ} \mathrm{F}\end{array}$ & $\begin{array}{c}\text { Tube Side } \Delta \\
\text { psia }\end{array}$ \\
\hline $\begin{array}{l}\text { Data Points } \\
\text { Used for } \\
\text { Interpolation/ } \\
\text { Extrapolation }\end{array}$ & $\begin{array}{c}5 \\
6 \\
10 \\
11\end{array}$ & \begin{tabular}{|c|}
5.91 \\
10.06 \\
9.32 \\
11.00 \\
\end{tabular} & \begin{tabular}{|l|}
107.92 \\
104.66 \\
210.14 \\
220.54 \\
\end{tabular} & \begin{tabular}{|l|}
0.00 \\
0.38 \\
0.51 \\
1.01 \\
\end{tabular} & $\begin{array}{l}5.91 \\
9.68 \\
8.81 \\
9.99 \\
\end{array}$ & \begin{tabular}{|c|}
66.00 \\
114.43 \\
99.93 \\
114.14 \\
\end{tabular} & $\begin{array}{l}106.04 \\
110.17 \\
106.77 \\
111.09 \\
\end{array}$ & \begin{tabular}{|l|}
124.71 \\
142.27 \\
128.65 \\
134.00 \\
\end{tabular} & $\begin{array}{l}0.092 \\
0.234 \\
0.249 \\
0.291 \\
\end{array}$ \\
\hline 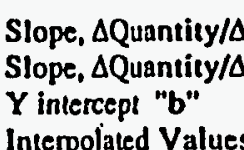 & $\begin{array}{l}f-g a \\
\text { apo }\end{array}$ & $\begin{array}{l}\text { Flow "m2" } \\
\text { ion Rate "m }\end{array}$ & 200 & $\begin{array}{r}0.0030 \\
0.1169 \\
-1.0721 \\
0.70\end{array}$ & $\begin{array}{c}-0.0030 \\
0.8831 \\
1.0721 \\
9.30\end{array}$ & $\begin{array}{l}-0.0721 \\
11.2813 \\
7.8578 \\
106.25\end{array}$ & $\begin{array}{c}-0.0150 \\
1.1907 \\
100.1189 \\
109.03\end{array}$ & $\begin{array}{c}-0.1019 \\
4.1111 \\
111.4855 \\
132.22\end{array}$ & $\begin{array}{c}0.0003 \\
0.0329 \\
-0.1334 \\
0.259\end{array}$ \\
\hline
\end{tabular}




\begin{tabular}{|c|c|c|c|c|c|c|c|c|c|}
\hline $\begin{array}{c}\text { Evaporation Rate } \\
\text { Off-gas Flow }\end{array}$ & $\begin{array}{c}10 \\
300\end{array}$ & $\begin{array}{l}\text { Evaporation } \\
\text { Rale, gpm }\end{array}$ & $\begin{array}{l}\text { Off-gas Flow } \\
\text { SCFM }\end{array}$ & $\begin{array}{l}\text { Water Lost in } \\
\text { off-gas, GPM }\end{array}$ & $\begin{array}{l}\text { Condensate } \\
\text { Flow, GPM }\end{array}$ & $\begin{array}{l}\text { Condenser U } \\
\text { Btu/hr ft^2 F }\end{array}$ & $\begin{array}{l}\text { Condensate } \\
\text { Temp, }{ }^{\circ} \mathrm{F}\end{array}$ & $\begin{array}{c}\text { Off-gas Temp } \\
\text { of }\end{array}$ & $\begin{array}{c}\text { Tube Side } \Delta \\
\text { psia }\end{array}$ \\
\hline Data Points. & 10 & 9.32 & 210.14 & 0.51 & 8.81 & 99.93 & 106.77 & 128.65 & 0.249 \\
\hline & 11 & 11.0 & & 1.0 & 9. & & & & 0.291 \\
\hline Inte & 14 & 9.6 & & 0.9 & 8. & & & & 283 \\
\hline & 15 & & & 1.52 & 9.33 & & & & 0.314 \\
\hline \multirow{3}{*}{\multicolumn{4}{|c|}{ 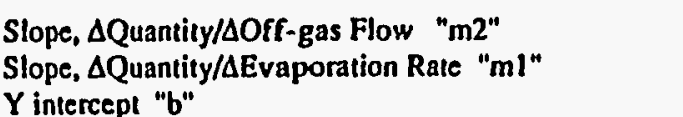 }} & 0.0040 & .0 .0040 & -0.0 & $\overline{0.0346}$ & & 0.0003 \\
\hline & & & & 0.3953 & 0.6047 & & 3.4463 & & 0.0276 \\
\hline & & & & -4.0679 & 4.0679 & 27.4655 & 66.8513 & 87.8815 & -0.0642 \\
\hline \multicolumn{2}{|c|}{ Interpolaied Values $=>$} & 10 & 300 & 1.08 & 8.92 & 104.07 & 111.69 & 131.65 & 0.289 \\
\hline
\end{tabular}

\begin{tabular}{|c|c|c|c|c|c|c|c|c|c|}
\hline $\begin{array}{c}\text { Evaporation Rale } \\
\text { Off-gas Flow }\end{array}$ & $\begin{array}{r}10 \\
400 \\
\end{array}$ & $\begin{array}{c}\text { Evaporation } \\
\text { Rale, gpm }\end{array}$ & $\begin{array}{c}\text { Off-gas Flow } \\
\text { SCFM }\end{array}$ & $\begin{array}{l}\text { Water Lost in } \\
\text { off-gas, GPM }\end{array}$ & $\begin{array}{l}\text { Condensate } \\
\text { Flow, GPM }\end{array}$ & $\begin{array}{l}\text { Condenser U } \\
\text { Btu/hr ft^2 F }\end{array}$ & $\begin{array}{l}\text { Condensale } \\
\text { Ternp. }{ }^{\circ} \mathbf{F}\end{array}$ & \begin{tabular}{|c|} 
Off-gas Temp \\
${ }^{\circ} \mathrm{F}$
\end{tabular} & $\begin{array}{c}\text { Tube Side } \Delta \\
\text { psia }\end{array}$ \\
\hline Dala Points & 14 & 9.64 & 329.43 & 0.96 & 8.68 & 100.86 & 110.65 & 129.60 & 0.283 \\
\hline Used for & 15 & 10.85 & 279.94 & 1.52 & 9.33 & 110.84 & 115.52 & 136.51 & 0.314 \\
\hline Interpolation/ & 18 & 9.48 & 422.97 & 0.92 & 8.56 & 98.30 & 110.10 & 127.40 & 0.312 \\
\hline Extrapolation & 19 & 10.76 & 332.25 & 2.33 & 8.44 & 99.46 & 115.51 & 132.77 & 0.332 \\
\hline
\end{tabular}

Slope, $\Delta$ Quantily/AOff-gas Flow "m2"

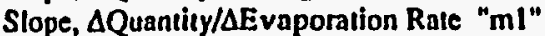
$Y$ intercept "b"

Interpolated Values $=>$

\begin{tabular}{|l|l}
\hline 10 & \\
\hline
\end{tabular}

0
1
-1

0.0052 8.44

\begin{tabular}{|c|c|c|c|c|c|c|c|c|c|}
\hline $\begin{array}{c}\text { Evaporation Rate } \\
\text { Off-gas Flow }\end{array}$ & $\begin{array}{c}10 \\
500\end{array}$ & $\begin{array}{c}\text { Evaporation } \\
\text { Rate, gpm }\end{array}$ & $\begin{array}{c}\text { Off-gas Flow } \\
\text { SCFM }\end{array}$ & \begin{tabular}{|l|} 
Water Lost in \\
off-gas, GPM
\end{tabular} & $\begin{array}{l}\text { Condensate } \\
\text { Flow, GPM }\end{array}$ & \begin{tabular}{|l|} 
Condenser U \\
Btu/hr f(^2 F
\end{tabular} & $\begin{array}{l}\text { Condensate } \\
\text { Temp, }{ }^{\circ} \mathrm{F}\end{array}$ & $\begin{array}{c}\text { Off-gas Temp } \\
\text { of }\end{array}$ & $\begin{array}{c}\text { Tube Side } \Delta \\
\text { psia }\end{array}$ \\
\hline Data Points & 14 & 9.64 & 329.43 & 0.96 & 8.68 & 100.86 & 110.65 & 129.60 & 0.283 \\
\hline Used for & 15 & 10.85 & 279.94 & 1.52 & 9.33 & 110.84 & 115.52 & 136.51 & 0.314 \\
\hline Interpolation/ & 18 & 9.48 & 422.97 & 0.92 & 8.56 & 98.30 & 110.10 & 127.40 & 0.312 \\
\hline Extrapolation & 19 & 10.76 & 332.25 & 2.33 & 8.44 & 99.46 & 115.51 & 132.77 & 0.332 \\
\hline
\end{tabular}


Slope, $\Delta Q$ Quantity/ $\Delta$ Off-gas Flow "m2" Slope, $\Delta$ Quantity/AEvaporation Rate " $\mathrm{ml}$ " $Y$ intercept "b"

Interpolated Values $\Rightarrow$

\begin{tabular}{|l|l|}
\hline 10 & 500 \\
\hline
\end{tabular}

\begin{tabular}{c|c|c|c|c}
\hline & 0.0052 & -0.0052 & -0.0721 \\
1.0802 & -0.0802 & 0.4021 \\
-11.3489 & 11.3489 & 122.8774 & \\
\hline 500 & 2.06 & 7.94 & 90.84 & \\
\hline
\end{tabular}

0.0028

$\begin{array}{lll}4.0090 & 3.2576 & 0.0004\end{array}$

108.4336

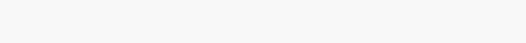

\begin{tabular}{|c|c|c|c|c|c|c|c|c|c|}
\hline $\begin{array}{c}\text { Evaporation Rate } \\
\text { Off-gas Flow }\end{array}$ & \begin{tabular}{|l|}
8.795 \\
504.5
\end{tabular} & $\begin{array}{l}\text { Evaporalion } \\
\text { Rate. gpm }\end{array}$ & $\begin{array}{l}\text { Off-gas Flow } \\
\text { SCFM }\end{array}$ & $\begin{array}{l}\text { Water Lost in } \\
\text { off-gas, GPM }\end{array}$ & $\begin{array}{l}\text { Condensate } \\
\text { Flow, GPM }\end{array}$ & \begin{tabular}{|l|} 
Condenser U \\
Bu/hr ft^2 F
\end{tabular} & $\begin{array}{c}\text { Condensate } \\
\text { Temp, }{ }^{\circ} \mathrm{F}\end{array}$ & \begin{tabular}{|c|}
$\begin{array}{c}\text { Off-gas Temp } \\
{ }^{\circ} \mathrm{F}\end{array}$ \\
\end{tabular} & $\begin{array}{c}\text { Tube Side } \Delta \\
\text { psia }\end{array}$ \\
\hline Data Points & 13 & 5.99 & 348.05 & 0.63 & 5.36 & 60.19 & 104.99 & 112.09 & 0.153 \\
\hline Used for & 14 & 9.64 & 329.43 & 0.96 & 8.68 & 100.86 & 110.65 & 129.60 & 0.283 \\
\hline Interpolation/ & 17 & 6.10 & 451.07 & 0.89 & 5.20 & 58.07 & 104.01 & 109.98 & 0.168 \\
\hline Extrapolation & 18 & 9.48 & 422.97 & 0.92 & 8.56 & 98.30 & 110.10 & 127.40 & 0.312 \\
\hline
\end{tabular}

Slope, $\Delta$ Quantity/AOff-gas Flow "m2"

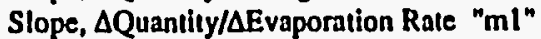

$Y$ intercept " $b$ "

Interpolated Values $\Rightarrow$

\begin{tabular}{|l|l|}
\hline 8.79495 & 504 \\
\hline
\end{tabular}

\begin{tabular}{|c|c|c|c|c|c|c|}
\cline { 2 - 7 } & 0.0012 & -0.0012 & -0.0213 & -0.0076 & -0.0209 & 0.0002 \\
& 0.0597 & 0.9403 & 11.3514 & 1.6173 & 4.8238 & 0.0403 \\
& -0.0896 & 0.0896 & -0.9164 & 97.7544 & 90.2582 & -0.1749 \\
\hline 504.5 & 1.05 & $\mathbf{7 . 7 4}$ & 88.17 & 108.16 & 122.13 & 0.296 \\
\hline
\end{tabular}

\begin{tabular}{|c|c|c|c|c|c|c|c|c|c|}
\hline $\begin{array}{c}\text { Evaporation Rate } \\
\text { Off-gas Flow }\end{array}$ & $\begin{array}{c}2.638 \\
1562\end{array}$ & $\begin{array}{c}\text { Evaporation } \\
\text { Rate, gpm }\end{array}$ & $\begin{array}{c}\text { Off-gas Flow } \\
\text { SCFM }\end{array}$ & $\begin{array}{c}\text { Water Lost in } \\
\text { off-gas, GPM }\end{array}$ & $\begin{array}{c}\text { Condensate } \\
\text { Flow, GPM }\end{array}$ & $\begin{array}{c}\text { Condenser U } \\
\text { Btu/hr fi² F }\end{array}$ & $\begin{array}{c}\text { Condensate } \\
\text { Temp, }{ }^{\circ} \text { F }\end{array}$ & $\begin{array}{c}\text { Off-gas Temp } \\
{ }^{\circ} \text { F }\end{array}$ & $\begin{array}{c}\text { Tube Side } \Delta \\
\text { psia }\end{array}$ \\
\hline Data Points & 12 & 2.83 & 326.19 & 0.43 & 2.40 & 25.75 & 103.90 & 99.49 & 0.062 \\
Used for. & 13 & 5.99 & 348.05 & 0.63 & 5.36 & 60.19 & 104.99 & 112.09 & 0.153 \\
Interpolation, & 16 & 2.97 & 481.03 & 0.66 & 2.31 & 24.90 & 101.64 & 97.11 & 0.087 \\
Extrapolation & 17 & 6.10 & 451.07 & 0.89 & 5.20 & 58.07 & 104.01 & 109.98 & 0.168 \\
\hline
\end{tabular}

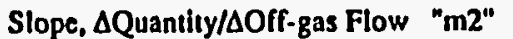

Slope, $\Delta$ Quantity/AEvaporation Rate "ml"

$Y$ intercept "b"

Interpolated Values $\Rightarrow>$

2.63838

\begin{tabular}{|c|c|c|c|c|c|c|}
\hline & 0.0017 & -0.0017 & -0.0199 & -0.0135 & -0.0206 & 0.0001 \\
& 0.0714 & 0.9286 & 10.7312 & 0.5322 & 4.0255 & 0.0276 \\
& -0.3521 & 0.3521 & 2.2276 & 106.6854 & 94.9572 & -0.0594 \\
\hline 1561.9 & 2.51 & 0.13 & -0.47 & 86.97 & 73.36 & 0.222 \\
\hline
\end{tabular}




\begin{tabular}{|c|c|c|c|c|}
\hline & A & B & C & D \\
\hline \multicolumn{5}{|l|}{67} \\
\hline \multirow{2}{*}{\multicolumn{5}{|c|}{$\frac{68}{69}$}} \\
\hline & & & & Off-gas Flow \\
\hline$\frac{70}{71}$ & $\begin{array}{l}\text { Evaporation Rate } \\
\text { Off-gas Flow }\end{array}$ & 50 & Rate, gpm & SCFM \\
\hline 72 & Data Points & $\underline{I}$ & $=$ INDIRECT(ADDRESS $(\mathrm{B} 72+6,3))$ & $=$ INDIRECT(ADDRESS(B72+6,4)) \\
\hline 73 & Used for & 2 & $=$ INDIRECT (ADDRESS $(B 73+6,3))$ & =INDIRECT(ADDRESS $(B 73+6,4))$ \\
\hline 74 & Interpolation & 4 & =INDIRECT(ADDRESS $(B 74+6,3))$ & =INDIRECT(ADDRESS $(B 74+6,4)$ ) \\
\hline 75 & Extrapolation & 5 & =INDIRECT(ADDRESS $(\bar{B} 75+6,3))$ & $=$ INDIRECT(ADDRESS $(B 75+6,4))$ \\
\hline 76 & & & & \\
\hline 77 & STope, $\Delta$ Quantify/ $\Delta$ Off-gas Flow "m2" & & & \\
\hline 78 & Slope, $\Delta Q$ Quantily/ $\Delta$ Evaporation Rate " $\mathrm{ml}$ & & & \\
\hline 79 & Y intercept "b" & & & \\
\hline$\frac{80}{81}$ & Interpolated Values $=>$ & & $=870$ & $=B 71$ \\
\hline 81 & & & & \\
\hline$\frac{82}{83}$ & & & & \\
\hline 84 & & & & \\
\hline 85 & & & & \\
\hline 86 & & & & \\
\hline 87 & & - & & \\
\hline 88 & & & & \\
\hline 89 & & - & & \\
\hline 90 & & $\ldots$ & - & \\
\hline$\frac{91}{92}$ & & & & \\
\hline 93 & & & & \\
\hline 94 & & & & \\
\hline 95 & & & & \\
\hline 96 & & & & \\
\hline 97 & & & & \\
\hline 98 & & & & \\
\hline
\end{tabular}




\begin{tabular}{|c|c|c|}
\hline & $\mathbf{E}$ & $\mathbf{F}$ \\
\hline \multicolumn{3}{|l|}{67} \\
\hline \multicolumn{3}{|l|}{68} \\
\hline \multicolumn{3}{|l|}{69} \\
\hline 70 & Water Lost in & Condensate \\
\hline 71 & off-gas, GPM & Flow, GPM \\
\hline 72 & $=$ INDIRECT(ADDRESS $(872+6,5))$ & $=$ INDIRECT(ADDRESS $(B 72+6,6))$ \\
\hline 73 & $=$ INDIRECT (ADDRESS $(B 73+6,5))$ & $=$ INDIRECT $(A D D R E S S(B 73+6,6))$ \\
\hline 74 & IINDIRECT(ADDRESS $(B 74+6,5))$ & =INDIRECT(ADDRESS(B74+6,6)) \\
\hline 75 & =INDIRECT(ADDRESS(B75+6,5)) & INDIRECT(ADDRESS(B75+6,6)) \\
\hline \multicolumn{3}{|c|}{\begin{tabular}{l|l|l|l|}
76 & 0 \\
\end{tabular}} \\
\hline 77 & $=$ TRANSPOSE(LINEST(E72:E75,C72:D75,TRUE,FALSE)) & =TRANSPOSE(LINEST(F72:F75,C72:D75,TRUE,FALSE)) \\
\hline 78 & =TRANSPOSE(LINEST(E72:E75,C72:D75,TRUE,FALSE)) & =TRANSPOSE(LINEST(F72:F75,C72:D75,TRUE,FALSE)) \\
\hline 79 & $=$ TRANSPOSE(LINEST(E72:E75,C72:D75,TRUE,FALSE)) & =TRANSPOSE(LINEST(F72:F75,C72:D75,TRUE,FALSE)) \\
\hline 80 & $=\mathrm{C} 80+\mathrm{E} 78+\mathrm{D} 80 \cdot \mathrm{E} 77+\mathrm{E} 79$ & $=\mathrm{C} 80^{*} \mathrm{~F} 78+\mathrm{D} 80^{\circ} \mathrm{F} 77+\mathrm{F} 79$ \\
\hline \multicolumn{3}{|c|}{$\mathrm{C}_{\mathrm{S}}$} \\
\hline \multicolumn{3}{|l|}{$\overline{82}$} \\
\hline \multicolumn{3}{|l|}{ B3 } \\
\hline \multicolumn{3}{|l|}{84} \\
\hline \multicolumn{3}{|l|}{85} \\
\hline \multicolumn{3}{|l|}{86} \\
\hline \multicolumn{3}{|l|}{ 87 } \\
\hline \multicolumn{3}{|l|}{8} \\
\hline \multicolumn{3}{|l|}{89} \\
\hline \multicolumn{3}{|l|}{90} \\
\hline \multicolumn{3}{|l|}{91} \\
\hline \multicolumn{3}{|l|}{$\overline{92}$} \\
\hline \multicolumn{3}{|l|}{93} \\
\hline \multicolumn{3}{|l|}{94} \\
\hline \multicolumn{3}{|l|}{95} \\
\hline \multicolumn{3}{|l|}{96} \\
\hline \multicolumn{3}{|l|}{97} \\
\hline 98 & & \\
\hline
\end{tabular}




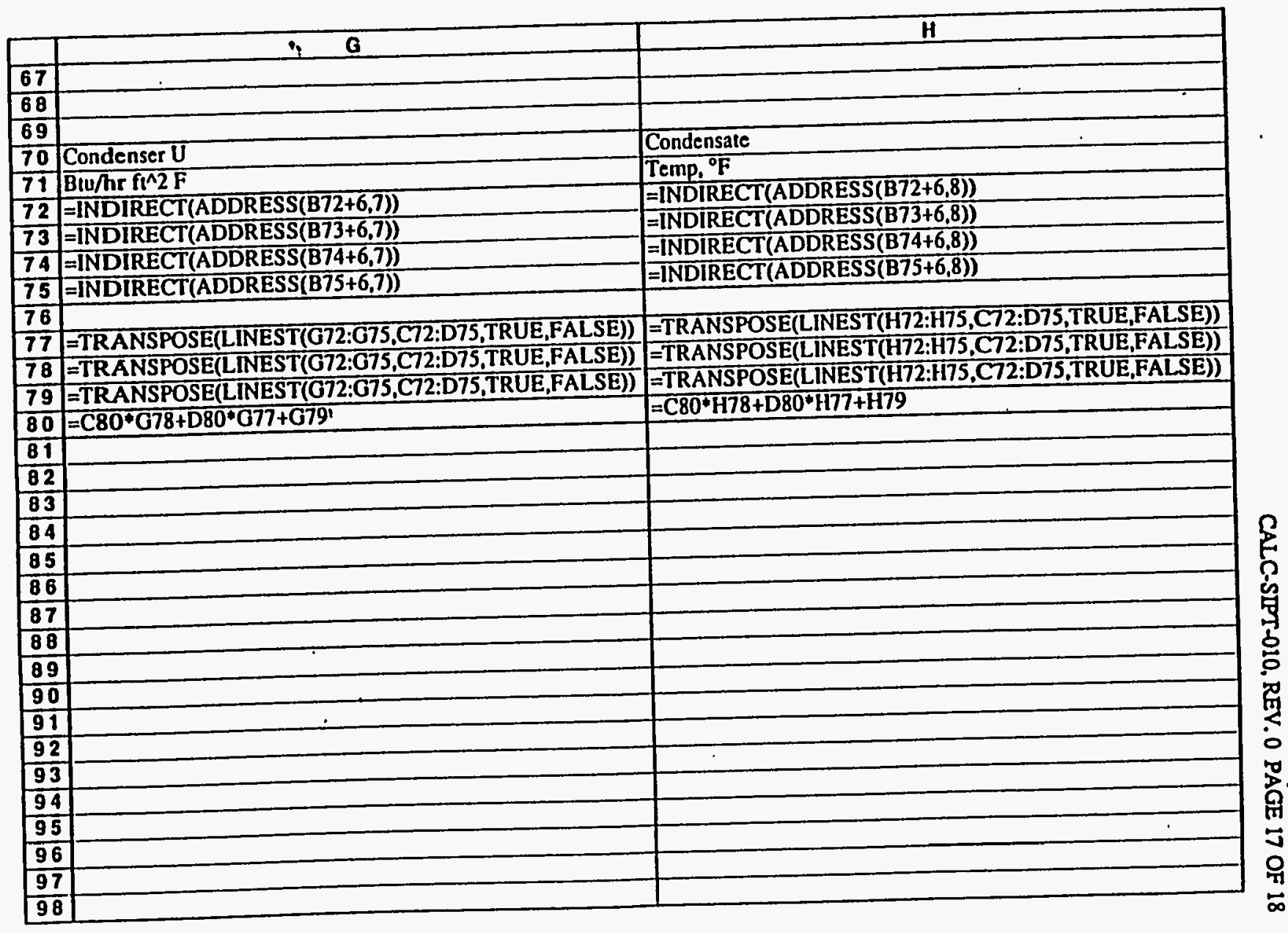




\begin{tabular}{|c|c|c|}
\hline & I & $\mathbf{J}$ \\
\hline \multicolumn{3}{|c|}{67} \\
\hline 68 & &. \\
\hline \multicolumn{3}{|c|}{69} \\
\hline 70 & OIf-gas Temp & Tube Side $\Delta$ \\
\hline 71 & ${ }^{\circ} \mathrm{F}$ & psia \\
\hline$\overline{72}$ & =INDIRECT(ADDRESS(B72+6,9)) & $=$ INDIRECT(ADDRESS $(\mathrm{B} 72+6,10))$ \\
\hline 73 & $=$ INDIRECT(ADDRESS $(B 73+6,9))$ & =INDIRECT(ADDRESS $(B 73+6,10))$ \\
\hline 74 & =INDIRECT(ADDRESS(B74+6,9)) & $=$ INDIRECT(ADDRESS $(B 74+6,10))$ \\
\hline 75 & $=$ INDIRECT(ADDRESS $(875+6,9))$ & $=$ INDIRECT $($ ADDRESS $(B 75+6,10))$ \\
\hline \multicolumn{3}{|c|}{ 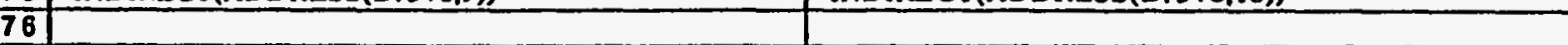 } \\
\hline 77 & FTRANSPOSE(LINEST(172:175,C72:D75,TRUE,FALSE)) & =TRANSPOSE(LINEST(J72:375,C72:D75,TRUE,FALSE)) \\
\hline 78 & $=$ TRANSPOSE(LINEST(172:175,C72:D75,TRUE,FALSE)) & =TRANSPOSE(LINEST(J72:J75,C72:D75,TRUE,FALSE)) \\
\hline 79 & =TRANSPOSE(LINEST(172:175,C72:D75,TRUE,FALSE)) & =TRANSPOSE(LINEST(J72:J75,C72:D75,TRUE,FALSE)) \\
\hline 80 & $=C 80^{\circ} 178+D 80^{*} 177+179$ & $=\mathrm{C} 80^{*} \mathrm{~J} 78+\mathrm{D} 80^{*} \mathrm{~J} 77+\mathrm{J} 79$ \\
\hline 81 & $=-2$. & \\
\hline \multicolumn{3}{|l|}{82} \\
\hline 83 & & 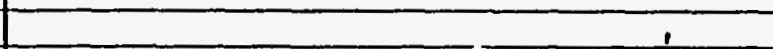 \\
\hline 84 & & $\because$ \\
\hline \multicolumn{3}{|l|}{85} \\
\hline \multicolumn{3}{|l|}{86} \\
\hline \multicolumn{3}{|l|}{87} \\
\hline \multicolumn{3}{|l|}{88} \\
\hline \multicolumn{3}{|l|}{89} \\
\hline \multicolumn{3}{|l|}{90} \\
\hline \multicolumn{3}{|c|}{91} \\
\hline \multicolumn{3}{|l|}{92} \\
\hline \multicolumn{3}{|l|}{$\overline{93}$} \\
\hline \multicolumn{3}{|l|}{94} \\
\hline \multicolumn{3}{|l|}{95} \\
\hline \multicolumn{3}{|l|}{96} \\
\hline \multicolumn{3}{|l|}{97} \\
\hline 98 & & \\
\hline
\end{tabular}


Appendix M

Condenser Heat Transfer Process Data Tables 


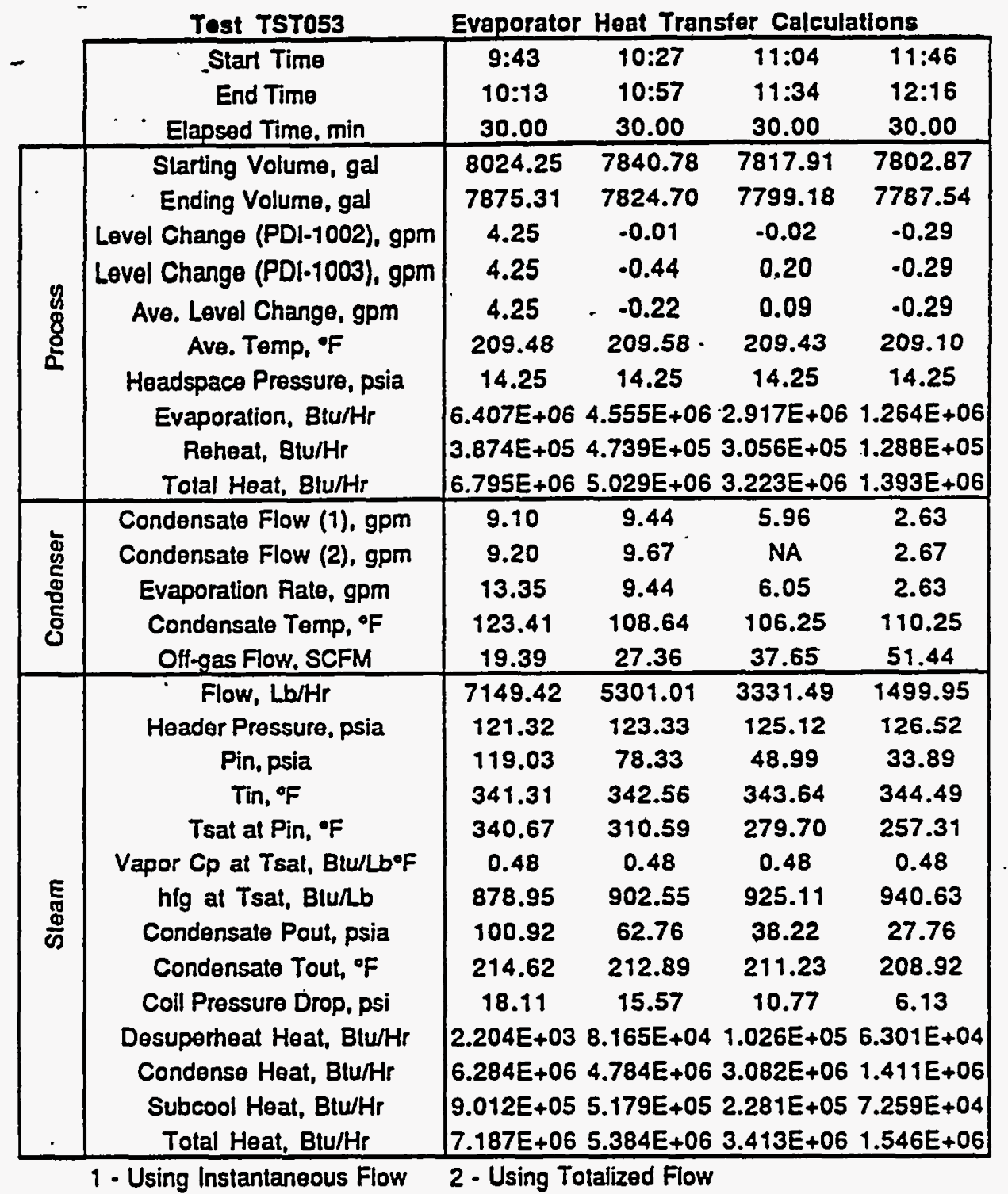

M.1 


\begin{tabular}{|c|c|c|c|c|c|}
\hline & Test $T$ & \multicolumn{4}{|c|}{ Condenser Heat Transfer Calculations } \\
\hline & Start Time & $9: 43$ & $10: 27$ & $11: 04$ & $11: 46$ \\
\hline & End Time & $10: 13$ & $10: 57$ & $11: 34$ & $12: 16$ \\
\hline & Elapsed Time, min & 30.00 & 30.00 & 30.00 & 30.00 \\
\hline \multirow{6}{*}{ 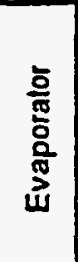 } & Starting Volume, gal & 8024.25 & 7840.78 & 7817.91 & 7802.87 \\
\hline & Ending Voluma, gal & 7875.31 & 7824.70 & 7799.18 & 7787.54 \\
\hline & Ave. Process Tomp. $\bullet F$ & 209.48 & 209.58 & 209.43 & 209.10 \\
\hline & Headspace Pressure, psia & 14.254 & 14.251 & 14.254 & 14.253 \\
\hline & Evaporation Rate, gpm & 13.35 & 9.44 & 6.05 & 2.63 \\
\hline & Process hfg. Btu/lb & 971.93 & 971.86 & 971.96 & 972.17 \\
\hline \multirow{7}{*}{ 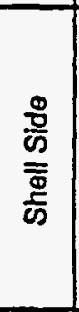 } & Flow, gpm & 350.00 & 350.78 & 350.68 & 351.82 \\
\hline & $\operatorname{Tin}^{\bullet} \cdot F$ & 87.85 & 85.16 & 83.32 & 81.25 \\
\hline & Tout, $\bullet F$ & 124.73 & 113.51 & 101.73 & 89.27 \\
\hline & $\Delta T$, of & 36.88 & 28.34 & 18.40 & 8.02 \\
\hline & Pin, psia & 42.558 & 42.508 & 42.514 & 42.585 \\
\hline & Pout, psia & 37.649 & 37.548 & 37.546 & 37.577 \\
\hline & $\Delta P, p s i$ & 4.909 & 4.961 & 4.967 & 5.008 \\
\hline \multirow{10}{*}{$\begin{array}{l}\stackrel{D}{0} \\
\text { ch } \\
\$ \\
\stackrel{D}{\Xi}\end{array}$} & Condensate Flow (1), gpm & 9.10 & 9.44 & 5.96 & 2.63 \\
\hline & Condensate Flow (2), gpm & 9.20 & 9.67 & NA & 2.67 \\
\hline & Condensate Temp, ${ }^{\circ} F$ & 123.41 & 108.64 & 106.25 & 110.25 \\
\hline & Condense Heat, Btu/Hr & $4.375 E+06$ & $4.563 E+06$ & $2.879 E+06$ & $1.267 E+06$ \\
\hline & Subcool Heat, Btu/Hr & $3.874 E+05$ & $4.739 E+05$ & $3.056 E+05$ & $1.288 E+05$ \\
\hline & Off-gas Flow, SCFM & 19.39 & 27.36 & 37.65 & 51.44 \\
\hline & Off-gas Flow, ACFM & 24.31 & 33.17 & 44.04 & 57.74 \\
\hline & Off-gas Temp, ^F & 158.43 & 142.46 & 126.43 & 104.88 \\
\hline & Off-gas Pressure, psia & 13.949 & 14.049 & 14.169 & 14.228 \\
\hline & Pressure Drop. $\Delta P$, psi & 0.305 & 0.202 & 0.085 & 0.025 \\
\hline \multirow{5}{*}{ 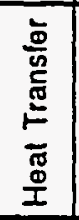 } & $\Delta T$, Cooling Water, ${ }^{\circ} F(3)$ & 25.14 & 26.13 & 16.48 & 7.22 \\
\hline & Condense LMTD. ${ }^{\circ} \mathrm{F}$ & 96.77 & 108.61 & 115.75 & 123.41 \\
\hline & Subcool LMTD, •F & 65.88 & 59.85 & 59.93 & 66.38 \\
\hline & Weighted $\Delta t, \cdot F$ & 93.22 & 100.88 & 106.25 & 114.34 \\
\hline & Condenser $\mathrm{U}, \mathrm{Blu} / \mathrm{Hr} \mathrm{f}^{\wedge} 2^{\circ} \mathrm{F}$ & 113.38 & 110.80 & 66.51 & 27.09 \\
\hline \multirow{4}{*}{ 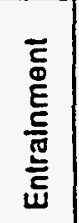 } & at Off-ãc Tomn flazah & & & & \\
\hline & $\begin{array}{l}v \text { at Off-gas Temp, } \mathrm{fl}^{\wedge} 3 \mathrm{hb} \\
\text { Calculated } \mathrm{H} 2 \mathrm{O}, \mathrm{gpm}\end{array}$ & $\begin{array}{l}80.31 \\
0.04\end{array}$ & $\begin{array}{c}116.53 \\
0.03\end{array}$ & $\begin{array}{c}173.55 \\
0.03\end{array}$ & $\begin{array}{c}308.57 \\
0.02\end{array}$ \\
\hline & Áctual $\mathrm{H} 2 \mathrm{O}, \mathrm{gpm}$ & 4.25 & 0.00 & 0.09 & 0.00 \\
\hline & Difference, gpm & 4.21 & -0.03 & 0.06 & .0 .02 \\
\hline \multirow{3}{*}{ 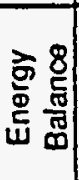 } & Total Heat In, Btu/Hr & \multirow{2}{*}{\multicolumn{4}{|c|}{ 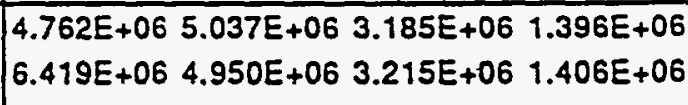 }} \\
\hline & Total Heat Out, Btu/Hr & & & & \\
\hline & $\%$ Difference & -34.78 & 1.72 & -0.96 & -0.75 \\
\hline
\end{tabular}

1 - Using Instantaneous Flow 2 - Using Totalized Flow 3 - To condense process 
Page F4 of F11

\begin{tabular}{|c|c|c|c|c|c|c|}
\hline & Test T5T038 & \multicolumn{5}{|c|}{ Evaporator Hoat Transfor Calculations } \\
\hline & Start Time & $12: 44$ & $13: 22$ & $14: 00$ & $14: 45$ & $15: 26$ \\
\hline & End Time & $13: 16$ & 13:52 & $14: 33$ & 15:04 & $15: 51$ \\
\hline & Elapsed Time. min & 32 & 30 & 33 & 19 & 25 \\
\hline \multirow{10}{*}{$\begin{array}{l}\text { 岁 } \\
8 \\
8 \\
0\end{array}$} & Slarting Volume, gal & 7762.72 & 7752.20 & 7752.23 & 7708.13 & 7515.07 \\
\hline & Ending Volume, gal & 7752.49 & 7736.45 & 7744.84 & 7572.13 & 7503.46 \\
\hline & Level Change (PDl-1002), gpm & -0.06 & 0.01 & 0.15 & 6.80 & 0.05 \\
\hline & Level Change (PDI-1003), gpm & 0.05 & -0.16 & 0.62 & 7.32 & -0.06 \\
\hline & Ave. Lovel Change, gpm & 0.00 & -0.08 & 0.38 & 7.06 & .0 .01 \\
\hline & Ave. Temp, $\bullet F$ & 209.01 & 209.48 & 209.76 & 210.10 & 209.68 \\
\hline & Headspace Pressure, psia & 14.25 & 14.25 & 14.25 & 14.38 & 14.26 \\
\hline & Evaporation, Btu/Hr & $1.270 E+06$ & $2.853 E+06$ & $4.844 E+06$ & $6.509 E+06$ & $4.988 E+06$ \\
\hline & Reheat, Btu/Hr & $1.308 E+05$ & $3.042 E+05$ & $4.783 E+05$ & $2.712 E+05$ & $4.923 E+05$ \\
\hline & . Total Heat, Btu/Hr & $1.401 E+06$ & $3.157 E+06$ & $5.322 E+06$ & $6.780 E+06$ & $5.480 E+06$ \\
\hline \multirow{5}{*}{ 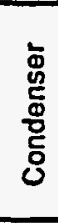 } & Condensale Flow (1), gpm & 2.63 & 5.91 & 9.68 & 6.50 & 10.36 \\
\hline & Condensate Flow (2), gpm & 2.53 & 5.77 & 9.76 & NA & NA \\
\hline & Evaporation Rate, gpm & 2.63 & 5.91 & 10.06 & 13.56 & 10.36 \\
\hline & Condensate Temp. ${ }^{\circ} \mathrm{F}$ & 109.12 & 106.04 & 110.17 & 125.73 & 113.91 \\
\hline & Off-gas Flow, SCFM & 110.68 & 107.92 & 104.66 & 56.52 & 111.06 \\
\hline \multirow{14}{*}{$\begin{array}{l}\frac{E}{\varpi} \\
\text { ๘ }\end{array}$} & Flow, Lb/Hr & 1501.21 & 3353.61 & 5510.84 & 7154.89 & 5917.23 \\
\hline & Header Pressure, psia & 126.97 & 125.99 & 124.25 & 122.60 & 123.59 \\
\hline & Pin, psia & 33.94 & 50.49 & 85.41 & 120.31 & 90.53 \\
\hline & $\operatorname{Tin},{ }^{\circ} \mathrm{F}$ & 344.77 & 344.15 & 343.08 & 342.04 & 342.69 \\
\hline & Tsat at Pin, ${ }^{\circ} F$ & 257.40 & 281.62 & 316.62 & 341.49 & 320.72 \\
\hline & Vapor $C p$ at Tsat, Btu/Lb०F & 0.48 & 0.48 & 0.48 & 0.48 & 0.48 \\
\hline & htg at Tsat, Bturb & 940.57 & 923.75 & 897.90 & 878.28 & 894.74 \\
\hline & Condensate Pout, psia & 27.80 & 39.81 & 69.79 & 102.35 & 73.86 \\
\hline & Condensate Tout, of & 209.00 & 211.04 & 212.91 & 215.22 & 213.48 \\
\hline & Coil Pressure Drop. psi & 6.13 & 10.68 & 15.62 & 17.96 & 16.67 \\
\hline & Desuperheat Heat, Btw/Hr & $6.319 E+04$ & $1.010 E+05$ & $7.024 E+04$ & $1.912 E+03$ & $6.264 E+04$ \\
\hline & Condense Heat, Btu/Hr & $1.412 E+06$ & $3.098 E+06$ & $4.948 E+06$ & $6.284 E+06$ & $5.294 E+06$ \\
\hline & Subcool Heat, Btu/Hr & $7.266 E+04$ & $2.367 E+05$ & $5.715 E+05$ & $9.035 E+05$ & $6.346 E+05$ \\
\hline & Total Heat, Blu/hr & $1.548 E+06$ & $3.436 E+06$ & $5.590 E+06$ & $7.189 E+06$ & $5.992 E+06$ \\
\hline
\end{tabular}


Page F5 of F11

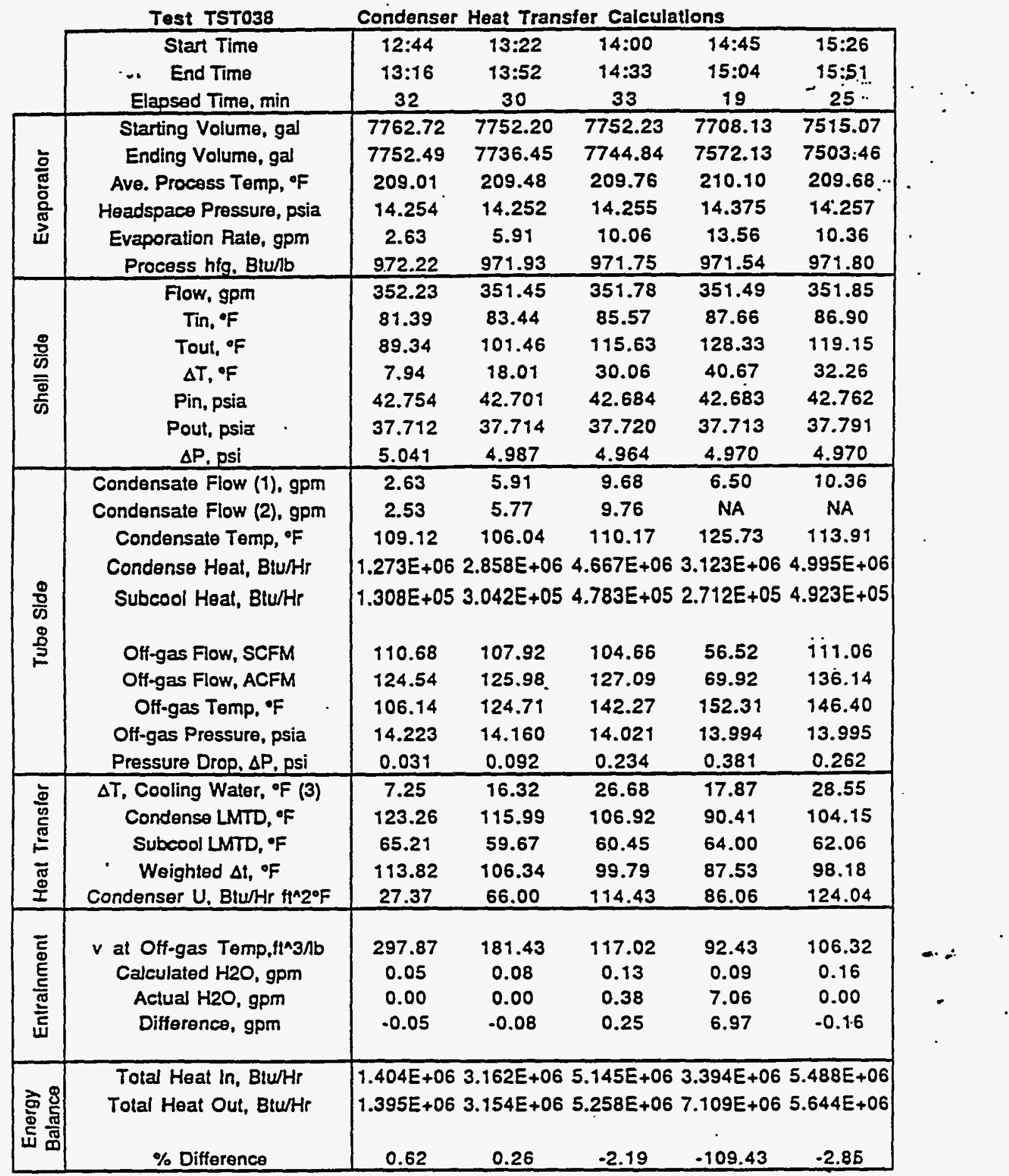

1 . Using Instantaneous Flow 2 - Using Totalized Flow 3 - To condense process 
Page F6 of F11

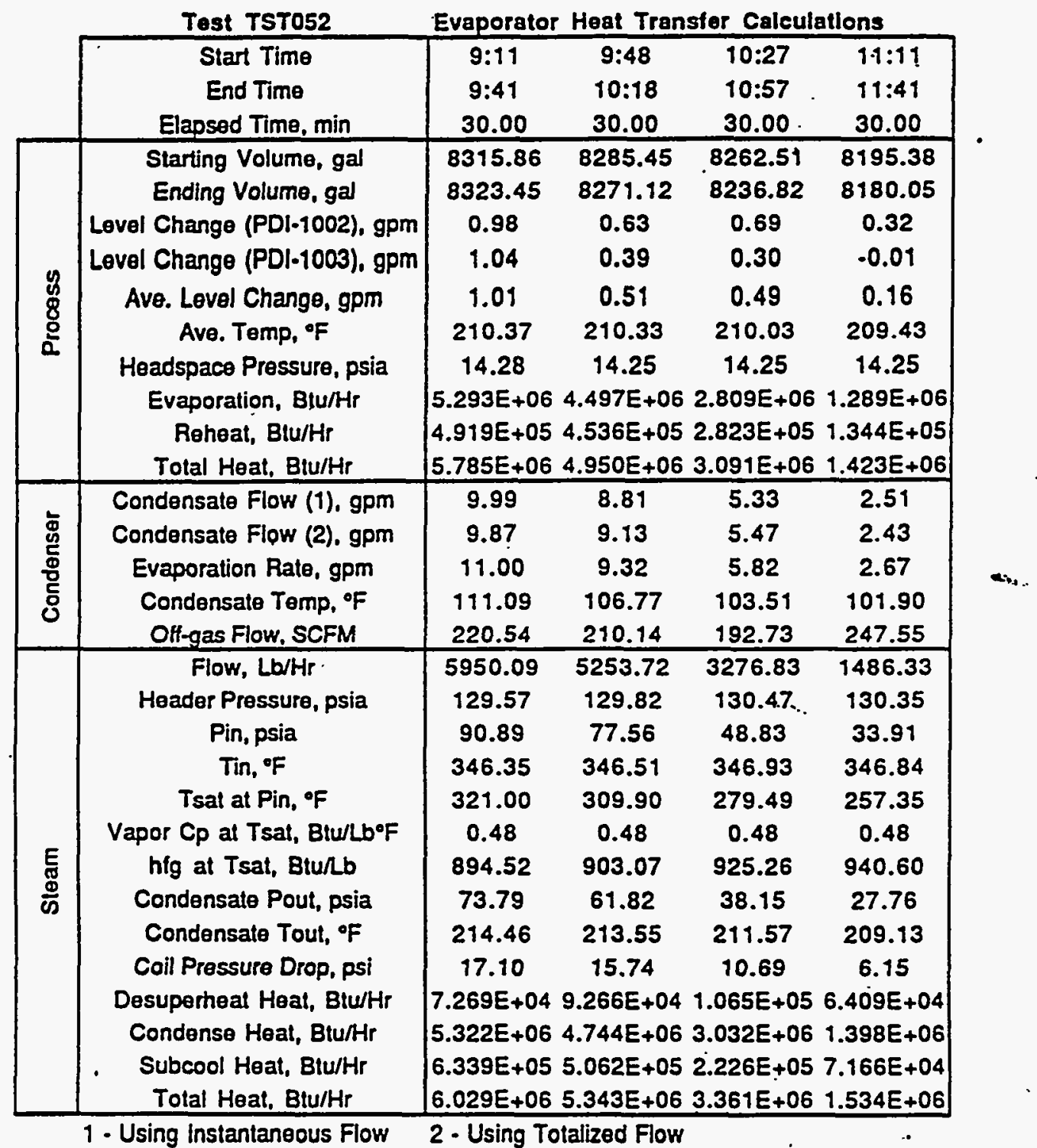




\begin{tabular}{|c|c|c|c|c|c|}
\hline & \multirow{4}{*}{$\frac{\text { Tost TST052 }}{\text { Start Time }}$} & \multicolumn{4}{|c|}{ Condenser Heat Transfer Calculatlons } \\
\hline & & $9: 11$ & $9: 48$ & $10: 27$ & $11: 11$ \\
\hline & & $9: 41$ & $10: 18$ & $10: 57$ & $11: 41$ \\
\hline & & 30.00 & 30.00 & 30.00 & 30.00 \\
\hline \multirow{6}{*}{ 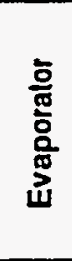 } & Starting Volume, gal & 8315.86 & 8285.45 & 8262.51 & 8195.38 \\
\hline & Ending Volume, gal & 8323.45 & 8271.12 & 8236.82 & 8180.05 \\
\hline & Ave. Process Temp, $\bullet F$ & 210.37 & 210.33 & 210.03 & 209.43 \\
\hline & Headspace Pressure, psia & 14.279 & 14.252 & 14.254 & 14.253 \\
\hline & Evaporation Rale, gpm & 11.00 & 9.32 & 5.82 & 2.67 \\
\hline & Process hig. Btu/b & 971.36 & 971.39 & 971.58 & 971.97 \\
\hline \multirow{7}{*}{$\begin{array}{l}\frac{8}{\overline{0}} \\
\frac{\bar{\sigma}}{\bar{\sigma}} \\
\frac{5}{\omega}\end{array}$} & Flow, gpm & 354.86 & 355.01 & 355.11 & 355.07 \\
\hline & $\operatorname{Tin},{ }^{\circ} \mathrm{F}$ & 81.80 & 81.06 & 80.63 & 77.21 \\
\hline & Tout, $\bullet F$ & 113.87 & 109.39 & 98.36 & 85.21 \\
\hline & $\Delta T,{ }^{\bullet} F$ & 32.06 & 28.33 & 17.73 & 8.00 \\
\hline & Pin, psia & 43.049 & 42.995 & 42.940 & 42.898 \\
\hline & Pout, psia & 37.996 & 37.950 & 37.863 & 37.804 \\
\hline & $\Delta P, p s i$ & 5.053 & 5.045 & 5.077 & 5.094 \\
\hline \multirow{10}{*}{ 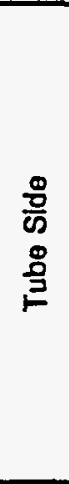 } & Condensate Flow (1), gpm & 9.99 & 8.81 & 5.33 & 2.51 \\
\hline & Condensate Flow (2), gpm & 9.87 & 9.13 & 5.47 & 2.43 \\
\hline & Condensate Temp. ${ }^{\circ} F$ & 111.09 & 106.77 & 103.51 & 101.90 \\
\hline & Condense Heat, Bturhr & $4.813 E+06$ & $4.254 E+06$ & $2.575 E+06$ & $1.215 E+06$ \\
\hline & Subcool Heat, Btu/Hr & $4.919 E+05$ & $4.536 E+05$ & $2.823 E+05$ & $1.344 E+05$ \\
\hline & Off-gas Flow, SCFM & 220.54 & 210.14 & 192.73 & 247.55 \\
\hline & Off-gas Flow, ACFM & 264.75 & 249.75 & 221.05 & 275.44 \\
\hline & Off-gas Temp, •F & 134.00 & 128.65 & 113.54 & 99.08 \\
\hline & Off-gas Pressure, psia & 13.988 & 14.002 & 14.137 & 14.204 \\
\hline & Pressure Drop, $\Delta P$, psi & 0.291 & 0.249 & 0.117 & 0.049 \\
\hline \multirow{5}{*}{ 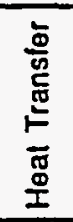 } & $\Delta T$, Cooling Water, ${ }^{\circ} \mathrm{F}(3)$ & 27.24 & 24.07 & 14.54 & 6.86 \\
\hline & Condense LMTD. ${ }^{\circ} \mathrm{F}$ & 109.56 & 112.54 & 118.80 & 127.62 \\
\hline & Subcool LMTD, 'F & 65.54 & 62.78 & 60.51 & 63.73 \\
\hline & Weighted $\Delta t_{1} \cdot{ }^{\circ} \mathrm{F}$ & 103.13 & 104.56 & 108.47 & 116.03 \\
\hline & Condenser $\mathrm{U}$. Btu/Hr $\mathrm{ft}^{\wedge} 2^{\circ} \mathrm{F}$ & 114.14 & 99.93 & 58.45 & 25.81 \\
\hline \multirow{4}{*}{ 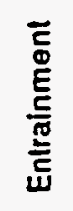 } & $v$ at Off-gas Temp,f^^3/b & 143.48 & 163.38 & 243.12 & 359.94 \\
\hline & Calculated $\mathrm{H} 2 \mathrm{O}$, gpm & 0.22 & 0.19 & 0.11 & 0.09 \\
\hline & Actual $\mathrm{H} 20, \mathrm{gpm}$ & 1.01 & 0.51 & 0.49 & 0.16 \\
\hline & Difference, gpm & 0.78 & 0.33 & 0.38 & 0.06 \\
\hline \multirow{3}{*}{ 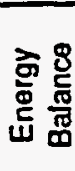 } & Total Heat in, Btu/Hr & \multirow{2}{*}{\multicolumn{4}{|c|}{ 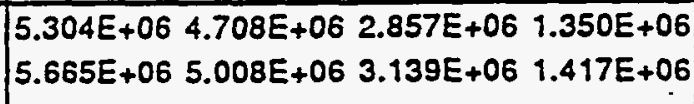 }} \\
\hline & Total Heat Out, Btu/Hr & & & & \\
\hline & $\%$ Difference & -6.80 & .6 .38 & -9.86 & -4.99 \\
\hline
\end{tabular}

1 - Using instantaneous Flow 2 - Using Totalized Flow 3 - To condense process 


\begin{tabular}{|c|c|c|c|c|c|}
\hline & Test TST051 & Evaporator & \multicolumn{3}{|c|}{ Heat Transfer Calculations } \\
\hline & Start Time & $13: 37$ & $14: 15$ & $14: 53$ & $15: 31$ \\
\hline & End Time & $14: 07$ & $14: 46$ & $15: 23$ & $16: 01$ \\
\hline & Elapsed Time, min & 30 & 31 & 30 & 30 \\
\hline \multirow{10}{*}{$\begin{array}{l}\text { בै } \\
8 \\
\text { o } \\
0\end{array}$} & Starting Volume, gal & 8190.53 & 8135.11 & 8003.72 & 7962.80 \\
\hline & Ending Volume, gal & 8126.62 & 8051.83 & 7970.78 & 7940.49 \\
\hline & Level Change (PDI-1002), gpm & 1.63 & 0.97 & 0.64 & 0.50 \\
\hline & Level Chango (PDl-1003), gpm & 1.40 & 0.95 & 0.62 & 0.36 \\
\hline & Ave. Level Change, gpm & 1.52 & 0.96 & 0.63 & 0.43 \\
\hline & Ave. Temp, ${ }^{\circ} \mathrm{F}$ & 210.21 & 210.07 & 209.72 & 209.19 \\
\hline & Headspace Pressure, psia & 14.33 & 14.30 & 14.25 & 14.25 \\
\hline & Evaporation, Blu/Hr & $5.223 E+06$ & $4.639 E+06$ & $2.889 E+06$ & $1.367 E+06$ \\
\hline & Reheat, Btu/Hr & $4.384 E+05$ & $4.280 E+05$ & $2.790 E+05$ & $1.256 E+05$ \\
\hline & Total Heat, Btu/Hr & $5.661 E+06$ & $5.067 E+06$ & $3.168 E+06$ & $1.493 E+06$ \\
\hline \multirow{5}{*}{ 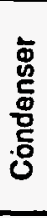 } & Condensale Flow (1). gpm & 9.33 & 8.68 & 5.36 & 2.40 \\
\hline & Condensate Flow (2), gpm & 9.20 & 8.39 & 5.33 & 2.40 \\
\hline & Evaporation Rate, gpm & 10.85 & 9.64 & 5.99 & 2.83 \\
\hline & Condensate Temp. ${ }^{\circ} \mathrm{F}$ & 115.52 & 110.65 & 104.99 & 103.90 \\
\hline & Off-gas Flow, SCFM & 279.94 & 329.43 & 348.05 & 326.19 \\
\hline \multirow{14}{*}{$\begin{array}{l}\text { E } \\
\text { d } \\
\text { W }\end{array}$} & Flow, Lb/Hr & 5971.23 & 5219.79 & 3284.96 & 1499.24 \\
\hline & Header Pressure, psia & 129.67 & 130.70 & 130.20 & 130.57 \\
\hline & Pin, psia & 91.54 & 78.43 & 48.99 & 33.81 \\
\hline & $\operatorname{Tin},{ }^{\circ} \mathrm{F}$ & 346.38 & 346.99 & 346.73 & 346.96 \\
\hline & Tsat at Pin, ${ }^{\circ} \mathrm{F}$ & 321.50 & 310.68 & 279.70 & 257.17 \\
\hline & Vapor Cp at Tsat, Blu/LbF & 0.48 & 0.48 & 0.48 & 0.48 \\
\hline & hig at Tsat, Blunb & 894.13 & 902.48 & 925.11 & 940.72 \\
\hline & Condensate Pout, psia & 74.55 & 62.71 & 38.41 & 27.73 \\
\hline & Condensale Tout, ${ }^{\circ} \mathrm{F}$ & 214.23 & 213.37 & 211.36 & 208.89 \\
\hline & Coil Pressure Drop, psi & 17.00 & 15.72 & 10.58 & 6.08 \\
\hline & Desuperheat Heat, Btu/Hr & $7.159 E+04$ & $9.131 E+04$ & $1.061 E+05$ & $6.486 E+04$ \\
\hline & Condense Heat, Btu/Hr & $5.339 E+06$ & $4.711 E+06$ & $3.039 E+06$ & $1.410 E+06$ \\
\hline & Subcool Heal, Blu/Hr & $6.405 E+05$ & $5.079 E+05$ & $2.245 E+05$ & $7.238 E+04$ \\
\hline & Total Heat. Btu/Hr & $6.051 E+06$ & $5.310 E+06$ & $3.370 E+06$ & $1.548 \mathrm{E}+06$ \\
\hline
\end{tabular}




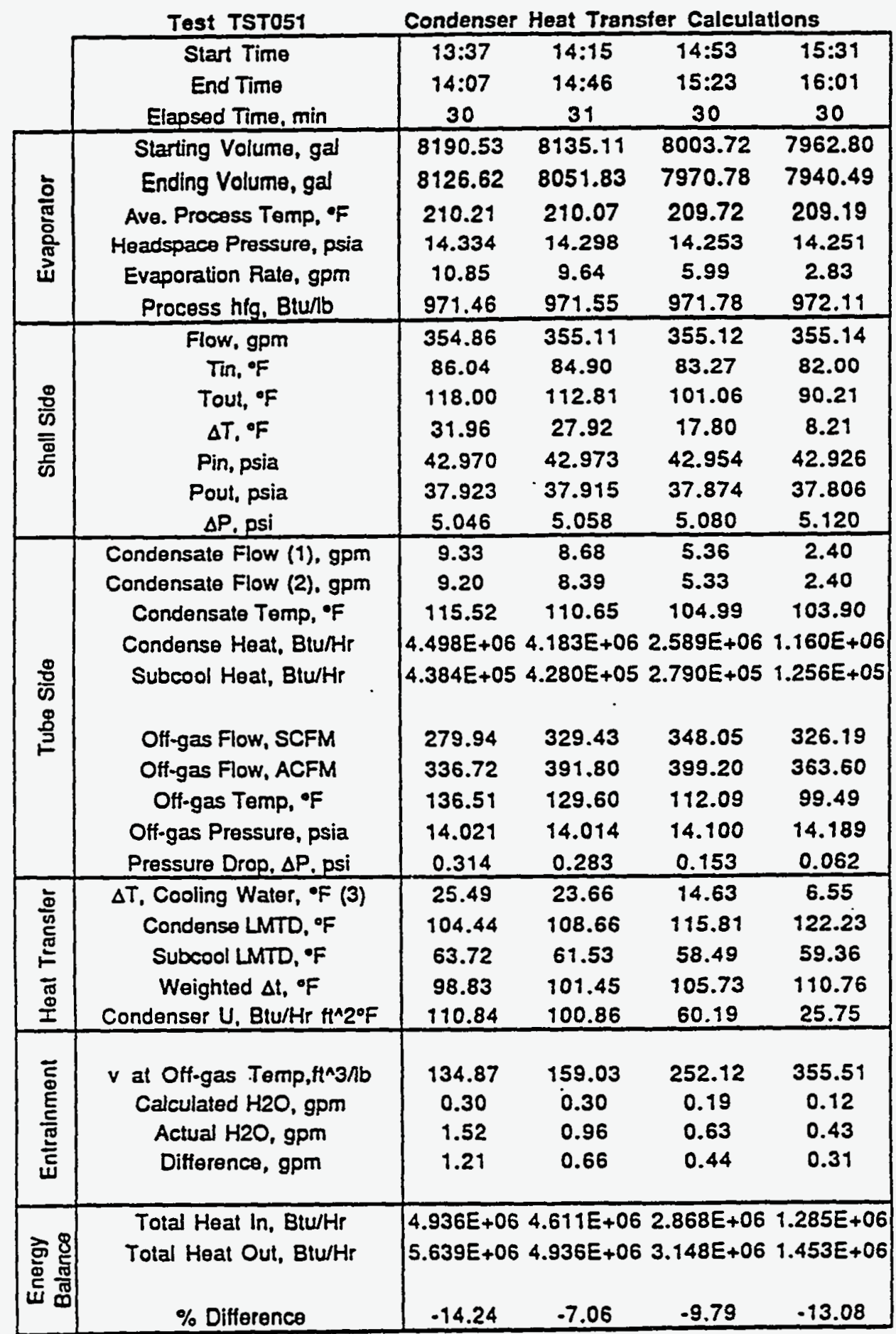

1. Using Instantaneous Flow 2 - Using Totalized Flow 3 - To condense process 
Test TST050

Evaporator Heat Transfer Caleulations

\begin{tabular}{|c|c|c|c|c|c|}
\hline & & & & & \\
\hline & $\begin{array}{c}\text { Start Time } \\
\text { End Time } \\
\text { Elapsed Time, min }\end{array}$ & $\begin{array}{l}12: 27 \\
12: 57 \\
30.00\end{array}$ & $\begin{array}{l}13: 02 \\
13: 32 \\
30.00\end{array}$ & $\begin{array}{l}13: 38 \\
14: 08 \\
30.00 \\
\end{array}$ & $\begin{array}{l}14: 14 \\
14: 44 \\
30.00\end{array}$ \\
\hline & Starting Volume, gal & 8539.83 & 8424.81 & 8337.99 & 8236.27 \\
\hline & Ending Volume, gal & 8446.28 & 8356.59 & 8285.03 & 8201.67 \\
\hline & Level Change (PDJ-1002), gpm & 2.39 & 0.96 & 0.91 & 0.69 \\
\hline & vel Change (PDI-1003), gpm & 2.26 & 0.87 & 0.88 & 0.62 \\
\hline & Ave. Level Change, gpm & 2.33 & 0.92 & 0.89 & 0.66 \\
\hline & Ave. Temp, •F & 210 & 210. & 210.38 & 209.81 \\
\hline & ure, psia & 14.42 & 14.41 & 14.40 & 14.38 \\
\hline & tion, Btu/Hr & $5.181 E+06$ & $4.561 E+06$ & $2.941 E+06$ & $1.431 E+0$ \\
\hline & 1. Blu/Hr & $3.977 E+05$ & 4.2 & 2.751 & \\
\hline & Total & 5.578 & $4.987 E+06$ & $3.216 E+06$ & $1.555 E+C$ \\
\hline & Condensale & 8.44 & 8.56 & 5.20 & .31 \\
\hline 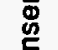 & Con & 8.60 & 8.53 & 5.10 & 2.27 \\
\hline & Evar & 10.76 & 9.48 & 6.10 & 2.97 \\
\hline & $\circ \mathrm{F}$ & 115 & 110 & 104 & .64 \\
\hline & Off-gas & 332 & 422.97 & 451.07 & 1.03 \\
\hline & Flow, Lb/Hr & 5988.64 & 5304.11 & 326 & 0.75 \\
\hline & Header Pressure, psia & 128.62 & 128.74 & 129.65 & 0.66 \\
\hline & Pin, psia & 90.91 & 77.70 & 49.44 & 33.86 \\
\hline & $\operatorname{Tin},{ }^{\circ} \mathrm{F}$ & 345.91 & 345.96 & 346.51 & 344.76 \\
\hline & Tsat at Pin, ${ }^{\bullet} F$ & 321.01 & 310.03 & 280.29 & 257.26 \\
\hline & Vapor $C p$ at Tsat, Btu/LbF & 0.48 & 0.48 & 0.48 & 0.48 \\
\hline & hfg at Tsat, Btu/Lb & 894.51 & 902.98 & 924.69 & 940.66 \\
\hline$\frac{\mathscr{\omega}}{\omega}$ & Condensate Pout, psia & 73.80 & 61.80 & 39.07 & 27.66 \\
\hline & Condensale Tout, ${ }^{\circ} \mathrm{F}$ & 215.06 & 214.24 & 212.08 & 209.16 \\
\hline & Coil Pressure D & 17.11 & 15.90 & 10.37 & 6.20 \\
\hline & Desuperheal Hoat, Blu/Hr & $7.183 E+04$ & $9.184 E+04$ & $1.042 E+0$ & $6.242 E+0$ \\
\hline & Condense Heal, BlurHr & $5.357 E+06$ & 4.789E+06 & $3.020 E+06$ & $1.393 E+0$ \\
\hline & Subcool Heat, Btu/Hr & $6.345 E+05$ & $5.081 E+05$ & $2.228 E+0$ & $7.123 E+0$ \\
\hline & Total Heat, Btu/Hr & $6.063 E+06$ & $5.389 E+06$ & $3.347 E+06$ & $1.527 E+0$ \\
\hline
\end{tabular}

1 . Using Instantaneous Flow

2 - Using Totalized Flow 
Page F11 of F11

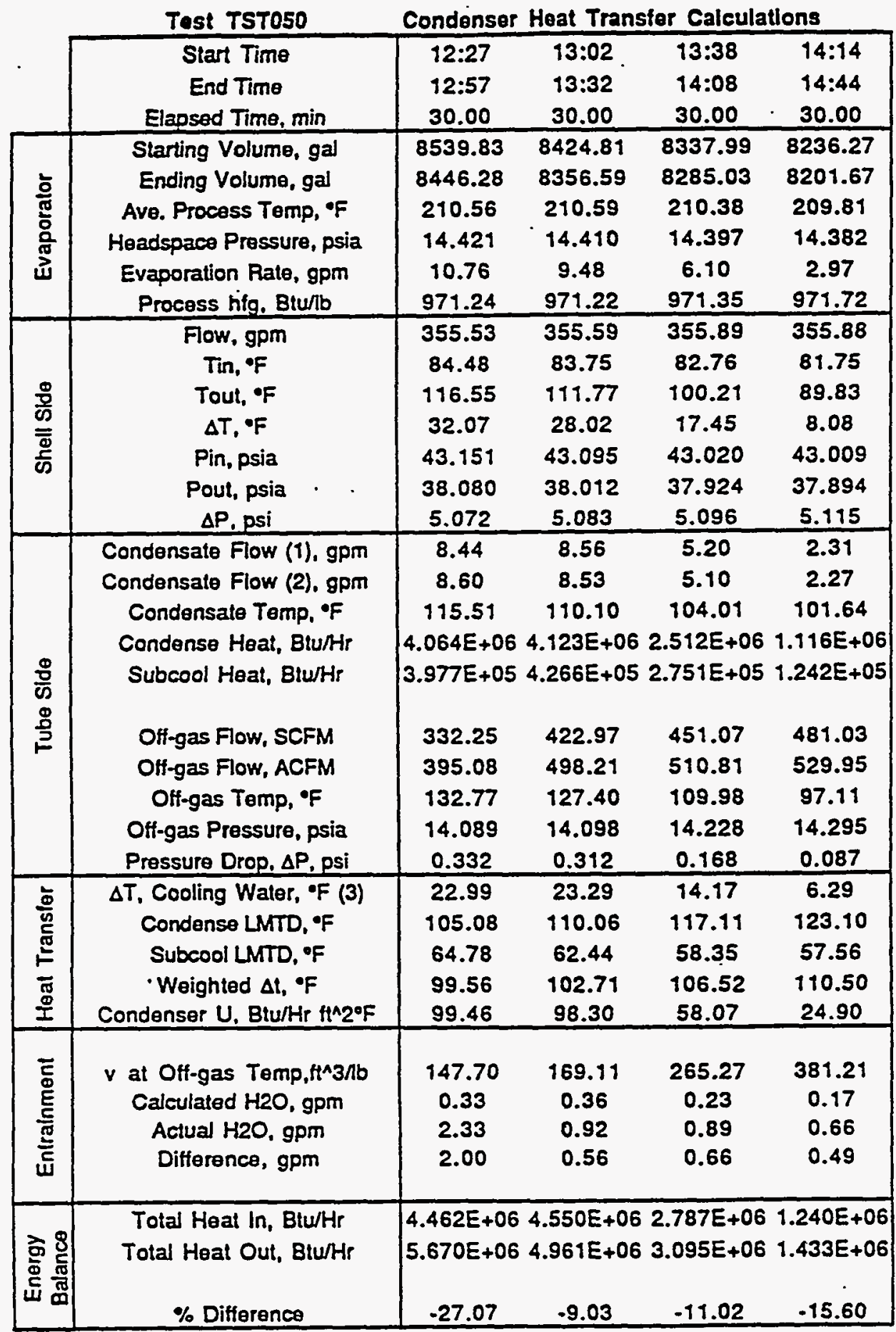

1 . Using Instantaneous Flow 2 - Using Totalized Flow 3 - To condense process 
Appendix N

Interpolated Data at Standard Conditions - Summary Tables 
Table G-1. Process Variables vs. Evaporation Rate at 50 SCFM Off-gas Flow

\begin{tabular}{|c|c|c|c|c|c|c|}
\hline $\begin{array}{c}\text { Evaporation } \\
\text { GPM }\end{array}$ & $\begin{array}{c}\text { Water Lost in } \\
\text { off-gas, GPM }\end{array}$ & $\begin{array}{c}\text { Condensate } \\
\text { Flow, GPM }\end{array}$ & $\begin{array}{c}\text { Condenser U U } \\
\text { Btu/hr ft^ } 2 \text { F }\end{array}$ & $\begin{array}{c}\text { Condensate } \\
\text { Temp, }{ }^{\circ} \mathrm{F}\end{array}$ & $\begin{array}{c}\text { Off-gas Temp } \\
{ }^{\circ} \mathrm{F}\end{array}$ & $\begin{array}{c}\text { Tube Side } \Delta \\
\text { psia }\end{array}$ \\
\hline 2.500 & 0.021 & 2.48 & 25.40 & 110.17 & 104.69 & 0.022 \\
5.500 & 0.056 & 5.44 & 60.42 & 106.91 & 122.68 & 0.077 \\
8.000 & 0.086 & 7.91 & 91.48 & 107.77 & 135.10 & 0.155 \\
10.000 & 0.181 & 9.82 & 1.15 .85 & 109.55 & 143.86 & 0.224 \\
\hline
\end{tabular}

Table G-2. Process Variables vs. Evaporation Rate at 100 SCFM Off-gas Flow

\begin{tabular}{|c|c|c|c|c|c|c|}
\hline $\begin{array}{c}\text { Evaporation } \\
\text { GPM }\end{array}$ & $\begin{array}{c}\text { Water Lost in } \\
\text { off-gas, GPM }\end{array}$ & $\begin{array}{c}\text { Condensate } \\
\text { Flow, GPM }\end{array}$ & $\begin{array}{c}\text { Condenser U } \\
\text { Btu/th f^^ }{ }^{\wedge} \text { F }\end{array}$ & $\begin{array}{c}\text { Condensate } \\
\text { Temp, }{ }^{\circ} \mathrm{F}\end{array}$ & $\begin{array}{c}\text { Off-gas Temp } \\
{ }^{\circ} \mathrm{F}\end{array}$ & $\begin{array}{c}\text { Tube Side } \Delta \\
\text { psia }\end{array}$ \\
\hline 2.500 & -0.016 & 2.52 & 25.90 & 109.63 & 104.74 & 0.028 \\
5.500 & 0.020 & 5.48 & 60.92 & 106.37 & 122.73 & 0.083 \\
8.000 & 0.185 & 7.82 & 90.41 & 108.09 & 133.69 & 0.162 \\
10.000 & 0.280 & 9.72 & 114.79 & 109.87 & 142.45 & 0.231 \\
& & & & & & \\
\hline
\end{tabular}

Table G-3. Process Variables vs. Evaporation Rate at 200 SCFM Off-gas Flow

\begin{tabular}{|c|c|c|c|c|c|c|}
\hline $\begin{array}{c}\text { Evaporation } \\
\text { GPM }\end{array}$ & $\begin{array}{c}\text { Water Lost in } \\
\text { off-gas, GPM }\end{array}$ & $\begin{array}{c}\text { Condensate } \\
\text { Flow, GPM }\end{array}$ & $\begin{array}{c}\text { Condenser U } \\
\text { Btu/hr ft^ } 2 \text { F }\end{array}$ & $\begin{array}{c}\text { Condensate } \\
\text { Temp, }{ }^{\circ} \mathrm{F}\end{array}$ & $\begin{array}{c}\text { Off-gas Temp } \\
{ }^{\circ} \mathrm{F}\end{array}$ & $\begin{array}{c}\text { Tube Side } \Delta \\
\text { psia }\end{array}$ \\
\hline 2.500 & 0.121 & 2.38 & 24.25 & 104.65 & 100.35 & 0.041 \\
5.500 & 0.338 & 5.16 & 56.71 & 102.69 & 113.87 & 0.105 \\
8.000 & 0.508 & 7.49 & 84.42 & 105.62 & 123.24 & 0.198 \\
10.000 & 0.703 & 9.30 & 106.25 & 109.03 & 132.22 & 0.259 \\
\hline
\end{tabular}


Table G-4. Process Variables vs. Evaporation Rate at 300 SCFM Off-gas Flow

\begin{tabular}{|c|c|c|c|c|c|c|}
\hline $\begin{array}{c}\text { Evaporation } \\
\text { GPM }\end{array}$ & $\begin{array}{c}\text { Water Lost in } \\
\text { off-gas, GPM }\end{array}$ & $\begin{array}{c}\text { Condensate } \\
\text { Flow, GPM }\end{array}$ & $\begin{array}{c}\text { Condenser U U } \\
\text { Btu/hr ft^2 F }\end{array}$ & $\begin{array}{c}\text { Condensate } \\
\text { Temp, }{ }^{\circ} \mathrm{F}\end{array}$ & $\begin{array}{c}\text { Off-gas Temp } \\
{ }^{\circ} \mathrm{F}\end{array}$ & $\begin{array}{c}\text { Tube Side } \Delta \\
\text { psia }\end{array}$ \\
\hline 2.500 & 0.289 & 2.21 & 23.05 & 102.93 & 98.06 & 0.051 \\
5.500 & 0.564 & 4.94 & 54.88 & 104.41 & 110.76 & 0.130 \\
8.000 & 0.720 & 7.28 & 83.12 & 107.34 & 122.06 & 0.217 \\
10.000 & 1.079 & 8.92 & 104.07 & 111.69 & 131.65 & 0.289 \\
\hline
\end{tabular}

Table G-5. Process Variables vs. Evaporation Rate at 400 SCFM Off-gas Flow

\begin{tabular}{|c|c|c|c|c|c|c|}
\hline $\begin{array}{c}\text { Evaporation } \\
\text { GPM }\end{array}$ & $\begin{array}{c}\text { Watcr Lost in } \\
\text { off-gas, GPM }\end{array}$ & $\begin{array}{c}\text { Condensate } \\
\text { Flow, GPM }\end{array}$ & $\begin{array}{c}\text { Condenser U } \\
\text { Btu/hr ft^ } 2 \mathrm{~F}\end{array}$ & $\begin{array}{c}\text { Condensate } \\
\text { Temp, }{ }^{\circ} \mathrm{F}\end{array}$ & $\begin{array}{c}\text { Off-gas Temp } \\
{ }^{\circ} \mathrm{F}\end{array}$ & $\begin{array}{c}\text { Tube Side } \Delta \\
\text { psia }\end{array}$ \\
\hline 2.500 & 0.511 & 1.99 & 21.11 & 102.61 & 96.77 & 0.063 \\
5.500 & 0.725 & 4.78 & 53.31 & 104.20 & 108.85 & 0.146 \\
8.000 & 0.877 & 7.12 & 81.37 & 107.67 & 120.48 & 0.240 \\
10.000 & 1.541 & 8.46 & 98.05 & 112.33 & 129.25 & 0.326 \\
\hline
\end{tabular}

Table G-6. Process Variables vs. Evaporation Rate at 500 SCFM Off-gas Flow

\begin{tabular}{|c|c|c|c|c|c|c|}
\hline $\begin{array}{c}\text { Evaporation } \\
\text { GPM }\end{array}$ & $\begin{array}{c}\text { Water Lost in } \\
\text { off-gas, GPM }\end{array}$ & $\begin{array}{c}\text { Condensate } \\
\text { Flow, GPM }\end{array}$ & $\begin{array}{c}\text { Condenser U } \\
\text { Btu/hr f^^2 F }\end{array}$ & $\begin{array}{c}\text { Condensate } \\
\text { Temp, }{ }^{\circ} \mathrm{F}\end{array}$ & $\begin{array}{c}\text { Off-gas Temp } \\
{ }^{\circ} \mathrm{F}\end{array}$ & $\begin{array}{c}\text { Tube Side } \Delta \\
\text { psia }\end{array}$ \\
\hline & & & & & & \\
2.500 & 0.682 & 1.82 & 19.13 & 101.25 & 94.71 & 0.076 \\
5.500 & 0.896 & 4.60 & 51.32 & 102.85 & 106.78 & 0.159 \\
8.000 & 1.000 & 7.00 & 79.24 & 106.91 & 118.39 & 0.263 \\
10.000 & 2.063 & 7.94 & 90.84 & 112.61 & 126.31 & 0.365 \\
\hline
\end{tabular}


Table G-7. Process Variables vs. Off-gas Flow at an Evaporation Rate of $2.5 \mathrm{gpm}$

\begin{tabular}{|c|c|c|c|c|c|c|}
\hline $\begin{array}{c}\text { Off-gas Flow } \\
\text { SCFM }\end{array}$ & $\begin{array}{c}\text { Water Lost in } \\
\text { off-gas, GPM }\end{array}$ & $\begin{array}{c}\text { Condensate } \\
\text { Flow, GPM }\end{array}$ & $\begin{array}{c}\text { Condenser U } \\
\text { Btu/hr ft^2 F }\end{array}$ & $\begin{array}{c}\text { Condensate } \\
\text { Temp, }{ }^{\circ} \mathrm{F}\end{array}$ & $\begin{array}{c}\text { Off-gas Temp } \\
{ }^{\circ} \mathrm{F}\end{array}$ & $\begin{array}{c}\text { Tube Side } \Delta \\
\text { psia }\end{array}$ \\
\hline & & $\cdot$ & & & & \\
50.00 & 0.021 & 2.48 & 25.40 & 110.17 & 104.69 & 0.022 \\
100.00 & -0.016 & 2.52 & 25.90 & 109.63 & 104.74 & 0.028 \\
200.00 & 0.121 & 2.38 & 24.25 & 104.65 & 100.35 & 0.041 \\
300.00 & 0.289 & 2.21 & 23.05 & 102.93 & 98.06 & 0.051 \\
400.00 & 0.511 & 1.99 & 21.11 & 102.61 & 96.77 & 0.063 \\
500.00 & 0.682 & 1.82 & 19.13 & 101.25 & 94.71 & 0.076 \\
\hline
\end{tabular}

Table G-8. Process Variables vs. Off-gas Flow at an Evaporation Rate of $5.5 \mathrm{gpm}$

\begin{tabular}{|c|c|c|c|c|c|c|}
\hline $\begin{array}{c}\text { Off-gas Flow } \\
\text { SCFM }\end{array}$ & $\begin{array}{c}\text { Water Lost in } \\
\text { off-gas, GPM }\end{array}$ & $\begin{array}{c}\text { Condensate } \\
\text { Flow, GPM }\end{array}$ & $\begin{array}{c}\text { Condenser U } \\
\text { Btu/hr ft^2 F }\end{array}$ & $\begin{array}{c}\text { Condensate } \\
\text { Temp, }{ }^{\circ} \mathrm{F}\end{array}$ & $\begin{array}{c}\text { Off-gas Temp } \\
{ }^{\circ} \mathrm{F}\end{array}$ & $\begin{array}{c}\text { Tube Side } \Delta \\
\text { psia }\end{array}$ \\
\hline & & & & & & \\
50.00 & 0.056 & 5.44 & 60.42 & 106.91 & 122.68 & 0.077 \\
100.00 & 0.020 & 5.48 & 60.92 & 106.37 & 122.73 & 0.083 \\
200.00 & 0.338 & 5.16 & 56.71 & 102.69 & 113.87 & 0.105 \\
300.00 & 0.564 & 4.94 & 54.88 & 104.41 & 110.76 & 0.130 \\
400.00 & 0.725 & 4.78 & 53.31 & 104.20 & 108.85 & 0.146 \\
500.00 & 0.896 & 4.60 & 51.32 & 102.85 & 106.78 & 0.159 \\
\hline
\end{tabular}

Table G-9. Process Variables vs. Off-gas Flow at an Evaporation Rate of $8 \mathrm{gpm}$

\begin{tabular}{|c|c|c|c|c|c|c|}
\hline $\begin{array}{c}\text { Off-gas Flow } \\
\text { SCFM }\end{array}$ & $\begin{array}{c}\text { Water Lost in } \\
\text { off-gas, GPM }\end{array}$ & $\begin{array}{c}\text { Condensate } \\
\text { Flow, GPM }\end{array}$ & $\begin{array}{c}\text { Condenser U } \\
\text { Btu/hr ft^2 F }\end{array}$ & $\begin{array}{c}\text { Condensate } \\
\text { Temp, }{ }^{\circ} \mathrm{F}\end{array}$ & $\begin{array}{c}\text { Off-gas Temp } \\
{ }^{\circ} \mathrm{F}\end{array}$ & $\begin{array}{c}\text { Tube Side } \Delta \\
\text { psia }\end{array}$ \\
\hline 50.00 & 0.086 & 7.91 & 91.48 & 107.77 & 135.10 & 0.155 \\
100.00 & 0.185 & 7.82 & 90.41 & 108.09 & 133.69 & 0.162 \\
200.00 & 0.508 & 7.49 & 84.42 & 105.62 & 123.24 & 0.198 \\
300.00 & 0.720 & 7.28 & 83.12 & 107.34 & 122.06 & 0.217 \\
400.00 & 0.877 & 7.12 & 81.37 & 107.67 & 120.48 & 0.240 \\
500.00 & 1.000 & 7.00 & 79.24 & 106.91 & 118.39 & 0.263 \\
\hline
\end{tabular}


Table G-10. Process Variables vs. Off-gas Flow at an Evaporation Rate of $10 \mathrm{gpm}$

\begin{tabular}{|c|c|c|c|c|c|c|}
\hline $\begin{array}{c}\text { Off-gas Flow } \\
\text { SCFM }\end{array}$ & $\begin{array}{c}\text { Water Lost in } \\
\text { off-gas, GPM }\end{array}$ & $\begin{array}{c}\text { Condensate } \\
\text { Flow, GPM }\end{array}$ & $\begin{array}{c}\text { Condenser U } \\
\text { Btu/hr ft^2 F }\end{array}$ & $\begin{array}{c}\text { Condensate } \\
\text { Temp, }{ }^{\circ} \mathrm{F}\end{array}$ & $\begin{array}{c}\text { Off-gas Temp } \\
\text { of }\end{array}$ & $\begin{array}{c}\text { Tube Side } \Delta \\
\text { psia }\end{array}$ \\
\hline & & & & & & \\
50.00 & 0.181 & 9.82 & 115.85 & 109.55 & 143.86 & 0.224 \\
100.00 & 0.280 & 9.72 & 114.79 & 109.87 & 142.45 & 0.231 \\
200.00 & 0.703 & 9.30 & 106.25 & 109.03 & 132.22 & 0.259 \\
300.00 & 1.079 & 8.92 & 104.07 & 111.69 & 131.65 & 0.289 \\
400.00 & 1.541 & 8.46 & 98.05 & 112.33 & 129.25 & 0.326 \\
500.00 & 2.063 & 7.94 & 90.84 & 112.61 & 126.31 & 0.365 \\
\hline
\end{tabular}




\section{Appendix O}

Condenser Performance Graphs 


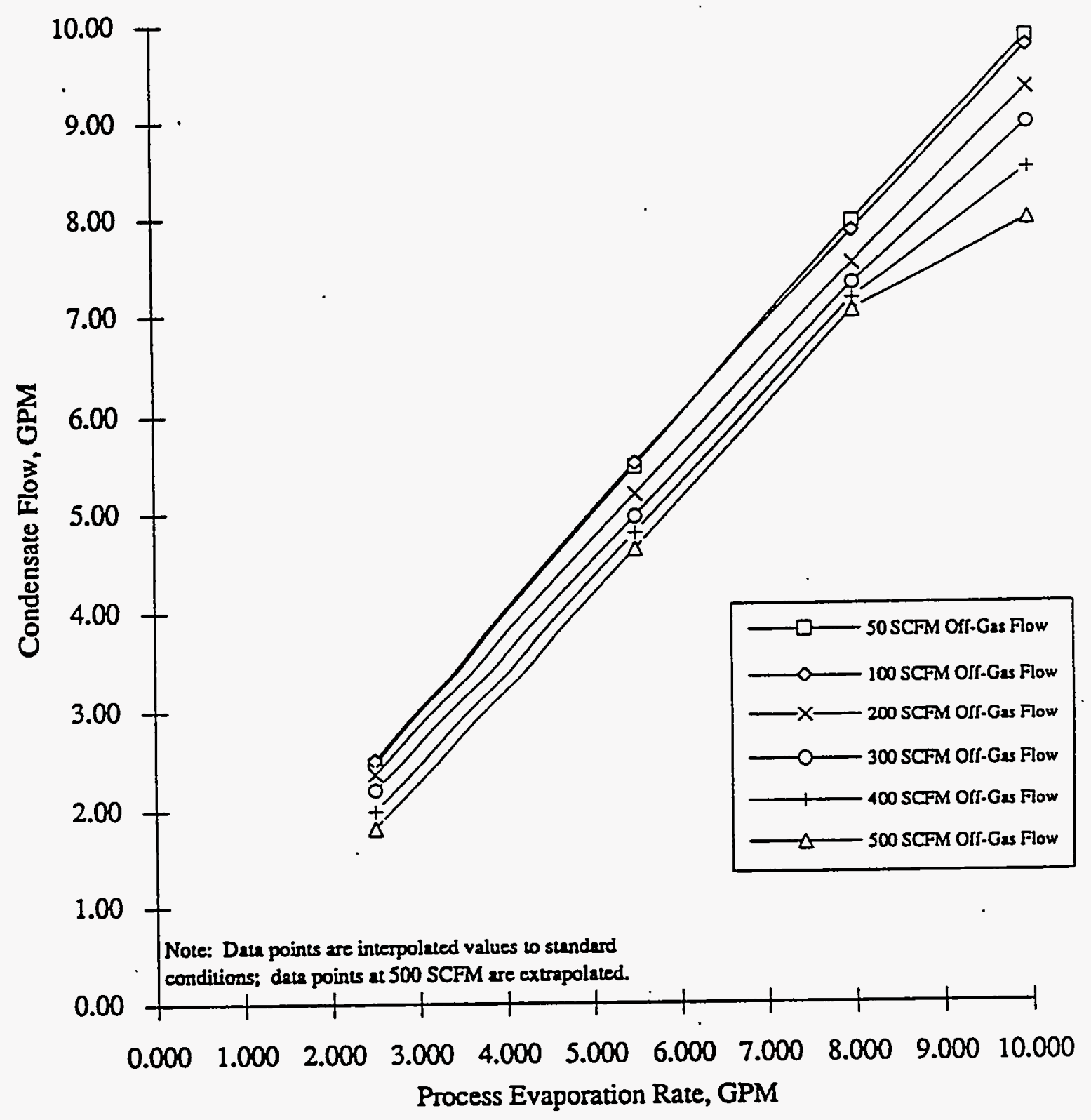

Figure O.1. Process Condensate Flow Versus Process Evaporation Rate

0.1 


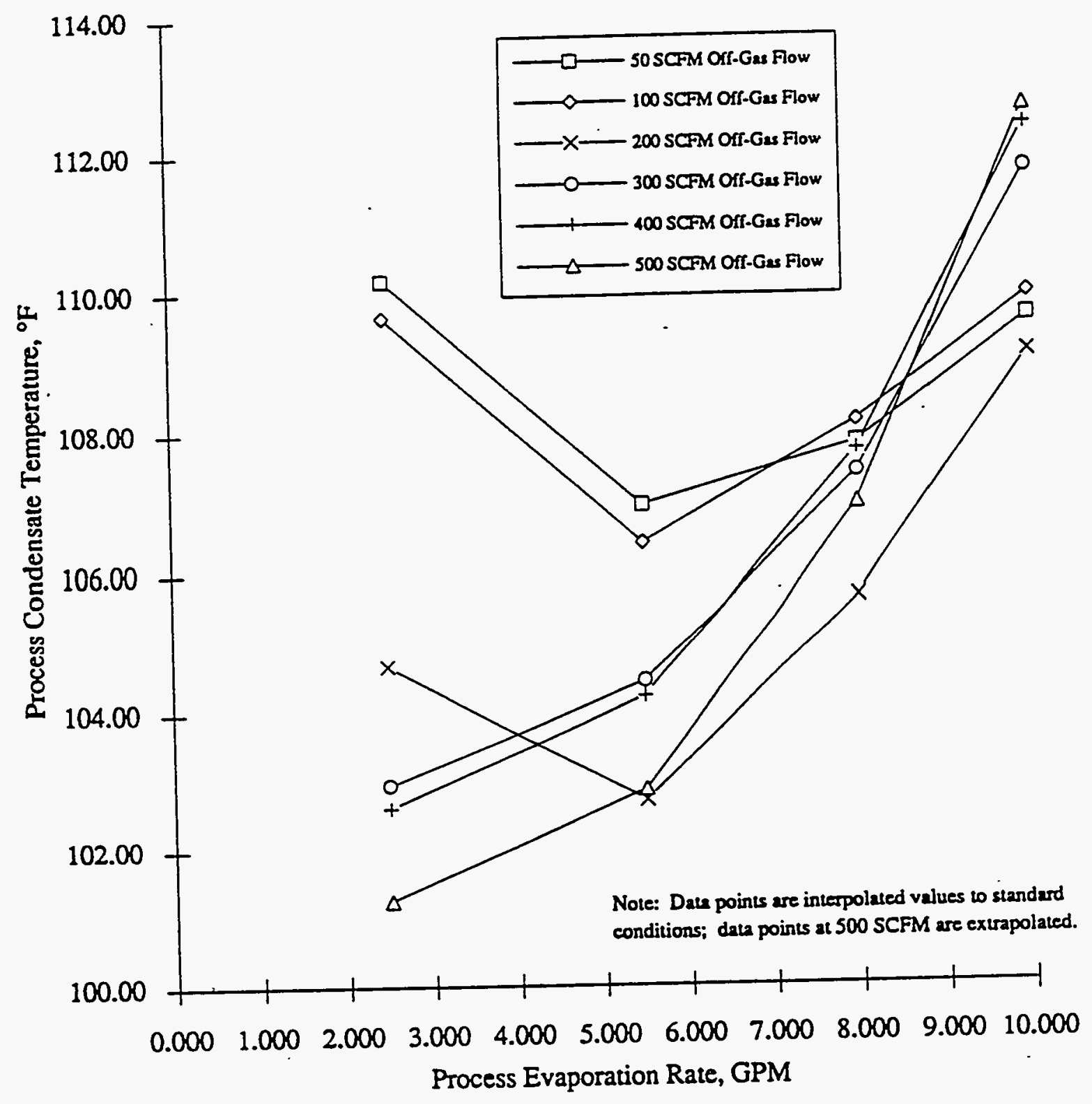

Figure 0.2. Process Condensate Temperature Versus Process Evaporation Rate 


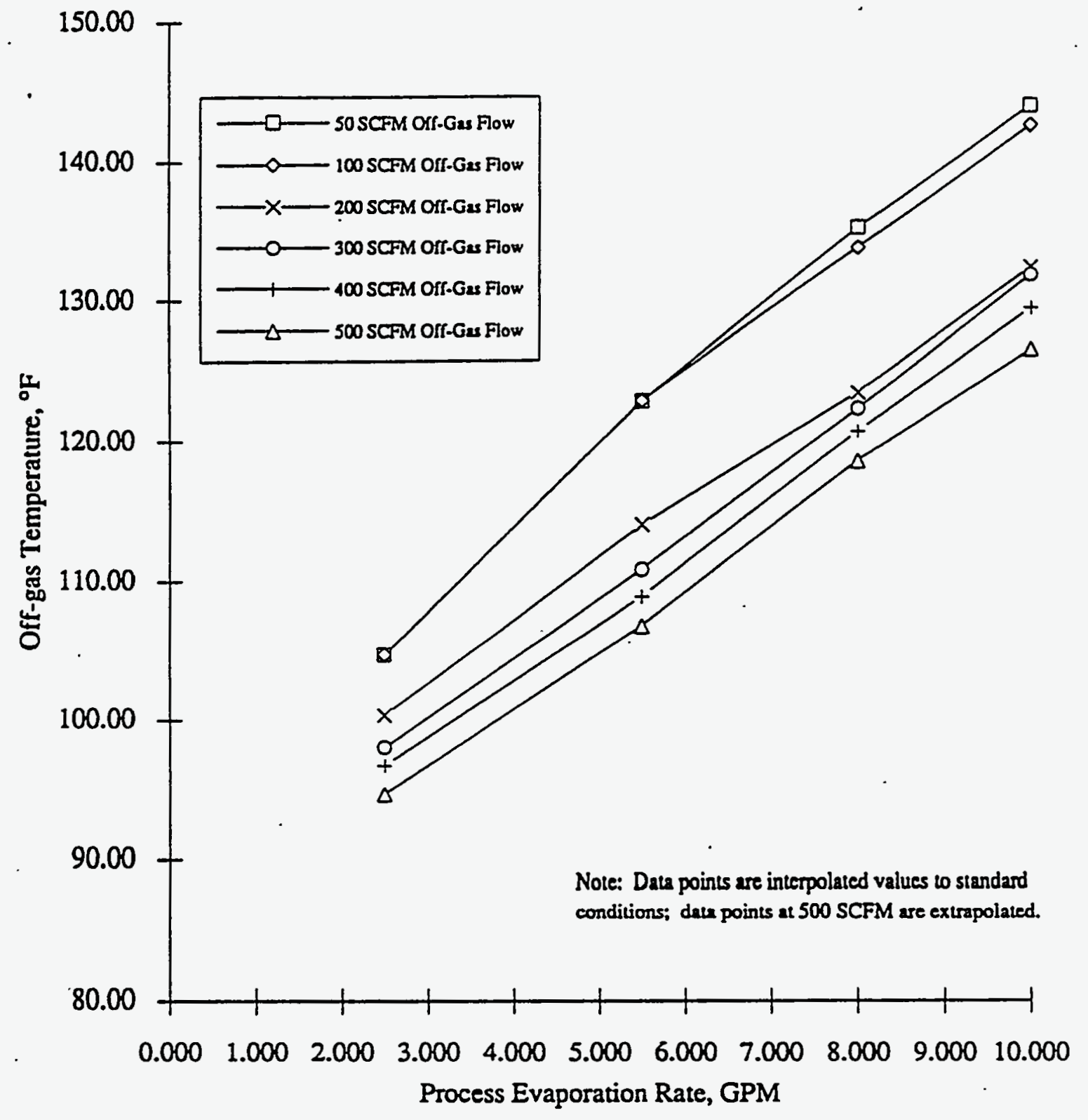

Figure 0.3. Off-Gas Temperature Versus Process Evaporation Rate

0.3 


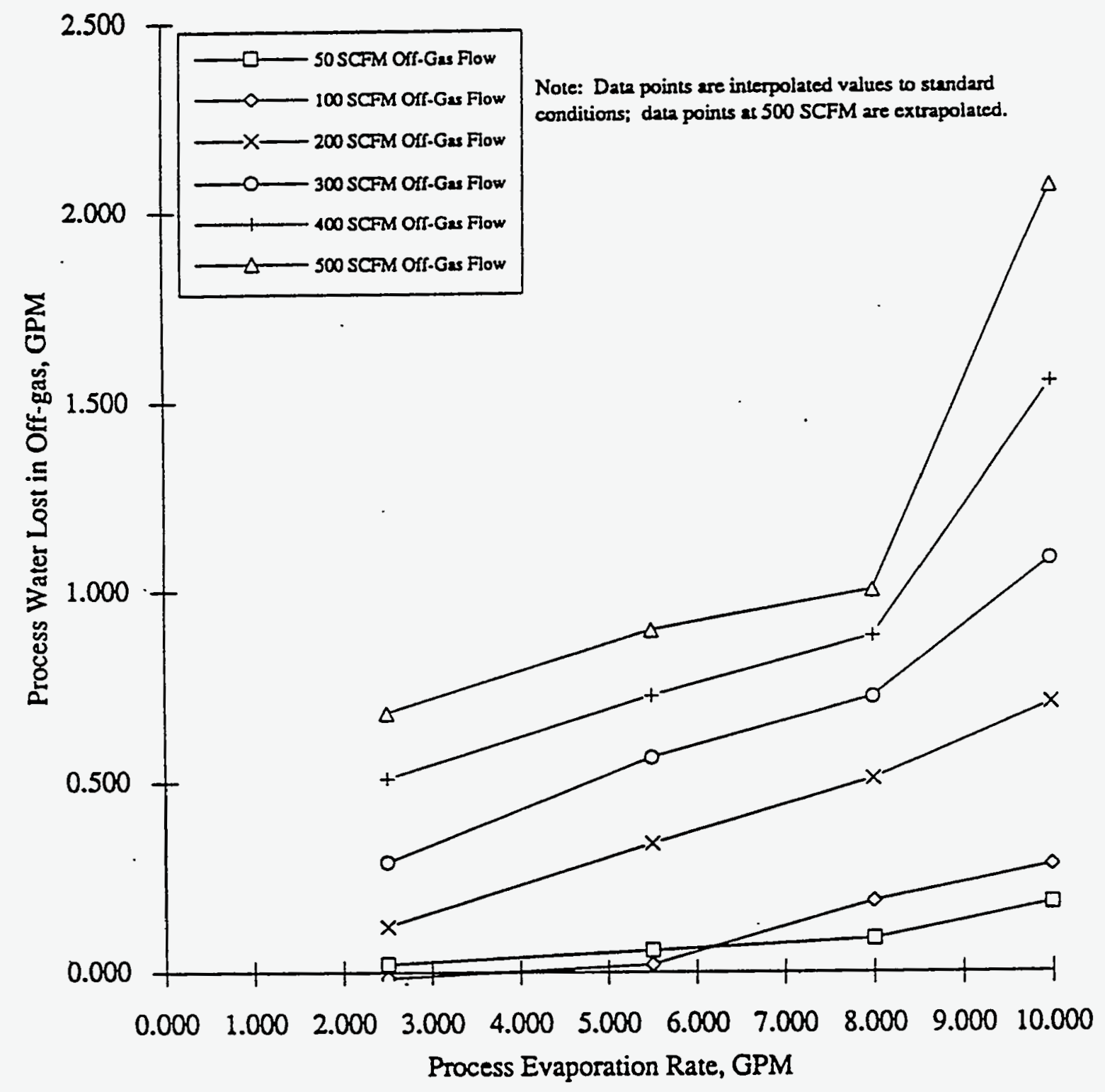

Figure 0.4. Process Water (Vapor and Droplets) in Off-Gas Versus Process Evaporation Rate 


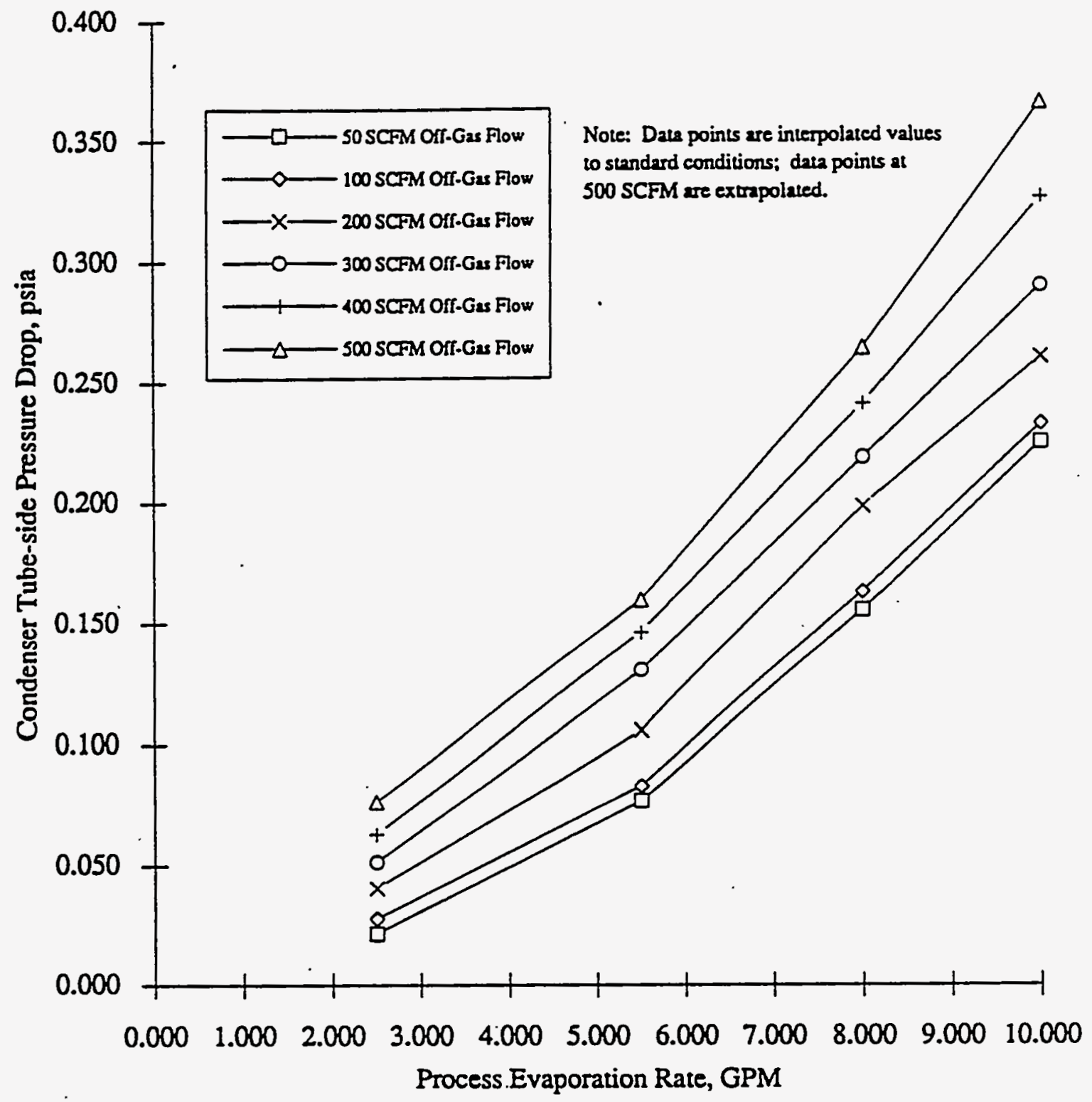

Figure O.5. Condenser Tube-Side Pressure Drop Versus Process Evaporation Rate 


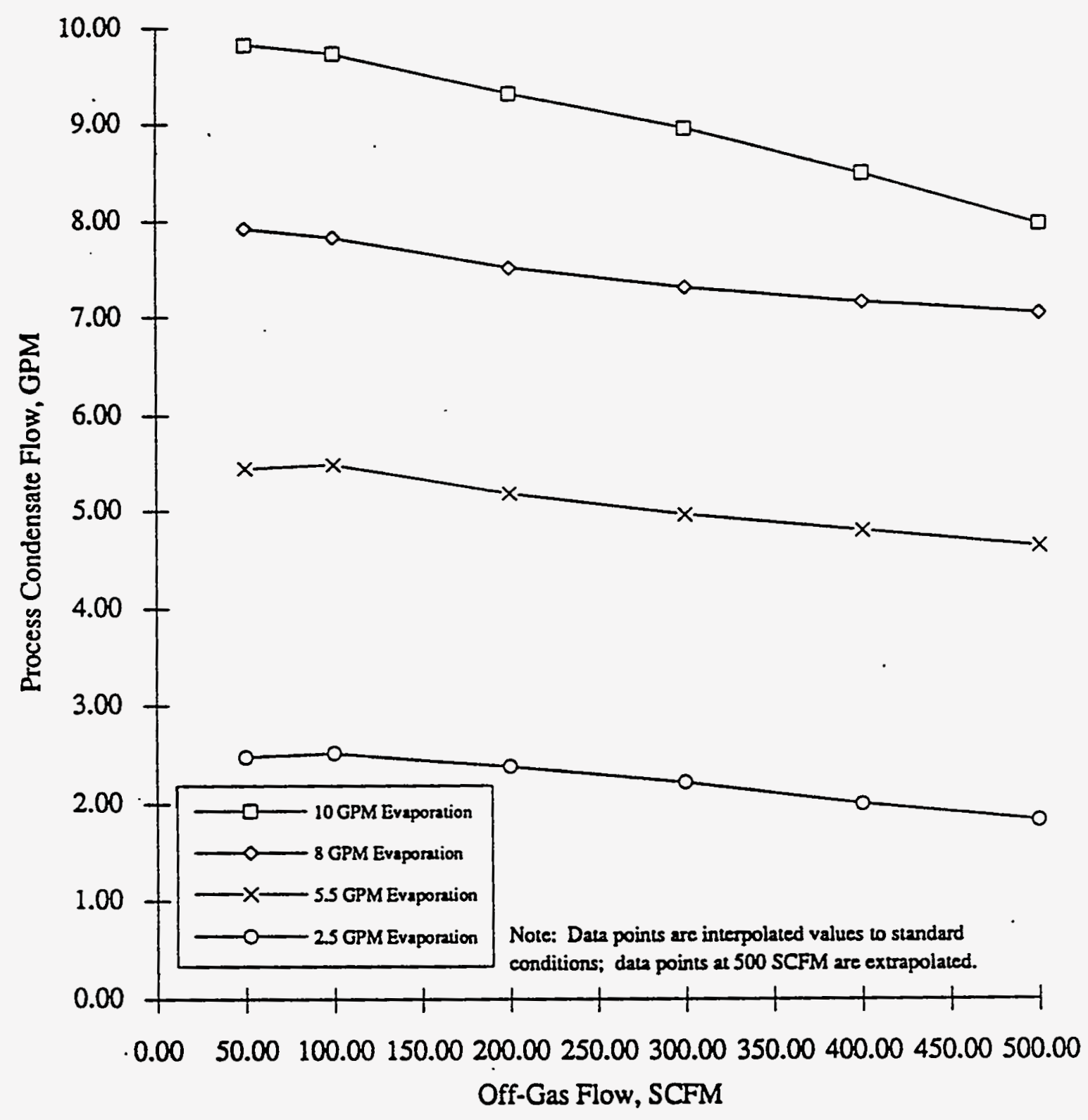

Figure O.6. Process Condensate Flow Vèrsus Off-Gas Flow

0.6 


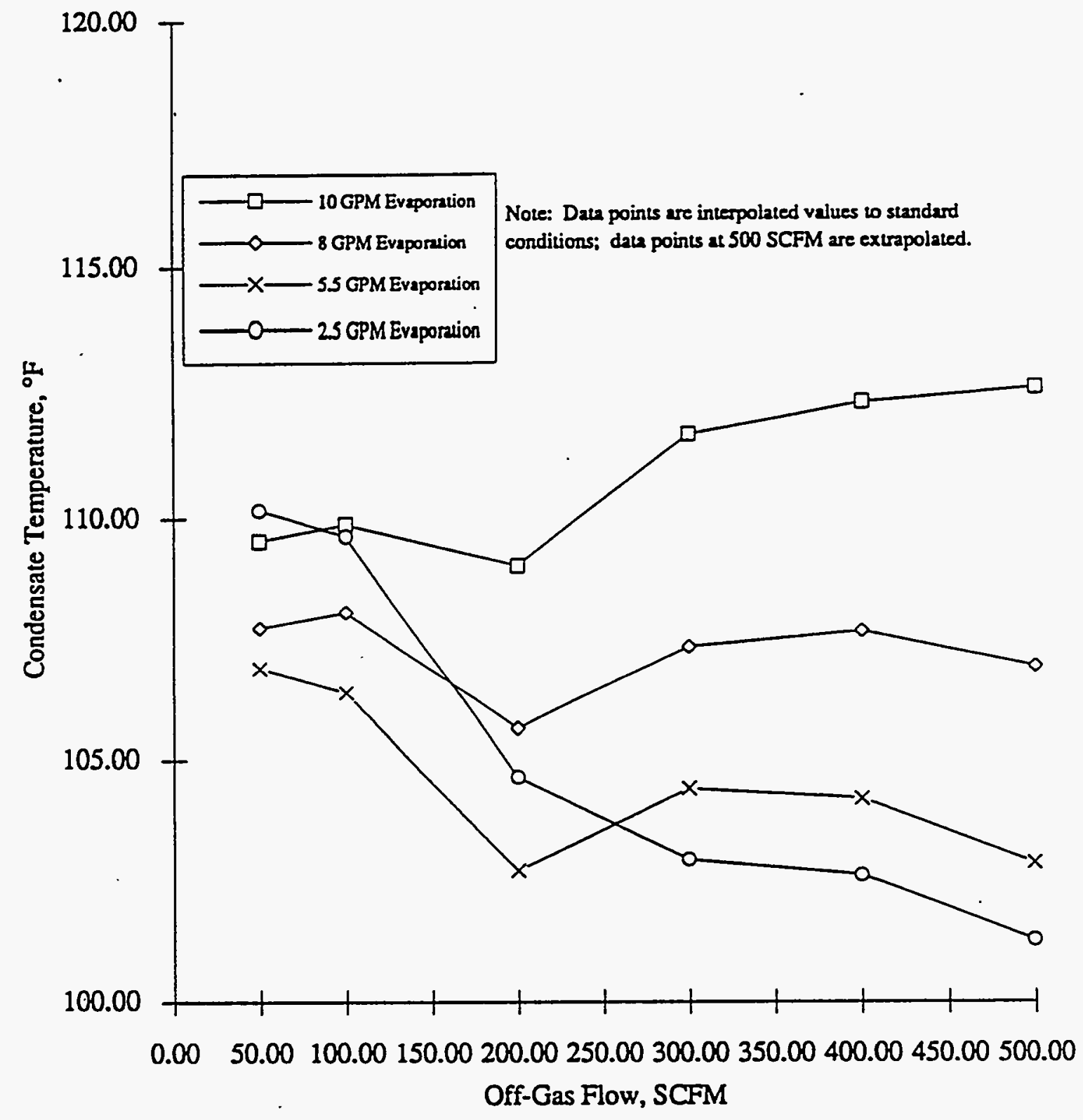

Figure 0.7. Process Condensate Temperature Versus Off-Gas Flow 


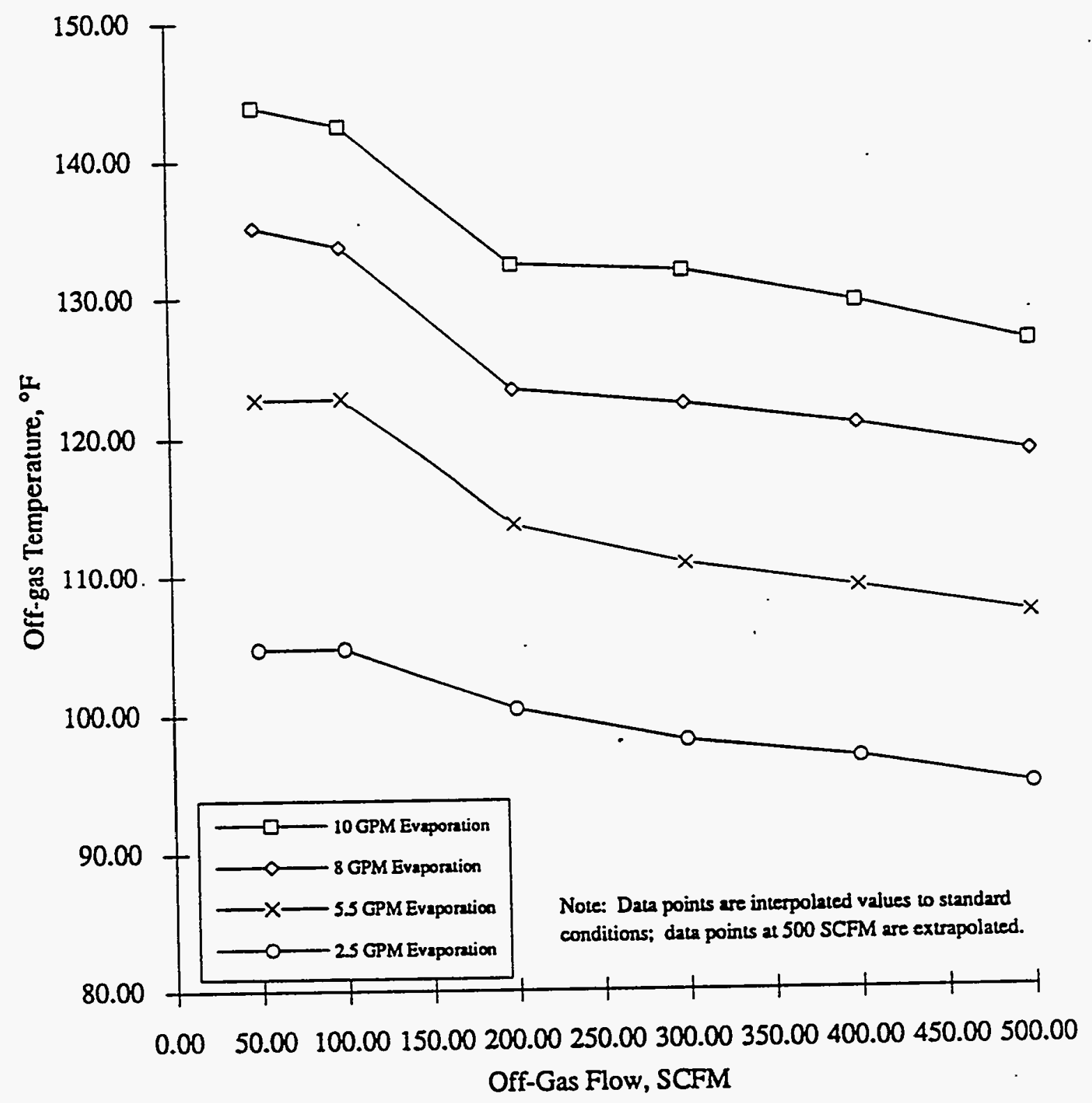

Figure O.8. Off-Gas Temperature Versus Off-Gas Flow 


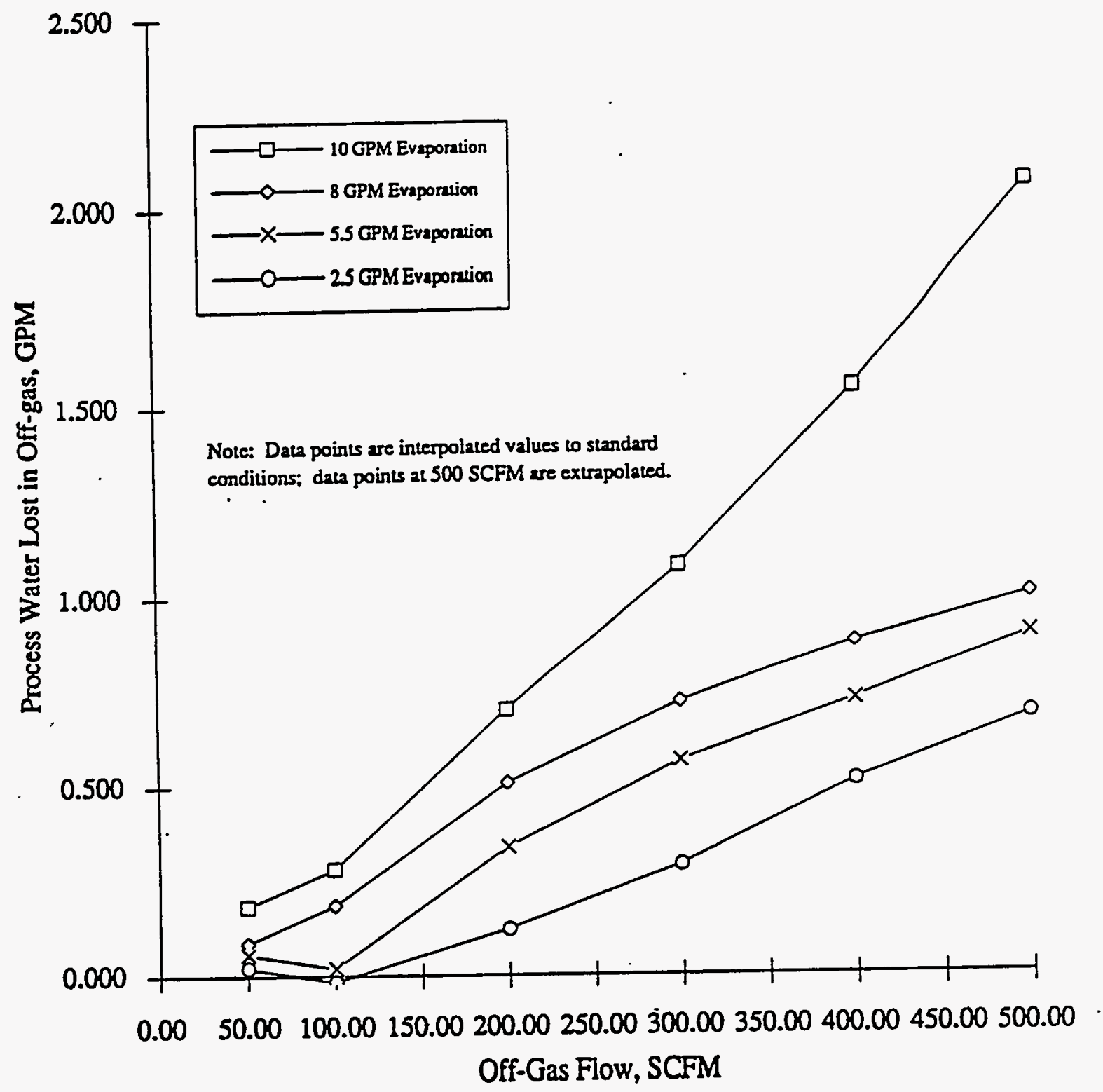

Figure 0.9. Process Water (Vapor and Droplets) in Off-Gas Versus Off-Gas Flow 


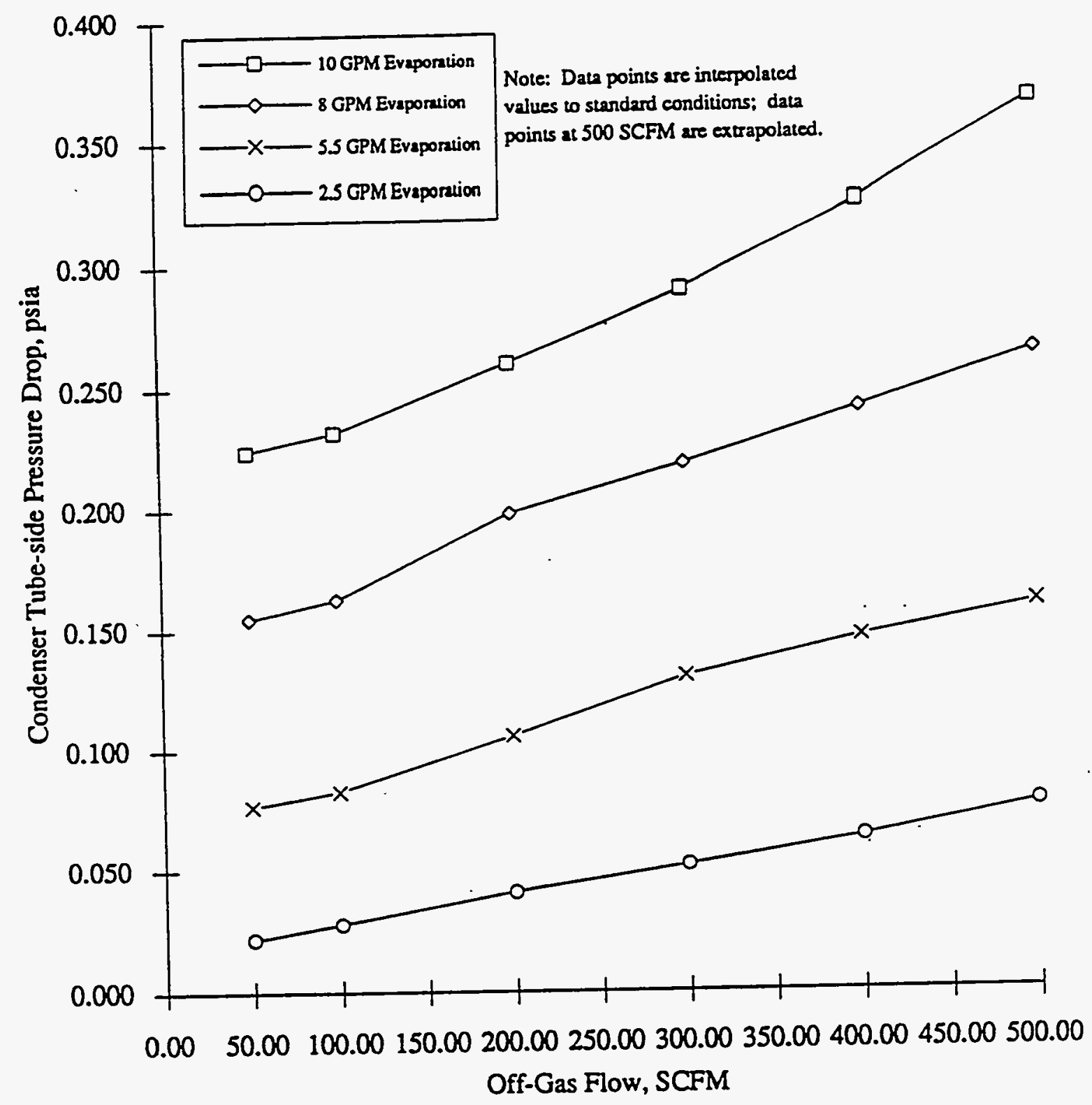

Figure 0.10. Condenser Tube-Side Pressure Drop Versus Off-Gas Flow 


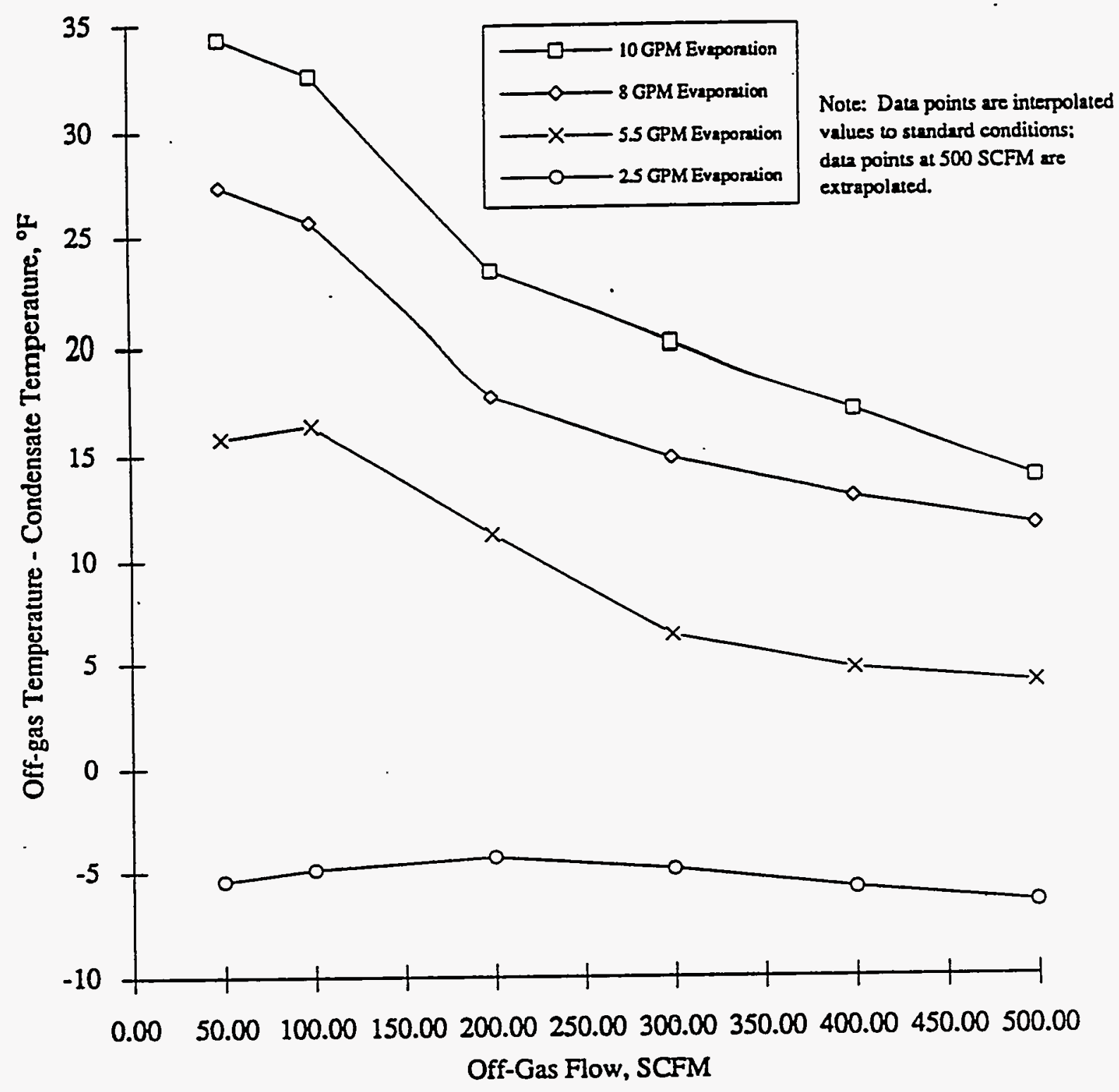

Figure O.11. Off-Gas Temperature - Condensate Temperature Versus Off-Gas Flow 
Appendix $\mathbf{P}$

Condenser Shell-Side Pressure Drop Calculation 
Detailed Design Data Package

Item 1.2b - Condenser Shell-Side Pressure Drop

Page 14 of 27

Calculation/Analysis Coversheet

Project: SIFT

Title/SUbJect: SIFT CONIENSER SHEU-SITE TESSSUEE TEED

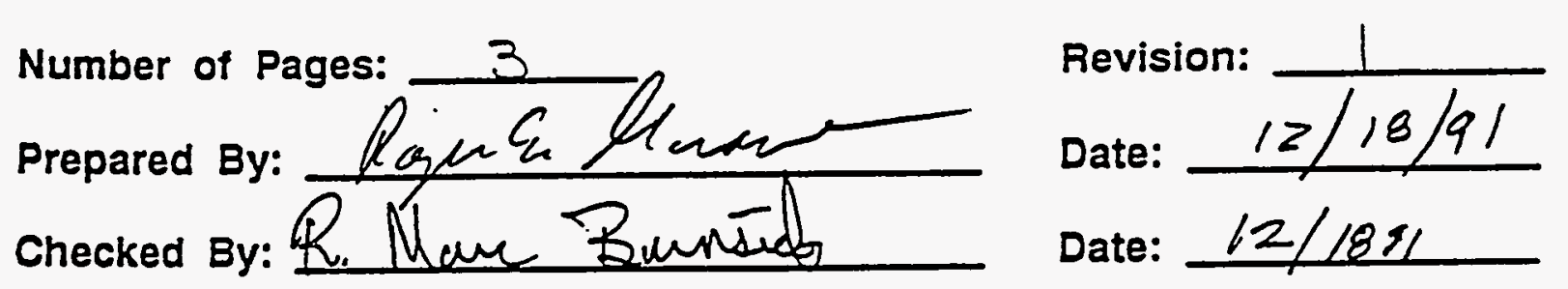

P.1 
Shell Side Pressure Drop Calculation

Given: 1) Flow rate $=350 \mathrm{gpm}$

2) All dimensions per HWVP drawing

(ref. 1)

Objective: Calculate the flange to flange shell side pressure drop across the SIPT condenser.

\section{Solution:}

Define input variable:

$a:=350.0 \mathrm{gpm}$ - shell side flow rate

Calculate the cross flow area as described on p. 138, ref 2 . The description indicates that the cross flow area is based on a "hypopthetical tube row possessing the maximum flow area and corresponding to the center of the shell" (p.138, ref2). The length of the cross flow area is the length of free space along the diameter of the shell. The height of the cross flow area is the distance between baffles. The variables needed for this for this calculatlation are shown below:

$$
\begin{array}{ll}
p_{t}:=\frac{15}{16} & \text { in, Tube pitch } \\
d_{0}:=\frac{3}{4} & \text { in, Tube outside diameter } \\
c:=p_{t}-d_{0} \quad c=0.188 & \text { in, Tube clearance } \\
10:=22.624 & \text { in, Inside diameter of shell } \\
B:=7+\frac{27}{32} & \text { in, baffle spacing }
\end{array}
$$

The standard equation for calculating the cross flow area is shown below:

$$
a_{s}:=\frac{10 \cdot c \cdot B}{P_{t} \cdot 144} \quad z_{s}=0.246 \quad f t * 2 \text {, Cross-flow Area (eq 7.1, p. 138, ret.2) }
$$

Equation 7.1 does not include a center riser and assumes a maximum number of tubes for the specified shell diameter. The cross flow area equation was modified to accomodate the center riser and the free space outside the tube bundle (in particular near the center riser). The resulting equation is shown below:
nt: $:=10$
Number of tubes across the diameter
$\sigma_{r}:=8.625$
in, outside diamter of riser
$a_{r g}:=\frac{\left[\left[10-d^{t}\right]-\left[n t \cdot d^{o}\right]\right]^{B}}{144}$
$f \cdot 2$, modified cross flow area
$a_{r g}=0.354$

Calculate the mass flow rate
$w:=a \cdot 8.289 \cdot 60 w=1.741 \cdot 10^{5}$
$\mathrm{lb} / \mathrm{hr}$, Flow in
$G_{s}:=\frac{W}{a_{10}} \quad G_{s}=4.917 \cdot 10^{5}$
$\mathrm{lb} /(\mathrm{hr})(\mathrm{ft}-2)$, Mass flow rate 


$$
\begin{aligned}
& d_{\bullet}:=\frac{4 \cdot\left[.5 \cdot p_{i} \cdot 86 \cdot p_{t}-\frac{\frac{1}{2} \cdot p^{2} \cdot d_{0}^{2}}{4}\right]}{\frac{1}{2} \cdot p \cdot d_{0}} \quad \text { in, equivalent diameter (eq. 2.5, p. 139, ref } 1 \text { ) } \\
& d_{\bullet}=0.533 \quad \text { ft, equivalent diameter }
\end{aligned}
$$

Calculate the Reynold's number to determine the friction factor

Assume shell side water temperature in $=80 \mathrm{deg} . F$

Assume shell side water temperature out $=110 \mathrm{deg} . F$

(sheet 50, ref. 3 )

$$
\begin{array}{ll}
\frac{[80+110]}{2}=95 & \text { deg. } F \text {, average bulk } \\
m:=.77 \cdot 2.42 \mathrm{~m}=1.863 & (\mathrm{~b} /(\mathrm{hr} f \mathrm{ft}) \text {, bulk visc } \\
\text { Ros }_{\mathrm{s}}:=\frac{D_{0} \cdot \mathrm{G}_{\mathrm{s}}}{\mathrm{m}} \quad \mathrm{Re}_{\mathrm{s}}=1.172 \cdot 10^{4} & \text { Reynold's number }
\end{array}
$$

deg. $F$, average bulk temperature

(b/(hr ft), bulk viscosity for shell side (fig. 14, p. 823 , ref. 2)

Therefore:

$f:=.00203$

$\mathrm{ft}^{-2}$ /in `2, (Function of Reynold's \# based fig. 29, p.839, ref. 2)

Calculate the viscosity ratio

Assume wall temperature $=214 \mathrm{deg} . F$

(sheet 50, ref. 3)

$m_{x}:=.25 \cdot 2.42 \quad m_{x}=0.605$

$\mathrm{lb} /(\mathrm{hr} \mathrm{ft}$ ), wall viscosity for shell side (fig. $14, \mathrm{p} .823$, ref. 2 )

$I_{s}:=\left[\frac{\mathrm{m}}{\mathrm{m}_{\mathrm{r}}}\right]^{.14} \quad \mathrm{I}_{\mathrm{s}}=1.171$

shell side viscosity ratio (p. 174, ref. 2)

Calculate the pressure drop

$$
\begin{aligned}
& D_{8}:-\frac{10}{12} \\
& N:=10 \\
& :=1 \\
& P_{8}:=\frac{1 \cdot .680_{8}^{2} \cdot D_{8} \cdot[N+1]}{5.22 \cdot 10^{10} \cdot D_{8} \cdot 8 \cdot I_{s}} \\
& P_{8}=3.749
\end{aligned}
$$

$\mathrm{ft}$, Inside diameter of shell

Number of baffles

specific gravity

psi, pressure drop, (eq. 7.44 , p. 147, Ref. 2)

psi, condenser pressure drop for $350 \mathrm{gpm}$ flow rate

\section{P.3}


Detailed Design Data Package

References:

Item 1.2b - Condenser Shell-Side Pressure Drop

1. HWVP Drawing (QA file) (sk-3-27805)

2. Kern, D.Q., "Process Heat Transfer", Chapter 7, 1950

3. Fluor Process Calculations, MF-0016 


\section{Appendix Q}

Calculation of Line Loss for Condenser Shell-Side Pressure Drop 
Detailed Design Data Package

$\therefore$

Item 1.2b - Condenser Shell-Side Pressure Drop

Page 24 of 27

Call. No. C.ALC, SIPT-OC:
Page coven of

Calculation Coversheet

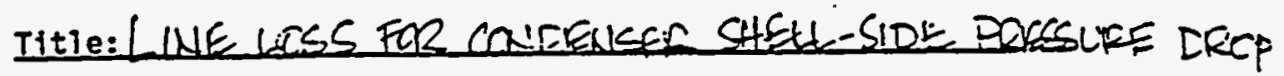
Project: HouND

Performed by: $R_{1} E$, Graves Date: $12 / 4 / 91$

Reviewed by: Cnetuntot

Date: $|2-| 0-9 \mid$

References): 1: CPANE. 10885. Flow of Fluids Through Valves, Fittings, and Pipe.

Q.1 
Detailed Design Data Package Item $1.2 b$ - Condenser Shell-Side Pressure Drop Page 25 of 27

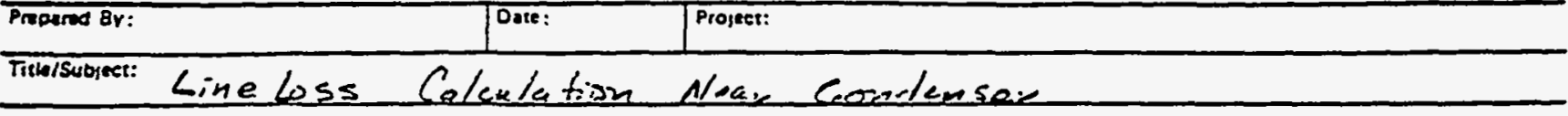

Pequired: Calculate pressure losses in the lines from the insut pressure transdueer to the Condenser mput is flonge and from the condenser output flange to the output pressure thansduser.

gren: line description shown in diagram below

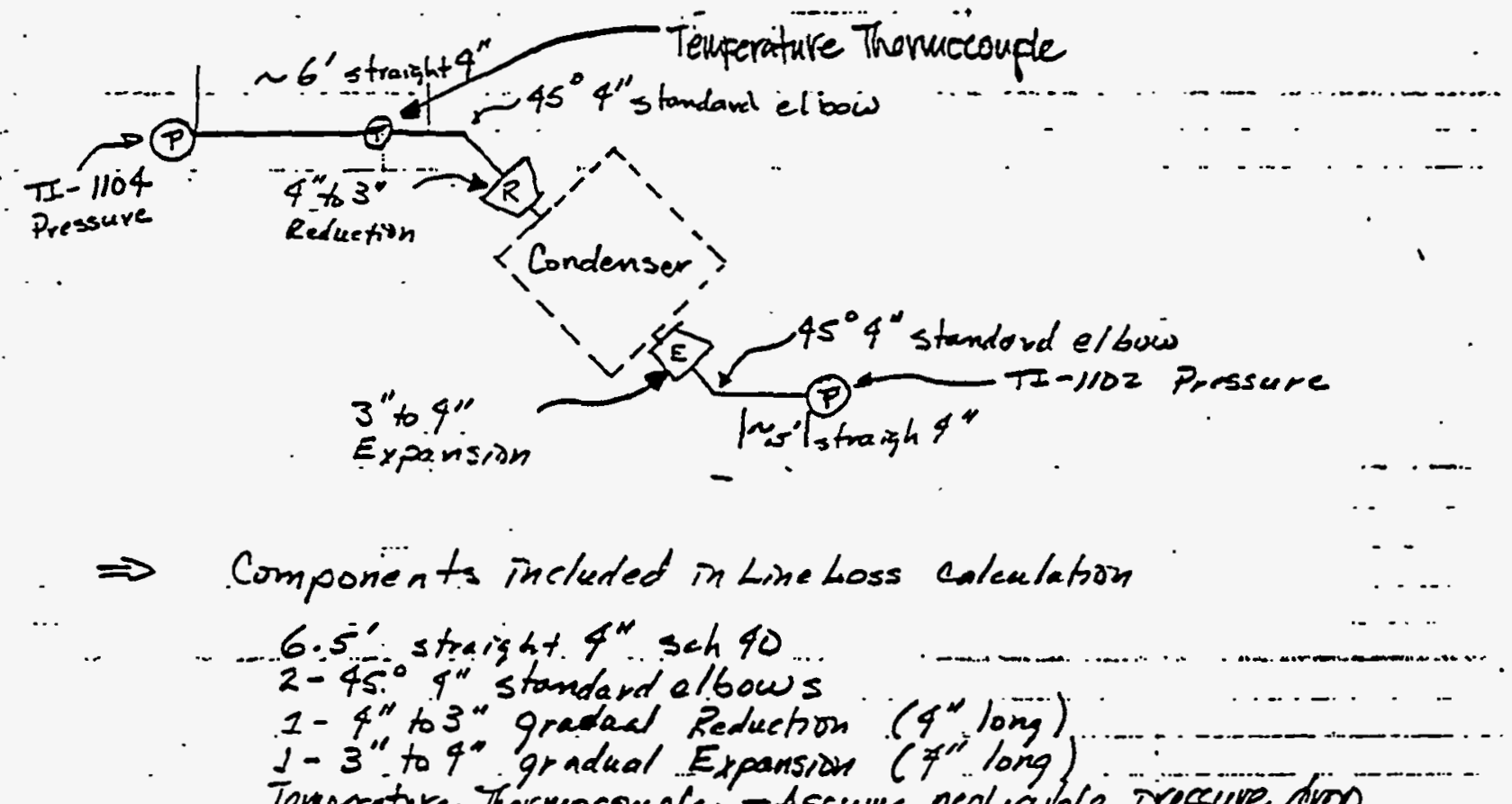

- 3 to $9 "$ "gradual Expansion (7". long

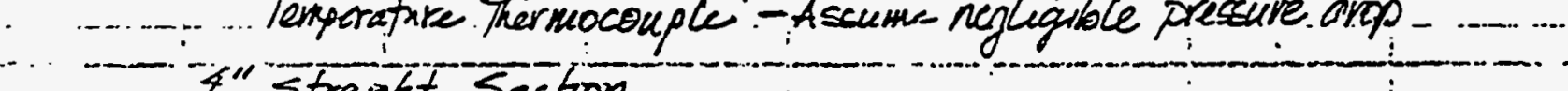

-..". Straight Section. folues for pressure as a function o velocity. from ......

- P B-14 of Crane's Flow of Flude were D/sted in the.........

....... Spreadsheet EXCEL... Data covering flow rates

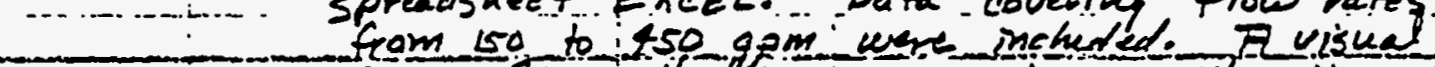

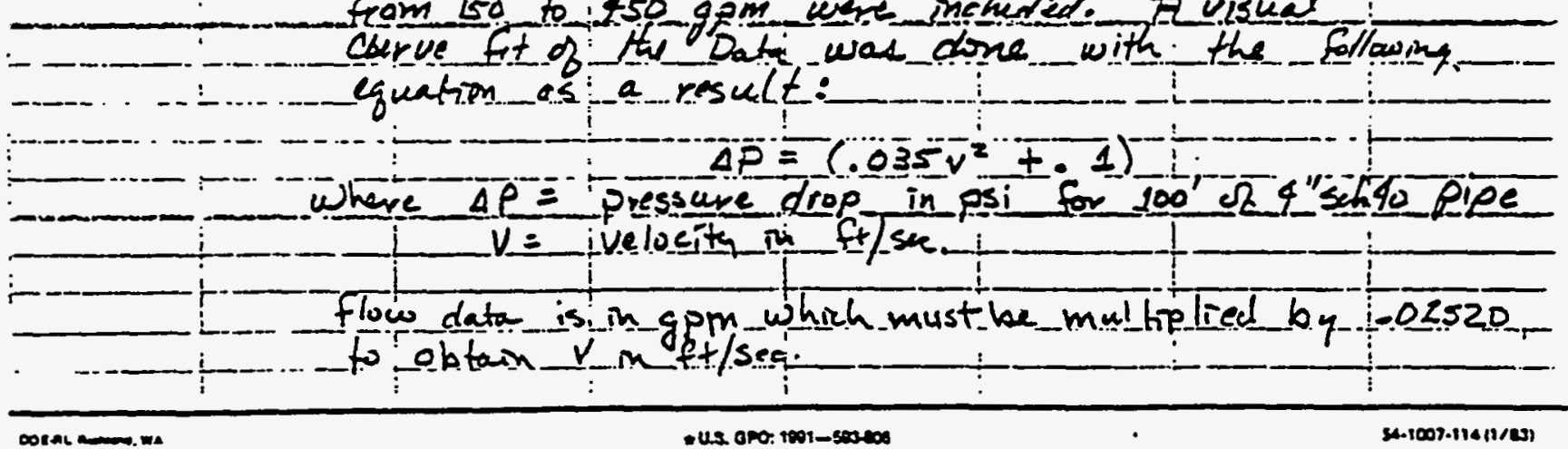

Q.2 
pressure drop is linear with respeetts pipe length

$\Rightarrow$ Sor 6.5. $\Delta P^{\prime}=.065 \Delta P$

$$
\begin{aligned}
& =(.065)\left(.035 v^{2}+.1\right) \\
\text { where } & v \text { is velocity in } 4^{\prime \prime} \text { pipe }
\end{aligned}
$$

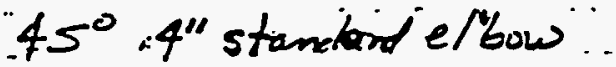

$$
\begin{aligned}
& \Delta P=\frac{h_{L} \rho}{144} \\
& \text { E-23 P 3-5 CEANEE } \\
& \dot{h_{c}}=k \frac{k^{2}}{z_{g}} \\
& E_{q} 2-2 \text { P. 2-8 CRANE } \\
& e=62 \\
& g=32.2
\end{aligned}
$$

$\Rightarrow \Delta P=.006686 k v^{2}$

for $45^{\circ}$ ellow $k=16$ ft PA-29 CRANRE

$F_{t}=.017$ for 4 " $P A-26$ COSNE

$\Rightarrow \quad K \equiv .256$.

$\Rightarrow \Delta P=001712 \mathrm{v}^{2}$. for one kitsow

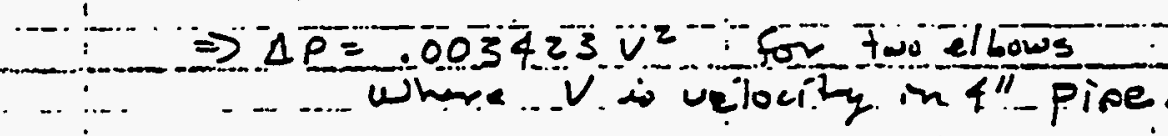

4". to 3" reductom

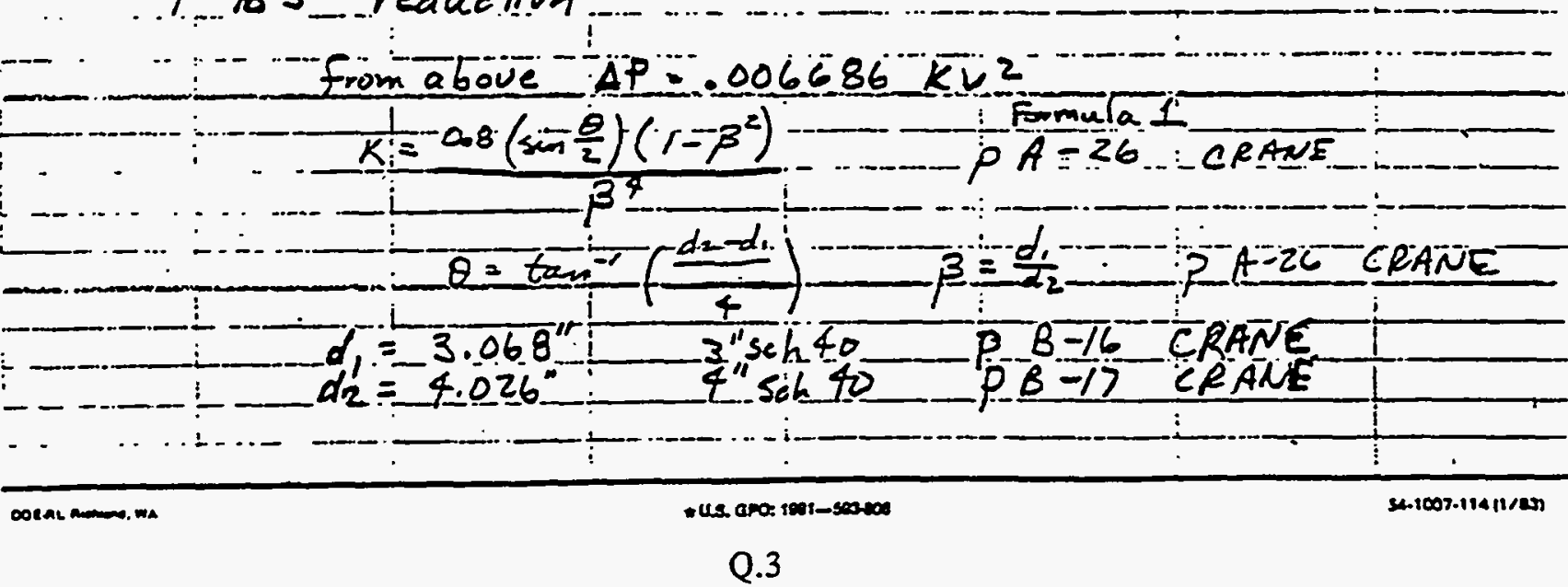




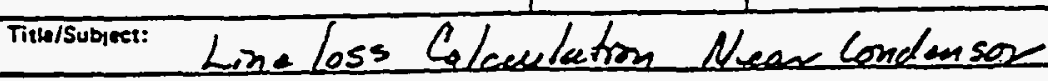

$4 "$ to 3 "reduction (cont.)

$$
\begin{aligned}
s & =\tan ^{-1}\left[\frac{(4.026-3.068}{4^{\prime \prime}}\right]=13.657 \\
\beta & =.76205 \\
\Rightarrow K & =.11827 \ldots \ldots
\end{aligned}
$$

$$
\begin{aligned}
\Delta P & =(-006686)(.11827) v^{2} \\
& =.000791 v^{2}
\end{aligned}
$$

whene $v$ is the avereyz velocity of $3^{\prime \prime}+4^{\prime \prime}$ pipe

3" to 4" Enlargement

From above $\quad \triangle P=.006686 \mathrm{KV} 2$

$$
K=\frac{.2 .6\left(\sin \frac{\theta}{2}\right)\left(1-\beta^{2}\right)^{2}}{R^{4}} \text {... Frombe } 3 \text { PA-26 CRANE }
$$

$$
\theta=-13.652^{\circ} \cdots \beta=.76205
$$$$
\rightarrow k=. .16 .1157
$$

$\rightarrow \quad A P=.001077 V^{2}$

where Vis the average velocity of $3+4$ ". pipe

$\therefore$ Line Loss, $.4 P_{c}=(.065)\left(.035 v_{1}^{2}+.1\right)+.003423 \bar{v}_{1}^{2}$

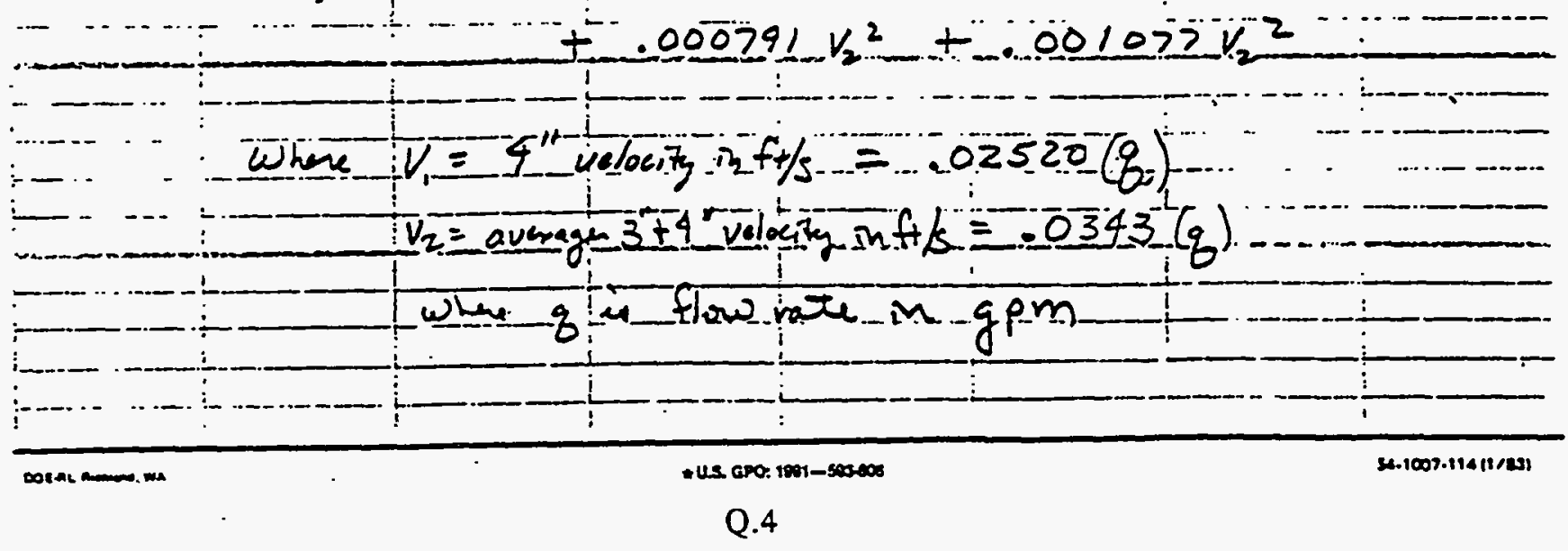


Appendix R

Condensate Analyses 
Conderaste Aralysis

Weight Pereenx Solids

Page $\mathrm{C2}$ of $\mathrm{Cl3}$

\begin{tabular}{|c|c|c|c|c|c|c|c|}
\hline Date & Sample Na. & Firing at $105 \mathrm{C}$ & Location & Date & Sample Na. & Firing at $105 \mathrm{C}$ & Location \\
\hline & & (Slunv) $11 \%$ & & & & (Sluny) wi\% & \\
\hline $12 / 30 / 92$ & SIPT 2-4.1.1 & & Condensale Lime. & $1 / 14 / 93$ & SIPT 2-9.4.3 & & Aerosol HCl Rinsate \\
\hline & SIPT 24.1 .2 & & Conderasite Line & & SIPT 2-9.4.4 & -0.01 & Condereste $1 / 4^{\circ}$ Valve \\
\hline & SIPT 24.13 & & Condersate Line & & SIPT 2.9.4.5 & & $1 / 4^{\circ}$ Condersole Valve \\
\hline & SIPT 2-4.1.4 & & Condereate Trep & & SIPT 2-9.4.6 & 0.01 & $11 / 2^{\circ}$ Condersate Vaive \\
\hline & SIPT 24.1.5 & & Conderosté Line & I/15/93 & |SIITT 2-9.5.4 & & Anti-Fosm Cornpound \\
\hline & SIPT 24.1.6 & & Condenaste Line & & SIPT 2-9.5.1 & & Aerocol filler \\
\hline & SIPT 24.1.7 & & Condeneste Line & & SIPT 2-9.5.2 & & Aerceal DI Water Rinsate \\
\hline & SIPT 24.1.8 & & Condenate Trap & & SIPT 2-9.5.3 & & Aerceol HCI Rinsule \\
\hline & SIPT 24.1.9 & & Condencente Eine & & SIPT 2-9.5.5 & 0 & $14^{-}$Conderease Valve \\
\hline & SIPT 24,1.10 & & Condertate Line & & SIPT 2.9.5.6 & & I $R^{-}$Condensate Trap \\
\hline & SIPT 24.1.11 & & Conderaite Line & & SIPT 2.9.5.8 & 0 & $1 / 4^{-}$Condersate Valve \\
\hline & SIPT 2-4.1.12 & & Condencele Trap & & SIPT 2.9.5.9 & & $17^{\circ}$ Conderente Trap \\
\hline & SIPT 24.1.13 & & Acrosol, Off-gas & & SIPT 2.9.5.10 & & Condereate from HB-14 \\
\hline & SIPT 24.1.14 & & Acroeol, OI-gas & $1 / 23 / 93$ & SIPT 2.9.7.1 & 0 & $114^{-}$Conderuste Valve (Top) \\
\hline & SIPT 2-1.1.15 & & Actosol, Ofr-gas & & SITT 2.9.7.2 & & $12^{-}$Condensale Trap (Bottom) \\
\hline & SIPT 24.1.16 & & Aerosol. OII.gas & & SIPT 2-9.7.3 & & $12^{-}$Condeneste Trap (Botom) \\
\hline $1 / 6 / 93$ & SIPT 28.1.1 & & Actosol. OIf-gas & & SIPT 2-9.7.4 & 0.005 & $11^{-}$Condersale Vaive \\
\hline & SIPT 2.8.1.2 & & Atroeol, Off-gas & & SIPT 2-9.7.5 & & $1 / /^{\circ}$ Condervale Trap \\
\hline & SIPT 2.8.1.3 & & Atrosol. OTl-gas & & SIPT 209.7.6 & & Atrosol Sample Filltr \\
\hline & SIPT 28.1.4 & & Acrocol. Ofi-gas & & SIPT 2-9.7.7 & & Acrosol Sample DI Rinsate \\
\hline & SIFT 2.8.1.5 & & Acrosol, Olf.gas & & SIPT 2.9.7.8 & & Acrosol Sample HCI Rireale \\
\hline & SIPT 2.8.1.6 & & Actosol, On. & $1 / 2803$ & SITT 2.15.1.I & & Acrosol Filter \\
\hline & SIFT 2.8.1.7 & & Aerosol Ofr-gas & & SIPT 2.15.1.2 & & Acrosol DI Waler Rirsalte \\
\hline & SIFT 2.8.1.8 & & Acroed Ofi-gas & & SIFT 2.15.1.3 & & Acrosol HCI Rinsale \\
\hline & SIPT 2.8.1.9 & & Aerceol OlT-gas & & SIPT 2+15.1.4 & -0.03 & $1 / 4^{-}$Condentate Valve \\
\hline & SIFT 2-8.1.10 & 0 & Conderuste Line & & SIPT 2-15.1.5 & & $114^{\circ}$ Condensale Valve \\
\hline & SIFT 2.8.1.11 & & Condensete Trap & & SIPT 2-15.1.6 & -0.03 & I/4-Condensale Valve \\
\hline & SIPT 2.8.1.12 & -0.01 & Condersule Line & & S1PT 2-15.1.7 & & $112^{-}$Condensale Trap \\
\hline & SIPT 2.8.1.13 & -0.01 & Conderwate Line & & SIPT 2.15.1.8 & & Aerosol Filier \\
\hline & SIPT 2.8.1.14 & & Condersule Trap & & SIPT 2.15.1.9 & & Actosol DI Water Rinsute \\
\hline & SIPT 2-8.1.15 & 0 & Conidetrate Line & & Sirt 2.13.1.10 & & Actosol HCl Rirsate \\
\hline & SIPT 208.1.16 & & Conderente Line & & SIPT 2-15.1.11 & 0.03 & $1 / 4^{-}$Conderante Valve \\
\hline & SIPT 2.8.1.17 & 0 & Condensite Line & & SIPT 2-15.1.12 & & $1 / 4^{-}$Condensate Valve \\
\hline & SIPT 2-8.1.18 & & Condentaste Trep & & |SIPT 2.13.1.13 & & $1 / 4^{-}$Condersale Valve \\
\hline & SIPT 2.8.1.19 & 0 & Condereste Line & & SIPT 2+15.1.14 & & I/2 Condereste Trup \\
\hline & SIPT 2-8.1.20 & & Condemale Line & & SIPT 2-15.1.15 & & Aetosol Filier \\
\hline & SIPT 2-3.1.21 & 0 & Condersate Line & & SIPT 2.15.1.16 & & Aerosol DI Water Riresie \\
\hline & SIPT 2-8.1.22 & & Condervale Trep & & SIFT 2.15.1.17 & & Acrosol HCI Rinsale \\
\hline & SIPT 2-8.1.23 & & Acrosol. Oft.gess & & SIPT 2-15.1.18 & -0.03 & $1 / 4^{\circ}$ Condensate Valve \\
\hline $1 / 13 / 93$ & ISIPT 2-9.1.1 & & Acrosol. & & SIFT 2-15.1.19 & & 1/4" Condendite Valve \\
\hline & SIPT 2-9.1.2 & & DI Water Rinsale & & SIPT 2.15.1.20 & -0.02 & $11^{\circ}$ Condensate Valve \\
\hline & SIPT 2-9.1.3 & & IICI Rinate & & |SIPT 2.15.1.21 & & II/. Condersale Trap \\
\hline & SIPT 2-9.1.4 & & $1 \Omega^{\circ}$ Condensale Trap & $2 / 193$ & |SIPT 2-16.1.1 & & Aerosol Filter \\
\hline & SIPT 2-9.1.5 & 0.01 & $1 / 4^{\circ}$ Condensate Sample & & SIPT 2-16.1.2 & & Aerosol DI Waler Rinsale \\
\hline & SIPT 2-9.1.6 & & $11^{-}$Condereate Sample & & ISIPT 2-16.1.3 & & Acrosol HCI Rinsale \\
\hline & SIPT 2-9.1.7 & & $1 / \Omega^{\circ}$ Condensale Sample & & SIPT 2-16.1.4 & -0.03 & 11/4- Condensule Trap \\
\hline & SIPT 2-9.1.8 & 0 & $14^{\circ}$ Conderaste Sample & & SIPT 2.16.1.5 & & $1 / 2^{-}$Condersale Trap \\
\hline & |SIPT 2-9.2.4 & 0 & I/2- Condersate Sarmple & & SIFT 2-16.1.6 & & I/ $2^{-}$Condemsate Trap \\
\hline & SIPT 2-9.2.1 & & Aerosol & & SIPT 2-16.1.7 & & I/2 Condersale Trap \\
\hline & SIPT 2-9.2.2 & & DI Water Rinesale & & ISIPT 2-16.1.8 & -0.03 & II $\Omega^{\circ}$ Condknsale Trap \\
\hline & SIPT 2.9.2.3 & & HCI Rinsole & $2 / 2 / 93$ & ISIPT 2-16.2.1 & & Atrosol Filter \\
\hline & SIPT 2.9.2.5 & & $1 / \Omega^{-}$Condensale Sample & & |SIPT 2-16.2.2 & & Aerosol DI Water Rinsale \\
\hline & SIPT 2.9.2.6 & 0 & $11 \Omega^{\circ}$ Condeneate Sample & & SIPT 2.16.2.3 & & Acrosol HCl Rinsate \\
\hline $1 / 14 / 93$ & |SIPT 2.9.3.1 & -0.01 & II/2 Condersate Sample & & SITT 2-16.2.4 & & $1 \Omega^{-}$Condersite Trap \\
\hline & SIPT 2.9.3.2 & & Aerosol DI Water Rinsale & & ISIPT 2-16.2.5 & -0.03 & $1 / 4^{-}$Condersate Trap \\
\hline & SIFT 2.9.3.3 & & Acrosol HCI Rinsale & & ISt1'T 2-16.2.6 & & $12^{-}$Condersule Trap \\
\hline & SIPT 2-9.3.4 & & Aerosol Filter & & SIPT 2-16.2.7 & -0.03 & $11 / 4-$ Condensale Trap \\
\hline & SIPT 2-9.3.5 & & $14^{\circ}$ Condensale Sample & & SIगT 7-16.2.8 & & $1 / 2^{*}$ Condensole Trap \\
\hline & SIPT 2.9.3.6 & & I $\Omega^{\circ}$ Condereate Sample & & |SIPT 2-16.3.1 & $\cdot$ & Aerosol Filier \\
\hline & SIPT 2.9.3.7 & 0 & $1 n^{\circ}$ Conderasule Sample & & SIIT 2-16.3.2 & & Acrosol DI Water Rinsate \\
\hline & SIPT 2-9.4.1 & & Acrosol filler & & SIPT 2.16.3.3 & & Acrosol HCl Rinsale \\
\hline & |SIPT 2-9.4.2 & & Aerosol DI Water Rinsale & & ISIPT 2-16.3.4 & 0.03 & $114^{-}$Condersate Trap \\
\hline
\end{tabular}

R.1 
Conderoute Aralyzis

Weidx Pereers Solids

Page $\mathrm{C} 3$ of $\mathrm{Cl} 3$

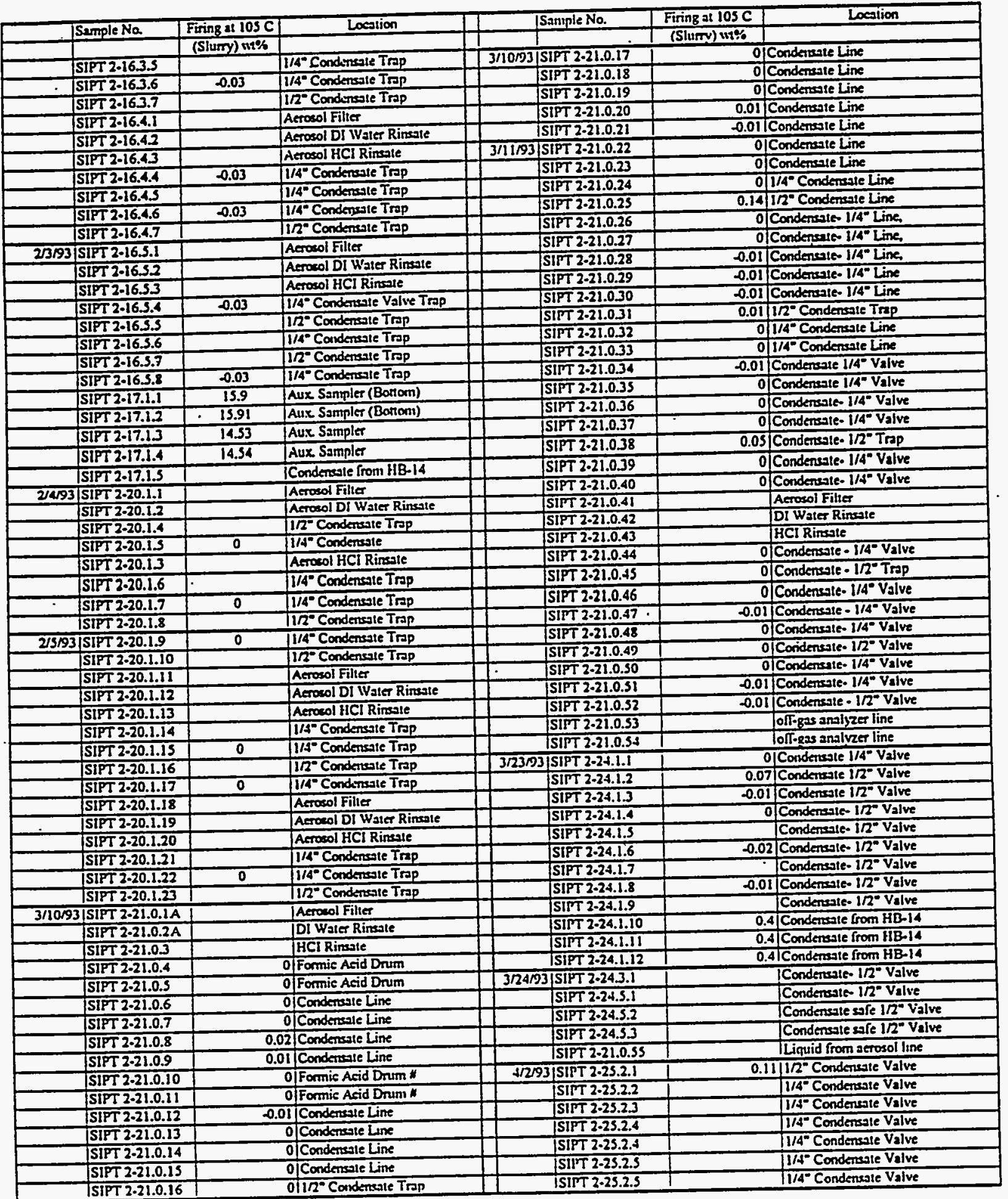




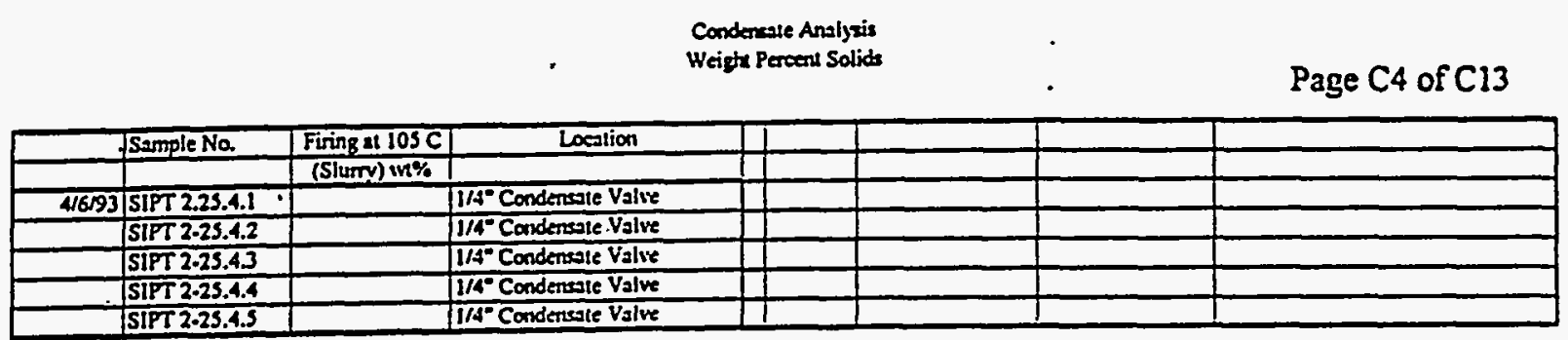


Page $\mathrm{C} 5$ of $\mathrm{Cl3}$

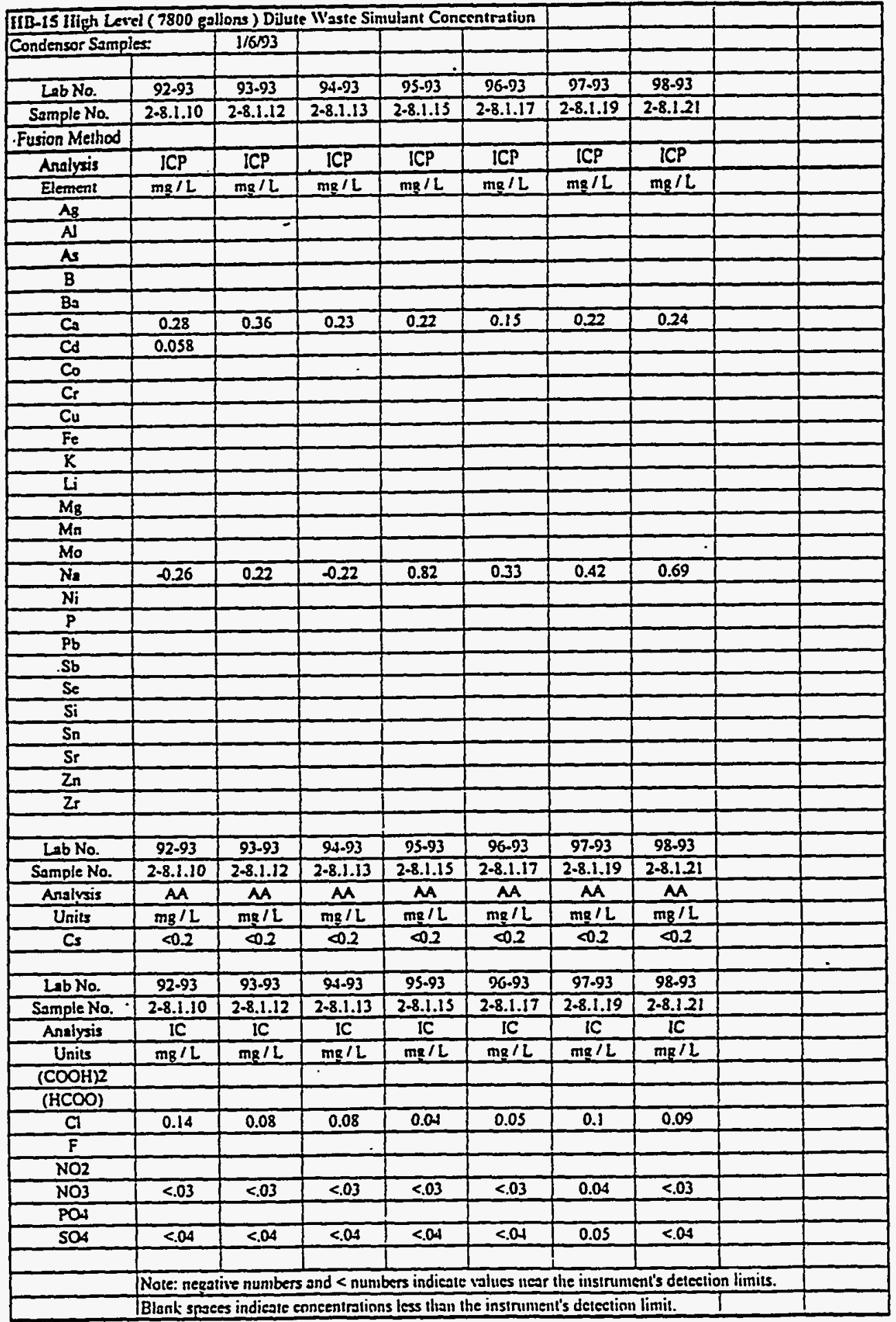

R. 4 
Page $\mathrm{C} 6$ of $\mathrm{C} 13$

\begin{tabular}{|c|c|c|c|c|c|c|c|c|c|}
\hline \multicolumn{10}{|c|}{ HB-15 Low Letcl ( 5700 gallons) Dilute Waste Simujant Concentration } \\
\hline \multicolumn{2}{|c|}{ Condensor Somples: } & $12 / 30 / 92$ & & & & & & & \\
\hline & & & & & & & $16=07$ & 16607 & 16709 \\
\hline Lab No. & 159.92 & $160-92$ & $161-92$ & 162.92 & $103-92$ & $104-92$ & 163.92 & 166.92 & $\frac{167-92}{29}$ \\
\hline Sample No. & 24.1 .1 & $2-4.1 .2$ & $2-4.1 .3$ & $2-4.1 .5$ & 24.1 .6 & $2-4.1 .7$ & $2-4.1 .9$ & 24.1 .10 & $2-4.1 .11$ \\
\hline Fusion Method & & & & & & & & & \\
\hline Aralysis & $\mathrm{ICP}$ & ICP & ICP & ICP & ICP & ICP & ICP & $\mathrm{ICP}$ & ICP \\
\hline Element & $\mathrm{mg} / \mathrm{L}$ & $m g \sqrt{2}$ & $\mathrm{mg} / \mathrm{L}$ & $\mathrm{mg} / \mathrm{L}$ & $m g / L$ & $\mathrm{mg} / \mathrm{L}$ & $\mathrm{mg} / \mathrm{L}$ & $m g$ & $m g /$ \\
\hline $\mathrm{Ag}$ & & & & & & & & & \\
\hline Al & & & & & & & & & \\
\hline As & & & & & & & & & \\
\hline B & & & & & & & & & \\
\hline $\mathrm{Ba}$ & & & & & & & & & \\
\hline $\mathrm{Ca}$ & 0.37 & 0.32 & 0.29 & -0.16 & 0.21 & 0.2 & 0.25 & 0.24 & 0.16 \\
\hline $\mathrm{Cd}$ & & & & & & & & & \\
\hline $\mathrm{Co}_{0}$ & & & & & & & & & \\
\hline $\mathrm{Cr}$ & & & & & & & & & \\
\hline $\mathrm{Cu}$ & & & & & & & & & \\
\hline $\mathrm{Fe}$ & & & & & & & & & \\
\hline $\mathrm{K}$ & & & & & & & & & \\
\hline $\mathrm{Li}$ & & & & & & & & & \\
\hline $\mathrm{M}_{8}$ & & & & & & & & & \\
\hline $\mathrm{Mn}$ & & & & & & & & & \\
\hline Mo & & & & & & & & & \\
\hline $\mathrm{Na}$ & $\infty .2$ & -0.2 & -0.2 & $\infty .2$ & $\infty .2$ & $<0.2$ & $\infty .2$ & 0.25 & $\infty .2$ \\
\hline $\mathrm{Ni}$ & & & & & & & & & \\
\hline$P$ & & & & & & & & & \\
\hline $\mathrm{Pb}$ & & & & & & & & & \\
\hline $\mathrm{Sb}$ & & & & & & & & & \\
\hline Se & & & & & & & & & \\
\hline $\mathrm{Si}$ & 0.26 & 0.24 & 0.22 & -0.17 & -0.14 & 0.17 & 0.14 & -0.12 & -0.1 \\
\hline $\mathrm{Sn}$ & & & & & & & & & \\
\hline St & & & & & & & & & \\
\hline $\mathrm{Ti}$ & & & & & & & & & \\
\hline $2 \pi$ & & & & & & & & & $\therefore$ \\
\hline $\mathrm{Zr}$ & & & & & & & & & \\
\hline Lab No. & $159-92$ & $160-92$ & 161.92 & 162.92 & $163-92$ & $164-92$ & 165.92 & $166-92$ & $167-92$ \\
\hline Sample No. & $2-4.1 .1$ & 24.12 & $2-4.1 .3$ & $2-4.1 .5$ & $2-4.1 .6$ & $2-4.1 .7$ & 24.1 .9 & 24.1 .10 & 24.1 .11 \\
\hline Anaiysis & $A A$ & $A A$ & $A A$ & $A A$ & $A A$ & AA & $A A$ & $A A$ & $A A$ \\
\hline Units & $m g / L$ & $m g / L$ & $m g / L$ & $\mathrm{mg} / \mathrm{L}$ & $m p / L$ & $\mathrm{mg} / \mathrm{L}$ & $m g / L$ & $m g / L$ & $m g / L$ \\
\hline$C_{s}$ & $\infty .2$ & $\infty .2$ & 4.2 & 4.2 & $\infty .2$ & $\infty .2$ & $\infty .2$ & 4.2 & $\infty .2$ \\
\hline Lab No. & $159-92$ & $160-92$ & 161.92 & 162.92 & $163-92$ & 164.92 & 165.92 & $166-92$ & $167-92$ \\
\hline Sumple No. & $2-4.1 .1$ & $2-4.1 .2$ & 24.1 .3 & $2-4.1 .5$ & $2-4.1 .6$ & $2-4.1 .7$ & $2-4.1 .9$ & $2-4.1 .10$ & $2-4.1 .11$ \\
\hline Analysis & IC & IC & IC & IC & IC & IC & IC & IC & IC \\
\hline Units & $m=/$ & me/L & $\mathrm{m} / \mathrm{L}$ & $\mathrm{m} / \mathrm{L}$ & $m=\Omega$ & $\mathrm{m} g / 2$ & $m \varepsilon$ & $m g / L$ & $m \geqslant / L$ \\
\hline $\mathrm{Cl}$ & 0.06 & 0.06 & 0.06 & 0.05 & 0.06 & 0.05 & $<.05$ & 0.04 & 0.03 \\
\hline NO3 & $<.05$ & $<.05$ & $<.05$ & $<.05$ & $<.03$ & $<.03$ & $<.05$ & $<.03$ & $<.03$ \\
\hline $\mathrm{SOA}$ & $<.05$ & $<.05$ & $<.05$ & $<.05$ & $<.02$ & $<.05$ & $<.05$ & $<.04$ & $<.04$ \\
\hline & Nole: ne & numb & $\mathrm{dd}<\mathrm{nII}$ & $s$ indiea & alues ne & ie instn & s detec & limits. & \\
\hline & Blank spa & indicatec & icentratic & $\operatorname{coss}$ than & $=$ instrume & s detext & imit. & & \\
\hline
\end{tabular}


Page $\mathrm{C7}$ of $\mathrm{Cl3}$

\begin{tabular}{|c|c|c|c|c|c|c|c|c|c|}
\hline \multicolumn{10}{|c|}{ HB-15 High Level ( 7800 gallons) Concentmied Waste Simulant Concenerntion } \\
\hline \multicolumn{2}{|c|}{ Condensor Samples: } & \multirow{2}{*}{$22 / 93$} & \multirow{2}{*}{ 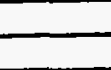 } & \multirow{2}{*}{ 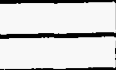 } & \multirow{2}{*}{-1} & \multirow{2}{*}{ 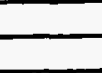 } & \multirow{2}{*}{ 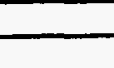 } & \multirow{2}{*}{$\cdot$} & \multirow{2}{*}{ 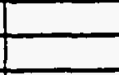 } \\
\hline & & & & & & & & & \\
\hline Lab No. & 259.93 & $260-93$ & 261.93 & 262.93 & 263.93 & 264.93 & 265.93 & $266-93$ & \\
\hline Sample No. & 16.1 .4 & 16.1 .8 & 16.2 .5 & 16.2 .7 & 16.3 .4 & 16.3 .6 & 16.4 .4 & 16.4 .6 & \\
\hline \multicolumn{10}{|l|}{ Fusion Method } \\
\hline Analyzis & ICP & ICP & ICP & ICP & $\mathrm{ICP}$ & ICP & $\mathrm{ICP}$ & ICP & \\
\hline Element & $m g / L$ & $m g / L$ & $\mathrm{mB} / \mathrm{L}$ & $m g / L$ & $\mathrm{mg} / \mathrm{L}$ & $\mathrm{mg} / \mathrm{L}$ & $\mathrm{mg} / \mathrm{L}$ & $m_{B} / L$ & \\
\hline$A_{B}$ & & & &. & & & & & \\
\hline \multicolumn{10}{|l|}{$\frac{A_{8}}{A !}$} \\
\hline \multicolumn{10}{|l|}{ As } \\
\hline \multicolumn{10}{|l|}{ A } \\
\hline \multicolumn{10}{|l|}{$\frac{B}{B 2}$} \\
\hline $\mathrm{C}_{1}$ & 0.17 & 023 & 0.18 & 0.2 & 0.23 & 0.2 & 0.21 & 0.19 & \\
\hline \multicolumn{10}{|l|}{$\mathrm{cd}$} \\
\hline \multicolumn{10}{|l|}{$\mathrm{Co} \cdot$} \\
\hline \multicolumn{10}{|l|}{$\mathrm{Cr}$} \\
\hline $\mathrm{Cu}$ & & & & & & & & & \\
\hline $\mathrm{Fe}$ & & & & & & & & & \\
\hline$K$ & & & & & & & & & \\
\hline $\mathrm{Li}$ & & & $\therefore$ & & & & & & \\
\hline$M_{8}$ & & & & & & & & & \\
\hline $\mathrm{Mn}$ & & & & & & & & & \\
\hline Mo & & & & & & & & & \\
\hline $\mathrm{Na}$ & $\infty .2$ & $<02$ & 0.2 & 0.2 & 0.2 & $<0.2$ & 0.2 & 0.3 & \\
\hline $\mathrm{Ni}$ & & & & & & & $\therefore$ & & \\
\hline$P$ & & & & & & & & & \\
\hline $\mathrm{Pb}$ & & & & & & & & & \\
\hline Si & 38.3 & 9.96 & 5.85 & 6.75 & 5.92 & 5.28 & 5.5 & 5.1 & \\
\hline Sr & & & & & & & & & \\
\hline $\mathrm{Ti}$ & & & & & & & & & \\
\hline $2 n$ & & &. & & & & & & \\
\hline $2 r$ & & & & & & & & & \\
\hline & & & & & & & & & \\
\hline Sample No. & $259-93$ & $260-93$ & 361.93 & 262.93 & 263.93 & $264-93$ & 265.93 & $366-93$ & \\
\hline Analysis & $\mathbf{A}$ & $A A$ & $A A$ & $A$ & $\mathrm{AA}$ & AA & AA & AA & \\
\hline Units & $m e / 2$ & $m e / L$ & $\mathrm{mg} / \mathrm{L}$ & $\mathrm{m} / \mathrm{L}$ & $\mathrm{mg} / \mathrm{L}$ & migl & $m g / L$ & $m g / l$ & \\
\hline $\mathrm{Cs}_{3}$ & $\infty .2$ & $\infty .2$ & $<0.2$ & $\infty .2$ & $<0.2$ & $<0.2$ & $\infty .2$ & $<0.2$ & \\
\hline Leb No. & 259.93 & 260.93 & 261.93 & 362.93 & $263-93$ & 264.93 & $265+93$ & $266-93$ & \\
\hline Sample No. & 16.1 .4 & 16.1 .8 & 16.2 .5 & 162.7 & 16.3 .4 & 16.3 .6 & 16.4 .4 & 16.4 .6 & \\
\hline Ans/ysis & IC & IC & IC & IC & IC & IC & IC & IC & \\
\hline Units & $\mathrm{mg} / \mathrm{L}$ & $\mathrm{mg} / \mathrm{L}$ & $m g / L$ & $m g / L$ & $m g / L$ & $\mathrm{mg} / \mathrm{L}$ & $\mathrm{mg} / \mathrm{L}$ & $m_{R} / L$ & \\
\hline$F$ & & & & & & & & & \\
\hline $\mathrm{Cl}$ & 0.09 & 0.07 & 0.07 & 0.06 & 0.06 & 0.06 & 0.07 & 0.06 & \\
\hline NO2 & & & & & & & & & \\
\hline $\mathrm{POA}$ & & & & & & & & & \\
\hline $\mathrm{NO3}$ & $<.05$ & $<.05$ & 0.06 & $<.05$ & $<.05$ & $<.05$ & $<.05$ & $<.05$ & \\
\hline SO4 & $<.05$ & $<.05$ & $<.05$ & $<.05$ & $<.05$ & $<.05$ & $<.03$ & $<.03$ & \\
\hline$(\mathrm{COOH}) 2$ & & & & & & & & & \\
\hline$(\mathrm{HCOO})$ & & & & & & & & & \\
\hline & Nole: neg & e number: & ind < num & $\pi$ indicate & alues near & e instrume & 's delection & limits. & \\
\hline & Blank strac & indieale $c$ & seentmation & ess than th & instrumes & detection & mit. & & \\
\hline
\end{tabular}


Page $\mathrm{C} 8$ of $\mathrm{Cl3}$

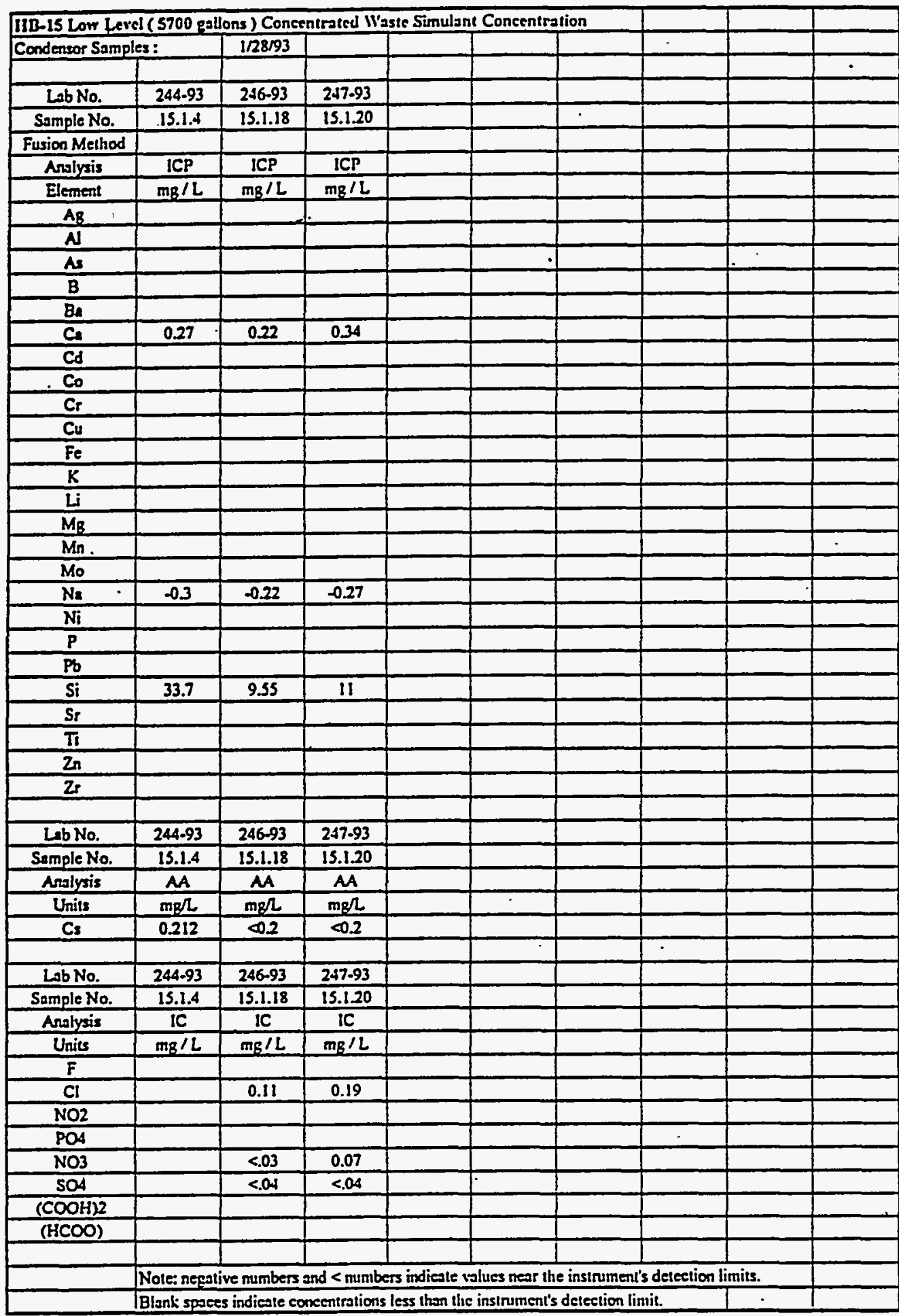

\section{R.7}


Page $\mathrm{C} 9$ of $\mathrm{Cl} 3$

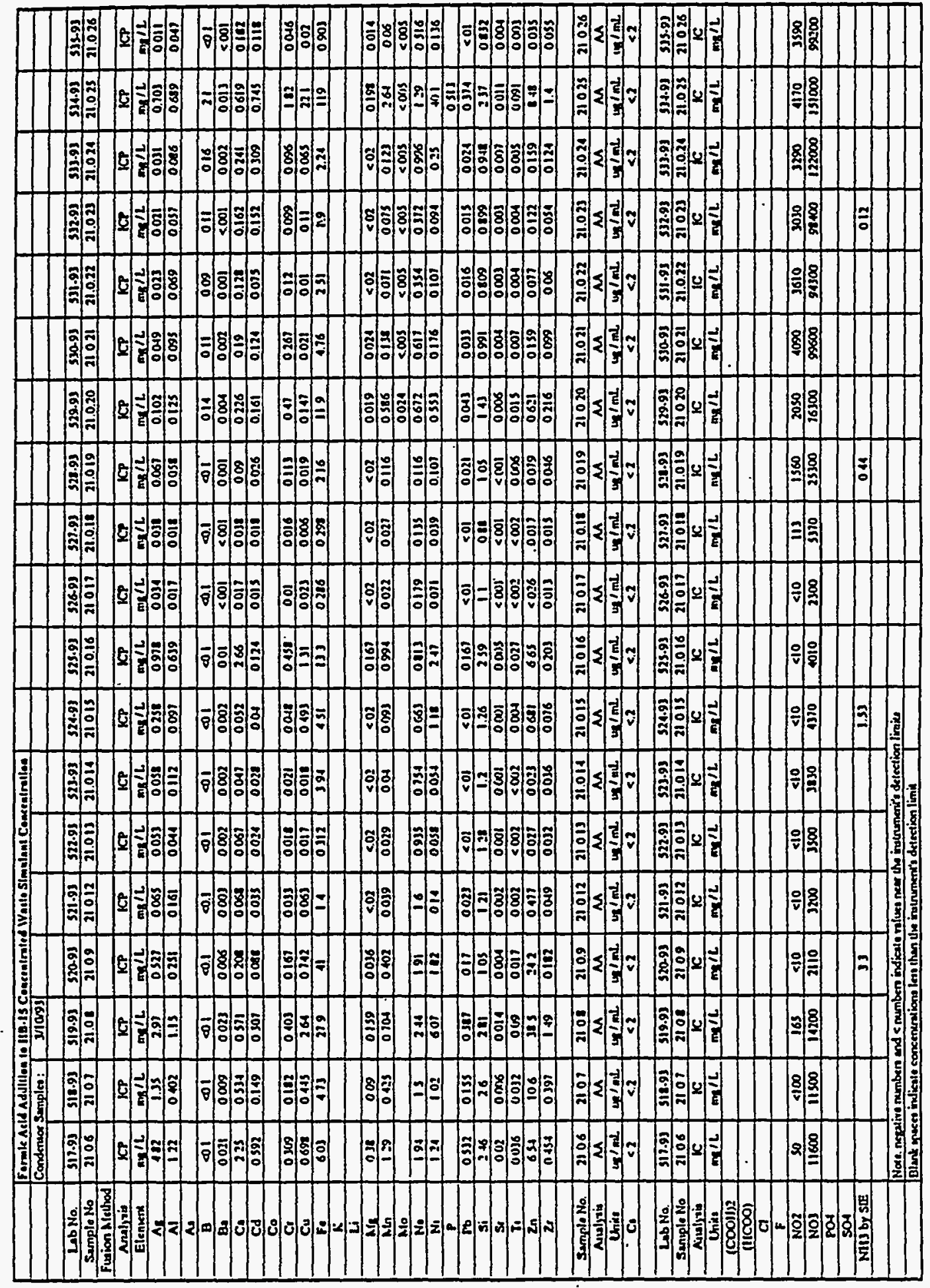


Page $\mathrm{Cl} 10$ of $\mathrm{Cl} 3$

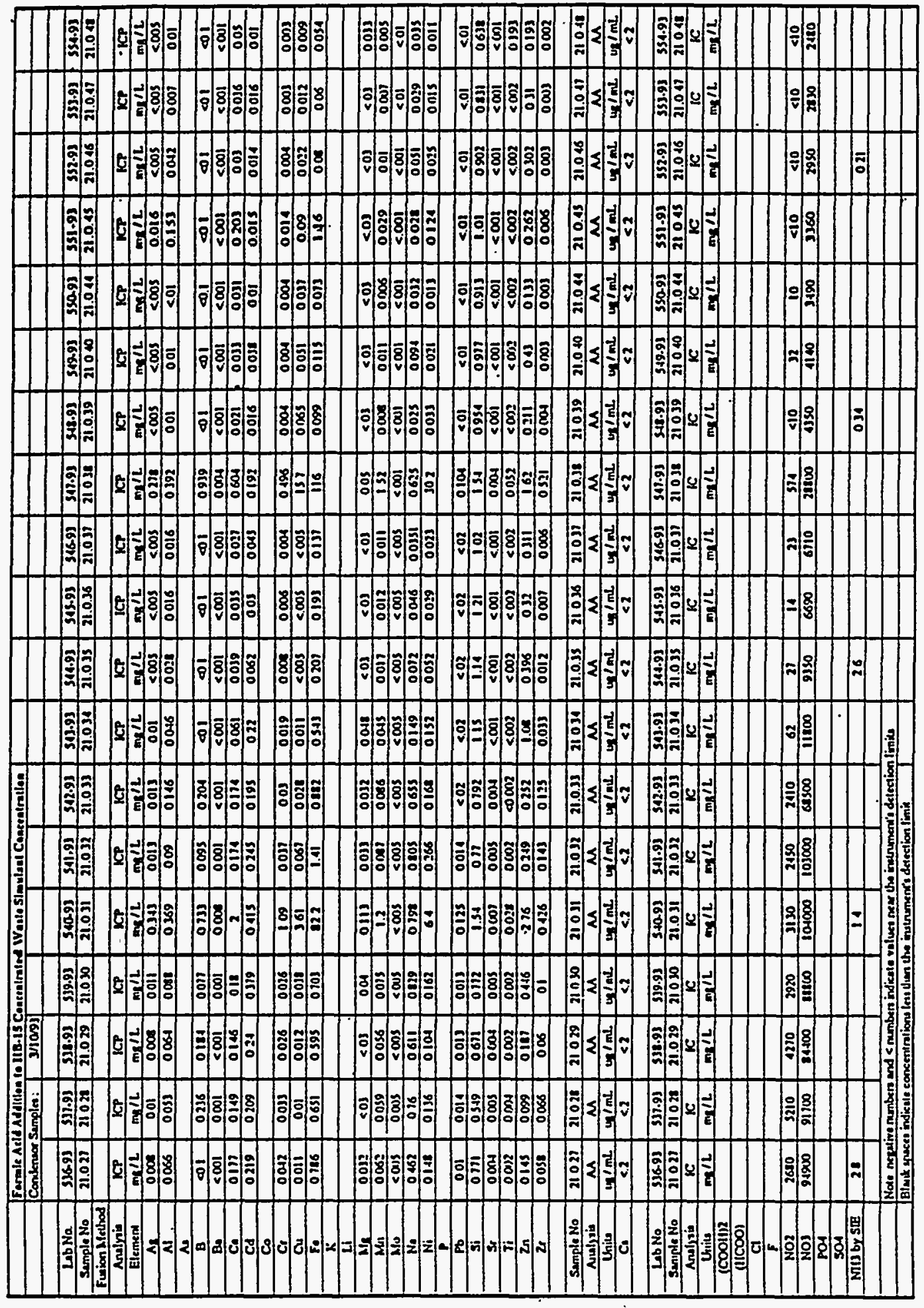


Page $\mathrm{Cl1}$ of $\mathrm{Cl} 3$

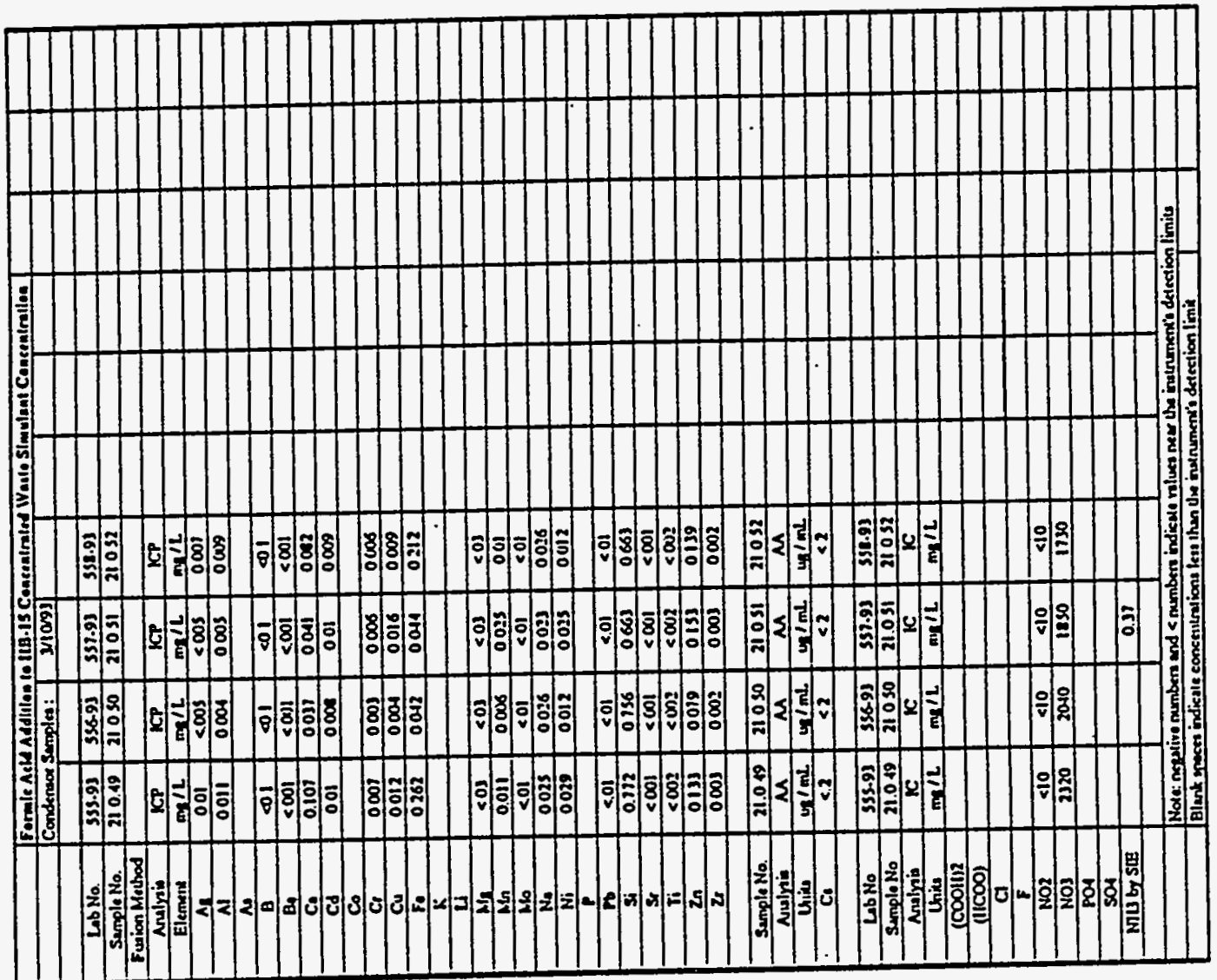

R. 10 
Page $\mathrm{Cl2}$ of $\mathrm{Cl3}$

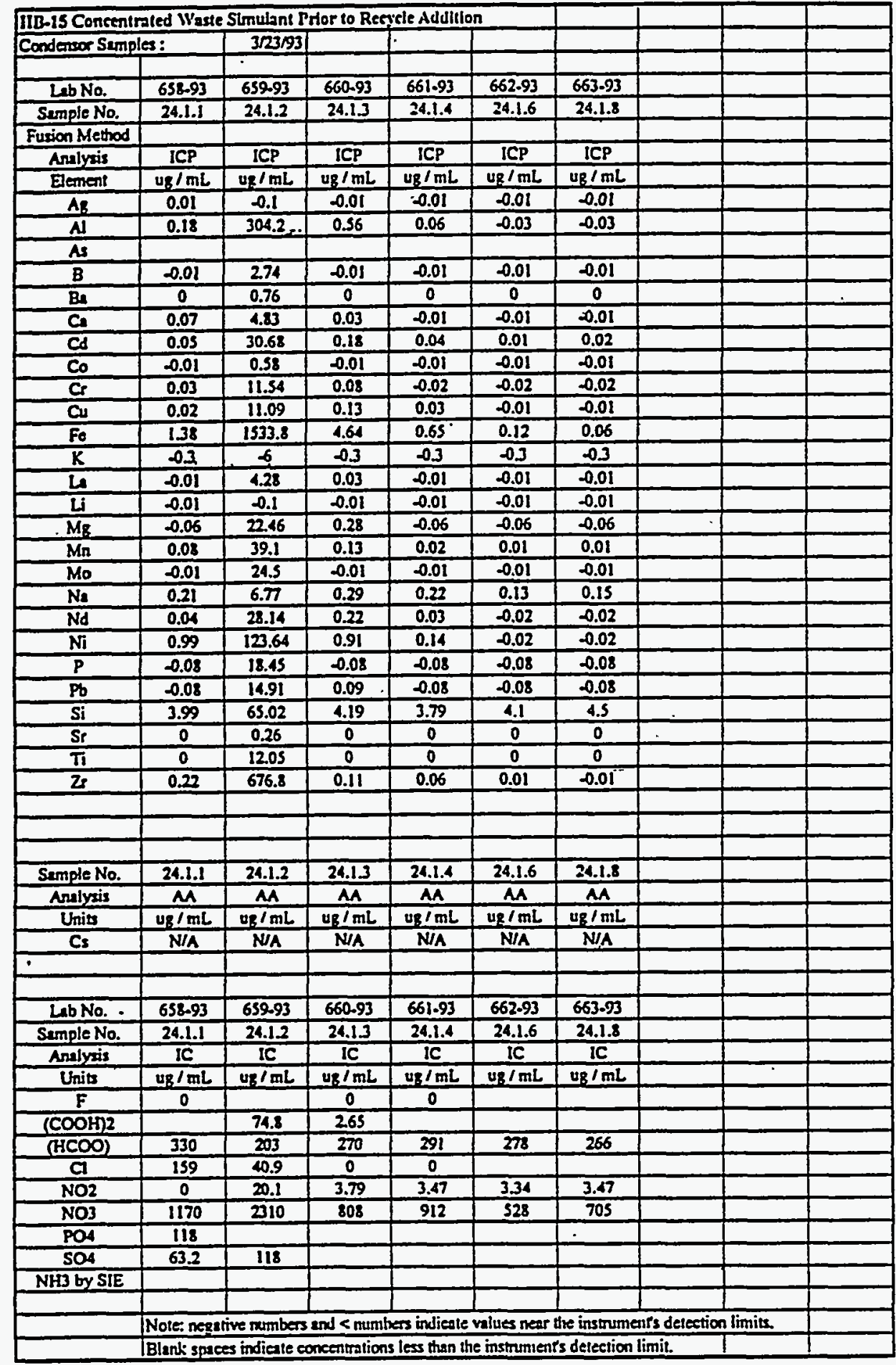

R. 11 
Page $\mathrm{Cl} 3$ or $\mathrm{Cl}$

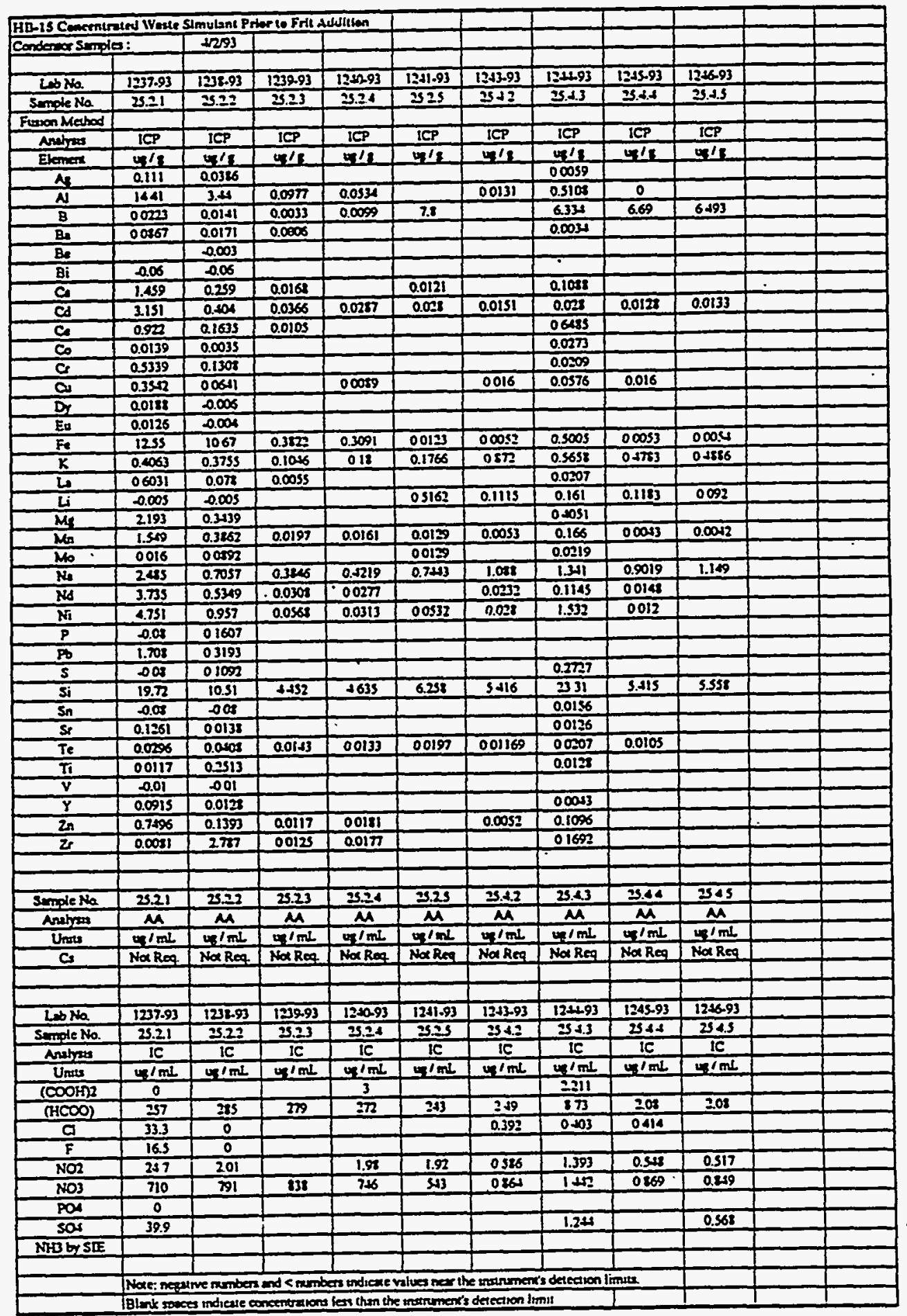

R. 12 


\section{Appendix S}

\section{Additional Condenser Performance Tables}




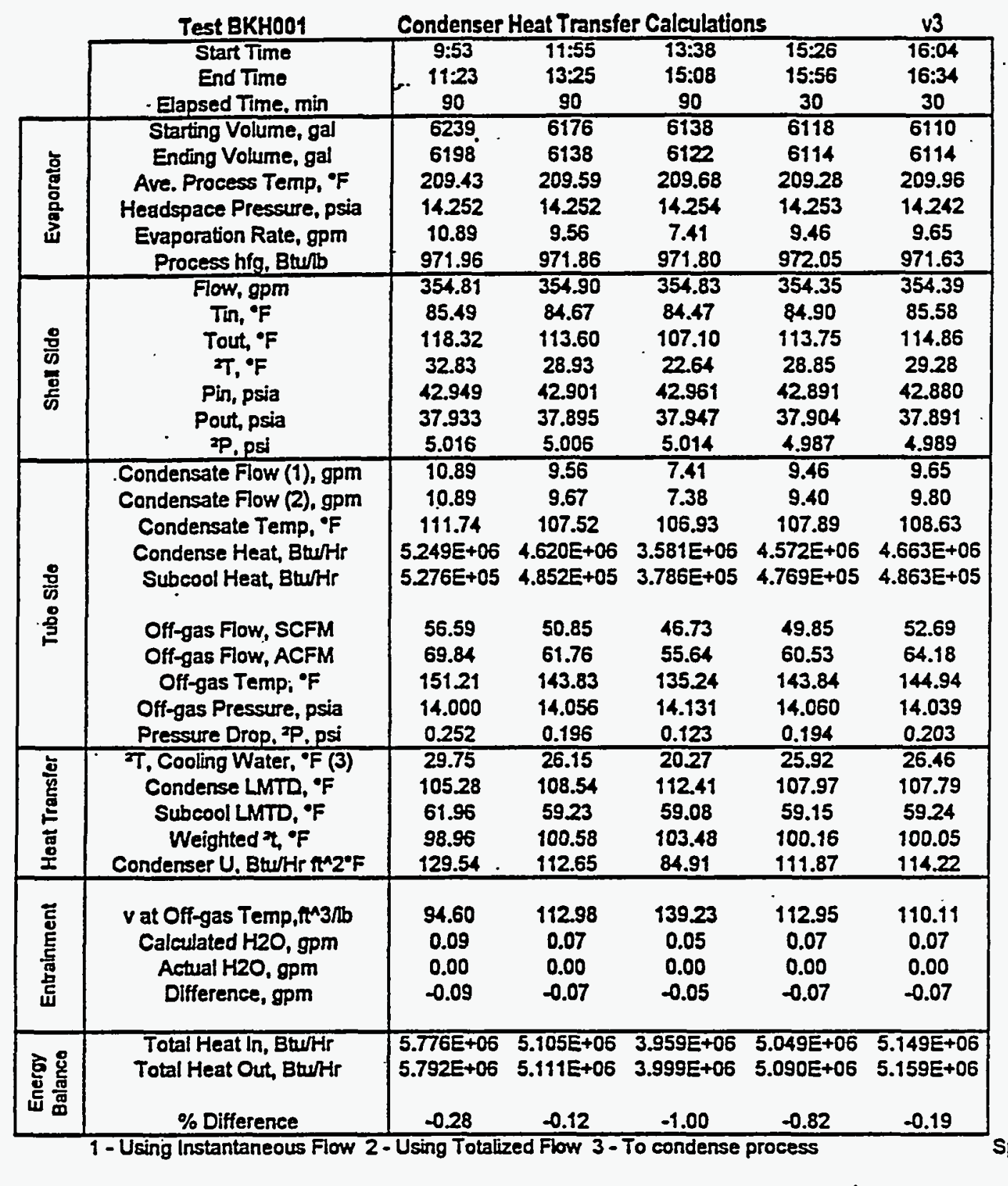

Sp.G. 1.03

NCAW1 Low Level Diute 4/5/94 10:14 AM

S.1 


\begin{tabular}{|c|c|c|c|c|c|c|}
\hline & Test BKHOOI & \multicolumn{4}{|c|}{ Evaporator Heat Transfer Calculations } & v3 \\
\hline & Start Time & $9: 53$ & $11: 55$ & $13: 38$ & $15: 26$ & $16: 04$ \\
\hline & End Time & $11: 23$ & 13:25 & 15:08 & $15: 56$ & 16:34 \\
\hline & Elapsed Time, $\min$ & 90 & 90 & 90 & 30 & 30 \\
\hline \multirow{10}{*}{ 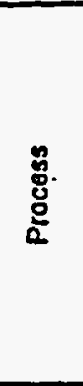 } & Starting Volume, gal & 6239 & 6176 & 6138 & .6118 & 6110 \\
\hline & Ending Volume, gal & 6198 & 6138 & 6122 & 6114 & 6114 \\
\hline & Level Change (POl-1002), gpm & 0.16 & 0.04 & 0.06 & 0.02 & 0.16 \\
\hline & Level Change (PDI-1003), gpm & 0.10 & 0.09 & 0.04 & 0.09 & 0.03 \\
\hline & Ave. Level Change, gpm & 0.13 & 0.06 & 0.05 & 0.06 & 0.09 \\
\hline & Ave. Temp, ${ }^{\circ} F$ & 209.43 & 209.59 & 209.68 & 209.28 & 209.96 \\
\hline & Headspace Pressure, psia & 14.25 & 14.25 & 14.25 & 14.25 & 14.24 \\
\hline & Evaporation, Btu/Hr & $5.240 E+08$ & $4.613 E+08$ & 3.575E+08 & 4.564E+06 & $4.657 E+06$ \\
\hline & & $5.276 E+05$ & $52 E+05$ & $3.786 E+05$ & 4.769E+05 & $4.863 E+05$ \\
\hline & Total Heat, Btu/Hr & $5.767 E+06$ & $5.098 E+06$ & $3.954 E+06$ & $5.041 E+06$ & $5.143 E+06$ \\
\hline \multirow{4}{*}{ 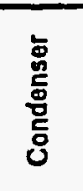 } & Condensate Flow (1), gpm & 10.89 & 9.56 & 7.41 & 9.46 & 9.65 \\
\hline & & 10.89 & 9.67 & 7.38 & 9.40 & 9.80 \\
\hline & vaporation Rate, gpm & 10.89 & 9.56 & 7.41 & 9.46 & 9.65 \\
\hline & ndensate Temp, ${ }^{\circ} F$ & $\begin{array}{c}111.74 \\
55.59\end{array}$ & 107.52 & $\begin{array}{l}106.93 \\
46.73\end{array}$ & $\begin{array}{l}107.89 \\
49.85\end{array}$ & $\begin{array}{c}108.63 \\
5269\end{array}$ \\
\hline \multirow{14}{*}{ 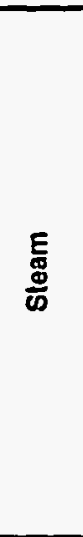 } & Flow, $\mathrm{L} / \mathrm{H} \mathrm{Hr}$ & 5998.13 & 5272.36 & 4152.35 & 5259.40 & 5281.42 \\
\hline & Header Pressure, psia & 128.85 & 129.06 & 129.26 & 128.64 & 128.81 \\
\hline & Pin, psia & 89.42 & 76.35 & 59.01 & 76.78 & 76.08 \\
\hline & $\operatorname{Tin} .{ }^{\circ} \mathrm{F}$ & 345.96 & 346.09 & 346.24 & 345.83 & 345.94 \\
\hline & Tsat at $\mathrm{Pin},{ }^{\circ} \mathrm{F}$ & 319.84 & 308.83 & 291.62 & 309.21 & 308.59 \\
\hline & Vapor $C p$ at Tsat, Btur $b^{\circ} F$ & 0.48 & 0.48 & 0.48 & 0.48 & 0.48 \\
\hline & hfg at Tsat, Bturb & 895.46 & 903.88 & 916.61 & 903.59 & 904.06 \\
\hline & Condensate Pout, psia & 72.51 & 60.78 & 46.21 & 60.95 & 60.71 \\
\hline & Condensate Tout. ${ }^{\circ} \mathrm{F}$ & 213.19 & 212.75 & 211.89 & 213.06 & 212.60 \\
\hline & Coil Pressure Drop. psi & 16.91 & 15.57 & 12.80 & 15.82 & 15.37 \\
\hline & Desuperheat Heat, Btur Hr & $7.548 E+04$ & $9.466 E+0.4$ & $1.093 E+05$ & $9.279 E+04$ & $9.504 E+04$ \\
\hline & Condense Heat, Btu/Hr & $5.371 E+06$ & $4.766 E+06$ & $3.806 E+06$ & $4.752 E+06$ & 4.775E+06 \\
\hline & Subcool Heat, Btu/Hr & $6.397 E+05$ & $5.066 E+05$ & $3.310 E+05$ & $5.057 E+05$ & $5.069 E+05$ \\
\hline & Total Heat, Btu/Hr & & $7 E+06$ & & $5.351 E+06$ & $5.377 E+06$ \\
\hline \multirow{4}{*}{ 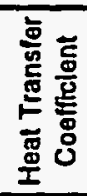 } & Desuperieat LMTD, ${ }^{\circ} \mathrm{F}$ & 123.01 & 116.88 & 106.93 & 117.29 & 116.30 \\
\hline & $\operatorname{tion}^{2 t}, \mathrm{~F}^{\circ} \mathrm{F}$ & & & & 99.93 & 98.63 \\
\hline & LMTD, ${ }^{\circ} \mathrm{F}$ & 31.56 & 27.88 & 22.06 & 29.35 & 26.51 \\
\hline & Weighted $x, F$ & 87.54 & 80.10 & 67.96 & 81.60 & 78.66 \\
\hline \multirow{5}{*}{$\frac{\frac{\mathrm{g}}{\mathrm{g}}}{\overline{\bar{g}}}$} & Speed, rom & $\frac{202.70}{84.99}$ & $\frac{195.34}{85.00}$ & 85.01 & $\frac{191.19}{45.03}$ & $\frac{199.27}{127.67}$ \\
\hline & Amps & 33.82 & 33.71 & 33.69 & 24.50 & 50.92 \\
\hline & Voltages, Volts & 460.00 & 460.00 & 460.00 & 460.00 & 460.00 \\
\hline & Motor Horsepower & 7.01 & 6.79 & 6.75 & 0.00 & 36.57 \\
\hline & Agitator Pout. Btu/Hr & 17.831 & 17.275 & 17,168 & 0,000 & \\
\hline \multirow{4}{*}{ 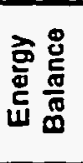 } & Tank Losses, Btu/Hr & 207000 & 207000 & 207000 & 207000 & 207000 \\
\hline & Total Heat in, Btu/Hr & $6.104 E+06$ & $5.384 E+06$ & $4.264 E+06$ & $5.351 E+06$ & $5.470 E+06$ \\
\hline & Total Heat Out, Btu/Hr & $5.974 E+05$ & 5.305E+05 & 4.161E+06 & $5.248 E+06$ & $5.350 E+06$ \\
\hline & $\%$ Difference & 2.12 & 1.47 & 2.41 & 1.93 & 2.19 \\
\hline
\end{tabular}

NCAWI Low Level Dilute 4/5/94 10:18 AM 


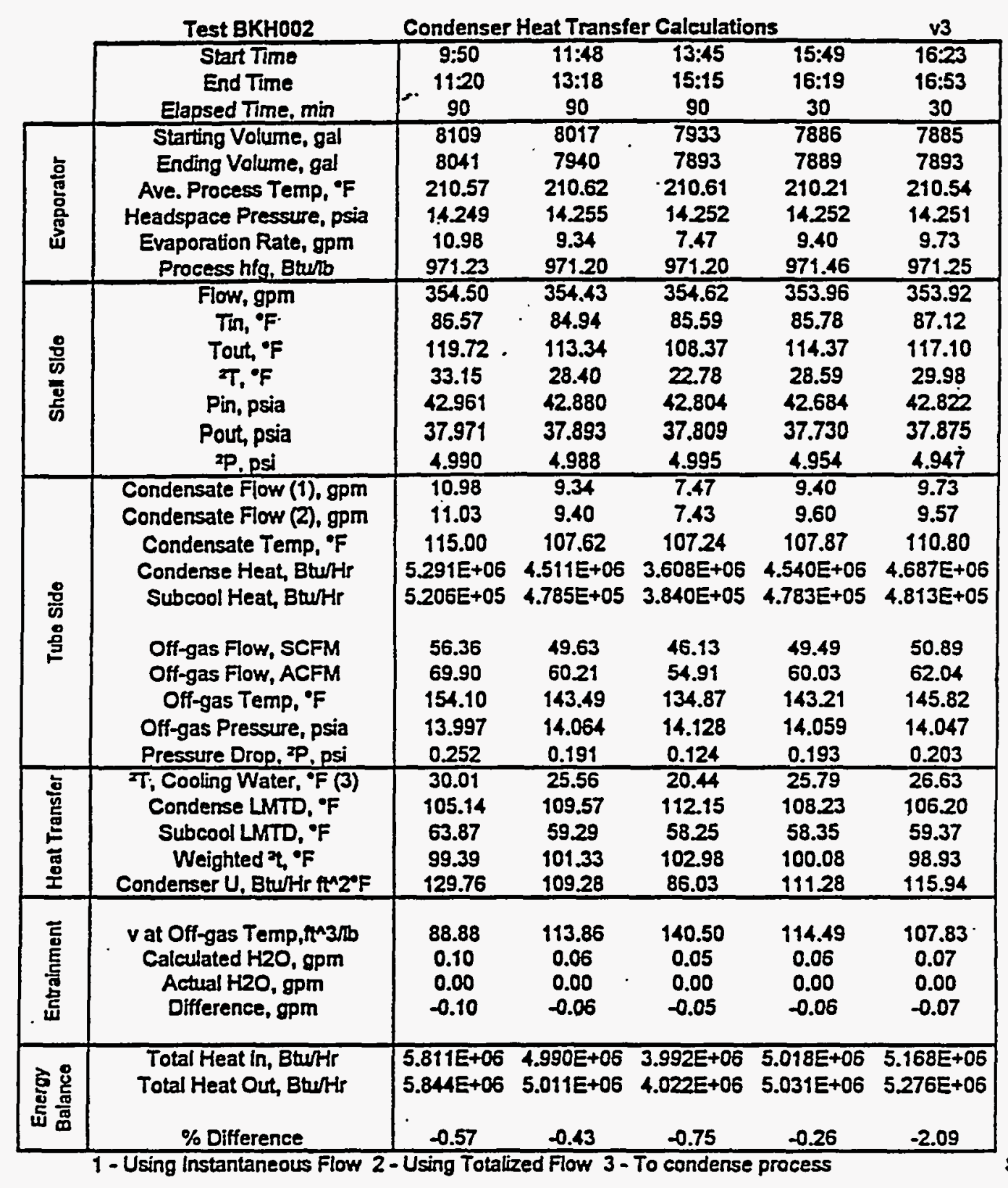

Sp.G. 1.03

NCAW1 High Level Dilute 4/5/94 10:26 AM 


\begin{tabular}{|c|c|c|c|c|c|c|}
\hline & Test BKH0O2 & Evaporator & Heat Transfe & er Calculatio & ons & v3 \\
\hline & Start Time & $9: 50$ & $11: 48$ & $13: 45$ & $15: 49$ & $16: 23$ \\
\hline & End Time & $11: 20$ & $13: 18$ & $15: 15$ & 16:19 & $16: 53$ \\
\hline & Elapsed Time, $\min$ & 90 & 90 & 90 & 30 & 30 \\
\hline \multirow{9}{*}{ 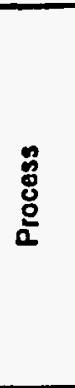 } & Starting Volume, gal & 8109 & 8017 & 7933 & 7886 & 7885 \\
\hline & Ending Volume, gal & 8041 & 7940 & 7893 & 7889 & 7893 \\
\hline & Level Change (PDl-1002)_gpm & 0.25 & 0.07 & -0.08 & 2.62 & -6.76 \\
\hline & Level Change (PDl-1003), gpm & -0.31 & -1.04 & 0.89 & -9.70 & 28.19 \\
\hline & Ave. Level Change, gpm & -0.03 & -0.49 & 0.41 & .3 .54 & 10.72 \\
\hline & Ave. Temp, ${ }^{\circ} \mathrm{F}$ & 210.57 & 210.62 & 210.61 & 210.21 & 210.54 \\
\hline & Headspace Pressure, psia & 14.25 & 14.25 & 14.25 & 14.25 & 14.25 \\
\hline & Evaporation, Btu/Hr & $\begin{array}{l}5.286 E+06 \\
5206 F+05\end{array}$ & $\begin{array}{l}4.507 E+06 \\
.785 F+05\end{array}$ & $\begin{array}{l}3.605 E+06 \\
3.840 E+05\end{array}$ & $\begin{array}{l}4.535 E+06 \\
4.783 E+05\end{array}$ & $\begin{array}{l}4.683 E+06 \\
4.813 E+05\end{array}$ \\
\hline & Total Heat. Btur $\mathrm{Hr}$ & $5.806 E+06$ & $4.985 E+06$ & $3.989 E+06$ & $5.013 E+06$ & $5.164 E+06$ \\
\hline \multirow{5}{*}{ 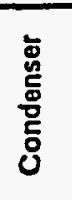 } & Condensate Flow (1). gpm & 10.98 & 9.34 & 7.47 & 9.40 & 9.73 \\
\hline & Condensate Flow (2), gpm & 11.03 & 9.40 & 7.43 & 9.60 & 9.57 \\
\hline & Evaporation Rate, gpm & 10.98 & 9.34 & 7.47 & 9.40 & 9.73 \\
\hline & Condensate Temp, ${ }^{\circ} \mathrm{F}$ & 115.00 & 107.62 & 107.24 & 107.87 & 110.80 \\
\hline & Off-gas Flow, SCFM & 56.36 & 49.63 & 46.13 & 49.49 & 50.89 \\
\hline \multirow{14}{*}{$\begin{array}{l}\text { E్ } \\
\text { हू }\end{array}$} & Flow, LbrHr & 6048.51 & 5184.85 & 4170.47 & 5238.02 & 5279.89 \\
\hline & Header Pressure, psia & 125.87 & 126.37 & 126.61 & 126.20 & 125.97 \\
\hline & Pin, psia & 90.87 & 75.62 & 60.15 & 77.55 & 75.46 \\
\hline & $\operatorname{Tin}^{\circ} \mathrm{F}$ & 344.29 & 344.58 & 344.67 & 344.39 & 344.26 \\
\hline & Tsat at Pin, ${ }^{\circ} F$ & 320.98 & 308.18 & 292.89 & 309.89 & 308.04 \\
\hline & Vapor $C p$ at Tsat, BtuL $b^{\circ} F$ & 0.48 & 0.48 & 0.48 & 0.48 & 0.48 \\
\hline & hfg at Tsat, Bturb & 894.54 & 904.40 & 915.65 & 903.08 & 904.45 \\
\hline & Condensate Pout, psia & 73.60 & 59.97 & 47.04 & 61.55 & 59.62 \\
\hline & Condensate Tout, ${ }^{\circ} \mathrm{F}$ & 214.85 & 214.03 & 213.00 & 214.69 & 213.75 \\
\hline & Coil Pressure Drop, psi & 17.26 & 15.65 & 13.11 & 16.00 & 15.83 \\
\hline & Desuperheat Heat, Btu/Hr & $6.792 E+04$ & $9.092 E+04$ & 1.041E+05 & $8.706 E+04$ & $9.213 E+04$ \\
\hline & Condense Heat, Btu/Hr & $5.411 E+06$ & $4.689 E+06$ & $3.819 E+06$ & $4.730 E+06$ & 4.775E+06 \\
\hline & Subcool Heat, Btu/Hr & $6.419 E+05$ & $4.881 E+05$ & $3.332 E+05$ & $4.987 E+05$ & $4.978 E+05$ \\
\hline & Total Heat, Bturtir & $6.120 E+06$ & $5.268 \mathrm{E}+06$ & $4.256 E+06$ & $5.316 E+06$ & $5.365 E+06$ \\
\hline \multirow{5}{*}{ 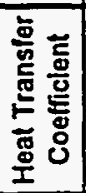 } & Desuperheat LMTD, ${ }^{\circ} \mathrm{F}$ & 121.69 & 114.80 & 106.07 & 116.08 & 114.66 \\
\hline & Condensation $z^{2} \cdot \mathrm{F}$ & 110.41 & 97.56 & 82.28 & 99.68 & 97.50 \\
\hline & Subcool LMTD, $\bullet F$ & 32.65 & 28.08 & 22.57 & 30.67 & 27.63 \\
\hline & Weighted $x_{0} \cdot F$ & 88.42 & 79.53 & 68.47 & 82,47 & 79.14 \\
\hline & Boiling UU, Btu/Hr $\pi^{\wedge} 2^{*} \mathrm{~F}$ & & 193.12 & 181.21 & 187.94 & 197.67 \\
\hline \multirow{4}{*}{ 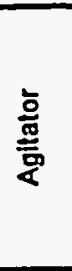 } & $\begin{array}{l}\text { Speed, mpm } \\
\text { Current, Amps }\end{array}$ & $\begin{array}{l}84.98 \\
34.93\end{array}$ & $\begin{array}{l}85.00 \\
35.10\end{array}$ & $\begin{array}{l}85.02 \\
35.12\end{array}$ & $\begin{array}{l}45.09 \\
24.60\end{array}$ & $\begin{array}{c}127.34 \\
57.41\end{array}$ \\
\hline & Voltages, Volts & 460.00 & 460.00 & 460.00 & 460.00 & 460.00 \\
\hline & Motor Horsepower & 9.20 & 9.53 & 9.56 & 0.00 & 45.77 \\
\hline & Agitator Pout, Blu/Hr & 23.399 & 24.234 & 24,319 & 0.000 & 116,446 \\
\hline \multirow{4}{*}{ 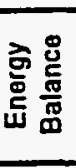 } & Tank Losses, Btu/Hr & 207000 & 207000 & 207000 & 207000 & 207000 \\
\hline & Total Heat in, BturHr & $6.144 E+06$ & $5.292 E+06$ & $4.280 E+06$ & $5.316 E+06$ & $5.482 E+06$ \\
\hline & Total Heat Out, Btu/Hr & $\begin{array}{c}6.013 E+\infty 6 \\
2.13\end{array}$ & $\begin{array}{l}5.193 E+06 \\
1.89\end{array}$ & $\begin{array}{l}4.196 E+06 \\
1.97\end{array}$ & $\begin{array}{c}5.220 E+06 \\
1.81\end{array}$ & $\begin{array}{c}5.371 E+06 \\
2.02\end{array}$ \\
\hline & $\%$ Dilierence & 2.73 & & 7.91 & & $\frac{2.02}{1.33}$ \\
\hline
\end{tabular}

NCAW1 High Level Dilute 4/5/94 10:25 AM 


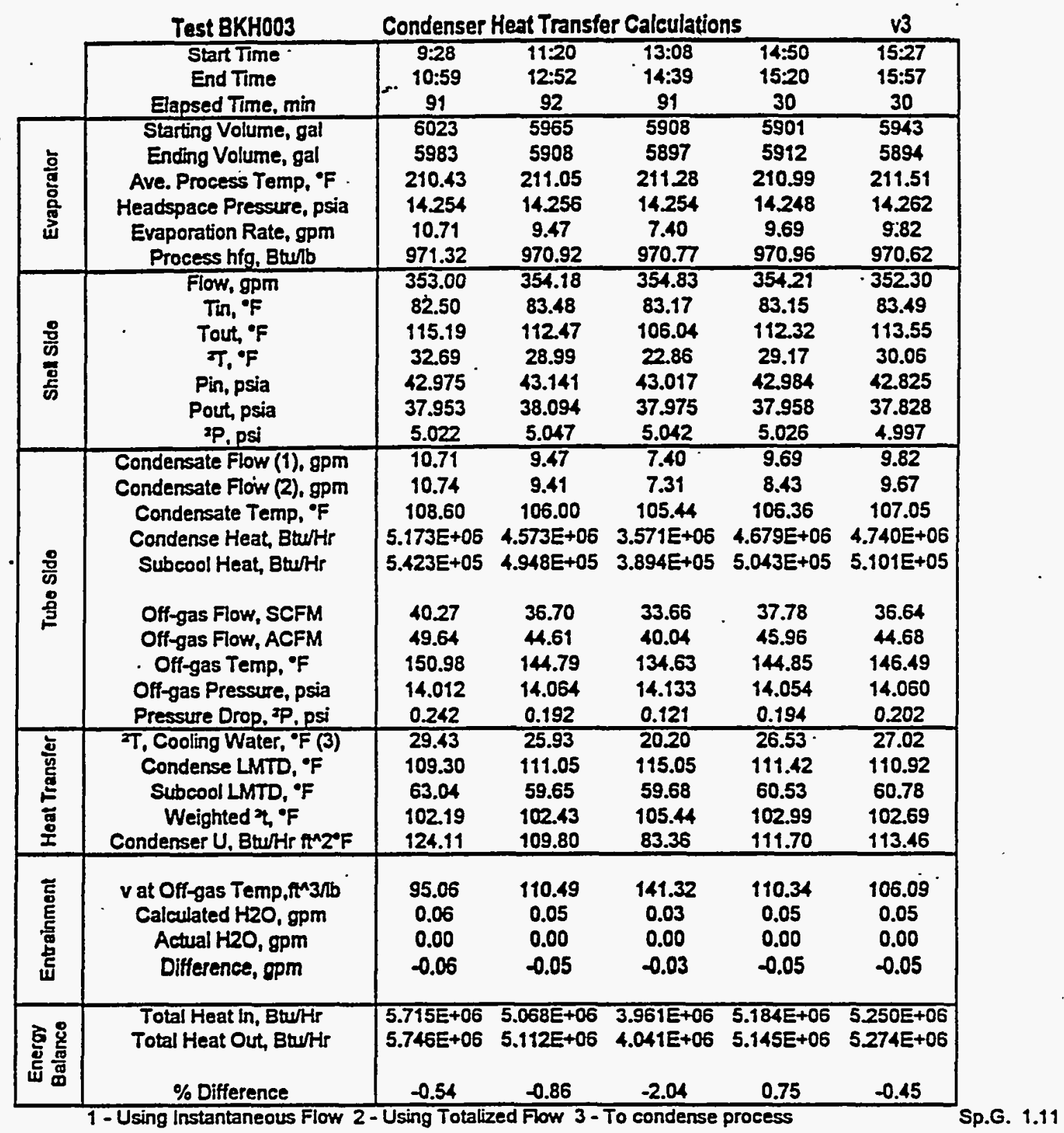

NCAW1 Low Leve' Concentrate 4/5/94 10:31 AM 


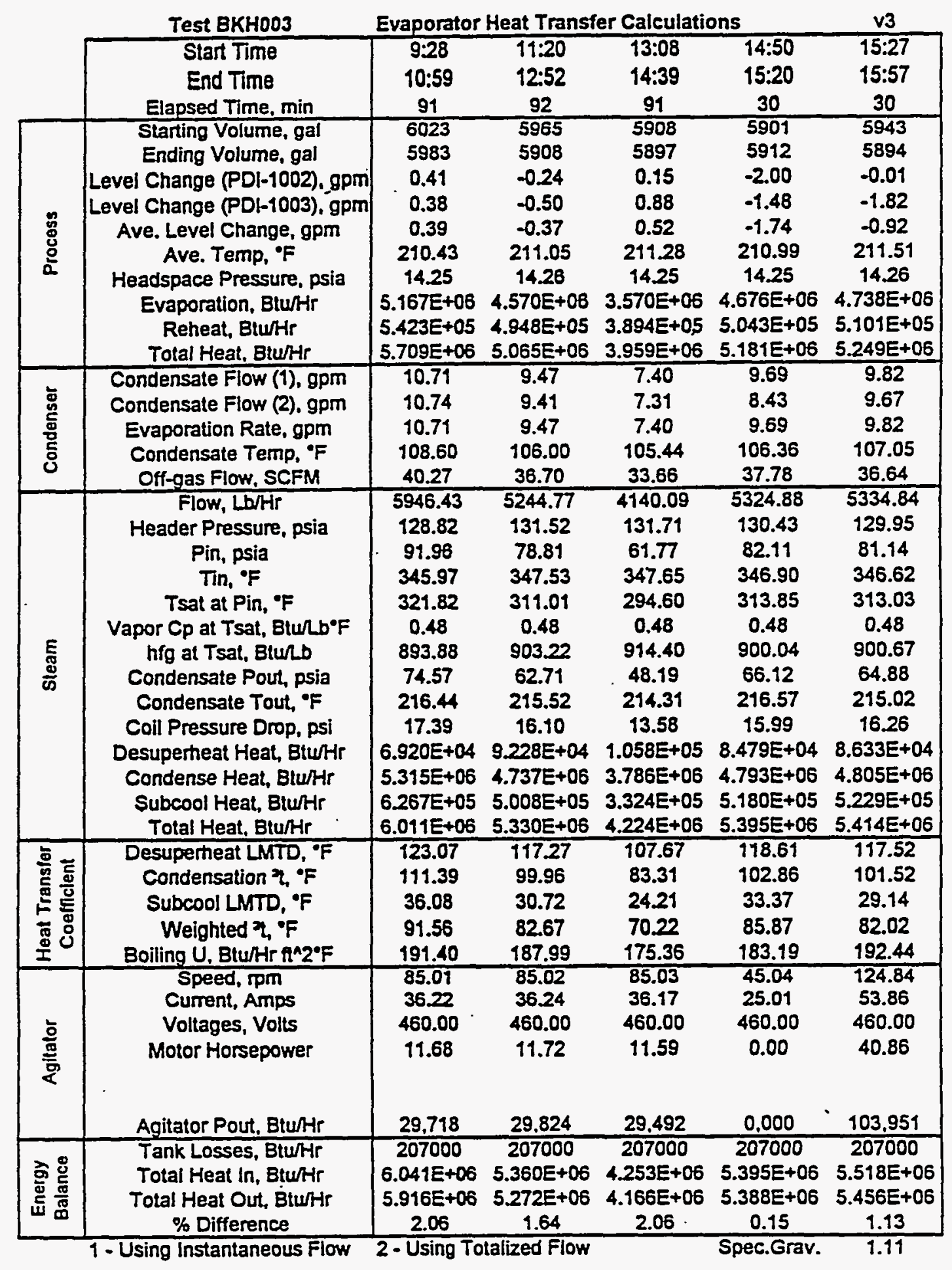

NCAW1 Low Level Concentrate 4/5/94 10:32 AM 


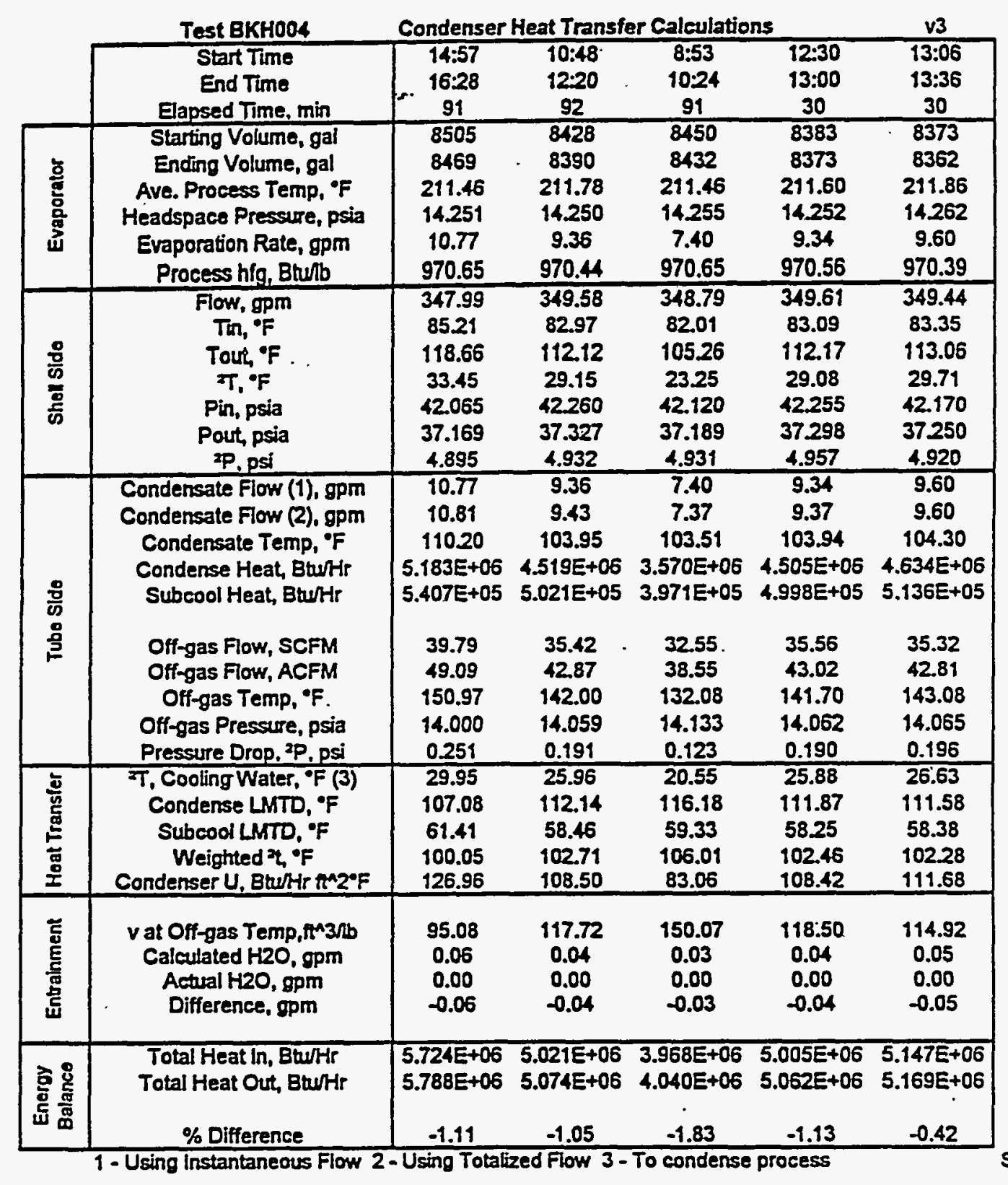




\begin{tabular}{|c|c|c|c|c|c|c|}
\hline & Test BKHOO4 & \multicolumn{5}{|c|}{ Evaporator Heat Transfer Calculations } \\
\hline & Start Time & $14: 57$ & $10: 48$ & $8: 53$ & $12: 30$ & $13: 06$ \\
\hline & End Time & $16: 28$ & $12: 20$ & $10: 24$ & $13: 00$ & 13:36 \\
\hline & Elapsed Time, $\min$ & 91 & 92 & 99 & 30 & 30 \\
\hline \multirow{9}{*}{ 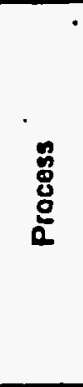 } & Starting Volume, gal & 8505 & 8428 & 8450 & 8383 & 8373 \\
\hline & Ending Volume, gal & 8469 & 8390 & 8432 & 8373 & 8362 \\
\hline & Level Change (PDI-1002), Apm & 4.38 & 0.14 & -0.14 & -0.07 & 0.11 \\
\hline & Level Change (PDl-1003), gpm & 0.67 & 0.17 & -0.30 & -1.40 & 5.33 \\
\hline & Ave. Level Change, gpm & 2.53 & 0.15 & -0.22 & -0.73 & 2.72 \\
\hline & Ave. Temp, ${ }^{\circ} \mathrm{F}$ & 211.46 & 211.78 & 211.46 & 211.60 & 211.86 \\
\hline & Headspace Pressure, psia & 14.25 & 14.25 & 14.26 & 14.25 & 14.26 \\
\hline & Evaporation, Btu/Hr & $5.181 E+06$ & $4.518 E+08$ & $3.569 E+08$ & 4.504E+08 & $4.633 E+06$ \\
\hline & $\begin{array}{l}\text { Reheat, Bturtr } \\
\text { Total Heat, Bturtir }\end{array}$ & $\begin{array}{l}5.407 E+05 \\
5.722 E+06\end{array}$ & $\begin{array}{l}5.021 E+05 \\
5.021 E+06\end{array}$ & $\begin{array}{l}3.971 E+05 \\
3.966 E+06\end{array}$ & $\begin{array}{l}4.998 E+05 \\
5.004 E+06\end{array}$ & $\begin{array}{l}5.136 E+05 \\
5.147 E+06\end{array}$ \\
\hline \multirow{5}{*}{ 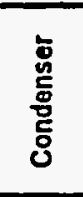 } & Condensate Flow (1), gpm & 10.77 & 9.36 & 7.40 & $\theta .34$ & 9.60 \\
\hline & Condensate Flow (2), gpm & 10.81 & 9.43 & 7.37 & 9.37 & 9.60 \\
\hline & Evaporation Rate. gpm & 10.77 & 9.36 & 7.40 & 9.34 & 9.60 \\
\hline & Condensate Temp. ${ }^{\circ} \mathrm{F}$ & 110.20 & 103.95 & 103.51 & 103.94 & 104.30 \\
\hline & Off-gas Flow, SCFM & 39.79 & 35.42 & 32.55 & 35.56 & 35.32 \\
\hline \multirow{14}{*}{ 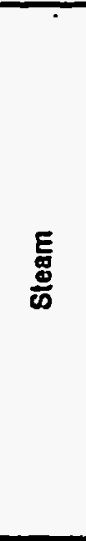 } & Flow, Lb/Hr & 6011.31 & 5222.61 & 4199.01 & 5236.00 & 5229.21 \\
\hline & Header Pressure, psia & 128.97 & 130.72 & 132.11 & 131.15 & 130.44 \\
\hline & Pin, psia & 93.40 & 78.25 & 62.55 & 78.91 & 77.78 \\
\hline & Tin, ${ }^{\circ} \mathrm{F}$ & 346.08 & 347.07 & 347.92 & 347.32 & 346.91 \\
\hline & Tsat at Pin, ${ }^{\bullet} F$ & 322.93 & 310.52 & 295.42 & 311.10 & 310.10 \\
\hline & Vapor Cp at Tsat, Blu/LbF & 0.48 & 0.48 & 0.48 & 0.48 & 0.48 \\
\hline & hfo at Tsat. Bturb & 893.01 & 902.60 & 913.79 & 902.15 & 902.92 \\
\hline & Condensate Pout, psia & 75.49 & 61.66 & 48.34 & 62.50 & 61.26 \\
\hline & Condensate Tout, " $F$ & 218.77 & 217.57 & 216.62 & 219.31 & 216.16 \\
\hline & Coil Pressure Drop. psi & 17.91 & 16.59 & 14.21 & 16.41 & 16.53 \\
\hline & Desupeneat Heat, Btu/Hr & $6.704 E+04$ & $9.198 E+04$ & $1.062 E+05$ & $9.138 E+04$ & $9.275 E+04$ \\
\hline & Condense Heat, Btu/Hr & $5.368 E+06$ & 4.714E+08 & 3.837E+06 & 4.724E+06 & $4.722 E+06$ \\
\hline & Subcool Heat, Btu/Hr & $6.261 E+05$ & 4.854E+05 & $3.309 E+05$ & $4.806 E+05$ & 4.912E+05 \\
\hline & Total Heat, BturHr & $6.061 E+06$ & $5.291 E+06$ & $4.274 E+06$ & $5.296 E+06$ & $5.306 E+06$ \\
\hline \multirow{5}{*}{ 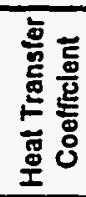 } & Desuperheat LMTD, ${ }^{\circ} \mathrm{F}$ & 122.68 & 116.06 & 108.09 & 116.68 & 115.67 \\
\hline & Condensation $2 \varphi^{\circ} \mathrm{F}$ & 111.47 & 98.74 & 83.95 & 99.51 & 98.24 \\
\hline & Subcool LMTD, $\bullet F$ & 38.23 & 32.77 & 28.24 & 35.89 & 30.03 \\
\hline & Weighted $\eta_{0} F$ & 93.14 & 83.53 & 73.18 & 85.90 & 81.35 \\
\hline & Boiling U. Btu/Hr n^ $2^{*} F$ & 189.74 & 184.68 & & 179.73 & 190.15 \\
\hline \multirow{4}{*}{ 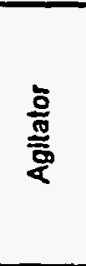 } & $\begin{array}{l}\text { Speed, rpm } \\
\text { Current, Amps }\end{array}$ & $\begin{array}{l}84.99 \\
37.47\end{array}$ & $\begin{array}{l}85.02 \\
37.68\end{array}$ & $\begin{array}{l}85.01 \\
37.58\end{array}$ & $\begin{array}{l}45.04 \\
25.02\end{array}$ & $\begin{array}{l}125.10 \\
62.99\end{array}$ \\
\hline & Voltages, Votts & 460.00 & 460.00 & 460.00 & 460.00 & 460.00 \\
\hline & Motor Horsepower & 14.05 & 14.43 & 14.24 & 0.00 & 52.94 \\
\hline & Agitator Pout. Btw/Hr & 35,738 & 36.719 & 36.232 & 0.000 & 134,672 \\
\hline \multirow{4}{*}{ 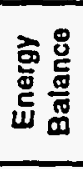 } & Tank Losses, Btu/Hr & 207000 & 207000 & 207000 & 207000 & 207000 \\
\hline & Total Heat in, Btu/Hr & $6.097 E+06$ & $5.328 E+06$ & $4.310 E+06$ & $5.296 E+06$ & $5.440 E+06$ \\
\hline & Total Heat Out, Btu/Hr & $5.929 E+06$ & $5.228 E+06$ & 4.173E+ 06 & $5.211 E+06$ & $5.354 E+06$ \\
\hline & \% Difference & 2.76 & 1.89 & 3.18 & 1.60 & 1.59 \\
\hline & 7 - Using instantan & 2-Using To & talized Flow & & Spec.Grav & 9.11 \\
\hline
\end{tabular}

NCAW1 High Level Concentrate 4/5/94 10:39 AM 


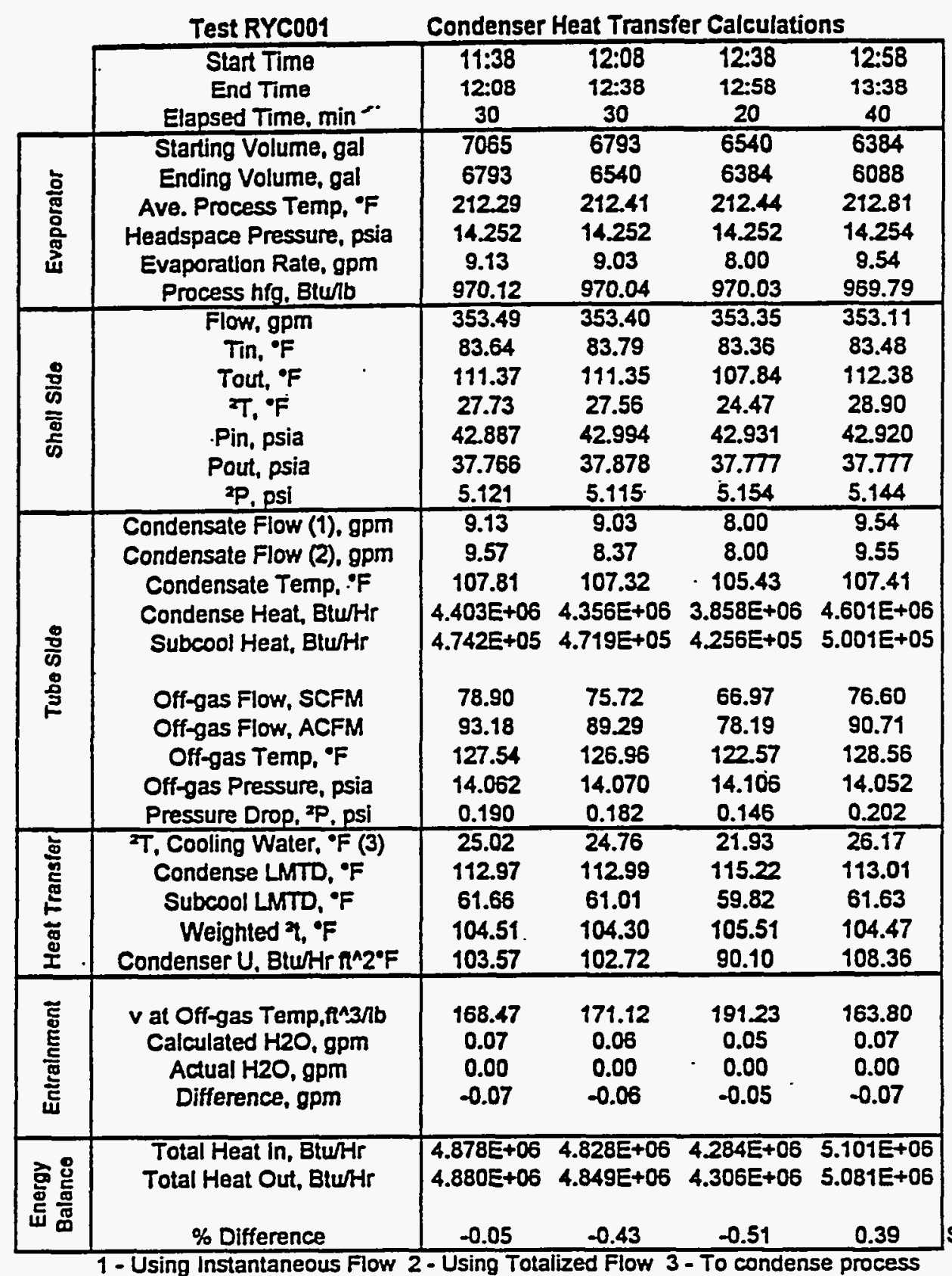

Sp.G. 1.13

NCAW1 Formated with Recycle 4/5/94 10:44 AM 


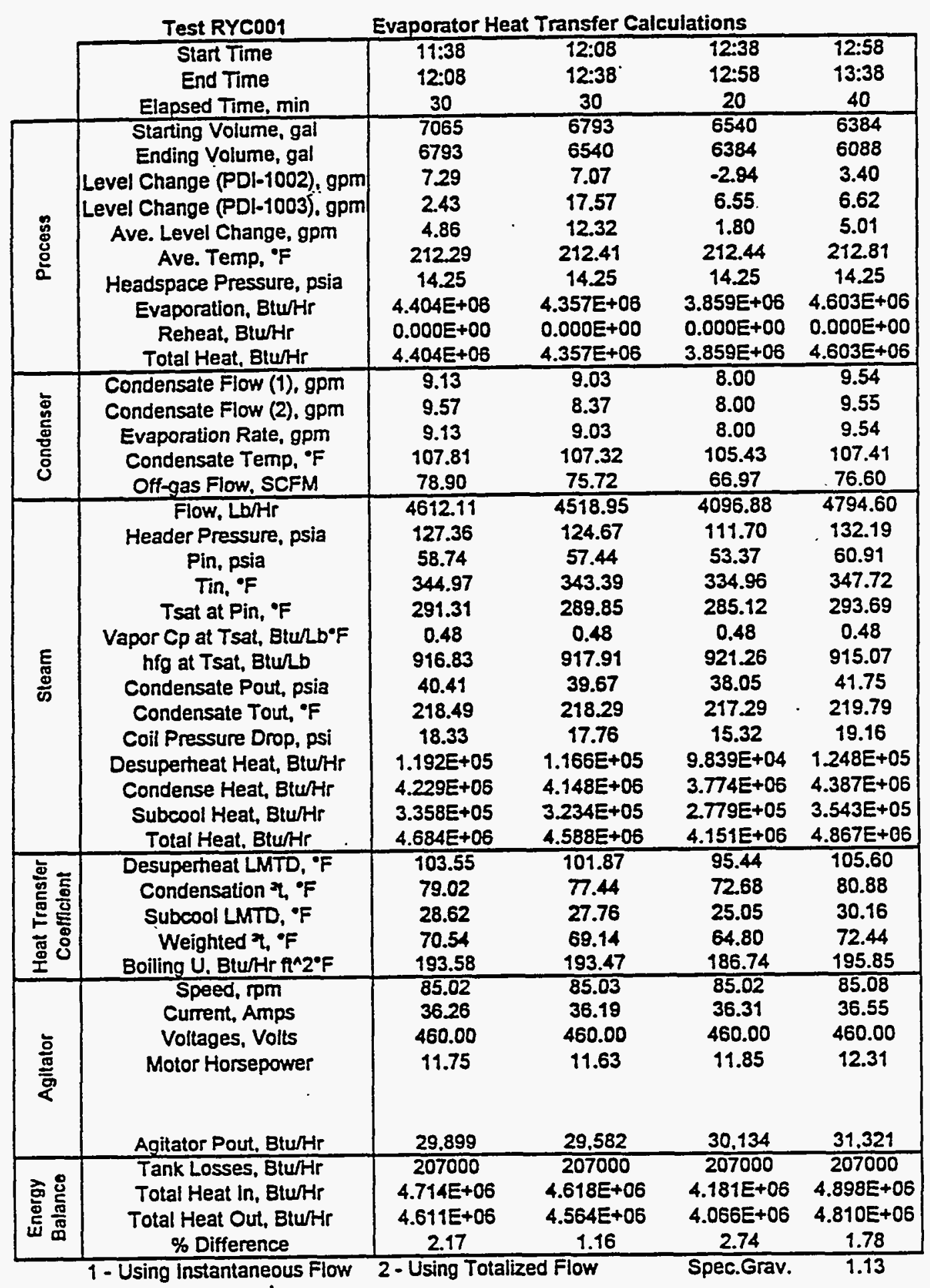

NCAW1 Fomated with Recycle 4/5/94 10:49 AM 


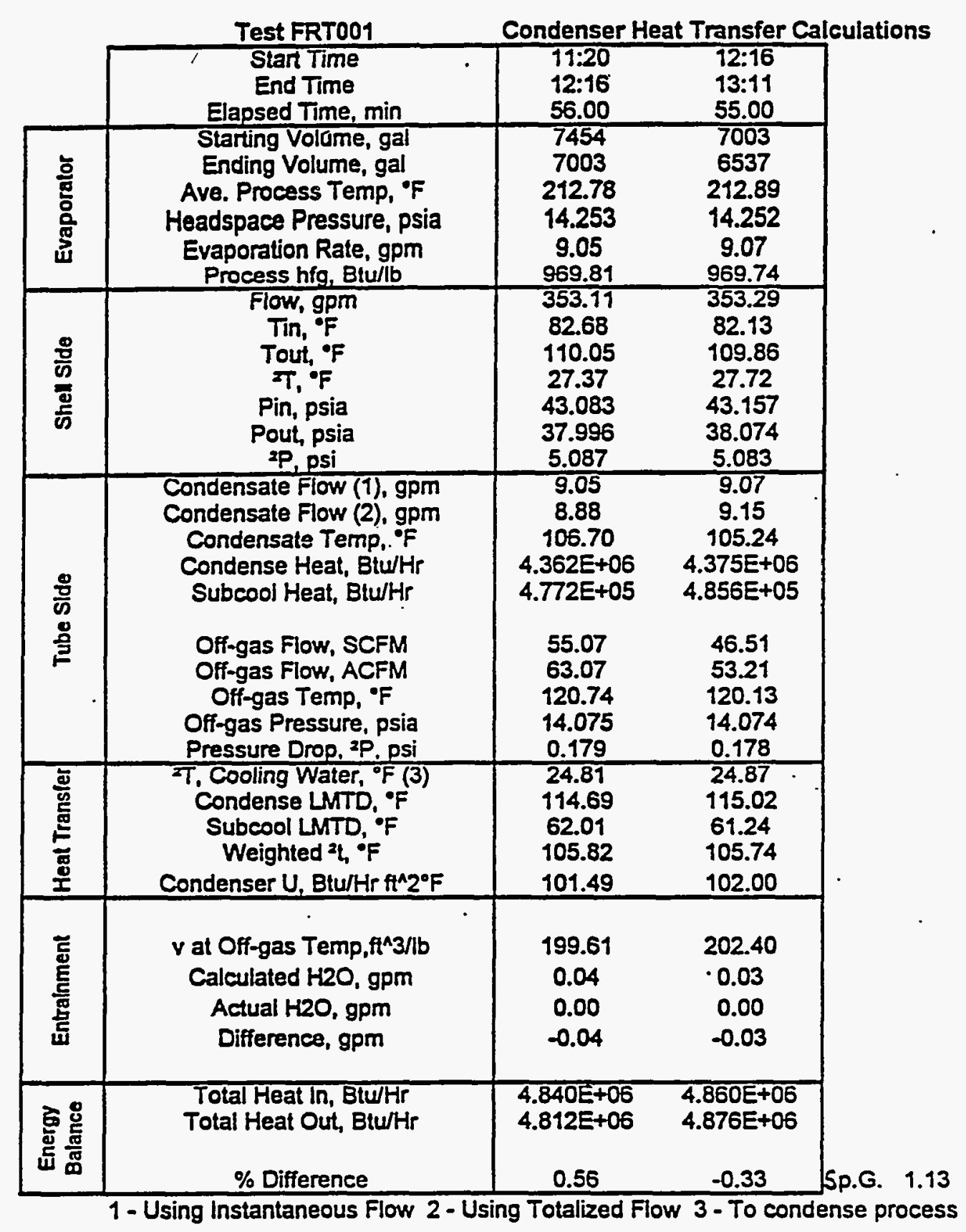

NCAW1 Frit Addition 4/5/94 10:54 AM 


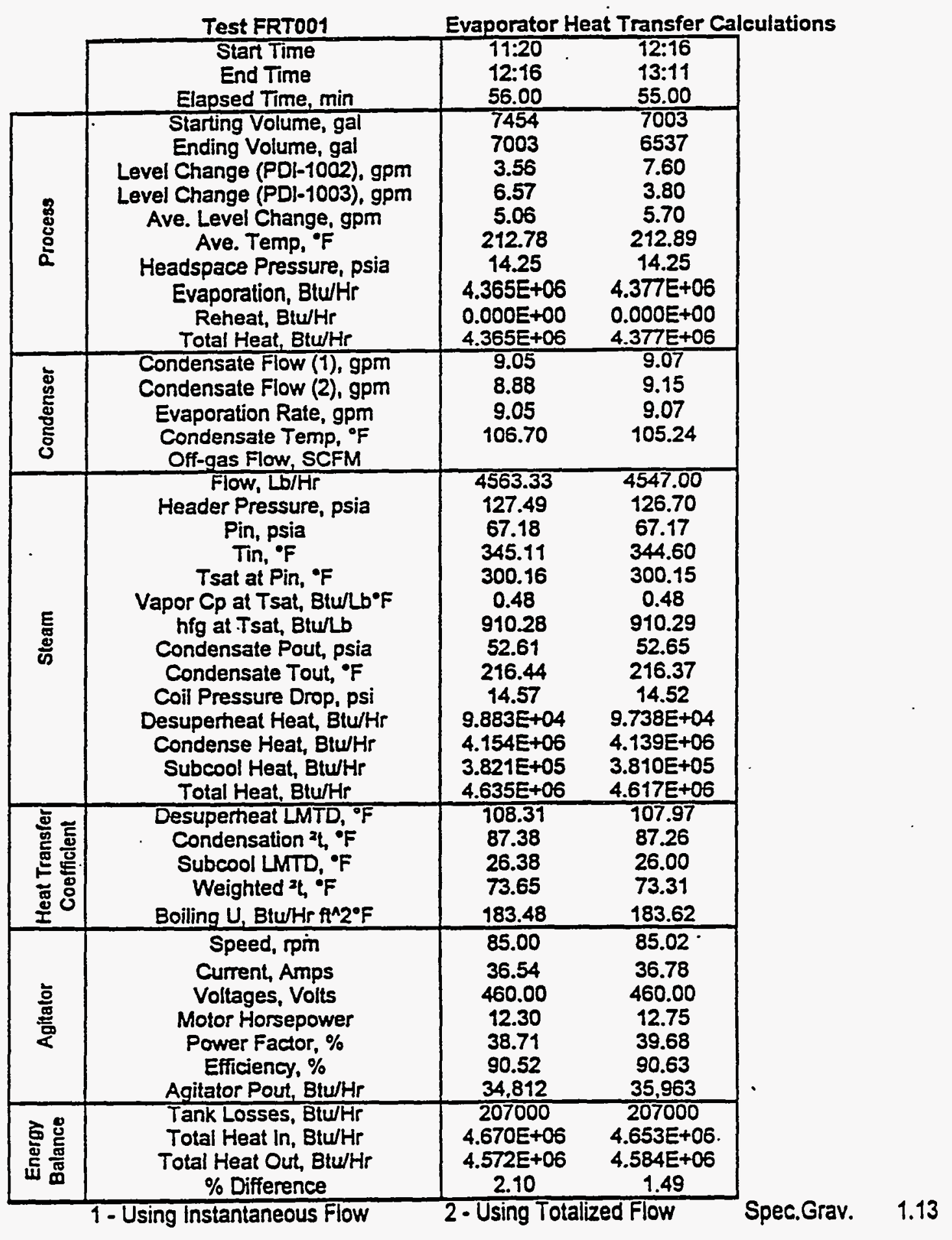

NCAW1 Frit Addition 4/5/94 10:59 AM 


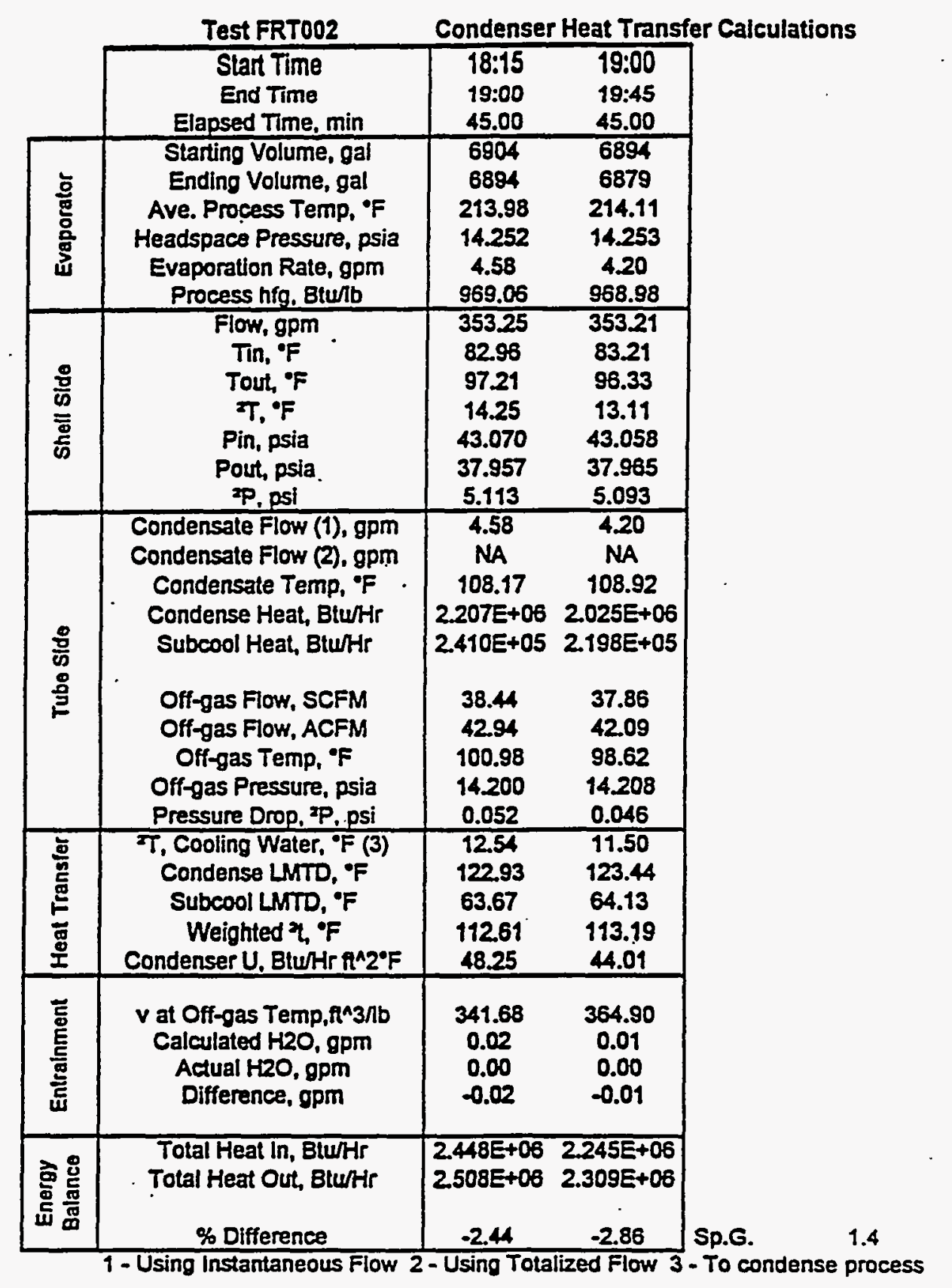

NCAW1 Melter Feed 4/5/94 11:02 AM 


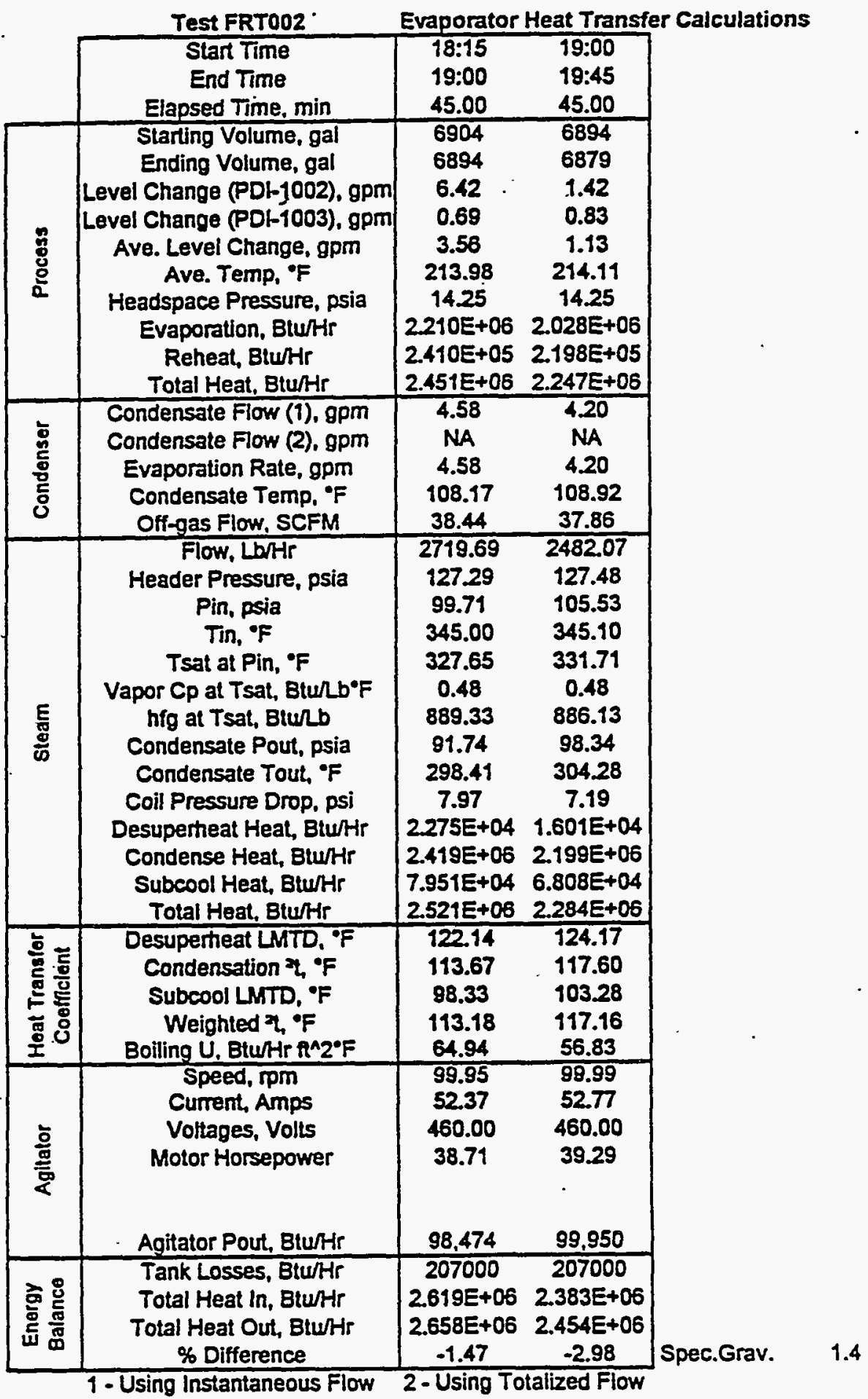

NCAW1 Melter Feed 4/5/94 11:04 AM 
Appendix T

HWVP Slurry Flow Pressure Drop Data and Calculations 


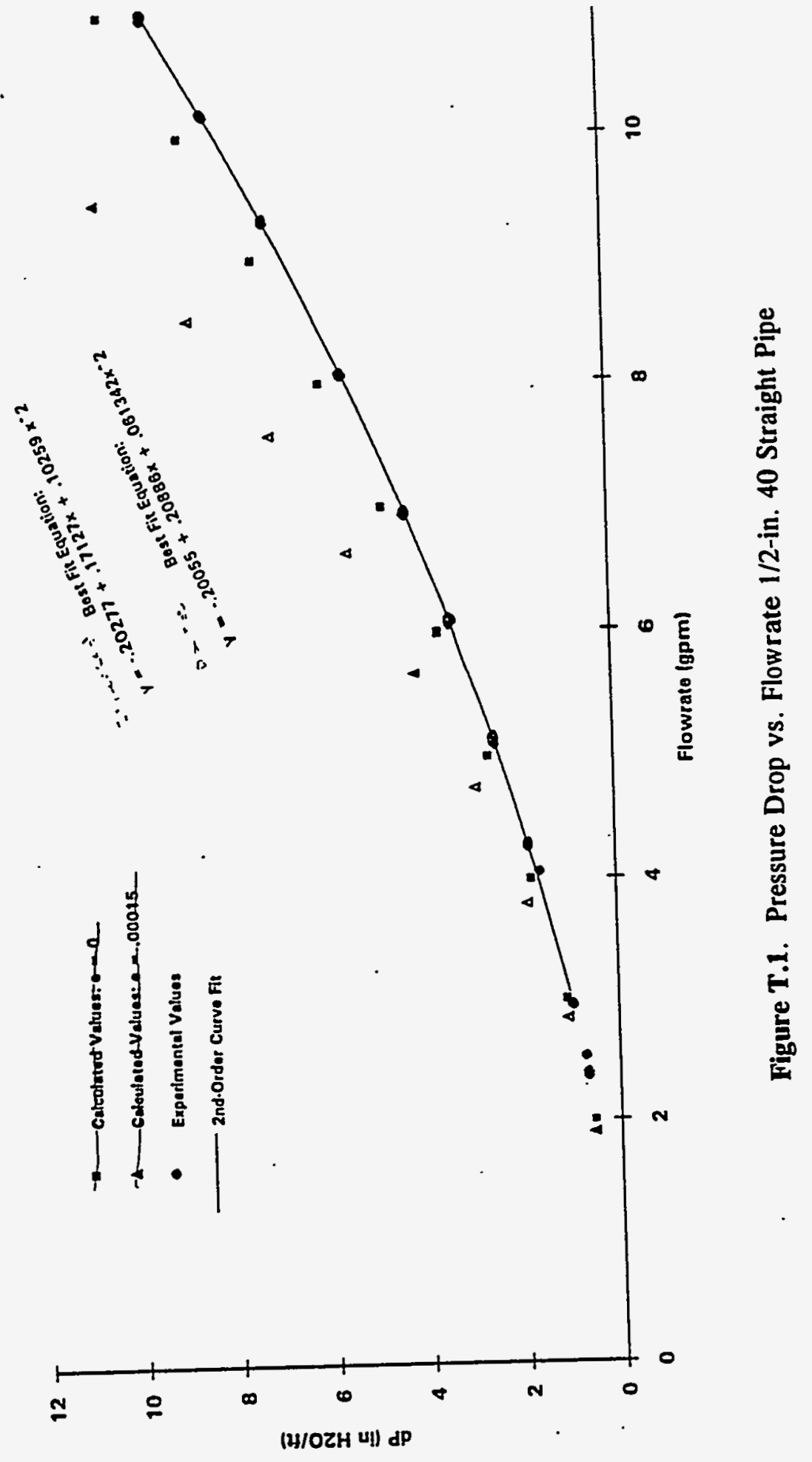




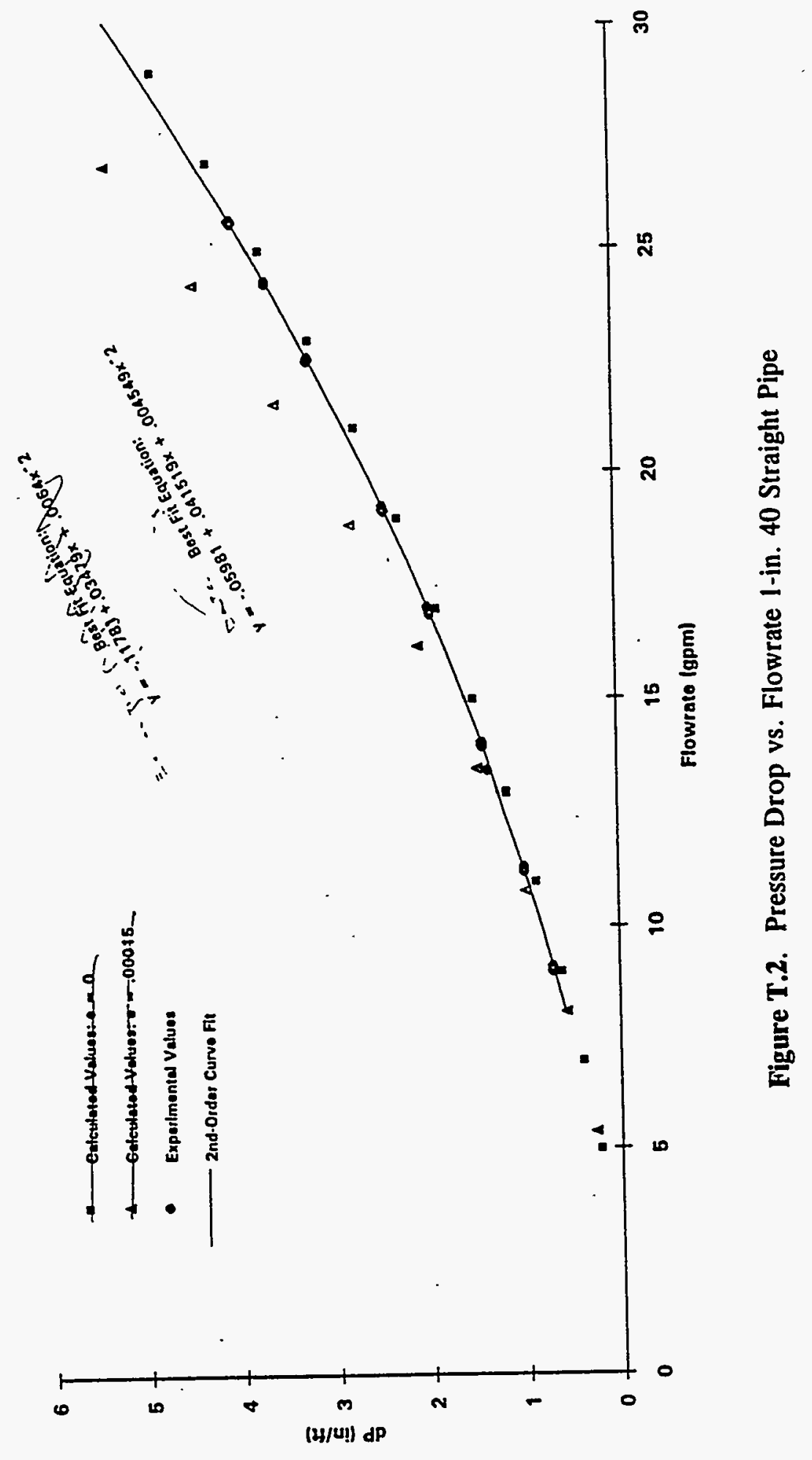




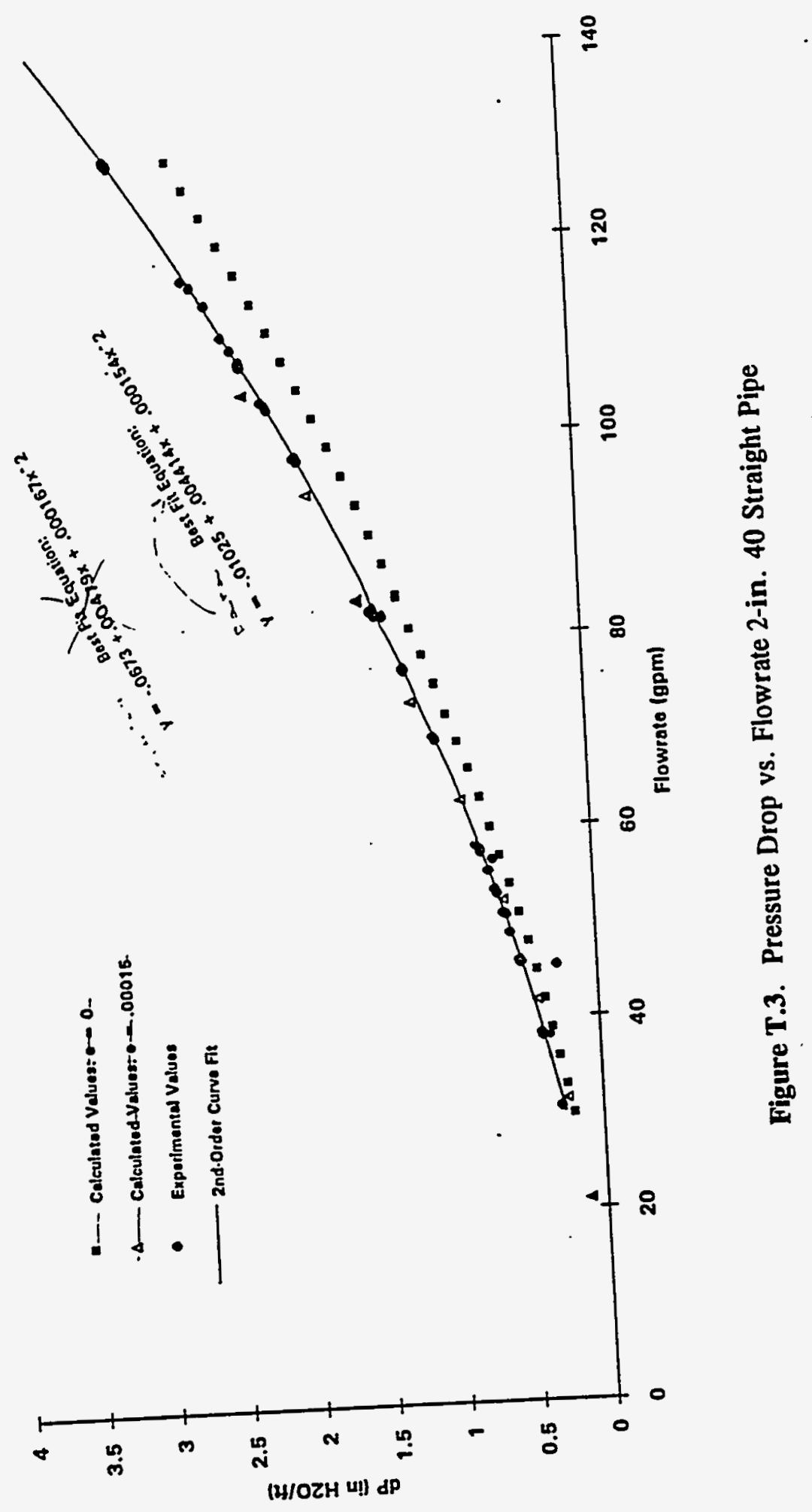




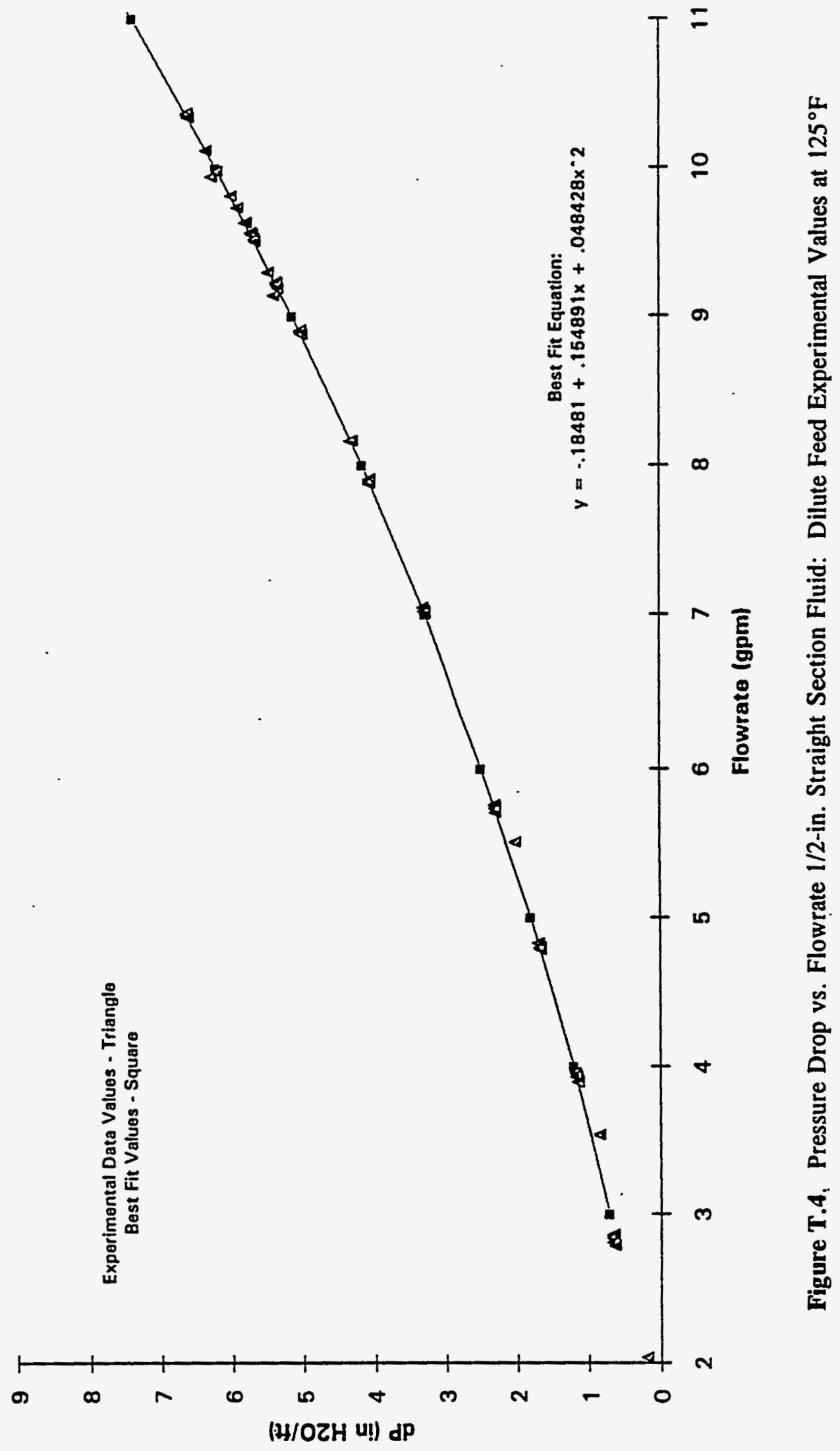

T.6 


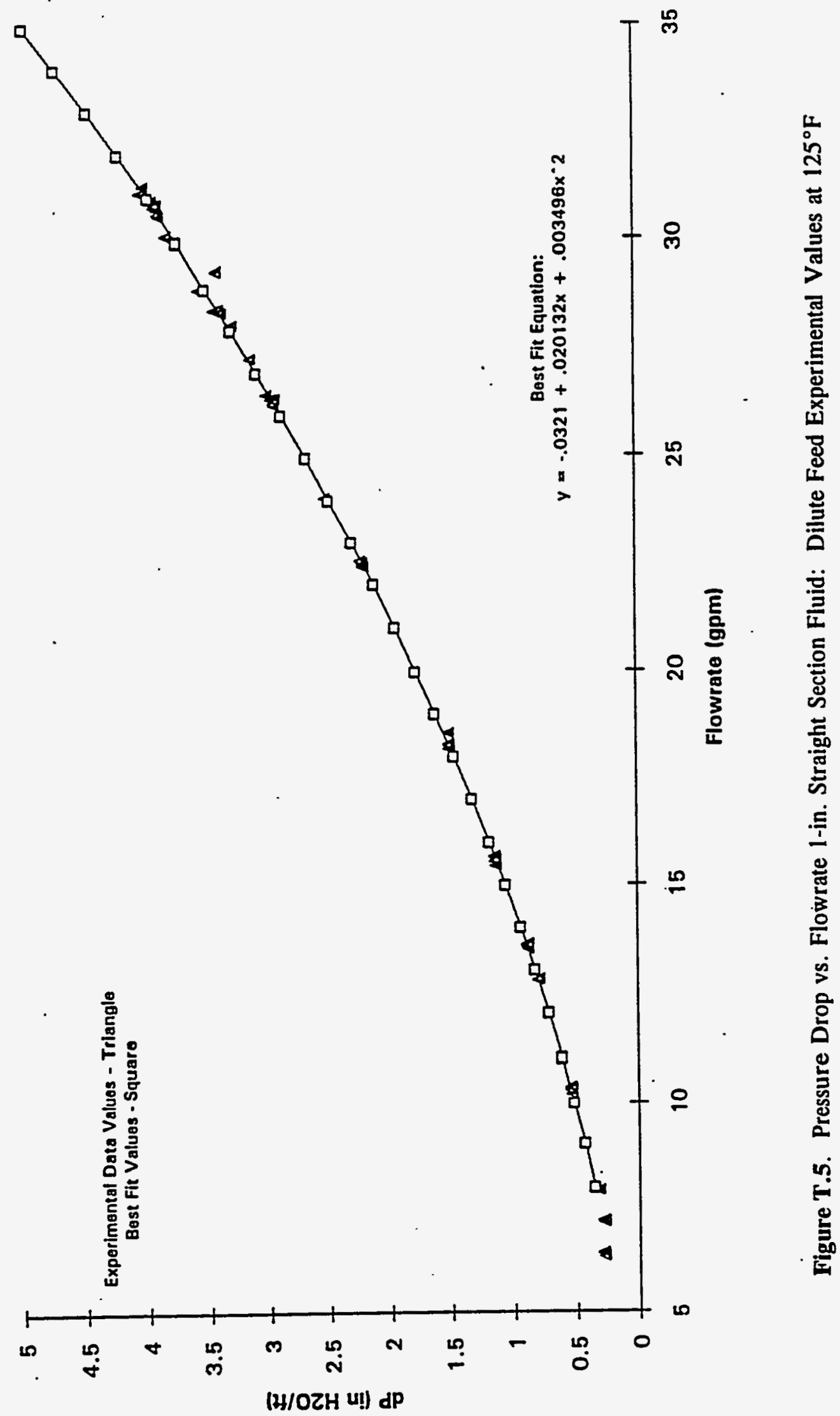

T.7 


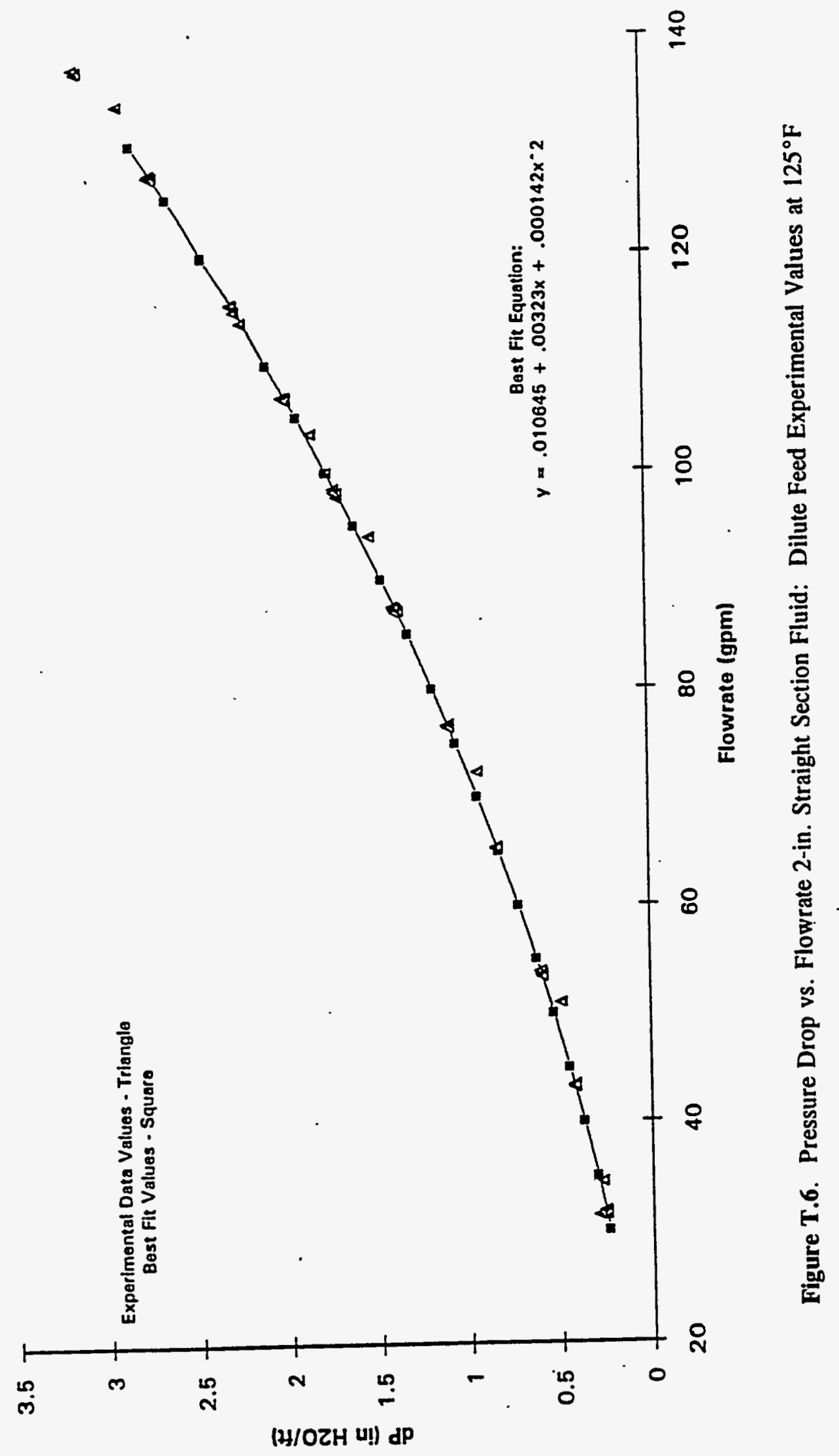




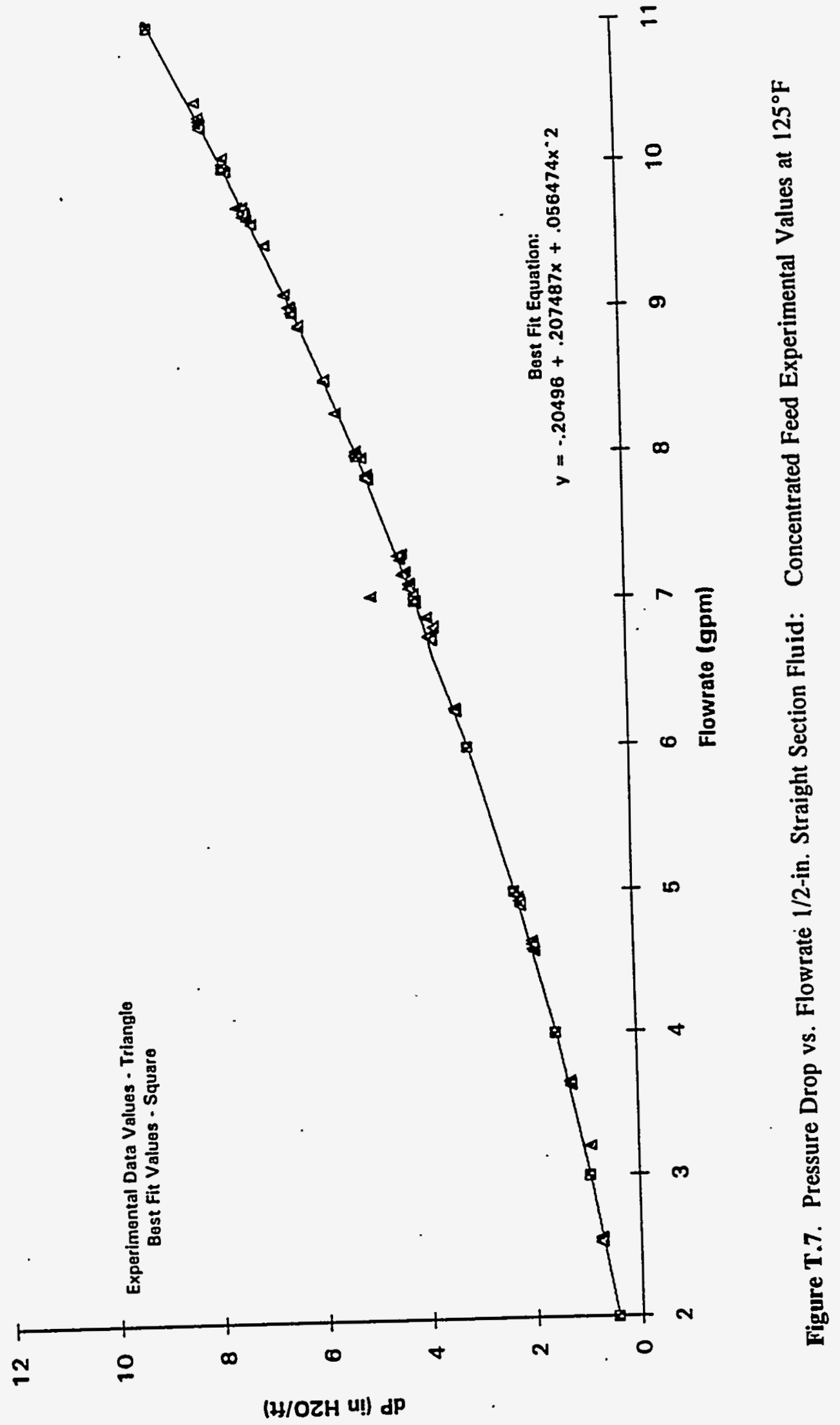




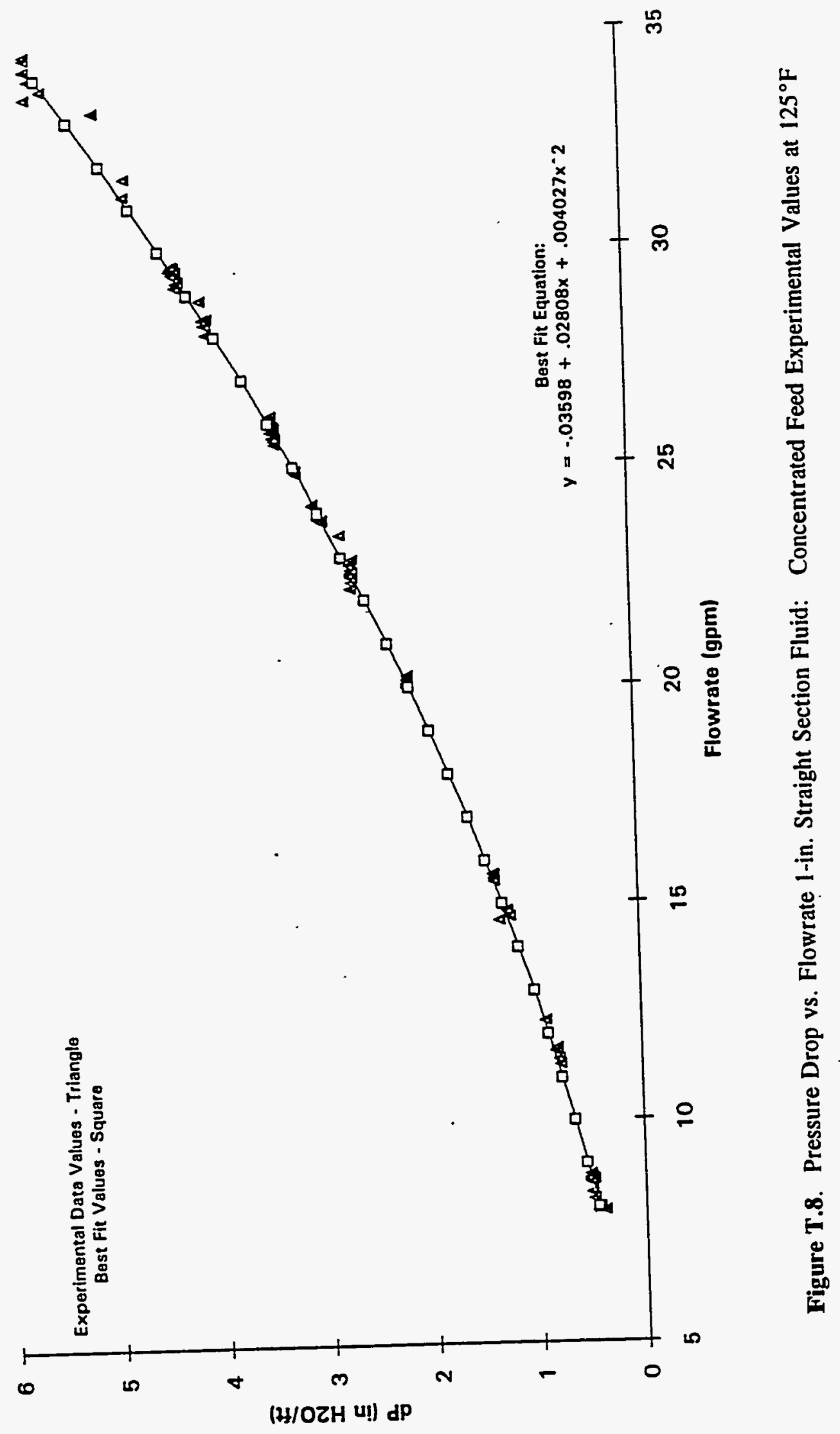

T.10 


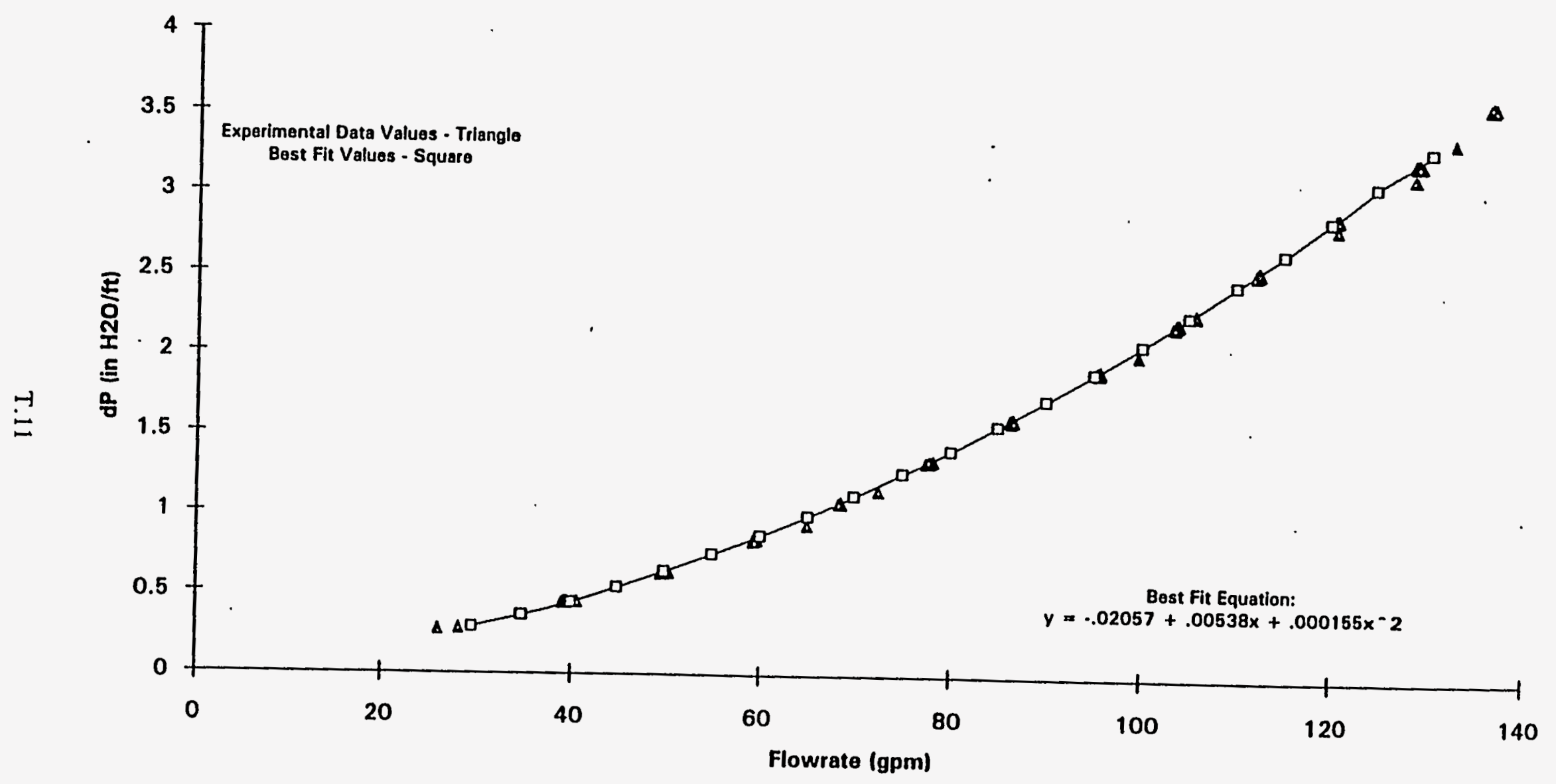

Figure T.9. Pressure Drop vs. Flowrate 2-in. Straight Section Fluid: Concentrated Feed Experimental Values at $125^{\circ} \mathrm{F}$ 

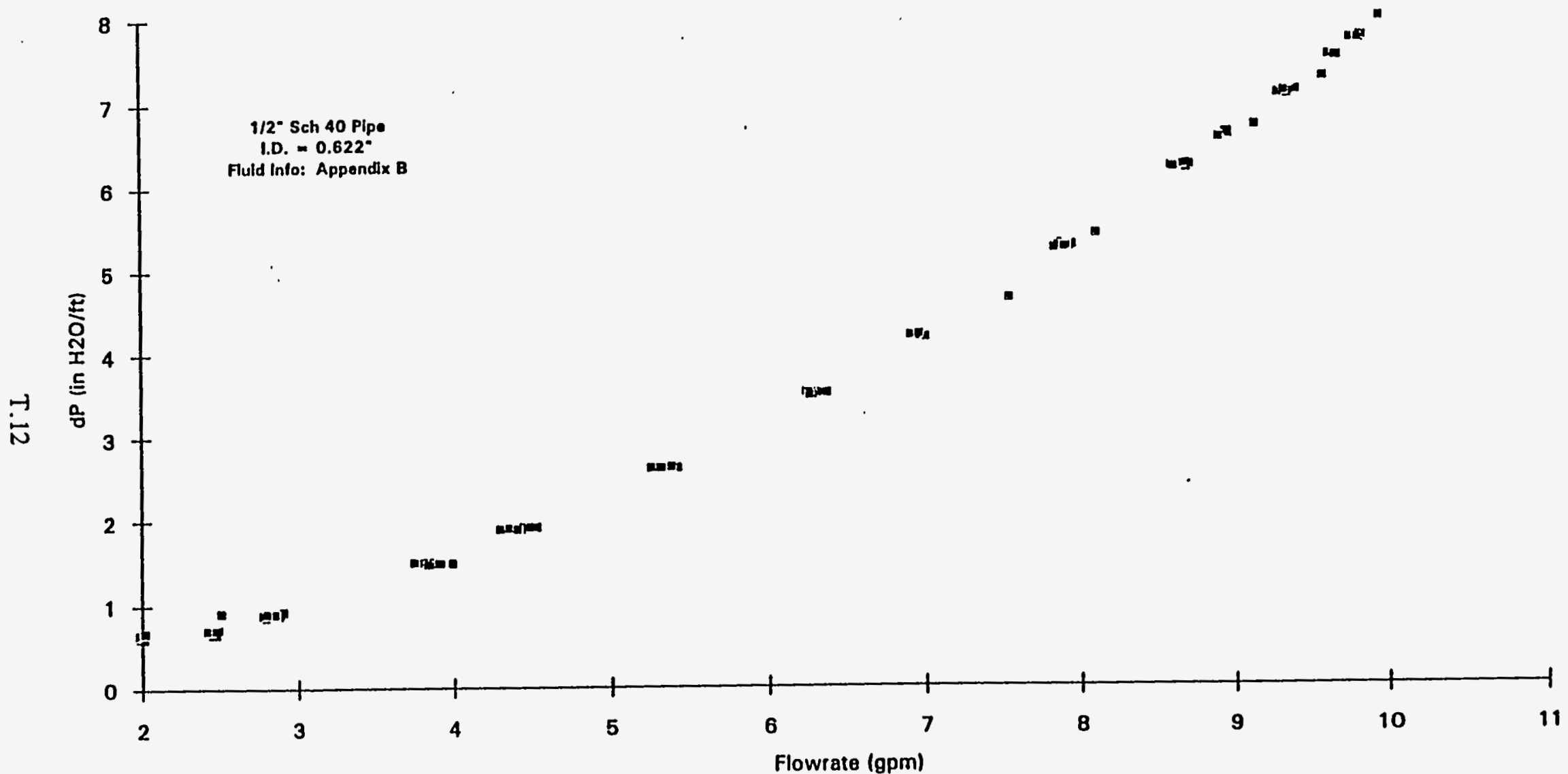

Figure T.10. Pressure Drop vs. Flowrate Fluid 1/2-in. Schedule 40 Pipe: Formated Feed 


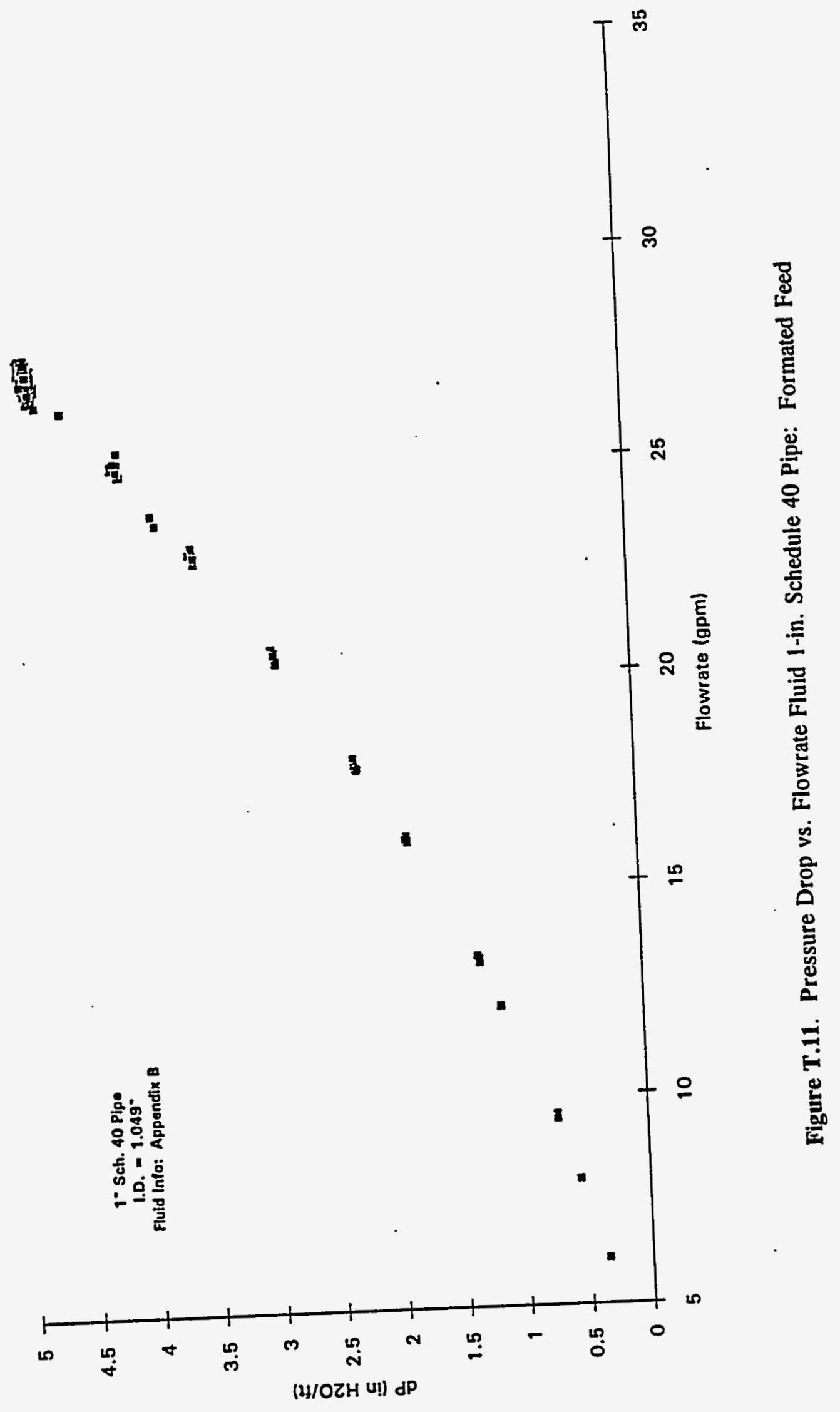

T.13 


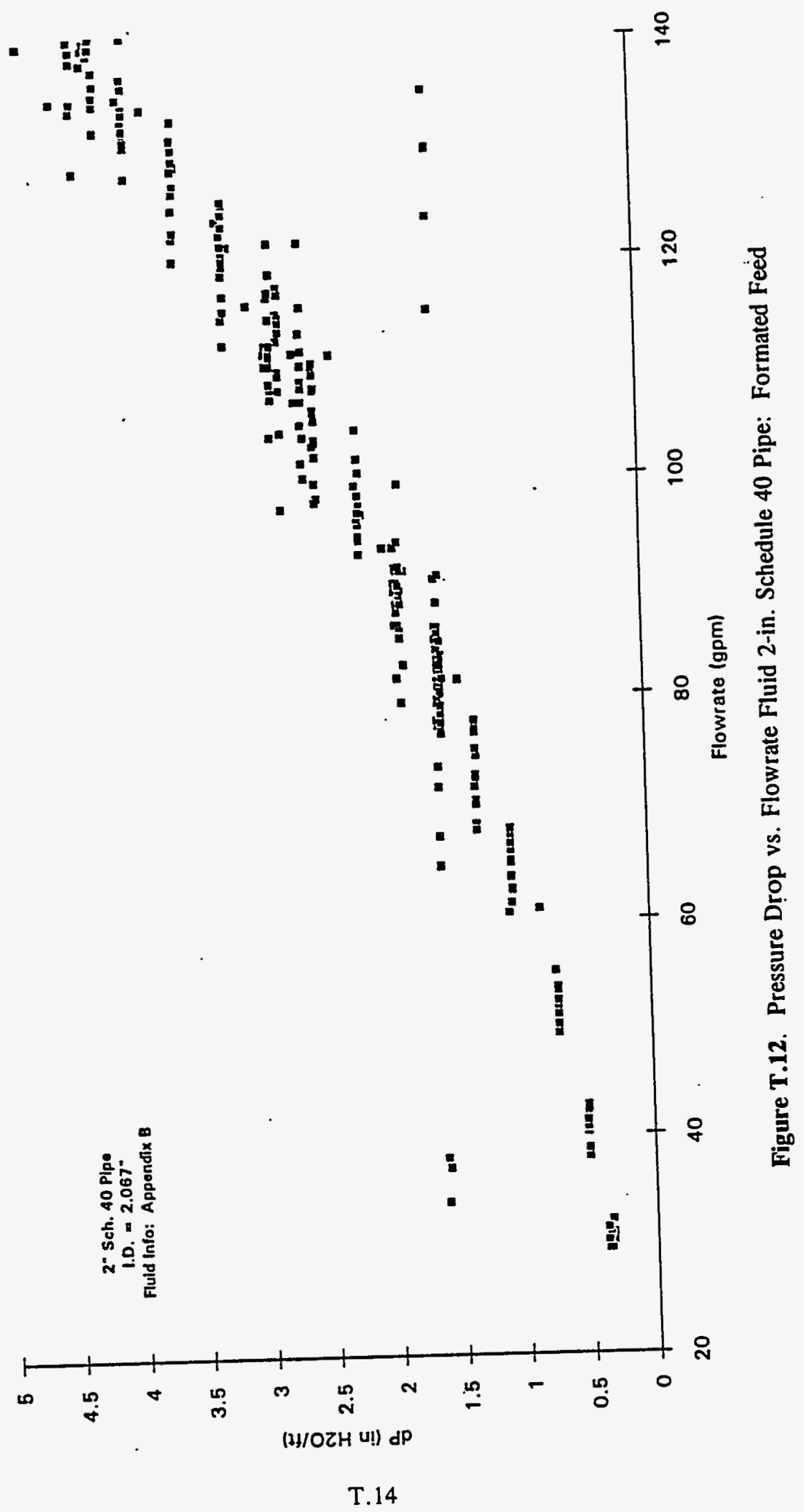




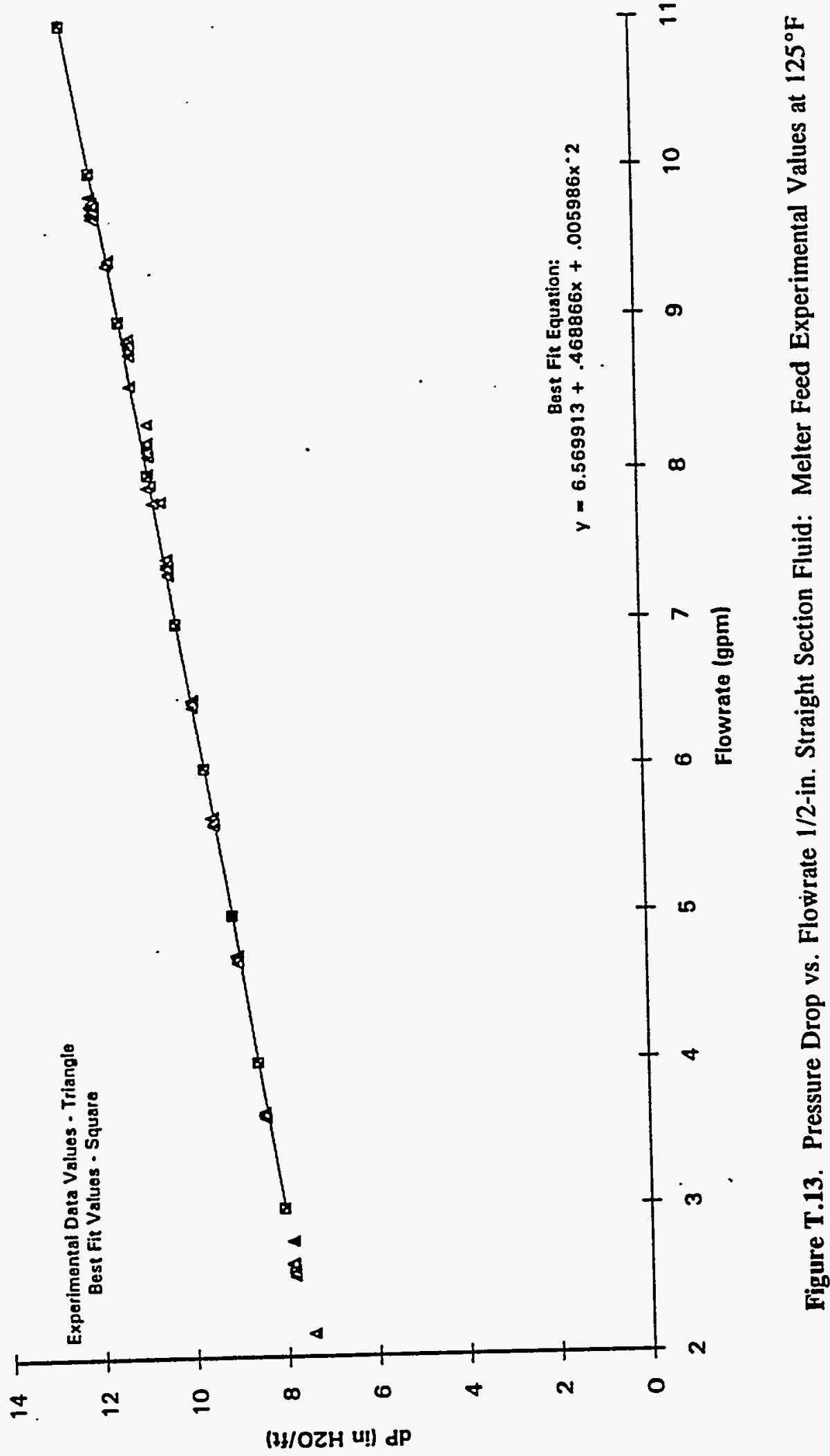

T.15 


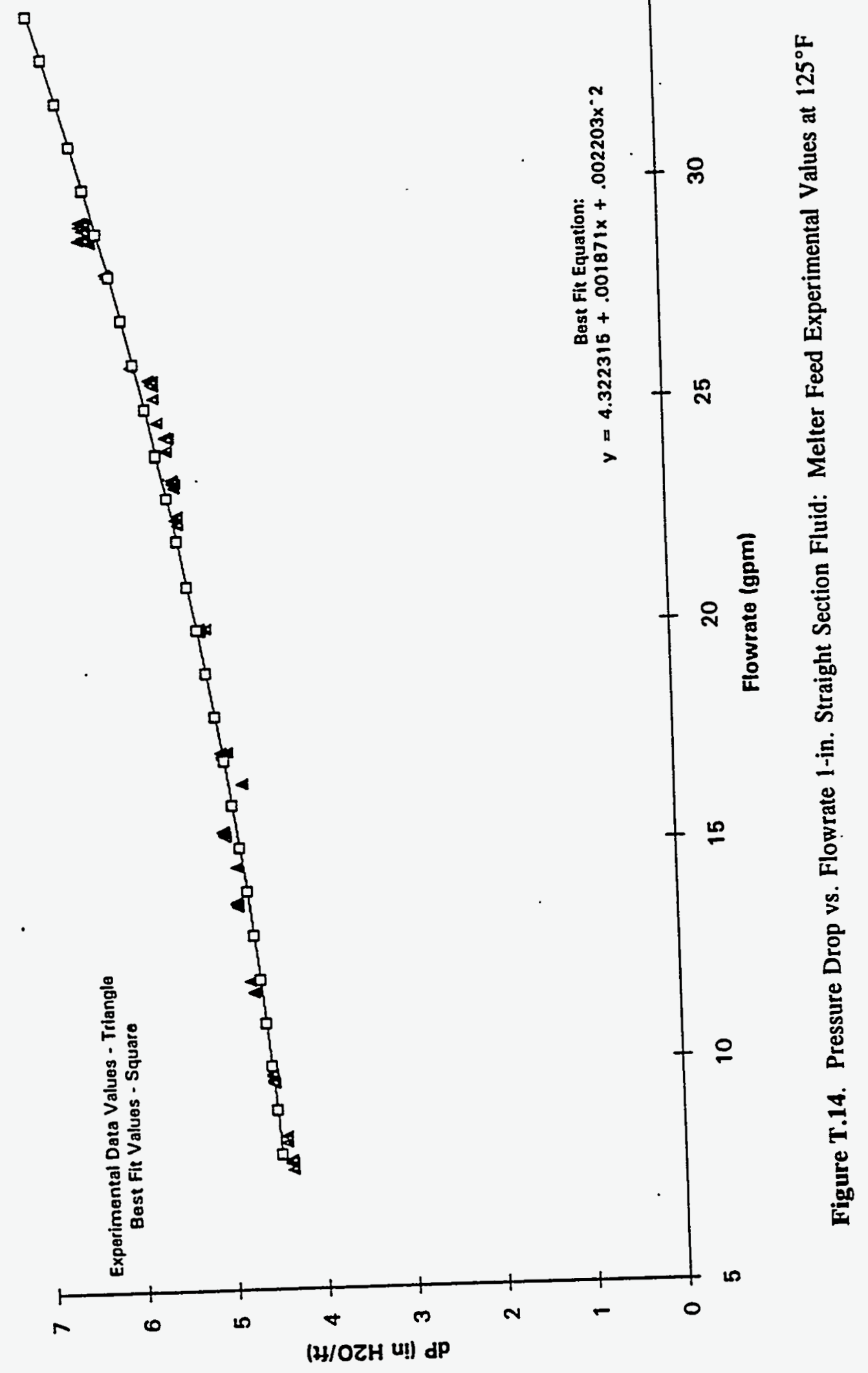

T.16 

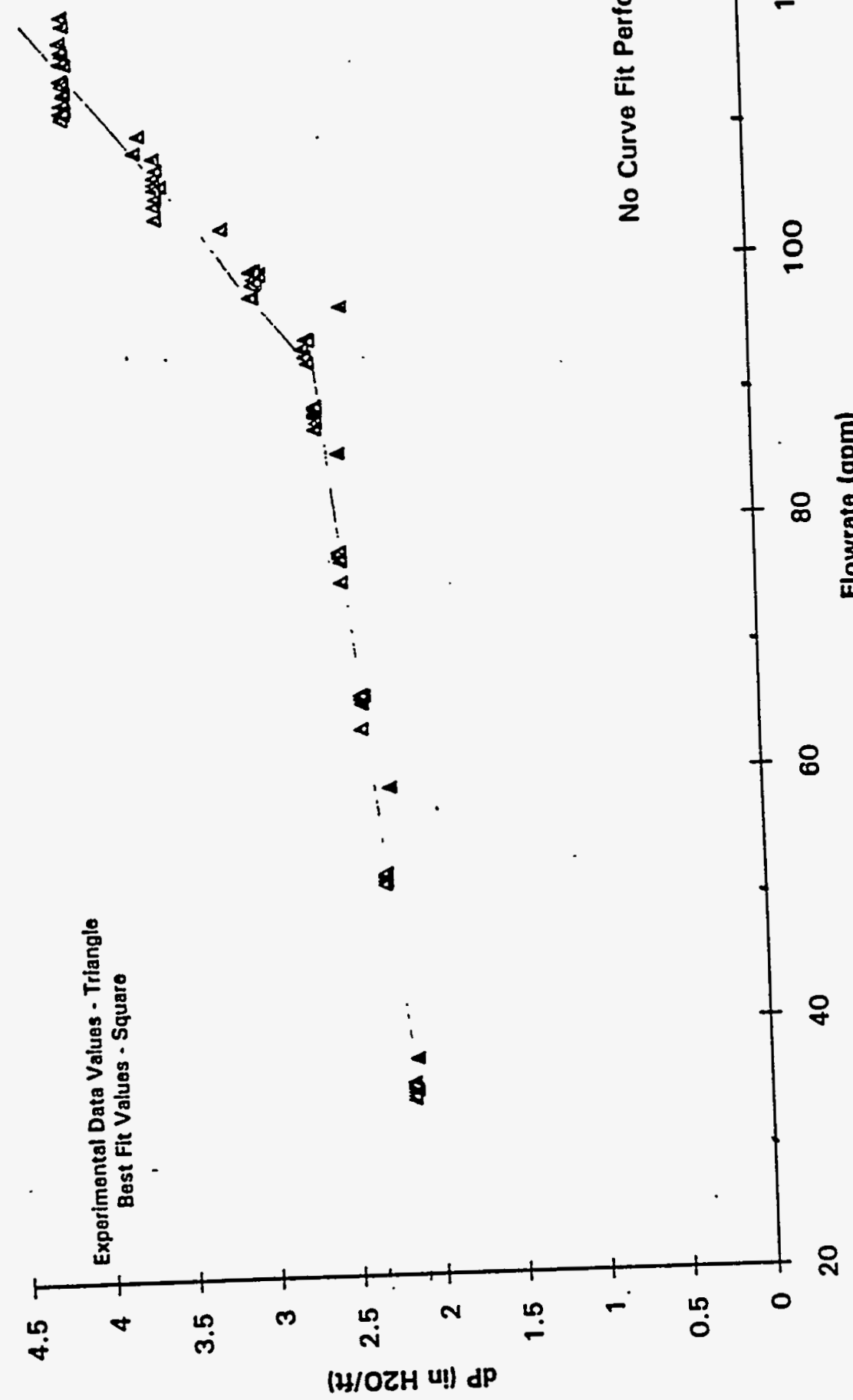

T.17

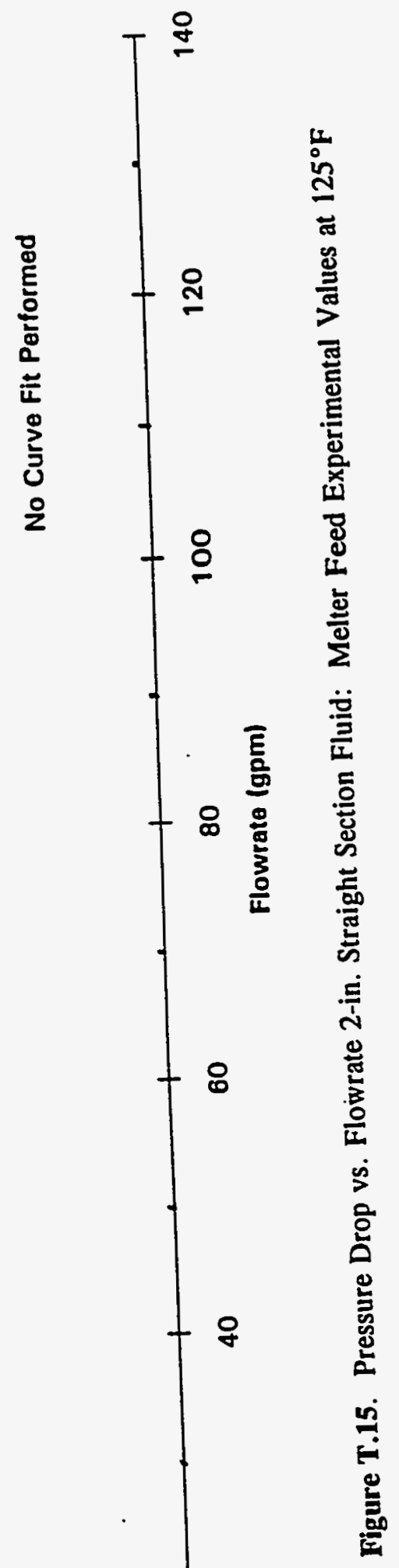




\section{Appendix U}

\section{Slurry Flow Engineering Analyses}




\section{Engineering Analysis}

Preliminary results from testing with water as the test medium revealed a difference between the experimental pressure drop values and calculated pressure drop values. In all cases, the experimental values were less than the expected (calculated) values using a typical commercial steel pipe roughness $(e=0.00015$ ). A sample pressure drop calculation for water is included in the appendix. The experimental pressure drop with water was about the value calculated for smooth pipe $(e=0)$. There were a number of possible reasons for this difference: 1) the geometric configuration of the instrumentation being used to measure the differential pressure in the pipe was causing turbulent effects inside the remote seal unit. As stated above, the differential pressure system consists of a transmitter and two remote seal units placed a specified distance apart. This remote seal unit utilizes a diaphragm system which transmits the force of the local pressure to the transmitter. The diaphragm is housed in a spool piece (remote seal) which is inserted directly into the process piping. Inside the spool piece, the diaphragm is recessed above the pipe which creates a void in which the fluid can expand and contract rapidly. and cause pressure fluctuations near the diaphragm, 2) the system (pipe loop) itself is causing a problem, 3) the experimental procedure being followed is causing a problem, 4) instrumentation (flow and pressure) was not properly "zeroed" prior to each test run, 5) the material being used (process piping) possessed "extra smooth" surfaces causing a diminished pressure drop, or 6) calculations of expected data were made incorrectly or specific system parameters were assumed incorrectly. These probable reasons and the steps taken to validate their applicability are explained in more detail below. All validation tests were performed using water as the test medium.

Reason \#1: Pressure fluctuations caused by geometric configuration of dP remote seal units.

Problem: The remote seal units were selected in order to avoid problems with solids buildup inside tubing and instrumentation. The use of direct-tap pressure measurement would require a significant amount of flushing to keep the process tubes from plugging with solid material,i.e., mainly frit. A cross-section of one of the remote seals is shown in the appendix. Originally, it was hypothesized that pressure fluctuations were induced from rapid expansion and contraction of the fluid as it passed through the remote seal. Theoretically, the fluid should be static at the diaphragm face in order to transmit an accurate pressure signal. The manufacturer of the remote seais is PI Components Corp., Houston, Texas. After reviewing the preliminary results, they were unable to explain the difference in readings. Their past experience has shown that the remote seal units have been used successfully in flow processes similar to the STL testing. Also, it was felt that the relative effect of each remote seal would be "washed-out" since each remote seal would be experiencing similar turbulent effects.

Resolution: In order to validate the proposal that the remote seals were solely responsible for the difference between experimental and expected pressure drop values, additional tests with water were conducted using alternate instrumentation. At the time, no 
differential pressure transmitters were available. In order to obtain approximate results, two absolute pressure transmitters with direct tap connections were used in the 2 in. and 1 in. straight test sections. The use of absolute pressure transmitters to measure differential pressure is not recommended. Additional error is induced from the subtraction of two absolute readings to obtain the differential pressure value. Also, the error from each separate instrument must be accounted for. Results from these tests (Figures A.1 and A.2) provided similar results as tests using the remote seal units.

A differential transmitter with the proper calibration range $\left(0\right.$ to 250 in. $\mathrm{H}_{2} \mathrm{O}$ ) was later obtained. Validation tests were performed using this instrument installed in the 1" straight test section with direct tap connections. Results (Figure A.3) again did not show a difference with the results using the remote seal units.

The conclusion was made that there was insufficient evidence to show that the remote seal units were responsible for the difference between experimental and calculated pressure drop values. The instruments appear to be producing valid data.

Reason \#2: The system (pipe loop) itself is causing a problem.

Problem: The pipe loop was designed using several rules of thumb for placement of fittings, instrumentation, valves, etc. It is important that the flow become fully developed before the test section in which the differential pressure is being measured. The recommended distances before and after any fittings or instruments is 10 and 40 pipe diameters, respectively. These parameters were used during the design and have been field verified.

One possibility investigated was that the pipe was not full during certain segments of the testing procedure. This would seriously effect both pressure and flow readings. The reasoning behind this was that the test loop is located about $10 \mathrm{ft}$ above the main feed tank. The return line from the STL travels over and above the tank and then straight down with no restrictions. This $10 \mathrm{ft}$ drop could possibly be creating a negative pressure back up into the process piping, thereby reducing the downstream pressure. This was not felt to be a high probability since downstream valves were being used to decrease the flowrate during testing and thereby ensuring a full pipe during most flow conditions. However, to ensure that a full pipe was always maintained, a slight modification in the return line (downstream of all test sections) of the test loop was installed. This modification consisted of a 12 in. "jog" in the line which caused the pipe upstream to always be full since the water had to essentially "climb" the pipe in order to get over the jog in the line. The results do not show any significant difference in the correlation between expected and experimental data. An example of the results of testing before and after this modification in the 1/2-in. test line is shown in Figure A.4. 
Resolution: The above discussion leads to the conclusion that it is highly probable that a full pipe is being maintained during testing procedures. The difference in experimental pressure drop, before and after modification, is due to the difference in water temperature as evidenced in the calculated values (See Figure A.4).

Reason \#3: The experimental procedure being followed is causing a problem.

Problem: The only way that the procedure is causing a problem is if a full pipe is not maintained. As mentioned above, the use of downstream valves for flow control and the return line modification clearly eliminates this problem.

Resolution: The procedure is not causing the differences observed between experimental and calculated $\Delta P$ results.

Reason \#4: The instrumentation (flow and pressure) was not properly "zeroed" prior to each test run.

Problem: After careful observation of STL data prior to and immediately following pressure drop test runs, it was observed that many of the instruments were not returning to zero as expected, nor were they zero prior to the test run. This "zero bias" could be affecting the data obtained during each run. After discussions with the manufacturer, it was concluded that the instruments can be re-zeroed in the field without any effect on the calibration. Table 4 shows the zero values before and after several of the runs. All the listed non-zero values can be correctly set during future testing by re-zeroing the instruments in the field prior to a test. While this bias could explain some of the discrepancy, most of the values are small and don't significantly affect the overall validity of the data.

Resolution: The testing procedure will be modified to include re-zeroing of the instrumentation prior to a test whenever nonzero values are displayed. The nonzero bias induced is very small and does not explain the discrepancy observed.

Reasons \#5 and \#6: Actual pipe has lower roughness than that used in calculations, and calculations of expected data were made incorrectly or specific system parameters were assumed incorrectly.

Problem: Several unbiased personnel have reviewed the pressure drop calculations and all have approved of the assumptions and methodology. The real problem lies in the fact that the calculation of pressure drop is only an "estimate" of what is actually occurring. The general equation for calculating pressure drop for a Newtonian fluid in a circular pipe, known as Darcy's formula and expressed in feet of fluid, is: 


$$
\mathrm{h}_{\mathrm{L}}=\frac{\mathrm{fL} \mathrm{v}^{2}}{\mathrm{D} 2 \mathrm{~g}_{\mathrm{c}}}
$$

where $\quad h_{L}=$ head loss

$\mathrm{f}=$ friction factor

$\mathrm{L}=$ length of pipe section

$\mathrm{v}=$ velocity

$\mathrm{D}=$ inside diameter

g = gravitational constant

This equation may be written to express pressure drop in pounds per square inch, by substitution of proper units, as follows:

$$
\Delta \mathrm{P}=\frac{\rho \mathrm{fl} v^{2}}{144 \mathrm{D} 2 \mathrm{~g}_{\mathrm{c}}}
$$

where $\rho=$ density of fluid

Each term in the above equation has an associated uncertainty. The term with the largest uncertainty (and variability) is the friction factor. The friction factor is obtained by use of the Moody Diagram which is a graphical representation of the friction factor as a function of pipe roughness and Reynolds Number. The roughness of commercial steel can vary significantly. The roughness value used in the calculation of pressure drop for the STL testing was $0.00015 \mathrm{ft}$. (a) This value is for new commercial steel pipe. It is possible that the stainless steel which is being used in the STL is actually smoother than expected. This would cause a significant decrease in pressure drop and explain much of the discrepancy observed. As yet, a method for absolute determination of pipe roughness in the STL piping has not been pursued. Calculations using a roughness value of zero were performed. In all cases, the experimental $\Delta \mathrm{P}$ curve lies between the $\Delta \mathrm{P}$ curve for roughness equal to 0.00015 and roughness equal to 0 within experimental error.

(a) Hydraulic Institute - Engineering Data Book, 2nd Edition. 1990, page 25. 
Resolution: Due to the fact that validation tests with alternate differential pressure instrumentation have given similar results as the remote seal units, there is sufficient evidence to assume that the pipe roughness value used in the calculation of pressure drop was greater than what the actual pipe roughness is in the STL system.

Due to the fact that the experimental data lies between the data using a roughness of 0.00015 and a roughness of 0 , this problem alone is felt to have caused the majority of the differences in $\Delta P$ observed. While the experimental pressure drop data does not exactly match the expected pressure drop, the results appear to be valid.

\section{Summary}

The baseline experimental pressure drop data with water as the test medium does not closely match the expected data obtained through using data for commercial pipe calculations. Possibilities for this discrepancy have been analyzed and the results indicate that the experimental data is valid. Test results show that the tests are repeatable and show accurate trends. The difference between experimental data and calculated data appears to be due to a difference in pipe roughness values used in the calculation and the actual roughness of the STL piping system. 


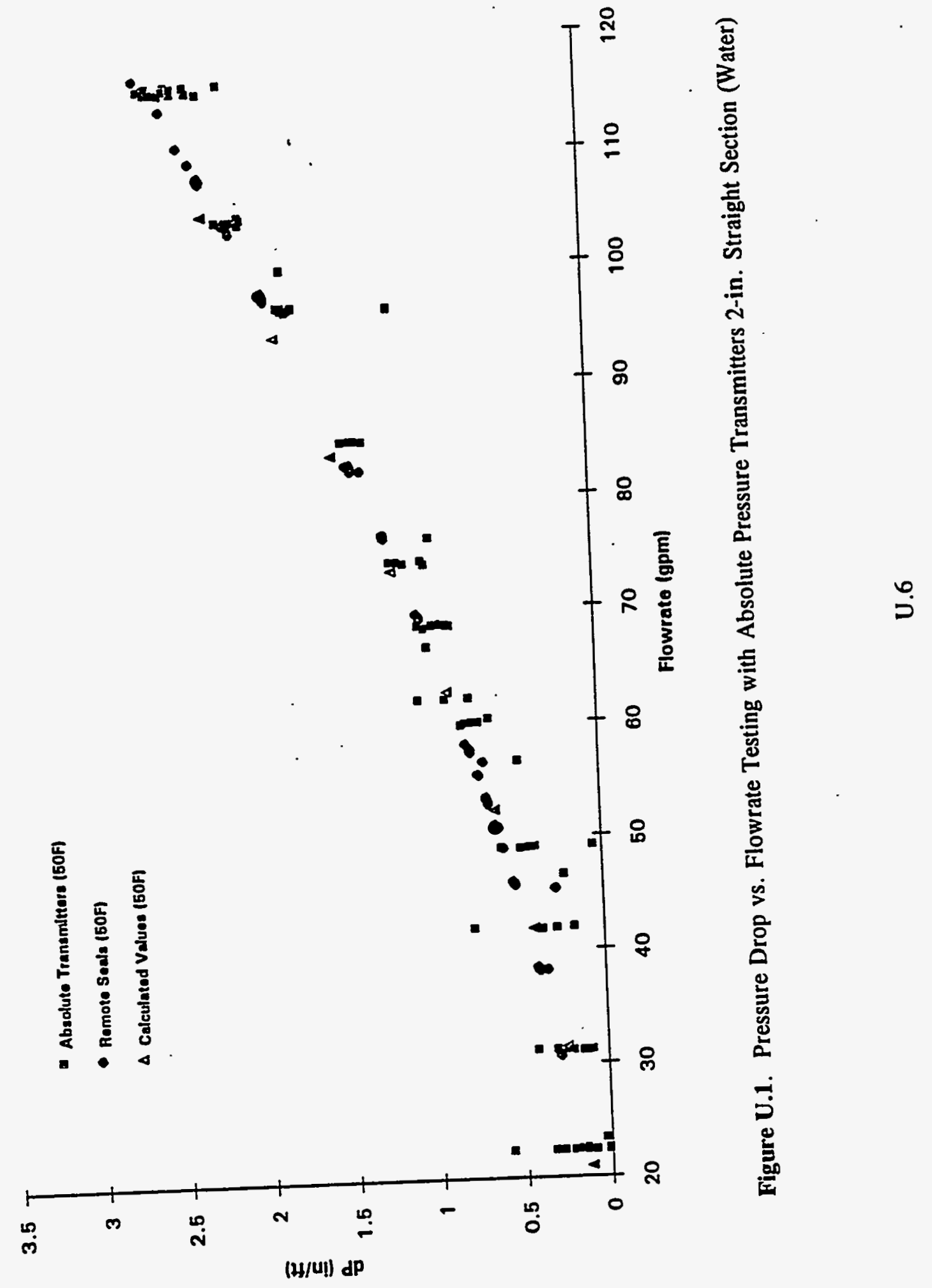




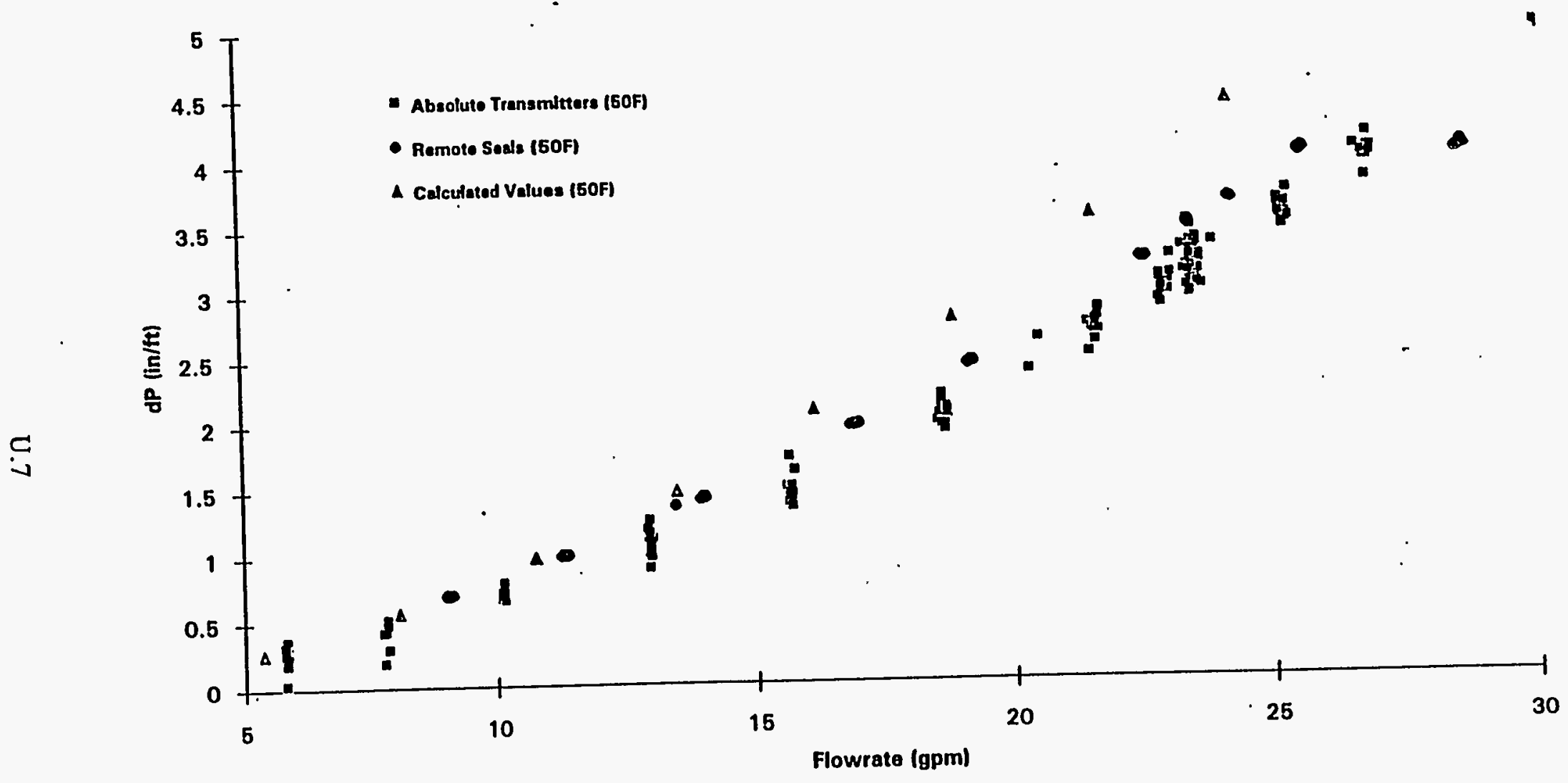

Figure U.2. Pressure Drop vs. Flowrate Testing with Absolute Pressure Transmitters 1-in. Straight Section (Water) 


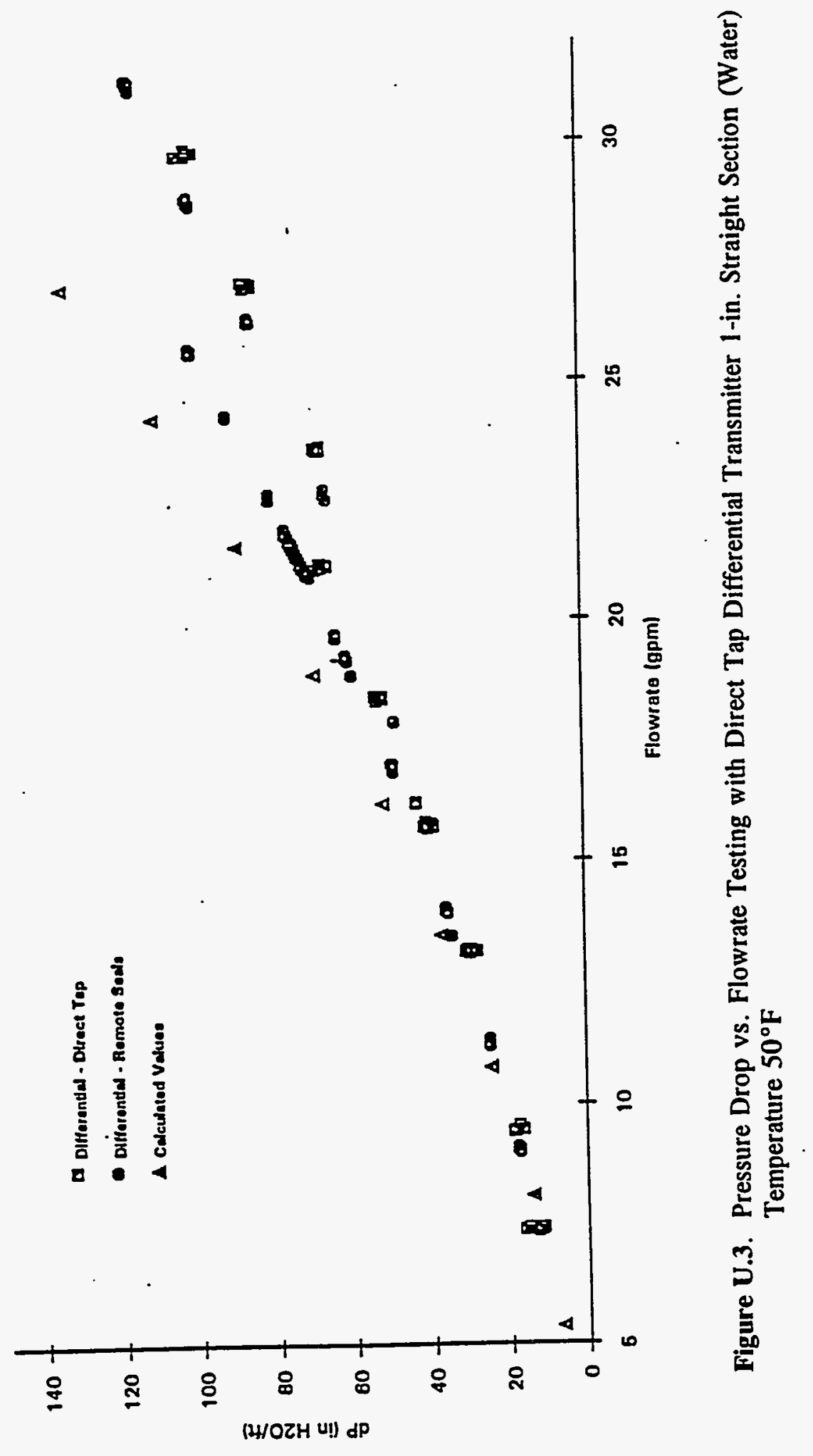

U. 8 


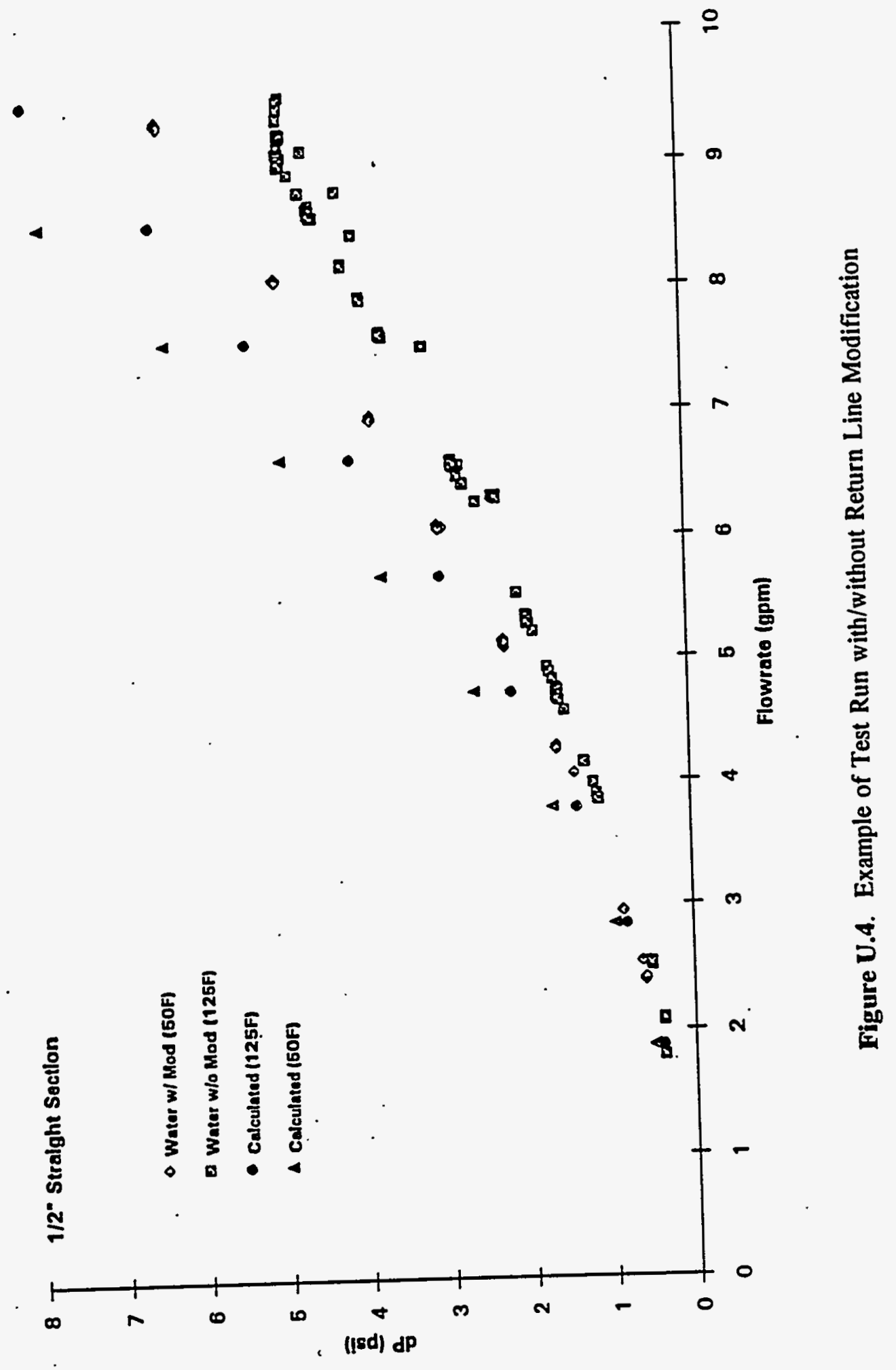

9 
Appendix V

Pressure and Flow Run Data Plots on Melter Feed Line 


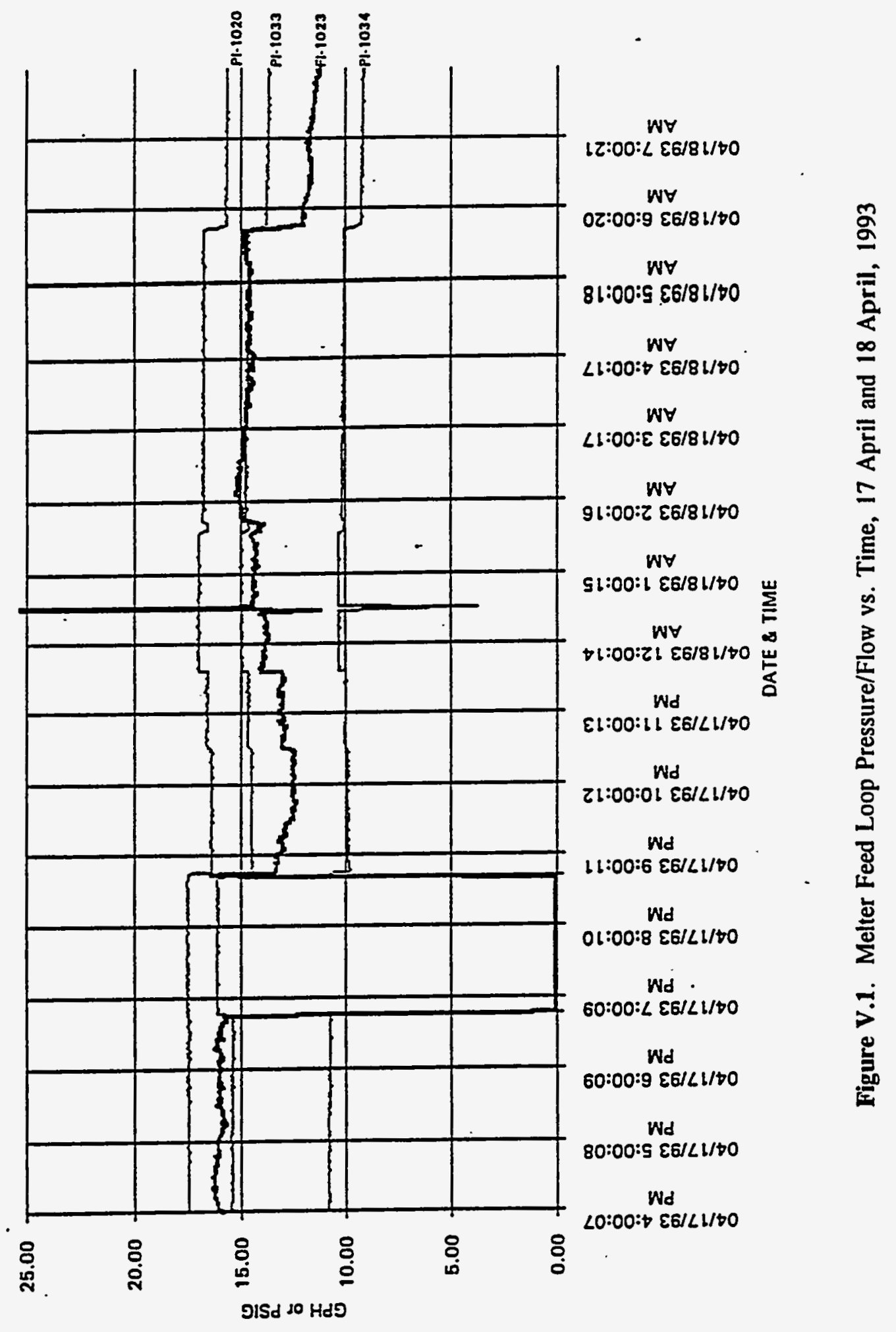

V.1. 


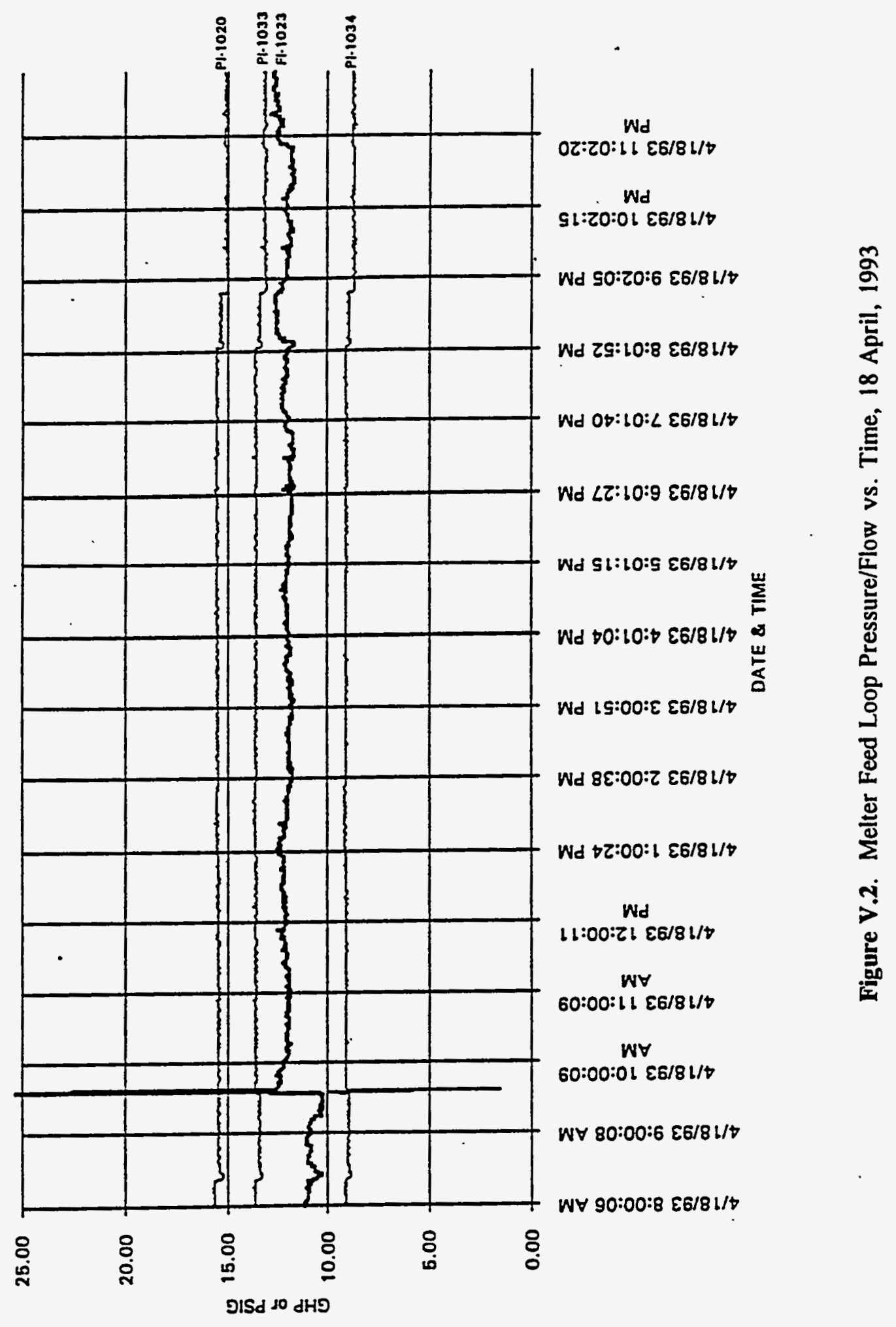




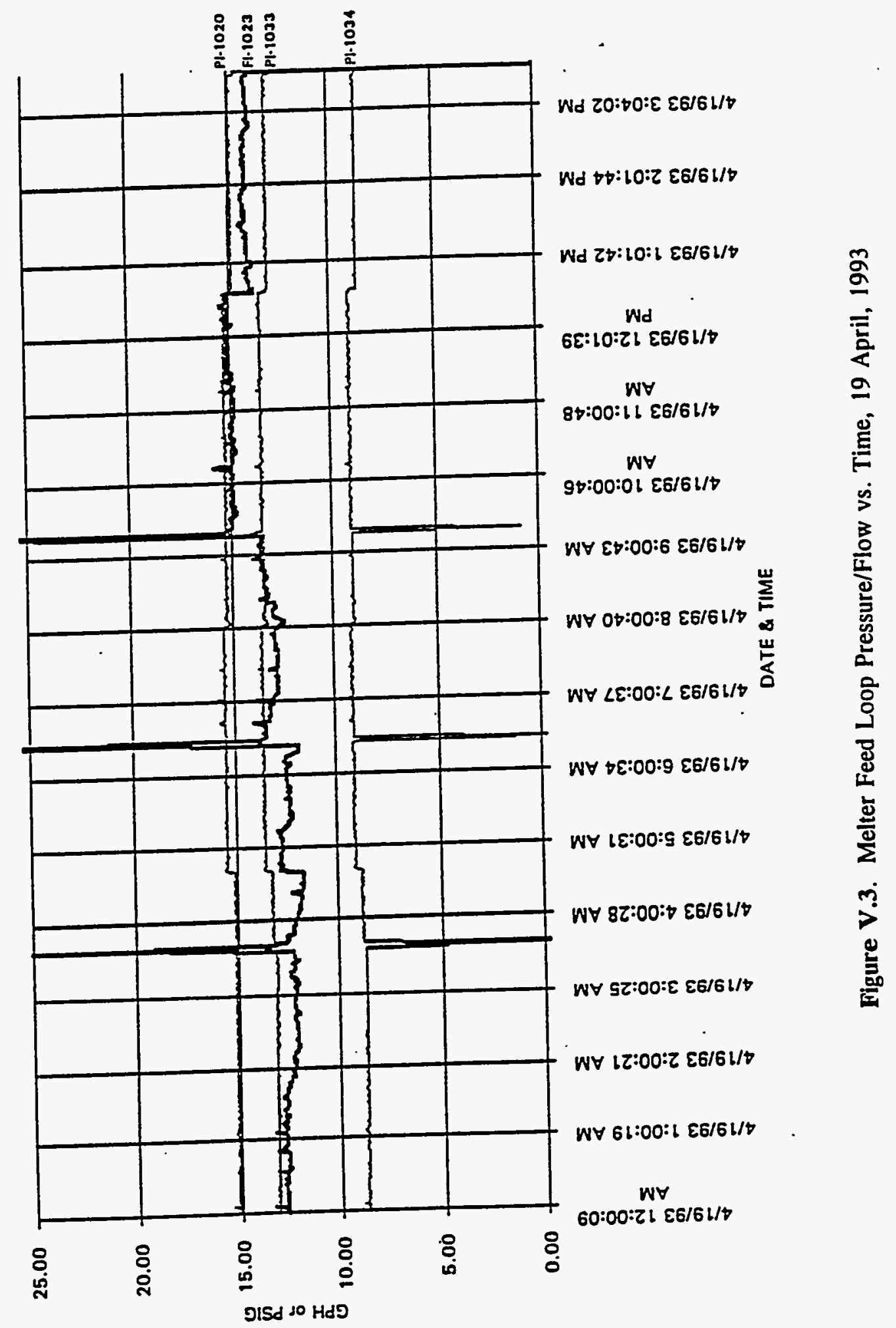




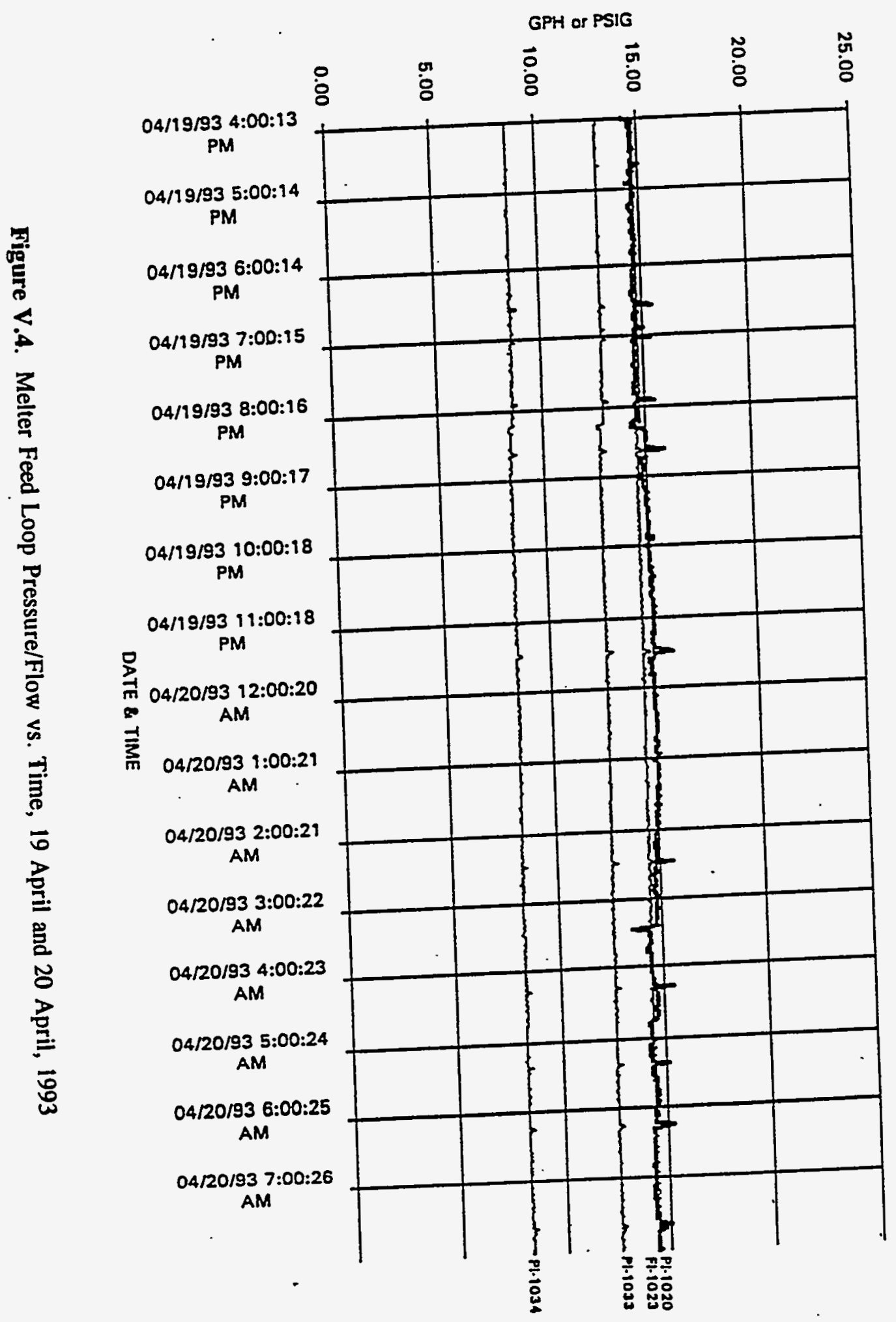




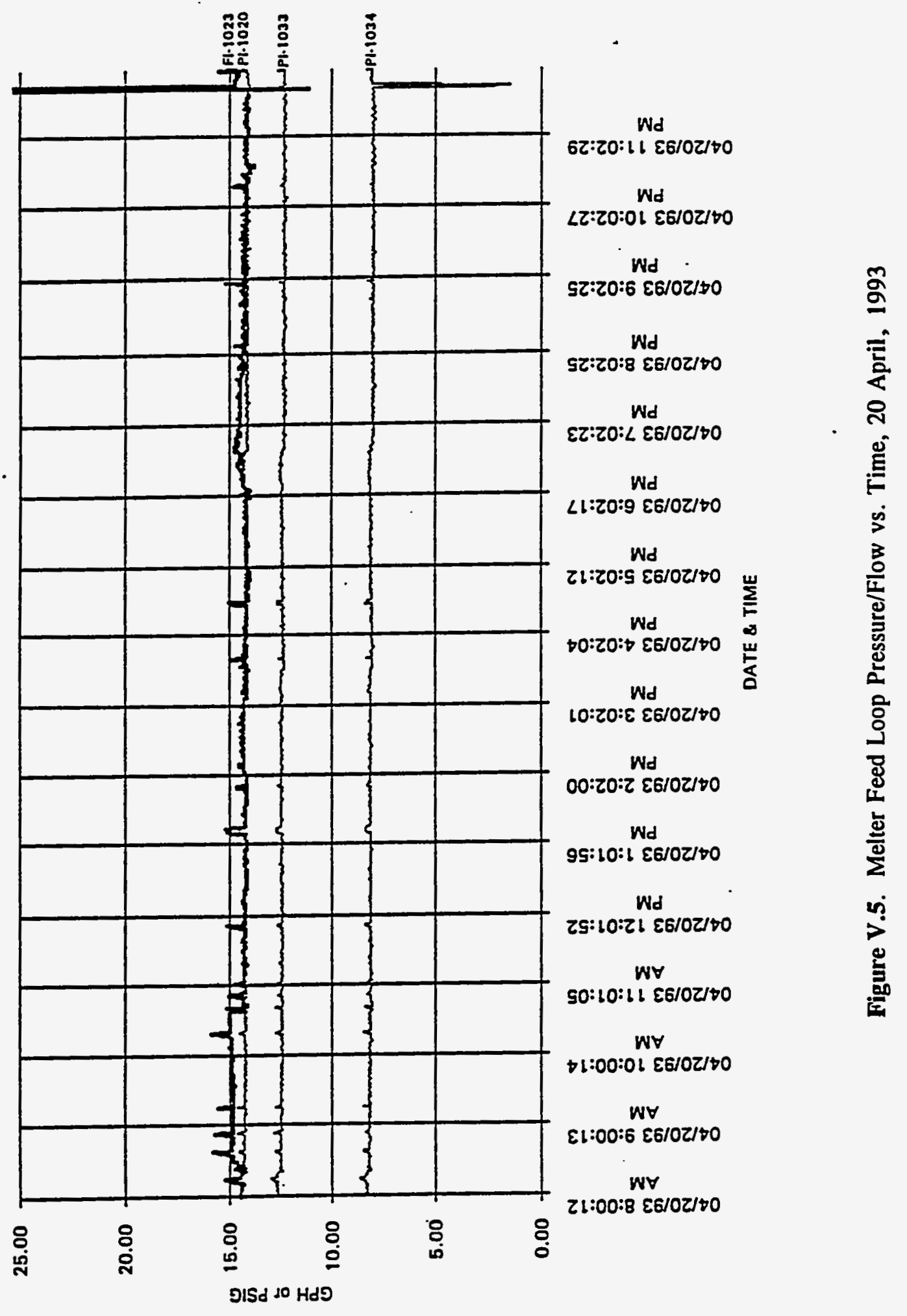


$9^{\circ} \Lambda$

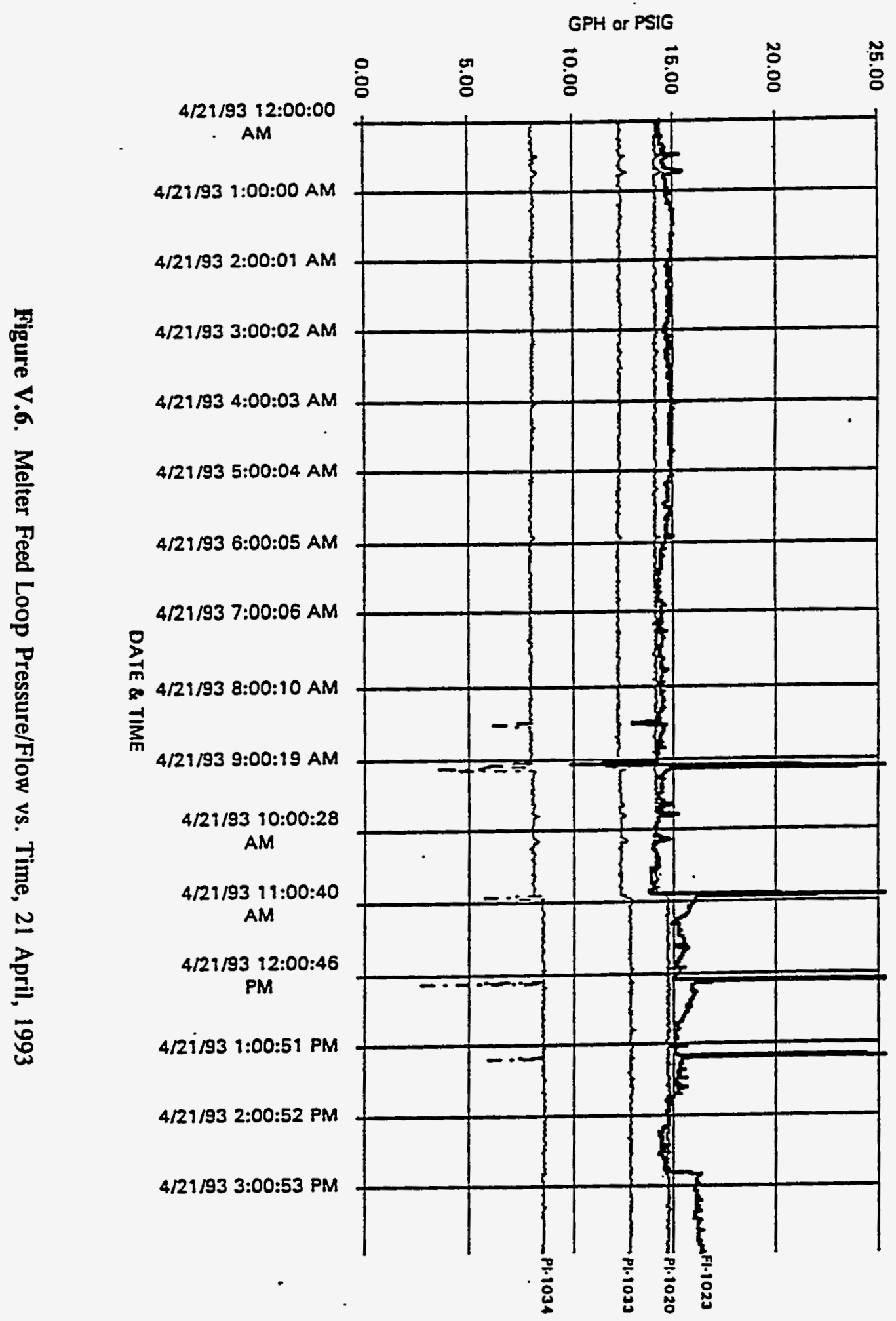




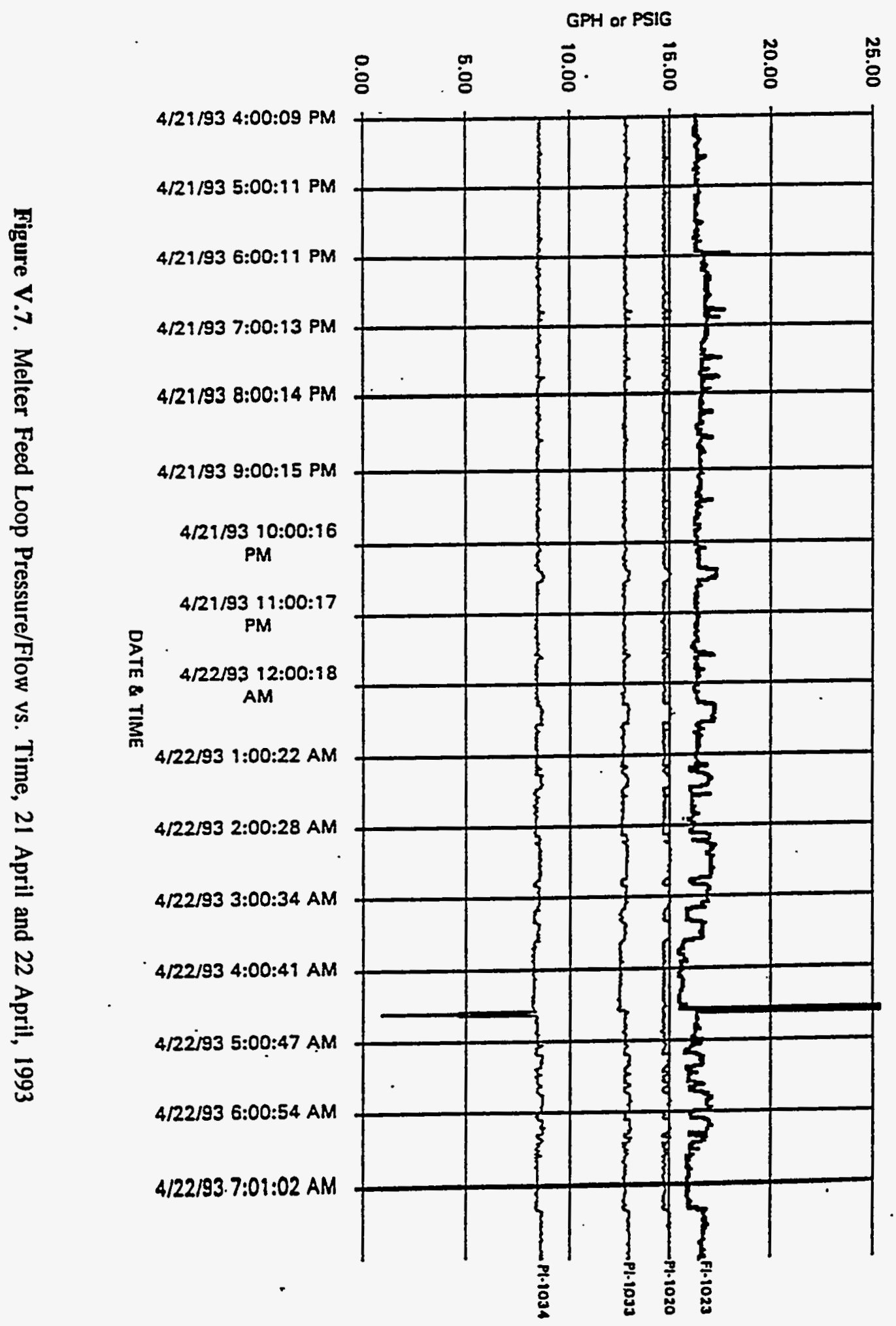




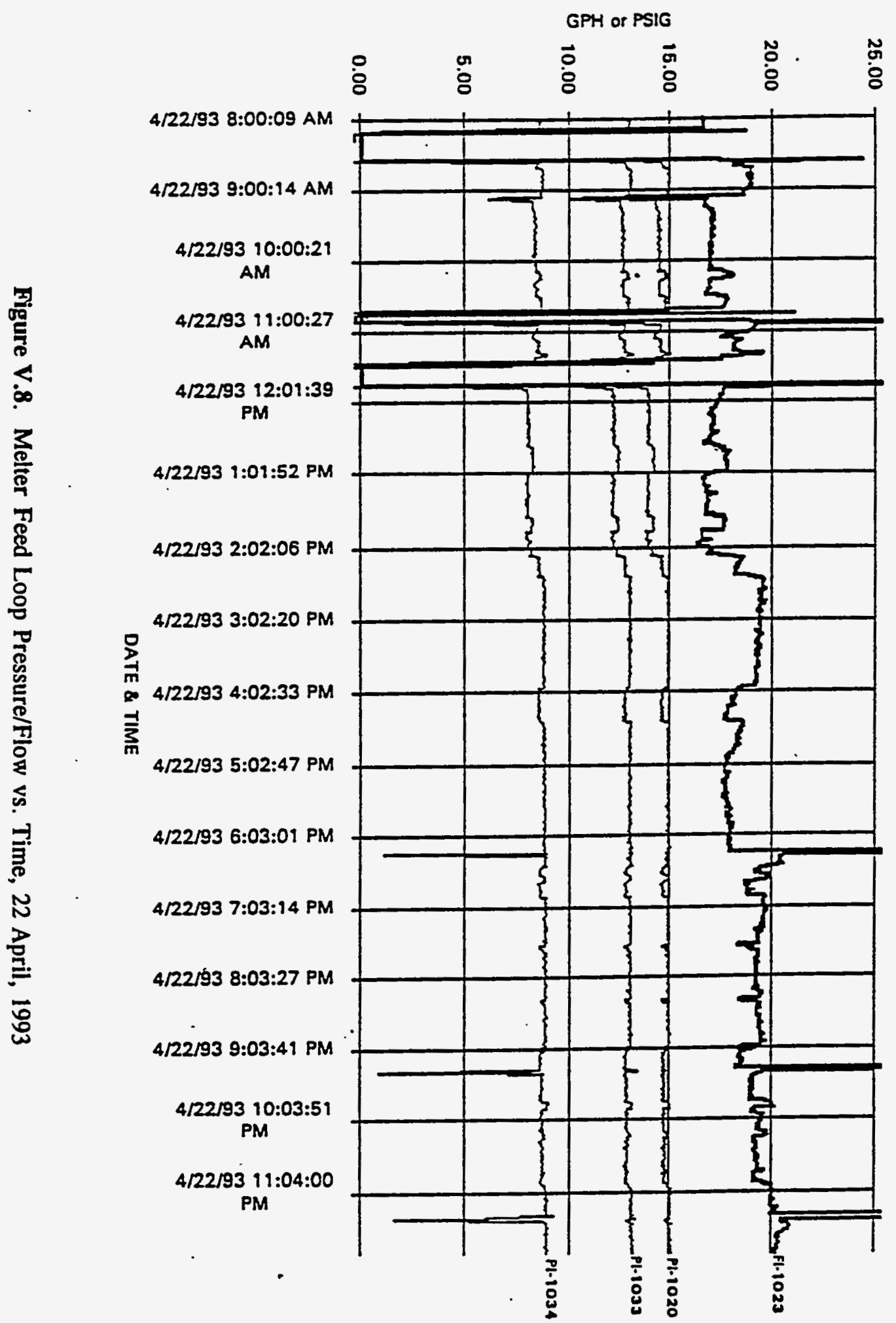


$6 \Lambda$

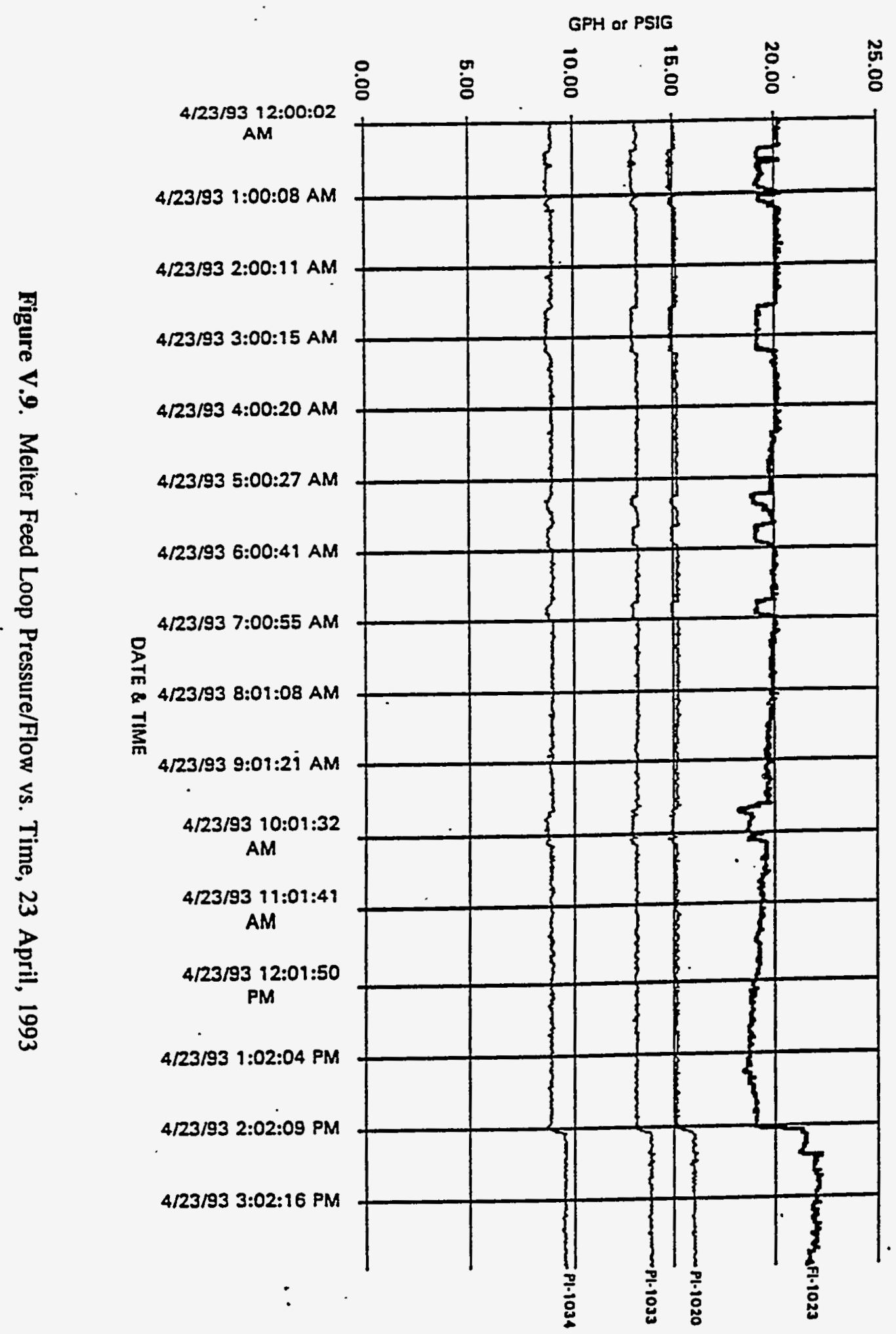


$0 I^{\circ} \Lambda$

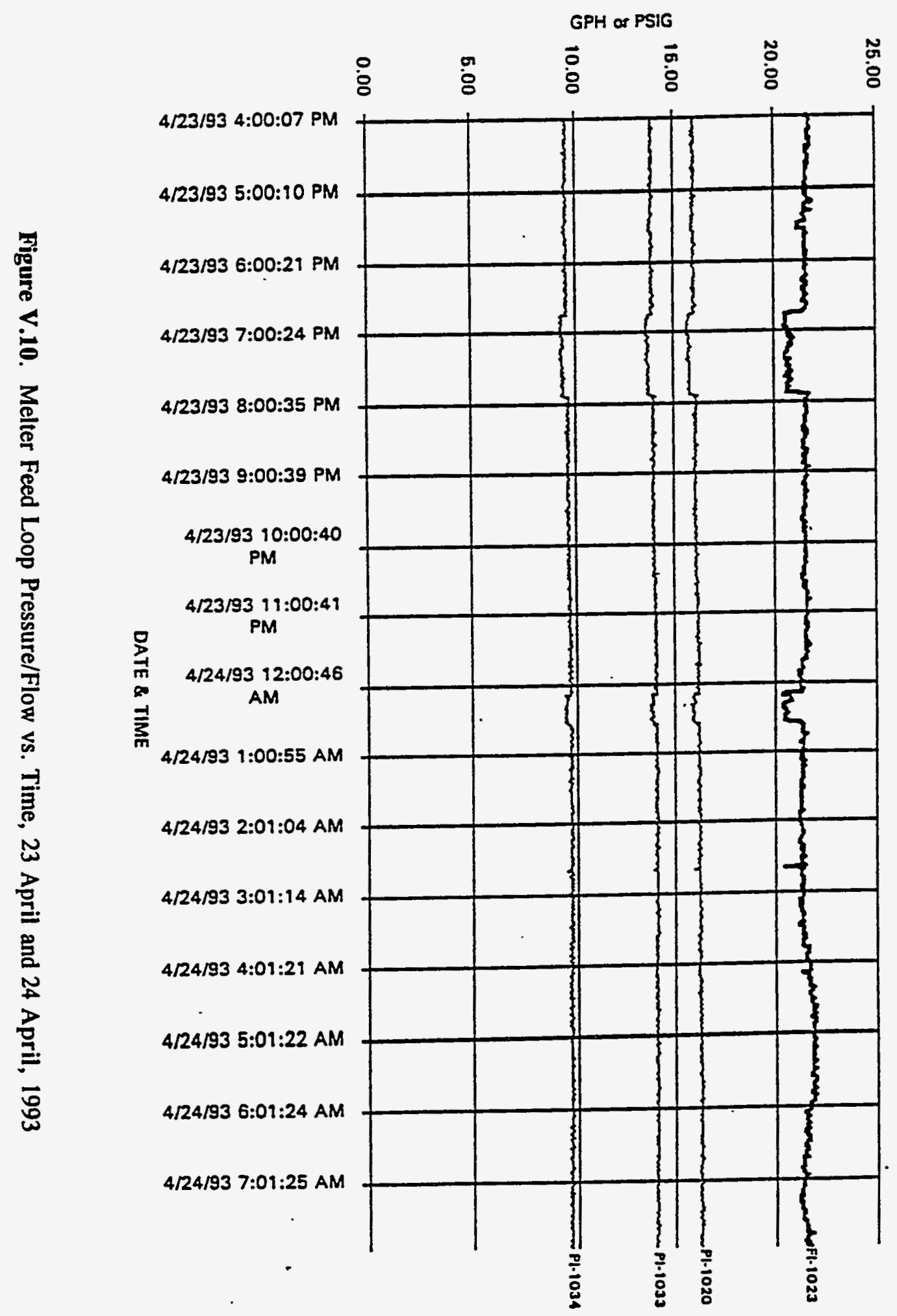


$I^{\circ} \Lambda$

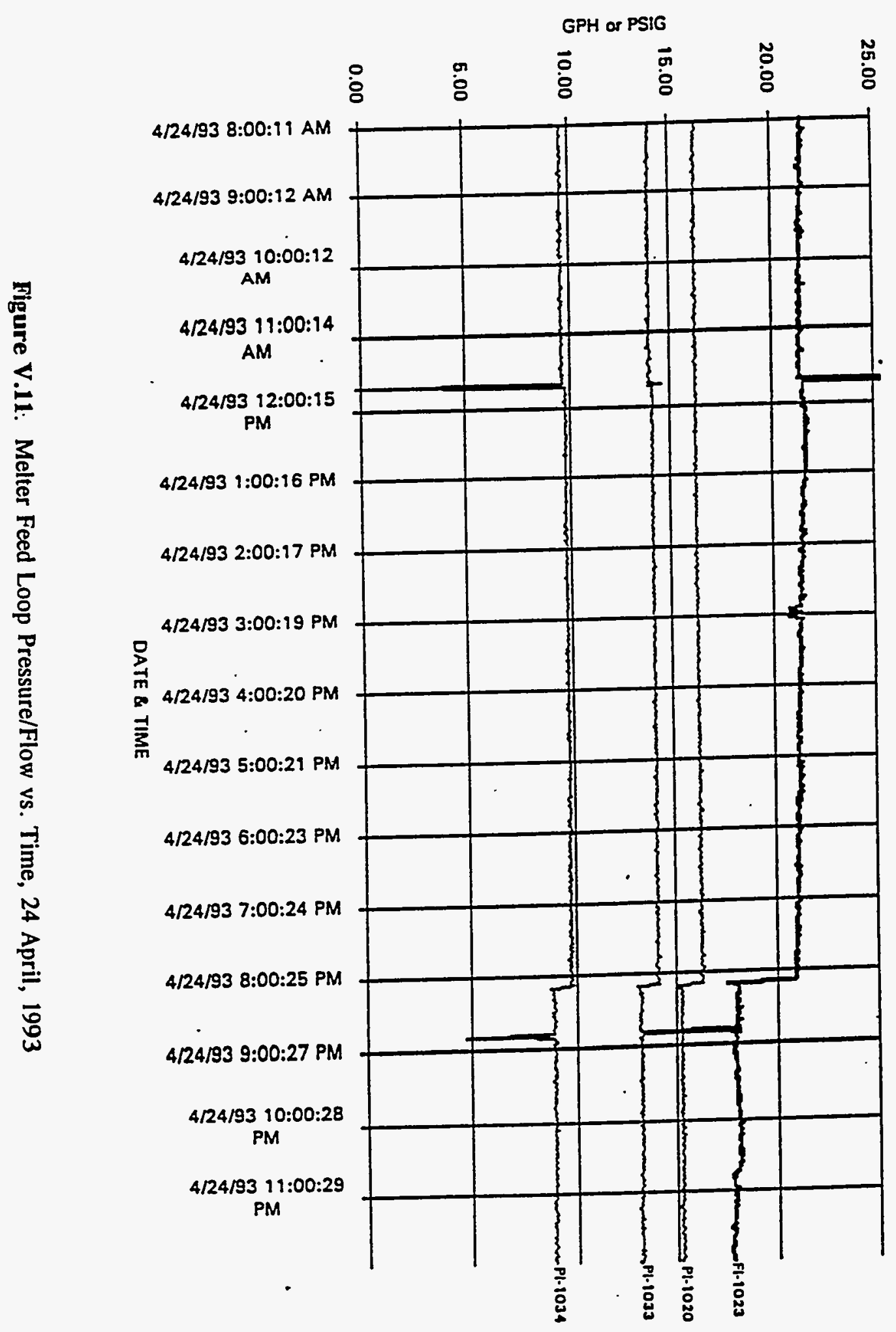




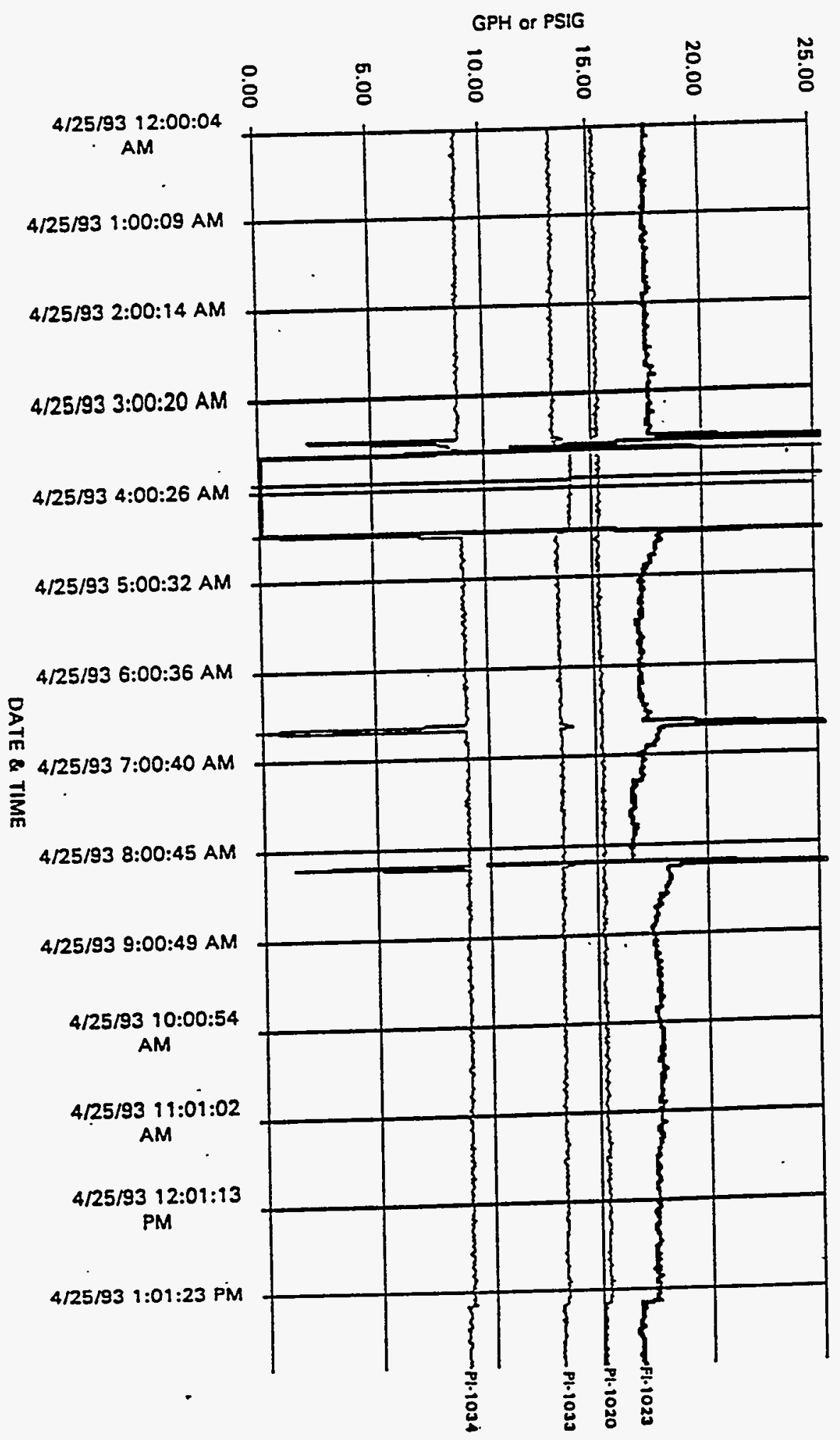


$\varepsilon I^{*} \Lambda$

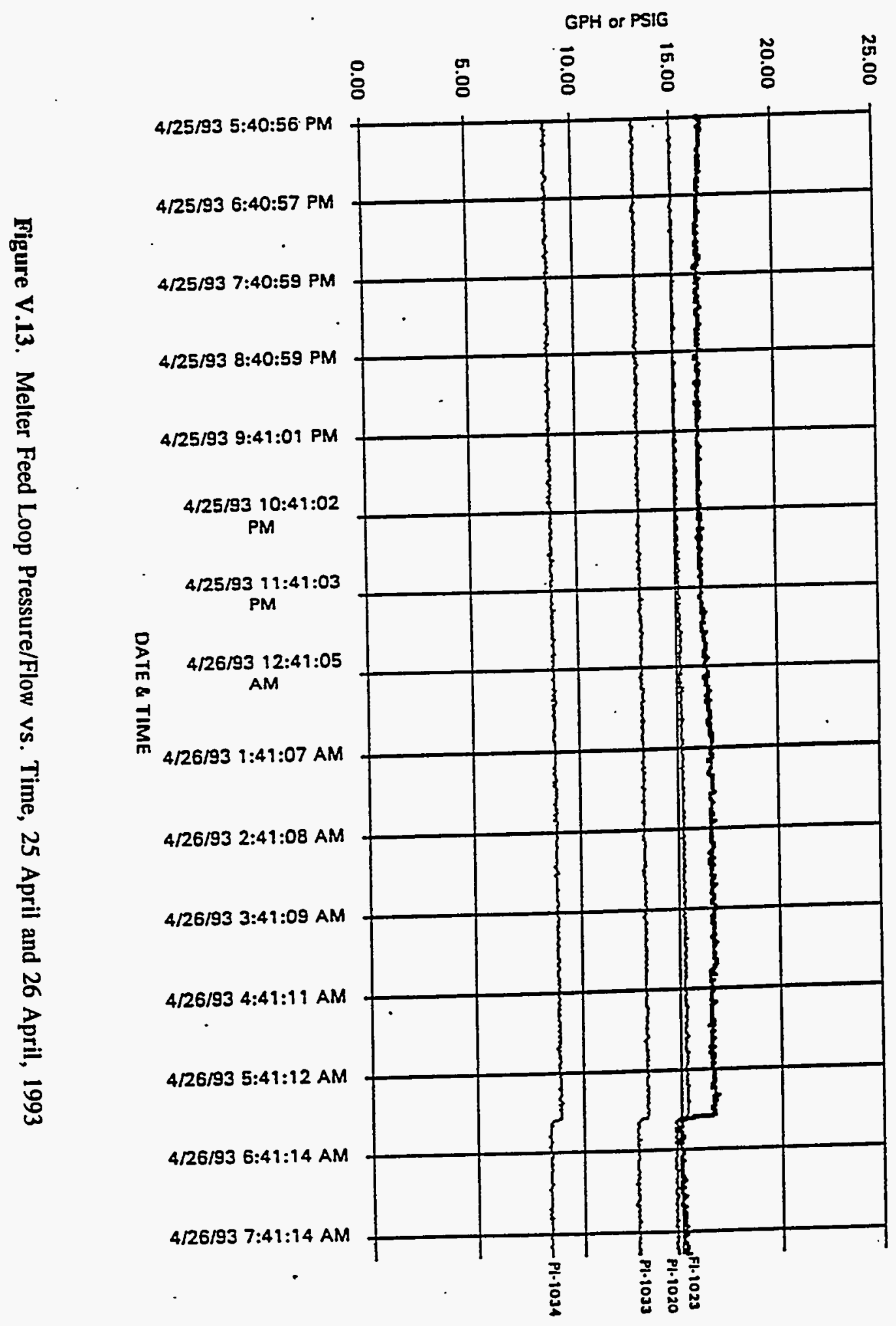




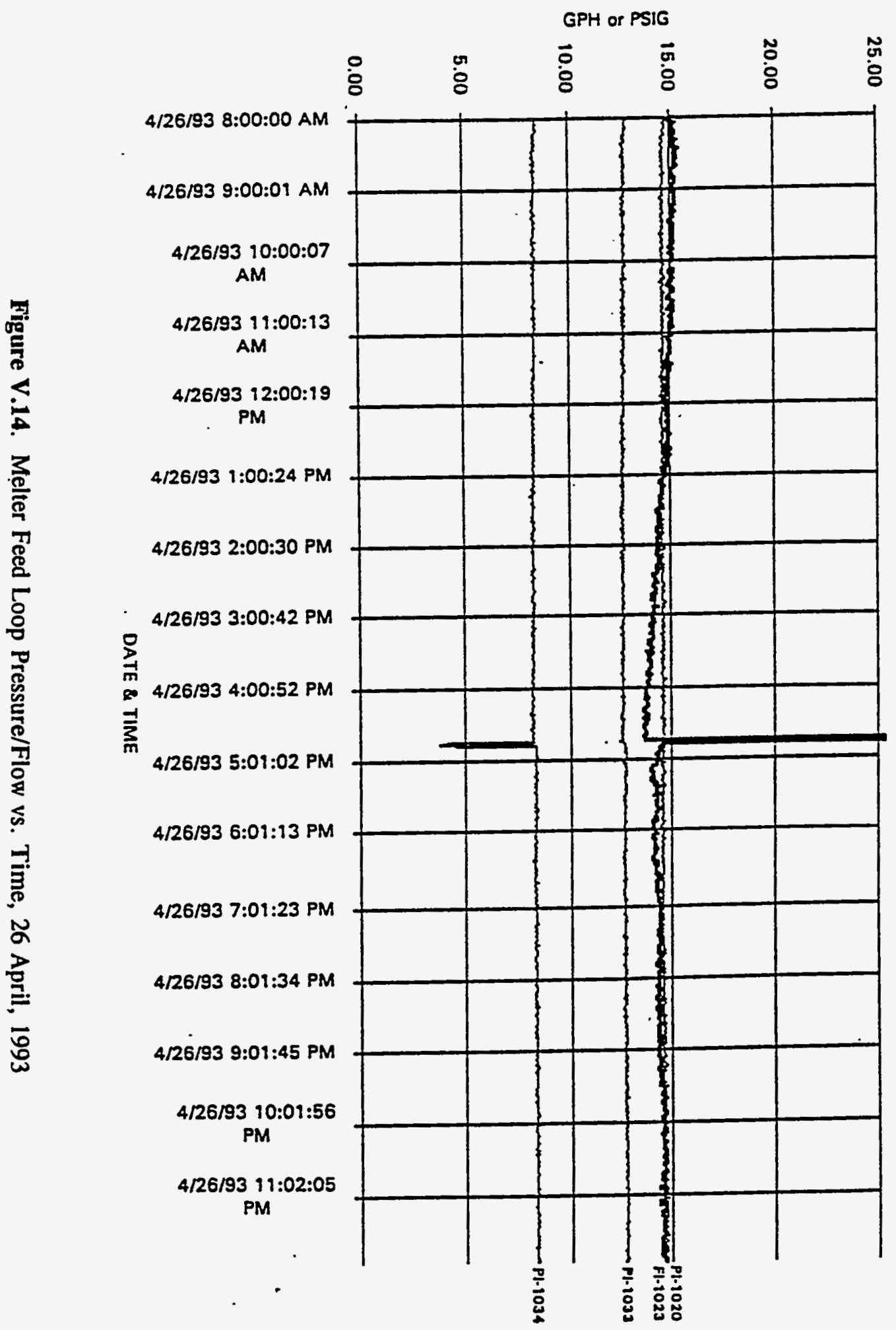


$\mathrm{SI}^{*} \Lambda$

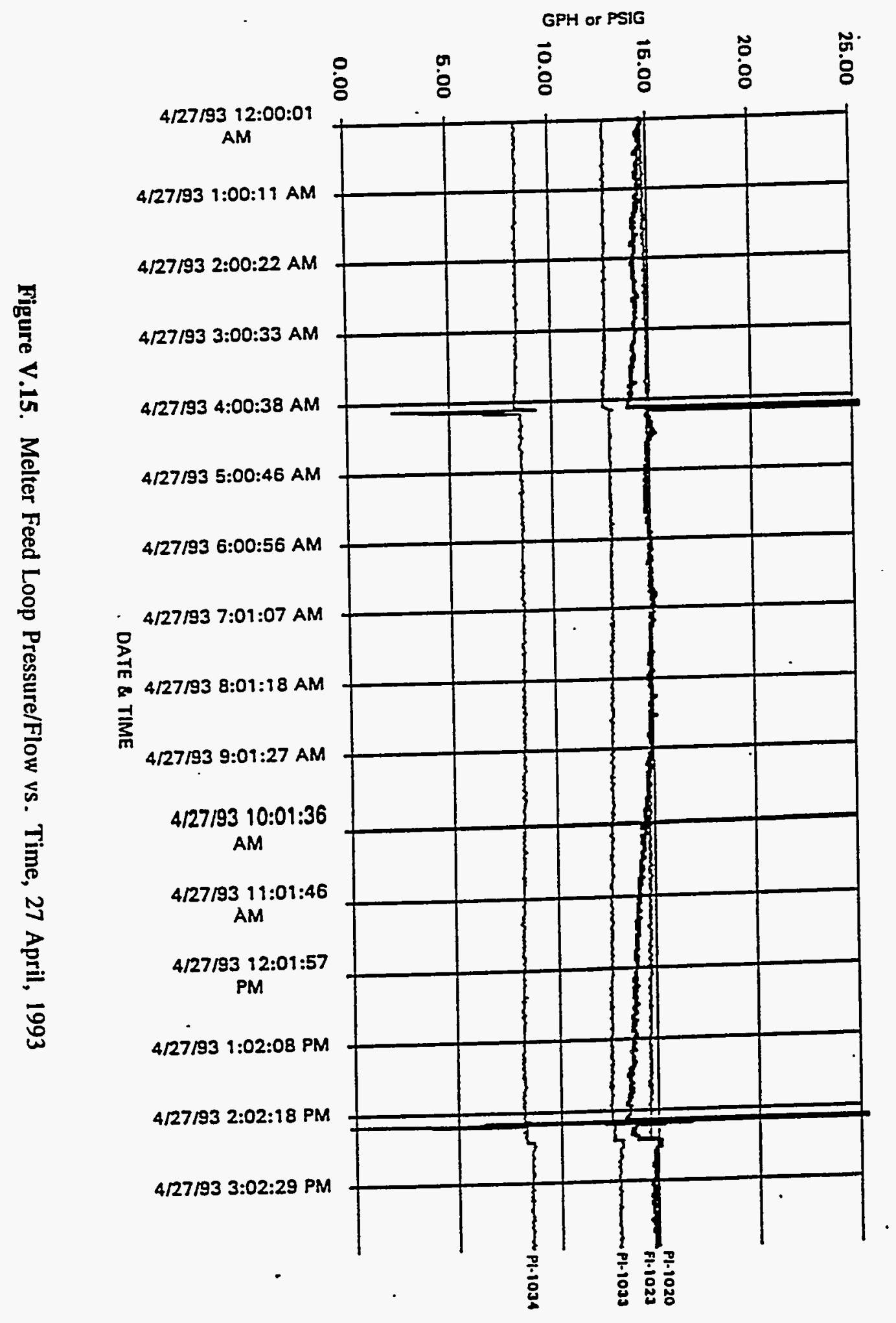




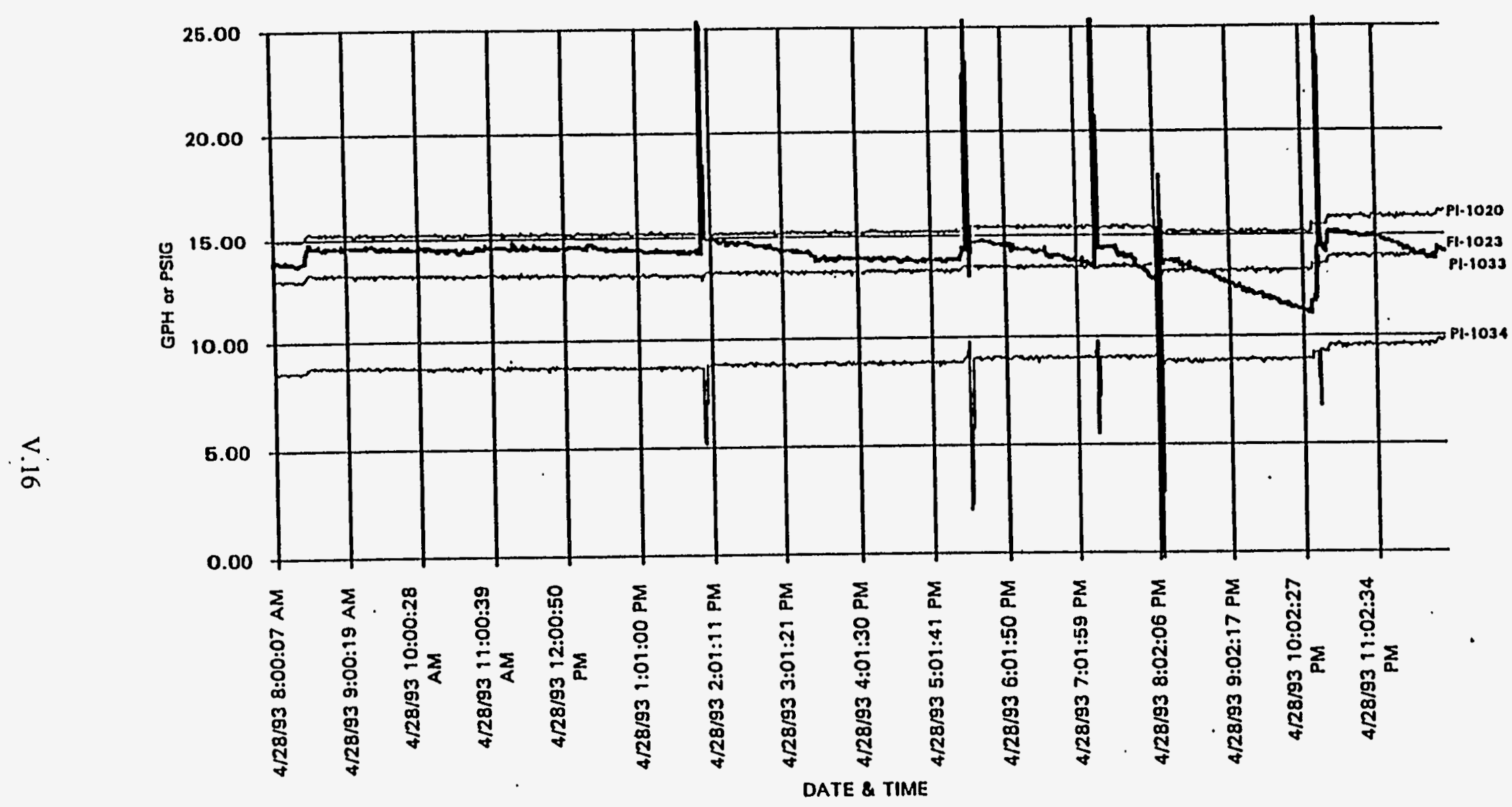

Figure V.16. Melter Feed Loop Pressure/Flow vs. Time, 28 April, 1993 
$\angle I^{\circ} \Lambda$

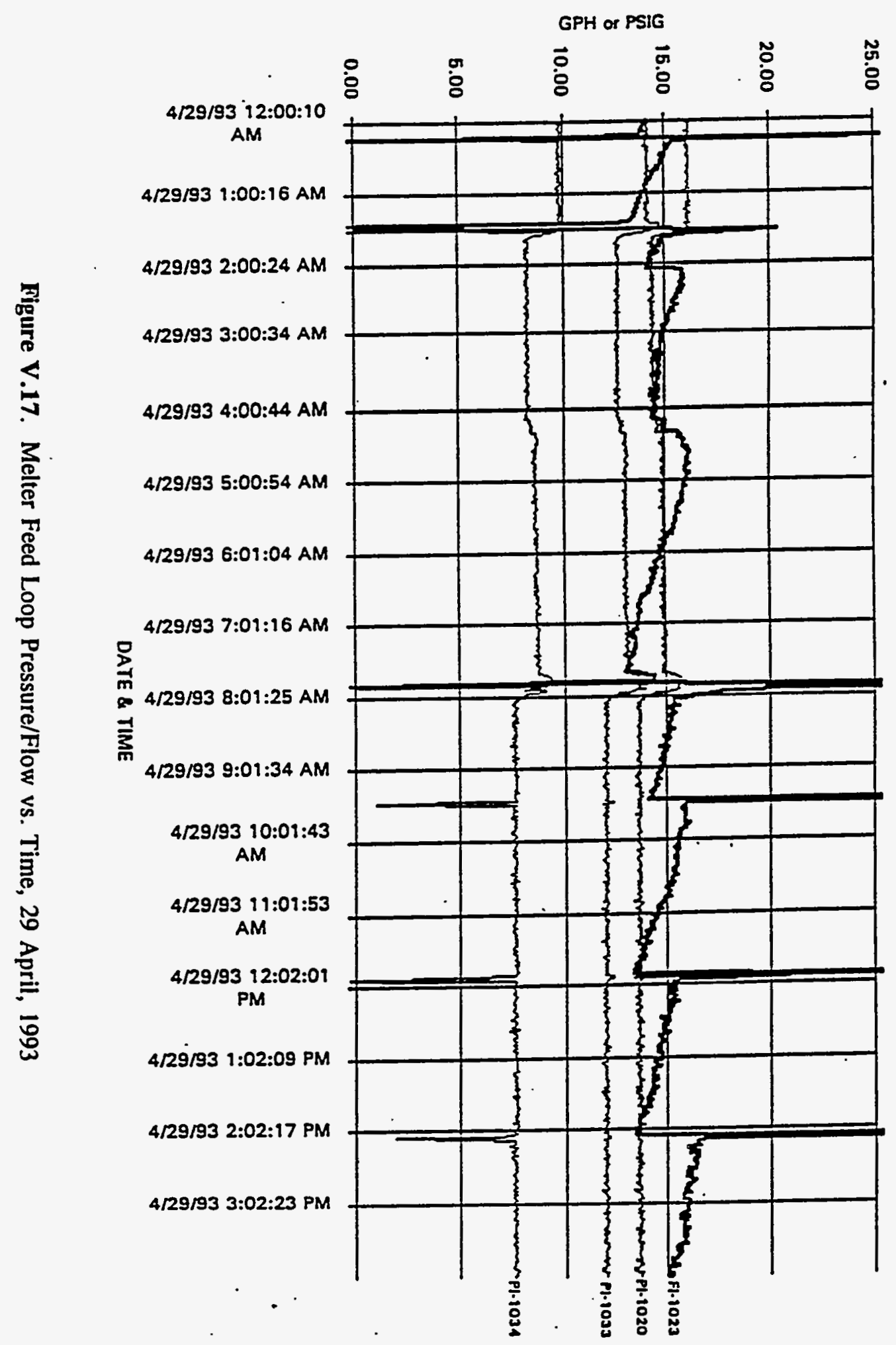




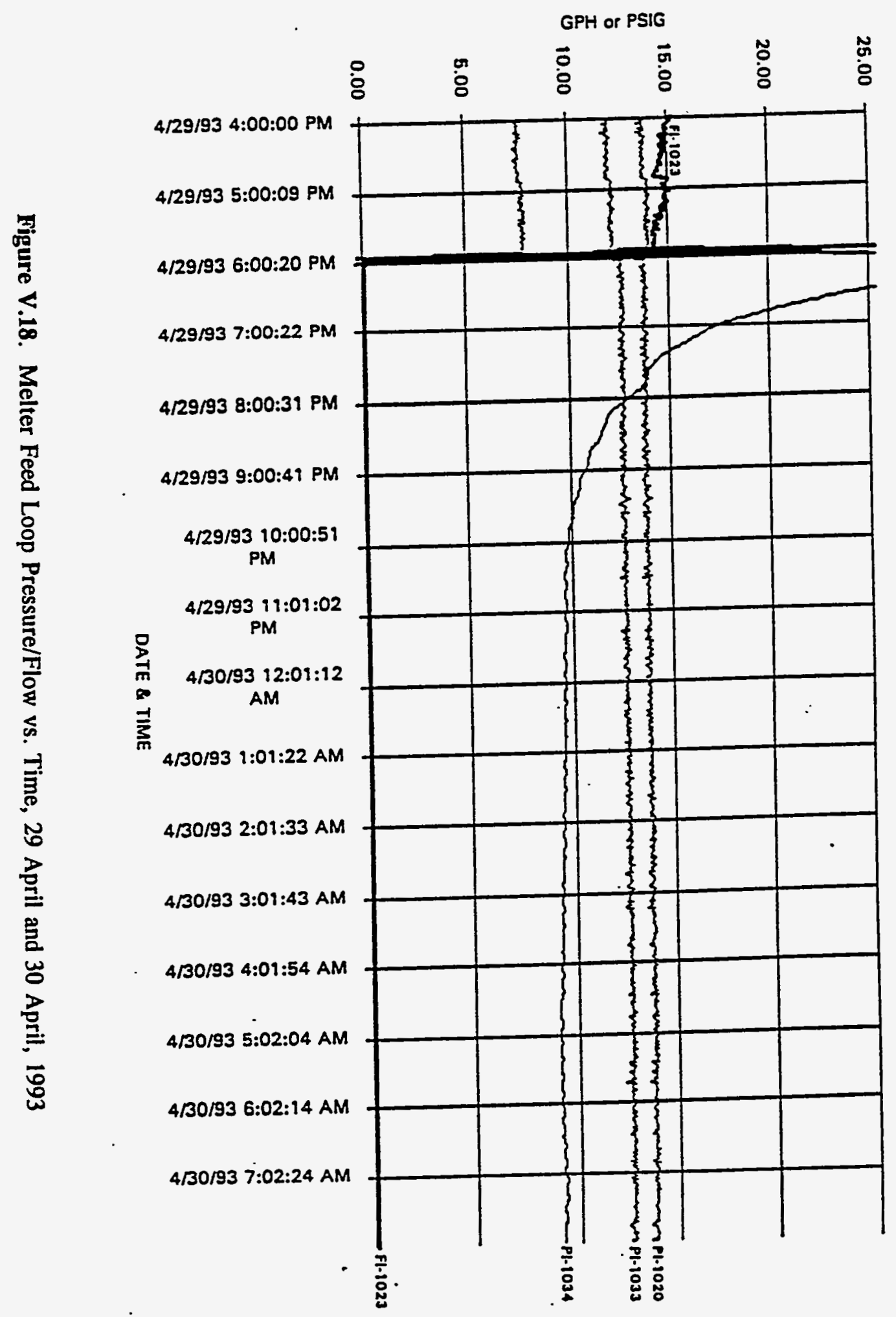


Appendix W

Pressure and Flow Run Data Plots on Melter Feed Recycle Loop 


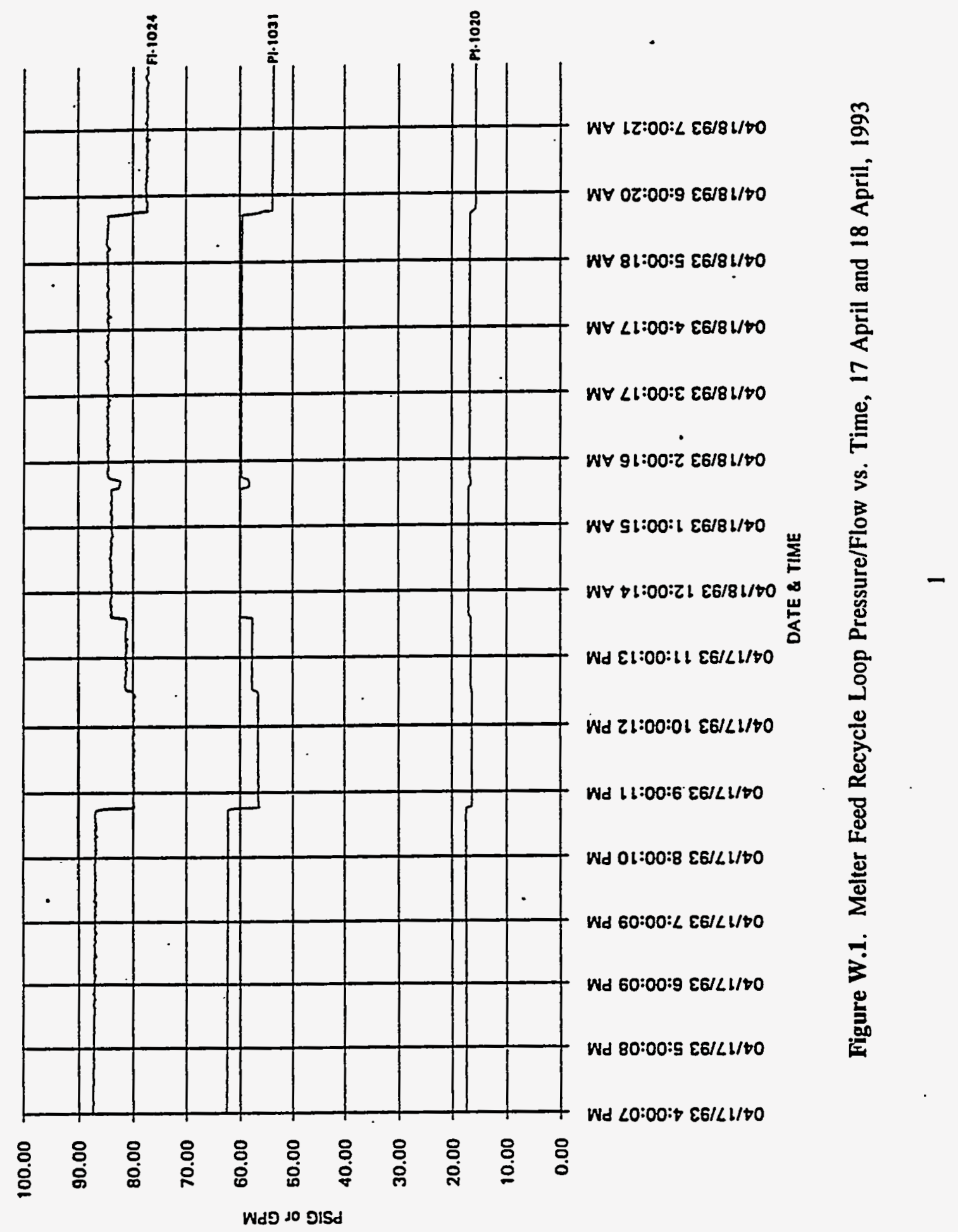

W.1 


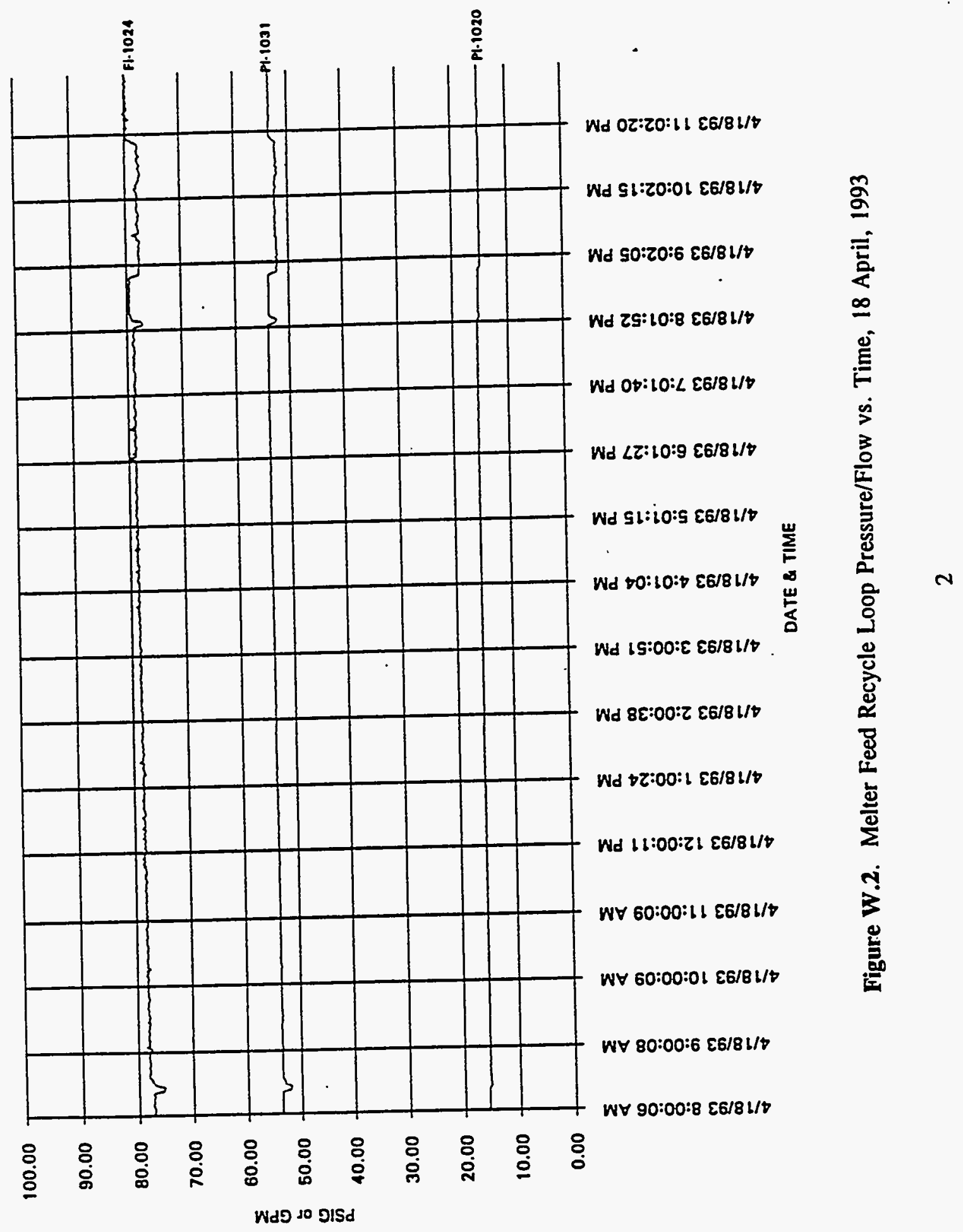


$\varepsilon M$

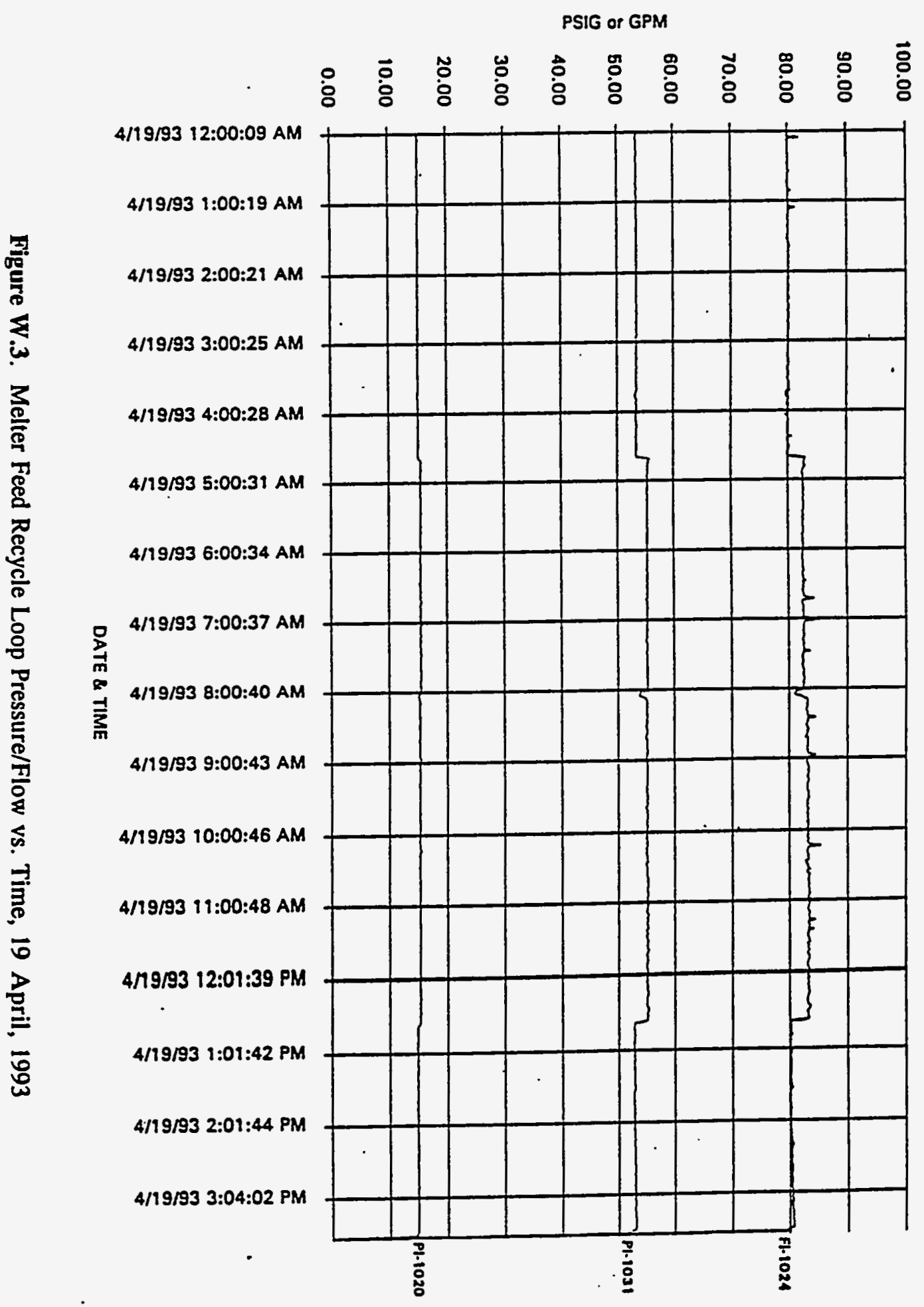




\section{$D M$}

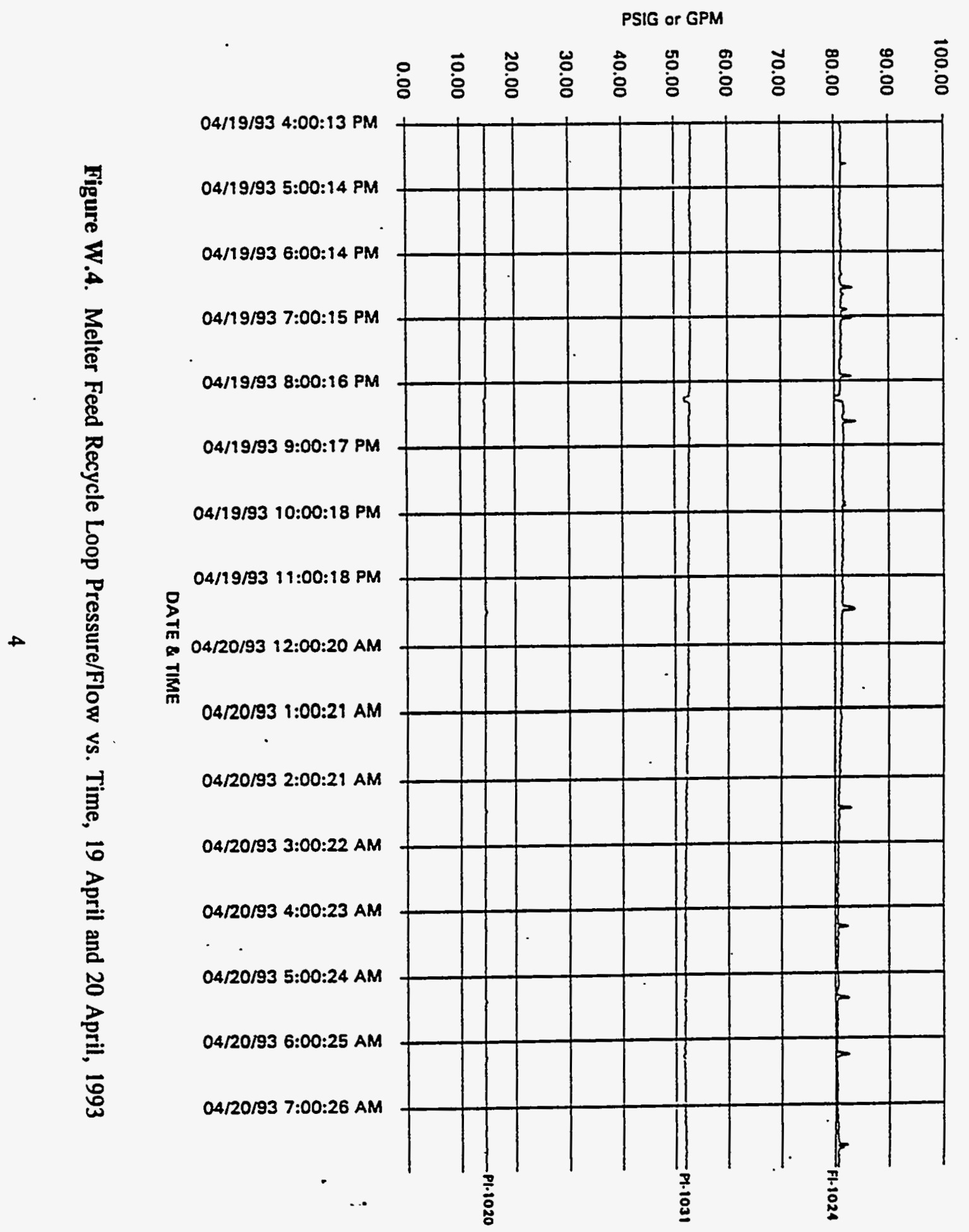




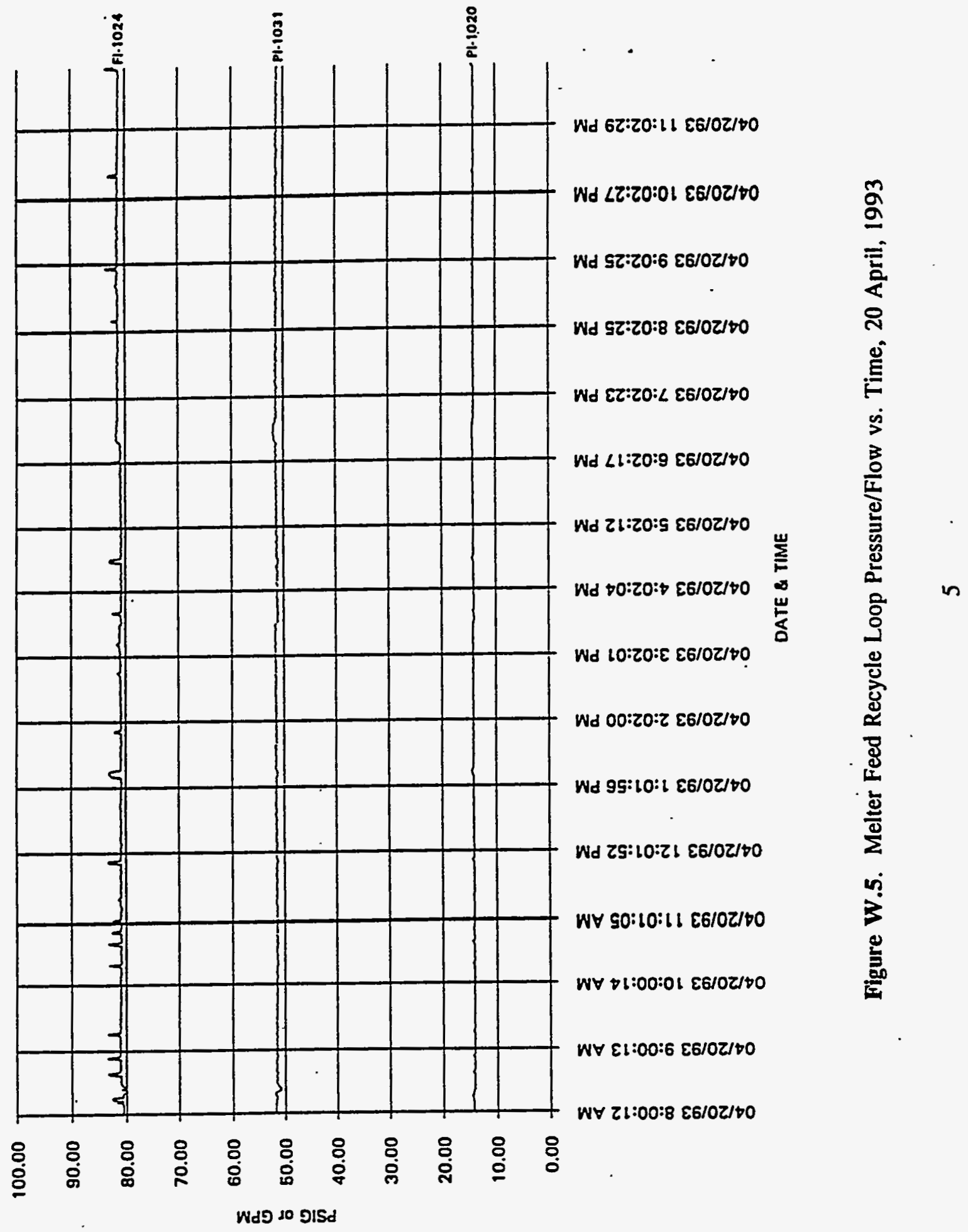

W. 5 


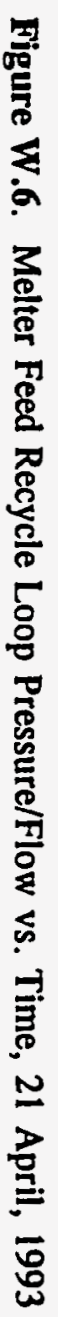

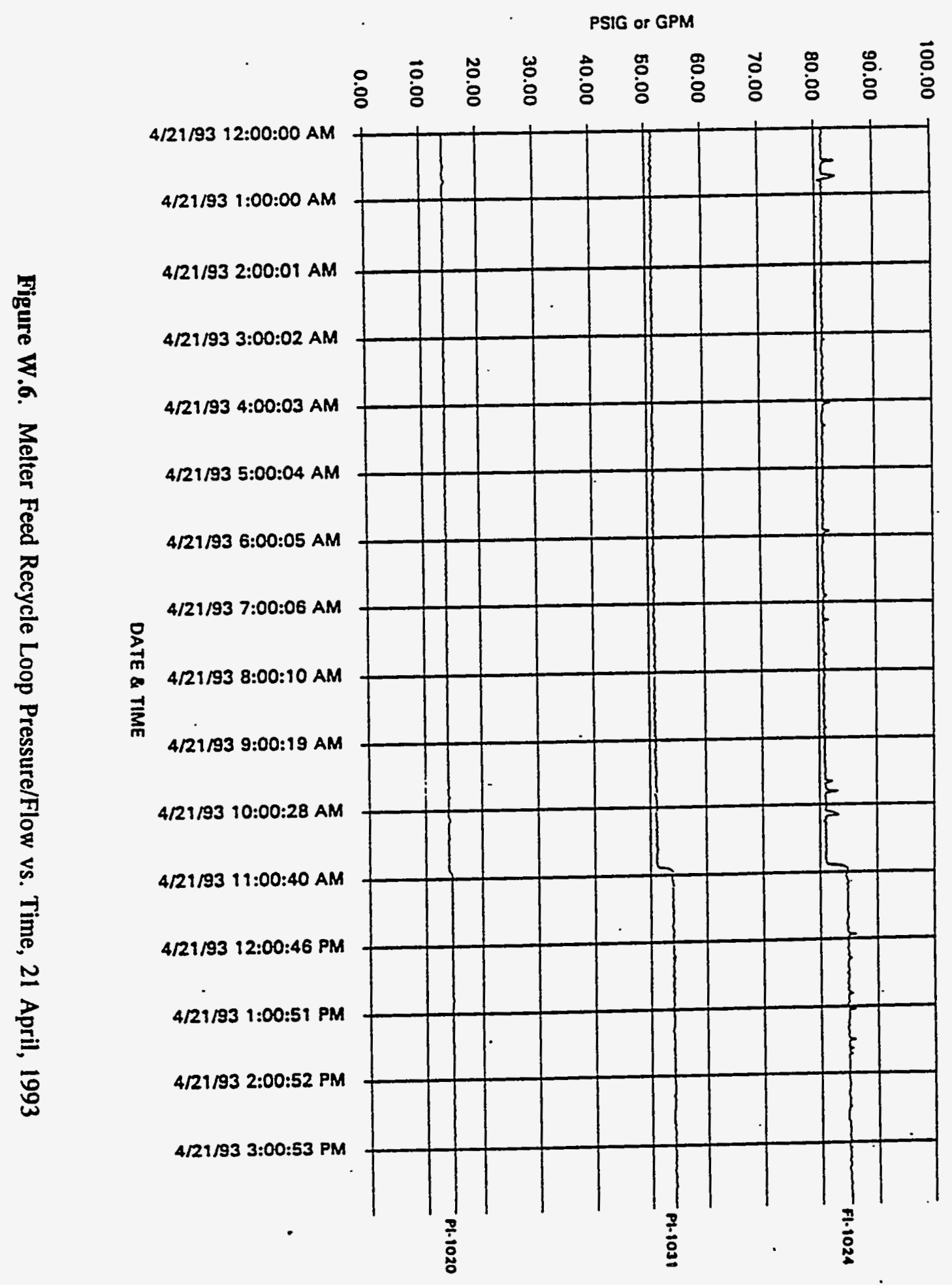




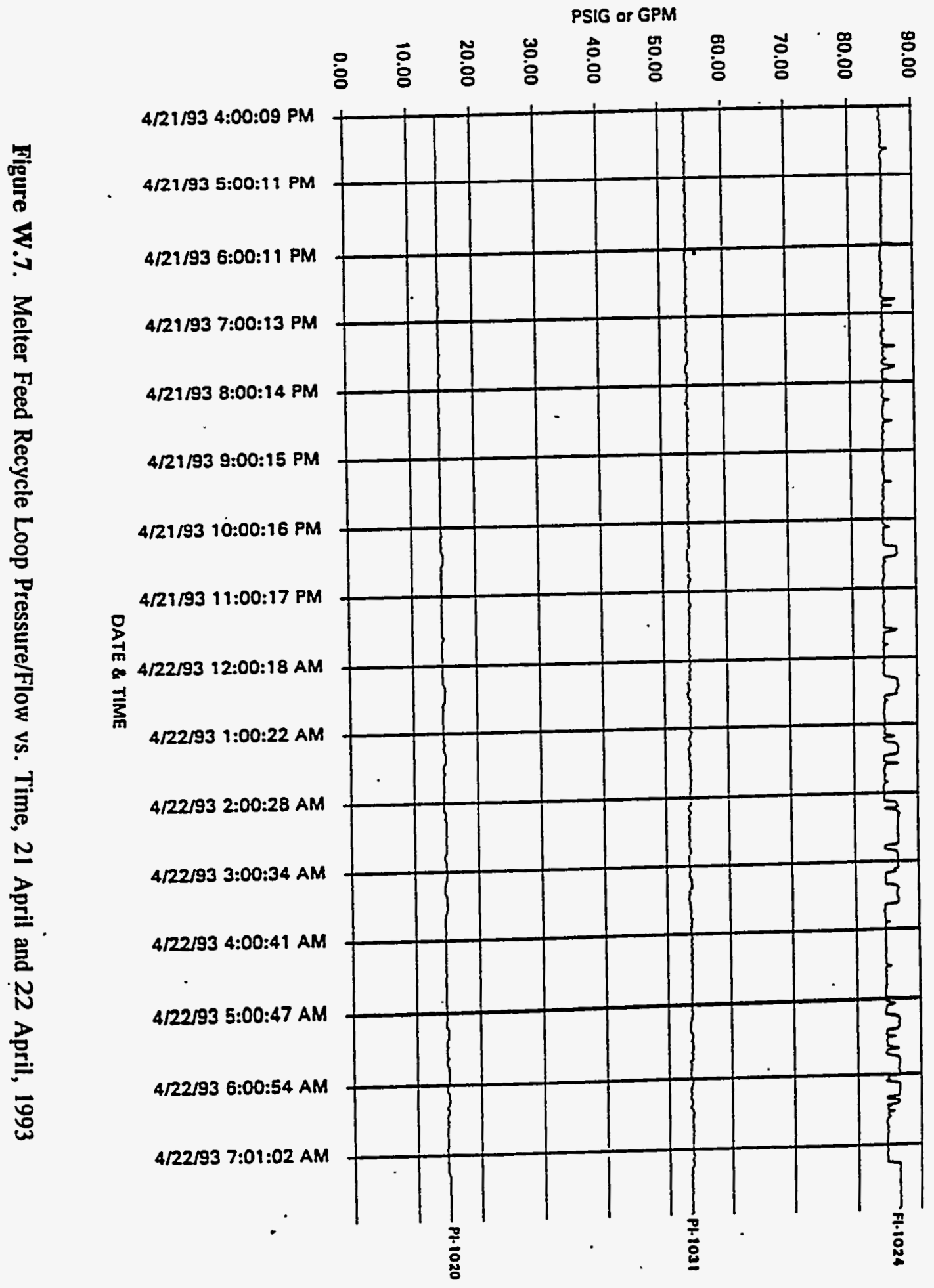


$8^{\circ} M$

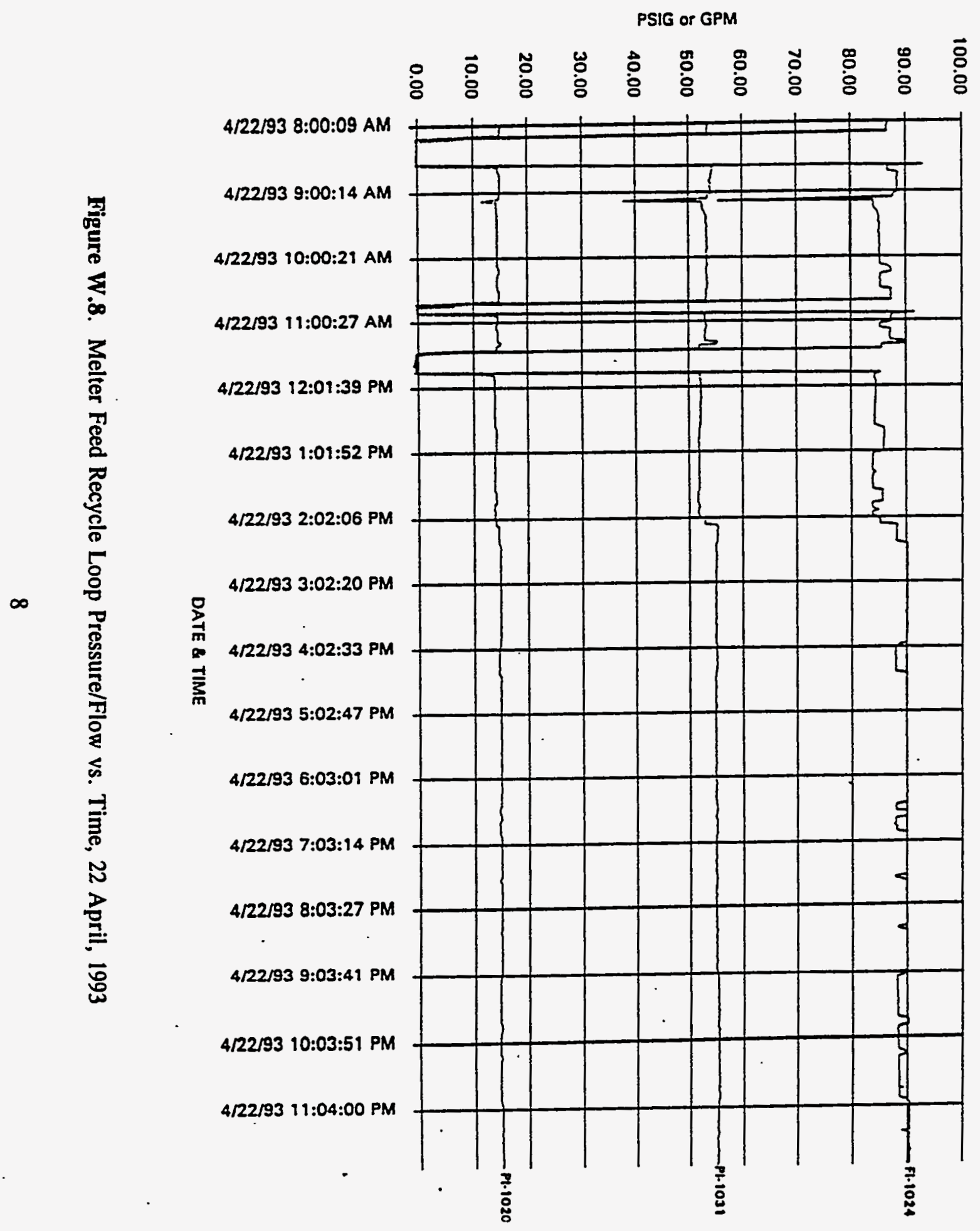




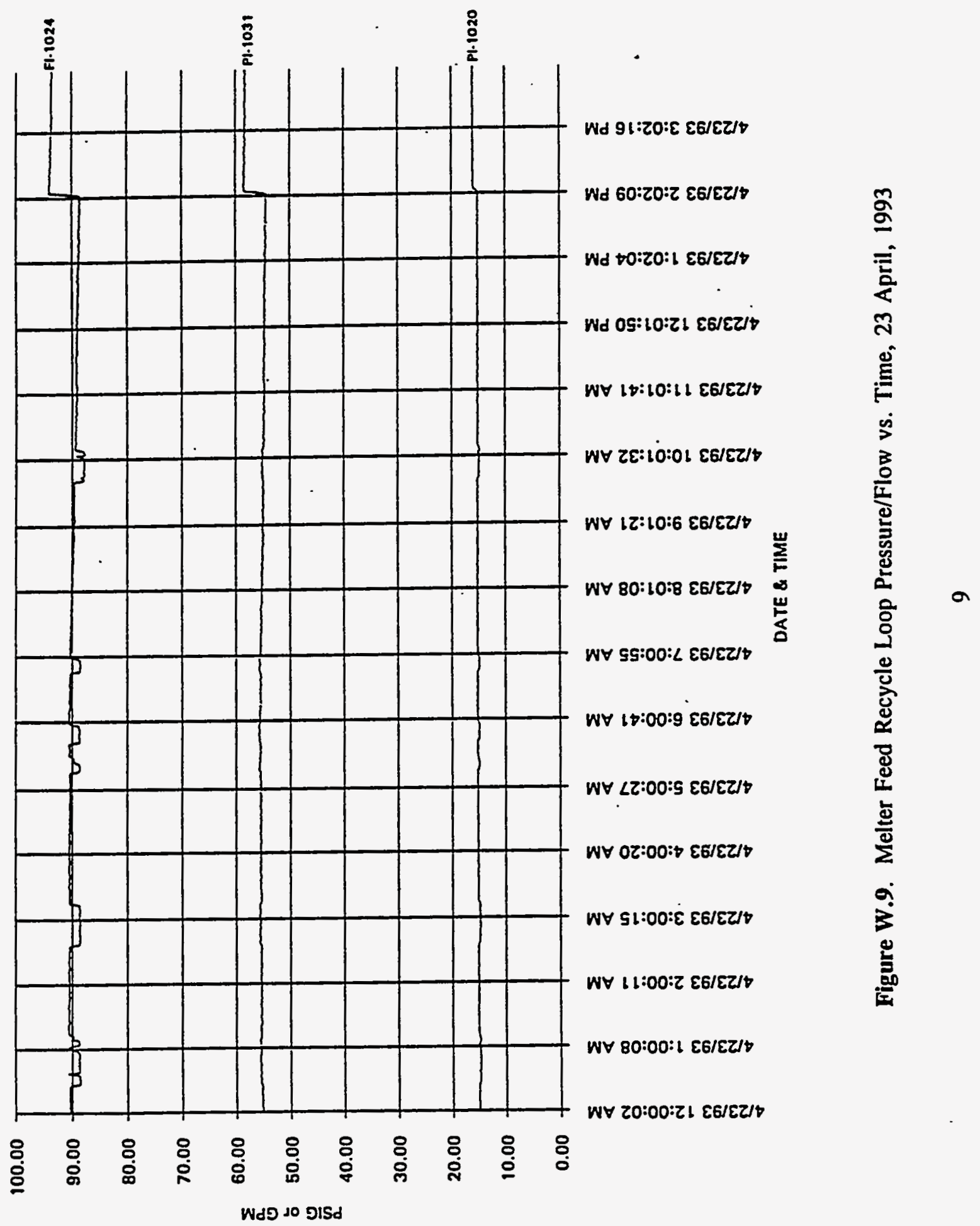

W.9 
$O I^{\circ} M$

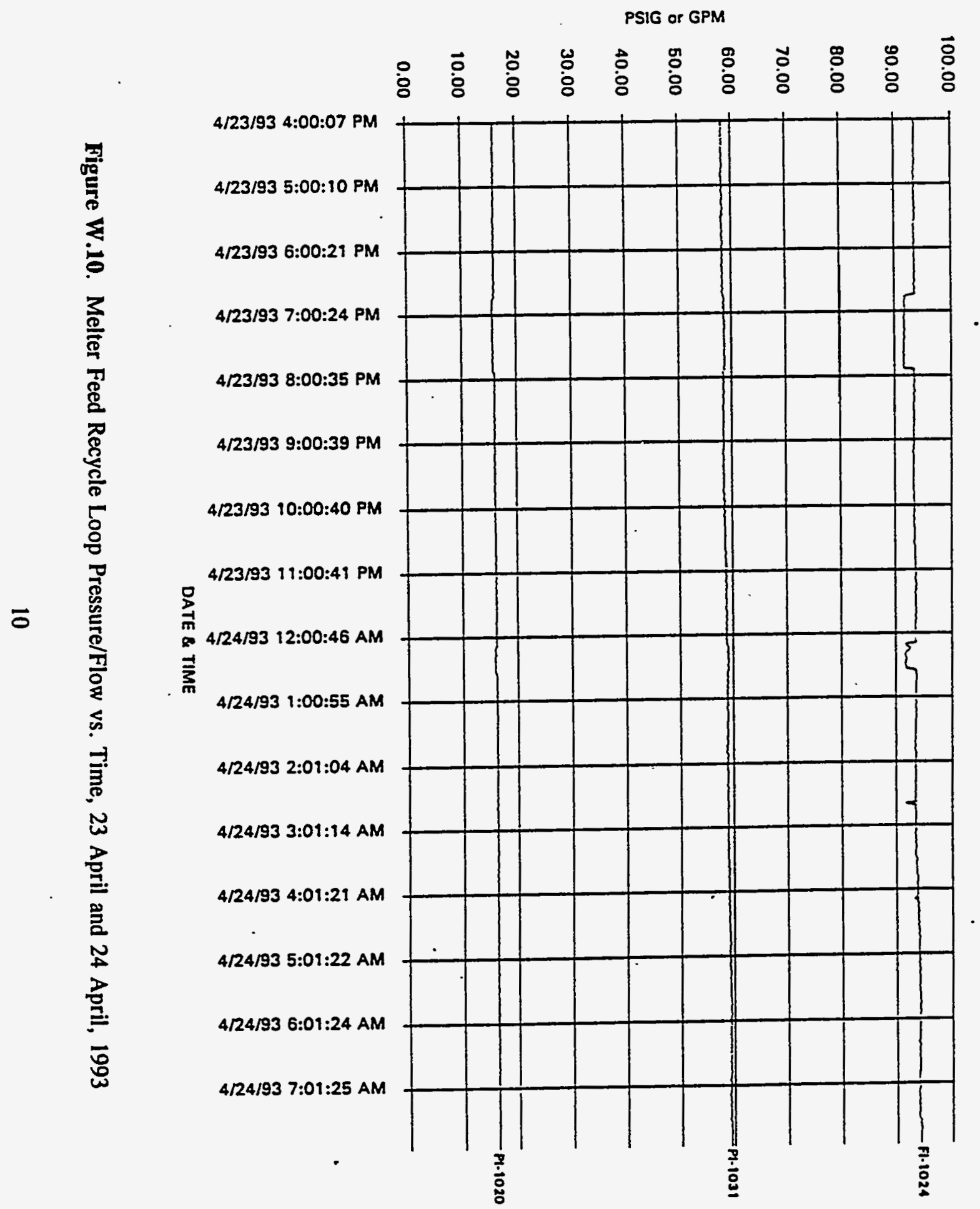




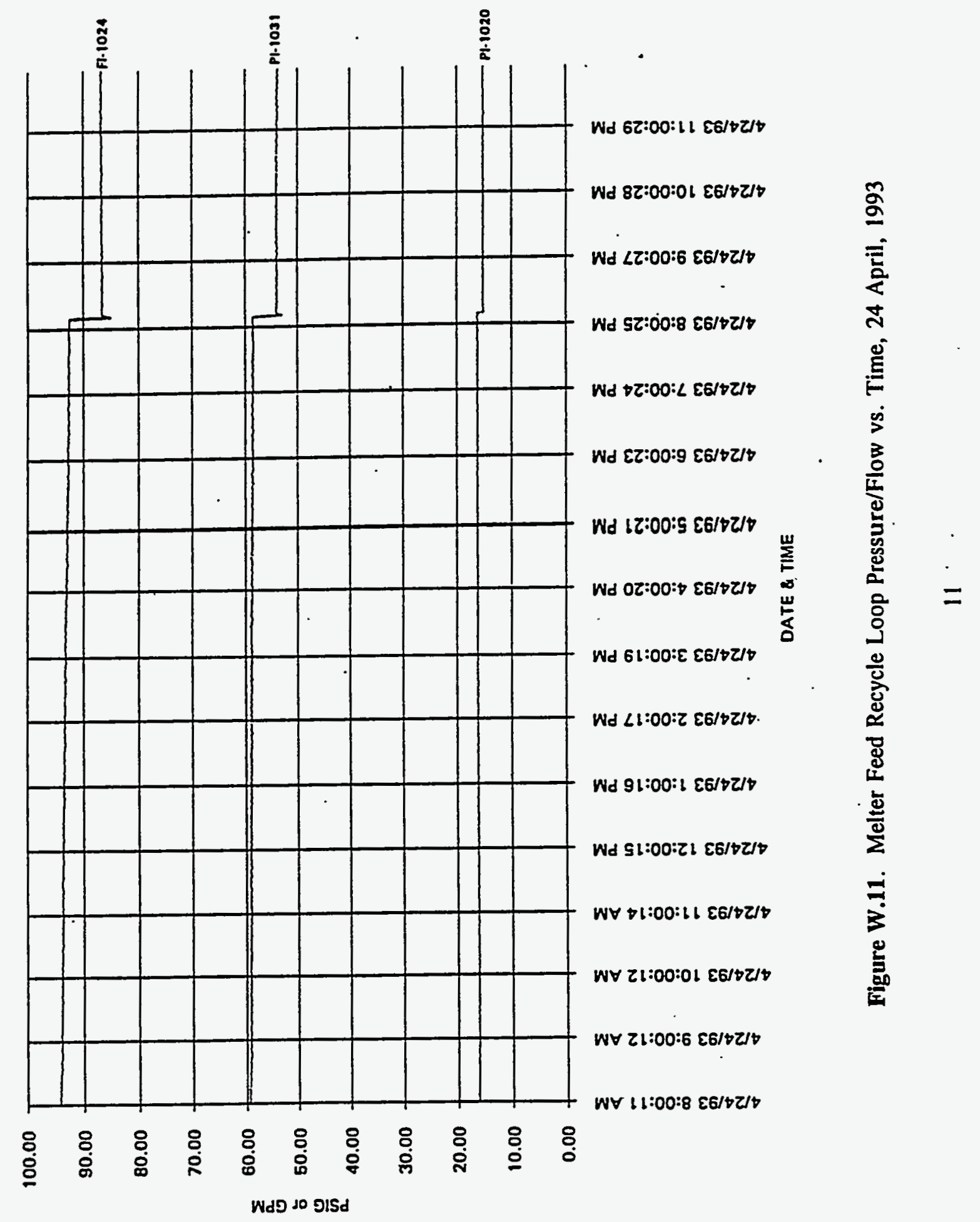

W.11 
$2 I^{\prime} M$

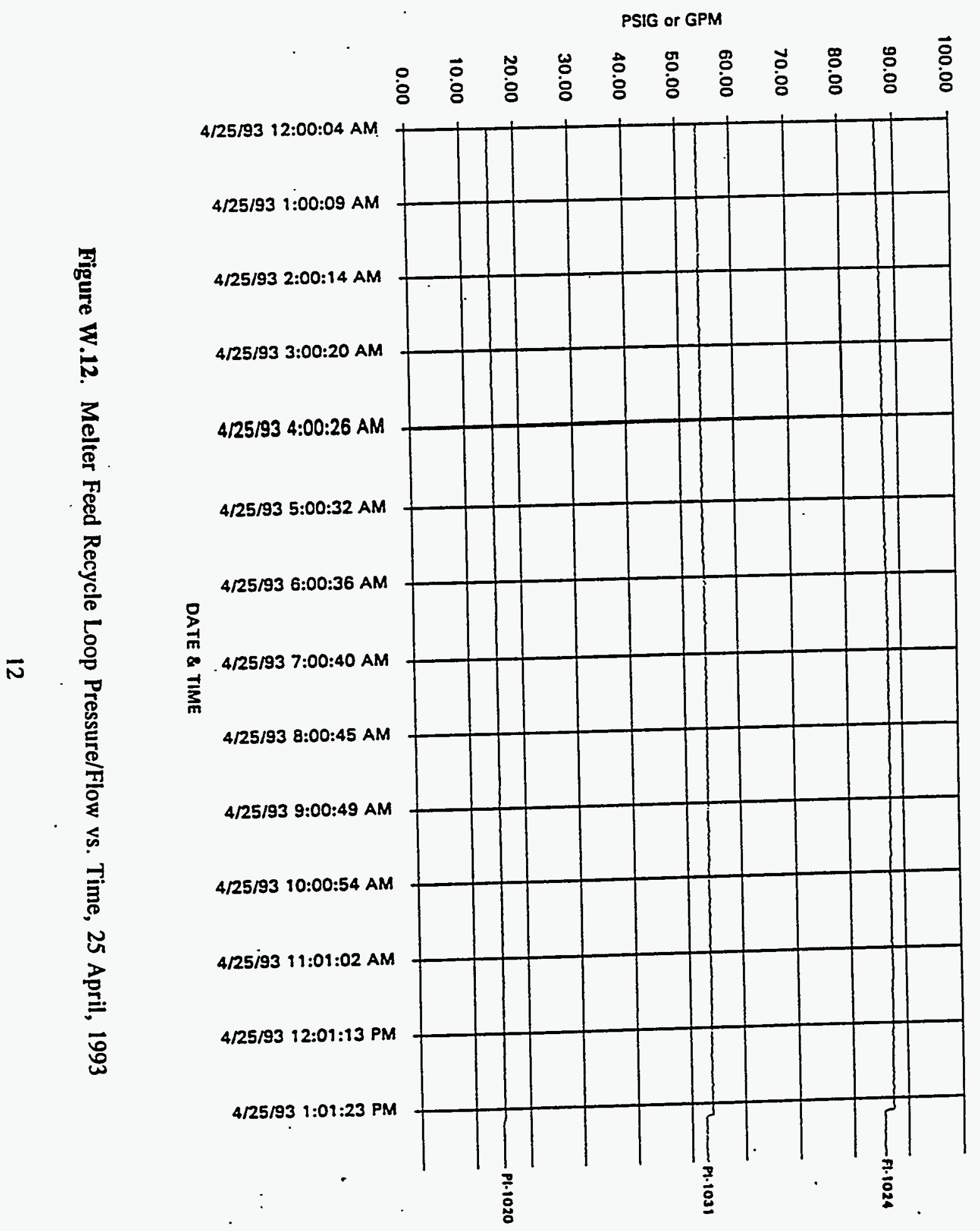


$E I^{\circ} M$

PSIG or GPM

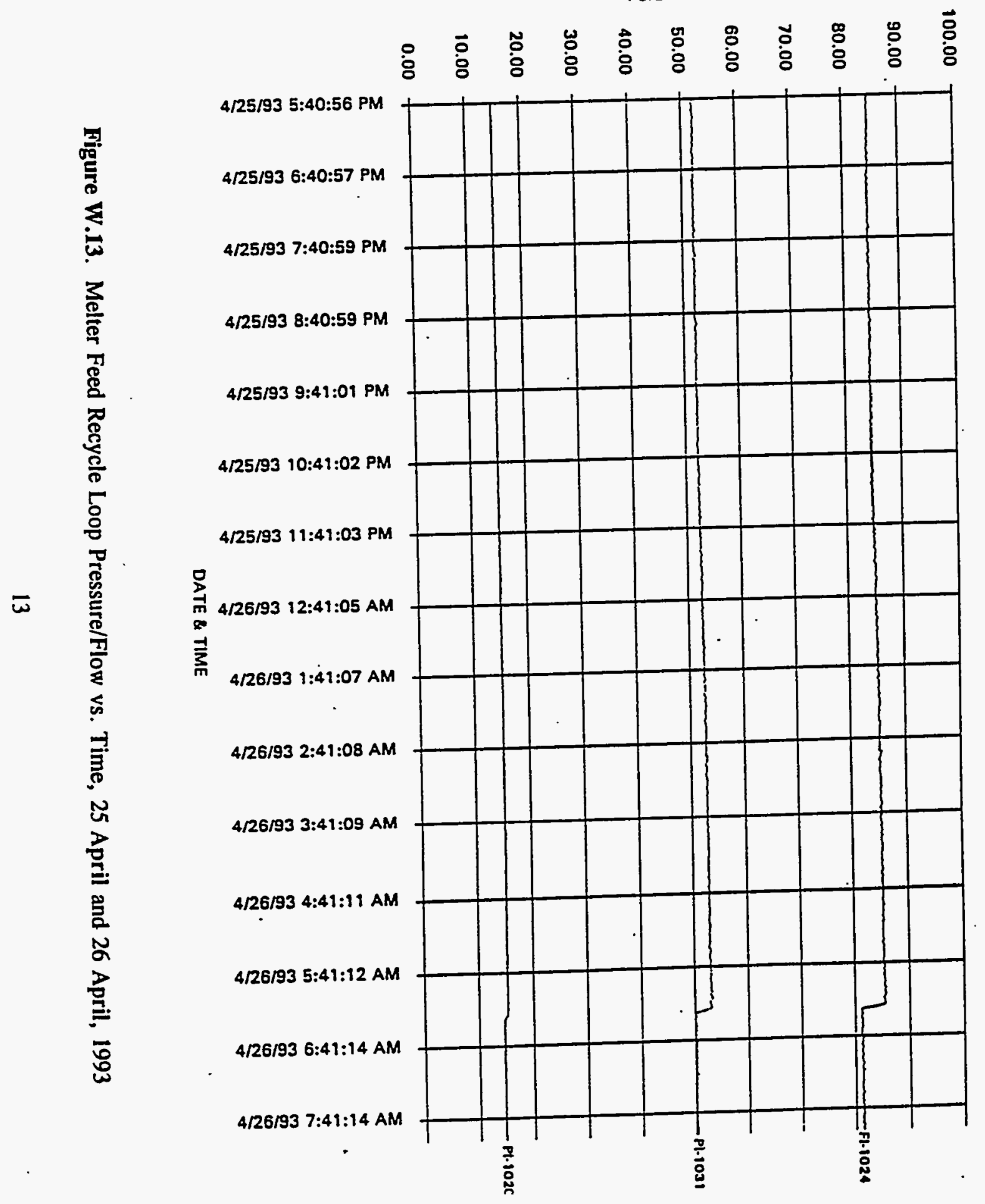


$\nabla I^{\circ} M$

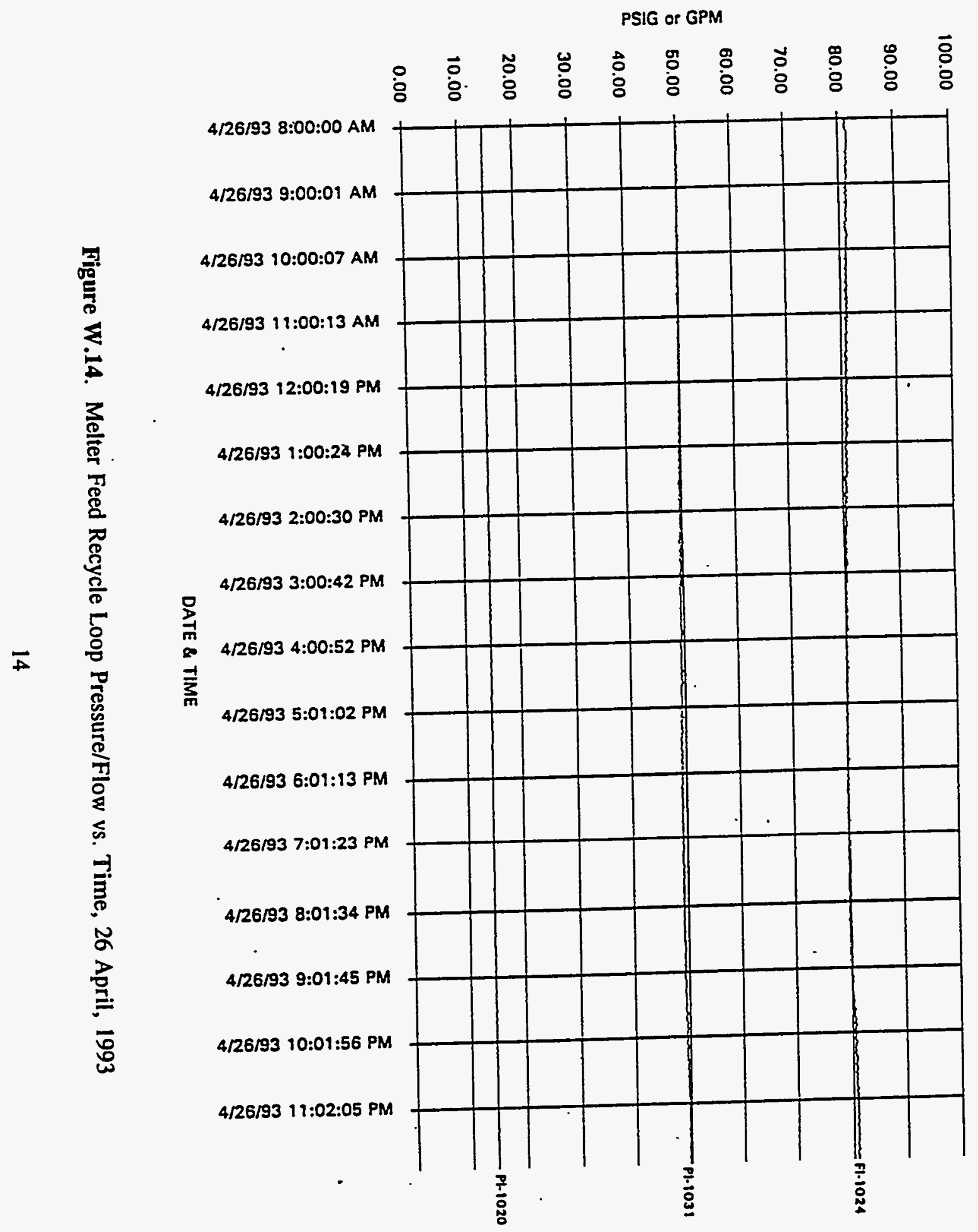




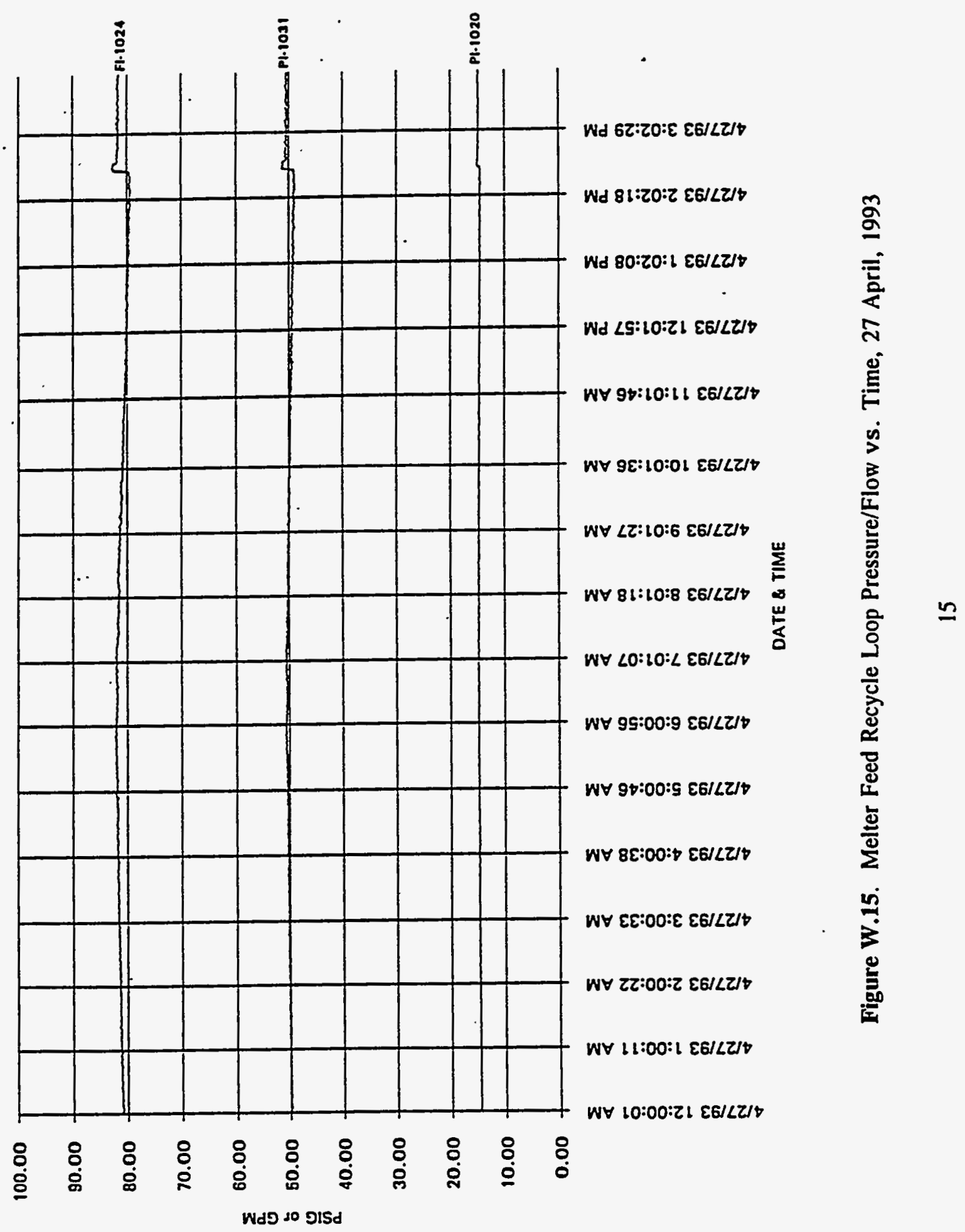

W.15 
$91^{\circ} \mathrm{A}$

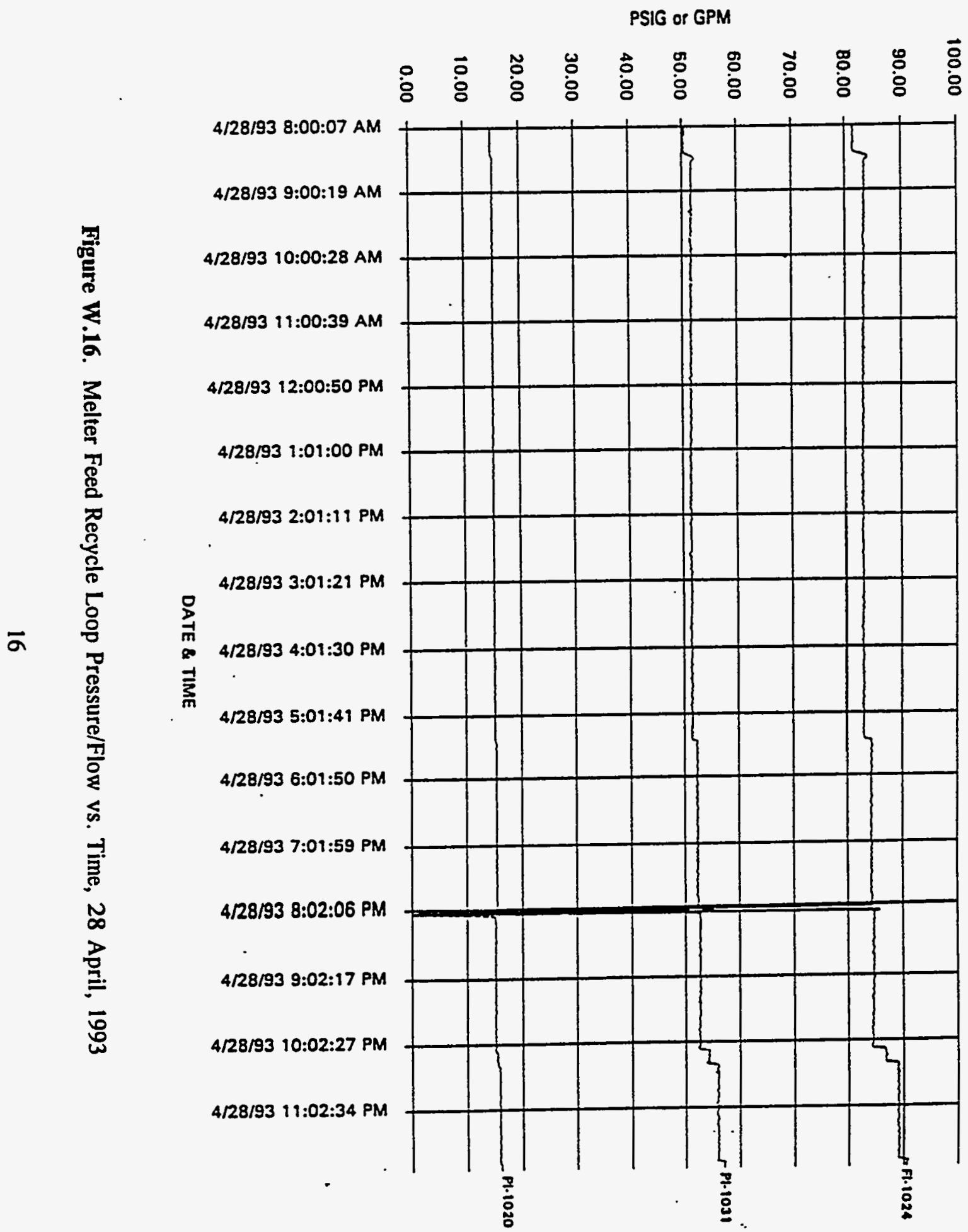


$\angle I^{\circ} M$

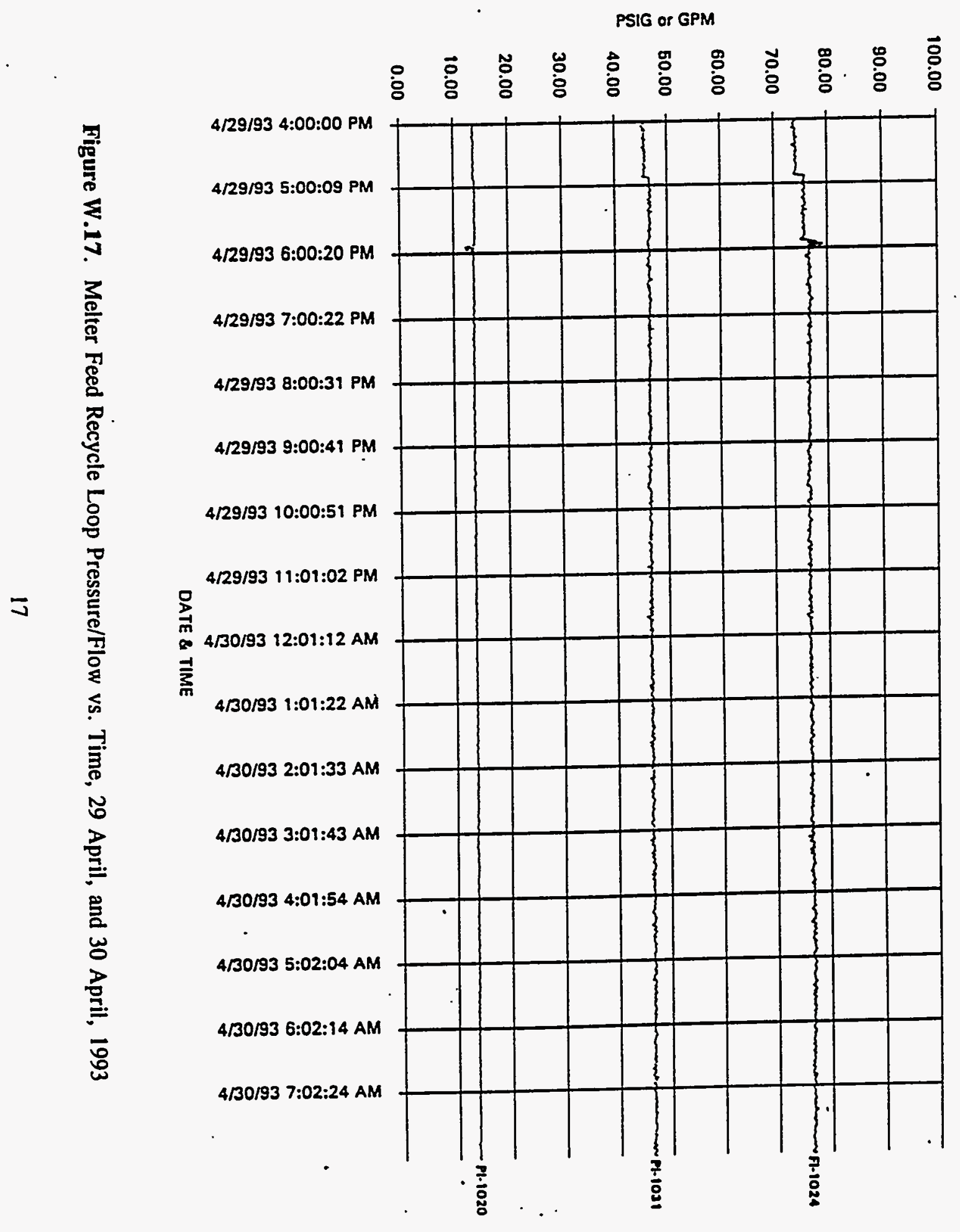




\section{Appendix X}

Summary of Log Book and Laboratory Record Book Entries 



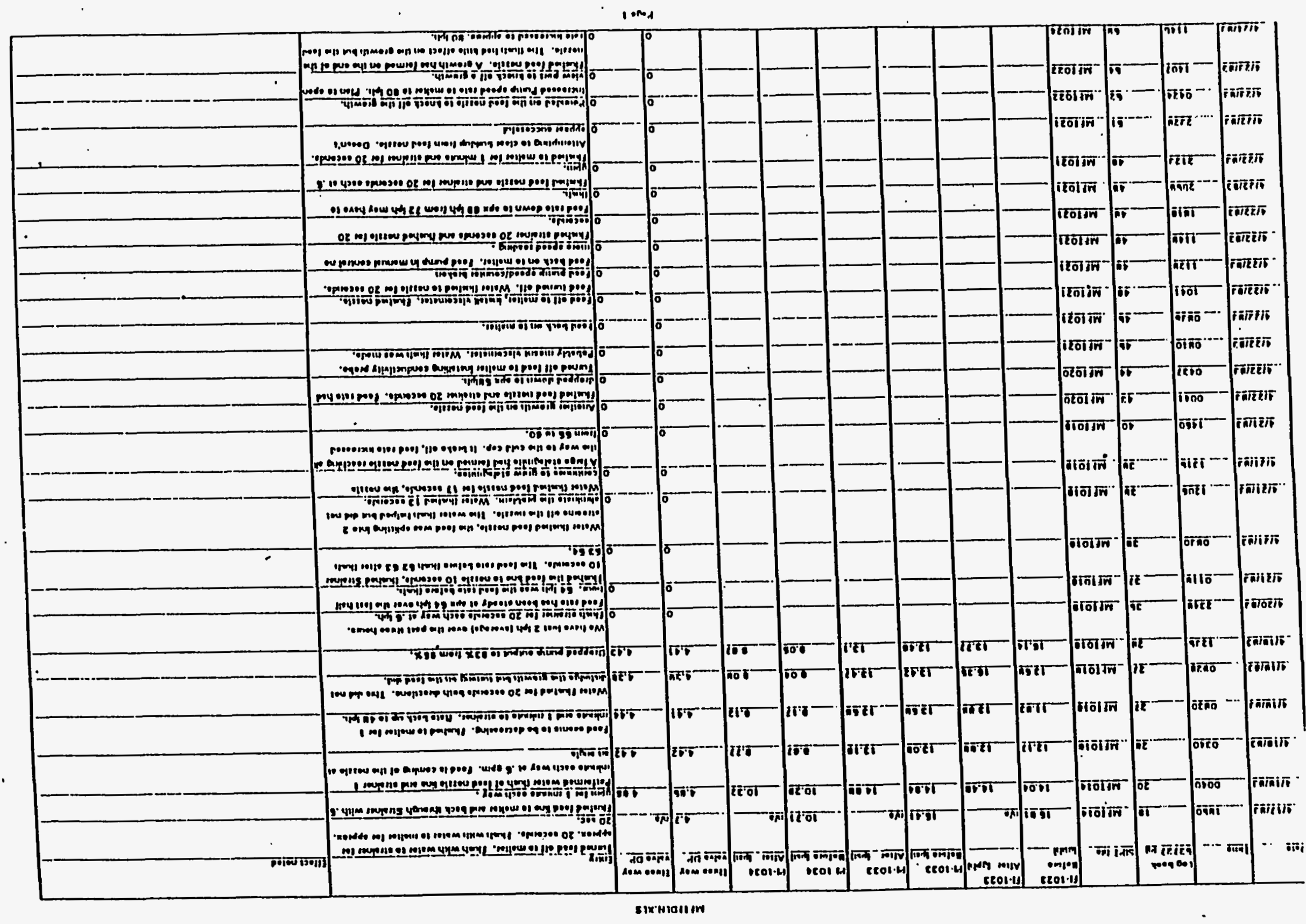


sonat

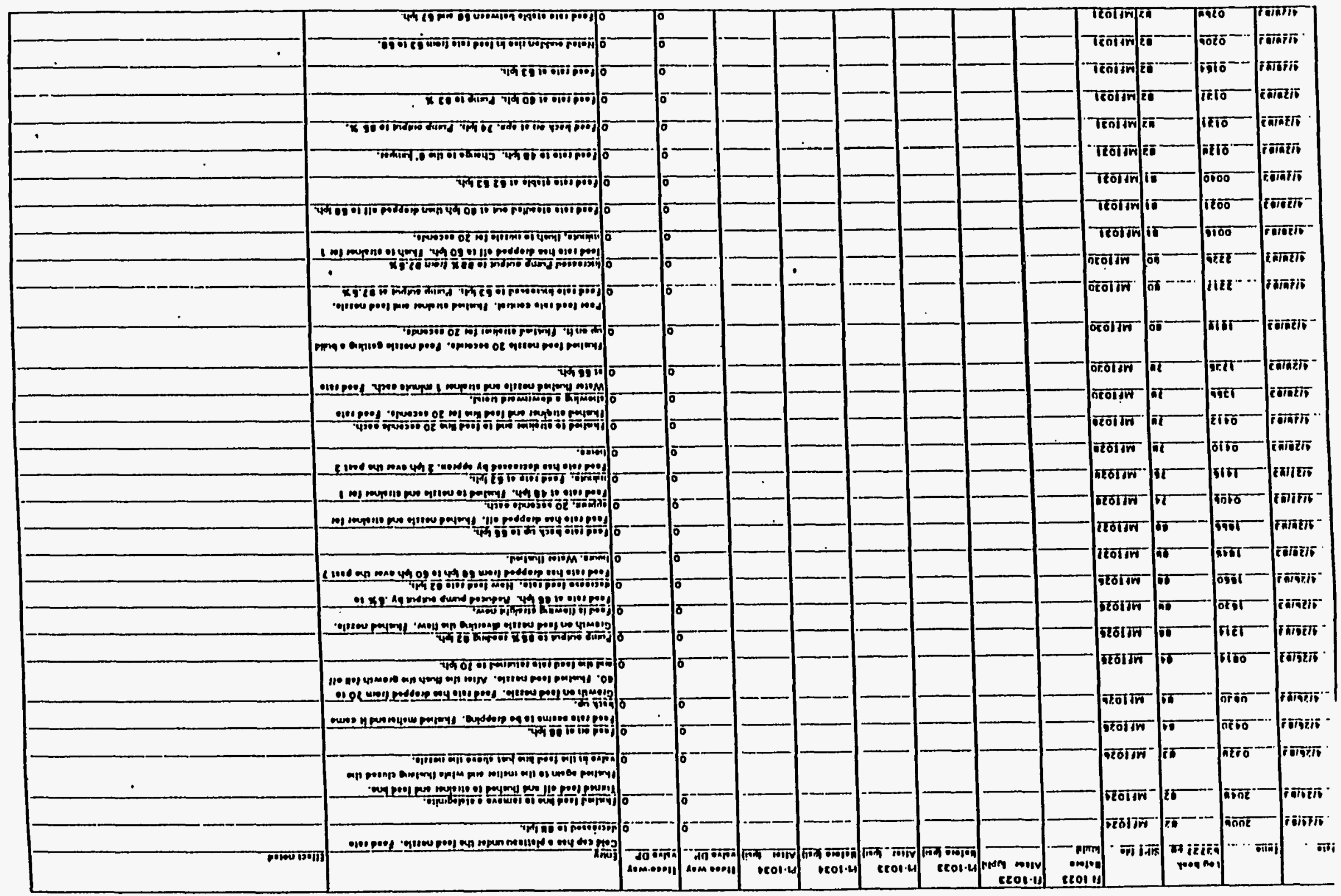




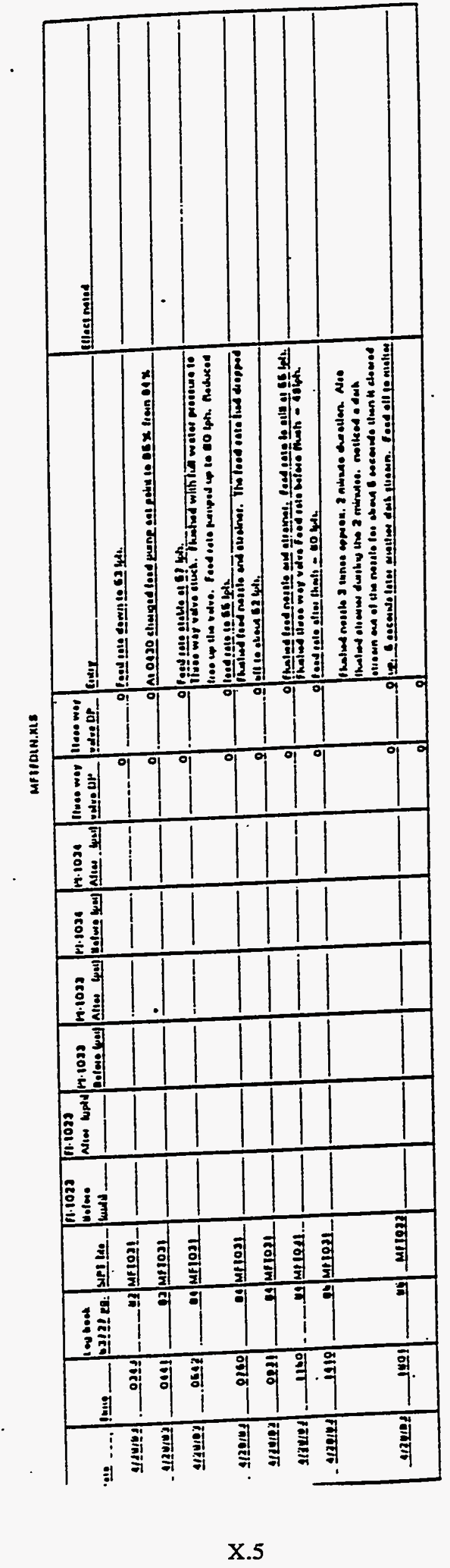


Appendix Y

\section{Reynold's Number Calculation for Melter Feed Line and Recycle Loop}


Reynolds Number For Waste Simulant in Melter Feed Line Properties of melter feed as determined by lab

$\rho:=1.3 \cdot \frac{\mathrm{gm}}{\mathrm{mL}}$

$$
\operatorname{Re}(V, d, \mu):=\frac{\rho \cdot d \cdot V}{\mu}
$$

Where $\mu$ is the effective viscosity

From April 24, 1993, SIPT 2-27.0.41, Linear Fit (not Bingham) $R=0.97$

उy $:=27.28 \cdot \mathrm{Pa}$

$$
\tau y=18.332 \cdot \mathrm{lb} \cdot \mathrm{ft}^{-1} \cdot \sec ^{-2}
$$

$n:=.007495 \cdot \frac{\mathrm{Pa}}{\left(\sec ^{-1}\right)}$

$n=0.005 \cdot 1 b \cdot f^{-1} \cdot \sec ^{-1}$

$$
\mu(D, V):=\frac{\pi y \cdot D}{(6 \cdot V)}+n
$$

For feed line just before melter, $3 / 8$ " tube

Effective Viscosity for V1d2 velocity

$$
\begin{aligned}
V_{1} d 2 & =1.361 \cdot f t \cdot \sec ^{-1} \\
\mu 1 & :=\mu\left(d 2 . V_{1 d 2}\right) \\
\mu 1 & =0.757 \cdot \text { poise }
\end{aligned}
$$

$$
\begin{aligned}
& d 2=0.245 \cdot \text { in } \\
& \text { Effective viscosity for } \\
& V 2 d 2 \text { velocity } \\
& V 2 d 2=2.382 \cdot f t \cdot \sec ^{-1} \\
& \mu 2:=\mu(d 2, V 2 d 2) \\
& \mu 2=0.465 \cdot \text { poise }
\end{aligned}
$$

$\operatorname{Re}(V 1 d 2, d 2, \mu 1)=44.3$

For feed line just before melter, 3 / 8 " pipe

Effective Viscosity for V1d1 velocity

Effective viscosity for V2d1 velocity

$$
\begin{aligned}
& d 1=0.423 \cdot \text { in } \\
& \text { V2d1 }=0.799 \cdot f t \cdot \sec ^{-1} \\
& \mu 2:=\mu(d 1, V 2 d 1) \\
& \mu 2=2.081 \cdot \text { poise } \\
& \operatorname{Re}(V 2 d 1, d 1, \mu 2)=16.349
\end{aligned}
$$$$
\mathrm{V} \text { Id } 1=0.457 \cdot f t \cdot \mathrm{sec}^{-1}
$$$$
\mu 1:=\mu(d 1, V 1 d 1)
$$$$
\mu 1=3.585 \cdot \text { poise }
$$$$
\operatorname{Re}(V 101, d 1, \mu 1)=5.4
$$

Reynolds Number for Waste Simulant in Recycle Loop, 2" Pipe For recycle loop, 2" pipe

$$
\begin{aligned}
& \text { Effective Viscosity for } \\
& \text { V1d3 velocity } \\
& \text { V1d3 }=7.362 \cdot f t \cdot \sec ^{-1} \\
& \mu 1:=\mu(d 3, V 1 d 3) \\
& \mu 1=1.139 \cdot \text { poise }
\end{aligned}
$$

$\operatorname{Re}\left(V_{1 d 3}, d 3, \mu 1\right)=1.345 \cdot 10^{3}$

$$
\begin{gathered}
d 3=2.067 \cdot \text { in } \begin{array}{c}
\text { Effective Viscosity for } \\
V 1 d 3 \text { velocity }
\end{array} \\
V 2 d 3=8.605 \cdot f t \cdot \sec ^{-1} \\
\mu 2:=\mu(d 3, V 2 d 3) \\
\mu 2=0.985 \cdot \text { poise } \\
\operatorname{Re}(V 2 d 3, d 3, \mu 2)=1.817 \cdot 10^{3}
\end{gathered}
$$


Reynolds Number Calculation for Melter Feed Loop and Recycle

Properties of water:

$\rho:=988.037 \cdot \frac{\mathrm{kg}}{\mathrm{m}^{3}}$ at $50 \mathrm{C} \quad \mu:=\frac{1}{100} \cdot$ poise
$p=0.988 \cdot \frac{\mathrm{gm}}{(\mathrm{mL})}$

Melter Feed Line, Fl-1023 (gpm), 3/8* SS pipe (0.423 in. ID)

$Q 1=2 \cdot \frac{\text { gal }}{\min } \quad Q 2:=0.35 \cdot \frac{\text { gal }}{\min } \quad$ Range of how-rates tested

$d 1:=0.423 \cdot$ in $\quad$ flow meter pipe diameter

d2: $:=245 \cdot$ in

d3 := 2.057 in

$V(Q, d):=\frac{Q}{\left[\pi \cdot\left(\frac{d}{2}\right)^{2}\right]}$

3/8" Pipe Velocity

3/8- Tube Velocities

2 Pipe Velocities

Vqd1 $:=V(Q 1,0.423 \cdot$ in $)$

$V_{1 d 2}:=V(01,0.245 \cdot \mathrm{in})$

$V 1 d 3:=V\left(\pi 7 \cdot \mathrm{gal}^{\prime} \min ^{-1} \cdot 2.057 \cdot \mathrm{in}\right)$

$V 2 d 1:=V(a 2,0.423 \cdot i n)$

$V 2 d 2:=V(02,0.245 \cdot i n)$

$V 283:=V\left(90 \cdot 9 a 1 \cdot \mathrm{min}^{-1}, 2.067 \cdot \mathrm{in}\right)$

VIdq $=0.457 \cdot \frac{\pi}{\sec }$

$V_{1 d 2}=1.361 \cdot \frac{\pi}{\sec }$

$v_{1 d 3}=7.362 \cdot \frac{f t}{\sec }$

$v_{2 d} d=0.799 \cdot \frac{\pi}{\sec }$

$V_{2} d 2=2.382 \cdot \frac{\pi}{\sec }$

$v_{2 d 3}=8.605 \cdot \frac{\pi}{\sec }$

$\operatorname{Re}(V, d):=\frac{\rho-d \cdot V}{\mu} \quad$ Reynolds Number

Reynold's Number for Water Flow in Melter Feed Line

$0.20 \mathrm{gpm}$

245 in

0.423 in

2 in
$\operatorname{Re}\left(V_{102}, d 2\right)=2550.8$

$\operatorname{Re}(V 1 d 1 . d 1)=1477.4$

$\pi \mathrm{gpm}$

$\operatorname{Re}(V 1 d 3, d 3)=1.164 \cdot 10^{5}$
$0.35 \mathrm{gpm}$

$\operatorname{Re}(V 202,02)=4463.9$

$\operatorname{Re}(V 2 d 1, d 1)=2585.5$

$90 \mathrm{gpm}$

$\operatorname{Re}\left(V_{2} \mathrm{~d} 3, d 3\right)=1.361 \cdot 10^{5}$

Crane source: Re $>4000$ then flow is turbulent

For mefter feed waste simulant, whose viscosity $\gg 1$ cp (water viscosity) flow is most Dkely laminar. 
Appendix Z

Pumping Sample Calculations 
TOTAL AEAS CAlCUIATON

$$
H_{T}=H_{0}-H_{S}
$$

WHERE: HS= TaAL HEAO

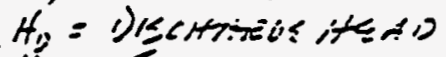

$$
\begin{aligned}
& r_{E}^{\prime}=\text { SucTTod ritent:] }
\end{aligned}
$$

LIVEN:

$$
\begin{aligned}
& Q=1006 \mathrm{PM}
\end{aligned}
$$

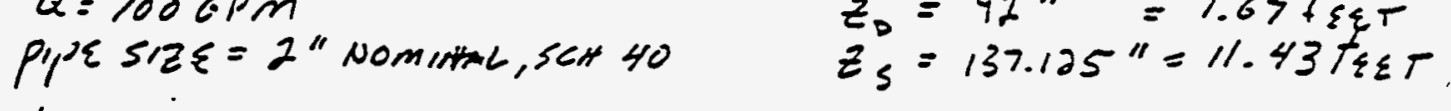

$$
\begin{aligned}
& \text { Hfo rimpzBATURE }=52^{\circ} \mathrm{C} \text { (1250F) } \bar{\tau}_{\omega}=73 "=1.92 \mathrm{f \varepsilon \varepsilon T}
\end{aligned}
$$

Suction lives

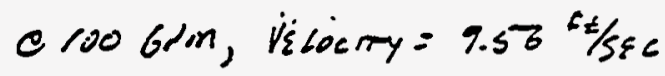

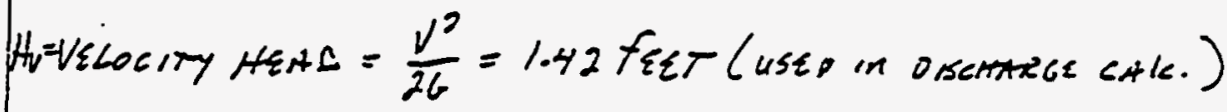

pipe Friction LoSS, $h_{f}=17.4$ fiET per 100 teE, of pipe

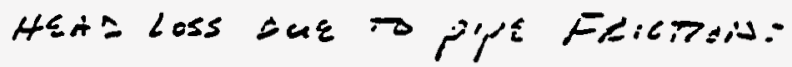

$$
h_{f_{s}}=17.4\left(\frac{11.43}{100}\right)=1.99 \text { f } 4 \varepsilon T .
$$

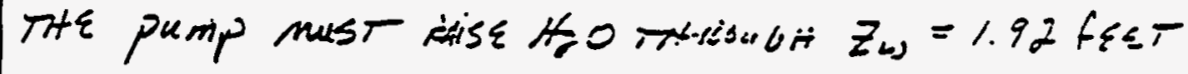

$$
H_{s}=z_{\omega}+h_{f_{s}}=1.92+1.99=3.91 \mathrm{fE \varepsilon T}
$$

SUCTION LIFT SO $\mathrm{H}_{S}=-3.91$ FEET

$125 C H+26 E$ LINE

HMOUNT OF Firs ESFEL DSCASTEQE TRAISUMITER:

STRAlotT PIPE $\approx 45 "$

$1-$ E130w (20186 EAO1115, 12/ $=1.0$ )

$1-45^{\circ}$

$H_{D}=H_{C}+H_{V}+Z_{i}+h_{f_{D}}$

$H_{f}=$ DSG HARGS CAGE REAdinG
1

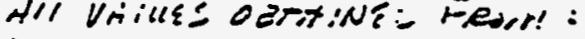

"Hydrallic instTtate-EnGingezing

iATA Rook", 7mo Eoirtens, 1990 


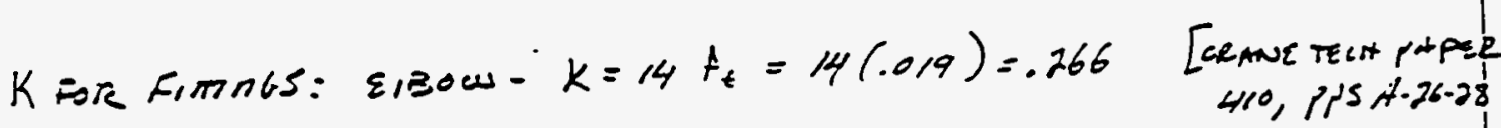
$\left.410,1 t^{2} n^{2}-26-28\right]$ $46-K \cong .13$

$$
\begin{aligned}
& h_{\text {fipq }}=17.4\left(\frac{45 / 12}{100}\right)=.653 \text { f } \leqslant \leqslant T \\
& h_{f_{\text {firmass }}}=k \frac{v^{2}}{26}=[-13+-26 t] 1.42=.562 \mathrm{fE \varepsilon T} \\
& h_{f_{0}:}=.653+.562=1.01 \text { fqET }
\end{aligned}
$$

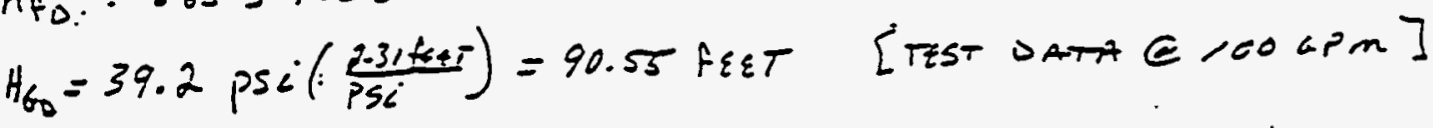

$$
\begin{aligned}
& Z_{0}=92^{\circ} \\
& H_{0}=90.55+.1 .42+92 / 12+1.21=100.85 \\
& \text { Hror }=H_{0}-H_{s}=100.85-(-3.91)=104.8 \mathrm{fEET} \text { C } 10067 \mathrm{~m}
\end{aligned}
$$


Table Z.1. Sample Spreadsheet for Transfer Pump Characterization Testing

\begin{tabular}{|c|c|c|c|c|c|c|c|c|c|c|}
\hline $\begin{array}{c}\text { Flow Rate } \\
\text { (gpm) }\end{array}$ & $\begin{array}{l}\text { Velocity } \\
\text { (ft/sec) }\end{array}$ & $\begin{array}{l}\text { Pump } \\
\text { Speed } \\
\text { (rpm) }\end{array}$ & $\begin{array}{l}\text { Velocity } \\
\text { head (ft) }\end{array}$ & $\begin{array}{l}\text { Pipe I.D. } \\
\text { (in) }\end{array}$ & $\begin{array}{l}\text { Density } \\
\left(1 \mathrm{~b} / \mathrm{ft}^{\wedge} 3\right)\end{array}$ & $\begin{array}{l}\text { Reynolds } \\
\text { Number }\end{array}$ & $\begin{array}{c}\text { Initial } \\
\text { Guess for } \\
\text { Friction } \\
\text { Factor }\end{array}$ & $\begin{array}{l}\text { Friction } \\
\text { Factor }\end{array}$ & $\begin{array}{l}\text { Weight } \\
\text { Cells (lbs) }\end{array}$ & Gallons \\
\hline 213.32 & 20.40 & 1504.69 & 6.47 & 2.067 & 64.064 & 334653.4 & \begin{tabular}{|c|}
0.019 \\
\end{tabular} & 0.019984 & 66127.13 & 8005.032 \\
\hline 213.09 & 20.38 & 1504.84 & 6.45 & & & 334292.5 & & 0.019985 & 66087.94 & 8000.288 \\
\hline 213.27 & 20.39 & 1501.46 & 6.46 & & & 334574.9 & & 0.019984 & 66127.13 & 8005.032 \\
\hline 212.97 & 20.36 & 1501.4 & 6.45 & & & 334104.3 & & 0.019985 & 66086.27 & 8000.086 \\
\hline 213.19 & 20.38 & 1500.85 & 6.46 & & & 334449.4 & & 0.019984 & 66088.41 & 8000.345 \\
\hline 213.06 & 20.37 & 1500.48 & 6.45 & & & 334245.5 & & 0.019985 & 66086.52 & 8000.116 \\
\hline 212.96 & 20.36 & 1499.73 & 6.44 & & & 334088.6 & & 0.019985 & 66088.89 & 8000.403 \\
\hline 213.19 & 20.38 & 1499.74 & 6.46 & & & 334449.4 & & 0.019984 & 66088.41 & 8000.345 \\
\hline 213.11 & 20.38 & 1499.64 & 6.45 & & & 334323.9 & & 0.019985 & 66090.08 & 8000.547 \\
\hline 212.77 & 20.34 & 1499.56 & 6.43 & & & 333790.5 & & 0.019986 & 66087.46 & 8000.23 \\
\hline 213.04 & 20.37 & 1499.47 & 6.45 & & & $334214: 1$ & & 0.019985 & 66126.41 & 8004.945 \\
\hline 213.06 & 20.37 & 1499.58 & 6.45 & & & 334245.5 & & 0.019985 & 66088.65 & 8000.374 \\
\hline 212.89 & 20.36 & 1499.56 & 6.44 & & & 333978.8 & & 0.019985 & 66126.41 & 8004.945 \\
\hline 212.67 & 20.33 & 1499.62 & 6.43 & & & 333633.7 & & 0.019986 & 66125.94 & 8004.888 \\
\hline 212.74 & 20.34 & 1499.38 & 6.43 & & & 333743.5 & & 0.019986 & 66086.04 & 8000.058 \\
\hline 212.81 & 20.35 & 1498.84 & 6.44 & & & 333853.3 & & 0.019986 & 66127.36 & 8005.06 \\
\hline 212.84 & 20.35 & 1498.64 & 6.44 & & & 333900.4 & & 0.019986 & 66087.46 & 8000.23 \\
\hline 212.62 & 20.33 & 1498.97 & 6.42 & & & 333555.2 & & 0.019987 & 66084.85 & 7999.914 \\
\hline 212.37 & 20.31 & 1498.43 & 6.41 & & & 333163 & & 0.019988 & 66126.65 & 8004.974 \\
\hline 212.9 & 20.36 & 1498.15 & 6.44 & & & 333994.5 & & 0.019985 & 66126.17 & 8004.916 \\
\hline 212.29 & 20.30 & 1498.26 & 6.40 & & & 333037.5 & & 0.019988 & 66127.13 & 8005.032 \\
\hline 204.29 & 19.53 & 1498.84 & 5.93 & & & 320487.2 & & 0.020024 & 66086.52 & 8000.116 \\
\hline 196.34 & 18.77 & 1498.31 & 5.48 & & & 308015.4 & & 0.020063 & 66125.7 & 8004.859 \\
\hline 196.33 & 18.77 & 1498.08 & 5.48 & & & 307999.7 & $\cdot$ & 0.020063 & 66126.41 & 8004.945 \\
\hline 196.17 & 18.76 & 1498.06 & 5.47 & & & 307748.7 & & 0.020064 & 66086.75 & 8000.144 \\
\hline 196.07 & 18.75 & 1498.21 & 5.46 & & & 307591.8 & & 0.020064 & 66088.65 & 8000.374 \\
\hline 196.44 & 18.78 & 1498.43 & 5.48 & & & 308172.3 & & 0.020062 & 66086.98 & 8000.172 \\
\hline 196.48 & 18.79 & 1498.24 & 5.49 & & & 308235 & & 0.020062 & 66086.04 & 8000.058 \\
\hline 196.32 & 18.77 & 1498.02 & 5.48 & & & 307984 & & 0.020063 & 66088.17 & 8000.316 \\
\hline 196.54 & 18.79 & 1498.04 & 5.49 & & & 308329.1 & & 0.020062 & 66086.75 & 8000.144 \\
\hline 196.27 & 18.77 & 1498.16 & 5.47 & & & 307905.6 & & 0.020063 & 66086.75 & 8000.144 \\
\hline
\end{tabular}


Table Z.1. (contd)

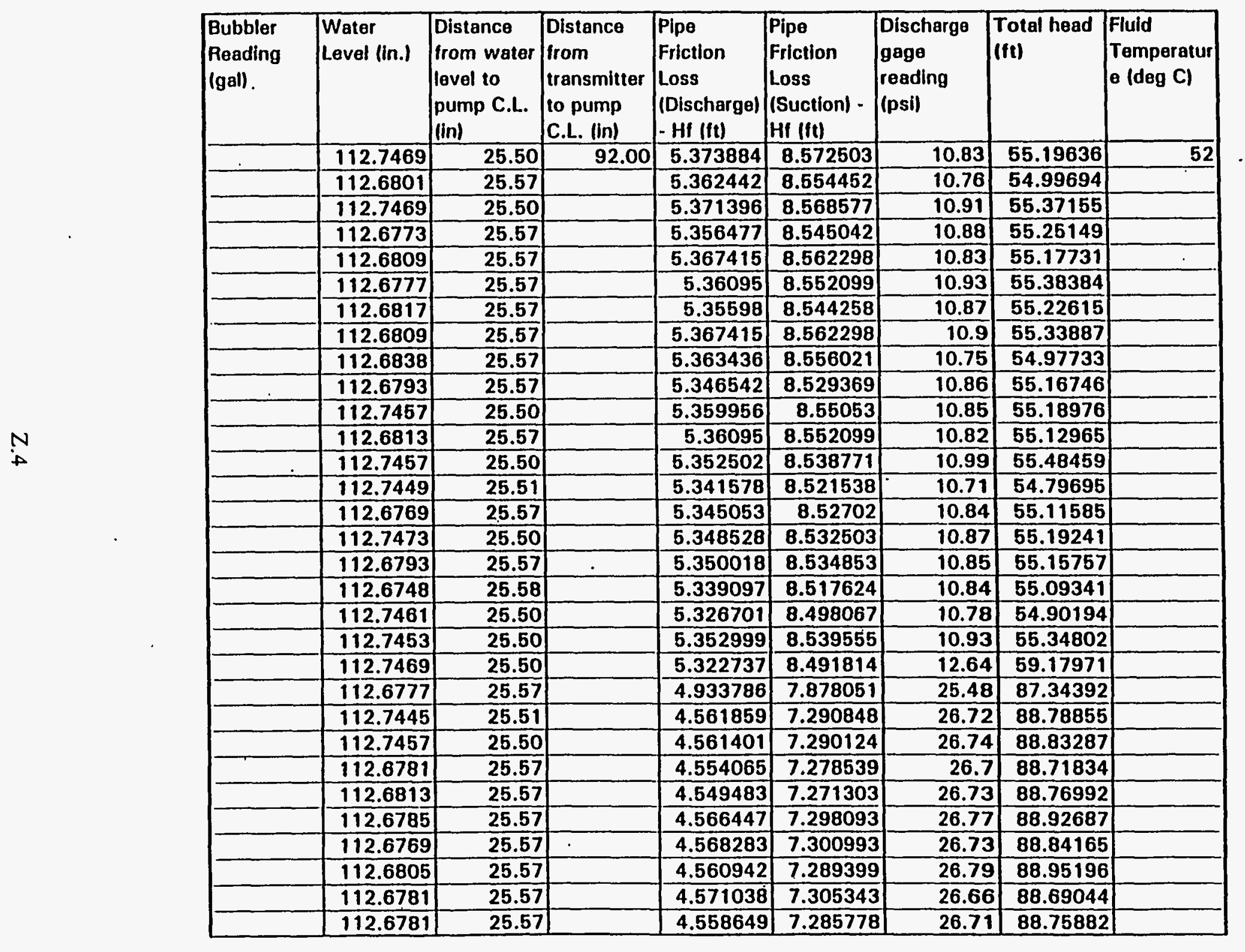


Table Z.1. (contd)

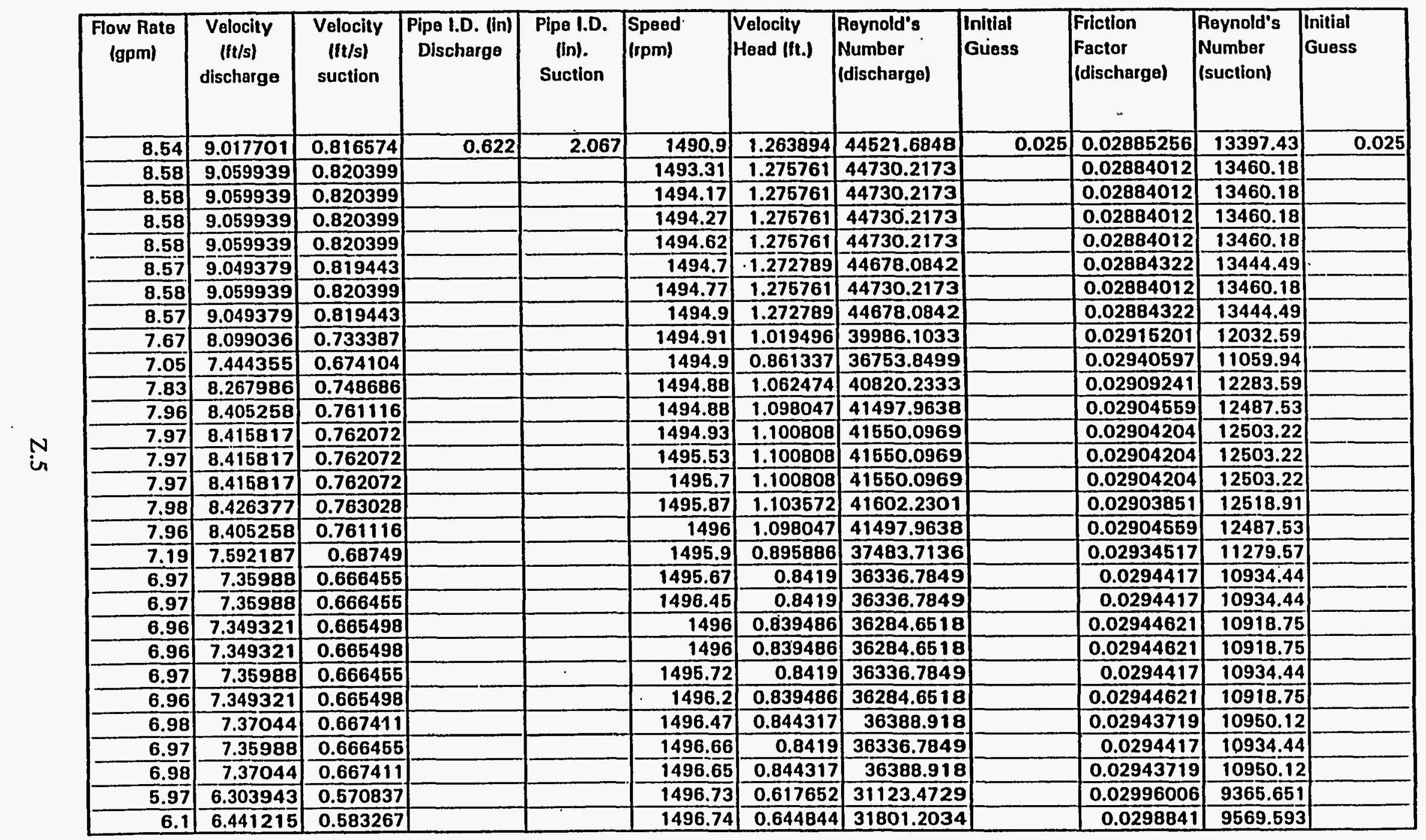


Table Z.1. (contd)

\begin{tabular}{|c|c|c|c|c|c|c|c|c|c|c|c|}
\hline \begin{tabular}{|l} 
Friction \\
Factor \\
(suction)
\end{tabular} & $\begin{array}{l}\text { Weight } \\
\text { Cells (lbs) }\end{array}$ & Gallons & $\begin{array}{l}\text { Bubbler } \\
\text { Reading } \\
\text { (gall) }\end{array}$ & \begin{tabular}{|l} 
Water Level| \\
(in.)
\end{tabular} & \begin{tabular}{|l|} 
Distance \\
from water \\
level to \\
pump C.L. \\
(in.)
\end{tabular} & \begin{tabular}{|l|} 
Distance \\
from \\
transmitter \\
to pump \\
C.L. (in.) \\
\end{tabular} & \begin{tabular}{|l|} 
Pipe Friction \\
Loss \\
(Discharga) - \\
Hf (ft) \\
\end{tabular} & \begin{tabular}{|l|} 
Pipe \\
Friction \\
Loss \\
(Suction) - \\
Hi (III) \\
\end{tabular} & \begin{tabular}{|l|} 
Dischargo \\
gage reading \\
(psi)
\end{tabular} & $\begin{array}{l}\text { Total head } \\
\text { (ft) }\end{array}$ & $\begin{array}{l}\text { Fluid } \\
\text { Temperature } \\
\text { (deg Cl }\end{array}$ \\
\hline 0.03083 & 64972.4 & 7865.246 & & 110.7781 & 28.66 & \begin{tabular}{|r|}
97.56 \\
\end{tabular} & 6.42380234 & 0.019824 & 33.22 & 94.89356 & $52 C$ \\
\hline 0.030793 & 64972.88 & 7865.304 & & 110.7789 & 28.66 & & 6.48132517 & 0.020001 & 33.15 & 94.8015 & \\
\hline 0.030793 & 64974.06 & 7865.447 & & 110.7809 & 28.66 & & 6.48132517 & 0.020001 & 33.31 & 95.17062 & \\
\hline 0.030793 & 64972.64 & 7865.275 & & 110.7785 & 28.66 & & 6.48132517 & 0.020001 & 33.29 & 95.12466 & \\
\hline 0.030793 & 64972.88 & 7865.304 & & 110.7789 & 28.66 & & 6.48132517 & 0.020001 & 33.27 & 95.07846 & \\
\hline 0.030802 & 64973.82 & 7865.410 & & 110.7805 & 28.66 & & 6.46692069 & 0.019957 & 33.29 & 95.10707 & \\
\hline 0.030793 & 64974.77 & 7865.533 & & 110.7822 & 28.66 & & 6.48132517 & 0.020001 & 33.3. & 95.14743 & \\
\hline 0.030802 & 64972.16 & 7865.217 & & 110.7777 & 28.66 & & 6.46692069 & 0.019957 & 33.24 & 94.9919 & \\
\hline 0.031698 & 64972.4 & 7865.246 & & 110.7781 & 28.66 & & 5.23541857 & 0.016157 & 33.28 & 93.59559 & \\
\hline 0.032416 & 64972.16 & 7865.217 & & 110.7777 & 28.66 & & 4.46175613 & 0.013769 & 33.99 & 94.3001 & \\
\hline 0.031527 & 64972.88 & 7865.304 & & 110.7789 & 28.66 & & 5.44496831 & 0.016803 & 33.76 & 94.95654 & \\
\hline 0.031392 & 64972.88 & 7865.304 & & 110.7789 & 28.66 & & 5.61821586 & 0.017338 & 33.63 & 94.86586 & \\
\hline 0.031382 & 64974.54 & 7865.505 & & 110.7818 & 28.66 & & 5.63165356 & 0.017379 & 33.69 & 95.02034 & \\
\hline 0.031382 & 64972.16 & 7865.217 & & 110.7777 & 28.66 & & 5.63165356 & 0.017379 & 33.7 & 95.04376 & \\
\hline 0.031382 & 64974.54 & 7865.505 & & 110.7818 & 28.66 & & 5.63165356 & 0.017379 & 33.65 & 94.92802 & \\
\hline 0.031372 & 64972.4 & 7865.246 & & 110.7781 & 28.66 & & 5.64510711 & 0.017421 & 33.68 & 95.01382 & \\
\hline 0.031392 & 64974.3 & 7865.476 & & 110.7814 & 28.66 & & 5.61821586 & 0.017338 & 33.59 & 94.77333 & \\
\hline 0.032245 & 64974.3 & 7865.476 & & 110.7814 & 28.66 & & 4.6311251 & 0.014292 & 33.9 & 94.29652 & \\
\hline 0.032515 & 64972.4 & 7865.246 & & 110.7781 & 28.66 & & 4.36636986 & 0.013475 & 34.16 & 94.57731 & \\
\hline 0.032515 & 64972.4 & 7865.246 & & 110.7781 & 28.66 & & 4.36636986 & 0.013475 & 34.14 & 94.53115 & \\
\hline 0.032528 & 64973.82 & 7865.418 & & 110.7805 & 28.66 & & 4.35451796 & 0.013438 & 34.08 & 94.37816 & \\
\hline 0.032528 & 64974.3 & 7865.476 & & 110.7814 & 28.66 & & 4.35451796 & 0.013438 & 34.17 & 94.58582 & \\
\hline 0.032515 & 64972.4 & 7865.246 & & 110.7781 & 28.66 & & 4.36636986 & 0.013475 & 34.18 & 94.62347 & \\
\hline 0.032528 & 64973.35 & 7865.361 & & 110.7797 & 28.66 & & 4.35451796 & 0.013438 & 34.12 & 94.47055 & \\
\hline 0.032503 & 64974.3 & 7865.476 & & 110.7814 & 28.66 & & 4.37823761 & 0.013511 & 34.12 & 94.49904 & \\
\hline 0.032515 & 64975.01 & 7865.562 & & 110.7826 & 28.66 & & 4.36636986 & 0.013475 & 34.23 & 94.7385 & \\
\hline 0.032503 & 64973.59 & 7865.39 & & 110.7801 & 28.66 & & 4.37823761 & 0.013511 & 34.26 & 94.82226 & \\
\hline 0.033932 & 65001.38 & 7868.754 & & 110.8275 & 28.61 & & 3.25974369 & 0.01006 & 34.74 & 94.57754 & \\
\hline 0.033727 & 64973.59 & 7865.39 & & 110.7801 & 28.66 & & 3.39462655 & 0.010476 & 34.59 & 94.39778 & \\
\hline
\end{tabular}




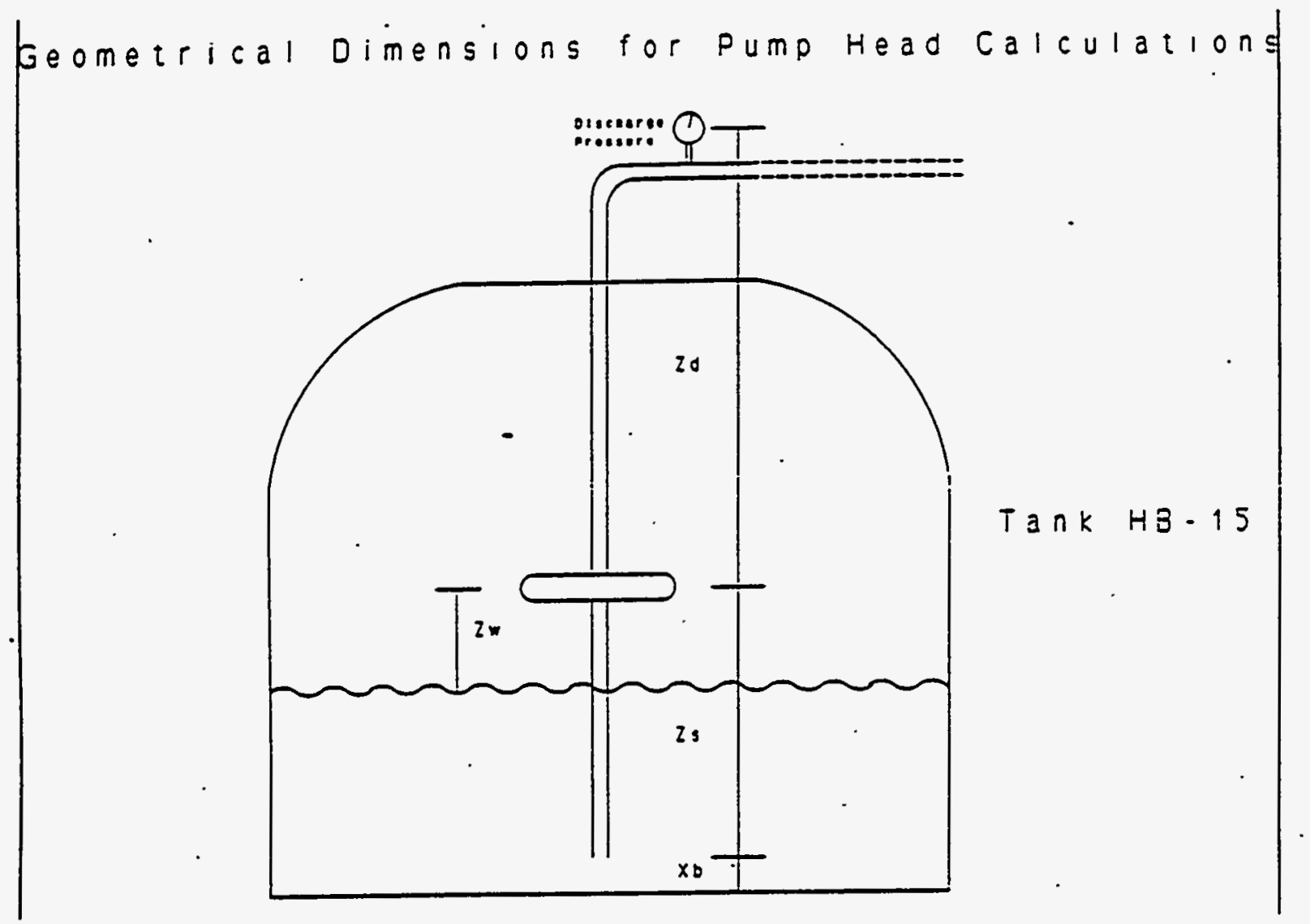

Figure Z.1. Geometrical Dimensions for Pump Head Calculations 


\section{Appendix AA}

Key Formating Test Events 
Table AA.1. Key Test Events for the Formating and Digestion of NCAW Simulant Without Noble Metals

\begin{tabular}{|c|c|c|c|}
\hline Date & $\begin{array}{l}\text { Military } \\
\text { Time }\end{array}$ & $\begin{array}{l}\text { Min from } \\
\mathrm{HCOOH} \\
\text { Start }(0 \\
\text { min }=\text { Onset } \\
\cdot \text { of } \\
\text { HCOOH } \\
\text { Addition }) \\
\end{array}$ & Key Test Event \\
\hline 10MAR93 & $18: 35$ & -85 & Begin Heating to $95^{\circ} \mathrm{C}$ \\
\hline I0MAR93 & $18: 57$ & -63 & $\begin{array}{l}\text { Adding Dow Coming Anti-foam. Tank temperature } \\
=65^{\circ} \mathrm{C} \\
\text { Measured steam flow @ =6700 pph }\end{array}$ \\
\hline 10MAR93 & $19: 26$ & -34 & $\begin{array}{l}\text { Steam to }=20 \%(2100 \text { pph measured }) \\
\text { Slurry temperature @ } 94.5^{\circ} \mathrm{C} \\
\text { No condensate flow. }\end{array}$ \\
\hline IOMAR93 & 19:57 & $\begin{array}{l}-3 \text { (Offgas } \\
\text { Set 20:00 } \\
\text { to } 0 \mathrm{~min})\end{array}$ & $\begin{array}{l}\text { Begin Formic Acid Addition (1st drum of } 90 \mathrm{wt} \% \\
\text { HCOOH) } \\
\text { Vacuum at }=5 \text { in. } \mathrm{H}_{2} \mathrm{O} \\
\text { Slurry Temperanre } 95 \pm 0.5^{\circ} \mathrm{C}\end{array}$ \\
\hline IOMARQ33 & 19:58 & $\overline{-2}$ & $\begin{array}{l}\text { Pressure increases from }-5 \text { in. } \mathrm{H}_{2} \mathrm{O} \text { to }-0.72 \text { in. } \\
\mathrm{H}_{2} \mathrm{O} \text { over } 45 \text { sec. Next } 15 \text { sec pressure decreases to } \\
-6.75 \text { in. } \mathrm{H}_{2} \mathrm{O} \text {. Pressure and offgas flow fluxuating } \\
\text { rapidly. }\end{array}$ \\
\hline IOMAR93 & $20: 03$ & $\overline{3}$ & $\begin{array}{l}\text { Fomic Acid Addition Rate } 1.1 \mathrm{gpm} \text { (Flucruating, } \\
\text { Range }=0.8 \text { to } 1.4 \mathrm{gpm} \text { ) }\end{array}$ \\
\hline 10MAR93 & $20: 39$ & 39 & End of the Addition of 1 st drum of $\mathrm{HCOOH}$ \\
\hline 10MAR93 & $20: 44$ & 44 & $\begin{array}{l}\text { Flushing } \mathrm{HCOOH} \text { addition system } \\
\text { Pressure increase (Safety Interlock Activated) } \\
\text { Pressure renums to }-5 \text { in. of } \mathrm{H}_{2} \mathrm{O}\end{array}$ \\
\hline IOMAR93 & $21: 06$ & 66 & $\begin{array}{l}\text { Begin addition of } 2 \text { nd drum of HCOOH (Safety } \\
\text { Interlock Activated) }\end{array}$ \\
\hline $\begin{array}{l}\text { 10MA- } \\
\text { R93 }\end{array}$ & 21:08 & 68 & $\begin{array}{l}\text { Begin addition of 2nd drum of HCOOH (Safety } \\
\text { Interlock Activated) }\end{array}$ \\
\hline I0MAR93 & $21: 12$ & $\overline{72}$ & $\begin{array}{l}\text { Begin addition of 2nd drum of } \mathrm{HCOOH} \text { (Safety } \\
\text { Interlock Activated) } \\
\text { Note: Positive pressure spikes @ } 2.55,3.78 \text {, and } \\
1.2 \text { in. } \mathrm{H}_{2} \mathrm{O} \text {. Surge may have been greater but } \\
\text { readings taken every } 15 \text { sec. }\end{array}$ \\
\hline 10MAR93 & $21: 20$ & 80 & $\begin{array}{l}\text { Decreased Tank Pressure to - } 10 \text { in } \mathrm{H}_{2} \mathrm{O} \text {, Airflow @ } \\
\text { 50ACFM }\end{array}$ \\
\hline I0MAR93 & $21: 30$ & 90 & $\begin{array}{l}\text { Begin addition of } 2 \text { nd drum of } \mathrm{HCOOH} \text { Pressure } \\
\text { increased to }-4 \text { in } \mathrm{H}_{2} \mathrm{O} \text {, Airflow @ } 120 \text { to } 160 \\
\text { ACFM }\end{array}$ \\
\hline
\end{tabular}


Table AA.1. (contd)

\begin{tabular}{|c|c|c|c|}
\hline Date & $\begin{array}{l}\text { Military } \\
\text { Time. }\end{array}$ & $\begin{array}{l}\text { Min from } \\
\text { HCOOH } \\
\text { Stan }(0 \\
\text { min=Onset } \\
\text { of } \\
\text { HCOOH } \\
\text { Addition) }\end{array}$ & Key Test Event \\
\hline IOMAR93 & $22: 25$ & 145 & End of the Addition of 2nd dram of $\mathrm{HCOOH}$ \\
\hline IOMAR93 & $22: 31$ & 151 & Flushing HCOOH addition system \\
\hline I0MAR93 & $21: 37$ & 158 & Flushing $\mathrm{HCOOH}$ addition system (again) \\
\hline 10MAR93 & $22: 47$ & 168 & $\begin{array}{l}\text { Begin addition of 3rd dram of HCOOH Average } \\
\mathrm{HCOOH}=1.2 \mathrm{gpm}\end{array}$ \\
\hline IOMAR93 & $23: 31$ & 211 & End of the Addition of $3 \mathrm{rd}$ drum of $\mathrm{HCOOH}$ \\
\hline IOMAR93 & $23: 32$ & 212 & Flushing $\mathrm{HCOOH}$ addition system \\
\hline IOMAR93 & $23: 39$ & 220 & Begin addition of 4th drum of $\mathrm{HCOOH}$ \\
\hline IIMAR93 & $00: 21$ & 261 & End of the Addition of 4 th drum of $\mathrm{HCOOH}$ \\
\hline IIMAR93 & $00: 27$ & 267 & Flushing HCOOH addition system \\
\hline IIMAR93 & $00: 34$ & 274 & Begin addition of 5 th drum of $\mathrm{HCOOH}$ \\
\hline 11MAR93 & $01: 17$ & 317 & End of the Addition of 5 th drum of $\mathrm{HCOOH}$ \\
\hline IIMAR93 & $01: 19$ & 319 & Flushing HCOOH addition system \\
\hline 11MAR93 & $01: 25$ & 325 & Begin addition of 6 th drum of $\mathrm{HCOOH}$ \\
\hline IIMAR93 & $01: 55$ & 355 & End of the Addition of 6 th drum of $\mathrm{HCOOH}$ \\
\hline IIMAR93 & $02: 01$ & 361 & Flushing $\mathrm{HCOOH}$ addition system \\
\hline 11MAR93 & $02: 08$ & 368 & Begin addition of 7 th drum of $\mathrm{HCOOH}$ \\
\hline IIMAR93 & $02: 24$ & 384 & $\begin{array}{l}\text { End of the Addition of } 7 \text { th drum of HCOOH (Partial } \\
\text { drum added) } \\
\text { Total HCOOH added }=320 \mathrm{gal}\end{array}$ \\
\hline I1MAR93 & $02: 34$ & 394 & $\begin{array}{l}\text { Flushing } \mathrm{HCOOH} \text { addition system } \\
\text { End Formating }\end{array}$ \\
\hline I1MAR93 & $02: 45$ & 405 & $\begin{array}{l}\text { Cooling water to coils reduced } \\
\text { Begin hearing siurry }\end{array}$ \\
\hline IIMAR93 & $03: 00$ & $\overline{420}$ & $\begin{array}{l}\text { Total Condensate }=423 \mathrm{gal} \\
\text { Note: Condensate refluxed back to tank }\end{array}$ \\
\hline $11 \mathrm{MAR} 93$ & $03: 06$ & 426 & Tank Temperarure at $98.4^{\circ} \mathrm{C}$ \\
\hline 11MAR93 & $03: 10$ & 430 & $\begin{array}{l}\text { Condensate routed to collection tank } \\
\text { No longer refluxing } \\
\text { Total Condensate }=458 \text { gal refluxed back into SRAT }\end{array}$ \\
\hline 11MAR93 & $03: 14$ & 435 & Fank Temperanure at $99^{\circ} \mathrm{C}$ \\
\hline
\end{tabular}


Table AA.1. (contd)

\begin{tabular}{|l|l|l|l|}
\hline Date & $\begin{array}{l}\text { Military } \\
\text { Time }\end{array}$ & $\begin{array}{l}\text { Min from } \\
\text { HCOOH } \\
\text { Start }(0 \\
\text { min=Onset } \\
\text { of } \\
\text { HCOOH } \\
\text { Addition) }\end{array}$ & Key Test Event \\
\hline 11MAR93 & $07: 12$ & 672 & $\begin{array}{l}\text { Shut off steam to coils } \\
\text { End digestion } \\
\text { Total Condensate collected during Digestion } \approx 874 \\
\text { gal }\end{array}$ \\
\hline 11MAR93 & $07: 15$ & 675 & Cooling water to 115 gpm \\
\hline 11MAR93 & $09: 48$ & 828 & $\begin{array}{l}\text { Cooling water off } \\
\text { Total Condensate collected during test }=1343.6 \text { gal }\end{array}$ \\
\hline
\end{tabular}


Appendix AB

Formating Nitrogen Mass Balance Calculations 


\section{Ollgas Syslem Condensale Scale-Up Calculatlons}

Sivene end Asaumpellens

Rate of ollgas through analyzers $\rightarrow 2.314$ SLPM (or 0.1032 molos/m/n)

Formic Acld Addition t-0 to $\$ 15$ minutes of 416 min

Average NOx concentratlon - $2.87 \%$ (Dotermined by averaging NOx\% over the lime perlod indlcalod)

Approximate measured full-scale NOx amount generaled durling formallng $\rightarrow>1200$ moles (See Flgure 6.7)

Dlgestion l-415 to 795 minules or 380 min

Average NOx concentrallon $-0.826 \%$ (Delermined by averaging NOx\% over the tlme perlod indlcated)

Approximale measured lull-scale NOx emount generaled during dlgestion $\Rightarrow 1000$ moles (See Floure 6.7)

\section{Equallens:}

Formic Acld Addilion Full Scalo Moles of NOx due to Condensale -

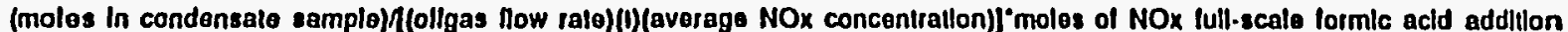

Digestion Full Scale Moles ol NOx due to Condensale

(moles In condensate sample)/(ollgas llow rate)(I)(average NOx conceniralion)) ${ }^{\prime}$ oles of NOx full-scale dlgestion

\begin{tabular}{|c|c|c|c|c|}
\hline Phase & $\begin{array}{c}\text { Condensolo } \\
\text { Niliale } \\
\text { (g/L) }\end{array}$ & $\begin{array}{c}\text { Condonsalo } \\
\text { Volume } \\
\text { L }\end{array}$ & $\begin{array}{l}\text { Condensale } \\
\text { Nitrate } \\
\text { (moles) }\end{array}$ & $\begin{array}{l}\text { Full-scale } \\
\text { Molos NOx } \\
\text { due to } \\
\text { condensale }\end{array}$ \\
\hline Formic Acid Addliton & 640 & 0.0075 & $7.74 E-02$ & 256 \\
\hline Digestion & 530 & 0.01 & 8.55E.02 & 264 \\
\hline & & & Sum & 520 \\
\hline
\end{tabular}


ODP Calculations for Nibogen Mase Balance

\begin{tabular}{|c|c|c|c|c|c|c|}
\hline Samplo no. & NO3. $(g / 2)$ & NO2- $(g / 2)$ & eal & $t$ & NO3. (moles) & NO2- (molos) \\
\hline SIPT2-17.3.6 & 7.7 & 24 & 7400 & 28011.06 & 3478.00 & 14614.04 \\
\hline SIPT2-17.3.7 & 7.5 & 23 & 7100 & 28011.90 & 3388.54 & 14005.98 \\
\hline SIPT2-21.9.4 & 18 & 2.0 & 6850 & 25172.01 & 7308.26 & 1586.08 \\
\hline SIPT2-21.0.5 & 10 & 2.0 & 6650 & 25172.01 & 7300.26 & 1586.99 \\
\hline & InIIIal & Final & & & . & \\
\hline $\begin{array}{l}\text { Ave NO3- (Sluiry) } \\
\text { Ave NO2. (Slutry) }\end{array}$ & $\begin{array}{l}3433.72 \\
14310.46\end{array}$ & $\begin{array}{l}7300.26 \\
1586.09\end{array}$ & & & - & \\
\hline
\end{tabular}

\begin{tabular}{|c|c|c|c|c|c|c|c|c|}
\hline \multicolumn{9}{|l|}{ Mass Balanco lor Nlirogion } \\
\hline $\begin{array}{l}\text { Inltial Nlirogen } \\
\text { in Slurry (moles) }\end{array}$ & $\begin{array}{l}\text { Final Nitrogen } \\
\text { In Slurry (moles) }\end{array}$ & $\begin{array}{l}\text { N2O and } N 1 O x \\
\text { Oflgas Nlliogen } \\
\text { (molos) }\end{array}$ & $\begin{array}{l}\text { Nilliogen in } \\
\text { Condensalo } \\
\text { (moles) }\end{array}$ & $\begin{array}{l}\text { Estimale of } \\
\text { NOx glven olf } \\
\text { over } 1 \text { days }\end{array}$ & $\begin{array}{l}\text { Esilmate of } N \text { from } \\
\text { N2O glven off } \\
\text { over } 4 \text { days }\end{array}$ & $\begin{array}{l}\text { Folmaling } \\
\text { Ollgas Systom } \\
\text { Cond Molos of } \mathrm{N}\end{array}$ & $\begin{array}{l}\text { Digestion } \\
\text { Olfgas System } \\
\text { Cond Molos of N }\end{array}$ & $\begin{array}{c}\% \text { Niltrogon } \\
\text { Accounted lor } \\
\text { by Mass Balance }\end{array}$ \\
\hline 17741 & 0095 & 6148 & 345 & 180 & 169 & 256 & 264 & 92 \\
\hline
\end{tabular}


Calculatlons for the Estlmaled Percent of NO from the Disproportlonation of Niltrous Actd Formate Balanco

\begin{tabular}{|cc|}
\hline $\begin{array}{c}\text { Total NOX } \\
\text { (moles) }\end{array}$ & $\begin{array}{c}\text { At the end of dlgestlon } \\
\text { Slurry volume } \\
10228\end{array}$ \\
& 25173 \\
& \\
& lon Chromalography \\
HCOO. (g/L) & 14 \\
SIPT 2-21.8.4 & 13 \\
SIPT2.21.8.5 & \\
\hline
\end{tabular}

Sluily Chemlsliy Equallons
(1) $\mathrm{HCOOH} \rightarrow \mathrm{H} 2+\mathrm{CO} 2$
(2) $\mathrm{NaNO} 2+3 \mathrm{HCOOH} \rightarrow 2 \mathrm{NO}+\mathrm{CO} 2+2 \mathrm{NaCOOH}+2 \mathrm{H} 2 \mathrm{O}$
(3) $2 \mathrm{NaNO} 2+4 \mathrm{HCOOH} \rightarrow \mathrm{N} 2 \mathrm{O}+2 \mathrm{CO} 2+2 \mathrm{NaCOOH}+3 \mathrm{H} 2 \mathrm{O}$
(4) $\mathrm{MnO} 2+3 \mathrm{HCOOH} \rightarrow \mathrm{Mn2}++2 \mathrm{HCOO}+2 \mathrm{H} 2 \mathrm{O}+\mathrm{CO} 2$
(5) $3 \mathrm{HNO} \rightarrow \mathrm{H}++\mathrm{NO} 3+2 \mathrm{NO}+\mathrm{H} 2 \mathrm{O}$

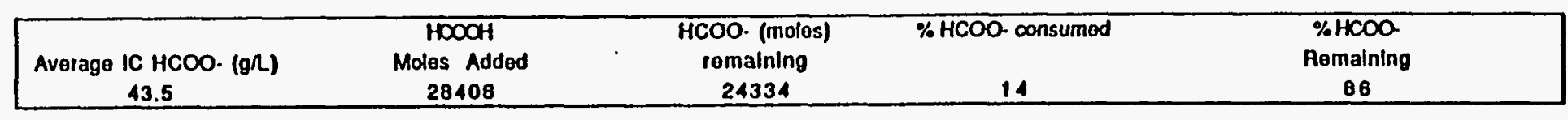

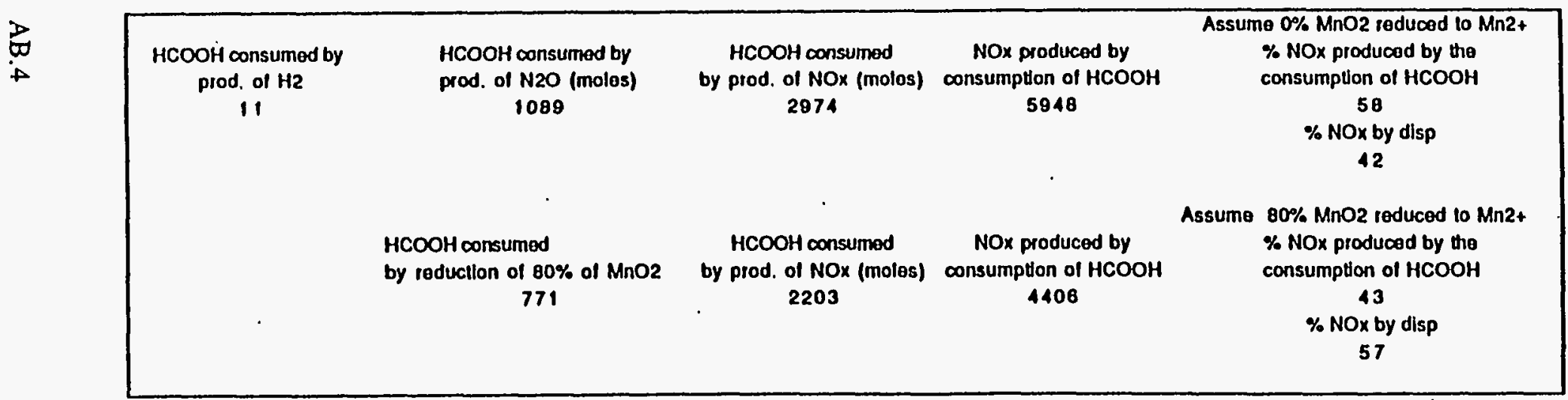

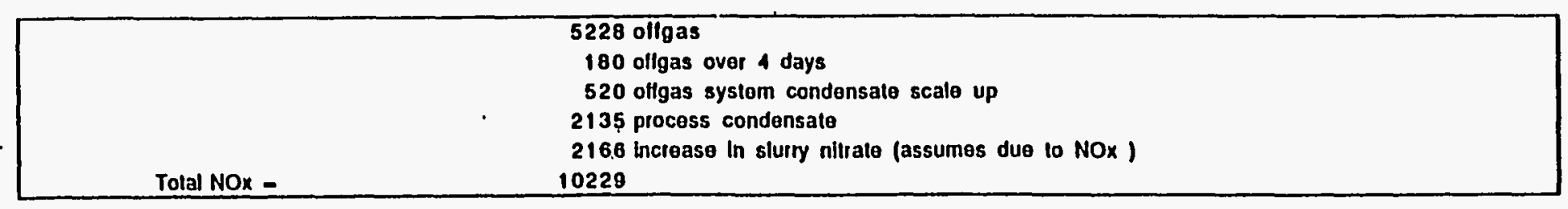




\section{Appendix AC}

Condensate Analyses 
Table AC.1. Condensate Analysis

\begin{tabular}{|c|c|c|c|c|c|}
\hline Simple No. & If Finng af $105 \mathrm{Cl}$ & Location & ISample No. & Finng at $105 \mathrm{C}$ & Location \\
\hline & T (Slumy) w\% & & & (Slumy) m\% & \\
\hline 1230192 ISIPT $2-4.1 .1$ & & Condensale Line & I/1493ISIPT 2.9.4.3 & & Aerosol HCl Rinsate \\
\hline ISIPT 2-4.1.2 & & Condensate Line & ISIPT 2-9.4.4 & -0.01 & Condensate $1 / 4^{\circ}$ Valve \\
\hline ISIPT 2-4.1.3 & & Condensate line & ISIPT 2-9.4.5 & & II/4 Condensale Valve \\
\hline SIPT 2-4.1.4 & & Condensate Trap & ISIPT 2-9.4.6 & -0.01 & IIC Condensate Value \\
\hline SIPT 2-4.1.5 & & Condensate Line & 1/25/93ISIPT 2-9.5.4 & I & Anti-Foam Compound \\
\hline ISIPT 2-4.1.6 & & Condensale Line & ISIPT 2-9.5.1 & & Aerosol Fine? \\
\hline ISIPT 2-4.1.7 & & Condensate Line & ISIPT 2-9.5.2 & & Aerosol DI Water Rinsate \\
\hline ISIPT 2-4.1.8 & & Condensate Trap & ISIPT 2-9.5.3 & & Aerosol HCl Rinsale \\
\hline ISIPT 2-4.1.9 & & Condensate Lne & ISIPT 2-9.5.5 & $\overline{0}$ & T1/4 Condensale Valve \\
\hline ISIPT 24.9 .90 & & Condensate Line & ISIPT 2-9.5.6 & & III Condensale Trap \\
\hline ISIPT 24.9.91 & & Condensate Line & ISIPT 2-9.5.8 & 0 & $11 / 4^{\circ}$ Condensale Valve \\
\hline ISIPT 2-4.9.12 & & Condensate Trap & ISIPT 2-9.5.9 & & II $C$ Condensale Trap \\
\hline ISIPT 2-4.1.13 & & Aerosol Off cas & ISIPT 2-9.5.10 & & ICondensale from HB-14 \\
\hline ISIPT 2-4.1.14 & & Aerosol. OH-cas & 1/23/931SIPT $2 \cdot 9.7 .1$ & 0 & (114 Condensale Vatve (Top) \\
\hline ISIPT 2-4.1.15 & & Aerosol. Ofl-gas & ISIPT 2.9.72 & & 11/2 Condensate Trap (Bottom) \\
\hline ISIPT 2-4.1.16 & & Aerosol. Of-oas & ISIPT $2 \cdot 9.7 .3$ & & II 2 Condensale Trap (Botrom) \\
\hline 1/693ISIPT 2-8.1.1 & & IAereso. OH-cas & ISIPT $2-9.7 .4$ & 0.005 & Ti/4 Consensale Value \\
\hline ISIPT 28.1 .2 & & Aerosol. OH-cas & ISIPT 2-9.7.5 & & II $\bar{L}$ Condensate Trap \\
\hline ISIPT 2-8.1.3 & & Aerosol. Orf-ces & ISIPT 2-9.7.6 & & IAerosal Sample Fitter \\
\hline ISIPT 2-8.1.4 & & Aeroso, Ofl-cas & ISIPT 2-9.7.7 & & Aerosal Samole DI Rinsate \\
\hline ISIPT 2-8.1.5 & $\cdot$ & Aeroso, OH-gas & ISIPT 2-9.7.8 & 1 & TAerosol Samole HCI Rinsale \\
\hline ISIPT 2-8.1.6 & & Aeroso, Off-aas & 1/28193!SIPT 2-15.1.1 & 1 & IAerosol Finer \\
\hline ISIPT 2-8.1.7 & & Aerosol. OH_oes & ISIPT 2-15.1.2 & & |Aerosol DI Waler Rinsate \\
\hline ISIPT 2-8.1.8 & & Aerosol, Ofl-ces & ISIPT 2-15.1.3 & I & Aerosol HCI Rinsate \\
\hline ISIPT 2-8.1.9 & & Aerosol. Ofl-ces & ISIPT 2-15.1.4 & -0.03 & $11 / 4^{\circ}$ Condensate Vatve \\
\hline ISIPT 2-8.1.10 & 0 & Condensate Line & ISIPT 2-15.1.5 & & $19 / 4^{\circ}$ Consensate Valve \\
\hline ISIPT 2-8.1.11 & & iCondensate Trze & ISIPT 2-15.1.6 & 0.03 & I/5 Condensate Valve \\
\hline ISIPT 2-8.1.12 & 0.01 & Condensate Line & ISIPT 2-15.1.7 & 1 & I1/ Condensate Trao \\
\hline ISIPT 2-8.1.13 & -0.01 & Condensate Line & ISIPT 2-15.1.8 & $\mathrm{i}$ & IAerosol Fitier \\
\hline ISIPT 2-8.1.14 & & ICondensate Trap & ISIPT 2-15.1.9 & 1 & |Aerosol DI Water Rinsale \\
\hline ISIPT 28.1.15 & 0 & Condensate line & ISIPT 2-15.1.10 & I & |Aerosol HCl Rinsate \\
\hline ISIPT 2-8.1.16 & & Condensate Line & ISIPT 2-15.1.11 & -0.03 & $1114^{\circ}$ Condensate Valve \\
\hline ISIPT 28.1.17 & 0 & Condensate Line & ISIPT 2-15.1.12 & & TI/ Consensale Valve \\
\hline ISIPT 228.1.18 & & ICondensate Trap & ISIPT 2-15.1.13 & I & $11 / 4^{\circ}$ Condensate Valve \\
\hline ISIPT 28.1.19 & 0 & ICondensate Line & ISIPT 2-15.1.14 & & 19V Condensate Trap \\
\hline ISIPT 2-8.1.20 & & Conjensate Line & ISIPT 2-15.1.15 & & Aerosol Finer \\
\hline ISIPT 2-8.1.21 & $\mathbf{0}$ & Condensate Line & ISIPT 2-15.1.16 & & IAerosol DI Water Rinsate \\
\hline ISIPT 2-8.122 & & ICondensale Trap & ISIPT 2.15.1.17 & & |Aerosol HCI Rinsate \\
\hline ISIPT 28.9 .23 & & IAerosal Ofl-cas & 1SIPT 2.15.1.18 & -0.03 & $11 / 4^{\circ}$ Condensate Valve \\
\hline 1/1393ISIPT 2.9.1.1 & 1 & |Aerosol & ISIPT 2-15.1.19 & & $11 / 4^{\circ}$ Condensate Value \\
\hline ISIPT 2-9.1.2 & & IDI Water Rinsate & ISIPT $2-15.1 .20$ & -0.02 & $11 / 4^{\circ}$ Condensale Valve \\
\hline ISIPT 2-9.1.3 & & IHCl Rinsate & ISIPT 2-15.1.21 & 1 & II $\overline{2}$ Condensate Trad \\
\hline ISIPT 2-9.1.4 & & $11 \sqrt{2}$ Condensale Tras & 21/931StPT 2-16.1.1 & 1 & IAerosol Finer \\
\hline ISIPT $2-9.1 .5$ & -0.01 & $1 / 4$ Condensate Sample & ISIPT 2-16.1.2 & & Aerosol DI Water Rinsale \\
\hline ISIPT 2-9.1.6 & & $1 / 4$ Condensate Sample & ISIPT 2-16.1.3 & & Aerosol HCI Rinsate \\
\hline ISIPT 2-9.1.7 & & $1 \sqrt{2}$ Condensale Samole & ISIPT 2-16.1.4 & 0.03 & $114^{\circ}$ Condensale Trap \\
\hline ISIPT 2-9.1.8 & 0 & 1/4 Condensate Sample & ISIPT 2-16.1.5 & $\therefore$ & II $\Omega$ Condensate Trap \\
\hline ISIPT 2-9.2.4 & 0 & II/ Condensate Sample & ISIPT 2-16.1.6 & & II/ Condensate Trap \\
\hline ISIPT 2-9.2.1 & & IAerosol & ISIPT 2-16.1.7 & & TI/ 2 Condensate Trap \\
\hline ISIPT 2-9.2.2 & & IDI Water Rinsate & ISIPT 2-16.1.8 & -0.03 & III⿸ Condensate Trap \\
\hline ISIPT 2-923 & & IHCl Rinsale & 2293ISIPT 2-16.2.1 & 1 & IAerosol fitier \\
\hline ISIPT 2-9.2.5 & & $11 \sqrt{\Omega}$ Condensaie Sample & ISIPT 2-16.2.2 & & |Aerosol DI Water Rinsale \\
\hline ISIPT 2.9 .2 .6 & 0 & $11 / 2$ Condensate Samole & ISIPT 2-16.2.3 & I & |Aerosol HCI Rinsate \\
\hline 1/14/93ISIPT 2.9.3.1 & -0.01 & $11 \bar{Z}$ Condensate Sample & ISIPT 2.16.2.4 & $i$ & III Condensate Trap \\
\hline ISIPT $2 \cdot 9.3 .2$ & & |Aerosol DI Water Rinsale & ISIPT 2-16.2.5 & -0.03 & $11 / 4^{-}$Concensate Trap \\
\hline ISIPT 2-9.3.3 & & |Aerosol HCl Rinsale & ISIPT $2-16.26$ & 1 & I1V Condensate Trap \\
\hline ISIPT 2-9.3.4 & & TAerosol Filie? & ISIPT 2-16.2.7 & -0.03 & T1/5 Consensate Trap \\
\hline ISIPT 2-9.3.5 & & $11 / 4$ Condensate Sample & ISIPT 2-16.2.8 & i & TIL Consensate Trap \\
\hline ISIPT 2.9 .3 .6 & 1 & TIR Condensate Sample & ISIPT 2-16.3.1 & $\mathrm{i}$ & Aerosol Fiter \\
\hline ISIPT $2 \cdot 9.3 .7$ & 0 & II $\sqrt{Z}$ Condensate Sample & ISIPT 2-16.3.2 & & Aerosol DI Water Rinsale \\
\hline ISIPT 2-9.4.1 & & IAerosol Fine? & ISIPT 2-16.3.3 & & Aerosd HCI Rınsale \\
\hline ISIPT 2-9.4.2 & & |Aerosol DI Water Rinsate & ISIPT $2-16.3 .4$ & 20.03 & 11/4- Condensale Trap \\
\hline ISample No. & IFining at $105 \mathrm{C}$ & Location & ISample No. & I Finng at $105 \mathrm{C}$ & Location \\
\hline & (Slumy) was & & 1 & (Slumy) w\% & \\
\hline ISIPT 2-16.3.5 & & $1 / 4^{\circ}$ Condensale Trap & 3/0193ISIPT 2-21.0.17 & 8 & OjCondensate Line \\
\hline ISIPT 2-16.3.6 & -0.03 & 11/4 Condensale Trap & ISIPT 2-21.0.18 & 1 & OlCondensate Line \\
\hline
\end{tabular}


Table AC.1. (contd)

\begin{tabular}{|c|c|c|c|}
\hline ISIPT 2-16.3.7 & II/ Condensale Trap & ISIPT 2-21.0.19 I & OlCondensale Line \\
\hline SIPT 2-16.4.1 & Aerosol Finer & ISIPT 2.29 .0 .20 & 0.01 Condensate Line \\
\hline SIPT $2-16.4 .2$ & Aerosol DI Water Rinsale & ISIPT 2.21.0.21 & D.09|Condensate Line \\
\hline SIPT 2-16.4.3 & Aerosol HCl Rinsale & 311/931SIPT 2-21.0.22 & OjCondensale Lne \\
\hline SIPT 2-16.4.4 & $1 / 4^{\circ}$ Condensate Trap & SSIPT 2.21.0.23 & O|Condensate Line \\
\hline SIPT 2-16.4.5 & $1144^{\circ}$ Condensate Trap & ISIPT 2-21.0.24 & 0/1/4 Condensale Line \\
\hline SIPT 2-16.4.6 & $1 / 4^{\circ}$ Condensate Trap & ISIPT 2-21.0.25 & $0.14 \mid 1 \sqrt{2}$ Condensate Line \\
\hline ISIPT 2-16.4.7 & II $\sqrt{2}$ Condensate Trap & ISIPT 2-21.0.26 & olCondensate- 1/4- Line, \\
\hline 23193|SIPT 2.16.5.1 & Aerosol Fiter & ISIPT 2-21.0.27 & o/Condensale- $1 / 4-$ Line. \\
\hline SIPT 2-16.5.2 & Aeroso Di Water Rinsate & ISIPT 2-21.0.28 & 0.01 Condensale $1 / 4^{-}$Line, \\
\hline ISIPT 2-16.5.3 & Aerosol HCI Rinsate & ISIPT 2-21.0.29 & D.01/Condensate $1 / 4^{\prime \prime}$ Line \\
\hline SIPT 2-16.5.4 & 19/4- Condensate Valve Trap & ISIPT 2-21.0.30 & -0.01/Condensate- $1 / 4^{\circ}$ Line \\
\hline SIPT 2-16.5.5 & $1 \sqrt{\zeta}$ Condensate Trap & ISIPT 2-21.0.31 & 0.01/1/2 Condensate Trap \\
\hline SIPT 2-16.5.6 & $11 / 4^{\circ}$ Condensale Trap & ISIPT 2-21.0.32 & 0/3/4 Condensate Line \\
\hline SIPT 2-16.5.7 & $19 \sqrt{2}$ Condensate Trap & ISIPT 2.21.0.33 & 0| $/ 4^{-}$Condensate Line \\
\hline ISIPT 2-16.5.8 & $11 / 4$ Condensale Trap & ISIPT 2-21.0.34 & $0.09 /$ Condensate $1 / 4^{-}$Valve \\
\hline ISIPT 2-17.1.1 & Aux Sampler (Bonom) & ISIPT 2-21.0.35 & O|Consensate $1 / 4^{\circ}$ Valve \\
\hline ISIPT 2-17.1.2 & Atx Sampler (Sottom) & ISIPT 2-21.0.36 & o|Condensate-1/4" Valve \\
\hline ISIPT 2-17.1.3 & Atx Sampler & SIPT 2-21.0.37 & O1Conoensate - $/ 4^{\circ}$ Valve \\
\hline ISIPT $2-17.1 .4$ & Aux Sampter & iSIPT 2-21.0.33 & $0.05 \mid$ Condensate- IR Trap \\
\hline ISIPT 2-17.1.5 & Condensate from HB-14 & ;SIPT 2-21.0.39 & 0|Condensate-1/4- Valve \\
\hline 2/493|SIPT 2-20.1.1 & Aerosol Finter & iSIPT 2-21.0.40 & OCondensate-1/4 Valve \\
\hline ISIPT 2-20.1.2 & Aeroso DI Water Rinsate & ISIPT 2-21.0.41 & Aerosol Filler \\
\hline ISIPT 2-20.1.4 & II/Z Condensale Trap & ISIPT 2.21.0.42 & DI Water Rınsale \\
\hline ISIPT 2-20.9.5 & $11 / 4$ Condensale & ISIPT 2.21.0.43 & HCl Rinsale \\
\hline ISIPT 2-20.1.3 & Aerosd HCl Rinsale & ISIPT 2-21.0.44 & OlCondensate - $1 / 4^{\prime \prime}$ Valve \\
\hline ISIPT 2-20.1.6 & $11 / 4$ Condensate Trap & iSIPT 2-21.0.45 & O1Condensate - i/2 Trap \\
\hline SIPT 2-20.1.7 & T114 Concensale Trap & ISIPT 2-21.0.46 & OIConsensate - I/4 Valve \\
\hline ISIPT 2-20.1.8 & $11 \sqrt{\Sigma}$ Condensate Trop & ISIPT 2-21.0.47 & D.01 Consensale - $115^{-}$Valve \\
\hline $25593 \mid S T P T 2 \cdot 20.1 .9$ & $11 / 4^{\circ}$ Consensate Trap & ISIPT 2-21.0.48 & OiCondensale - I/4 Valve \\
\hline SIPT 2-20.1.10 & $11 \sqrt{\zeta}$ Condensate Trap & ISIPT 2-21.0.49 & D|Condensale $1 \sqrt{2}$ Valve \\
\hline SIPT 2-20.1.11 & Aerosol Finer & ISIPT 2-21.0.50 & OlCondensale- $1 / \mathrm{f}^{-}$Value \\
\hline ISIPT 2-20.1.12 & Aerosol DI Water Rinsate & ISIPT 2-21.0.51 & -0.01/Condensale- 1/4 Valve \\
\hline ISIPT 2-20.1.13 & |Aerosd HCl Rinsate & ISIPT 2-21.0.52 & 0.01 Condensate $-1 \sqrt{2}$ Valve \\
\hline ISIPT 2.20.1.14 & $11 / 4^{\circ}$ Condensale Trap & ISIPT 2-21.0.53 & loff-gas anabyzef line \\
\hline $\mid$ SIPT 2-20.1.15 & $11 / 4$ Consensale Trap & ISIPT 2-21.0.54 | & loffogas anahzer line \\
\hline |SIPT 2-20.1.161 & $11 \sqrt{Z}$ Consensate Trap & $3 / 23 / 93$ ISIPT 2-24.1.9 & O|Condensate $1 / 4$ Valve \\
\hline ISIPT 2-20.1.17 & II/4 Condensate Trap & ISIPT $2 \cdot 24.1 .2$ & $0.07 \mid$ Condensate 9.2 Valve \\
\hline $\mid$ SIPT $2-20.1 .18$ & IAerosol Fither & ISIPT 2-24.1.3 & D.01/Condensate $1 \Omega$ Valve \\
\hline ISIPT 2-20.1.19] & Aefosol DI Water Rinsate & :SIPT 2-24.1.4 & O|Condensate $1 / \bar{L}$ Vatve \\
\hline ISIPT 2-20.1.20| & Aerosol HCI Rinsate & ISIPT 2-24.1.5 & ICondensate- $1 / 2$ Valve \\
\hline |SIPT 2-20.1.21 & $19 / 4^{\circ}$ Condensate Trap & ISIPT 2-24.1.6 & D.02/Condensale $1 \sqrt{2}$ Valve \\
\hline$|S I P T 2-20.122|$ & 1116 Consensale Trap & ISIPT 2-24.1.7 & Condensate $1 / 2$ Valve \\
\hline |SIPT 2.20.1.23| & $11 / 2$ Condensate Trap & ISIPT 2-24.1.8 & D.011Condensale $-1 \sqrt{Z}$ Valve \\
\hline आ1093|SIPT 2-21.0.1A| & Aerosol fitter & ISIPT 2-24.1.9 & Condensate- I/ Valve \\
\hline $\mid$ SIPT 2-21.0.2A & IDI Water Rinsate & ISIPT 2-24.1.10 & $0.4 \mid$ Condensate from HB-14 \\
\hline ISIPT 2-21.0.3 & IHCI Rinsate & ISIPT 2-24.1.11 & $0.4 /$ Condensate from $\mathrm{HB}-14$ \\
\hline ISIPT 2-21.0.4 & OlFormis Acid Drum & ISIPT 2-24.1.12 & 0.41 Condensate from HB-14 \\
\hline ISIPT 2.21 .0 .5 & OlFormic Aeid Drum & 324931 SIPT $2-24.3 .1$ & Condensate $\sqrt{2}$ Vatue \\
\hline SIPT 2-21.0.6 & OlCondensale Line & ISIPT 2.24.5.1 & Condensate- $1 \sqrt{Z}$ Valve \\
\hline SIPT 2-21.0.7 & OCondensate line & ISIPT 2-24.5.2 & Condensale safe $1 / \bar{L}$ Valve \\
\hline SIPT 2-21.0.8 & 0.02 Condensate Line & ISIPT 2-24.5.3 & Condensate safe $1 / 2$ Valve \\
\hline SIPT 2-21.0.9 & $0.01 \mid$ Condensate Line & ISIPT 2-21.0.55 । & ILiguid from aerosol hine \\
\hline SIPT 2-21.0.10 & OlFormic Acid Drum \# & 4293ISIPT 2.25.2.1 । & 0.11 II $\bar{C}$ Conjensate Valve \\
\hline |SIPT 2-21.0.19| & OjFomic Acid Drum & ISIPT 2-25.2.2 & 11/4" Condensate Value \\
\hline $\mid$ SIPT 2-21.0.12| & D.011Candensate Line & ISIPT 2-25.2.3 & J/4 Conoensate Valve \\
\hline SIPT 2-21.0.13 & OjCondensate Line & ISIPT 2-25.2.4 & $11 / 4^{\circ}$ Condensate Varve \\
\hline SIPT 2-21.0.14 & OlCanderssate Line & ISIPT 2-25.2.4 & 1919 Condensate Valve \\
\hline ISIPT 2-21.0.15 & O|Condensate Line & ISIPT 2-25.2.5 & $11 / 4^{\circ}$ Consensate Valve \\
\hline ISIPT 2-21.0.16 & $011 \sqrt{\Sigma}$ Condensate Trap & ISIPT 2.25 .2 .5 & $11 / 4^{\circ}$ Consensale Valve \\
\hline ISample No. I & Firng at $105 \mathrm{Cl} \quad$ Location & 1 & \\
\hline 1 & (SluTV) Wt\% & & \\
\hline 4/6/93ISIPT 2.25.4.1 & $11 / 4^{\circ}$ Condensale Valve & & \\
\hline ISIPT $2-254.2$ & $11 / 4^{*}$ Condensate Valve & $T$ & \\
\hline
\end{tabular}


Table AC.1. (contd)

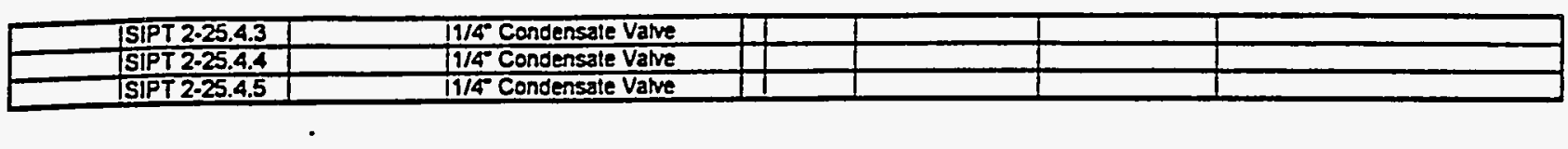

AC. 3 
Appendix AD

Fluid Transport Information 


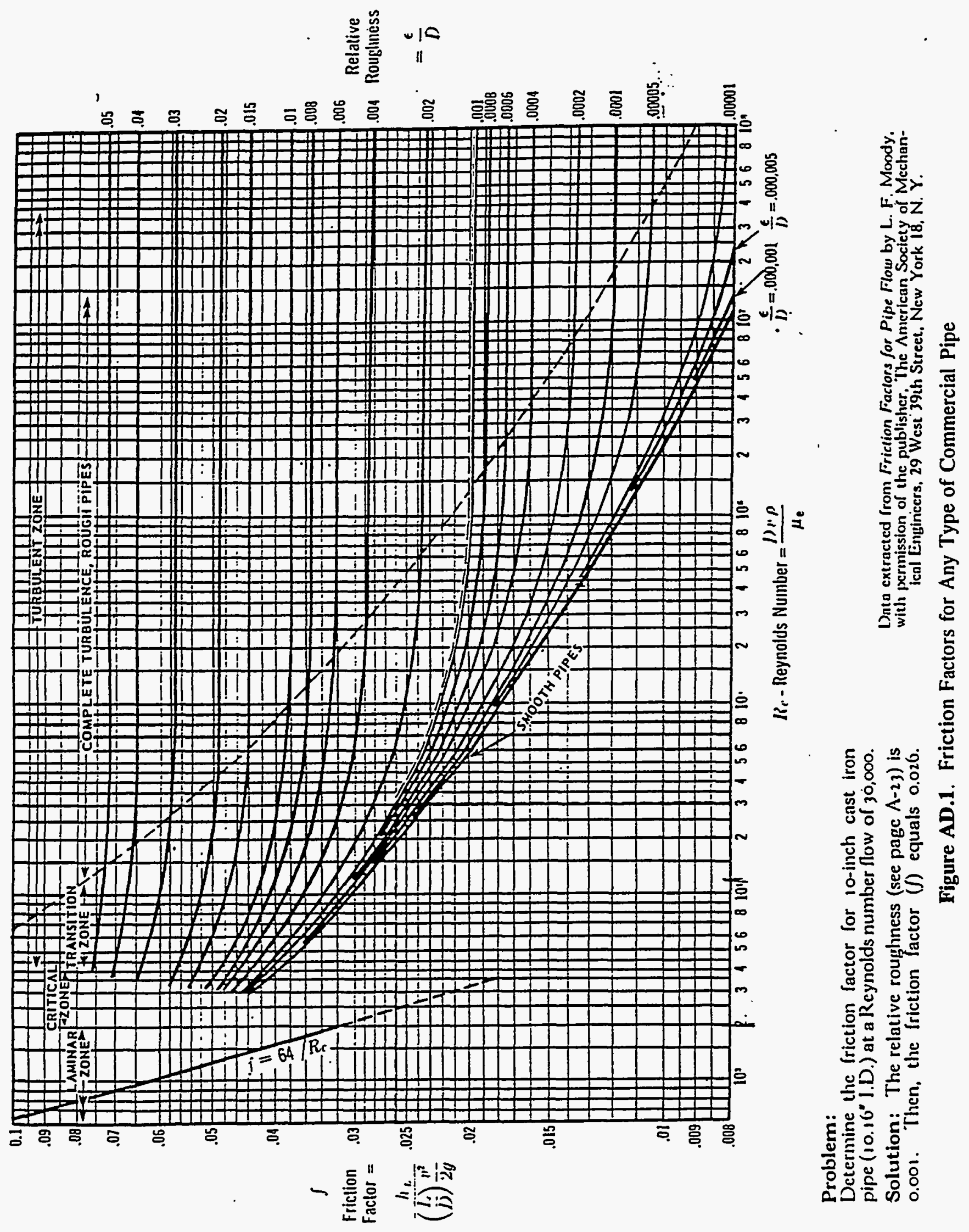

AD. 1 


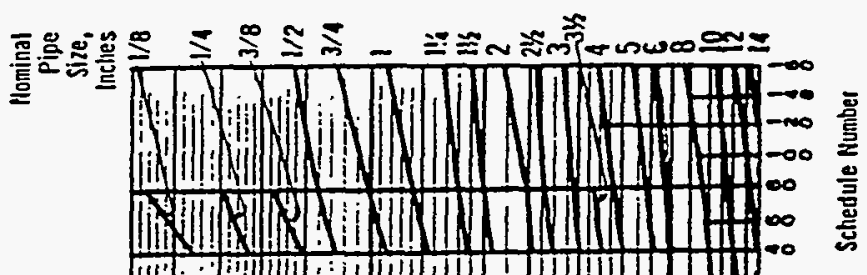

을

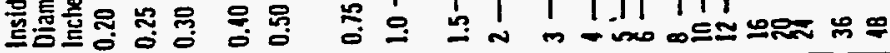

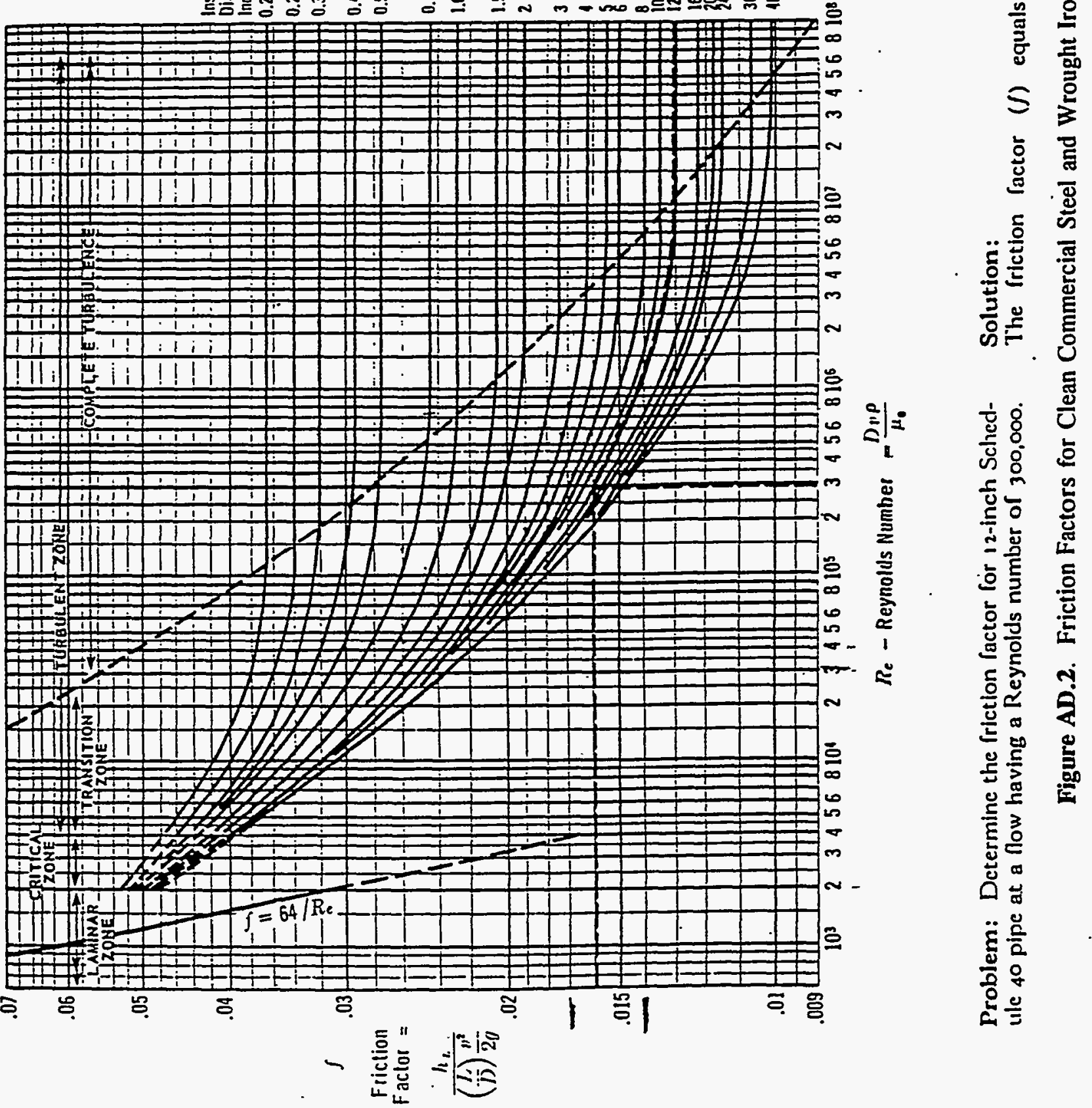

AD. 2 


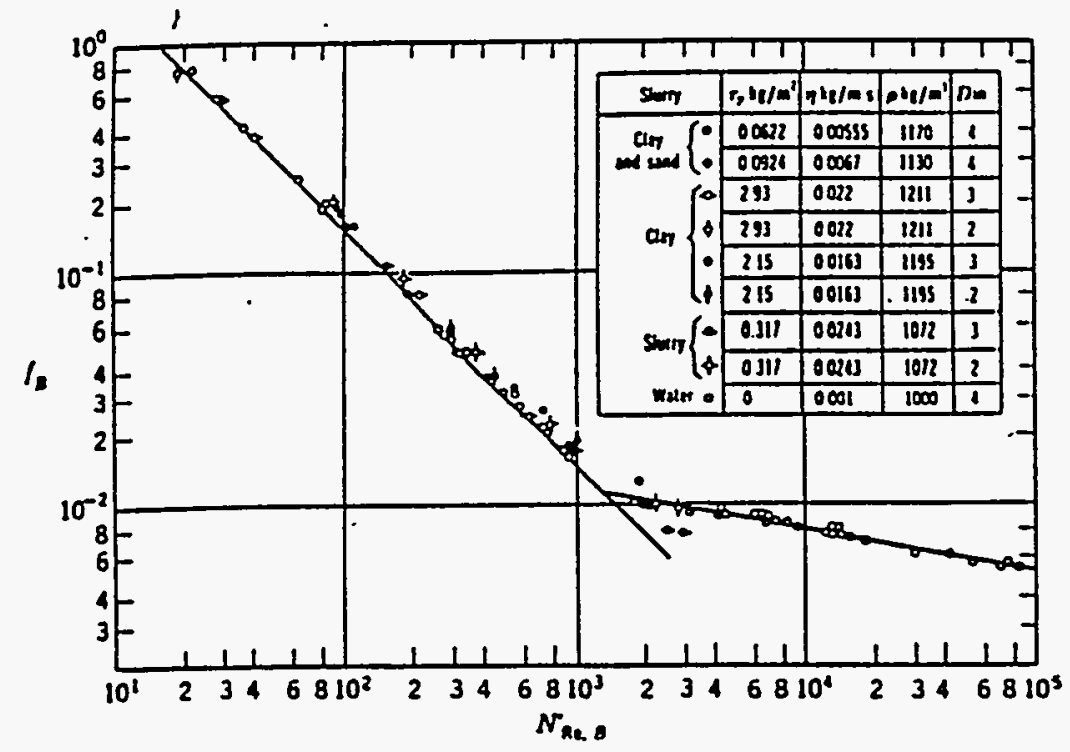

Figure AD.3. Experimental Correlation of Equations 3.17 and 3.18 for Bingham Plastic Flow in Tubes (36)

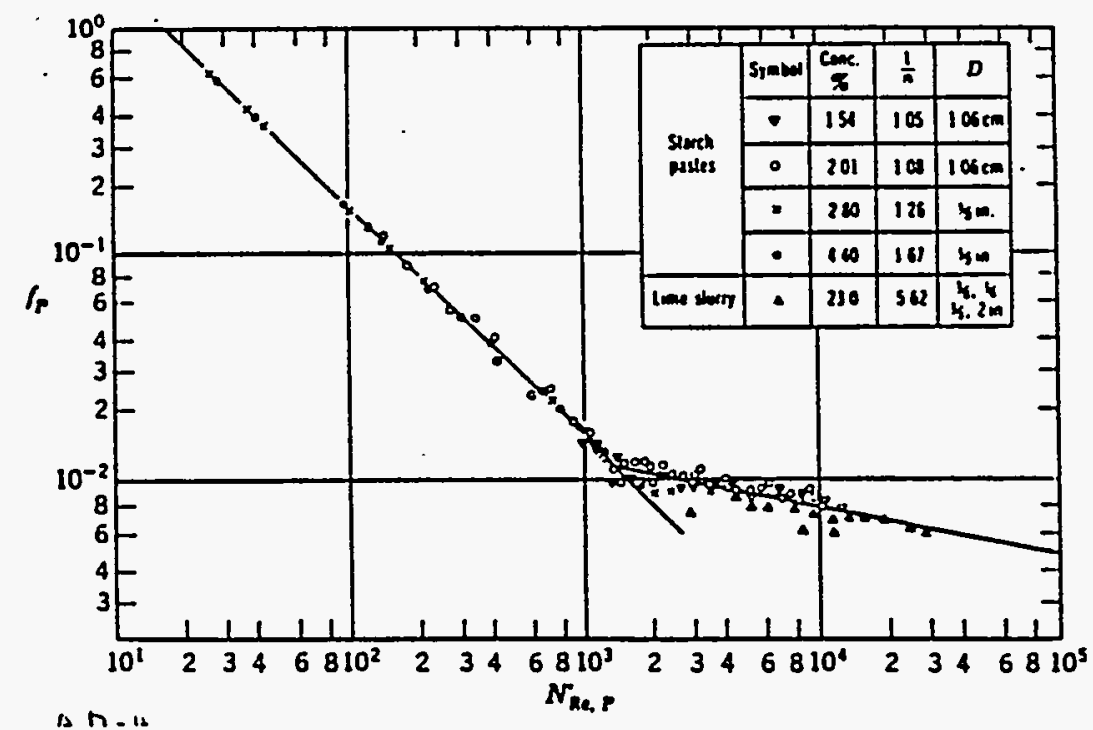

Figure AD.4. Experimental Correlation of Equations 6.33 and 6.34 for Power Law Fluids in Tubes (36) 
Table AD.1. Representative Equivalent Length in Pipe Diameters $(L / D)$ of Various Valves and Fittings

\begin{tabular}{|c|c|c|c|}
\hline$\cdot$ & $\cdot$ & Description of Product & $\begin{array}{l}\text { Equivalent Length } \\
\text { In Pipe Diameters } \\
(L / D)\end{array}$ \\
\hline \multirow{2}{*}{$\begin{array}{l}\text { Globe } \\
\text { Valves }\end{array}$} & $\begin{array}{l}\text { Stem Perpendic- } \\
\text { ular to Run }\end{array}$ & $\begin{array}{l}\text { With no obstruetion in flat, bevel, or piug type seat } \\
\text { With wing or pin guided disc }\end{array}$ & $\begin{array}{l}340 \\
450\end{array}$ \\
\hline & Y-Pattern & $\begin{array}{l}\text { (No obstruction in fiat, bevel. or plug type seat) } \\
\text { - With stem } 60 \text { degrees from run of pipe line } \\
\text { - With stem } 45 \text { degrees from run of pipe line }\end{array}$ & $\begin{array}{l}175 \\
145 \\
\end{array}$ \\
\hline \multicolumn{2}{|r|}{ Angle Valves } & $\begin{array}{ll}\text { With no obstruction in flat, bevel, or plug type seat } & \text { Fully open } \\
\text { With wing or pin guided dise } & \text { Fully open } \\
\end{array}$ & $\begin{array}{l}145 \\
200\end{array}$ \\
\hline \multirow{3}{*}{$\begin{array}{l}\text { Gate } \\
\text { Valves }\end{array}$} & $\begin{array}{l}\text { Wedge, Dise, } \\
\text { Double Disc, } \\
\text { or Plug Disc }\end{array}$ & $\begin{array}{r}\text { Fully open } \\
\text { Threc-quarers open } \\
\text { One-hall open } \\
\text { One-quarter open }\end{array}$ & $\begin{array}{r}13 \\
35 \\
160 \\
900\end{array}$ \\
\hline & Pulp Stock & $\begin{array}{l}\text { Fully open } \\
\text { Threc-quarters open } \\
\text { One-half open } \\
\text { One-quarter open }\end{array}$ & $\begin{array}{r}17 \\
50 \\
260 \\
1200 \\
\end{array}$ \\
\hline & \multicolumn{2}{|l|}{ Conduit Pipe Line } & 30 \\
\hline $\begin{array}{l}\text { Check } \\
\text { Yalves }\end{array}$ & \multicolumn{2}{|c|}{$\begin{array}{l}\text { Conventional Swing } \\
\text { Qearway Swing } \\
\text { Globe Lift or Stop; Stem Perpendicular to Run or Y-Pattern } \\
\text { Angle Lift or Stop }\end{array}$} & $\begin{array}{c}135 \\
50 \\
\text { Same as Globe } \\
\text { Same as Angle } \\
150 \\
\end{array}$ \\
\hline \multicolumn{2}{|c|}{ Foot Valves with Strainer } & $\begin{array}{ll}\text { With poppet lift-rype dise } & 0.3 \dagger \ldots \text { Fully open } \\
\text { With leather-hinged dise } & 0.4 \dagger \ldots \text { Fully open } \\
\end{array}$ & $\begin{array}{r}420 \\
75 \\
\end{array}$ \\
\hline \multirow{2}{*}{\multicolumn{3}{|c|}{$\begin{array}{l}\text { Butterfly Valves (8-inch and larger) } \\
\text { | Straight-Through | Rectanoular plup por area eaual to } 100 \mathrm{c} \text { of pipe area }\end{array}$}} & 40 \\
\hline & Straight-Through & Rectangular plug port arca equal to $100 \%$ of pipe area Fully open & 18 \\
\hline Cocks & Three-Way & $\begin{array}{ll}\text { Rectangular plug port area equal to } & \text { Flow straight through } \\
80 \% \text { of pipe area (fully open) } & \text { Flow through branch } \\
\end{array}$ & $\begin{array}{r}44 \\
140 \\
\end{array}$ \\
\hline \multirow{4}{*}{ Fittings } & \multicolumn{2}{|c|}{$\begin{array}{l}90 \text { Degree Standard Elbow } \\
45 \text { Degree Standard Elbow } \\
90 \text { Degree Long Radius Elbow }\end{array}$} & $\begin{array}{l}30 \\
16 \\
20\end{array}$ \\
\hline & \multicolumn{2}{|c|}{$\begin{array}{l}90 \text { Degree Street Elbow } \\
45 \text { Degree Street Elbow } \\
\text { Square Corner Elbow }\end{array}$} & $\begin{array}{l}50 \\
26 \\
57 \\
\end{array}$ \\
\hline & Standard Tee & $\begin{array}{l}\text { With flow through run } \\
\text { With flow through branch }\end{array}$ & $\begin{array}{l}20 \\
60\end{array}$ \\
\hline & \multicolumn{2}{|c|}{ Close Pattern Return Bend } & 50 \\
\hline Pipe & \multicolumn{2}{|c|}{$\begin{array}{l}90 \text { Degree Pipe Bends } \\
\text { Miter Bends } \\
\text { Sudden Enlargements and Contrections } \\
\text { Entrance and Exit Losses }\end{array}$} & $\begin{array}{l}\text { See Page A-27 } \\
\text { See Page A-27 } \\
\text { See Page A-26 } \\
\text { See Page A-26 }\end{array}$ \\
\hline \multicolumn{3}{|c|}{$\begin{array}{ll}\text { "Exact equivalent length is } & \text { tMinimi } \\
\text { equal to the length between } & \text { drop (ps } \\
\text { flange faces or welding ends. } & \text { sufficient }\end{array}$} & $\begin{array}{l}\text { 2s. see page } \\
\text { feet of end } \\
\text { ee page } 2-10 .\end{array}$ \\
\hline
\end{tabular}




\section{Resistance Due to Sudden Enlargements and Contractions}

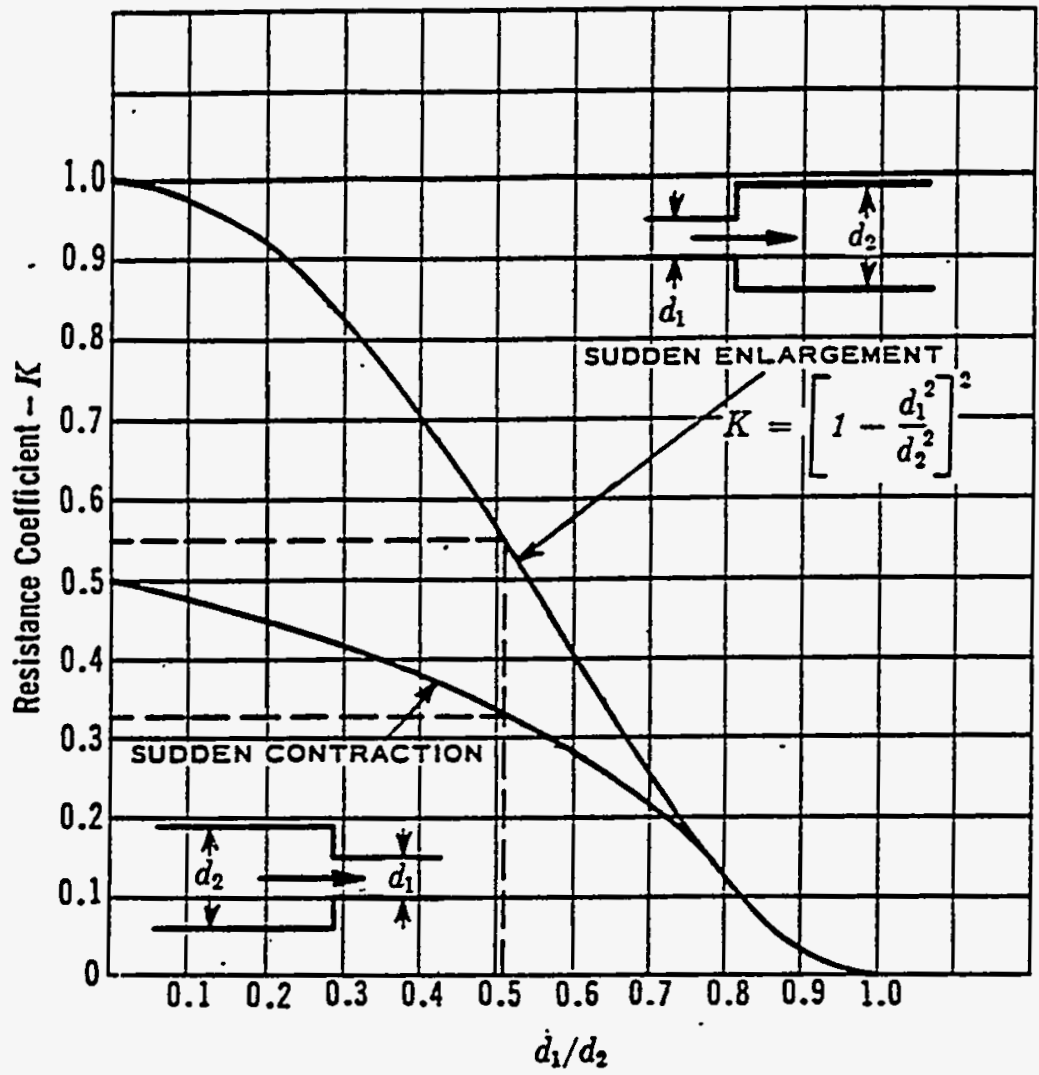

Sudden enlargement: The resistance coefficient $K$ for a sudden enlargement from 6-inch Schedule to pipe to 12 -inch Schedule 40 pipe is 0.55 , based on the 6-inch pipe size.

$$
\frac{d_{1}}{d_{2}}=\frac{6.065}{11.938}=0.51
$$

Sudden contraction: The resistance coefficient $K$ for a sudden contraction from 12-inch Schedule 40 pipe to 6-inch Schejule 40 pipe is 0.33 , based on the 6-inch pipe size.

$$
\frac{d_{1}}{d_{2}}=\frac{6.065}{11.038}=0.51
$$

* Note: The values for the resistance coefficient, $K$, are based on velocity in the small pipe. To determine $K$ values in terms of the greater diameter, multiply the chart values by $\left(d_{2} / d_{3}\right)^{4}$.

\section{Resistance Due to Pipe Entrance and Exit}

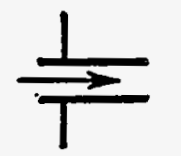

$K=0.78$

Inward

Projeding Pipe

Entronee

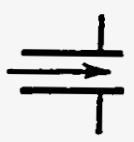

$K=1.0$

Projecting

Pipe

Exil

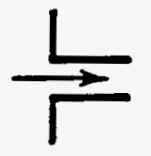

$K=0.50$

Sharp

Edged

Entrance

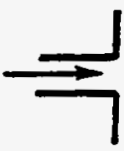

$K=1.0$

Sharp

Edged

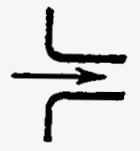

$x=0.23$

Stightly

Rounded

Entronoe

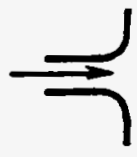

$r=1: 0$

Roundor

Exat

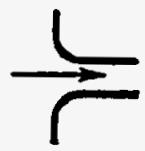

$x=0.04$

Woll

Rounded

Enrenee
Problem: Determine the total resistance coefficient for a pipe one diamecer long having a sharp edged entrance and a sharp edged exit.

Solution: The resistance of pipe one diameter long is small and can be neglected $(K=f L / D)$.

From the diagrams, note:

Resistance for a sharp edged entrance $=0.5$

Resistance for a sharp edged exit $\quad=1.0$

Then.

the total resistance, $K$, for the pipe $=1.5$

Figure AD.5. Resistance in Pipe 


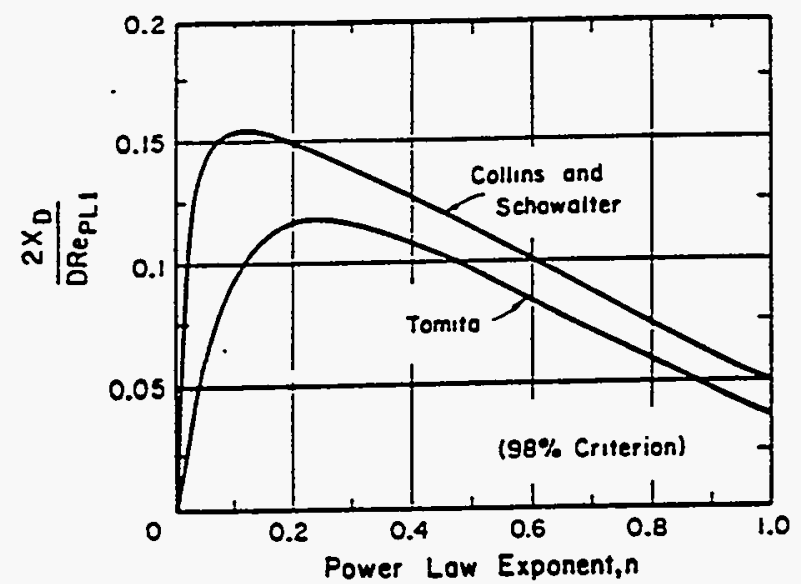

Figure AD.6. Entrance Length for Laminar Flow of Power Law Pseudoplastics. (From Collins M. and W. R. Schowaiter, A.1.Ch.E. Joumal, 9, 804. 1963.)

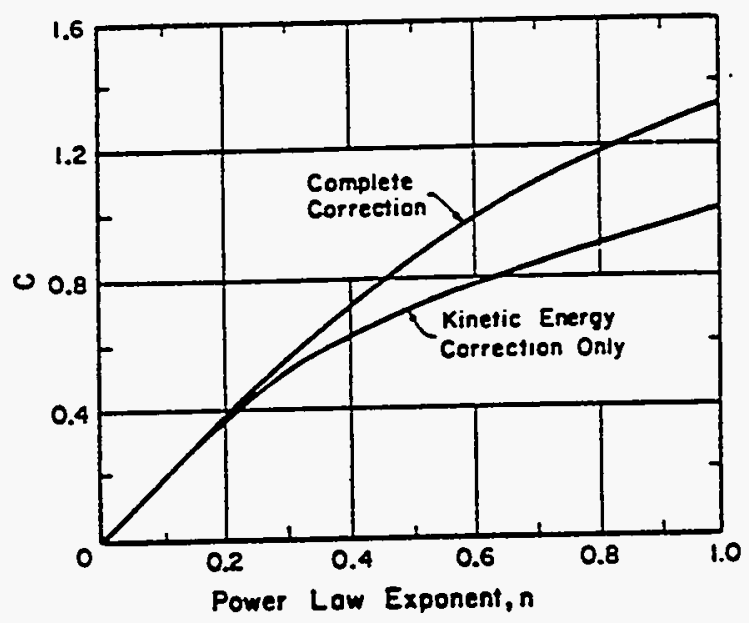

. Figure AD.7. Excess Dimensionless Entrance Length Pressure Drop, C, for the Laminar Flow of Power Law Psdeudoplastics. (From Collins, M. and W. R. Schowalter, A.1.Ch.E. Journal, 9, 804. 1963.) 